\title{
Tank 241-AY-102 Leak Assessment Supporting Documentation: Miscellaneous Reports, Letters, Memoranda, and Data
}

\author{
J.K. Engeman, C.L. Girardot, D.G. Harlow \& C.L. Rosenkrance \\ Washington River Protection Solutions \\ Richland, WA 99352 \\ U.S. Department of Energy Contract DE-AC27-08RV14800

$\begin{array}{lll}\text { EDT/ECN: } & \text { DRF } & \text { UC: N/A } \\ \text { Cost Center: } & \text { 2KE00 } & \text { Charge Code: } 201334 \\ \text { B\&R Code: } & \text { N/A } & \text { Total Pages: } 559\end{array}$

Key Words: DST, 241-AY-102, leak assessment, leak, tank construction

Abstract: This report contains reference materials cited in RPP-ASMT-53793, Tank 241-AY-102 Leak Assessment Report, that were obtained from the National Archives Federal Records Repository in Seattle, Washington, or from other sources including the Hanford Site's Integrated Data Management System database (IDMS).

TRADEMARK DISCLAIMER. Reference herein to any specific commercial product, process, or service by trade name, trademark, manufacturer, or otherwise, does not necessarily constitute or imply its endorsement, recommendation, or favoring by the United States Government or any agency thereof or its contractors or subcontractors.

\section{APPROVED \\ By Julia Raymer at 3:23 pm, Dec 18, 2012}

Date

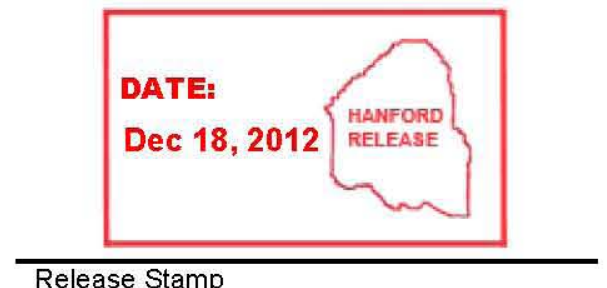

Release Stamp

\section{Approved For Public Release}




\section{Tank 241-AY-102 Leak} Assessment Supporting Documentation: Miscellaneous Reports, Letters, Memoranda, and Data

Prepared for the U.S. Department of Energy

Assistant Secretary for Environmental Management

Contractor for the U.S. Department of Energy

Office of River Protection under Contract DE-AC27-08RV14800

\section{washingtonriver protectionsolutions}

P.O. Box 850

Richland, Washington 99352 


\section{EXECUTIVE SUMMARY}

This report provides reference documents and other information supporting RPP-ASMT-53793, Tank 241-AY-102 Leak Assessment Report. The report contains the reference materials cited in the leak assessment report that were obtained from the National Archives Federal Records

Repository in Seattle, Washington, or from other sources including the Hanford Site's Integrated Data Management System database (IDMS). The documents which are either not available or not easily found in IDMS are presented to provide detailed background information for RPPASMT-53793. The first seven sections deal with construction, waste transfers-liquid levels, chemistry, ultrasonic testing, annulus sample results, leak detection pit sample results, and historical annulus continuous air monitor (CAM) notifications all of which coincide with the RPP-ASMT-53793 document outline. Time lines are also available in Section 8.0 that list events occurring between 1968 and 2012 relating to overall operations and the annulus leak detectors, $\mathrm{CAM}$, and inspections. 


\section{CONTENTS}

1.0 Supporting Documentation for RPP-ASMT-53793, Section 3.0, Tank AY-102

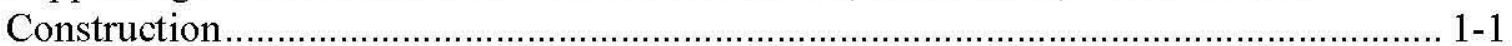

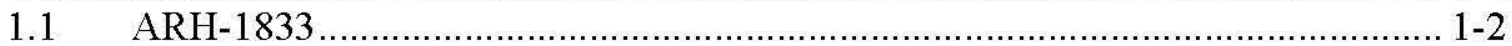

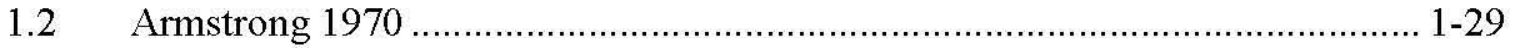

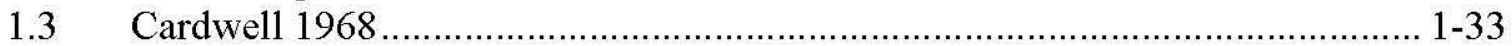

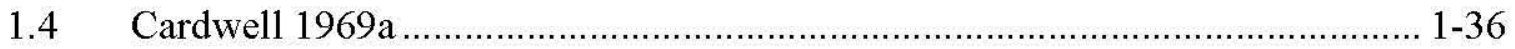

1.5 Cardwell 1969b .......................................................................... 1-39

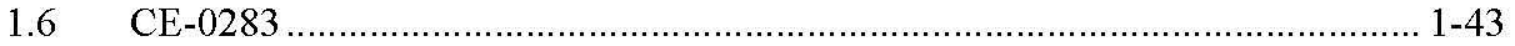

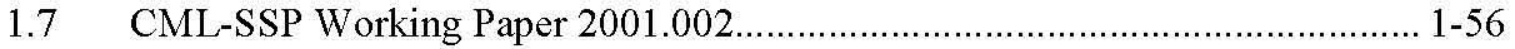

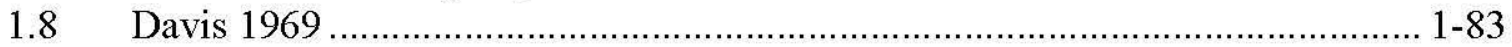

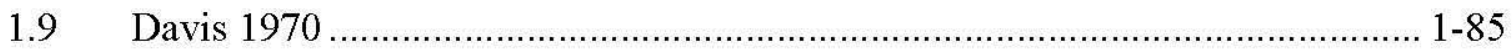

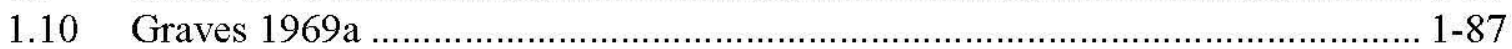

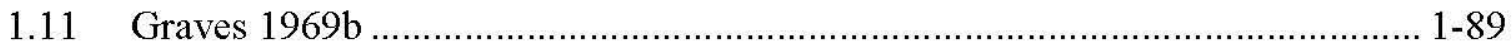

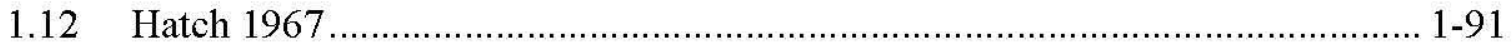

1.13 HES QA Report 1969 ....................................................................... 1-97

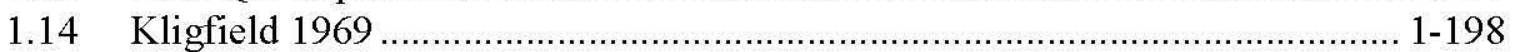

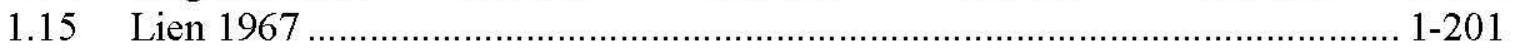

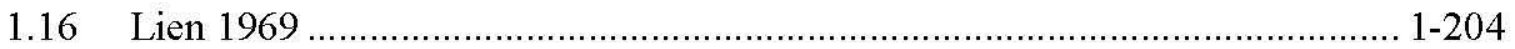

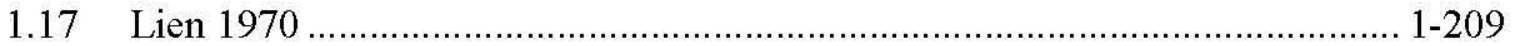

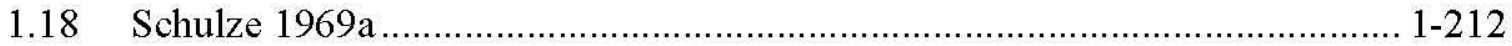

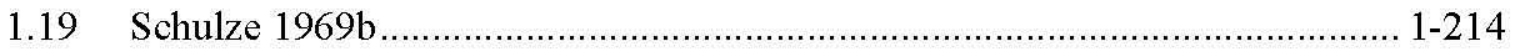

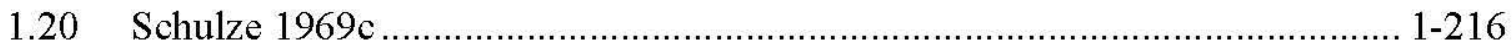

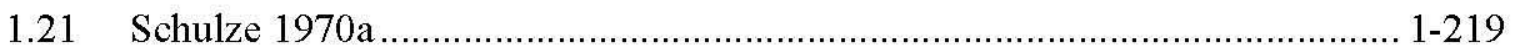

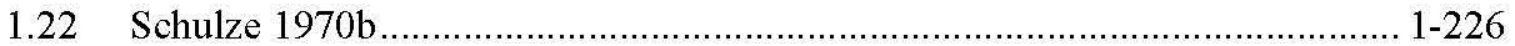

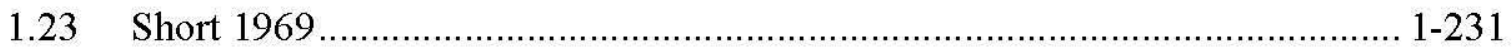

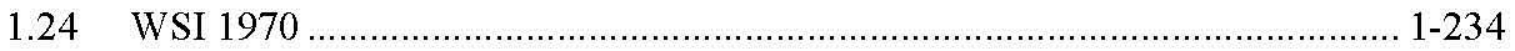

2.0 Supporting Documentation for RPP-ASMT-53793, Section 4.1.1, Waste

Transfers and Liquid Level............................................................................... 2-1

2.1 Tank AY-102 Liquid Level Data- February 1971 through December 1980 ....... 2-2

2.2 Tank AY-102 Status Reports …………………………………………..... 2-6

2.3 AY Farm Liquid Level Readings- February 1976 ........................................ 2-24

2.4 AY Farm Liquid Level Monthly Reports ……………………………….... 2-26

2.5 Tank AY-102 Liquid Level Readings- October $1976 \ldots \ldots \ldots \ldots \ldots \ldots \ldots \ldots \ldots \ldots \ldots \ldots \ldots \ldots . . .2-30$

2.6 Tank AY-102 Liquid Level Readings- September 1998 through July 2000 ..... 2-32

3.0 Supporting Documentation for RPP-ASMT-53793, Section 4.1.4, Chemistry............... 3-1

$3.1 \quad$ Occurrence Report 74-30 ...................................................................... 3-2

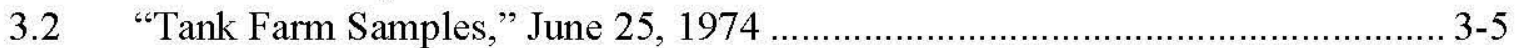

3.3 "Analyses of Tank Farm Sample," July 21, 1976 …….................................... 3-7

3.4 "Analyses of Tank Farm Samples," August 10, 1978 ...................................... 3-9

3.5 "Analyses of Tank Farm Samples," September 1, 1978 ................................. 3-11

3.6 "Analytical Data for Tanks 101-AZ, 102-AZ, 103-TX, and 102-AY Hot and Synthetic Liquors," September 21, 1979 ............................................... 3-13 
3.7 "Relative Random Error Standard Deviation and Accuracy in Hanford Waste Liquor Analytical Data," December 3, 1979 ........................................ 3-20

3.8 Analytical Results Tank 102-AY- March 1980 through September 1980 ........ 3-29

3.9 "Composition of Waste from Tanks 101AY and 102AY," April 15, 1982 ...... 3-35

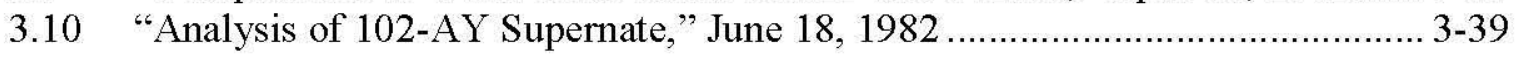

3.11 SD-WM-PE-018 ........................................................................... $3-41$

3.12 "Laboratory Support for Upcoming 242-A Evaporator Campaign Run 84-5," May 10, 1984.

3.13 "Chemical Compositions of 102-AY, 101-AW, 105-AN, and 104-AW,"

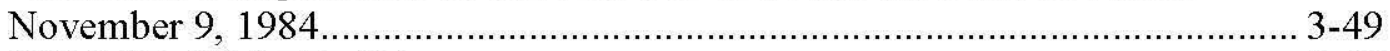

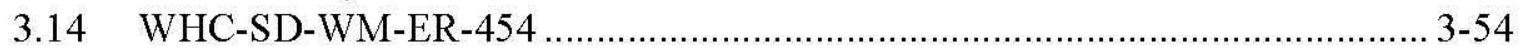

3.15 Tank AY-102 Report Analysis January 1988 ….......................................... 3-62

3.16 "Tank 102-AY Solids Heel Analysis," April 21, 1989..................................... 3-67

3.17 "Revised Report on the Results of 102-AY Characterization,"

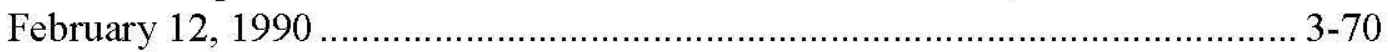

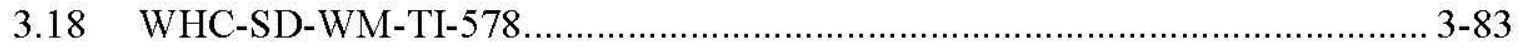

3.19 Tank AY-102 Report Analysis- February 1990 ............................................. 3-88

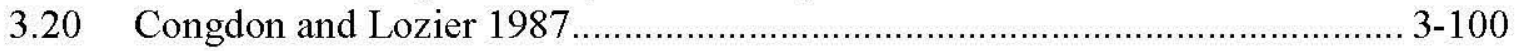

3.21 WSRC-TR-94-0250 ..................................................................... 3-11

4.0 Supporting Documentation for RPP-ASMT-53793, Section 4.1.8,

Tank AY-102 Ultrasonic Testing............................................................................ 4-1

5.0 Preliminary Annulus Sample Results for RPP-ASMT-53793, Section 4.2.7,

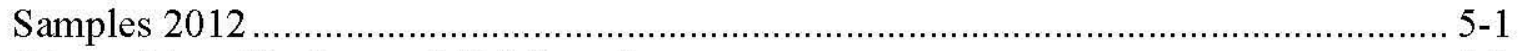

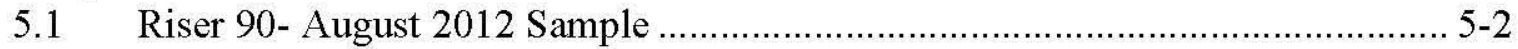

5.2 Riser 83- September 2012 Sample.............................................................. 5-19

5.3 Riser 90- October 2012 Samples ................................................................ 5-52

6.0 Preliminary Leak Detection Pit Sample Results for RPP-ASMT-53793, Section 4.3.5, Leak Detection Pit Sample Results................................................... 6-1

6.1 Leak Detection Pit September 2012 Samples ........................................... 6-2

7.0 Tardiff, G. R., 2001 (Draft), Evaluation of AY-102 Annulus CAM Readings ............. 7-1

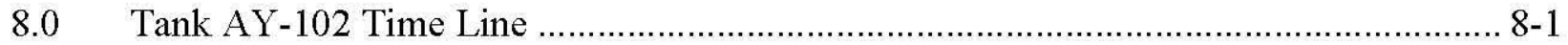

8.1 Tank AY-102 Annulus ENRAF Leak Detectors Time Line ............................ 8-2

8.2 Tank AY-102 Continuous Air Monitor Time Line............................................. 8-5

8.3 Tank AY-102 Operational Time Line......................................................... 8-8

8.4 Tank AY-102 Annulus Visual Inspection Time Line.................................. 8-19 


\section{TRADEMARK DISCLOSURE}

ENRAF is a registered trademark of Enraf B. V., Delft, Netherlands.

Kaolite is a registered trademark of Babcock \& Wilcox Company.

Linde is a registered trademark of Linde AG Corporation.

HEPA is a registered trademark of HEPA Corporation. 


\subsection{Supporting Documentation for RPP-ASMT-53793, Section 3.0, Tank AY-102 Construction}

\begin{tabular}{|c|c|}
\hline 1.1 & ARH- $1833 \ldots \ldots \ldots$ \\
\hline 2 & Armstrong $1970 \ldots \ldots \ldots \ldots \ldots \ldots . . . . .$. \\
\hline & 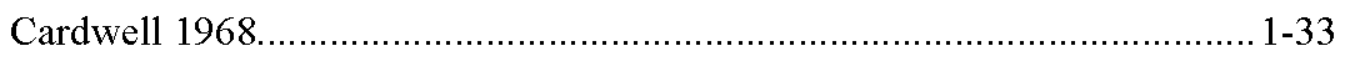 \\
\hline & 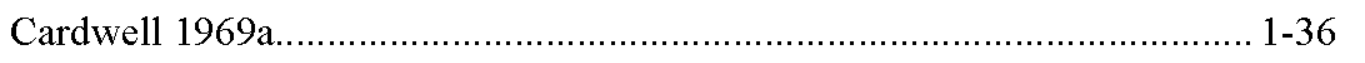 \\
\hline & 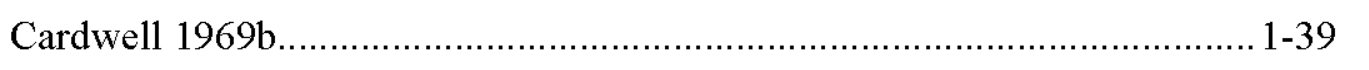 \\
\hline & CE-0283.............. \\
\hline & CML-SSP Working Paper 2001.002.... \\
\hline & 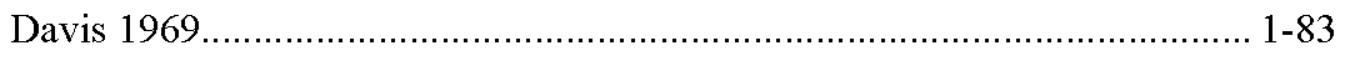 \\
\hline & Davis $1970 \ldots . .$. \\
\hline 10 & Graves 1969a.... \\
\hline 11 & Graves $1969 b \ldots .$. \\
\hline .12 & Hatch $1967 \ldots \ldots \ldots \ldots \ldots . . . . . .$. \\
\hline 13 & HES QA Report $1969 \ldots$ \\
\hline 14 & Kligfield $1969 \ldots \ldots \ldots \ldots . . . .$. \\
\hline .15 & Lien $1967 \ldots \ldots \ldots \ldots$ \\
\hline 1.16 & Lien $1969 .$. \\
\hline 17 & Lien $1970 \ldots \ldots$ \\
\hline 18 & Schulze $1969 a \ldots$ \\
\hline 19 & Schulze $1969 b \ldots$. \\
\hline .20 & Schulze $1969 \mathrm{c} \ldots$ \\
\hline 21 & Schulze $1970 \mathrm{a} .$. \\
\hline 1.22 & Schulze $1970 \mathrm{~b} . . .$. \\
\hline 1.23 & Short $1969 \ldots \ldots . .$. \\
\hline & WSI $1970 \ldots \ldots$ \\
\hline
\end{tabular}


Rev. 0

1.1 ARH-1833, 1970, Investigation of the 241-AY Insulating Refractory Task Force Report, Atlantic Richfield Hanford Company, Richland, Washington. 


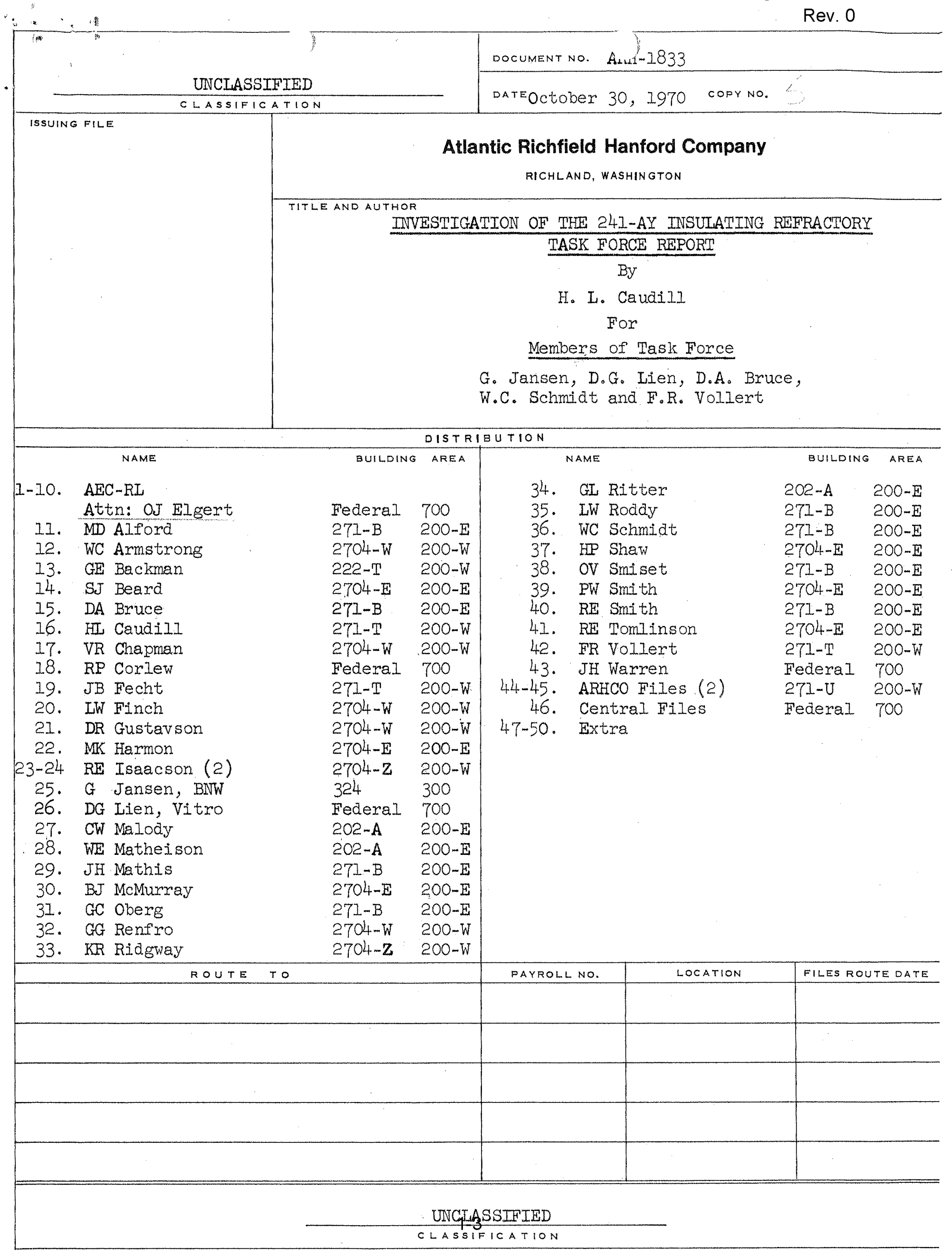




\author{
By \\ H. L. Caudill \\ For \\ Task Force \\ Members of Task Force \\ G. Jansen \\ DoG。 Lien \\ W.C. Schmidt \\ F.R. Vollert \\ D.A. Bruce \\ Chemical Processing Division \\ October 30,1970




\section{INVESTIGATION OF THE 241-AY INSULATING REFRACTORY}

\section{TASK FORCE REPORT}

\section{TABIE OF CONTENTS}

$\underline{\text { Page }}$

I. INTRODUCTION . . . . . . . . . . . . . . . . . . . . I

II. CONCLUSION . . . . . . . . . . . . . . . . . . . . . . . . I

III. INVESTIGATIONS . . . . . . . . . . . . . . . . . . . 2

A. Visual Inspections.................. . 2

B. Sample Evaluations . . . . . . . . . . . . . 3

1. Chemical Analysis. . . . . . . . . . . . . 3

2. Physical Analysis. . . . . . . . . . . . 4

C. Thermal Evaluation - Assumed Leak. . . . . . . . . 5

D. Pressure Evaluation. . . . . . . . . . . . . 7

E. Structural Evaluation. . . . . . . . . . . . . 7

IV. REFERENCES . . . . . . . . . . . . . . . . 10 
UNCLASSTFIED

ARH -1833

Page 1

\section{INVESTICATION OF THE 241-AY INSULATING REFRACTORY}

TASK FORCE REPORT

\section{INTRODUCTION}

The design of the 24I-AY Tank incorporates a tank-in-tank concept with the primary or inner-tank stress relieved at an elevated temperature to minimize nitrate stress corrosion cracking. To protect the concrete base slab from excessive temperature during the stress relieving of the primary tank, a castable refractory (Kaolite 2200-LI*) was placed between the bottoms of the tanks. This refractory serves as the foundation for the primary tank. Inspections in the annulus between the primary and secondary tanks made prior to preparing the tanks for service revealed deterioration and cracling of the refractory material. A comprehensive visual inspection of the refractory was undertaken and physical samples were removed for analysis and tests. The deterioration was found to be primarily in the surface of the refractory slab. The deteriorated refractory material. was found to be quite friable with little structural strength.

As a result of these preliminary findings, a task force was formed to identify and evaluate the kinds and extent of problems that might exist or develop as a result of the observed condition of the refractory materia.1 and to recommend corrective action if needed.

This report presents the results of the investigation and evaluations which have been completed by the task force.

II. CONCLUSION

Four potential problem areas were identified for evaluation. These were 1) structural support problems, i.e., the refractory is the foundation for the primary tank, 2) thermal gradient problems expected in the system should a leak in the primary tank develop and release radioactive solution into the refractory, 3) high pressure steam that might form between and damage the tanks if a leak should occur in the primary tank at elevated operating temperatures, and 4) operational reliability problems related to monitoring and surveillance.

The structural analyses indicated that the loss of competence of the refractory material under the primary shell knuckle would compromise the integrity of the tank. The loss of six to twelve inches of the refractory materials beyond the primary tank knuckle would generate stresses in the primary tank greater than the allowable specified in the ASME Pressure Vessel Code, Section II, Nuclear Vessels.

\footnotetext{
*Trade name of Babcock \& Wilcox Co., Refractories Division, Augusta, Georgia
} 
UNCLASSIFIED $\quad$ ARH-1833

Page 2

The evaluation and analyses of the other three potential problem areas identified indicated that the associated risk would not be significantIy increased by the refractory's noted condition.

As a result of the structural analyses, a course of action was proposed which included removal of approximately two feet of the refractory from the outer perimeter under the primary tank and replacement with reinforced concrete. This course of action was implemented.

III. INVESTIGATIONS

A. Visua] Inspections

After stress relief and hydrostatic test, an annulus cleanup crew reported cracking and spalling in the visible refractory in both 24I-AY tanks 101 and 102. Thus, it was decided to enter the annulus of each tank, make a formal visual inspection of the exposed part of the slab, photograph deteriorated areas, and take samples of the material to determine the extent and nature of the problem.

Tank 102 - The condition of the refractory in TK-1.02, as observed on the outer periphery, was described as follows:. The surface of the slab was generally deteriorated to an average thickness of $3 / 4$ to I inch. (Localized surface deterioration much greater than 1 inch thick were noted.) The deteriorated surface readily broke off in friable flakes, $i_{\text {.e., }}$ the surface was nearly cohesionless. Compem tent refractory existed below. Also, a few cracks through the slab's 8 inch thickness were visible on the periphery. The only marked differences from this condition were: Two areas, identified as individual $10^{\circ}$ pours, were soft and friable for the entire thickness. One area, also an individual $10^{\circ}$ pour, was in very good condition with minimal surface deterioration (less than 1/4 inches) relative to the rest of the $102 \mathrm{slab}$. Figure $I$ is a photograph showing the typical condition of the 102 refractory. Figure 2 shows one of the extremely poor areas, while Figure 3 is a photograph of a crack in the 102 refractory. Figure 4, AY Tank 102 Condition Plot, shows the location of these general refractory conditions.

Tank 101 - The general condition of the refractory in TK-101, as observed on the periphery, varied from good (less than $1 / 4$ inches deterioration) to a condition of $3 / 4$ inches surface deterioration. (Localized surface deterioration much greater than 1 inch thick were noted.) One localized badly fractured area was noted on the periphery. Also, a few cracks through the 8 inch thickness occurred around the slab. The deteriorated surface broke off in friable flakes, $i . e$, the surface was nearly cohesionless. Competent refrac-. tory existed below. Figure 5 is a photograph of the badly fractured 
area. Figure 6 is a photograph of the $3 / 4$ inch surface deterioration. Figure 7 is a picture of surface deterioration less than $1 / 2$ inches. Figure 8 is the picture of a typical crack and Figure 9 is a photograph of a good area in 101. Figure 10, AY Tank 101 Condition Plot, locates these general refractory conditions.

B. Sample Evaluations

Two samples were taken from each tank for laboratory analysis. One of the samples from each tank was a darker colored material concentrated at the top in a crusty formation. The other samples, one from each tank, represented the more competent material and was light colored. The following results were reported:

1. Chemical Analysis

TANK 102

\begin{tabular}{|c|c|c|c|}
\hline $\begin{array}{l}\text { Element As } \\
\text { Oxide } \\
\end{array}$ & $\begin{array}{l}\text { 102-A } \\
\text { Light }\end{array}$ & $\begin{array}{l}102-B \\
\text { Dark }\end{array}$ & $\begin{array}{c}\text { Manufacturer's } \\
\text { Data } \\
\end{array}$ \\
\hline $\begin{array}{l}\mathrm{SiO}_{2} \\
\mathrm{Al}_{2} \mathrm{O} \\
\mathrm{Fe}_{2} \mathrm{O}_{3} \\
\mathrm{TiO}_{2} \\
\mathrm{CaO} \\
\mathrm{MgO} \\
\mathrm{Na}_{2} \mathrm{O} \\
\text { Specific Gravity } \\
\text { Moisture }\end{array}$ & $\begin{array}{l}37.6 \\
35.4 \\
0.99 \\
1.4 \\
15.5 \\
0.6 \\
1.1 \\
0.53 \\
12.5\end{array}$ & $\begin{array}{l}38.1 \\
36.9 \\
1.04 \\
1.6 \\
15.7 \\
0.4 \\
1.5 \\
-.-1 \\
9.3\end{array}$ & $\begin{array}{c}37.4 \\
40.7 \\
0.9 \\
1.7 \\
18.6 \\
0.4 \\
0.3 \\
0.785 \\
\ldots . .\end{array}$ \\
\hline \multicolumn{4}{|c|}{ TANK 101} \\
\hline $\begin{array}{l}\text { Element As } \\
\text { Oxide } \\
\end{array}$ & $\begin{array}{l}\text { 101-A } \\
\text { Light }\end{array}$ & $\begin{array}{l}\text { 101-B } \\
\text { Dark }\end{array}$ & $\begin{array}{c}\text { Manufacturer's } \\
\text { Data }\end{array}$ \\
\hline $\begin{array}{l}\mathrm{SiO}_{2} \\
\mathrm{Al}_{2} \mathrm{O} \\
\mathrm{Fe}_{2} \mathrm{O}_{3} \\
\mathrm{TiO}_{2} \\
\mathrm{CaO}^{\circ} \\
\mathrm{MgO} \\
\mathrm{Na}_{2} \mathrm{O} \\
\text { Specific Gravity } \\
\text { Moisture }\end{array}$ & $\begin{array}{l}37.0 \\
35.4 \\
0.92 \\
1.6 \\
16.2 \\
0.8 \\
0.7 \\
0.75 \\
12.7\end{array}$ & $\begin{array}{r}33.0 \\
31.2 \\
16.6 \\
1.4 \\
12.1 \\
0.4 \\
2.3 \\
-1 .- \\
8.9\end{array}$ & $\begin{array}{l}37.4 \\
40.7 \\
0.9 \\
1.7 \\
18.6 \\
0.4 \\
0.3 \\
0.785\end{array}$ \\
\hline
\end{tabular}




\section{X-Ray Diffraction Analyses}

Two samples were taken from Tank 101. for examination, one from the top or friable layer and one from the bottom of the kaolite pad. Both samples contained the anhydrous calcium aluminum silicate $\left(\mathrm{CaAl}_{2} \mathrm{Si}_{2} \mathrm{O}_{8}\right)$ mineral called anorthite. The bottom sample, in addition, contained several hydrous compounds: $\mathrm{AI}(\mathrm{OH})_{3}, 3 \mathrm{CaO}-\mathrm{Al}_{2} \mathrm{O}_{3}-6 \mathrm{H}_{2} \mathrm{O}$, and $\mathrm{Ca}_{2} \mathrm{SiO}_{4}-\frac{\mathrm{I}}{2} \mathrm{H}_{2} \mathrm{O}$. The sample from the top contained only $\mathrm{CaCO}_{3}$ in addition to anorthite.

\section{Ion-Exchange Properties}

The Ion exchange properties were tested with cesium-137 in the synthetic supernate solution and an equal amount of supernate and boiling waste solution. Test results showed that less than one percent of the cesium was adsorbed by either mixture.

Density

The measured density of the material was approximately 49 Ib/ ft 3 on a fired basis.

\section{Supernate Retention}

The material gained approximately 80 percent by weight in the synthetic solution or the equivalent of 39.2 lbs. of solution per 1 t 3 of material.

\section{Physical Analysis}

Deteriorated Surface Layer - Intact samples of the deteriorated surface from both tanks were examined and found to afford negligible resistance to compressive and sliding loads. The samples crumbled to a cohesionless state when subjected to these loadings.

Material Below Deteriorated Surface Layer (Competent Material) Samples of this material were taken from each tank and compres.sion tested by $B$ \& $W$ Refractories Division. The reported results were: Tank 101, 425 to 439 psi; Tank 102, 272 to 279 psi. Subsequent samples were taken and compression tested on project. Results were Tank 101, 428 to 764 psi; Tank 102, 158 to 285 psi It was noted from these tests that the refractory from the bottom of the two slabs was significantly stronger than that near the top. All samples compression tested were below the deteriorated surface previously described. The specified minimum strength for the refractory is 200 psi. 
C. ThermaI Evaluation

Thermal analyses were made by Battelle-Northwest Laboratories based on laboratory results and assumptions made from published information (References 1 and 2). These analyses indicate that no problems are expected from the postulated thermal conditions.

Temperature excursions vere estimated for Kaolite 2200-LI with 70 percent voids assuming three undetected leak conditions. * A bulge in the primary liner above the Kaolite of 4 inches was assumed to be part of the Kaolite voids.

A maximum temperature only $3.8^{\circ} \mathrm{F}$ above the inner steel liner temperature (maximum liner temperature approximately $350^{\circ} \mathrm{F}$ ) was estimated for Kaolite saturated with supernate solution.

If the solution in the voids evaporates and nore solution seeps into the remaining voids until they are filled with dried supernate, the maximum temperature in the Kaolite would be $13.1^{\circ} \mathrm{F}$ above the inner steel liner temperature.

In the unlikely event that all the volds beneath the liner would be filled with sludge, the temperature would be somewhat higher and would be strongly dependent on the age of the sludge. Sludge with a volumetric heat generation rate of $60(\mathrm{Btu}) /(\mathrm{hr})$ (ft3) would create a maximum temperature in the Kaolite that is $51.4^{\circ} \mathrm{F}$ above the inner steel liner temperature.

The inner steel liner temperature would also rise somewhat because of the heat flowing into the sludge from the Kaolite. The amount of this additional temperature rise is difficult to estimate, but it would be small for a tank under nomal operating conditions.

Assumptions

The following assumptions were made during the calculations:

1. Supernate has a heat generation rate of $0.5 \mathrm{Btu} /(\mathrm{hr})$ (gal) and a specific gravity of 1.1 .

2. The Kaolite has a void fraction of 0.70 . It picks up 80 wt\% supernate resulting in a final composition of 39.2 lb. of supernate.

* Leak detection systems exist in the annulus and should give an early notice of tank failure. Thus, the tank contents should be transferred before these temperature rises occur. 
UNCLASSIFIED

ARH-1833

Page 6

3. Solidified supernate would concentrate the heat generation by a factor of four.

4. The maximum local Kaolite thickness is 8 inches.

5. The maximum local bulge in the steel inner tank liner is 4 inches.

6. All of the bulge is filled with the same material that is permeating the volds of the Kaolite.

7. All the heat generated below the inner liner goes upward into the tank. This is equivalent to assuming that the bottom of the tank is insulated.

Thermal Conductivities

The thermal conductivities of the composites of Kaolite with imbibed materials are crucial in determining the temperature rises.

The thermal conductivity of Kaolite as given by the manufacturer is $0.129 \mathrm{Btu} /(\mathrm{hr})\left(\mathrm{ft}^{2}\right)\left({ }^{\circ} \mathrm{F} / \mathrm{ft}\right)$. At low temperatures this is due to a mixture of 70 vol $\%$ air (thermal conductivity $=0.0514 \mathrm{Btu} /(\mathrm{hr}$ ) $\left(\mathrm{ft}^{2}\right)(\mathrm{F} / \mathrm{ft})$ and 30 vol $\%$ pure Kaolite. The correlations of Harper and Sahrigi (I. \&E. C Fundamentals 3:318-24 (1964) and of Hamilton and Crosser (I. \&E. C Fundamentals 1:187-91 (1962) both predict an extrapolation to a thermal conductivity of pure, dense Kaolite of $0.66 \mathrm{Btu} /(\mathrm{hr})\left(\mathrm{ft}^{2}\right)\left({ }^{\circ} \mathrm{F} / \mathrm{ft}\right)$. There could be 10 - 20 percent error in the estimates because of the large extrapolation from 30 vol \% Kaolite.

The thermal conductivity of aqueous supernate is estimated to be $0.36 \mathrm{Btu} /(\mathrm{hr})\left(\mathrm{ft} \mathrm{t}^{2}\right)\left({ }^{\circ} \mathrm{F} / \mathrm{ft}\right)$. The thermal conductivity of the superm nate Kaolite composite is estimated to be $0.44 \mathrm{Btu} /(\mathrm{hr})\left(\mathrm{ft}^{2}\right)\left({ }^{\circ} \mathrm{F} / \mathrm{ft}\right.$ ) by the methods of Hamiton and Crosser and of Cheng and Vachon (Int. J. Heat \& Mass Transfer 12:249-64 (1968).

The thermal conductivities of solidified supernate and dry sludge are estimated to be $0.45 \mathrm{Btu} /(\mathrm{hr})\left(\mathrm{ft}^{2}\right)\left({ }^{\circ} \mathrm{F} / \mathrm{ft}\right)$. By the above methods, the thermal conductivities of solidified supernate - Kaolite and dry sludge - Kaolite composites are estimated to be 0.51 $\mathrm{Btu} /(\mathrm{hr})(\mathrm{fte})\left({ }^{\circ} \mathrm{F} / \mathrm{ft}\right)$. 
UNCLASSIFIED

ARH-1833

Page 7

Calculations

The temperature rise from the inner steel linex to the bottom of the Kaolite is calculated from the equation:

$$
\begin{aligned}
& T=\frac{S_{k} I_{k} I_{c}}{k_{c}}+\frac{S_{k} I_{k}^{2}}{2 k_{k}}+\frac{S_{c} I_{c}^{2}}{2 k_{c}} \\
& S_{k}=\text { volumetric heat generation rate in Kaolite composite, } \\
& S_{c}=\text { volumetric heat generation rate of material in bulge } \\
& \text { above Kaolite, Btu/(hr) (ft3) } \\
& l_{k}=\text { Kaolite thickness, ft. } \\
& I_{c}=\text { thickness of bulge above Kaolite ft. } \\
& \mathrm{k}_{\mathrm{C}}=\text { thermal conductivity of material in bulge above } \\
& \text { Kaolite, Btu/(hr) ( } \left.\left.\mathrm{ft}^{2}\right) \text { ( }{ }^{\circ} \mathrm{F} / \mathrm{ft}\right) \text {. } \\
& \mathrm{k}_{\mathrm{k}}=\text { thermal conductivity of Kaolite composite, } \mathrm{Btu} /(\mathrm{hr}) \\
& \left(f t^{2}\right)(\circ \mathrm{F} / \mathrm{ft}) \text {. }
\end{aligned}
$$

The first term is the temperature rise through the bulge above the Kaolite due to heat generation in the Kaolite, the second term is the temperature rise through the material in the bulge above the Kaolite due to its own heat generation. The terms are approximately of equal importance.

D. Pressure Evaluations

Some concern existed over the potential blockage of the air distribution channels which were provided in the refractory slab. If a primary tank leak were to occur at the operating temperature and with these channels tightly plugged, high pressure steam could form between and damage the tanks. However, it appears doubtful that conditions could exist which would not permit slight movement of the steel Inex with subsequent pressure release before damaging the innex tank.

B. Structural Evaluetion

The task force concluded from visual obsentations and from studying the photographs of the refractory that further deterioration would 
occur if the AY tanks were operated as is. With further deterioration, support would be lost from under the primary tank knuckle, i.e., the primary bottom would be cantilevered over its deteriorated foundation. See Figure 11. Therefore, stress analyses of the primary tank assuming increments of support loss under the knuckle were attempted in order to determine how much foundation deterioration could be tolerated.

\section{Stress Analyses and Results}

1. Pittsburg Des Moines Company, (PDM), the AY steel tank fabricators, stress analyzed the primary tank assuming 6 inches and 12 inches of knuckle support Ioss and using their axisymmetric thin shell computer program AX2. PDM was requested to do these analyses because they had adapted AX2 to this structure and stress checked the design for a variety of loads prior to fabrication. The results of the early PDM analyses were transmitted December 18, 1968 (Reference 3). The latest PDM analyses calculated stress intensities, as defined in $\mathrm{N}-412$ of the ASME Pressure Vessel Code, Section III, Nuclear Vessels, for the extreme fibers of the primary shell plate. The results (Reference 4 ) for 6 inches and 12 inches of support loss are plotted in Figure 12 and Figure 13, respectively. The maximum stress intensities corresponding to 6 and 12 inches 1 oss are 41515 psi and 67633 psi. As expected, the maximum stresses would occur where the primary bottom resumes contact with the foundation.

PDM's AX2 employs the "stiffness method", $1 . e$. , the shell is idealized as a series of smaller shell bodies interconnected by nodes. Twenty-four such shell elements were modeled for the runs reported here. The program assembles a stiffness matrix and load vectors, modifies the stiffness matrix to account for boundary conditions, and then solves for node displacements.

2. Also, the primary tank was analyzed to determine the affect of foundation loss using AXISOL, a program for computing deflections and stresses in axisymmetric solids. The knuckle region (expected location of maximum stresses) was idealized as 541 finite elements and isolated as a free body. The most realistic boundary conditions that could be assumed for the isolated body, and still apply AXISOL, were very conservative. The maximum stress intensities the AXISOI analyses gave were 57308 psi and 83900 psi for zero and 3 inches foundation loss, respectively. The conservatism of this analysis shows when comparing the results to those of AX2. 
AXISOI is a finite element program for elastic-plastic analysis of axisymmetric solids, and has been in use at Hanford since 1967. To apply AXISOL, the continuous structure is divided into a system of elements interconnected at node points. The program developes equilibrium equations in terms of unknown nodal displacements. The solution of this set of equations is then obtained and manipulated to give final results.

3. In addition to the AX2 and AXISOI analyses just described, Computer Sciences Corporation (CSC) was delegated to attempt a one time best effort analysis of the primary tank with deteriorated foundation using their axisymmetric thin shell program, ESHELI. The analytical modeI CSC used for the ESHELI analyses was not as refined as the one used for the AXe analysis, i.e., the tank was only broken up into seven shell elements for the ESHELI runs. Therefore, a direct comparison between results of AX2 and ESHELI analyses is not practical. However, the ESHELU analyses do indicate significant stress increases for progressing knuckle support Ioss (Reference 5 ).

According to ASME Section III, the stress intensity in the primary tank at the specified maximum operating temperature must be compared to an allowable value of $(35 \mathrm{~m}) 52500 \mathrm{psi}$. The PDM AX2 results indicate that the structure likely could tolerate 6 inches of foundation deterioration, but that support losses greater than 6 inches would put the vessel in questionable status.

The AXISOL analyses show stress intensities significantly greater than the above $\left(3 \mathrm{~S}_{\mathrm{m}}\right)$ value if only a small amount of foundation loss occurs under the tank.

The general conclusion from the AX? and AXISOL analyses is that good knuckle support is very critical to the safety of the primary tank. Also, based on the inspection of the as-built refractory and its demonstrated physical properties or the surface, support losses from under the knuckle greater than 6 inches are credible. Therefore, the task force recommended a structural modification to the insulative refractory before operating the AY tanks 101 and 102. The modification must provide adequate support under the primary knuckle and confine the refractory back in from the knuckle such that the primary bottom is also supported. The proposed modification, subsequently implemented, is to remove the outer I foot 9 inches of the refractory and replace with reinforced, shrink compensating concrete, (see Drawing $\mathrm{H}-2-35299$ ). Other pertinent details of the modification are: Tank fluid level must be lowered to 36 inches maximum, during repair, the work must be accomplished using 8 foot (maxim mum) skip pours around the perimeter, and channels will be formed in the new concrete matching the originals. 


\section{REFERENCES}

1. B \& W Kaolite 2200-II Average Properties, Babcock \& Wilcox Refractories Division, January 9, 1968.

2. Letter, G. Jansen, Jr. to H.I. Caudi11, "Temperatures in Kaolite in the AY Tank Farms After a Waste Leak", dated June 3, 1970.

3. Stress Analyses for 241-AY Primary Liner, Pittsburg Des Moines Company, PDM Contract 38570, December 18, 1968.

4. Effects of Foundation Deterioration, Part I, Purex Waste Storage Facility, PDM Contract 38570, June 5, 1970.

5. Letter, J.C. Go, Computer Sciences Corporation to F.R. Vollert, "Tank Support and Stress Analysis, dated June 15, 1970. 


\section{FIGURE 1}

TYPICAI 3/4 IN. REFRACTORY SURFACE DETERTORATION, TANK 102

$S$

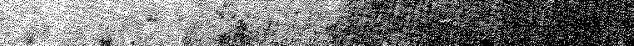

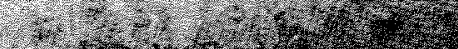

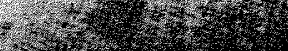

\% -

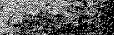
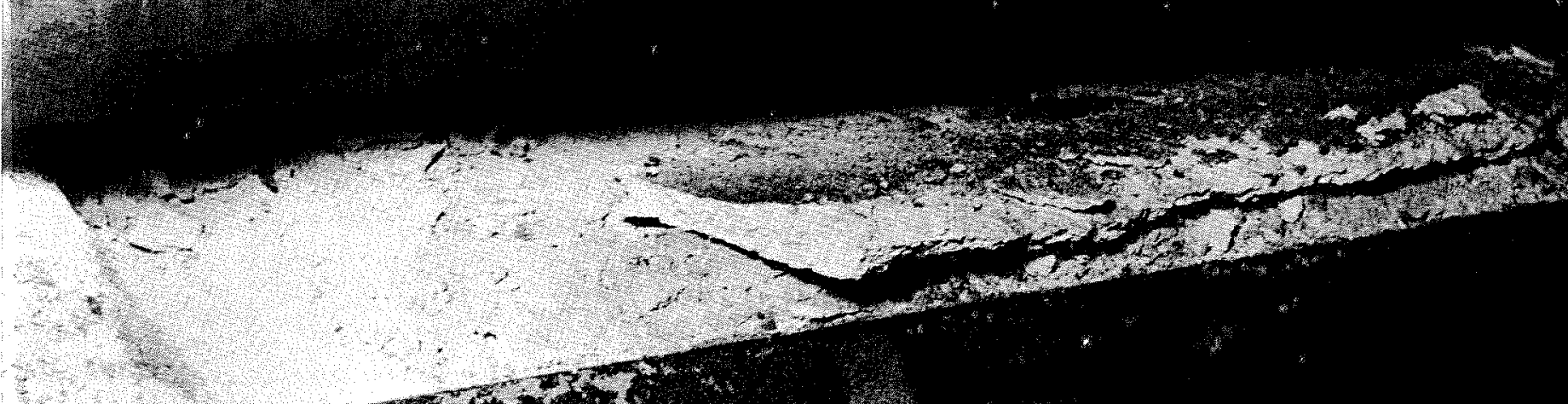

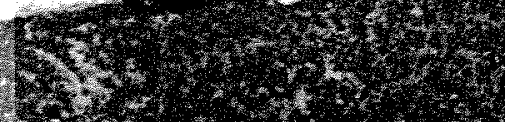

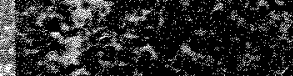
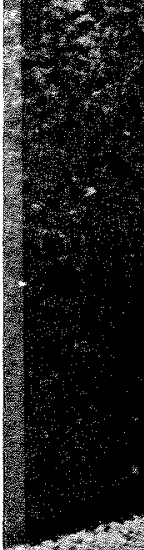

(3)
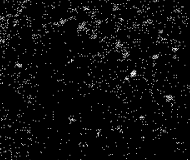
FIGURE?

EXTREMEIY POOR SECTION OF REFRACTORY

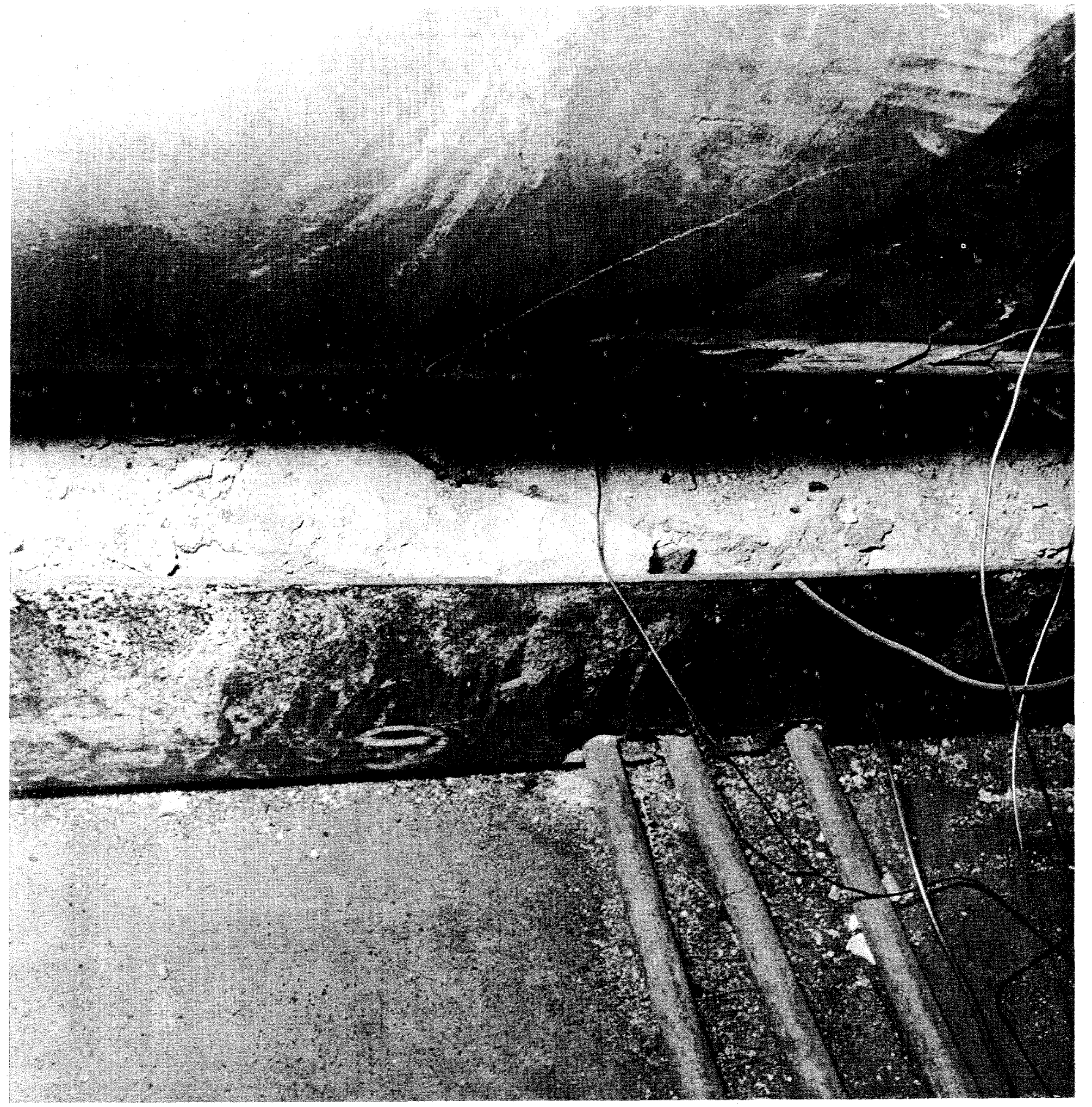




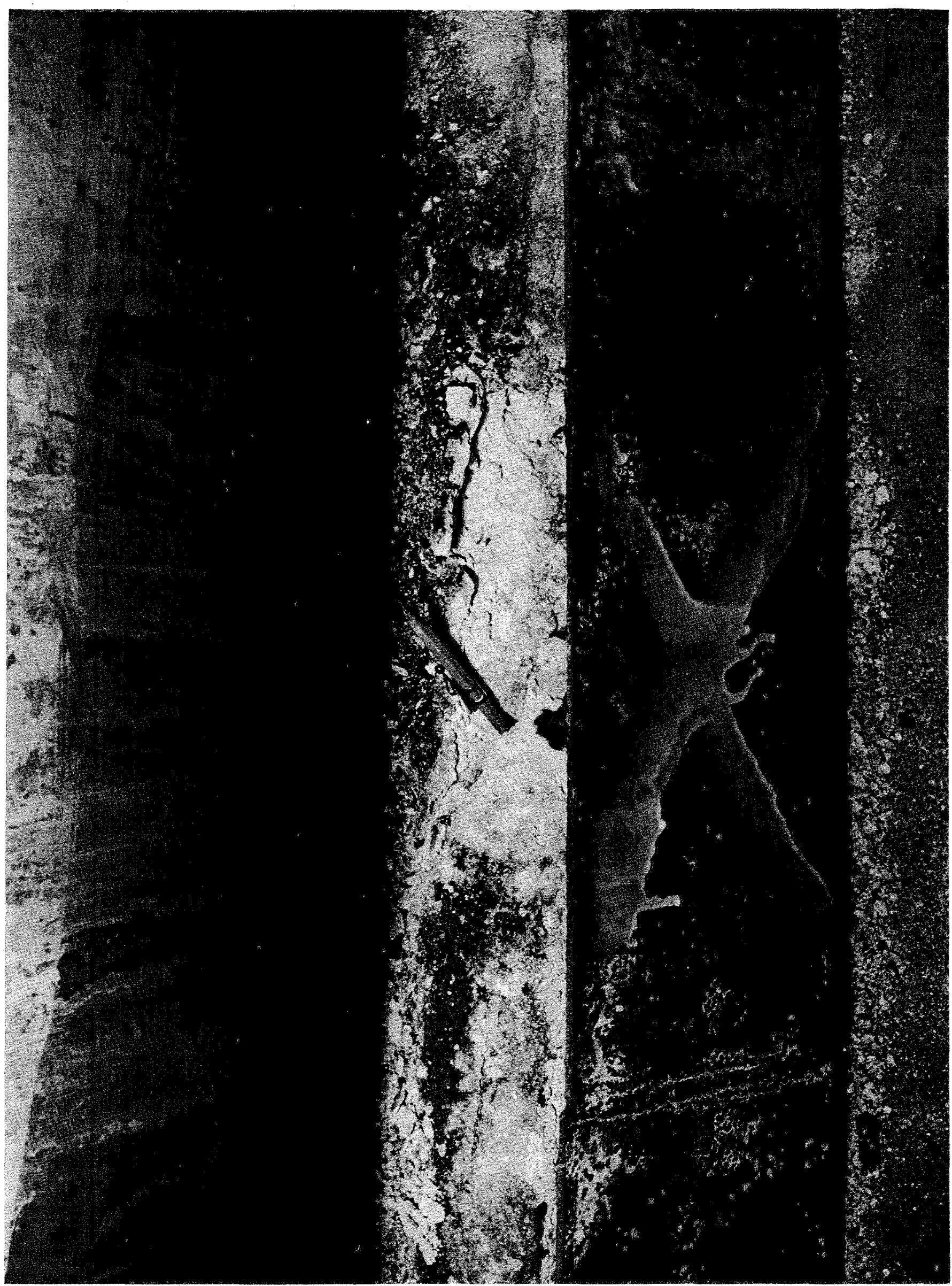


FIGURE 4

\section{AY TANK 102 CONDITION PLOT}

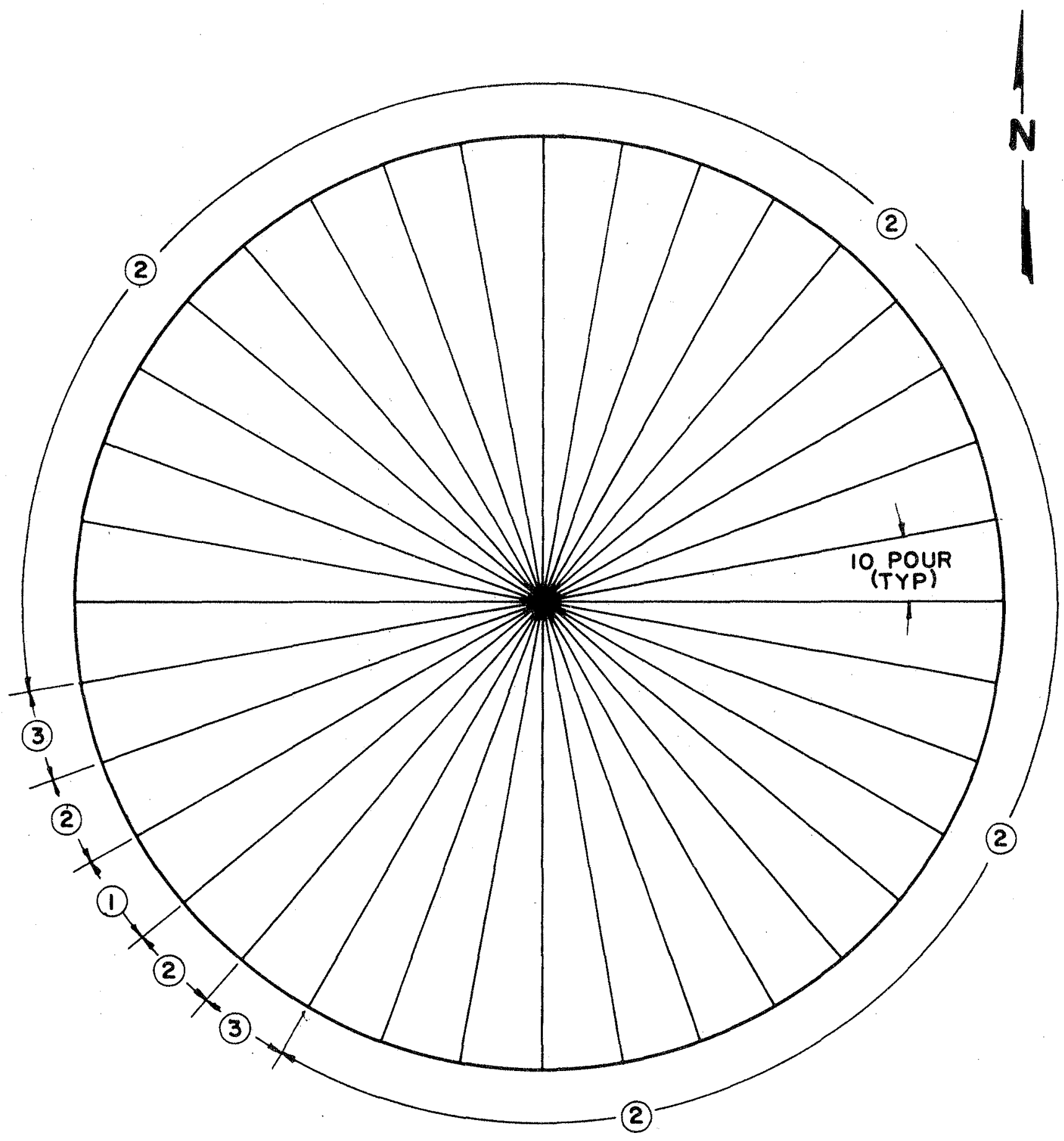

LEGEND

(1)- 6000

(2)- SURFACE DETERIORATION $=\frac{3}{4}-1$ IN.

(3)- VERY POOR 


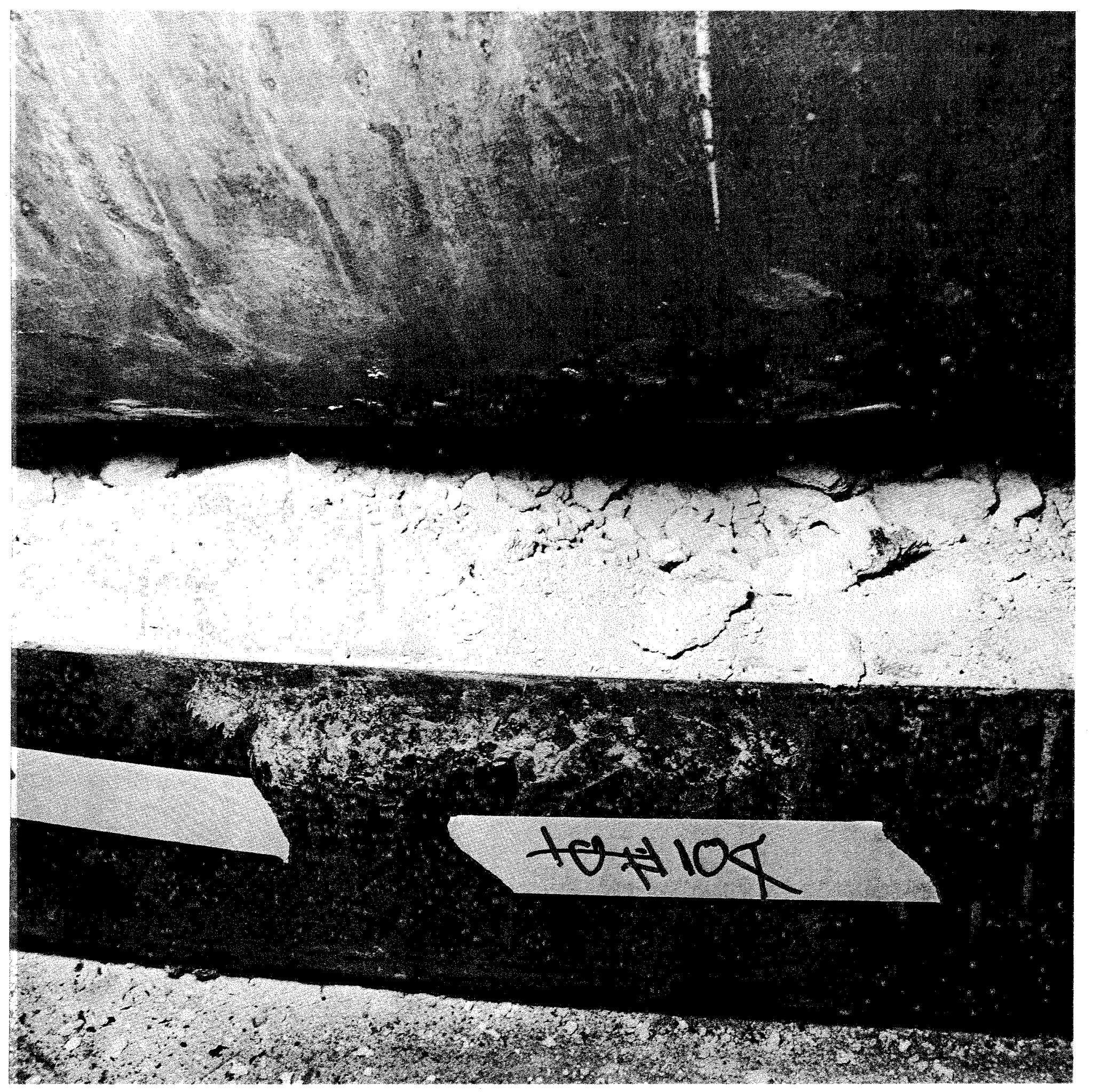




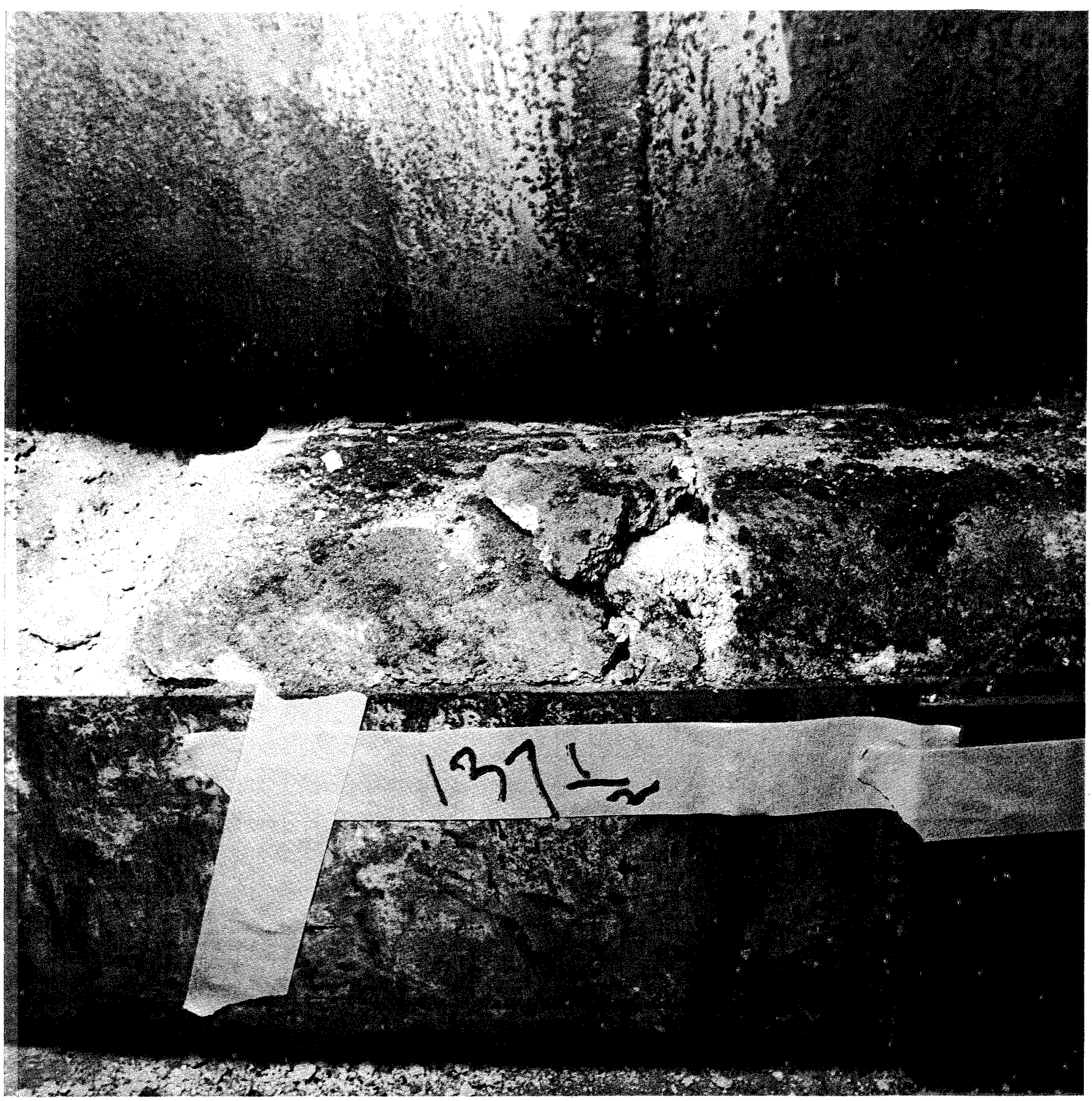


REFRACTORY SURFACE DEIERTORATION

IESS THAN I/2 IN., TANK 101

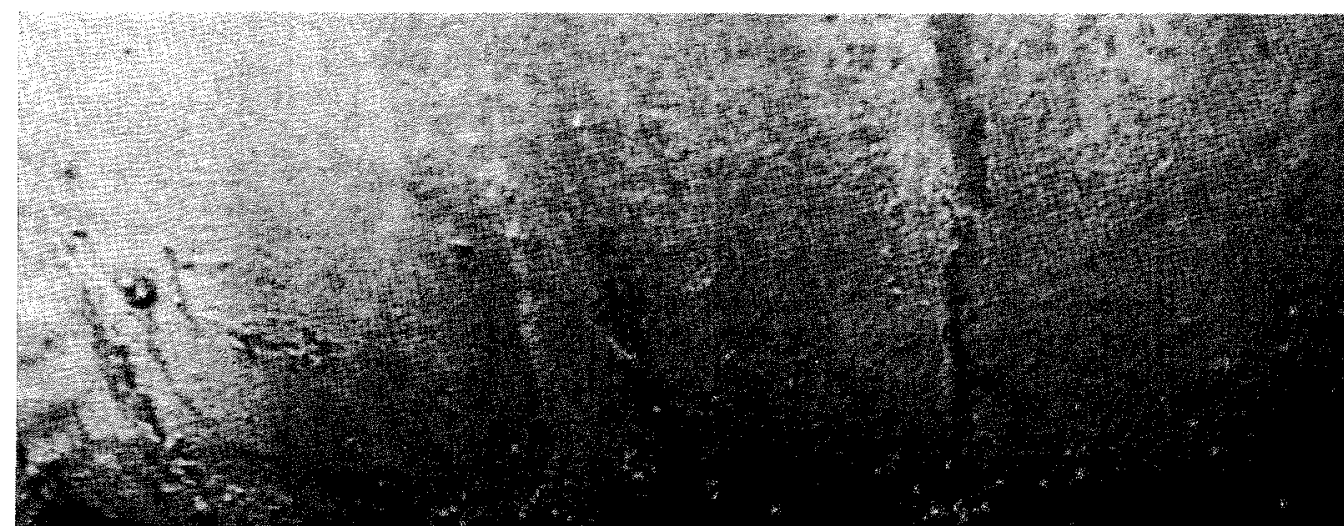

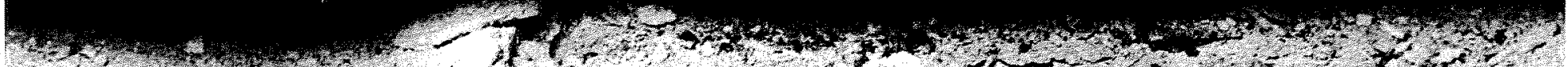

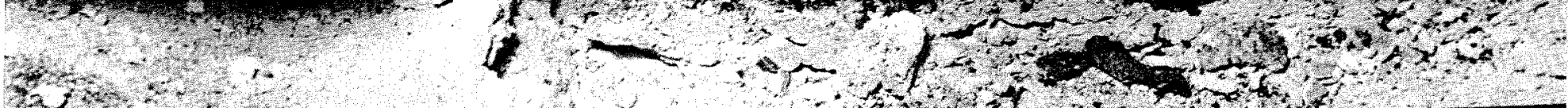

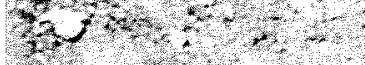

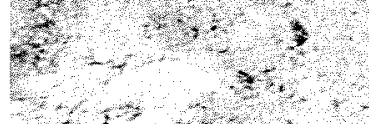

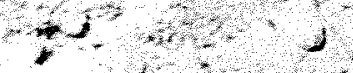

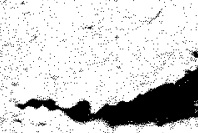

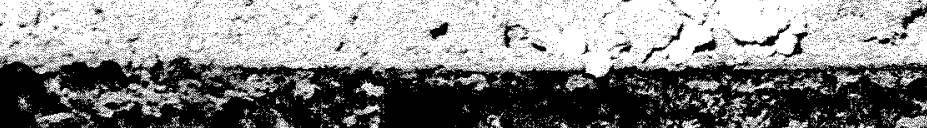

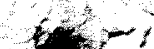
$-x^{2}+2$
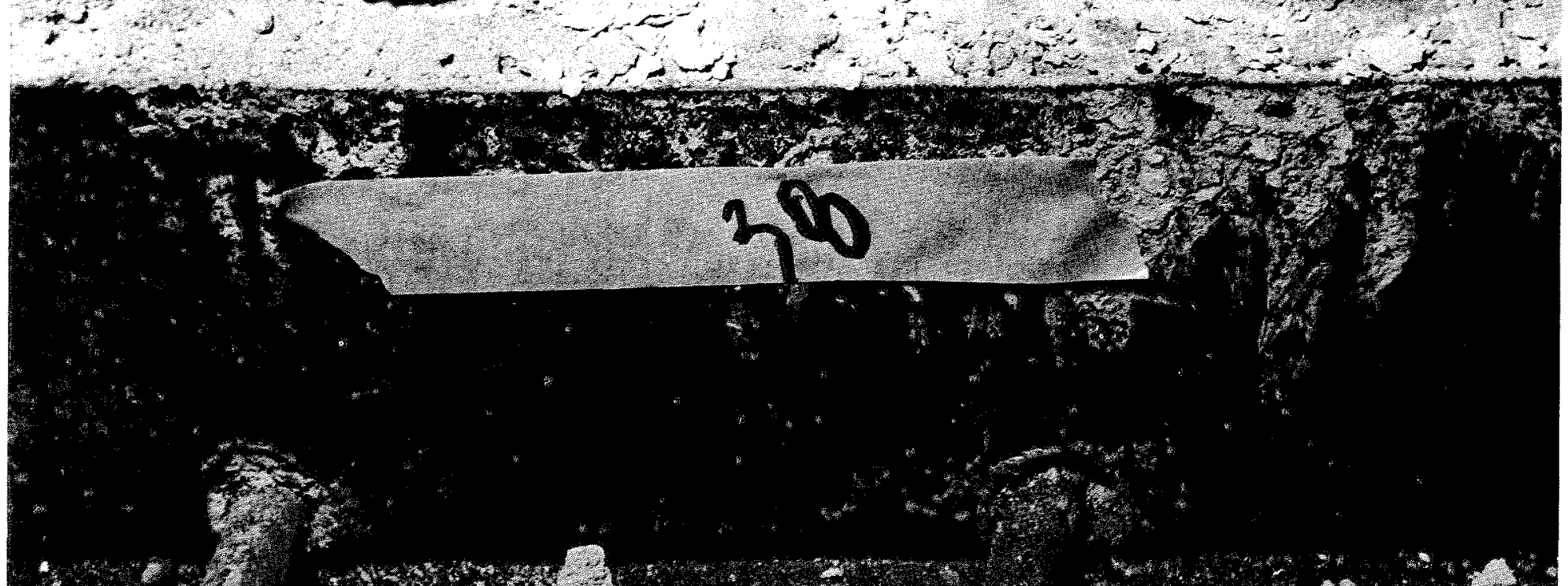

(3)

1. 63243

wotrat 


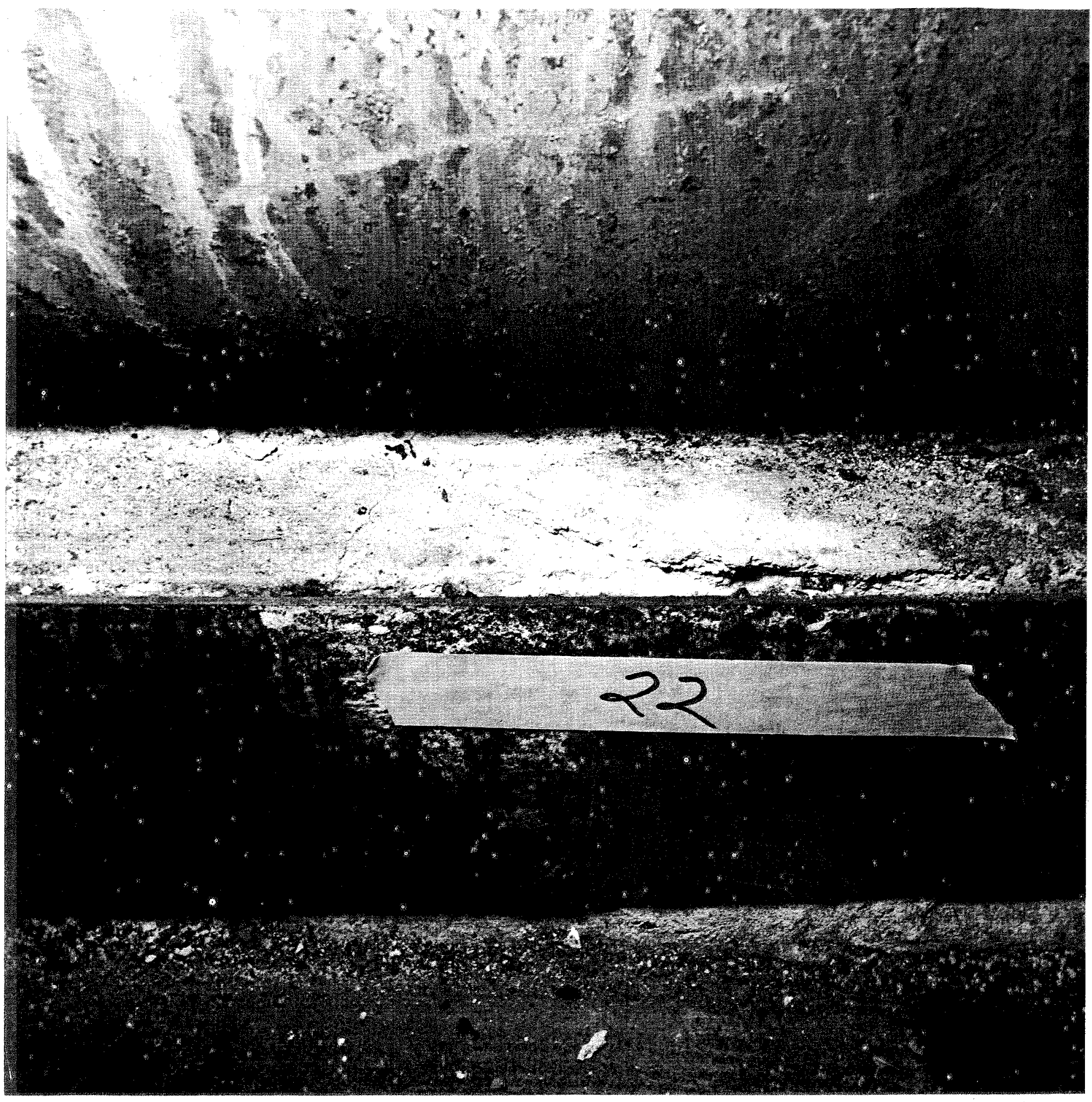




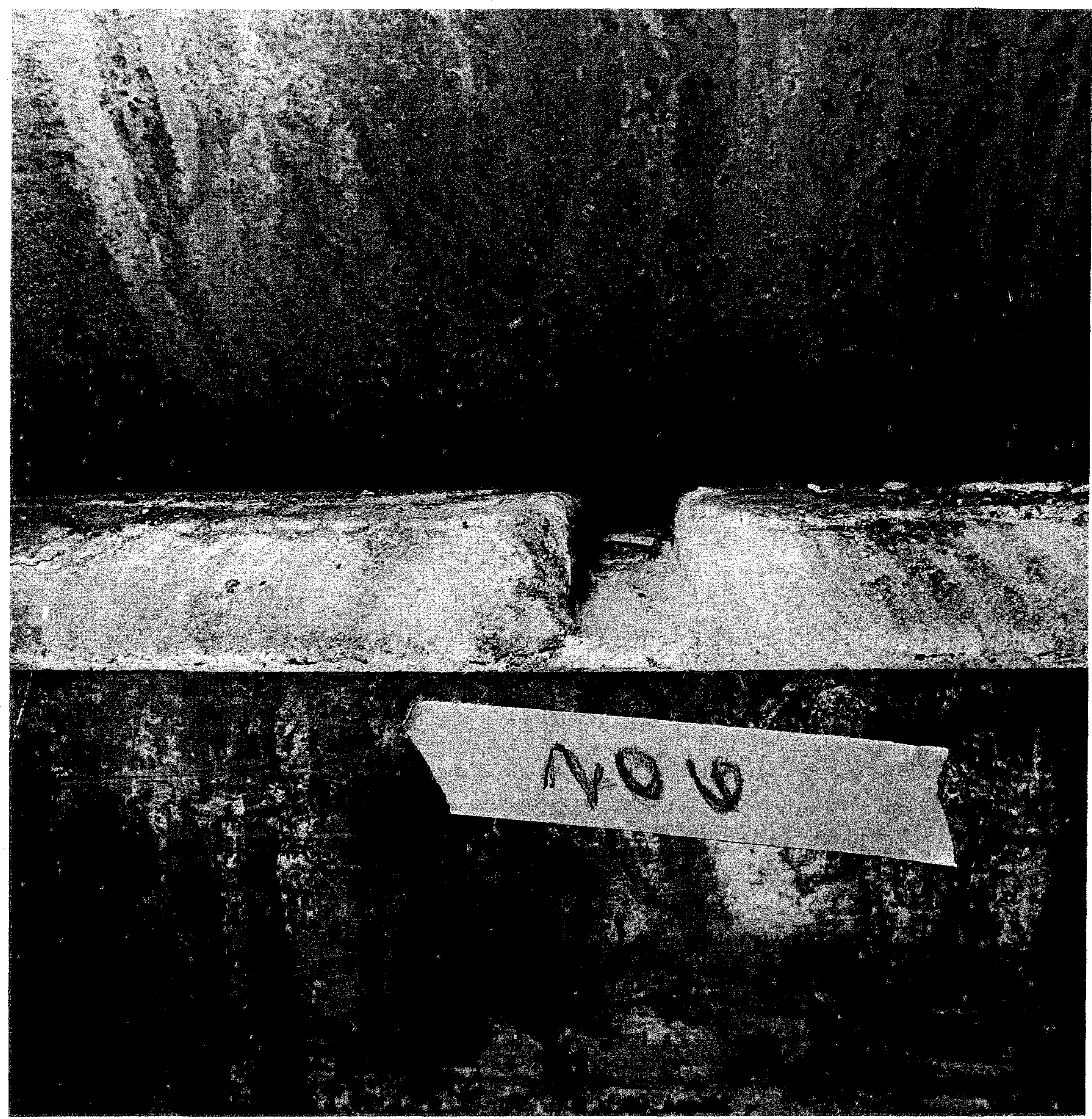




\section{AY TANK 101 CONDITION PLOT}

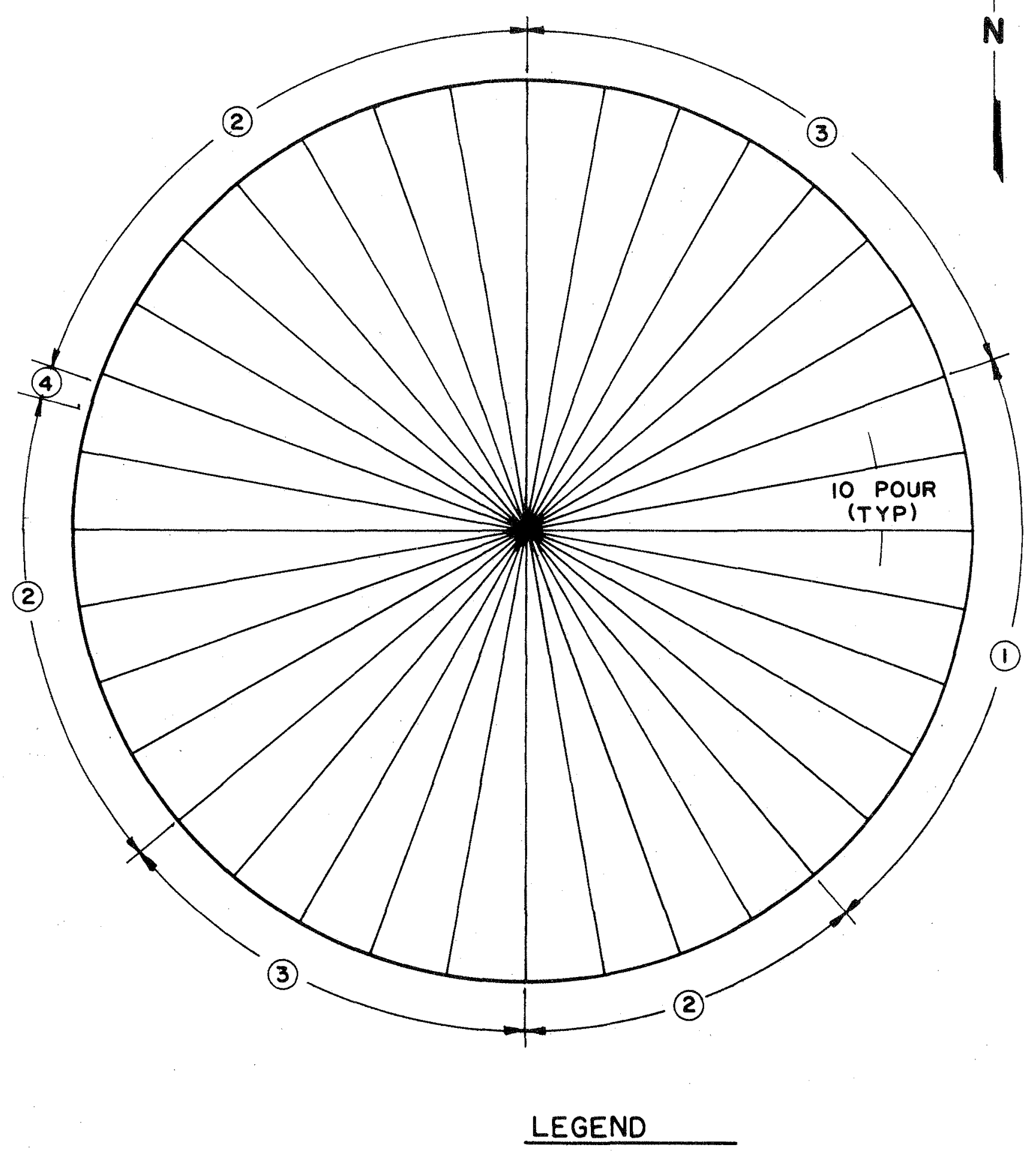

(1) - GOOD CONDITION

(2) - SURFACE DETERIORATION $<1 / 2 I N$.

(3) - SURFACE DETERIORATION $\approx 3 / 4 I N$.

(4) - BADLY FRACTURED AT PERIPHERY 


\begin{tabular}{l} 
FIGURE $-\|$ \\
SUPPORT LOSS AT PRIMARY KNUCKLE \\
\hline
\end{tabular}

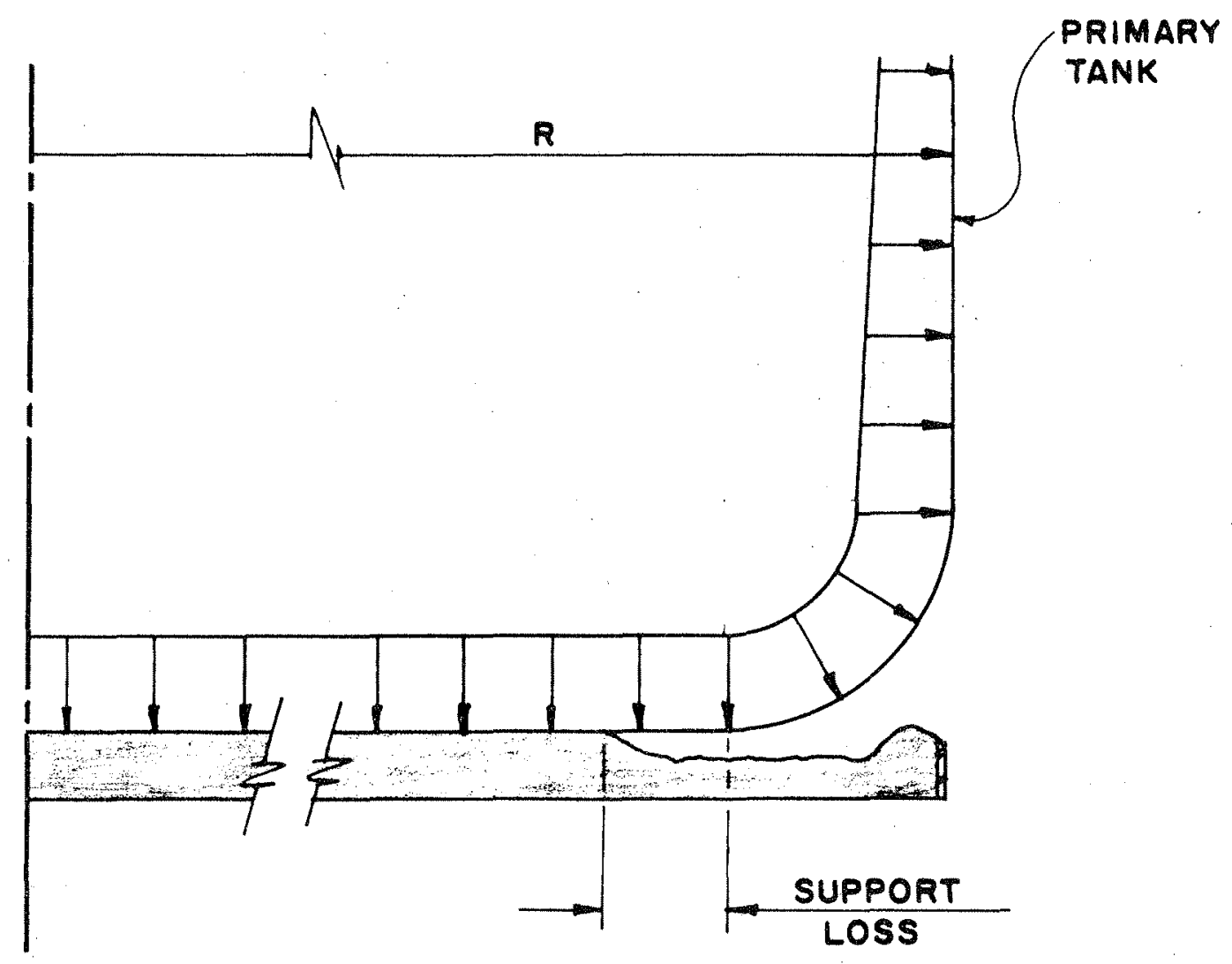


FIGURE-12

Rev. 0

\section{STRESS INTENSITY PLOT FOR \\ 6 IN. SUPPORT LOSS \\ (AXZ RESULTS)}

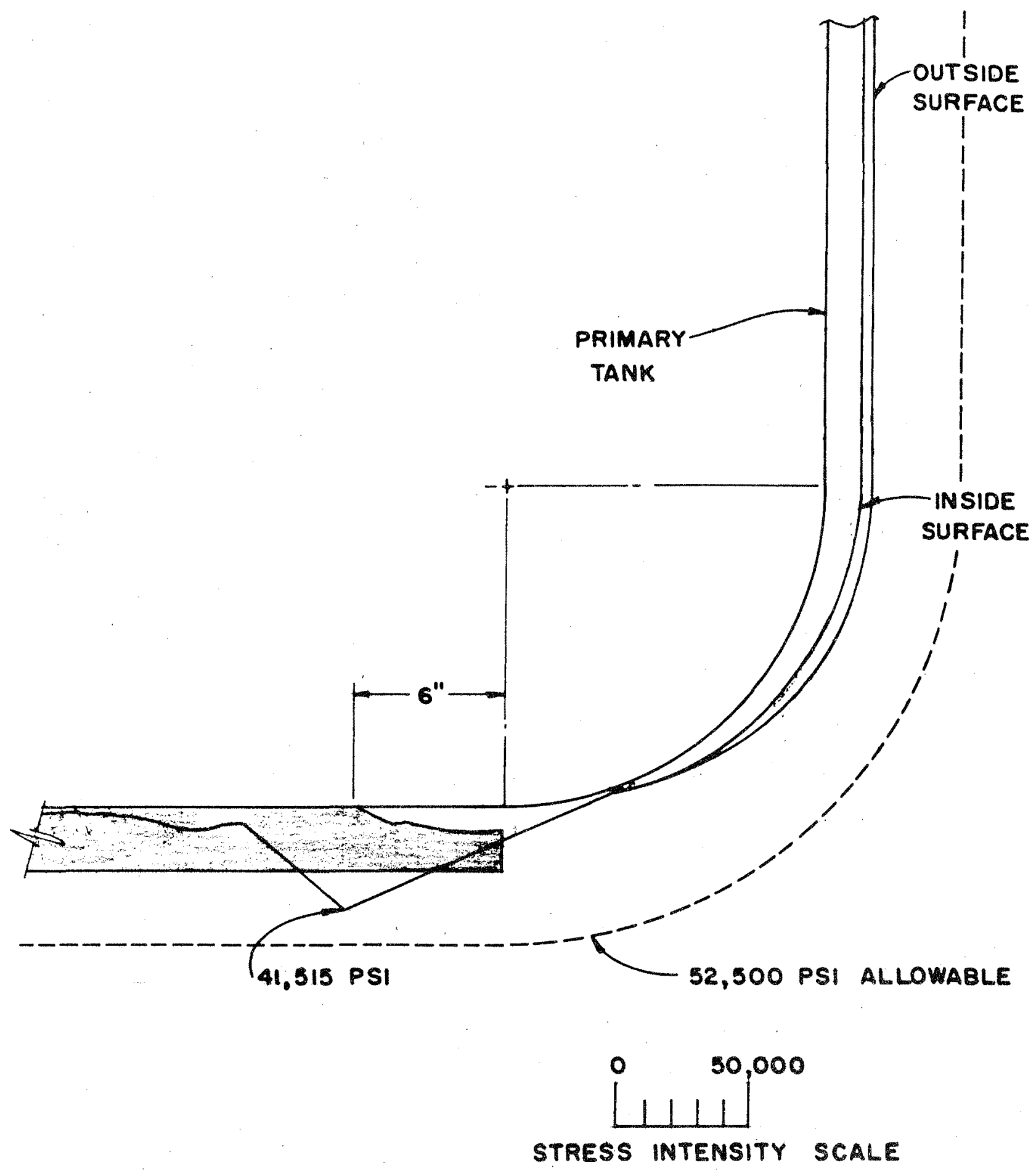


FIGURE - 13

Rev. 0

\section{STRESS INTENSITY PLOT FOR \\ 12 IN. SUPPORT LOSS \\ ( AXZ RESULTS)}
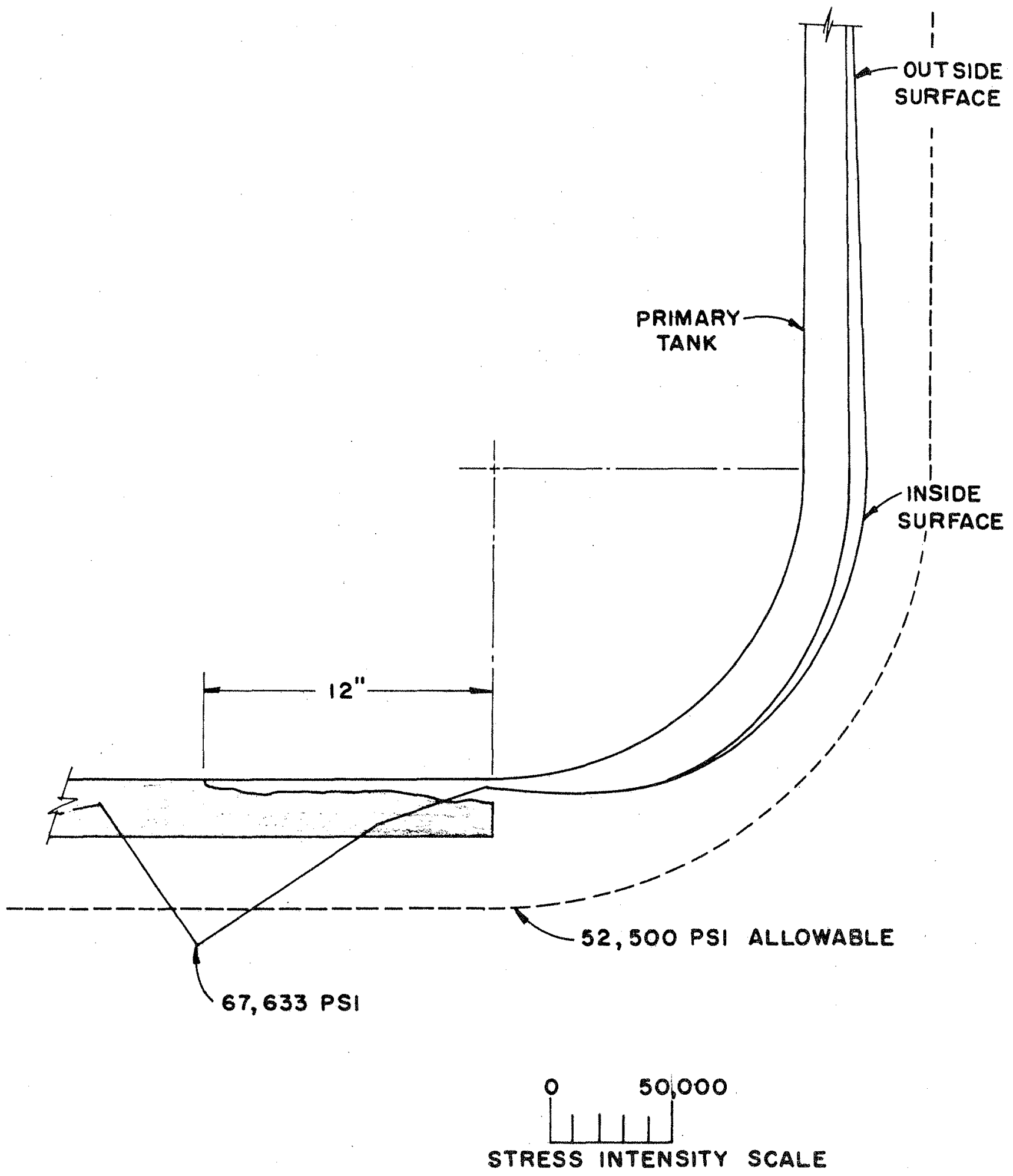


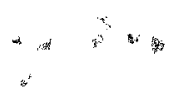

1.2. Armstrong, W. C., 1970, "Project IAP-614 - PUREX Tank Farm Expansion Post Weld Heat Treating Tanks 241-AY 101 and 10," (Letter to File, February 2), Atlantic Richfield Hanford Company, Richland, Washington. 


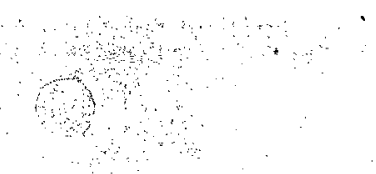

$\therefore$

Whas

no:

Fron:

cusjoctos abrotar 2,7370

yise

W. A. Armatrong USG

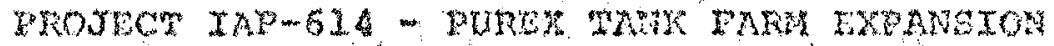

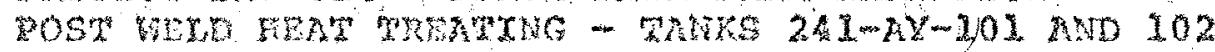

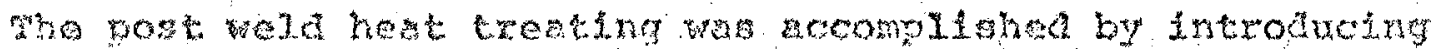

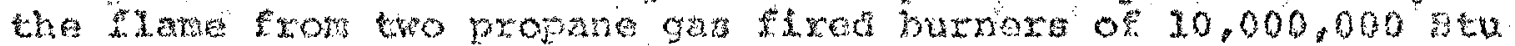

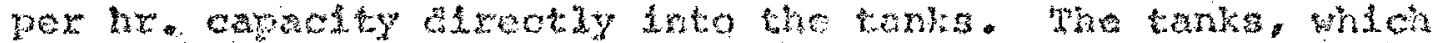

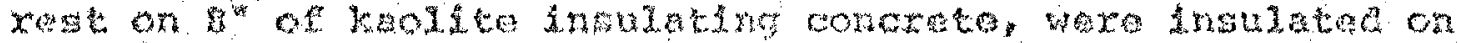

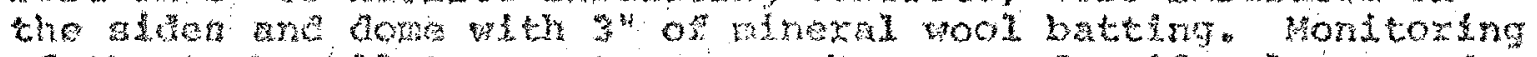

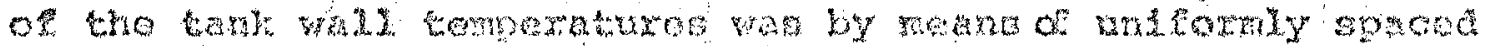

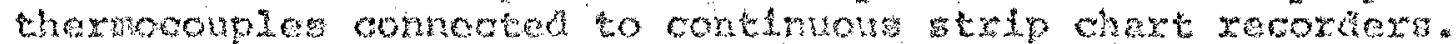

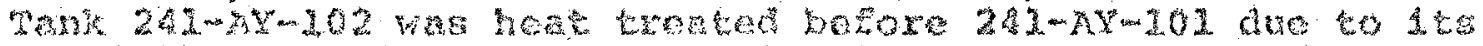

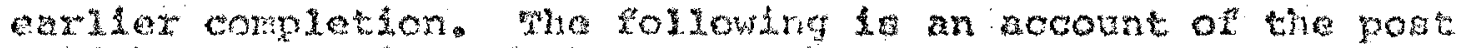

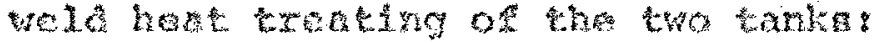

Tank $2-2-1+20 z$

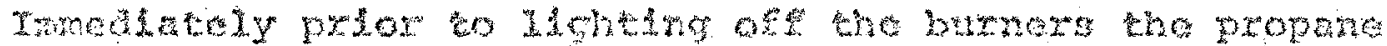

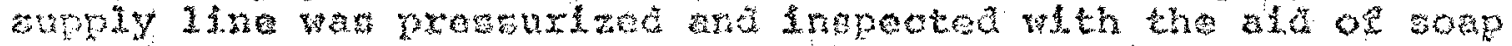

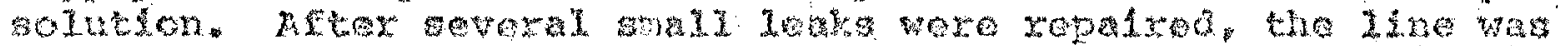

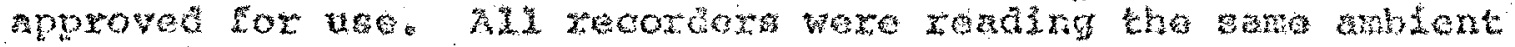
tormperatare.

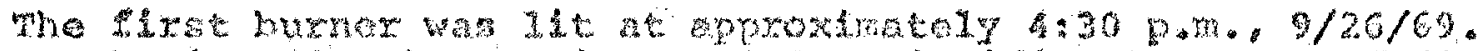

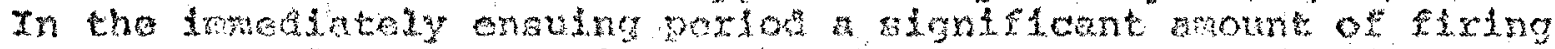

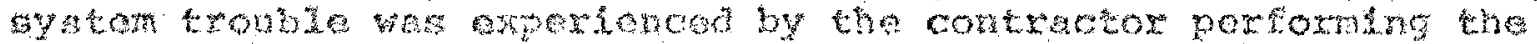

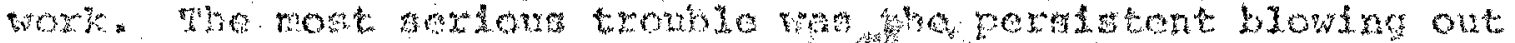

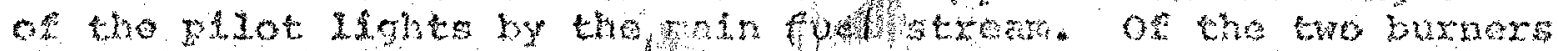

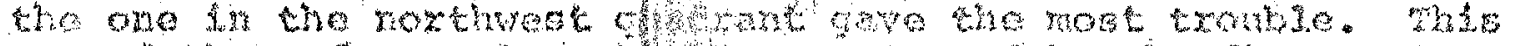

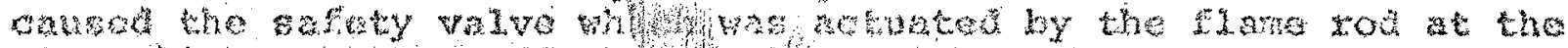

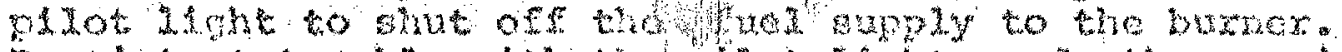

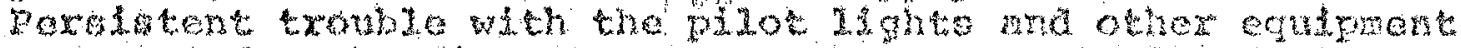

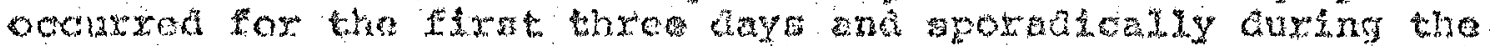

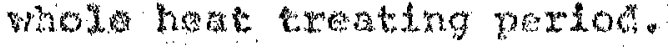

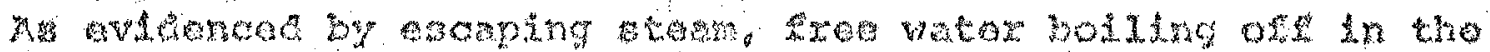

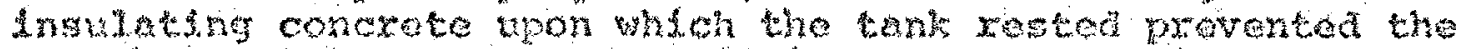

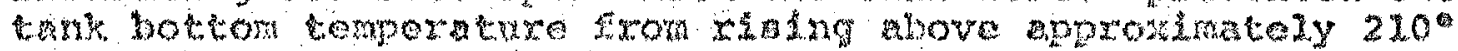
artat the nighto $9 / 20 / 09$ 
Rev. 0

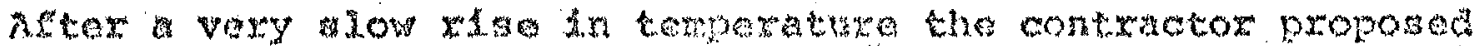

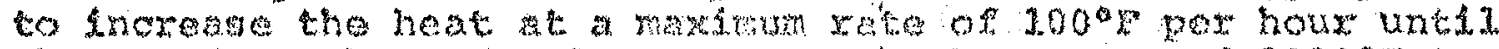

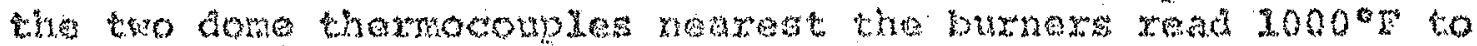

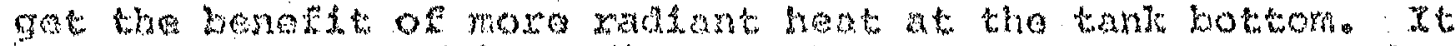

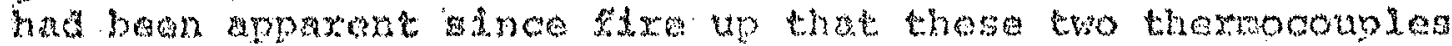

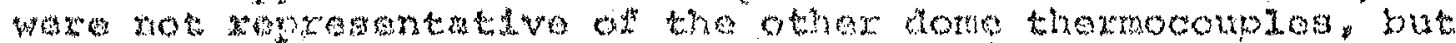

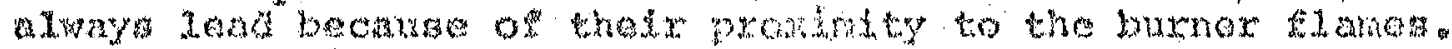

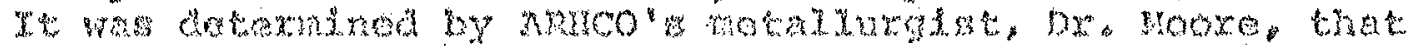

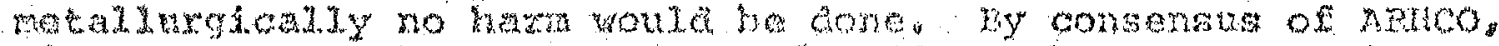
v1tact a

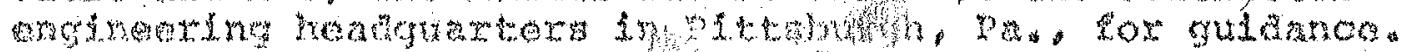

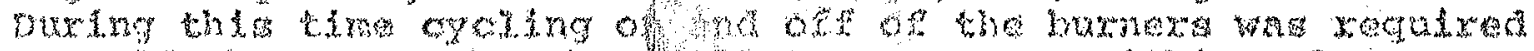

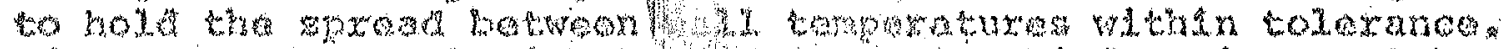

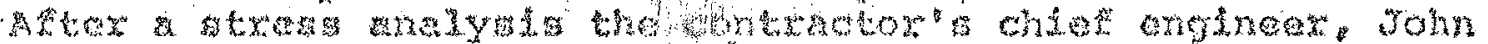

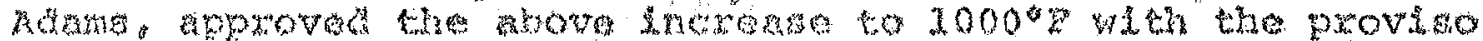

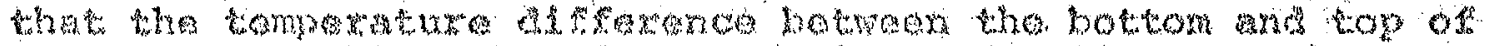

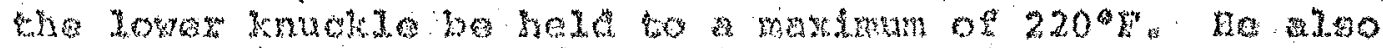

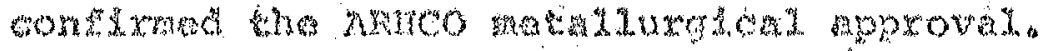

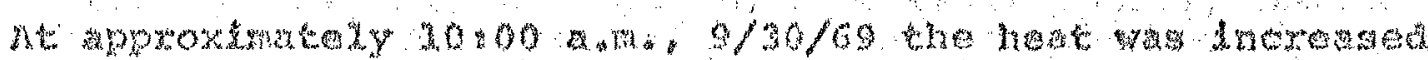

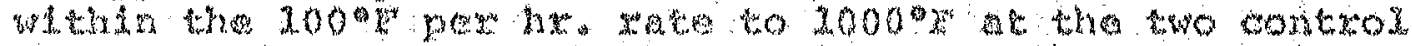
How

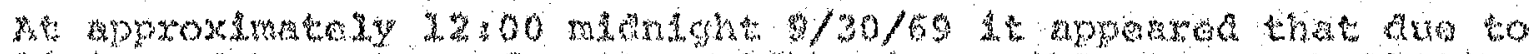

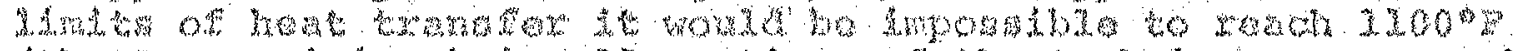

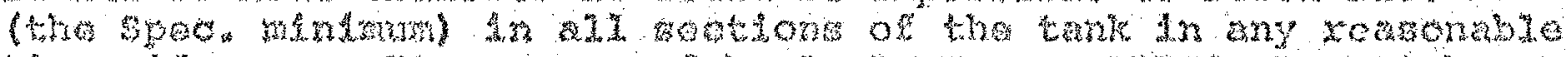

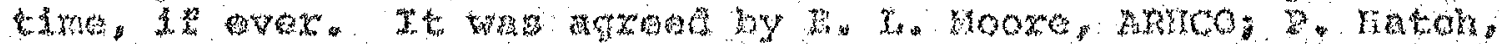

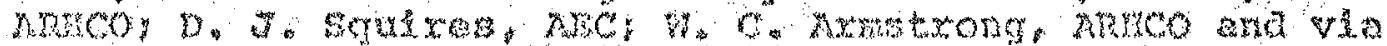

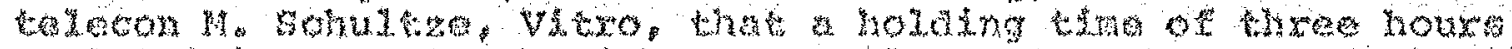

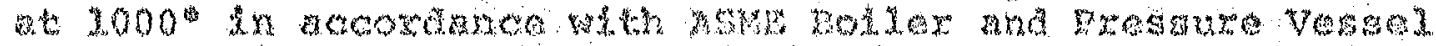

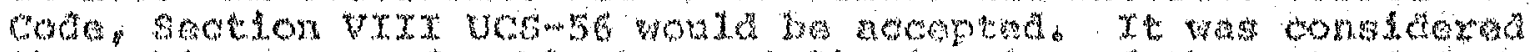

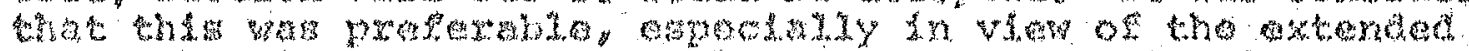

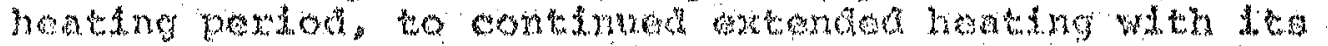

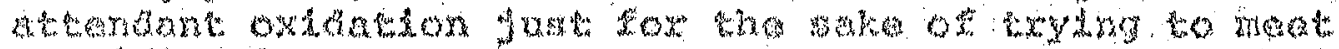

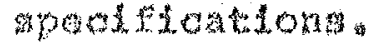

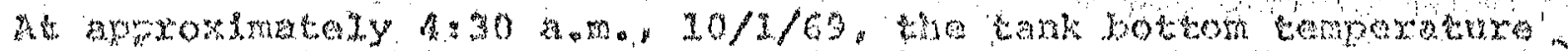

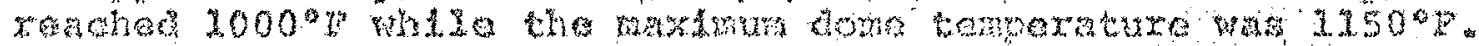

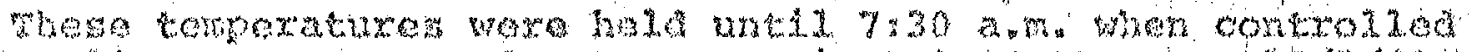

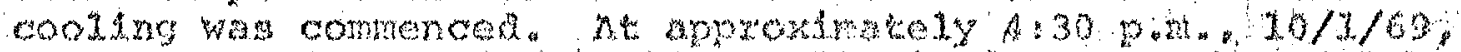

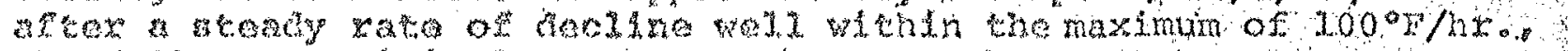

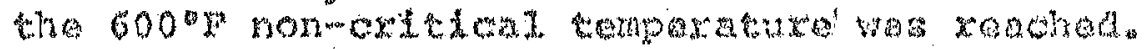

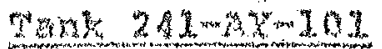

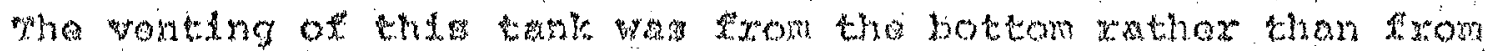

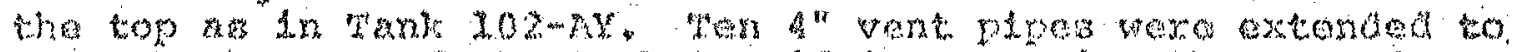

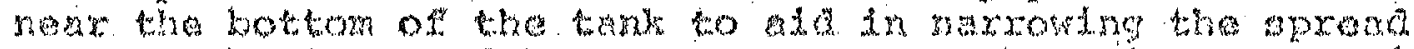

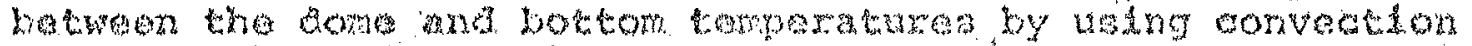

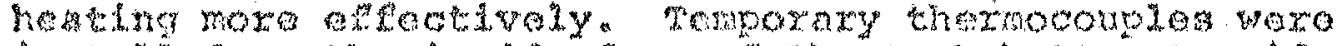

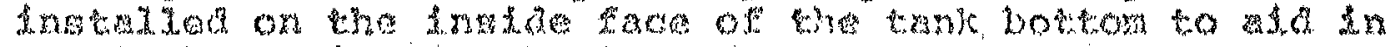

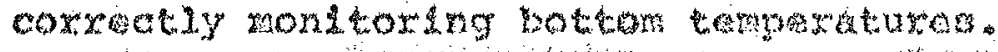




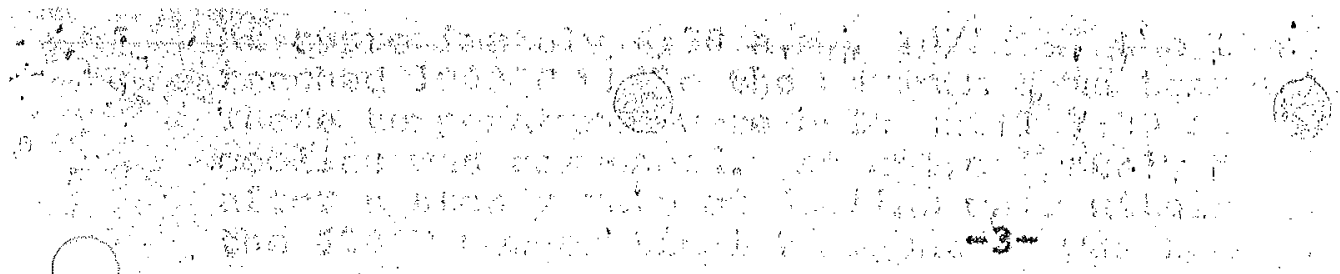

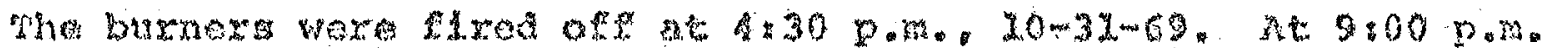

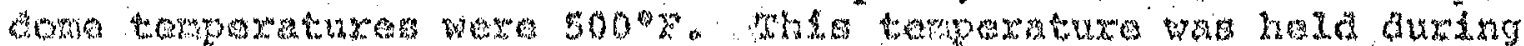

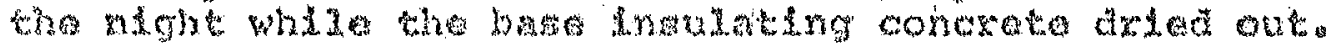

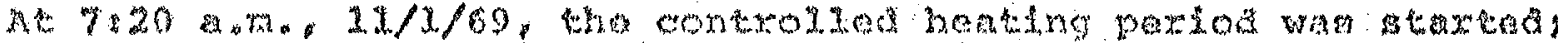
2.

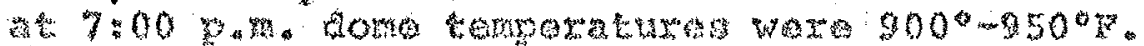

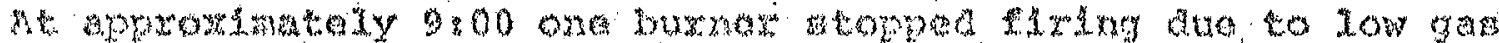

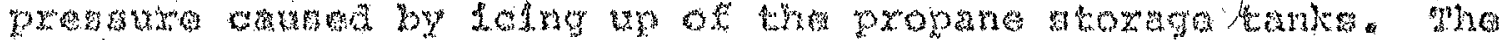

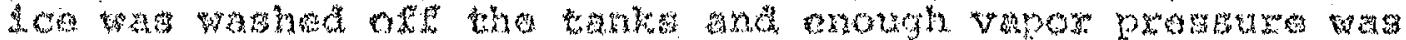

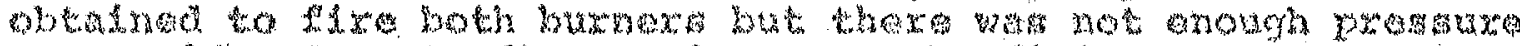

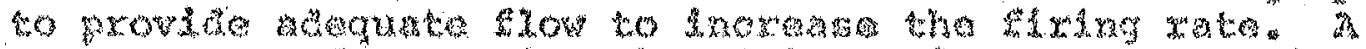

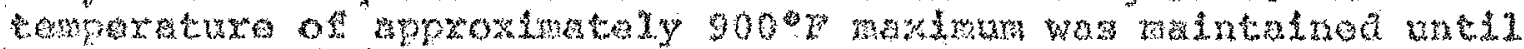

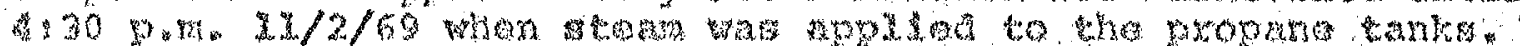

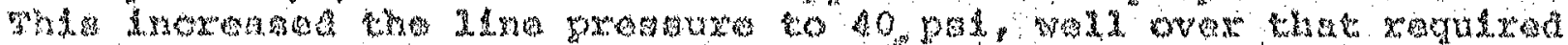

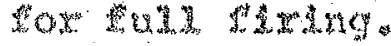

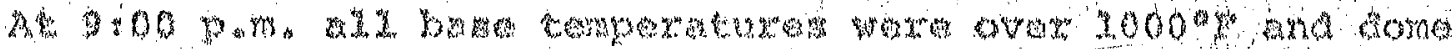

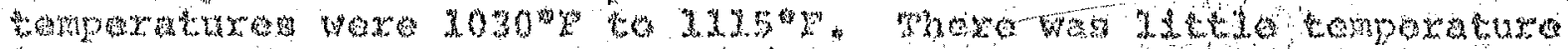

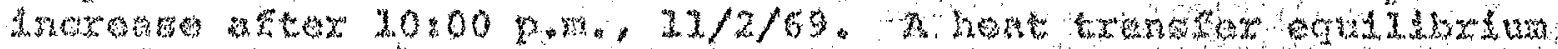

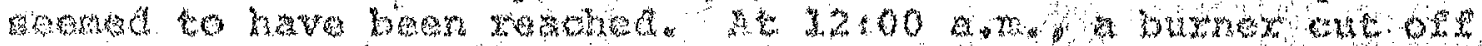

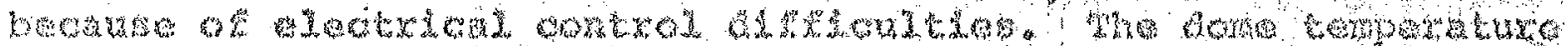

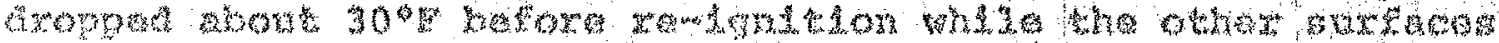

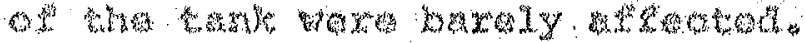

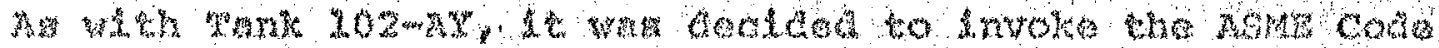

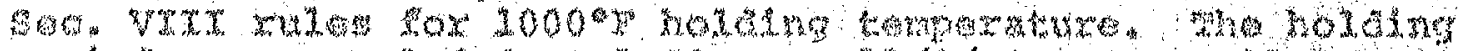

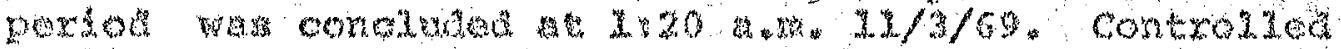

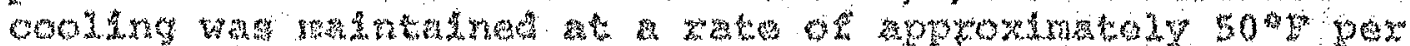

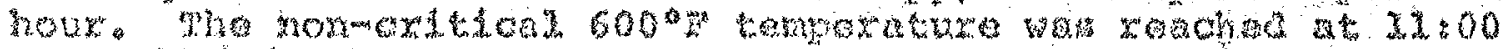

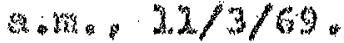

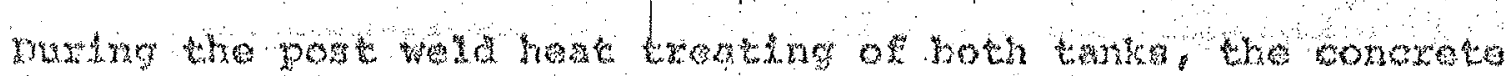

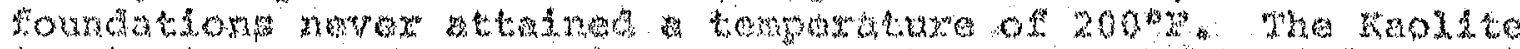

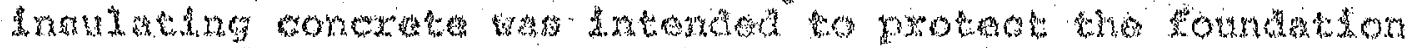

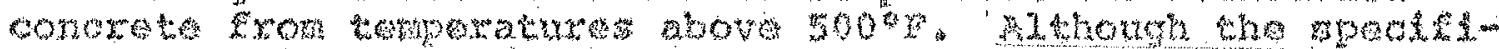

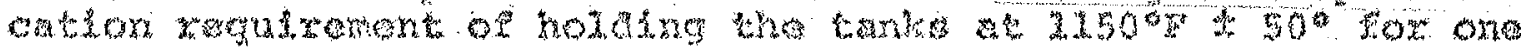

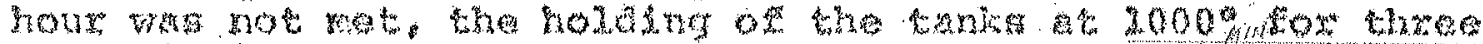

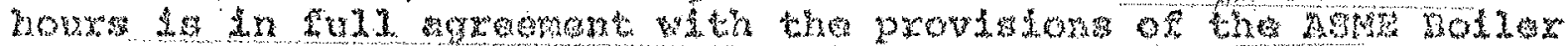

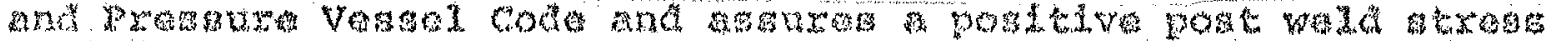

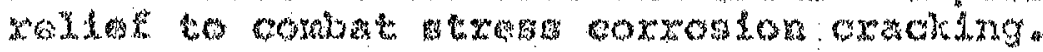

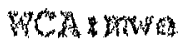

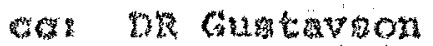

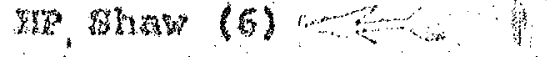


Rev. 0

1.3 Cardwell, C. W., 1968, "Inspection Report - PDM Provo Shops," (Interoffice memorandum to G. Kligfield, December 18), Vitro Hanford Engineering Services, Richland, Washington. 
tis

\section{INTER - OFFICE MEMORANDUM}

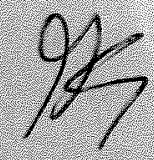

Date December 18, 1968

Mr. G. Kligfield

FROM

C. W. Cardwe11

The following report was submitted by out Mr. A. Short on December 14, 1968 and delineates the cause and effects of the themal distortion of the knuckle plates fabricated for Tank 102 secondary. Al also describes the inordinate width of some areas of weld repairs in addition to the convex-concave irregviarities of the knuckle plate sections. The corrective measures to the secondary bottom plate described by $A 1$ as possible procedure to be used in the field has not been fully evaluated. We quote:

During the fabrication of the $1 / 4$ inch lower knuckle plates for secondary tanks 101 and 102, it became apparent the excessive distortion would be experienced in the flat sections of the plates as a result of repeated weld repairs. The complete avoidance of thermally-caused distortion is nearly impossible in butt-welded steel plate as thin as $1 / 4^{n}$, especially if there are repeated weld repairs. The degree of distortion seems to be directly proportional to the number and magnitude of the weld repairs.

"Wherever several second and third repairs were necessary, and elose enough together so that the distortive forces became cumulative to a common area, then the distortion appeared, in some cases, to be in excess of that allowed in the governing specification, HWS-7789. In a few cases attempts were made to flatten the aistorted areas in the hydraulic press, but an "oil-can" effect was the only result, and no measurable suecess was achieved. It was therefore decided to stress relieve the repaired plates and then make another attempt to straighten them in the hydraulic press.

"Stress relieving of al1 1/4" lower knuckle plates for seconaary tank 102 took place on Saturday, Dec. 7, in conformance with the approved PDM procedure. The following Monday morning, Dec. 9, the plates were removed from the heating oven and an immediate attempt was made to flatten some of the most distorted areas. Virtually the same measure of success was experienced as before, exeept that in some areas a little straightening was possible. In the areas where the distortion assumed a roughly cireular shape, a11 attempts to straighten them were completely unsuccessful. It appeared that the most advisable solution would be to ship them to the work site, fabricate the bottoms and perhaps the first course of side plates, complete all welding, and then employ 
INTER - OFFICE MEMORANDUM

carefully regulated flame-shrinking to return the entire bottom, as a unit, to conform to the flatness tolerance required in HWS-7789. That approach was agreeable to al1 the involved PDM people here at the Provo plant.

Weanesday, Dec. 11, before the plates were loaded on the truck for transportation to the erection site, a check was made to determine areas that were suspected of being out of tolerance for flatness. Fach plate was placed in its normal position on an area of flat concrete floor, then visually examined for irregularities. In the suspect areas a straight edge was placed across the top center of a convexity so that it also intersected the bottom center of a contiguous concavity, and the difference measured. The horizontal distance from the center of the convexity to the center of the concavity was also measured in order to determine the slope per foot. Admittedly, the method was inaccurate, but we were not attempting to establish definite and specifie values, because those values would change as soon as the plates became an integral part of the welded bottom. Our efforts were only to document the existence of a condition.

"The areas that are suspected of being out of tolerance are identified by seam number as called out on PDM Dwg. S-6, contract number 38570, and are as follows: Seams A4, A9, A13, A15, A25.

"In addition to the convex-concave irregularities, it is also to be noted that in some areas of repaired welas, the width of the weld had increased from the original nominal 1/2", to a dimension of $1-3 / 4$ wide. For $1 / 4^{\text {"t }}$ plate this is considered completely unnecessary. However, in spite of the undesirable width, the quality of the welds are within acceptable limits." End of quote.

C. W. Cardwel]

CWC:ms

ec: ES Davis

A Short

FE Proj. File

FIS IB 
1.4 Cardwell, C. W., 1969a, "Installation of Kaolite Insulation," (Letter to H. E. Eager, February 20), Vitro Hanford Engineering Services, Richland, Washington. 


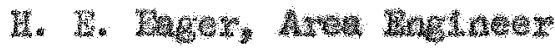

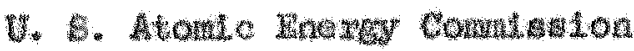

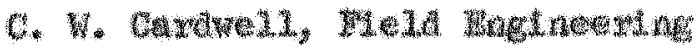

Eebruarar 20,

69

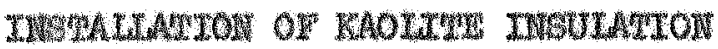

Hoject IA- 614

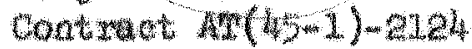

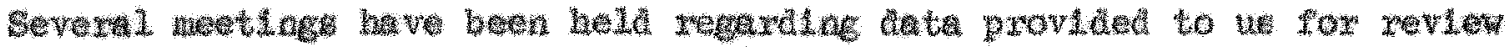

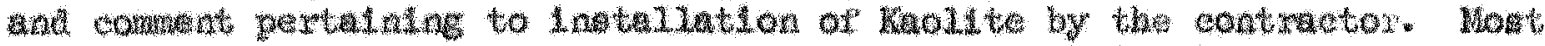

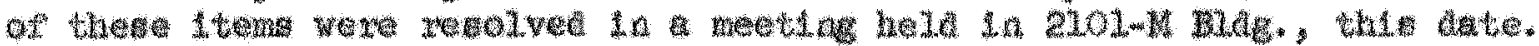

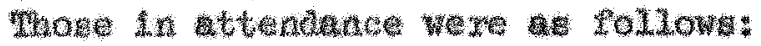

MuIco

W. C. Armstrone
21220-110

C. H. Gartwi:

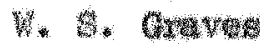

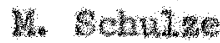

A. Short

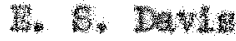

Act

1. N. Dagex"

3. Eandater:

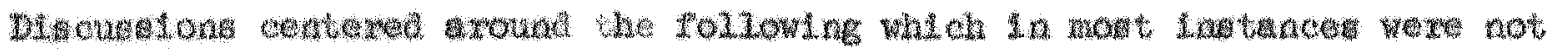

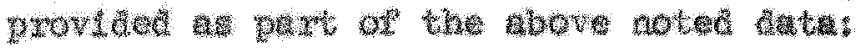

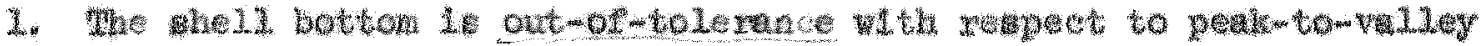

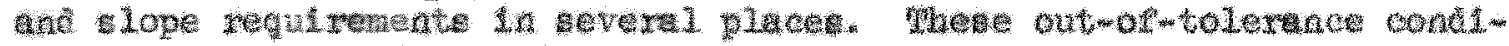

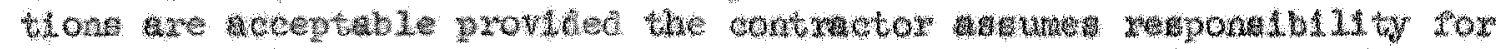

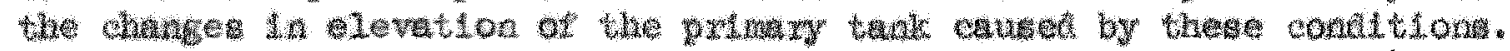

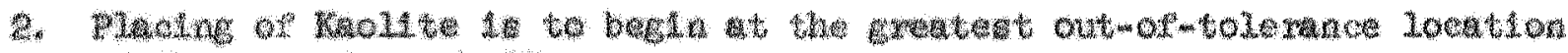
at the weondary elued.

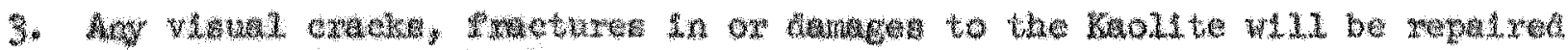

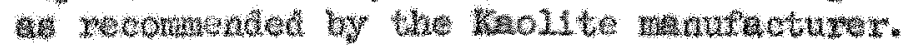

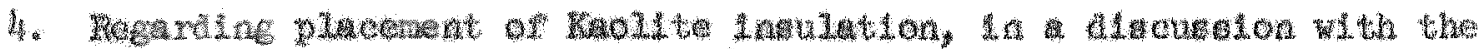

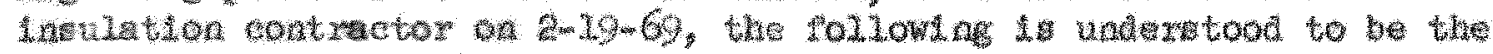

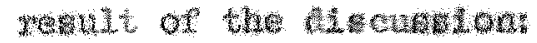

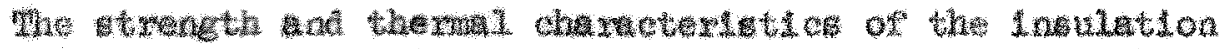
With not be atrected by the type of jolnt erated by the proposect placesuent wethoda.

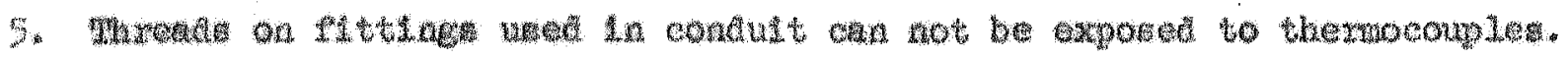

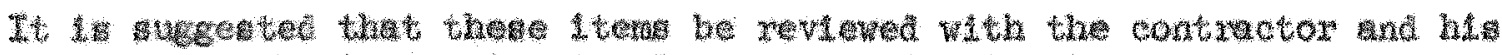

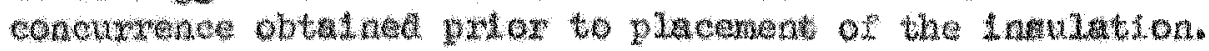

$$
\begin{aligned}
& 3 / 2 y / 69 \text { ess prathing }
\end{aligned}
$$

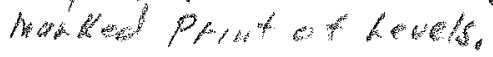

CWo/

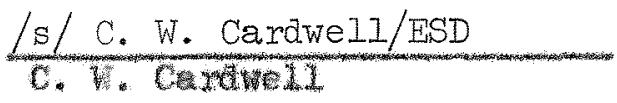


February 14,1969

C. W. Cardwell

W. S. Graves

Purex Tank Farm Expansion IAP-614

Minimur Thlckness Insulating Conerete

Conflming alscuss Lons with $A$. Short and $E$. S. Davis, flve inches of Kaolite insulating concrete is gufficient to protect the base concrete during stressmrelleving of the primery tank. This Judgenent is based upon the Battelle report BNL-F97, detail requirements on the sumilar project at Bavennah RIver, teats run by Nooter in Salnt Loul s for the Savannah River project, and Vitro calculations.

It was with this information in mind that a "humped" bottom 3 " in helght could be accepted since this st111 left $5^{\text {in }}$ of Insulation ava11able. The condition the aix inlet plpes requireg a minimun thick

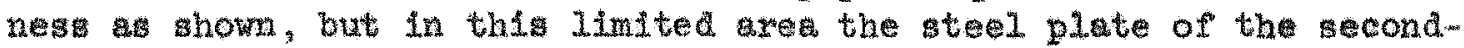

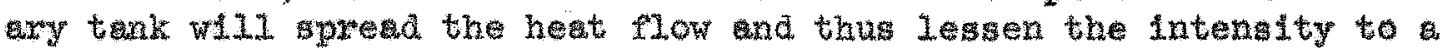
batisfactory level.

Please note that P1ttsburgh-Des Molnes is technically responsible for adequate thieknes as required by their stress-relief procedure as noted in Specifleation TWS-7789 Para. 9. Our drawing specify only a minum acceptable thickness the airuinlet pipes.

\section{Original Signed By \\ W. S. Groves \\ W. B. Gravea}

WSE: NW

ce: GK/CAS

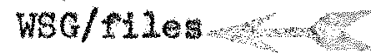


Rev. 0

1.5 Cardwell, C. W., 1969b, "Design Change 2124-17," (Letter to H. E. Eager, April 7), Vitro Hanford Engineering Services, Richland, Washington. 


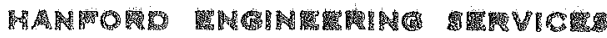

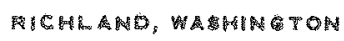

DATE AprL1 T, 1969

To: H. E. Eager, Area Engineer

U. S. Atomic Energy Commission

FROM:

PRON. OR SUS IECT

C. W. Cardwell $/ \mathrm{d} / \mathrm{dm}$

Field Engineering

Project IAP 614

Contrect $\operatorname{Ar}(45-1)-2124$

PDM Contract 38570

241-AY Purex Tank Farm Expansion

Design Change 2124-17

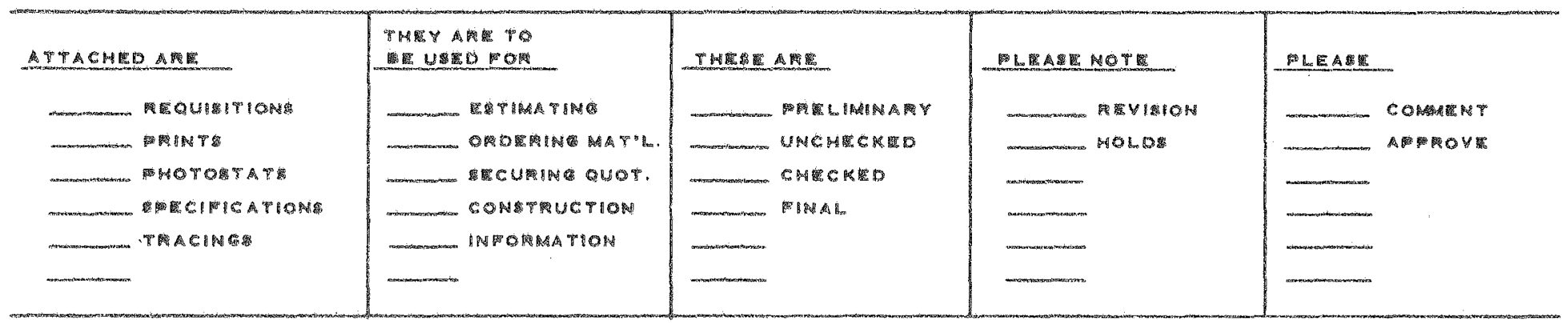

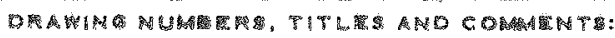

Transmitted herewith are one original and five copies with attachment of subject Design Change. Please forward to the Operating Contractor for his consideretion.

CWC/ESD: MS

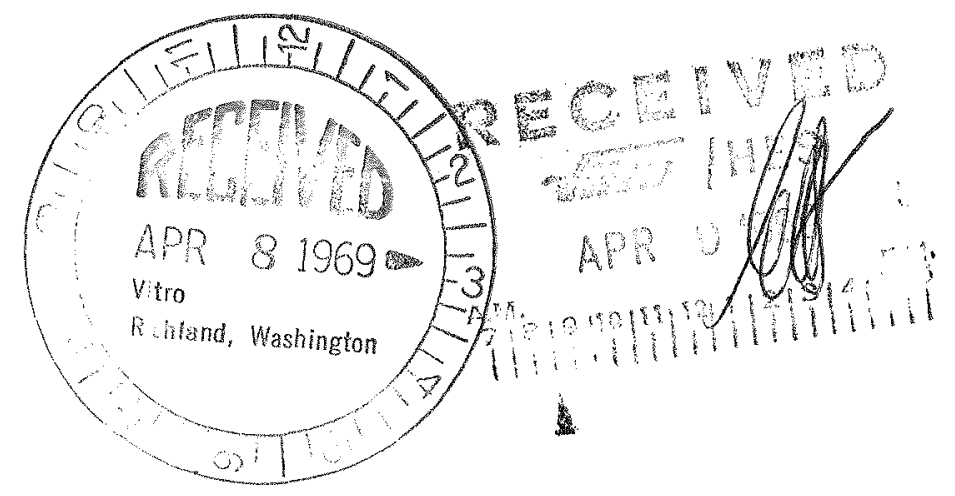


3

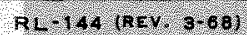

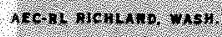

U. S A TOMIC ENERGY COMMISsION RICHLAND OPERATIONS OFFICE

RICHLAND. WASHINGT ON

\section{RECORD OF DESIGN CHANGE}

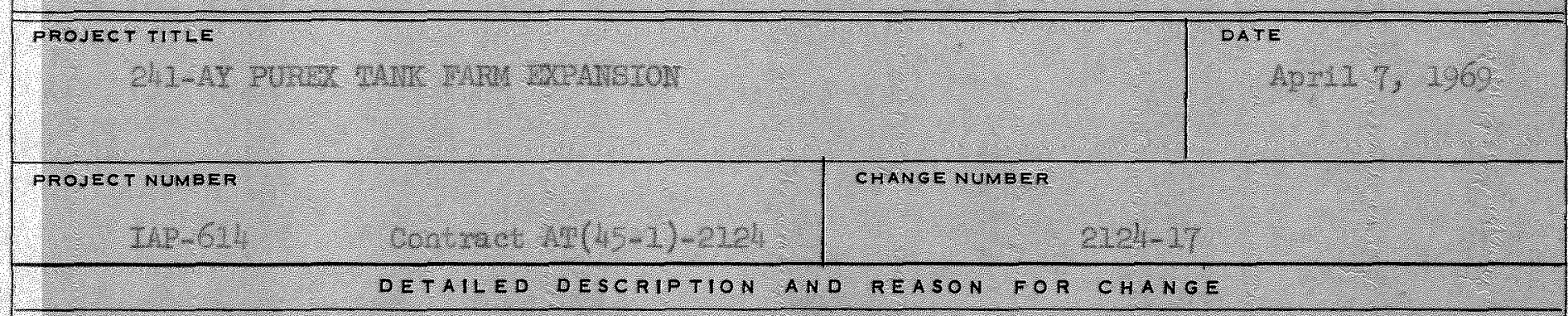

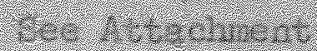

SHOULD "AS BUILT" BE RECORDED ON PLANS?

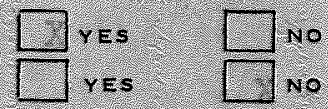

REQUESTED EY

IS DESIGN AFFECTED?

\begin{tabular}{|c|c|c|}
\hline OPERATING CONTRACTOR & $\begin{array}{l}\text { ARCHTECT ENGINEERS } \\
(\text { AS REOUIRED) }\end{array}$ & A TOMIC ENERG Y COMMISSION \\
\hline
\end{tabular}

COPY DISTRIBUTION:

1. WHITE - AEC-RL, E\& C FILES

2. GREEN - AEC-RL, AREA ENGINEER.

3. YELLOW - PROJECT ENGINEER
4. PINK - ARCHITECT ENGINEER

5. YELLOW - OPERATING CONTRAGTOR

6 GOL DENROD - CONSTRUCTION CONTRACTOR (CPFF ONIY) 


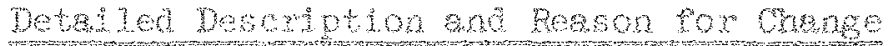

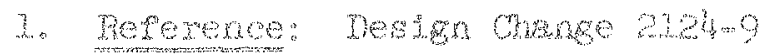

Deaciption:

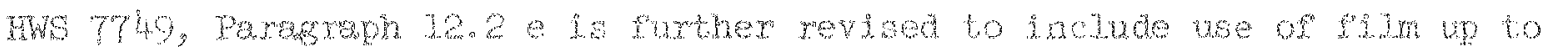

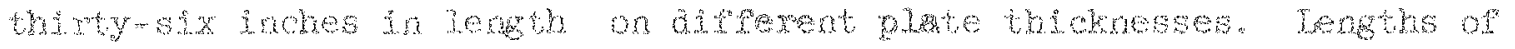

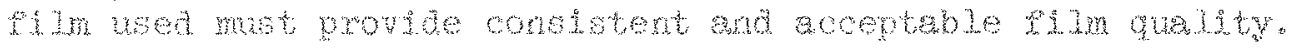

Reason:

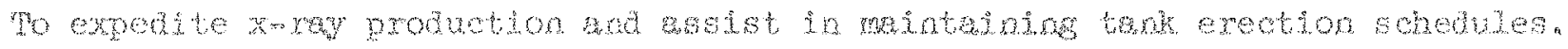
Cost:

Mone

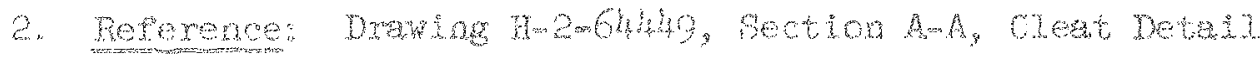

Deserint ion:

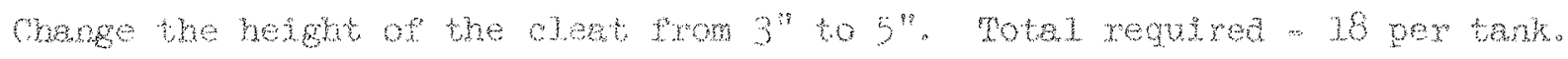
Regson:

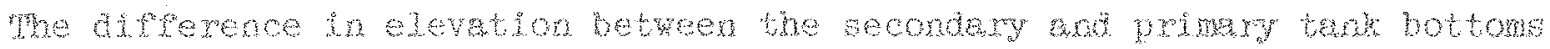

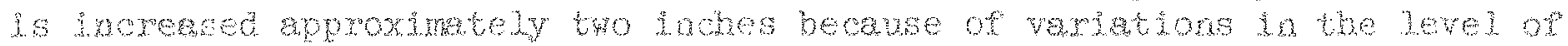

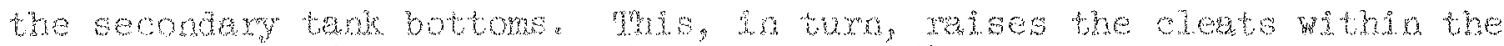

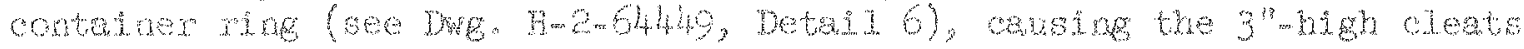
to becone inefiective.

Cost:

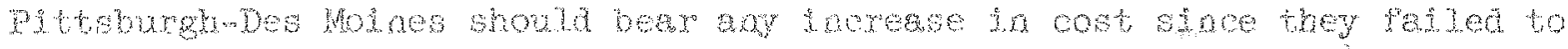

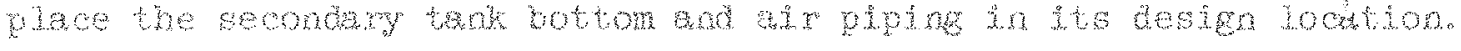


Rev. 0

1.6 CE-0283, 1967, "Report on a Study of Possible Insulating Materials for Use Between Tank Shells 241-AY Tank Farm," Vitro Hanford Engineering Services, Richland, Washington. 
DATE October 23, 1967

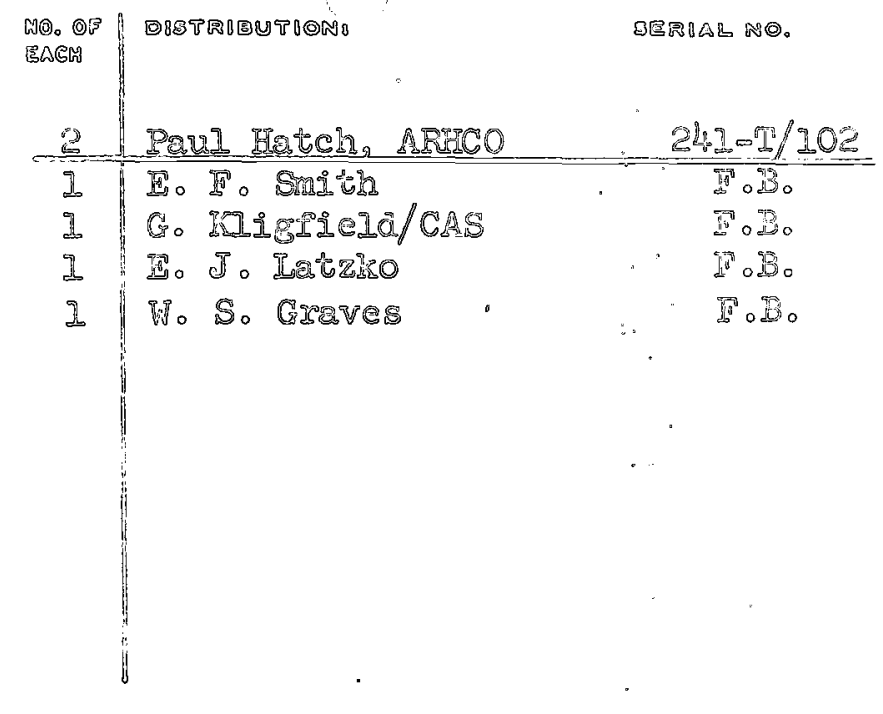

PROS. 0 R SURSETI

IAP-614 (CE-0283)

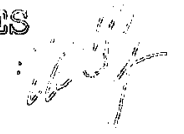

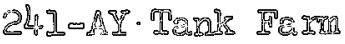

Tntra dan Insulation

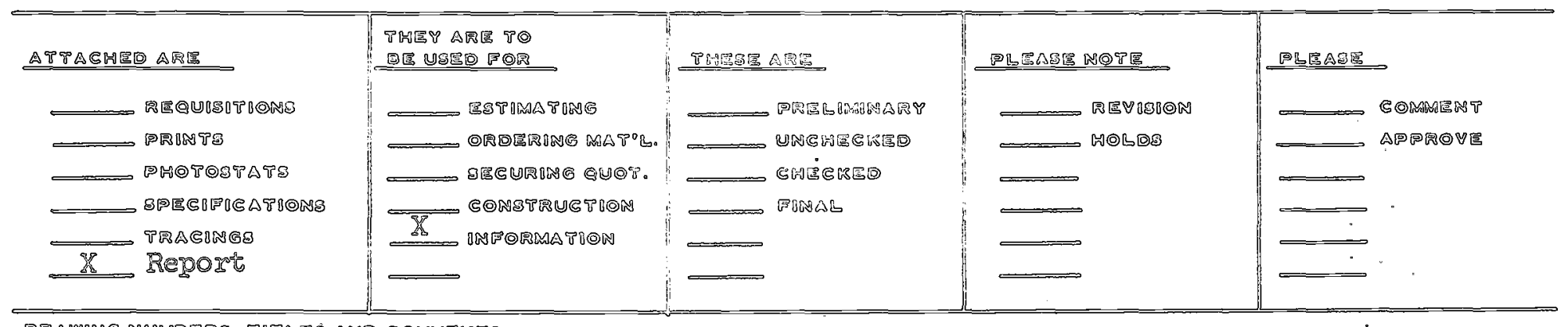




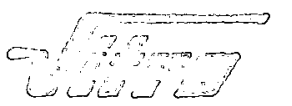

\section{REPORS ON $A$ SIUTI}

0.9

POSETBLI INSULNIITG MATRIALS

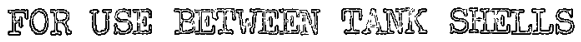

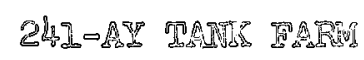

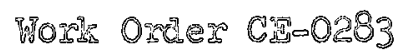

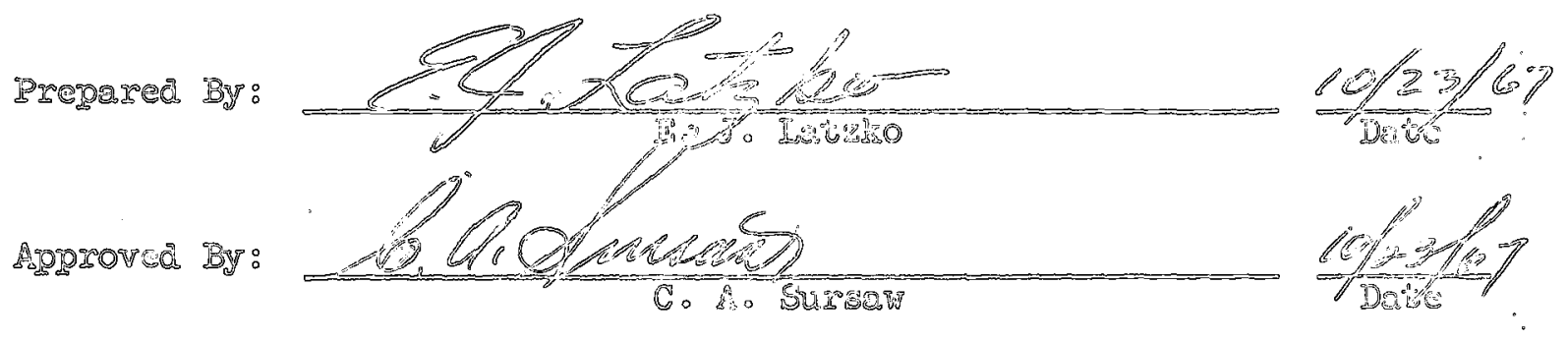

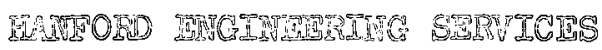

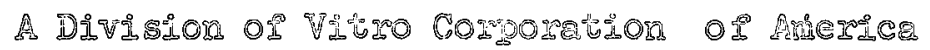




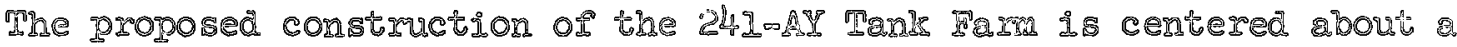

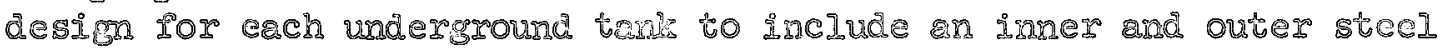
shell. Tach shell shal be or welded construction at the site.

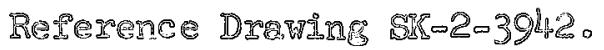

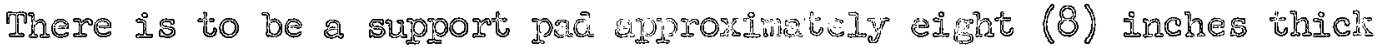
potween shelds at the bothou

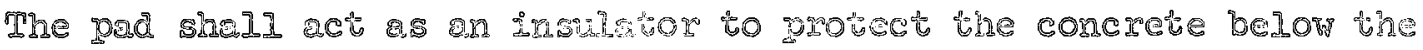

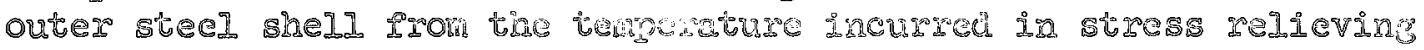

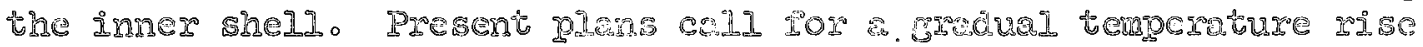

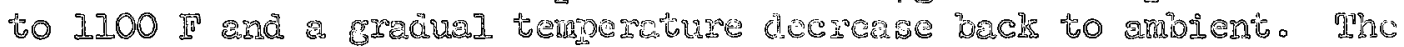

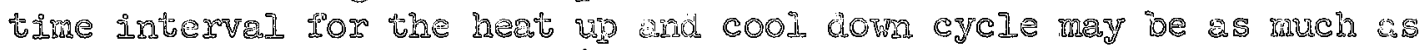
trentyo four hours to hold the rejoving temperature for thinty minutes.

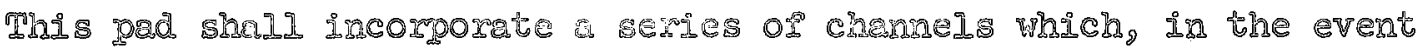

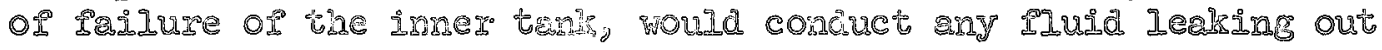
to a drexin in the out is tais.

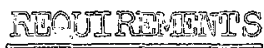

Tise reçuำ

A. Installation

L. To be Lajd or pourec at the sone.

2. To support jiner taxk mo concrete dome erection equipment.

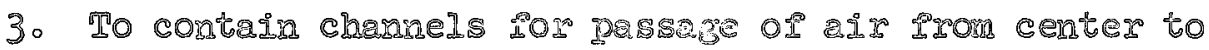
periphery during norma operation ma stored flud to

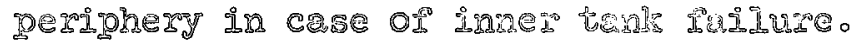

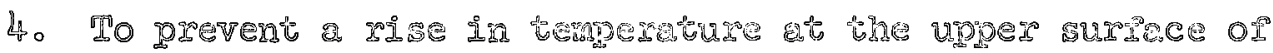

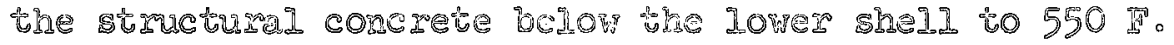

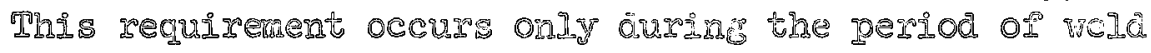
stress relieving the inner mhald. Braed upon a net

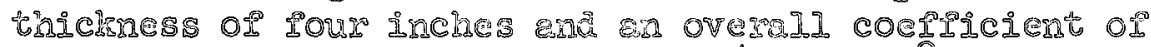

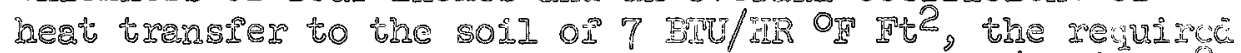

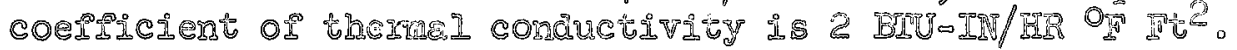


B.

Oxderaton

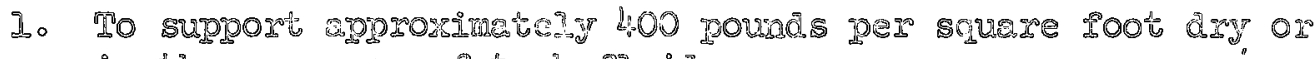
din the presence or thatis Pluzio.

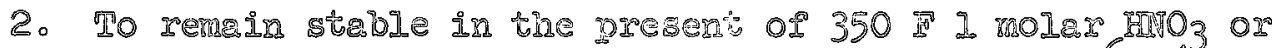

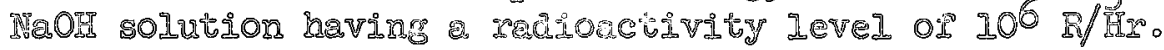

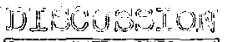

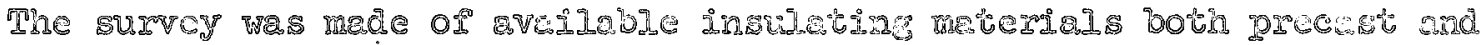
castale at the site.

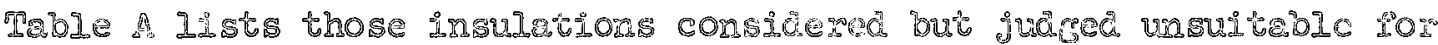

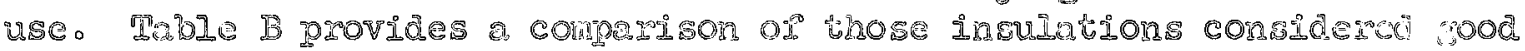

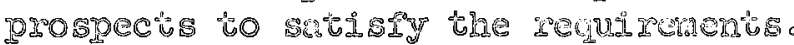

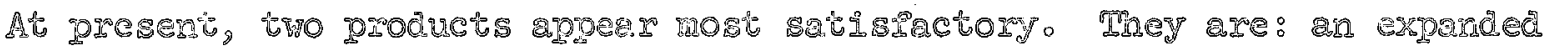

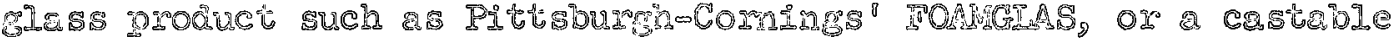

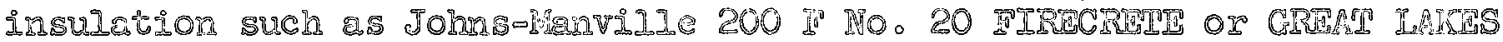

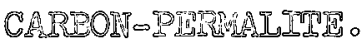

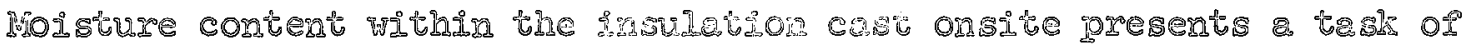
dry

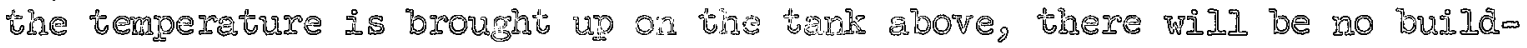
up or pressure within to break urge sab sab.

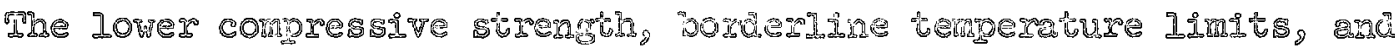

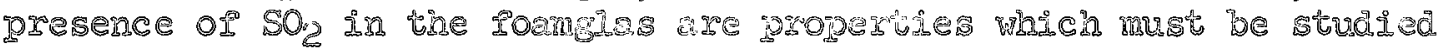
furcther to complete this evalnuturoro

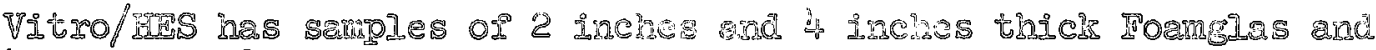

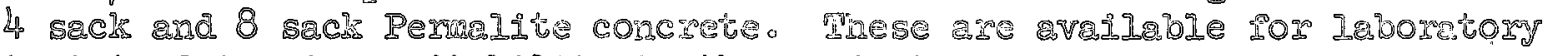

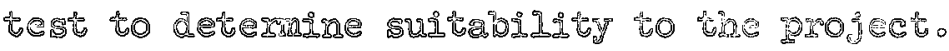




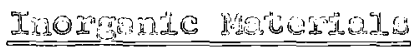

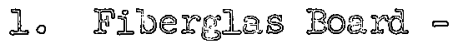
ADI Rranufocturers

2. Asbegtos Boanc

3. Mํำ

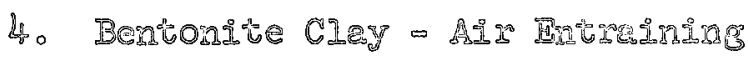
Adaliturye to Ceraent

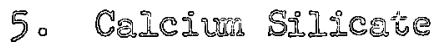

\section{Organde frateraials}

Lo Polgrspethane Rif Unareo

2. Berotube Sheet o Foamed

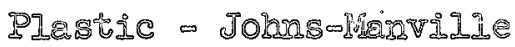

3. PoIystyrene - Johns Manvilde
Poor compressive strengtin Jyysascopic

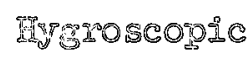

Poor compregstre strength

".jง agencis ond

IIS

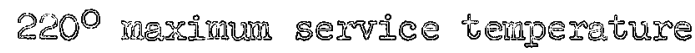

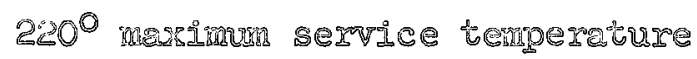

1750 \% 
IINSUINAION COMPART SOM

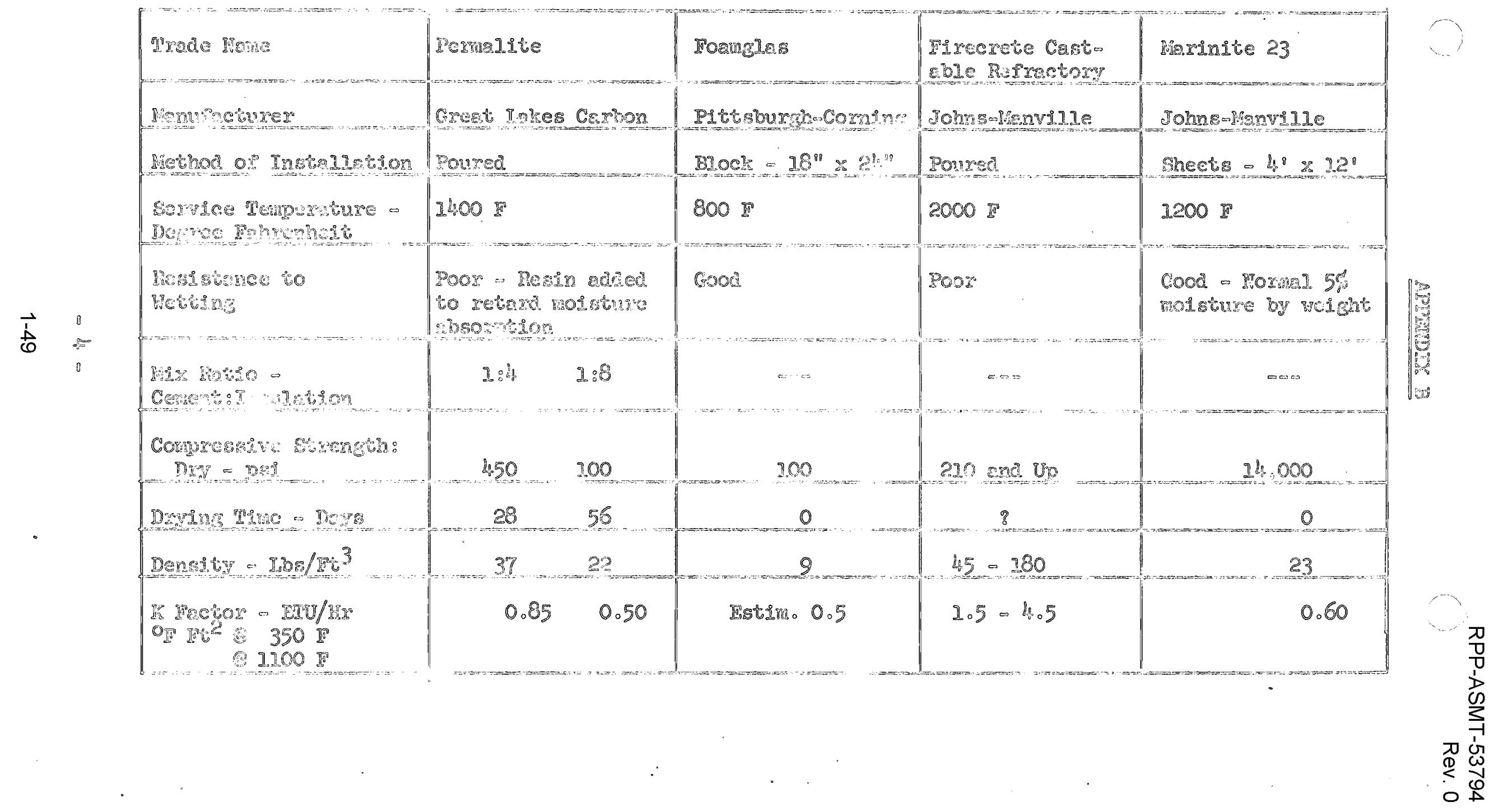




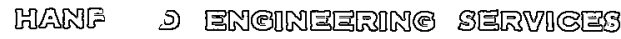
RIELISND, WASHDNGTON

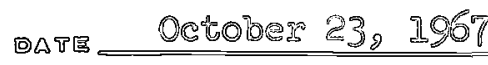

TO: Pand Har.t, APECO

FROM:

PROS。OR SLBSECT

TA9-6I4 (CG

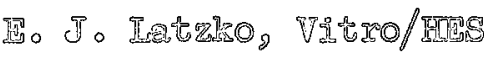

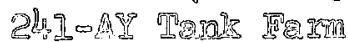

Inth
Rev. 0

\begin{tabular}{|c|c|c|}
\hline $\begin{array}{l}\text { COO。 } \\
\text { EASM }\end{array}$ & DOETROEUTUE & 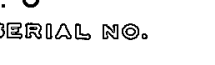 \\
\hline 2 & PanI Hech, ARTCO & $24.30 \pi / 202$ \\
\hline I & 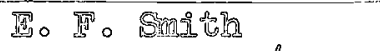 & I. \\
\hline d & 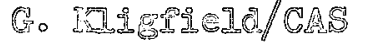 & 雭。通。 \\
\hline I & 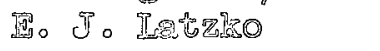 & 鼠。溥。 \\
\hline I & 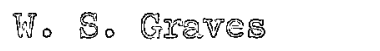 & 留。暒。 \\
\hline
\end{tabular}

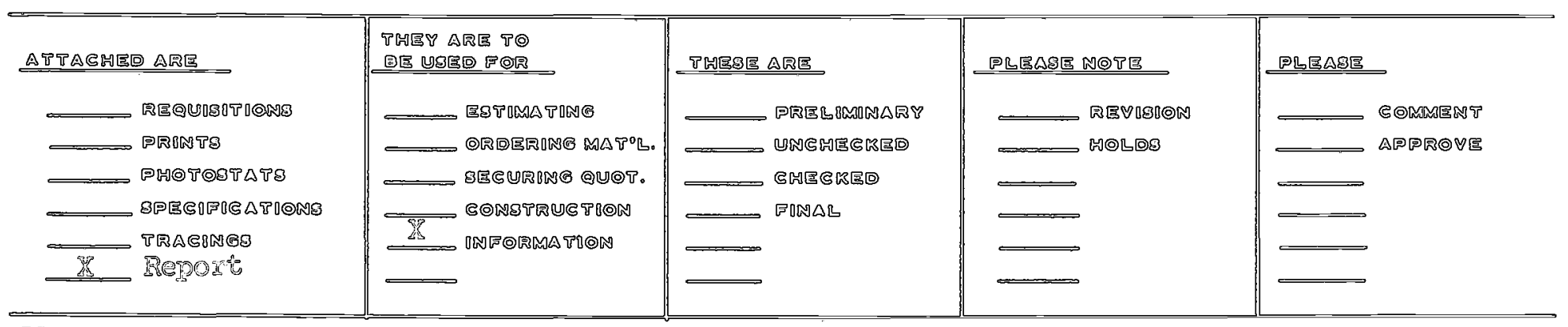

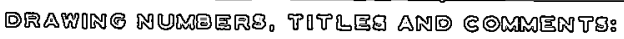


DREPORT ON AS STUMY

Oा

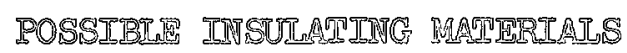

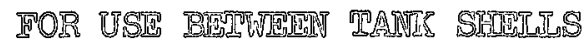

24, IDAY TAMIS TAROM

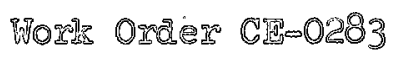

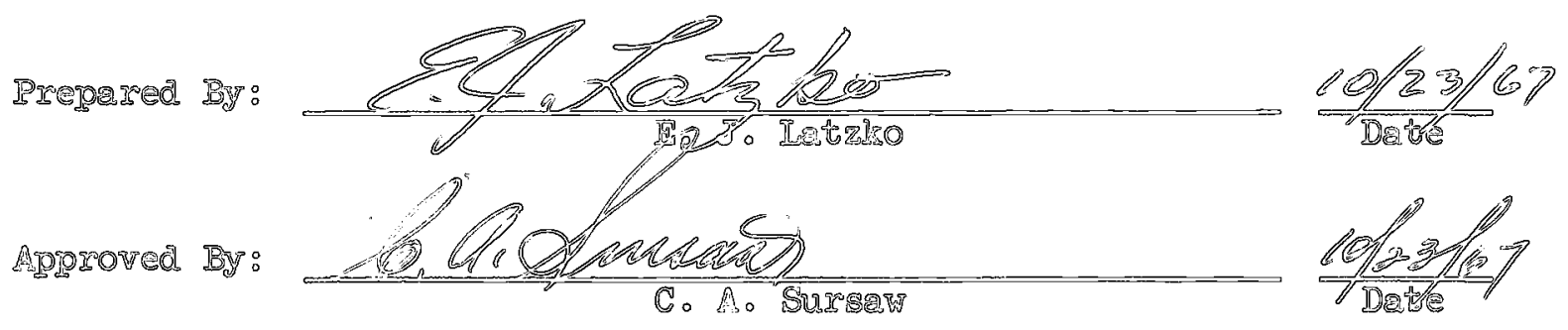

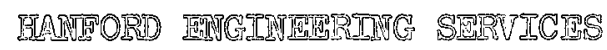

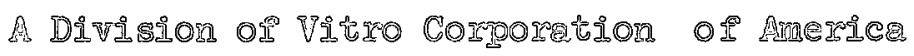




\section{INTIRODUCTIOOR}

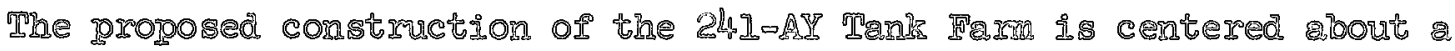

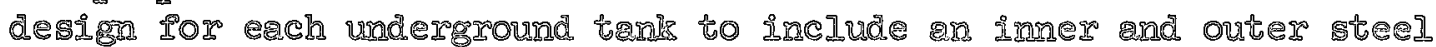

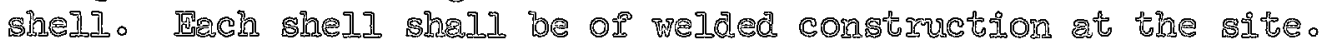

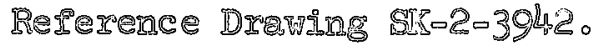

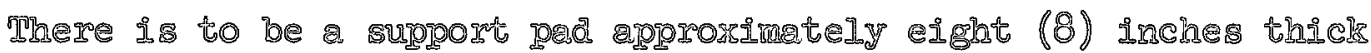
betwean shella at the bottomo

The pad shln act as an insulato to protect the concrete beIow the

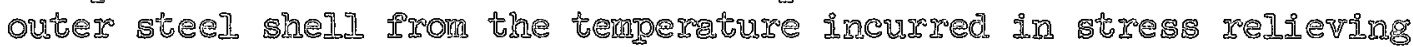

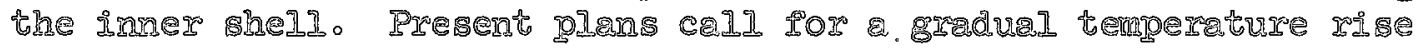

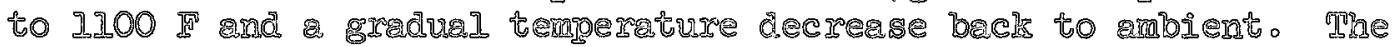

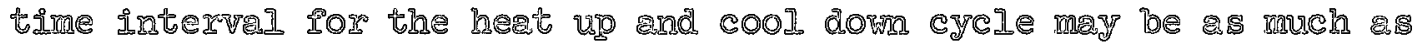

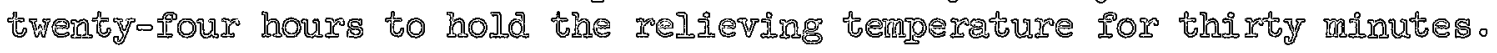

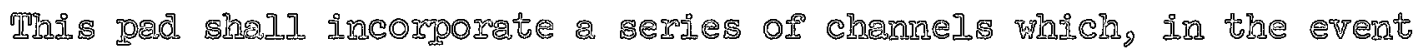

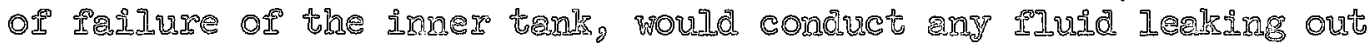
to ars

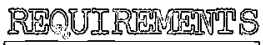

nhe requirements of the Insulating alab are as follow:

Ao Insta_L.

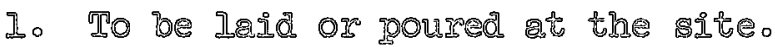

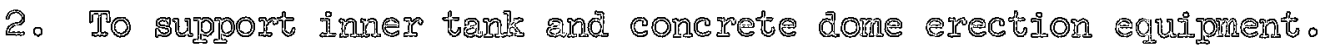

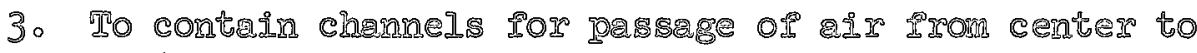
paraㄱ. Terighery

4. Wo prevent a rase in temperature at the urper surarace or the structuren conerete below the lower shell to 550 in.

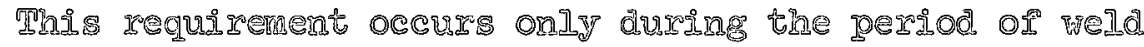
stress redieving the inner shell. Based upon a net

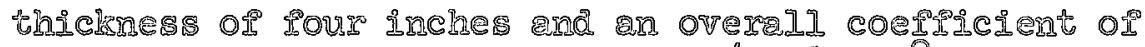

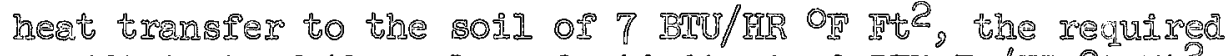
com 
Rev. 0

\section{B. Orometion}

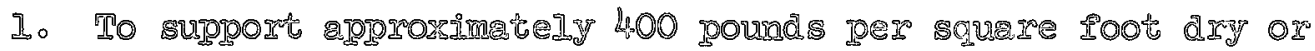
in the greserce of tan Iludid.

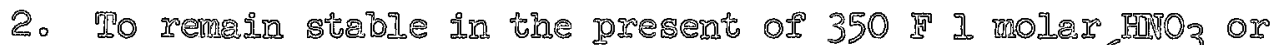

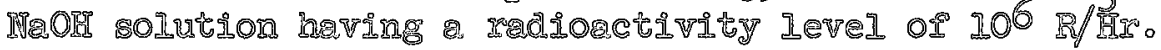

\section{DISCUSSTOR}

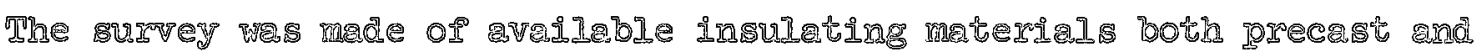
cagtable at the siot?

TabI A If

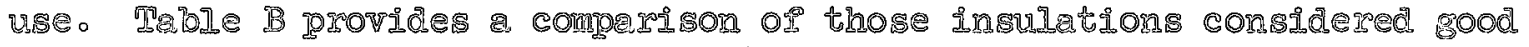
prospects to satis sty the requinements.

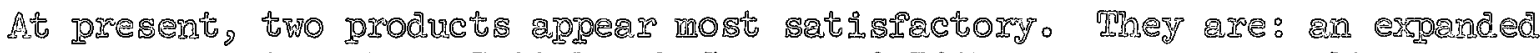

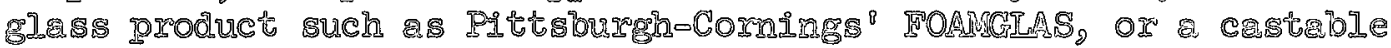

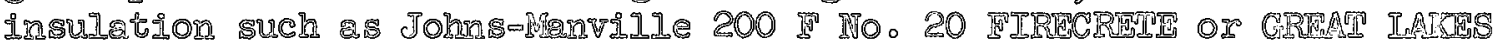

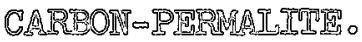

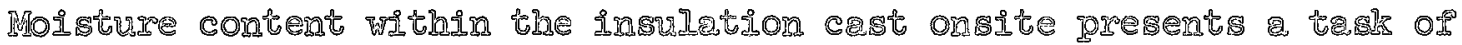

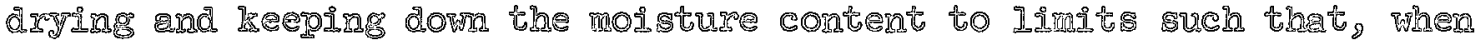
the termersture is brought ung on the tank rbove, there wild be no builde uro or pressure within to oreaks un the slab.

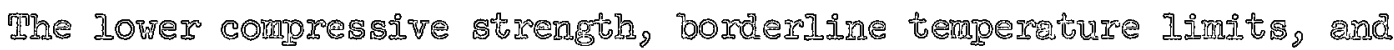

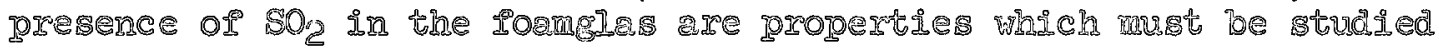
furthers to complete this evaluatsono

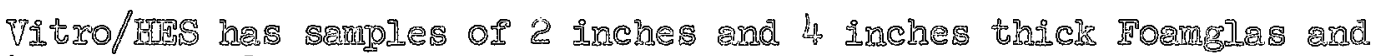
4 sack and 8 sack permalite concrete. Whe test to deteraine sujtability to the groject. 


\section{APPIARIDIX A}

\section{Insulations Considerect and Rejected}

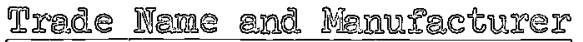

\section{Reason LొO Re Rection}

\section{Inomganc Raterials}

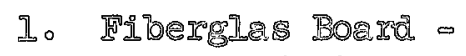
A21 Banuferetrirers

2. Agbegtog Bom rô?

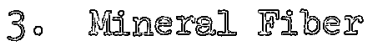

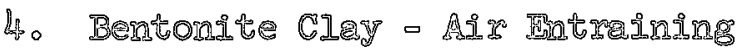
Adolits

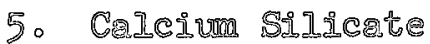

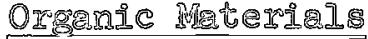

I. Polyurethane Rif grid rom Ung 190

2. Aerotrbe Sheet o rowat

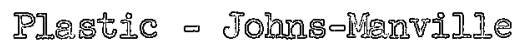

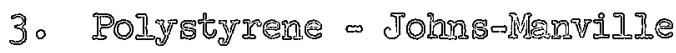

POOr comgressive strengh o Ply

Byrgroseogic

Poor compressive gtrength

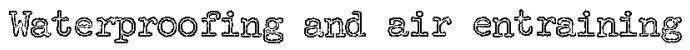
agente only

Ifygro SCON IC

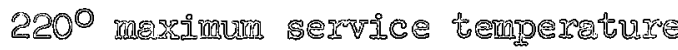

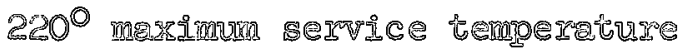

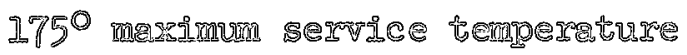




\section{INSUILAIIOR COMPARISONY}

\begin{tabular}{|c|c|c|c|c|c|}
\hline \multirow{10}{*}{$\overrightarrow{\dot{G}}$} & 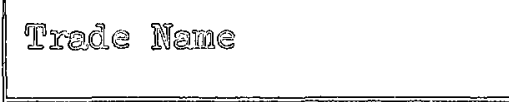 & Ferralite & Foarm & $\begin{array}{l}\text { Tismecirete Casto } \\
\text { able RePretory }\end{array}$ & Magring 23 \\
\hline & Manouncturers & Great Irages Carbon & PIttsbursh-Cornaing & John:Mangr. & 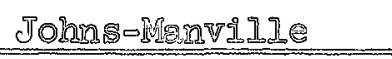 \\
\hline & 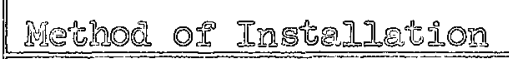 & Povgreed & BIock $=20^{\circ 1}=244^{5}$ & Ponged & Sheets $=44^{\prime}$ II $22^{\circ}$ \\
\hline & 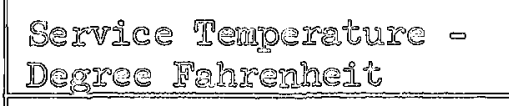 & 21400 Ti & 800 置 & 2000 贸 & 2200 霜 \\
\hline & 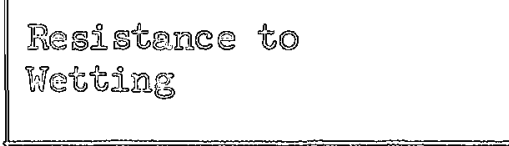 & 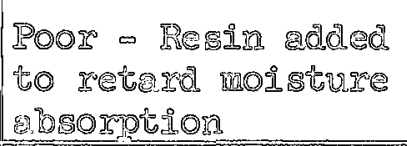 & Good & Poose & 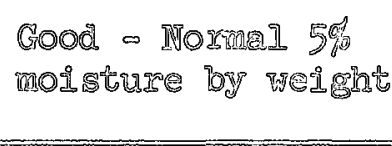 \\
\hline & 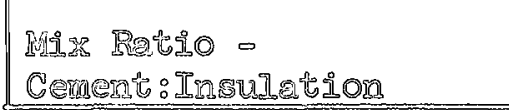 & $20: 42 \quad 2: 8$ & $\infty$ & $\rightarrow \infty$ & $-\infty 00$ \\
\hline & $\begin{array}{l}\text { Compressive strength: } \\
\text { Drst o gas }\end{array}$ & 450 & 200 & 210 and Uro & $I 4,000$ \\
\hline & 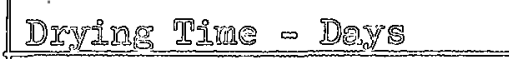 & 56 & 0 & 8 & 0 \\
\hline & 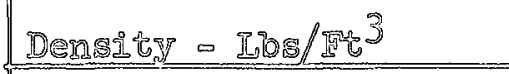 & 37 & 9 & $45=180$ & 23 \\
\hline & 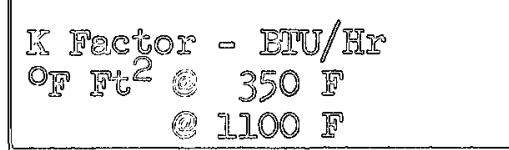 & 0.85 & 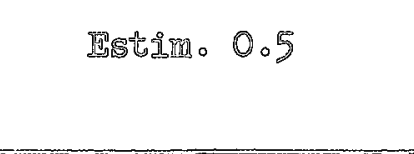 & $1.5 \cdot 4.5$ & 0.60 \\
\hline
\end{tabular}


Rev. 0

1.7 CML-SSP Working Paper 2001.002, 2001, Literature Study on Degradation Products of Known Emissions, Centre of Environmental Science (CML), Leiden University, Leiden, Netherlands. 


\title{
Literature study on degradation products of known emissions.
}

\author{
Project within Chlorine Chain Follow-up Research Programme on chlorinated \\ microcontaminants (OVOC)
}

CML-SSP Working Paper 2001.002

Leiden, March 2001

Authors: René Kleijn ${ }^{1}$, Ayman Elshkaki ${ }^{1}$, Arjan de Koning ${ }^{1}$, Arnold Tukker ${ }^{2}$

(C) Copyright 2001 Centre of Environmental Science (CML), Leiden University

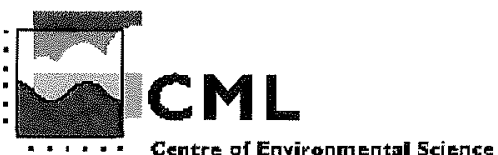

${ }^{1}$ Centre of Environmental Science

${ }^{2}$ TNO-STB

Leiden University

P.O. Box 9518

2300 RA, Leiden

phone: +31715277480

fax: +31715277434

email: kleijn@cml.leidenuniv.nl

http://www.leidenuniv.nl/cml

P.O. Box 6030

$2600 \mathrm{JA}$, Delft

phone: +31 152695450

fax: +31152695460

email: tukker@stb.tno.nl

http://www.stb.tno.nl 
Commissioned by the Ministry of Housing, Spatial Planning, and the Environment (VROM, DGM; contract nr. 99230300), the Ministry of Transport, Public Works, and Water Management (VW, Rijkswaterstaat), the Association of the Dutch Chemical Industry $(\mathrm{VNCl})$ and the Netherlands Society for Nature and Environment (SNM). 


\section{Table of Content}

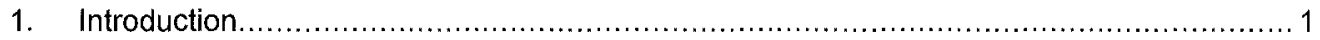

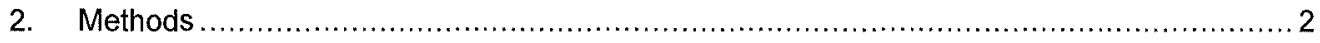

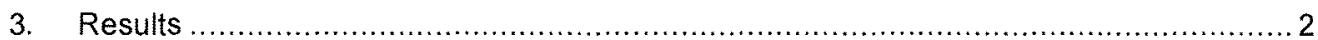

3.1. Degradation of chlorinated organic compounds in general...................................... 2

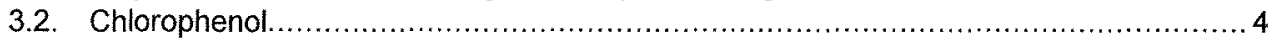

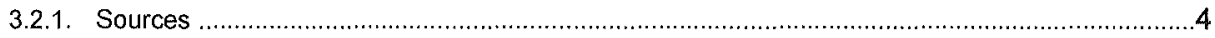

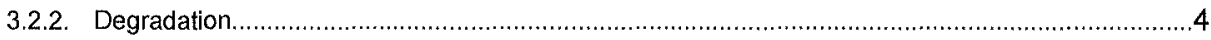

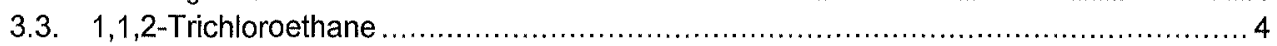

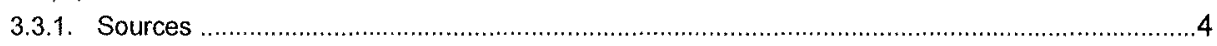

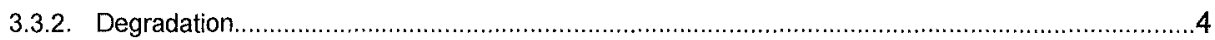

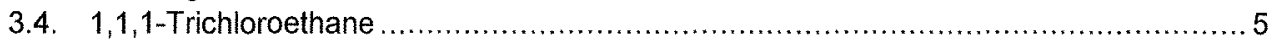

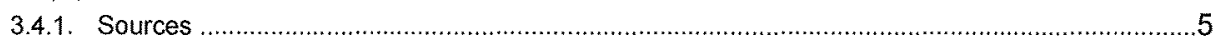

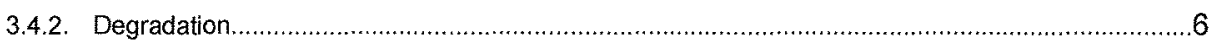

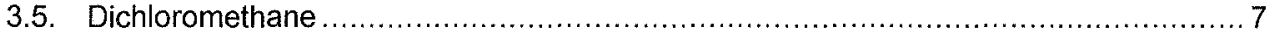

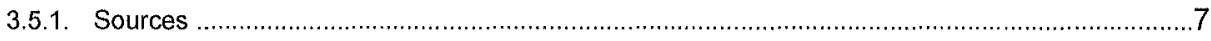

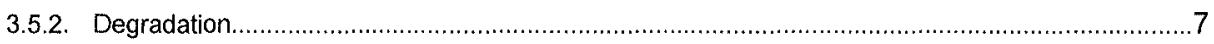

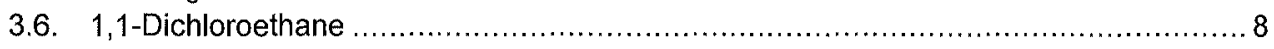

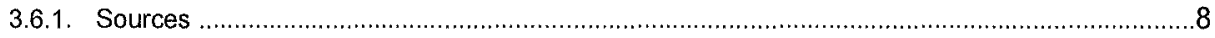

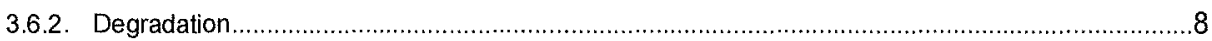

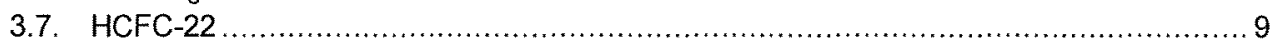

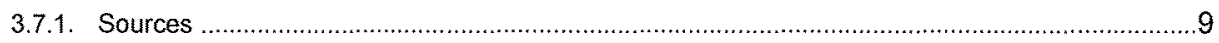

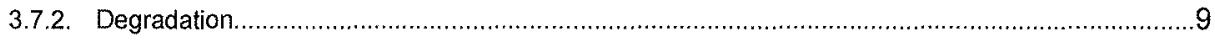

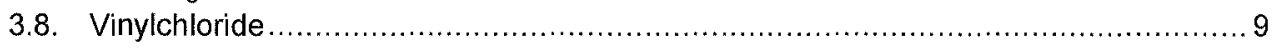

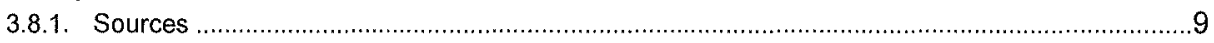

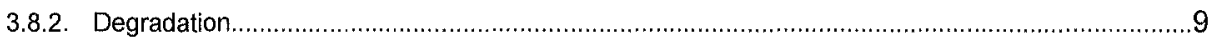

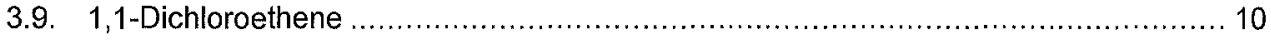

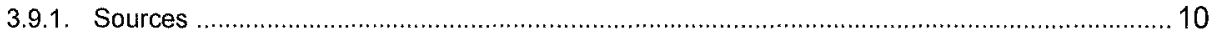

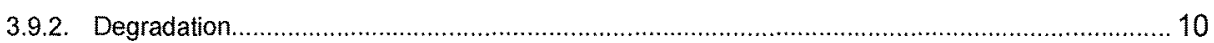

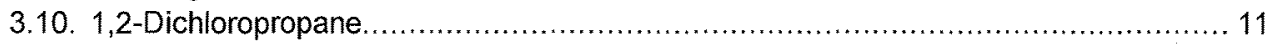

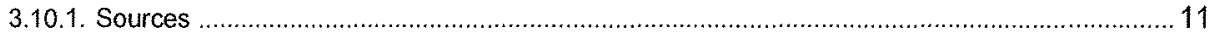

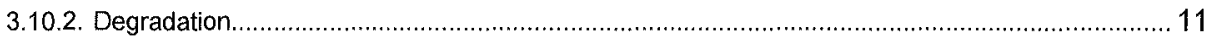

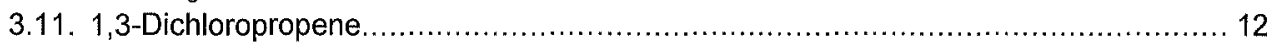

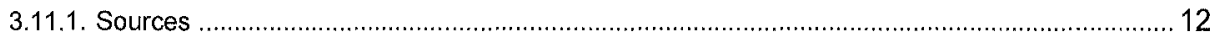

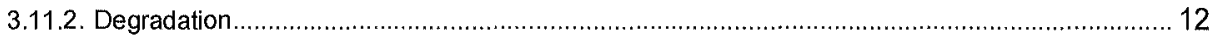

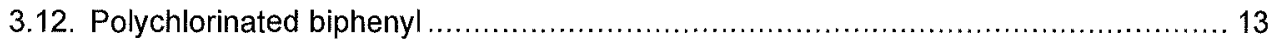

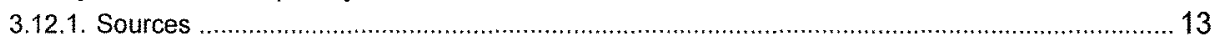

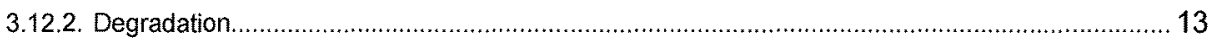

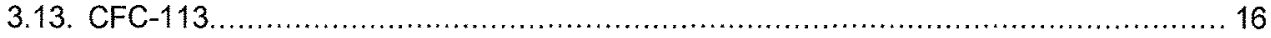

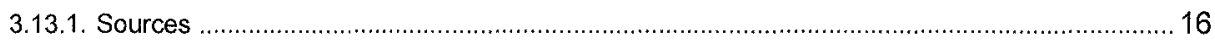

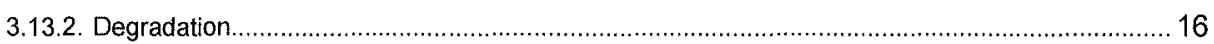

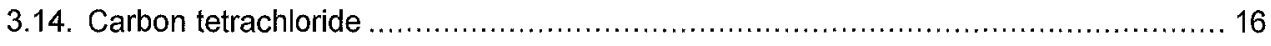

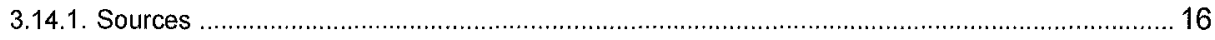

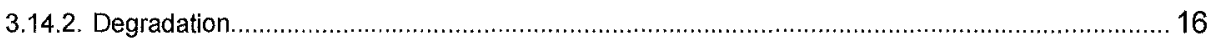

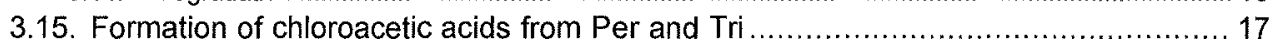

3.16. Expected atmospheric degradation products of other substances................... 18

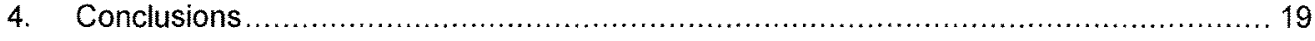

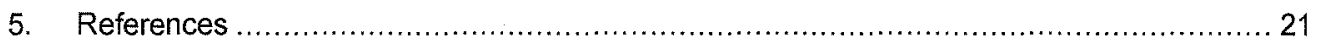


Rev. 0

CML 


\section{Introduction}

This report is one of a series of reports generated in the framework of the OVOC research programme'. The OVOC programme was started as a follow-up to the Dutch chlorine chain study, which made an inventory of chlorine flows and - emissions in the Dutch society ${ }^{2}$. In the discussion following publication of the latter study, the a central question was if unexpected sources and unexpected pathways still could contribute to pollution of the environment with yet unknown persistent, bioaccumulative and toxic chlorinated compounds (PBTs). Figure 1 gives an overview of the knowledge problem that the whole OVOC programme wants to tackle. A considerable amount of chlorinated organic substances can be found in environmental media, such as sediments and fish fat. Initial data available for the OVOC project partners gave the strong suggestion that 'traditional' compounds such as DDT, PCBs, etc can explain just a limited amount of this organochlorine ${ }^{3}$. This problem formed an important driver for the whole OVOC research programme. There are various potential sources for the fraction of 'unknown' organochlorine, part of which of human origin. It concerns:

1. Historical releases from sources which do not exist any more;

2. Sources of naturally produced organochlorine;

3. Releases of yet undetected organochlorine compounds from known (point) sources, a possibility which is often put into relation to the reactivity of chlorine and the formation of byproducts in production processes;

4. Degradation products formed from high-volume emissions of known organochlorine compounds.

The OVOC programme focuses on a measurement campaign related to point 3. However, the other elements are addressed in a number of limited sub-projects. Apart from the questions addressed above, it is of course very useful to obtain more knowledge about the type of degradation products of organochlorine compounds currently emitted can be found in environmental media. This point is the central issue in this report.

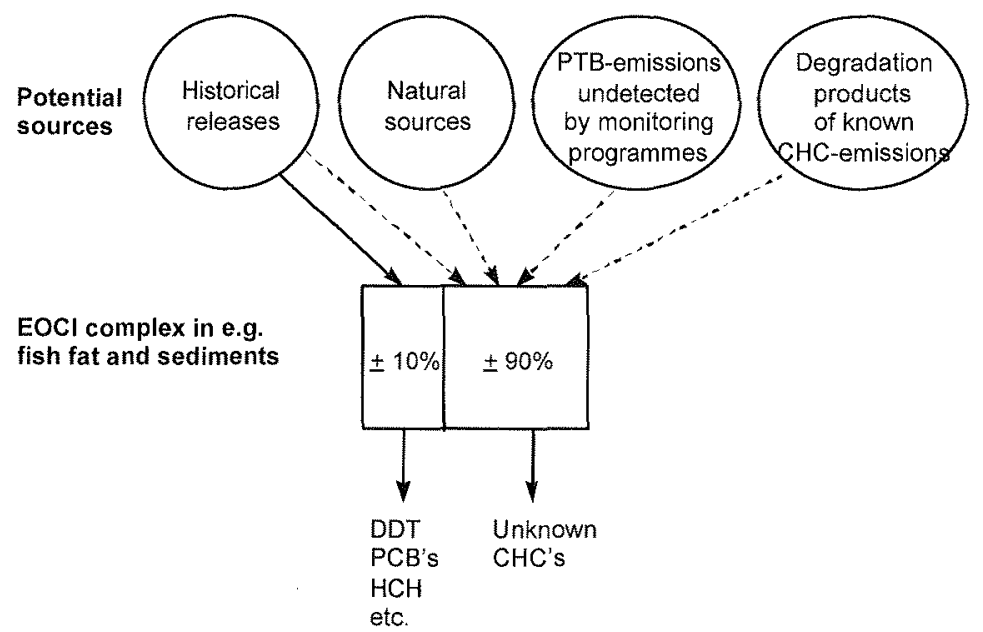

Figure 1. Potential sources of organo-chlorine compounds in the environment.

\footnotetext{
${ }^{1}$ Van Hattum B., H. Pols, M. van den Berg, W. Seinen, A. Brouwer, A. Tukker, R. Kleijn, J.W.W. Wegener (1998). Proposal Research Programme Chlorine Chain Follow-Up Studies (OVOC). Institute for Environmental Studies, Vrije Universiteit, Amsterdam (In Dutch, English translation July 1999)

${ }^{2}$ A. Tukker, R. Kleijn, E. v.d. Voet (eds.). A chlorine balance for the Netherlands. TNO-STB and CML, Apeldoorn, 1995

${ }^{3}$ Particularly the paper of Wesen et al. of 1995 , as summarised under No. 85 in Appendix B.
} 
The question which should be answered in this report is thus: which degradation products can be expected from chlorinated compounds which are in the standard monitoring programs. Since it is not straightforward to determine which compounds are likely to produce hazardous degradation products we started top down in the list of total emissions of chlorinated substances in Netherlands presented in the Chlorine Chain study [25]. Thus degradation products of substances with very low emissions are missed in this exercise. This also implies that most substances which are mainly emitted to water are not discussed because emissions to water are often very small compared to emissions to air. PCBs are an exception to this rule because for PCBs it is well known that degradation products have an important environmental impact see [28] and paragraph 3.12 of this text. Pesticides are not discussed. The amount literature on the degradation of chlorinated compounds is overwhelming. In this report a selection of this literature is used to describe the main pathways and products of degradation. In a separate spreadsheet (htto://www.leidenuniv. $\mathrm{n} / \mathrm{cm} / \mathrm{ssp} /$ degradation.html) an overview is given of a large number of other references which could be useful to answer more specific questions.

\section{Methods}

Three sources of information have been used to find degradation pathways for organochlorine compounds which have the highest emissions in the Netherlands:

- literature databases;

- in house literature;

- the internet.

Several literature databases have been tested for their use within this project, in the end a choice was made for The Web of Science of the ISI (Institute for Scientific information) which can be found on http://wos.library.tudelft.nl/CIW.cgi. Next to that the in house literature was search for possible information on degradation pathways and products. Thirdly an internet search was done. Since the quality of data found on the internet is often hard to assess this data was verified via the literature database when possible.

\section{Results}

\subsection{Degradation of chlorinated organic compounds in general}

Organic chemicals discharged into the environment are subject to different reactive species and by the reactions with these species, further toxic by-products can be produced. Although the rate of biodegradation of a chemical compound largely depends upon its structure, also other parameters such as the concentration of the reactive species in the environment, the season and time of day are of importance.

Organic compounds share the same major atmospheric removal or degradation mechanisms, which include the following:

- photochemical oxidation by hydroxyl $(\cdot \mathrm{OH})$ radicals;

- photolysis in the troposphere;

- deposition and uptake at the earth's surface;

- reaction with other reactive species such as chlorine atoms, nitrate radicals at night and ozone.

The same is true for the surface water where hydrolysis is the main chemical degradation route. However, in surface water, sediments and soil, biological degradation is the main degradation route for many compounds. 
In general the more hydrogen is substituted for chlorine in a substance, the more difficult the degradation of the organochlorine compound will be. The chlorine group acts as a stabiliser making (bio)chemical transformation processes (elimination or substitution reactions) more difficult. For instance the rate constants for the gas-phase reactions of the $\cdot \mathrm{OH}$ radical with PCBs decreases from approximately $2.7 \times 10^{-12} \mathrm{dm}^{3}$.molecule ${ }^{-1} \cdot \mathrm{s}^{-1}$ for 2-chlorobiphenyl to approximately $0.6 \times 10^{-12} \mathrm{dm}^{3}$. molecule ${ }^{-1} \cdot \mathrm{s}^{-1}$ for $2,3,3^{1}, 4^{\prime}, 6$ pentachlorobiphenyl [23].

Extremely persistent in the environment are those organochlorine compounds where elimination or substitution reactions are almost completely prevented. This is specially the case for the following groups of substances [24]:

1) neopentylalkanes<smiles>CC(C)(C)CCl</smiles>

2) halogen atoms at a bridgehead<smiles>ClC12CCC(CC1)CC2</smiles>

3) di, tri and tetra halogen carbon atoms<smiles>ClC(Cl)Cl</smiles>

4) vinyl and aryl halogenated compounds<smiles>C=CCl</smiles><smiles>Clc1ccccc1</smiles>

The removal of halogen substituents is a key step in biodegradation. Dehalogenation can occur in through three classes of reactions [29].

1) Oxidative dehalogenation occurs in aerobic conditions and involves fortuitous loss of halogens substituents during oxygenation of the aromatic ring.

2) Hydrolyic dehalogenation occurs in both aerobic and denitrifying conditions an involves the replacement of a halogen substituent by a hydroxyde group with water as the source of the oxygen atom.

3) Reductive dehalogenation occurs almost exclusively under anaerobic conditions and involves substitution of the halogen atom by a hydrogen atom. Chlorinated benzenes and chlorofenols can be totally dehalogenated by reductive dehalogenation.

In the following paragraphs, degradation pathways are given for the organochlorine compounds which have the highest emissions in the Netherlands. In paragraph 3.16 an overview is given of possible degradation products of number of other chlorinated compounds in the atmosphere. 


\subsection{Chlorophenol}

\subsubsection{Sources}

Chlorophenolic compounds are basic chemical ingredients for many products made in the chemical industry, including pesticides like 2,4-D and 2,4,5-T [24]. If reaction conditions in the production of chlorophenols are not well controlled, impurities like dioxane or furanes may result [24]. Also chlorophenolic compounds are an unwanted by-product of bleaching of pulp with chlorine [1].

\subsubsection{Degradation}

In water and on solid surfaces

Experimental work on the degradation and transformation of pentachlorophenol (PCP) showed that photolysis by sunlight is the main degradation pathway in water, organic solvents and on solid surfaces $[2,35]$. The first step in the photolysis of PCP is a photonucleophilic substitution of hydroxide for chloride to provide three possible tetrachlorodiols. The tetrachlorodiols are then oxidised to their corresponding quinones, followed by further displacement of chloride to form the hydroxytrichloroquinones and dichlorohydroxyquinones (chloranilic acids). Tetrachlorophenols and trichlorophenols are also thought to be formed early by photoreduction but are expected to undergo similar photonucleophilic and photooxidation reactions. Transformation products of PCP include tetrachlororesorcinol and various dimeric benzoquinones [2,35]. Half-lives that have been report in situ are in the order of $2-4.7$ days $(\mathrm{pH}$ 7.3-10.3; 10-21 $\left.{ }^{\circ} \mathrm{C}\right)[35]$.

Biodegradation of PCP in water is much faster in aerobic conditions than in anaerobic conditions. Therefore PCP persists much longer in sediments (up to decades) than in water [35]. Furthermore degradation products like tetrachlorocatechol are very persistent too.

In soils Under aerobic and anaerobic natural conditions slow and partial degradation of chlorophenols has been observed [1]. Aerobic biodegradation of chlorophenols proceeds through the formation of catechols and under anaerobic conditions, reductive dehalogenation is the preferred metabolic pathway. PCP transformation products in soil under natural conditions that have been reported [3] include: tetra- and trichlorophenols, pentachlorobenzene, chlorinated dioxines.

\subsection{1,1,2-Trichloroethane}

\subsubsection{Sources}

$1,1,2$-Trichloroethane $(1,1,2-E T C$, cas no. 79-00-5) is used as a chemical intermediate in the production of 1,1 dichloroethene and a limited amount is used as a solvent for chlorinated rubber, fats, oils, waxes and resins [4]. This indicates that in addition to the point source pollution from chemical production, it can be found a in number of limited pollution sources [4].

\subsubsection{Degradation}

In the aquatic environment In aquatic system, volatilisation is the major route for 1,1,2-ETC removal. Half-life value of evaporation of 21 minutes has been reported [4]. ETC undergoes a pH-independent and a base catalysed hydrolysis at environmental $\mathrm{pH}$ 's $[4,27]$. The neutral hydrolysis process is a substitution reaction leading to the formation of an alcohol while the base catalysed reaction is 


\section{CML}

an elimination reaction giving rise to 1,1-dichloroethane and $\mathrm{HCl}$. The hydrolysis rate of 1,1,2 ETC is $5.9 \times 10^{-3} \mathrm{I} \cdot \mathrm{mol}^{-1} \cdot \mathrm{s}^{-1}$ at $25^{\circ} \mathrm{C}[4]$.

In the atmosphere

The environmental distribution model of 1,1,2-ETC predicts that $99 \%$ will be found in the atmosphere and less than $1 \%$ in the aquatic environment [4]. It has been found that 1,1,2-ETC will be degraded by reaction with photochemically produced hydroxyl radicals $(\cdot \mathrm{OH})$, the residence times are in the range of a few months [4]. Reaction products from photooxidation include phosgene, $\mathrm{Cl}_{2}, \mathrm{HCl}$ and $\mathrm{CO}_{2}$. The half-life values and degradation products in different compartment are listed in Table 1.

Table 1 Half-life and degradation products of 1,1,2-trichloroethane in different environmental compartments [4].

\begin{tabular}{llll}
\hline Compartment & Mechanism & Degradation & Products \\
\hline De-ionised water & Reaction with $\mathrm{OH}$ & $\mathrm{K}=1.1 \times 10^{8} \mathrm{dm}^{3} \cdot \mathrm{mol}^{-1} \cdot \mathrm{s}^{-1}$ & $\mathrm{CH} / 2 \mathrm{Cl}-\mathrm{CHCl}$ \\
Dilute aqueous solution & Homogeneous hydrolysis & $\mathrm{T}_{1 / 2}=139.2 \mathrm{y}$ & \\
Aqueous solution & Hydrolysis & $\mathrm{T}_{1 / 2}=37 \mathrm{y}$ & \\
Aqueous solution & & $\mathrm{T}_{1 / 2}=135 \mathrm{y}$ & \\
Surface water & Volatilisation & $T_{1 / 2}=4.5 \mathrm{~h}$ & \\
Sea water & No degradation & \\
Atmosphere & Hydrolysis $+\mathrm{DHH}$ & $\mathrm{T}_{1 / 2}=170 \mathrm{~d}$ & 1,1 dichloroethylene \\
& Reaction with $\cdot \mathrm{OH}$ & $T_{1 / 2}=49 \mathrm{~d}$ & \\
& & & \\
\hline
\end{tabular}

Biological degradation

Aerobic degradation of 1,1,2-ETC seems to be non-existent or very slow [4]. Under anaerobic conditions, it undergoes dehalogenation [4] The microbial transformation of 1,1,2-ETC in different systems listed in Table 2.

Table 2 Microbial transformation of 1,1,2-trichloroethane in different environmental compartments [4]

\begin{tabular}{llll}
\hline System & Redox condition & Degradation & Reaction products \\
\hline $\begin{array}{l}\text { Aqueous biodegradation } \\
\text { Pseudomonas putida PpG786 }\end{array}$ & $\begin{array}{l}\text { Anaerobic } \\
\text { Aerobic dehalogenation } \\
\text { Oxydative pathway } \\
(85 \%)\end{array}$ & $\begin{array}{l}\mathrm{T}_{1 / 2}=1-4 \mathrm{y} \\
70 \%\end{array}$ & $\begin{array}{l}\text { Chloroacetic acid + } \\
\text { glyoxylic acid } \\
\text { Vinyl chloride }\end{array}$ \\
Aqueous biodegradation & $\begin{array}{l}\text { Reductive pathway(15\%) } \\
\text { Aerobic }\end{array}$ & $\mathrm{T}_{1 / 2}=6-12 \mathrm{~m}$ & \\
\hline
\end{tabular}

\subsection{1,1,1-Trichloroethane}

\subsubsection{Sources}

$1,1,1-$ Trichloroethane $(1,1,1-\mathrm{ETC}$, cas no 71-55-6) is mainly used in metal cleaning and as a solvent in various formulations including adhesives, paint, varnishes, ink and solvents. It is also 
used as a propellant and solvent in aerosols and as an intermediate in the production of vinylidene chloride [4]. High levels of 1,1,1-ETC have been reported to occur in a number of ground water samples at polluted spots in Europe as well as in the USA and Japan [4].

\subsubsection{Degradation}

In the aquatic environment

1,1,1-ETC undergoes a pH-independent and a base catalysed hydrolysis at environmental $\mathrm{pH}$ 's $[4,27]$. The neutral hydrolysis process is a substitution reaction leading to the formation of an alcohol while the base catalysed reaction is an elimination reaction giving rise to 1,1dichloroethane and $\mathrm{HCl}$. The hydrolysis rate of $1,1,1 \mathrm{ETC}$ is higher than $5.9 \times 10^{-3} \mathrm{I} . \mathrm{mol}^{-1} \cdot \mathrm{sec}^{-1}$ at $25^{\circ} \mathrm{C}$ [4]. Half lives are reported varying from $0.5-10$ years at temperatures from 10 to $25^{\circ} \mathrm{C}$. In sea water $(\mathrm{pH}=8)$ shorter half-lives have been reported: 39 weeks at $10^{\circ} \mathrm{C}[36]$.

Photodegradation is negligible at the earth's surface [36].

Since degradation is so slow volatilisation is the major route for 1,1,1-ETC loss from water. Halflives of $17-23 \mathrm{~min}$ have been reported for evaporation [4].

In the atmosphere

The environmental distribution model of 1,1,1-ETC predicts that $99 \%$ will be found in the atmosphere and less than $1 \%$ in the aquatic environment [4]. It has been found that 1,1,1-ETC will be degraded by reaction with hydroxyl radicals $(\cdot \mathrm{OH})$. The residence time in the atmosphere varies from less than one year to ten years. Reaction products from photo-oxidation include phosgene, $\mathrm{Cl}_{2}, \mathrm{HCl}$ and $\mathrm{CO}_{2}[4]$. The half-life values and degradation products in different compartment are listed in Table 3 . It is estimated that $15 \%$ of the global emissions is transported to the stratosphere where it is degraded by uv radiation of shorter wavelengths [36] In this process free radical chlorine atoms are released which destroy ozone via a process in which they are regenerated to repeat the process.

Table 3 Half-life and degradation products of 1,1,1-trichloroethane in different environmental compartments [4].

\begin{tabular}{|c|c|c|c|}
\hline Compartment & Mechanism & Degradation & Products \\
\hline De-ionised water & Reaction with $\mathrm{OH}^{\circ}$ & $\mathrm{K}=4 \times 10^{7} \mathrm{dm}^{3} / \mathrm{mol} . \mathrm{s}$ & $\begin{array}{l}\mathrm{CH}_{3} \mathrm{CCl}_{2} \\
\text { 1,1dichloroethylene }\end{array}$ \\
\hline Aqueous solution & Homogeneous hydrolysis & $\mathrm{T}_{1 / 2}=1.1 \mathrm{y}$ & \\
\hline Aqueous solution & Hydrolysis and $\mathrm{DHH}$ & $T_{1 / 2}=0.5-2.5 y$ & $\begin{array}{l}\text { Acetic acid }+1,1- \\
\text { dichloroethylene }\end{array}$ \\
\hline Sea water & Hydrolysis and $\mathrm{DHH}$ & $T_{1 / 2}=0.8 y$ & \\
\hline $\begin{array}{l}\text { Narraganset Bay sea } \\
\text { water }\end{array}$ & Volatilisation & $\begin{aligned} \mathrm{T}_{1 / 2} & =11 \mathrm{~d} \text { summer } \\
& =24 \mathrm{~d} \text { winter }\end{aligned}$ & \\
\hline Atmosphere & Reaction with $\cdot \mathrm{OH}$ & $T_{1 / 2}=3215 d$ & \\
\hline Sediment & $\begin{array}{l}\text { Neutral and base } \\
\text { catalysed hydrolysis }\end{array}$ & $T_{1 / 2}=450 \mathrm{~d}$ & \\
\hline
\end{tabular}


Biological degradation

Aerobic degradation of 1,1,1-ETC seems to be non existent or very slow [36]. No aerobic degradation was found in soil samples after 27 weeks [36]. Under anaerobic conditions, reductive dehalogenation can yield in an biodegradation rate of $>99.5 \%$ [4]. The degradation products of 1,1,1-ETC are 1,1-dichloroethane and acetic acid. The microbial transformation of

Table 4 Microbial transformation of 1,1,1-trichloroethane in different environmental compartments [4].

\begin{tabular}{llll}
\hline System & Redox condition & Degradation & Reaction products \\
\hline & & & \\
Aqueous biodegradation & Anaerobic & $\mathrm{T}_{1 / 2}=20-40 \mathrm{~m}$ & \\
Aqueous biodegradation & Aerobic & $\mathrm{T}_{1 / 2}=5-10 \mathrm{~m}$ & \\
Methanogenic sludge & Reductive $\mathrm{DH}$ & $98 \%$ & 1,1 dichloroethane \\
sediment & Anaerabic & $100 \%$ & 1,1 dichloroethane \\
& & & \\
\hline
\end{tabular}

1,1,1-ETC in different systems listed in Table 4. Biodegradation of 1,1,1-ETC has been reported for sediments under anaerobic conditions with total disappearance after 4 to 5 months, the major degradation product being 1,1-dichlorethane [36].

\subsection{Dichloromethane}

\subsubsection{Sources}

Dichloromethane (DCM, cas no. 75-09-2) is used in many industrial processes such as metal cleaning, paints, extracting agent, paints and varnish removers, aerosol propellants, degreasing and cleaning fluids, blowing agent in the urethane foam production and refrigerant. It is further used as a solvent in insecticides and as a fumigant $[4,5]$.

\subsubsection{Degradation}

In the aquatic environment

The volatilisation is the main mechanism for DCM loss from aquatic system. Half-lives of volatilisation ranging from 5.3 hours in a $1 \mathrm{~m}$ deep water system to $36-38$ hours in rivers and 3337 days in seas have been reported [4]. Photochemical degradation as well as reductive dehalogenation and hydrolysis in surface water is insignificant $[5,37]$. In water the reaction with the $\cdot \mathrm{OH}$ radical is the dominant degradation pathway when sunlight is present resulting in halve lives of 68 years.

DCM is biologically degraded under anaerobic conditions via methyl chloride but no accumulation was observed. The half-life of DCM in an anaerobic water/sludge system was reported to be 11 days [37].

In the atmosphere

DCM released into the atmosphere will degrade by reaction with $\cdot \mathrm{OH}$ with an expected half-life of several months [4]. DCM will not be subject to direct photolysis [4]. The reaction of DCM with a hydroxyl radical is fast (completed in about 5 minutes) and gives the reaction products $\mathrm{CO}, \mathrm{HCl}, \mathrm{CO}_{2}$ and $\mathrm{COCl}_{2}$ (phosgene) or $\mathrm{CHOCl}$ formylchloride and later $\mathrm{CO}$ and $\mathrm{HCl}[5]$. Phosgene is stable in the atmosphere. The hypothetical reaction mechanism is [5]: 


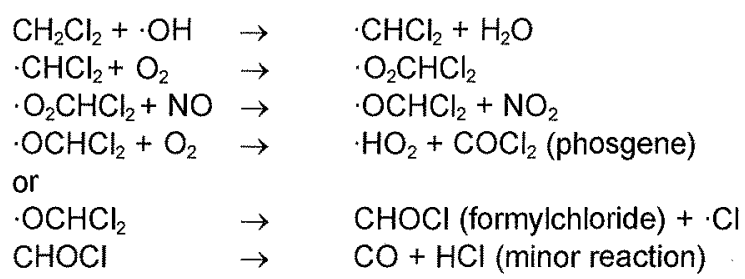

Formyl chloride may be taken up by cloud droplets, hydrolysed to formic acid and wet deposited as such, or dry deposited to the ocean or land surfaces and than hydrolysed. The overall lifetime for wet or dry deposition is probably a few months or shorter [37]. However degradation in the troposphere via reaction with $\mathrm{OH}$ radical to $\mathrm{CO}, \mathrm{CO}_{2}$ and $\mathrm{HCl}$ is probably a more rapid process.

Phosgene is slowly hydrolysed in the gas phase but this process is very rapid once it is dissolved in liquid water to give $\mathrm{CO}_{2}$ and $\mathrm{HCl}[37]$.

In soils

DCM is reported to biodegrade completely under aerobic conditions within 6 hours to 7 days. Under anaerobic conditions, $86-92 \%$ conversion to $\mathrm{CO}_{2}$ was obtained [4].

\subsection{1,1-Dichloroethane}

\subsubsection{Sources}

1,1-Dichloroethane (1,1-EDC, cas no 75-34-3) is an important intermediate in the production of 1,1,1-trichloroethane. It has a minor application as solvent for caoutchouc (natural rubber) and silicone greases, and as coupling agent in antiknock gasoline [4].

\subsubsection{Degradation}

In the aquatic environment

In aquatic systems, volatilisation is the major pathway for removal of the compound. Calculated half-life value are reported to be 22 minutes under natural conditions [4], but measurements in the natural environment shows that the half-life of removal from rivers by volatilisation is in the order of 10-30 days [4].

In the atmosphere

In the atmosphere, the major environmental sink for 1,1-EDC is the reaction with $\mathrm{OH}$ [4]. The half-life is about 2 months [4]. The reported degradation products are formyl chloride, $\mathrm{HCl}, \mathrm{CO}_{2}$, $\mathrm{CO}$ and monoacetylchloride [4]. 


\section{CML}

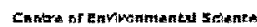

\subsection{HCFC-22}

\subsubsection{Sources}

HCFC-22 $\left(\mathrm{CHClF}_{2}\right.$, cas no 75-45-6) is an important industrial chemical having a range of applications [26] It is used as a chemical intermediate, aerosol propellant, blowing agent for foams, and in refrigeration and air-conditioning applications [26]. Annual emission in 1990 was estimated in the order of $195.2 \times 10^{6} \mathrm{~kg}[26]$.

\subsubsection{Degradation}

The dominating degradation process for HCFCs in the atmosphere is by reaction with the hydroxyl radical $\cdot \mathrm{OH}$. Other degradation processes such as reaction with $\cdot \mathrm{Cl}$ atoms, $\cdot \mathrm{NO}_{3}$, or $O\left({ }^{3} \mathrm{P}\right)$ atoms are negligible. The lifetime reported is 13.3 years according to UNEP. The principal products expected from HCFCs and HFCs are:

- Acid halides $\mathrm{CF}_{3} \mathrm{C}(\mathrm{O}) \mathrm{Cl}$ and $\mathrm{CF}_{3} \mathrm{C}(\mathrm{O}) \mathrm{F}$

- Carbonyl halides $\mathrm{CF}_{2} \mathrm{O}, \mathrm{CFClO}, \mathrm{CCl}_{2} \mathrm{O}, \mathrm{HCFO}$, and $\mathrm{HCClO}$

- Aldehydes $\mathrm{CX}_{3} \mathrm{CHO}$

The principal end-products of atmospheric degradation of $\mathrm{HCFC}-22$ are $\mathrm{HCl}, \mathrm{COF}_{2},\left(\mathrm{HF}, \mathrm{CO}_{2}\right)$.

\subsection{Vinylchloride}

\subsubsection{Sources}

Vinylchloride (VC, $\mathrm{C}_{2} \mathrm{H}_{3} \mathrm{Cl}$, cas no $\left.75-01-4\right)$ is a bulk chemical which is used as a monomer in the production of PVC [24]. Annual total world production of VC was about 26 million tonnes in 1995 [40].

\subsubsection{Degradation}

In the aquatic environment

In aquatic systems, volatilisation is the primary loss process for VC in natural water. Other physical and chemical degradation processes such as photodegradation, oxidation and hydrolysis do not appear to play a major role [4]. It appears that photolysis of VC in water containing photosensitiser, i.e. humic materials may be fairly rapid. VC has low adsorption potential to soil and sediment [4].

Biological degradation of VC can occur in surface water as well as in ground water by a limited number of microorganisms, but biodegradation is rather slow [4]. The biodegradation studies have given contradictory results but VC degradation by micro-organism seems to be a little faster (several weeks) under anaerobic conditions than under aerobic conditions (several months) $[4,40]$. The main degradation products include glycolic acid or $\mathrm{CO}_{2}$ after aerobic conversion and ethane, ethene, methane or chloromethane after anearobic transformation [40].

\section{In the atmosphere}

The partitioning of VC into environmental compartments has been calculated to be $99.99 \%$ air; $0.01 \%$ water; $<0.01 \%$ soil and $<0.01 \%$ sediment [40]. In the atmosphere, the major degradation pathway for $\mathrm{VC}$ is the photochemical oxidation. The products of the reaction are $\mathrm{HCl}$, formaldehyde, formyl chloride, $\mathrm{CO}, \mathrm{CO}_{2}$, chloroacetylaldehyde, acetylene, chloroethylene and $\mathrm{H}_{2} \mathrm{O}$. The recent typical half-life values in air are listed in Table 5. 
Table 5 Recently reported half-lives of removal of VC from the atmosphere [4].

\begin{tabular}{lll}
\hline Medium & Mechanism & Result \\
\hline & & \\
Ambient air & Photochemical & $T_{1 / 2}=1.5-1.8 \mathrm{~d}$ \\
Smog & Photochemical & $\mathrm{T}_{1 / 2}=3-7 \mathrm{~d}$ \\
Air & Photochemical & $15 \%$ degradation \\
Air & Reaction with $\mathrm{O}_{3}$ & $\mathrm{~T}_{1 / 2}=4.2-33 \mathrm{~d}$ \\
Air & Reaction with $\mathrm{OH}$ & $\mathrm{T}=3 \mathrm{~d}$ \\
& & \\
\hline
\end{tabular}

Chloroacetylaldehyde has often been reported to be the main degradation product.

Chloroacetylaldehyde in itself is a rather stable intermediate [40]. Formyl chloride is a stable potential toxicant [40].

Reactions with ozone as well as direct photolysis appears to be relatively insignificant [4].

\subsection{1,1-Dichloroethene}

\subsubsection{Sources}

1,1-Dichloroethene (1,1-dichloroethylene, 1,1-DCE, cas no 75-35-4) is used for captive organic chemical synthesis and in the production of polyvinylidene chloride polymers [4].

\subsubsection{Degradation}

In the aquatic environment

In aquatic systems, volatilisation is the principal mechanism for removal of 1,1-DCE from water [4]. Half-lives of 1.6 hours have been reported. Photolysis and hydrolysis of DCE are not likely to be significant processes. Dehalogenation has proved to be a minor importance in soil and sediment [4].

In the atmosphere

In the environment, atmospheric radicals $\mathrm{OH}$ and $\mathrm{NO}$ are playing a major role in the degradation of the compound resulting in the production of chloroacetyl chloride, phosgene, formaldehyde, carbon monoxide and nitric acid [4]. Overall degradation half-life is expected to be a few days [4]. The compound may also react with a chlorine atom, peroxy-radicals and ozone. Photolysis of the compound in the presence of nitrogen oxides is also rapid with a half-lives shorter than 2 hours [4]. An overview of degradation pathways in different environmental compartments is given in Table 6. 
Table 6 Half-life and degradation products of 1,1-dichloroethene in different environmental compartments [4].

\begin{tabular}{llll}
\hline Compartment & Mechanism & Degradation & Products \\
\hline Dilute aqueous solution & hydrolysis & $\mathrm{T}_{1 / 2}=1.2 \times 10^{8} \mathrm{y}$ & \\
Aqueous solution & Volatilisation & $\mathrm{T}_{1 / 2}=1.6 \mathrm{~h}$ & \\
Atmosphere & reaction with $\mathrm{OH}$ & $\mathrm{T}_{1 / 2}=3 \mathrm{~d}$ & $\mathrm{HCHO}$ and $\mathrm{COCl}_{2}$ \\
& photolysis & $\mathrm{TH}_{1 / 2}<2 \mathrm{~h}$ & \\
\hline
\end{tabular}

\section{Biodegradation}

Biotransformation of 1,1-DCE is believed to be an important process [4]. Under aerobic conditions, no evidence was found for the degradation of the compound. Under anaerobic conditions, the compound is partially to completely converted to vinyl chloride [4].

\subsection{1,2-Dichloropropane}

\subsubsection{Sources}

1,2-Dichloropropane (1,2-DCP, cas no 78-87-5) is a volatile compound which is released into the environment primarily through its use as a soil fumigant [4]. Furthermore it is used in gum processing, oil processing, organic chemical synthesis, in rubber making, wax making and in the making of scouring compounds [38]. It is used in furniture finishing, dry cleaning fluid, paint remover and metal degreasers.

\subsubsection{Degradation}

An overview of degradation pathways in different environmental compartments is given in Table 7.

Table 7 Half-life and degradation products of 1,2 -dichloropropane in different environmental compartments [4].

\begin{tabular}{llll}
\hline Compartment & Mechanism & Degradation & Products \\
\hline Water stream & Volatilisation & $\mathrm{T}_{1 / 2}=5.5 \mathrm{~h}$ & \\
Aqueous solution & Volatilisation & $\mathrm{T}_{1 / 2}=8.3 \mathrm{~h}$ & \\
Demineralised water & Hydrolysis & $\mathrm{T}_{1 / 2}=8613 \mathrm{~d}$ & Chloro-1 propanol-2 \\
& & $\mathrm{T}_{1 / 2}=840 \mathrm{~min}$ & \\
Demineralised water & Photolysis & $\mathrm{T}_{1 / 2}=30 \mathrm{~min}$ & \\
Demineralised water + & Photolysis + oxidation acid \\
$\mathrm{H}_{2} \mathrm{O}_{2}$ & reaction with $\cdot \mathrm{OH}$ & $\mathrm{T}_{1 / 2}=6.2 \mathrm{~d}$ & \\
Atmosphere & & & \\
\hline
\end{tabular}

In the aquatic environment

In aquatic systems, 1,2-DCP will be lost primarily by volatilisation. Half-lives ranging from 5 to 8 hours in a typical river and of 10 days in a lake [4]. 1,2-DCP is resistant to hydrolysis with an estimated half-life ranging between 25 and 200 weeks. Photolysis is not likely to be very important, since a half-life of much more than 14 hours was reported [4]. 
In the atmosphere

The primary mode of degradation in air is through reaction with $\cdot \mathrm{OH}$ radicals [4]. Adsorption to particulate matter seems to be necessary for appreciable direct phototransformation. The calculated half-life on the basis of reaction with hydroxyl radicals was $>313$ days (hydroxyl concentration of $1 \times 10^{6} \mathrm{~cm}^{3}$ )

In Soil

Biodegradation rates depends heavily on local circumstances. Little or no chemical degradation has been observed in laboratory and field studies. More than $98 \%$ was found $12-20$ weeks after application to sandy loam soil and medium loam soil.

\subsection{1,3-Dichloropropene}

\subsubsection{Sources}

1,3-Dichloropropene (1,3-DCP trans- and cis-isomer mixture, cas no 542-75-6) is widely used as a soil fumigant for parasitic plant nematodes [4].

\subsubsection{Degradation}

In the aquatic environment

In aquatic environment, 1,3-DCP will be lost primarily by volatilisation. Half-lives ranging from 20 to $30 \mathrm{~min}$ [4]. Chloropropenes are sensitive to hydrolysis. However, the rate depends on the conditions in the aqueous medium. Temperature plays a major role [4]. The products formed are the corresponding allylic alcohols with concomitant release of chloride ions. Half-lives range from $1.5-2.0$ days at $29^{\circ} \mathrm{C}$ to $91-100$ days at $2^{\circ} \mathrm{C}$ [4]. Photolysis seems to be possible, no conclusions can be made on its importance for degradation [4].

In the atmosphere

In the atmosphere, $\cdot \mathrm{OH}$ radicals are playing the major role in the degradation of 1,3-DCP. Absorption to particulate matter seems to be necessary for an appreciable direct phototransformation to occur. Direct photodegradation results in the formation of $\mathrm{CO}_{2}$ and phosgene [38]. The atmospheric life time is approximately $2-3$ days at a $\cdot \mathrm{OH}$ concentration of 5 $\times 10^{5} \mathrm{~mol} \cdot \mathrm{cm}^{-3}[4]$.

In soil

1,3-DCP was reported to have a half-life in soil between 3 and 37 days without any correlation between organic matter of the soil, or with $\mathrm{pH}$ but with increasing rate when moisture content and temperature rise [38]. The major degradation products, cis- and trans-3-chloroallyl alcohols [4]. An overview of degradation pathways is given in Table 8 . Although between 15 and $80 \%$ decomposition of field applications of 1,3-dichloropropene has been shown, the large amount that can be adsorbed ( $80-90 \%)$ can result in soil residues existing months after application is completed [38]. An important intermediate in the degradation is 3-chloro-allyl alcohol which is also the product of chemical hydrolyses is moist soils [38] . 
Table 8 Half-life and degradation products of 1 ,-dichloropropene in different environmental compartments [4].

\begin{tabular}{llll}
\hline Compartment & Mechanism & Degradation & Products \\
\hline Aqueous solution & Volatilisation & $\mathrm{T}_{1 / 2}=20-30 \mathrm{~min}$ & \\
Demineralised water & Hydrolysis & $\mathrm{T}_{1 / 2}=6 \mathrm{~d}(\mathrm{cis})$ & Chloropropenol-3 \\
& & $\mathrm{T}_{1 / 2}=7 \mathrm{~d}($ trans) & hydrochloric acid \\
Aqueous solution & Hydrolysis & $\mathrm{T}_{1 / 2}=4.8 \mathrm{~d}$ & \\
Atmosphere & reaction with $\mathrm{OH}$ & $\mathrm{T}=3 \mathrm{~d}(\mathrm{cis})$ & \\
& & $\mathrm{T}=2 \mathrm{~d}$ (trans) & \\
Soil and sediment (wet & Hydrolysis & $\mathrm{T}_{1 / 2}=3-25 \mathrm{~d}$ & 3-chloroacrylic acids \\
soil) & & & \\
\hline
\end{tabular}

Biodegradation

The aerobic degradation of 1,3-DCP seems possible with a half-life ranging from 7 days with unadapted bacterial cultures to $<6$ days for adapted bacteria [4]. The biodegradation rates will strongly depend on moisture content, oxygen concentration in the soil and temperature. Degradation products of 1,3-DCP in aerobic soil include 3-chloroallyl alcohol, 3-chloroacrylic acid, numerous minor carboxylic acid metabolites and carbon dioxide [9].

\subsection{Polychlorinated biphenyl}

\subsubsection{Sources}

Polychlorinated biphenyl (PCBs cas no 1336-36-3) have been widely used as hydraulic fluid, dielectric fluid in transformers, cutting fluid, carbonless copy papers etc [31]. Total global production has been estimated at 1200000 tons [32].

\subsubsection{Degradation}

In the atmosphere

In general PCBs in the troposphere could be degraded by four mechanisms: photolysis, Reaction with ozone, reaction with the $\cdot \mathrm{OH}$ radical and reaction with the $\cdot \mathrm{NO}_{3}$ radical.

Reactions of ozone and the $\mathrm{NO}_{3}$ radical with PCBs in the atmosphere have not been observed [23]. Reaction of the $\cdot \mathrm{OH}$ radical with PCBs has been studied rather well and seems to be the only important troposheric loss process for the gas-phase PCBs [23]. Reaction products have not been given. Only a very few studies deal with the photolysis of PCBs in the troposhere [23]. Tropospheric lifetimes for PCBs given by [15] are shown in Table 9. 
Biodegradation

Biodegradation of PCBs in soil is considered to be very complex due to various physicochemical factors involved. Isotope labelling technique seem to be the best way to trace fate of PCBs in the environment [13]. Using the isotope labelled PCB congener 11 (3,3'-chlorobiphenyl) as a low chlorinated coplanar biphenyl, 3-chlorobenzoic acid was found to be the major biodegradation product. PCB-11 was readily degraded by micro-organisms. In another study [14], it has been reported that in addition to chlorobenzoic acid as biodegradation product of PCBs, there are some other metabolites such as 2,3-dihydro-2,3-dihydroxy-2'-chlorobiphenyl and 2,3-dihydroxy-2'-chlorobiphenyl. A general pathway for the biodegradation of PCBs by micro-organism [29] is given in Figure 1 and corroborates the findings of [14] and [30].

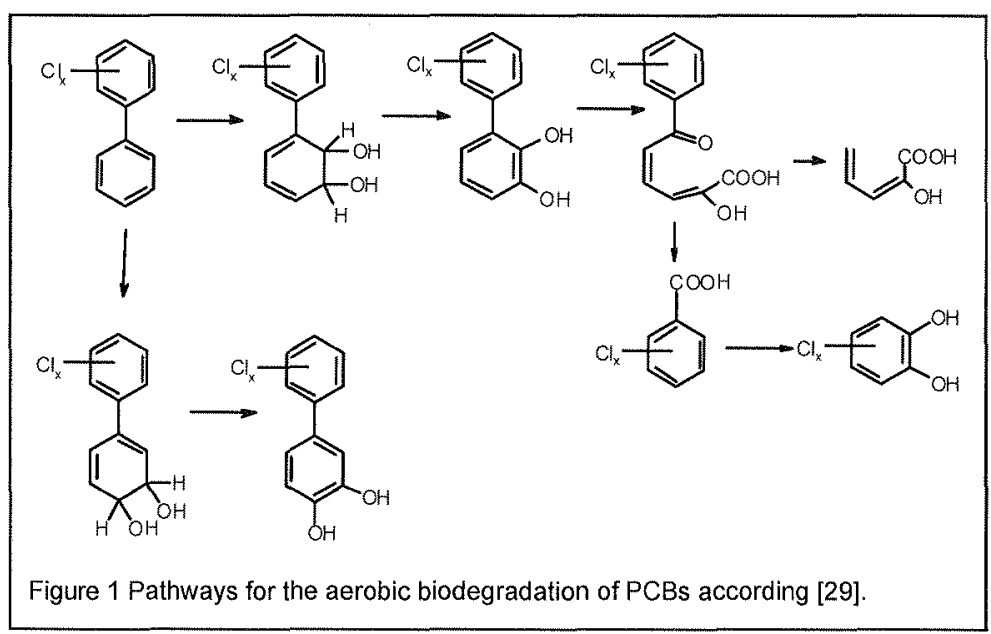

However the metabolism of PCBs by vertebrate is different form the degradation by microorganisms [29]. In vertebrate the PCB is transformed in a hydrolysed species but alternatively may also be coupled with endogenous molecules like gluthatione (GSH). Metabolites of PCB like the hydroxylated congeners as well as the lipophylic methyl-sulfonyl compounds have been found in wildife [29]. A general pathway for the biotransformation of PCBs in vertebrate is given in Figure 2. 


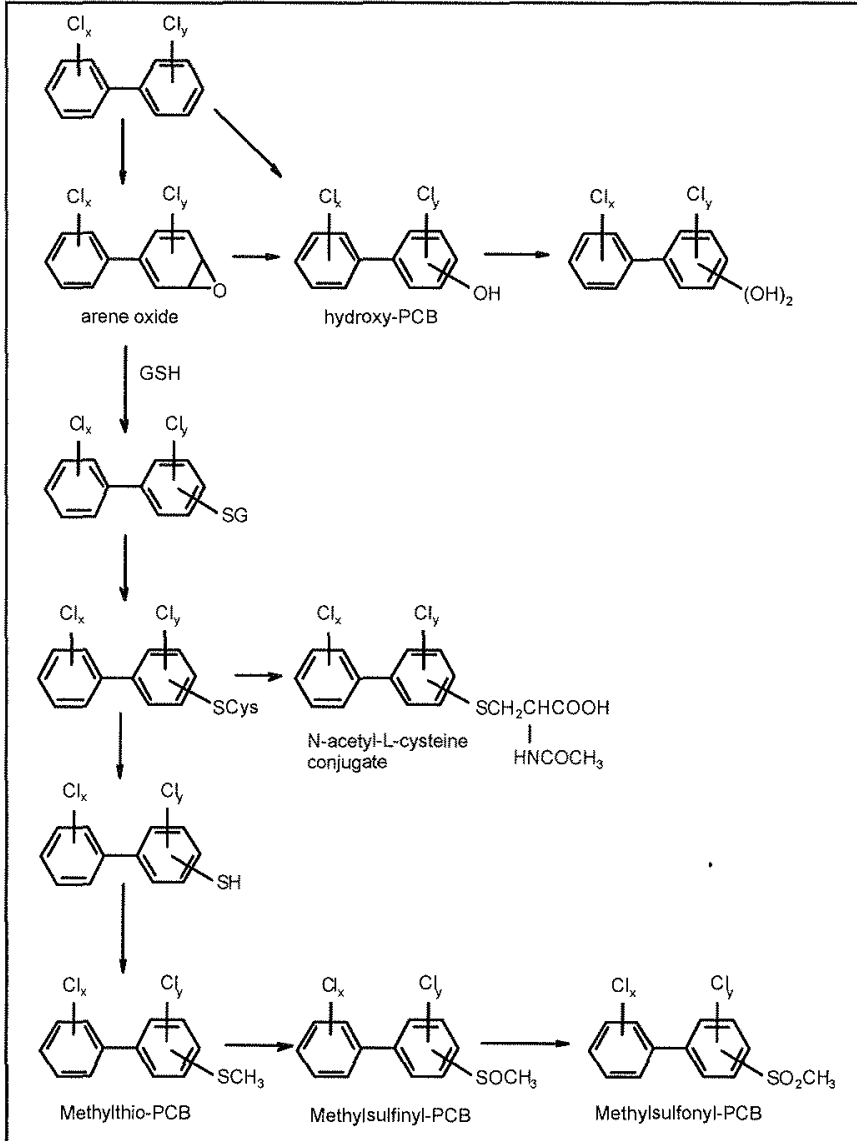

Figure 2. Metabolic pathways of PCB transformation in vertebrates.

The following half-life times (h) of some PCB congeners in air, water, soil and sediment at average temperature $+7^{\circ} \mathrm{C}$ have been suggested [15].

Table 9 Half-lives for some PCB congeners in air, water, soil and sediment at an average temperature of $+7^{\circ} \mathrm{C}[15]$

\begin{tabular}{llrrrr}
\hline & Structure & $\begin{array}{r}\text { Air } \\
{[\mathrm{hr}]}\end{array}$ & $\begin{array}{r}\text { Water } \\
{[\mathrm{hr}]}\end{array}$ & $\begin{array}{r}\text { Soil } \\
{[\mathrm{hr}]}\end{array}$ & $\begin{array}{r}\text { Sediment } \\
{[\mathrm{hr}]}\end{array}$ \\
\hline & & & & & \\
PCB 28 & 244'-trichloro & 152 & 1450 & 26000 & 26000 \\
PCB 52 & 22'55'-tetra- & 1500 & 30000 & 87600 & 87600 \\
PCB 77 & 33'44'-tetra- & 3000 & 60000 & 87600 & 87600 \\
PCB 101 & 22'455'-penta- & 3000 & 60000 & 87600 & 87600 \\
PCB 105 & 233'44'-penta- & 3000 & 60000 & 60000 & 87600 \\
PCB 118 & 23'44'5-penta- & 3000 & 60000 & 87600 & 876000 \\
PCB 126 & 33'44'5-penta- & 6000 & 120000 & 165000 & 165000 \\
PCB 138 & 22'44'5'-hexa- & 6000 & 120000 & 165000 & 165000 \\
PCB 153 & $22^{\prime} 44^{\prime} 55^{\prime}$ '-hexa- & 6000 & 120000 & 165000 & 165000 \\
PCB 169 & 33'44'55'-hexa- & 12000 & 240000 & 330000 & 333000 \\
PCB 180 & 22'344'55'-hepta- & & & & \\
\hline
\end{tabular}




\subsection{CFC-113}

\subsubsection{Sources}

CFC-113 (1,1,2-trichloro-1,2,2-trofluoroethane, cas no 76-13-1) has been used widely as cleaning agent, propellant and blowing agent in the foam production.

\subsubsection{Degradation}

Chlorodifluoroacetic acid (CDFA) was detected in rain and snow samples from various regions of Canada [17]. A degradation study suggests that CDFA is recalcitrant to biotic and abiotic degradation relative to dichloroacetic acid (DCA) and may accumulate in the aquatic environment. On the basis of the existing experimental data, they postulate that CDFA is a degradation product of CFC-113.

The degradation pathway of CFC-113 in water under anaerobic conditions has been studied [18]. $\mathrm{CFC}-113$ was transformed to $\mathrm{HCFC}-123 \mathrm{a}$ with a half-life time of 5 days at $20^{\circ} \mathrm{C}$. under the same conditions, HCFC-123a was then further dechlorinated to HCFC-133 and HCFC-133b.

Microbial degradation of HCFC-123 was observed in anoxic fresh water and salt marsh sediments, and the recovery of 1,1,1-trifluoro-2-chloroethane indicated the involvement of reductive dechlorination, no degradation of HCFC-123 was observed in aerobic soils [19].

\subsection{Carbon tetrachloride}

\subsubsection{Sources}

Carbon tetrachloride or tetrachloromethane $\left(\mathrm{CCl}_{4}, \mathrm{CT}\right.$, cas no 56-23-5) has been used in fire extinguisher manufacture, dry cleaning operations, refrigerator manufacture, aerosols, metal degreasing, fumigant and chlorinating organic compounds [10]. The Montreal protocol of 1990 and its subsequent amendments established the phase-out by 1996 of production and use of carbon tetrachloride [39]

\subsubsection{Degradation}

In the atmosphere

Practically all CT released into the environment is present in the atmosphere [39] because CT does not degrade readily in the atmosphere significant global transport is expected. Estimates of the atmospheric lifetime (overall persistence in troposphere and stratosphere combined) are in the rage from 2 to 100 years. with $40-50$ years generally being accepted as the most reasonable value.

Degradation in the atmosphere by photodegradation is very slow because CT has a low reactivity towards hydroxyl radicals. Estimated life-time in the troposphere due to photolysis is in the order of 500 years. The principal degradation process of CT occurs in the stratosphere by photolysis, where it is dissociated by short wave length $(190-220 \mathrm{~nm})$ UV radiation to form trichloromethyl radical and chlorine atoms. The estimated half-life for this process is in the order of 18- 80 years for this photodissociation process [39]. This reaction is responsible for the ozone depletion properties of CT according: 


$$
\begin{aligned}
& \mathrm{CCl}_{4}+\mathrm{h} ? \rightarrow \cdot \mathrm{CCl}_{3}+\cdot \mathrm{Cl} \\
& \cdot \mathrm{CCl}_{3}+\mathrm{O}_{2} \rightarrow \rightarrow \mathrm{COCl}_{2}+\mathrm{CLO} . \\
& \cdot \mathrm{Cl}+\mathrm{O}_{3} \rightarrow \mathrm{ClO}+\mathrm{O}_{2} \\
& \mathrm{ClO}+\mathrm{O} \rightarrow \cdot \mathrm{Cl}+\mathrm{O}_{2}
\end{aligned}
$$

In the aquatic environment

Abiotic degradation like hydrolysis and photodegradation does not seem to play an important role. It has been found that under anaerobic conditions, tetrachloromethane has been transformed to trichloromethan (chloroform) by bacteria. No dichloromethane, chloromethane, or methane was produced $[20,39]$. This observations was confirmed by another group which conducted a field experiment in which CT was found to transform to chloroform (CF) and carbon disulfide $\left(\mathrm{CS}_{2}\right)$ in a ratio of about $2: 1$ [21].

\subsection{Formation of chloroacetic acids from Per and Tri}

Trichloroacetic acid is a know product of atmospheric degradation of tetrachloroethene (global average yield $5 \%$ ) and to a much lesser extend of 1,1,1-trichloroethane [17]. Dichloracetic acid is a known product of atmospheric degradation of trichloroethene (average global yield $0.5 \%$ ). Average concentrations in European rainwater range from 100-150 ng/l. The concentrations in rainwater samples are similar to those calculated on degradation models. Hoekstra et al., 1999 [34] made a mass balance for Trichloroacetic acid in soils. TCAA is found soils and sources may be natural or anthropogenic, most likely via the degradation of tetrachloroethene. Although the degradation of tetrachlorethene in the atmosphere could be a source of TCAA is soils the mass balance calculations provide tentative evidence of formation within the soil itself. Von Sydow et al., 1999 [33] analysed chloroactetates in samples of snow, firn and glacier ice in remote areas including Antarctica, the Russian tundra and northern Scandinavia. The levels found were too high to be explained by direct anthropogenic emissions of chloroacetic acids and their salts. It was also difficult to trace the occurrence of these compounds back to the degradation of compounds like 1,1,1-trichloroethane, trichloroethene and tetrachloroethene. 


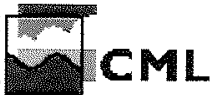

3.16. Expected atmospheric degradation products of other substances.

\begin{tabular}{|c|c|c|c|c|c|c|c|}
\hline Compound & Cas $\mathrm{rn}$. & $\mathrm{K}_{\mathrm{OH}} \times 10^{12}$ & $\mathrm{~K}_{03} \times 10^{18}$ & $\begin{array}{l}\text { Photolysis } \\
\text { probability }\end{array}$ & $\begin{array}{l}\text { Physical removal } \\
\text { probability }\end{array}$ & $\begin{array}{l}\text { Residence time } \\
\text { [days] }\end{array}$ & Possible reaction products \\
\hline Ally chloride & $107-05-1$ & 28 & 18.3 & Possible & Unlikely & 0.3 & $\begin{array}{l}\mathrm{HCO}_{2} \mathrm{H}, \mathrm{H}_{2} \mathrm{CO}, \mathrm{ClCH}_{2} \mathrm{CHO}, \mathrm{ClCH}_{2} \mathrm{CO}_{2} \mathrm{H} \text {, chlorinated hydroxyl } \\
\text { carbonyls }\end{array}$ \\
\hline Benzyl chloride & $100-44-7$ & 3 & 0.004 & Possible & Unlikely & 3.9 & $\phi \mathrm{CHO}$, chloromethylphenols, ring cleavage products \\
\hline Bis(chloromethyl)ether & $542-88-1$ & 4 & - & Possible & Probable & $0.02-2.9$ & $\mathrm{HCl}, \mathrm{H}_{2} \mathrm{CO}$, chloromethylformate, $\mathrm{ClHCO}$ \\
\hline Carbon tetrachloride & $56-23-5$ & $<0.001$ & - & - & Unlikely & $>11,000$ & $\mathrm{Cl}_{2} \mathrm{CO}$ \\
\hline Chlorobenzene & $108-90-7$ & 0.4 & $<5 \times 10^{-5}$ & Possible & Unlikely & 28 & Chlorophenols, ring cleavage products \\
\hline Chloroform & $67-66-3$ & 0.1 & - & - & Unlikely & 120 & $\mathrm{Cl}_{2} \mathrm{CO}$ \\
\hline Chloromethyl methyl-ether & $107-30-2$ & 3 & - & Possible & Probable & $0.004-3.9$ & Decomposition products, chloromethyl, methyl formate, $\mathrm{CHHCO}$ \\
\hline Chloroprene & $126-99-8$ & 46 & 8 & Probable & Unlikely & 0.3 & $\begin{array}{l}\mathrm{H}_{2} \mathrm{CO}, \mathrm{H}_{2} \mathrm{C}=\mathrm{CClCHO}, \mathrm{OHCCHO}, \mathrm{ClCOCHO}, \mathrm{H}_{2} \mathrm{CCHCCIO} \\
\text { chlorohydroxyl acid, aldehydes }\end{array}$ \\
\hline Epichlorhydrin & $106-89-8$ & 2 & - & Possible & Unlikely & 5.8 & $\mathrm{H}_{2} \mathrm{CO}, \mathrm{OHCOCHO}, \mathrm{ClCH} 2 \mathrm{C}(\mathrm{O}) \mathrm{OHCO}$ \\
\hline Ethylene dichloride & $25323-30-2$ & 0.22 & - & Possible & Unlikely & 53 & $\mathrm{ClHCHO}, \mathrm{H}_{2} \mathrm{CClCOCl}, \mathrm{H}_{2} \mathrm{CO}, \mathrm{H}_{2} \mathrm{CClCHO}$ \\
\hline Hexachlorocyclopentadiene & $44-47-4$ & 59 & 8 & Probable & - & 0.2 & $\mathrm{Cl}_{2} \mathrm{CO}$, diacylchlorides, ketones \\
\hline Methyl chloride & $74-87-3$ & 0.14 & - & Possible & Unlikely & 83 & $\mathrm{Cl}_{2} \mathrm{CO}, \mathrm{CO}, \mathrm{CHCO}$ \\
\hline Methyl chloroform & $71-55-6$ & 0.012 & - & Possible & Unlikely & 970 & $\mathrm{H}_{2} \mathrm{CO}, \mathrm{Cl}_{2} \mathrm{CO}$ \\
\hline Perchloroethylene & $127-18-4$ & 0.17 & 0.002 & Possible & Unlikely & 67 & $\left.\mathrm{Cl}_{2} \mathrm{CO}, \mathrm{Cl}_{2} \mathrm{ClOH}\right) \mathrm{COCl}$ \\
\hline Phosgene & $75-44-5$ & 0 & - & - & Possible & - & $\mathrm{CO}_{2}, \mathrm{HCl}$ \\
\hline Polychlorinated biphenyl & $1336-36-3$ & $<1$ & $5 \times 10^{-5}$ & Possible & Unlikely & $>11$ & Hydroxy PCB's, ring cleavage products \\
\hline Trichloroethylene & $79-01-6$ & 2.2 & 0.006 & Possible & Unlikely & 5.2 & $\mathrm{Cl}_{2} \mathrm{CO}, \mathrm{CHCO}, \mathrm{CO}$ \\
\hline Vinylidene chloride & $75-35-4$ & 4 & 0.04 & Possible & Unlikely & 2.9 & $\mathrm{H}_{2} \mathrm{CO}, \mathrm{Cl}_{2} \mathrm{CO}, \mathrm{HCO}_{2} \mathrm{H}$ \\
\hline
\end{tabular}


Table 10 Reaction products of some chlorinated aliphatic compounds with $\cdot \mathrm{OH}$ and Cl radicals [16].

\begin{tabular}{llll}
\hline Compound & cas rn & Products after reaction with $\cdot \mathrm{OH}$ & $\begin{array}{l}\text { Products after reaction } \\
\text { with } \cdot \mathrm{Cl}\end{array}$ \\
\hline $\mathrm{CH}_{3} \mathrm{Cl}$ & $74-87-3$ & $\mathrm{HCOCl}, \mathrm{CH}_{2} \mathrm{ClO}_{2} \mathrm{H}$ & \\
$\mathrm{CH}_{2} \mathrm{Cl}_{2}$ & $5-09-2$ & $\mathrm{HCOCl}, \mathrm{CHCl}_{2} \mathrm{O}_{2} \mathrm{H}, \mathrm{COCl}_{2}$ & \\
$\mathrm{CH}_{3} \mathrm{CCl}_{3}$ & $25323-89-1$ & $\mathrm{CH}_{3} \mathrm{COCl}, \mathrm{CCl}_{3} \mathrm{CHO}, \mathrm{COCl}_{2}$ & \\
$\mathrm{CH}_{2}=\mathrm{CHCl}$ & $75-01-4$ & $\mathrm{HCHO}, \mathrm{HCOCl}$ & \\
$\mathrm{CHCl}=\mathrm{CHCl}$ & $540-59-0$ & $\mathrm{HCOCl}$ & \\
$\mathrm{CH}_{2}=\mathrm{CCl}_{2}$ & $75-35-4$ & $\mathrm{HCHO}, \mathrm{COCl}_{2}$ & $\mathrm{CH}_{2} \mathrm{ClCOCl}$ \\
$\mathrm{CHCl}_{2} \mathrm{CCl}_{2}$ & $79-01-6$ & $\mathrm{HCOCl}, \mathrm{COCl}_{2}$ & $\mathrm{CHCl}_{2} \mathrm{COCl}$ \\
$\mathrm{CCl}_{2}=\mathrm{CCl}_{2}$ & $127-18-4$ & $\mathrm{COCl}$ & $\mathrm{CCl}_{3} \mathrm{COCl}$ \\
\hline
\end{tabular}

\section{Conclusions}

In this literature study degradation pathways and products of high emission chlorinated compounds in the Netherlands have been identified. Degradation pathways depend on the initial emission compartment on the type of the emission (free compound or adsorbed to particles) and on the environmental conditions such as temperature, intensity and availability of solar radiation and availability of micro-organisms. Degradation products of low emission compounds, including a large number of emissions to surface water, were not studied. Degradation products of substances which are emitted to air and transformed in the environment can be expected to end up in other environmental compartments.

An overview of the result of this study is given in the table on the next page. It contains the main degradation products of all the substances discussed in the atmosphere or soil / water system. Main purpose of this table is to give a quick overview of the substances which can be detected in the environment for a long time to come. The persistence of the original substance and its degradation products is denoted qualitative by $a+,++$ or.$+++ A$ ' + ' sign means that the substance has transformed within approximately one week, a ' ++ ' sign means that the substance will be transformed in several weeks time and a ' +++ ' means that it will take months or more for the substance to be transformed. Degradation is in the soil / water system discriminated between aerobic and anaerobic conditions. 


\section{cmL}

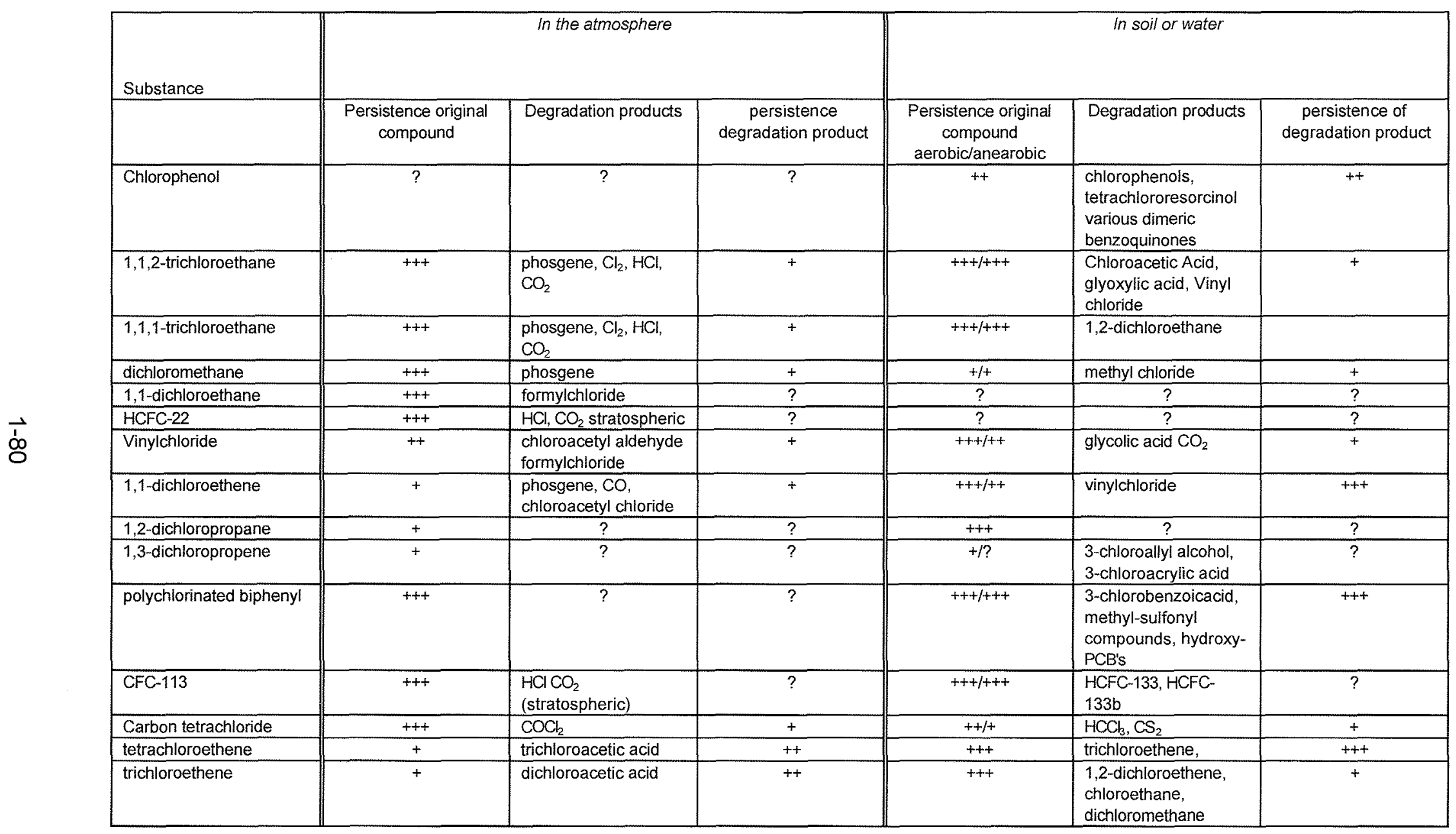




\section{References}

1- Annachhatre, A.; Gheewala, S., Biodegradation of chlorinated phenolic compounds. Biotechnology Advances. 14 (1996) 35-56.

2- Liber, K; Solomon, K.; Carey, J., Persistence and fate of 2,3,4,6-tetrachlorophenol and pentachlorophenol in Limnocorrals. Environmental Toxicology and Chemistry. 16 (1997) 293305.

3- Zaborina, O.; Baskunov, B.; Baryshnikova, L.; Golovleva, L., Degredation of pentachlorophenol in soil by streptomyces rochei 303. Journal of Environmental Science and Health, Part B, 32 (1997) 55-70.

4- Mergaert, K.; Vanhaecke, P., Updating of data concerning the impact of certain dangerous substances on the aquatic environment. 1991, Ecolas, Antwerpen, Belgium, 263p.

5- Slooff, W.; Ros, J., Integrated criteria document dichloromethane, RIVM rep. No. 758473009, 1988, RIVM, The Netherlands.

6- Hester, R.; Harrison, R., Volatile organic compounds in the atmosphere. The Royal Society of Chemistry, 1995, Letchworth, UK.

7- Manahan, S.E., Environmental Chemistry, 5th edition, 1991, Lewis Publishers, Chelsea, Michigan, USA.

8- Batzer, F.R.; Balcer, J.L.; Peterson, J.R.; Wolt, J.D., Fate of 1,3-dichloropropene in anaerobic soils. ACS symposium series. 652 (1997) 60-78.

9- Verschueren, K., Environmental data on organic chemicals, 3rd edition,

10- Lorah, M.M; Olsen, L.D., Natural attenuation of chlorinated volatile organic compounds in a freshwater tidal wetland: field evidence of anaerobic biodegradation. Water Resources Research. 35 (1999) 3811-3827.

11- Lorah, M.M.; Olsen, L.D., Degradation of 1,1,2,2-tetrachloroethane in a freshwater tidal wetland: field and laboratory evidence. Environmental Science and Technology. 33 (1999) 227-234.

12- Kubatova, P.; Matucha, M.; Erbanova, P.; Novotny, C.; Vlasakova, V.; Sasek, V., Investigation into PCB biodegradation using uniformly C-14-labelled dichlorobiphenyl. Isotopes. Environmental and Health Studies. 34 (1998) 325-334.

13- Flanagan, W.P.; May, R.J., Metabolite Detection As Evidence For Naturally - Occurring Aerobic PCB. Biodegradation In Hudson River Sediments. Environmental Science and Technology. 27 (1993) 2207-2212.

14- Sinkkonen, S.; Paasivirta, J., Degradation half-life times of PCDDs, PCDFs and PCBs for environmental fate modelling. Chemosphere. 40 (2000) 943-949.

15- Zetzsch, C.; Becker, K.., Das luftchemische verhalten von Fluchtigen organohalogenverbindungen. 1989, VDI Bericht NO.745

16- Martin, J.; Franklin, J.; Hanson, M.; Solomon, K.; Mabury, S.; Ellis, D.; Scott, B.; Muir, D., Detection of chlorodifluoro-acetic acid in precipitation: A possible product of fluorocarbon degradation. Environmental Science and Technology. 34 (2000) 274-281.

17- Lesage, S.; Brown, S.; Hosler, K., Degradation of chlorofluorocarbon-113 under anaerobic conditions. Chemosphere, 24 (1992) 1225-1243.

18- Oremland, R.; Lonergan, D.; Culbertson, C.; Lovley. D., Microbial degradation of hydrochlorofluorocarbons $\left(\mathrm{CHCl}_{2} \mathrm{~F}\right.$ and $\left.\mathrm{CHCl}_{2} \mathrm{CF}_{3}\right)$ in soils and sediment. Applied and Environmental Microbiology. 62 (1996) 1818-1821.

19- Picardal, F.; Arnold, R.; Couch, H.; Little, A.; Smith, M., Involvement of cytochromes in the anaerobic biotransformation of tetrachloro methane by Shewanella-Putrefaciens 200 . Applied and Environmental Microbiology, 59 (1993) 3763-3770.

20- Devlin, J.; Muller, D., Field and laboratory studies of carbon tetrachloride transformation in a sandy aquifer under sulphate reducing conditions. Environmental Science and Technology, 33 (1999) 1021-1027.

21- Franklin, J., Dow Chemical, Personal communication.

22- Atkinson, R., Atmospheric chemistry of PCBs, PCDDs and PCDFs. In: Hester, R.E.; Harrison, R.M. (1996) Chlorinated Organic Micropollutants. The royal society of chemistry, $183 \mathrm{p}$.

23- Engbersen. J.F.J.; de Groot, FE., Bio-organische chemie, 1988, Pudoc wageningen, 476 p. 
24- Tukker, A.; Kleijn, R.; Van der Voet, E. (red.), Een chloorbalans voor Nederland, Deel III: Achtergronden, bijlagen en Peer-review. TNO beleidstudies en advies, Apeldoorn 1995.

25- Midgley, P.M.; Fisher, D.A. The production and release to the atmosphere of chlorodifluoromethane (HCFC 22). Atmospheric Environment. 27A (1993) 2215-2223.

26- Miyamoto, K.; Urano, K., Reaction rates and intermediates of chlorinated organic compounds in water and soil. Chemosphere. 32 (1996) 2399-2408.

27- Waid, J.S. (ed.) PCBs and the environment. 1986, CRC Press, Boca Raton.

28- De Voogt, P., Ecotoxicology of chlorinated aromatic hydrocarbons. In: Hester, R.E.; Harrison, R.M. (1996) Chlorinated Organic Micropollutants. The royal society of chemistry, $183 p$

29- Seeger, M.;Timmis, K.N.; Hofer, B., Bacterial pathways for the degradation of polychlorinated biphenyls. Marine Chemistry. 58 (1997) 327-333.

30- Swackhamer, D.L., Studies of polychlorinated biphenyls in the great lakes. In : Hester, R.E.; Harrison, R.M. (1996) Chlorinated Organic Micropollutants. The royal society of chemistry, $183 \mathrm{p}$.

31- Macdonald, R.W.; Barrie, L.A.; Bidleman, T.F.; Diamond, M.L.; Gregor, D.J.; Semkin, R. G.; Strachan, W.M.J.; Li, Y.F.; Wania, F.; Alaee, M.; Alexeeva, L..B.; Backus, S.M.;

Bailey, R.; Bewers, J.M.; Gobeil, C.; Halsall, C.J.; Harner, T.; Hoff, J.T.; Jantunen, L.M. M.; Lockhart, W.L.; Mackay, D.; Muir, D.C.G.; Pudykiewicz, J.; Reimer, K.J.; Smith, J.N.;

Stern, G.A ; Schroeder, W.H.; Wagemann R.; Yunker, M.B., Contaminants in the Canadian Arctic: 5 years of progress in understanding sources, occurrence and pathways The Science of the Total Environment. 254 (2000) 93-234.

32- Von Sydow, L., Boren, H., Grimvall, A. Chloroacetates in snow, firn and glacier ice., Chemosphere, Dec. 1999, 39(14), p.2479-2488.

33- Hoekstra, E.J., de Leer, E.W.B. and Brinkman, V.A.Th. (1999): Mass Balance of Trichloroacetic Acid in the Soil Top Layer, Chemosphere 38, 551-563.

34- WHO (1987). Pentachlorophenol. Environmental Health Criteria 71. WHO Geneve.

35- WHO (1992). 1,1,1-trichloroethane. Environmental Health Criteria 136. WHO Geneve.

36- WHO (1996). Methylene Chloirde (second edition). Environmental Health Criteria 164. WHO Geneve.

37- WHO (1993). 1,3-Dichloropropene, 1,2-dichloropropane and mixtures. Environmental Health Criteria 146. WHO Geneve.

38- The WHO Environmental Health Criteria Series, No. 208, Carbon tetrachloride, 1999, World Health Organization, Geneva, 177 pages, ISBN 9241572086

39- The WHO Environmental Health Criteria Series, No. 215, Vinyl Chloride, 1999, World Health Organization, Geneva, 1999, 356 pages, ISBN 9241572159 
Rev. 0

1.8 Davis, E. S., 1969, “241-AY Tank Farm Expansion - Welding Quality Control,” (Letter to H. E. Eager, June 9), Vitro Hanford Engineering Services, Richland, Washington. 


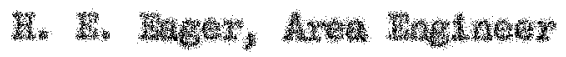

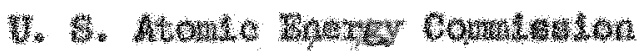

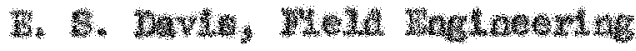
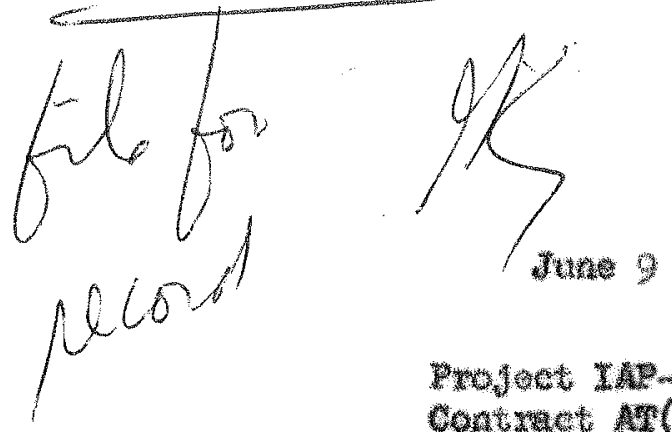

69

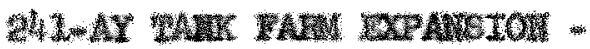

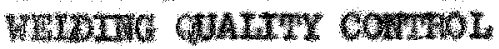

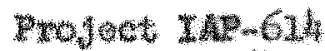

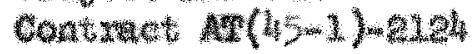

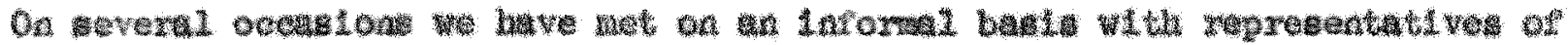

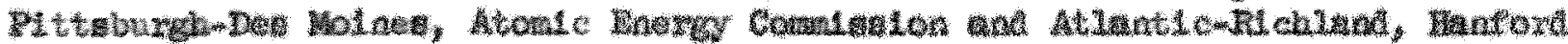

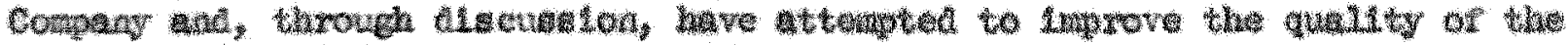

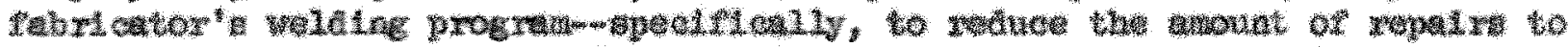

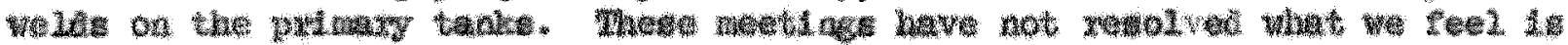

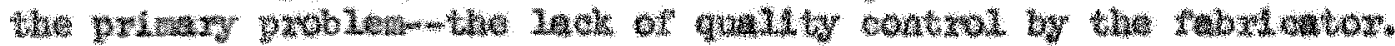

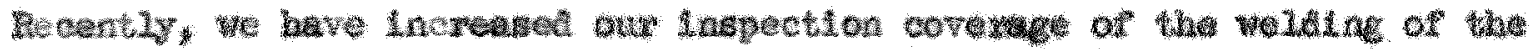

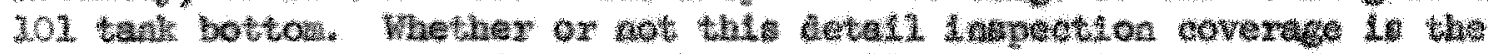

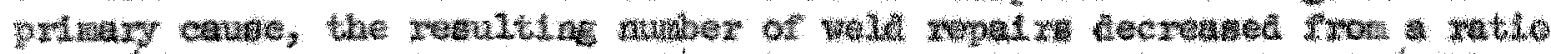

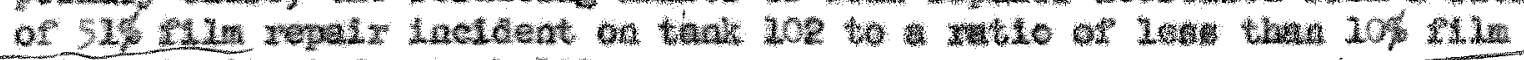

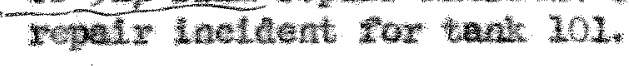

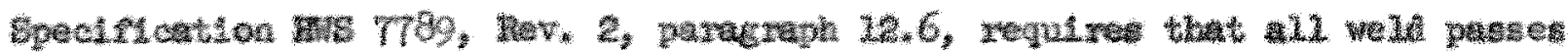

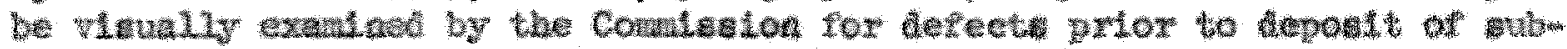

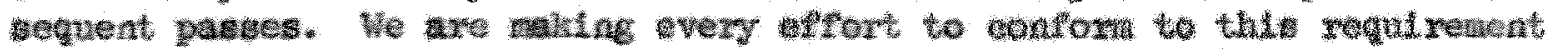
by bav1ag gualip.

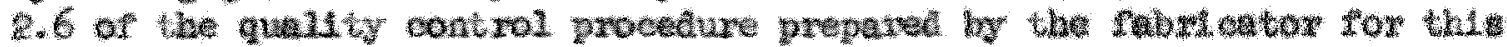

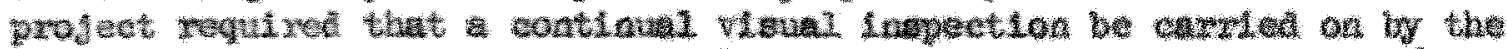

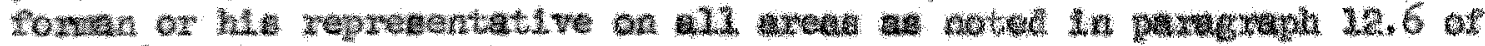

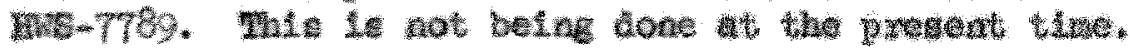

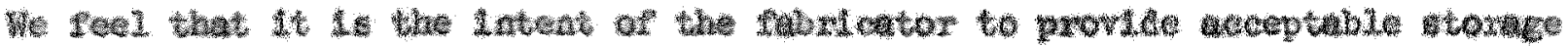

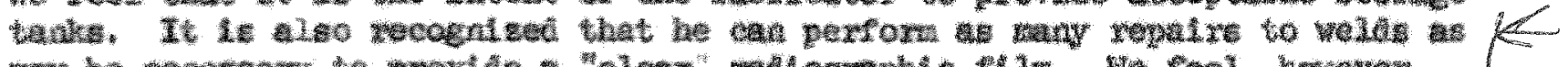

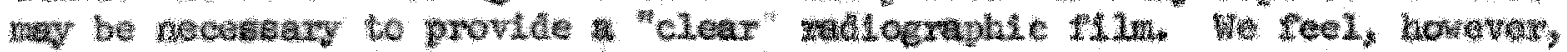

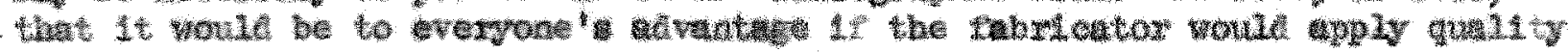

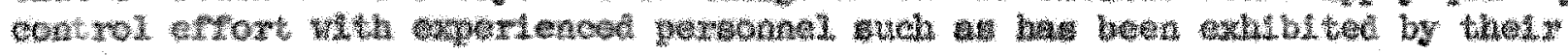
gob vorendutin.

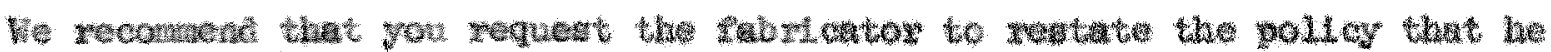

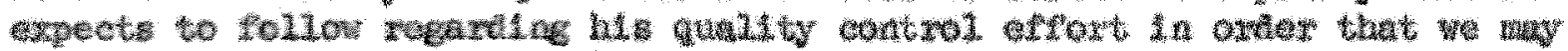

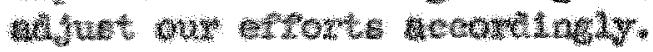

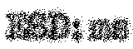

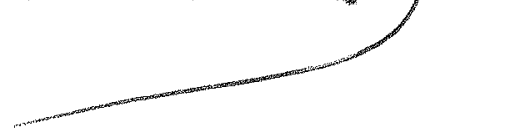

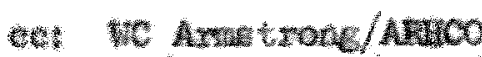

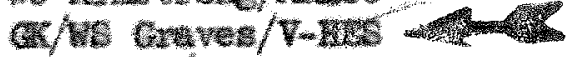

A. Short/Vwrs

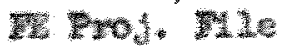

WL 2 Ls 
Rev. 0

1.9 Davis, E. S., 1970, "Willard Smith, Inc. Refractory Tests," (Letter to J. H. Slaughter, U.S. Atomic Energy Commission, October 2), Vitro Hanford Engineering Services, Richland, Washington. 


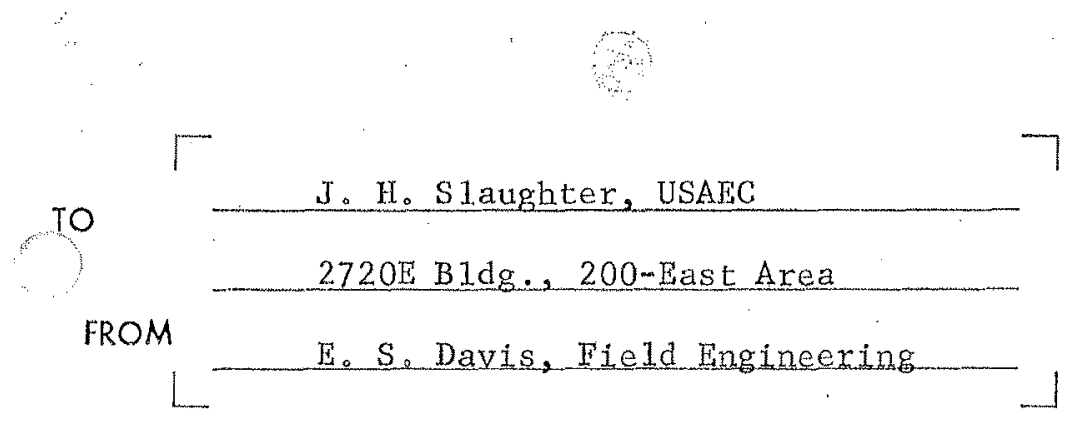

SUB.JECT

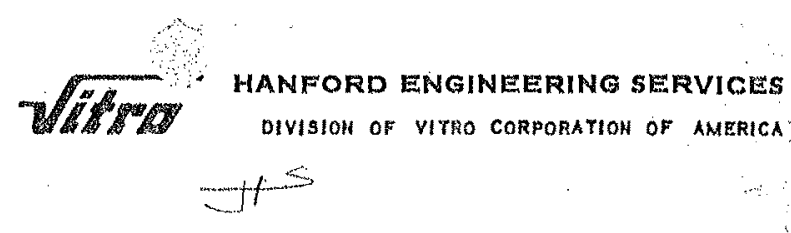

DATE

October 2, 19,70

JOB NO. Project TAP-614

The results of tests using materials subjected a second time to freezing conditions do not necessarily provide conclusive evidence that freezing alone has caused all the problems with loadmarrying capabiltty. The material used in the tests cotld have been subjected to several water saturations and freenings.

T agree with Mr。Smith that materials saturated with water and then subjected to freezing aftex curing are affected, and protection of this refractory material from freezing, if used in AZ tank construction, should be made mandatory.

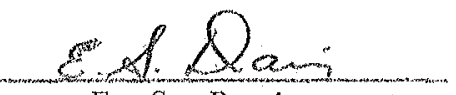

E. S. Davis

HSD:ms

cc: PE Proj. File

GK/EFS

A. Short:

A. EC.RL OFFlO

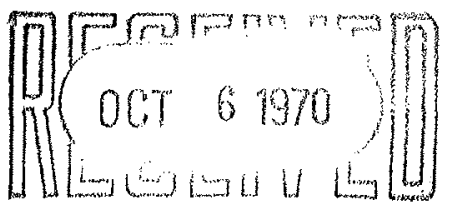

PROJECT ENGR. BR. 
Rev. 0

1.10 Graves, W. S., 1969a, "PUREX Tank Farm Expansion IAP-614 Minimum Thickness Insulating Concrete," (Letter to C. W. Cardwell, February 14), Vitro Hanford Engineering Services, Richland, Washington. 
c. W. Cardwell

W. S. Graves

Purex Tank Farm Expansion IAP-614

Minimum Thlekness Insulating Concrete

Confluing alscussion with $A$. Short and $E$. S. Devis, five Inches of Kaolite insulating concrete is wufficient to protect the base concrete during stress-relfeving of the primery tank. This Judgement is based upon the Battelle report BNL-797, detall requirenents on the strilar project at Bayann Rivex, tats run by Nooter in Salnt Louls for the Savanah Rivex project, and vitro calculations.

It was with this information in wind that "humped" bottom 3 " in helght could be ccepted since this still left $5^{\text {fi }}$ of lnaulation avallable. The conalton at the al inlet plpes requires a minimum thickness as show, but in this Limfted wat the steel plate of the second ary tank w11 spread the heat 1 low and thus lassen the intengity to Eatisfactory Level.

Plesse note that Plttsburgh Des Molnes is technlcally responsible for adequete thicknes sequired by thel stress-relief procedure as noted in Specipleation WWS-7789 Para. 9. Our drawings specify only a rinimum accetable thickness the air-inlet plpes.
Original Signed by
W. S. Graves
W. B. Graves

WSG: fwk

ce: GK/CAS

WSG/11e 
1.11 Graves, W. S., 1969b, "PUREX Tank Farm Addition," (Letter to C. W. Cardwell, March 18), Vitro Hanford Engineering Services, Richland, Washington. 


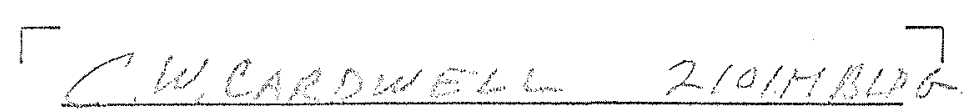

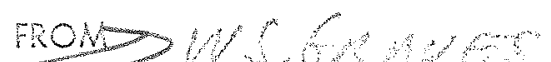

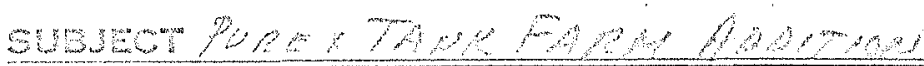

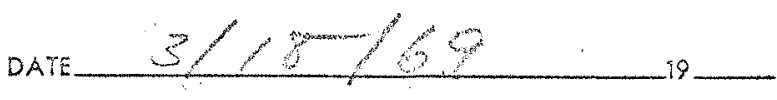

Dos no. $T P^{2}-6+6$

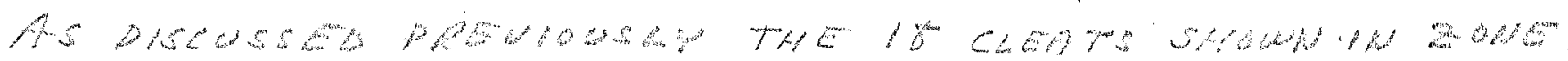

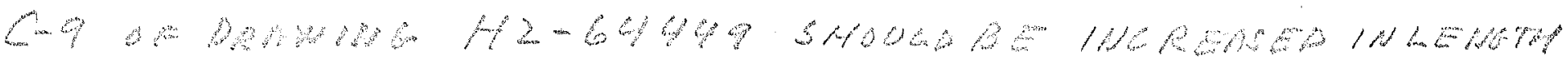
70 क M

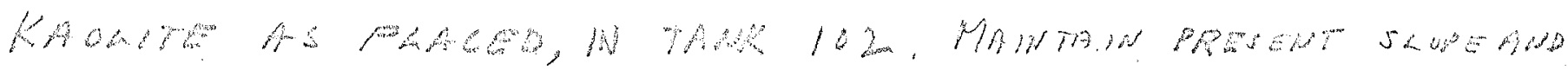

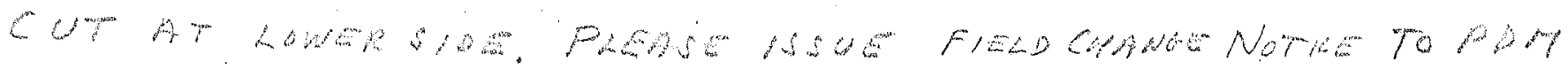

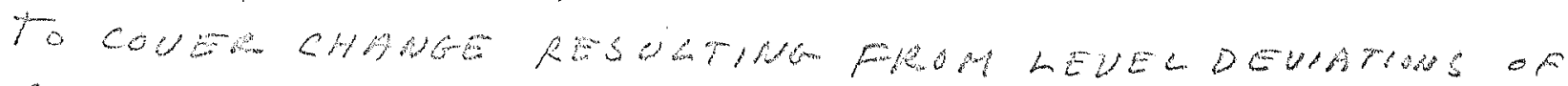

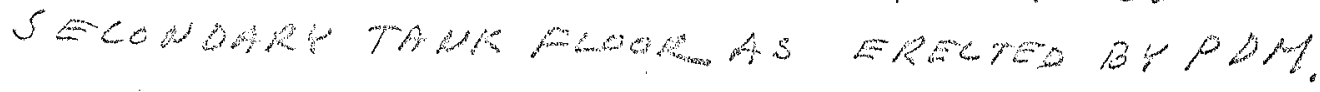

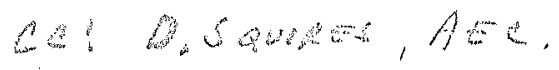

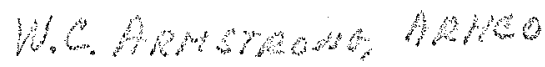

$$
\begin{aligned}
& 6 / 6 / 6,9
\end{aligned}
$$


Rev. 0

1.12 Hatch, P., 1967, "Trip Report - Savannah River Plant Waste Tank Discussions and ITT Stress Analysis Study," (Interoffice memorandum to G. C. Obert, December 1), Atlantic Richfield Hanford Company, Richland, Washington. 
DATE: December 1, 1967

TO: $\quad$ G. O. Oberg

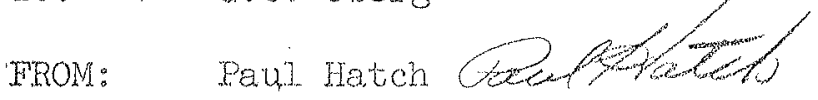

SUBJECT: TRIP REPORT - SAVANNAH RTVER PIANT WASTL TANK DISCUSSTONS AND IIT STRESS ANALYSIS STUDY

On Noverber 14 and 15, 1967 , Waste Tank discussjons were held with representatives from ARHCO, BLO, E.I. duPont, SRO, and Savannah River Plant and with Professor K.P. Milbradt and Dr. Stuart Swartz of the Thinois Institute of Technology at Chicago, Nlinois, respectively. The purpose of these meetings was to discuss the Savannah River PIant waste tank specifications and to inspect their current waste tank conm struction progress. The following information outlines the salient points of the discusstons.

Savannal River Plant

Savanah Rivex people stated the maximum opening requirement for pexj.. scoping, rodding, visual inspection, Jiv camexa coverage, and punping of the arnular space in pest waste tank operations has been a five-inch openting used for periscope observation, roading and visual inspection and an elght to ten inch opening for punping. Maximum available opening is 36 mnches. Howerer, they have never had occasion to use this large diameter opening to date.

The Savanah River people have never obsexved a hydrogen buildmp problem in the annular space and state that air is forced into the annulus to 1) keep the steel dry and to reduce oxidation; e) to partially cool the contents of the tank; and 3) to bxing leakage out from under the trank as quickly as possible in the event a tank leak occurs. A $6000 \mathrm{cfm}$ forced air capacity is being provided for annulus purge of the new tanks, Fhe Savonnah River Plant Tanks 14 and 16 were receiving high-level waste at the time they developed cracks and subsequent moisture was detected in the anmular space. Apparently the fine cracks acted as particulate filter since the moisture in the annular space carried mostiy cesium. Most of the moisture was evaporated by increasing the air flow. The end result was a residue salt cale of six and twelve inches thick, respectively. There has been no heating problem because of this salt cake. An air flow of 1500 crm has been more than adequate to dry excessive moisture from the annulus and heal the fine cracks. Prembeting of the annulus atr can be misleading because of a differential humidity between sumen and winter. Fumidity and temperature should be the prime considerations in'design of the amulus air system.

$\Leftrightarrow \int_{2} \Leftrightarrow$

H.

Q.L.

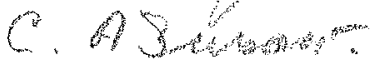




\author{
G.C. Oberg \\ Page 2 \\ December. 1, 1967
}

The moisture in the annular space is detected by a series of conductivity probes one being able to measure in one foot vertical increments for a total of six feet, the other two being at a lower atstance probabiy one inch off the bottom of the tank. Savanmak River plant would recommend that prior to service, whused tanks be filled with water containing a rust inhibitor or that a recycle aju aryer be installed to prevent excessive sceling of the banks.

Discussion tas beld on the construction of the current tank and spectfically SRP Specification 5098 for both primary and secondary steel Iiners on project 981232 . Craftsmanship remains the major problem with a reject weldmate ranging between 10 to 20 pereert. DuPont and Nooter both interpret the X..ray photographs along with a third paxty inspector, to determine poox weld locations. The heating quenching process to lowex the high spots to meet bottom liner flatness tolerences in the above specification is still applicable even though duPont authorized Nooter to use an intexim criss-cross submerged are process to expedite the con.. struction sohedule. SRP feels this is not the propex way bo lower the high spots and would recomend using the heating quenching processing to bring ali pletes back Into speciflcation. Savannah River Plant would recommend a tolerance of $+1 / 4$-inch on the concrete pad on which the secondary liner would lay and a tolexance of $+1 / 4$ minch on the refractory. B. If Westerbrook of auPont stated there are compantes thet spectalize in tank flattening and that Hooter did not necesserily possess all the techniques sone of these compenies might have. It would be worthinile to contact some of these companies and incorporate some of their techniques into our specification. M. Westerbrook is going to forward the names of some companies who spectalize in this field.

Tt was suggested thet ARHCO might Iet some fabricator inspect the dome riser layout plen to detexmine is this layout could be adapted to bumex locations for stress relieving. Above all, z't was recommended the tank contractor be kept involyed in constuction of the tenks in every phase possible.

We requested that sone of our experimental stress relief specimens be put in thein tanks for stress relief. However, dupont pointed out that putting a specimen inside a tank would not be representotive of tank annealing since the tank itself is only heated on one side and the specimen would be heated fxom two sides. ARHCO vill forward a drawing of our specimen geometry for review from which four specimens will be made. Two specimens will be used for control and two for stress rem lieving by the method we select which we can then test at oux own site.

The domes of the SRP tarks will be supportbed by a 2.3 ounce pressure per square inch during the stress relieving operation. Also, there will be 
Q.C. Oberg

Page 3

December 1, 1967

a superstrueture above the dome of the tank which will have hanger sup-w ponts at selected points. These poirts will not necessarily coincide With the J Bolt antargemem thet dupont hes selected for attaching the steel liner into the concrete. Hooter will remove all temporary hanging supports which they position during stresswrelief.

A field inspection was made at the construetion site. Construction is approximately ten pexcent complete. To expedite progress, the first. tank, lamk 32, was accepted even though the bottom datness tolexances on the secondary liner wexe not met. A compromise was made in that the contractor would add an extra thickness of irsulation to off'- set the halfwinch out of tolexance. The second tank urider construction, Tank 3I, appears to have a similax problem in that Nooter has not been able to bxing the tank back into flatness requixenent in one location. Each time they bring it with specification in one location, the bulge moves to another Jocation and seems to orient around the center column of the tarik. Crissmeross, submerged aromelds were used as a flattenirg method alomg with heating and quenohing.

Waste Tank Evaluation Study by the Intinots Xnstitute of Iechnology

The desion of the new AY Tank Farm was discussed at length by Professor Mibrad, Dextex Lien, WILtem C. Axmstrong, and C.D. Comptom and the author. of particular interest was the subject of dome optimization and betng abje to andlyze the steel tank with existing computer analyses. Pxofessor Milbradt inaicated that he could optimize the dome geometry for the least stress condition by December 10, 1967. The steel tank analyses is to be completed by December 4, 1967. These analyses will turalsh minimum geometxhcal thicknesses and reinforcing steel requirem mentes:

A cost estimate was made for computer analysis at the Illinois Institute of Technology on Project IAP.614 by Professor Milbradt. It was esti. mated that approximately $\$ 3,000$ minimum would be needed for computer time and man hours. This is Jess than the budgeted amount of $\$ 6,000$ already appropriated wor this purpose.

Vitro/HEs will keep close contact with Professor Miloradt during the finalization of the minimum plate thjokness for the steel tanks and design conerete shell. This may involve additional trips to either Chicago or to Hanford by Vitro/HES or Professor Milibradt as the need arises. Prolessor Ml loradt was adyised thet the AY Tamk Fam design information was most critical at this particular point in time and that other vork should be delayed temporarily. 
G.C. Operg

Page 4

December 1, 1967

Currently, the Ilinois Institute of Technology hes no cepability for computex analyses of earthquake situations; they expect to have this capabijity within a year and anticipate that they wil use the freem Pree mode of vibration analyses superimposed on the static load analysis.

- Professor Milbradt requested copies of the Housnier Repoxt which has been submitted to the Hanford Project for earthquake andyses of reactors.

Professor Milibradt made a call. to the Portland Cement Association to determine the heat effects on concrete to establish a realistic temperam ture point for stress relieving the inner liner. Me following tabula tion shows a comparison between temperature and permanent loss of compressive strength.

$\begin{array}{cc}\text { Concrete Temperature } & \text { Strength Loss } \\ 200 \mathrm{~F} & 18 \% \\ 500 \mathrm{~F} & 4 \% \% \\ 800 \mathrm{~F} & 52 \% \\ 1,000 \mathrm{~F} & 80 \%\end{array}$

Cement Morter Cube Temperature

$$
\begin{array}{r}
572 \mathrm{E} \\
930 \mathrm{~F} \\
1,209 \mathrm{~F}
\end{array}
$$

Strength Ioss

$12 \%$

$50 \%$

$8 \% \%$

Mel Abrahms, a PCA expert in firebrick and insulative concreves was contacted by Professor Milbredt. Mr. Abrahms recommended that the moisture be driven from the suggested Kaolyte insulating mat under the primary tank. A $150 \mathrm{~F}$ temperature should be held for a two-week period. He felt that there would be some danger of destroying sone of the properties of insulating mat if it were heated rapidly nithout previous drying.

Backfinl axound the tanks should be according to old HAlo specifications without specific compaction requjmomt.

Professor Mitloradt indicated that the steel dome liner anchors could be J.-Bolts hooked directly into the concrete shell whout provisions for expansion. The worst situation would be local ripping of the done which would not be a detrimental factor. 


\section{Atlantic Richfield Hanford Company}

G.C. Oberg

Page 5

Decenber 1, 1967

A general. discusston was held on putting access ports through the concrete haunch area of the waste tank to the annular space. It was summerized that this would present some problems; however, they could be covercome by providing a specificallymdesigned collar to which all severed reinforcing steel could be welded. This collar would then transfer the Joads around the opening and back juto the opposing reinforcing steel.

PH: $\sin x^{\circ}$

Distribution: W.C. Armstrong

C.D. Compton $\mathrm{AEC}$

J.B. Fecht

W.S. Graves - HES madrom

P. Hatch

D.G. Lien wES

H.P. Shat

E.E. Smith w HES 
Rev. 0

1.13 HES QA Report, 1969, Multiple QA Reports January to November, Vitro Hanford Engineering Services, Richland, Washington. 
FE DNCES: Procedure for material control; weldor performance qualifications, vendor drawings, mill and material certifications, erection drawings

HWS-7789, Rev. 2, Par. $2.0-\mathrm{b}, \mathrm{c}$ and $\mathrm{g}$.

OTHER DATA: PDM welding procedures $68-80,63,110,60-112,68-80 \mathrm{~A}$

Welding procedure specification DB 119-197

Drawings 38570 , sheets 1 and 8

Drawings 38570 QC -6

Date

$172-69$

D18tribut1on:

W. S. Graves

A. Short

Project File

QC Bile (2)

1. Check equipment to ascertain capability of specific job performance.

HWS-7789, Rev. 2, Par. 1.1.1; Par. 11.2 c.

$\therefore$ Automatic sub-arc MACHIVKREJEUED-SFE CENTER TOAEE $12 / 3 / 68$

$\therefore$ Welding machines (manual shielded arc)

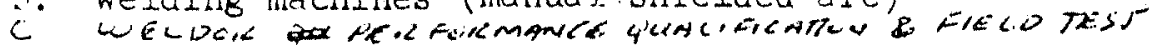

2. Check mill and material certification and markings

a. Plate material

b. Weld rod

c. Clips and miscellaneous steel

d. Stencil marks on exterior of tank

3. Check fabrication for:

a. Joint geometry and spacing

b. Welding sequence

c. Welding procedures

d. Handling

e. Excessive distortion

f. Good workmanship practices.

IC SEECETER POM TOAEC IASO/68

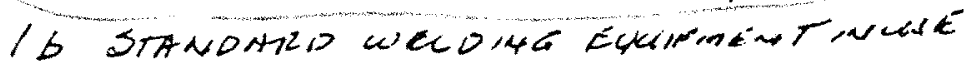

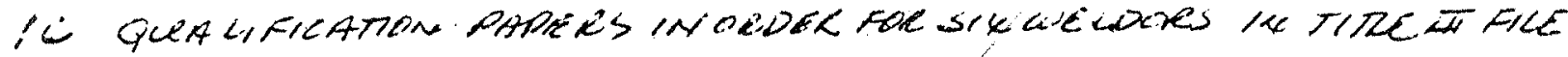
DERARKS AND/OR SAFETY FEATURFS

1. Check for tank groundins ok

2. Ascertain that cribbing for supporting tank bottom is adequate and properly placed to prevent injury to personnel. OK

3. Wear hard hats, gloves, eye protection.ck 
REFERENCES: Procedure for material control; weldor performance qualifications, vendor drawings, mill and material certiE.S.DAUIS

Date:

fications, erection drawings

Hh'S-7789, Rev. 2, Par. 2.0 - b, c and g.

\section{$2-18-69$}

Distribution:

W. S. Graves

A. Short

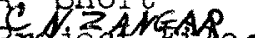

QC File (2)

OTHER DATA: PDM welding procedures 68-80, 63,110, 60-112, 68-80A

Welding procedure specification DB 119-197

Drawings 38570 , sheets 1 and 8

Drawings 38570 aC- 6

1. Check equipment to ascertain capability of specific job performance. HWS-7789, Rev. 2, Par. 11.1; Par. 11.2 c.

a. Automatic sub-arc

k. Welding machines (manual shielded arc)

2. Check mill and material certiflcation and markings

a. Plate material - SEE ATTACHED LETER

b. Weld rod

c. Clips and miscellaneous steel

d. Stencil mariks on exterior of tank

3. Check fabrication for:

a. Joint geometry and spacing

b. Welding sequence

c. Welding procedures

d. Handling

e. Excessive distortion

f. Good workmanship practices.

\section{REMARKS AND/OR SAFETY FEATURES}

1. Check for tank grounding

2. Ascertain that cribbine for supporting tank bottom is adequate and properly placed to prevent injury to personne1.

3. Wear haxd hats, gloves, eye protection. 
REFERENCBS: Procedure for material control; weldor performance qualifications, vendor drawings, mill and material certifications, erection drawings

HWS-7789, Rev. 2, Par. 2.0 - b, c and g.

Inspected by:

collani

Date:

$1-23-69$

D1stribution:

W. S. Graves

A. Short

Project File

QC File (2)

OTHER DATA: PDM welding procedures 68-80, 63, 110, 60-112, 68-80A

Welding procedure speclfication DB $119-197$

Drawings 38570 , sheets 1 and 8

Drawings 38570 QC-6

1. Check equipment to ascertain capability of specific job performance.

HWS-7789, Rev. 2, Par. 11.1; Par. 11.2 c.

a. Automatic sub-arc

b. Welding machines (manual shielded arc)

2. Check mill and material certification and markings

a. Plate material-CNECK CONTAuMG- SEE NOTE

b. Weld rod - FLEETWECD 5P E GOIO-SAMPES RETANES

c. Clips and miscellaneous steel.

d. Stencil marks on exterior of tank

3. Check fabrication for:

a. Joint geometry and spacing

b. Welding sequence

c. Welding procedures sex wort

d. Handling - scevert

e. Excessive distortion

f. Good workmanship practices.

2A-FOUR BOTDM PLATES HOUL YET TO BE MARECD

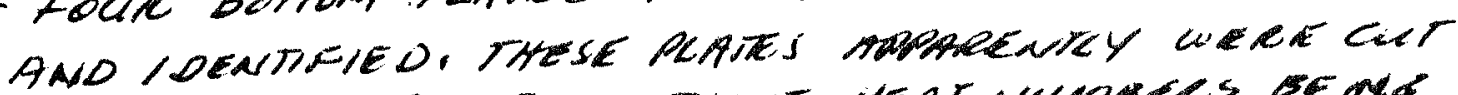

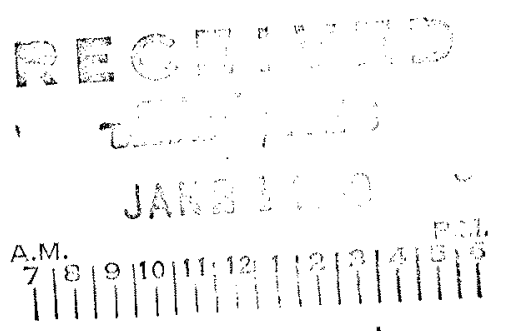

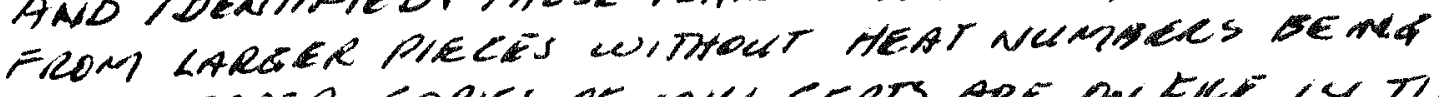

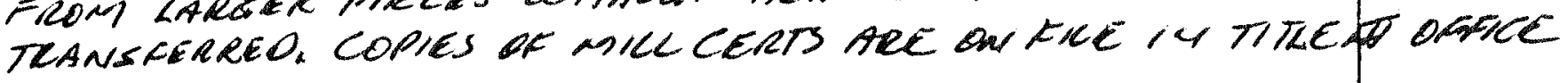

\section{REMARKS AND/OR SAFETY FEATURES}

1. Check for tank grounding

2. Ascertain that cribbing for supporting tank bottom is adequate and properly placed to prevent injury to personnel.

3. Wear hard hats, gloves, eye protection.

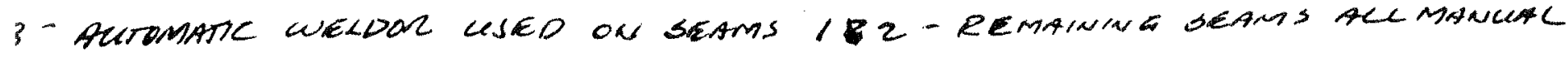

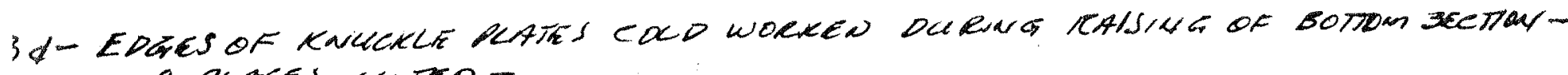
8 pLACES 
 \\ -}

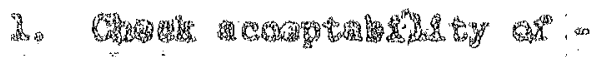

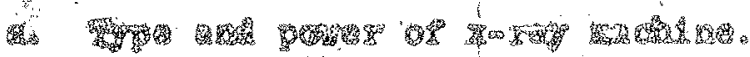

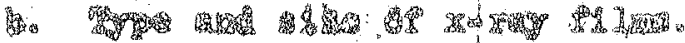

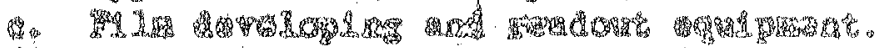

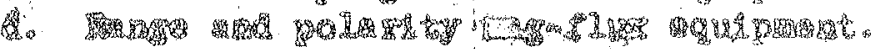

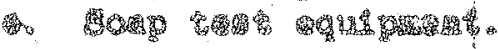

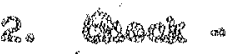

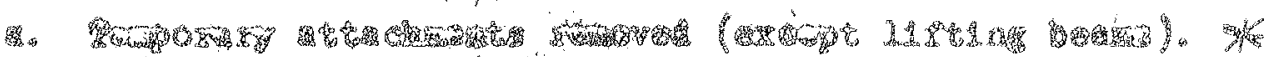

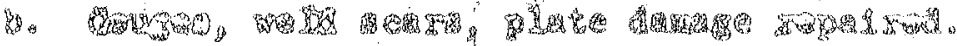

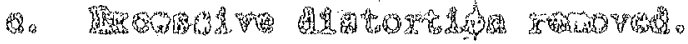

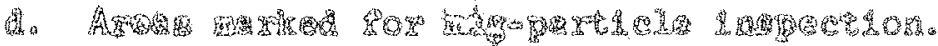

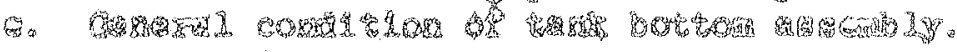

3. $\mathrm{N}^{2} \mathrm{x}$

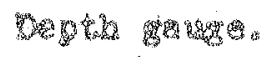

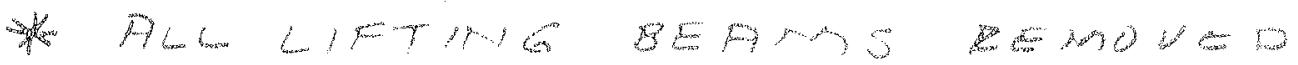
BO

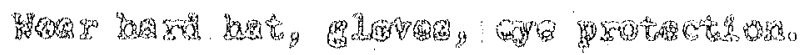

갈

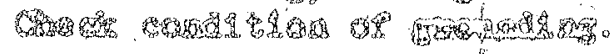


PROJECT IAP-614 Contract AT(45-1)-2124

-3- Preparation of secondary tank bottom for radiography magnetic

TEATURE particle and vacuum leak test. 102

REFERENCES: PDM radiographic inspection procedure RP-I. Magnetic particle inspection MP-4.

Drawing 38570 QC- 6 . Drawing $38570 \mathrm{MT}-10$.

HWS 7789, Rev. 2, Section 12.0 weld inspection.

OTHER DATA:

Radiation signs.

Prepared by:

E. S. Davis $1 / 2$

Inspected by: E.SOge/s

Date:

$2-12-69$

Distribution:

Gentes

ZMAGEK

Strors

Qe $F / L$

\section{Requil rements}

1. Check acceptability of -

a. Type and power of $x$ may machine.

b. Type and size of $x-$ ray films.

c. Fylm developing and readout equipment.

d. Range and polarity mag-plux equipment.

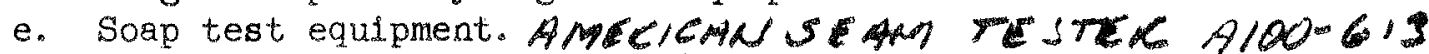

2. Check AMTeribut PIPE SREL

a. Temporary attachments removed (lfting beams).

b. Gouges, weld scars, plate damage repaired.* *

c. Excessive distortion removed.

d. Areas marked for mag-particle inspection. * *

e. General condition of tank bottom assembly.

3. Tools =

Depth gauge.

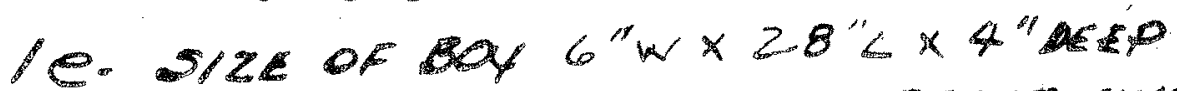

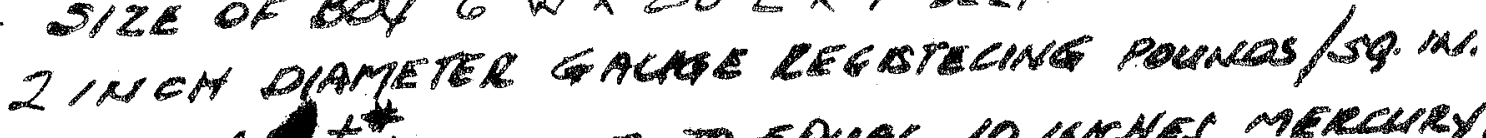

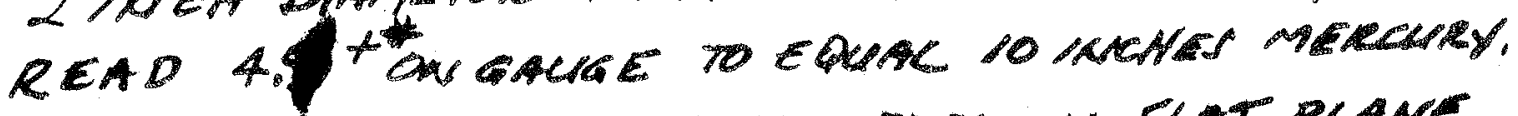
ACLEPTHLE FOR TFSTMA UALAS IA HLTT PLANE.

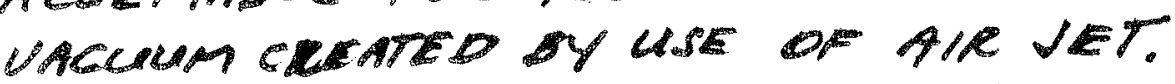

\section{RRMARRS ANDTOR SAFETX FEATURES}

Wear hard hat, gloves, eye protection.

Check cribbing, tank grounding.

Check condition of groundtan.

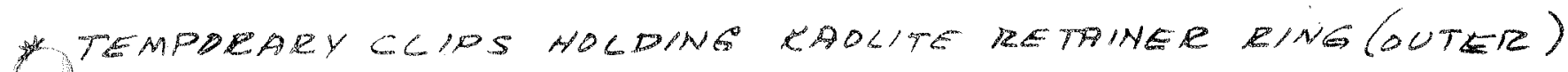

W THS KOEK CAN PROCEED AS SOON RS FLATTENING H COMPLETE AND WATEIR GAN BE REMOWED FEOM TANK BOTTDAI.

ABOH 
$\frac{\text { PROJECT IAP-614 Contract AT }(45-1)-2124}{-3-\text { Preparation of secondary tan }}$

$-3-$ Preparation of secondary tank bottom for radiography, magnetic
FSATURE
particle, and vacuum leak test. TANK $10 \mathrm{C}$

REIFERENCES:

PDM radiographic inspection procedure RP-1.

Magnetic particle inspection MP-4.

Drawing $38570 \mathrm{QC}-6$. Drawing $38570 \mathrm{MT}-1 \mathrm{O}$

HWS 7789 , Rev. 2, Section 12.0 weld inspection.
Rev 0

Prepared by:

E. S. Davis $1 / 20 / 69$

Inspected by:

Douls

Date:

$1-30 \cdot 69$

D1stribution:

Geaves

ZANAER SHERT

QC $F /<E$

Radiation signs.

\section{Requi rements}

1. Check acceptability of -

a. Type and power of $x$-ray machine.

b. Type and size of $x$-ray films.

c. F1.Im developing and readout equipment.

d. Range and polarity mag-flux equipment.

e. Soap test equipment.

2. Check -

a. Temporary attachments removed (except lifting beams).

b. Gouges, weld scars, plate damage repaired. T SEE 160 Te

c. Excessive distortion removed.

d. Areas marked for mag-particle inspection.

e. General condition of tank bottom assembly.

3. Tools -

Depth gauge.

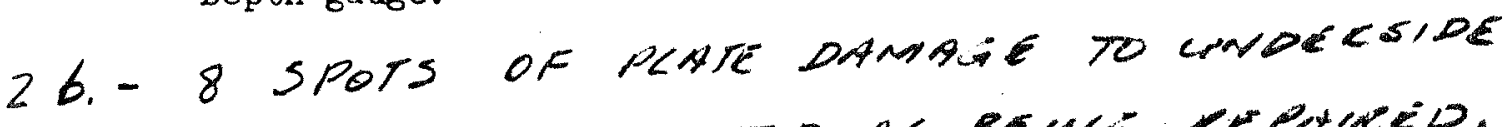

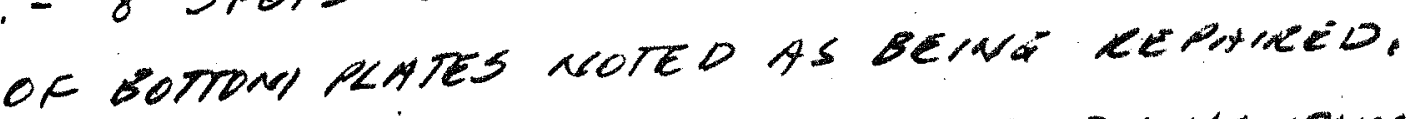

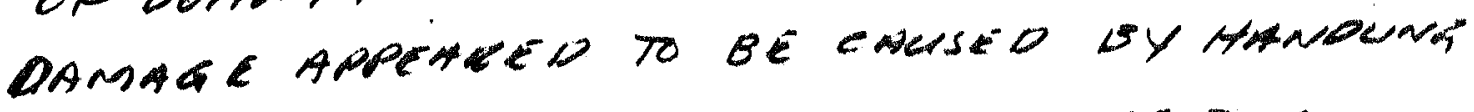
DEUICES. REPAIR WAS MADE BYLECDIAOA I GRINOIMG, REBMARKS AND/OR SAFETY FEATURES

Wear hard hat, gloves, eye protection.

Check cribbing, tank grounding.

Check condition of grounding. 
FRENCES: PDM malographic lingection procedure RF-i.

Magnetic particle iaspection MP-h.

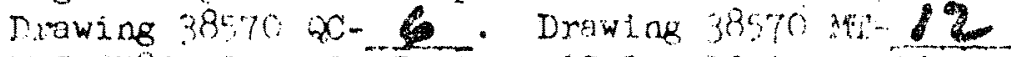

HWS roga, Rav. 2 , seotion ia. weja inspetton.

WEK DATA:

Radiation signs.

Toste?

Distribut10n:

Regul rements

Acceptance

1. Cheok acceptability of.

․ Type and power of x.ray machine. 250 KUA porer-ruse

b. Type and size of $x$ aray rilms. $36^{N}$ LENATH USED

c. Flin developl ne and readiut equipment,

$\therefore$ Range ard polardty mag.. slux equipment.

e. Soap test equipment.

2. Check -

a. Temporary attachments removed (axcep liotig beams).

b. Gouges, weld scars, filate damake romsim?

$\therefore$ Fxcessfue aistortion removed.

i. Aress maked for mag-particle inspaction.

e. General condition of tank bot tom issemily

3. Tools -

Depth griuge.

1.6. QUALITY NOT ACEEARTHCE OW SEDERAC FICNS - SEE CEMER PDA TO VITRO 1-21-69

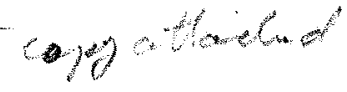

\section{WWTS ANT/OR SARTTY FRATTRES}

wear hard hisi, gloves, oje protection. OK

check cribbing, tark grounding. OK

Creck ccritstion of grounding.

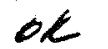


OJECT IAP-614 Contract ATS(45-1)-2124

RPP-AEFHם

-4- Inspection (radiography-magnetic particle) and repa1r

MURe bottom secondary tank

19RarCE: PDM radlographlc inspection procedure RP-1.

Magnet1c particle inspection MP-4.

Drawing 38570 \% 2 . Draw1ng 38570 Mr 6

HWS 7789, Rev. 2, Section 12.0 yeld inspection.

HW 7 Bg, Rev. 2, Section 12.0 veld

\section{FTRR DATA:}

Radiation signs.

ZAMGAR

\section{Regui rements}

1. Radograph ali weld seams in bottom, knuckle plates and those adolning first shell course.

2. Check Lor

a. F1lm and $x$-ray qualsty.

b. Proper latexpretation and marking of flim.

c. Recording of defect.

3. Repair all defective welas.

a. Visually check all welds prior to repalr.

b. Ascertain that repair procedure is acceptable.

c. Check and record $x$ ray 1 in of repaizs.

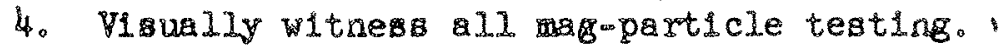

a. Coat1nualiy check testiag equipment.

b. Record position and location of testo.

c. Ascertala that all areas are repaired satistactory.

5. Visually check all areas top and botton for objectloable defects.

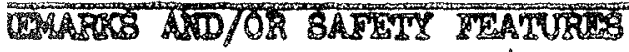

1. Wear hard bato, Loves, eye protection.

2. Check cribolng, tank roundiag.

3. Lintan afe distance to preveat ray exporure.

4. Check scafrolding, brekets, Ladder for safe access. 


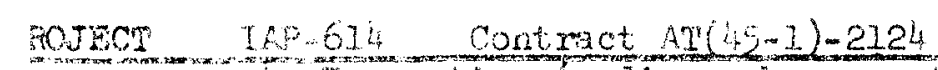

-4- Inspertion (radicraphy-magnet fe ferticle) and repair Prepared by:

\section{RATTEE} botton secondery lank

THAN 102

2. S. Davis $/ 22 / 69$

Ineperted by:

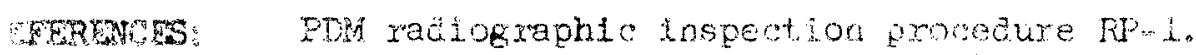

L4el-

Dnte:

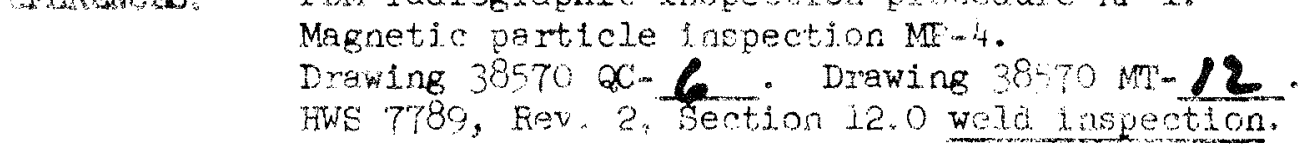

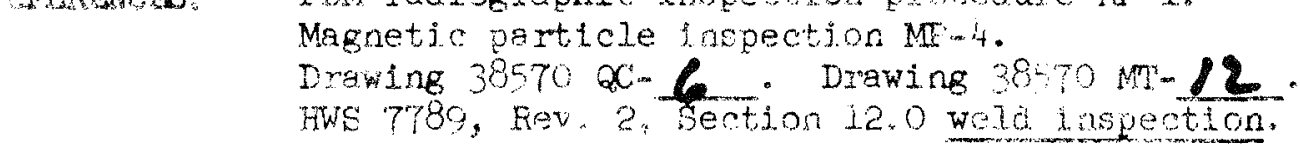

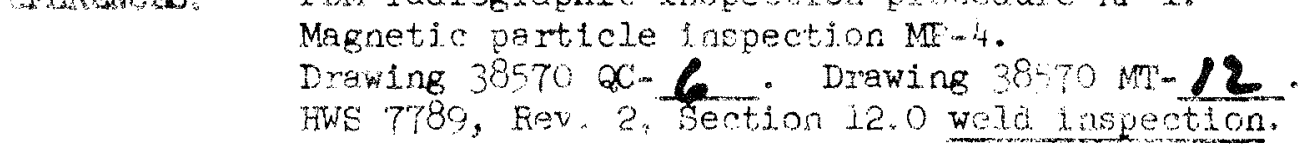




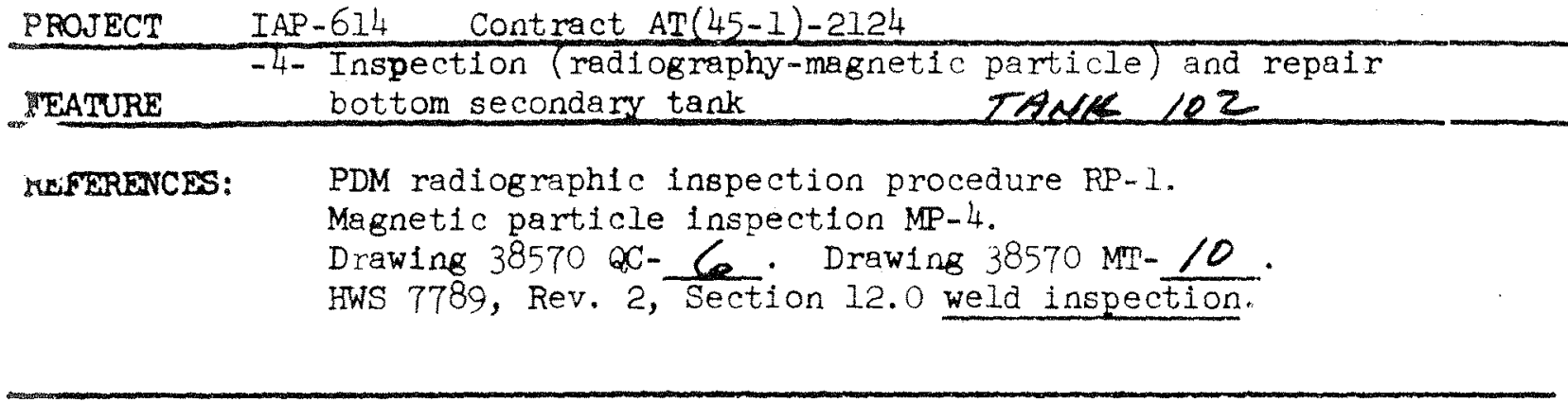

OTHER DATA:

Radiation signs.

Prepared by:

E. S. Davis 1/21/

Inspectaed by:

Date

$1-28-69$

Distribution:

GRAES

ZAnGer

stoet

QCFE

\section{Requi rements}

1. Radiograph all weld seams in bottom, knuckle plates and those adjoining first shell course.

2. Check for -

a. Film and $x$-ray quality.

b. Proper interpretation and marking of film.

c. Recording of defects.

3. Repair all defective welds.

a. Visually check all welds prior to repair.

b. Ascertain that repair procedure is acceptable. - SECNO TE

c. Check and record $x *$ ray film of repairs.

4. Visually witness all mag-particle testing. "

a. Continualiy check testing equipment.

b. Record position and location of tests.

c. Ascertain that all areas are repaired satisfactory.

5. Visually check all areas top and bottom for objectionable defects.

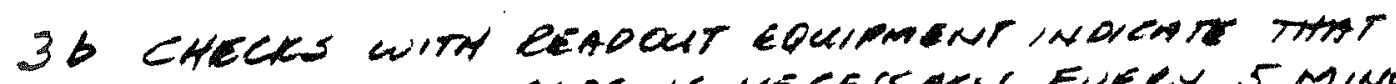

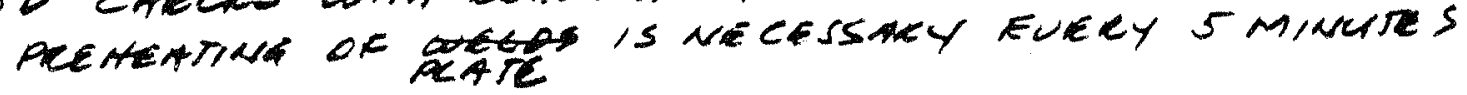

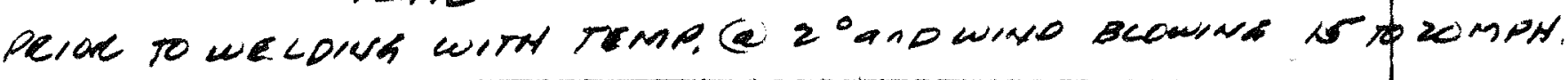

\section{MARKS AND/OR SAFETY FEATURES}

1. Wear hard hats, gloves, eye protection.

2. Check cribbing, tank grounding.

3. Maintain safe distance to prevent $x$-ray exposure.
4. Check scaffolding, brackets, ladders for safe access. 


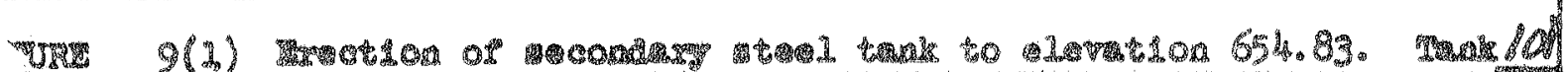
Igos ctis

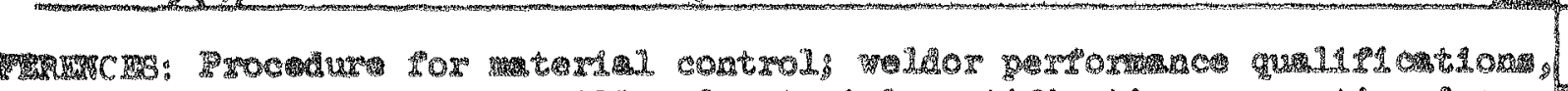

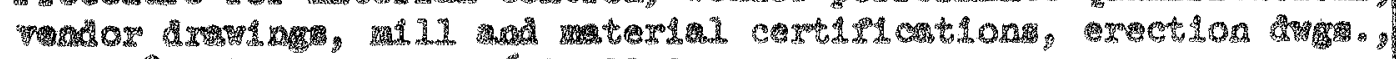

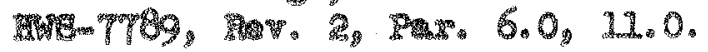

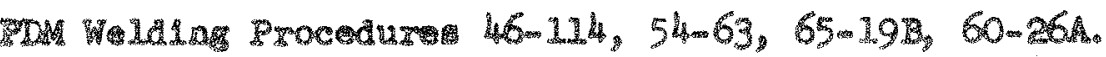

DI: tollowition:

7. LA

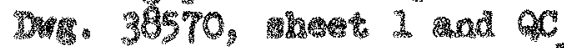

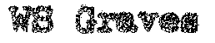

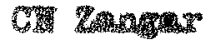

A. Short

ac 1 (a)

\section{Requiraments}

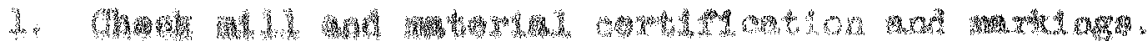

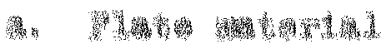

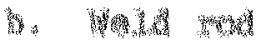

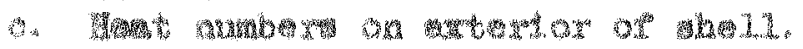

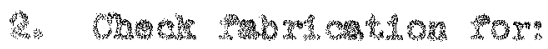

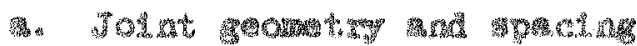

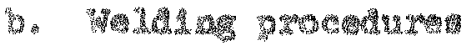

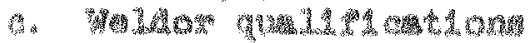

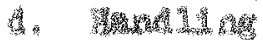

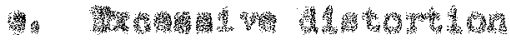

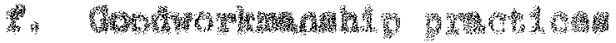

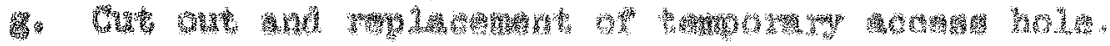

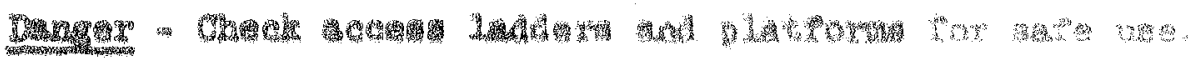

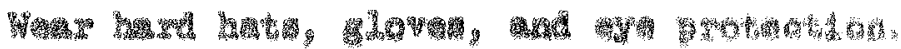

ry 


PROIECT IAP-614 Contract AT(45-1)-2124

Preperes by: IRS Devis $1 / 23 / 69$

THN 102 /ST Coke Inspected by:

WATURE 2(1) Erection of secondary steel tank to elevation 654.83. Tank Date:

REFERENCES: Procedure for material control; weldor performance qualifications,

vendor drawlings, mill and materlal certiflcations, erection dwgs., HWS-7789, Rev. 2, Par. 6.0, 11.0. His-7789, Rev. 2, Par. 6.0, 11.0.

Distribution:

PDM Welding Procedures 46-114, 54-63, 65-19B, 60-26A.

Welding procedure specification DBI19-197.

Dwg. 38570, sheet 1 and $Q \mathrm{C}+5$.

WS Graves

CN Zangar

A. Short

a File (2)
Requiremonts

1. Check mlil and material certification and markings.

a. Plate material

b. Weld rod

c. Heat numbers on exterfor of shell.

2. Check fabrication for:

a. Joint geometry and spacing

b. Welding procedures -SEE NOE

c. Weldor qualifications - SFNOR

d. Handling

e. Bxcessive distortion

f. Goodworkmanship practices - SEk uore

g. Cut out and replacement of temporary access hole.

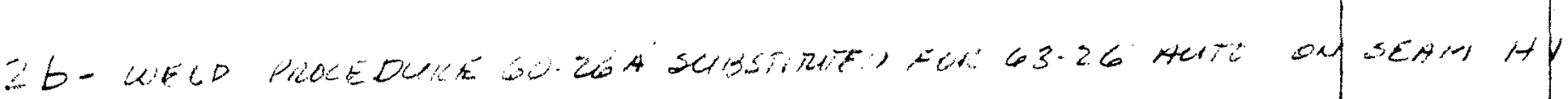

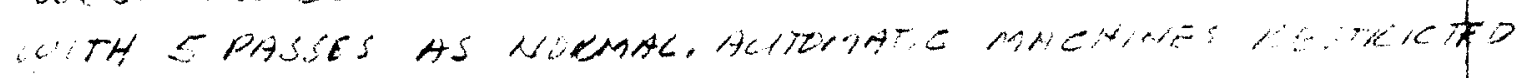
BY LIFTIAG ERATS

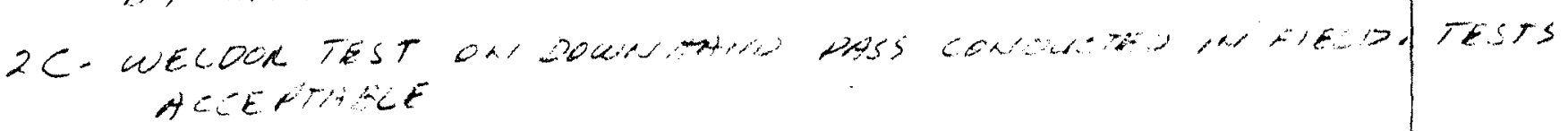

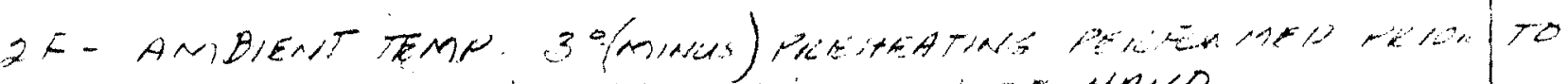
WECDING NETAL WAKM TO'TEUEH OF MAND EMARKS AND/ TR SAFFT: FFITIRPC

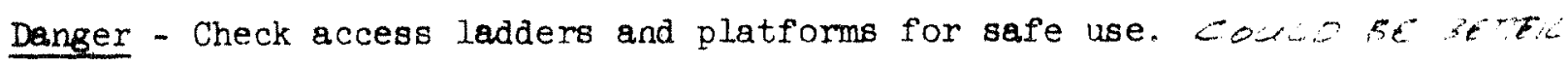

Wear hard hats, gloves, and eye protection.

Check for tank grounding. $6 k$ 


MPJACT IAP-614 Contract AR (45-1)-2124

HNK 102 1STCOXSE

Prepared by:

S Divis $1 / 23 / 69$

Hure 9 (1) arection of secondary teel tank to elevation 654.83. Tank

Inspected by:

Procedure for material control; weldor performance qualifications,

Date:

vendor drawings, hili and terial certiflcations, erection dwgo, HW18-7789, Rev. 2, Par. 6.0, 11.0.

$1-24-69$

Distribution:

W6 Graves

CN Zangar

A. Short

OC Fle (2)

OMMER DATA: PLM Weld1ng Procedures 46-114, 54-63, 65-19B, 60-26A.

Welalng procedure specification DBl19-197.

Dwe. 38570 , sheet 1 and $9 \mathrm{C}$

5

Requil rements

1. Check $\mathrm{ml} 1 \mathrm{l}$ and material certiflcation and markings.

a. Plate material $9515-6760$ STAMWE ON RINIES

b. Weld rod E6010 SAMMLE TAKEX-UJED ON SEAM HA

c. Heat numbers on exterior of shell. SEE NOTE

2. Check fabrication for:

a. Joint geometry and spacing yes

b. Welding procedures yes

c. Weldor qualificationg yes

d. Handlin yes

e. Drcessive distortion yes

f. Coodworkmanship practices SEE NiCTE

8. Cut out and replacement of temporary access hole.

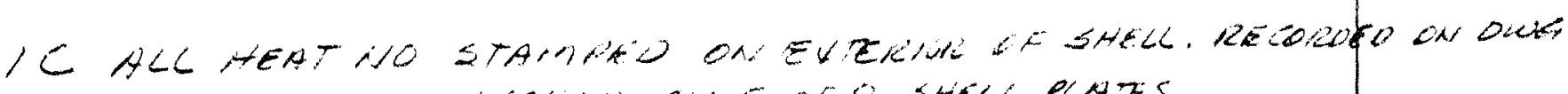

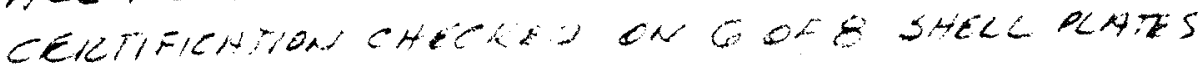

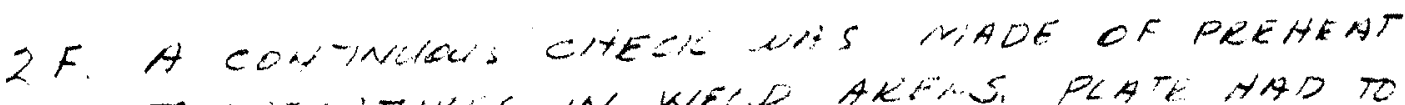

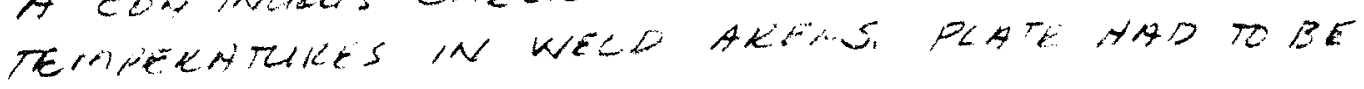
WARM TO A UARE WHD

MARKS AND/DR SAFFT FFITIRFS

Danger - Check access ladders and platforms for safe use.

Wear hard hats, gloves, and eye protection.

Check for tank grounding. 


PROJECT IAP-614 Contrect Ar(45-1)-2124

rur: I 9(1) Irection of mecondary eteel tank to elevation 654.83. Trank Inspected by:

REFHERECIS: Procedure for materiel control; weldor performance quallifications,

Dete:

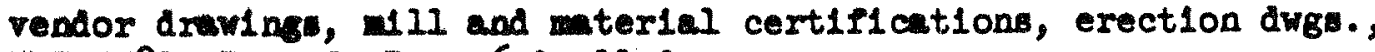

\begin{abstract}
vendor drawlins, w11 and materlal
BWs-7789, Rev. 2, Par. $6.0,11.0$.
\end{abstract}
OTHER DATA: PDM Welding Procodure 46-114, 54-63, 65-19B, 60-26A.

Welding procedure specification DBII9-197.

DWg. 38570 , sheet 1 and $9 C$

1. Check mill and material certiflcation and markings.
a. Plate material
b. Weld rod
c. Heat numbers on exterior of shell.
d. TEMPORARY ATHACAMEMTS. PAKA 7.06 HWS7789.

2. Check fabrication for:

a. Joint geometry and spacing

b. Welding procedures

c. Weldor quallelications

d. Handling

c. Brcessive distortion

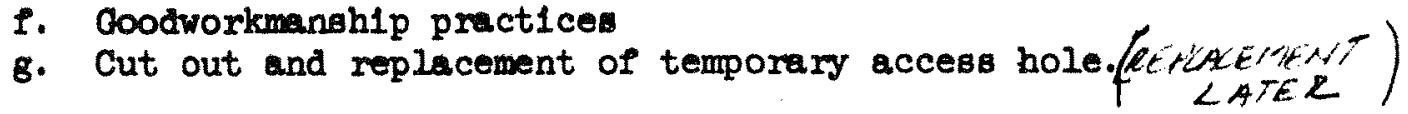

WS Graves

Cr Zangar

A. Short

a Fle (2)

Id. ATAACHED LETTEN POM TO VITRO DATED 2-18.6?

\section{REARKS AND/OR SAFETY FEATURES}

Danger - Check access ladders and platforms for safe use.

Wear hard hatg, gloves, and eye protection.

Check for tank grounding. 


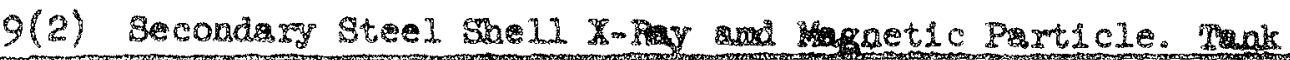

PDW radographic Inspection procedure RP. 1 ,

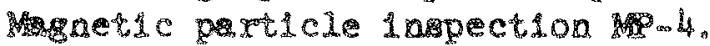

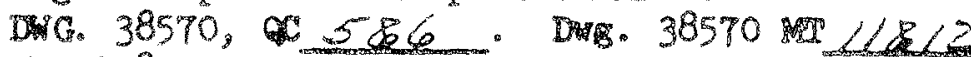

HWS-T789, Rer, 2, Section 12.0 reld laspect10n.
D.

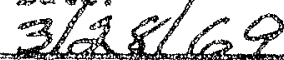

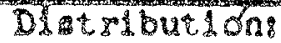

Wh Graves

CN Zangar

A. Short

QC File (2)

\section{Requí rement:}

1. Acceptsibity of equipment

3. X-ray chine or source (record data)

b. Type and alge of 81 in

c. Min development and readout equiphent

d. Funge nalarity of protic protcle equipment.

2. Ghesk

12. Tenory stischments renoved

b. Couges, Hela cara, plate damage reparred SEE NOTE

c. Axcentive distortion

a. Ares for forkedic particle inspection

e. Repair of temporary openting.

3. Greak

4. Qus ilty of radiographs

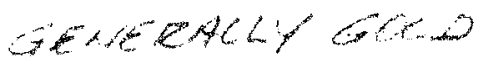

b. Helds requing repalr

c. Record of xalographic teating and repar

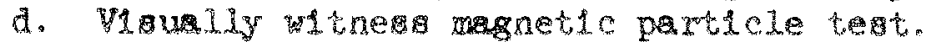

NCTE: SOME WECD SCABS PEANA, BUT WALL

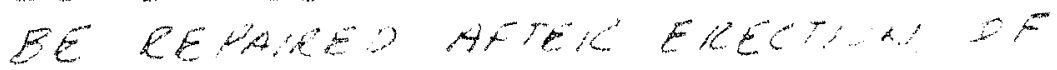

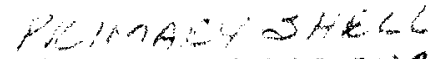

SWOT KADIOSEAWAS WELE AOADE AT EANDEN LOCATHASS.

MARES ANDTJR SAFET MEATTAES

1. Stay clear of radograph work.

2. Check cribbing, tank ground ang.

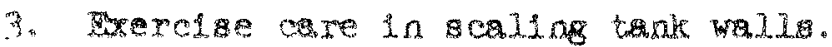

14. Wear hard hats, gloves and eye protection. 


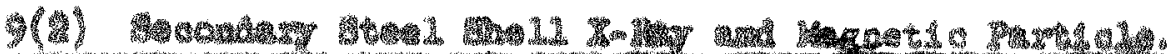

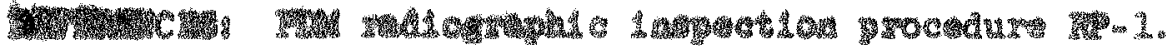

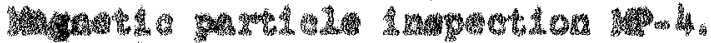

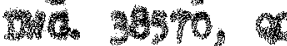
H.

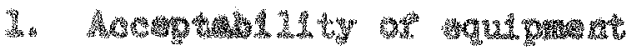

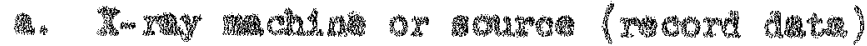

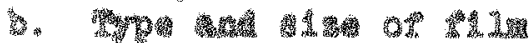

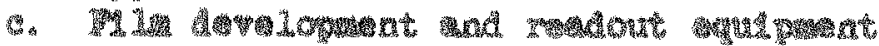

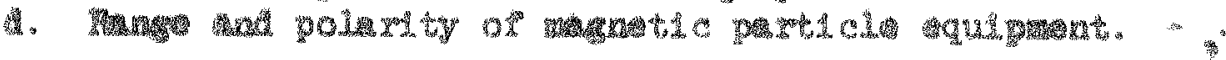

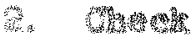

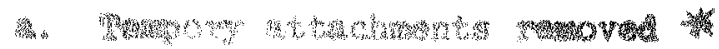

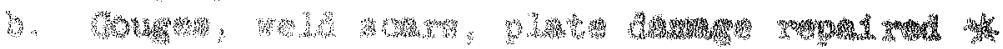

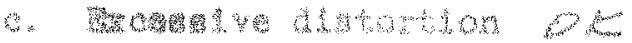

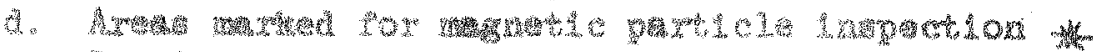

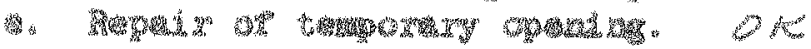

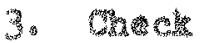

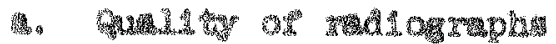

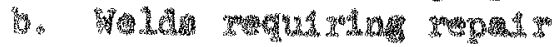

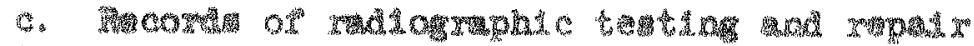

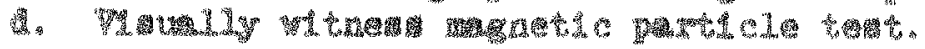

HF

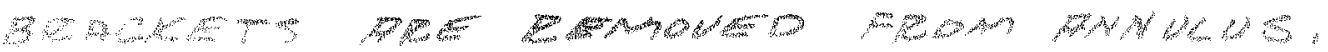

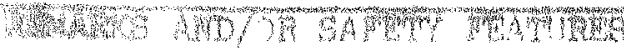

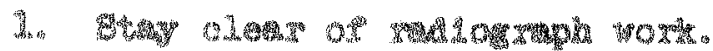

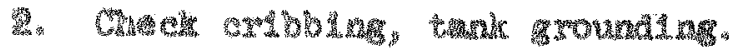

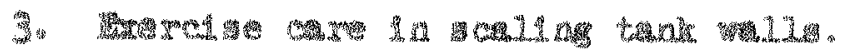

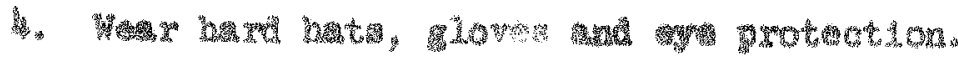


IAP-614 $=$ Contract AT $(45-1)-2124$

$\rightarrow=$ Installation of materis to be imbedded in tank bottor insulation. Tank $/ O /$
Contract spec. HWS-7789, Para. 8.0 for carbon steel p1pe:

PDM Dwg. 38570 9, Rev, 3, for placement of plpe; HiWS 7793, Rev. 3, for thermocouples;

PDM Dkg. 38570.10 for placement of condust.

Note: For orlentation of condust and thermocouples for tank 101; see PDM Dwts. 38570-11.

129. DATA: See PDM DWg. 38570, Rev. 3, for insulation retaining ring
details and drain slot details. Important check office

5e PDM Dwg. 38570, Rev. 3, for insulation retaining ring
deta1l.s and drain slot details. Important check office on latest data pertaining to any of the above 1.tems.

\section{Requd remento}

Plpe: S1ze $4 "$ schedule 40 carbon steel.

Welaling op plpe - \$/13/60

Wrap pipe with $10 \mathrm{mil}$ polyethylene sheets.

Tape sheets at jolnts and pipe ends.

Support plpe on prefabricated insulation blocks.

Minimum clearance l." on bottom, $2 \frac{1}{2}$ " on top.

sound wel

Preptred by:

E. S. Davis 1/30/69

Inspected by:

see becew

Date:

Dis tribution:

WS Graves

CN Zanga and

A. Short

ac Flle 


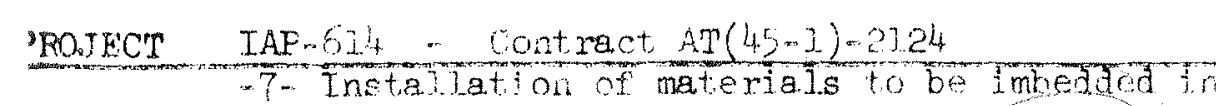

NEATURE

E. S. Davis $1 / 30 / 69$

Inspected by: tank bottom insulation. Tank - 101

WFERECE: oritact spec. HWS 7789, Para. 8.6 for carbon steel pipe:

DDM Iro. 3870.9 , Rev. 3, for placement of pipe;

E.S.ODOUS

HWs 77 ?, Rev. 3 , for thermocouples:

ITM towg 38579 if for placement of conduit.

Note: For orientation of conduit and thermocouples for tauk 101; see POM Dwg. 38:70.1\%.

Date

sececteces

Dietribution:

WS Graves

CN Zangar

A. Short

QC FYle

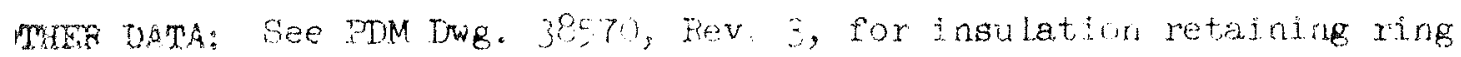
detaijs and dirir slot detaizs. Importint . check office on latest sats pertajning to any of the arove items.

Requi rementa

Pipe: Size it's shedule wh carbon steel.

Weldins of pipe - requirements wone "obtain structuraliy sound wel.

Qrap pipe with io mil polyethyjene sheets. Two weop 6 mic 3-17-6

Tape sheets at iojuts and pire ends.

Supprt vife on profabricated insulation bucks.

Minimum clearance in on bottom, 21" on top.

$3-17-69$

$3-18-69$

$3-18-69-3-25-69$

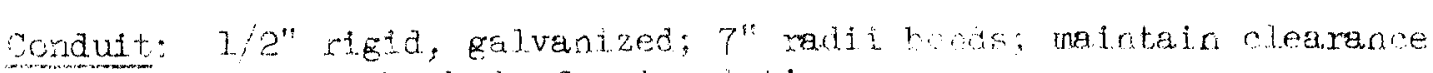

from tank shel: for insidatjon.

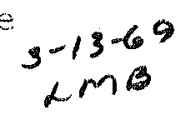

insctetin lietalner Rings:

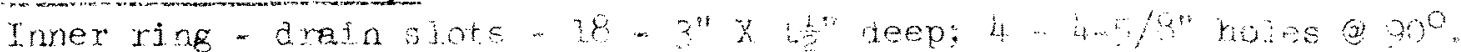

miter rine

ofit she? tottin Howspors

Gereral. therk for fuantity of pipes $4 \quad$ and condute 25 ,

mentation and iontion of emledments, temp covers for ends

of ail openinge pricr to placement of concete, all embedments secured.

ELEUATHON OF PIPES- NOTE

Tancer. - Fxexcise caution in scaling ladders.

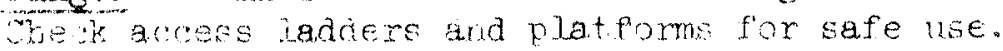

wear bar hats, gloves, eve protection.

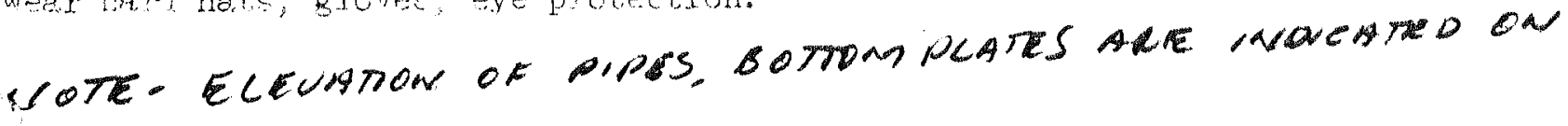

HEPARED DEAWING. 
OJECT IAP-614 - Contract AT (45-1)-2124

-7- Installation of materiala to be lmbedded in tank bottom 1nsulation. rank

A

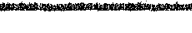

102

TWREMCE: Contract Spec. HWS-7789, Para. 8.0 for carbon steel plpe:

PDM DWg. 38570-9, Rev. 3, for placement of plpe;

HWS-7793, Rev. 3, for thermocouples;

PDM DWg. 38570 - 10 for placement of condult.

Note: For orfentation of condult and thermocouples for tank 101; see PDM Dwg. 38570-11.

IITR DATA: See PDM DWg. 38570, Rev. 3, for insulation retaining ring detalls and drain slot deta1ls. Important - check office on latest data pertalning to any of the above 1tems.

Inspected by:

E S DAvis

Date:

Jee Becow

Distribution:

WS Graven

CN Zangar

A. Short

QC File

\section{Requi rement}

Pipe: Size 4" schedule 40 carbon steel.

Welding of pipe - requirements - none - obtain structurally sound weld.

Trap plpe with $10 \mathrm{mli}$ polyethylene sheets. TWO WeAPs $6 \mathrm{mic} 2 / 24 \mathrm{kQ}$

Tape sheets at jolnts and pipe ends.

Support pipe on prefabricated insulation blocks.

Minlmum clearance $1^{\text {t }}$ on bottom, $2 \frac{1}{2}$ " on top.

$2 / 200 / 60$

$2 / 26 / 69$

$2 / 2.5 / 6$

Cnndult: $1 / 2^{\prime \prime}$ rig1d, galvanized; " 7 " rad11 bends; from tank ahell for 1nsujation. $\angle M B$

Insulation Retainer Rings:

Inner ring - drain slots - $18-3^{\text {t }} \times 11_{2}^{\prime \prime}$ deep; $4-4-5 / 8^{* r}$ holes $990^{\circ}$.

Outer ring - to fit shel1. bottom ALWNSOrs

1

General: Check for quantity of plpes

9

and conduits $25,2-25 \cdot 69$

orientation and location of embedments, temp. covers for ends

of all openings prior to placement of concrete, a.1 embedments secured.

Acceptance

Yes

Yes

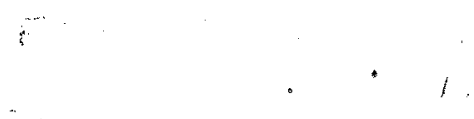

\section{WMARKS AND/OR SATETY FEATURES}

Danger - Exercise caution in scalling ladders.

Check access ladders and platforms for safe use.

Wear hard hats, gloves, eye protection.

HOTE FLEJATON ON PIPES, BOTTOM LRATS, INDCAED OM

MALKED PDM DWE $Q .6$ 


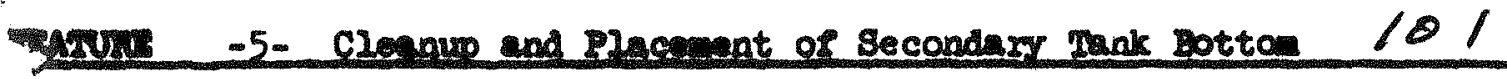

Incosegted.

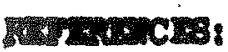

PDM Dwe. 38570-4, Rev. 6

Dwg. H-2.64306, Rev. 3, Tank Foundat1on P1an

ontes

1980. 101969

Diotelbutloa:

WB Grves

CI Zaraser

A. Short

ac I1e

\section{Dow1. DasA:}

\section{nequil remeats}

1. See that $1 / 2^{\prime \prime} \times 6^{\prime \prime} \times 2^{\prime}-10^{\prime \prime} 0 . D$. ring $\mathrm{W} / 4-1 / 2^{\prime \prime}$ holes is properly located and welded on the inside of the ming to the bottom lde of the secondury bottom tank.

2. Ruve protection cover for concrete foundation lab.

3. Coupletely clean al axtraneou material from foundation lab and arain loto.

4. M11 central dralnege well vith cermic flber lavulation por note Deta11 6, draning B-2-64449 before lowering secondary tanic bottom. wote type and mouracturer of invulation used.

5. Mantain cleanlinese of bundation lab during lowexing of secondaxy tank bottom.

6. Rewove 1fting beem and ettrchment (wee fouture number' 3 for repelr and feature number 4 for menetic particle tent of veld acars).

Accertance

Ye

OK

$O K$

$O K$

$O K$

OK

OK

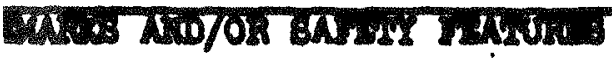

1." Wear hard bat, cloven, ege protection.

2. Check crlbbing, tay clear of Juck ead/or creno. 


PROJECT IAP-614 Contract AT (45-1)-2124

IEATURE -5- Cleanup and Placement of Secondary Tank Bottom

E. SRe Patis 2/10/69

REM ERENCES: PDM DWg. $38570-4$, Rev. 6

Dwg. H-2-64306, Rev. 3, Tank Foundation Plan

RE $=10$

|HES

FEB12 $100 \%$

MMHER DATA:

सIIIIIIIIIIIIIIIII

Inspected by:

E.S.DPuls

Date:

Distribution:

WS Graves

CN Zangar

A. Short

QC File

\section{Requil rements}

1. See that $1 / 2^{\prime \prime} \times 6^{\prime \prime} \times 2^{\prime}-10^{\prime \prime}$ O.D. ring $W / 4-1 / 2^{\prime \prime}$ holes is properly located and welded on the inside of the ring to the bottom side of the secondary bottom tank.

2. Remove protection cover for concrete foundation slab.

3. Completely clean all extraneous material from foundation slab and drain slots.

1. Fill central drainage well with ceramic fiber insulation per note Detal1 6, drawing H-2-64449 before lowering secondary tank bottom. Note type and manufacturer of insulation used.

5. Malntain cleanliness of foundation slab during lowering of secondary tank bottom.

6. Remove lifting beam and attachment (see feature number 3 for repairs and feature number 4 for magnetic particle tests of weld scars).

3. ICE MELTEO FEOM DRAINS BY USE LF PRONHNC HEATEKS

\section{MARKS AND/OR SAFETY FEATURES}

1. Wear hard hat, gloves, eye protection.

2. Check cribblng, stay clear of jacks and/or crane.

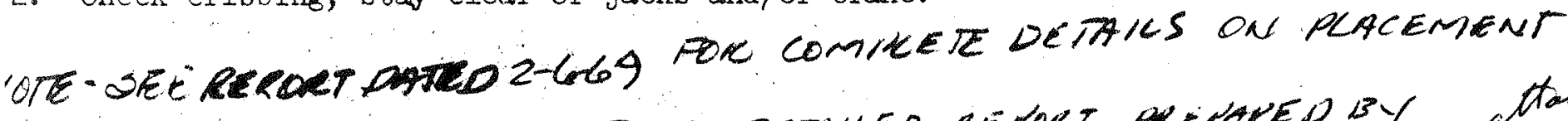

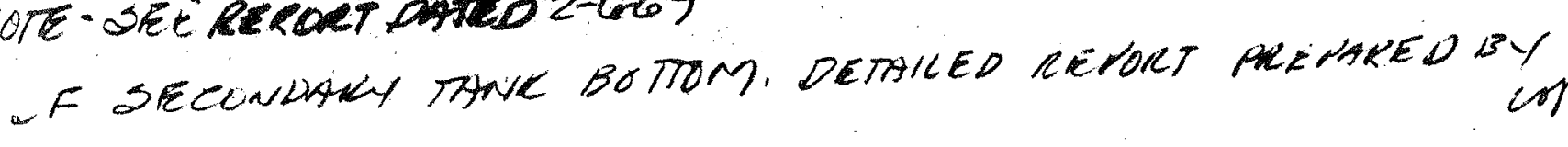
? $54<T$ 


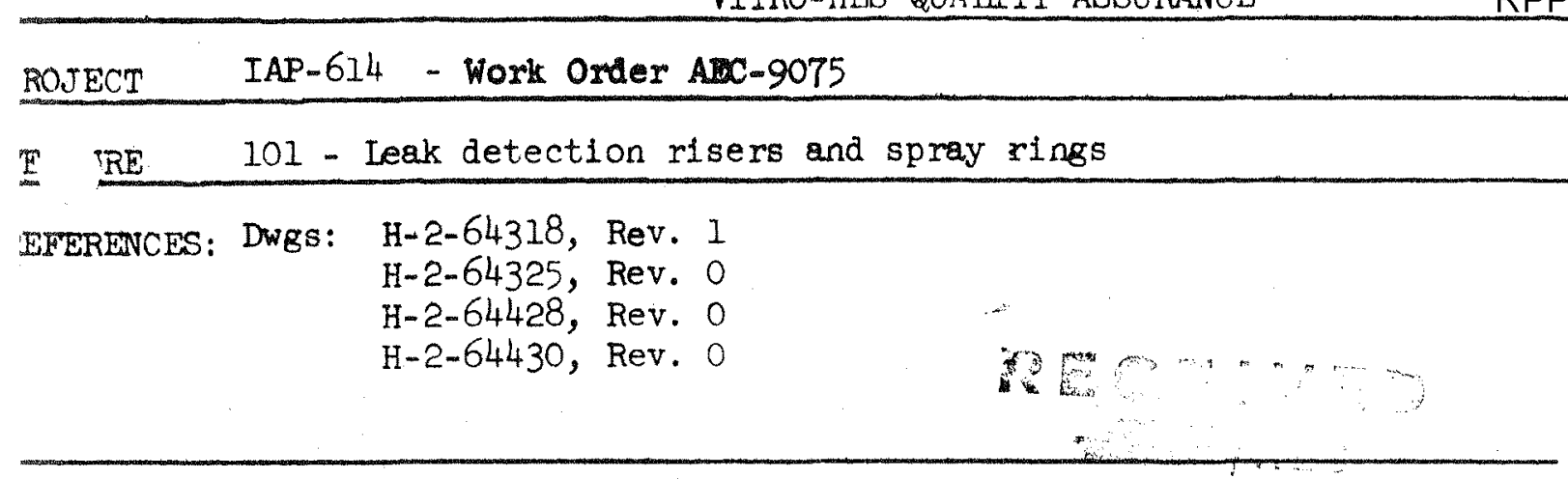

THER DATA: HWS-7792, Process and Service Piping APR23 USAS B31.1.0 - 1967, Power Plping Number reguired - 3

Date:

$\frac{2}{\text { Distribution: }}$

WS Graves

CN Zangar

A. Short

QC File

1. Material:

a. ASTM A53 or Al20 - certified and marked.

b. 6", $24^{\prime \prime}$ and $30^{\prime \prime}$ - schedule 20 .

c. 1" - schedule 40 .

d. Factory-appl1ed, coal-tar enamel. whot

2. Fabrication:

a. Welding procedures - list.

b. Weldor qualifications - examined.

c. Welds inspected - HWS 7792 , page 25.

d. Overall length - adjusted to fleld conditions -

approximate elevation 623.25 to 668.79 .

e. Pipe penetrations - note detail 90, Dwg. H-2-64325, has one?

less penetration.

f. Pipe braces.

8. Spray ring:

(1) Nozzle mfg. - SST material.

(2) Plate material - ASTM A36.

(3) Pressure test $150 \mathrm{psi.}$

h. All dimensions checked.

i. Workmanship

(continued on sheet 2)

$$
\begin{aligned}
& \text { Po } \\
& y= \\
& \text {, }
\end{aligned}
$$

Acceptance

\begin{tabular}{l|l} 
Yes & iro \\
\hline
\end{tabular}

\section{EMARKS AND/OR SAFETY FEATURES}

safety:

Wear hard hats, eye protection and gloves.

NOTE-2d. TANK 101 NONTH RISER EUISTINA ELEUIS 623.24 "101 SOUTH RISER $, " 1,623.57$ ?

TANK102 R/Sだル

., 62332 


PRAJECT IAP-614 - Work Order AEC-9075

Rev. 0

TATURE

101 - Leak detection, risers and spray rings.

\section{Requirements}

(continued from sheet 1 )

3. Installation:

a. Welds Inspected

b. Connecting or penetrating piping and supports installed.

c. Elevation checked.

d. Protective coatling applied at weld foints and repalred.

e. Protective cover maintalned.

f. Workmanship
Acceptance

Yes

No




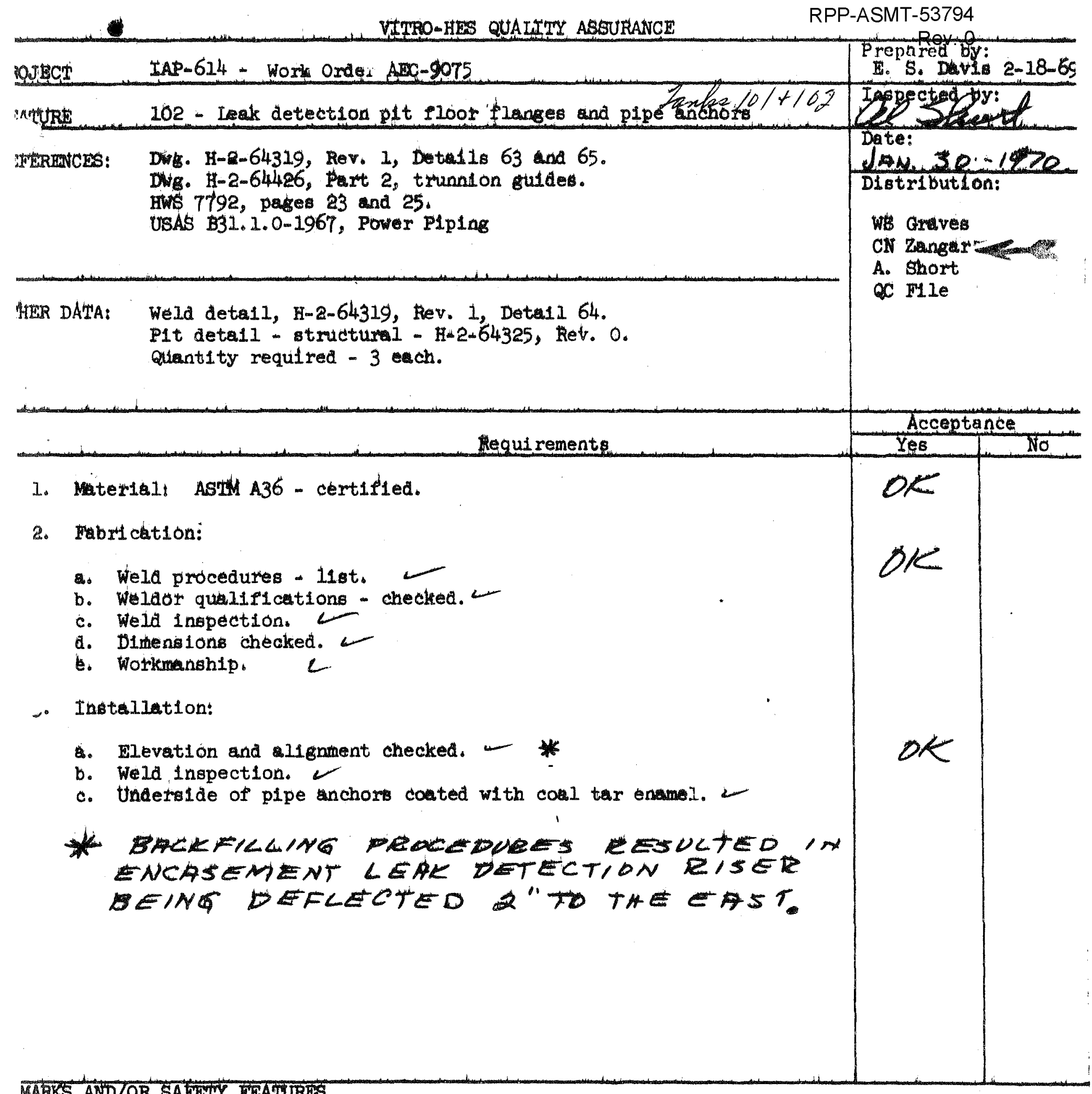

\section{MARKS AND/OR SATEIT TETURTS}

1. Wear hard hat, eye protection and glovea. 


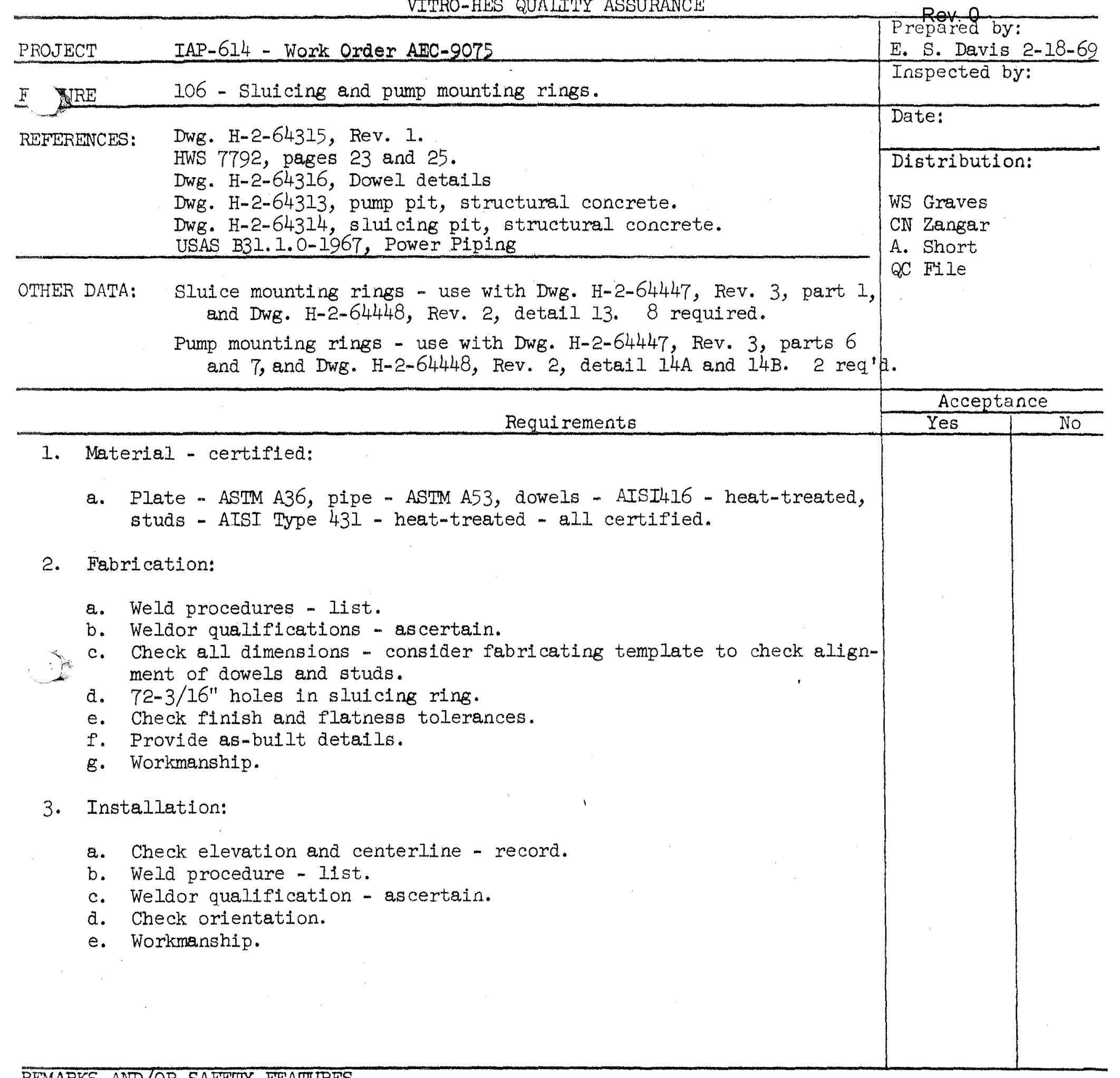

\section{REMARKS AND/OR SAFETY FEATURES}

Wear hard hats, gloves and eye protection.

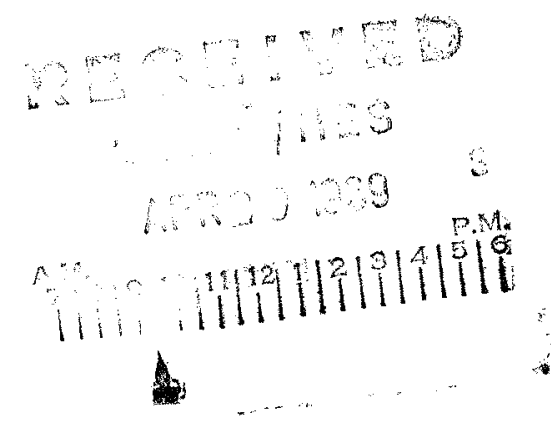




IPOJECT IAP-6.14 ARC-9075

REIERENCES: H-2-64419, Rev. 4 - 2 a. slipon flanges for risere \#7 and \#24;

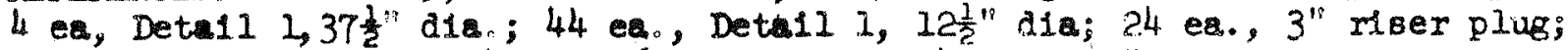
6 ea., 4" riser plug; 14 ea., 6" meer plug; 4 ea. $12 "$ reex plug; 2 ea., 16" riser plug; 4 en. $24^{*}$ riser plug; 4 en., $42^{\prime \prime}$ rlser plug; 44 ea., $5-5 / 8$ " $0 . D . X 2^{\prime \prime} I . D . X I / 8^{n}$ plates for riser \#2.

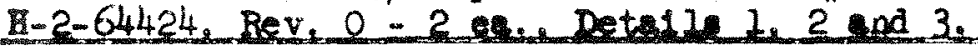

Preperted by:

E. S. Devis 3\%.13-69

Ingegtestson

Date:

MAR, $2-197 c$

Dietribution:

CN Zangar

WS Greves

A. Short

QC File

OTHER DATA: H-2-64447, Rev. 3, Penetration Schedule

H-2-64448, Rev. 2, Tank Penetration Deta1le

HWS-7792, Paint Schedule, Page 104

I. Material - (check for identification)

a. P1pe and pipe fittings - ASTM A53, carbon steel (type E or 5 ).

b. Flanger ASTM AI81, Grade I, carbon steel (A-36 if cut from plate)?

c. Plate and flatbar, ASTM A36, carbon steel. -

d. Rod ASTM Alo7, carbon steel. -

e. Concrete - 3000 psi.

2. Fabrication

a. Weld procedures - l1st.

b. Weldor qualifications - cortain

c. Check all dimensions - ascextain within $1 / 8$ " tolerance. -

d. Reinforcing teel - size and placement. -

e. Workmaship. $C$

1. As-bulit details -

8. Palnting - zinc chromate on exposed surfaces. *

3. Instaliation

a. Check for proper fit.

b. Palnting - 2 finlsh coats - Lloss enamel on exposed surfaces.

* PAINING HA NOT BEEN CDMPLETED

\section{KEMARKS AND/OR SATETY FEATURES}

Wear hard hats and glasses. 


\begin{tabular}{|l|l|l|}
\hline BROJECT IAP $614 \quad$ AMC-9075 & \\
\hline
\end{tabular}

Prepared by:

E. S. Devis $3-13-69$

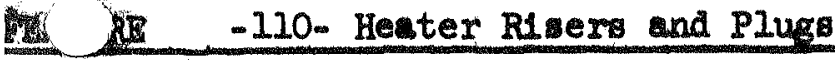

Inspected by:

RWHERUNCES: H-2-64419, Rev. 4 - 2 ea., slipon flanges for riserr \#7 and \#24;

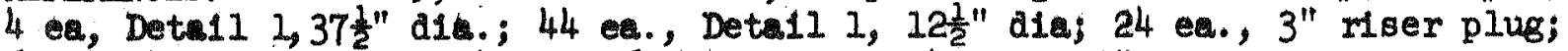
6 ea., 4" riser plug; 14 ea., 6" riser plug; 4 ea., 12" Hser plug; 2 ea., $16^{\prime \prime}$ riser plug; 4 ea., $24^{\prime \prime}$ riser plug; 4 ea., $42^{\prime \prime}$ Her plug; 44 ea., $5-5 / 8$ "

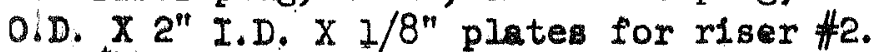

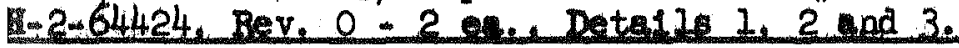

Date:

JTHER DATA: H-2-64447, Rev. 3, Penetration schedule

H-2-64448, Rev. 2, Tank Penetration Dete1le

HWS-7792, Peint Schedule, Page 104

Distribution:

CN Zangar

WS Greves

A. Short

$Q \mathrm{C}$ File

1. Material - (check for identification)

a. P1pe and pipe f1ttingB - ASTM A53, carbon steel (type E or S).

b. Flanges ASTM AI81, Grade $I$, carbon steel (A-36 if cut from plate).

c. Plate and latbar, ASTM A36, carbon steel.

d. Rod ASTM AIO7, carbon steel.

e. Concrete - 3000 pis.

2. Fabrication

a. Weld procedures - list.

b. Weldor qualifications - ascertain.

c. Check all almensions - ascertain vithin 1/8" tolerance.

a. Relnforcing teel - bize and placement.

e. Wortwenshlp.

1. As-built deta1ls

g. Painting - zinc chromate on exposed aurfaces.

3. Instaliation

a. Check for proper fit.

b. Painting - 2 Inish coats - eloss enamel on exposed surfacer.

\section{RELARKS AKD/OR SAFET FEATURES}

Wear hard hats and glasses. 


\begin{tabular}{|c|c|}
\hline OJECT & $A B C-9075$ \\
\hline AIURE & -107- Pump and Slulce P1t Adaptor Flanges \\
\hline WWENRTCES: & $\begin{array}{l}\mathrm{H}-2-64425 \text {, Rev. O - one each, Deta1ls } 1 \text { and } 2 . \\
\mathrm{H}-2-57331 \text { - long \& short dowels, parts } 7 \text { and } 8 . \\
\mathrm{H}-2-57332 \text { - stud, part } 1 \text {; lock1ns p1n, part } 10 . \\
\mathrm{H}-2-3146 \text { - nut retainer, part } 5 \text {. } \\
\mathrm{H}-2-64426 \text { - ttunnion add trunnion guldes }\end{array}$ \\
\hline
\end{tabular}

IKaA DAMA: H-2-44615 - pump adaptor flange assembly

H-2-41304 - Hanfort Blulcer.

H-2-64315 - slulcing pump mounting rings.

Nereve

Q. 2manx.

A.

ale (1)

1. Material (check for Ident1fication)

a. Flanges, gusset, trunnion gulde - ASTM A-36 C'stl.

b. Dowels - Als1 416 S.S., quench and stress relleved to 35-40 Rockwell.

c. Studs - Alsl, Type 431 S.S.

d. Iocking pin - AISI 304 or $304 \mathrm{t}$.

e. Trunnion, ber ball - ASTM AlO7.

Fabrication

1. Weld procedure. ᄂ

b. Weldor qualiflcations. L

c. Check all dimensions; uscertain within tolerances. -

a. Workmanship - Plntsh. -

e. As-bullt detalls. r

3. Installation

a. Check fit up and remotability.

(EEMOTABILITY WILL BE CHECKED A LATER DATE) 


\begin{tabular}{|c|c|}
\hline POJECT & IAP- 614 \\
\hline TRE & -107- Pump and Sluice P1t Adaptor Flanges \\
\hline PFERENCES: & $\begin{array}{l}\text { H-2-64425, Rev. O - one each, Detalis } 1 \text { and } 2 . \\
\text { H-2-57331 - long \& short dowels, parts } 7 \text { and } 8 . \\
\text { H-2-57332 - stud, part I; locking p1n, part } 10 . \\
\text { H-2 } 3146 \text { - nut retalner, part 5. } \\
\text { H-2-64426 - trunnion and trunnion guides }\end{array}$ \\
\hline
\end{tabular}

MIER DATA:

H-2-44615 - pump adaptor flange assembly

H-2-41304 - Hanford slutcer.

H-2-64315 - sluicling \& pump mounting rings.

1. Material (check for identification)

a. Flanges, gusset, trunnion guide - ASTM A-36 C'stl.

b. Dowels - Alsl $416 \mathrm{~S} . \mathrm{S} .$, quench and stress relleved to 35-40 Rockwell.

c. Studs - AlS1, Type 431 S.S.

d. Locking pin - AlSI 304 or 304L.

e. Trunnion, bar ball - ASTM AlOT.

2. Fabrication

a. Weld procedure.

b. Weldor qualifications.

c. Check all dimensions; ascertain within tolerances.

d. Workmanship - Iintsh.

e. As-bullt detalis.

3. Installation

a. Check fit up and remotability.

Wear hard hats and eye protection.

ma

Prepared by:

E. S. Devis 3-14-69

Inspected by:

Date:

D1stribution:

Acceptance

Yes

No

Requi rements 


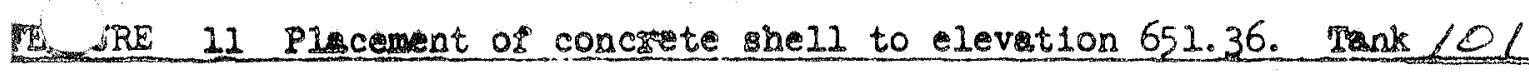

DS Dos $3-17-62$

RERERENCFS: DTW1AN H-2-64310

HWS-TT91

Inspected by:

\& Dam

Dete:

$4 \cdot 15 \cdot 6225 \cdot 20 \cdot 60$

Distribution:

WS Gree

Co Zongt $r$

A. Short

ac Ie (2)

OTHER DATA:

Relnforch steel fabricstor's cut sheets

Rryuiruments

1. Check primary tank sheil for completenes

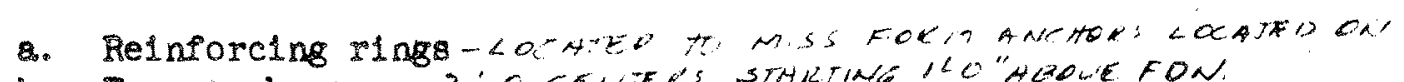

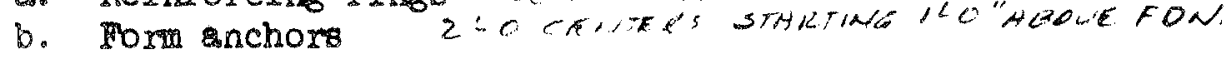

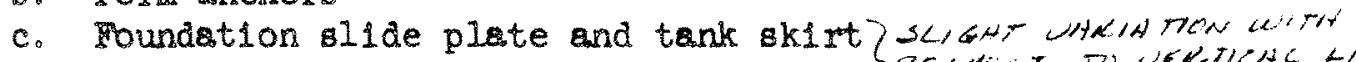

d. Expansion spece. PROTECTED WITH GRESHET TI WRTIIAC LINE

2. Check placenent of relnforcine steel
8. Spacing
b. Number and size of bars.
$\sin$
s.t.

3. Check formork
8. Specing and tie rods
b. Brocing
c. Construction joint-wet CWT LATAWIC AT EASH VOWY
d. Slgn pour 11 p.

4. Check placing of concrete - NLACFO MA THKEA LIFTS

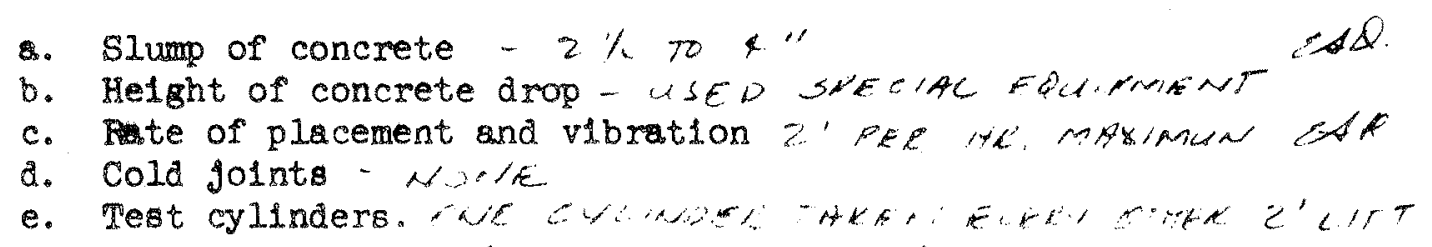
(continued on sheet 2) RQMARES ANI, TI APET: FIT TH:

1. Wear hard hats, gloves and eye protection.

2. Check scaffolding and ladders before using.

3. Stay clear of cranes handing material. 
VIRO-YIBS GUALTTY ASSURANCE

RPP-ASMT-53794 2

Marser Prosect IAP-614 Cortset AXC-9075

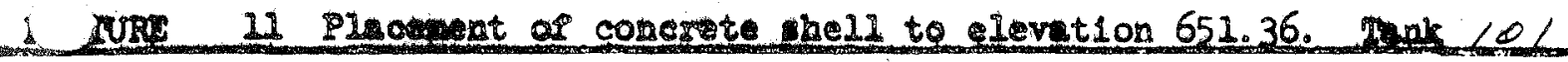

5. Curin of concrete

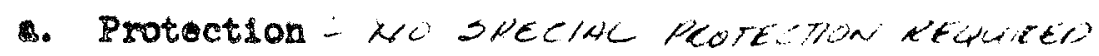

6.

7. Wopelr of concrete and Pliling of tie-bolt holes. iAA

8. Inturistion of eulant in expunsion space Edf

NOTES MADE ON THNE IOE MPBLY TZ FHE, OI.

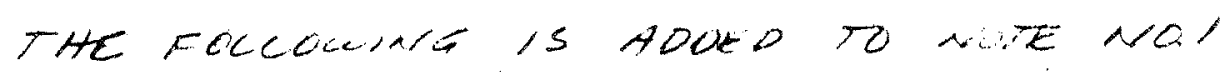

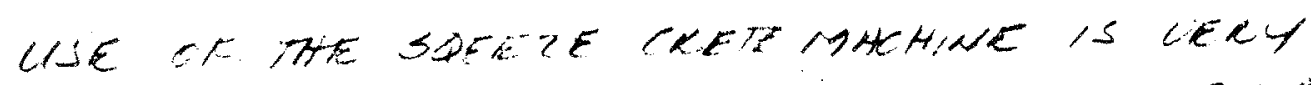

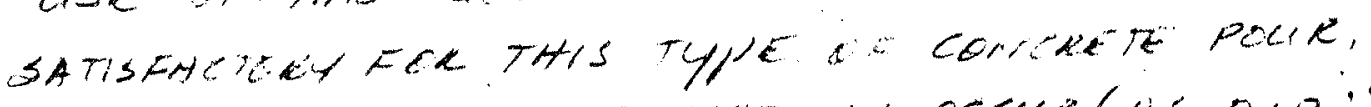
HOW

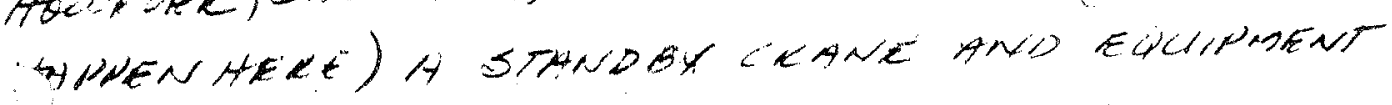
IS MECESSHEY TO PREUFMT COLD NOINTS

$$
\sin 10
$$

$1-129$ 


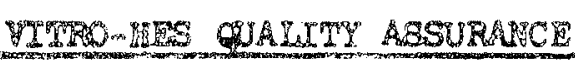

RPP-ASMT-53794 2

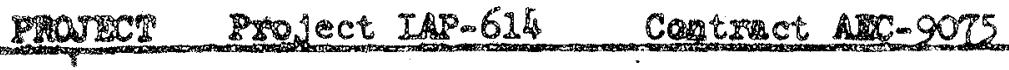

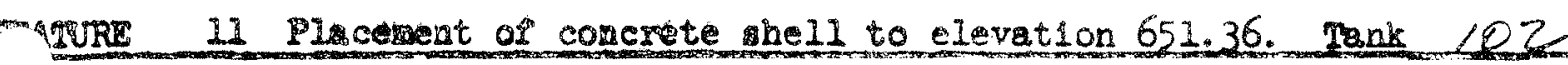

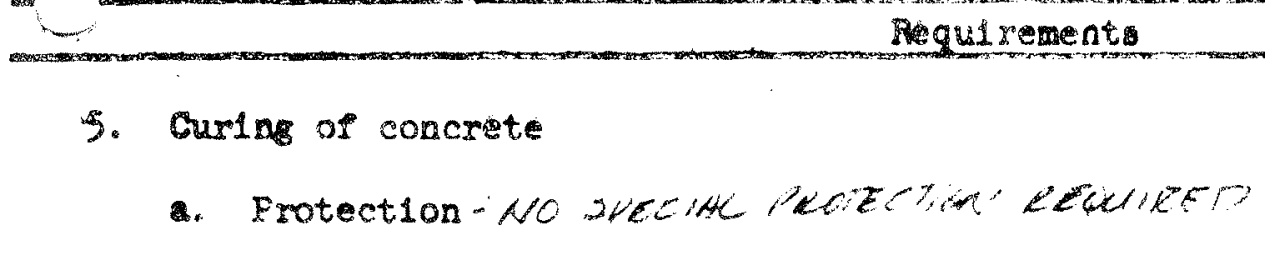

6. Prin removal

o. Nepair of concrete ad pliling of tie-bolt holes.

8. Instaliation of sealant in expansion space

MOTES

" "SQUEEZE-CRETE" MATIANE USED TO HZACE CONICCET

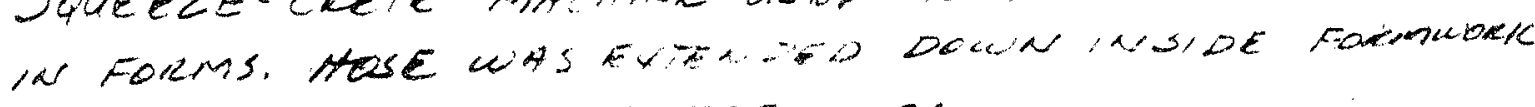
ECIMANATNG AEED TOR TREMMIES.

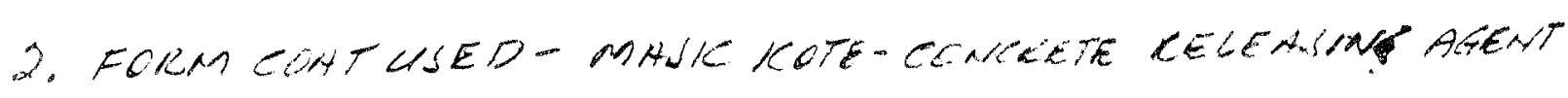
MFE BU SYMOAS MAF́ CO

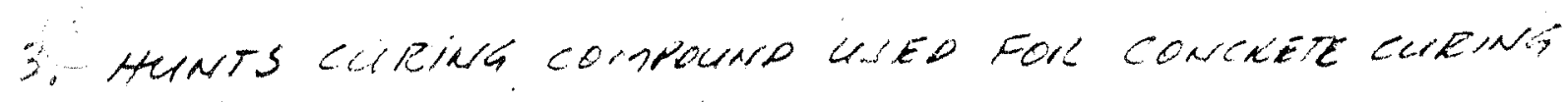
AFTER FCW LENOJAC

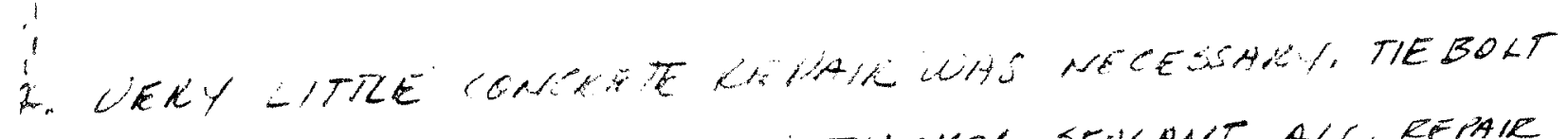
HOLES WERE TILCED WITH. THIOKOL SEHCANT. ALC RERAR

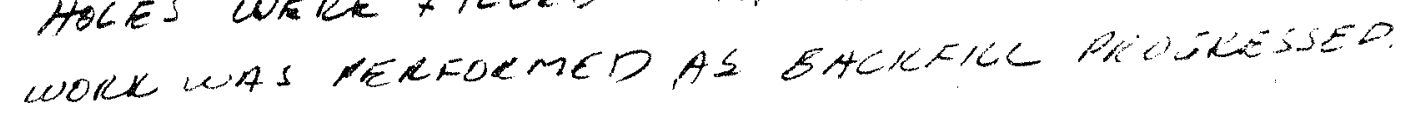

5. THIOKCL SEMCANT PLACED UI EXPANSTONOWAEE IS A ONE-COMPONENT THIOKOC SEMLANT MFG BY THE GILACE CO. (HOWNCEX ONE)

24

$1-131$ 


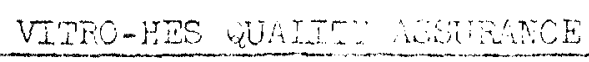

RPP-ASMT-53794

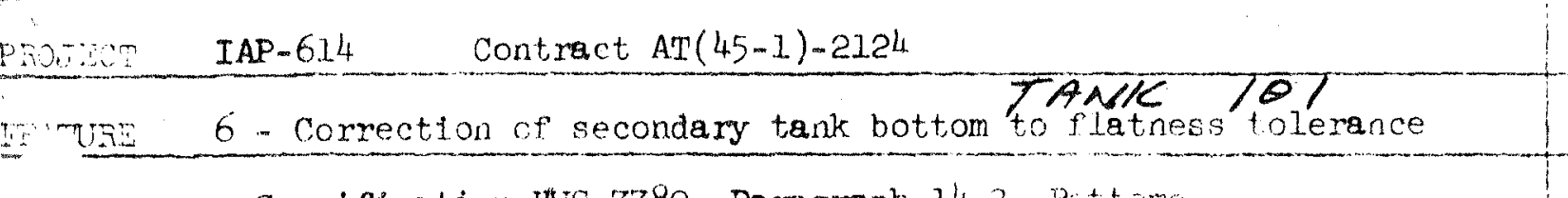

Rev 0

E. S. Davis $3 / 27 / 60$

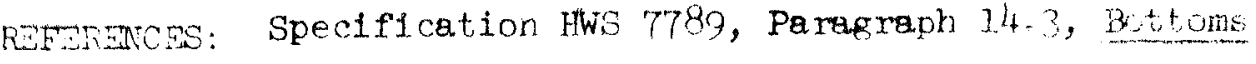

E. DAVY

Date:

SEE scow

Distribution:

WS Graves

CN Banger

A. Short

aC File (2)

ELEVATIONS ATE CHARTED ON DEA WING

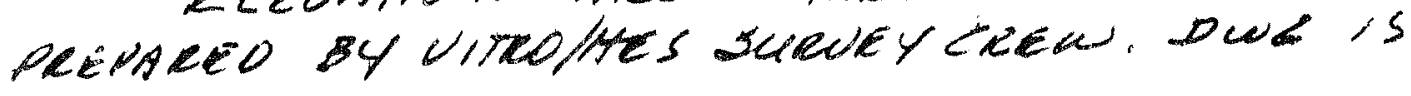
ADAPTED FROM POM DWK QC 4

Feglizenents

$\therefore \operatorname{septarce}$

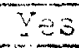

1. Flatness:

a. Peak-to-valiey not to exceed $2^{\prime \prime}$.

b. One peak-to-valley tolerance of $3^{\prime \prime}$ in $30 \mathrm{sq}$. ft.

2. Distortions:

a. Slopes shall not exceed $3 / 8^{\prime \prime}$ per foot.

SURVEY MAOE LN 3-10.65

Ia. SIS DLACES ERCEED Z"TOLENAWE

6. ONE PLACE HOS PEAL TE UACLEY TOLETANA $O F=$

2. SLOPE EUCEEDS $3 / 8$ "/FOOT AS NOTED ON survey,

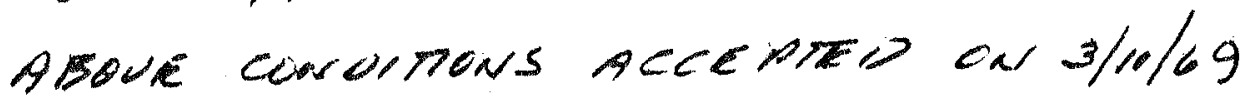

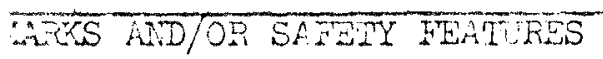

1. Wear hard hats, gloves and eye protection.

EK- Al Shat

2. Check access ladders to platforms for safe use.

$1-132$ 
VITRO-HES GUILTY AESURANE

RPP-ASMT-53794

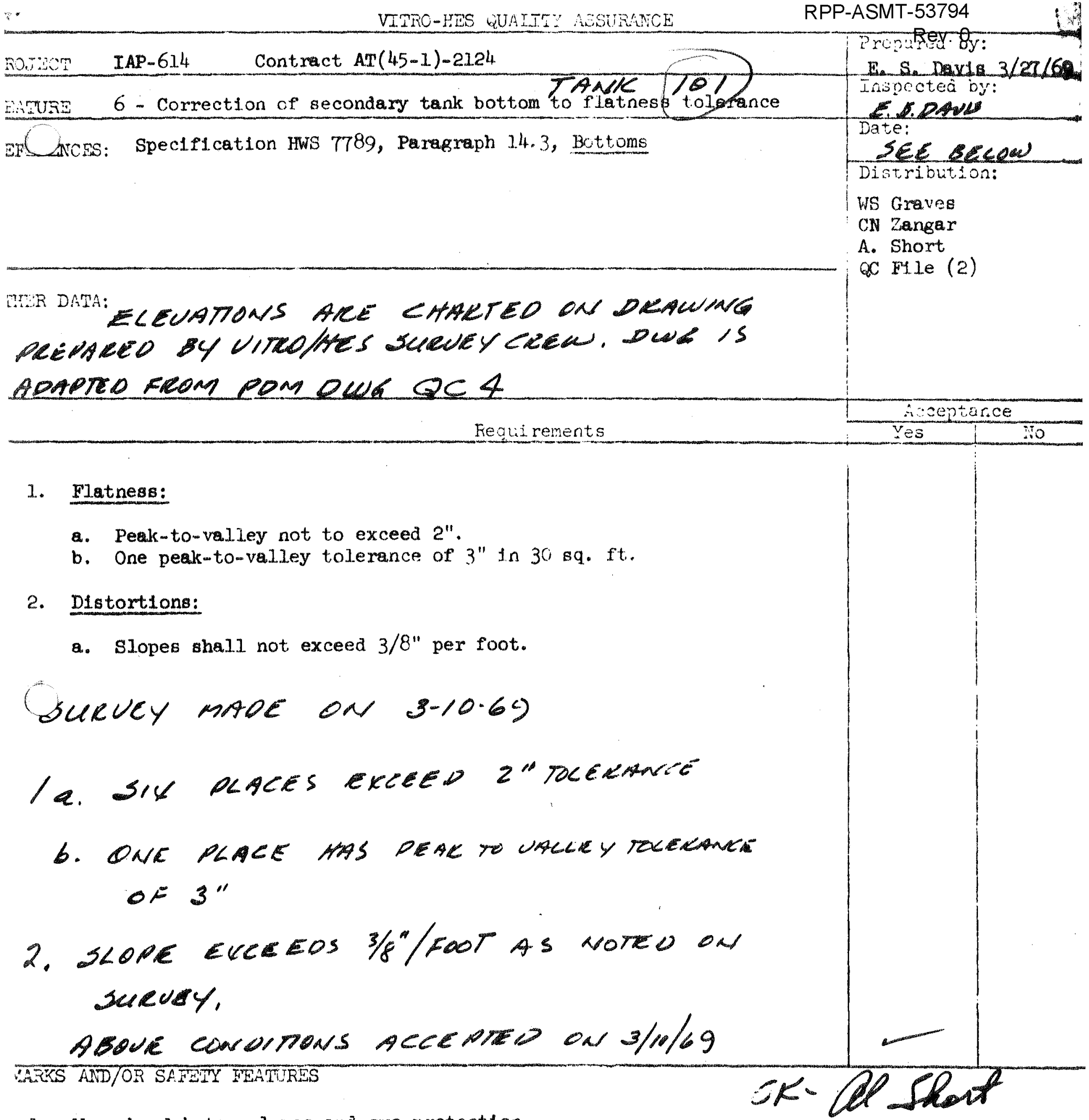

1. Wear hard hats, gloves and eye protection.

2. Check access ladders to platforms for safe use.

$1-133$ 


JUET IAP-614 Contract $\operatorname{Ar}(45-1)-2124$

IR DATA:

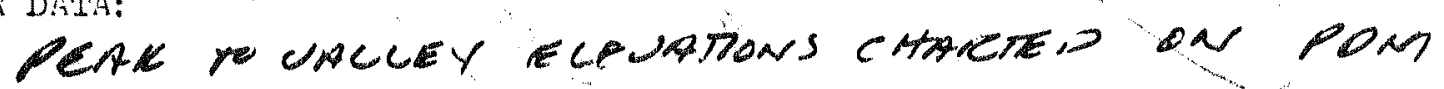
DWG QC 6 BY UITEO FIELD SURUEYCLEW $242-19-602$

1. Flatness:

a. Peak-to-valley not to exceed 2".

b. One peak-to-valley tolerance of $3^{\prime \prime}$ in 30 sq. ft.

2. Distort1ons:

a. Slopes shall not exceed $3 / 8^{\prime \prime}$ per foot.

1 a.22 PLACES EGCEEDED 2 "PEAK-TO-UACEW TOCERARCE. b. WONE EXCEROLU S" TOLERARLE.

2a. SLOPE APNRACBED " IN SEvENC LOCATONS.

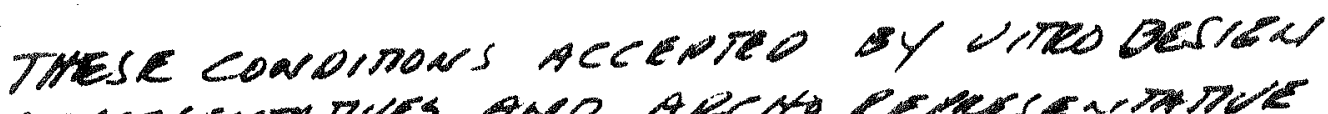

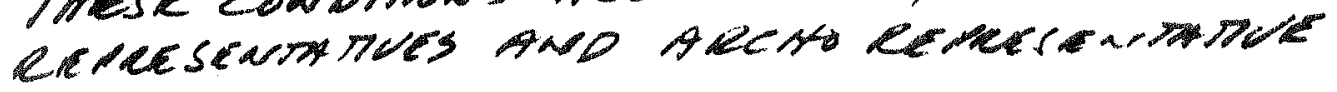

REXS AND/OR SAFETY FEATURES

1. Wear hard hats, gloves and eye protection.

2. Check access ladders to platforms for safe use. 


$\begin{array}{llll}\text { POJECT } & \text { IAP-614 }- \text { Contret AT(45-1)-2124 } \\ \text { EATURE } & 10(1) \text { Installation of protect1ve cover1ng over Kool1te Insulation }\end{array}$

EFEY TES:

aws 7789 , Paragraph 13.0 a

\section{$7 K / 01$}

E. S. Fourdia 4/3/69

Inspegted by: 1

Date:

$6-12-69$

Distribution:

WS Grave

CN Zangar

A. Bhort

ac Mle (2)

THER DATA:

\section{Requirements}

1. Check that conduit risers for themocouples are cut off level with surface of lasulating concrete and exposed ends covered to prevent entry or debris. $*$

2. Check protection of insulation concrete by use of plywood and $2^{\text {"t }} \times 10^{\text {" }}$ timber supports.

3. Check that ends of air piping have protective covering to prevent entry of debris.

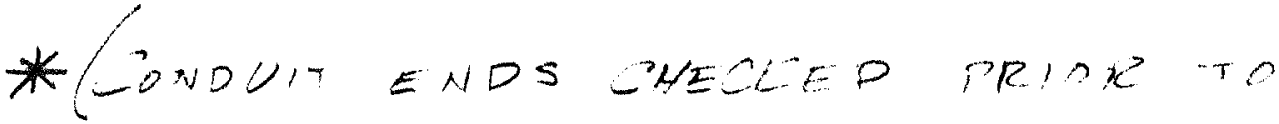

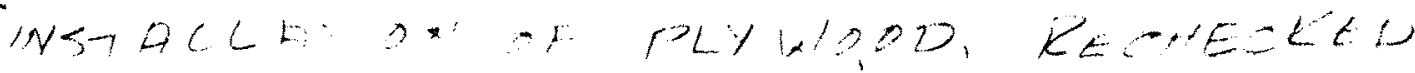

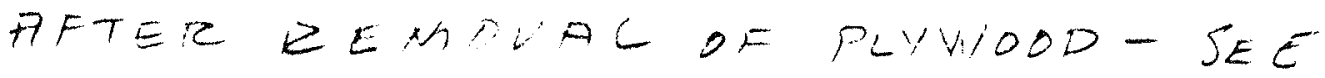

$$
\begin{aligned}
& \text { DAILY } 12=6-11-60)
\end{aligned}
$$

EMARKS AND/OR SAFETY FEATURES

Wear hard hats, eye protection and gloves.
Acceptance

Yes 1 No

No


SOJECT IAP-614 - Contract AT $(45-1)-2124$

E: A TUEE 10 (2) Assembly of primary tank bottom up to top of knuckle plates

REFERENCES: Procedure for material control; weldor performance

HWS 7789 , Rev. 2, Par. 2.0 -b, $-\mathrm{c}$ and $-\mathrm{g}$.

TK 101

Prepared by:

E. S. Devis $4 / 3 / 69$

ingpegiec by:
qualifications, vendor drawings, mill and material
certiflcations, erection drawings.
qualifications, vendor drawings, mill and material
certiflcations, erection drawings.

THER DATA: PDM Welding Procedures 57-34A manual, 68-81A auto, 68-81 auto,

(manual welding permissible - see letter AEC to PDM, dated $3 / 18$ ).

Welding Procedure Specification DB 119-197.

PDM DWg. 38570, sheet 7 .

PDM Dwg. 38570 QC 4 or 8.

\section{Requirements}

1. Check equipment to ascertain capability of speciflc job performance.)

HWS 7789, Rev. 2, Par. 11.1; Par. 11.2 c:

a. Automat1c sub-arc.

b. Welding machines (manual shielded arc.)

2. Check mlll and material certification and markings:
a. Plate material.
b. Weld rod.
c. Clips and miscellaneous steel.
d. Stenc1l marks on exterior of tank.

3. Check fabrication for:
a. Joint geometry and spacing.
b. Welding sequence.
c. Welding procedures.
a. Handling.
e. Excessive distortion.
f. Good workmanship pract1ces.

4. Review handling procedure for ralsing tank bottom.

\section{WARKS AND/OR SAFETY FEATURES}

1. Check for tank grounding.

2. Ascertain that cribbing for supporting tank bottom is adequate and properly placed to prevent injury to personnel.

3. Wear hard hats, gloves and eye protection.

WITH THE EXCEPTION OF POTTIOAS OD THEEE LANG SEAMS, DF, AG, \& AK, MANUAL KELDNG WAS IMPLOVEO ON THE LPEE SIDES OF ACL JONTS, 


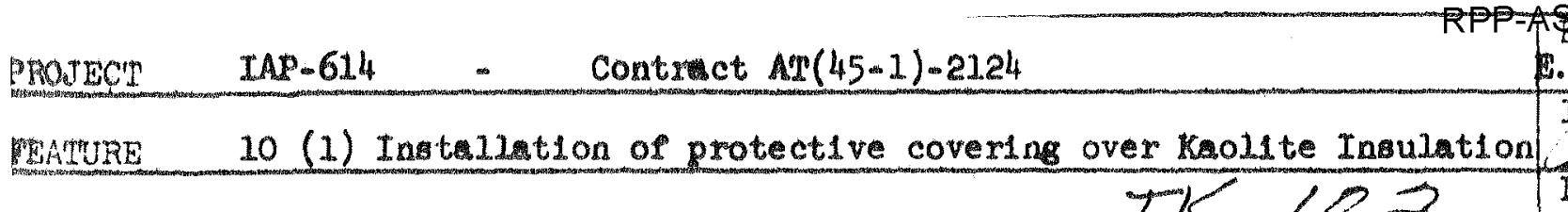
REPENCES:

HWS 7789, Furaph $13.0 \mathrm{n}$

$7 \% / 20$

1. Check that condult risers for thermocouples are cut off level with surface of insulating concrete and exposed ends covered to prevent entry of dobris.

2. Check protection of insulation concrete by use of plywood and $2^{\prime \prime} \times 10^{\prime \prime}$ timber supports.

3. Check that ends of $1 \mathrm{r}$ plping have protective coverding to prevent entry of debris.

(SEE DETALS IN DALY $200-5 / 10 / 60$ )

Wear hard hats, eye protection and gloves. 
QJect IA-614 Contrubt Ag (45-1)-2124

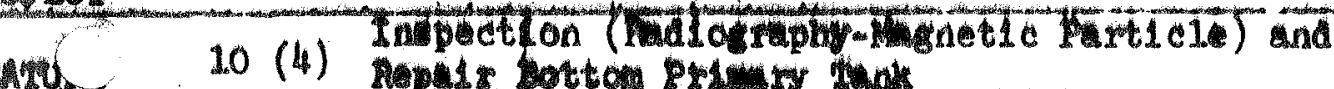

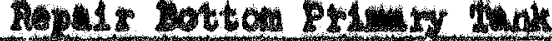

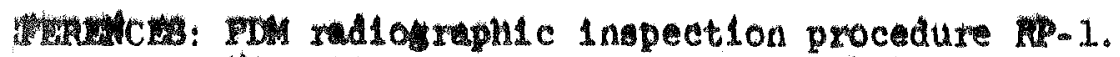

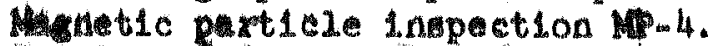

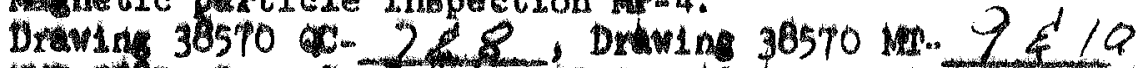

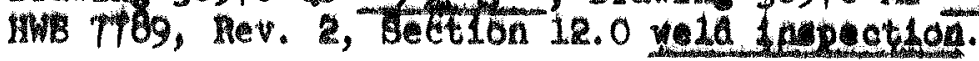

CHem DATA:

adistion 18 se.

\section{Requirement:}

1. Mlogreph 11 weld semme in bottom, knuckle plates and those adjolning first hel.1 course.

2. Check for -

4. Mith $x$ - Iny quatity.

b. Proper 1nterpretation and mings of film. SEE NOTE I

c. Recording of derect.

ᄀ. Ropar all defective welds.

4. Viruily check 11 welas priot to repalr.

b. Ascotrin that repis procedure is acceptable.

c. Check and recora $x$ - ray flim of repalr

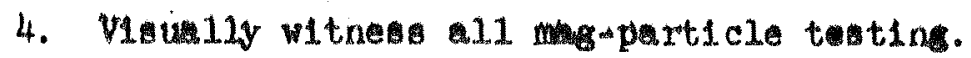

- Continumily check testins equipment.

b. Mecord position and location of test. (PDM RECOEDs)

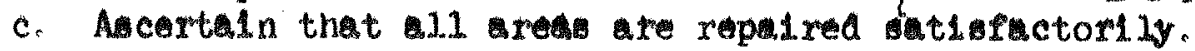

5. Visudiy check all ares top and bottom for objectionmble dafect. NOT 1. DE 343 REUECTABLE DETECIJ FONND IN THIS BOTTON THE PONAN PADHOERPHER FOUNDOM R94. THE EEASON PPPEARS TO SE THE FLVORE CEENT BULB TYPE VIEWER ME USES DOES NOT SEEAA TO PEOVIDE SUFFICIENT ILLUMINATIDN.

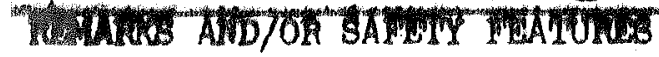

1. Wear hard hat, Lloves and protection.

2. check crbbin, tank sroundin.

3. Mintin alce distance to prevent $x-x y$ expowure.

4. Check caftoldns, breckets, ladder for anfe access. 


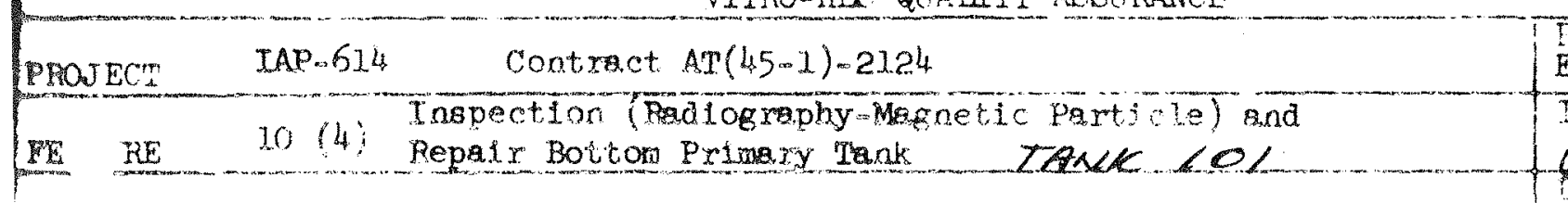

REFERENCES: FOM Tealographic inspecton pooedure RP I.

Magnetic perticla fispection Mpols.

\section{Jiantne $385706 \mathrm{C}$. Drawing $38570 \mathrm{Me}-3-4$ \\ HWS 789. ReV 2 ; section ia o weld inspecion \\ $=$ \\ $\cdots+\cdots$ \\ HW}

\section{CMTER INATA:}

Radiation signs.

Preparad by:

E. S. Davis $4 / 14 / 69$

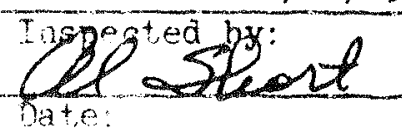

bate:

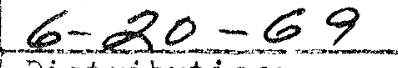

Distribution:

ws Craves

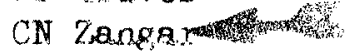

A. Short.

or File (2)

Requirements

1. Rodjograph all weln seams la botrom kruckle platas and those adjotning first she rll course.

i. Check for

9. Film and x-ray qualitya

b. Propar interpretation and maktag of film to

$\therefore$ Reonding of aefecoso.

3. Repalr all defect vo we?ds.

a. Viaualiy chers ali welds prior to repalm.

b. Ascemtalu the repatr procedure is acceptatio

o Check and yecord ym ray fim of repars

4. vasuliy htoress all mag pattole testing.

a. Continualiy heok lesting equipment.

b. Recom wostion and location of tests.

$\therefore$ Ascertaln shat all areac ase repalred satisfactorly.

5. V1sually dieck al a peas top and botrom for objectionable defects.

\section{WMARKS AND/OR SAFFYY FRATTRES}

1. Wear kaxd hats gloves and eye protection.

2. Check arobling, tark grounding.

3. Malateln safe distance to prevent $x$-ray exposure.

4. Ckeck acaffold ng. brackets. ladders for safe access.

\section{F In several areas of AW seam dye penetrant WAS USED AS A SUPPLEMENT TO RAPIOGEAPNY.}




\begin{tabular}{|c|c|}
\hline PROJ ECT & IAP-6I4 Contract AT $(45-1) \cdots 212^{4}$ \\
\hline ATURE & $\begin{array}{l}10 \text { (3) Preparation of Primary Tenk Bottom for Radiography, } \\
\text { Magnetio Particle, and Vecuum Leak Test. Zhsk <o }\end{array}$ \\
\hline REFERENCES: & 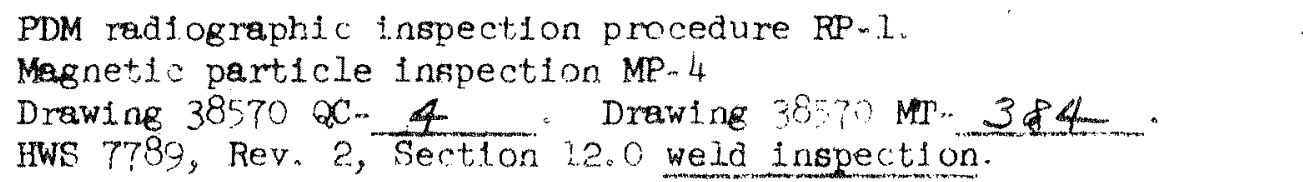 \\
\hline
\end{tabular}

OTHER DATA:

Prenared by: E. S. Davis $4 / 15 / 69$

Ingegted by:

bate: $20<6$

Distribution:

WS Graves

CN Zangar

A. Short

QC File (2)

Padiation slens.

1. Check acceptability of -

a. Type and power of $x$-ray machine.

b. Type and size of $x$-ray films.

c. FyIm developing and readout equipment.

d. Range and polarity mag...f. I ux equipment.

e. Soap test equipment. NOT USED YET

2. Check -
a. Temporary attachments removed (TD $11 \mathrm{fting}$ beams).
b. Gouges, weld scars, plate damage repaired.
c. Excessive distortion removed. NOT ERUIR
d. Areas marked for mog-particle inspection.
e. General condition of tank bottom assembly.

3. Tools -

Depth gauge.

\section{WARKS AND/OR SAFETY FEATURES}

1. Wear hard hat, gloves and eye protection.

2. Check cribbing, tank grounding.

3. Check condition of grounding. 
Mas IAP-614 Contract AT( $45.12-2124$

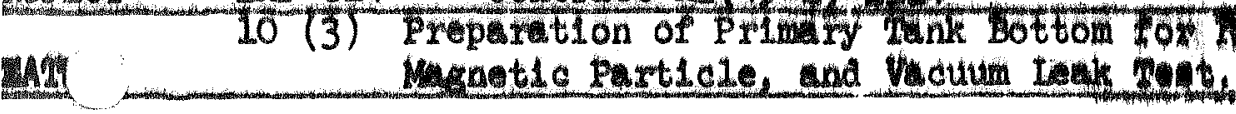

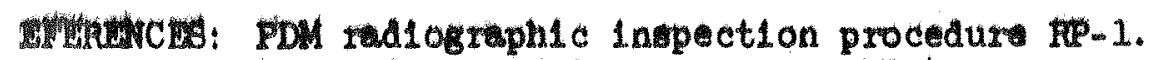

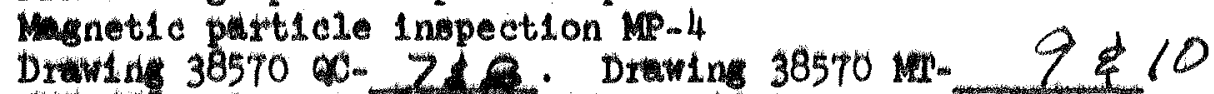
Htw8 7789 , Rev. 2, Bection 12.0 vela indrection.

W6 Graves

CN Zangter

A. Short

ar te $(2)$

MIUT DAMA:

Rudiation alus.

nequi remento

2. Check acceptability of -

a. Type and power of $x$-x my mine.

b. Type and lze of $x$ - ru films.

c. HIIn developlng and readout equipment.

d. Hange nd polstity mass 1 lux equipment.

- Soap tost equipment. (NOT PEEFDEMED YET)

Check

a. Temporm attachment removed (axcept $11 \mathrm{fting}$ beans).

b. Gouges, weld scars, plate damage repalred.

c. Heceldive alatortion renoved. (RLL WHAN TOLEEANCE) I

a. Areas marked for mag-particle inapeotion. ( $s E \in$ NOTE)

e. Genert 1 condition of tank bottom assembly. $S O O D$

3. Tools -

Depth gauge.

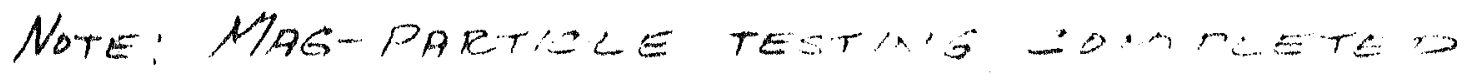
ON ALL ADElZONTI BOTTOM AREO

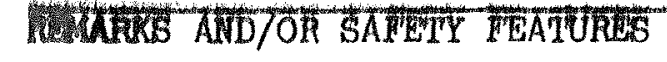

1. Wear hard hat, glove and eye protect 10 in.

2. Cheok cribblas, tank grounding.

3. check condition of grounding. 


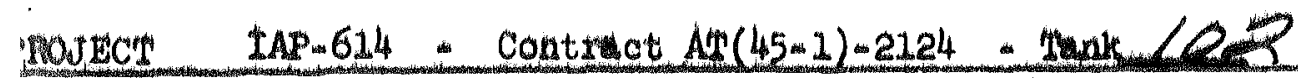 \\ DAdURE 10(5) Cleanup and placesent of primsin tank bottom}

Preptreat doy:

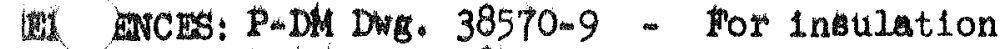

P-DW DWg. 38570-12- For instrumentation

P.DM DWg. 38570.4, Rev. 7 - Hor cleats

HWS 7789, Rev.2 2 sted tank

HWS 7 t93 - Instrumentation

E. S. Dav1s $4 / 28 / 69$

Inspectod by

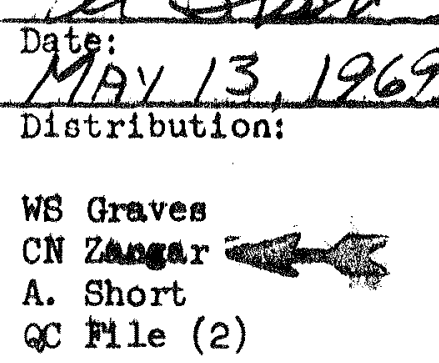

THER DATA:
Review manufacturer's recomendation for installation
of atrein geger.

Requidements

1. See that 18 cleat are completely installed.

2. Remove protection cover from insulating concrete.

3. V1Bualiy check concrete for dange and/or necessary repalrs.

4. Check all alx plping, centrol air chamber and air slots for cleanliness.

5. Check 1nstaliation of thexmocouples in 1nsulating concrete.

check reslotance and 1dent1fication.

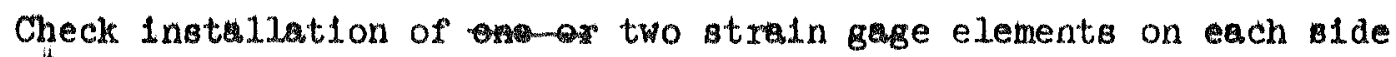
of primary sheli.t.

7. Mintain cleanliness as tank botton is cowered.

8. Check insextion of cleats into central alr chamber.

9. Malntaln safe distance durdng lowering of tank bottom.

10. Remove lifting beams and attachments (see feature number 10 (3) for repal and feature number $10(4)$ for tagnet1c particle teats of weld cars).

\section{MARKS AINDTOR SAFETY FEATURES}

1. Weat haxd hat, gloven and eye protection.

2. Check cribbing, stay clear of jacks andor crane. 


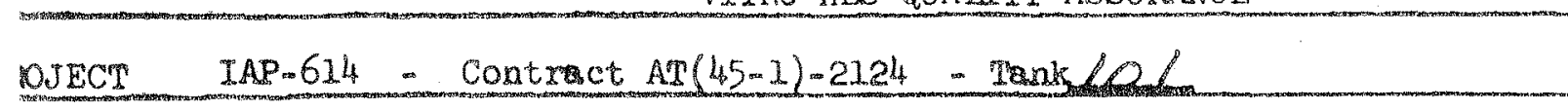

Prepared by: E. S. Dev1s $4 / 28 / 69$

i. E $\quad 10(5)$ Cleanup and placement of primary tank bottom

\section{IFERENCES: P-DM DWg. 38570-9 - For insulation}

P.DM DWg. 38570-1/ - For instrumentation

P.DM Dwg. 38570. 4, Rev. 7 a For cleats

HWS 7789 , Rev. 2 -. Steel tanks

HWS 7793 - Instrumentation

Inspegted by:

TER DATA:

Review manufacturer's recommendation for installation

of strajn gages.

1. See that 18 cleats are completely installed.

2. Remove protection cover from insulating concrete.

3. Visually check concrete for damage and or necessary repairs.

4. Check all air piping, central air chamber and atx slots for cleanliness.

Date:

Luswar 136

Distribut1on:

WS Graves

CN Zangar

A. Short

QC Flle (2)

5. Check installation of thexmocouples in insulating concrete.

Check resistance and identification.

6. Check Installation of one or two strain gage elements on each stae of prims,xy sheld.

7. Malntain cleanliness as tank bottom is comenter.

8. Check insertion of cleats into central air chamber.

9. Maintain safe distance during lowering of tank bottom.

10. Remove lifting beans and attachments (see fature number 10 (3) for repalrs and feature number $10(4)$ for magnetic particle tests of weld acars).

\section{MUARKS AND/OR SAFETY FEATURES}

1. Wear hard hat, gloves and eye protection.

2. Check cribbing, stay clear of jacks and/or crane. 


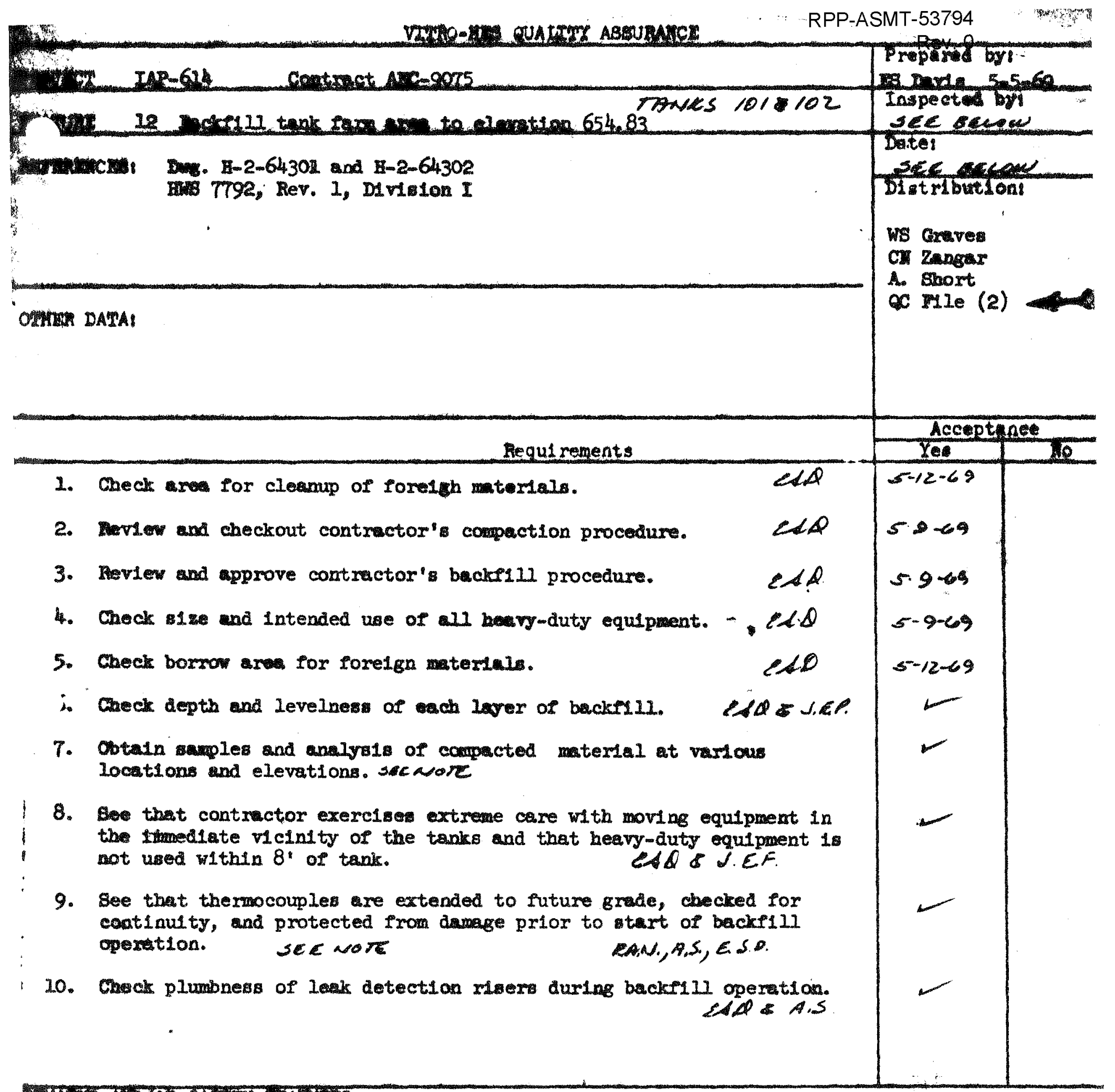

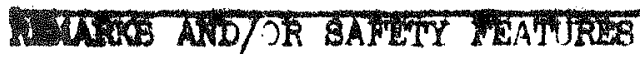

1. Vear buxd bats, gloves, and eyre protection.

2. De of noving equipwent. 


\section{PHoTn EAP 6/4}

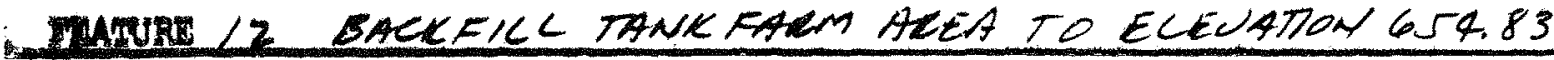

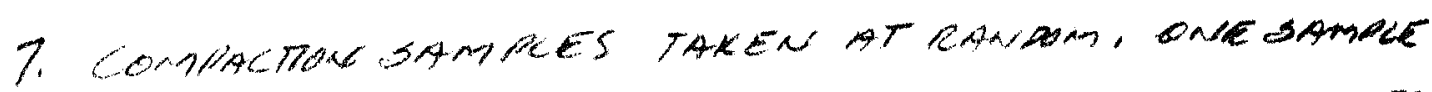
CALED-BLT ANOTHER SAMMLE THKEN IN THE SHME LOCAMON INDCATED COMPACDON WAS ACCEPTHSCE

9. FOUNDATON THERMOCOUNES WERE BCAMAHT UP SIDE

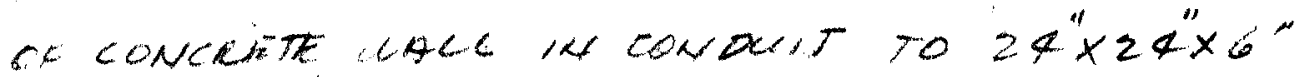
STEG Bar COCHED AT APReax ELEW 649.00

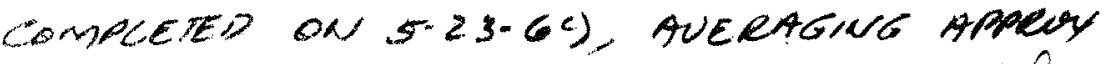
THREE (3) FEET HE SHIFT 2010 
1. Check for cleamp of sorelin fertals. 240 Accept nee

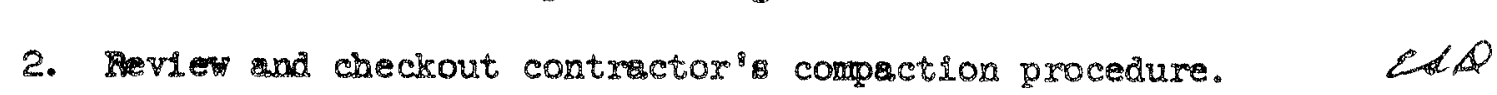
$5=12-69$

3. Review and approve contrector" beckinl procedure. 20 5.29

4. Check size and lntended use of 11 hesy-duty equipment.

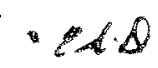

5. Check borrow for Porelga fater.

- Check depth and levelaess of esch layer of backf111.

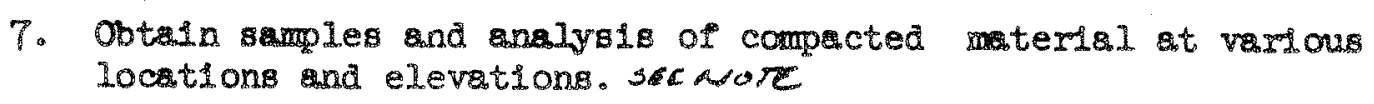

8. See that contractor exercises extreme csre with noviag equipment in the 1tmedlate Viclntty of the tonks and that hesvymduty equipment is not used whin $8^{\circ}$ of tank.

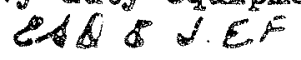

9. See that thermocouples re extended to future grade, checked for continulty, and protected irom damge prior to start of backilil opertion.

$$
\text { sec wore }
$$

RAN., A.S., ESP.

10. Check plumbness of leak detection risers duriag bsckilil operstion. EA.s $A . S$ 
RPP-ASMT-53794

VITRO-HES QUALITY ASSURANCE

sheet 02

PROJECT $\mp A P 614$

BEALURE 2 BACEEICL THNK FAKM HEEA TO ECEUATION 6 TA.83

NOTS:

SWING SHIFP BEGWNAR 5.12-C9 AND

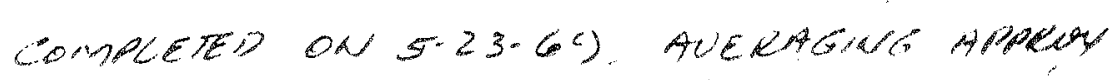
THRER (3) FEET AE SAM

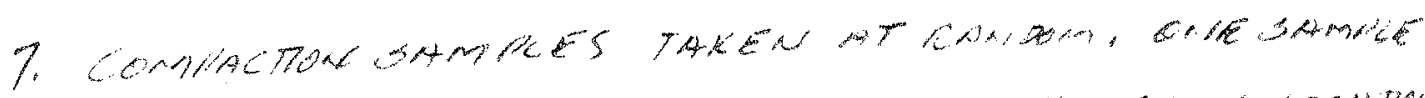

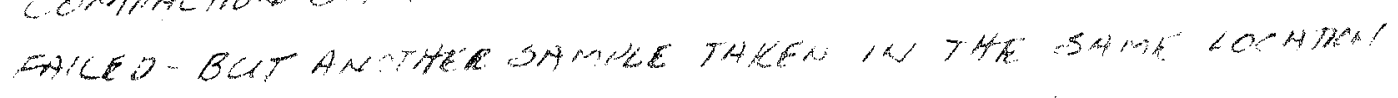

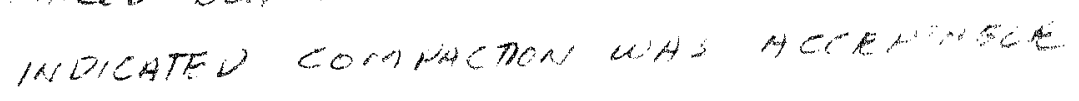

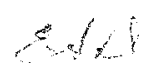

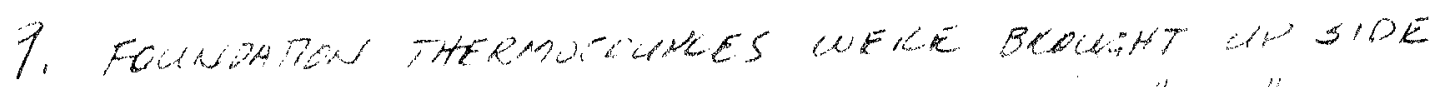

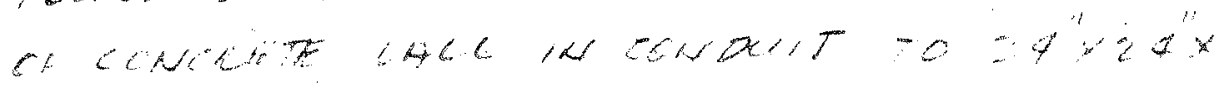

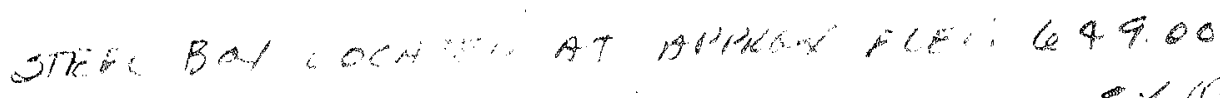

$1-150$ 


\section{HOI I. 615

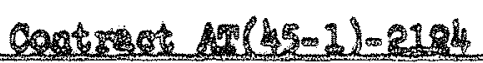 Tak' 103 Matrex 106 \\ tolergoces}

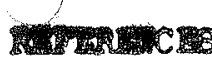

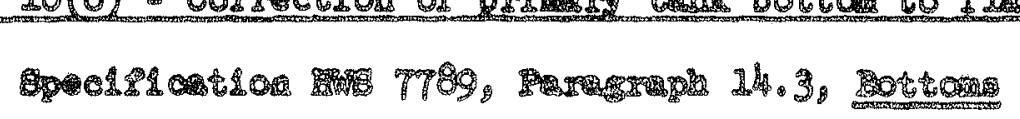

\begin{abstract}
(and
\end{abstract}

.

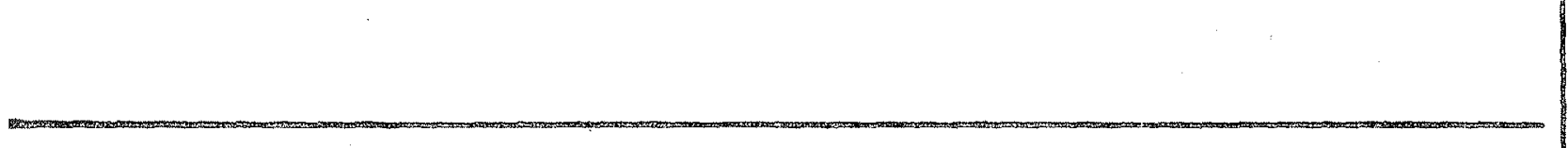

Dete:

$8-62$

D18t11but108:

W Orevar

Co:

A. bort

1.10 (2)

OTIXA DAPA:

\title{
Requs roments
}

\section{20t8es:}

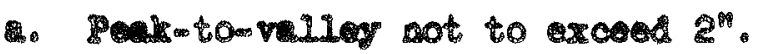

b. On par-tom Ley tolerence of $1 \mathrm{~g} 30$ m. It.

\section{210tansogs}

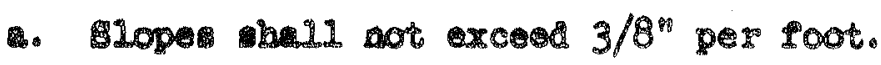

HLL WEL SEAMS UP TO THE MOP OF THE BOTTOAN KNUCKLES, WERE UPCUUAN TESTED BND COUNO TO BE WITHOUT OEFETS.

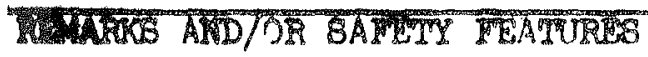

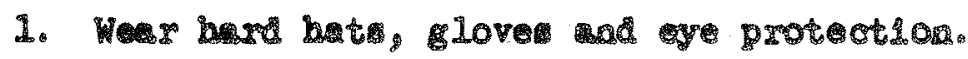

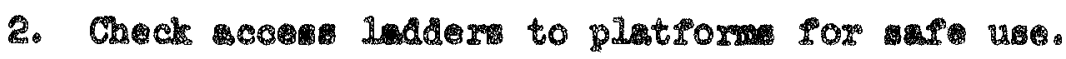


1. Flatness:

a. Peak-tomvalley not to exceed $2 "$.

b. One peak-tom viley tolerance of $3^{\prime \prime}$ in $30 \mathrm{sq}$. $\mathrm{ft}$.

2. Distortions:

a. Slopes shal1 not exceed $3 / 8$ " per foot.

1. Wear hard hat gloves and eye protection.

2. Check access ladders to platforms for safe use. 


\begin{tabular}{|c|c|}
\hline PloJ'LCL & IAP-614 - Contruct AT(45-1)-2124 \\
\hline 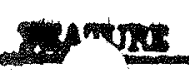 & -8. Inuzetion in Botton of paks. pan $\angle 01$ - \\
\hline netrate & 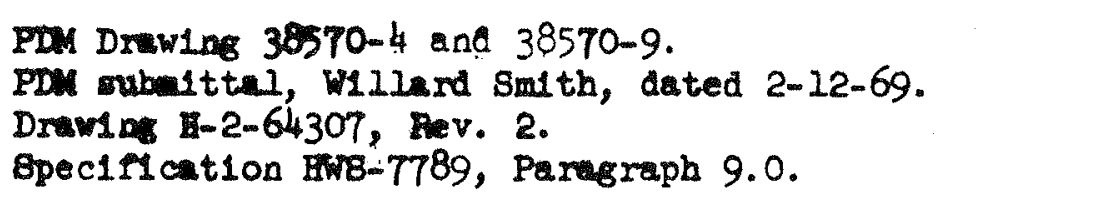 \\
\hline
\end{tabular}

Frepared by: E. S. Davis

OHER DATA:

Battelle - Evaluation of Kmollte-2200.

Inspectod by: sie below

Date:

i. 2969

Dietribution:

WS Greves

CR Zangar

A. Short

A F1le

\section{Requi remeat.}

1. Review foature No: 7 as cheak ombedded material.

2. Conditions of onvirons pertulatas to:

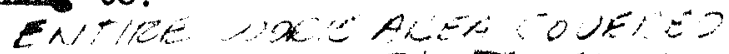

a. Protection of tank bottom and terlals. WITH TARAGCLLN

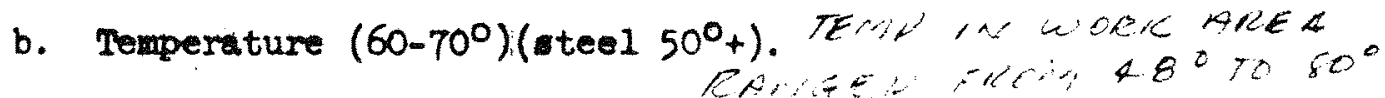

3. Formork:

a. Migtain inimum $1^{\prime \prime}$ under pipe and $2 \frac{1}{2}$ " over pipe thickness of 1asulation at the four 4-1ach vent pipes. All other pleces minimum of $5^{\prime \prime}$ thick insulation. M $1 \mathrm{~N} 7^{\prime \prime}$

b. JolntB - configuration and trotment to maintain strength and

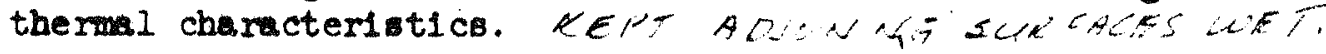

c. Screeds and blockouts - afr trenches and traingages.

4. Plecement:

qts.

a. Mixin - 78/water/6-40 bags (3 to 5 minutes). $3 \mathrm{mg} / \mathrm{h}$. ACE $5 \%$ LAL SATEW

b. Hach batch piaced withia 20 minutes - vibrator.

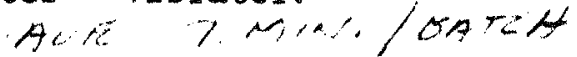

c. Obtaln samples - one each 10 batches or minimum of ive each day. 3 To $45 A$ S

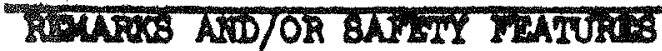

2. Wear hard hats, gloves and eye protection.

2. Check alr inside trak enclowre for polsonous gases.

3. Wear alr filter men near batch ixlng operation.

4. Sxercise care entering and exiting tank.

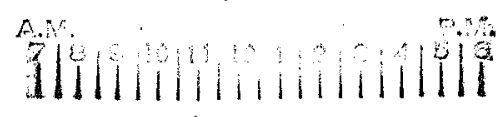

Acceptance

Yes

r

$\longleftarrow$

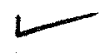


VITRO-HES QUALITY ASSURANCE

RPP-ASMT-53794

PROJECT IAP-614 - Contract AT (45-1)-2124

FrAPPE $-8-$

Insulate

$$
\text { lotion In bottom of tanks. Tank }
$$

5. Curing:

a. Covered with moist burlap for twenty -four hours - then air dried for ninety-six hours. AIR DRICD CNTIL TEST SHow 200 PSI- USUALLY 72 Hour

b. Tests - shall not be less than 200 psi (wet or dry).

$$
3 \text { day } 4 \text { day } 5 \text { day } 6 \text { day } I \text { day }
$$

Batch \#1

Batch \#2

Batch \#3 TESTS RESULTS OAI FILE

Batch \#4

Batch \#5

SAMPLE ATTACHED

Batch \#6

Batch \#7

Batch \#8

Batch \#9

6. Repairs - give nature and description of repair.

ONLY REPAIRS NECESSARY WRIT SHAPING UP TRENCHES WITE EDGES HAD BEEN KNOCKED OFF ELEVATION OF ILAOCITE ON FILE

NOTE: ONE CRACK APPEALED IN KAOLITE JUST AS PRIMARY SHELL BOTTOM WAS LOWE ERE AFTER COMMOTION OR WRCDIA HE CRACK WAS $1 / 6$ WIDE OR SMRCLEIZ AND WAS REPAIRED BY SEALING WITH KAOLITE SEAL MIL $1-154$

$\operatorname{sen} 2 \cos$ $R C L A C$ CS Dar 


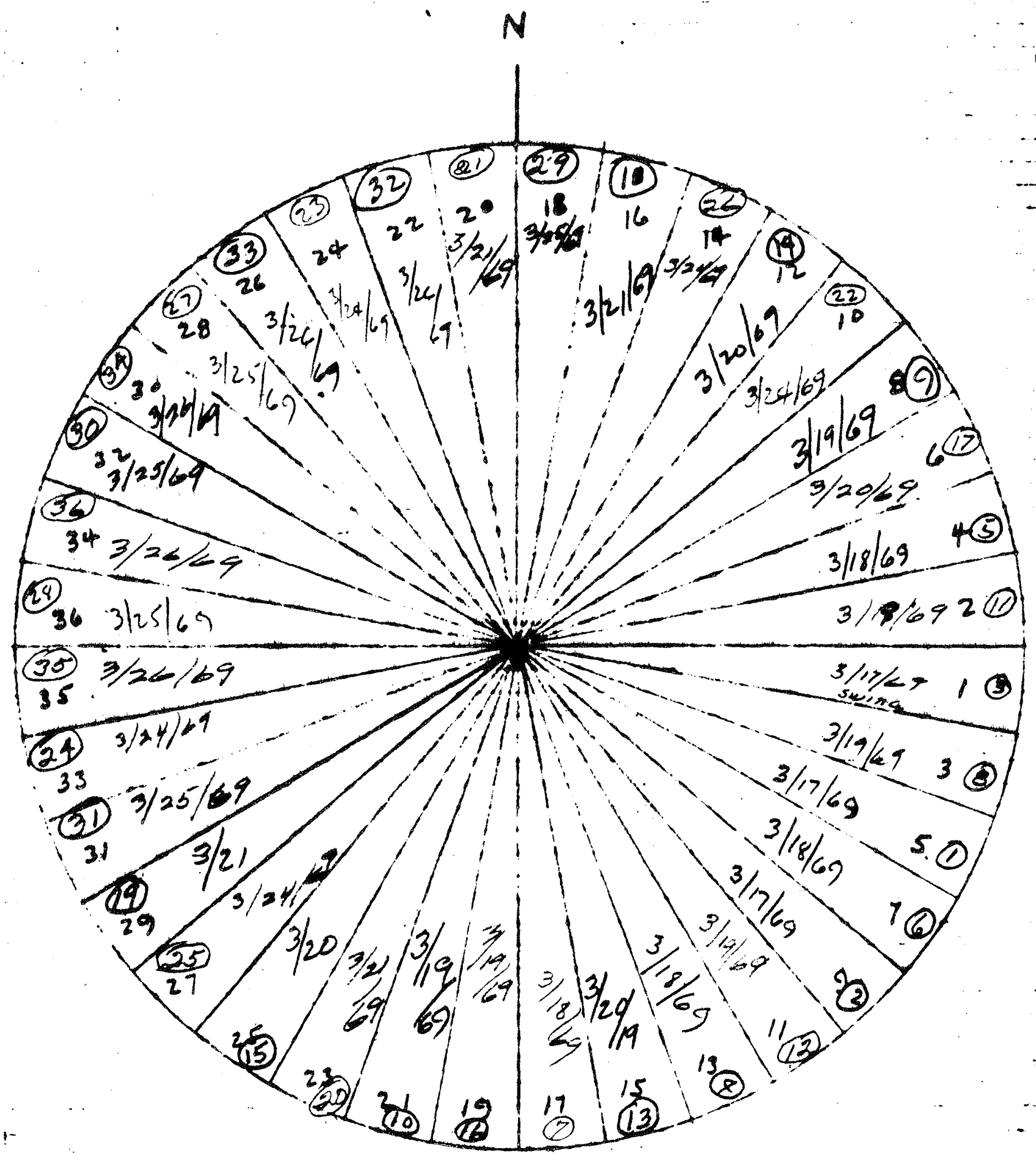




\section{Kalute Meanes - 3-24-69}

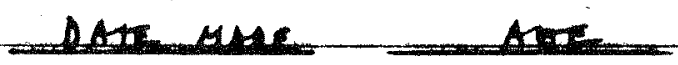

$$
3-17-69
$$

7

7

7

u

4

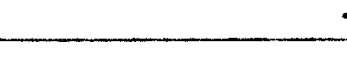

" (cyulume)

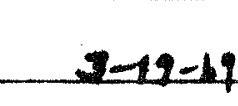

*

I

(4

4

$1-20-19$

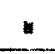

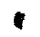

4

11

$3-21-69$

*

"

u

7

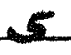

5

5

5

5

4

4

4

4

4

3

3

3

3

990

840

450

essude

sected

*

7

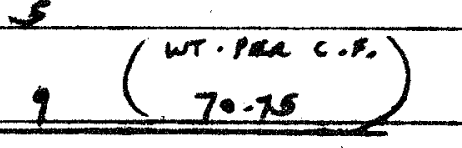

283

590

440

II

635

810

3

635

435

19

20

15

340

12

735

6

420

25

450

20

200

23

475

29

300

16 


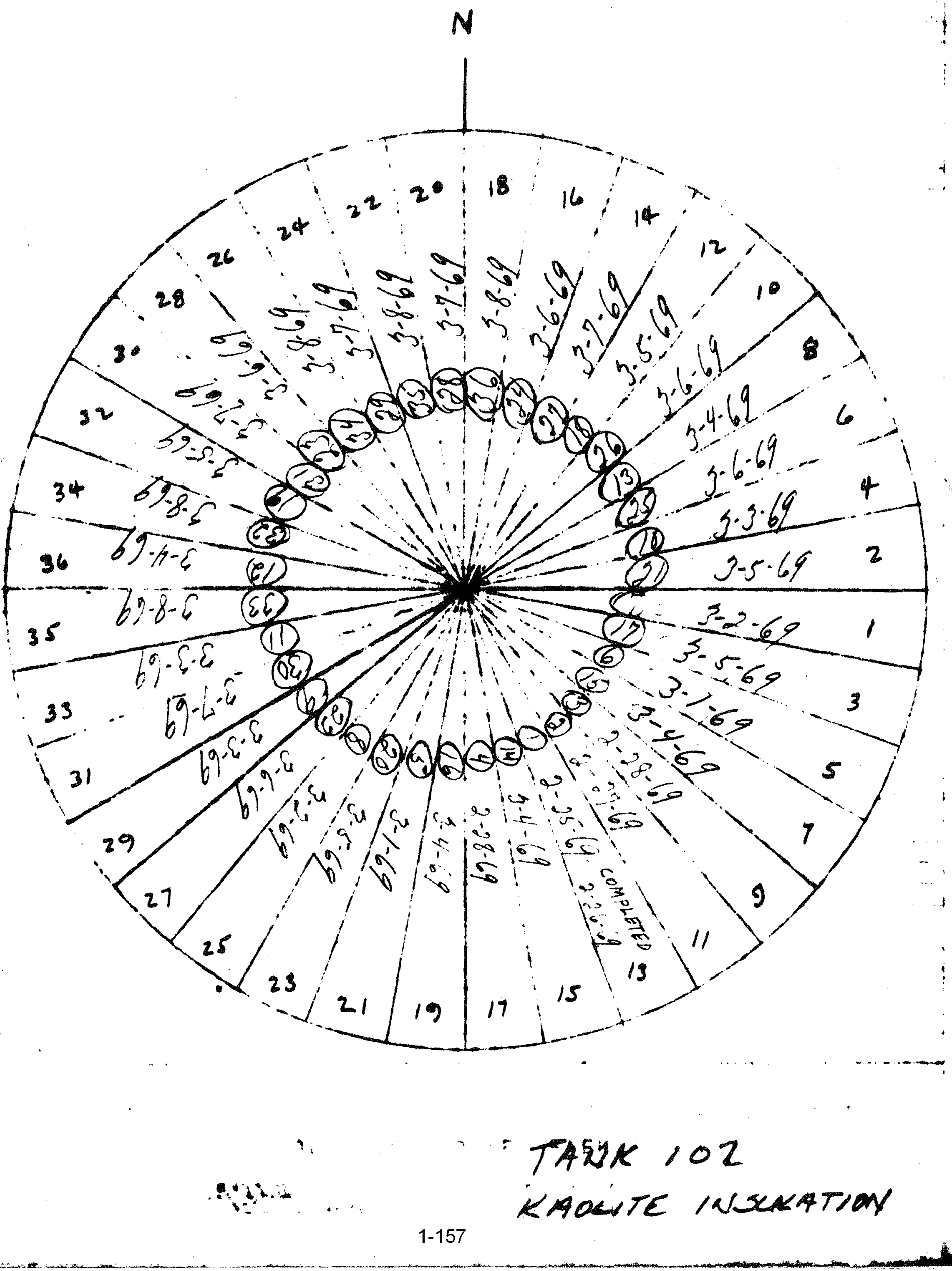




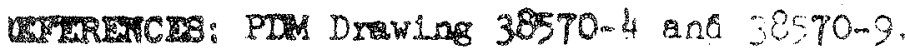

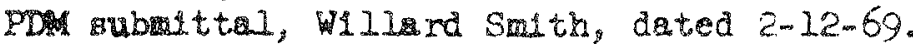

Dat:

Drat 2-2-64307, Rev. 2.

Spec1P1 cat10n HFE-T789, Pareqraph 9.0.

\section{D1ฐt 1but doa:}

WS Grave

CN Zanger

A. Short

ac Elie

TMWR DATA:

Battella . Evaluation of Krollte-2200.

\section{Requs rento}

1. Revien feature No: $^{7} \mathrm{~T}$ as a check on embeded meterials.

2. Conditions of environs pertaling to:

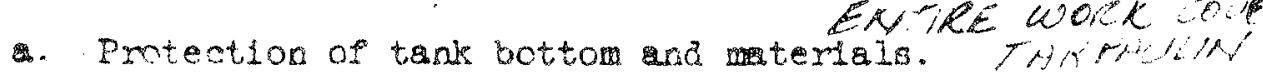

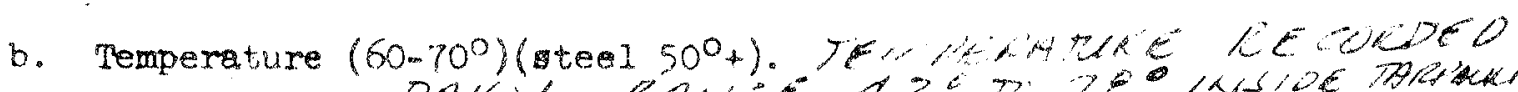

3. Formork:

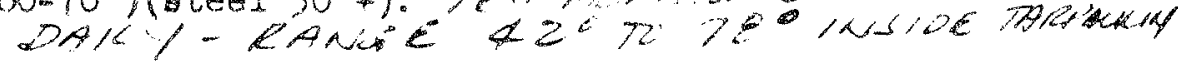

1. Matain minimum 1" under pipe and $2 \frac{1}{2} "$ over plpe thickness of 1 iasulation at the pour $4-1$ nch vent pipes. Ail other places -

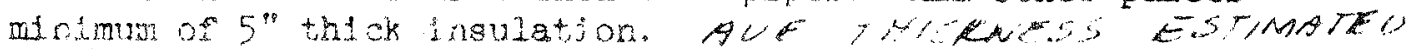
Mivindin? "

b. Jolnts configuration and reatment to malatedn etrength and therres characteristice.

c. Screeds and blockouts - a1 trenches and traingages.

t. Placement:

Pts.

a. Mixing - $78 /$ watier $/ 6-40$ bags (3 to 5 minutes). $15 \%$ ro 6 Got $/ 6,404$

b. Fach batch piaced withia 20 minutes - vibrator. AvefACE 7 rintas

c. Obtelia samples - one each 10 batches or minimum of five each day.

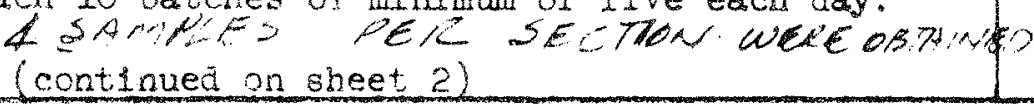

\section{OMARRS ANTO/OR EAFETY FEATURS}

- Wear hara hate, Gloves and eye protection.

3. Check air inside tank enclosure for polsonous grases.

3. Wear air filter wen near batch alxing operation.

tixercise care enteriag and exiting tank.

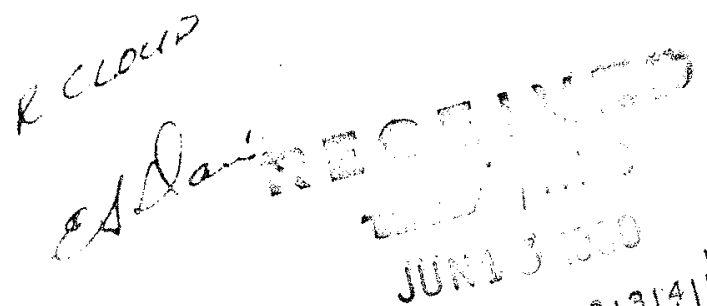


RPP-ASMT-53794

Rev. 0

VITRO-HES SALTY ASSURANCE

sheet 2

HaIrneT INP-614 - Contract AT (45-1)-2124

IRE . - 8- Insulation in bottom of tank. Tank 102 .

$$
\text { Requirements }
$$

(continued from sheet 1)

5. Curing:

a. Covered with moist burlap for twenty-four hour g - then air dried for ninety-six hours. AIR DIEIED TILC TEST NDICAR

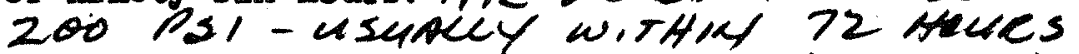

b. Tests - shall not be less than 200 pal (wet or dry).

3 day 4 day 5 day 6 day I day

Batch 1

Batch 2

batch $\neq 3$

Batch th $^{4}$

Batch 15

Batch 16 $2 A M P L E$

Batch $\# 7$

Batch $\# 8$

Batch $\# 9$
SERIES OF TEST RESULTS
ON FL

REsult ATTH

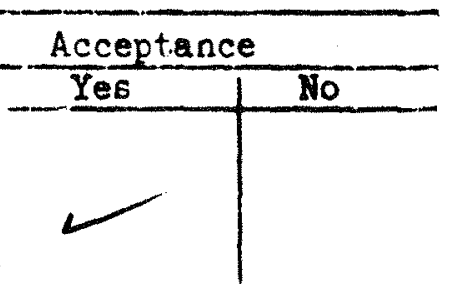

Acceptance

6. Repair - give nature and description of repair.

(a )-SURFACE CRACKS-IDZZMCAES DEEP

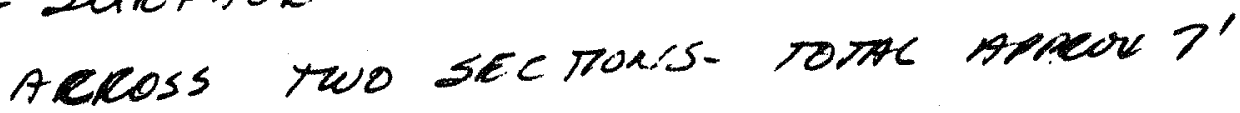
LONG. CIZACKS WERE DUG OUT $\triangle$ NOW MATERIAL INSTALLED.

CRACKS OCCURRED HS RESULT OF REEKING OR PLATE BENEATH.

(b) SURFHEE WNEVEN AND TOO HGGH$A$ IS' SEGMENT, W IE COINER CUMS $1 / 4$ "T $3 / 8$ " TOO HIGH. FINAL ELEVATIONS - voted on pom wa */o

1-159

h.

$A$ 
BAOWTE Banks-3-11-b

DAT MAR AEE

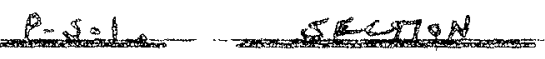
$3-4-1$

1

245

$+2$

38

7

$7 / 3$

19

3

1

80

13

$\frac{4}{3-8)}$

7

65

8

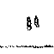

3

35

452

36

470

310

3

465

34

8

3

520

22

10

3

415

18 


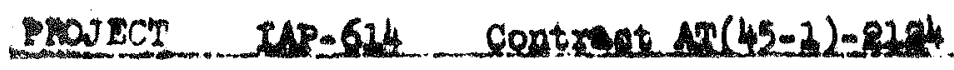

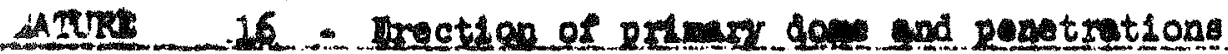

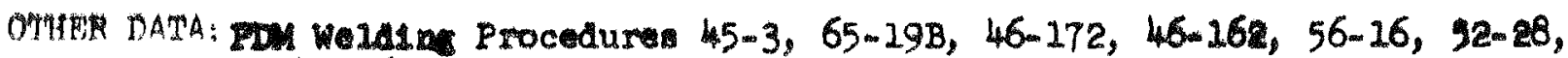
$55-49,60-112$. Welain Procodure Speciflation DN19-197.

Dut. 38570, theet $15,23,24,25$, through 15 . 15 .

Diat.e:

Freptred by:

1.6. Dart $6-10-69$

Irigigated by

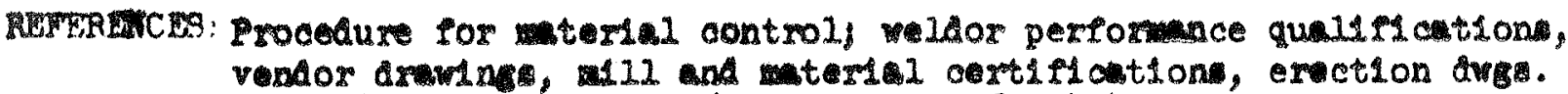

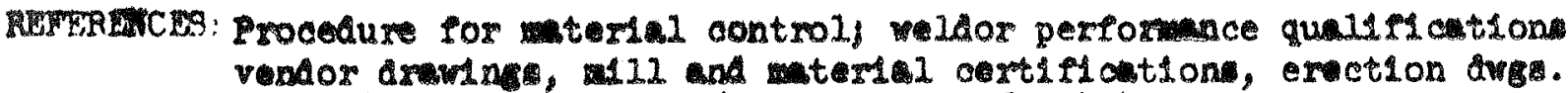
HWB-T789, Rev. 2, Per. 6.0, 11.0, 12.6, 14.4. Design Change 2124-16
Oct 16.965

Dist,rtbutión:

Tre Ore

CH rangar

A. Bhort

ac 1. (2)

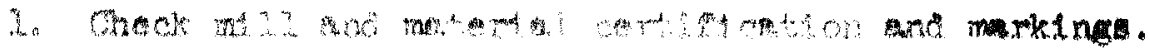

2. Pl.

b. [a

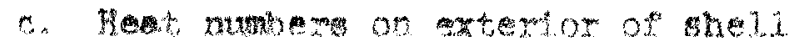

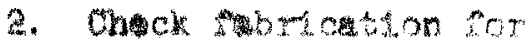

* Joint spacins

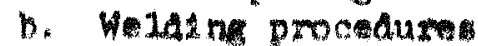

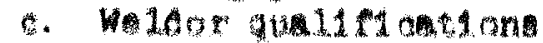

0. HoHIIna

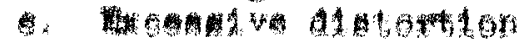

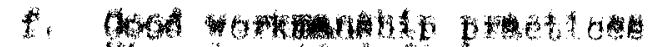

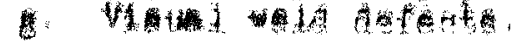

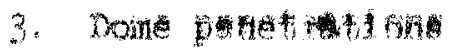

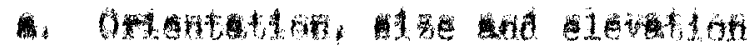

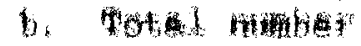

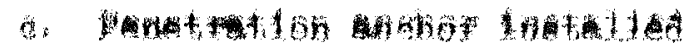

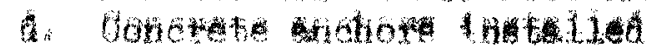

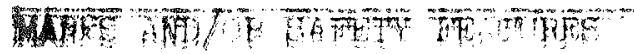

Requi remeats

Acreptance

YQ8 - KO

OK

21

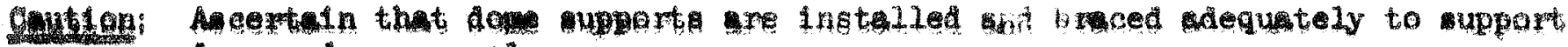
one peremel.

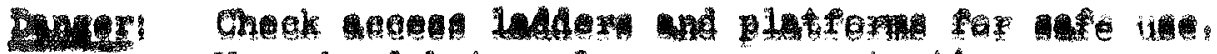

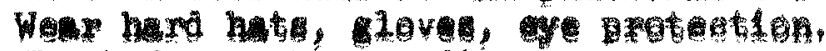

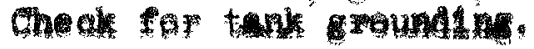




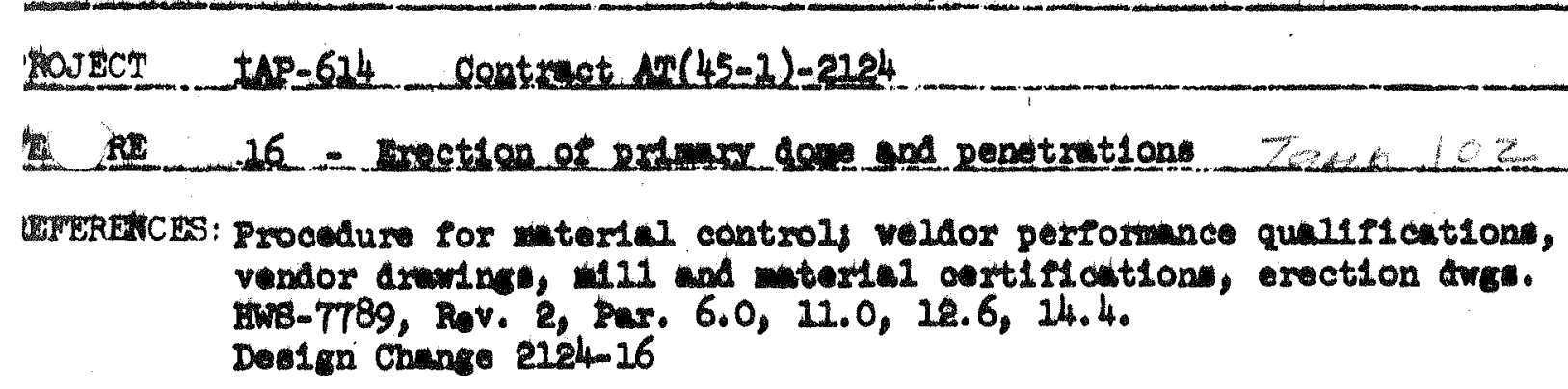

TTHFR DATA: PDM Wela1n Procedure 45-3, 65-19B, 46-172, 46-162, 56-16, 52-28, $55-49,60-112$.

Welding Procedure Bpec1lication DB119-197.

Dirg. 38570 , sheet $15,23,24,25$, through I- 15 .
Frepared by: 2.8. Dav110 $6-10-69$

Inghigted Det,e:

SEPT.24, 1965 Dist ribution?

WB Greves

CII Zangter

A. Short

$\infty$ Hile (2)

1. Check mil and material certiflcation and markings.
a. Plote teriul
b. Weld rod
c. Heat number on exterior of nell

2. Chock rubration for
a. Jolint pucin
b. Weldin procedure
c. Weldor quallet1 tion.
d. Hendilns
c. Dxcenture diutortion
1. Good rorkmandhi.p practices
B. Visual wold derect.

3. Dome ponetitions
a. Orientation, size and levation *
b. Total number
c. Penetrution anchor instilled
a. Concrete anchor Installed

Penetrations *6 (42") \& a (4") were INSTALLED DUT OF TOLERANCE BUT NO INTERFERANCE WAS ANTICIPATED, SO THEY WILC REMAIN THEEE REAPVS ANTOR SAFETY FE TITES

Cution: Ascertain that dome mpports are Installed and broced adequately to support dome and pertonnel.

Danter: Check access ladder and platrorms for afe use.

Wear hard hats, gloven, eye protection.

Check for tank grounding. 


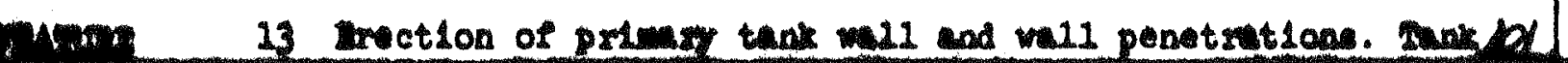

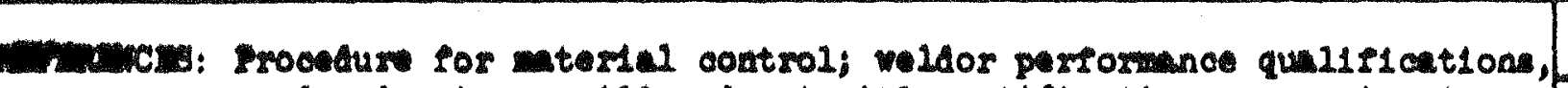

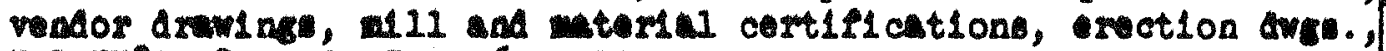
-7789, Nev. 2, Par. $6.0,11.0$.

1. Check mill and terial certifloution and markines.

c. Plate meterial

b. Wald rod.

D. Heat number on exterfor of nell.

1. Creok rabricution for:
A. solat pactins
b. Meldine procedure.
a. Weldor quilifications
4. Haling
-. Decentve dintortion
2. Good workmanth1p proticen
8. Shell penetration
h. V1 ural weld defects.

26 ACCEPTABLE MODIFICATIONS WEEE MADE IN WELD PROCEDURES.

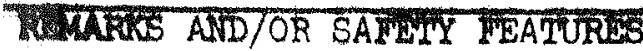

Dnser - Check accum Indder and platform for safe use.

itim

Wemp hard hat gloves, and eye protection.

Oheck gor tank grounding. 


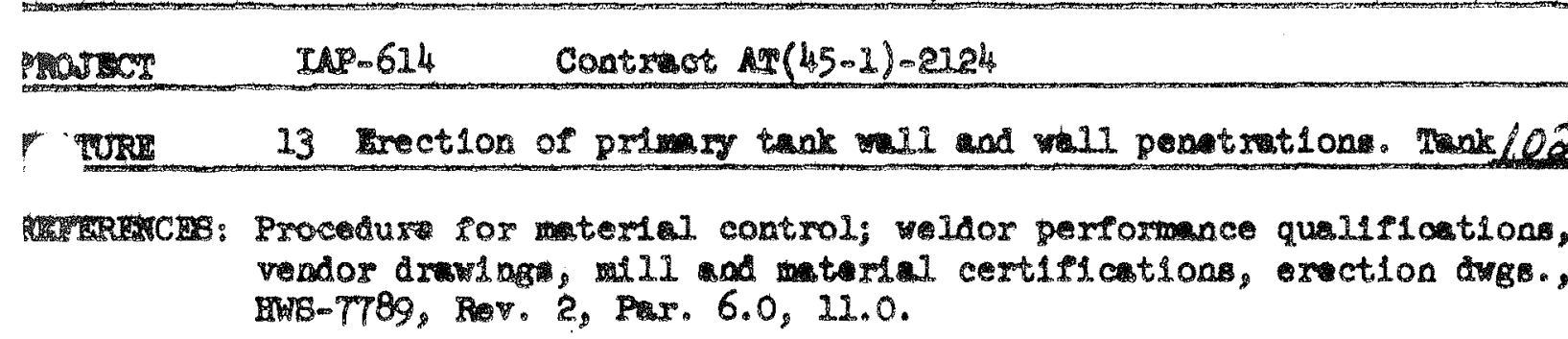

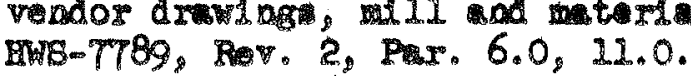

1. Check mil1 and matertal certiflcation and rages.

- Plate texplat

b. Id mod.

c. Heat nubere on extrextox of shell.

2. Check ontion for:

- Jolat apactas ok

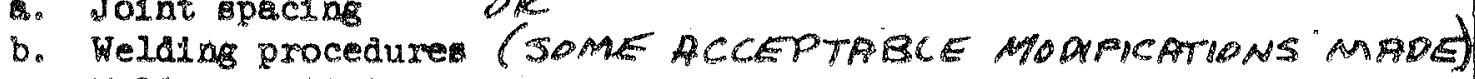

c. Weldor qual11 cations

*. Landilng

2. Bxcesalve alstortion De

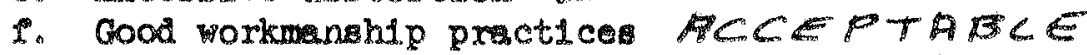
6. Shel1 penetrions

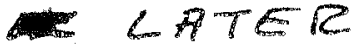

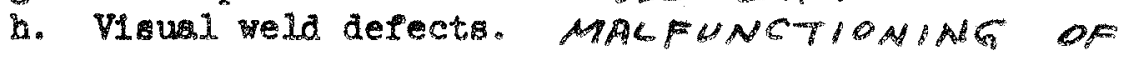

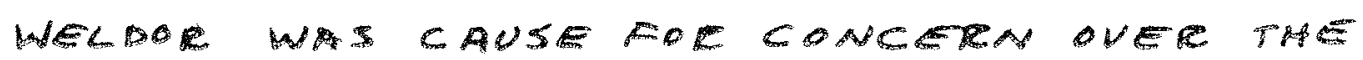

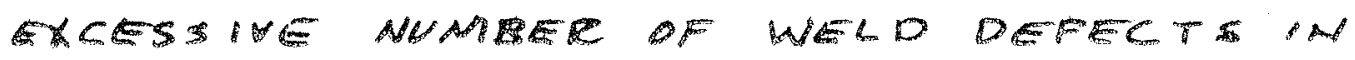

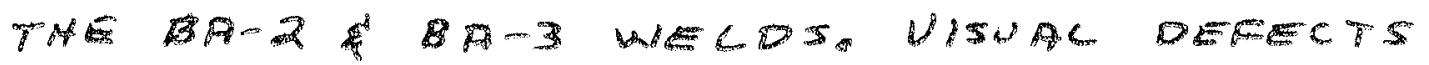

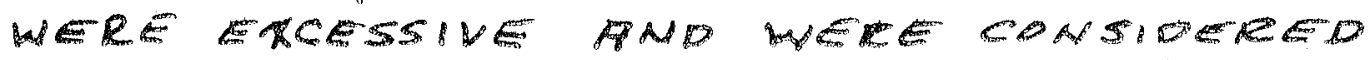

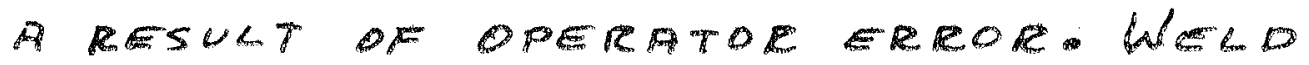

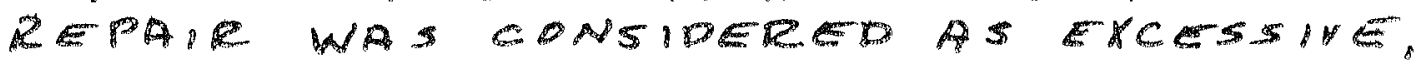

\section{WIRKS ANO/OR SAFETY FETURES}

Dager - Check sccess ladder and platioms for safe ure.

Weax han bats, gloves, and eye protection.

Theck for tonk groundiag. 


\begin{tabular}{|c|c|c|}
\hline Platet & $\operatorname{tap}-624$ & Contzect Ar (45-1)-2124 \\
\hline
\end{tabular}

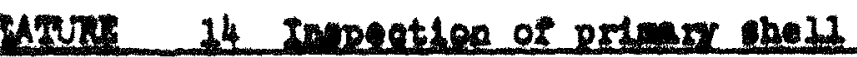

FW Ralosteph1c Procedure Re-1

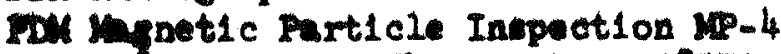

DWe. $38570, \infty$ 3 Dwe. 38570 Mx
Rasation sens -

HWB 7789 , Rev. 2, Section 12.0 Weld Inspection
Prepared by: Derle $6-12-69$

\section{TxNe}

Inspeted by: Date: Qci 12,1265 Distribution:

ms oraves

Cir zanear

A. Short

QC M1e (2)

\section{Requil rements}

1. Indosmph ell butt selds.

2. Chot for:

a. H.Im and $x-$ ray quality

b. Proper interpretation and marking of 11 la

c. nocordin of defects.

3. Impix 11 deroctive velds

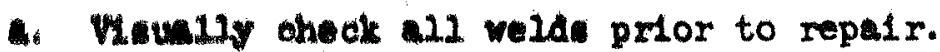

b. Aow in thet repalr procedure is acceptable.

c. Oheck and record $x$-ray llin of repal

4. V1

- Continuly dyeck testing equipent.

b. Reord powtion und locetion of tert.

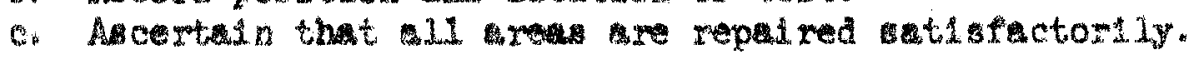

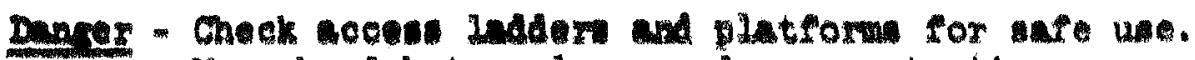
wear hast hate, clove and protection.

chook for tank grounding. 


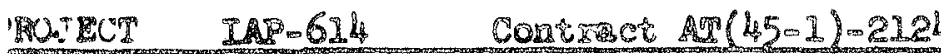

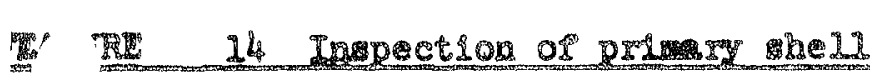

198 Davin $6-11-69$

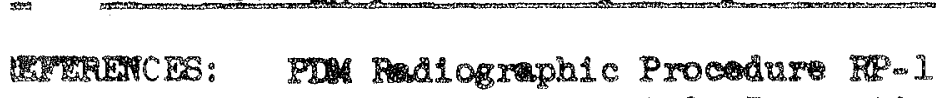

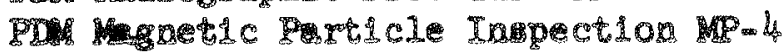
Dow $38570,-2,2$

Inspgcted by:

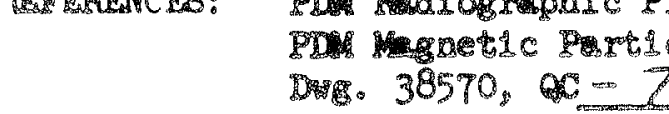

Date:

$5=97 \cdot 16,2968$

Distribution:

WS Crave

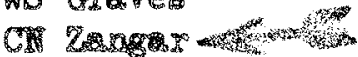

A. $500 x^{\circ}$

ac 12

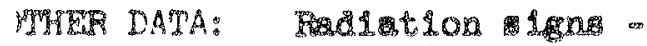

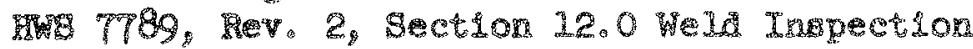

Aroulrements

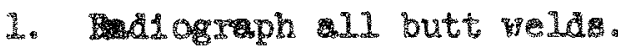

2. Gocks:

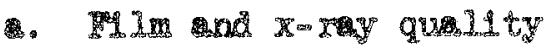

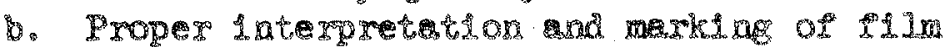

c. Recording or derects.

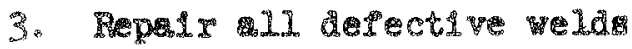

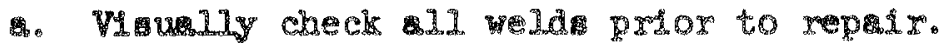

b. Acertaln that ropal procedure 1. acceptable.

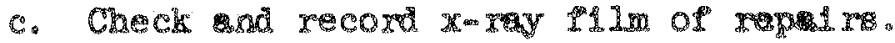

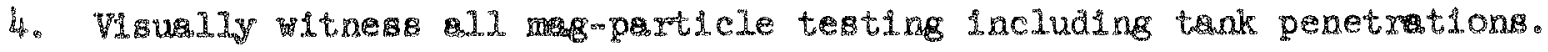

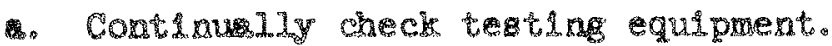

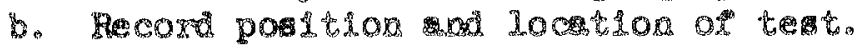

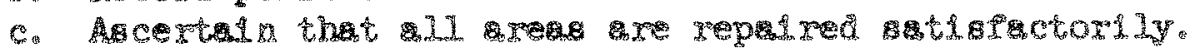

Derger - Check acces ladder phatom for sale vae. Wear har hot, glover and gye protection

Check ros tank ground Ing. 


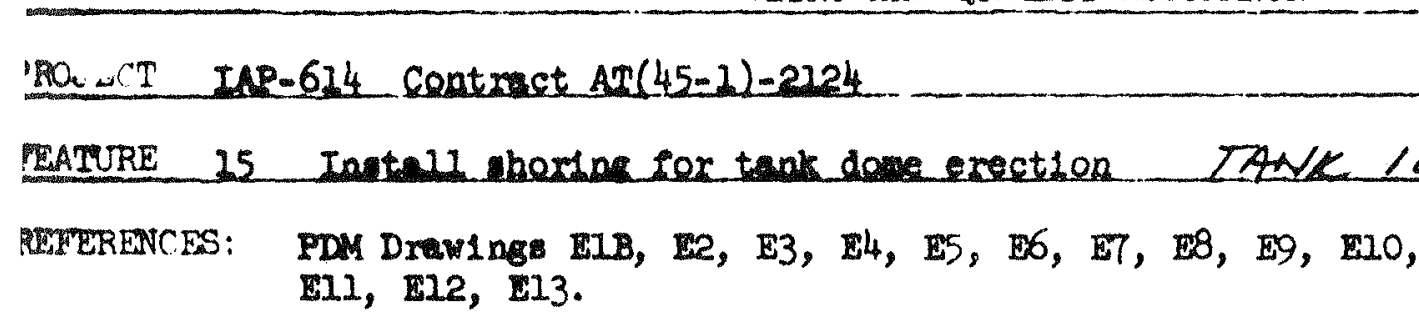
E11, E12, E13.

1. Witnes that contractor exerts care in placing and assembling support system inside tank.

2. Check location of supports.

sew that correct bases are used for dome erection and concrete placement.

4. Bethet carfolding is installed on support system for safe personne 1 use.

5. 5o that crous-bracing 1s tightened for erection of dame, loosened for

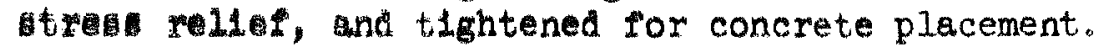

6. Check tank bottom for needed repalr where oupport columne are to be Jocated.

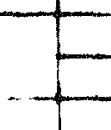

Acceptance Yeis

to

No

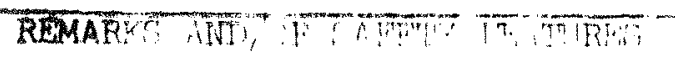

Caution: Ascertain that dome supports are installed and braced adequately to support dome and personnel.

anger: Check acces ladders and platforms for safe use. Wear hard hats, gloves and eye protection. 
Rev. 0

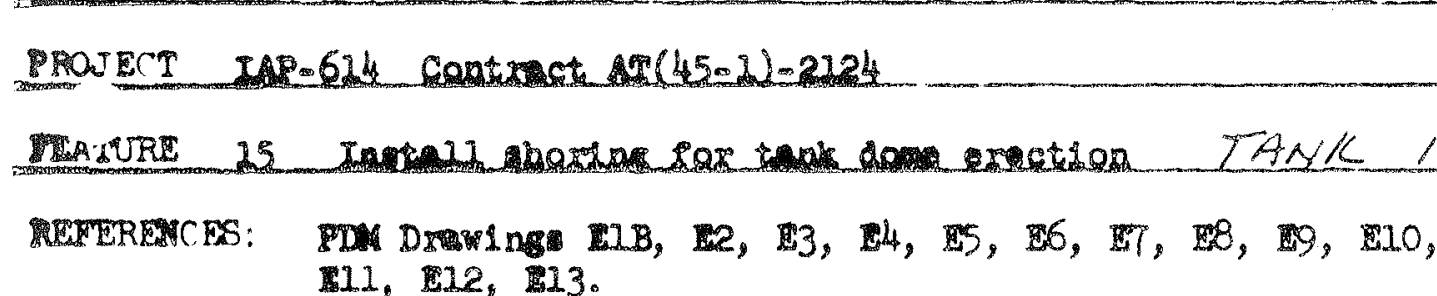
11, 12, 핑.

OTHER DATA: HWS-T789, Rev. 2, Pregreph 17.0.

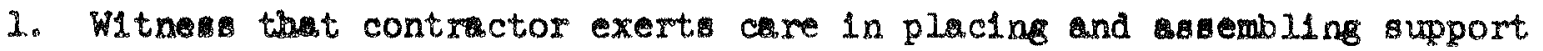
yyt in ido tank.

2. Check location of upports.

$D R$

3. Soe that correct bases re used ror dome exection and concrete placent.

$O K$

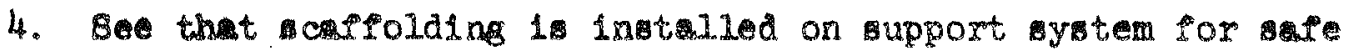
peronnel use.

A. ghort

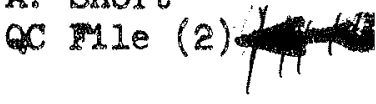
As $z a-7.69$

WB Grises

CN Zansex

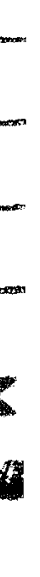




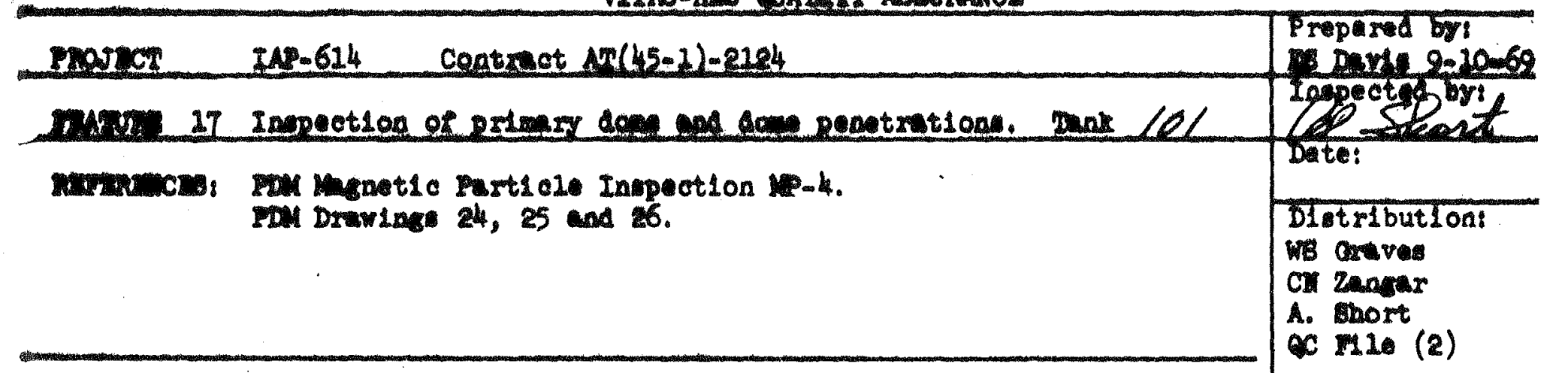

OTHWR DATA: EHB-T7B9, Paresrahe 12.5, 12.6, and 14.5

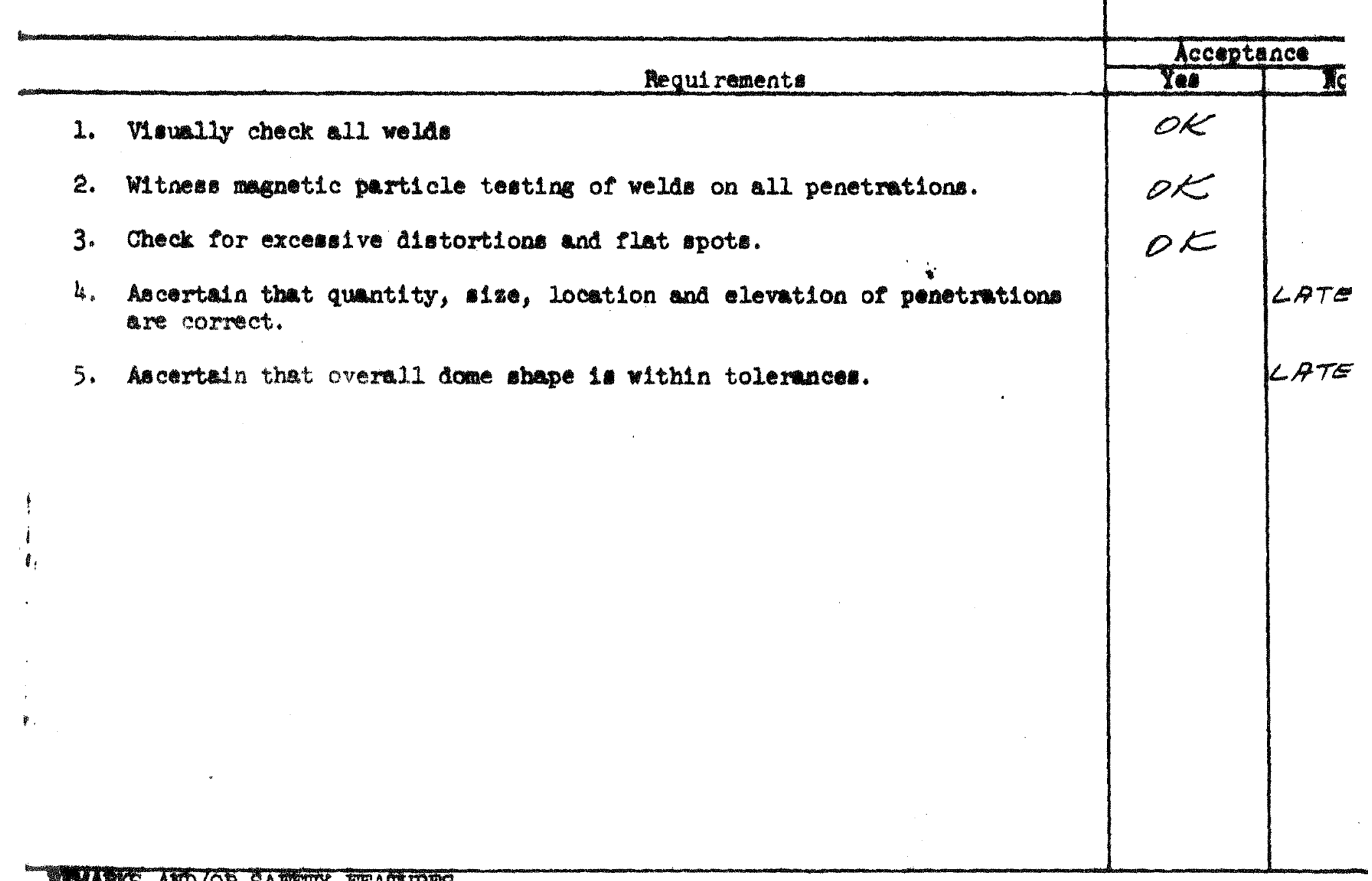

NUTKRS ATD/OR SAFET FEATTRES

Ceut1on: Ascertin that dome spport are 1notalled and breced adequately to support dome and perfomis.

Danger: Check ccest Iadder and plattorms for safe ume.

Be very cautlous around openings in dome.

Wear har hats, glove and rye protection.

Check for tank rounding. 


PNOJIC IAP-614 Contzet AN(45-2)-2124

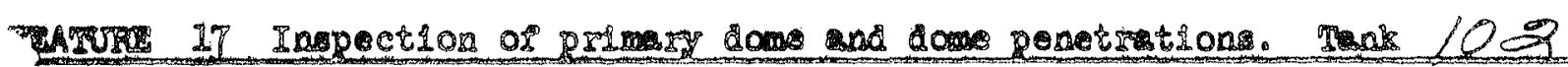

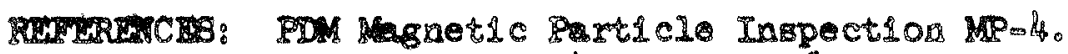
PD D Ings 24. 25 ad 26.

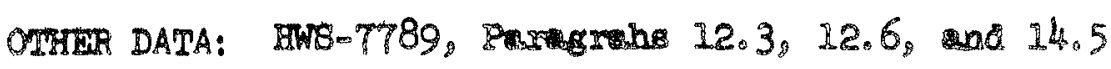

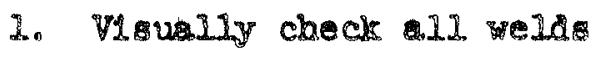

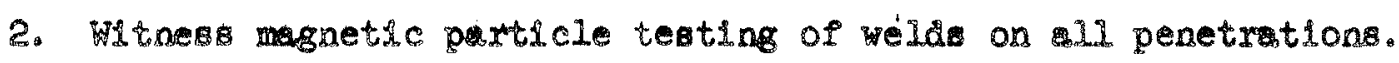

3. Check Por excessive distortion and Ilst pots.

4. Asceralo that quantity, ste, lochtion and levation of penetrations ine costect.

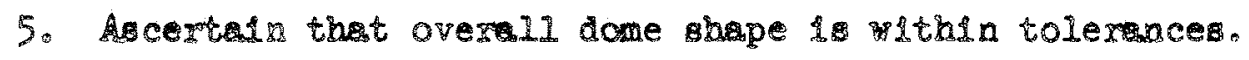

Caut1on: Ascertain that done supports are 1natalled and breced adequately to support dome and personinel.

Denger: Check access ladders and platrorms for safe use.

Be very chutlous round opentage in ome.

Wes har hats, glover and eye protection.

Coeck ror tank grounding. 


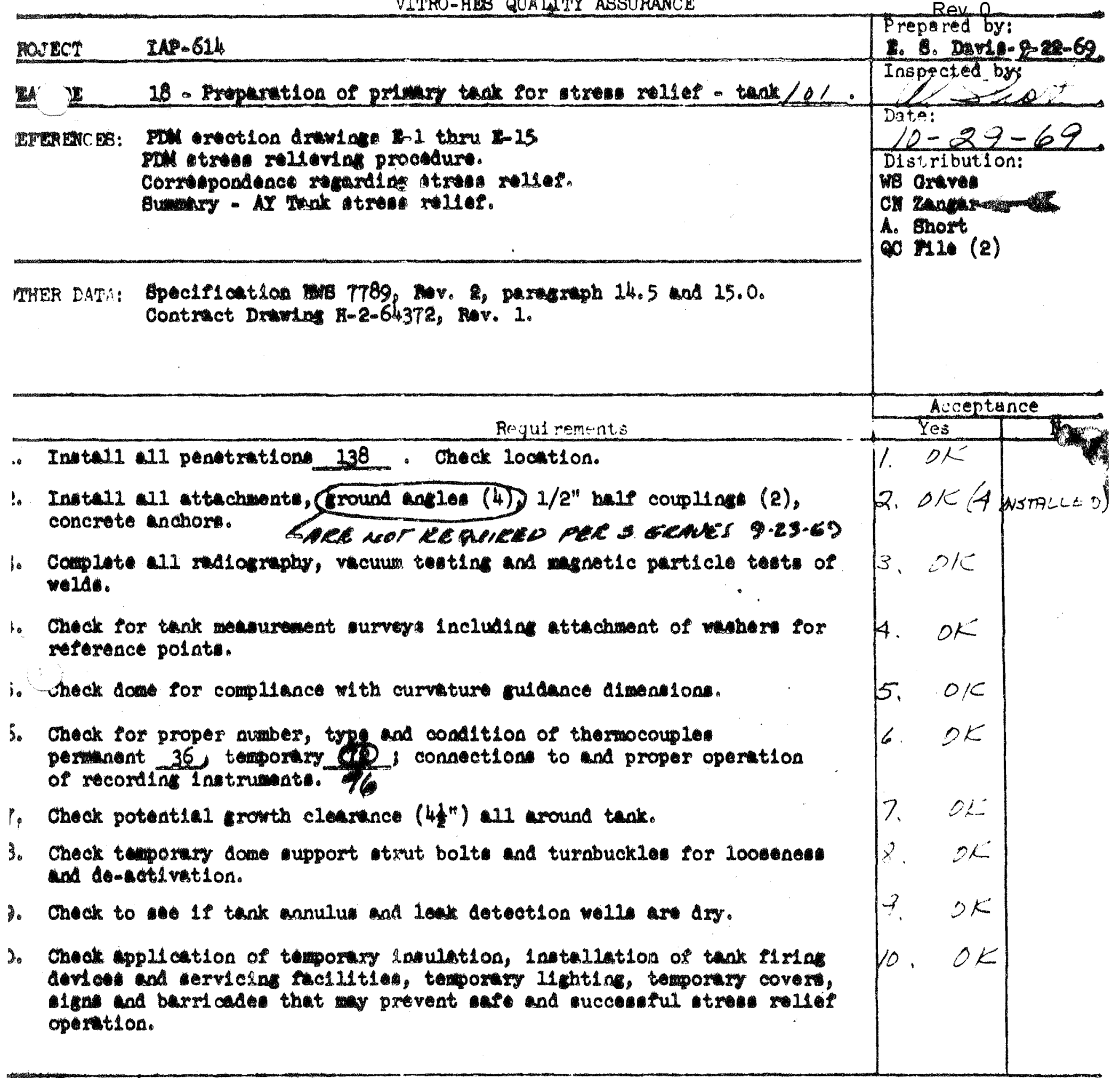

WUMRKS ANT/ R CNFETY TE TRI:

woar hard hat, love and protoction. Cheek 11 caffolde, 1ndder,

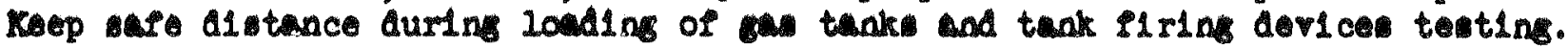

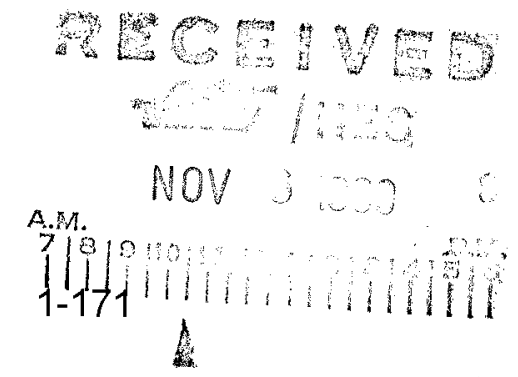




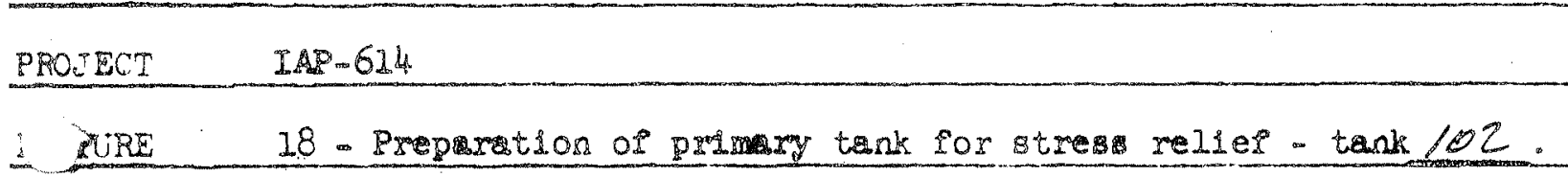

REFERFNCFS: PDM erection dratag E- I thru E-15 PDis stres relseving procedure. Correspondence regarding stress relief. Summary - AY Tenk stress relief.

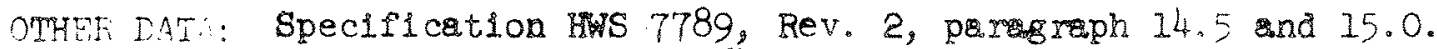
Contrect Drwing H-2.64372, Rev. I.

Rirui rementes

1. Install all penetrations 138 . Check location.

2. Install all attachments, ground angles (4) $1 / 2^{\prime \prime}$ half couplings (2), concrete anchors.

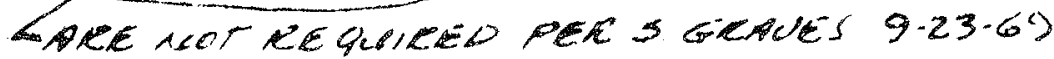

3. Complete all radiography, vacuum testing and magnet1c particle tests of welds.

4. Check for tank measurement surveys incluaing attachment of washers for reference polnts.

5. Check dome for compliance with clirvature guidance dimensions.

6. Check for proper number, type and condition of thermocouples permanent 36 , temporary 72 ; connections to and proper operation of recording instruments.

7. Check potential growth clearance ( $\left.4 \frac{1}{2} "\right)$ all arouna tank.

8. Check temporary dome support, strut bolts and turnbuckles for looseness and de-activation.

9. Check to see if tank annulus and leak detection wells are dry.

.0. Check application of temporary insulation, installation of tank firing devices and servicing facilities, temporery lighting, temporary covers, signs and barricades that may prevent sare and successful stress relief operetion.

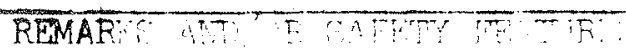

Wear hard hats, gloves and eye protection. Check all scaffolds, ladders, walkways for proper installation prior to personnel use. Keep safe distance during loading of gas tanks and tank firing devices testing. 
RPP-ASMT-53794

Rev. 0

February 27,1969

W.S. Graveg/E.E. Smith

Max Schulz

AY Tanks IAP-614 -18

On 2/13/69 Jerry Semershein called and asked whether he could use A285, Grade C material for the Packing Compression Ring, Drawing 1-2-64448, Revision 2, Detail 28, zone C-10. I told bim titis would be ok.

On 2/14/69 Eermershein called to ask if he could use API gL pipe for the 30 " Sch. 10 pipe shown on Drawing $5-2-64419$, Revision 3 , Risers Mo. 2 and 3 , Zone $\mathrm{E}-2$. I told him this would be or.

$\operatorname{Max} \operatorname{Schujze}$

MS: da

ce: CW Carctzela

G. KA\&tileid

M. Schulze/File

Zangar/Qt Fe i

$1-173$ 


LIAS IASE14

repared by:

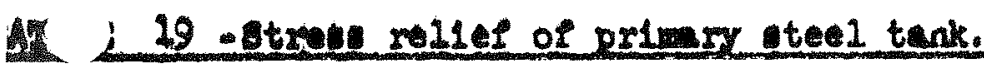

mank $20 \angle$ L. B. Dav1 $9-23-69$

Winces:

EDA trese relleving procedure

Insected by

D1stribut1on:

Ws Grave:

CI Zangar

A. Bhort

QC Flie (2)

HeAR DATA: Bpecle1cation wis 7789, paragraph 15.0

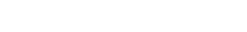

S2 Requi remente

1. Verify that 108 the rwocouples ar operating and that the temperature of oach is road and cecorded every 15 minutes.

2. During beating-up period, the aximum temperature alferential may not vary more than $200^{\circ} \mathrm{y}$ between any two areas. Verify.
3. Above $600^{\circ} \mathrm{y}$ the of heating or te of cooling not exided $100^{\circ} \mathrm{y}$ per hour. verify.

4. Holding twerture remain at $1150^{\circ} \mathrm{y} \pm 50^{\circ} \mathrm{F}$ for perlod of one hour. VErlfy. HLL THEEAMOCOUPLES EXCEEDED $1000^{\circ} \mathrm{F}$, AND THAT TEMPERATURE WAS HELD FOR 4 HOUES,

5. Observe and/or note comments pertalning to the following:

\section{a. Signe and barricadeo}

b. Number and apparent purpose of personnel at the immediate ite.

c. Any noticeabie difliculty with Plring mechanitum.

a. Any not I ceable fumes, moke, $f 1$ re, or other heat-genereted phenomena.

- Any noticesble movement of 1 neulation.

1. Any thernocouple or Instrument fallure.

g. Unumbal growth or movement of tank.

* C. SONE DIFFICULT" WAS EXPERIENGED KEEPING Z

BUENER IGNITED PILIR TO ACTUAL STATTTUD.

LATERT THE PRODANE TANKS EROZE MUN CEDUES:

LWE WKE SUUES SO THAT DIFFICULTY WASEYTERIEWESD

IN MGINTH NO THE ATTHINED TEMIERATURE.

\section{WULE AND}

wear hard hats, cloved and eye protection.

When in the 1mmediate viclnity of the tank, have attundby person observing your actions. Do not lolter in the immediate ares of the tank.

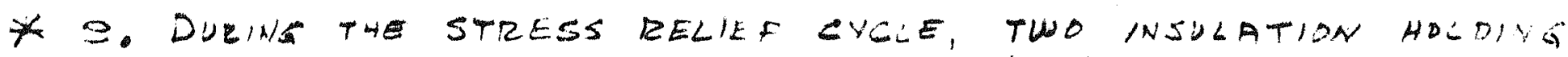

$$
\begin{aligned}
& \text { BANDS BEBKE IS D EESULT OF THETEMAL GEOWTH DF THE TANK, } \\
& \text { f. SOMEKHAT ERZATIE READINAS WERE OBTONED FROM A FEW } \\
& \text { THEEMDLOURLES W THE KADLITE. A WIDE RANGE DE } \\
& \text { TEMPERATURES KIAS ALSD EXHIBTED BY THE SAME } \\
& \text { THERMOCOUTCLS, } \quad 1-174
\end{aligned}
$$




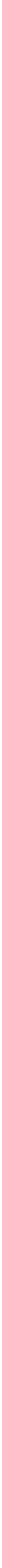

\section{WARKS AND/OR SAFETY FEATURES}

Wear hard hats, gloves and eye protection.

When in the Immediate vicinity of the tank, have a standby person observing your actions. Do not loiter in the immediate area of the tank. 
RPP-ASMT-53794

VIURO-HES QUALITY ASSURANCE

Rev 0 set 2

PROJECT

5. MURE

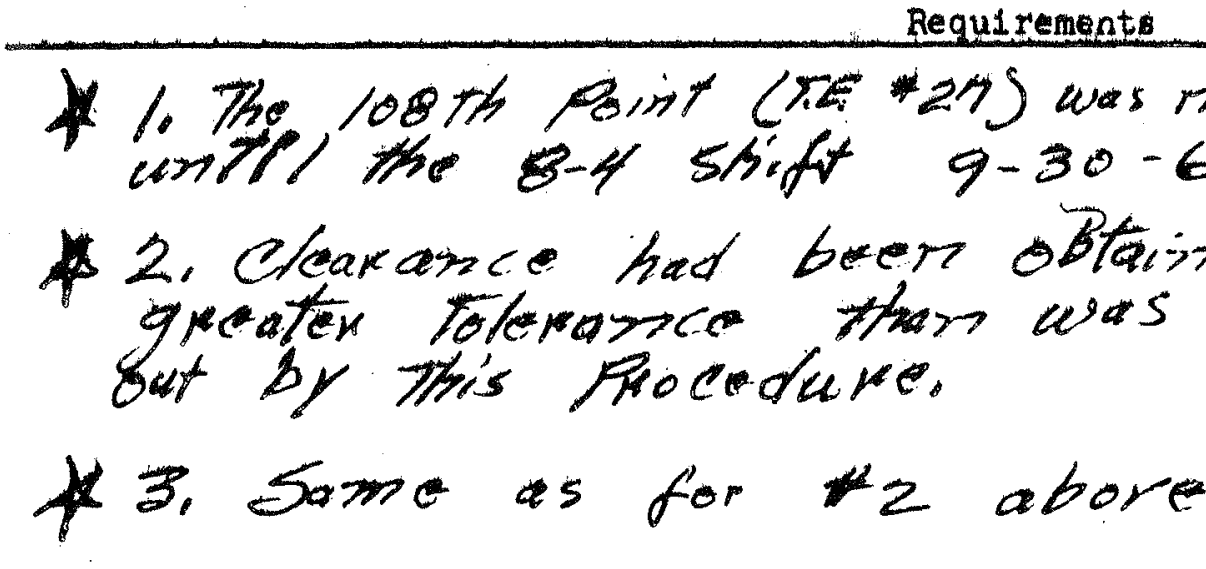

4 4. This requirement was modified accept a widen spread \& hold the temperature on the vessel for a longer tire. Thee hours for this instance.

K 5 ,

(a) signs and barricades were ntimimal

(b.) number and Purpose of Personnel at the immediate site was winberinble at times.

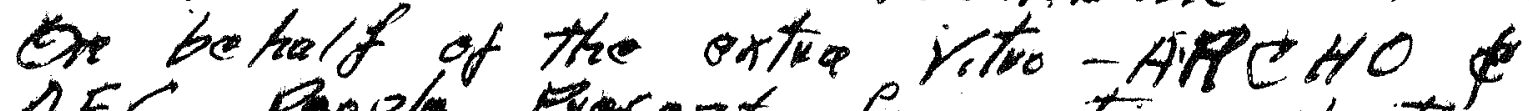
AEC poop le present furn time tr time it could be said that they all were 'help got the work done.

(c) firing equip Controls were not put Through dry kun s, in a manner of allow trouble fore operations

(d) $O K$

(e) ok

(8) - Assuring that the hot Junction's of the

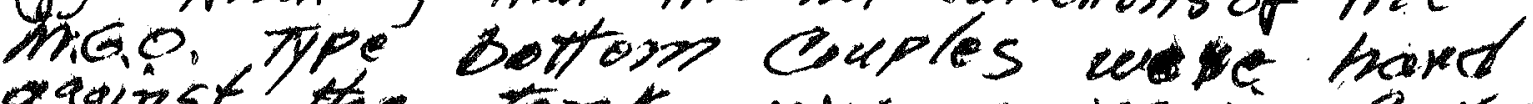
against the tank, was \& major Cause i Concern \& pRobable temperature nincording exp or A small ain gap, ore w the short temp rise Time acCused question able results Tin: *26 \& 27 were be ld against the skin

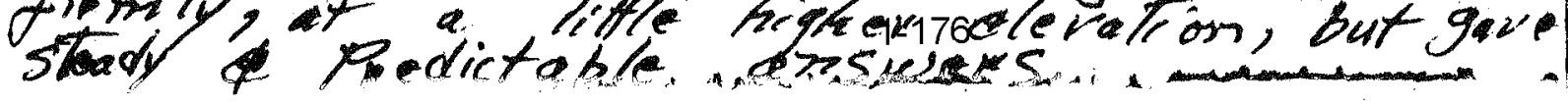


RPP-ASMT-53794

VITRO-HES QUALTTY ASSURANCE

$00 \times 3$

PROJECT

F. URE

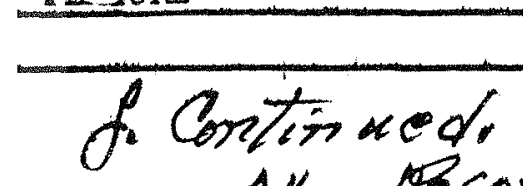

All Pecorders Parformed very well. chart utoll aligsnment Caubad a few spots of mal printiong as did bits of forcian material on the Selector swiches. RPM. Should heep Repes $\$$ /on other items clear, so recorder doors can be opened Propexly for Chant or lecorder mainten arce,

The Frtive Pecorder Case assembIy would be \& Should be out sereral foef from the tonk "walls t Poxmit easy acecss to the park consections, wher efrecking is requined. (G) OK.

AT. $500^{\circ}$ ABOUE AMEIENT AT ELEUATION 654.83 TANK ELPANOED N-S $25 / \% "$ ", EU, $2 \%$

AT $1150^{\circ}$ ABOUE AMBIENT. AT ELE UATION 654.83 TANK EXIDANOED W-S 7\%", EU 7\%"

CHACTS FIZON RECORDEIC WEILE SENT TO PITSBUKG BY CONTEACTOR

$1-177$ 


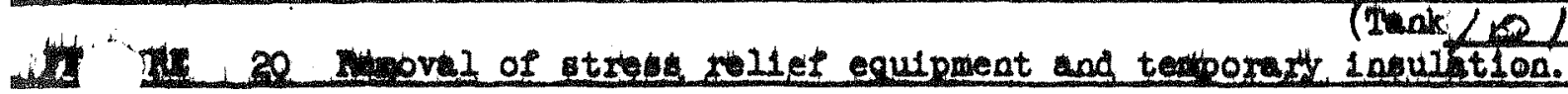

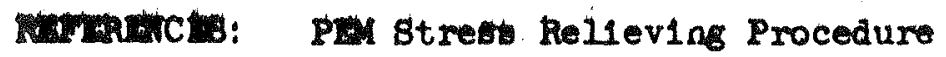

1. Shercise care to prevent damage to perment thermocouples and wirlag. All wirlog is to be returned to the original protective boxes. *

$D K$

2. Require that all temporm inmulstion be removed from the annulus.

3. See that annulue pace is thoroughly cleaned.

4. Conduct eritical examination of the interlor of the tank.
- Dxcesive oxidation NONE
b. Impingenent of flame on metar surece NONE
c. Irregularities in tank conflguration $N O N E$
a. Crecks
$N \mathcal{N E}$

5. Whes survey of interior tak dimendions.

6. Check propane tanks and IInes for pressure andor lowkge. CARELESSNESS. THEY HAVESINCE BEEN R PATR DD.

\section{R-IARK AND/OR SAFLTY WEATRES}

1. Wear herd hat, gloves, and eye protection.

2. Have assurance that ix in tank is clean and askfe to breath.

S Check ladders and scaffoldiag for wafe use.

4. Enter tank with care and lways in the presenes of another person. 


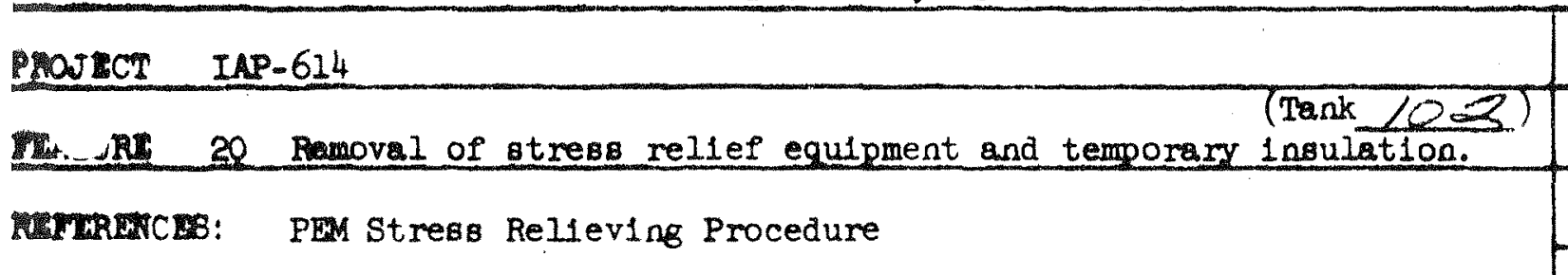

Prepared by:

E.S. Devis $10-3-69$

Ingqe ged by

bate:

Distribution:

WS Graves

CN Zangar

A. Short

QC File (2)

OTHLR DATA: Speciflcation HWS 7789, paragraph 14.0

\section{Acceptunce}

Requil rements

Yes

$0 / C$

All wirling is to be returned to the original protective boxes. *

2. Require that all temporary Insulation be removed from the annulus.

3. See that annulus space is thoroughly cleaned.

4 Conduct critical examination of the interior of the tank.
a. Bxcessive oxidation
b. Impingement of flame on metal surfaces
c. Irregularities in tank configuration
d. Cracks

5. W1tness survey of interior tank almensions.

$$
\text { (NOT WITNESSED) }
$$

$O K$

$O K$

6. Check propane tanks and lines for pressure and/or leakage.

* number 4 thetrmocouple (n the tank foundation) WAS DESTCOYED DURING STRESS RELIEF BY A $110 \mathrm{~V}$ WIRE FROA PDW STRESS LELIEF EQUIP. BEING ALLOWED TU SHORT OUT ON THE THERMOCOUPCE SHEATH AND BUIMING THROUGH,

\section{RUMIRKS AND/OR SAFETY FEATTRES}

1. Wear hard hat, gloves, and eye protection.

2. Have assurance that air in tank is clean and safe to breath.

Check ladders and scaffolding for safe use.

4. Enter tank with care and always in the presence of another person. 


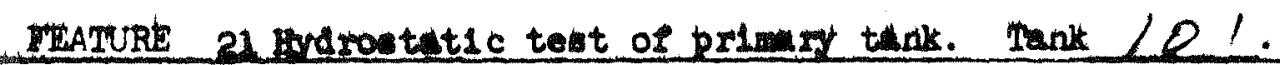
REFERENCES: FaI Drawing - He

WB Gatives

C. 2ingar-

A. Bhort

ac IIIe (2)

OTHER DATA: HWS T789, partraph 16.0

\section{Requi rements}

1. See that four vessel penetration are blanked closed.

2. M1l tank to a depth of $39^{\prime} \pm 1^{\prime \prime}$.

3. Coat all accensible welds with blue chalk.

4. Inspect all coated veld for leakage after a nolding period of 24 nours.

5. Hote any new irregularities in tank conflguration.

1. Wear hard hats, Ploves, and eye protection.

2. Check scaffoldiog in anoulus before using.

3. Enter annulus only when other personnel are present. 


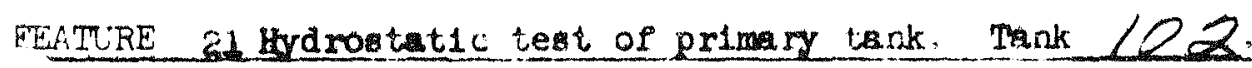

REFERENCFS: POW DNWInR - FE?

E. S. Dev18 10-3-

Inspegted by:

inte:

Qri. 15,1462

Nistrihution:

WS Graves

CN Zangar

A. Short

ax FIle (2)

IMHER IATA: HWS 7789 , peragraph 16.0

\section{R: $111 \cdots m \cdot m=$}

See that four vessel penetrations ate hiaked ciosed.

$\therefore$ Fuli. tank to a depth of $39^{\circ}+$.". $^{\prime \prime}\left(39^{\prime}-10^{\prime \prime}\right)$

- Coat ali accessible welds with tiue chalk.

- Inspect alj coated welds for leakage apter a bolding pertad of 24 hours.

Note any new irregularities in tank configuration. (NONE)

KAOEME INSULATINE CONELETE IS SOMEMHAT

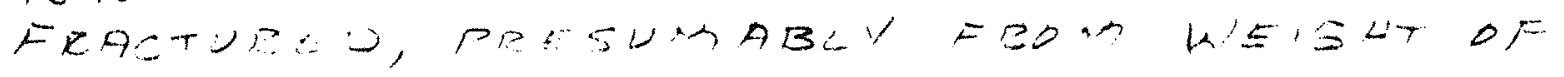
WATER USED IN HYDEO.

Wear hard hat cioves, and eye protection.

Check scafiolding to annilus before usting.

Erter annulus only wives other personnel are present. 


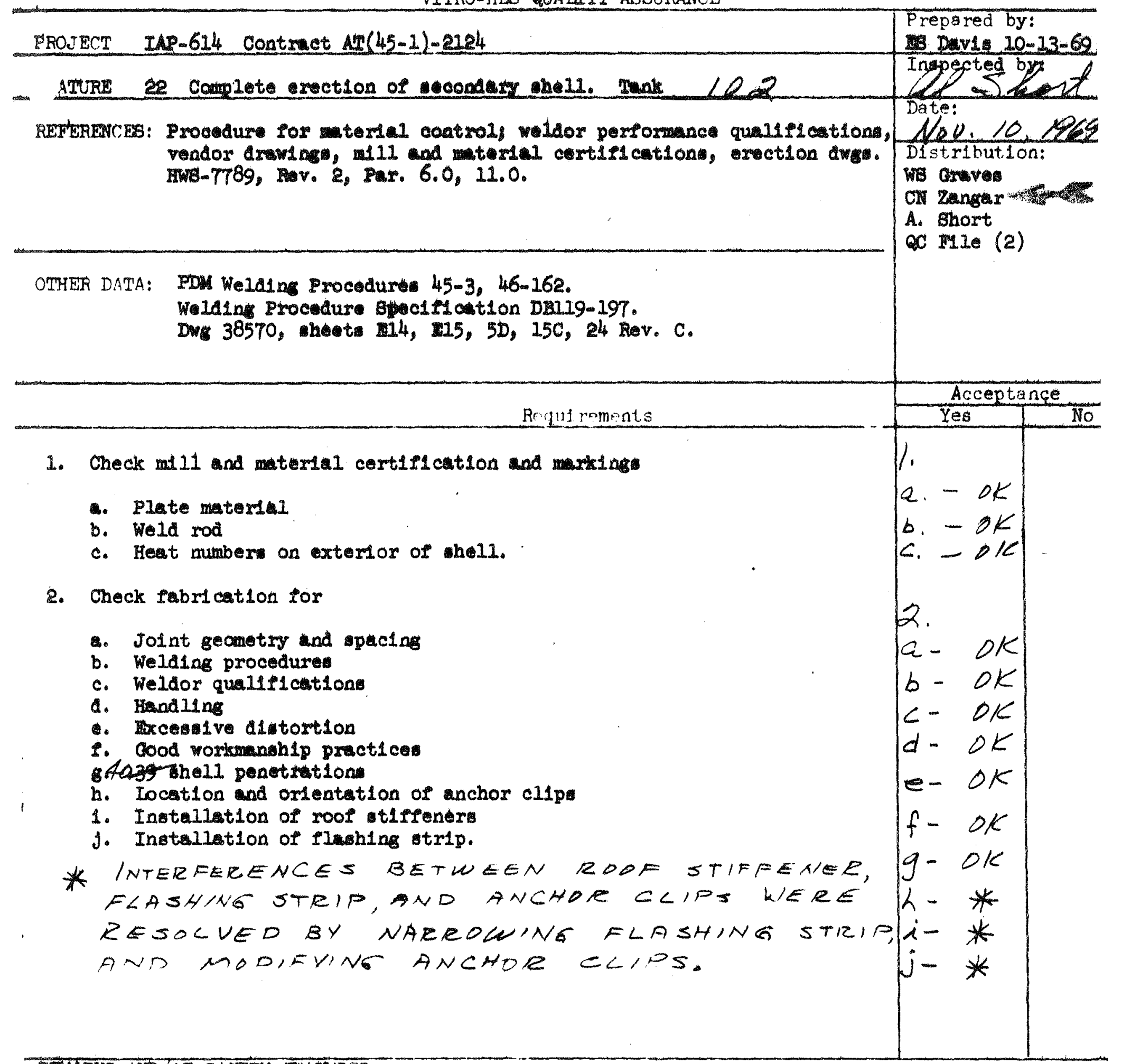

Danger - Check access ladder and platforms for safe use. Wear hard hat, gloves and eye protection. 
Rev. 0

PRO.TECT IAP-614 AAC-9075

E URE (23) placement of concrete over cone - tank $10 /$ ZNe PouR

REFERENCES: DWgB. H-2-64310, Rev. 0; H-2-64311, Rev. 0; H-2-64312, Rev. 0; Revised sketch, dated 10-30-69, supplementing Dwg. H-2-64312, Rev. 0 . Specification HWS 7791, Rev. 1
Soule Steel Company drawings $\mathrm{E}-2$ Soule Steel Company drawings E-2, E-3, and E-4; cut oheets 2 thru

ES Dav1s 11-5-69

Inspected by:

SEE SLCOW

Date:
$12-29-69$

Distribution: WS Graves

OTHER DATA: ACI 318-66, AWS D12.1

6.
CN Zangar

A. Short

QC File (2)

1. Check dome support pads; see that support $X-b r a c 1 n g$ is tightened.

2. Check dome, existing concrete and relnforcing steel for cleanliness.

3. Check placement of reinforcing steel.

$$
12-16-69
$$

SEENORE

a. S1ze and number of bars

b. Clearunce from dome steel

c. Add1tion 1 relnforcement around penetrations

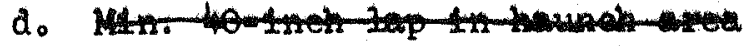

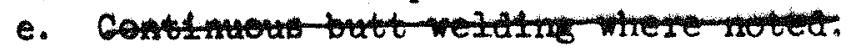

4. Check formork.

$\left.\begin{array}{l}\text { allgnment } \\ \text { b. Tle rods and bracing } \\ \text { c. Construction jolnt. }\end{array}\right\}$ ONCY SCKEEDS REQWIRED

5. Check placing of concrete.

$(2 \cdot 17 \cdot 6 \%$

\section{$3 / 4 "$ - AGGLCGATE}

a. High exly strength 3000 \# concrete with type III cement

b. Slump of concrete - 2 to 4 inches

c. Temperature conditions for cold weather wATER HEATED

a. Free drop - not more than f1ve feet

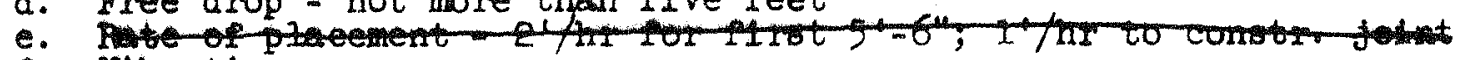

f. Vibretion

g. FInIsh - curved edge to screed

(continued on page 2)

ROMARKS AND/OR SAFETY FEATURES

Wear hard hats, gloves and eye protection.

Stay clear of concrete handing equipment.

CONCEETE MILTRUCKS- ONECWANE HANOLMG $1 / 2$ YO BUCKETI

MANGNIETE USEO TO MENSURE THNK PMESXIEE WHS FICLED WIFH

$50 \%$ ZEREX B $50 \%$ WA 
RPP-ASMT-537.94

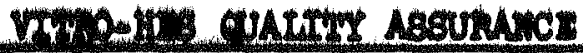

ineet. 2

matror 21514

ANC-90T5

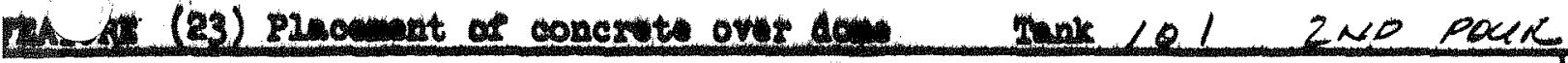
$12-17-62$

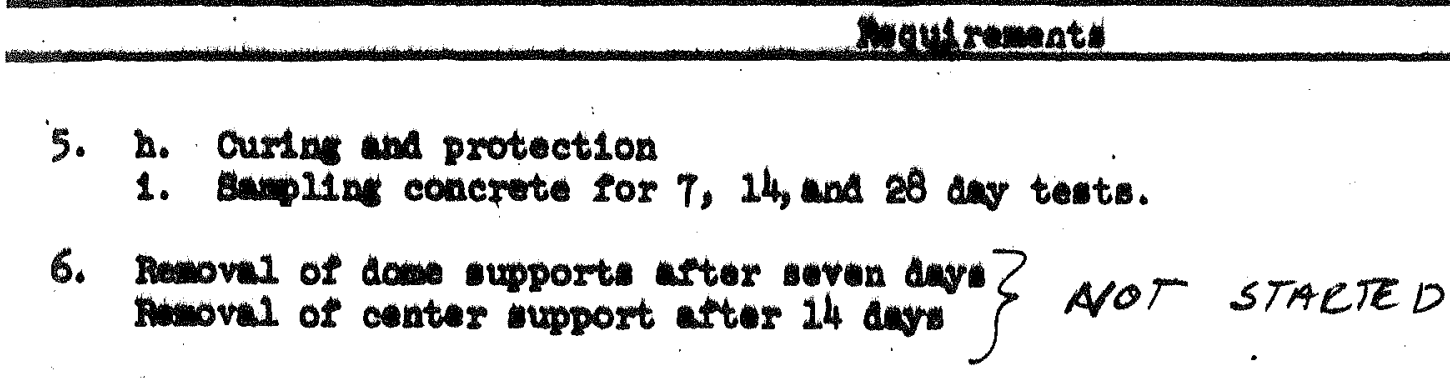

7. Revilte of concrete saple test.

A. Woven avy - BREAK MADE 12-24.69 390.3930-4 CYC1NOEES

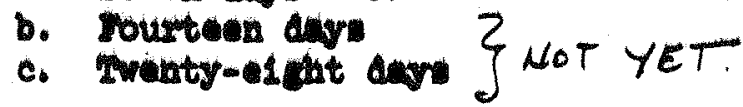

8. PRESSURE OF $3 / 4$ NSI WIAS MAMINTHIAEP DURIWG THE CONCEETE PLACENENT AND FOR THREE DAYS. THCREAFTL ISD. AOTES.

2. REMOUAL OF BUCKAEMD FLOM PEUUICUS POUR LOAS VERY DIFFICULT ANO ACTUALCY PELAYED PUCACING

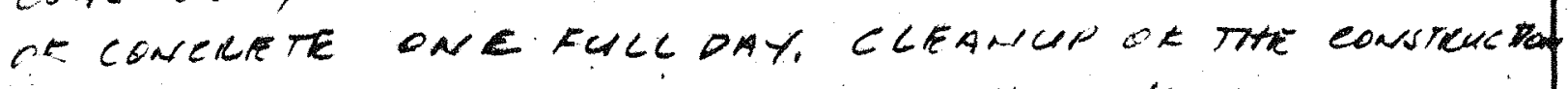
DOINT WAS NOT. COWHETED UNTC ONE HOWK NKEVIOUS TO: THE FINISH OE CONCLEL PLCEMENT OF THSSPOUK.

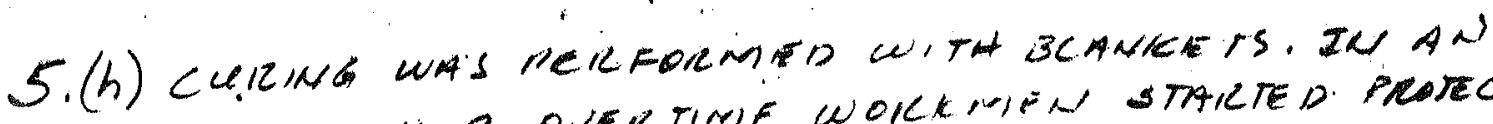
ATTEMAT TO AUO10 OJELTINE WOKKMIEN STALTED PRATECDON. OF CONCRETTE. TOO SOON AFTER PLACEMENT LEANING AN UNUSUAL NUMBER OF FOOT PRINTS IN THE FINISHFD SUCSACE. Acceptance Yes 10 SRENOTE an. THESE FOOTPRNTS WERE FILLED ON 7.23.69. SREUCURAL DAMACE TO THE CONCLETE IS MIL.

RECORD OF POUR-

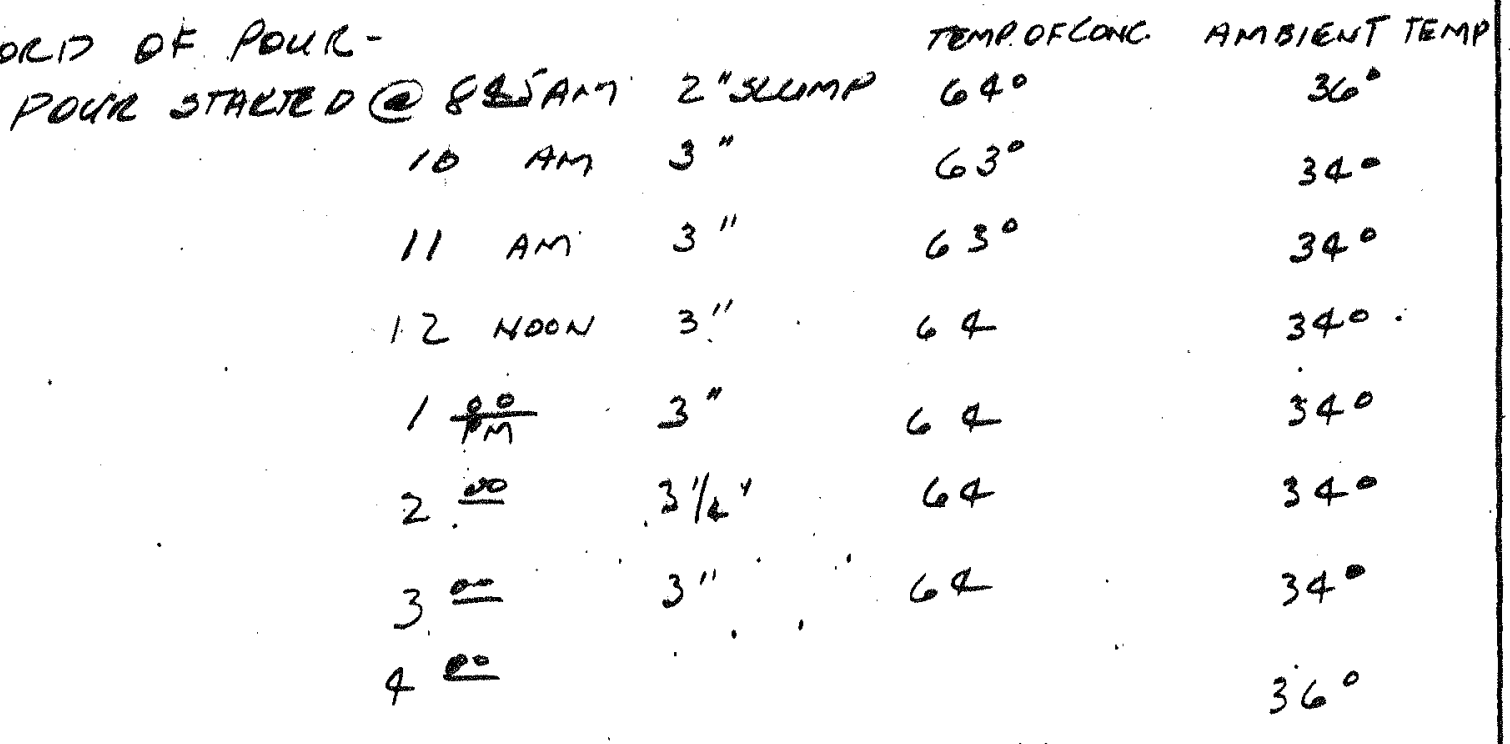

TANE redSSURE(NN:

$18^{3} 4$

$18 \frac{1}{2}$

$18 \%$

18

17 (peeros)

1.73

18

$18 \%$

POIR COMVETEO $340 \mathrm{pm}$ TOTHC CU.128-162 
FEATURE (23) Placement of concrete over dome - tank Lof Inspected by:

REFERENCA: DWgs. H-2-64310, Rev. 0; H-2-64311, Rev. O; H-2-64312, Rev. O; Rev1sed sketch, dated 10-30-69, supplement1ng Dwg. H-2-64312, Rev. 0 . Specification HWS 7791, Rev. I Soule steel Company drawings $\mathrm{E}-2, \mathrm{E}-3$, and E-4; cut sheets 2 thru 6 . SRE BECOW

Da.te: $12-49$

Distribution: WS Graves CN Zangar A. Short QC File (2)

OTHER DATA: ACI $318-66$, AWS D12.1

Requirements 1. Check dome support pads; see that support X-bracing 1s tightened.

2. Check dome, existing concrete and relnforcing steel for cleanliness.

3. Check placement of reinforcing steel.

a. Size and number of bars

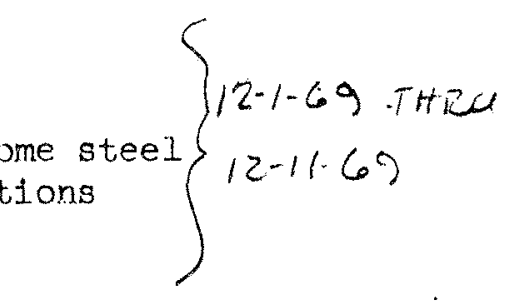

b. Clearance from formork and shell and dome steel

c. Additional reinforcement a round penetrations

d. Min. 40-1nch lap in haunch area

e. Cont1 nuous butt welding where noted.

4. Check formwark.
a. Alignment
b. Tie rods and bracing
c. Construction joint.

5. Check placing of concrete.
Che "AlGCEATC
a. High early strength 3000\# concrete with type III cement $11-24-69$
b. Slump of concrete - 2 to 4 inches
$12-11-69$
c. Temperature conditions for cold weather
d. Free drop - not more than five feet $5^{1}-6^{\prime \prime} ; 1^{1 / h^{\prime}} x^{-1 /-69}$ to constr. joint
f. Virition $\angle A D=12-11-69$
g. FInish - curved edge to screed $12.11-69<80$

$$
\left\{\begin{array}{l}
12.8 .69+424 \\
12-11-69
\end{array}\right.
$$
(continued on page 2)

\section{REMARKS AND/OR SAFETY FEATURES}

Wear hard hats, gloves and eye protection.

Stay clear of concrete handling equipment.

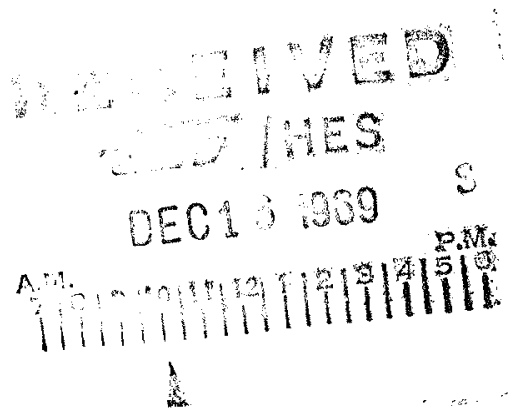


Rev. 0

FL URE (23) Placement of concrete over dome

Tank

5. h. Cuming and protection

$12-11-69$

$\operatorname{SAP}$

1. Sampling concrete for 7, 14, and 28 day tests.

$\angle A A$

6. Removel of dome supports after seren days

Removal of center support after it days

7. Results of concrete sample iest

a. Seven days

b. Fourteen days

c. Twenty elght days

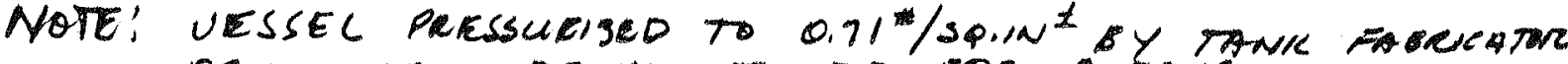
PRESSURE TO BE MAINTO MNEO FOR 3 DAYS

PRESSURES RECOROED $12-11-69$

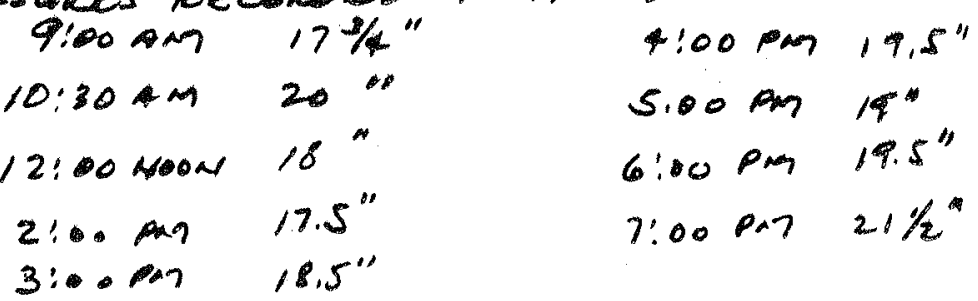

CONCRETE PLACED IN 10 WIETS TOTAL YARDS 06

8. SNow do leE cousefo uprex portions

$9110 \mathrm{AM}$ - IST LIFT. 2'DEEP - SLUMP $4 \mathrm{~L}^{\circ}$ - TEMP AMB $33^{\circ}$ CONGECTE TEM 10110 AM - 2ND CIFT - 2'DEAP - 2\%

$11: 10$ AM- 3RD HET - Z' - 3"

$34^{\circ}$

$56^{*}$

$12: 30 \mathrm{pm}-4 M$ LIET -

'

350

1:30.pan - 5B LAFT.

$t^{\prime}$

2:30 pon - 6N $\angle 1 F T$.

$\ell^{\prime}$

$3^{n}$

$37^{\circ}$

$3 *$

3:30 PM- $7^{+1}$ LET -

,

$3^{*}$

$38^{\circ}$

$38^{\circ}$

4:30PM- $8^{M} \angle F T$.

1

3

$37 \%$

$6: 00 \mathrm{pm}-9^{4} \mathrm{LIFT}$

,

$3 "$

$38^{\circ}$

$7 ! 15 \mathrm{pM}-10^{M} \mathrm{LIFT} \quad 1: 6^{\circ}$

$2 / 2 "$

$38^{\circ}$

$163^{\circ}$

$64^{\circ}$

$64^{\circ}$

$64^{\circ}$

$64^{\circ}$

62

$64^{\circ}$

$64^{\circ}$

CONCRETE PLACEMENT COMPLETEO@ \&:HOPM

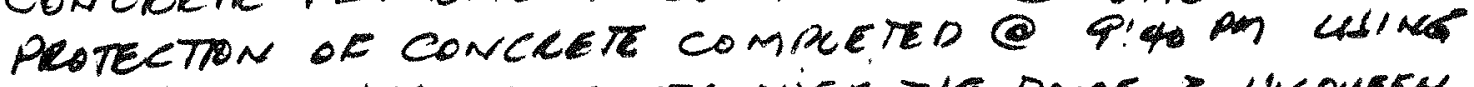
BLANKETS 2 UISQUEEN PLASTI OUEK THE DOME T UISQUEKA

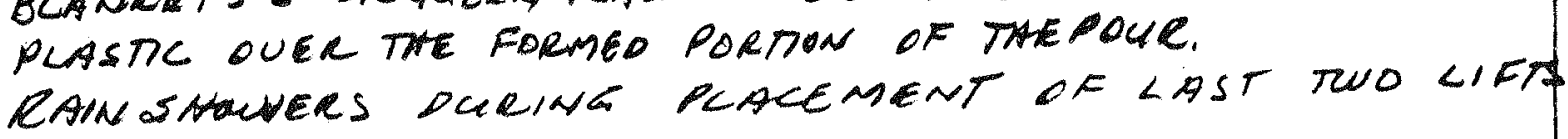




\section{HE. JRE (23) PIscenent of concrete over done - tank 102}

REIERLACUS: DWE. H-2-64310, Rev, O; H-2-64311, Rev. 0; H-2-64312, Rev. 0; Hevlsed ketch, dated 10-30-69, supplement1ns DwE. H-2-64312, Rev. 0 . Spec1P1cation HWB TT91, Rev. I Boule Bteel Company arwings $\mathrm{E}-2, \mathrm{E}-3$, and $\mathrm{E}-4$; cut bheet 2 thru 6
Inspected by: SEC BELOW Date:

$12-2-62$

Distribution: WB Gruve: CN zangar -

A. Short oc Nile (2)

OTHER DATA: AC1 318-66, AWB D12.1

Requil rements

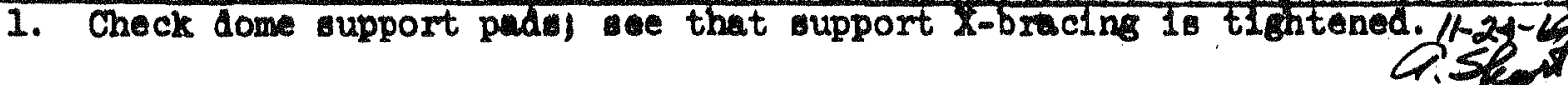

2. Check dome, existing concrete and relnforcing teel for cleanliness. $11-14-69<48$.

3. Check placement of relnforcing ateel.
a. 5120 and number of bars
b. Clearnce Irom formork and shell and dome teel $11-25-69$ \& 80 .
c. Additional reinforcement around penetration $1 /-22.69 .9$. Shat
d. Min. 40-1nch Iap in baunoh area
$11-20-69<42$
e. Cont1nuous butt welding where noted.
$11-25-69$

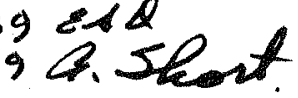

4. Check Pormork.
a. Algnment
b. Tle rods and brecins
c. Construction jolnt.

$11-25-69$
$11-24-69$
$11-24-69$

5. Check placing of concrete.

3/4" A662C4ATE

a. High early trength 3000 ol concrete 1 th type III cement $11-24-69$

b. Slump of concrete - 2 to 4 Inche $11.25-69 \& \& D$

c. Temperature conditions for cold weather $11-25-69$

d. Ire Arop - not more than elve feet - S14 FEET - 11-25-69

e. Pute of placement $2^{\prime} / \mathrm{hr}$ for f1rst $5^{\prime}-6^{\prime \prime} ; 1^{\prime} / \mathrm{hr}$ to contr. joint

f. Vibration

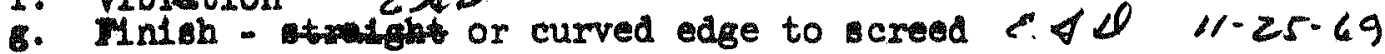

(cont1nued on page 2)

\section{REMAKKS AND/OR SAFETY FEATURES}

Wear hard hats, glove and eye protection.

Stay clear of concrete handing equipment.

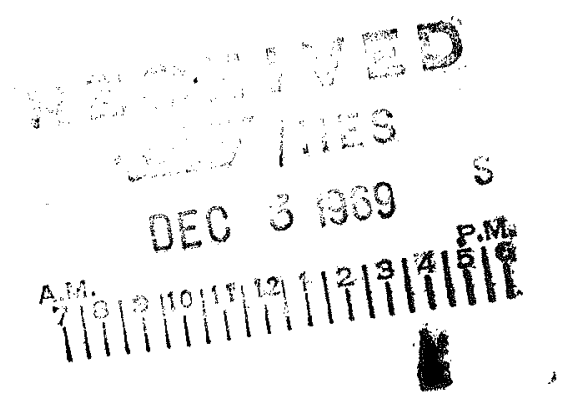


Twak

\section{Equil rements}

Acceptance

5. h. Curing protection

1. Bamping concrete for 7,14 , and 28 day tests.

$11-25-69 E 20$

$\angle \& D$

6. Rewovel of dome upporti after seven duys

Romovel of center upport after 14 days

7. Rewult of concrete sample test.
c. Beven daye
SIK DAY Becte $3000^{\circ}$
b. Tourteen days
c. Iwenty-1ght dav
NOTES- VESSEL PRESSURIECD TO $0.71 \%$ SANA BY TTWK FABRICATIR - REHUTS AL LEAD DN MANOMETER USING 502 WATR- $50 \%$ ZEREX

$$
\begin{aligned}
& 11-25=69 \\
& 500 \mathrm{pm}-17^{\prime \prime} \\
& 9130 \mathrm{~mm}-19 \% \\
& \text { 5lo man - } 10^{\circ} \\
& \text { 10:00 Am. } 18 \% \\
& 655 \mathrm{~mm}-19 \% \\
& 11.00 \mathrm{~m}-19^{\prime \prime} \\
& 700 \mathrm{pm}-18 \% \\
& 12: 00 \mathrm{M} \cdot 17 K^{\circ}
\end{aligned}
$$

PRESSCLRE MAINTHINCD FOR SDAYS TILL 7i30 PM $11-20-69$ EONCRETE WAS PLACED 1210 LIFTS AS FOLLOWS:

geginama 0 eled. $651.36-$

8:30AM - GeouT

9:DUAM - IST LIFT - 2,DCEP - SLUMP $2 "$

$10: 45 \mathrm{AM}$ - 2N18

$2^{-}+\frac{1}{2}$

$32^{\circ}$

$11: 35 \mathrm{AM}$

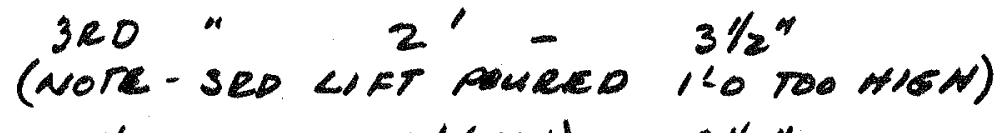

$12: 35 \mathrm{pm}$ - $4 \mathrm{M} " \mathrm{H}$ "(MA4) $3 \% "$

$1 ! 25 p m-5 \% 1 \%$ (max) $3 \%$

$34^{\circ}$

$2: 15 \mathrm{PAq}-\quad 64 \mathrm{LIRT}$

1 (mer) 3\%"

$3: 10 \mathrm{pm}-7 \mathrm{MET}$

'(M) $3 \%$

4! $10 \mathrm{PM}-8^{\mathrm{M}} \angle 1 \mathrm{KT}$

$3 \% "$

36. copharte $4165 \% 10^{\circ}$

$5: 35 \mathrm{PAO}-\mathrm{qH}^{\mathrm{B}} \angle \mathrm{FT}$

$3 / 4$

$6: 45$ pay. $10^{4} 405$ 
protext

RPP-ASMT-53794

IRE

EN TRE

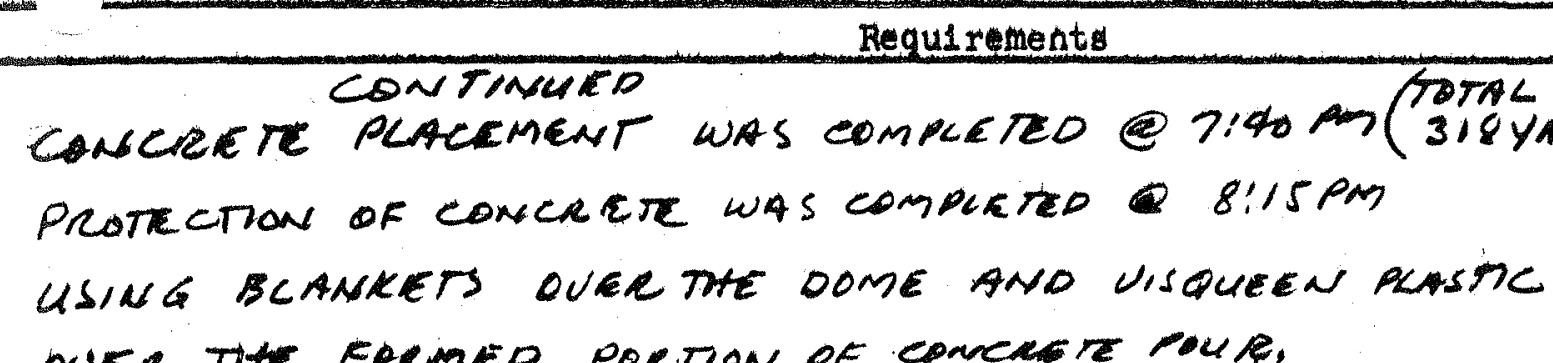
DUER THE RORMED PORTION OF CONCNE TOUR.

AMBIENT TEMP. 12 MIDNIGNT $30^{\circ}$ - TEMP OE AIR SANCE BETWEEN CONCRETE \& HCANERT PROTECTON $-58^{\circ} \mathrm{F}$.

$$
12-1-69
$$

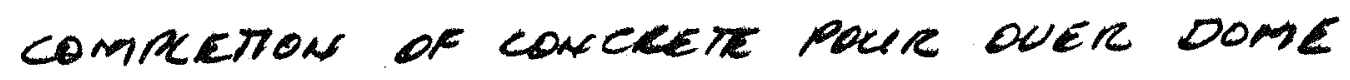

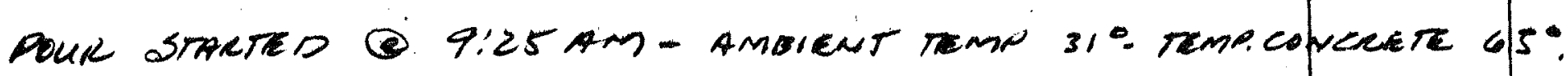

PRESSURE IN TISNK OK SLUMP 3 ". VOINT DAMPENED WITH WATEL.

10:00 AM PRESSURC IN TWNK $9 \%$

$10 ! 30 \mathrm{AM}$

$19 \% "$

12:00 Noon

$20 \%$

1100 PN

$19 "$

2:00 PM

$17 \frac{1}{12}$

$3: 00 \mathrm{pm}$

$203 / 4 "$

Rev. 0

CONCRETE SAMPLES MAKEN O 9ILTAM

11:00 Aar

$12: 00$ NOON 3"SLUMP AMBIENT TEMP 320

$2: 40 \mathrm{pM}$

Pour cong pLETED 2:50 pas

PROTECTION STGRTE O 3!DOPAS COUERED WITH BLANEETS

TEMP, OF. AIR SPACE BETWEEN CONCEETE \& BLANEET

(2:00 MIDNIGHT -. 


N0.5OT IAP-614 Contract AT(45-1)-2124

indse 6 -Correction of secondary tank bottom to flatness tolorance

ar ArCEs: Specification HWS 7789 , Paragraph 14.3 , Bcttoms

Propurcó by:

E. S. Davis $3 / 27 / 60$

ro

MTR DATA: ELEUATONS ARE CHALTED ON DEAWING

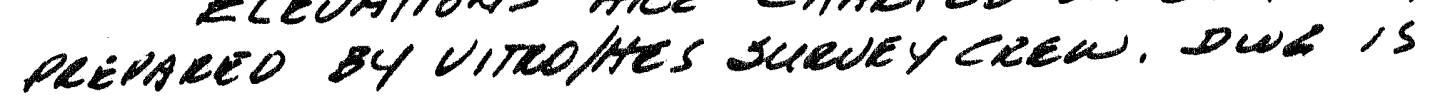

APAPTED FROM POM OWK QC 4

\section{Date:}

SEE secew

Distriblition:

WS Graves

CN Zangar

A. Short

QC File (2)

1. Flatness:

a. Peak-to-valley not to exceed $2 "$.

b. One peak-to-valley tolerance of $3^{\prime \prime}$ in $30 \mathrm{sq}$. ft.

2. Distortions:

a. Slopes shall not exceed $3 / 8$ " per foot.

Gurvey made ON 3-10.65)

la. SIS PLACES EXCEED $2 "$ TOLENANCE

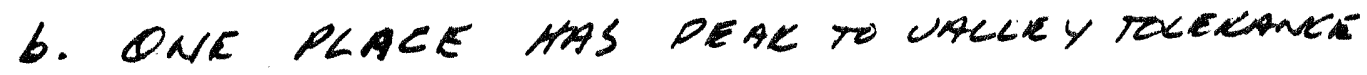
OF $3^{\prime \prime}$

2. SLOPE EUCEEOS $3 / 8$ "/FOOT AS NotTo on suevery,

ABOUE CONUITONS ACCEDTED ON $3 / 10 / 69$

BARKS AND/OR SAFETY FEATIRES

1. Wear hard hats, gloves and eye protection.

2. Check access ladders to platforms for safe use. 


OJUCM IAP-614 Contract AT(45-1)-2124
FERENCES: Specification HWS 7789 , Paragraph 14.3 , Bottoms

PCAK YO UACLEY RCPUATONS CHARED ON PON DWG QC 6 BY UITRO FIELD SURUEYCREW $24 \quad 2-19-109$

1. Flatness:

a. Peak-to-valley not to exceed $2^{\prime \prime}$.

b. One peak-to-valley tolerance of $3^{\prime \prime}$ in 30 sq. ft.

2. Distortions:

a. Slopes shall not exceed $3 / 8^{\prime \prime}$ per foot.

1 I.22 PLACES EREEEDED $2 "$ PEAK-TO-DAUEY TOCERATCE.

HINONE EXCEROEL 3 "TOLERANLE.

2a. SLOPE APNEACHED, "IN SEvEMA LOCATIONS.

THESR CONDInONS ACCENTEO WY UITES GeSIEA

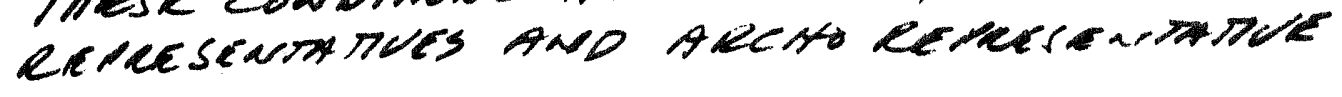

ARKS AND/OR SAFETY FEATURES

1. Wear hard hats, gloves and eye protection.

2. Check access ladders to platforms for safe use. 


\begin{tabular}{|c|c|}
\hline a sect & IN-614 Controt Ar (45-1)-2124 \\
\hline nat & 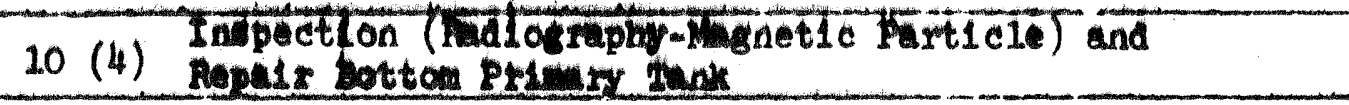 \\
\hline 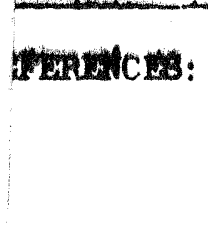 & 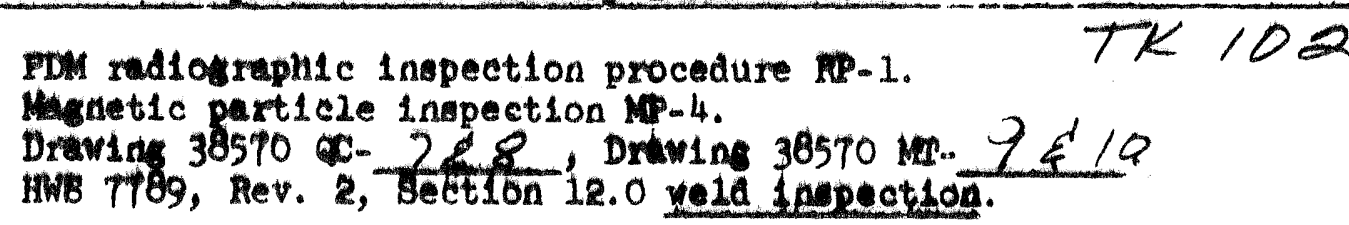 \\
\hline
\end{tabular}

prepored by: 2. B. Dar1d $4 / 14 / 69$

In geg by tote: stees Dlstribution:

WB Graves

Cl zangar

A. Short

C Fle (2)

MTER DATA:

Mation signs.

Requirements
1. malogreph 11 weld seans in bottom, knuckle plates and those
adjolning irst heli course.

2. Check for -

a. Fim and $x$-ray quality.

b. Proper 1nterpretation and rkins of 11m. SEE NOTE I

c. Hecorting of defect.

j. Resir all defective welds.

a. Viousily check all welas priot to repair.

b. Ascertain that repait procedure is acceptable.

c. Check and recort $x$-ray 11 in of repalrs.

4. Visulin witnes 3.11 particle tosting.

a. Continua11y check testins equipment.

b. Record polition and location of test. (PDM RECOEDs)

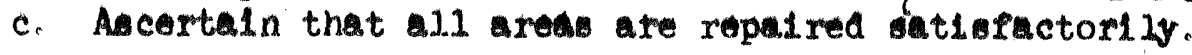

5. V1ounily check all reas top and bottom for objectlonmble defect.

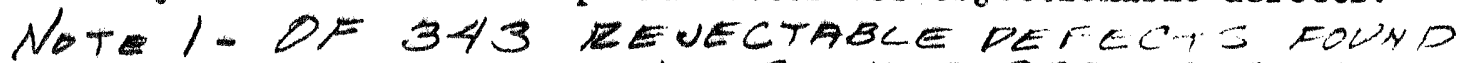
IN THIS BOTTON, THE IONAM PADMERAPHER FOUND ON 294 . THE REASON APPEARS TO $S E$ THE FLVORESCENT BULB TYPE VIEWER HE USES DOES NOT SEEMA TO MEOVIDE SUFFICIENT ILLUMINATION.

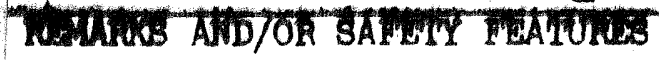

1. Wear hard hat, gloves and pye protection.

2. Check cribbing, tank grounding.

3. Mantain oufe distance to prevent $x-r$ axpoure.

4. Check cafrolding, brackets, ladder for wafe access. 


\section{Pit jurmente}

1. See that four vessol penetrations are hiarked cioged.

2. Fyli tank to a deptk of $39^{\circ}+i^{\prime \prime} . \quad\left(37^{\prime}-10^{\prime \prime}\right)$

3. Coat all accessible welds with thue chalk.

4. Inspect all coated welda for leakage after a bolding perfad of 24 hours.

5. Note any new irregularities in tank configuration. (NoN

KAOE TE INSULATINE CONELETE IS SOMEWHAT

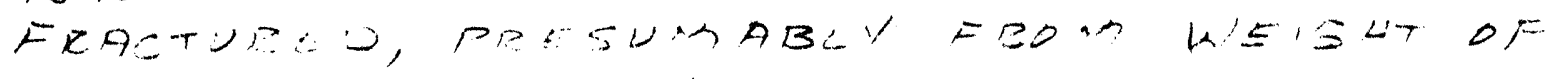
WATER USED IN HYDEO.

\section{$\overline{E T}$}

IEMAR

.. Wear lard hat, fioves, ard eye firotection.

$\therefore$ Check scaffolding in annilus before ustug.

$\therefore$ Erter annulus only when cther personnel are present. 


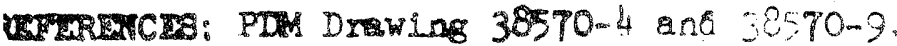

PD aubuttol, W11lard Smith, deted 2-12-69.

Date:

Draw1 - $2-64307$, Rev. 2.

D18t516ut100:

Specle1 cat1on IRE-T789, Paragraph 9.0.

WS Groves

CN Zangar

A. Short

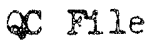

MUER DATA:

Bettelia - Evalustion of Krolite-2200.

\section{Reguiremente}

2. Review feature Ro: 7 as a check an embeddec materials.

2. Conditions of environs pertalniag to:

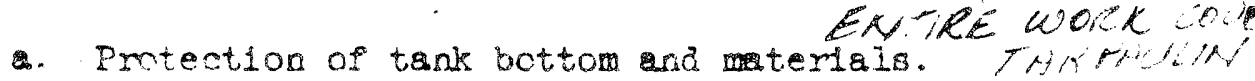

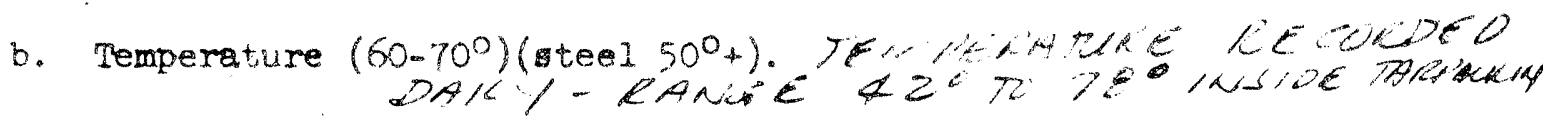

3. Formork:

1. Mntaln minfmum $I^{\prime \prime}$ under pipe and $2 \frac{1}{2} "$ over pipe thickness of Iasulation at the four 4-1nch vent pipes. All other places -

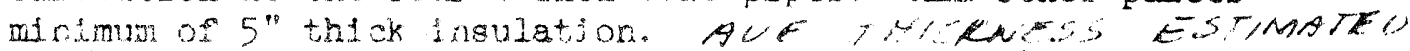
mivinuer "P".

b. Jolnts " conflguration ad treatment to malntaln strength and

therug characteristice.

c. Screeds and blockouts - als trenches and tratagages.

4. Placement:

qts.

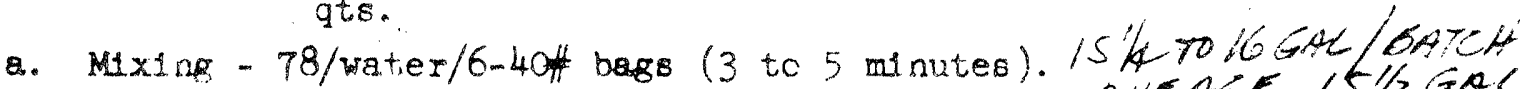

AUCACE $151 / 2 G A C$

b. Fach batch piaced within 20 minutes - vibrator. AuQpife 7 pirvaths

c. Obtaln samples - one each 10 batches or mintmum of five each day. 4 SAMHE: DER SEETHON WERE OBTH (continued on sheet 2 )

\section{EMARRS AND/OR EAFETY FEATURES}

1. Wear hard hats, gloves and eye protection.

2. Check air InsIde tank enclosure for poisonous gases.

3. Wear alr filter when near batch alding operation.

4. Exercise care enteriag and exiting tank.

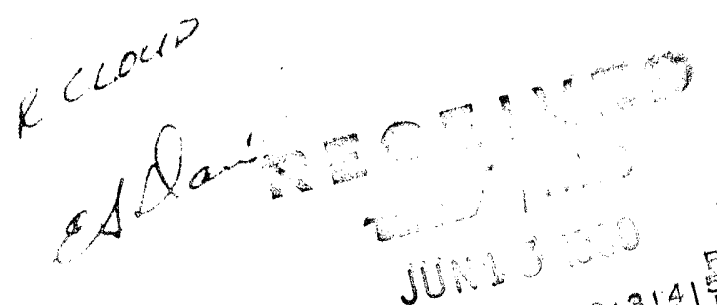

| $\left.1\right|^{3}$ 
RPP-ASMT-53794

Rev. 0

VITRO-HES WUAITTY ASSURANCE

sheet 2

ENECT IAP-614 - Contract Ar(45-1)-2124

2 RE - 8. Insulation in bottom of tanke. Tank 102

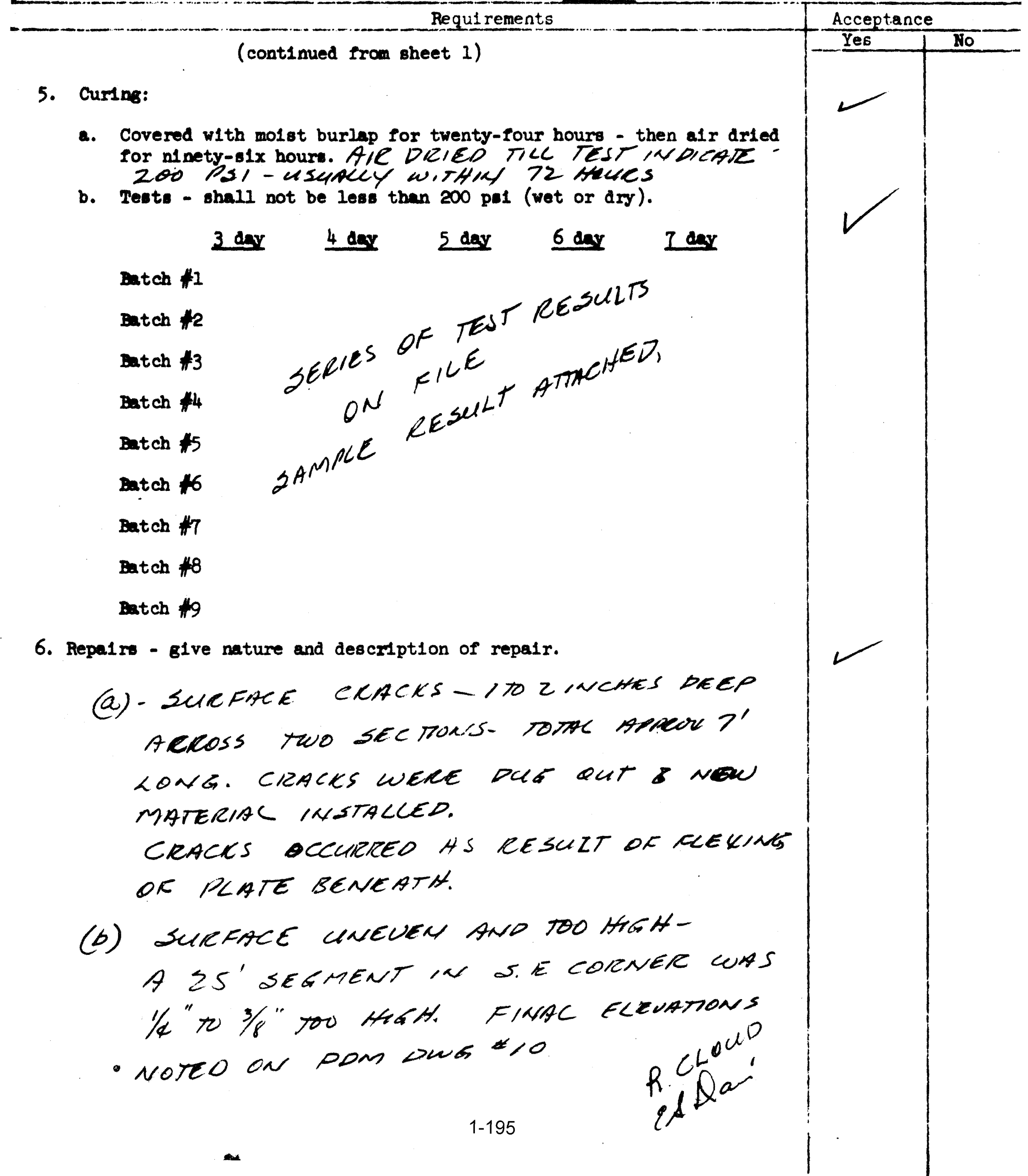


BAOWTE Bans-3-11-G

Datr par Aere $3-4=1$ 1 e-sede $\frac{-\cos 20}{4}$

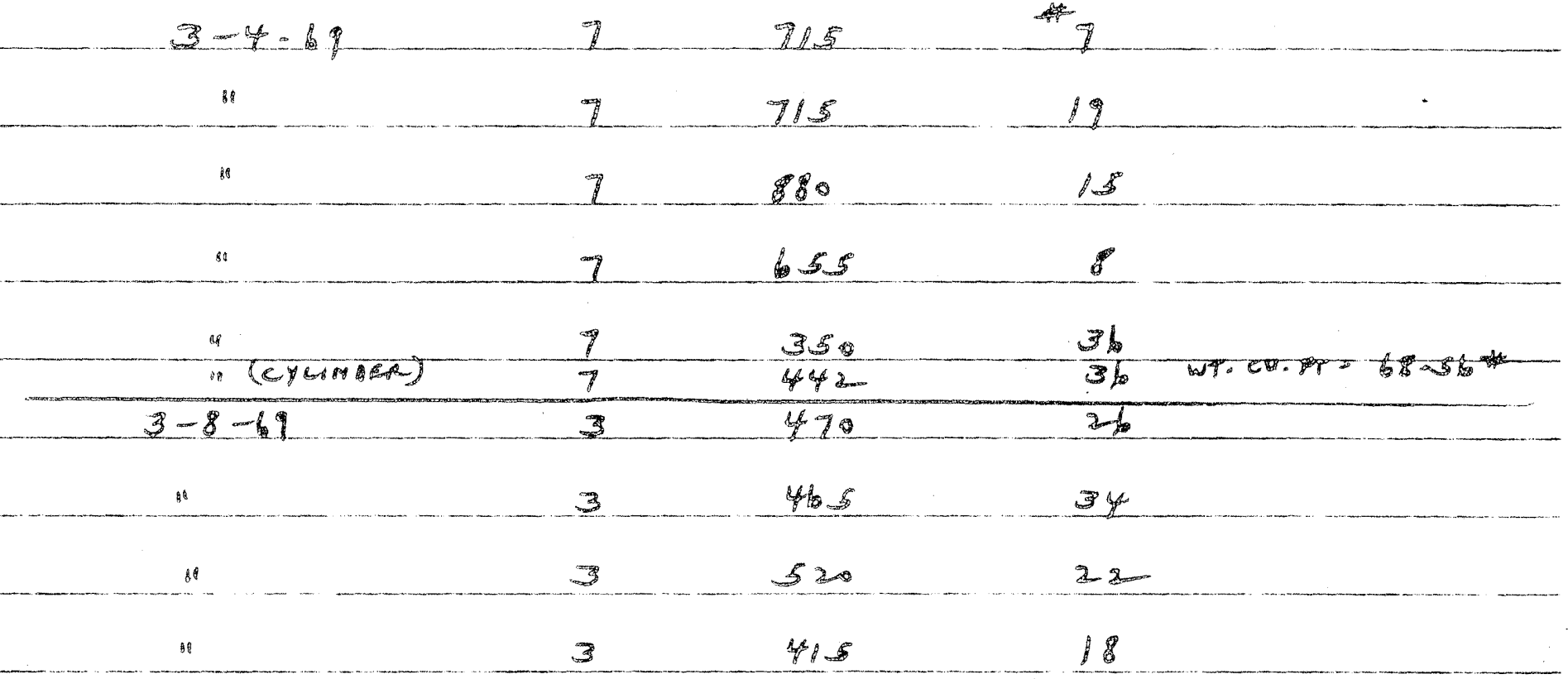




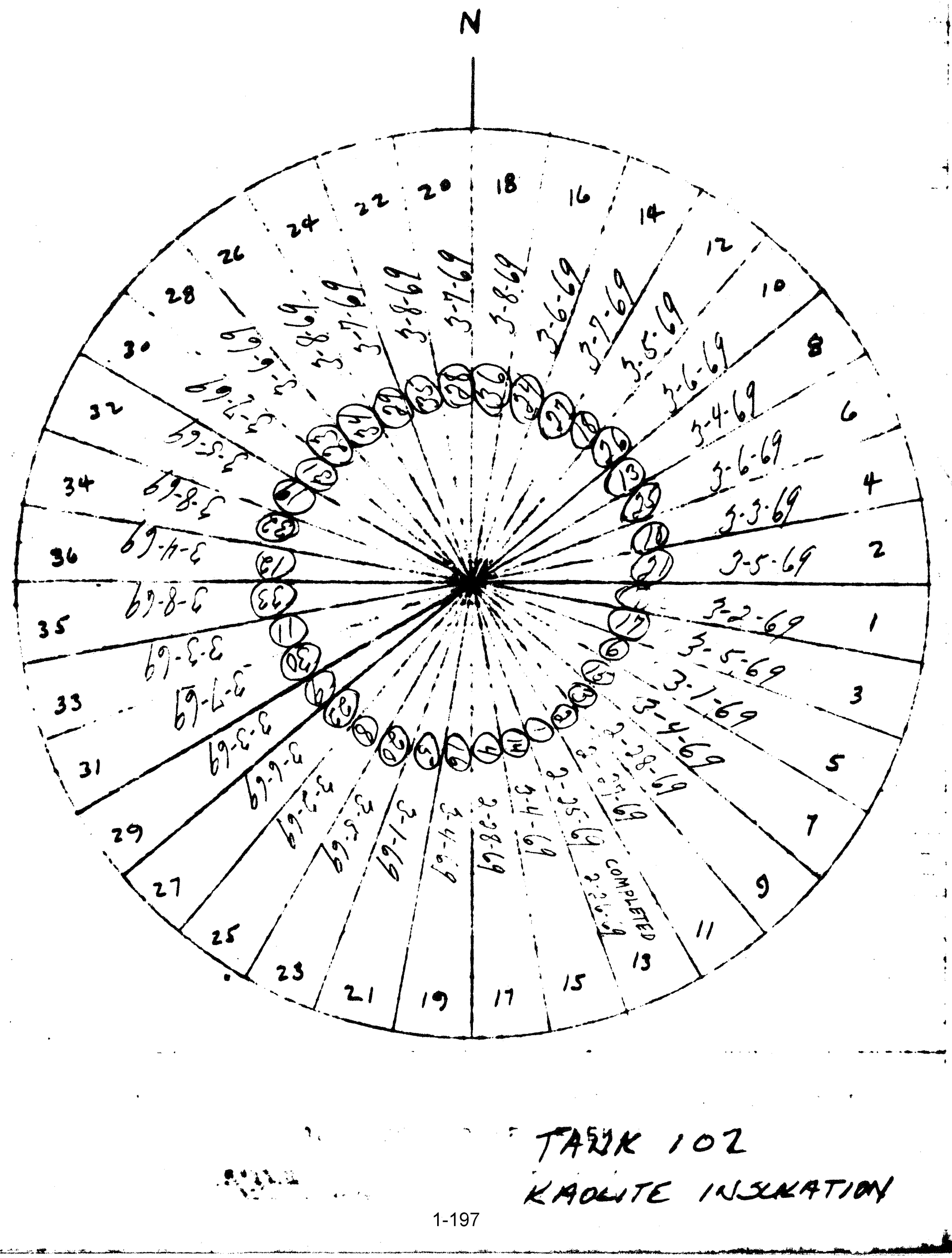


Rev. 0

1.14 Kligfield, G., 1969, "AY Tank Farm Welding," (Letter to B. Kirz, June 10), Vitro Hanford Engineering Services, Richland, Washington. 
BPP-ASMT-5B794

TO

Ben Kirz

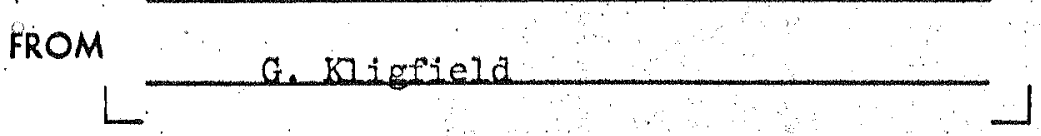

DATE

June 20 ,

1969

SUBJECT

AY Tank Farm Welding

JoB No. $T A P-6 / 4$

$(2-1)$

(3)

In the past few weeks I have met with our Title III

people and the contractor (Hugo Stein) to discuss the incidents

of repair on the Welding of the primary tanks. We were led to

believe that once we got into the heavier walls (the primary

tank) we would not be experiencing as many rejectable welas as

we had previously. The net results of the welding on the bottoms

for tanks 101 and 102 are generally good in terms of flatness

but in tank 102 there was a fit-up problem and one of the seams

had to be repaired several times to meet our rigid specifications.

The remaining part of the tank bottom was in pretty good condi-

tion. There were more weld repairs than I would have liked. In

tank 101 we feel that the welding has been decidedly improved;

whether this is a case of more inspection or better welders is a

matter of contention. There has been a continuous pro and con

on the merits of the automatic welding, and really today I can't

say which is giving us the better results. We know that the

automatic welding on the secondary tank horizontal welds went

along beautifully. There is a feeling that the machine with pro-

pedjustment and operation should do the same thing on the primary

tank. Hugo Stein wants to get the machine into an operating con-

dition and prove to us that good welds-looks and integrity--can

be made and will be made with this machine. We think that the

machine needs close supervision and care when out of use as well

as while welding.

In the past week I have had lengthy meetings with our people and PDM people, and find each trying to do a good job. A better understanding between our inspector and Hugo Stein is what is needed. In my meetings Friday we sat across the table and reviewed each item of controversy and hope we have reached agreements whereby our inspector AI Short is the Commission representative and, in a dispute, his decisions are final. Hugo Stein understands this and will work on this basis; he still believes that in 
several areas where we Lndicated a posible rejection when the weld would be completed that he would be able to prove to us that the welds would be in good order. We have left this up to him; we have stressed that repair incidents should be reduced and we all agreed that had the automatic welder been in better working condition the present disputes might not exist. The PDM specialist on the automatic welder will be in next week and make adjustments so the automatic welder can be put back in operation with confidence; in the mean time we have authorized the use of manual welding so that the job will not be held up.

After our across-table meeting we went down into the tank to examine several of the weld areas that were under discussion and asked Mr. Wormiey, ARHCO, Metallurgist, to join us for his opinion. I would say that he backed up our concern; that is, indications that we may have a problem in reading $x$-rays with several of the welds with too great a notch between passes (code allows rejection if $x$-ray shows possible masking of defects). Again Hugo Stein stressed the fact that these were good welds, and he is sure that there would be a definition such that the $x$-rays could be read and he felt that the final welds would be acceptable, but he said that he would have to concede to our final decision.

I feel strongly that we have taken the right action, on-site, with the people involved and see no need calling in Mr. Kinghorn at this time, although I did feel that Mr. Bach, who has been working closely with Hugo Stein and has been a good catalyst in this controversial period, should stay on the job until we get the welding with the machine on a good solid basis. I have called Bob. Wendlandt at Seattle and have expalined that it would be most inopportune to pull Bach off the job at this time, and to see if he could arrange to have him stay on for another few weeks. I will keep close touch with the job and keep you advised on progress.

\section{Otirinal signed By QCONOE HLERLD}

\section{G. Kligfield}

$\mathrm{GK} / \mathrm{js}$

cc: G Knoeber

H Eager (2)

CW Cardwel1 (2)

H. $\operatorname{Stein}(2)$

$B$ Armstrong/ $J$ Wormley

WS Graves

M Schulze. 
Rev. 0

1.15 Lien, D. G., 1967, "Computer Study of AY Tank," (Trip Report to Chicago, Illinois, November 27), Vitro Hanford Engineering Services, Richland, Washington. 
W. B. Graves

M. H. Piskadlo

D. G. Iien

TRIP REYON - COMPUNER STUDY OF AY DATE

On November 15 , a reeting was hald with Professor K. MIJoredty Illinols Institute of Techology; P. Hatch and W. Amistrong, Atlantic FichPleld; C. Compton, ABC-Rz; and the author at the IIlinola Institute of Technology, Chicego, Iulinols. Whe following are the main points of the meeting:

1. The primary steel tank w11 be anclyzed by the computed to determine minimu plate thlekness, bottom knuckle radiue, shet. top expansion jolnt shape. This fnforration will be evallabie to us December 4, 1967.

2. The ellipticel dome geometry w111 be set by IIjinots Institute or Technology using a $15^{\circ} 0^{\prime \prime}$ minox axis.

3. The steel dome or the primary tank u11 be supported by the concrete dome through Helson type weld anchors, experiston anchors are not required.

4. Stifien primazy tank bottom at center a1r plenura. Al10y $1 / 0^{\circ}$ clcarance at alr plenu between tank bottom stitmer tre embedded steel ring.

5. Compacted bacisf112 is not regutred around tankis. It is too expensive for the benerdt 1 t grovides.

6. Computerfzed certhquake areaysis of buxied tenk problem $1 \mathrm{a}$ approximately one year away.

7. A circumperentinl expansion jolnt in the bece slab separtateng wall. footing from slab may be more advantaceous and lews costiy thon sliding jolnt between wall and beve slab. Both w172 be investigated by computer.

8. A crushable losd bearing materta3 should be provided betwema outer liner and concrebe wall at botton knuekle to provide for exponsion. No roduction 18 to be mada in $15^{7}$ conerete wall? at this point. This material shoutd extend epproxtmately $3^{\prime}$ up wall. 
TO: W. S. Graves

M. H. Pakado

9. Mr. Hatch infomed us that hydrogen buL1d-up in annatar speed would be negligible end thould not be constdered in dester.

10. If the cecondary liner is used as a conerete pom at wese of dome in annulus area, it should not be stastened to matraxy tank. There should be a free folnt at this Junction

11. Keolite 20 and insulating conerete 1 m general was discused. Professor Mibradt contacted Hol Avextes of Portland Conent

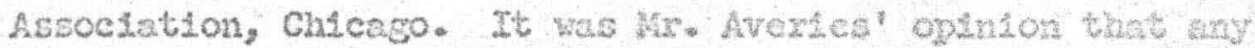
insulating concrete that was to be exposed to high terperatures such as streas relieving wovid produce abovld recelve goectsh handing. Care should be taken to ensure that one surferee was free and that all molsture was dxiven ofl belore stress relieving.

DCL:hw

ce: G. Maigield/C. A. Surgav DEL/Fila

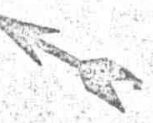


Rev. 0

1.16 Lien, D. G., 1969, "241-AY Tank 102- Insulating Concrete IAP-614,” (Interoffice memorandum to W. S. Graves, November 3), Vitro Hanford Engineering Services, Richland, Washington. 


\section{TH HANFORD ENGINRERING SEFWOES \\ DIVISION OF VITRO CORPORATIOK OF AMERICA}

\section{INTER - OFFICE MEMORANDUM}

DATE November 3, 1969

ro

W. S. Graves

FrOM D. G. Lien

SUBJECT 24I-AY TANK 102 - INSULATING CONCRETE
(LOCATION ON DEPARTMENT)

(WOCATION OR DEPARTMENT) $|A P-6| 4$

On October 17, 1969, Al Short and I visited the AY Tank Farm site and investigated the insulating concrete in Tank 102. At this time Tank 102 had been stress relleved and fllled with water for the hydro test.

Visual examination of the insulating concrete at the base of the primary tank disclosed considerable cracking and spalling of the surface layer around the tank periphery. A couple of cracks were approximately $1 / 4^{\prime \prime}$ wide, several feet deep, and extended the full height of the insulating concrete. The concrete top surface felt spongy to the touch. Many of the air passage slots were partially blocked by spalled concrete.

There was no visual evidence of tank settlement or Indication of large unsupported areas around the periphery of the primary tank. The bent plate ring around the insulating concrete was in place except for one break of approximately one inch at a plate splice. 'There was no indication of concrete spalling beyond the retainer plate.

It is my op inion that the surface cracking and spalling of insulating concrete was a direct result of stresses incurred during thermal stress relief of the primary tank. More specifically, tensile stresses in the perlphery of the insulating concrete and stresses produced by skin friction from expansion and contraction of primary tank:

At this time I feel the insulating concrete is adequately supporting the primary tank but feel it would be wise to examine the concrete aga in after the primary tank hydro test water has been removed.

DGL:hl

co: M. H. Plskadlo

$D G L / F \| e$ 


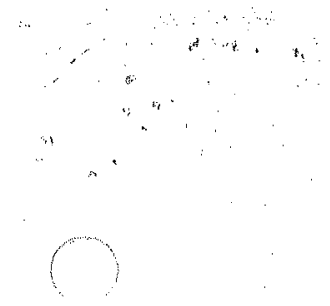

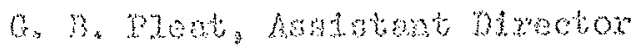

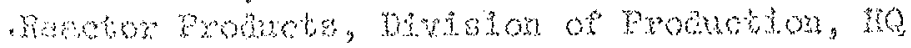

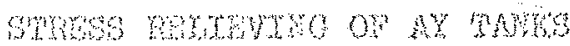

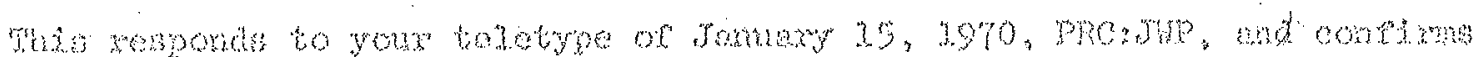

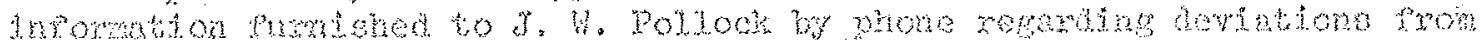

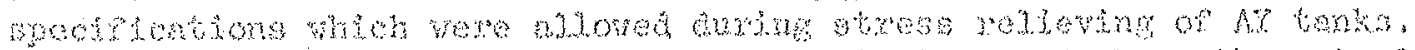

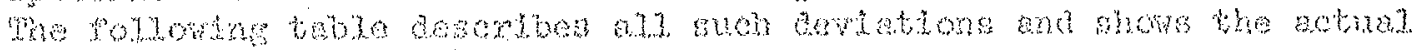
conthions obtentad:

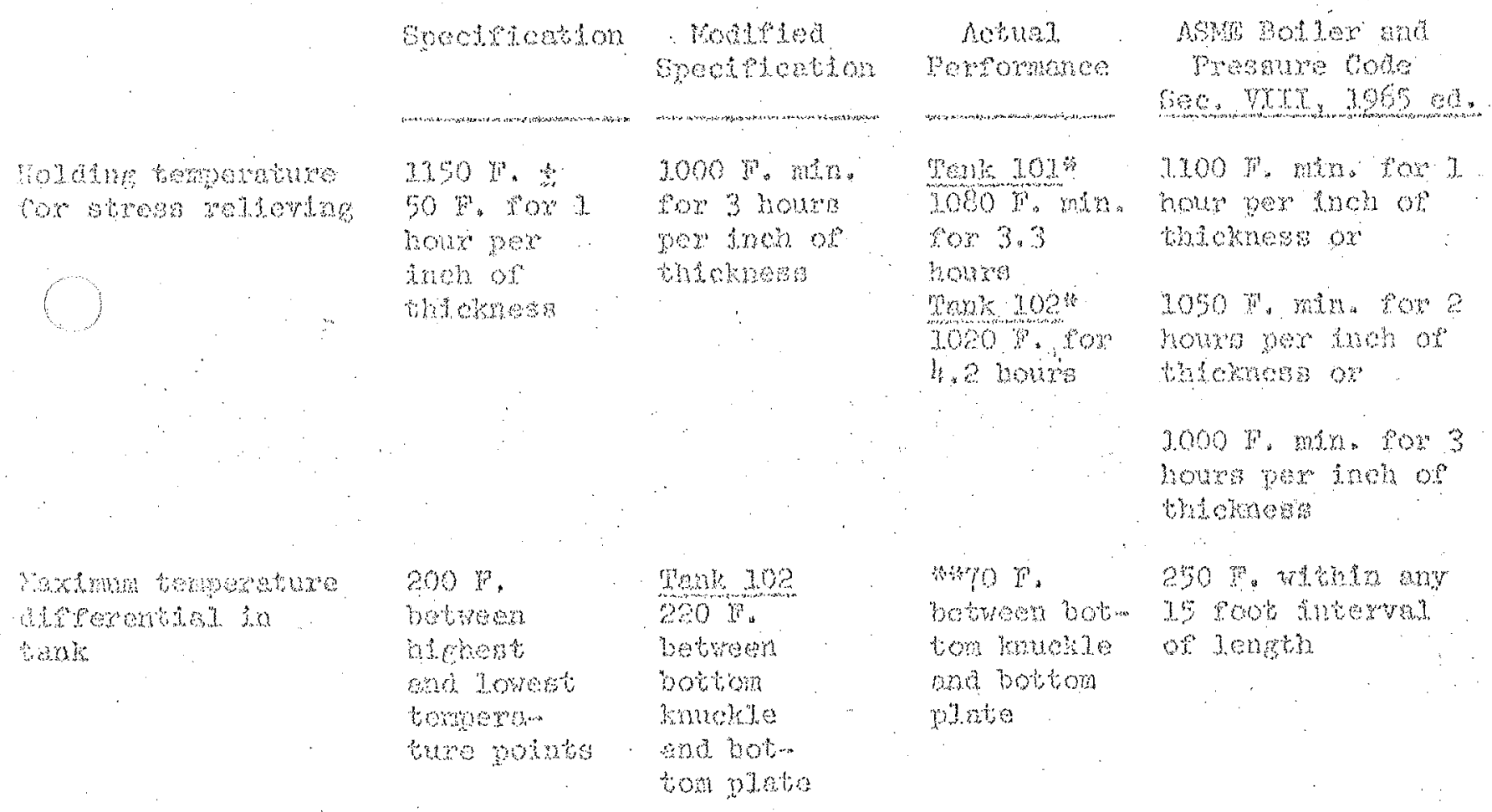

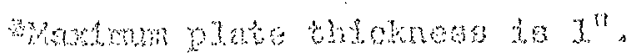

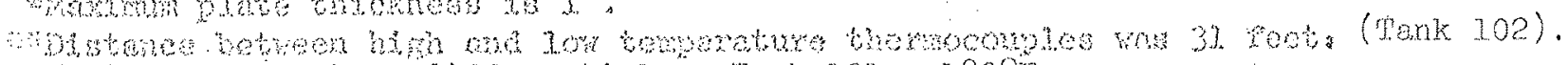
Maximum temperature differential on Tank 20] - $180 \% \mathrm{~F}$

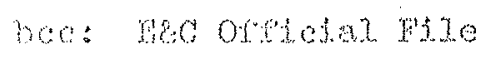

mo mearing rato

woj. mar. o. J. Eilgent

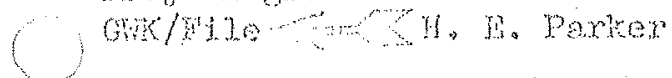

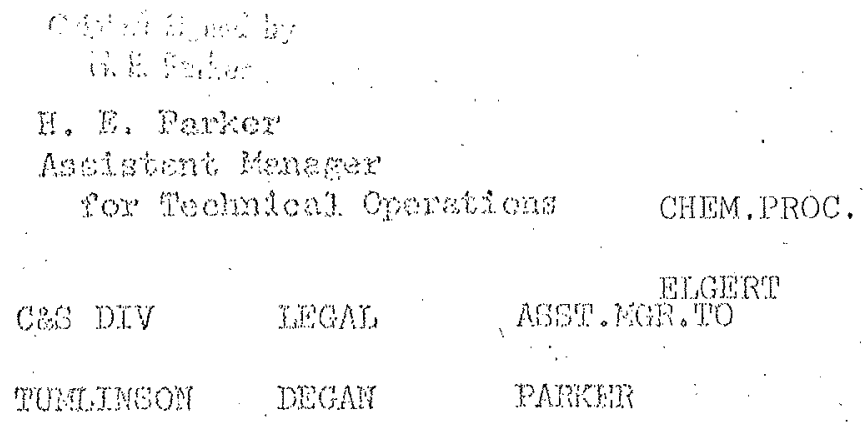

DEGAM

FTGSTR

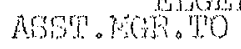

PAYTHW

KTIR

TRTHA 

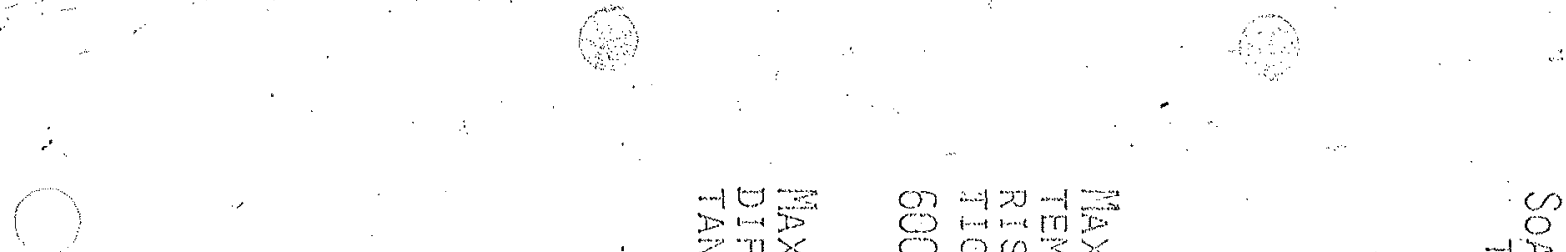

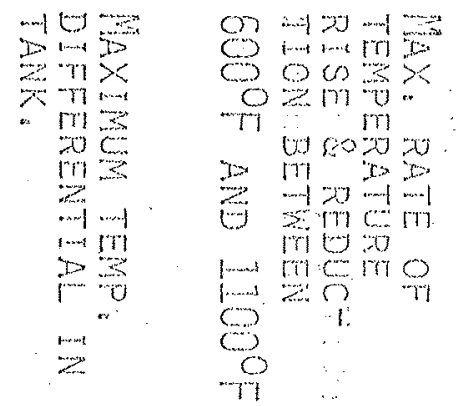

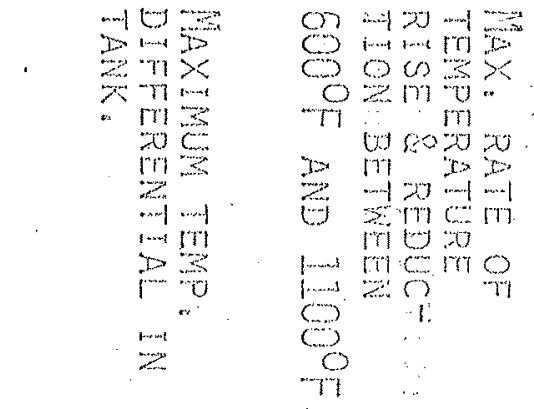

$$
\begin{aligned}
& 0 \text { ․․ } \\
& \Leftrightarrow m i \\
& \text { …… } \\
& \text { - } \quad \pm 00
\end{aligned}
$$

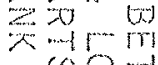

$$
\begin{aligned}
& \text { (⿻) } \\
& \text { to } 0 \\
& <0 \% \\
& \begin{array}{c}
1 \\
0 \\
0 \\
0 \\
0 \\
0 \\
0 \\
0 \\
0
\end{array}
\end{aligned}
$$

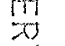

$$
\begin{aligned}
& <x \\
& x: 1 \cdots 1 \\
& 1=-1 \\
& 5 \\
& \text { กำ } \\
& \operatorname{lic}_{0}< \\
& \text { I } \\
& \cdots
\end{aligned}
$$

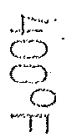

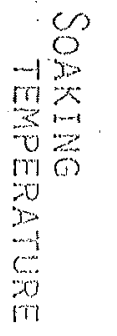

$$
\begin{aligned}
& \text { ज大 } \\
& 902920 \\
& 30-16 \\
& \text {... } \\
& \text { त्रs }
\end{aligned}
$$

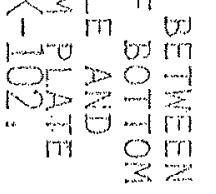

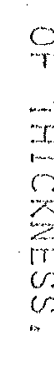

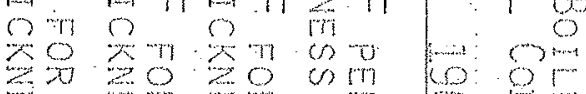

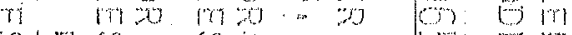

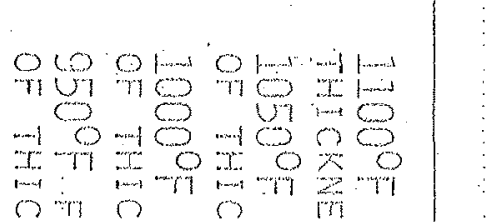$$
\text { (1) }
$$$$
\therefore
$$
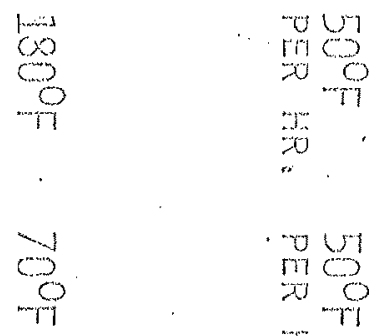

$\frac{4}{0}$
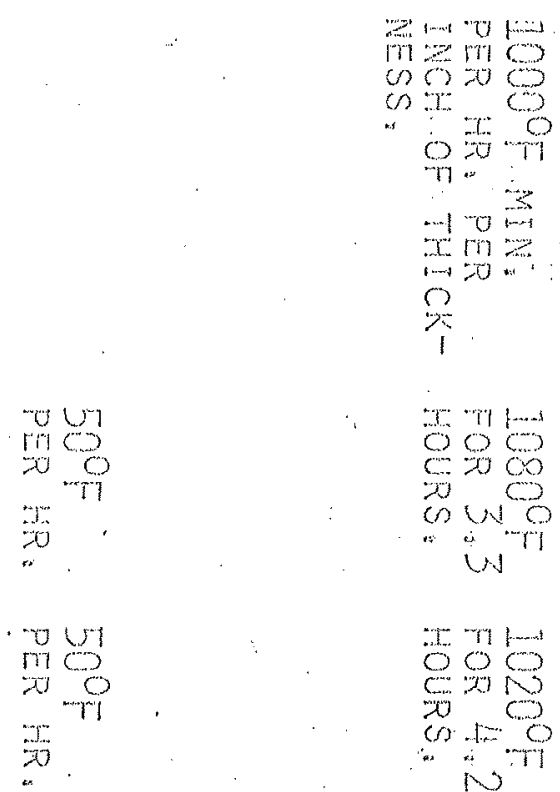

$\cos$

90

(i)

(1)

$\rightarrow \pi$

$n \leftrightarrow$

cos

$m$

$17 \%$

को

i il

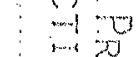
260

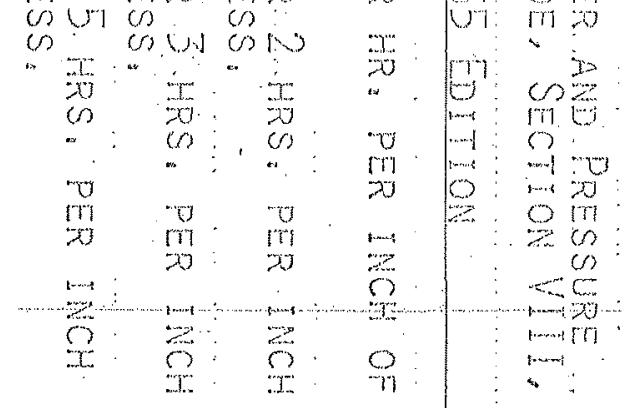

$$
\begin{aligned}
& \geqslant 3
\end{aligned}
$$

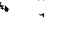


Rev.

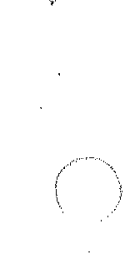

,

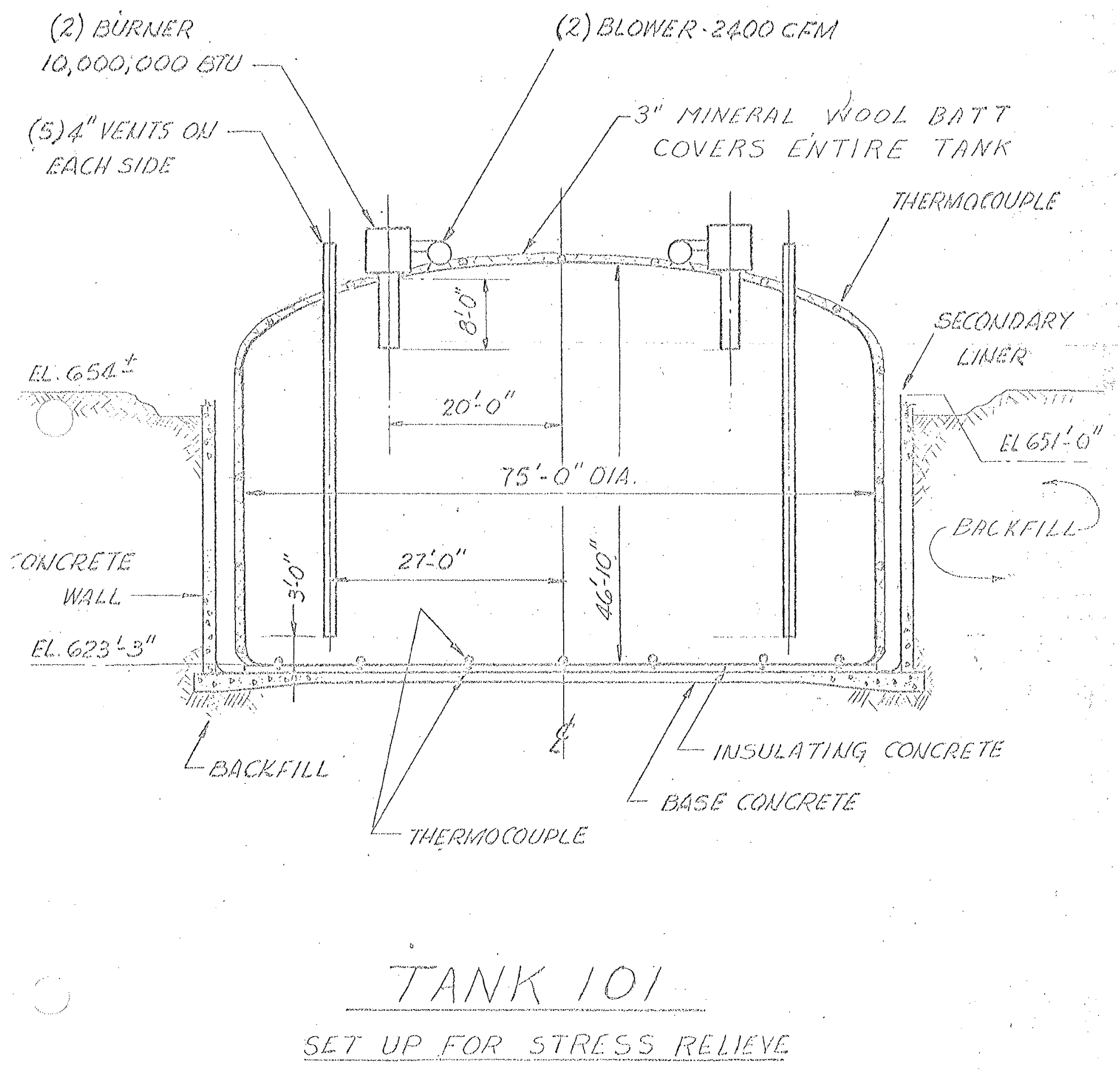


Rev. 0

1.17 Lien, D. G., 1970, "Field Trip to AY Tank Farm," (Letter to G. Kligfield, July 10), Vitro Hanford Engineering Services, Richland, Washington. 
INTER - OFFICE MEMORANDUM

Date July 10, 1970

D. G. Lien

(LOCATION OR DEFARTAEET)

SUEJECT FIELD TRIP TO AY TANK FARM

On June 30, 1970 I visited the AY Tank Farm with John Slaughter (AEC), Ray Vollert (ARHCO), and Bob Caldwell (Vitro Field Engineer).

The Phase 1 repair work was in progress in Tank 102. Approximately two-thirds of the Group 1 perimeter refractory concrete had been removed (reference Drawing H-2-35299, Structure Modifications to Insulating Concrete). From observation during the removal and inspection of the removed refractory concrete I noted the following:

1) In all sections inspected there was solid concrete at the point of primary tank bottom contact with the refractory concrete (tangent point of primary tank knuckle) except for an occasional friable layer, approximately 1/4-inch thick, at surface.

2) Most of the refractory concrete was solid or in large pieces from metal retaining band inward except for surface friable layer.

3) The surface pictures previously taken prior to repair are not representative of the refractory concrete under the tank knuckle.

During the early discussions reference to possible refractory concrete repair work, it was the general op inion that the refractory concrete in Tank 101 was in better condition than that in Tank 102. Similar repair work to Tank 101 was subject to re-evaluation, based on what was encountered in the refractory concrete during the repair work in Tank 102.

In my opinion, based on my observations and inspection of the refractory concrete removed from Tank 102, a re-evaluation of extent of repair work to the refractory concrete is warranted.

One method of re-evaluating Tank 101's refractory concrete would be to select four or five of the worst surface appearing sections and remove a 4 to 6-foot section of refractory concrete back to tank knuckle (tangent point), noting the condition of refractory material. From this information and sample compression tests of the refractory concrete removed, a more educated approach can be made to the repair action required. 


\section{INTER - OFFICE MEMORANDUM}

It should also be noted that removing the refractory concrete

from under the tank knuckle and replacing it with concrete will have an unknown affect on tank knuckle stresses.

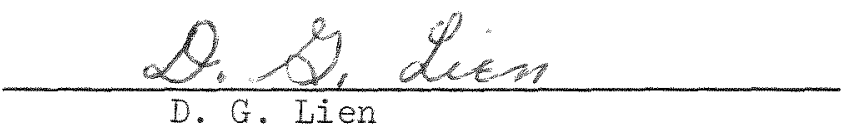

DGI:VS
ce: W. S. Graves
M. H. Piskadlo
C. A. Sursaw
D. G. Lien/File 
Rev. 0

1.18 Schulze, M., 1969a, “AY Tanks IAP-614,” (Letter to C. W. Cardwell, February 17), Vitro Hanford Engineering Service, Richland, Washington. 
February $1.7,2969$

C. H. Cardwe 12

M. Boluting

AX Tanka $\quad$ IAP -624

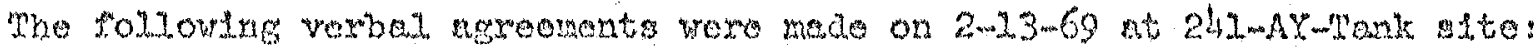

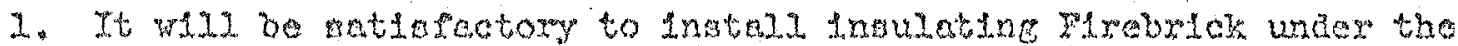
Ar P1pea, Drating K-3.64307. Rew. 2, to attnin propex elevetion of Ar Plpe sron rank Dottora.

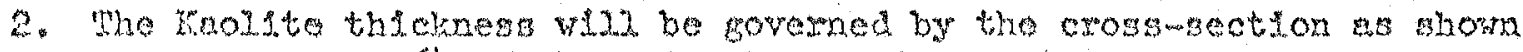

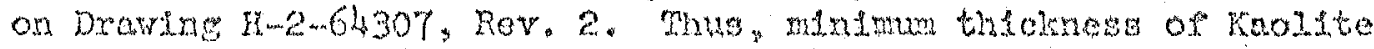

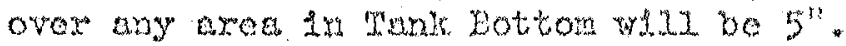

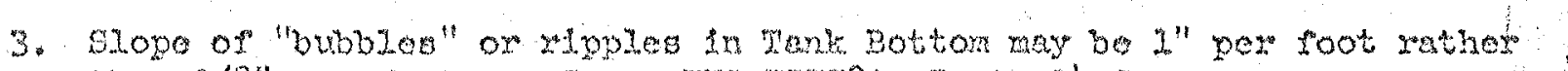

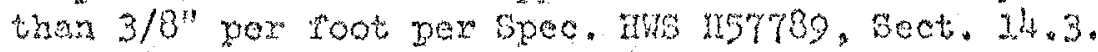

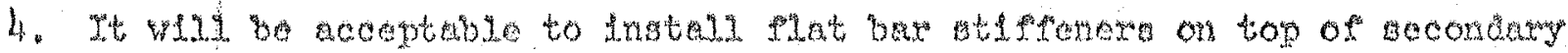

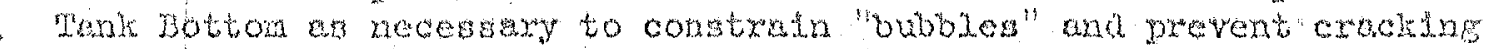

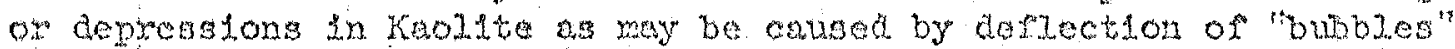

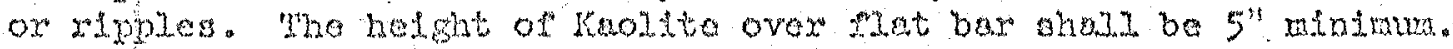

People at bus efte at the the of docusstons:

\begin{tabular}{|c|c|c|}
\hline$\triangle \mathrm{EC}$ & PDY & yetrod \\
\hline HE Dasex" & Dean Jach & Wh Graver \\
\hline DJ squires & Hugo stedn & A Short \\
\hline So Rodgero & $\begin{array}{l}\text { Ne revalandt } \\
\text { WF Sinth (aubcont.) }\end{array}$ & M schujze \\
\hline
\end{tabular}

M. Sohulze

WS: 0 ir

Co: His SRger

WS Artatsons:

Ch Knodber

VS Graves

menter

G Kugdido

an Elkins

怡/212es 
Rev. 0

1.19 Schulze, M., 1969b, "Subject IAP-614 PUREX Tank Farm Expansion - Insulating Concrete," (Letter to C. W. Cardwell, February 19), Vitro Hanford Engineering Services, Richland, Washington. 
Tebrusary 29,1969

C. W. Cardwe1.

W. B. Graves

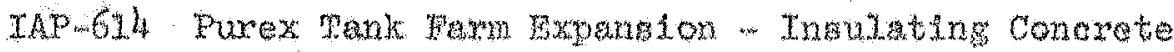

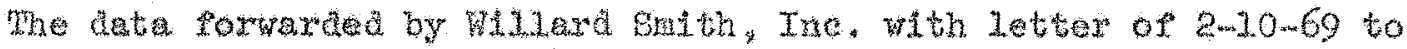

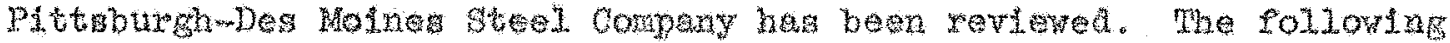
comments apply:

2. The axdings do not thow the angle of the concrete retalning form.

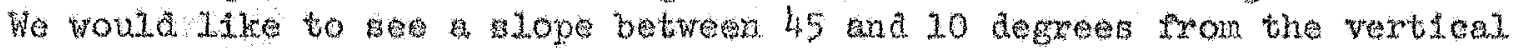

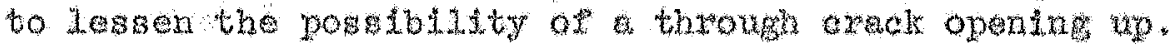

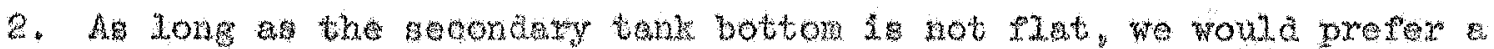

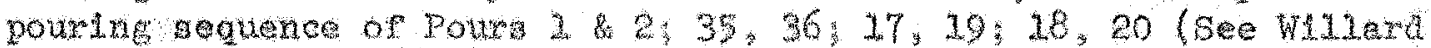

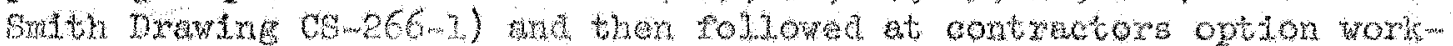

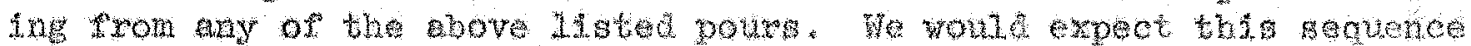

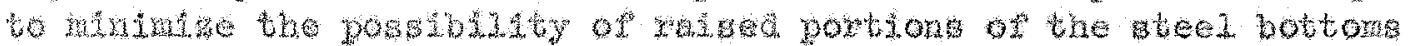

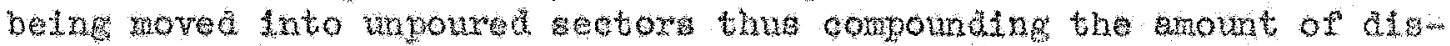

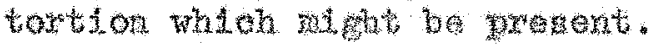

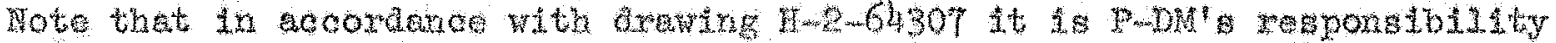

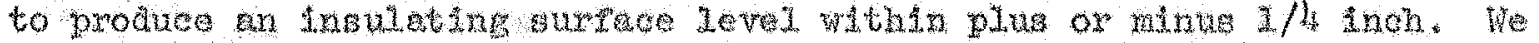

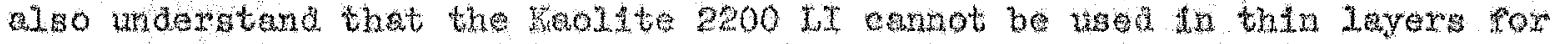

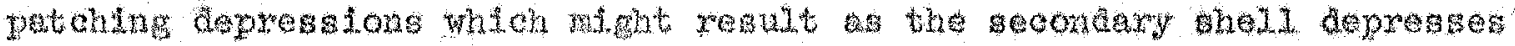
under the conorete Loaking.

$$
\begin{gathered}
\text { Orginal Signed gy } \\
\text { W. S. Graves } \\
\text { W. 8. Graves }
\end{gathered}
$$

WSQ: Thk

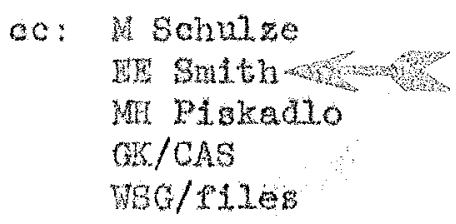


1.20 Schulze, M., 1969c, "Stress Relieving of TK 102 Tank on 9-30-69," (Letter to File, October 6), Vitro Hanford Engineering Services, Richland, Washington. 

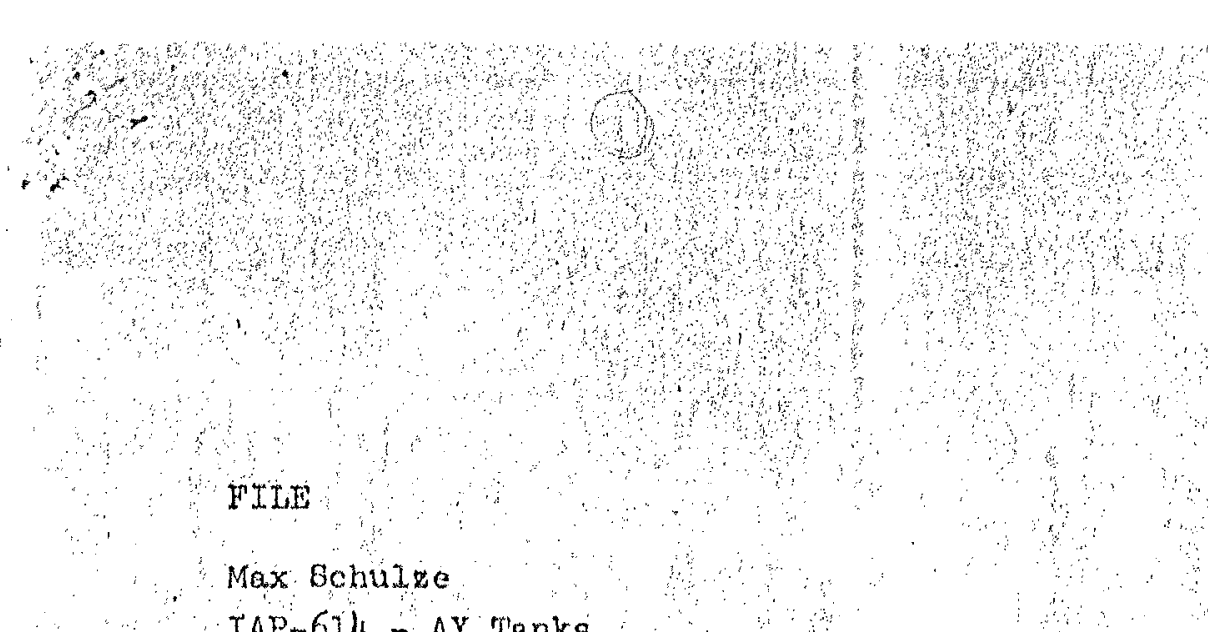

Rev. 0

Max Bchuze

$I A P-614-A X$ Tanks

Strest Relteving of TK 102 Tank on $9-30-69$

On Thesday, $9-30$ - 69 , I was called at home by Dave squirea sevaral times between 7.00 and $11: 30 \mathrm{pm}$. regarding progress and problems durling otress rellef of Tank 202. After the second call, about $8: 30$ or $9: 00, T$ tried to call serge Graves to aee if he: wanted to go out to the tanks but could not ratse him.

Squixes callea about $21: 30$ to tell me the he and the ARlico people, Bill Armstrong"; Poul Hatch, and Ernle Moore, had had a conference regerding rate-of-rlae and time-at-temperature. Hatch was concerned with possible bad effects on kaoljte subjected to a hlgh temperature for any leneth of time. They had decided to'sfe for three hours at $1000 \mathrm{~F}$ rather than go for the full $1200 \mathrm{~F}$ minimum for one hour. Squires vas concerned about possible contractual effecta and thaking of the precedent, 1969". I examed the alternates. Suppose the rate of -rise was too alow; should we teli them to shut the whole job down and start from scratch with a deforent eystem? Thts wan unacceptable to Hatch as being even worse. II polnted out inat 1t, indeed, they couldn't reach $1100 \mathrm{~F}$ "minimm they would be propostng a lower temperature and Ionger time in accordance with ABME Code. We would be hard put to deny their requeat only on the basis of "our apec says" In that the spec 1 s written around AsMe Code.

- Also, when the spec was written, discussion about this very problem had taken place and it was declded to keep this option in the hip pocket rather than aldow it out in the spec. It may be of intereat to note thet Bavennah fidver had this option in their spec. I In view of the fact that squires had trled to call both Kligfleld and Gravea: and could get no respanse, I told squires I would get out there $x$ ight away.

I arrived at the tank farm at about 12: $30^{\text {A }}$ and talked at ane length wh th Gquirea about the progres 3 and we read the charts. Squires lext at about $3: 30^{\text {f }}$ after heving recorded the readings every hour.

The ratemof rase through the midnight to $4: 00 \mathrm{gm}$. area was $40 \mathrm{~F}$ per hour and was the anme for themoouplea at ald potnts in the tank. the thermocouples in the tank bottom were performing errat tcelly with the exception of numbers $15,16,21$, and 23 which were fality constant and agreed wh the two thermocouples fastened to the knuckles. Temperature fin the base conerete was 180 fi consistently.

I talked wh thteln ard he wes not in favor of trie $1000 \mathrm{f}$ for three hours but wanted to stay wlth the origlnal apec to stey with the lioo F for one hour. I tola him this would be the 16 he woula hold the 40 per hour rise and that this would be only $I / 2$ hour ovex the new agreenent and I could bee no problem there. 


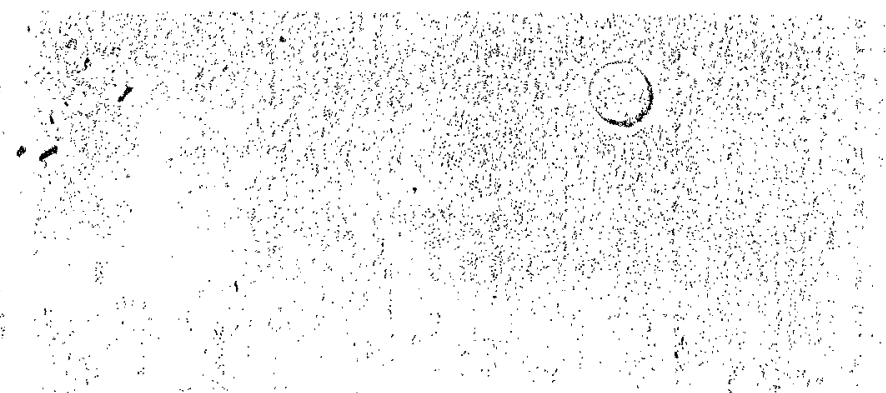

FTISH
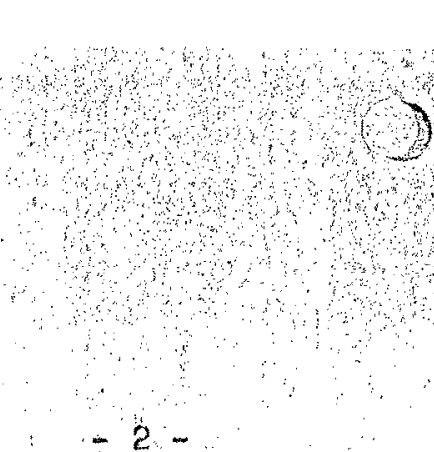

Rev. 0

Durlig this the the ARHCO people checked at intervads utid about 400 when 1511 Axnatrong came down to stay. At that time we were betting vexy close to the $1000 \mathrm{~F}$ in the bottom wlth radinga of $915,935,960$ and 1030 F, the knuckle reading beltig 970 and 980 . Dome temperature at that time wa in the $1080-1170$ range: At $4: 30 \mathrm{a}, \mathrm{m}$. we declded that we would accept the bottom an befng at 1000 F and started the thee hour count at that time although stein atily had the option of colng up per the orlginal apec tf he could. In the event temperature rise from 4:00 am. on was extremely alow and it was obvious that we had peaked out. Thus, white the dectalon to eo for the option of three houra at 1000 f was made for a different peason, it would have had to be made on the basta of the actual performance.

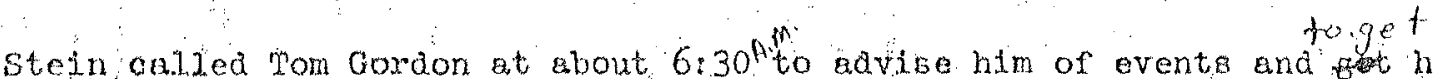
7:30 pito start the reduotion part of the cyele. He showed up at about $8 ; 00$. Herb Eager arrived In the morntag and wanted to document all happentugs. While I was giving him m account of the seaktrigmont tom Gordon interrupted and strenuous ly objected to any Laea that his equipment could not have continued beyond the posnts reached. He albo blamed the origlnal lone delay at hent up of the tank bottom to our thernocouples stating that it was his belief that thea thexmocouples were ly ing in watex in the Gaolite and wore not recordhg tank bothom temperature. It escapes me how tank bottom temperature could have been over $200^{\circ}$ th there was any water in the kalite for the thernocouples to lay it.

Upon return to Richland, a meeting was held In Ben Kirz' offlce with Krema, Kirz, Elkins, Knoeber, Kilefield and Graves. I was asked how I was are the tank was etrese rejleved and $\mathrm{I}$ etated that minimum temperatures vere besed on the cox elation between the four botton themocouples and the ones in the knuckle. Graves atated

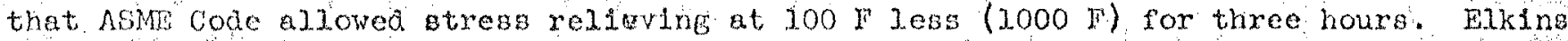
aked about an further rediction and conbequent time. A check in the code book showed that for 50 more reduction $(950.7)$ (ive hours at temperature would be requirea A quick check of my notes showed that weadings from 3:00 a.m. to 8:00 a.m. confirmed that this condtuton wes met e.1so.

Upon completion of the, meting. Kligfield and I talked to John Adena, PDM, Director of Research, and requested that he come out to Hanford as soon as posalble to aiscuss

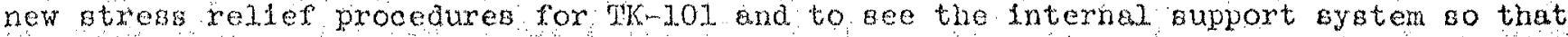
he could better appreclate the problems we anticlpate in the removal of the aupporta Adams statod that he would be unavallable through the midale of the week of $10 / 6$ and wanted to see the curves for stress rejlet of TK-102 and talk with Tom Goran prior to coming out. We later talked to Bob Wendlent, PDM, Bellevue, Washlngton, to lmpress

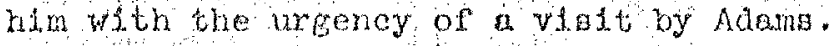

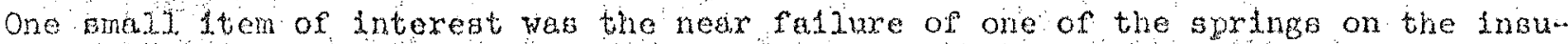
Istion holathg bande The spring had been loceted so that d. stradaled a gaj between bate in the insulation and was thus cxposed to tank shell temperature . Ihat area of the spring was mealed and quite rolaxa. Insulation was stufed into the arack behlnd the apring. I polnted this out to AI short In the morring so that on th-101 this could be prevented. 
Rev. 0

1.21 Schulze, M., 1970a, "IAP-614-AY Tanks Kaolite," (Interoffice memorandum to G. Kligfield, June 11), Vitro Hanford Engineering Services, Richland, Washington. 


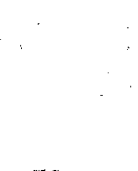

ro

G. Kligfiela

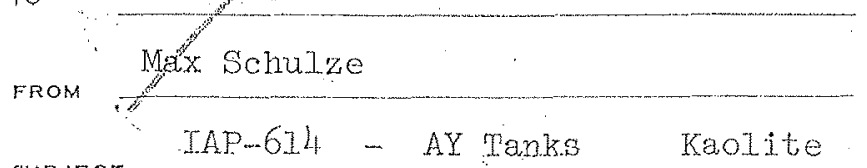

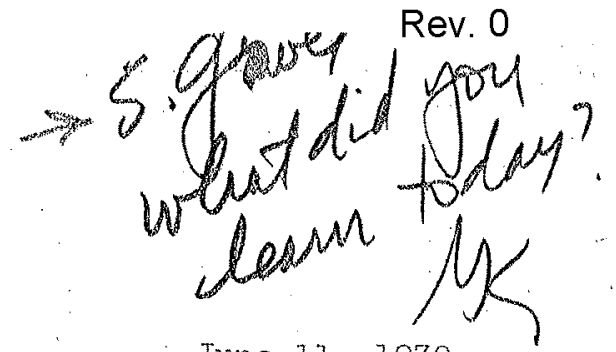

DATE June 11, 1970

(LOGATION OR DEPAPTMENT)

(LOCATIOH OR DEPARTMEVT)

I made telephone contacts with Ed Dickson, B\&W Refractories, Augusta, Ga., this week with the following of interest:

1. Dickson was the primary contact, with duPont, visiting the sp facility and conferring with Frnie Westbrook et al about their insulating concrete problens.

2. Djokson advised that chemical analygin of the RL samples was satisfactory for the product and that chemistries between friable and solid (hard) samples was within hundreaths of a percent. Reports will be forwarded to RL. Physical tests on solid samples met spees.

3. In Dickson's opinion, cracking fajlure at sR was due to the combination of Lock of plothess in pritmary end secondary tank bottoms plus radial growth of primary tank bottoms during stress relief resulting in shear stresses. for which the Waolite is not designed. Tt can be rationalized that the rriable materici. sheared and crumbled at RL lessening tendency. to crack in large lumps.

4. Dickson recomended repair by pouxting two foot wide full depth ring in place of present periphery. He strongly rebuffed any thought of less-.. than-full...depth repairs, whether Kaolite or structura, concrete, because of shear stresses.

5. Dickson believes that a redesign of insulating concrete pad is necessary as follows:

a. Stop pour at knuckle tangent.

b. Bevel outward for about $2-\cdots 3$ inches.

c. Pour outer ring beyond this to pick up support of primary bottom auring stress relier, if necessary. Pour in $61-8^{+}$segments. This will undoubtedly crack, etc., during stress relief and pieces can then be removed.

Note: This recommendation will be made to Nooter for the new SR tanks. 


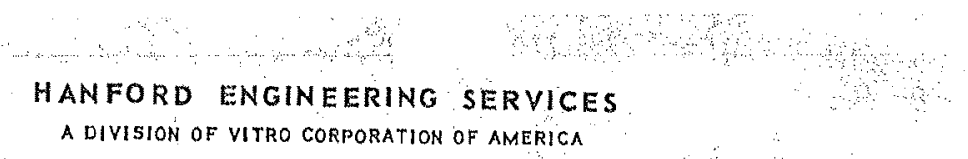

....

A DIVISION OF VITRO CORPORATION OF AMERICA

\section{INTER - OFFICE MEMORANDUH}

G. KIigfield

$-2$

June 11,1970

6. As to friable material, Dickson poses possibility of freezing after placement. I talked to Jim Trumbull, B\&W, Seattile, and he suggested that the anmuli collected a great deaj. of water which could have migrated into the concrete and subsequent low temperatures transmitted. through the primary tank bottom may have caused freezing of moisture in the top of the Kaolite.

7. Trumbull strongly recommended using a paddle mixer and a different system of pouring.

8. Trumbull and possibly. Dickson wil be here Monday to Jook at Kaolite and to engage in discussions as to present and past problems and future design. Trumbull wiII contact Vollert or Armstrong at ARHCO to make arrangements and Graves or K i gfield to advise what arrangements were made.

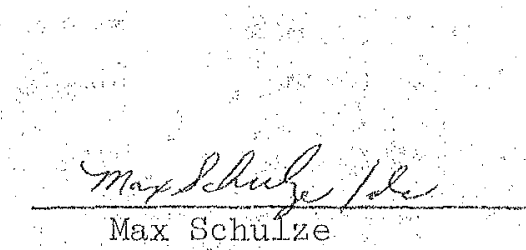

MS : ds

cc: WG. Graves
EFP Smith
IHE Smith
DG Iien
DJ Squires, AHC
B. Kirz/Kroeber
JH Slaughter
MS/File




\section{AY TANKS}

Inspection of Kaolite in TK-101 and Discussions-7/21/70

E.J. Dickson and J.I. Trumbull, B\&W, and Willard Smith arrived at AY tani site at about 11:15 a.m., put on coveralls and were lowered into TK-101 in company with E.F. Smith, Max Schulze, and Bob Caldwel1, V/HES. Some work was going on in the vessel to remove \#l sections of outer ring. Dickson was shown as-is Kaolite with friable surface, cracked Kaolite, and method of removal. Several times during the inspection of the annulus Dickson satisfied himself that there was some bellying-up or oil canning of the secondary bottom. Inspection of TK-101 was continued until noon at which time all parties were taken out of tank to go to $2101 \mathrm{M} \mathrm{BIdg.} \mathrm{for} \mathrm{lunch,} \mathrm{to}$ be followed by discussions.

DISCUSSION

Discussions were held in 2l0lM Bldg. Attendees:

Vitro $\quad$ AEC $\quad$ ARHCO Vendor

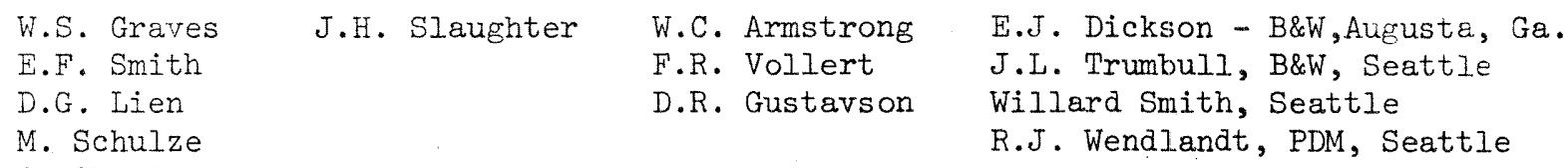

A. Short

E.S. Davis

B.A. Caldwel1

A. Pads in both TK-101 and 102 have a friable surface at the top which is not homogeneous with the balance of the Kaolite. Friable material has little or no compressive strength and will break up immediately and crumble under impact or compression.

B. The friable layer in TK-102 varies from about $3 / 4$ " to $1-3 / 4$ " thick whereas in TK-101 it generally varied from $1 / 4^{\prime \prime}$ to $1 / 2^{\prime \prime}$ thick.

TK-102 had one area in particular which contained a soft punky material which had no strength whatever and evidence of one or two other small locations of like material. 


\section{Possible causes of problems were discussed.}

(1) Addition of detergent. As Willard Smith poured the Kaolite with a Refractall Gun he found that it was necessary to add two cups of detargent per 200 lbs. of material per 16 gallons of water, all quantities nominal. The detergent acted as a lubricant for moving the Kaolite thru the hose; the Kaolite would not move without it. Maximum hose length was $100 \mathrm{ft}$. and $50 \mathrm{psi}$ air pressure was required. Dickson doubted that the detergent could cause any problems unless by migration of alkalies (sodium and potassium). Chemical analyses by B\&W on samples submitted covering full depth of material did not indicate any difference. When Dickson was asked whether he knew of any previous experience with the Refractall Gun, he replied that he did not know of any cast jobs being done this way but that dry and wet gunning processes were common. There was a question concerning tendency to segregate during pumping and Dickson agreed theoretically this could be but there was no evidence of this in TK-I0I that he could see.

(2) Vibrating - A question was raised concerning vibrating the poured material at SR and Dickson said that it was lightly vibrated there. Heavy vibrating will cause segregation, but again, there is no evidence of this in Tank 101 as segregation would mean that the cement fines would want to float to the top and the result would be a local strengthening of the top at the expense of the bottom. This does not describe the condition in TK-101 or 102. Large air bubbles in samples in Vollert's possession confirms the fact that vibrating was not excessive.

(3) Screeding - Dickson questioned Willard Smith as to method of screeding and was told that a wooden screed was used and screeding was done right over the frame starting at the outside or wide section and moving toward the center. Shirley Davis stated that the average pour lasted 2 hours and 15 minutes and that set-up time was 4 to 5 hours, and that the material was still plastic when forms were pulled.

(4) Curing - Willard Smith described the tent and heaters furnished. He stated that the humidity was about $90 \%$, but admitted that no measurements were taken or records kept on this point. After a pour was finished it would be covered with polyethylene. In some cases the polyethylene was pulled after 8 hours instead of 24 hours and woyld be off for up to 4 hours while stripping forms. Possibly some polyethylene was not reinstalled. Dickson asked whether the cast surface was wet at aIl times under the cover and stated that the material should be covered for 24 hours or until hydration is completed. This would require a material temperature of $65^{\circ}$ for 24 hours. He stated that dropping material temperature to $50^{\circ}$ would increase curing time to 7 days. He asked if there was a possible drying effect from the air flow. 
There was some discussion about possible effects of the loss of part of the tent during a wind storm, but this occurred during pouring in TK-101, the tank with the better Kaolite. There was some discussion about temperatures and generally it was observed that the lowest temperatures were encountered during and immediately after pouring in $\mathrm{TK}-102$.

(5) Stress Relief - The stress relief operation was described to Dickson. Particular stress was laid on the amount of steaming in the annulus. Dickson suggested that possibly the moisture was condensing against the secondary tank wall and that we had a recycling effect for some time. Dickson was questioned as to whether the presence of steam could in some way cause the friable surface. He replied that it could not. The question was rephrased with reference to steam possibly causing problems with the binder. Dickson said that it cannot cause problems with the type of binder we have, calcium aluminate. Problems could be caused with a calcium silicate binder.

(6) Binders - A discussion took place around the subject of binders. Kaolite 2000 uses a binder called alumnite which is calcium aluminate with 5\% iron. Kaolite $2200 \mathrm{LI}$ (low iron) uses a calcium aluminate with a lower iron content. The $K 2000$ has about twice the strength of the K 2200LI.

SR used K 20 modified to control chlorides. The binder in $K 20$ Modified as used by SR was High Early Portland Cement (Type III), a calcium silicate. Dickson was questioned as to resistance of $K 20$, K 2000 and $K$ 2200II to sulfates. He stated that he would get his laboratory working on this and provide answers as soon as possible. Dickson advised that the coefficient of expansion of Kaolite 2200LI is $3.3 \times 10^{-6}$.

The question was raised as to density of the calcium aluminate with reference to the aggregate and the reply was that the calcium aluminate is heavier dry and lighter wet.

(7) Storage - Dickson was asked about sensitivity of material to rain in the dry state and he replied that there is about a $10 \%$ strength loss per year during warehousing. High humidity, however, will make the material lump. Willard Smith stated that the material was pumped thru a $1 / 2^{\prime \prime}$ grid. Trumbull stated that B\&W now produces the material in shrink pack on pallets in the factory but that it would still be advisable to put a good polyethylene cover over it. 
D. Dickson gave his and $S^{\prime}$ 's view as to cause of failure, as follows:

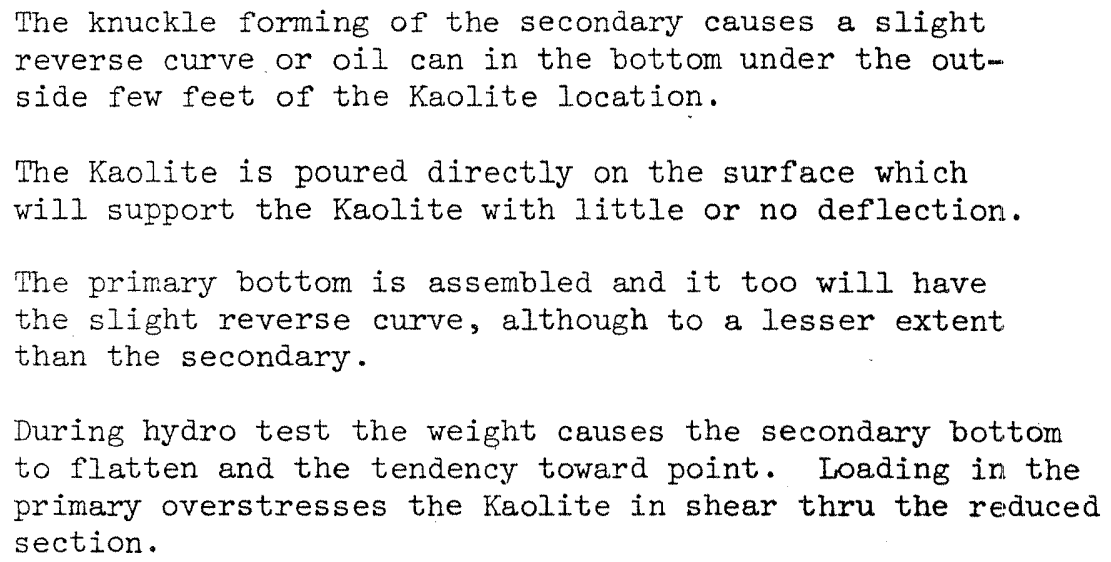

The meeting was terminated.

MS : ds

cc: Onsite Attendees

G.Kligfield 
Rev. 0

1.22 Schulze, M., 1970b, "Inspection of Kaolite in TK-101 and Discussion," (Meeting minutes, July 21), Vitro Hanford Engineering Company, Richland, Washington. 


\section{AY TANKS}

Inspection of Kaolite in TK-101 and Discussions-7/21/70

E.J. Dickson and J.I. Trumbull, B\&W, and Willard Smith arrived at AY tani site at about 11:15 a.m., put on coveralls and were lowered into TK-101 in company with E.F. Smith, Max Schulze, and Bob Caldwel1, V/HES. Some work was going on in the vessel to remove \#l sections of outer ring. Dickson was shown as-is Kaolite with friable surface, cracked Kaolite, and method of removal. Several times during the inspection of the annulus Dickson satisfied himself that there was some bellying-up or oil canning of the secondary bottom. Inspection of TK-101 was continued until noon at which time all parties were taken out of tank to go to $2101 \mathrm{M} \mathrm{BIdg.} \mathrm{for} \mathrm{lunch,} \mathrm{to}$ be followed by discussions.

DISCUSSION

Discussions were held in 2l0lM Bldg. Attendees:

Vitro $\quad$ AEC $\quad$ ARHCO Vendor

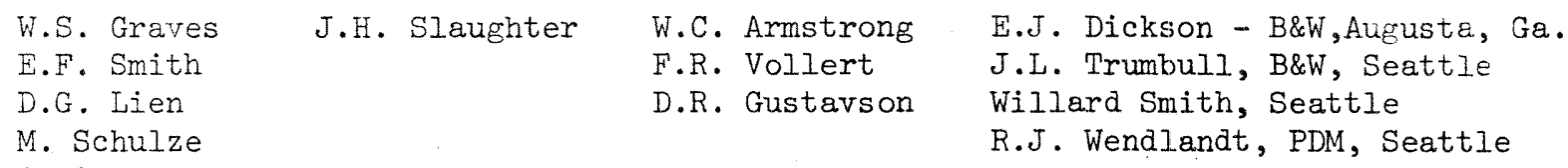

A. Short

E.S. Davis

B.A. Caldwel1

A. Pads in both TK-101 and 102 have a friable surface at the top which is not homogeneous with the balance of the Kaolite. Friable material has little or no compressive strength and will break up immediately and crumble under impact or compression.

B. The friable layer in TK-102 varies from about $3 / 4$ " to $1-3 / 4$ " thick whereas in TK-101 it generally varied from $1 / 4^{\prime \prime}$ to $1 / 2^{\prime \prime}$ thick.

TK-102 had one area in particular which contained a soft punky material which had no strength whatever and evidence of one or two other small locations of like material. 


\section{Possible causes of problems were discussed.}

(1) Addition of detergent. As Willard Smith poured the Kaolite with a Refractall Gun he found that it was necessary to add two cups of detargent per 200 lbs. of material per 16 gallons of water, all quantities nominal. The detergent acted as a lubricant for moving the Kaolite thru the hose; the Kaolite would not move without it. Maximum hose length was $100 \mathrm{ft}$. and $50 \mathrm{psi}$ air pressure was required. Dickson doubted that the detergent could cause any problems unless by migration of alkalies (sodium and potassium). Chemical analyses by B\&W on samples submitted covering full depth of material did not indicate any difference. When Dickson was asked whether he knew of any previous experience with the Refractall Gun, he replied that he did not know of any cast jobs being done this way but that dry and wet gunning processes were common. There was a question concerning tendency to segregate during pumping and Dickson agreed theoretically this could be but there was no evidence of this in TK-I0I that he could see.

(2) Vibrating - A question was raised concerning vibrating the poured material at SR and Dickson said that it was lightly vibrated there. Heavy vibrating will cause segregation, but again, there is no evidence of this in Tank 101 as segregation would mean that the cement fines would want to float to the top and the result would be a local strengthening of the top at the expense of the bottom. This does not describe the condition in TK-101 or 102. Large air bubbles in samples in Vollert's possession confirms the fact that vibrating was not excessive.

(3) Screeding - Dickson questioned Willard Smith as to method of screeding and was told that a wooden screed was used and screeding was done right over the frame starting at the outside or wide section and moving toward the center. Shirley Davis stated that the average pour lasted 2 hours and 15 minutes and that set-up time was 4 to 5 hours, and that the material was still plastic when forms were pulled.

(4) Curing - Willard Smith described the tent and heaters furnished. He stated that the humidity was about $90 \%$, but admitted that no measurements were taken or records kept on this point. After a pour was finished it would be covered with polyethylene. In some cases the polyethylene was pulled after 8 hours instead of 24 hours and woyld be off for up to 4 hours while stripping forms. Possibly some polyethylene was not reinstalled. Dickson asked whether the cast surface was wet at aIl times under the cover and stated that the material should be covered for 24 hours or until hydration is completed. This would require a material temperature of $65^{\circ}$ for 24 hours. He stated that dropping material temperature to $50^{\circ}$ would increase curing time to 7 days. He asked if there was a possible drying effect from the air flow. 
There was some discussion about possible effects of the loss of part of the tent during a wind storm, but this occurred during pouring in TK-101, the tank with the better Kaolite. There was some discussion about temperatures and generally it was observed that the lowest temperatures were encountered during and immediately after pouring in $\mathrm{TK}-102$.

(5) Stress Relief - The stress relief operation was described to Dickson. Particular stress was laid on the amount of steaming in the annulus. Dickson suggested that possibly the moisture was condensing against the secondary tank wall and that we had a recycling effect for some time. Dickson was questioned as to whether the presence of steam could in some way cause the friable surface. He replied that it could not. The question was rephrased with reference to steam possibly causing problems with the binder. Dickson said that it cannot cause problems with the type of binder we have, calcium aluminate. Problems could be caused with a calcium silicate binder.

(6) Binders - A discussion took place around the subject of binders. Kaolite 2000 uses a binder called alumnite which is calcium aluminate with 5\% iron. Kaolite $2200 \mathrm{LI}$ (low iron) uses a calcium aluminate with a lower iron content. The $K 2000$ has about twice the strength of the K 2200LI.

SR used K 20 modified to control chlorides. The binder in $K 20$ Modified as used by SR was High Early Portland Cement (Type III), a calcium silicate. Dickson was questioned as to resistance of $K 20$, K 2000 and $K$ 2200II to sulfates. He stated that he would get his laboratory working on this and provide answers as soon as possible. Dickson advised that the coefficient of expansion of Kaolite 2200LI is $3.3 \times 10^{-6}$.

The question was raised as to density of the calcium aluminate with reference to the aggregate and the reply was that the calcium aluminate is heavier dry and lighter wet.

(7) Storage - Dickson was asked about sensitivity of material to rain in the dry state and he replied that there is about a $10 \%$ strength loss per year during warehousing. High humidity, however, will make the material lump. Willard Smith stated that the material was pumped thru a $1 / 2^{\prime \prime}$ grid. Trumbull stated that B\&W now produces the material in shrink pack on pallets in the factory but that it would still be advisable to put a good polyethylene cover over it. 
D. Dickson gave his and $S^{\prime}$ 's view as to cause of failure, as follows:

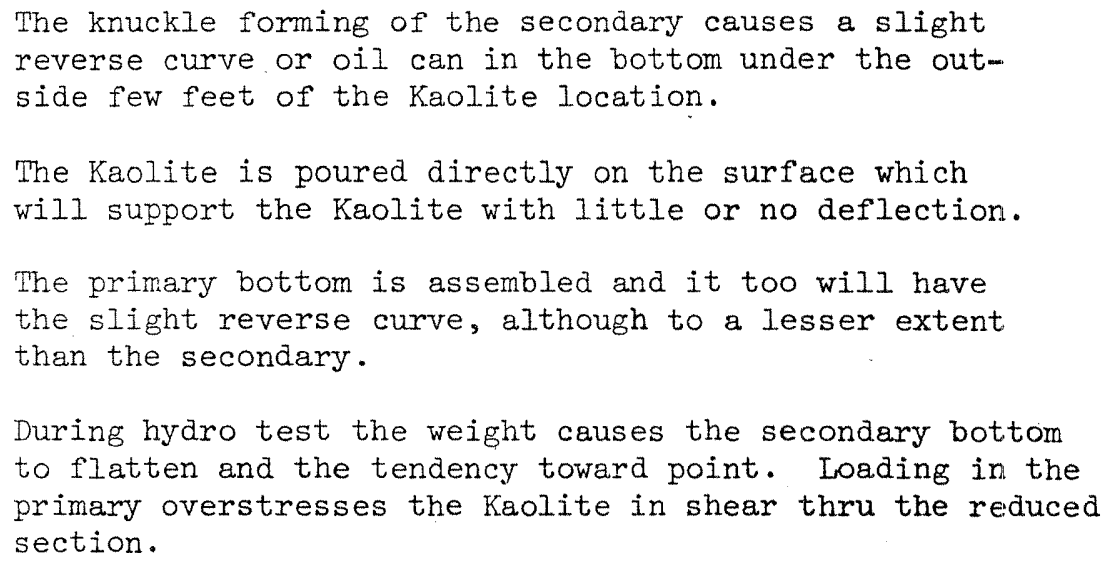

The meeting was terminated.

MS : ds

cc: Onsite Attendees

G.Kligfield 
Rev. 0

1.23 Short, A., 1969, "Nick DeStefano Visit to 241-AY Tank Farm - Project IAP-614," (Letter to C. W. Cardwell, June 18), Vitro Hanford Engineering Services, Richland, Washington. 
INTER - OFFICE MEMORANDUM

DATE June 18, 1969

to

From

suejec
C. W. Cardwe11

Al Short

Nick DeStefano Visit to 24I-AY Tank Farm - Project IAP-614

Mr. Ni ck Destefano, PDM Quality Control Supervisor for the Western Division, was on site on Monday and Tuesday, June 16 and 17 . On Tuesday morning he accompanied Bill Torrance, PDM Field Engineer on site, when Bill brought the previous night's ra,diographs to my office for my review. Mr. Sarge Graves was also in my office that morning. I wanted Sarge to see a radiograph that exhibited a classic example of the masking effect that irregular weld surface configuration causes so I asked BilI Torrance to bring XR-35 of the BA-2 joint in Tk-102 primary to my office for additional review. Mhe film covers three feet of weld about which there has been a substantial amount of contention with Hugo Stein regarding repairs to bring the weld erown into conformance with the ASME Sec. VIII radiography code.

Stein had welded two weld beads around the inside of the Tk-102 primary BA-2 joint. The PDM submerged-are "3-o'clock" welder was not functioning properly, and the surface configuration of the "Two-pass" weld was not in conformance to ASME. The lower weld pass in some places was below the plane surface of the adjoining plate. The upper weld had an excessive crown that arooped in some places, and In many places exhibited classic characteristies that are known to cause images on the radiograph that would mask internal weld defect images. In other places the fusion line between the upper and lower weld beads was below the surface of the plate. When at Stein's request, I started marking the weld surface for repair, Stein complained about my being too critical. I explained that many of the places that I had marked were unacceptable because of the abovementioned reasons. His reply was that he and I both knew how the radiograph would appear as a result of the irregular surface configurations, but that it was a "good" weld and he should not have to make any repalrs. (See my log - Tuesday, June 3, 1969.) Stein has remained adamant about the weld since then, even thoug it has since been repaired.

Therefore, the first film that was reviewed in my office yesterday (Tuesaay, June 17) was the XR-35. Two feet of the film had been found unacceptable because the fusion line between the upper and 1ower wela passes was so much closer to the plane surface of the adjoining plates than the crowns of the two weld beads. The resulting image on the radiograph could very easily be mistaken for lack of penetration with slag inelusions, or it could completely mask other defects. 
Rev. 0

\section{INTER - OFFICE MEMORANDUM}
C. W. Cardwe11
$-2-$
June 18,1969

When Nick DeStefano looked at the radiograph on the viewer in my office, he agreed that that section of the radiograph was completely unacceptable. I explained briefly that the radiograph represented an example of the weld condition about which Stein and I had disagreed. He told me that he would "get Stein straightened out on that."

The remaining radiographs that I reviewed while Nick was present were of the eight vertical joints in the $1 / 2^{\prime \prime}$ SR-2 shel1 course of Mk-102 primary, a total of eighty feet of film. In my review I found five areas of unacceptable weld that had been aceepted by the Conam radiograph interpreter. Dach time I called Mick's attention to the defect and solicited comments from him. He was completely surprized that the conam interpreter was missing the defects. When he asked what type of radiograph viewer Conam had at the site, I told him that it was a "Campco", using fluorescent bulbs for 111 umination. He was surprized that a radiography company would utilize that type of viewer on a job of this kina. Nick promised to contact the Portland supervisor of Conam and insist that he provide a high intensity viewer for this job as expeditiously as possibie.

Mick seemed quite surprized with several factors that he observed on site. One was Stein's intransigence in relation to repairing an obviously unacceptable weld. Another was the viewing equipment used by Conam, and their obviously rough handling of radiographic film prior to and/or during development. However, at no time aid Wick complain or indicate any degree of dissent or aisagreement with my interpretation of radiographs.

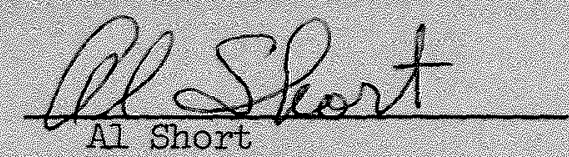

AS:ms

ce: A. Short

FE Proj. File 
Rev. 0

1.24 WSI, 1970, "PUREX Waste Storage Facility 241-AY Refractory," (Letter to J. Slaughter and B. Kirz, September 25), William Smith Inc., Seattle, Washington. 

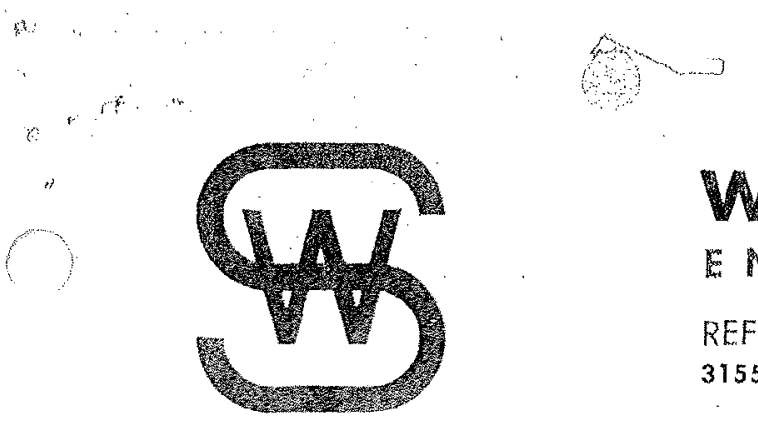

September: 25, 1970

United States Atomic Energy Commission

P. O. Box 550

Richland, Washington, 99352

Attention: Mx. Ben Kirz

Mr. John Slaughter

Subject: Purex Waste Storage Facility 24I-A.Y

Refractoxy

Gent1emen:

Subsequent to oux. July 21, 1970 , meeting at Hanford to inspect and discuss Kaolite 2200 LI in Tank 101, we ran some tests on pieces of Kaolite 2200 LI removed from the perimetex of the two Tanks 101 and 102.

Three inch thick cut pieces approximately 1011 \% 1011 wexe saturated with water and then frozen at approximately $10^{\circ} \mathrm{F}$; then heated to $500^{\circ} \mathrm{F}$ to remove ajl water. Some pieces wexe wet only approximately $1 / 4 . "$ deep and $3 / 4 "$ deep.

After this treatment, pieces of each type were cut into following shapes and subjected. to a constant 2,000\# load applied to steel plates on top and bottom of samples; hoxizontal force was applied to top plate to note effects.

A. M/11 Surface Wetted Samples

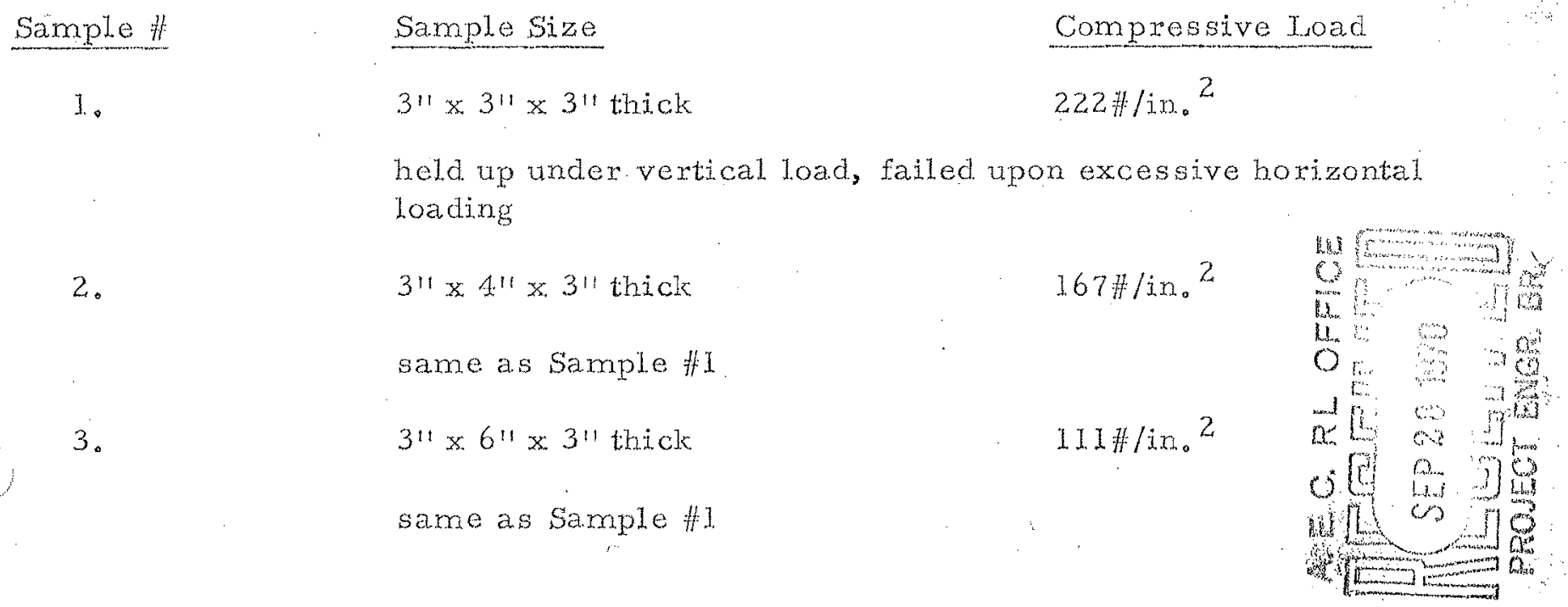


United States Atomic Enexgy Commission -2 -

Gonclusion: Verical load capability above 222 \#/in 2 ; horizontal load failure skimming inconclusive.

B. $3 / 4$ " Surface Wetted Samples
1.
$3^{11} \times 3^{11} \times 3^{11}$ thick.
$222 \# / \operatorname{in}^{2}$
held up undex vertical load, failed upon horizontal. loading substantially less than under "A" above.
2 .
$311 \times 411 \times 3^{\prime \prime}$ thick
167 H/in, 2
3.
saxne
. $311 \times 6^{\prime \prime} \times 3^{\prime \prime}$ thick $\quad 111$ H/in.2
same

Conclusion: same as "A.".

C. Completely wetted samples

1.

$3^{11} \times 3^{11} \times 3^{11}$ thick

crushed under vertical load only.

2.

$3 " \times 4 " \times 3 "$ thick

crushed under vertical load only.

3.

$3^{11} \times 66^{11} \times 3^{11}$ thick

III $\|_{1} / \mathrm{in}^{2}$

held up under vertical load, failed upon slight horizontal load.

Conclusion: After complete wetting, freezing, drying, treatment, vertical compressive load carrying ability was reduced to less than 167 \#/: ${ }^{2}$; horizontal load resisting ability substantially wreduced.

D. Completely wetted samples were cut into $2-1 / 2 "$ cubes and ma rked for vertical and horizontal loading and delivexed to Northwest Testing Laboratory fox testiog to destruction:

1. Vertical Loading
A.
149 m/in.2
B.
156

2. Horizontal Loading

C.
$259 \# / \operatorname{in}^{2}$

266 


\section{a}

United States Atomic Energy Commission

September: 25,1970

onclusion: Vertical load carrying capability is considerably lessened by freezing; hoxizontal load carrying capability is not appreciably lessened by freezing.

My opinion of these tests, is that it thoroughly substantuates oux originel presumption that freezing of Kaolite 2200 Ji, after proper curing procedures have been completed, xesults in a severely lowered load carrying capability。

We stili contend that the design for new tanks should be as described at our july 21, 1970 , discussion:

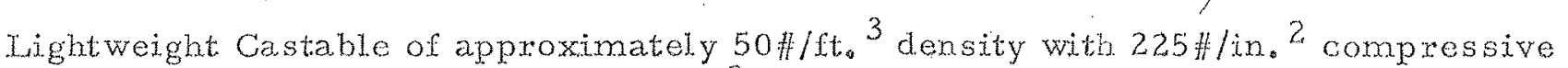
strength and approximately $k=1.60 @ 500^{\circ} \mathrm{F}$ should be usec ju center zone; heavy castable of approximately 120 स/ft. ${ }^{3}$ density with 3,000 $1 / \mathrm{jm}$. ${ }^{2}$ compressive strength and approximately $k=4.60 @ 500^{\circ} \mathrm{F}$ should be used for approximately 15 " perimeter under the tank knuckle, with a rigid retaining band.

We are now running tests on materials of this nature which utilize a CA25 bindex to see the effect of freezing on materials with this different binder. We will forwaxd these results shortly.

Youx very truly.

WITIARD SMTRH, INC.

WS/Iy

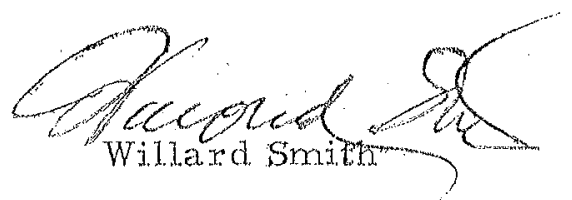

co: Vitro Hanford Engineexing Services

1392 George Washington Way

Richland, Washington, 99352

Attention: Mr. Max Schulze

Mr。Edgar Sraith

cc: Pittsburgh Des Moines Steel Company

700 - 108th Avenue N. E.

Bellevue, Washington, 98004

Attention: Mr. Bob Wendlandt 


\subsection{Supporting Documentation for RPP-ASMT-53793, Section 4.1.1, Waste Transfers and Liquid Level}

2.1 Tank AY-102 Liquid Level Data- February 1971 through December $1980 \ldots \ldots \ldots \ldots \ldots \ldots \ldots . . . . . . .2-2$

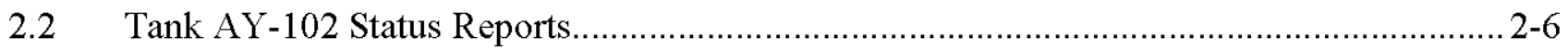

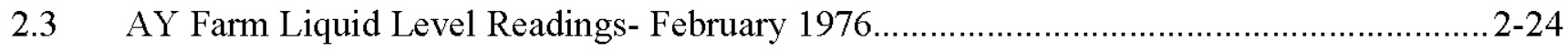

2.4 AY Farm Liquid Level Monthly Reports.................................................................. 2-26

2.5 Tank AY-102 Liquid Level Readings- October 1976.............................................. 2-30

2.6 Tank AY-102 Liquid Level Readings- September 1998 through July 2000.................... 2-32 
Rev. 0

2.1 Tank AY-102 Liquid Level Data- February 1971 through December 1980 
Tank AY-102 Liquid Levels

February 1971 through December 1980

\begin{tabular}{|c|c|c|}
\hline \multicolumn{3}{|l|}{ Liquid Level } \\
\hline Date & LL (in) & Reference \\
\hline Feb-71 & 96 & PPD-421-DEL \\
\hline Mar-72 & 86.5455 & WHC-MR-0132 \\
\hline Apr-72 & 86 & PPD-493-4-DEL \\
\hline Jul-72 & 91 & PPD-493-7-DEL \\
\hline $6 / 8 / 1973$ & 87.5 & RHO-CD-213 \\
\hline $11 / 2 / 1973$ & 76.75 & Status Report \\
\hline $12 / 1 / 1973$ & 77.5 & Status Report \\
\hline $1 / 2 / 1974$ & 78.5 & Status Report \\
\hline $2 / 1 / 1974$ & 74.75 & Status Report \\
\hline $3 / 1 / 1974$ & 75.5 & Status Report \\
\hline $4 / 1 / 1974$ & 74.5 & Status Report \\
\hline $5 / 1 / 1974$ & 77.75 & Status Report \\
\hline $6 / 1 / 1974$ & 74.25 & Status Report \\
\hline $7 / 1 / 1974$ & 73.75 & Status Report \\
\hline $8 / 1 / 1974$ & 79 & Status Report \\
\hline $9 / 1 / 1974$ & 76.5 & Status Report \\
\hline $10 / 1 / 1974$ & 72 & Status Report \\
\hline $11 / 1 / 1974$ & 73.5 & Status Report \\
\hline $12 / 1 / 1974$ & 74.5 & Status Report \\
\hline $1 / 1 / 1975$ & 76.75 & Status Report \\
\hline $2 / 1 / 1975$ & 76.75 & Status Report \\
\hline $3 / 1 / 1975$ & 74.5 & Status Report \\
\hline $2 / 10 / 1976$ & 76.5 & Status Report \\
\hline $3 / 8 / 1976$ & 75 & RHO-CD-213 \\
\hline $3 / 9 / 1976$ & 77.25 & RHO-CD-213 \\
\hline $4 / 10 / 1976$ & 76.5 & RHO-CD-213 \\
\hline $4 / 11 / 1976$ & 78.25 & RHO-CD-213 \\
\hline $5 / 8 / 1976$ & 77.25 & RHO-CD-213 \\
\hline $5 / 9 / 1976$ & 79.25 & RHO-CD-213 \\
\hline $9 / 30 / 1976$ & 76 & Status Report \\
\hline $10 / 22 / 1976$ & 22.75 & Status Report \\
\hline $10 / 23 / 1976$ & 15.25 & Status Report \\
\hline 10/25/1976 & 15 & Status Report \\
\hline 10/29/1976 & 14.25 & Status Report \\
\hline $10 / 30 / 1976$ & 20 & RHO-CD-213 \\
\hline $11 / 3 / 1976$ & 20 & RHO-CD-213 \\
\hline $1 / 9 / 1977$ & 20 & RHO-CD-213 \\
\hline $3 / 27 / 1977$ & 19 & RHO-CD-213 \\
\hline $4 / 30 / 1977$ & 47 & ARH-CD-822 APR \\
\hline
\end{tabular}

\begin{tabular}{|c|c|c|c|}
\hline Solids Level & & & \\
\hline Date & $\begin{array}{c}\mathrm{LL} \\
\text { (kgal) }\end{array}$ & LL (in) & Reference \\
\hline Jun-78 & 6 & 2.182 & WHC-SD-WM-TI-689 \\
\hline Mar-80 & 6 & 2.182 & WHC-SD-WM-TI-689 \\
\hline Apr-80 & 21 & 7.636 & WHC-SD-WM-TI-689 \\
\hline Mar-82 & 21 & 7.636 & WHC-SD-WM-TI-689 \\
\hline Apr-82 & 23 & 8.364 & WHC-SD-WM-TI-689 \\
\hline Dec-86 & 23 & 8.364 & WHC-SD-WM-TI-689 \\
\hline Jan-87 & 27 & 9.818 & WHC-SD-WM-TI-689 \\
\hline Mar-87 & 27 & 9.818 & WHC-SD-WM-TI-689 \\
\hline Apr-87 & 28 & 10.18 & WHC-SD-WM-TI-689 \\
\hline Dec-87 & 28 & 10.18 & WHC-SD-WM-TI-689 \\
\hline Jan-88 & 32 & 11.64 & \begin{tabular}{|l|l} 
WHC-SD-WM-TI-689 \\
\end{tabular} \\
\hline $9 / 4 / 1998$ & & 9.31 & Sediment Level Readings \\
\hline $11 / 15 / 1998$ & & 9 & Sediment Level Readings \\
\hline $11 / 19 / 1998$ & & 11.43 & Sediment Level Readings \\
\hline $12 / 1 / 1998$ & & 12.2 & Sediment Level Readings \\
\hline $12 / 29 / 1998$ & & 12.17 & Sediment Level Readings \\
\hline $2 / 26 / 1999$ & & 11.88 & Sediment Level Readings \\
\hline $3 / 9 / 1999$ & & 13.96 & Sediment Level Readings \\
\hline $3 / 11 / 1999$ & & 16.78 & Sediment Level Readings \\
\hline $3 / 16 / 1999$ & & 19.67 & Sediment Level Readings \\
\hline $3 / 22 / 1999$ & & 18.34 & Sediment Level Readings \\
\hline $3 / 29 / 1999$ & & 19.22 & Sediment Level Readings \\
\hline $3 / 31 / 1999$ & & 26.89 & Sediment Level Readings \\
\hline $4 / 5 / 1999$ & & 29.45 & Sediment Level Readings \\
\hline $4 / 29 / 1999$ & & 29.47 & Sediment Level Readings \\
\hline $5 / 20 / 1999$ & & 35.13 & Sediment Level Readings \\
\hline $6 / 7 / 1999$ & & 49.63 & Sediment Level Readings \\
\hline $7 / 6 / 1999$ & & 46.74 & Sediment Level Readings \\
\hline $8 / 5 / 1999$ & & 51.34 & Sediment Level Readings \\
\hline $9 / 8 / 1999$ & & 52.7 & Sediment Level Readings \\
\hline $10 / 4 / 1999$ & & 68.92 & Sediment Level Readings \\
\hline $11 / 2 / 1999$ & & 67.53 & Sediment Level Readings \\
\hline Feb-00 & & 66.74 & Sediment Level Readings \\
\hline Jul-00 & & 65.98 & Sediment Level Readings \\
\hline Sep-12 & 170 & 61.82 & PCSACS \\
\hline
\end{tabular}




\begin{tabular}{|c|c|c|}
\hline \multicolumn{3}{|l|}{ Liquid Level } \\
\hline Date & LL (in) & Reference \\
\hline $5 / 31 / 1977$ & 73 & ARH-CD-822 MAY \\
\hline $6 / 14 / 1977$ & 83 & RHO-CD-213 \\
\hline $6 / 24 / 1977$ & 82.75 & RHO-CD-213 \\
\hline $6 / 30 / 1977$ & 93.75 & RHO-CD-213 \\
\hline $8 / 5 / 1977$ & 93 & RHO-CD-213 \\
\hline $8 / 6 / 1977$ & 80.75 & RHO-CD-213 \\
\hline 9/23/1977 & 80.25 & RHO-CD-213 \\
\hline 9/30/1977 & 80.25 & RHO-CD-213 \\
\hline $12 / 5 / 1977$ & 79 & RHO-CD-213 \\
\hline $12 / 6 / 1977$ & 79.25 & RHO-CD-213 \\
\hline $12 / 8 / 1977$ & 79.25 & RHO-CD-213 \\
\hline $2 / 3 / 1978$ & 79 & RHO-CD-213 \\
\hline $4 / 1 / 1978$ & 126 & RHO-CD-213 \\
\hline $4 / 11 / 1978$ & 125.5 & RHO-CD-213 \\
\hline $4 / 19 / 1978$ & 129.75 & RHO-CD-213 \\
\hline $5 / 9 / 1978$ & 129.75 & RHO-CD-213 \\
\hline $5 / 15 / 1978$ & 132.25 & RHO-CD-213 \\
\hline $5 / 30 / 1978$ & 132 & RHO-CD-213 \\
\hline $5 / 31 / 1978$ & 132.5 & RHO-CD-213 \\
\hline $6 / 7 / 1978$ & 132.25 & RHO-CD-213 \\
\hline $7 / 13 / 1978$ & 136.25 & RHO-CD-213 \\
\hline $8 / 12 / 1978$ & 136.25 & RHO-CD-213 \\
\hline $9 / 10 / 1978$ & 139.5 & RHO-CD-213 \\
\hline $10 / 13 / 1978$ & 139 & RHO-CD-213 \\
\hline 10/15/1978 & 139.5 & RHO-CD-213 \\
\hline $11 / 22 / 1978$ & 139 & RHO-CD-213 \\
\hline 11/23/1978 & 140.25 & RHO-CD-213 \\
\hline $12 / 3 / 1978$ & 140.5 & RHO-CD-213 \\
\hline $12 / 4 / 1978$ & 141.75 & RHO-CD-213 \\
\hline $12 / 22 / 1978$ & 140.75 & RHO-CD-213 \\
\hline $1 / 5 / 1979$ & 140.25 & RHO-CD-213 \\
\hline $1 / 17 / 1980$ & 140.5 & RHO-CD-213 \\
\hline $1 / 18 / 1980$ & 141.25 & RHO-CD-213 \\
\hline $1 / 31 / 1980$ & 141.091 & RHO-CD-14 JAN \\
\hline $2 / 29 / 1980$ & 141.091 & RHO-CD-14 FEB \\
\hline $3 / 31 / 1980$ & 141.091 & RHO-CD-14 MAR \\
\hline $4 / 30 / 1980$ & 141.091 & RHO-CD-14 APR \\
\hline $5 / 16 / 1980$ & 141.25 & RHO-CD-213 \\
\hline $5 / 31 / 1980$ & 176.727 & RHO-CD-14 MAY \\
\hline $6 / 30 / 1980$ & 250.909 & RHO-CD-14 JUN \\
\hline $7 / 31 / 1980$ & 250.909 & RHO-CD-14 JUL \\
\hline $8 / 31 / 1980$ & 258.909 & RHO-CD-14 AUG \\
\hline $9 / 30 / 1980$ & 258.909 & RHO-CD-14 SEP \\
\hline
\end{tabular}

\begin{tabular}{|c|c|c|c|}
\hline \multicolumn{4}{|c|}{ Solids Level } \\
\hline Date & $\begin{array}{c}\mathrm{LL} \\
\text { (kgal) }\end{array}$ & LL (in) & Reference \\
\hline
\end{tabular}




\begin{tabular}{|c|c|c|}
\hline \multicolumn{3}{|l|}{ Liquid Level } \\
\hline Date & LL (in) & Reference \\
\hline $10 / 18 / 1980$ & 73.5 & RHO-CD-213 \\
\hline 10/31/1980 & 73.8182 & RHO-CD-14 OCT \\
\hline $11 / 12 / 1980$ & 73.5 & $\mathrm{RHO}-\mathrm{CD}-213$ \\
\hline $11 / 13 / 1980$ & 71.3 & RHO-CD-213 \\
\hline $11 / 16 / 1980$ & 71.35 & RHO-CD-213 \\
\hline $11 / 28 / 1980$ & 77.9 & RHO-CD-213 \\
\hline $11 / 30 / 1980$ & 77.8182 & RHO-CD-14 NOV \\
\hline $12 / 26 / 1980$ & 78.1 & $\mathrm{RHO}-\mathrm{CD}-213$ \\
\hline $12 / 27 / 1980$ & 82.6 & RHO-CD-213 \\
\hline $12 / 31 / 1980$ & 82.5455 & $\mathrm{RHO}-\mathrm{CD}-14 \mathrm{DEC}$ \\
\hline
\end{tabular}

\begin{tabular}{|c|c|c|c|}
\hline \multicolumn{4}{|c|}{ Solids Level } \\
\hline Date & $\begin{array}{c}\mathrm{LL} \\
\text { (kgal) }\end{array}$ & LL (in) & Reference \\
\hline
\end{tabular}

Note: Liquid level readings after 1980 were taken from PCSACS. 
2.2 Tank AY-102 Status Reports- November 1973 to March 1975 


$$
\begin{array}{r}
\text { RPP-ASMT-53794 } \\
\text { Rev. } 0
\end{array}
$$

STATUS REPORT - 241-AY TANK FARM

$$
\text { DATE: } 11-2-73
$$

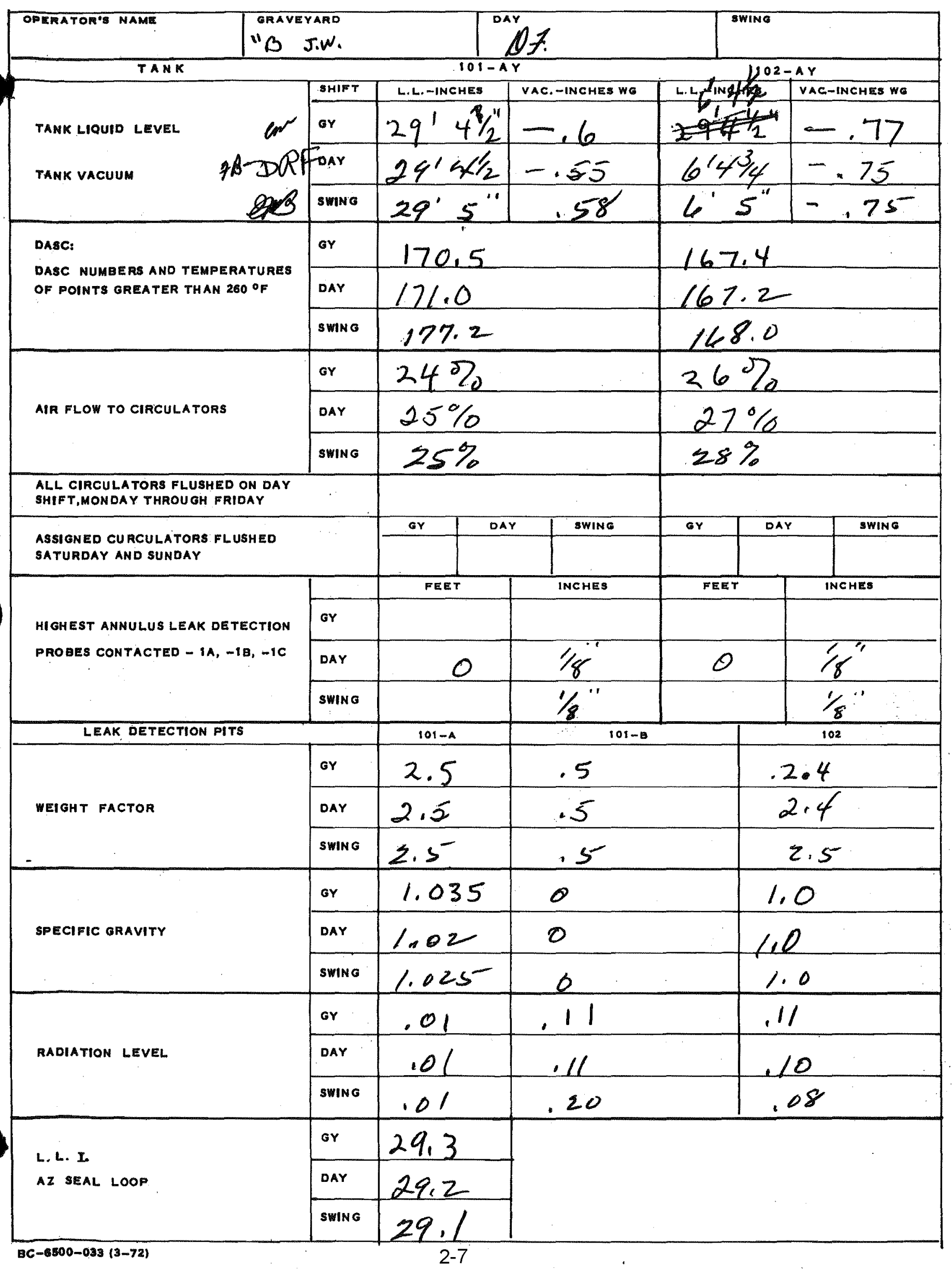




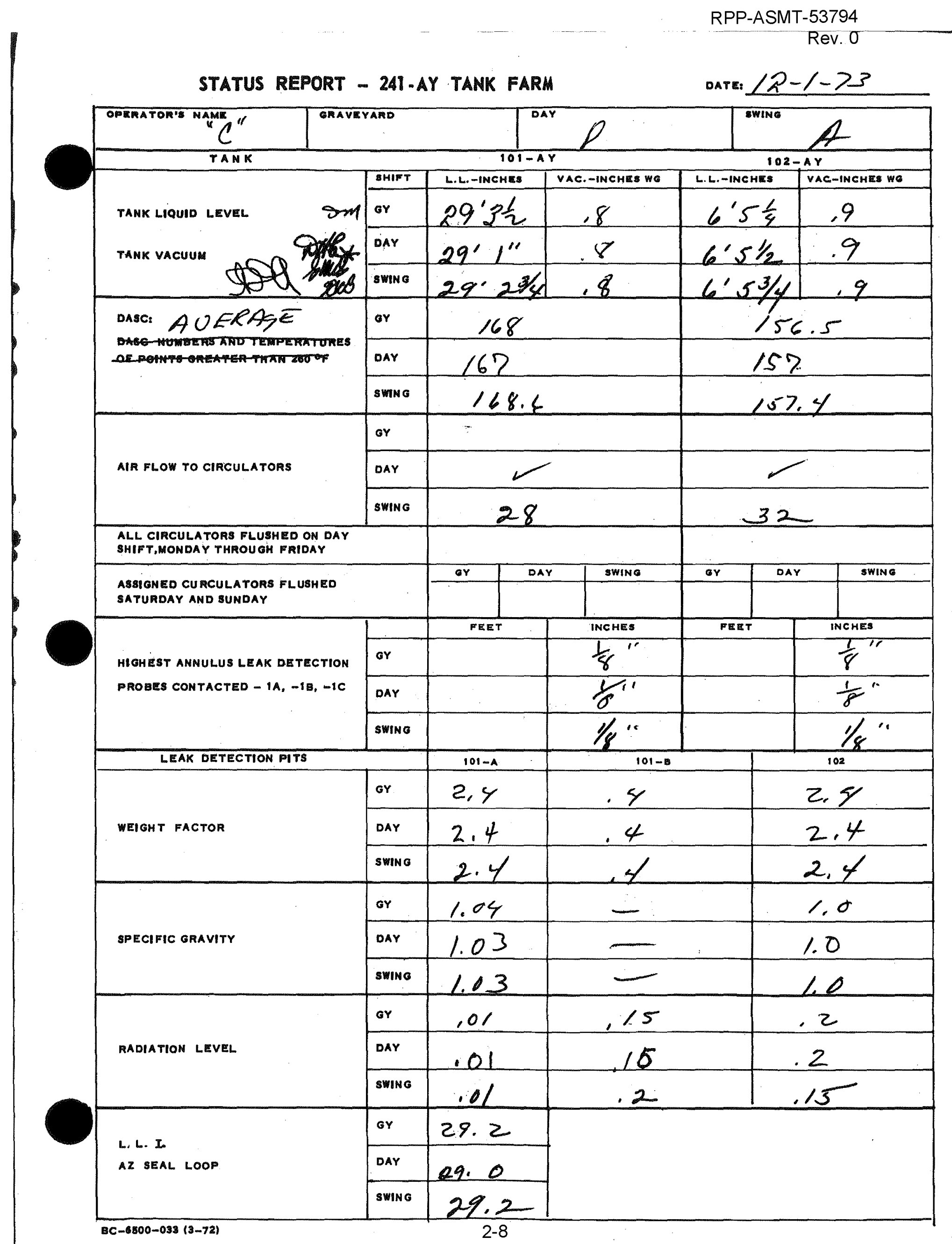


RPP-ASMT-53794

Rev. 0

STATUS REPORT - 241-AY TANK FARM DATE: $/ 2-25$

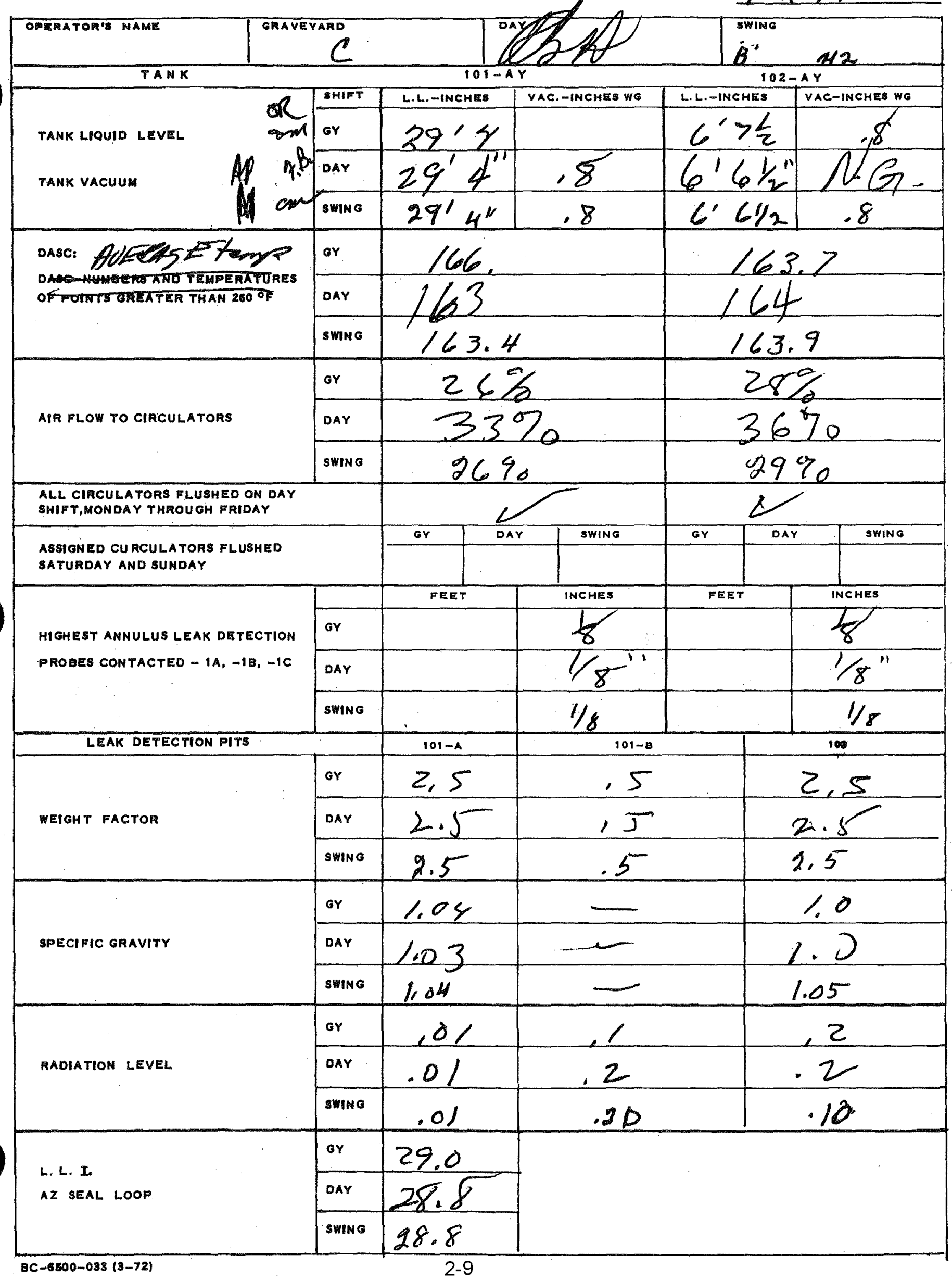


RPP-ASMT-53794

Rev: $\theta$

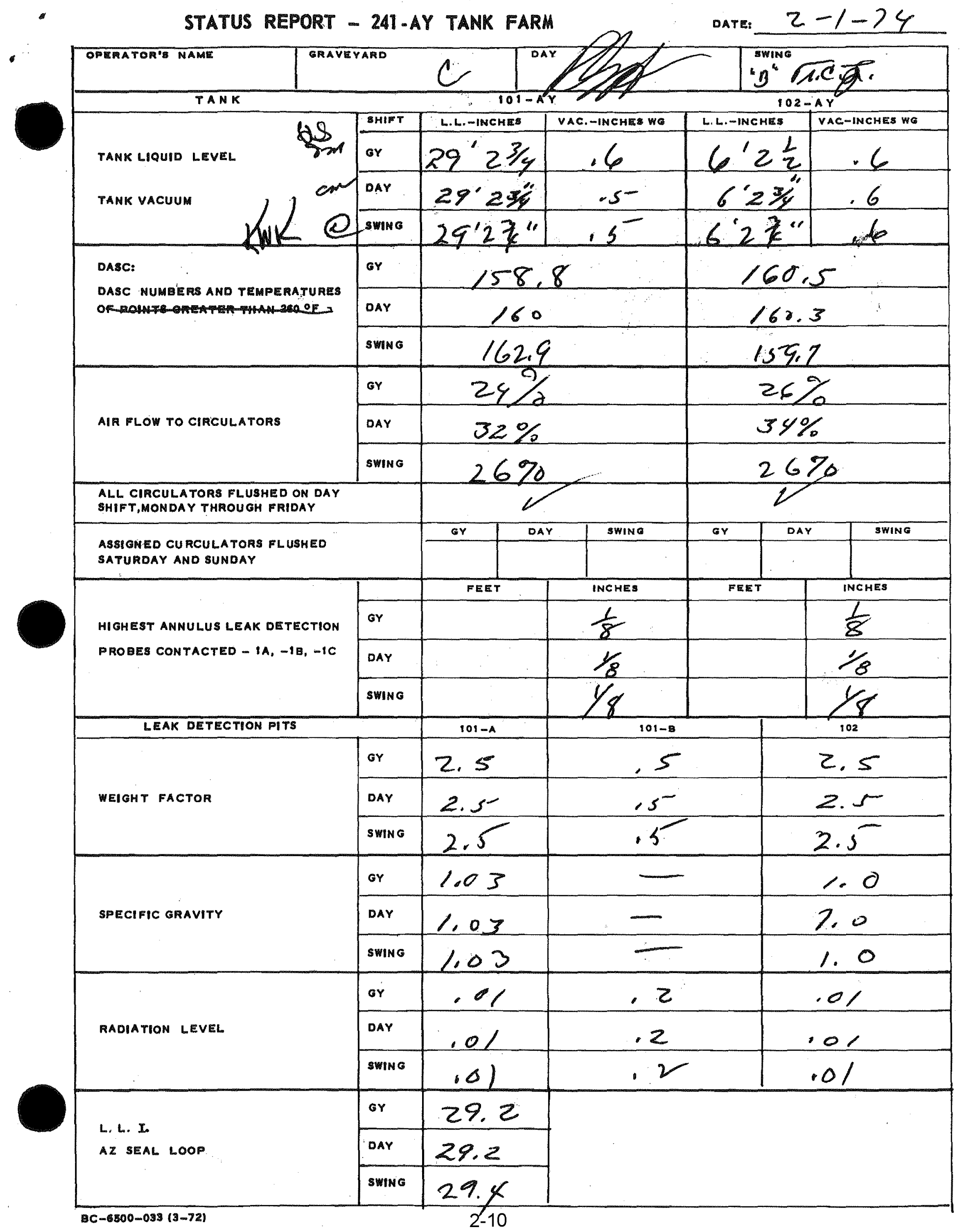




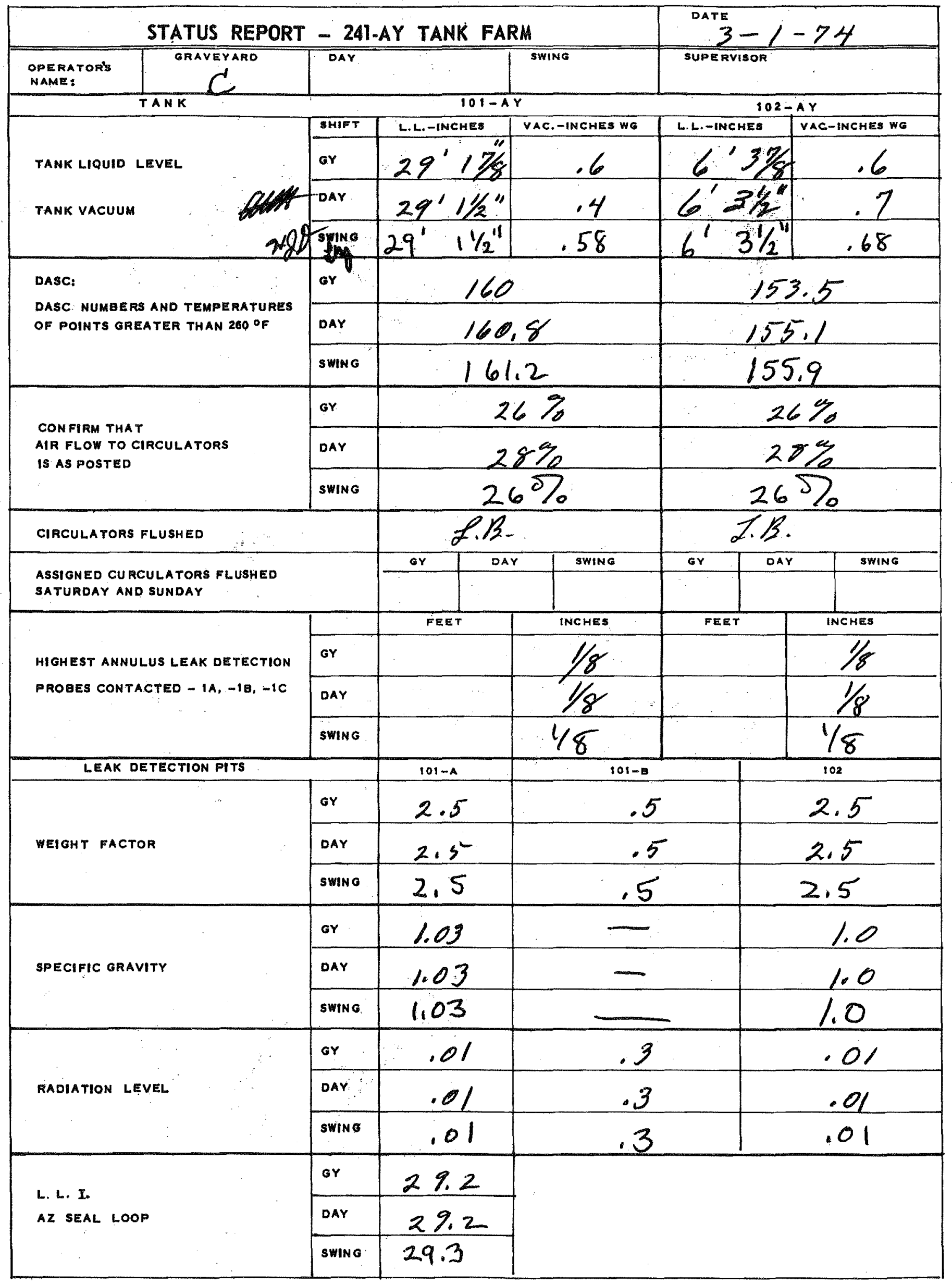




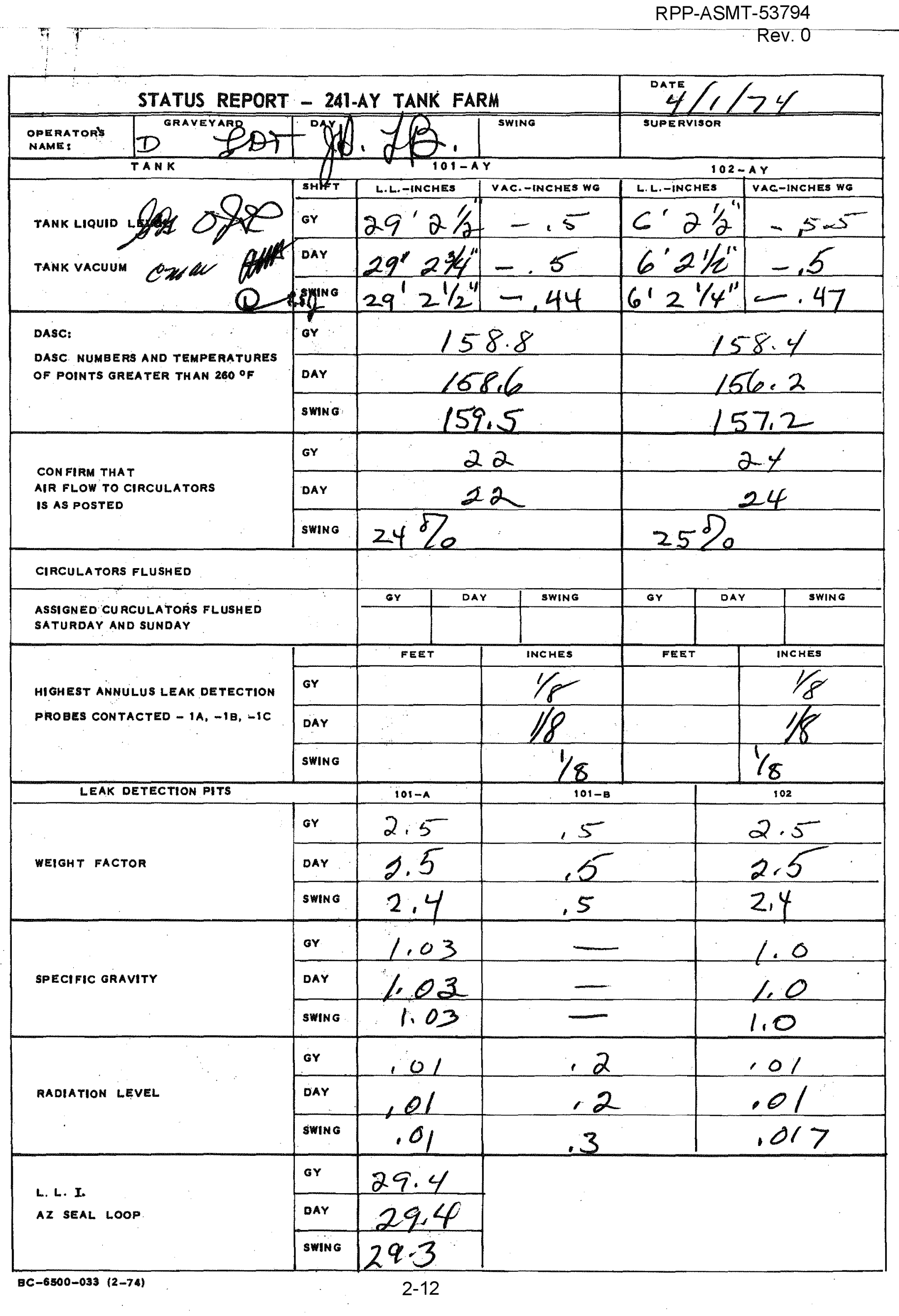




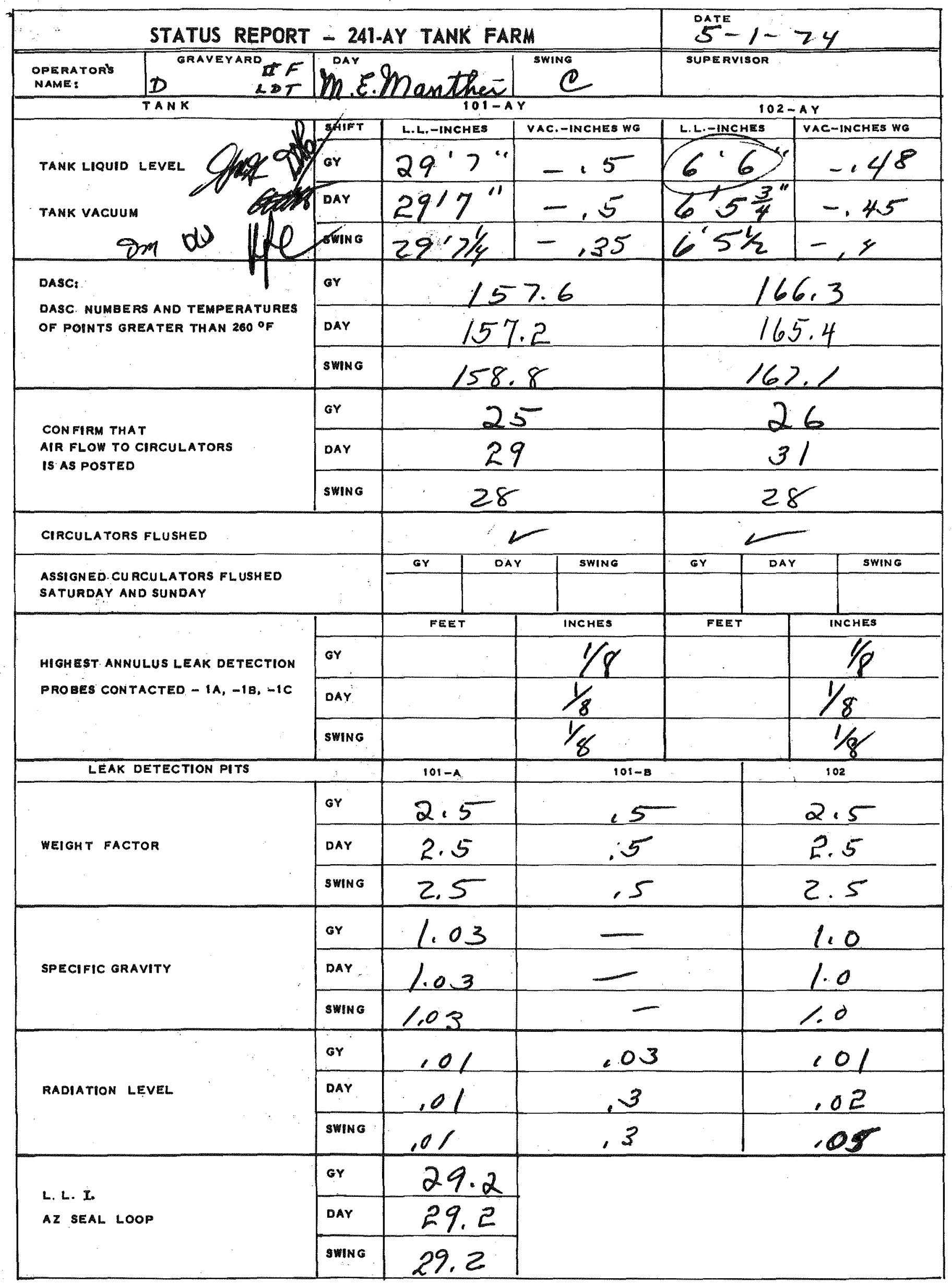




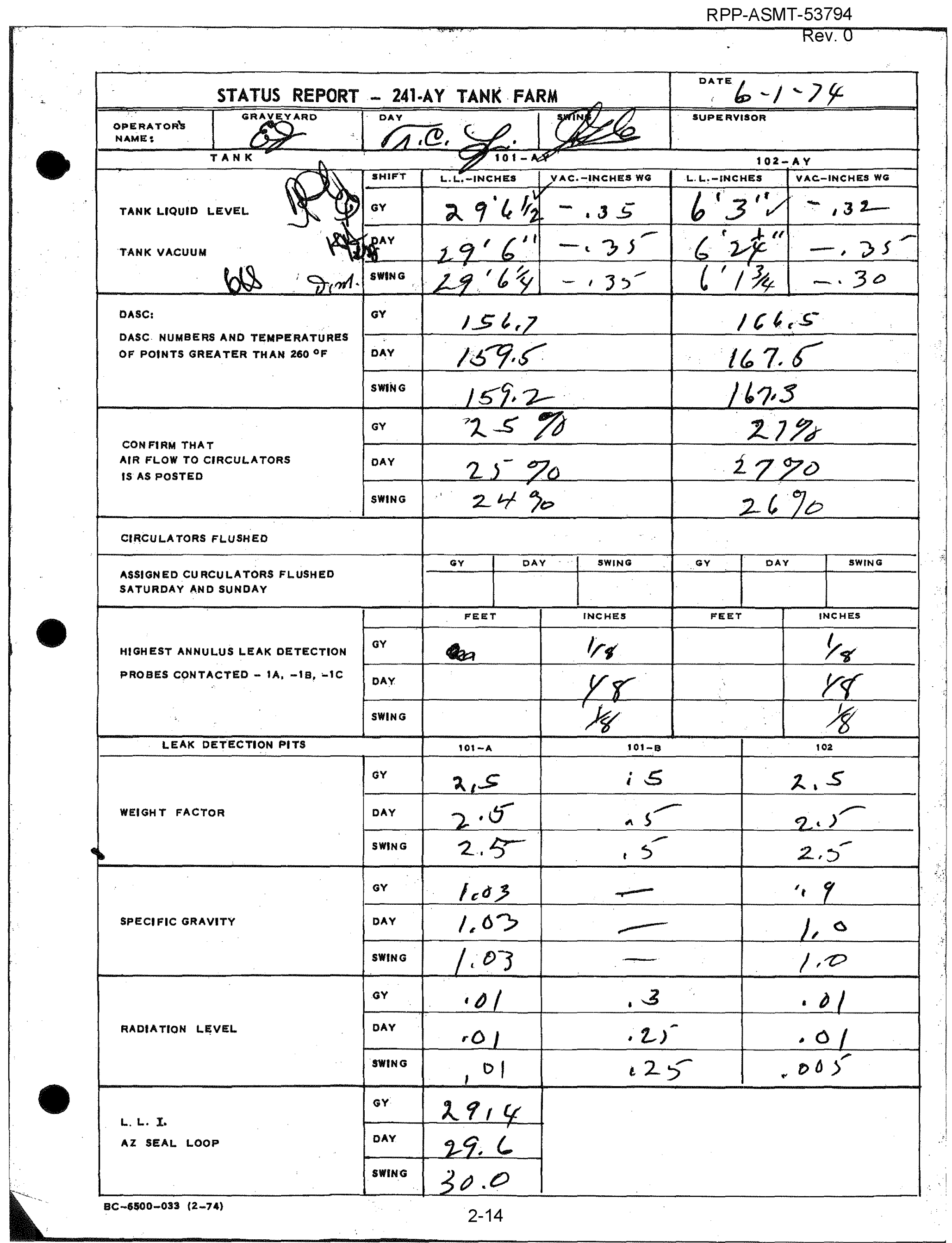




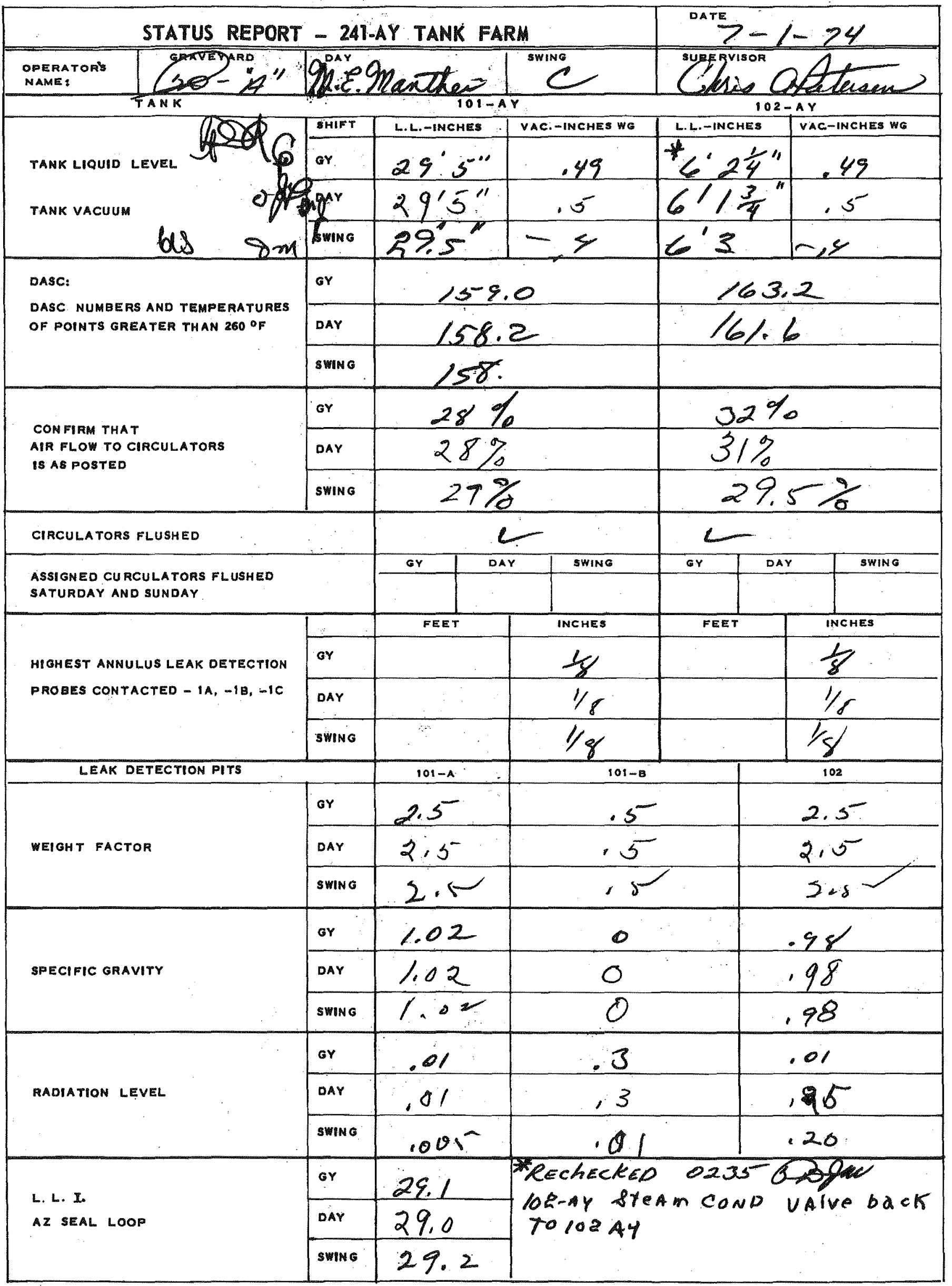




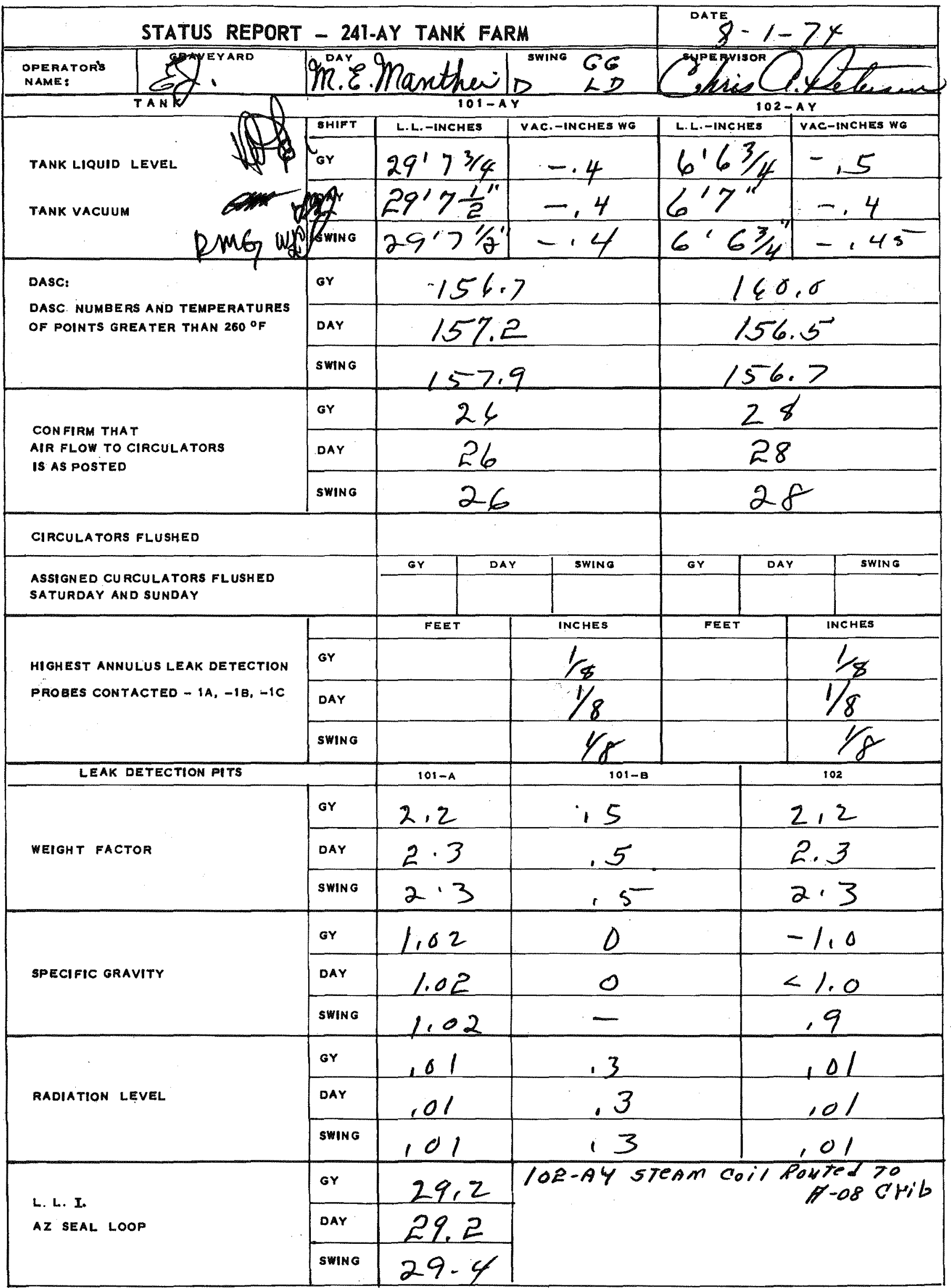


Rev. 0

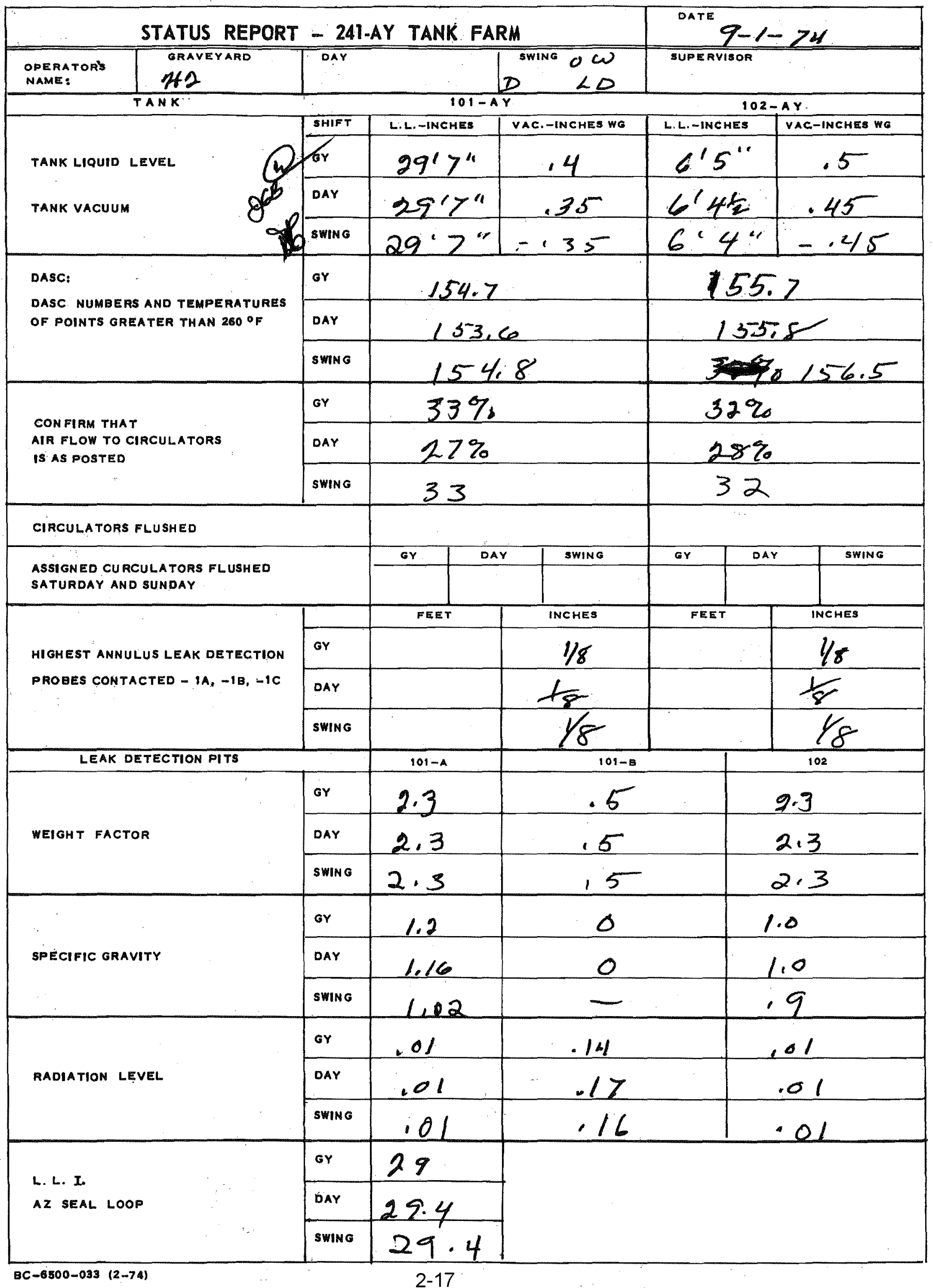




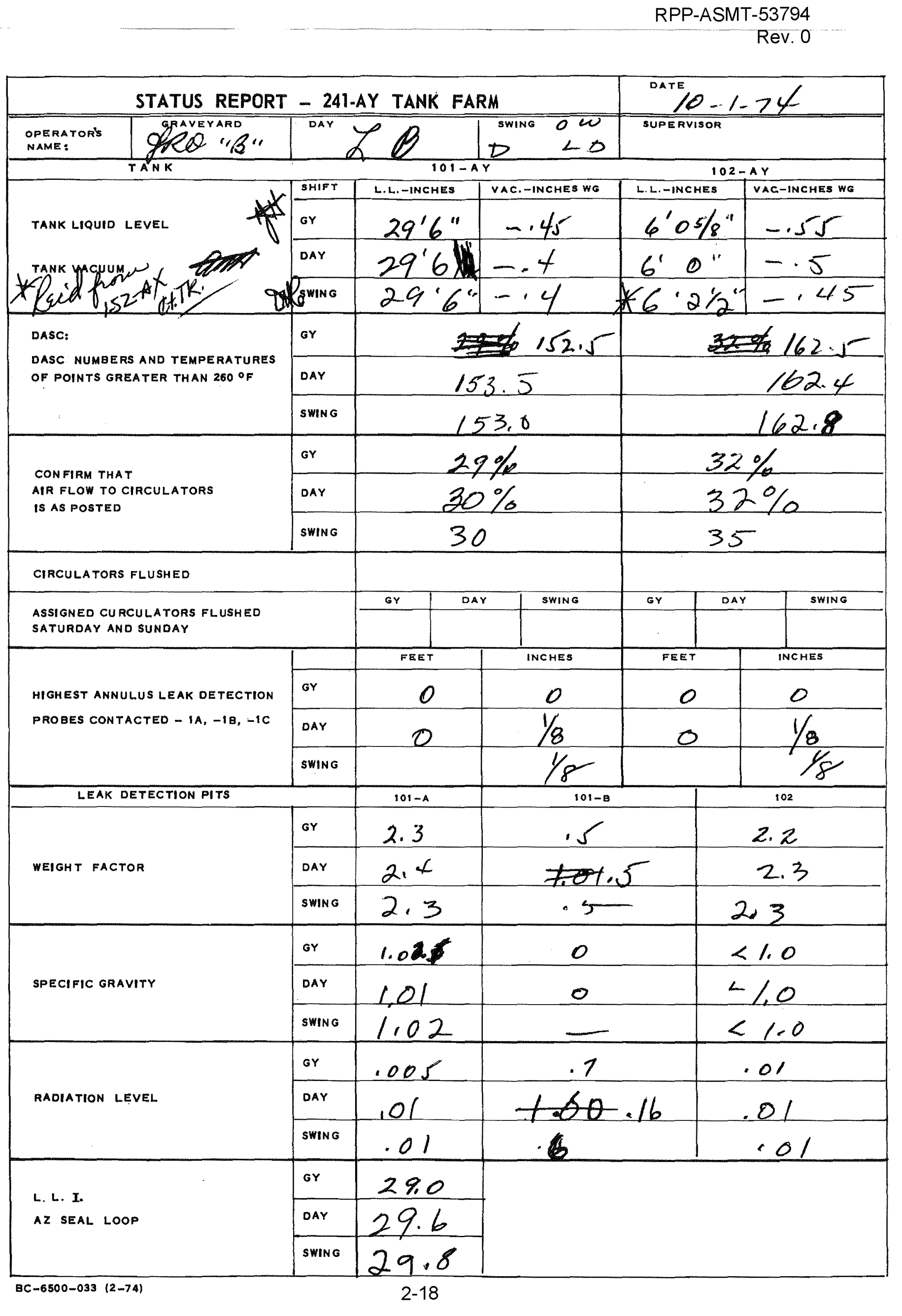




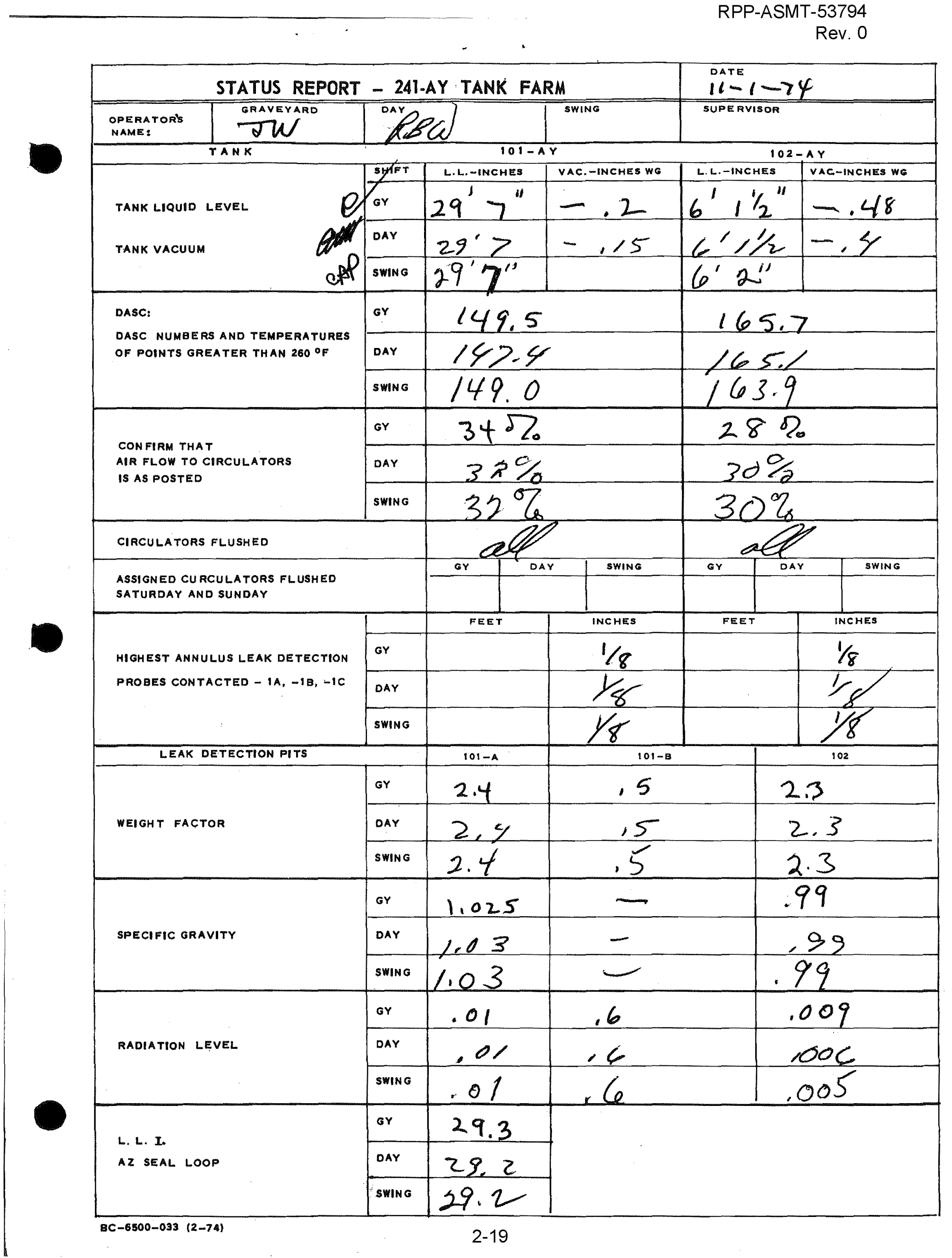




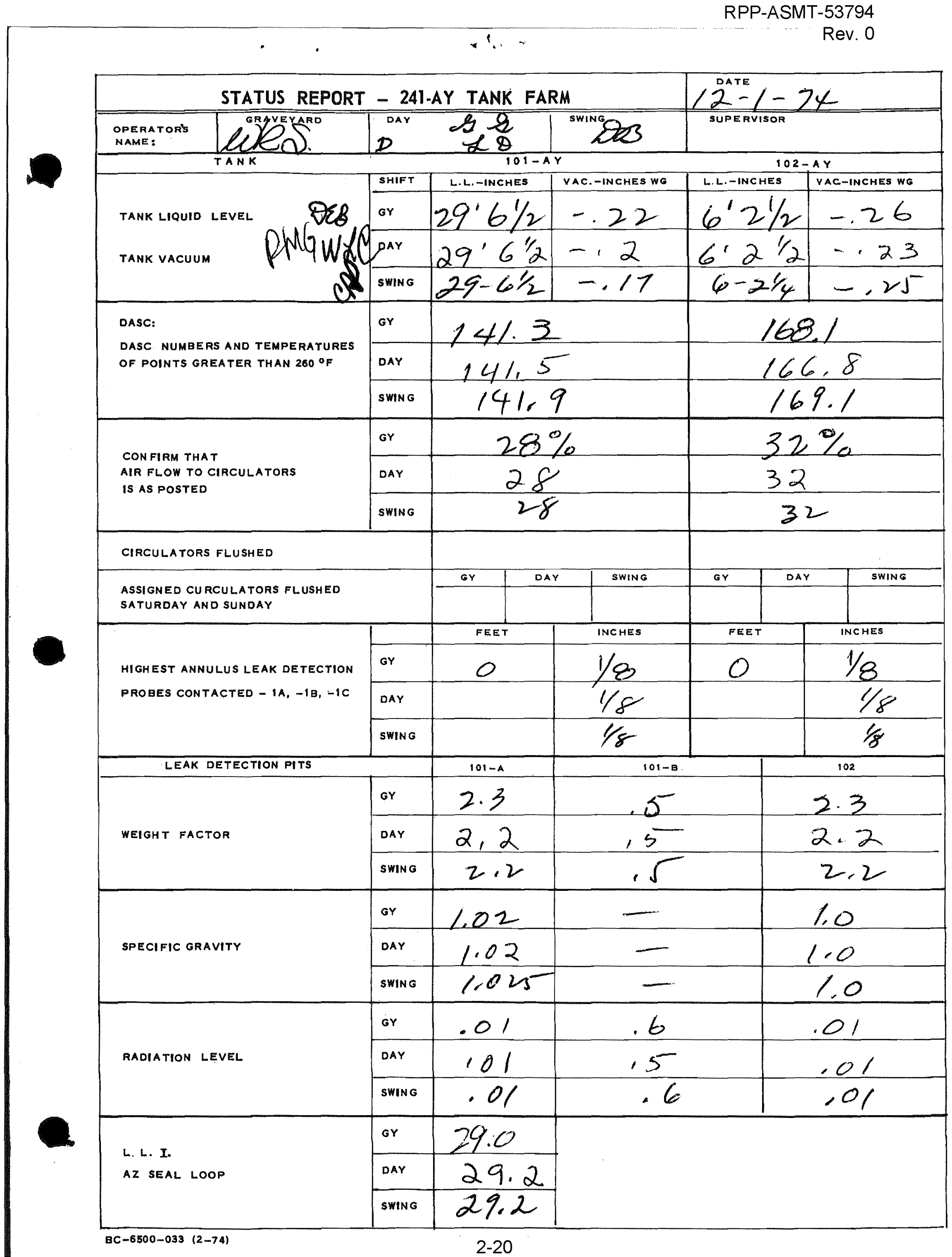




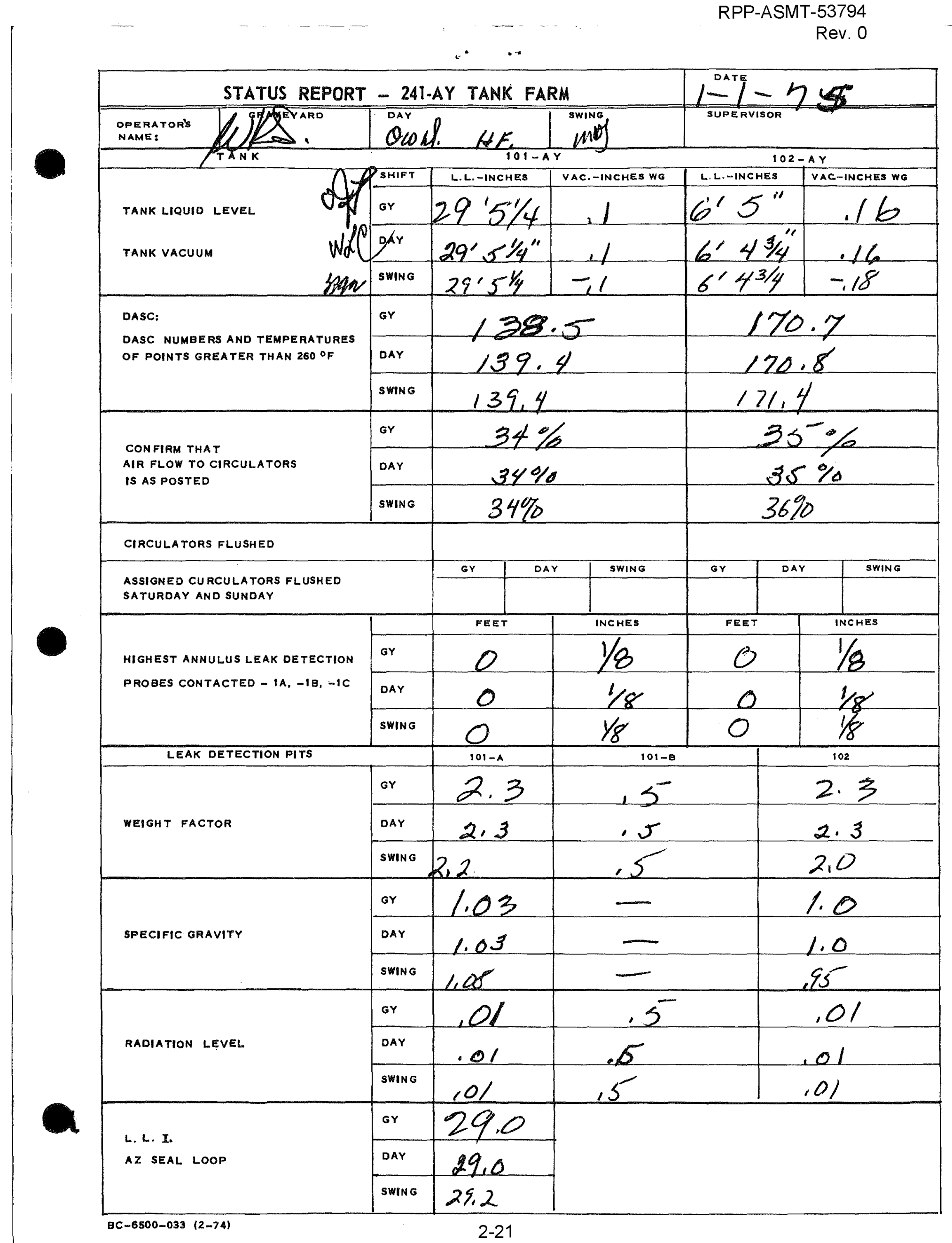




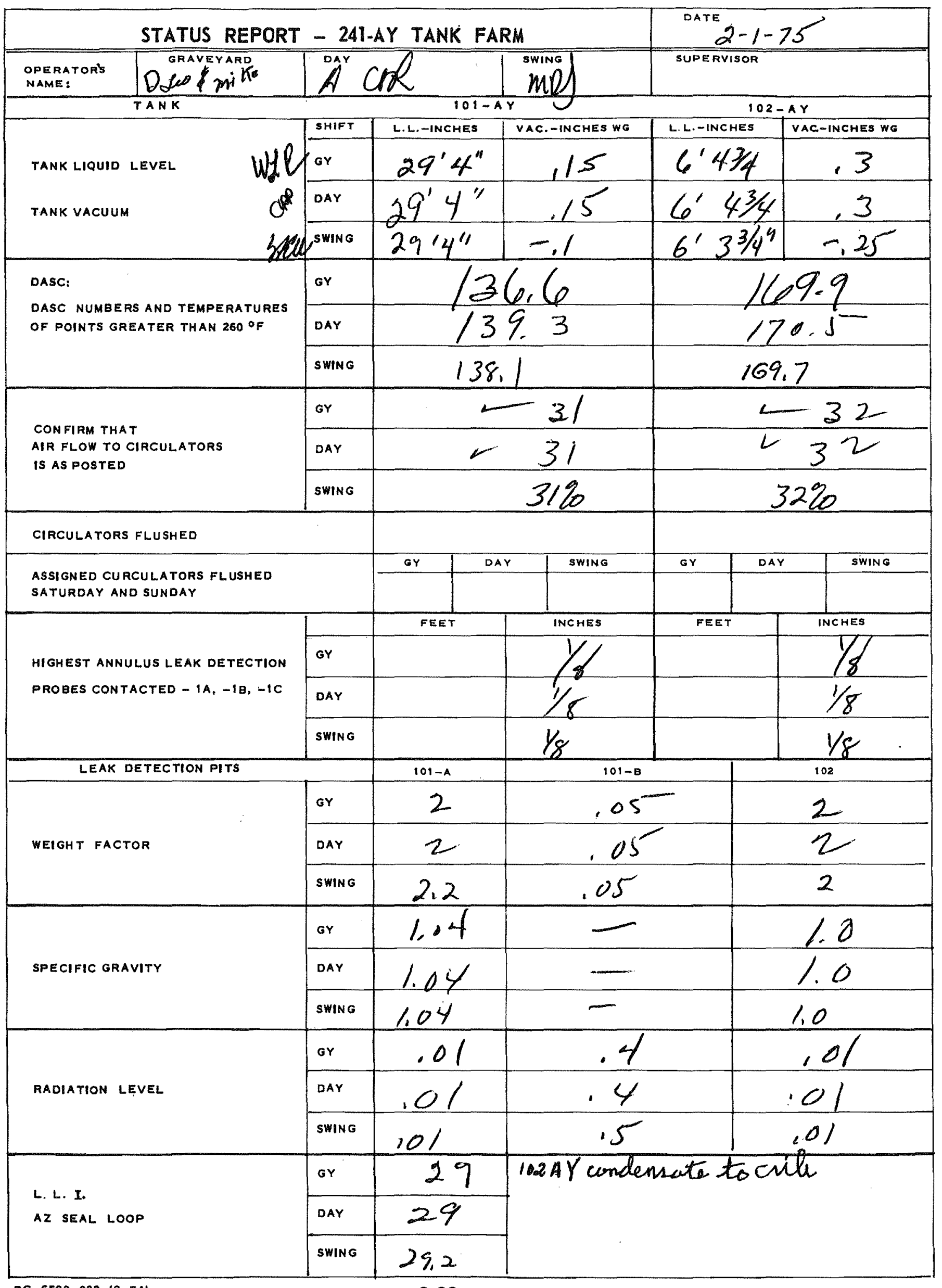




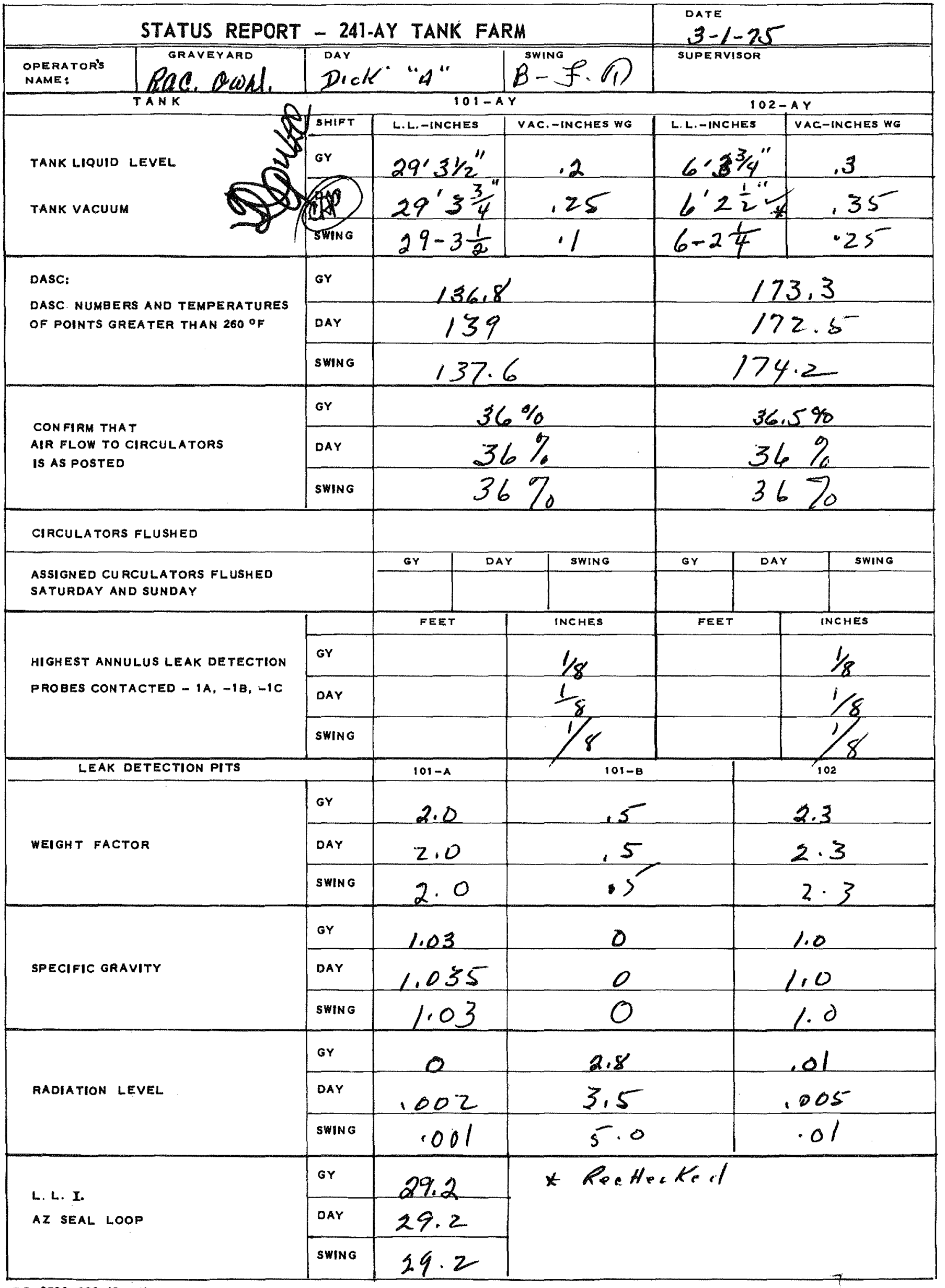


Rev. 0

2.3 AY Farm Liquid Level Readings- February 1976 
AY FARM L.L. FEBRUARY 1976

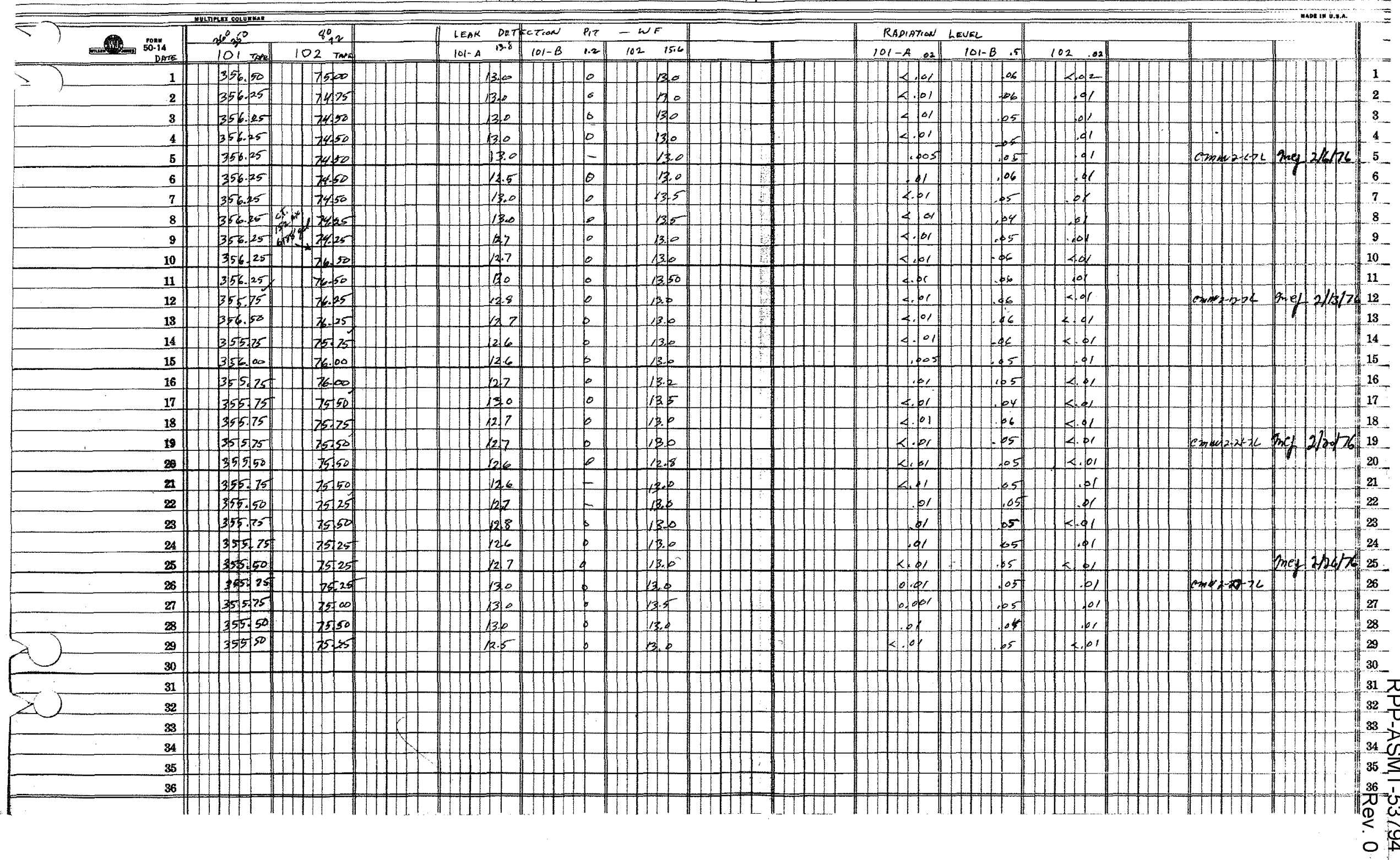


Rev. 0

2.4 AY Farm Liquid Level Monthly Reports- September 1976, April 1977 and May 1977 


\section{SECTION I\& $G$}

ALL VALUES IN $K$ GALLONS

TANK AVAIL TOTAL UNUS SPACE HASTE SPACE
INUENTORIES BY TANK.

REPORT DATE $9 / 30 / 76$
DOCUMENT NO. ARH-CD-702 I

PAGE 5

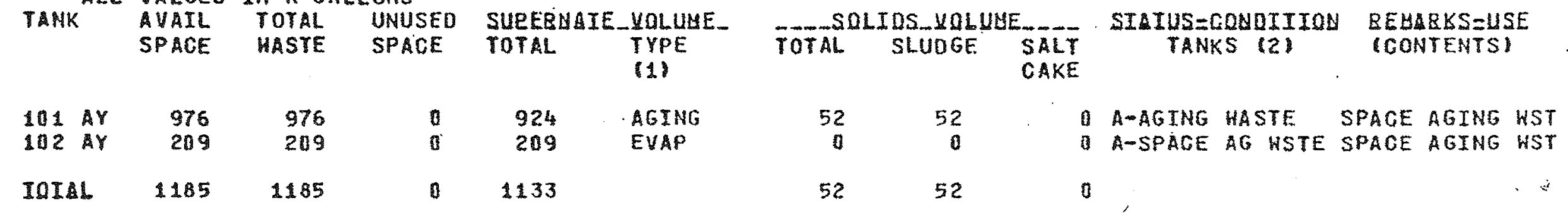

Ñ

(1) AGING: AGING HASTE RESID: HANFORD DEFENSE RESTQUAL LIQUOR (2) SEE PAGE 18 FOR COHPLETE STATUS-CONDITIONS

COMPILED BY IBNK_EARY_RBDCESS_ENGIUEEBIHG

RELEASED BY RLA UUIUG SCHEDULIUE_\&_DEEBAIIOU__COAIBOL
EVAP EYAPORATOR FEED

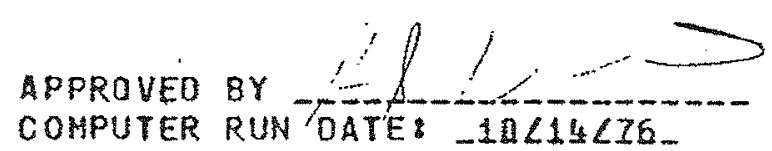


SFCrIOI! I: $C$

ALL VMLUES TM K TALLONS

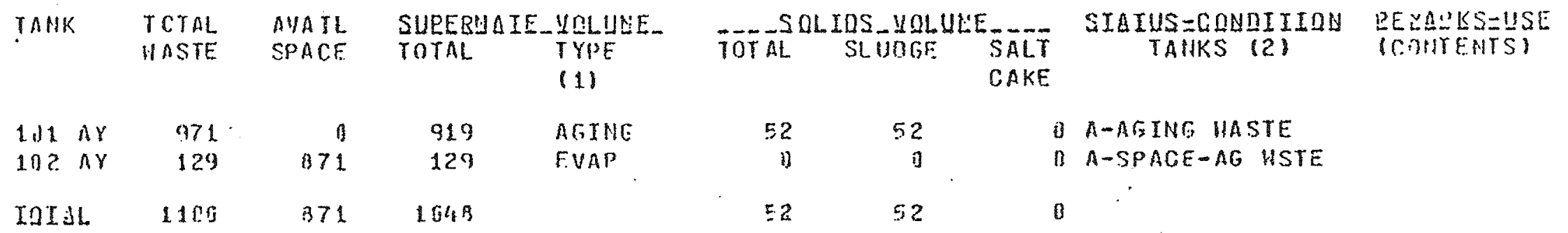

N

No

(1) AGING: AGTMG UASTE STABL: STARTLIZFM

RESID HAMFOPN NEFENSE RESTDUAL LIDUOR ISO ISOLATFO

$I \&$

EUAP EVAPORATOR FERO

(2) SFE PRGE ZI FOR COHPLETE STATUS-COHOITIOAS 
SFCTION I: C

ALL VALUES IH $K$ GALLONS

\begin{tabular}{|c|c|c|c|c|c|c|c|c|c|c|c|c|}
\hline TANK & $\begin{array}{l}\text { TOTAL } \\
\text { WASTE }\end{array}$ & $\begin{array}{l}\text { AVAIL } \\
\text { SPACE }\end{array}$ & $\begin{array}{c}\text { SUPEB } \\
\text { TOTAL } \\
.\end{array}$ & $\begin{array}{l}\text { UOLUUE- } \\
\text { TYPE } \\
11\end{array}$ & $\overline{T O T A L}$ & $\begin{array}{l}\text { TQS__YOLL } \\
\text { SLUDGE }\end{array}$ & $\begin{array}{l}\text { SALT } \\
\text { CAKE }\end{array}$ & $\begin{array}{r}\text { SIAIUS }=1 \\
\text { TAN }\end{array}$ & $(S)(2)$ & $\begin{array}{l}\text { BE } \\
\text { IO }\end{array}$ & $\begin{array}{l}=4 A R \\
=0 N T\end{array}$ & $\begin{array}{l}S S=U S E \\
\text { NNTSI }\end{array}$ \\
\hline $\begin{array}{l}101 \text { AY } \\
102 \text { AY }\end{array}$ & $\begin{array}{l}958 \\
241\end{array}$ & $\begin{array}{r}0 \\
799\end{array}$ & $\begin{array}{l}916 \\
201\end{array}$ & $\begin{array}{l}\text { AGING } \\
\text { AGING }\end{array}$ & $\begin{array}{r}52 \\
0\end{array}$ & $\begin{array}{r}52 \\
0\end{array}$ & $\begin{array}{l}5 \\
0\end{array}$ & $\begin{array}{ll}5 & A-A G \text { ING } \\
0 & A-A G \text { ING }\end{array}$ & $\begin{array}{l}\text { WASTE } \\
\text { WASTE }\end{array}$ & BNH & WST & RECEIVR \\
\hline TOIAL & 1169 & 799 & 1117 & & 52 & 52 & & $\mathbb{C}$ & & & & \\
\hline
\end{tabular}

INUENTORIES 3 Y TANK

REPORT DATE $5 / 31 / 77$
DOCUMENT NO. ARH-CD-822 MAY PAGE 8
(1) AGTNG: AGING HASTE


2.5 Tank AY-102 Liquid Level Readings- October 1976

Reference: Occurrence Report 76-148, 1976, Possible Specification Violation:

Liquid Level Decrease to Below a Minimum Level, Atlantic Richfield Hanford Company, Richland, Washington. 
TABIE I: TANK 102-AY RECORD OF TANK VACUUM AND LIQUID LEVEL

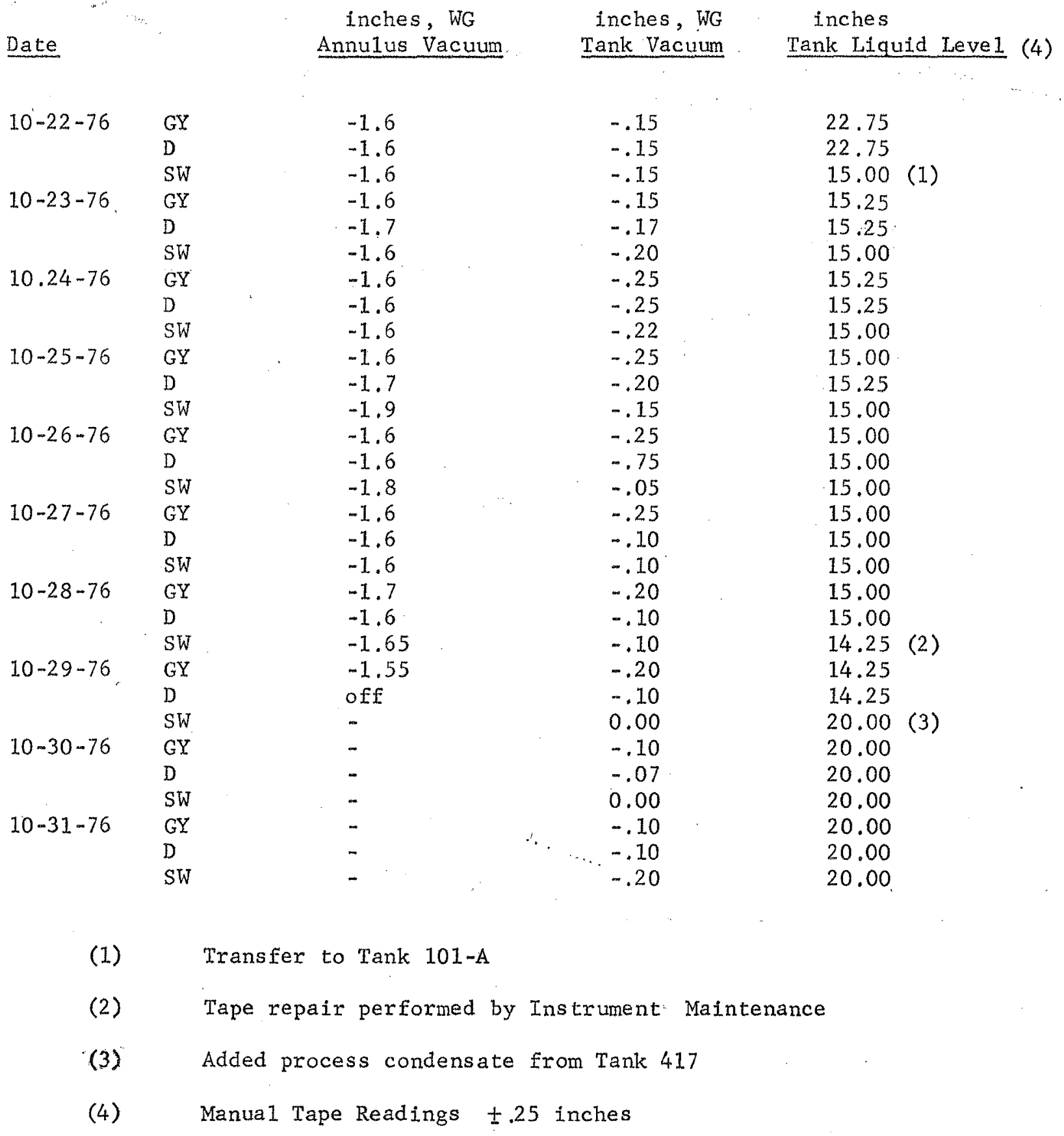


Rev. 0

2.6 Tank AY-102 Liquid Level Readings- September 1998 through July 2000 


\begin{tabular}{|c|c|c|c|}
\hline \multicolumn{4}{|c|}{ Sediment Level Readings for 241-AY-102 from ENRAF Densitometer } \\
\hline \multicolumn{4}{|c|}{\begin{tabular}{l|l|l} 
Source of Data: & \\
\end{tabular}} \\
\hline \multicolumn{4}{|c|}{ D - dat file } \\
\hline \multicolumn{4}{|c|}{$\mathrm{L}=$ activity $\log$ file } \\
\hline \multicolumn{4}{|c|}{$\mathrm{E}=\mathrm{e}-\mathrm{mail}$} \\
\hline \multicolumn{4}{|c|}{$T=$ text file } \\
\hline $\begin{array}{c}\text { Source of } \\
\text { Data }\end{array}$ & Date & Level (inches) & Questionable Date \\
\hline $\mathrm{T}$ & $9 / 4 / 98 \quad 10: 40$ & $\begin{array}{r}9.31 \\
\end{array}$ & \\
\hline $\mathrm{T}$ & $10 / 27 / 9816: 44$ & 9.15 & \\
\hline $\mathrm{L}$ & $11 / 15 / 9810: 14$ & 9.11 & \\
\hline $\mathrm{L}$ & $11 / 15 / 9811: 15$ & 9 & \\
\hline D & $11 / 18 / 98 \quad 18: 40$ & 9.46 & \\
\hline D & $11 / 19 / 9810: 28$ & 10.49 & \\
\hline D & $11 / 19 / 9818: 55$ & 11.43 & \\
\hline $\mathrm{D}$ & $11 / 20 / 9817: 54$ & 12.29 & \\
\hline $\mathrm{D}$ & $11 / 20 / 9823: 05$ & 12.16 & \\
\hline $\mathrm{L}$ & $11 / 21 / 989: 22$ & 12.64 & \\
\hline D & $11 / 21 / 9817: 28$ & 12.73 & \\
\hline$E$ & $11 / 23 / 980: 00$ & 12.9 & \\
\hline $\mathrm{L}$ & $11 / 24 / 98 \quad 17: 20$ & 12.78 & \\
\hline $\mathrm{L}$ & $11 / 25 / 989: 27$ & 12.47 & \\
\hline $\mathrm{D}$ & $11 / 30 / 9810.01$ & 12.4 & \\
\hline D & $12 / 1 / 989: 20$ & 12.2 & \\
\hline D & $12 / 7 / 98 \quad 13: 09$ & 12.11 & \\
\hline $\mathrm{D}$ & $12 / 17 / 98 \quad 10: 42$ & 12.14 & \\
\hline D & $12 / 17 / 9818: 28$ & 12.17 & \\
\hline D & $12 / 18 / 98 \quad 13: 20$ & 12.26 & \\
\hline $\mathrm{D}$ & $12 / 18 / 98 \quad 18: 14$ & 12.22 & \\
\hline $\mathrm{D}$ & $12 / 19 / 9813: 03$ & 12.28 & \\
\hline D & $12 / 19 / 9819: 46$ & 12.25 & \\
\hline $\mathrm{L}$ & $12 / 22 / 98 \quad 13: 22$ & 12.17 & \\
\hline $\mathrm{L}$ & $12 / 29 / 9813: 54$ & 12.17 & \\
\hline $\mathrm{L}$ & $1 / 6 / 9913: 18$ & 12.15 & \\
\hline $\mathrm{D}$ & $2 / 26 / 9913: 27$ & 11.88 & \\
\hline D & $3 / 4 / 9910: 03$ & 11.93 & \\
\hline $\mathrm{D}$ & $3 / 8 / 991: 02$ & 12.55 & \\
\hline $\mathrm{D}$ & $3 / 8 / 992: 31$ & 12.31 & \\
\hline $\mathrm{L}$ & $3 / 8 / 99 \quad 17: 45$ & 12.94 & \\
\hline $\mathrm{D}$ & $3 / 9 / 99 \quad 10: 02$ & 13.93 & \\
\hline $\mathrm{D}$ & $3 / 9 / 9913: 42$ & 13.88 & \\
\hline $\mathrm{D}$ & $3 / 9 / 9917: 15$ & 13.96 & \\
\hline $\mathrm{D}$ & $3 / 9 / 99 \quad 18: 40$ & 13.96 & \\
\hline D & $3 / 10 / 999: 34$ & 15.19 & \\
\hline $\mathrm{D}$ & $3 / 10 / 9917: 34$ & 15.71 & \\
\hline D & $3 / 10 / 9918: 31$ & 15.51 & \\
\hline $\mathrm{D}$ & $3 / 11 / 999: 52$ & 17.35 & \\
\hline $\mathrm{D}$ & $3 / 11 / 9911: 21$ & 16.78 & \\
\hline
\end{tabular}




\begin{tabular}{|c|c|c|c|}
\hline $\begin{array}{c}\text { Source of } \\
\text { Data }\end{array}$ & Date & Level (inches) & Questionable Date \\
\hline $\mathrm{L}$ & $3 / 12 / 999: 43$ & 18.85 & \\
\hline $\mathrm{D}$ & $3 / 15 / 999: 53$ & 20.16 & \\
\hline $\mathrm{D}$ & $3 / 16 / 9910: 31$ & 19.67 & \\
\hline $\mathrm{D}$ & $3 / 17 / 999: 00$ & 19.2 & \\
\hline $\mathrm{D}$ & $3 / 18 / 99 \quad 13: 30$ & 18.69 & \\
\hline $\mathrm{D}$ & $3 / 19 / 99 \quad 10: 11$ & 18.63 & · \\
\hline $\mathrm{D}$ & $3 / 22 / 99 \quad 10: 23$ & 18.34 & \\
\hline $\mathrm{D}$ & $3 / 23 / 99 \quad 10: 19$ & 18.21 & \\
\hline $\mathrm{D}$ & $3 / 25 / 999: 24$ & 18.05 & \\
\hline $\mathrm{D}$ & $3 / 29 / 993: 11$ & 18.74 & \\
\hline $\mathrm{D}$ & $3 / 29 / 994: 16$ & 18.57 & \\
\hline $\mathrm{D}$ & $3 / 29 / 999: 32$ & 18.87 & \\
\hline $\mathrm{D}$ & $3 / 29 / 99$ 18:02 & 19.22 & \\
\hline $\mathrm{D}$ & $3 / 30 / 999: 45$ & 20.3 & \\
\hline $\mathrm{D}$ & $3 / 30 / 99 \quad 17: 35$ & 20.17 & \\
\hline $\mathrm{L}$ & $3 / 31 / 999: 17$ & 26.89 & \\
\hline$L$ & $3 / 31 / 999: 27$ & & 23.98 \\
\hline $\mathrm{L}$ & $3 / 31 / 999: 32$ & & 22.14 \\
\hline$L$ & $3 / 31 / 999: 33$ & & 21.33 \\
\hline$L$ & $3 / 31 / 999: 39$ & & 21.35 \\
\hline$L$ & $3 / 31 / 999: 43$ & & 21.22 \\
\hline $\mathrm{L}$ & $3 / 31 / 999: 46$ & & 21.19 \\
\hline $\mathrm{L}$ & $3 / 31 / 9917: 10$ & 26.34 & \\
\hline $\mathrm{L}$ & $3 / 31 / 99 \quad 17: 13$ & & 23.94 \\
\hline $\mathrm{L}$ & $3 / 31 / 99 \quad 17: 14$ & & 23.65 \\
\hline $\mathrm{D}$ & $3 / 31 / 9917: 27$ & & 23.57 \\
\hline$D$ & $4 / 1 / 999: 56$ & & 20.34 \\
\hline $\mathrm{D}$ & $4 / 2 / 999: 11$ & & 21.02 \\
\hline $\mathrm{D}$ & $4 / 5 / 999: 35$ & 29.45 & \\
\hline $\mathrm{D}$ & $4 / 6 / 999: 13$ & 28.29 & \\
\hline $\mathrm{D}$ & $4 / 7 / 99 \quad 13: 34$ & 27.36 & \\
\hline $\mathrm{D}$ & 4/8/999:50 & 27.01 & . \\
\hline$D$ & $4 / 9 / 999: 33$ & 26.6 & \\
\hline D & $4 / 12 / 99 \quad 10: 23$ & 26.45 & \\
\hline $\mathrm{D}$ & 4/13/99 9:40 & 26.23 & \\
\hline $\mathrm{L}$ & $4 / 14 / 999: 08$ & 26.24 & \\
\hline $\mathrm{D}$ & $4 / 15 / 999: 17$ & 26.1 & \\
\hline $\mathrm{D}$ & $4 / 16 / 99 \quad 13: 22$ & 26.11 & \\
\hline D & $4 / 19 / 999: 36$ & 25.91 & \\
\hline D & $4 / 21 / 99 \quad 12: 50$ & 25.88 & \\
\hline $\mathrm{D}$ & 4/24/99 1:11 & 26,05 & \\
\hline D & $4 / 24 / 998: 32$ & 26.33 & \\
\hline D & $4 / 24 / 99 \quad 17: 11$ & 26.61 & \\
\hline $\mathrm{L}$ & $4 / 25 / 998: 47$ & 27.14 & \\
\hline$L$ & $4 / 25 / 999: 47$ & 27 & \\
\hline $\mathrm{D}$ & $4 / 25 / 99 \quad 16: 47$ & 27.24 & \\
\hline $\mathrm{D}$ & $4 / 26 / 999: 47$ & 27.84 & \\
\hline
\end{tabular}




\begin{tabular}{|c|c|c|c|}
\hline $\begin{array}{c}\text { Source of } \\
\text { Data }\end{array}$ & Date & Level (inches) & Questionable Date \\
\hline $\mathrm{D}$ & $4 / 26 / 99 \quad 17: 24$ & 27.96 & \\
\hline $\mathrm{D}$ & $4 / 27 / 9914: 28$ & 28.45 & \\
\hline $\mathrm{D}$ & $4 / 29 / 99 \quad 14: 29$ & 29.47 & \\
\hline $\mathrm{D}$ & $5 / 1 / 991: 05$ & 30.5 & \\
\hline D & $5 / 1 / 998: 48$ & 30.91 & \\
\hline $\mathrm{D}$ & $5 / 1 / 99 \quad 16: 35$ & 31.38 & \\
\hline $\mathrm{D}$ & $5 / 2 / 998: 30$ & 31.99 & \\
\hline $\mathrm{D}$ & $5 / 2 / 99 \quad 17: 17$ & 32.18 & \\
\hline $\mathrm{D}$ & $5 / 3 / 999: 44$ & 32.63 & \\
\hline $\mathrm{D}$ & $5 / 3 / 99 \quad 17: 18$ & 33.04 & \\
\hline $\mathrm{D}$ & $5 / 4 / 999: 35$ & 35.3 & \\
\hline D & $5 / 5 / 99 \quad 10: 08$ & 37.2 & \\
\hline $\mathrm{D}$ & $5 / 6 / 999: 03$ & 37.59 & \\
\hline D & $5 / 7 / 999: 02$ & 37.34 & \\
\hline D & $5 / 10 / 999: 58$ & 36.38 & \\
\hline $\mathrm{D}$ & $5 / 11 / 999: 31$ & 36.19 & \\
\hline D & $5 / 12 / 998: 53$ & 36.08 & \\
\hline D & $5 / 13 / 999: 38$ & 35.89 & \\
\hline$D$ & $5 / 14 / 998: 53$ & 35.7 & \\
\hline $\mathrm{D}$ & $5 / 17 / 999: 16$ & 35.35 & \\
\hline D & $5 / 18 / 999: 15$ & 35.18 & \\
\hline D & $5 / 19 / 999: 50$ & 35.17 & \\
\hline $\mathrm{D}$ & $5 / 20 / 9914: 02$ & 35.13 & \\
\hline D & $5 / 25 / 991: 39$ & 35.29 & \\
\hline $\mathrm{D}$ & $5 / 25 / 998: 56$ & 35.43 & \\
\hline D & $5 / 25 / 99 \quad 17: 29$ & 35.73 & \\
\hline $\mathrm{D}$ & $5 / 26 / 999: 31$ & 36.38 & \\
\hline $\mathrm{D}$ & $5 / 26 / 99 \quad 18: 48$ & 36.58 & \\
\hline D & $5 / 27 / 999: 31$ & 37.05 & \\
\hline $\mathrm{D}$ & $5 / 27 / 99 \quad 17: 58$ & 37.3 & \\
\hline $\mathrm{D}$ & $6 / 1 / 999: 39$ & 39.26 & \\
\hline D & $6 / 2 / 9910: 12$ & 38.69 & $\begin{array}{l}\text { Densitometer fixed, reference level } \\
\text { was high by } 1 \text { inch }\end{array}$ \\
\hline D & $6 / 4 / 991: 16$ & 39.94 & \\
\hline $\mathrm{D}$ & $6 / 4 / 999: 06$ & 40.96 & \\
\hline D & $6 / 4 / 9917: 15$ & 41.81 & \\
\hline D & $6 / 5 / 998: 33$ & 44.25 & \\
\hline D & $6 / 5 / 99 \quad 16: 48$ & 45.61 & \\
\hline D & $6 / 6 / 998: 19$ & 48.08 & \\
\hline D & $6 / 6 / 99 \quad 16: 41$ & 48.28 & \\
\hline $\mathrm{D}$ & $6 / 7 / 999: 38$ & 49.63 & \\
\hline D & $6 / 8 / 9913: 14$ & 51.07 & \\
\hline D & $6 / 9 / 999: 03$ & 50.47 & \\
\hline D & $6 / 10 / 999: 31$ & 49.94 & \\
\hline D & $6 / 14 / 9999: 30$ & 48.91 & \\
\hline $\mathrm{D}$ & $6 / 15 / 999: 25$ & 48.56 & \\
\hline $\mathrm{D}$ & $6 / 16 / 999: 11$ & 48.33 & \\
\hline
\end{tabular}




\begin{tabular}{|c|c|c|c|}
\hline $\begin{array}{c}\text { Source of } \\
\text { Data }\end{array}$ & Date & Level (inches) & Questionable Date \\
\hline $\mathrm{D}$ & $6 / 17 / 99 \quad 14: 30$ & 48.18 & \\
\hline $\mathrm{D}$ & $6 / 18 / 999: 18$ & 48.12 & \\
\hline $\mathrm{D}$ & $6 / 21 / 999: 29$ & 47.91 & \\
\hline $\mathrm{D}$ & $6 / 28 / 999: 08$ & 47.46 & \\
\hline $\mathrm{D}$ & $7 / 6 / 999: 17$ & 46.74 & \\
\hline $\mathrm{D}$ & $7 / 12 / 99 \quad 13: 14$ & 46.66 & \\
\hline D & $7 / 19 / 9910: 04$ & 46.63 & \\
\hline$D$ & $7 / 22 / 99 \quad 18: 23$ & 48.86 & \\
\hline $\mathrm{D}$ & $7 / 23 / 999: 16$ & 49.65 & \\
\hline D & $7 / 24 / 998: 27$ & 51.55 & \\
\hline $\mathrm{D}$ & $7 / 25 / 999: 03$ & 51.77 & \\
\hline $\mathrm{L}$ & $7 / 26 / 999: 40$ & 51.8 & \\
\hline $\mathrm{D}$ & $8 / 2 / 99 \quad 13: 12$ & 51.4 & \\
\hline $\mathrm{D}$ & $8 / 3 / 99 \quad 10: 06$ & 51.25 & \\
\hline D & $8 / 5 / 999: 00$ & 51.34 & \\
\hline $\mathrm{E}$ & $8 / 10 / 999: 30$ & 50.93 & \\
\hline D & $8 / 13 / 99 \quad 12: 55$ & 50.98 & \\
\hline $\mathrm{D}$ & $8 / 20 / 99 \quad 19: 12$ & 51.37 & \\
\hline $\mathrm{D}$ & $8 / 21 / 99 \quad 10: 17$ & 51.84 & \\
\hline $\mathrm{D}$ & $8 / 22 / 998: 47$ & 53 & \\
\hline $\mathrm{D}$ & $8 / 23 / 99 \quad 13: 47$ & 53.3 & \\
\hline $\mathrm{D}$ & $8 / 24 / 998: 45$ & 53.3 & \\
\hline $\mathrm{D}$ & $8 / 25 / 998: 38$ & 53.34 & \\
\hline $\mathrm{D}$ & $8 / 26 / 9914: 07$ & 53.1 & \\
\hline $\mathrm{D}$ & $8 / 30 / 99 \quad 10: 10$ & 52.88 & \\
\hline $\mathrm{D}$ & $9 / 8 / 99 \quad 10: 18$ & 52.7 & \\
\hline D & $9 / 11 / 999: 34$ & 53.88 & \\
\hline $\mathrm{D}$ & $9 / 12 / 9910: 25$ & 55.66 & \\
\hline $\mathrm{D}$ & $9 / 15 / 993: 11$ & 57.04 & \\
\hline $\mathrm{D}$ & $9 / 17 / 991: 56$ & 60.97 & \\
\hline $\mathrm{D}$ & $9 / 17 / 998: 32$ & 61.65 & \\
\hline $\mathrm{D}$ & $9 / 18 / 998: 30$ & 63.97 & \\
\hline $\mathrm{D}$ & $9 / 19 / 999: 00$ & 64.72 & \\
\hline $\mathrm{D}$ & $9 / 20 / 99 \quad 10: 03$ & 64.31 & \\
\hline $\mathrm{D}$ & $9 / 22 / 990: 57$ & 64.56 & \\
\hline $\mathrm{D}$ & $9 / 22 / 998: 59$ & 65.16 & \\
\hline $\mathrm{D}$ & $9 / 22 / 9920: 47$ & 65.73 & \\
\hline $\mathrm{D}$ & $9 / 24 / 999: 13$ & 65.82 & \\
\hline $\mathrm{D}$ & $9 / 25 / 991: 37$ & 66.69 & \\
\hline D & $9 / 25 / 998: 46$ & 67.12 & \\
\hline D & $9 / 27 / 990: 57$ & 67.67 & \\
\hline $\mathrm{D}$ & $9 / 27 / 999: 33$ & 68.21 & \\
\hline $\mathrm{D}$ & $9 / 29 / 990: 42$ & 68.26 & \\
\hline $\mathrm{D}$ & $9 / 29 / 998: 54$ & $687^{\circ}$ & \\
\hline
\end{tabular}




\begin{tabular}{|c|r|r|l|}
\hline $\begin{array}{c}\text { Source of } \\
\text { Data }\end{array}$ & \multicolumn{1}{|c|}{ Date } & Level (inches) & \multicolumn{1}{|c|}{ Questionable Date } \\
\hline & & & $\begin{array}{l}9 / 30 / 1999 \text { 12:34:17 Enraf } \\
\text { Profiles/Sediment Levels were not } \\
\text { taken on 9/30/99, date stamp should be } \\
10 / 1 / 99 . \text { Therefore date stamp } \\
\text { changed to 10/1/99. }\end{array}$ \\
\hline D & $10 / 1 / 990: 34$ & 69.37 & \\
\hline D & $10 / 4 / 999: 54$ & 68.92 & \\
\hline D & $10 / 5 / 9910: 26$ & 68.84 & \\
\hline D & $10 / 7 / 990: 59$ & 68.72 & \\
\hline D & $10 / 7 / 998: 46$ & 68.83 & \\
\hline D & $10 / 8 / 9910: 05$ & 68.76 & \\
\hline$D$ & $10 / 11 / 9910: 41$ & 68.5 & \\
\hline D & $10 / 14 / 9910: 26$ & 68.41 & \\
\hline D & $10 / 18 / 999: 09$ & 68.13 & \\
\hline D & $11 / 2 / 999: 32$ & 67.53 & \\
\hline$D$ & $2 / 1 / 0018: 56$ & 66.74 & \\
\hline L & $7 / 27 / 0010: 17$ & 65.98 & \\
\hline
\end{tabular}




\subsection{Supporting Documentation for RPP-ASMT-53793, Section 4.1.4, Chemistry}

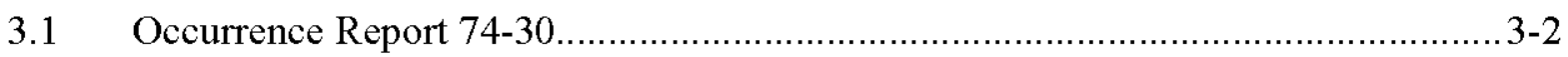

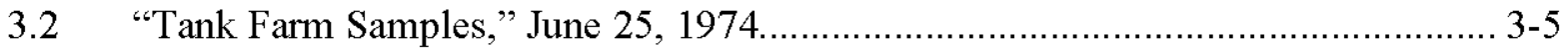

3.3 "Analyses of Tank Farm Sample," July 21, 1976............................................. 3-7

3.4 "Analyses of Tank Farm Samples," August 10, 1978 .......................................... 3-9

3.5 "Analyses of Tank Farm Samples," September 1, 1978 ......................................

3.6 "Analytical Data for Tanks 101-AZ, 102-AZ, 103-TX, and 102-AY Hot and Synthetic Liquors," September 21, 1979................................................... 3-13

3.7 "Relative Random Error Standard Deviation and Accuracy in Hanford Waste Liquor Analytical Data," December 3, 1979........................................ 3-20

3.8 Analytical Results Tank 102-AY- March 1980 through September 1980.............. 3-29

3.9 "Composition of Waste from Tanks 101AY and 102AY," April 15, 1982.............3-35

3.10 "Analysis of 102-AY Supernate," June 18, 1982 ............................................... 3-39

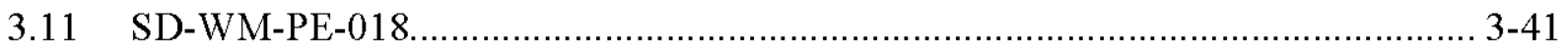

3.12 "Laboratory Support for Upcoming 242-A Evaporator Campaign Run

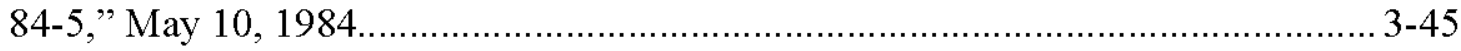

3.13 "Chemical Compositions of 102-AY, 101-AW, 105-AN, and 104-AW,"

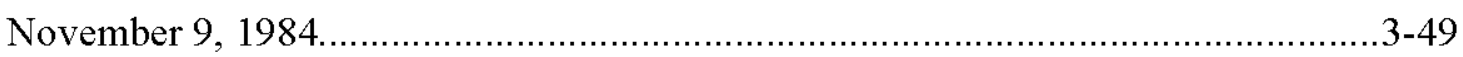

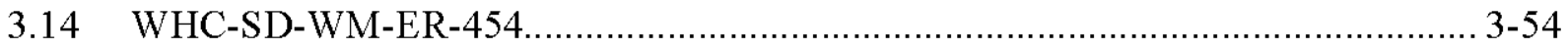

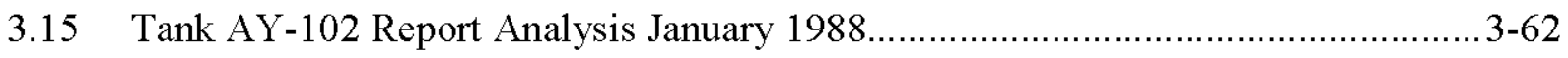

3.16 "Tank 102-AY Solids Heel Analysis," April 21, 1989.......................................67

3.17 "Revised Report on the Results of 102-AY Characterization,"

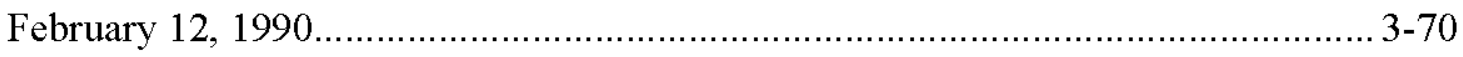

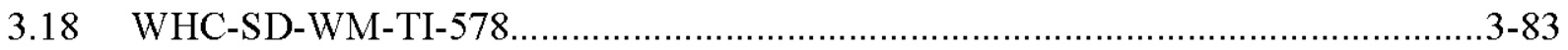

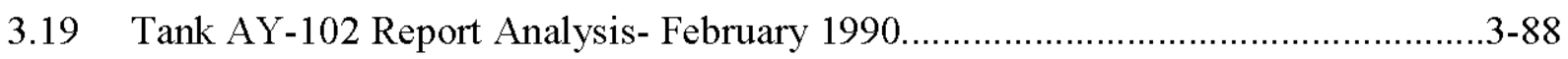

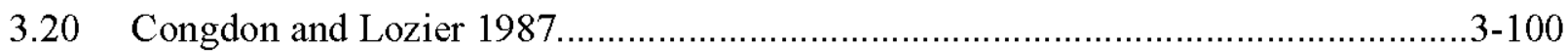

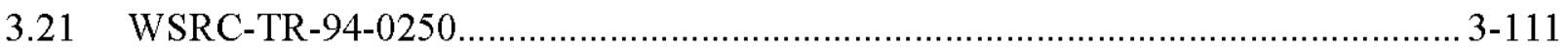


Rev. 0

3.1 Occurrence Report 74-30, 1974, Failure to Obtain Routine Monthly Samples in Tank 102-AY, Atlantic Richfield Hanford Company, Richland, Washington. 


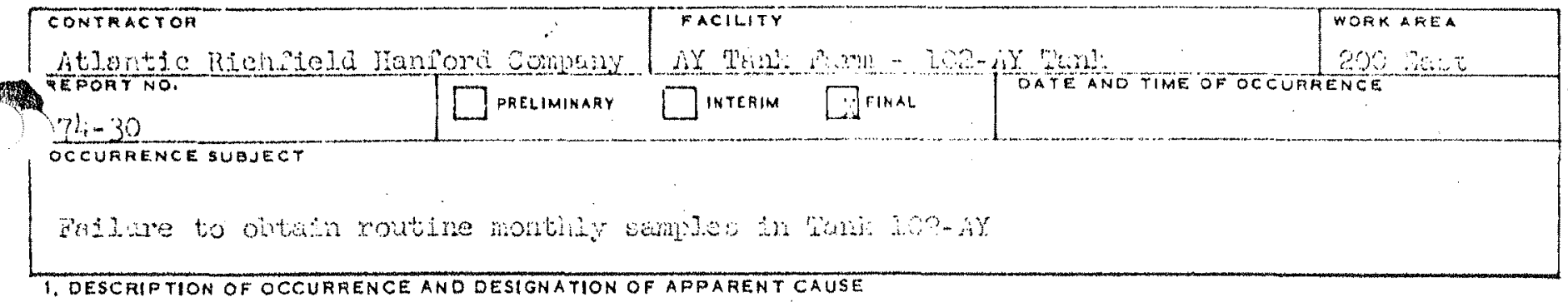

1. DESCFIPTION OF OCCURRENCE ANO DESIGNATION OF APPARENT CAUSE

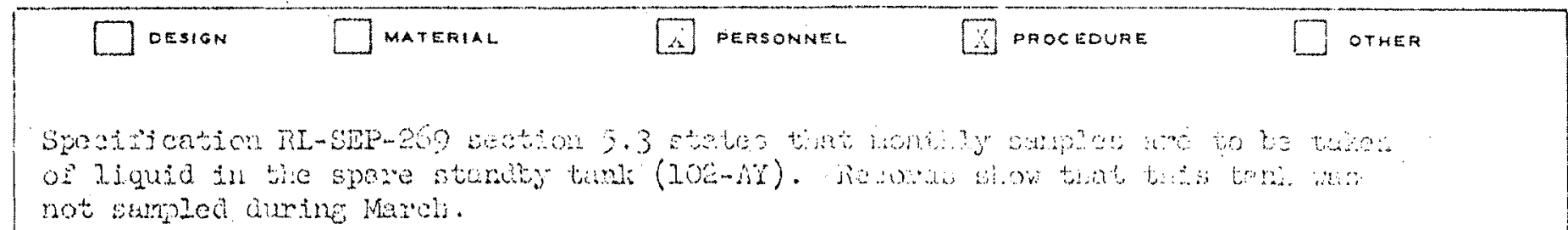

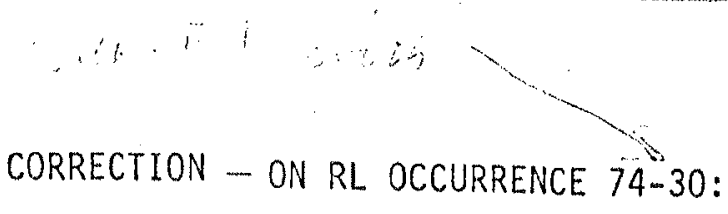

Page 1: No. 2 last sentence: should read

"a pH of $11.1 \ldots$...

instead of 1.1

$$
\begin{aligned}
& \text { bes: . Sa dachis } \\
& \text { G. Bunton, In. } \\
& \text { la compeli } \\
& \text { Go Dandow } \\
& \text { CW Mloxy } \\
& \text { Oo COS: } \\
& \text { IIP SHE: }
\end{aligned}
$$

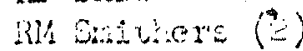

$$
\begin{aligned}
& \text { Cis stomine } \\
& \text { DA } 1 \text { ex } 1 \\
& \text { JH visuest } \\
& \text { L4 } \operatorname{Lin} 2: \\
& \text { certon ins. }
\end{aligned}
$$

2. OPERATING CONDITIONS OF THE FACILITY AT TIME OF OCCUARENCE (IF APPLICABLE)

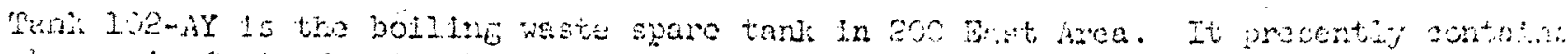

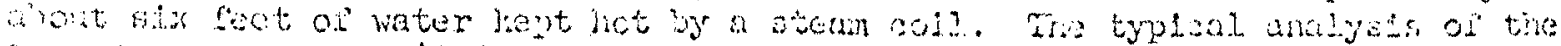

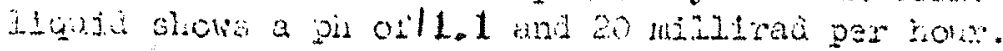




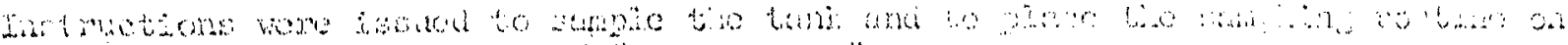

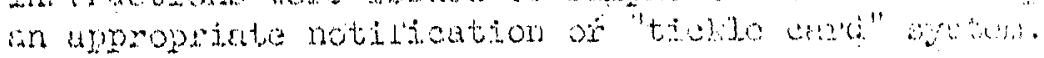

W

4. RECOMMENDATIONS

A. TEMPORARY CORFECTIVE ACTION

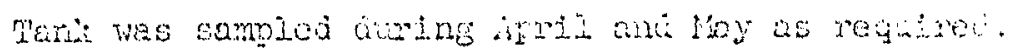

B. PERMANENT CORRECTIVE ACTION

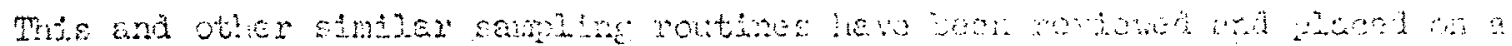
notisteation byetan.

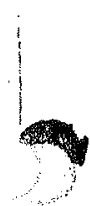

\begin{tabular}{|c|c|c|}
\hline CISDESIGN CHANGE NECEESARY & IF VES, WHEN & \\
\hline YyES $\quad \pi^{N O}$ & & \\
\hline $\begin{array}{c}\text { D. IS FURTHER EVALUATION NECESSAFY? } \\
\square \text { YES }\end{array}$ & IF YES, פY N'HOM & WME E ti \\
\hline
\end{tabular}

5. SIMILAR OCCURRENCE: BY REPORT NUMBER AND OCCURRENCE SUAJECT

\section{STM}

Nune.

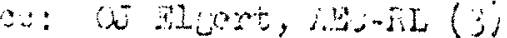

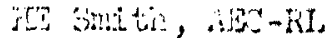

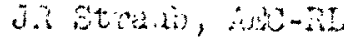

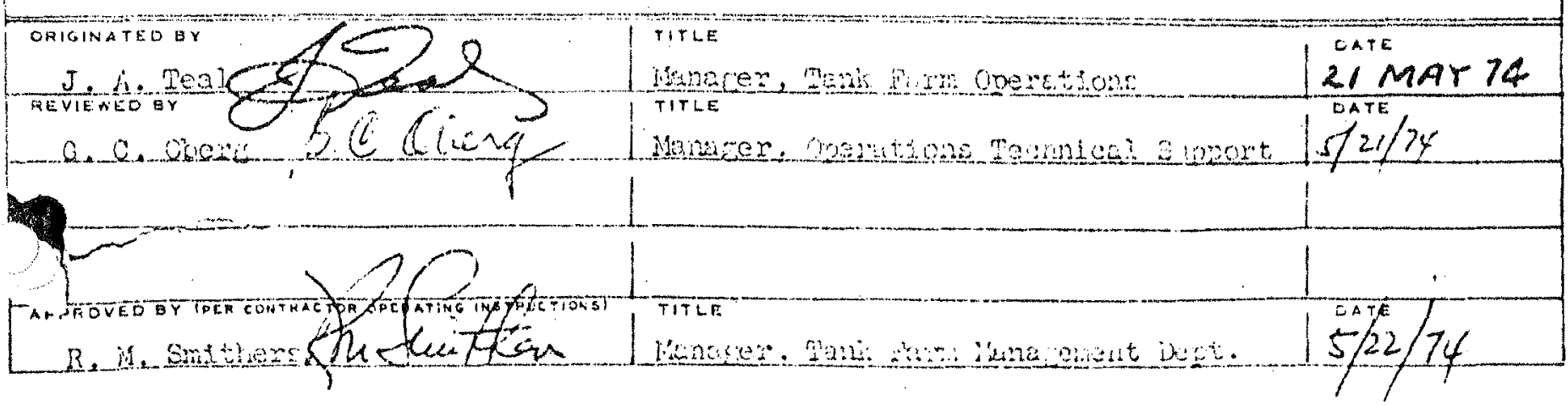


Rev. 0

3.2 Letter from R. E. Wheeler to R. L. Walser, "Tank Farm Samples," June 25, 1974. 
Rev. 0

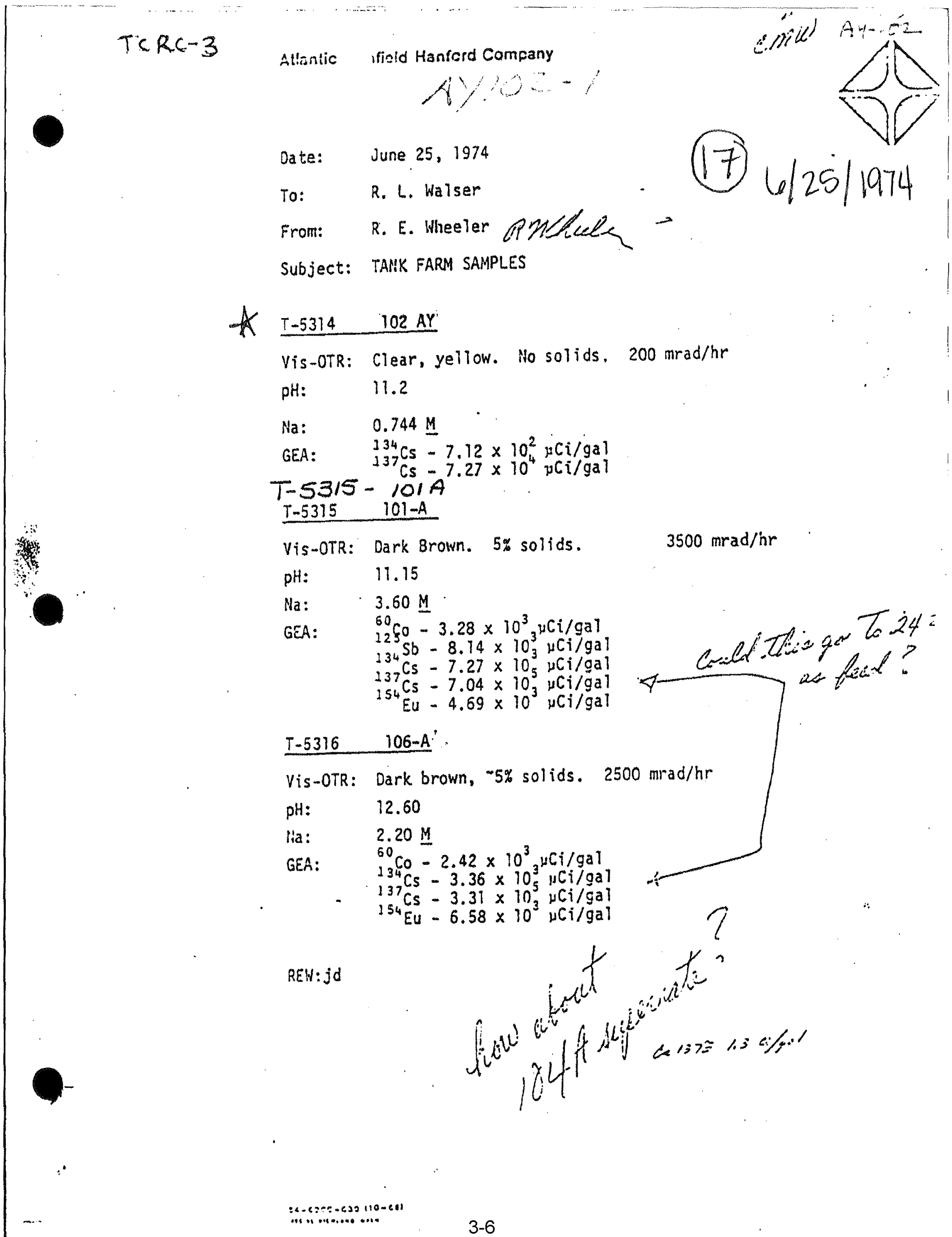


Rev. 0

3.3 Letter to J. C. Womack, "Analyses of Tank Farm Sample, Sample No. T5510 Tank 102-AY Received July 21, 1976, September 20, 1976. 
Date: $\quad 9-20,76$

To: I. C.WOMACK

From: Supervisor, Analytical Services

Subject: ANALYSES OF TANK FARM SAMPLE

Sample No:T55, o Tank: 102-AyReceived: $7-1-76$

VIS-OTR: Yellow, greens, Smmil TLACK specs, No organic 400 meao/h $\mathrm{pH} 10.2 \quad \mathrm{CO}_{3}{ }^{1} 8.88 \times 10^{-2} \mathrm{M} \quad \mathrm{Al} 2.05 \times 10^{-3} \mathrm{M}$

$\mathrm{SpG}=\mathrm{PO}_{4} \leq 1 \times 10^{-2} \mathrm{M}$

$\mathrm{Na}$

$-3_{2} 0.98 .16 \% \quad \mathrm{SO}_{4}=-\mathrm{M}$

$\mathrm{OH} 1,44 \times 10^{-2} M \quad \mathrm{M}=\mathrm{M}$

$\mathrm{NO}_{3} \leq 3 \times 10^{-3} \mathrm{M} \quad \mathrm{F}=\mathrm{M} . \mathrm{Hg}=$

$\mathrm{NO}_{2} \leq 1 \times 10^{-2} \mathrm{M}$

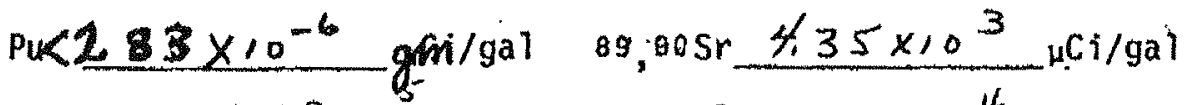

GEA: $137 \mathrm{Cs} 6.78 \times 10 \mu \mathrm{Ci} / \mathrm{gal} 206 \mathrm{RuRh} 3.26 \times 10^{4} \mathrm{\mu Cl} / \mathrm{gal}$

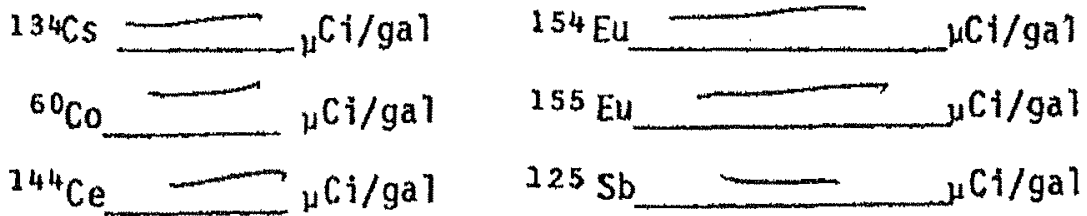

$344 \mathrm{Pr} \longrightarrow \mathrm{Ci} / \mathrm{ga} 1$

COOLING CURVE:

$35^{\circ}$ for

minutes

$30^{\circ}$ for

$25^{\circ}$ for

$20^{\circ}$ for

$15^{\circ}$ for

$10^{\circ}$ for

$5^{\circ}$ for

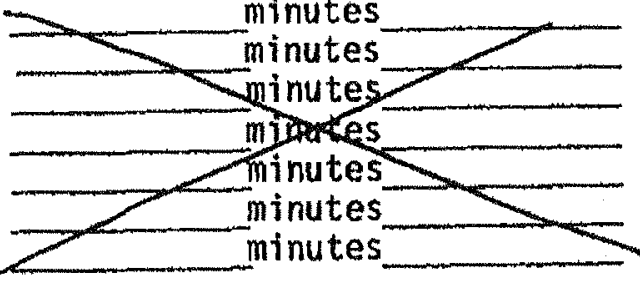

DTA: No Exotherms broou 200 $\mathrm{C}$ 
3.4 Letter, "Analyses of Tank Farm Samples," August 10, 1978. 


\section{Internal Letter}

Date: $8 / 10 / 78$

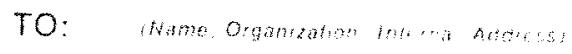

FON

$$
\begin{aligned}
& \text { Manager, Special Analysis } \\
& 2704-5 \text { Building } \\
& 200 \text { West Area } \\
& 2-2449
\end{aligned}
$$

Subject. Analyses of Tank Farm Samples

Serial No. $\frac{1986}{7 / 22 / 78}$ Tank $242-A E D \quad T K / 02 A Y$

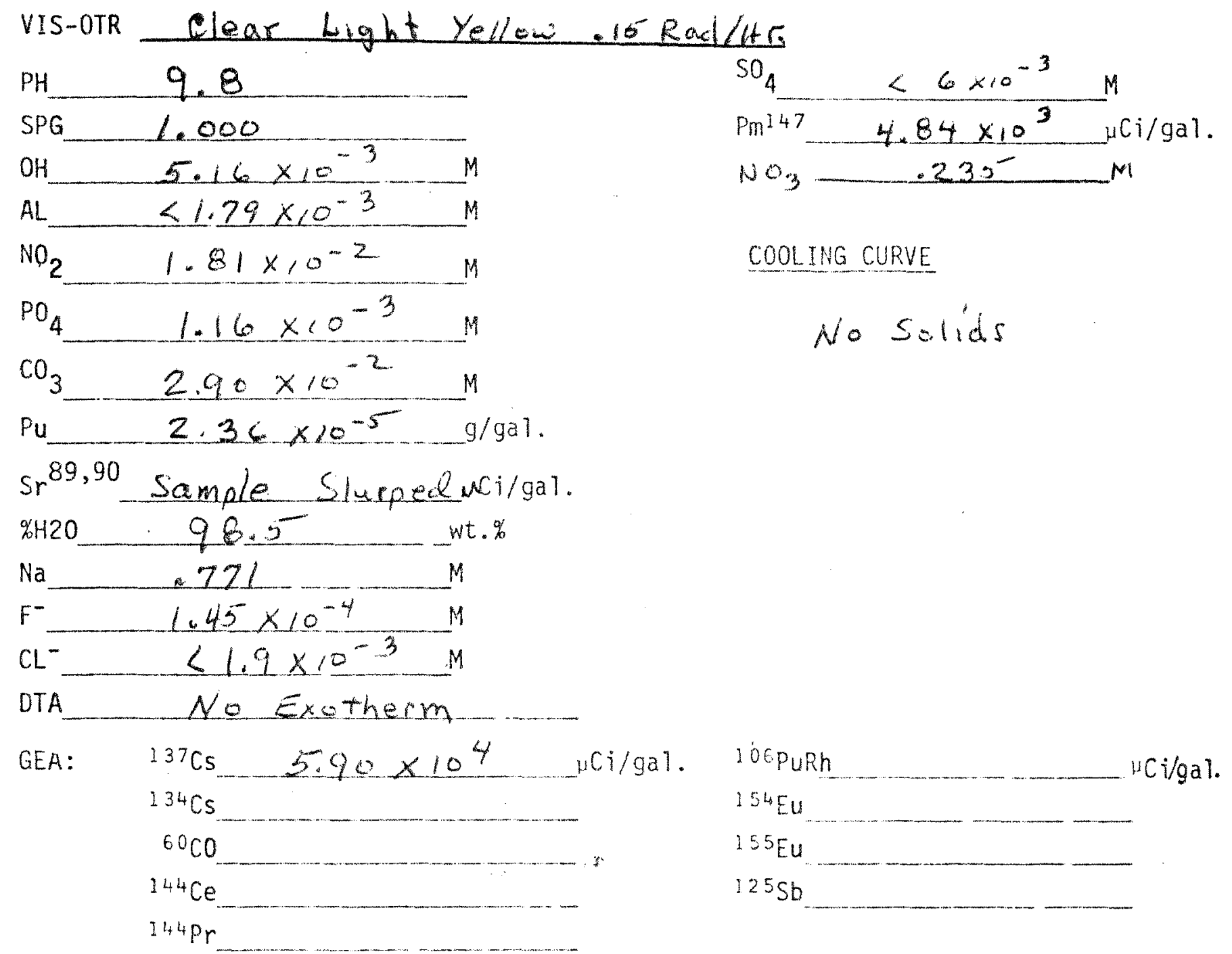


Rev. 0

3.5 Letter to D. R. Autery, "Analyses of Tank Farm Samples," September 1, 1978. 


\section{Internal LeLter}

in

$$
\text { wo: } \quad 9 / 1 / 78
$$

Sutuect:
Manager, Special Analysis 222-S Bidg.

200 West Area

2-2449

Analyses of Tank Farm Sampies

Serial No. $\frac{2517}{217(78}$ - Tank 102Ay.

Received

...

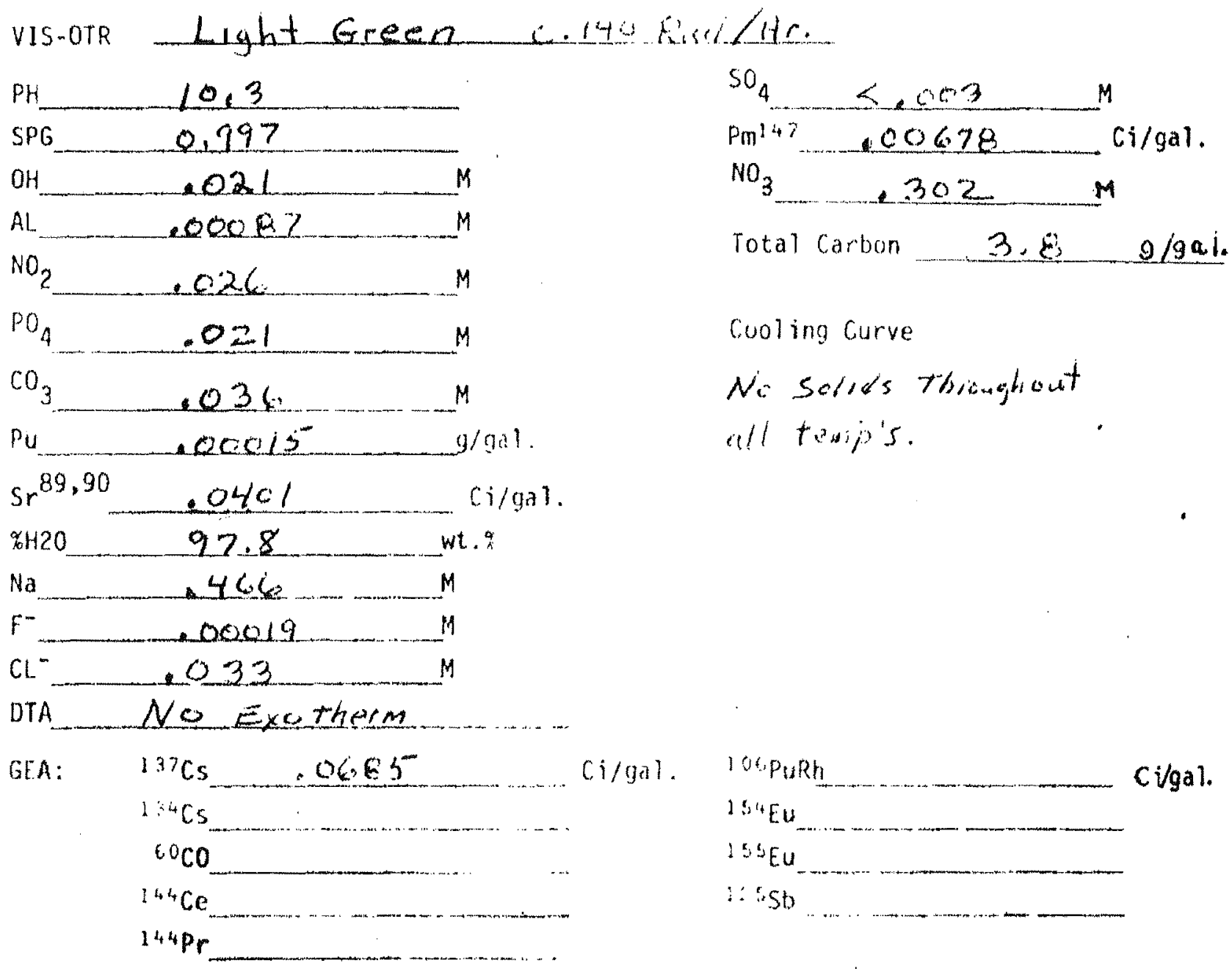


Rev. 0

3.6 Internal Letter 66120-79-151 from C. H. Delegard to L. D. Vanselow, " Analytical Data for Tanks 101-AZ, 102-AZ, 103-TX, and 102-AY Hot and Synthetic Liquors," September 21, 1979. 


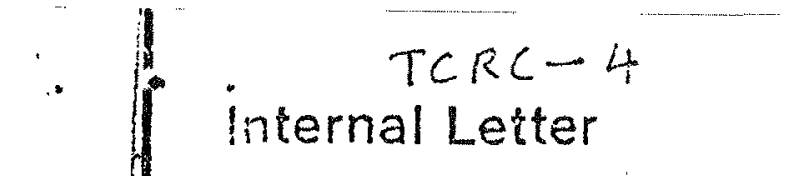

Date September 21,1979

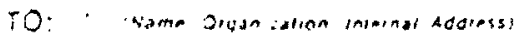

L. D. Vanselow

Sys tems Engineering

. 2750-E, 200 East

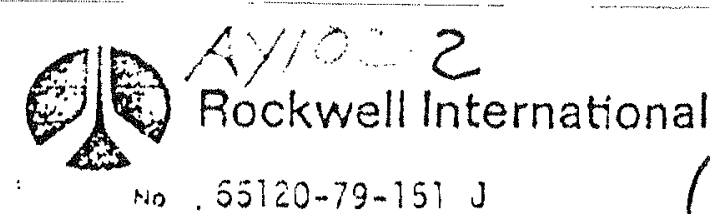

$A 4-10222$

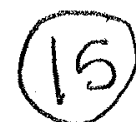

C. H. Delegard

Chemical Sciences Group

.222-5, 200 ivest

$.2-1571$

Supect. Analytical Data for Tanks 101-AZ; 102-AZ, 103-TX, and 102-AY Hot and Synthetic Liquors

Homogeneity of waste liquors held in a given tank has been accepted in practice, but never confirmed. This statistically-based experiment has been designed to test if tanked liquor is indeed homogeneous.

Four tanks; 101-AZ, 102-AZ, 103-TX, and 102-AY; were selected for this test. Each tank was sampled in four locations. Two samples, one near the top and one near the bottom surfaces of the liquor, were taken through each of two different risers in each tank. These samples were analyzed for density and chemical and radionuclide content by the Analytical Laboratory. Synthetic waste simulations were then prepared based on the ayerage of the four samples' analyses. In the case of Tank 101-AZ, howaver, two simulations (one for each riser) were prepared based on the average of the "top" and "bottom" samples" analyses. The synthetics were submitted and the original samples resubmitted together for analyses by the Analytical Laboratory.

The duplicate analyses of the original hot samples provide data to determine analytical error. Analyses of the synthetics help in evaluating our accuracy in simulating hot wastes. Statistical comparison of the four samples taken from each tank determine if the tank contents are homogeneous.

The analytical data, as obtained to date, are presented in the attached tables. The high organic carbon concentration in samples from Tank $102-A Z$ caused fluorescent interference in the laser Raman technique used to measure nitrate and sulfate. As indicated in the table, the laser Raman nitrate ion determination for the first set of hot samples was subJect to high error. To eliminate this error, the second set of hot samples was analyzed for nitrate by specific ion electrode. No al ternate technique for sulfate analys is exists. Paired comparison of the first and second nitrate analyses for the Tank 102-AZ should, therefore, not de used to ascertain analytical error. In a similar way, due to low concentration, aluminum and hydroxide in the Tank 102-AZ samples were quantified by atomic absorption and $\mathrm{pH}$ titration, respectively. The other tanks' samples' aluminum and hydroside values were determined by themal titration. These data should be considered separately in 
L. D. Vanselow

$+1$

Page 2

September 21,1979

evaluating analytical error. In each of the other physical, chemical, and radionuclide analyses, a single analytical method was used.

Please call me if you have any questions regarding this work.
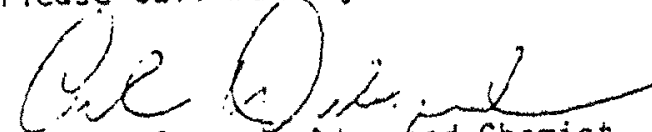

H. Delegard, Advanced Chemist

Waste Chemistry Unit

CHD: jkr

At tachment

Information: J. S. Buckingham

K. G. Carothers

G. T. Dukelow

F. R. Hill Jungfleisch Fay

$T$. A. Lane

D. L. Merrick

S. B. Will son-Wright

File Code: KF55E

Process Aids (8) 
$\stackrel{2}{\alpha}$

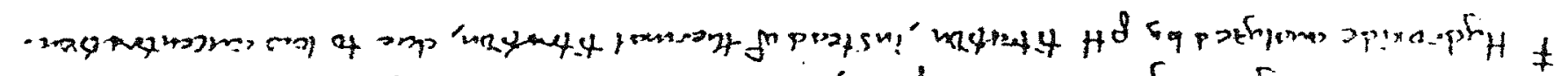

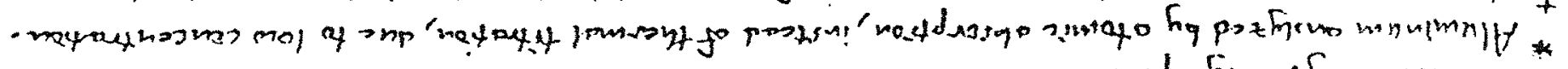

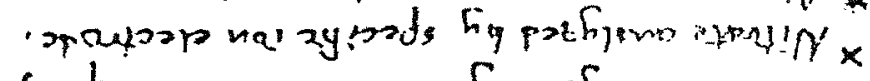

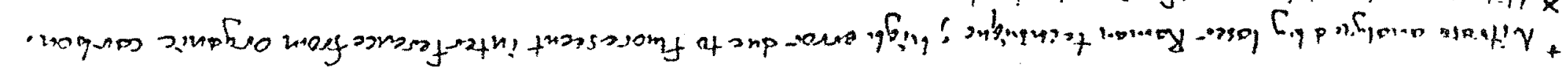

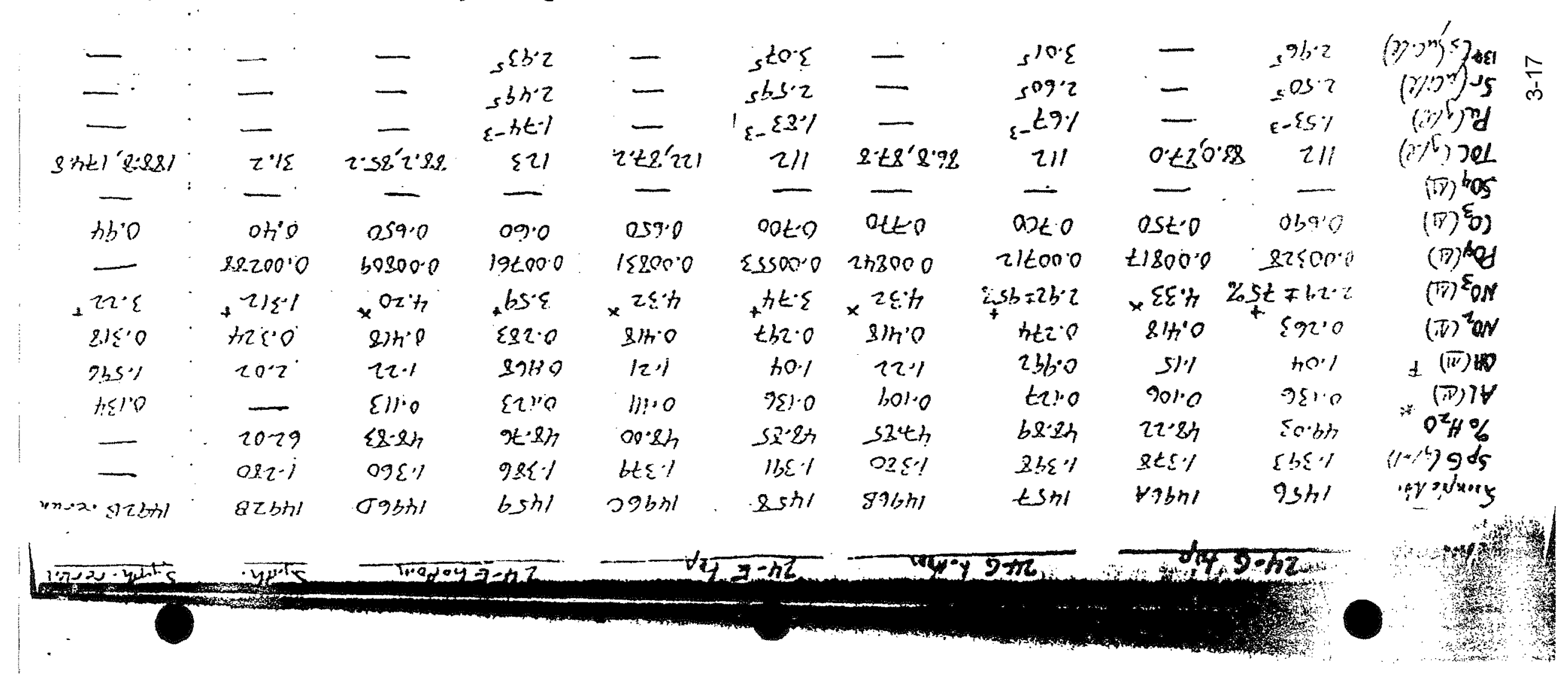




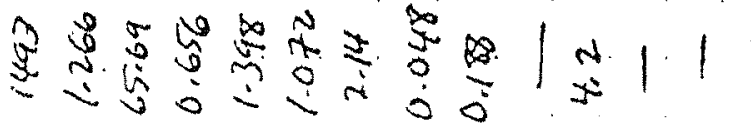

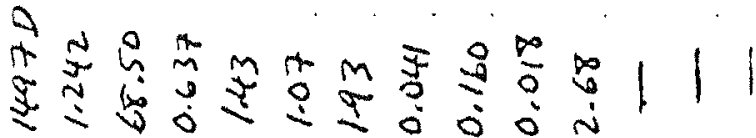

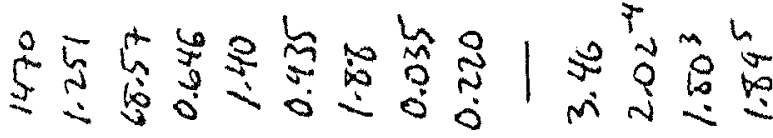

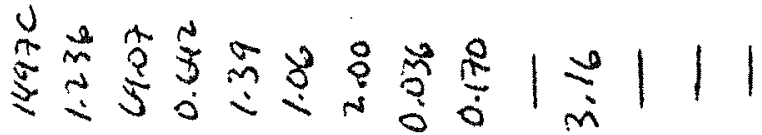

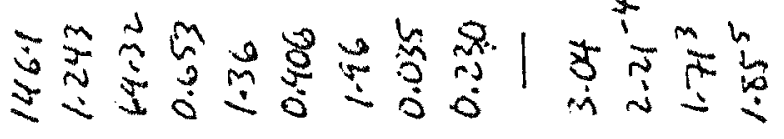

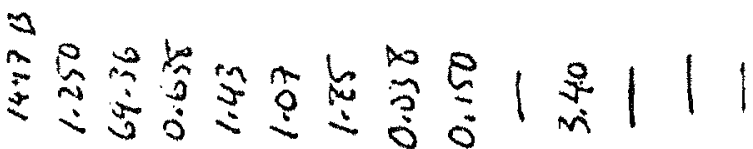

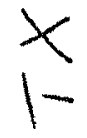

1

$M$

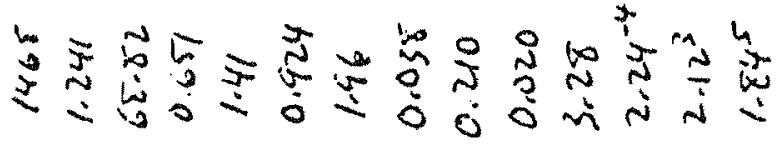

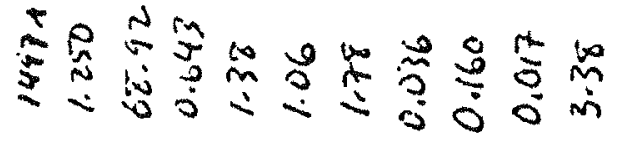

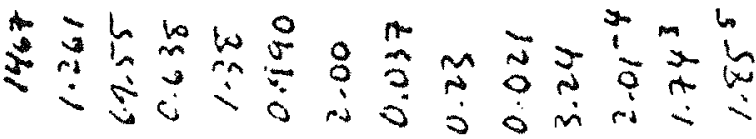

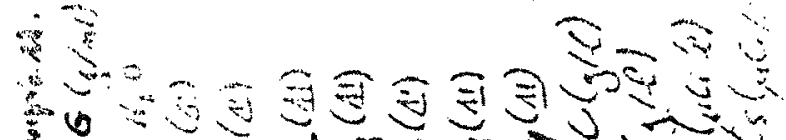

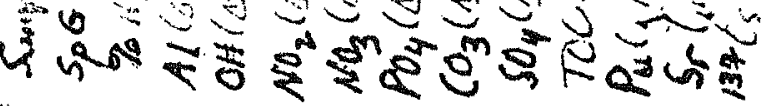




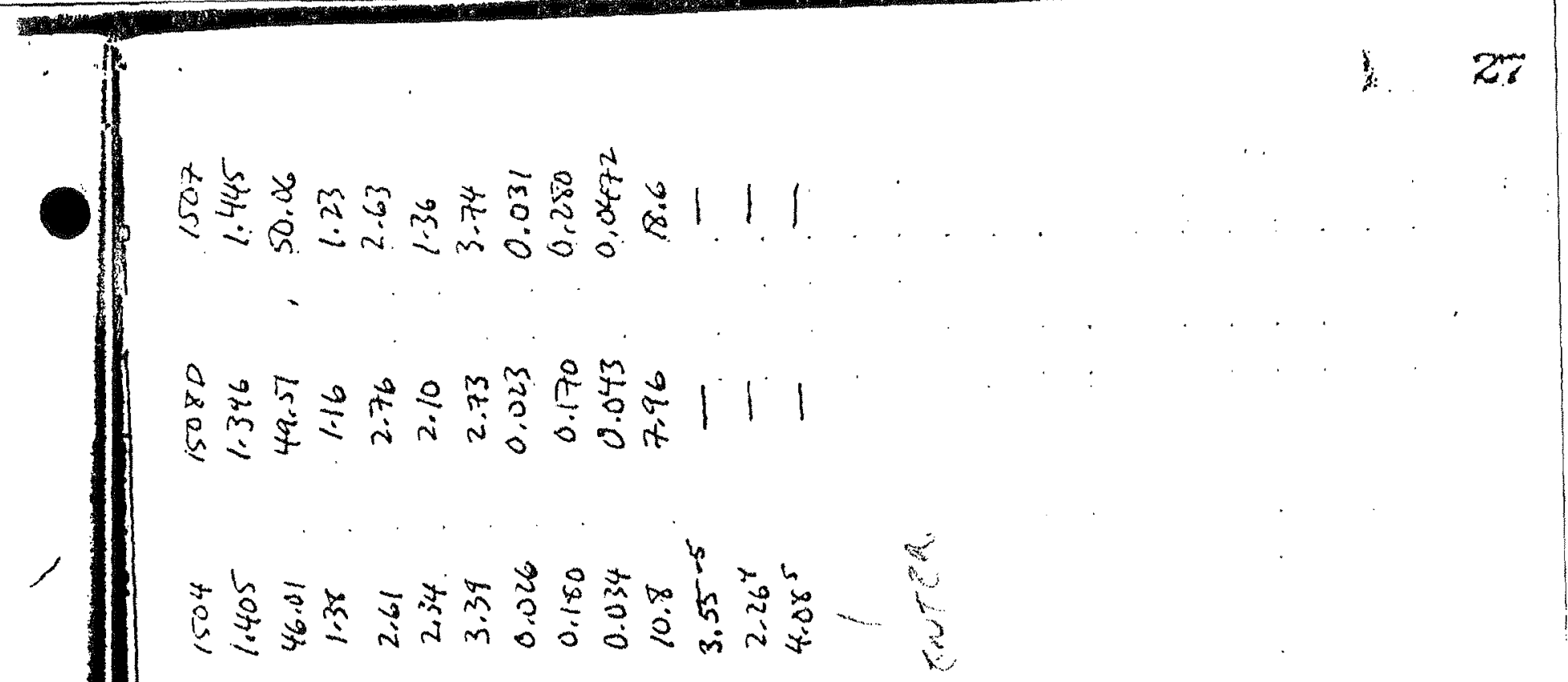

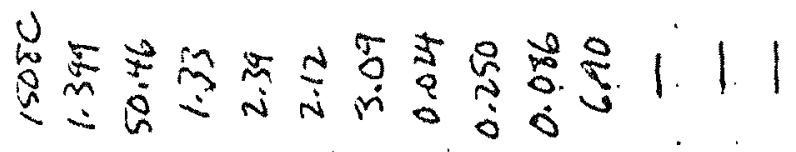

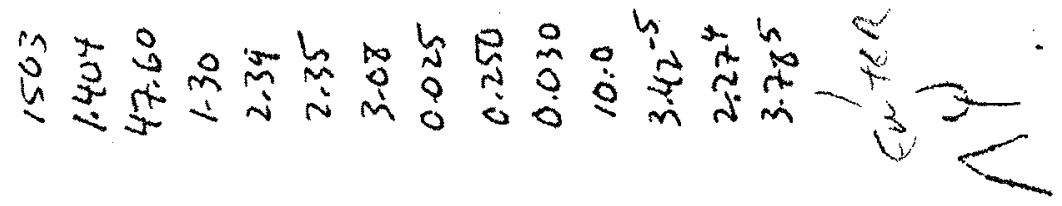

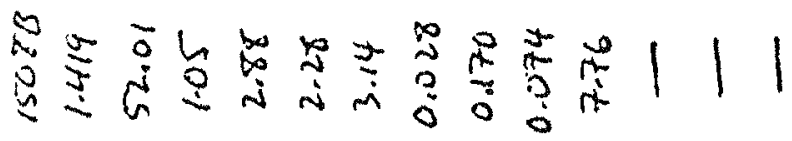

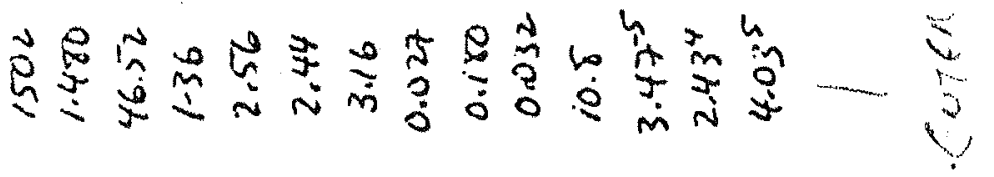

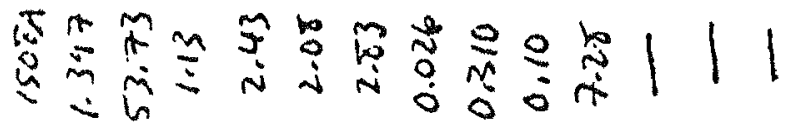

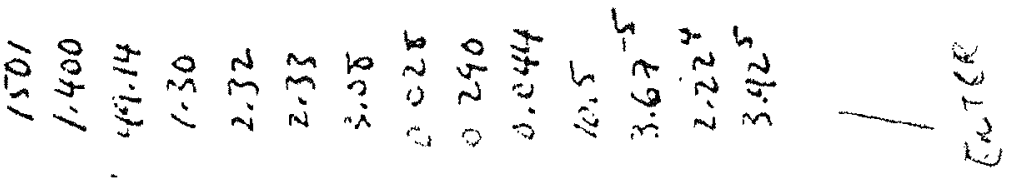

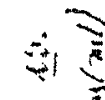

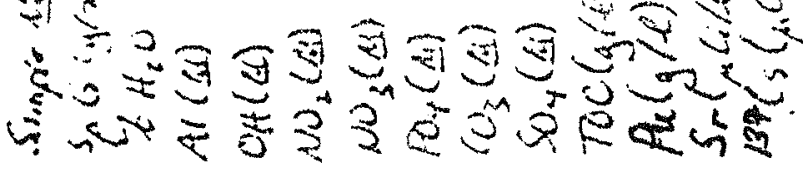


Rev. 0

3.7 Internal Letter 65124-79-029 from C. H. Delegard, "Relative Random Error Standard Deviation and Accuracy in Hanford Waste Liquor Analytical Data," December 3, 1979. 
Where $M_{1} i, M_{2} i=$ the first and second medsurements of sample and $n=$ total number of samples.

Since a given analysis (e.g., nitrite ion concentration) may exhibit a wide range of values in our set of waste liquor samples, the relative random error standard deviation (RRESO) was calculated as a more meaningful measure of random error. RRESO is:

$$
\text { RRESO }=\left(\frac{\sum_{i=1}^{n}\left(\frac{M_{1 i}-M_{2} i}{\bar{M}_{i}}\right)}{n-1}\right)^{2}
$$

where $\bar{M}=\left(M_{16}+y_{i}\right) / 2$. 
Those Listed

Page 2

December 3,1979

Each analytical technique was considered separately in evaluating RRESO. For example, aluminum was analyzed using thermal titration for samples with concentration $\approx 0.5 \mathrm{M}$ and by atomic absorption spectrometry for samples of $₹ 0.5 \mathrm{MA}$. The RRESD was calculated for each of these techniques individually.

Several factors contribute to RRESD. Besides the intrinsic RRESD of the analytical technique used, differing shifts, analysts, and standards recovery contribute to RRESO. Precipitation/dissolution of components in these high salt waste liquor samples is possible and would also contribute to RRESO.

The RRESD's calculated from the referenced data are presented in Table I. The RRESD's are a measure of the precision or reproducibility of the analytical data.

To crudely assess the accuracy of the AL waste liquor analyses, the percent recoveries of components were calculated for the five synthetic waste liquors prepared. Percent recovery equals:

$$
\text { Percent Recovery }=\frac{\text { Concentration, As Analyzed }}{\text { Concentration, As Prepared }} \times 100 \%
$$

The percent recoveries are presented in Table II. Except for aluminum and hydroxide, the standard deviation of these percent recoveries generally correspond to the RRESO's given in Table I. The hot and synthetic waste liquor analytical data used in these evaluations are shown in Table III.

This information is presented to aid in evaluating analytical data received from $\mathrm{AL}$. Please call me regarding any questions on this work.

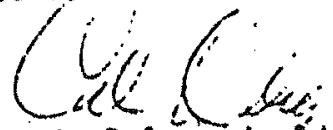<smiles>CCCCCC</smiles>

C. H. Delegard, Advanced Chemist

Was te Chemistry Unit

CHD: jkr

Those Listed

J.1. S. Bucktngham

D. A. Dodd

D. L. Herting

C. 3. Hanaker

J. E. Hortcin

K. Watate

IJ. R. Jewet:

F. H. Jung ieisch ...

L. P. McRae

M. E. Mitchell

K. J. Patterson

R. R. Rietz

W. H. Sant

A. E. Schilling

D. A. Sebelien

D. Shephard

D. L. Vebelacker

S. B. Wilson-idright

Proce is 
Table!

RELATIVE RANOCM ERROR STANDARD DEVIATION OF ANALYTICAL LABORATORY DATA ON HANFORD WASTE LIQUORS

\begin{tabular}{|c|c|c|c|c|c|}
\hline Analys is & Technique & $\begin{array}{l}\text { Procedure } \\
\text { Number }\end{array}$ & $\begin{array}{l}\text { Range of } \\
\text { Values } \\
\end{array}$ & $\begin{array}{c}\text { Relative } \\
\text { Random Error } \\
\text { Std. Deviation }\left(\begin{array}{c}\infty \\
0\end{array}\right) \\
\end{array}$ & $\begin{array}{c}\text { Number } \\
\text { Data Pairs }\end{array}$ \\
\hline $\operatorname{SpG}(g / \mathrm{ml})$ & welgh pipet & OW -03 & $1.236-1.456$ & 1.7 & 16 \\
\hline$\therefore \mathrm{H}_{2} \mathrm{O}$ & $105^{\circ} \mathrm{C}$ evap. & PWTF-01 & $44.06-69.55$ & 5.1 & 16 \\
\hline \multirow[t]{2}{*}{ Al (M) } & therm. titr. & ALTTM-0I & $0.637-1.44$ & 15 & 12 \\
\hline & AAS & AAS-0? & $0.106-0.136$ & 21 & 4 \\
\hline \multirow[t]{2}{*}{$\mathrm{OH}(\underline{M})$} & therm. titr. & ALTTY-01 & $1.36-3.04$ & 6.9 & 12 \\
\hline & pH titr. & $O H Y-01$ & $0.968-2.02$ & 21 & 4 \\
\hline $\mathrm{NO}_{2}(\underline{M})$ & color. & N02SP-01 & $0.263-2.58$ & 23 & 16 \\
\hline $\mathrm{NO}_{3}$ (iM) & Raman & AlIRAM-0I & $1.78-3.74$ & 8.8 & 12 \\
\hline $\mathrm{PO}_{4}$ (M) & extr./color. & PS-02 & $0.00288 * 0.043$ & 24 & 16 \\
\hline $\mathrm{CO}_{3}(\underline{M})$ & acid./gas anal. & $\operatorname{Co} 3|R-0|$ & $0.16-0.94$ & 20 & 16 \\
\hline $\mathrm{SO}_{4}(\underline{M})$ & Raman & ANRAM-01 & $0.017-0.10$ & 75 & 5 \\
\hline $\operatorname{Toc}(\mathrm{g} / 1)$ & pyrolysis & CTOTO-01 & $2.68-188.3$ & 25 & 16 \\
\hline
\end{tabular}




$$
\begin{gathered}
\text { TAble II } \\
\text { PERCENT RECOVERIES OF } \\
\text { SYNTHETIC WASTE COMPONENTS }
\end{gathered}
$$

Component

A1

$\mathrm{OH}$

$\mathrm{NO}_{2}$

$\mathrm{NO}_{3}$

$\mathrm{PO}_{4}$

$\mathrm{CO}_{3}$

TOC

\section{Percent Recovery}

$\begin{array}{lllll}102.6 & 99.4 & 102.7 & 101.4 & 92.1\end{array}$

$\begin{array}{lllll}101.7 & 102.3 & 158 & 100.8 & 106.5\end{array}$

$\begin{array}{lllll}100.8 & 97.2 & 113.9 & 114.2 & 57.5\end{array}$

$\begin{array}{lllll}114.8 & 107.3 & 102.7 & 109.7 & 117.7\end{array}$

$122 \quad 123$

$48.9 \quad 132$

140

$100.0 \quad 130$

$221 \quad 165 \quad 159$

$84.5 \quad 124$

$129 \quad 177$
Ave. :

Recovery

99.6

113.9

96.7

110.4

108.6

115.7

170
Standard

Deviation

$$
4.4
$$

25

23

6.0

34

23

33

The synthetic waste liquors were made without sulfate. EOTA and HEDTA were the chemicals used as organic carbon sources. 


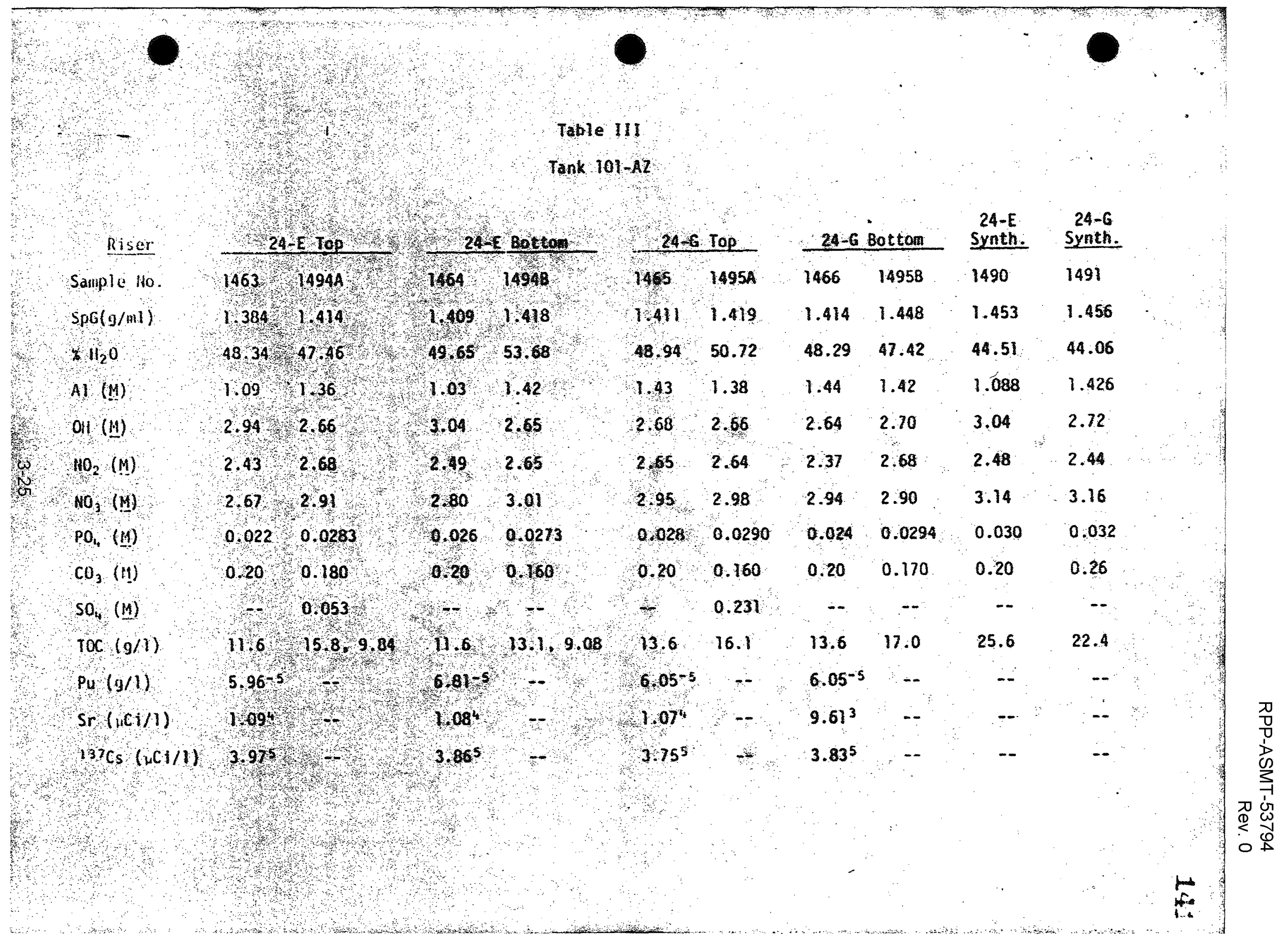




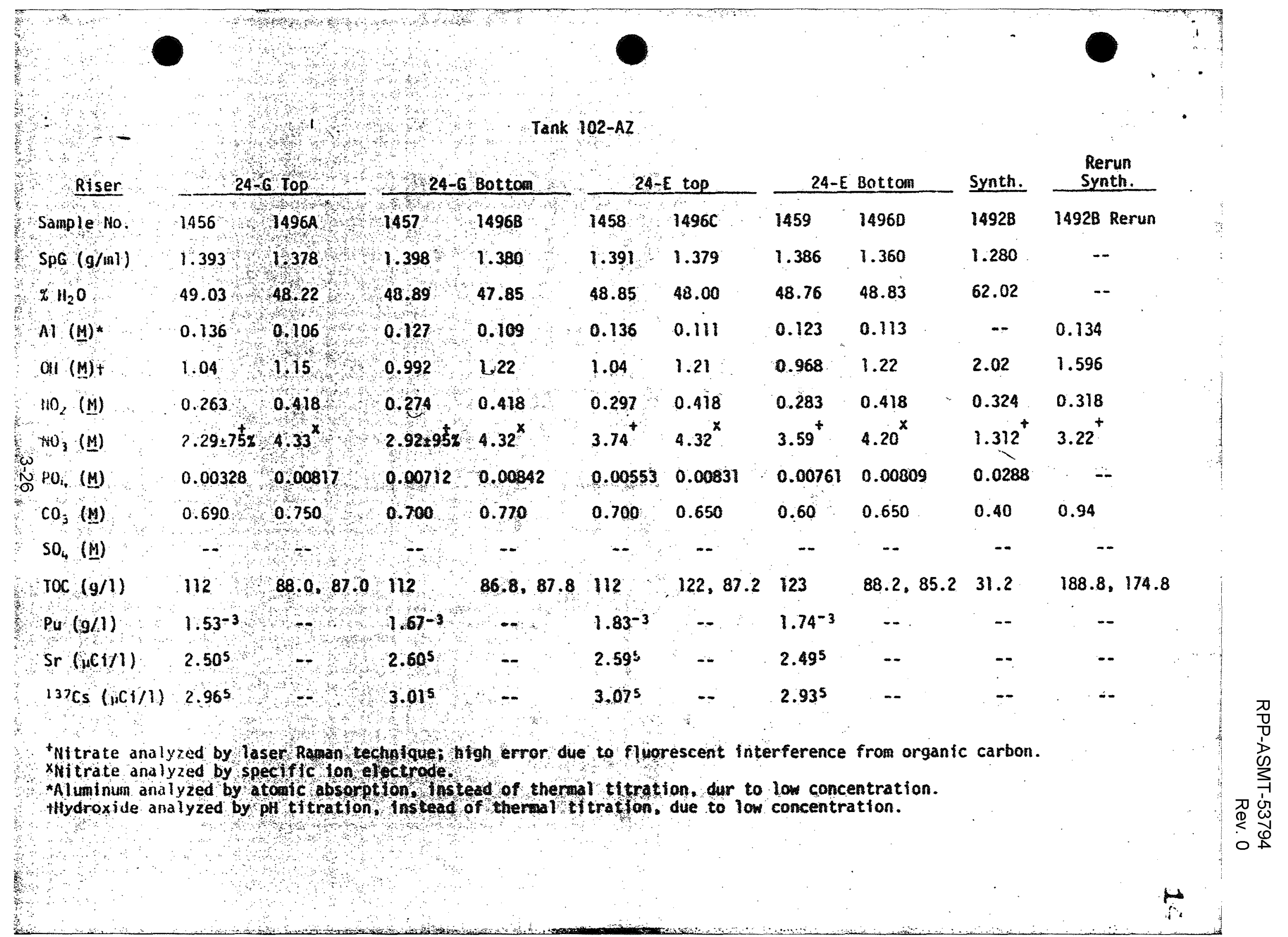




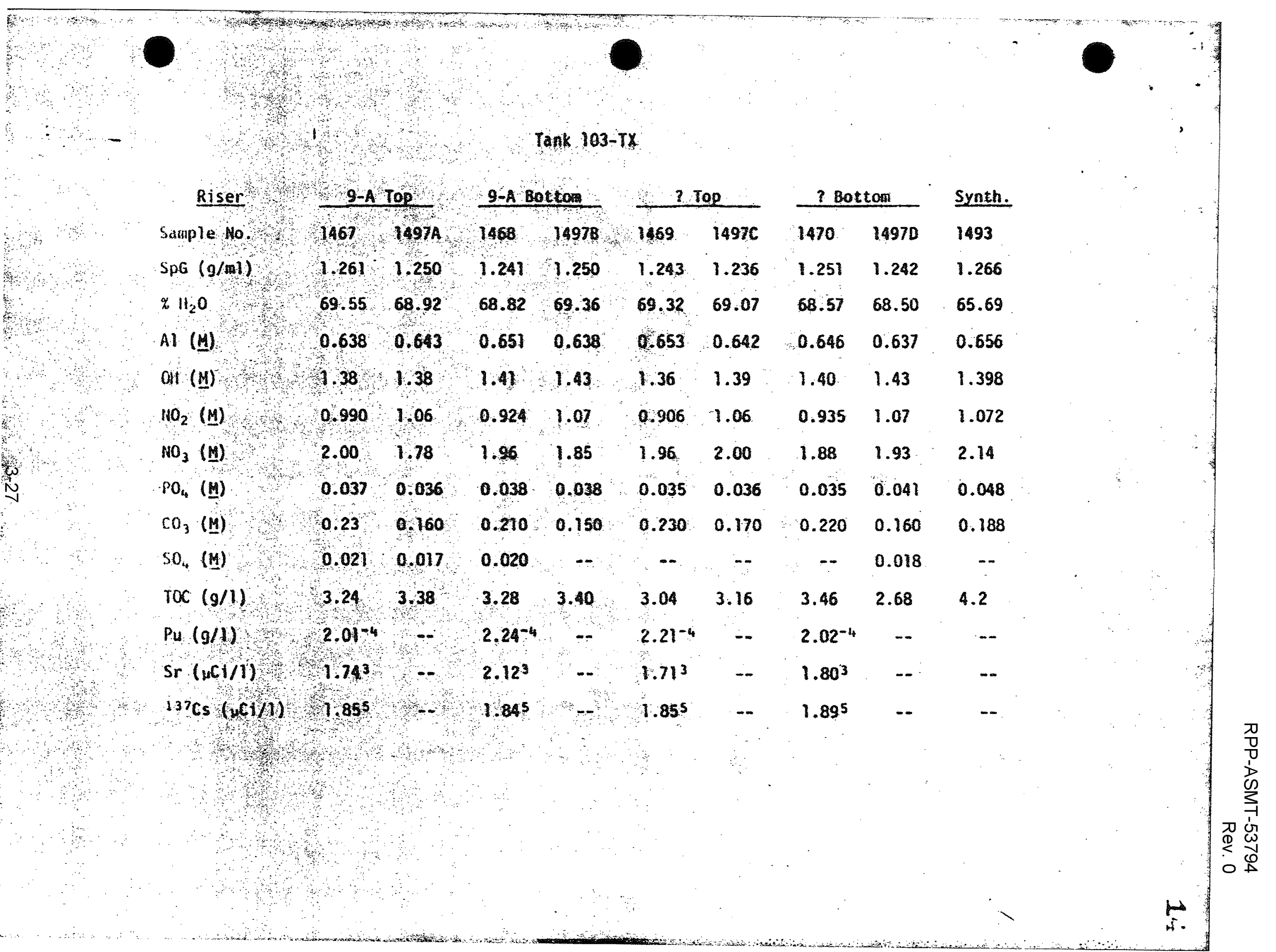




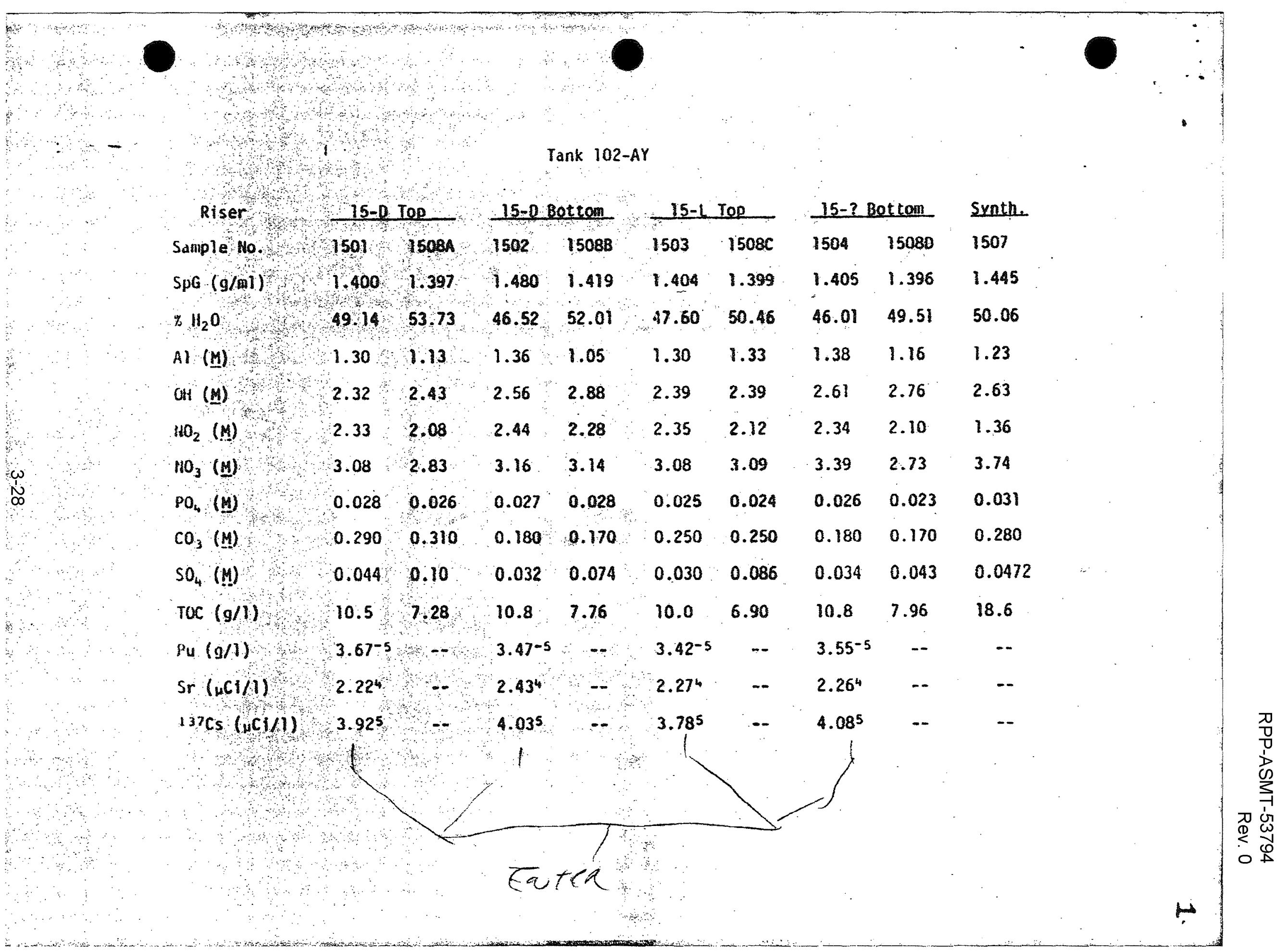


Rev. 0

3.8 Analytical Results Tank 102-AY from March 1980 through September 1980. 


\section{Su. : Analytical Results}

TANK SAMPLE NUMBER $102 A Y-242-A-6 \mathrm{~m}$

AL SERIAL NUMBER T8880

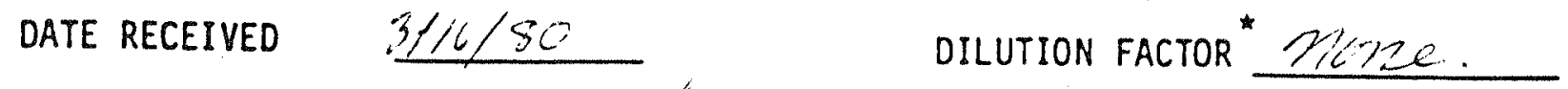

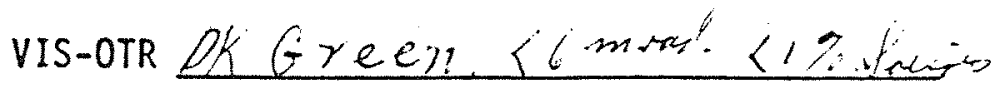

ANALYSIS

$\mathrm{pH}$

SpG

$\therefore \mathrm{H}_{2} \mathrm{O}$

) TA

A1

$\mathrm{OH}$

$\mathrm{NO}_{3}$

$\mathrm{NO}_{2}$

Pm 147

Sr 89,90

Pu

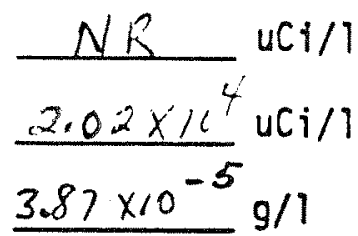

GEA

Cs-137

Cs-134

$4.1 / \times 10^{5}$ uci/1
RESULTS

$N R$

1.418

$50.5 \%$ wt $\%$

NR

$2.608 \mathrm{M}$

$1.397 \quad M$

$2.86 \quad M$

$2.42 M$

NA

ANALYSIS

$\mathrm{PO}_{4}$

$\mathrm{CL}$

F

$\mathrm{SO}_{4}$

$\mathrm{CO}_{3}$

TorgC
RESULTS

$6.24^{-3} \mathrm{M}$

$N R \quad M$

NR M

NR $M$

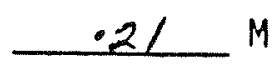

$-11.5 \mathrm{~g} / 1 \mathrm{c}$

NR :1

Cooling Curve

TEMP $\quad 50 \%$ SOLIDS

50 nu sicido

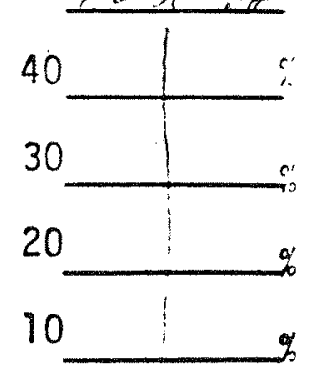
$u C i / 1$ $u \mathrm{Ci} / 1$ $u C i / 1$

NR $=$ Not Requested $\quad N D=$ Not Detected $3-3{ }^{\star}$ the dilution factor is included in the calculations. 


\section{Analytical Results}

TANK SAMPLE NUMBER $10 \geq A Y-242 \mathrm{ABm}$.

AL SERIAL NUMBER T\&\$S1

DATE RECEIVED $3 / / C / 80$

DILUTION FACTOR* PICZC

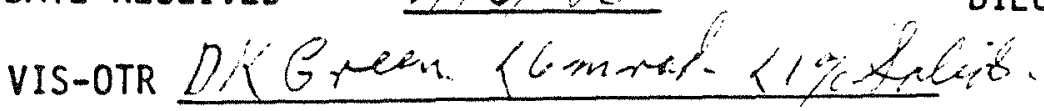

\begin{tabular}{|c|c|c|c|}
\hline ANALYSIS & RESULTS & & ANALYS \\
\hline $\mathrm{pH}$ & $N R$ & & $\mathrm{PO}_{4}$ \\
\hline$S p G$ & 1.414 & & $C L$ \\
\hline$: \mathrm{H}_{2} \mathrm{O}$ & $50.5 \%$ & wt \% & $F$ \\
\hline$\checkmark r A$ & $N R$ & & $\mathrm{SO}_{4}$ \\
\hline Al & $2 \cdot 6: 2$ & M & $\mathrm{CO}_{3}$ \\
\hline $\mathrm{OH}$ & 1.5.5: & M & TorgC \\
\hline $\mathrm{NO}_{3}$ & 3.17 & M & NA \\
\hline $\mathrm{NO}_{2}$ & 2.24 & M & \\
\hline
\end{tabular}

RESULTS

$$
6.41^{-3} M
$$$$
\text { NE } M
$$$$
N R \quad M
$$$$
\text { NR M }
$$
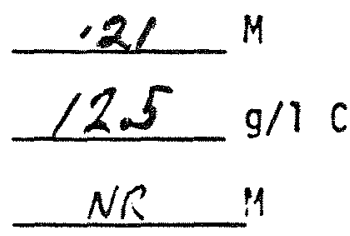

\section{Cooling Curve}

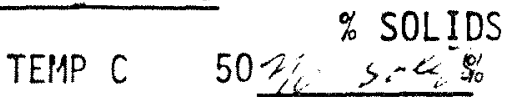

Pm 147

Sr 89,90

Pu

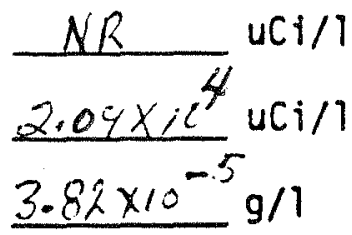

GEA

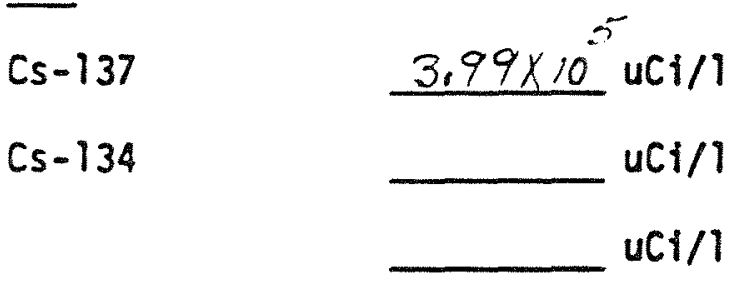
$\mathrm{uCi} / \mathrm{I}$ $u \mathrm{Ci} / \mathrm{l}$ $\mathrm{uCi} / \mathrm{l}$
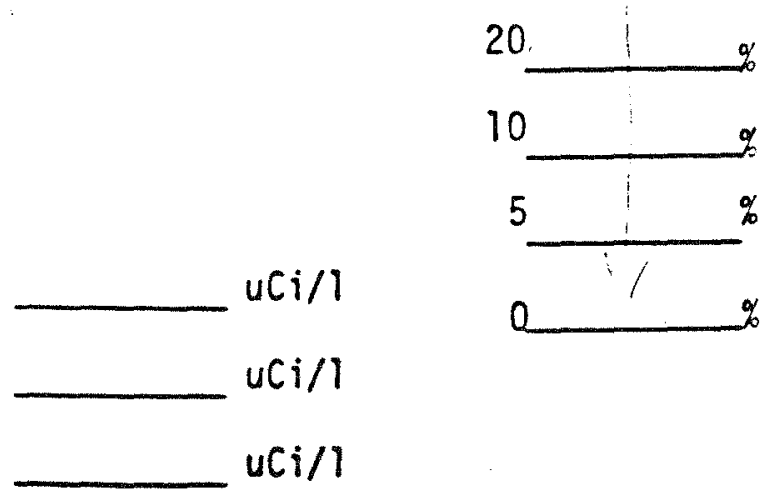

$N R=$ Not Requested $N D=$ Not Detected

3-3The dilution factor is included in the calculations. 


$$
\therefore \quad \quad \therefore \quad \therefore \text { RPPP-ASMT-537.94 } \quad \text { ReV.0. }
$$

Ranager. Services 222-S Laboratory

$200 \mathrm{~W}$

$2-2965$ or 2.2435

Analytical Results

TANK SAMLE WUMER $102-A Y \quad 242-A B M$

iL SERIAL RUMBR T T-2944

DATE RECEIVED $\quad 8-1-80$ DLUTION FACTOR" 2.2266

Vis-orr Lightegreen / cad/ur

AilALYSIS RESULTS

minusis

$\mathrm{PO}_{4}$

a

$: \mathrm{H}_{2} \mathrm{O} \quad 66.22 \mathrm{wt}:$

OrA

A)

ON

$\mathrm{po}_{3}$

10.

in 147

Sr 89.90

fu

GEA

$(5-1)]$

$3.08^{5} u(1 / 1$

Cs-134
$\frac{N R}{3}-u C 1 / 1$

8.06

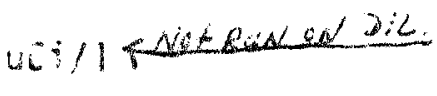

F

$\mathrm{SO}_{4}$

$\mathrm{CO}_{3}$

Torge

in
RESULTS

.064

$N R^{4}$

MR $M$

NR "

$.364 \mathrm{M}$

$14.39 / 1 \mathrm{C}$

$N \beta$ :

Coolina Curve

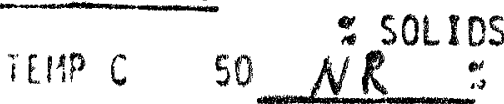

40

30

20

10

5

$461 / 1$

uci/l

$u C i / l$

HR = Not Requestad $W D=$ Hot Detcerazd

The dilution factor is included in the calculations. 
Manager. Services

222-5 Laboratory $200 \mathrm{~W}$

2-2985 or $2-2435$

Analytical Result:

THMK SAMPLE NUMBER

Al SERIAL NUMBER ZZZgLS

DATE RECEIVED $\triangle-1-80$

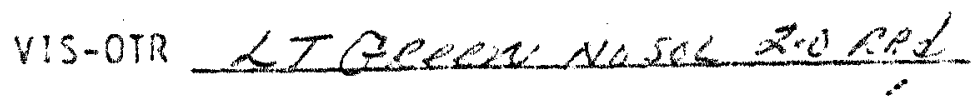

AHALYSIS

RESULIS

Amissis

RESULTS

or

NR

$\mathrm{PO}_{4}$

.062 .4

Spo

1.414 (CALE)

a

$N B$

$: \mathrm{H}_{2} \mathrm{O}$

61.37 :

F

U.A

NR

A)

.395

50

$\mathrm{CO}_{3}$

Torge

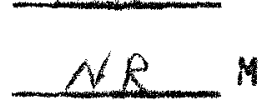

or

2.14 .4

in

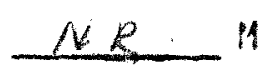

10

2.94 .4

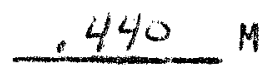

no.

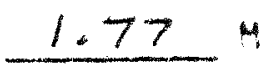

$14.69 / 1 \mathrm{C}$

$\angle R: 1$

Coolina Curve

$8 \mathrm{~m} 147$

$\frac{N R}{3} 6 / 11$

s. 89.90

$7.37 \times 10^{3}$ uci/

Pu

$3.87 \times 10^{-5} 9 / 1$ TEMPC

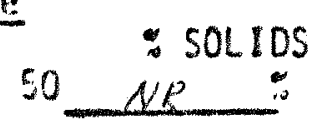

GEA

$(5-13)$

$3.03^{5} \mathrm{uc1/1}$ uCs/I

Cs-134 $401 / 1$ uCi/l

80

30

20

10

5

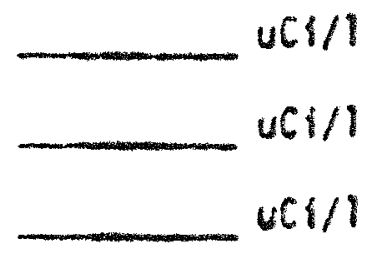

e

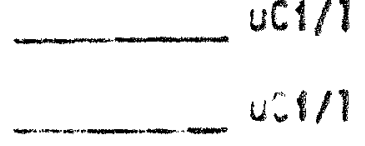

uci/l

NR - not Requestad M a Hat detucted

The dlifution factor is included in the relewidense 


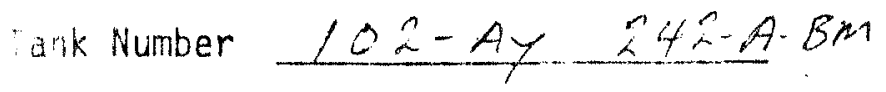

nL serial No. T-4876

Vate Received $9-22-80$

Dilution Factor NONE *

NILYSIS DTR IT.GREEN

RESULTS

ANALYSIS

RESULTS

$\mathrm{PH}$ .5 fadtir

$\mathrm{PO}_{4}$ $2.82^{-2} \mathrm{M}$

$3 \mathrm{PG}$

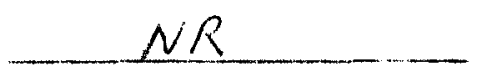

$\mathrm{Cl}^{-}$

NR M

1.429

$\mathrm{F}^{-}$

NR M

$\mathrm{H}_{2} \mathrm{O}$

wt. $\%$

UTA

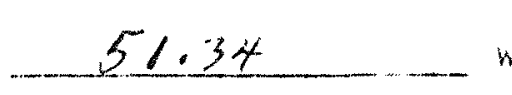

$\mathrm{SO}_{4}$

NR $M$

ird

NR

$\mathrm{CO}_{3}$

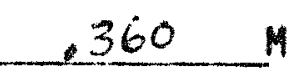

A)

$\frac{1.34}{2.01} M$

TorgC

$4.88 \quad 9 / 1$

if:

2.0

$\mathrm{Na}$

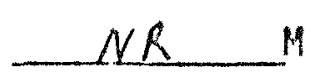

$10_{3}$

2.98

$10_{2}$

2.98
2.36

Cooling Curve

147

$\frac{N R}{4} \quad u C i / 1$

$\operatorname{sr} 89 / 90 \frac{1.40 \times 10^{4}}{5}$ uCi/1

$\mathrm{Pl} \quad 3.33^{-5} \quad 9 / 1$

Temp. C \% Solids

QEA

$C_{5} 1374.09 \times 10^{5} \mathrm{uCi} / 1$

Cs $134 \longrightarrow \mathrm{uCi} / 1$ $\mathrm{uCi} / \mathrm{I}$

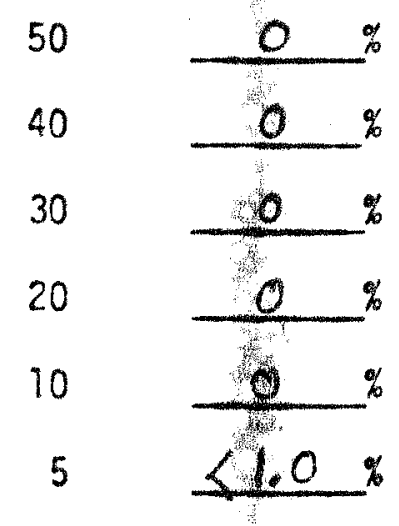

$M=$ Not Requested

N. V) Not Detected
The dilution factor is included in the calculations. 
Rev. 0

3.9 Internal Letter 65453-81-130 from M. T. Jansky to M. Teats, "Composition of Waste from Tanks 101AY and 102AY," April 15, 1981. 
TABLE I

Composition of Tank lolaY Waste (In Moles Per Liter)

\section{Component}

$\mathrm{NaAlO}_{2}$

$\mathrm{NaOH}$

$\mathrm{NaNO}_{2}$

$\mathrm{NaNO}_{3}$

$\mathrm{Na}_{2} \mathrm{CO}_{3}$

$\mathrm{Na}_{3} \mathrm{PO}_{4}$

TOC $(\mathrm{g} / \mathrm{L})$

$137 \mathrm{Cs}(\mathrm{uCi} / \mathrm{L})$

${ }^{90} \mathrm{Sr}(\mathrm{HCH} / \mathrm{L})$

${ }^{60} \mathrm{Co}(\mathrm{hCi} / \mathrm{L})$

$155_{\mathrm{EU}}(\mathrm{HCH} / \mathrm{L})$

$240 \mathrm{Pu}(\mathrm{g} / \mathrm{L})$

SPG

\section{Total STurry}

Not Available

1.04

1.15

1.92

0.55

0.79

19.4

$3.86 \times 10^{5}$

Not Available

390

1755

$4.79 \times 10^{-5}$

1.261

\section{Filtrate}

0.76

0.53

1.45

1.75

0.55

0.05

26.4

$3.41 \times 10^{5}$ Not Avallable 467 Not Avallabid

$5.3 \times 10^{-4}$

1.247

.
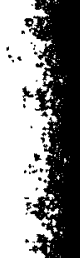

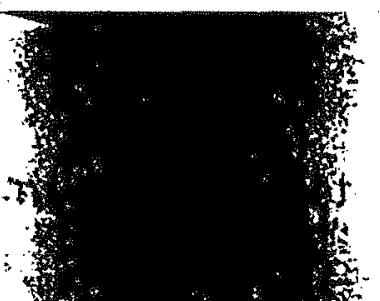

约
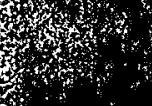
Rev. 0

\section{TABLE II}

$$
\text { Ay-102 4/15/1981 }
$$

\begin{tabular}{|c|c|c|}
\hline $\begin{array}{l}\text { Total slurry } \\
\text { (moles/liter) }\end{array}$ & $\begin{array}{c}\text { Filtrate } \\
\text { (moles/liter) } \\
\end{array}$ & $\begin{array}{l}\text { Sol ids* } \\
(\text { Wt. }: \Delta)\end{array}$ \\
\hline 1.12 & 0.83 & \\
\hline 1.88 & 2.05 & \\
\hline 1.97 & 0.47 & 21 \\
\hline 2.74 & 2.10 & \\
\hline 0.06 & 0.16 & 37 \\
\hline $0.06^{*}$ & $0.01 * *$ & $* *$ \\
\hline $8.9^{\prime}$ & 15.4 & $39 * *$ \\
\hline $3.74 \times 10^{5}$ & $3.38 \times 10^{5}$ & \\
\hline Not Available & Not Available & \\
\hline $1.20 \times 10^{-4}$ & $1.17 \times 10^{-5}$ & \\
\hline
\end{tabular}

- Weight percent solids are based on an estimated aluminum content

- Ses text for discussion 
Rev. 0

3.10 Internal Letter 65453-082-228 from J. V. Panesko to N. W. Kirch, "Analysis of 102-AY Supernate," June 18, 1982. 


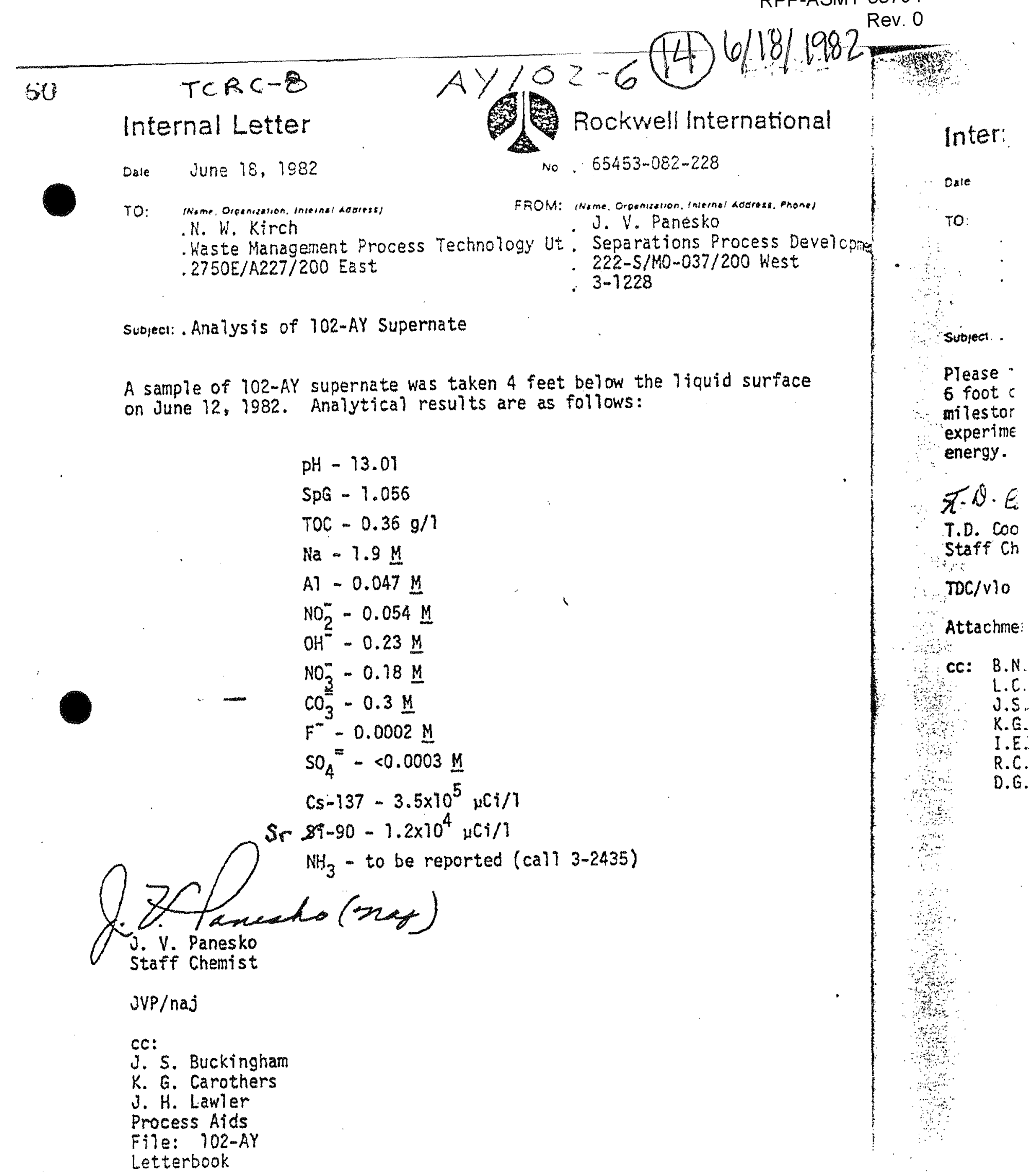


Rev. 0

3.11 SD-WM-PE-018, 1985, 242-A Evaporator/Crystallizer FY84 Campaign Run 84-3 Post Run Document, Rev. 0. 
SRIGINAL

Akwell Hanford Operations

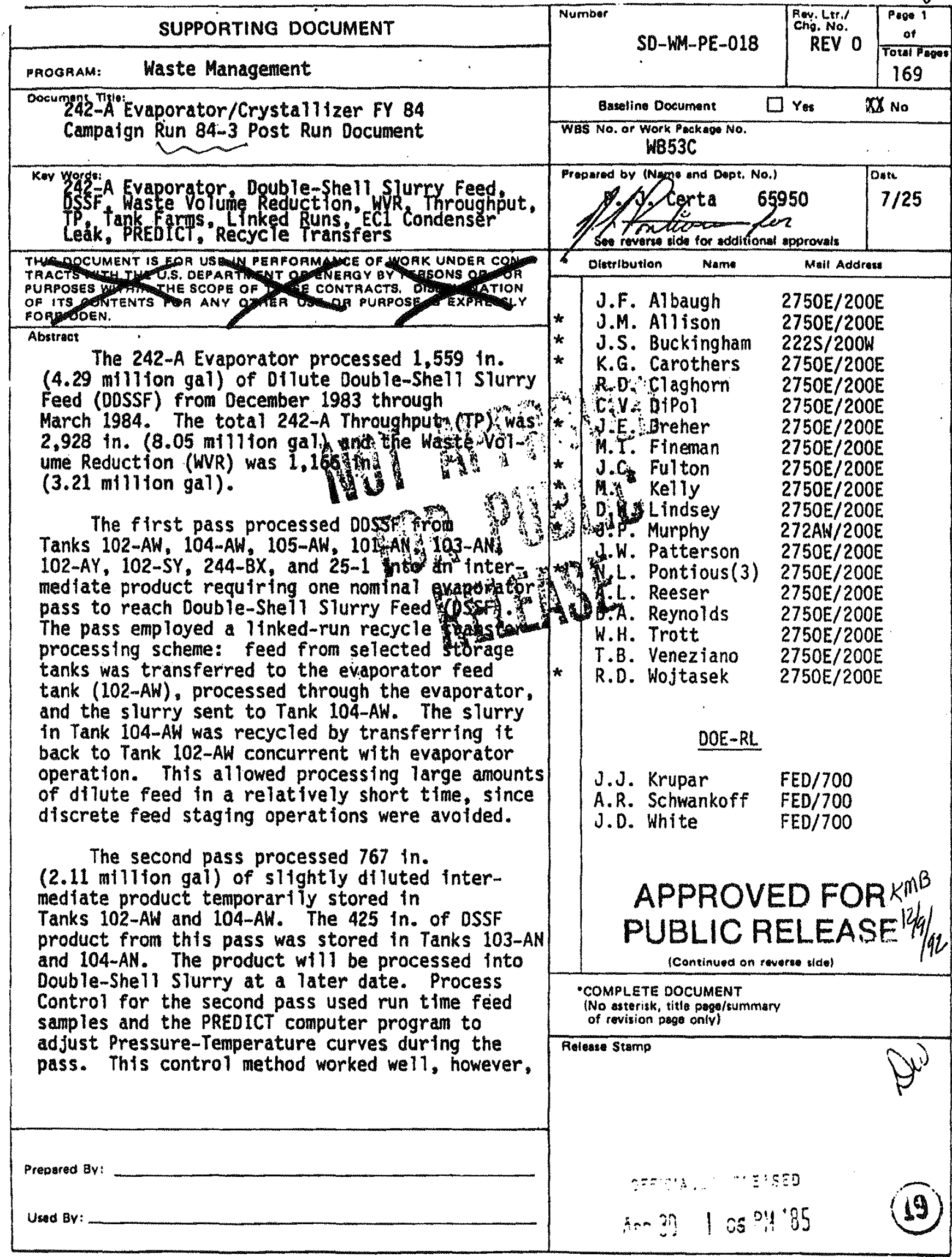
Evaporator Campaigh

$12 / 7 / 1983 \quad A 4-102$

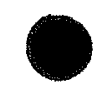

$$
\text { AY102-7 (12) }
$$

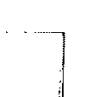

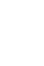




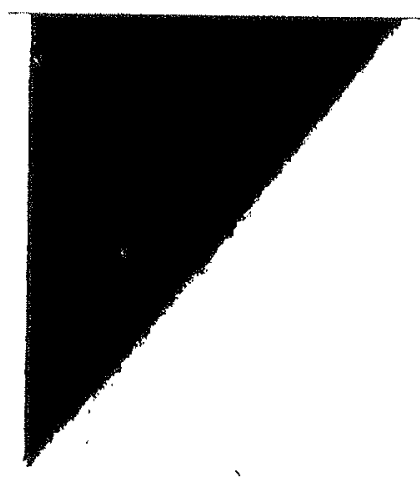

$$
\begin{aligned}
& \text { Ay-102 Evaporator Campaigh Sampleo. } \\
& 12 / 7 / 1983
\end{aligned}
$$

SAMPLE STATUS REPORT FOR T8916 102 -AY A-FD

DISPATCHED: $12-7-83$ 13:39

FECEIVED: 12-8-83 19:13

TIME:

SAMPLE HAS NOT BEEN SLURPED

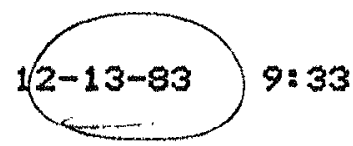

$\begin{array}{ll}\text { EXT. } & \text { DETER. } \\ * * * * & * * * * * * * * \\ 1001 & \text { APPR/OTR } \\ 1101 & \text { A1 } \\ 1.13 & \text { DH- } \\ 1 & \text { COS } \\ 1621 & \text { TOC } \\ 1763 & \text { DENSITY } \\ 2912 & \text { NO2 } \\ 2937 & \text { NO3 } \\ 3201 & \text { PH } \\ 3261 & \text { PO4 } \\ 3707 & \text { SO4 }\end{array}$

RESULTS OR STATUS

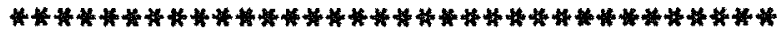

YELLOW - CLEAR NO SOLIDS NO .ORGANIC

1. $590 \mathrm{E}-01 \mathrm{M}$

5. 300E-O1 M

1. $680 E-01 \mathrm{M}$

4.620E-01 GM/L C

1. $085 E$ OO NONE

1.540E-O1 M

4. 830E-O1 M

1. $313 E$ O1 NONE

5. 3SOE-O3 M

3.280E-02 M

$\begin{array}{cc}\text { OUT OF GOOD } \\ \text { RANGE? ANS } \\ \text { *** } & * * \\ & \\ N & Y \\ N & Y \\ N & Y \\ N & Y \\ N & Y \\ N & Y \\ N & Y \\ N & Y \\ N & Y \\ N & Y\end{array}$

CHARGE

CODE

******

WBSSC

WBGSC

WB65C

WBBSC

WB65C

WBS $5 \mathrm{C}$

WB65C

WBESC

WB65C

WB65C

WB65C

END OF REPORT

SAMPLE STATUS REFORT FOR TB901

SERIAL NUMBER T8901 HAS NO ANALYSES DEFINED 


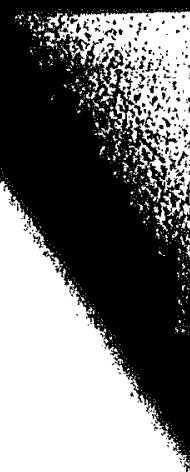

SAMPLE STATUS REPORT FOR T8917 102-AY A-FD SAMPLE HAS NOT BEEN SLURPED

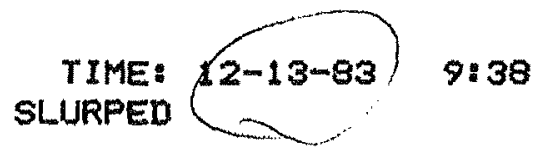
RECEIVED:

$\begin{array}{ccc}\begin{array}{c}\text { OUT OF } \\ \text { RANGE? } \\ * * *\end{array} & \begin{array}{c}\text { ANS? } \\ * * *\end{array} & \begin{array}{c}\text { CHARGE } \\ \text { CODE } \\ * * * * * \\ \text { WB65C } \\ \text { WB65C }\end{array} \\ N & Y & \text { WB65C } \\ N & Y & \text { WB65C } \\ N & Y & \text { WB65C } \\ N & Y & \text { WB65iC } \\ N & Y & \text { WB65C } \\ N & Y & \text { WB65C } \\ N & Y & \text { WB65C } \\ N & Y & \text { WB65C } \\ N & Y B 65 C \\ N & Y & \text { WE65C } \\ N & Y & \text { WB65C }\end{array}$

END OF REPORT

RESULTS OR STATUS

EXT. DETER. \#******** APPR/OTR APPR/OTR

1001

1101

1113

1601

1621

1763

2812

2937

3201

3261

3261

3707

Al

OH-

cos

TOC

DENSITY

$\mathrm{NO} 2$

No3

$\mathrm{PH}$

PO4

PO4

504

$1.560 \mathrm{E}-01 \mathrm{M}$

5. 400E-01 M

$1.790 E-01 \mathrm{M}$

1. OBSE OO NONE

1. $604 E-01 \mathrm{M}$

5. O1OE-O1 M

$1.262 E$ OL NONE

OUT FOR RERUN

5.840E-03 M

3. 280E-02 M
YELLOW 15\% DARK BROWN SOLIDS 1.7 RADS

ALL ANALYSES WILL BE RUN ON SUPERNATE

4.320E-O1 GM/L C

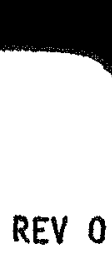

0 
Rev. 0

3.12 Internal Letter 65453-84-134 from M. T. Jansky to E. G. Gratny, "Laboratory Support for Upcoming 242-A Evaporator Campaign, Run 84-5," May 10, 1984. 


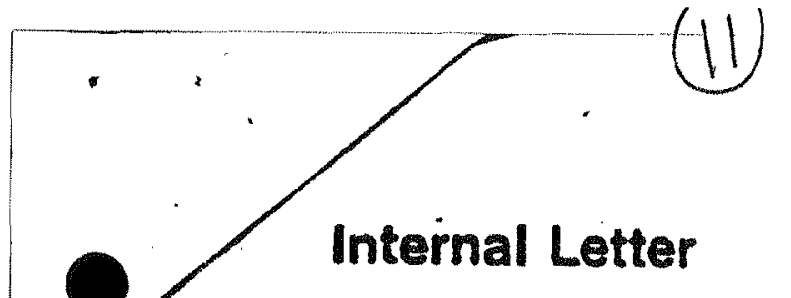

Date

May 10, 1984

ro:

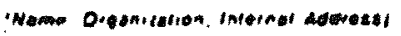
- E. G. Gratny
- Process Engineering
- 2750E/A100/200 East Area

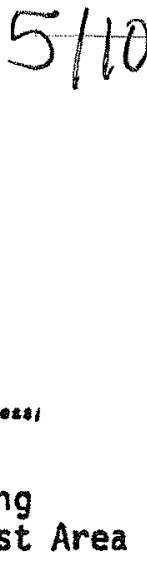

Rockwell International

so . 65453-84-134

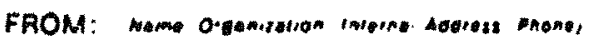

- M. T. Jansky

- Chemical Laboratory

- M0-037/2225/200 West Area

- 3-1571

Sublect: - Laboratory Support for Upcoming 242-A Evaporator Campaign, Run \&4-j

The Chemical Laboratory Unit (CLU) received six samples from various sources. Two samples were from Tank 102AY, two were from Tank 105 Ail, and tho were frcii Tank $105 \mathrm{Al}$. These samples were to be analyzed in support of the upcoming evaporator campaign producing double-shell slurry feed (DSSF), Run 34-5. Details of the laboratory șupport are discussed below.

Two samples were taken from Tank 102AY. The surface sample (R9833) anc the four feet sample (R9834) were both clear yellow solutions with only a s?ight trace of settled solids. Al iquots of each sample were prepared for anaiyses and subritted to Analytical Laboratories ( $\dot{A L}$ ) for analyses. The analytical data are shown in Table I.

Tro of the samples were from Tank 105Aii. The surface sampie, R9839, contaired approximately 15 volume percent black setilied solids (4 volume percent centrifuged solids). The four feet sample (RS840) appeared to contain oniy a trace of solids. The supernatants kere frepared for analyses and sut-itted to $A$. Solids from R9839 were dissoived and also subritted to AL. The anajytical data for Tank 105Ail are snown in Table II.

The final two samples, from Tank 105A:i, were R9S37 and R9s38. The deeper samfle, R983S, was a clear yellow soiution with a slight trace of solids. The surface sample, R9837, was very different. There were two phases fresent. There was approximately 65 volume percent istiscible organic floating over an aqueous phase. The organic phase was found to be 27.5 vclume percen: tributyl phosphate (TEP). Both phases were analyzed, with the results snown in Table III.

As the attached tables show, there are several analyses that are incompiete. Priority discrimination has prompted Al to piace these efforts in otiner directions, getting to these samples wien they can. The additional data wili be forwarded to you when it becores availatle. Updated tables wili follow imediately. Please call if you have eny questions in the interis.

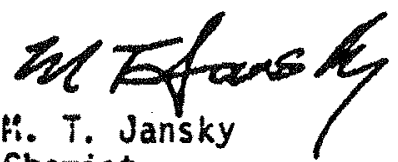

Cremist

IIT/pdk

คีะะ.
D. L. Herting

D. H. Lindisej

iv. L. Poniticus

L. H. Pscigers

T. B. Vinteziano

R. $3 \div 46$ liar $y \in: e r$
Notc: $1-10-94$ AY-10z

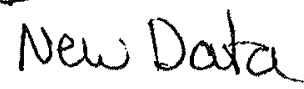

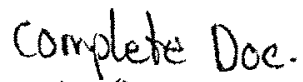

is Ret. Lib.

R. D. Hojtasek

Process Rids

File code wB

J. S. Euckingham :3l

k. G. Carothers 
TABLE I

Composition of Tank 102AY

(Supporting Run 84-5)

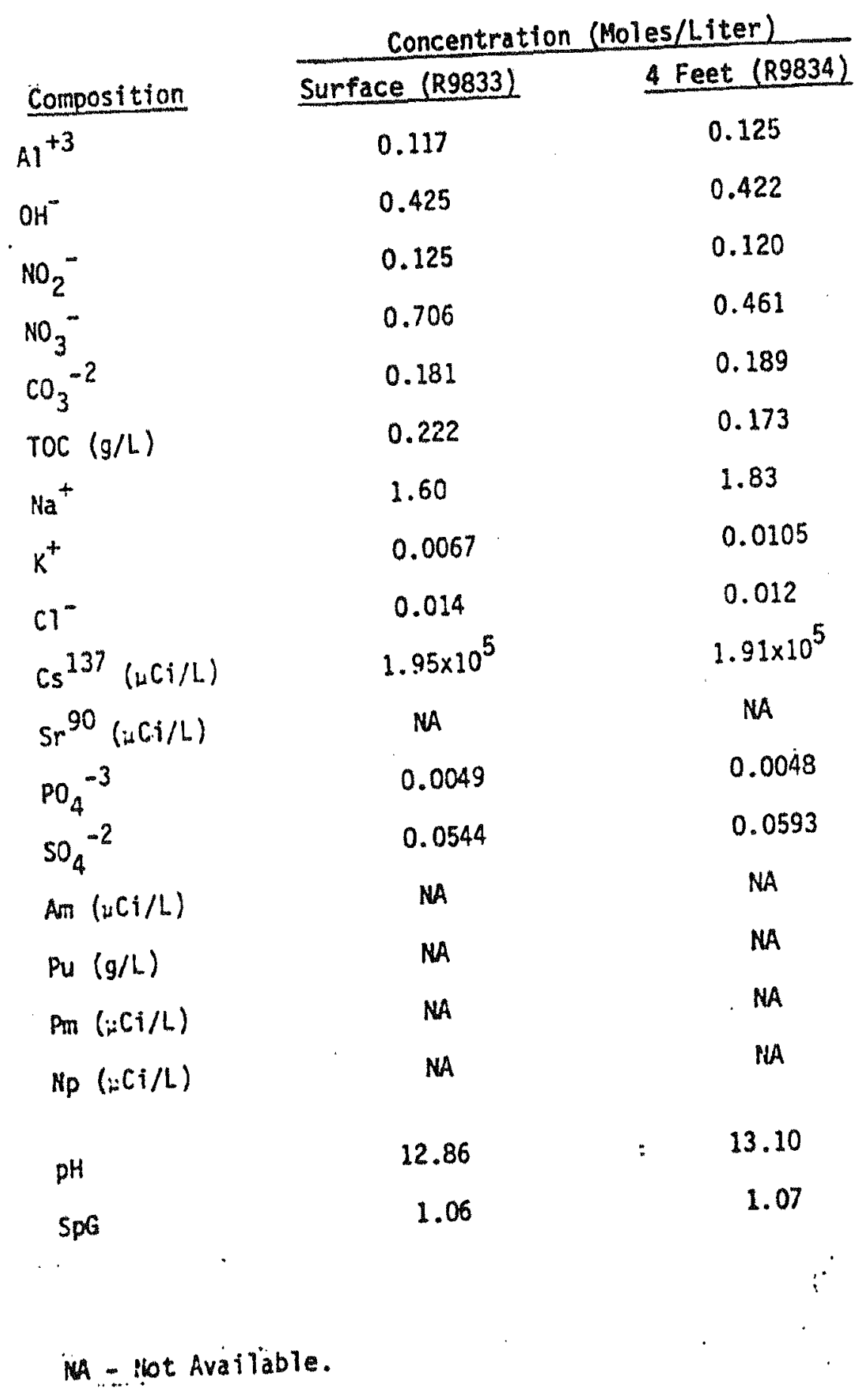


First Pass Samples.

\begin{tabular}{|c|c|c|c|}
\hline Tank & Sample $L^{*}$ & Samp le number & Date \\
\hline $102-S Y$ & & & $11-21-82$ \\
\hline \multirow[t]{2}{*}{ 104 AN } & $90 \mathrm{ln}$. & T8793 & $11-30-83$ \\
\hline & 284 in & T8797 & $11-30-83$ \\
\hline \multirow[t]{2}{*}{$103-A N$} & $74 \mathrm{ins}$ & T8882 & $12-05-83$ \\
\hline & $220 \mathrm{in.}$ & T8883 & $12-05-83$ \\
\hline \multirow[t]{2}{*}{ 101-AN } & 97 in. & . T8902 & $12-06-83$ \\
\hline & 289 in. & T8903 & $12-06-83$ \\
\hline \multirow[t]{2}{*}{ 102-AY } & $80 \mathrm{in.}$ & T8916 & $12-07-83$ \\
\hline & $240 \mathrm{in}$. & T8917 & $12-07-83$ \\
\hline 105-AW & & $\begin{array}{l}\text { T9706 } \\
\text { T9707 }\end{array}$ & $\begin{array}{l}1-06-84 \\
1-06-84\end{array}$ \\
\hline
\end{tabular}

* Measured from bottom of tank. 
Rev. 0

3.13 Internal Letter 65453-84-348 from B. M. Mauss to E. G. Gratny, "Chemical Compositions of 102-AY, 101-AW, 105-AN, and 104-AW," November 9, 1984. 
Rev. 0

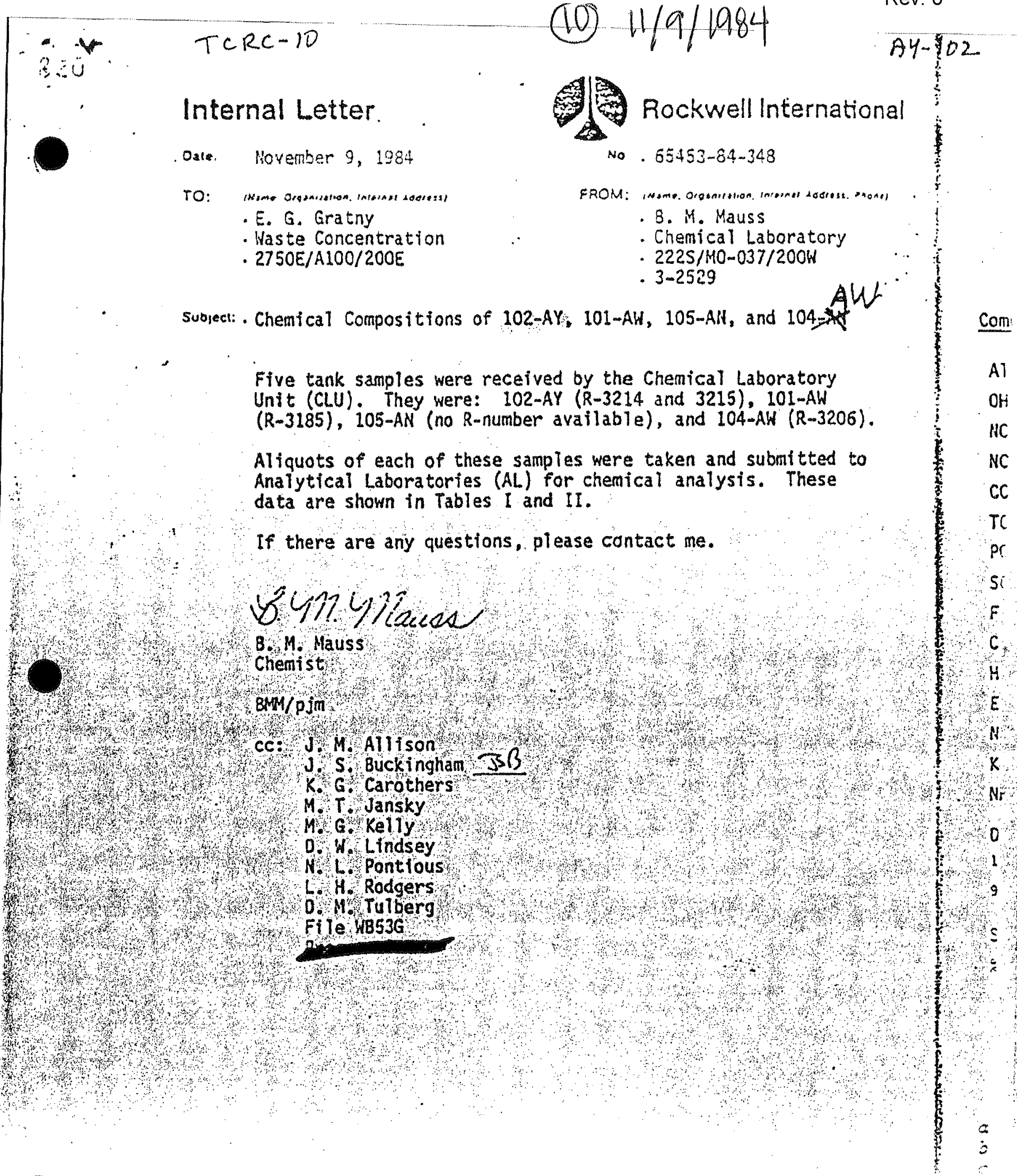

Five tank samples were received by the Chemical Laboratory

Unit (CLU). They were: 102-AY (R-3214 and 3215), 101-AW

Aliquots of each of these sampies were taken and submitted to Analytical Laboratories (AL) for chemical analysis. These data are shown in Tables I and II.

If there are any questions, please contact me.

bunyiónes

B. M. Mauss

$B M M / p j m$

CC: J. M.Allison

J. $S$. Buckingham $3 B$

M. T. Jansky

M. G. Kelly

D. W. Lindsey

0. N. Tulberg

File $\mathrm{NB} 53 \mathrm{G}$

AT

OH

$\mathrm{CC}$

TC

Pr

si

$F$

c. 
Rev. 0

\section{TRBLE I}

Composition of 102-AY Samples: $R-3214$ and $R-3215$

\section{Concentration (M)}

\section{Component}

$\underline{R-3214}$

a

0.265

0.013

0.315

0.056

0.215

0.003

$\mathrm{PO}_{4}$

$\mathrm{HSO}_{4}$

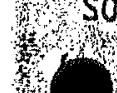

and

\section{HEOTA}

स EDTA

$N a$ $+2+3$

x $x$

$\mathrm{H}_{3} \mathrm{NH}_{3}$

Whot
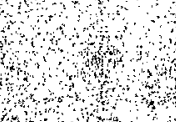

+

0.750

0.007

0.001

0.013

OTA

Ho Exotherm

$5.925 \times 10^{5}$

$2.318 \times 10^{4}$

$\mathrm{OS}_{\mathrm{s}}$ (uG//L)

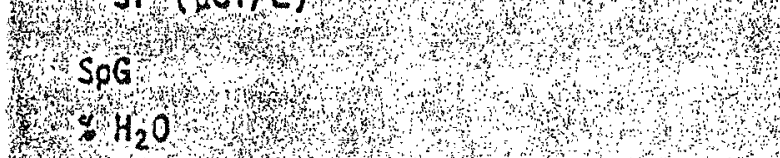

1.03

95,0

\section{R-3215}

0.005

0.327

0.023

0.430

0.065

0.238

0.003

0.020

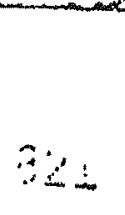

Sel ot detactsota

gata unavaliad

insutficient sampla 


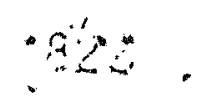

TABLE II

Composition of Tanks 101-AW (R-3135), 105-AN, and 104-AW (R-3206)

$(0$

Concentration (11)

\section{Component}

Al

OH

$\mathrm{NO}_{2}$

$\mathrm{NO}_{3}$

$\mathrm{CO}_{3}$

TOC.

$\mathrm{PO}_{4}$

$\mathrm{SO}_{4}$

$F$

$\mathrm{Cl}$

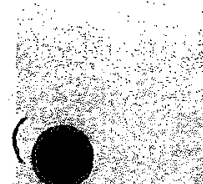

HEDTA

EDTA

$\mathrm{Na}$

$k^{\prime}$

$\mathrm{NH}_{3}$

OTA

$134 \mathrm{Cs}(\mu \mathrm{Ci} / \mathrm{L})$

${ }^{137} \mathrm{Cs}(\mathrm{uCi} / \mathrm{L})$

$90 \mathrm{Sr}(\mu \mathrm{Cl} / \mathrm{L})$

SpG $(\pi)$

$\approx \mathrm{H}_{2} \mathrm{O}$
$101-A W$

$a$

0.745

0.043

0.190

0.053

0.757

0.001

$a$

0.005

$a$

o

$b$

1.110

0.006

0.007

Exothern

1.5. $10^{2}$

$2.18 \times 10^{4}$

$4.25 \times 10^{2}$

1.024

94.7
105-AN

0.938

2.225

1.362

2.173

0.453

3.360

0.015

a

$a$

0.018

0.002

0.003

7.850

0.093

0.010

Exotherm

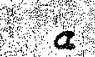

$3.60 \times 10^{5}$

$2.24 \times 10^{3}$

1.434

54.7
104-AK

0.868

3.100

1.405

2.725

0.502

4.675

0.040

0.080

a

0.150

b

b.

10.625

0.119

$a$

Exotherm

$8.55 \times 10^{5}$

$6.03 \times 10^{2}$

3.63 $\times 10^{4}$

1.410

54.7

- Gelow detactable linis

- "kata mevallable 


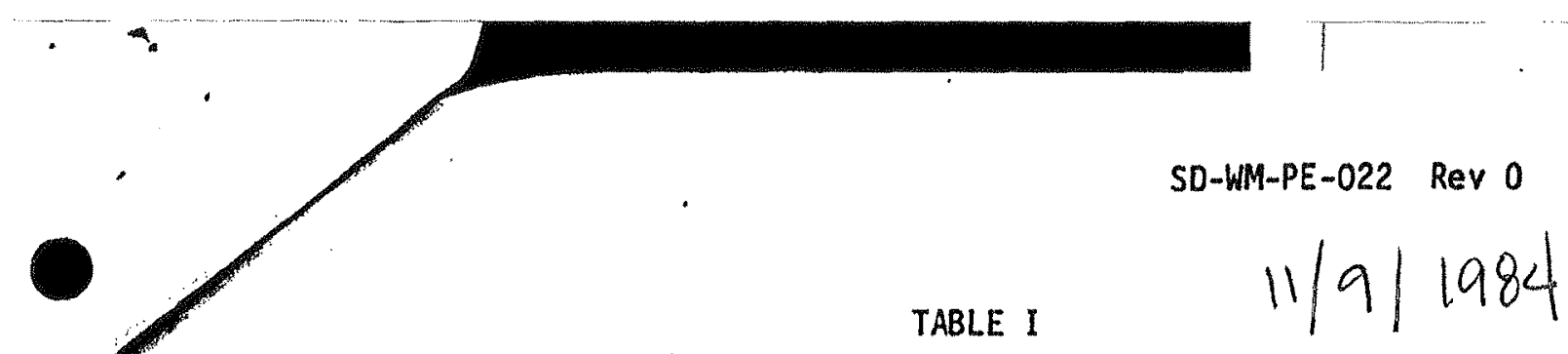

Composition of 102-AY Samples: $R-3214$ and $R-3215$

Concentration (M)

Component

A)

$\mathrm{OH}$

$\mathrm{NO}_{2}$

$\mathrm{NO}_{3}$

$\mathrm{CO}_{3}$

TOC

$\mathrm{PO}_{4}$

$\mathrm{SO}_{4}$

$F$

$\mathrm{Cl}$

HEDTA

EQTA

$\mathrm{Na}$

K

$\mathrm{NH}_{3}$

DTA

${ }^{137} \mathrm{Cs}(\mu \mathrm{Ci} / \mathrm{L})$

${ }^{\circ} \mathrm{Sr}\left({ }_{\mathrm{C}} \mathrm{Ci} / \mathrm{L}\right)$

SpG

$\% \mathrm{H}_{2} \mathrm{O}$
$R-3214$

$a$

0.265

0.013

0.315

0.056

0.215

0.003

0.007

a

0.003

$b$

$b$

0.750

0.001

0.013

No Exotherm

$5.925 \times 10^{5}$

$2.318 \times 10^{4}$

1.03

95.0
$R-3215$

0.005

0.327

0.023

0.430

0.065

0.238

0.003

0.020

0.003

0.001

a

0.988

0.002

$a$

No Exotherm

$7.525 \times 10^{-1}$

c

1.04

94.6 
Rev. 0

3.14 WHC-SD-WM-ER-454, 1997, Tank Characterization Report for Double-Shell Tank 241-AY-102, Rev. 0, Westinghouse Hanford Company, Richland, Washington. 


\section{WHC-SD-WM-ER-454 REV 0}

Rev. 0 -

APPENDIX A

ANALYTICAL RESULTS FOR THE 1987 CORE SAMPLE DOUBLE-SHELL TANK 241-AY-102 
Table A-1. Anion Content of 102-AY Waste and Derivatives.

\begin{tabular}{|c|c|c|c|c|c|c|c|c|c|c|}
\hline \multirow{2}{*}{ Anion } & \multicolumn{2}{|c|}{ Supernatant, $\mathrm{M}$} & \multicolumn{2}{|c|}{$\begin{array}{l}\text { Interstital } \\
\text { solution, } \mathrm{M}\end{array}$} & \multicolumn{2}{|c|}{$\begin{array}{l}\text { Composite sollds } \\
\text { mmolls }\end{array}$} & \multicolumn{2}{|c|}{$\begin{array}{c}\text { Washed solids } \\
\text { mmol/g }\end{array}$} & \multicolumn{2}{|c|}{ Wash, M } \\
\hline & Analysis & Analysis & Anatysts & Analysts & Analysis & $\begin{array}{l}2 n d \\
\text { Analysis }\end{array}$ & $\begin{array}{l}\text { Asts } \\
\text { Analysts }\end{array}$ & $\begin{array}{l}\text { 2nd } \\
\text { Analysis }\end{array}$ & Analysis & $\begin{array}{l}\text { 2nd } \\
\text { Analysis }\end{array}$ \\
\hline $\mathbf{F}$ & $9.3 \mathrm{E}-03$ & $8.7 \mathrm{E}-03$ & $7.5 \mathrm{E}-02$ & $6.1 \mathrm{E}-02$ & $1.8 \mathrm{E}-01$ & $9.3 \mathrm{E}-02$ & $1.6 \mathrm{E}-01$ & $6.9 \mathrm{E}-02$ & $3.7 \mathrm{E}-02$ & $2.4 \mathrm{E}-02$ \\
\hline $\mathrm{Cl}^{-}$ & $1.6 \mathrm{E}-02$ & $1.7 \mathrm{E}-02$ & $4.2 \mathrm{E}-01$ & $4.0 \mathrm{E}-02$ & $2.3 \mathrm{E}-01$ & $2.4 \mathrm{E}-01$ & $7.3 \mathrm{E}-02$ & $8.0 \mathrm{E}-02$ & $1.1 \mathrm{E}-01$ & $9.1 \mathrm{E}-02$ \\
\hline $\mathrm{NO}_{2}^{-}$ & $2.5 E-02$ & $2.4 \mathrm{E}-02$ & $1.7 \mathrm{E}-01$ & $1.6 \mathrm{E}-01$ & $1.1 \mathrm{E}-01$ & $1.8 \mathrm{E}-02$ & $2.4 \mathrm{E}-02$ & $4.7 \mathrm{E}-03$ & $5.0 \mathrm{E}-02$ & $3.7 \mathrm{E}-02$ \\
\hline $\mathrm{NO}_{5}-$ & $4.4 \mathrm{E}-03$ & $3.6 \mathrm{E}-03$ & $3.0 \mathrm{E}-02$ & $3.0 \mathrm{E}-02$ & $1.7 \mathrm{E}-02$ & $5.4 \mathrm{E}-03$ & $9.6 \mathrm{E}-03$ & $2.6 \mathrm{E}-03$ & $8.6 \mathrm{E}-04$ & $6.8 \mathrm{E}-03$ \\
\hline $\mathrm{PO}_{4}^{3-}$ & $5.5 \mathrm{E}-04$ & $<3 \mathrm{E}-06$ & $7.2 \mathrm{E}-03$ & $5.4 \mathrm{E}-03$ & $2.4 \mathrm{E}-02$ & $1.1 \mathrm{E}-02$ & $2.0 \mathrm{E}-02$ & $5.1 \mathrm{E}-03$ & $3.4 \mathrm{E}-02$ & $1.8 \mathrm{E}-03$ \\
\hline $\mathrm{SO}_{4}^{2-}$ & $1.1 \mathrm{E}-03$ & $1.1 \mathrm{E}-03$ & $1.2 \mathrm{E}-02$ & $1.2 \mathrm{E}-02$ & $8.1 \mathrm{E}-03$ & $7.6 \mathrm{E}-03$ & $2.7 \mathrm{E} .03$ & $4.0 \mathrm{E}-03$ & $3.4 \mathrm{E}-03$ & $2.8 \mathrm{E}-03$ \\
\hline TIC & $2.9 \mathrm{E}-02$ & $\mathbf{N M}$ & $2.8 \mathrm{E}-01$ & NM & NM & NM & NM & NM & $9.9 \mathrm{E}-02$ & NM \\
\hline TOC & $2.4 \mathrm{E}-02$ & $2.4 \mathrm{E}-02$ & $3.8 \mathrm{E}-01$ & $3.0 \mathrm{E}-01$ & NM & $\begin{array}{c}3.82 \mathrm{E}+0 \\
\mathrm{O}\end{array}$ & NM & $\begin{array}{c}2.19 \\
E+\infty 0\end{array}$ & $1.1 \mathrm{~B}-01$ & $7.8 \mathrm{E}-02$ \\
\hline
\end{tabular}

$\mathrm{NM}=$ Not measured.

TIC = Total inorganic carbon (inorganic carbon is carbonate or bicarbonate).

TOC = Tutal organic carbon. 
Table A-2. Elemental Concentrations in 102-AY Waste. (2 sheets)

\begin{tabular}{|c|c|c|c|c|c|c|c|c|c|c|}
\hline \multirow{2}{*}{ Anion } & \multicolumn{2}{|c|}{ Supernatant, M } & \multicolumn{2}{|c|}{$\begin{array}{l}\text { ningratial } \\
\text { ongtron } \mathrm{M}\end{array}$} & \multicolumn{2}{|c|}{ composilesolids? } & \multicolumn{2}{|c|}{$\begin{array}{l}\text { Winhed solids } \\
\text { mnol/s }\end{array}$} & \multicolumn{2}{|c|}{. 1. Wash $\mathrm{M}$} \\
\hline & Analysis & Aralysis & Analysis & Andisis: & rnilysis & Analysis & Analysis & Anilysis & ist & $\begin{array}{l}\text { 2nd } \\
\text { Analysis }\end{array}$ \\
\hline $\mathrm{Ag}$ & NM & $6.4 \mathrm{E}-05$ & NM & 5.7 B-04 & $\mathbf{N M}$ & $6.7 \mathrm{~B}-02$ & NM & $7.2 \mathrm{E}-03$ & NM & $1.6 \mathrm{E}-04$ \\
\hline Al & $5.9 \mathrm{E}-05$ & (5.1 E-05) & $5.6 \mathrm{E}-04$ & (2.3 E-04) & $1.2 \mathrm{E}+\infty$ & 1.6 & $1.1 \mathrm{E}+\infty$ & 9.4 E-01 & $2.4 \mathrm{E}-04$ & $\begin{array}{l}<6.6 \\
\text { E- } 05\end{array}$ \\
\hline B & $3.8 \mathrm{E}-04$ & 7.7 E.04 & $1.8 \mathrm{E}-03$ & $7.2 \mathrm{E}-03$ & $7.5 \mathrm{E}-02$ & 0.44 & $9.5 \mathrm{E}-02$ & $4.3 \mathrm{E}-01$ & $3.1 \mathrm{~B}-04$ & $1.9 \mathrm{E}-03$ \\
\hline $\mathrm{Ba}$ & $2.9 \mathrm{E}-06$ & $2.5 \mathrm{E}-06$ & $1.1 \mathrm{E}-05$ & $7.2 \mathrm{E}-05$ & $1.5 \mathrm{E}-02$ & $1.4 \mathrm{E}-02$ & $1.7 \mathrm{E}-02$ & $1.7 \mathrm{E}-02$ & $5.0 \mathrm{E}-06$ & $3.3 \mathrm{E}-05$ \\
\hline $\mathrm{Ca}$ & $1.1 \mathrm{E}-04$ & $8.3 \mathrm{E}-05$ & $1.0 \mathrm{E}-0 \mathrm{~S}$ & $6.5 \mathrm{E}-05$ & $4.2 \mathrm{E}-01$ & $2.8 \mathrm{E}-01$ & $4.6 \mathrm{E}-01$ & $3.1 \mathrm{E}-01$ & $2.5 \mathrm{E}-06$ & $4.0 \mathrm{E}-05$ \\
\hline Cd & NM & $<1 \mathrm{E}-06$ & NM & $<1 \mathrm{E}-06$ & $4.0 \mathrm{E}-03$ & $3.4 \mathrm{E}-03$ & $3.2 \mathrm{E}-03$ & $3.5 \mathrm{E}-03$ & NM & $<1 \mathrm{E}-06$ \\
\hline $\mathrm{Ce}$ & $<4 \mathrm{~B}-06$ & $<4 \mathrm{E}-06$ & $4 \mathrm{E}-05$ & $<1 \mathrm{E}-05$ & $8.6 \mathrm{E}-03$ & $7.2 \mathrm{E}-03$ & $7.1 \mathrm{E}-03$ & $6.2 \mathrm{E}-03$ & $<4 \mathrm{E}-06$ & $<3 \mathrm{E}-06$ \\
\hline $\mathrm{Cr}$ & $2.1 \mathrm{E}-04$ & $2.5 \mathrm{E}-04$ & $4.6 \mathrm{E}-03$ & $5.1 \mathrm{E}-03$ & $7.2 \mathrm{E}+02$ & $6.3 \mathrm{~B}-02$ & $7.1 \mathrm{E}-02$ & $7.3 \mathrm{E}-02$ & $1.3 \mathrm{~B}-03$ & $1.6 \mathrm{E}-03$ \\
\hline Dy & $<1 \mathrm{E}-07$ & $<1 \mathrm{E}-07$ & $<1$ B-06 & $<1 \mathrm{E}-06$ & ND & ND & ND & $<5$ E-05 & $<1 \mathrm{E}-07$ & $<1 B-06$ \\
\hline Pe & $7.2 \mathrm{E}-06$ & (1) $2 \mathrm{E}-06)$ & 5.4 E-05 & $<4$ B-06 & $1.6 \mathrm{E}+00$ & 1.4 & $1.5 \mathrm{E}+00$ & 1.4 & $<7$ E-06 & $<4 \mathrm{E}-06$ \\
\hline $\mathrm{Hg}_{\mathrm{g}}$ & NM & NM & NM & NM & $3.8 \mathrm{E}-04$ & NM & $2.0 \mathrm{E}-04$ & $\mathbf{M M}$ & NM & NM \\
\hline $\mathbf{K}$ & $1.1 \mathrm{E}-03$ & $1.1 \mathrm{E}-03$ & $1.4 \mathrm{E}-03$ & $1.6 \mathrm{E}-02$ & $1.5 \mathrm{E}-02$ & $5.9 \mathrm{E}-02$ & $2.6 \mathrm{E}-02$ & $2.1 \mathrm{E}-02$ & $4.1 \mathrm{E}-03$ & $5.0 \mathrm{E}-03$ \\
\hline La & $<4$ E -07 & $<4 \mathrm{E}-07$ & $<4$ E-06 & $<2 \mathrm{E}-06$ & $3.0 \mathrm{E}-02$ & $2.7 \mathrm{~B}-02$ & $3.5 \mathrm{E}-102$ & $3.5 \mathrm{E}-02$ & $<4 \mathrm{E}-07$ & $<4$ E- -107 \\
\hline $\mathrm{Li}$ & (Be-06) & $<1 \mathrm{E}-05$ & $<1$ E-04 & $<3 \mathrm{E}-05$ & ND & ND & ND & $<1 \mathrm{E}-03$ & (3 E-05) & $<3 \mathrm{E}-05$ \\
\hline$M_{B}$ & $2.3 \mathrm{E}-05$ & $1.7 \mathrm{E}-05$ & $1.8 \mathrm{E}-04$ & $<4$ E-06 & $3.0 \mathrm{E}-01$ & $2.6 \mathrm{E}-01$ & $3.5 \mathrm{E}-01$ & $3.5 \mathrm{E}-01$ & 5.3 E-05 & $8.7 \mathrm{E}-06$ \\
\hline Mn & $<2$ E-07 & $<2$ E-07 & $<2 \mathrm{E}-06$ & $<5 \mathrm{E}-07$ & $1.7 \mathrm{E}-01$ & $1.5 \mathrm{E}-01$ & $1.9 \mathrm{E}-01$ & $1.8 \mathrm{E}-01$ & 2 E-07 & $<1 \mathrm{E}-0\rangle$ \\
\hline Mo & $1.1 \mathrm{E}-06$ & $4.3 \mathrm{E}-06$ & 4.0 E-05 & $8.0 \mathrm{E}-05$ & (9 B-04) & (2 E-03) & (9 E-04) & (1 E-03) & $9.9 \mathrm{E}-06$ & 2.4 E-05 \\
\hline $\mathrm{Na}$ & $9.1 \mathrm{E}-02$ & $9.6 \mathrm{E}-02$ & $1.3 \mathrm{E}+\infty$ & 1.4 & a & 1.8 & a & 1.2 & $3.8 \mathrm{E}-01$ & $5.0 \mathrm{E}-01$ \\
\hline Nd & $<7$ E-07 & $<7$ E-07 & $<7$ E-06 & $<7 \mathrm{E}-07$ & $1.9 \mathrm{E}-02$ & $1.6 \mathrm{E}-02$ & $1.8 \mathrm{E}-02$ & $1.7 \mathrm{E}-02$ & $<7 \mathrm{E}-07$ & $<1$ E-06 \\
\hline
\end{tabular}


Table A-2. Elemental Concentrations in 102-AY Waste. (2 sheets)

\begin{tabular}{|c|c|c|c|c|c|c|c|c|c|c|}
\hline \multirow{2}{*}{ Anion } & \multicolumn{2}{|c|}{ Supernatap, M } & \multicolumn{2}{|c|}{$\begin{array}{l}\text { Interstitial } \\
\text { solution, } \mathrm{M}\end{array}$} & \multicolumn{2}{|c|}{$\begin{array}{c}\text { Composite solids } \\
\text { mmol/g }\end{array}$} & \multicolumn{2}{|c|}{$\begin{array}{c}\text { Washed solids } \\
\text { nunol/s }\end{array}$} & \multicolumn{2}{|c|}{ Wash, M } \\
\hline & Analysis & Antalysis & $\begin{array}{l}\text { 1st, } \\
\text { Analysis: }\end{array}$ & And & $\begin{array}{l}\text { 1/st? } \\
\text { Analysis }\end{array}$ & $\begin{array}{l}\text { 2nd } \\
\text { Analysis }\end{array}$ & $\begin{array}{l}1 \mathrm{st} \text { ' } \\
\text { Analysis }\end{array}$ & $\begin{array}{l}\text { 2nd } \\
\text { Analysis }\end{array}$ & $\begin{array}{l}\text { 1st } \\
\text { Analysis }\end{array}$ & $\begin{array}{l}\text { 2nd } \\
\text { Analysis }\end{array}$ \\
\hline $\mathrm{Ni}$ & $(1.4 \mathrm{E}-06)$ & $<2 \mathrm{E}-06$ & (1 E-05) & $<2$ E-05 & $5.6 \mathrm{E}-02$ & $4.7 \mathrm{E}-02$ & $6.5 \mathrm{E}-02$ & $5.7 \mathrm{E}-02$ & $<1$ E-06 & $<6 \mathrm{E}-06$ \\
\hline P & $1 \mathrm{E}-(04$ & (1 E-04) & 7 E-03 & $7.5 \mathrm{E}-3$ & $1.6 \mathrm{E}-01$ & $2.3 \mathrm{E}-01$ & $1.7 \mathrm{E}-01$ & $2.5 \mathrm{E}-01$ & $2.9 \mathrm{E}-03$ & 3.4 E-03 \\
\hline $\mathbf{R u}$ & $<1 \mathrm{E}-06$ & $<1 \mathrm{E}-06$ & $<1$ E-05 & $<1$ E-05 & ND & ND & ND & $<4$ E-04 & $<1 \mathrm{E}-06$ & $<2$ E-06 \\
\hline $\mathrm{Si}$ & 4.6 E-03 & $5.9 \mathrm{E}-03$ & $2.4 \mathrm{E}-02$ & $5.2 \mathrm{E}-03$ & 4.3 E-01 & $4.3 \mathrm{E}-01$ & $4.1 \mathrm{E}-01$ & 4.4 E-01 & 3.0 E-02 & $2.8 \mathrm{E}-02$ \\
\hline Sr & $2.6 \mathrm{E}-06$ & $1.6 \mathrm{E}-06$ & $1.0 \mathrm{E}-05$ & $<1 \mathrm{E}-08$ & $9.0 \mathrm{E}-03$ & $7.7 \mathrm{E}-03$ & $9.8 \mathrm{E}-03$ & $9.4 \mathrm{E}-03$ & $3.0 \mathrm{E}-06$ & $<2$ E-09 \\
\hline $\mathrm{Te}$ & $<2$ E-06 & $<2$ E-06 & $<2$ E-05 & $<2$ E-05 & (4 E-03) & ND & $3.9 \mathrm{E}-03$ & (3 E-03) & $2.4 \mathrm{E}-06$ & $<4$ E-06 \\
\hline$Z_{\mathbf{n}}$ & $5.0 \mathrm{E}-06$ & 3.7 E-06 & $1.7 \mathrm{E} .05$ & $1.6 \mathrm{E}-05$ & $5.8 \mathrm{E}-03$ & $8.1 \mathrm{E}-03$ & $7.0 \mathrm{E}-03$ & $7.9 \mathrm{E}-03$ & (3E-06) & $1.3 \mathrm{E}-05$ \\
\hline $\mathrm{Zr}$ & $<4$ E-07 & (7.6 E-07) & $4.1 \mathrm{E}-05$ & $<1$ E-(1)5 & $\mathbf{b}$ & $6.3 \mathrm{~B}-03$ & b & $5.2 \mathrm{E}-03$ & $3.9 \mathrm{E}-06$ & $(1.9 \mathrm{E}-06)$ \\
\hline
\end{tabular}

'Putassium Hydroxide fusion.

'Zirconium crucible used.

NM = Not measured (analysis not requested for sample).

$\mathrm{ND}=$ Nol detecled.

() = Indicates at detection limit. 
Table A-3. Concentration of Radioisotopes in 102-AY Waste and Wash Components.

\begin{tabular}{|c|c|c|c|c|c|c|c|c|c|c|}
\hline Radioisotope & Supermalans & Standa & Wash solution & Standal & $\begin{array}{l}\text { minetital } \\
\text { kounon }\end{array}$ & Sondard & oomposits & Standard & Whiced solids & $\begin{array}{l}\text { Standard } \\
+\%\end{array}$ \\
\hline${ }^{241} \mathrm{AsI}$ & $1.5 \mathrm{E}-06$ & & $6.67 \mathrm{E}-06$ & & $1.9 \mathrm{E}-04$ & & $1.82 E+01$ & & $1.57 \mathrm{E}+01$ & \\
\hline${ }^{14} \mathrm{C}$ & $\mathbf{N M}$ & & $\mathbf{N M}$ & . & $\mathbf{N M}$ & & $<1.0 \mathrm{E}-03$ & & $<3.2 \mathrm{E}-03$ & \\
\hline${ }^{242} \mathrm{Cm}$ & ND & & ND & & ND & & ND & & $5.41 \mathrm{E}-02$ & \\
\hline${ }^{243} \mathrm{Cm} \nu^{240} \mathrm{Cm}$ & ND & & ND & & ND & & $6.31 \mathrm{E}-01$ & & 5.41 E-01 & \\
\hline${ }^{60} \mathrm{Co}$ & ND & & ND & & $1.7 \mathrm{E}-02$ & $\cdot 4.5$ & $1.44 \mathrm{E}+\infty 0$ & 5.7 & $1.17 \mathrm{E}+\infty 0$ & 8.3 \\
\hline${ }^{134} \mathrm{Cs}$ & $4.95 \mathrm{E}-03$ & 11.0 & $5.41 E-03$ & 13.0 & $2.1 \mathrm{E}-02$ & 3.9 & ND & & ND & \\
\hline${ }^{137} \mathrm{Cs}$ & $4.32 \mathrm{E}+00$ & 3.5 & $1.09 \mathrm{E}+01$ & 3.5 & $4.4 \mathrm{E}+01$ & 3.4 & $2.65 \mathrm{~B}+02$ & 3.6 & $2.62 \mathrm{E}+02$ & 3.5 \\
\hline${ }^{154} \mathrm{Eu}$ & ND & & ND & & ND & & $5.14 \mathrm{E}+01$ & 3.1 & $4.38 \mathrm{E}+0 !$ & \\
\hline${ }^{129} \mathrm{I}$ & $\mathbf{N M}$ & & $\mathbf{N M}$ & & $\mathbf{N M}$ & & $<1.2 \mathrm{E}-03$ & & $<1.3 \mathrm{~B}-03$ & \\
\hline${ }^{238} \mathrm{Pu}$ & ND & & $\mathrm{ND}$ & & $1.25 \mathrm{E}-04$ & 5.7 & $1.14 \mathrm{E}+00$ & 5.2 & $9.82 \mathrm{E}-01$ & $s$ \\
\hline${ }^{239} \mathrm{Pu}{ }^{2+0} \mathrm{Pu}$ & $2.34 \mathrm{E}-04$ & 3.9 & $1.21 \mathrm{E}-05$ & 69 & $3.91 \mathrm{E}-04$ & 4.2 & $3.61 \mathrm{E}+00$ & 3.1 & $3.36 \mathrm{E}+\infty 0$ & 3.1 \\
\hline${ }^{100} \mathrm{Ru}$ & ND & & $1.89 \mathrm{E}-01$ & 10.0 & $6.8 \mathrm{E}-01$ & 4.1 & ND & & ND & \\
\hline${ }^{123} \mathrm{Sb}$ & ND & & ND & & $1.1 \mathrm{E}-01$ & 13.4 & $9.9 \mathrm{E}+00$ & 6.2 & $1.0 \mathrm{E}+01$ & 7.7 \\
\hline${ }^{79} \mathrm{Se}$ & $\mathbf{N M}$ & & $\mathbf{N M}$ & & $\mathbf{M M}$ & & $<5.40$ E-03 & & $<5.9 \mathrm{E}-03$ & \\
\hline${ }^{20} \mathrm{Sr}$ & $6.58 \mathrm{~B}+\infty$ & 5.9 & $1.26 \mathrm{E}+\infty 0$ & 5.7 & $2.52 \mathrm{E}+\infty 0$ & & $2.95 \mathrm{E}+04$ & & $3.09 \mathrm{E}+04$ & \\
\hline$=\mathrm{Tc}$ & $\mathbf{N M}$ & & $\mathbf{N M}$ & & $\mathbf{N M}$ & & $2.5 \mathrm{E}-02$ & & $1.8 \mathrm{E}-02$ & \\
\hline
\end{tabular}

Nute: $1 \mathrm{Ci}=3.7 \mathrm{E}+10 \mathrm{~Bq}$.

$N M=$ Not measured (analysis was not requested for this sample).

$\mathrm{ND}=$ Not detected. 
Table 4-2. Tank Characterization Summary for

Double-Shell Tank 241-AY-102. (3 sheets)

\begin{tabular}{|c|c|c|c|c|c|c|}
\hline \multirow{2}{*}{$\begin{array}{l}\text { } \\
\text { Analyte } \\
\text { an } \\
\end{array}$} & \multicolumn{4}{|c|}{ अे 1987 sludge sample } & \multicolumn{2}{|c|}{ 1994grab 6amples } \\
\hline & $\begin{array}{c}\text { Centrifuged } \\
\text { sludge } \\
\text { concentration }\end{array}$ & $\begin{array}{c}\text { Interstitial liquid } \\
\text { concentration }\end{array}$ & $\begin{array}{l}\text { Calculated } \\
\text { average liudge } \\
\text { concentration }\end{array}$ & $\begin{array}{l}\text { Total } \\
\text { projected } \\
\text { sludge } \\
\text { pventory }\end{array}$ & $\begin{array}{l}\text { Liquid } \\
\text { concentration } \\
\text { ४}\end{array}$ & $\begin{array}{l}\text { Total } \\
\text { projected } \\
\text { oupernatant } \\
\text { inventory }\end{array}$ \\
\hline \multicolumn{7}{|c|}{ (2) } \\
\hline & $\mu g / g$ & $\mu \mathrm{g} / \mathrm{g}$ & $\mu \mathrm{g} / \mathrm{g}$ & $\mathbf{k g}$ & $\mu \mathrm{g} / \mathrm{mL}$ & kg \\
\hline $\mathrm{Cl}^{+}$ & $8,340.0$ & $8,170.0$ & $8,247.5$ & $1,182.0$ & 94.2 & 255.5 \\
\hline$F$ & $8,490.0$ & $1,290.0$ & $4,573.2$ & 740.7 & 11.9 & 32.3 \\
\hline $\mathrm{OH}_{3}$ & $\mathbf{N M}$ & $\mathrm{NM}$ & $\mathrm{NM}$ & $\mathbf{N M}$ & 307.0 & 832.8 \\
\hline $\mathrm{NO}_{3}$ & 69.4 & $1,860.0$ & $1,043.5$ & 127.8 & 526.0 & $1,426.8$ \\
\hline $\mathrm{NO}_{2}^{-}$ & $3,970.0$ & $10,200.0$ & $7,359.1$ & 978.1 & 884.0 & $2,397.9$ \\
\hline $\mathrm{PO}_{4}{ }^{3-}$ & $1,660.0$ & 599.0 & $1,082.8$ & 167.7 & 65.6 & 177.9 \\
\hline $\mathrm{SO}_{4}^{2-}$ & 754.0 & $1,150.0$ & 969.4 & 133.9 & 160.0 & 434.0 \\
\hline \multicolumn{7}{|c|}{ W } \\
\hline & $\mu \mathrm{Ci} / \mathrm{s}$ & $\mu \mathrm{Ci} / \mathbf{g}$ & $\mu \mathrm{Ci} / \mathrm{g}$ & $\mathbf{C i}$ & $\mu \mathrm{Ci} / \mathrm{g}$ & $\mathrm{Ci}$ \\
\hline${ }^{241} \mathrm{Am}$ & 18.0 & $1.2 \mathrm{E}-04$ & 8.2 & 990.0 & $6.9 \mathrm{E}-04$ & 1.9 \\
\hline${ }^{14} \mathrm{C}$ & $<0.001$ & - & $<<0.001$ & $<0.1$ & - & $\ldots$ \\
\hline${ }^{212} \mathrm{Cm}$ & ND & ND & ** & - & $\therefore$ & - \\
\hline${ }^{13} \mathrm{Cs}$ & ND & $2.1 \mathrm{E}-02$ & $1.1 \mathrm{E}-02$ & 1.3 & $\cdots$ & - \\
\hline${ }^{17} \mathrm{Cs}$ & 270.0 & 44.0 & 147.1 & $18,000.0$ & 3.4 & $9,195.7$ \\
\hline${ }^{\infty} \mathrm{Co}$ & 1.4 & $1.7 \mathrm{E}-02$ & 0.6 & 79.0 & $\ldots$ & - \\
\hline $23424 \mathrm{Cm}$ & 0.6 & $\mathrm{ND}$ & 0.3 & 35.0 & - & - \\
\hline${ }^{154} \mathrm{Eu}$ & 51.0 & $\mathrm{ND}$ & 23.0 & $2,800,0$ & $-\infty$ & - \\
\hline${ }^{129} \mathrm{I}$ & $<0.0012$ & - & $<<0.0012$ & $<0.1$ & - & - \\
\hline${ }^{238} \mathrm{Pu}$ & 1.1 & $1.3 \mathrm{E}-04$ & 0.5 & 63.0 & - & - \\
\hline${ }^{2301200 \mathrm{Pu}}$ & 3.6 & $3.9 \mathrm{E}-04$ & 1.6 & 190.0 & $2.6 \mathrm{E}-05$ & 0.1 \\
\hline${ }^{106} \mathrm{Ru}$ & ND & 0.7 & 0.4 & 45.0 & - & + \\
\hline${ }^{125} \mathrm{Sb}$ & 9.9 & 0.1 & 4.6 & 560.0 & - & $\cdots$ \\
\hline${ }^{79} \mathrm{Se}$ & $<0.0054$ & $\mathrm{NM}$ & $<2.5 \mathrm{E}-03$ & $<0.3$ & - & - \\
\hline${ }^{90} \mathrm{Sr}$ & $23,585.0$ & 2.5 & $10,756.1$ & $1.7 \mathrm{E}+06$ & 0.2 & 599.5 \\
\hline . Tc & $2.5 \mathrm{E}-02$ & $\mathrm{NM}$ & $1.1 \mathrm{E}-02$ & 1.3 & - & - \\
\hline \multicolumn{7}{|c|}{ Physical property } \\
\hline & & . & $\mathrm{g} / \mathrm{mL}$ & & & \\
\hline $\begin{array}{l}\text { Grav } \\
\% \mathrm{H}_{2} \mathrm{O}\end{array}$ & 45.6 & 54.4 & - & $\cdots$ & 98.4 & $\infty$ \\
\hline $\mathrm{TGA} \mathrm{H}_{2} \mathrm{O}$ & - & $\cdots$ & .- & - & 98.5 & - \\
\hline $\mathrm{pH}$ & $\cdots$ & - & $\cdots$ & $\cdots$ & 11.1 & 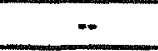 \\
\hline Density & 1.4 & $\ldots$ & 1.40 & 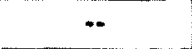 & 0.990 & $\cdots$ \\
\hline
\end{tabular}




\section{WHC-SD-WM-ER-454 REV 0}

Table 4-2. Tank Characterization Summary for Double-Shell Tank 241-AY-102. (3 sheets)

\begin{tabular}{|c|c|c|c|c|c|c|}
\hline \multirow[b]{2}{*}{$\begin{array}{l}\text { Analyte } \\
\text { an }\end{array}$} & \multicolumn{4}{|c|}{$\therefore 1987$ siudge sample } & \multicolumn{2}{|c|}{1994 grab samples } \\
\hline & $\begin{array}{l}\text { Centrifuged } \\
\text { sludge } \\
\text { concentration }\end{array}$ & $\begin{array}{c}\text { Interstitial liquid } \\
\text { concentration } \\
\vdots\end{array}$ & $\begin{array}{c}\text { Calculated } \\
\text { average sludge } \\
\text { concentration } \\
\end{array}$ & $\begin{array}{l}\text { Total } \\
\text { projected: } \\
\text { sludge } \\
\text { inventory }\end{array}$ & $\begin{array}{l}\text { Liquid } \\
\text { concentration } \\
\end{array}$ & $\begin{array}{l}\text { Total } \\
\text { projected: } \\
\text { supernatant: } \\
\text { inventory }\end{array}$ \\
\hline की & $3 x$ & 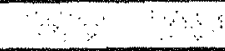 & Metal: & & $\therefore x+$ & 8 \\
\hline & $\mu \mathrm{g} / \mathrm{g}$ & $\mu \mathrm{g} / \mathrm{g}$ & $\mu \mathrm{g} / \mathrm{g}$ & $\mathbf{k g}$ & $\mu \mathrm{g} / \mathrm{mL}$ & $\mathrm{kg}$ \\
\hline $\mathrm{Al}$ & $37,800.0$ & 10.7 & 17.242 .6 & $2,920.6$ & 13.7 & 37.2 \\
\hline $\mathrm{Ba}$ & $1,990.0$ & 5.7 & 910.5 & 154.1 & - & $\ldots$ \\
\hline $\mathrm{B}$ & $2,770.0$ & 48.6 & $1,289.6$ & 217.2 & - & $=$ \\
\hline Cd & 414.0 & 0.1 & 188.8 & 32.0 & - & - \\
\hline $\mathrm{Ca}$ & $14,000.0$ & 1.5 & 6.384 .8 & $1,081.5$ & - & - \\
\hline $\mathrm{Ce}$ & 1.110 .0 & 3.5 & 508.1 & 86.0 & - & - \\
\hline $\mathrm{Cr}$ & 3.510 .0 & 252.0 & 1.737 .6 & 287.7 & $\ldots$ & - \\
\hline Dy & $\mathrm{ND}$ & $<0.163$ & $<0.1$ & $<0.02$ & - & - \\
\hline $\mathrm{Fe}$ & $83,700.0$ & 1.6 & $38,168.1$ & $6,465.6$ & $<0.550$ & $<1.5$ \\
\hline La & $3,960.0$ & 0.4 & $1,806.0$ & 305.9 & - & - \\
\hline $\mathrm{Li}$ & $\mathrm{ND}$ & $<0.451$ & $<0.2$ & $<0.04$ & - & - \\
\hline $\mathrm{Mg}$ & 6.800 .0 & 2.2 & $3,102.0$ & 525.4 & - & - \\
\hline $\mathrm{Mn}$ & $8,780.0$ & $<0.0686$ & $<4.003 .7$ & $<678.2$ & - & - \\
\hline Mo & 139.0 & 5.8 & 66.5 & 11.1 & - & - \\
\hline $\mathrm{Nd}$ & $2,660.0$ & $<0.554$ & $<1,213.3$ & $<205.5$ & - & - \\
\hline $\mathrm{Ni}$ & $3,020.0$ & 0.9 & 1.377 .6 & 233.3 & $\rightarrow$ & - \\
\hline $\mathbf{P}$ & $6,050.0$ & 225.0 & $2,881.2$ & 482.2 & - & - \\
\hline $\mathbf{K}$ & $1,450.0$ & 340.0 & 846.2 & 134.4 & - & $\ldots$ \\
\hline $\mathrm{Rh}$ & $\mathrm{ND}$ & $<1.55$ & $<0.8$ & $<0.1$ & - & - \\
\hline $\mathbf{R u}$ & $\mathrm{ND}$ & $<1.01$ & $<0.5$ & $<0.1$ & $m$ & 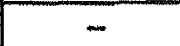 \\
\hline $\mathrm{Si}$ & $12,100.0$ & 410.0 & $5,740.6$ & 961.7 & 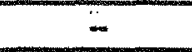 & - \\
\hline $\mathrm{Ag}$ & $7,240.0$ & 61.6 & $3,335.0$ & $\$ 63.3$ & - & - \\
\hline $\mathrm{Na}$ & $41,400.0$ & $31,000.0$ & $35,742.4$ & $5,238.5$ & $2,450.0$ & $6,645.9$ \\
\hline $\mathrm{sr}$ & 732.0 & 0.4 & 334.0 & 56.6 & - & - \\
\hline $\mathrm{Te}$ & 512.0 & $<2.56$ & $<234.9$ & $<39.7$ & - & - \\
\hline $\mathrm{Ti}$ & 342.0 & $<0.192$ & $<156.1$ & $<26.4$ & - & - \\
\hline $\mathrm{U}$ & 14.800 .0 & 9.760 .0 & $12,058.2$ & $1,785.7$ & - & - \\
\hline $\mathrm{Zn}$ & 455.0 & 1.1 & 208.1 & 35.2 & - & - \\
\hline $\mathrm{Zr}$ & 575.0 & 1.6 & 263.1 & 44.5 & - & - \\
\hline
\end{tabular}


Rev. 0

3.15 Tank AY-102 Report Analysis January 1988 
Rev. 0

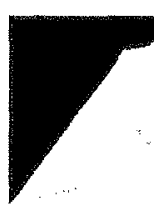

TCRC-28

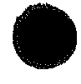

atging

TiNe $: 14: 45: 13$
$A Y 102-13$
(8) $1 / 29 / 88$
sample data

A $4-10^{2}$

\section{TEDORT A UALYSIS}

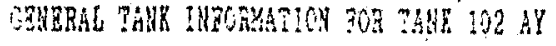

DAT IS ANAYSi $=01 / 29780$

SAHEL WWEER = FHLTOAO

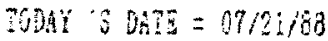

HASTE TYPR = naste solius

ThOTE : Three solids samples from $102 \mathrm{AY}$ uere wi red and analyzed for their Ifl content.

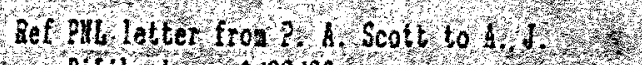

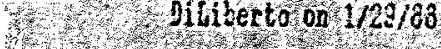

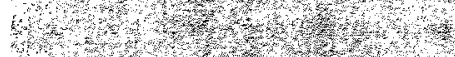

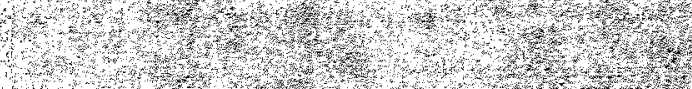

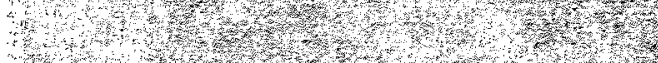

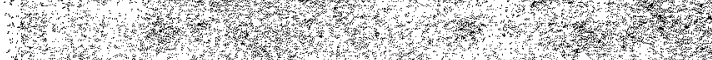

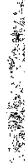

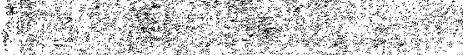

tort

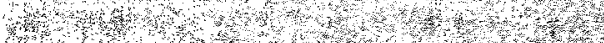

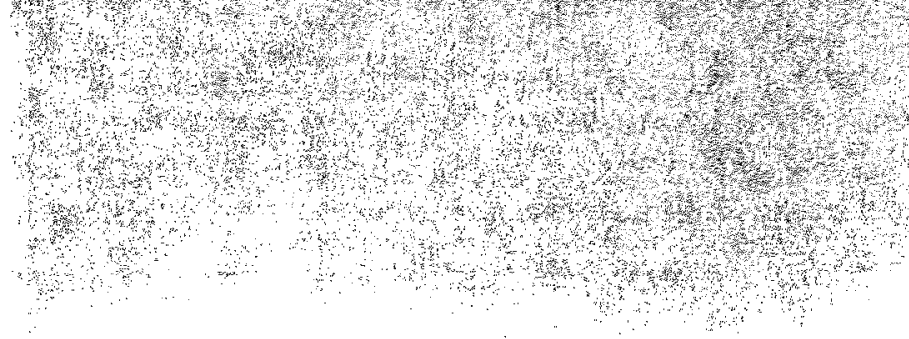

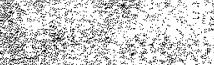

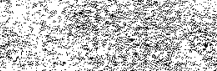

tr.

W.1. 
Rev. 0

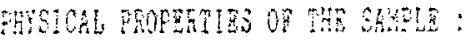

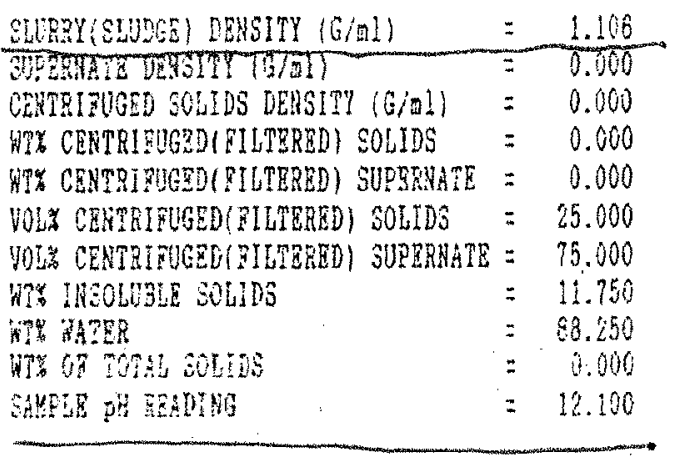

EUUD HBDOLOCI OF THA SAMPLS:

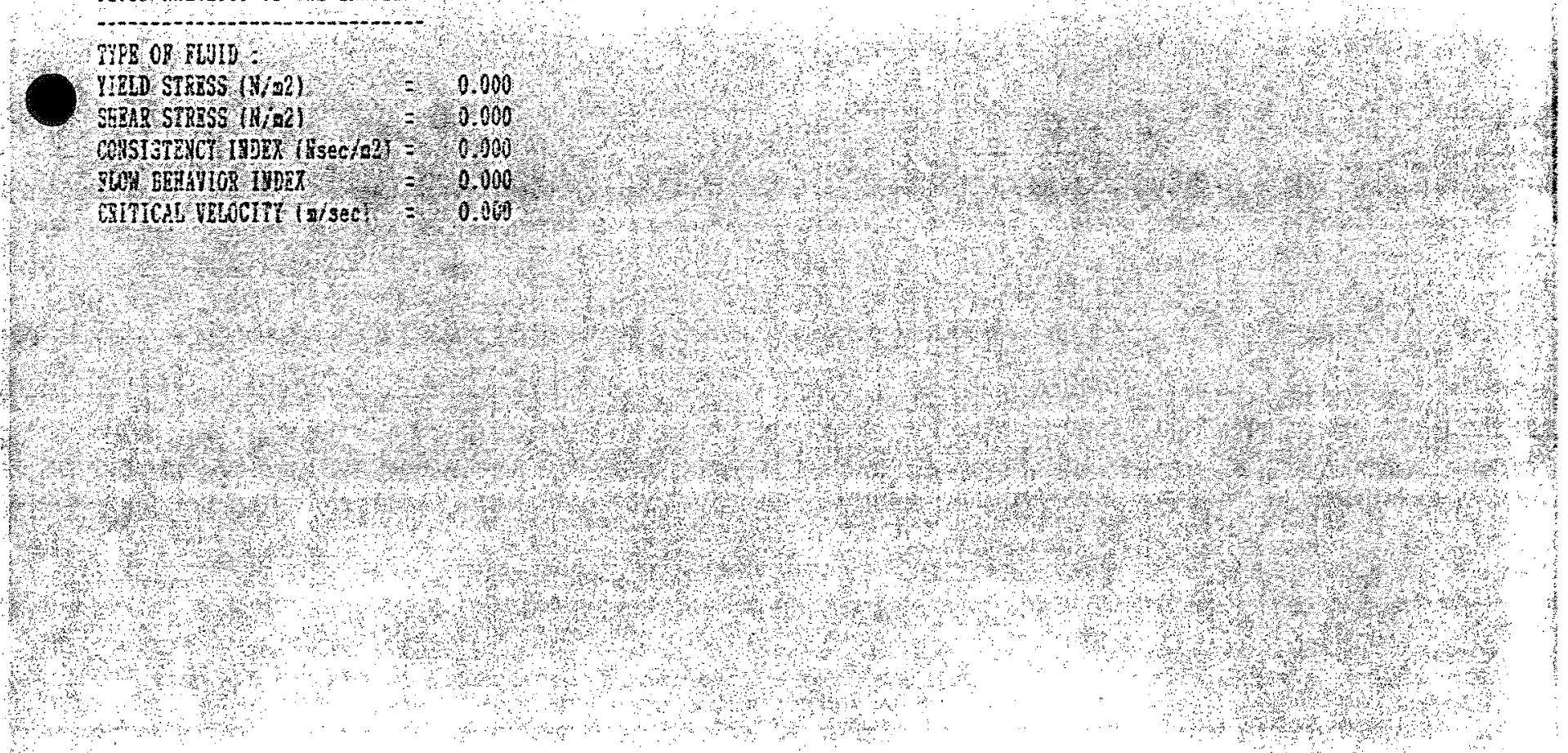




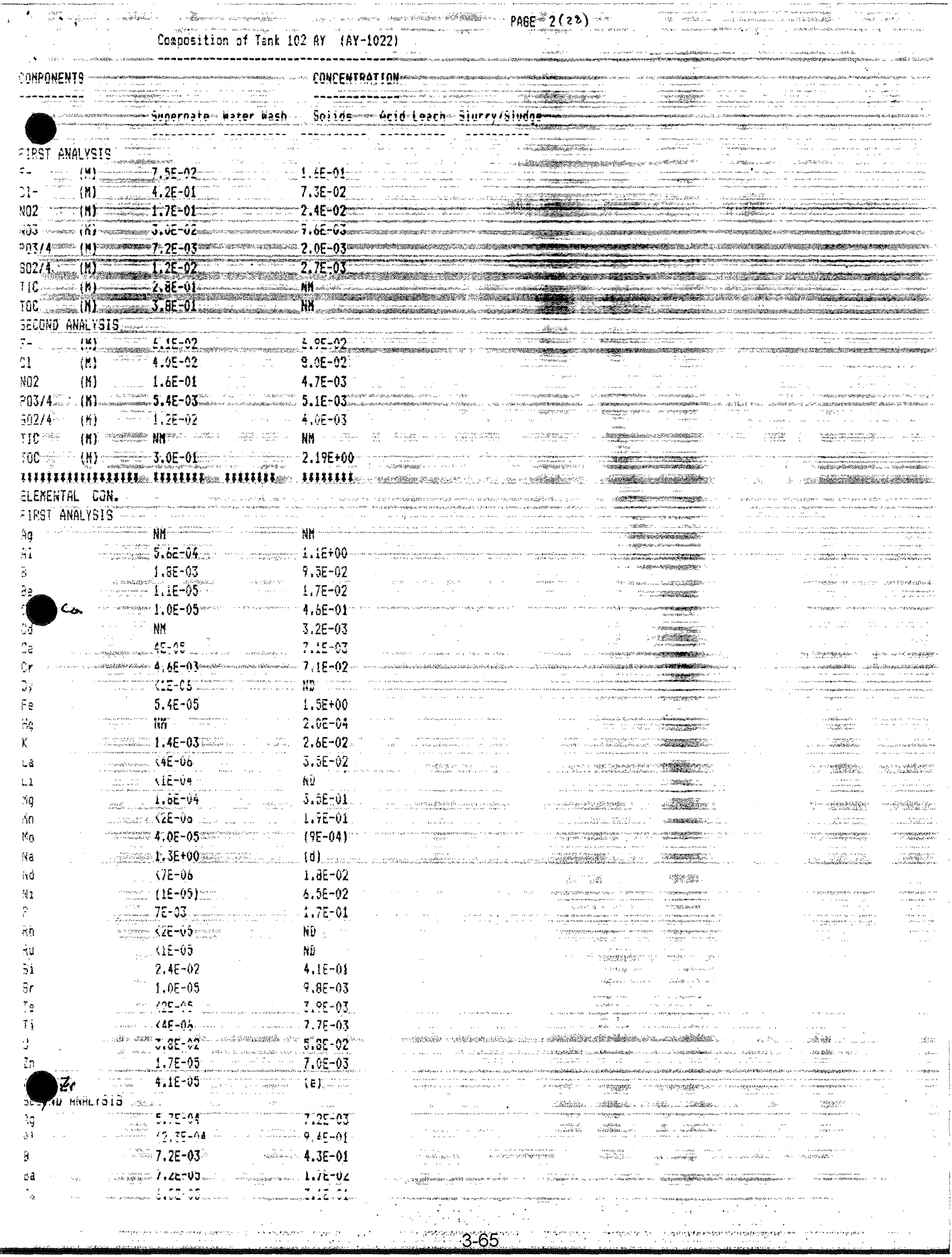




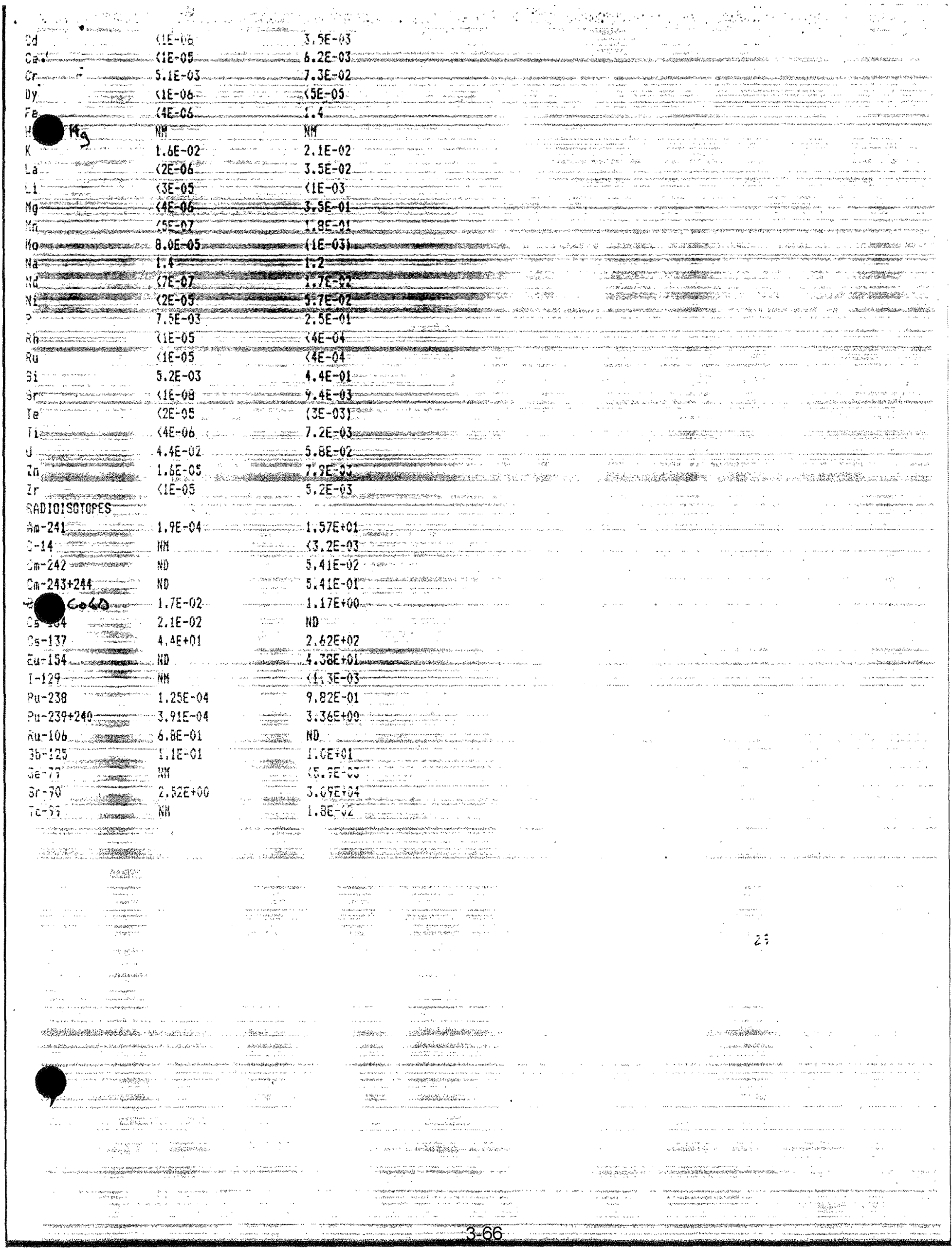


Rev. 0

3.16 Letter from J. C. Womack to H. F. Daugherty, "Tank 102-AY Solids Heel Analysis," April 21, 1989. 


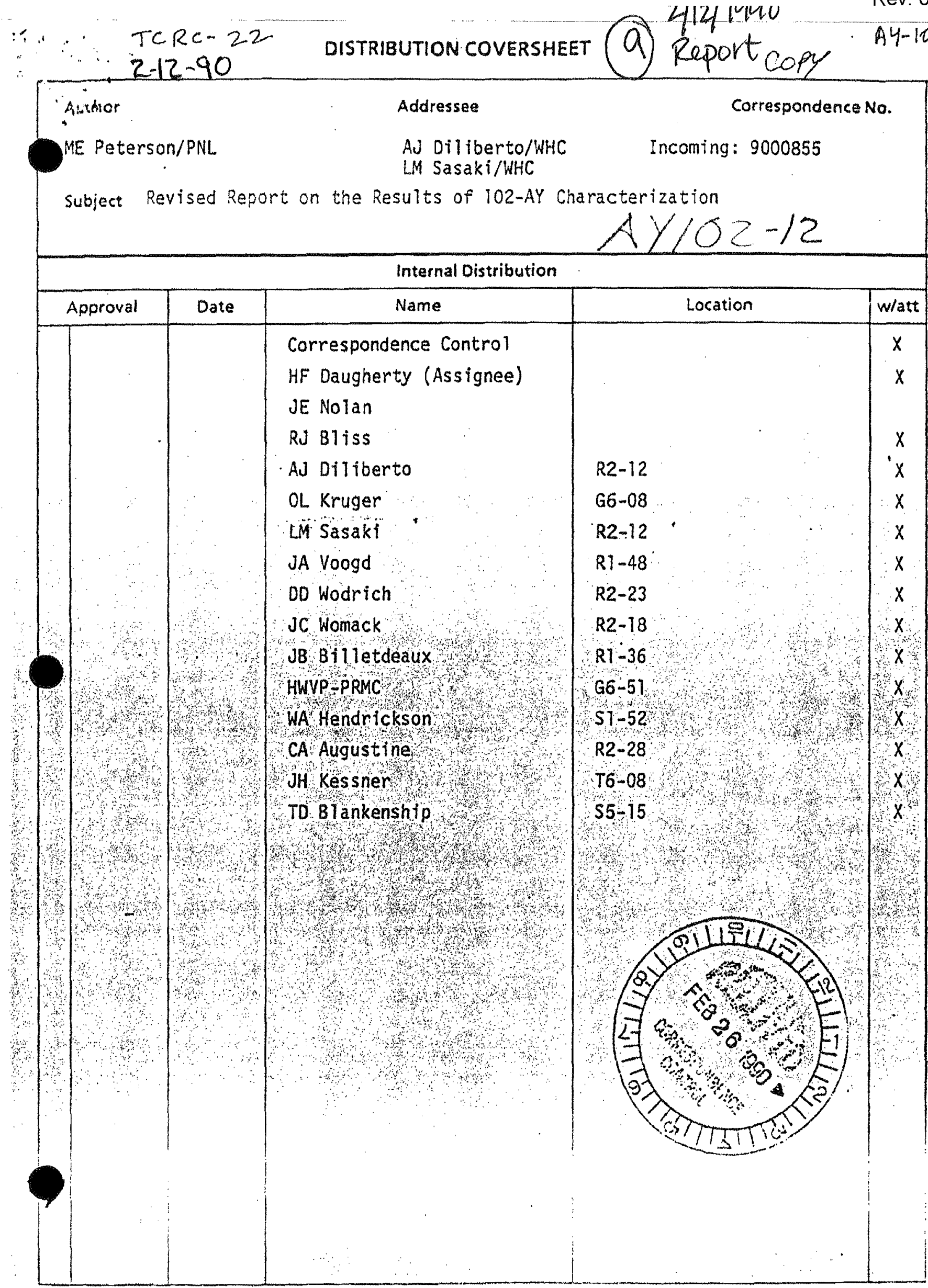


Rev. 0

\section{TCRC-2

\author{
DON'T SAY IT -.. Write It! \\ TO \\ H. F. Daugherty R2-53 \\ CC: A. J. Diliberto \\ L. M. Sasaki \\ D. D. Wodrich \\ JCW LB/File
}

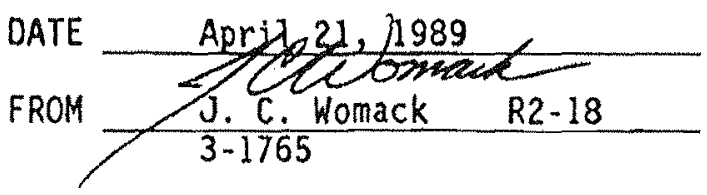

RECEIVEU

APR 241989

SUBJECT: TANK 102-AY SOLIDS HEEL ANALYSIS AJ OILU

Tank 102-AY will be the receiver tank for Hanford Waste Vitrification Plant (HWVP) feed resulting from the pretreatment of neutralized current acid waste (NCAW) at PUREX. The solids heel in Tank 102-AY was sampled and characterized in FY 1988 to determine its composition and to determine if in-tank washing was necessary prior to the addition of pretreated NCAW solids to the tank.

The HWV reviewed the results of the sample analyses on both washed and unwashed solids. As part of their feed characterization/qualification evaluation, HWVP requested some reanalyses be done to confirm some of the FY 1988 results, as well as some additional analyses. Our letter to Pacific Northwest Laboratories (PNL) (attached) was simply a reiteration of HWVP's request. The PNL has not yet committed to a schedule for completion of the analyses, but because of other ongoing priorities, it is expected to take at least 3 months. We will in turn transmit the results to HWVP for their evaluation.

The table on the next page provides additional information on the requested analyses. If the components of interest are not within the HWVP feed specifications, corrective actions could include heel washing, feed dilution, glass reformulation, or $\mathrm{plant/process} \mathrm{redesign.}$

srr

Attachment 
Rev. 0

3.17 Letter from M. Peterson to A. J. Diliberto and L. M. Sasaki, "Revised Report on the Results of 102-AY Characterization," February 12, 1990. 
February 12, 1990

Mr. A. J. DiLiberto

Ms. L. M. Sasaki

Westinghouse Hanford Company

MSIN. R2.-05

Richland, WA 99352

Dear Tony and Leela:

\section{REVISED REPORT ON THE RESULTS OF 102-AY CHARACTERIZATION}

Attached is the revised report documenting the results of the characterization of samples from DST 102-AY. This report summarizes the characterizations of this waste which were conducted in FY88 and FY89. This completes the requirements of milestone 10 of the technical program plan.

If you have any questions regarding this report, please call me at $376-8258$ or Randy scheele at 376-0956.

very truly yours

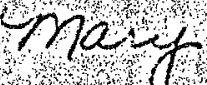

Marypeterson

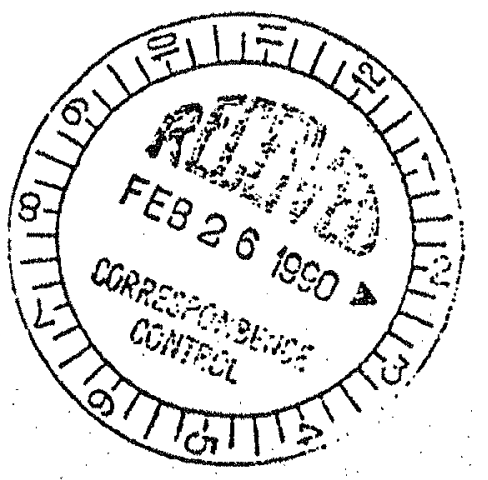

Technical Project Manager

Process Development Section

\section{MEP:pg}

Attachinent

CC. W. F. Bonner

R. D. Scheele

3. M. Tingey

File/LB 


\section{INTRDOUCTION}

In second quarter FY 1988, a total of four samples of waste from DST 102-AY were received from Westinghouse Hanford Company (WHC). Three of the samples were solids from the lower segment of the 102-AY waste core. The fourth sample consisted of supernate and solids from the upper segment of the core. Portions of the three solid samples were combined and submitted for radiochemical anaiysis to determine if the waste would be classified as TRU. The results of the radiochemical analyses indicated that the waste would be classified as TRU waste $(>100 \mathrm{nCl} / \mathrm{g})$. Physical, rheological and further chemfcal characterizations of the 102-AY waste were conducted to provide additional data for evaluating retrieval systems and/or treatment processes. This report provides the results of these characterizations.

\section{EXPERIMENTAL DESIGN AND PROCEDURES}

Four samples of waste from DST 102-AY were received. These samples were Jabeled 102-AY Seg-1, 102-AY Seg IR Top, 102-AY Seg IR Mid, and $102-A Y$ Seg IR Bot. The 102 .AY Seg.1 samples was approximately $99 \%$ supernate with the

Wremaining $1 \%$ cons fsting of dark reddish brown solids. The 102 -AY Top solths

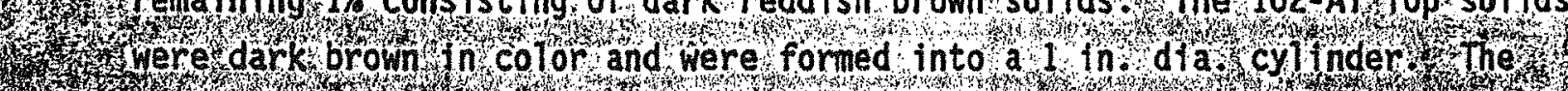
36 corestrod op to the shoulder of the jar, the 102-AY Bot solids were dark

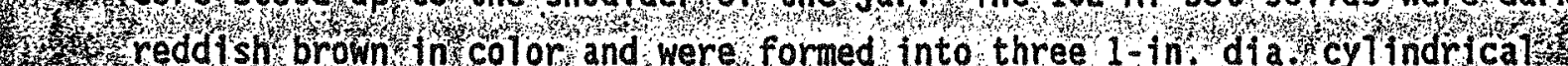

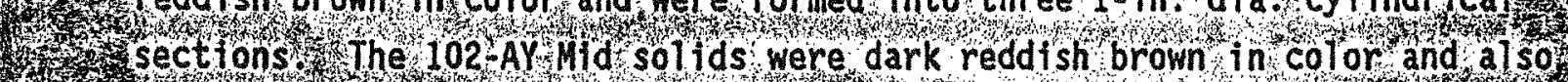

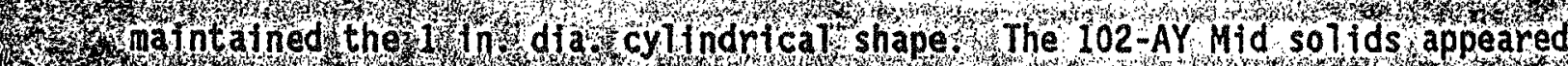

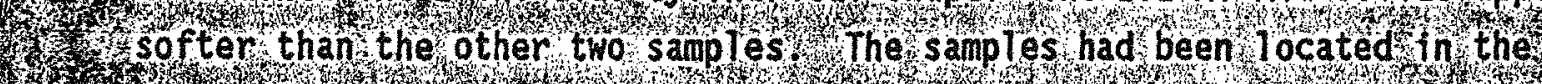

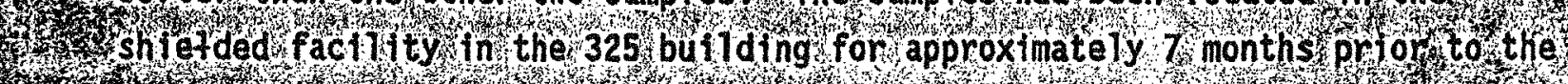

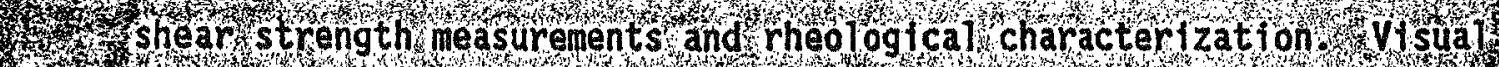

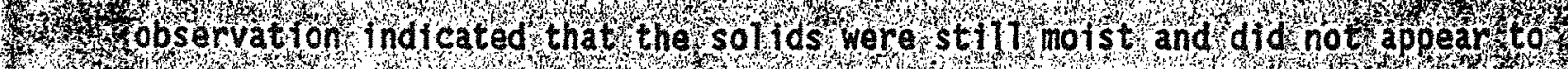

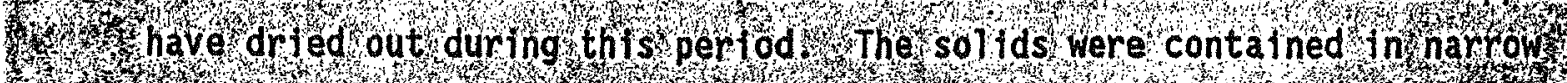
W. Wouthed jars which ififted access to the solids.

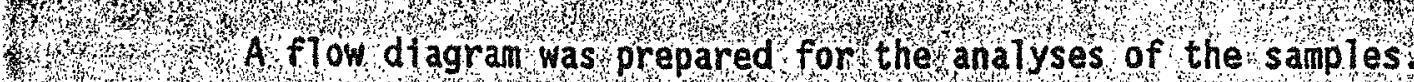
characterization performed was the shear strength. The shear strength was measured on each of the three solid samples using a shear vane and the Hake 
The chemical analyses were conducted to determine the concentration of antons, elements, total organic carbon and inorganic carbon. Inductively coupled argon plasma atomic emission spectroscopy (ICP) was used to determine the concentration of a majority of the elements. Mercury was determined using atomic absorption spectroscopy after separating the mercury from the solids using an EPA procedure. A water leach procedure was used to measure the chromium (VI)/chromium (III) and anions in the solids. In this water leach procedure, one volume of solids is washed with 100 volumes of DI water. This procedure assumes that the chromlum (VI) and the anions in the solids will dissolve in the large excess of water. The chromium (VI) concentration was measured in the water leach solution using UV/VIsible spectroscopy. The water leach solution was also analyzed for chromium (III) by adding an oxidant which converts the chromium (III) to chromium (VI) and analyzing for the resulting chromium (VI). The anions were measured us ing ion chromatography (IC). IC and ICP both provided a phosphorous/phosphate measurement. Total organic carbon (TOC) and total inorganic carbon (TIC) were, analyzed ws ing the coulonetric carbon analyzer.

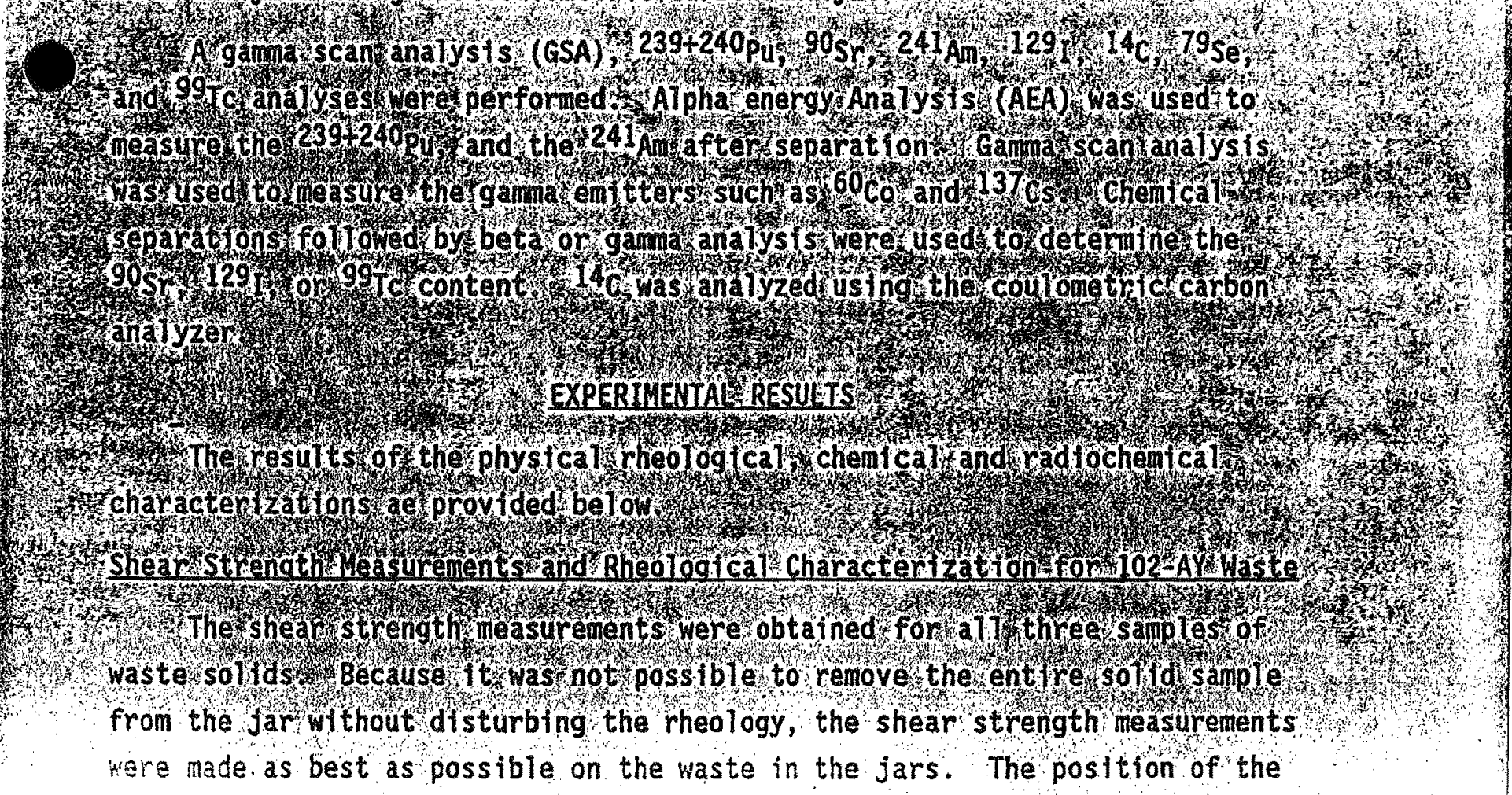

the jars required careful gotiting of the shear vane. The solids 
The chemicai analyses were conducted to deternine the concentration of anions, elements, total organic carbon and inorganic carbon. Inductively coupled argon plasma atomic emission spectroscopy (ICP) was used to detemine the concentration of a majority of the elements. Mercury was determined using atomic absorption spectroscopy after separating the mercury from the solids using an EPA procedure. A water leach procedure was used to measure the chromium (VI)/chromium (III) and anions in the solids. In this water leach procedure, one volume of solids is washed with 100 volumes of DI water. This procedure assumes that the chromium (VI) and the anions in the solids will dissolve in the large excess of water. The chronium (VI) concentration was measured in the water leach solution using UV/Visible spectroscopy. The water leach solution was also analyzed for chromium (III) by adding an oxidant which converts the chromium (III) to chromium (VI) and analyzing for the resulting chromium (VI). The anions were measured using ion chromatography (IC). IC and ICP both provided a phosphorous/phosphate measurement. Total organic carbon (TOC) and total inorganic carbon (TIC) were analyzed using the coulometric carbon analyzer.

A gamia scan analys is (GSA), $239+240 \mathrm{Pu}, 90 \mathrm{Sr}, 241_{\mathrm{Am}}, 129 \mathrm{I}, 1{ }^{4} \mathrm{C}, 79 \mathrm{Se}$, and 99 TC analyses were performed. Alpha energy Analysis (AEA) was used to measure the $239+240 \mathrm{pu}$, and the 241 Am after separation. Gamma scan analysis was used to measure the gamna emitters such as $60 \mathrm{Co}$ and $137 \mathrm{Cs}$. Chemical separations followed by beta or gamma analysis were used to determine the $90 \mathrm{Sr}, 129 \mathrm{I}$, or $99 \mathrm{TC}$ content. $14 \mathrm{C}$ was analyzed using the coulometric carbon analyzer.

\section{EXPERIMENTALL RESULTS}

The results of the physical rheological, chemical and radiochemical characterizations ae provided below.

Shear Strength Measurements and Rheological Characterization for 102-AY Waste

The shear strength measurements were obtained for all three samples of waste solids. Because it was not possible to remove the entire soltd sample from the jar without disturbing the rheology, the shear strength measurements yor made as best as possible on the wasta in the jars. The position of the 
- were not compacted in the jars with a uniform solid depth. Instead the solids maintained the shape of a 1 in. dia. cyclinder. The position of solids in each jar was assessed and the shear vane was positioned such that it was centered as best as possible in the solids and was located close to the bottom of the jars.

The smal1 shear vane $\left(H_{y}=D_{v}=0.975 \mathrm{~cm}\right)$ was used for these measurements. The shear strength was measured at the cell temperature which was approximately $35^{\circ} \mathrm{C}$. The shear vane rotational speed used for this evaluation was $0.3 \mathrm{rpm}$.

The results of the shear strength measurements are provided in Table 1 below. Visual observation suggested that the 102-AY-Mid sample would be softer than the remaining samples. The result that the 102-AY-Top solids have a higher shear strength is reasonable. The history of the pumping solids into DST-102-AY suggests that different layers of solids probably exist.

The solifds from all three samples were blended together to form a compos 1 te sol $1 \mathrm{ds}$ sample 1 The rheolog ical characterization was performed on a 1. 1 Volume dilution of the composite solids. The solids were diluted with delonized water. Rheological characterization of the composite solids was desired; however, the compos ite sollds would not fiow. They could not be poured into the viscometer. Rheological data for the $102-A Y$ waste was obtained with the Haake Rotovisco viscometer equipped with an 1500 measuring/drive head and the aV I sensor system.

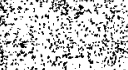

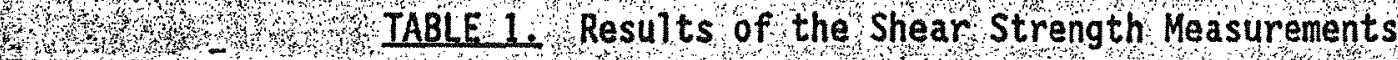

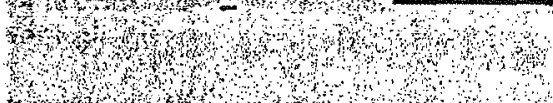

a

$\begin{array}{ll}\text { Waste Samples } & \begin{array}{c}\text { Shear strength } \\ \text { dynes/cm }\end{array} \\ \text { 102-AY-Top } & 53,639 \\ 102 \text {-AY-Middle } & 16,660 \\ 102 \text {-AY-Bottom } & 21,708\end{array}$


The rheogram for the diluted composite solids was obtained. The data from this plot was "fit" to the yield pseudoplastic model. The following rheological model was obtained.

$$
r=4.70+0.0191(\gamma) 0.84 \quad R^{2}=0.91
$$

where $r=$ shear stress

$\tau=$ shear rate

$R^{2}=$ regression coefficient

The rheological parameters along with the density of the $1: 1$ dilution $(1.2 \mathrm{~g} / \mathrm{mL})$ were input into the Hanks' computer model to obtain the critical Reynolds number and the critical velocity for transporting this material. A $3.067 \mathrm{in}$. 1.0. pipe diameter was selected for this evaluation. The critical Reynolds number is 10,470 and the critical velocity is $3.48 \mathrm{ft} / \mathrm{s}$.

\section{Physical Properties}

The physical properties for the composite solids, the $1: 1$ solids dilution, washed solids and supernate are provided in Table 2. Table 3 presents the soltids settling behavior for the 1,1 volume dilution for the duplicate analyses. The change in the solids measurements divided by the time period is the solids settling rate. The total measurement is the total volutie of material in the centrifuge cone.

\section{Chemical Properties}

Analysis of both the anjons and elements were performed in duplicate. The anion and elemental concentrations in the supernate, interstitial solution, composite solids, washed solids, and wash solution are presented in Tables 4 (anions) and 5 (elements). for those elements below the detection limits of the instruments, a "less than value is reported. This yalue is a factor of 5 higher than the detection limits for samples containing low concentrations of all of elenents. The 1 st and 2 nd Analysis column present the results of analys is which were performed approximately one year apart. Ouring that year interim partial avaporation of the samples occurred, and the anions and elements were concentronat. A correction factor was desermined 
TABLE2. Physical Properties of 102-AY Waste

\begin{tabular}{|c|c|c|c|c|}
\hline Property & $\begin{array}{l}\text { Composite } \\
\text { Solids } \\
\end{array}$ & $\begin{array}{l}\text { Aw-10mo } \\
\text { 1:1 Solids } \\
\text { Dilution }\end{array}$ & $\begin{array}{l}\text { Solids } \\
\text { \&ater } \\
\text { Wash }\end{array}$ & $\begin{array}{l}\text { Awi-102: } \\
\text { Supernate }\end{array}$ \\
\hline Density, $g / \mathrm{mL}$ & 1.4 & 1.2 & 1.2 & 1.00 \\
\hline Vol\% Settled Solids & 100.0 & 81.9 & NO $(a)$ & 0 \\
\hline Vol\% Centrifuged Solids & 79.0 & 51.0 & 38 & 0 \\
\hline $\begin{array}{l}\text { Centrifuged Solids } \\
\text { Density, } g / \mathrm{mL}\end{array}$ & 1.5 & 1.3 & 1.4 & 0 \\
\hline $\begin{array}{l}\text { Centrifuged Solution } \\
\text { Density, } g / \mathrm{mL}\end{array}$ & 1.0 & 1.02 & 1.1 & NA $(b)$ \\
\hline Particle Size, micron & ND & ND & ND & NA \\
\hline Wt: water & 54.4 & ND & 56 & ND \\
\hline Wt: Solids & 45.6 & ND & 44 & ND \\
\hline Wt: Oxide & 43.5 & ND & 37.72 & No \\
\hline
\end{tabular}

(a) $\mathrm{NO}=$ Not determined

(b) $N A=$ Not applicable

Table 3. Solids Settling Benavior for 102-AY $1: 1$ oilution

Time, $h$

0.00

1.17

3. 17

5.17

22.5
Solids $1, \mathrm{~mL}$

14.5

14.5

12. 3

12.0

12.0
Total \#1, $\mathrm{mL}$ Solids \#2, $\mathrm{mL}$

14.5

14.5

14.5

14.5

14.5
14.8

14.8

13.0

12.0

12.0

Total $=2, \mathrm{~mL}$

14.8

14.8

14.8

14.8

14.8

analysis. The data reported for the second analys is were corrected to take into account this concentration effect and enable a direct comparison of the 1st and 2nd analysis. The ratios used for this correction were $1,5,1,9$, 2.1, 2.3, and 5.7 for the supernate, interstitial solution, composite solids, washed solids, and wash solution respectively.

The major elements of the composite solids are aluminum, iron, and sodiun with the major anions comprising fluoride, chloride, and nitrite. The 
solution are potassium, sodium and uranium. Significant concentrations of all the anions except for phosphate were observed in these solutions. The primary element renoved in the washing procedure was the sodium.

A mass balance performed on the major elements indicated that for the 2nd analysis $50 \%$ of the aluminum, $88 \%$ of the iron, $97 \%$ of the sodium, and $124 \%$ of the uranium were recovered. Similar results were obtained in the 1st analysis with $76 \%$ of the aluminum, $80 \%$ of the iron, and $105 \%$ of the urantum being recovered. No sodium was reported for the 1 st analysis since only the sodium peroxide fusion was performed. The mass balances included comparing the concentrations of the major elements in the composite core with the concentrations of the same elements in the washed solids, wash solution, and the interstitial fluid. At the present time, no good explanation is available for the poor mass balance for aluminum. The remainder of the mass balances for the major elements found in the composite core indicate that the analytical results are accurate.

The total organic carbon data Indicates that a significant amount of organic matter is present in a11 the samples. The data also indicated that the concentration of the organic carbon in the interstitial solution was an order of magnitude higher than in the supernate. Because of the smal1 percentage of interstitial 1 fquid in the composite solids, only the top layer of the interstitfal solution could be decanted from the centrifuge cones. This top layer may have contained a high percentage of the organic carbon present in the solution due to separation of the aqueous and organic components, thus causing the data to indicate higher concentrations of organic carbon in the interstitial solution than actually existed. At the measured $\mathrm{pH}$ of the supernate of 9.5 , all of the total inorganic carbon should be bicarbonate.

Radiochemical Analyses

The results of the radiochemical analyses for the supernate, wash solution, interstitial solution, composite solids and washed solids is provided in Table 6 . In the aqueous samples, $137 \mathrm{Cs}$ is the principle radiolsotope present and it's high level of activity prevents the detection of other mad 


\section{- Supernate 1SL Data Solids}

$$
2 / 12 / 1990 .
$$

TABLE 4. Anion Content of 102-AY Waste and Derivatives

$$
\text { AY } 1022
$$
$4 \times-10$

\begin{tabular}{|c|c|c|c|c|c|c|c|c|c|c|}
\hline & \multicolumn{2}{|c|}{ suomate 4} & \multicolumn{2}{|c|}{$\begin{array}{l}\text { interstitial } \\
\text { solution, } 4 \\
\end{array}$} & \multicolumn{2}{|c|}{$\begin{array}{c}\text { Composite solids, } \\
\text { mmol/gat }\end{array}$} & \multicolumn{2}{|c|}{$\begin{array}{l}\text { Washed solide } \\
\text { molla }\end{array}$} & \multicolumn{2}{|c|}{ weth. } \\
\hline & $\begin{array}{l}\text { ist } \\
\text { knglysis }\end{array}$ & $\begin{array}{l}\text { Ind } \\
\text { Ansivsis }\end{array}$ & $\begin{array}{l}\text { 1st } \\
\text { Antysis }\end{array}$ & $\begin{array}{l}\text { 2nd } \\
\text { Ansingis }\end{array}$ & Antist & $\begin{array}{l}\text { 2nd } \\
\text { Aratysis }\end{array}$ & $\begin{array}{c}185 \\
\text { Anglusis }\end{array}$ & $\begin{array}{l}\text { 2nd } \\
\text { Ensiysis }\end{array}$ & $\begin{array}{l}\text { ist } \\
\text { Anoivsis }\end{array}$ & $\begin{array}{c}2 \mathrm{nd} \\
\text { Anolusis }\end{array}$ \\
\hline$F^{*}$ & $9.3 E-13$ & $8.7 E \cdot 03$ & $7.5 E-02$ & 6. $1 E \cdot 02$ & $1.8 \varepsilon-01$ & $9.3 E-02$ & $1.6 E-01$ & $6.9 E-02$ & $3.7 E-02$ & $2.4 E-02$ \\
\hline $0^{\circ}$ & $1.6 E=02$ & $1 . \pi E \cdot 02$ & 4.2E-01 & $4.0 E-02$ & $E=01$ & $2.4 E-01$ & $3 E-02$ & $8.0 E-02$ & 12.01 & 9.1E.02 \\
\hline $\mathrm{NO}_{2}{ }^{*}$ & $2.5 \varepsilon-02$ & $2.4 E=02$ & 1.TE-01 & $1.6 E-01$ & 1.1E-01 & $1.8 E-02$ & $2.4 \mathrm{E}-02$ & $4.7 \mathrm{E}=03$ & $5.08-02$ & 3.TE-02 \\
\hline . & $4.4 E-03$ & $3.68-03$ & $3.0 \mathrm{E}-02$ & $3.0 E-02$ & $1.7 E-02$ & $5.4 \varepsilon-03$ & $9.6 \mathrm{E}=03$ & $2,6 E-03$ & $8.6 \mathrm{E}-04$ & $6.8 E-03$ \\
\hline & $5.5 \mathrm{E}-04$ & $3 E-06$ & $7.2 E-03$ & $5.4 E-03$ & $2.48-12$ & $1.1 \mathrm{E}-02$ & $2.0 \varepsilon-02$ & $5.15 \cdot 03$ & $3.4 E=02$ & $1.8 E-03$ \\
\hline & $1.1 \mathrm{E}-03$ & $1.18 \cdot 03$ & $1.2 \varepsilon-02$ & $1.2 E=02$ & $8.1 E-03$ & $7.6 E \cdot 03$ & $2 . T_{E}=03$ & $4.0 \varepsilon-03$ & $3.4 \mathrm{E}-\alpha \mathrm{s}$ & $2.8 \varepsilon-03$ \\
\hline$\pi t c^{(a)}$ & $2.9 \varepsilon-02$ & $\mathrm{Ha}$ & $2.8 \varepsilon-01$ & MM & $M M^{(b)}$ & NM & $\mathrm{KM}$ & MM & $9.9 \mathrm{z} \cdot 02$ & HH \\
\hline$r \infty^{(\epsilon)}$ & $2.4 \mathrm{E}-02$ & $2.4 E-02$ & $3.8 \varepsilon-01$ & $3.0 \mathrm{E}-0 \mathrm{t}$ & MM & $3.82 \Sigma+00$ & NH & $2.19 E+00$ & $1.1 \mathrm{E} \cdot 01$ & $7.8 \varepsilon-02$ \\
\hline
\end{tabular}

$4 y-102$

(a) TIC a Total Inorganic Carbon. Inorganic carbon is carbonate or blcarbonate.

(b) NH = Hot measured.

(c) TOC = Total Organic carbon.
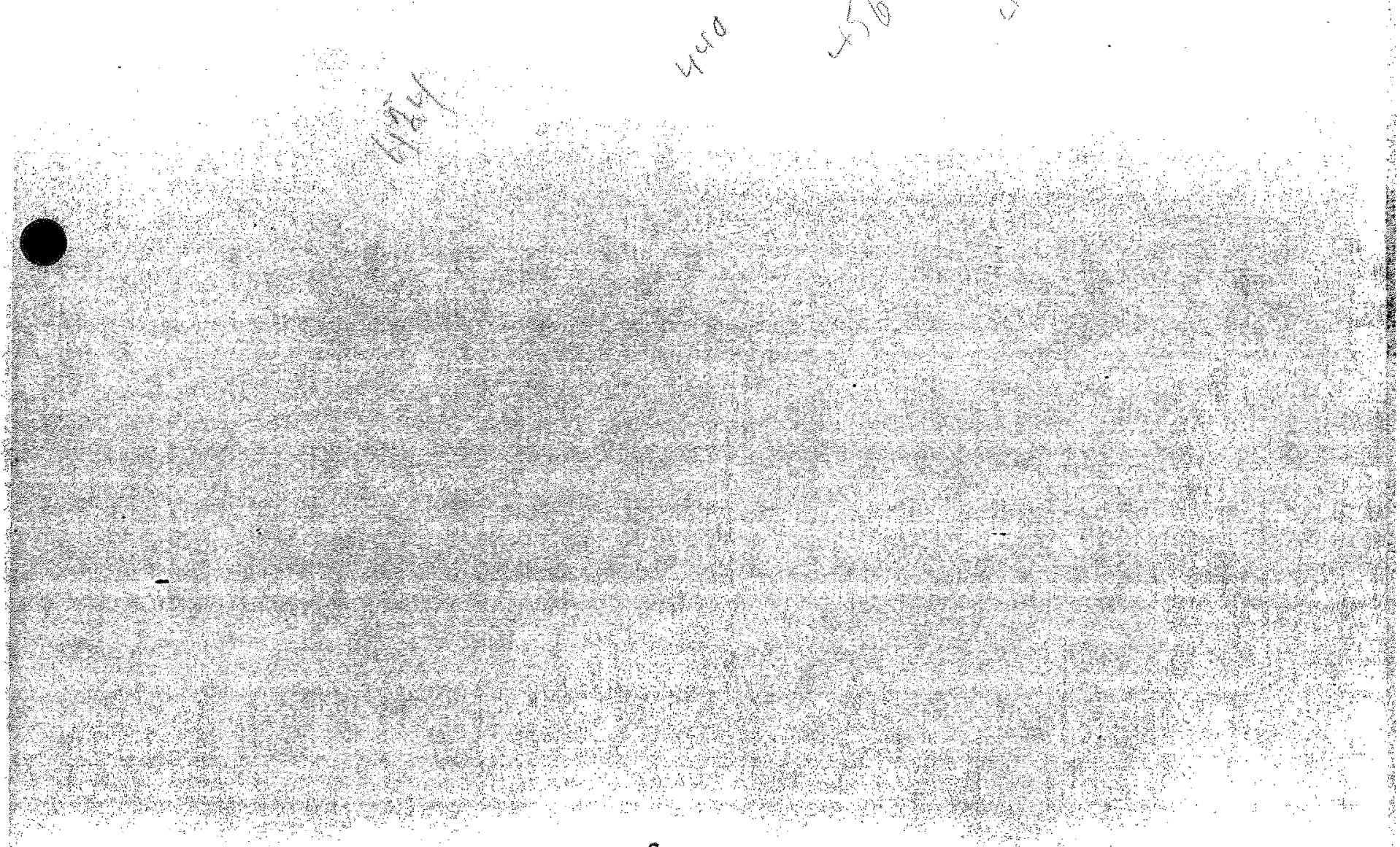


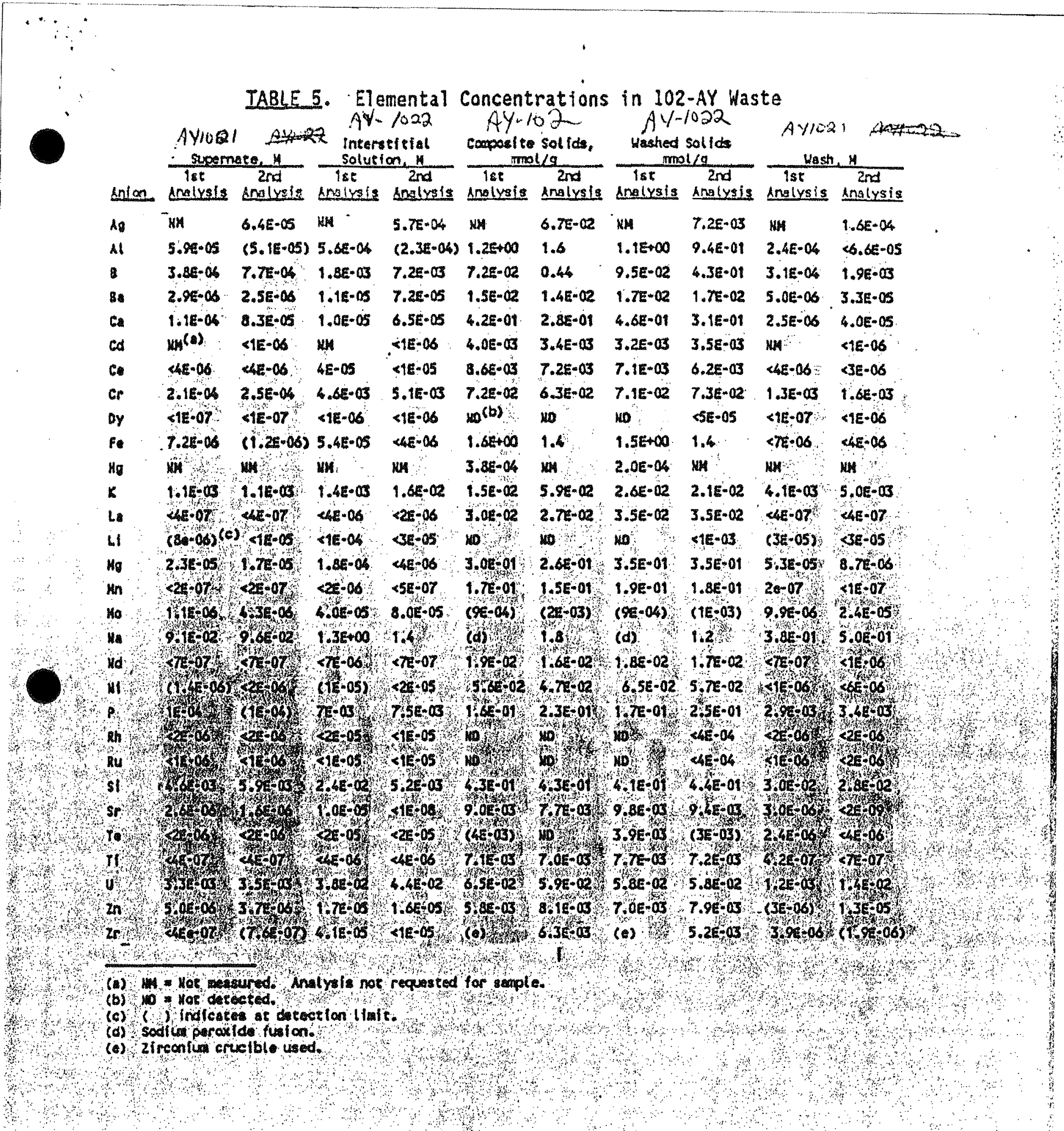


TABLE 6. Concentration of Radioi sotopes in 102-AY Waste and Wash Components

\begin{tabular}{|c|c|c|c|c|c|c|c|c|c|c|}
\hline Radiol sorooe & $\begin{array}{l}\text { supermate } \\
\text { sci/me }\end{array}$ & $\begin{array}{l}\text { std. } \\
\pm 0\end{array}$ & $\begin{array}{l}\text { Hash } \\
\text { solution } \\
\text { nef/me. }\end{array}$ & $\begin{array}{l}\text { std. } \\
\pm \\
\end{array}$ & $\begin{array}{l}A Y-1022 \\
\text { interstitial } \\
\text { soluteion } \\
\text { acu/mL } \\
\end{array}$ & $\begin{array}{l}\text { std. } \\
\pm \pm x \\
\end{array}$ & $\begin{array}{l}\text { Ay-102 } \\
\text { Composite } \\
\text { Solids } \\
\text { acila } \\
\end{array}$ & $\begin{array}{l}\text { std. } \\
\pm \\
\end{array}$ & $\begin{array}{l}\text { AY-102 } \\
\text { Washed } \\
\text { Soltids } \\
\text { aci/g. }\end{array}$ & $\begin{array}{l}22 \\
\text { std. } \\
\pm \% \\
\end{array}$ \\
\hline Ant-241 & $1.5 E-06$ & & $6.671:-06$ & & $1.9 E-04$ & & $1.82 \Sigma+01$ & & $1.57 \mathrm{E}+01$ & \\
\hline$c-14$ & $\mathrm{NB}(\mathrm{a})$ & & NAS & & NH & & $<1.0 E=03$ & & $3.2 \mathrm{E}-03$ & \\
\hline $0 n-242$ & No (b) & & $\$ 0$ & & w & & ND: : & & $5.41 E-02$ & \\
\hline $6 n-243+244$ & nD. & & 10 & & No & & $6.31 E \cdot 01$ & & $5.41 E-01$ & \\
\hline $\cos 60$. & MD & & 100 & & $1.7 E-02$ & 4.5 & $1.64 \mathrm{E}+00$ & 5.7 & $1.17 E+\infty$ & 8.3 \\
\hline $\operatorname{cs}=134$ & $4.95 E-03$ & 11.0 & $5.41 E-03$ & 13.0 & 2. $1 E-02$ & 3.9 & HD & & 10 & \\
\hline $\operatorname{cs}-137$ & $6.325+00$ & 3.5 & $109 \varepsilon+01$ & 3.5 & 4.4.4E+01 & 3.4 & $2.65 E+02$ & 3.6 & $2,62 E+02$ & 3.5 \\
\hline $84-154$ & Mo & & $10 \times$ & & $\log =$ & & $5.14 E+01$ & 3.1 & $4.38 E+01$ & 3,6 \\
\hline-129 & $\mathrm{NM}_{\mathrm{W}}$ & & m4 & & $M x$ & & $\alpha, 2=03$ & & $21,3 \mathrm{E} \cdot 0 \mathrm{~B}$ & in \\
\hline$P u-238$ & $\mathrm{No}_{\mathrm{O}}:$ & & $\omega_{0} / \%$ & & $1225=04$ & 5.7 & $1,14 \mathrm{E}+00$ & 5.2 & $9.821-01$ & 5 \\
\hline$P u-239+240$ & $2.34 E_{04}$ & 3.9 & $1921 E \times 0$ & 6.9 & $391 \mathrm{E}-04$ & 4.2 & $561 \mathrm{E}+00$ & 3.1 & $3,368+00$ & 3.1 \\
\hline $84-106$ & $\mathrm{No}_{2}$ & & $469=07$ & 10.0 & $6.88-01$ & 4.1 & 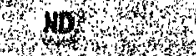 & & (n) & \\
\hline $5 b-125$ & & & & & T1E01 & 13.4 & $9 \% 91<\circ 00$ & 6.2 & 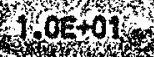 & 8.7 \\
\hline $5 e-79$ & & & 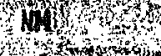 & & $2640 \%$ & & os $40 \mathrm{eg}$ & & $5.96-03$ & \\
\hline $\begin{aligned} s r-90 \\
r c-99\end{aligned}$ & $6558+00$ & 5.9 & $\begin{array}{l}126 \mathrm{et} \\
\mathrm{mos}\end{array}$ & 5.7 & $2,52 E+00$ & & 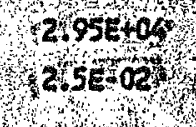 & (n) & $\begin{array}{l}3.0 \% e+04 \\
1.86-02\end{array}$ & 4 \\
\hline
\end{tabular}

(a) wa Not messured, analysis wes not requested for this sample. 


\section{ACKNOWLEDGEMENTS}

The chemical and radiochemical analyses were performed by PNL Chemistry and Analysis Section. The authors want to acknowledge and commend the efforts of Dale Archer, Diana Bellofatto, Merri11 Burt, Kathy Carson, John Ennen, Milt Goheen, Frank Hara, Lloyd Kellogg, Jean Ruggles, Rick Steele, Bob Stromatt, Barbara Vandercook, Mal in Weiler and Dana Widrig. Also, Garry Richardson of the Chemical Process Development Section conducted the experimental work and performed the physical characterization.

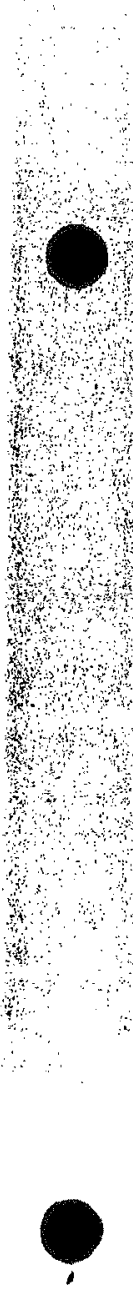


Rev. 0

3.18 WHC-SD-WM-TI-578, 1994, 101-AY, 102-AY, and 106-C Data Compedium, Rev. 0. 
WHC-SD-WM-TH-678, Hov. $\quad 2 / 90 \quad 1 / 29 / 80^{102-A Y} \quad 11 / 9184$

\begin{tabular}{|c|c|c|c|c|c|c|c|}
\hline Component & $\begin{array}{l}\text { Reforencea: } 1 \\
\text { Sollde } \\
\text { Reported } \\
\text { Arnount Units }\end{array}$ & $\begin{array}{l}\text { Dents: } 2 / 50 \\
\text { Ulgulds } \\
\text { Poported } \\
\text { Amount Units }\end{array}$ & $\begin{array}{l}\text { Riaterenes: } 2 \\
\text { Sollds } \\
\text { Reported } \\
\text { Amount Units }\end{array}$ & $\begin{array}{l}\text { Date: 1/28/88 } \\
\text { Ulqulds } \\
\text { Reported } \\
\text { Amount Units }\end{array}$ & $\begin{array}{l}\text { Raferenco: } \\
\text { Solds } \\
\text { Reportod } \\
\text { Amount } \\
\end{array}$ & Unte & $\begin{array}{l}\text { Dutw: : 1/9/94 } \\
\text { Ulquide } \\
\text { Roported } \\
\text { Amount Uni }\end{array}$ \\
\hline $\begin{array}{l}\text { Density } \\
\text { Bulk Donsilty } \\
\text { Particio Dannatty } \\
\times \text { Soldds }\end{array}$ & $\begin{array}{l}1.4 \mathrm{~d} / \mathrm{mL} \\
45.6\end{array}$ & $1.0 \mathrm{~g} / \mathrm{mL}$ & $1.3 \mathrm{~g} / \mathrm{mL}$ & & & & 5.2 \\
\hline
\end{tabular}

$\%$ Wator. $\quad 54.4$

Spocific thent

Softening Pt.

Particlo Sizo

Water Solubitity

Vhecosthy

Spe

CN

$\mathrm{CO} 3$

NO2

No3

PO4

94.8

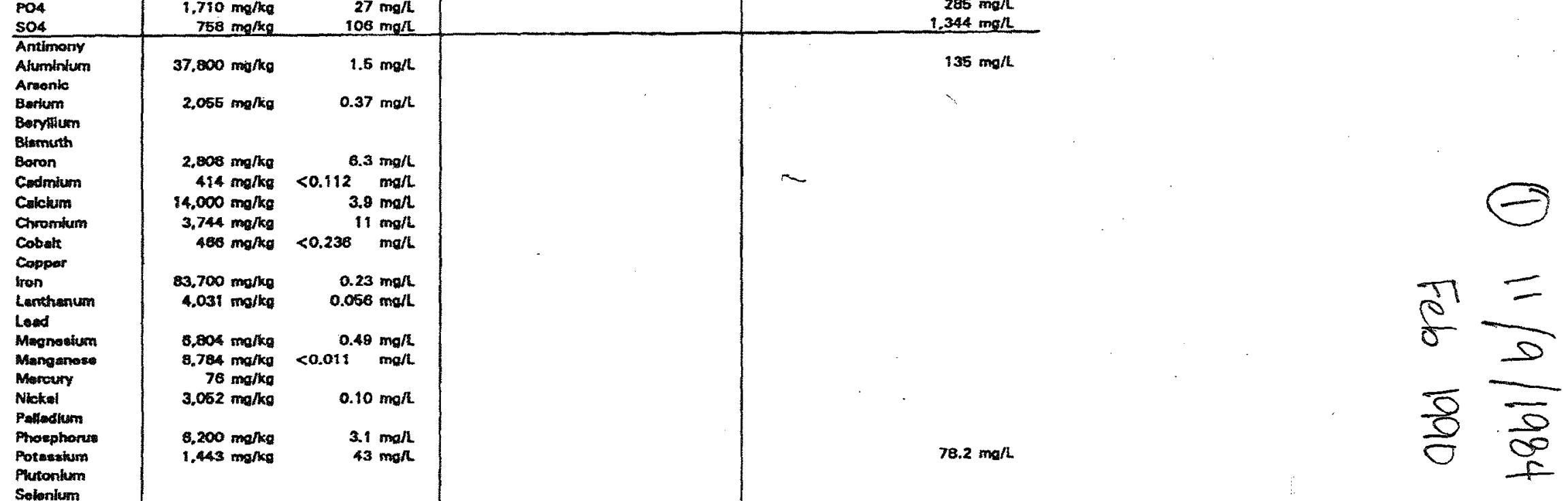

Solontum

silkeon

$12,040 \mathrm{mg} / \mathrm{kg}$

$149 \mathrm{mo} / \mathrm{h}$

$828 \mathrm{ma} / \mathrm{L}$

$23.128 \mathrm{mg} / \mathrm{L}$

$135 \mathrm{mg} / \mathrm{L}$

Page 8 


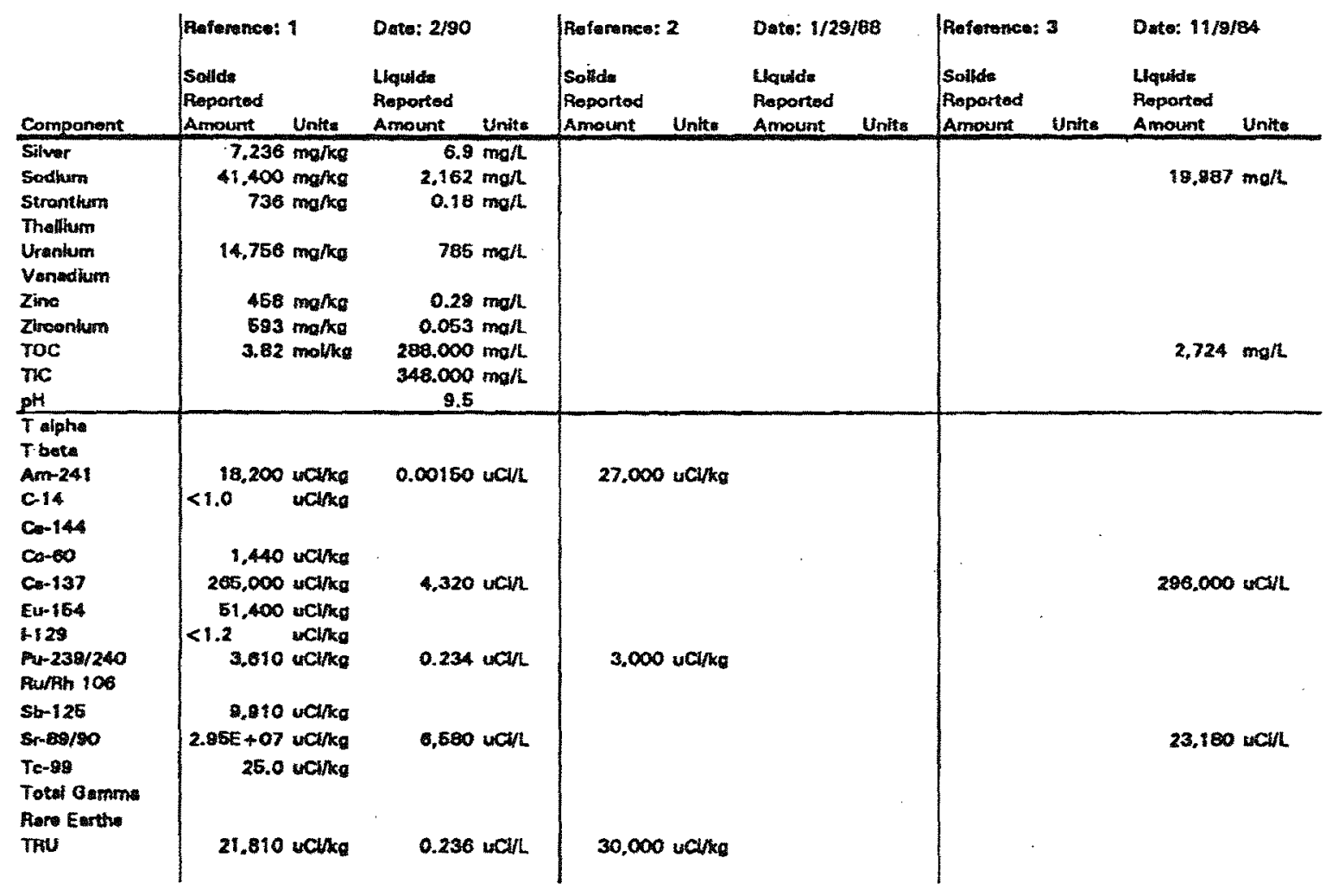




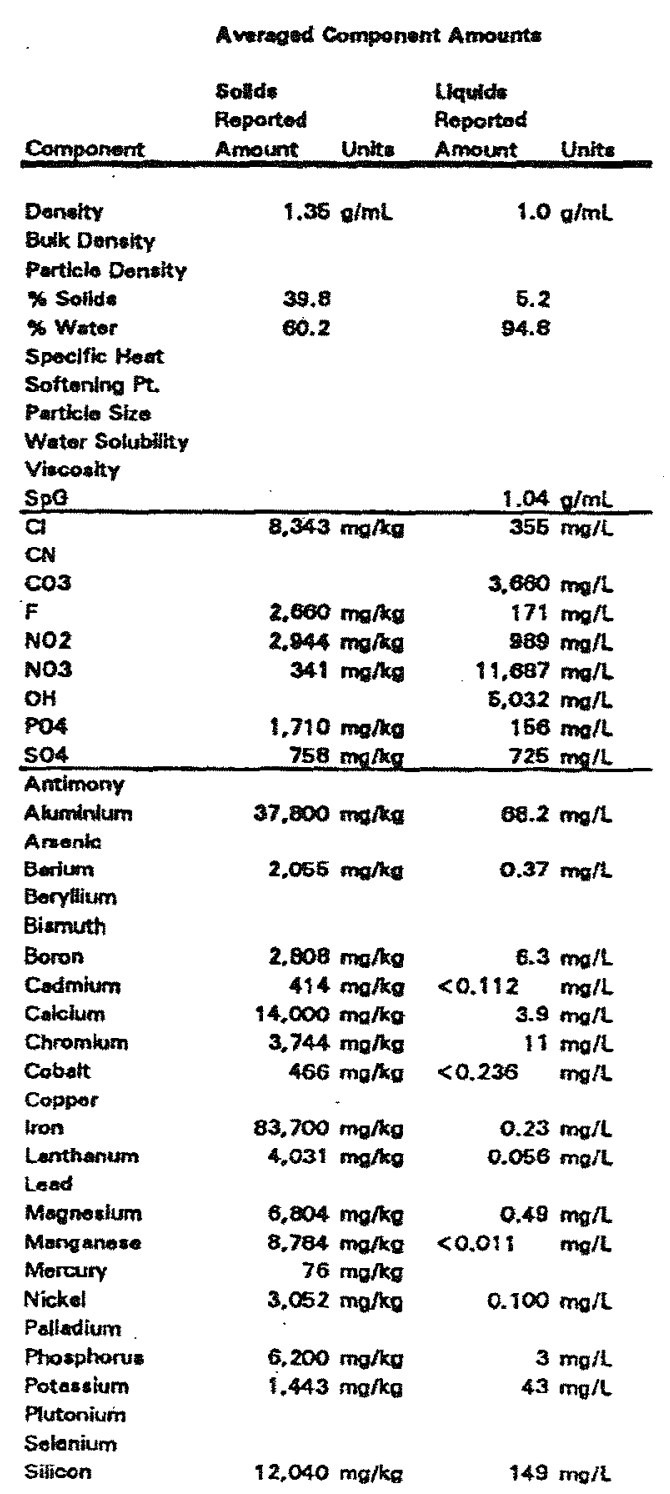

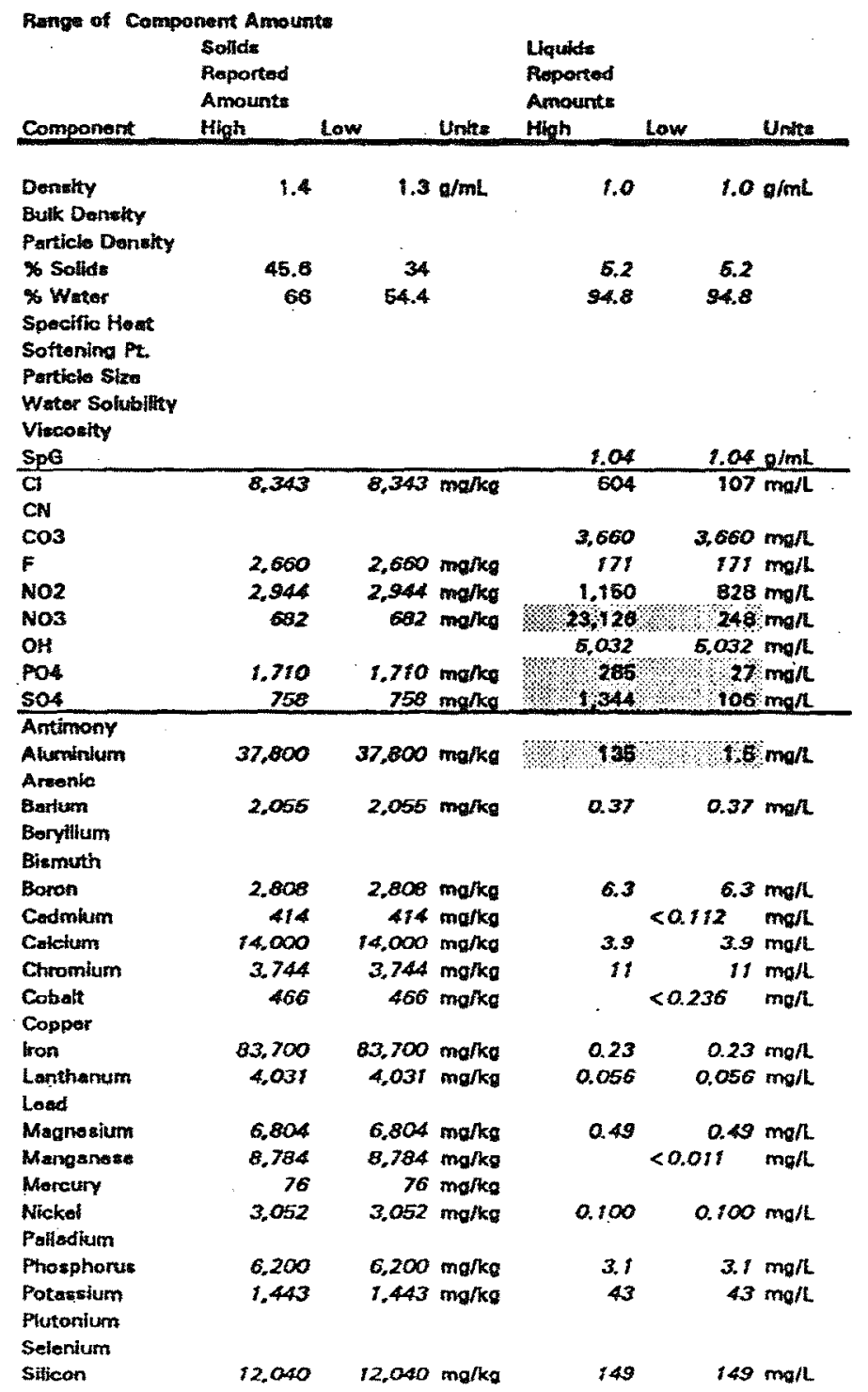

Pago 8 


\begin{tabular}{|c|c|c|c|c|}
\hline \multirow[b]{2}{*}{ Componont } & \multicolumn{4}{|c|}{ A veraged Componemt Amounts } \\
\hline & $\begin{array}{l}\text { Solde } \\
\text { Roported } \\
\text { Amount }\end{array}$ & Units & $\begin{array}{l}\text { Liquide } \\
\text { Reportod } \\
\text { Amaurt }\end{array}$ & Units \\
\hline Sitwer & \multirow{2}{*}{\multicolumn{2}{|c|}{$\begin{array}{r}7.236 \mathrm{mg} / \mathrm{kg} \\
41.400 \mathrm{mg} / \mathrm{kg} \\
736 \mathrm{mg} / \mathrm{kg}\end{array}$}} & \multirow{2}{*}{\multicolumn{2}{|c|}{$\begin{array}{r}6.8 \mathrm{mg} / \mathrm{t} \\
2.162 \mathrm{mg} / \mathrm{h} \\
0.18 \mathrm{mg} / \mathrm{L}\end{array}$}} \\
\hline $\begin{array}{l}\text { Sodium } \\
\text { Stromitum }\end{array}$ & & & & \\
\hline Thattium & \multirow{2}{*}{\multicolumn{2}{|c|}{$14.750 \mathrm{mg} / \mathrm{xag}$}} & \multirow{2}{*}{\multicolumn{2}{|c|}{$m / L$}} \\
\hline $\begin{array}{l}\text { Urantum } \\
\text { Vanedium }\end{array}$ & & & & \\
\hline Zine & \multirow{4}{*}{\multicolumn{2}{|c|}{$\begin{array}{l}468 \mathrm{mg} / \mathrm{kg} \\
883 \mathrm{mg} / \mathrm{kg} \\
3.82 \mathrm{~mol} / \mathrm{kg}\end{array}$}} & \multirow{4}{*}{\multicolumn{2}{|c|}{$\begin{array}{r}0.29 \mathrm{mg} / \mathrm{h} \\
0.044 \mathrm{mg} / \mathrm{h} \\
1506.000 \mathrm{mg} / \mathrm{h} \\
348.000 \mathrm{mg} / \mathrm{L} \\
9.5\end{array}$}} \\
\hline Ztrcontum & & & & \\
\hline & & & & \\
\hline $\begin{array}{l}\mathrm{TIC} \\
\mathrm{pH}\end{array}$ & & & & \\
\hline \multicolumn{5}{|l|}{ T alpha } \\
\hline$T$ bets & & \multirow{2}{*}{\multicolumn{2}{|c|}{$0.00150 \mathrm{uCl} / \mathrm{L}$}} \\
\hline $\begin{array}{l}\text { Am-241 } \\
c-14\end{array}$ & $<1.00$ & & & \\
\hline \multicolumn{5}{|l|}{ C. 144} \\
\hline Co.eo & 1,440 & uCI/kg & \multirow{2}{*}{\multicolumn{2}{|c|}{$160.160 \mathrm{wCl} / \mathrm{L}$}} \\
\hline C.-137 & 206.00 & uct/ka & & \\
\hline $\begin{array}{l}\text { Eu-154 } \\
+129 \\
\text { Pu-239/240 } \\
\text { Ru/Rh } 106\end{array}$ & $\begin{array}{r}51,400 \\
3,306\end{array}$ & $\begin{array}{l}\text { uci/ka } \\
\text { uCing } \\
\text { uci/kg }\end{array}$ & \multicolumn{2}{|c|}{$0.234 \mathrm{uCl} / \mathrm{h}$} \\
\hline $5 b-125$ & 8,810 & ucifikg & & \\
\hline Sr-69/80 & $2.26 E+07$ & uctikg & \multirow{2}{*}{\multicolumn{2}{|c|}{$14.860 \mathrm{uCl} / \mathrm{L}$}} \\
\hline Tc-99 & 25.6 & wC1/kg & & \\
\hline \multicolumn{5}{|l|}{ Total Gamm } \\
\hline Pare Earthe & & & & \\
\hline TRU & 26.201 & ucl/kg & 0.236 & $8 \mathrm{wcin}$ \\
\hline
\end{tabular}

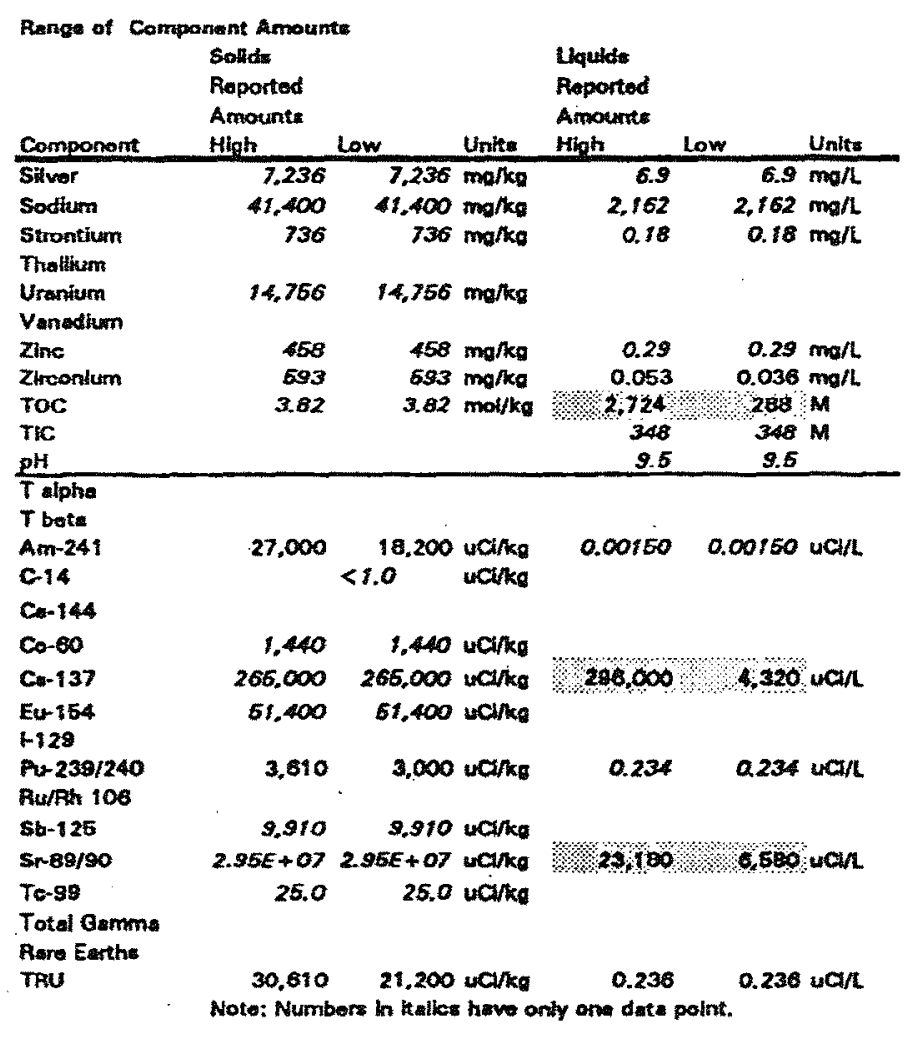


3.19 Tank AY-102 Report Analysis from February 1990 


\section{$\therefore \quad \operatorname{TCRC}-1$}

A +102

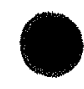

\section{AY $102 \cdot 16$}

\section{(6) $2 / 12 / 1990$ sample.}

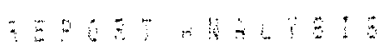

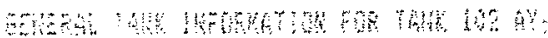

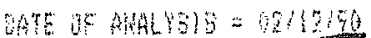

Ghat wher = Then

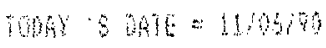
WhE WE=

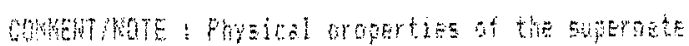

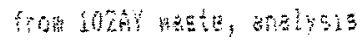

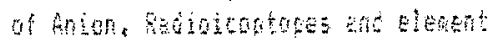

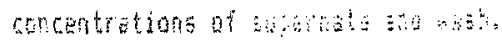

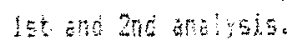

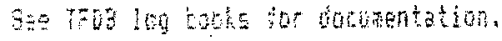

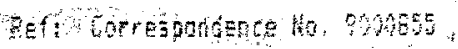




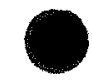

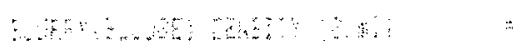

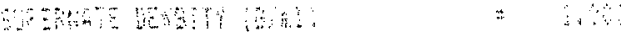

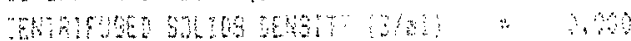

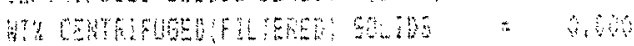

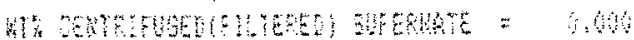

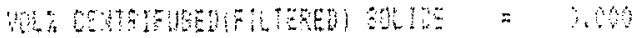

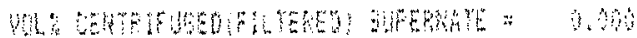

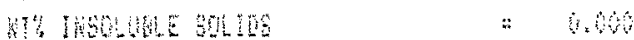

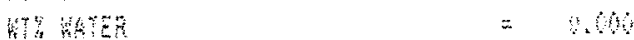

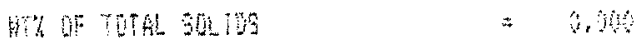

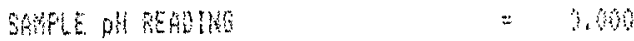

FUD HHEAGY OF THE BAPE:

THE THE :

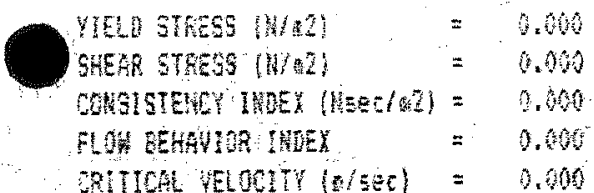


Supernate Waterwash

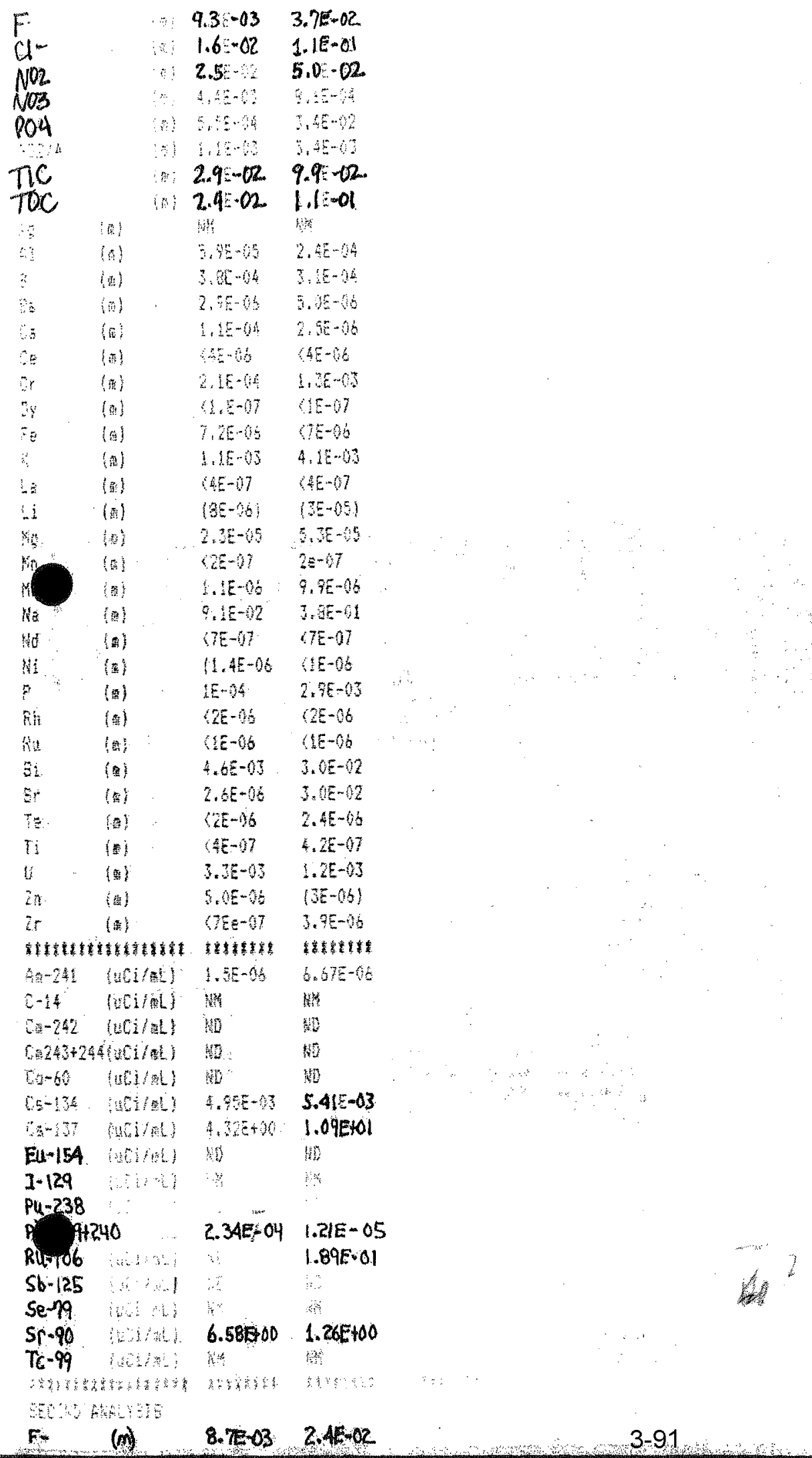




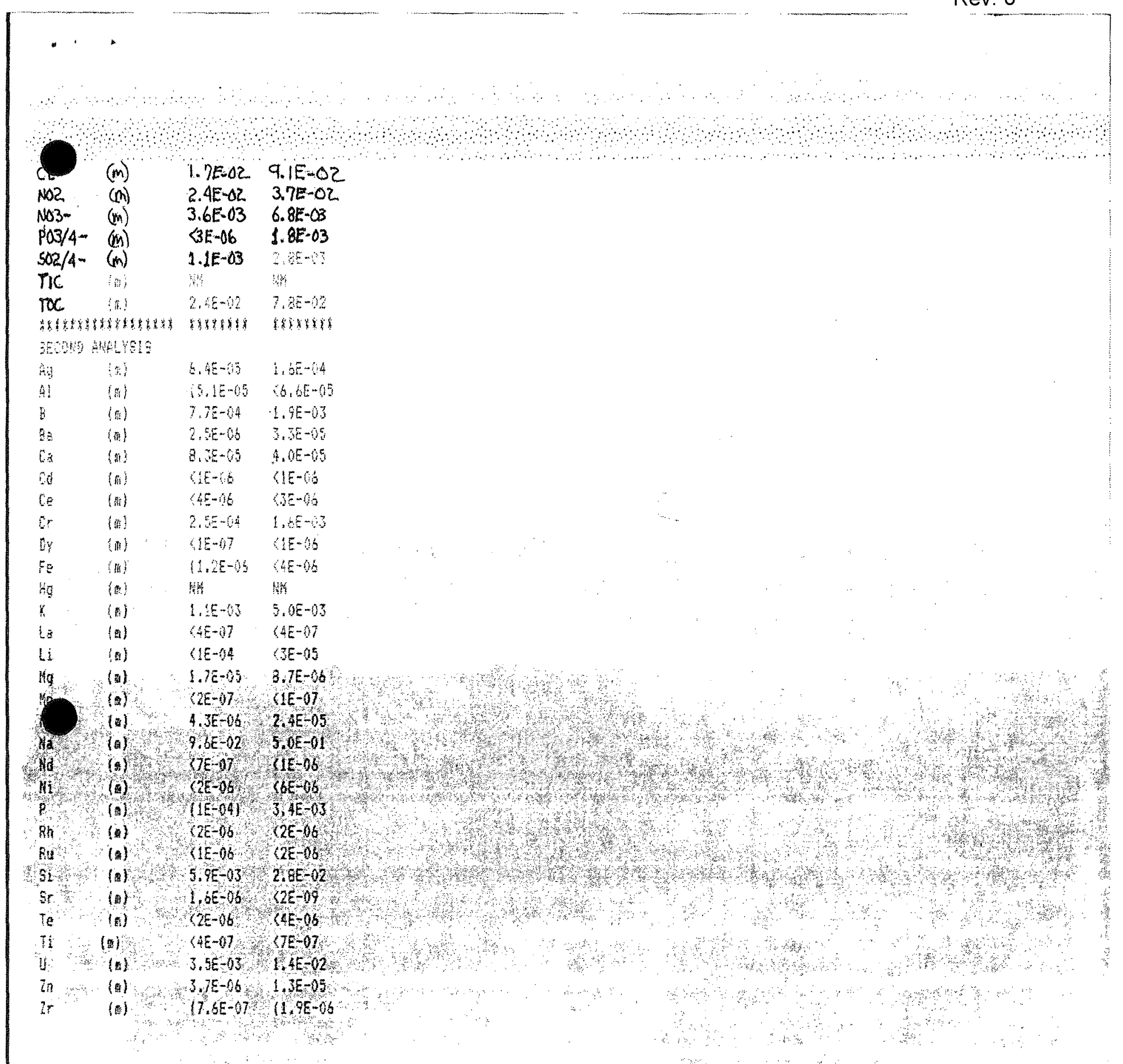




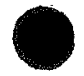

nets $1: 98$

FEPBET A

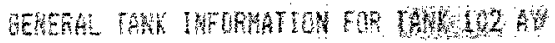

3rs

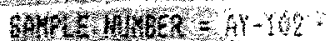

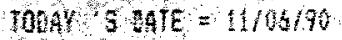

WSTE THE = IRU

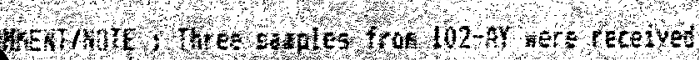

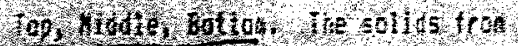
Whiret rogres were blended tagether

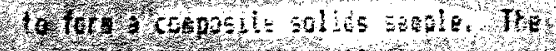

THE :12, $3: 4$

\section{(7) $2 / 12 / 90$ sudge data.}

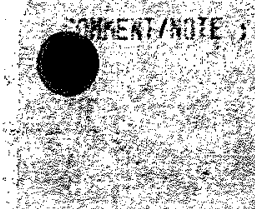

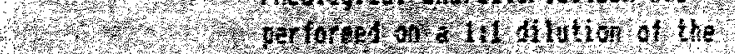

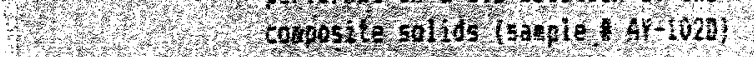

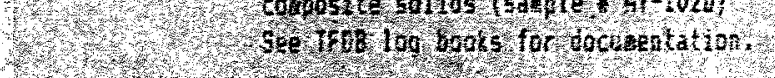

1
3

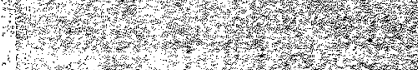

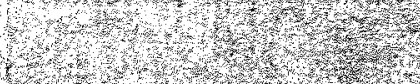

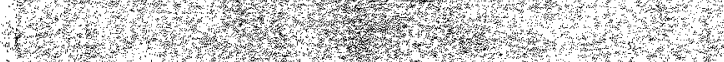

s.t.

Pl

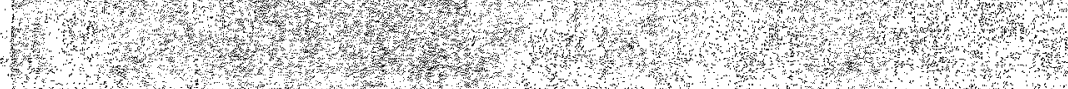

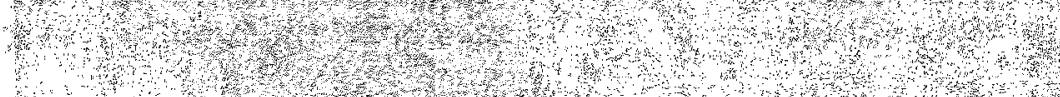

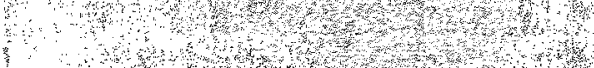

ats

mathos

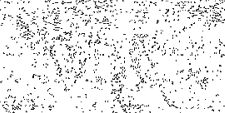

Sample?

11. Whan 


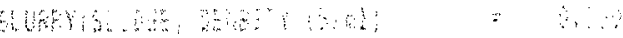

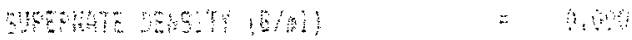

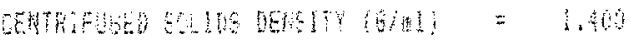

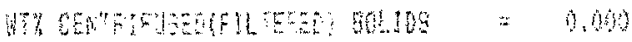

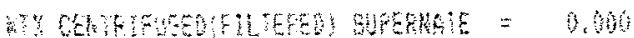

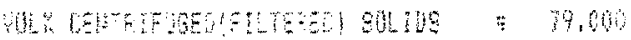

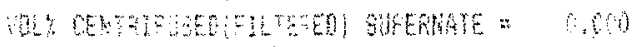

W5 log

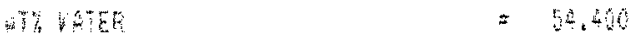

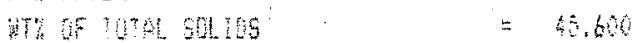

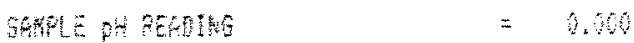

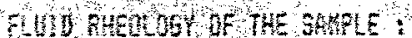

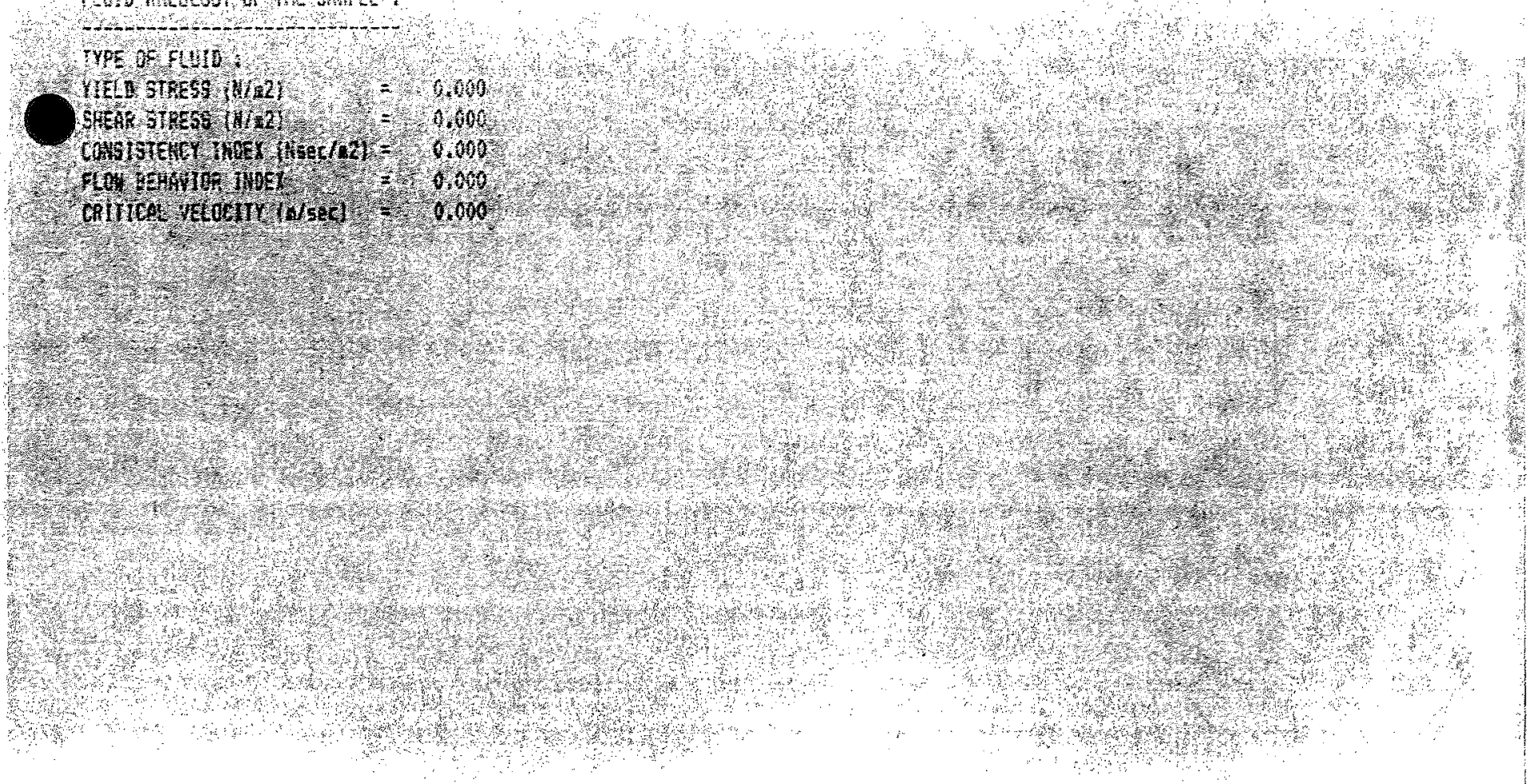


An-24i lucligi

C-14 foutigi

$C^{-}-242$ (UCi/q)

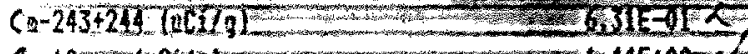

$(0-60=$ fuCHO

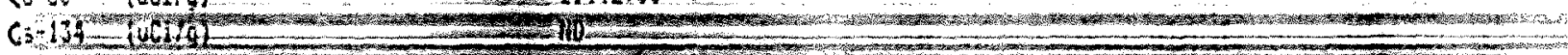

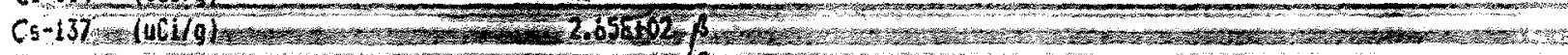

Eu-15i:

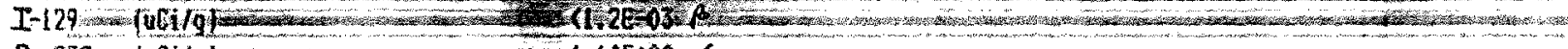

$P(\mathrm{a}-23 \mathrm{~g}-(\mathrm{uCi} / \mathrm{a})$

$1.14 E+60<$

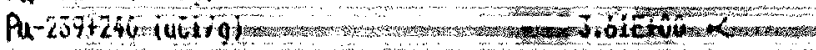

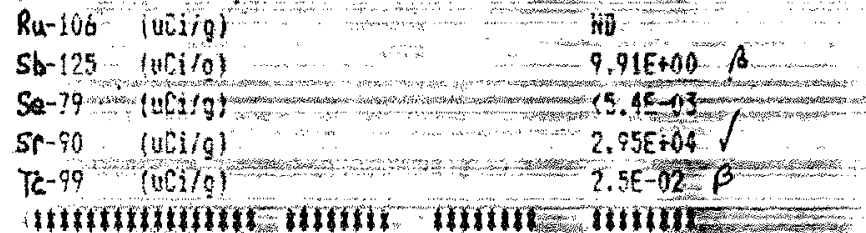

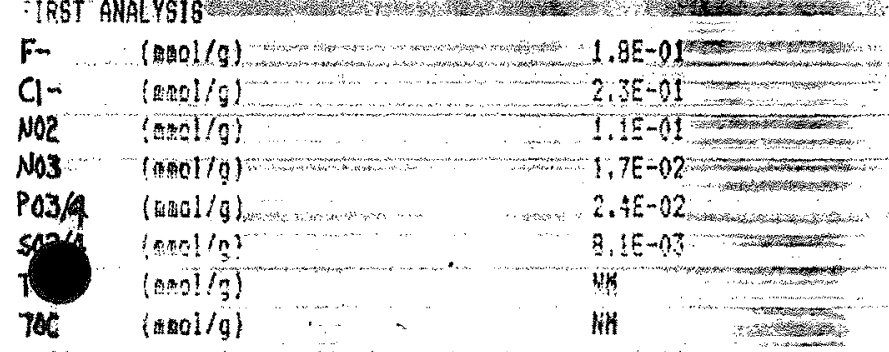

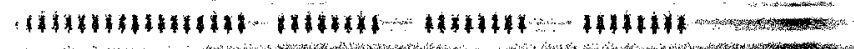

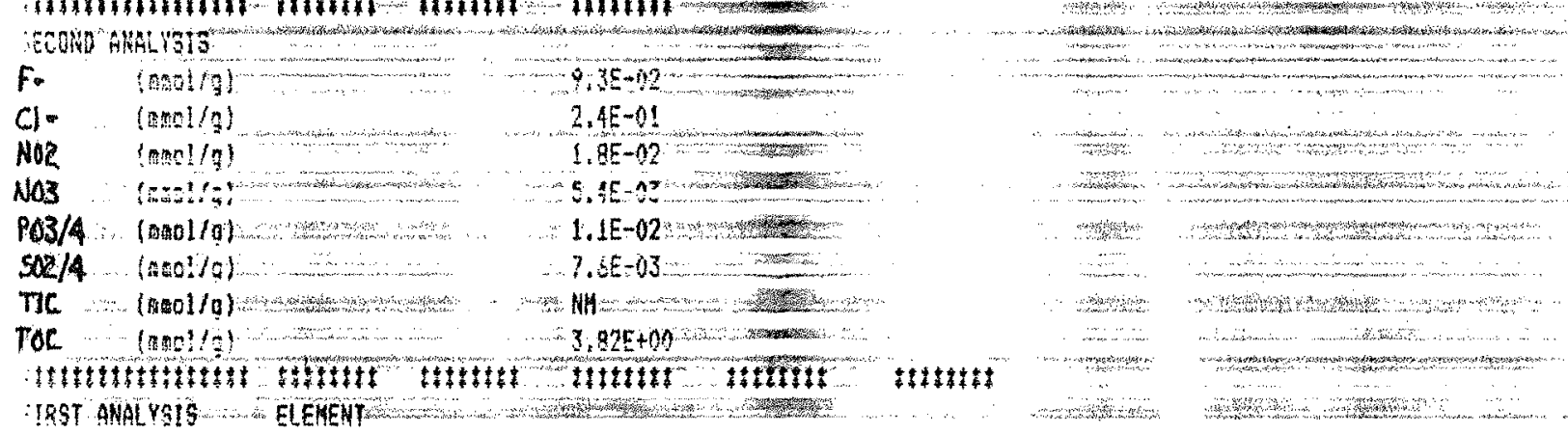

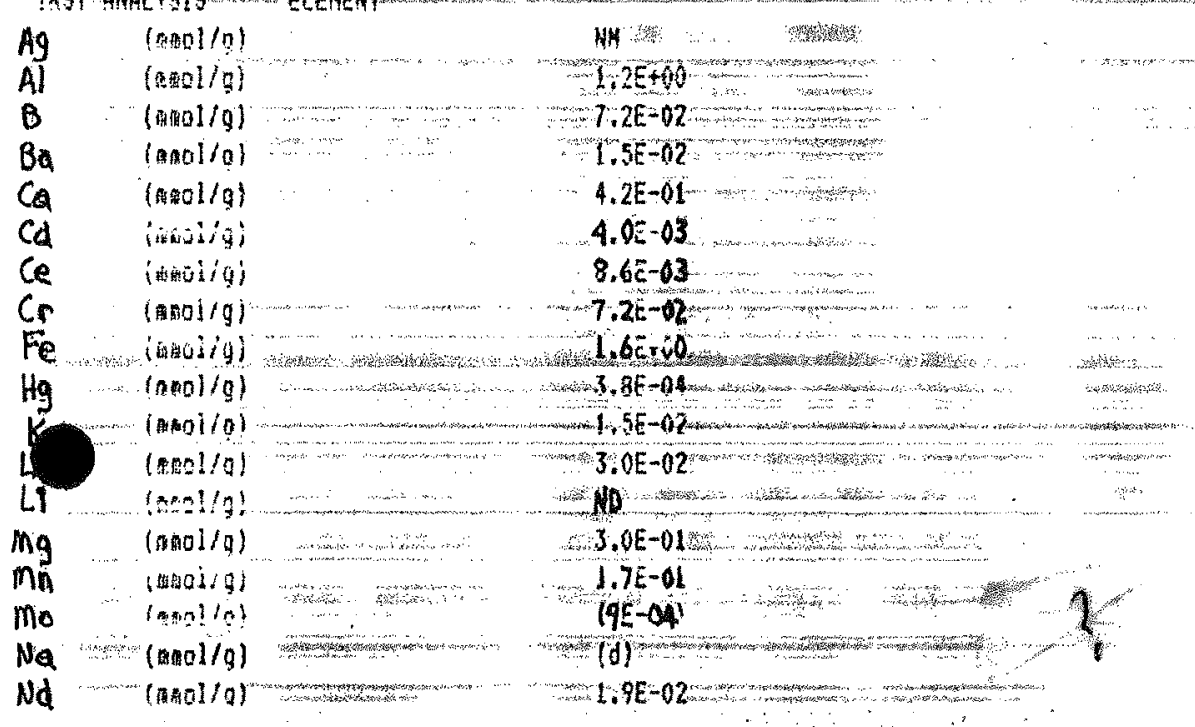

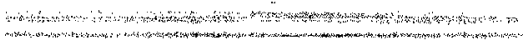
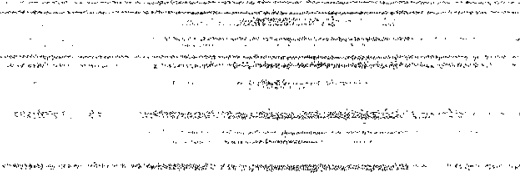
Rev. 0

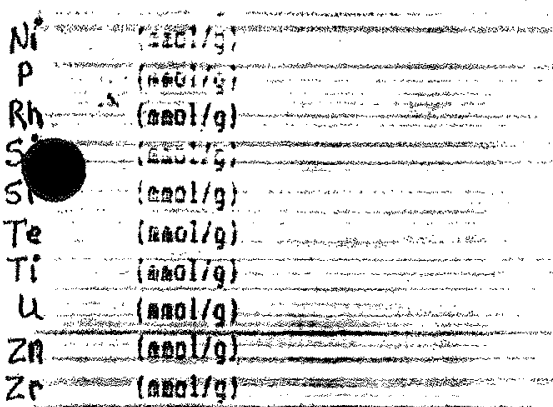

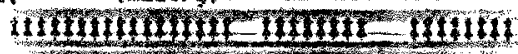

At

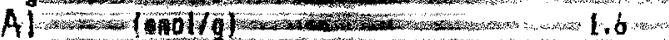

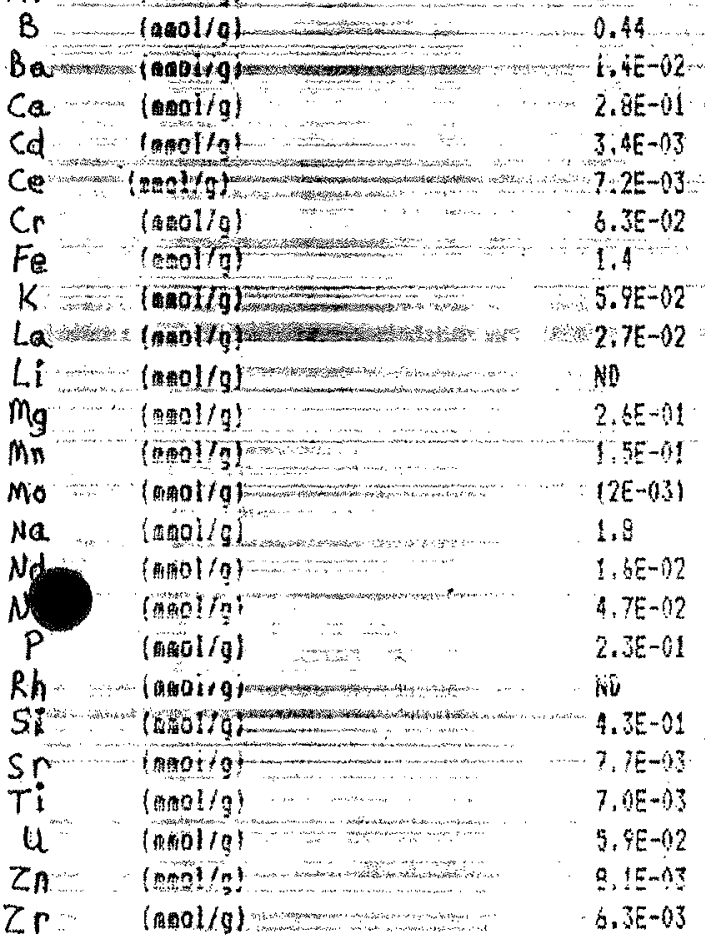

$\sin -\mathrm{s}_{2}$

$1, \infty+v i$

ND

$9.05-93$

$i 4 E-63 i$

$7.1 E-85$

$6.5 E-02$

$5.9 E-1) 3$

(e)

118416

a

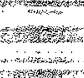

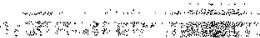

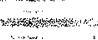

$1.4 E-02$

$2.8 \mathrm{E}-01$

$25-03$

6.3E- 02

4

Hit

E-11

$E-(03)$

$1,4 E-1) 2$

$7 E-12$

iii

$4.35-01$

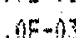

S. $9 E-02$

$2.3 E-03$

sinas

\section{(n)}

(1) ros

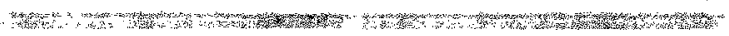

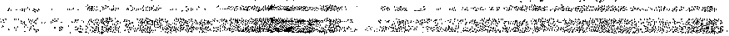

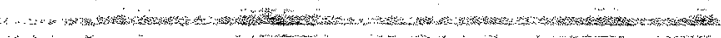
(n) mand

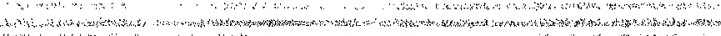
on

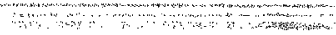

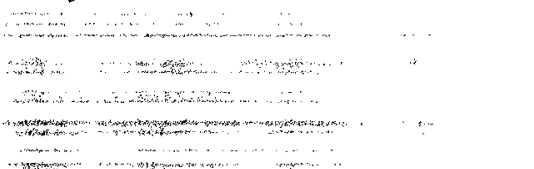

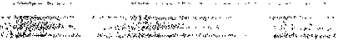
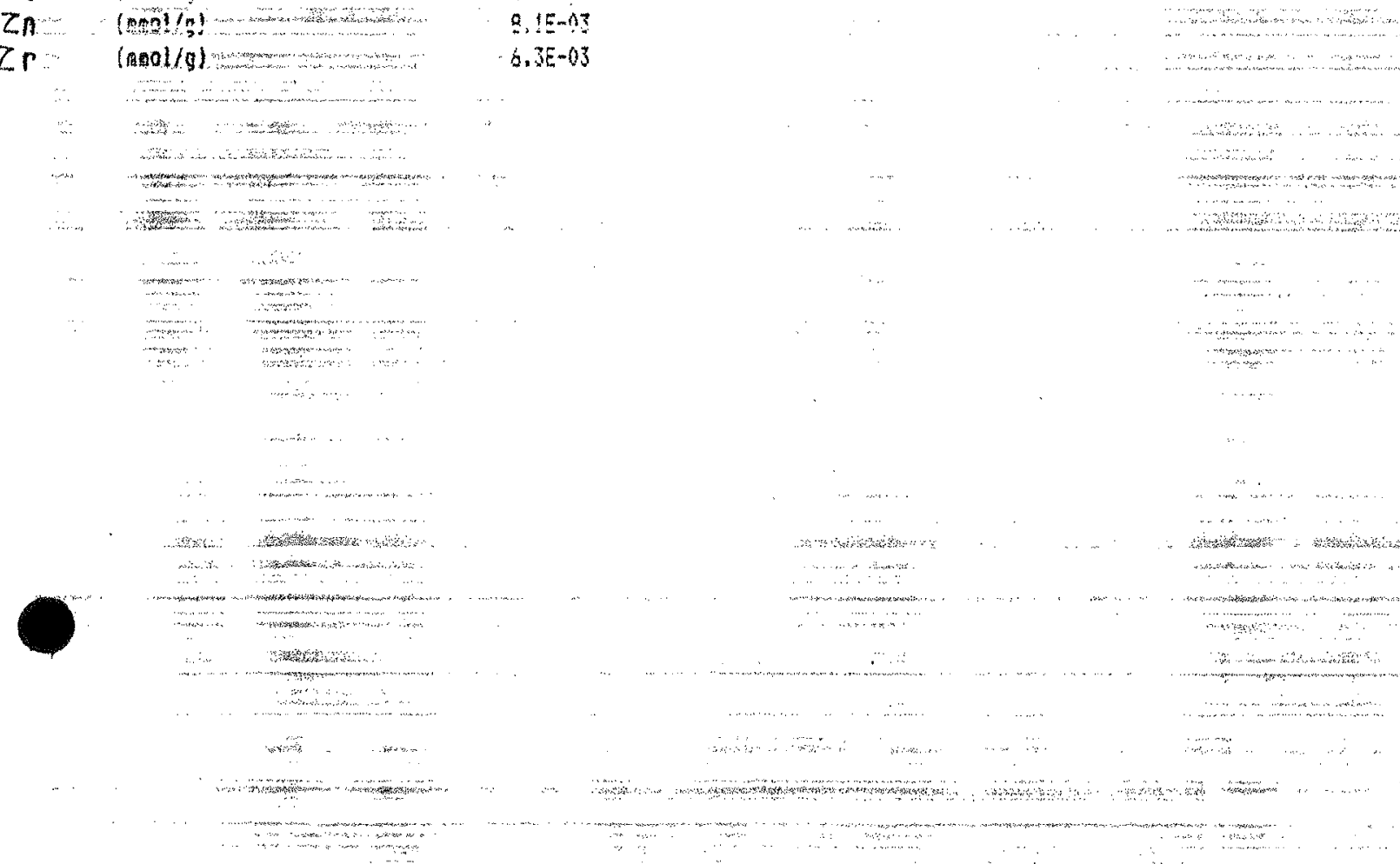
$T C R C-18$

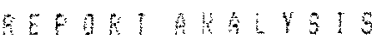

AY102.15 A4.102

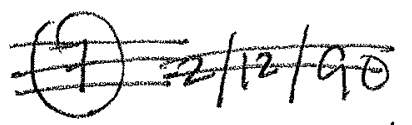

- stertated

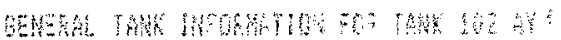

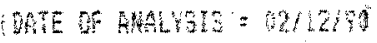

SAFLE WW

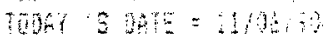

WABE THE = THL

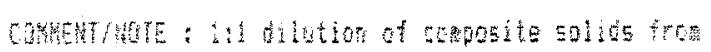

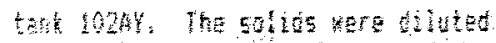
Composite Solids from $102 \mathrm{AY}$

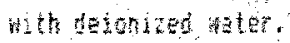

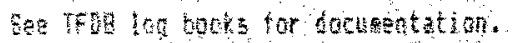

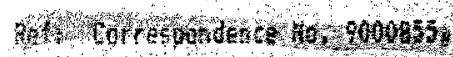

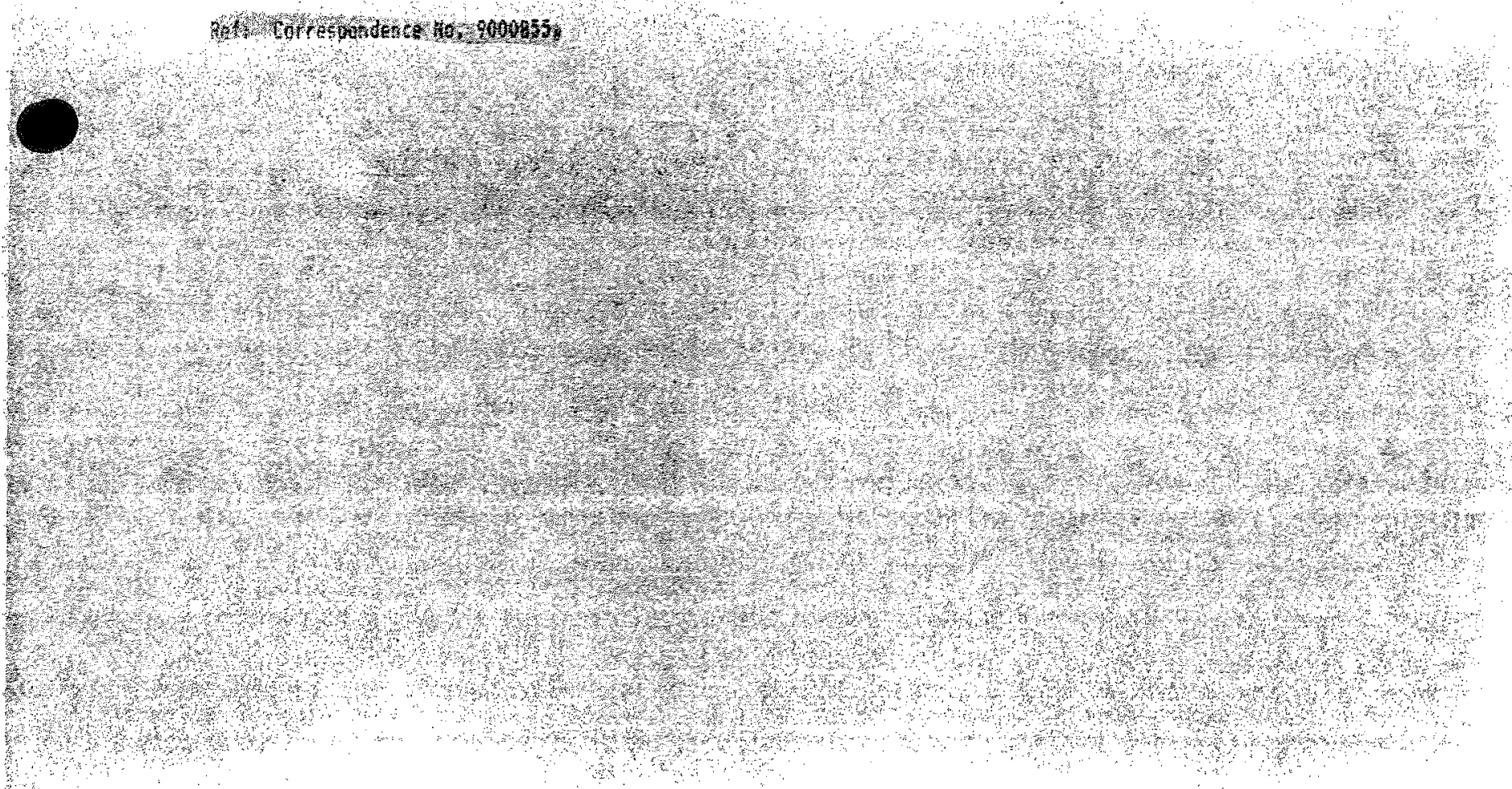




\begin{tabular}{|c|c|c|}
\hline 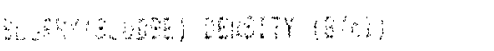 & $\therefore$ & $\therefore \therefore$ \\
\hline onom mont & : & 3.60 \\
\hline 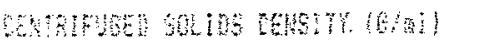 & $=$ & 3.200 \\
\hline 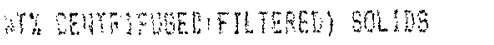 & $=$ & 0.30 \\
\hline 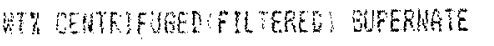 & $=$ & 0.000 \\
\hline 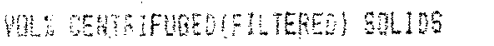 & $=$ & 5.000 \\
\hline 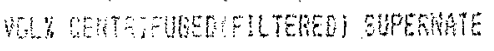 & $\approx$ & 0.600 \\
\hline 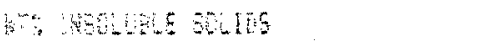 & $\therefore$ & 4.606 \\
\hline Wh buten & $=$ & 0.000 \\
\hline We of rotit gatse & $=$ & B. 100 \\
\hline SWPLE WH foulla & $=$ & 0.190 \\
\hline
\end{tabular}

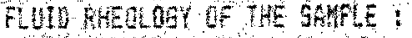

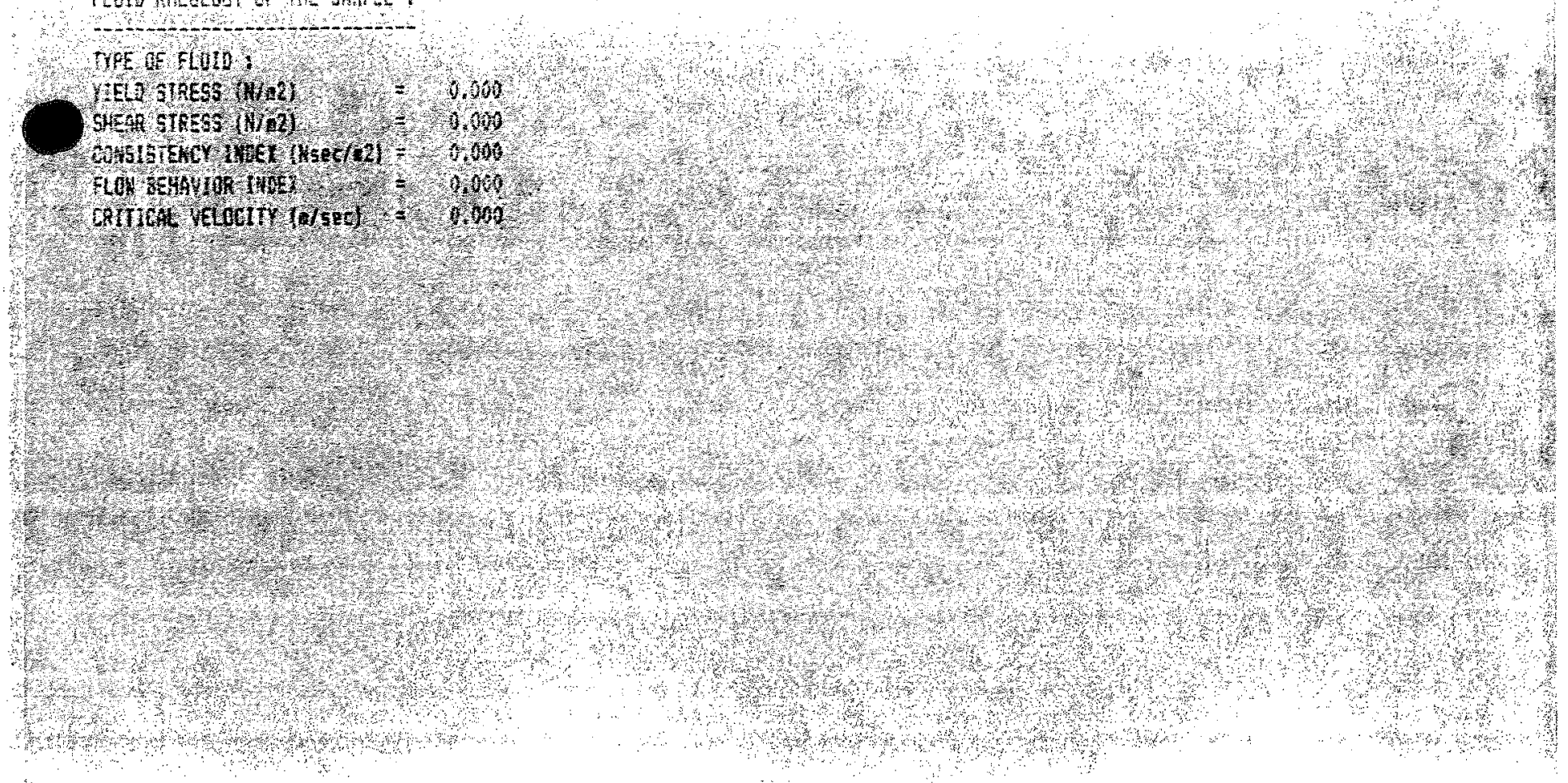




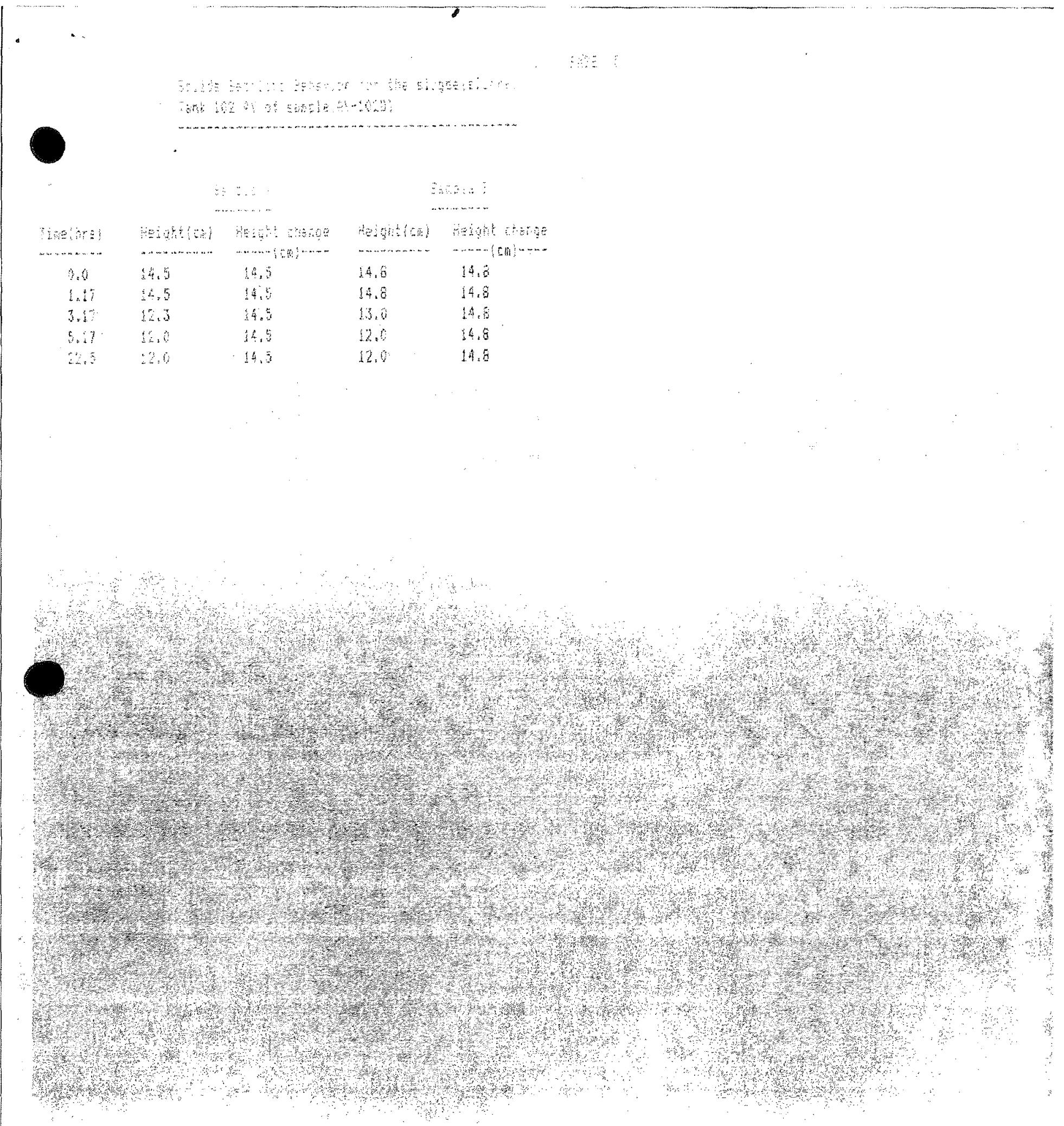


Rev. 0

3.20 Congdon, J. W., and Lozier, J. S., 1987, "Inhibition of Washed Sludge with Sodium Nitrite," (Memorandum DPST-87-379 to M. A. Ebra), Savannah River Laboratory, Aiken, South Carolina. 


\section{AUTHORIZATION FOR DISTAIBUTION OF TECHNICAL IMFORMATIO}

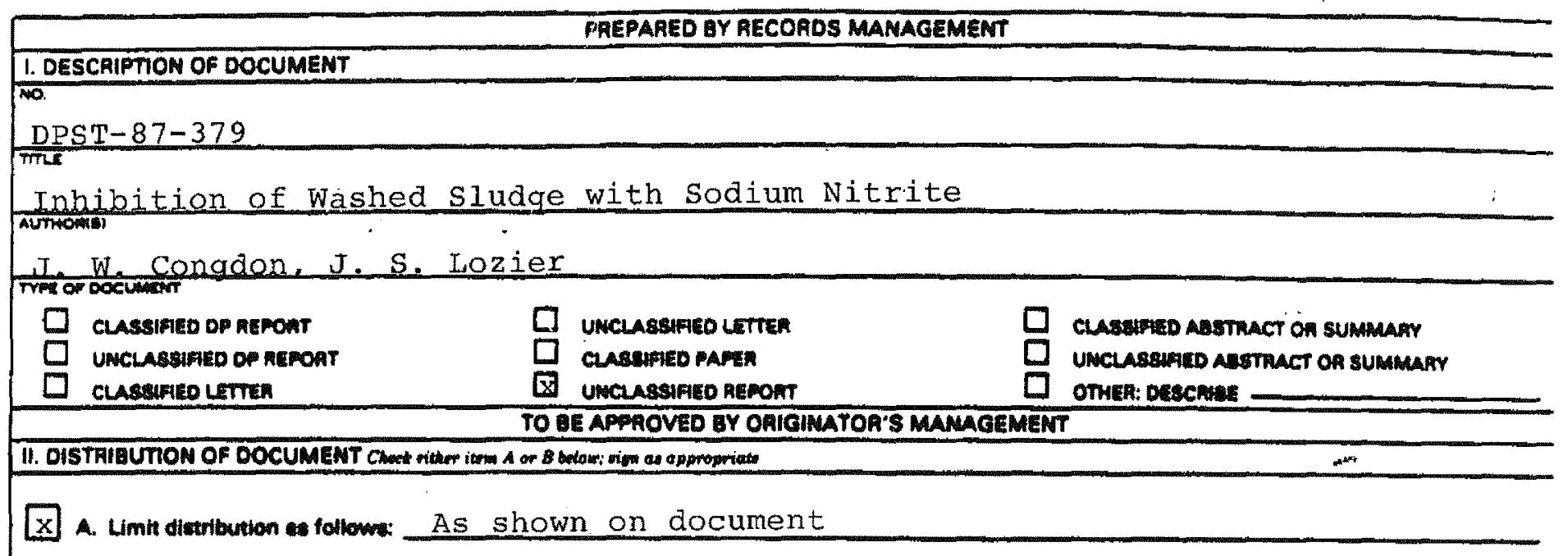

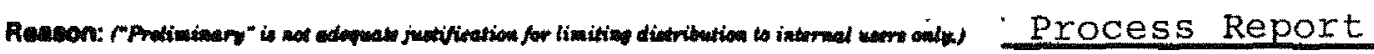

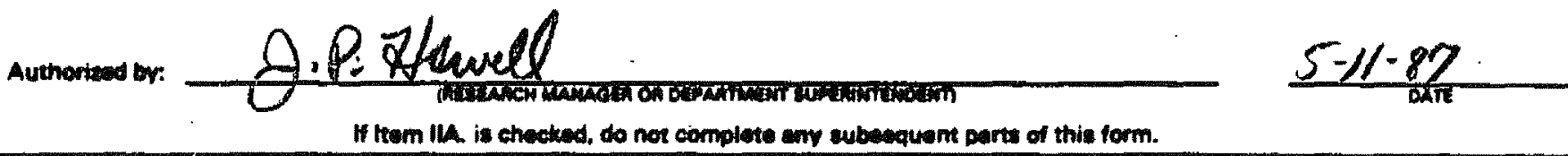

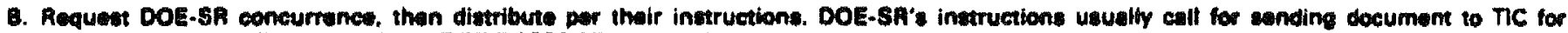
diatribution as specified on the form (DOE F \$332.15) ettuched to the document.

Authorized by:

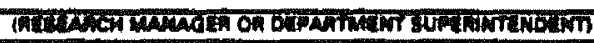

DATE TO BE APPAOVED FIAST GY ORIGIRATOR'S MAMAGEMENT, THEN BY RECOROS MANACEMENT

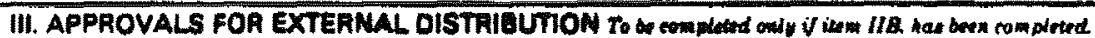
A. TEMANCAL COWTOM

Authorized by: - cunsufication

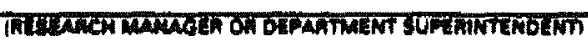
DATE

Reviewed by:

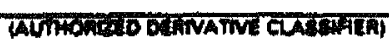

Authority for Classification Determinution

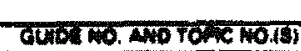

TO BE COMPLETED GY AECOROS MARAGEMENT

IV. CATEGOAY IF D AEPOAT

Approved by:

V. DOE RELEASES (Dater only) 


\section{Key Words: $\quad$ Waste Tank \\ Corrosion \\ SRL \\ RECORD COPY \\ Pitting \\ Nitrite \\ Inhibitors \\ Washed Sludge}

CC: J. E. Haywood, 703-A

S. B. Oblath, 773-A

W. B. Boore, 703-H

D. F. Bickford, 773-A

J. E. Black, 242-H

D. D. Walker, 773-A

P. D. d'Entremont, 703-H

R. E. Eibling, 773-A

J. S. Rybolt, 703-H

P. E. Zapp, 773-A

J. P. Howell, 773-A

L. F. Landon, 704-T

R. S. Ondrejcin, 773-A

SRL Records (4), 773-A

D. T. Hobbs, 773-A

April 7, 1987

\section{MEMORA N D UM}

TO: M. A. EBRA, 773-A

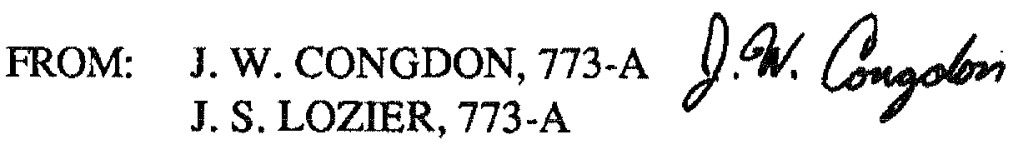

\section{INHIBITION OF WASHED SLUDGE WLTH SODIUM NITRITE}

\section{INTRODUCTION}

Washed sludge is an aqueous slurry consisting of a relatively dilute salt solution in equilibrium with several transition metal oxides and hydroxides. This slurry will be produced by in-tank washing of sludge and each batch will be stored for approximately two years in existing carbon steel (ASTM A-537) tanks. Batches of washed sludge will be removed periodically and sent to the DWPF for processing into glass. Washed sludge contains several species (nitrate, sulfate, chloride, and fluoride) which are known to act as pit inducing (aggressive) anions. ${ }^{1}$ 
Pitting of the waste tanks has been identified as a corrosion concern for washed precipitate ${ }^{2}$ which has a composition similar to washed sludge. This prompted concern about the corrosivity of washed sludge. Pitting is most likely to occur in the region just above ( 0 to $\left.6^{\prime \prime}\right)$ the waterline based on the corrosion mechanism described for washed precipitate. ${ }^{3}$

This report describes the results of electrochemical tests used to determine the relationship between the concentration of the aggressive anions in washed sludge and the minimum effective inhibitor concentration. Sodium nitrite was added as the inhibitor because of its compatibility with the DWPF process. 4

\section{SUMMARY}

A minimum of $0.05 \mathrm{M}$ nitrite is required to inhibit the washed sludge simulant solution used in this study. When the worst case compositions and safety margins are considered, it is expected that a minimum operating limit of nearly $0.1 \mathrm{M}$ nitrite will be specified. The validity of this limit is dependent on the accuracy of the concentrations and solubility splits reported in BDR-90. ${ }^{5}$ Sodium nitrite additions to obtain $0.1 \mathrm{M}$ nitrite concentrations in washed sludge will necessitate the additional washing of washed precipitate in order to decrease its sodium nitrite inhibitor requirements sufficiently to remain below the sodium limits ${ }^{4}$ in the feed to the DWPF.

Nitrate will be the controlling anion in "fresh" washed sludge unless the soluble chloride concentration is about ten times higher than predicted by the solubility splits in BDR-90. Inhibition of "aged" washed sludge will not be a problem unless significant chloride dissolution occurs during storage. It will be very important to monitor the composition of washed sludge during processing and storage.

\section{EXPERIMENTAL}

Cyclic potentiodynamic polarization tests were used to determine the pitting behavior of ASTM A-537 carbon steel in various compositions of synthetic washed sludge. The experimental procedure and equipment have been described previously. ${ }^{6}$ 
The composition of washed sludge simulant was based on data reported in BDR-90. Imbedded in BDR-90 are solubility splits for various species. These splits (Table 1) can have a significant effect on the soluble concentration of several species in washed sludge. For the simulant recipe, it was assumed that nitrate, sulfate, and fluoride were fully soluble. This is 3,2 , and 20 times the respective BDR-90 soluble values, and should adequately represent worst-case for these ions. The BDR-90 solubility value of $2 \%$ was used for chloride. All other species were added at the soluble concentrations reported in BDR-90. Several electrochemically important transition metals were added with precipitation allowed to occur in situ.

The various compositions of the test solutions (i.e. nitrite/aggressive anion ratios) were selected by a best guess approach based on the results of previous tests rather than a fixed matrix of compositions. Since the soluble fluoride concentration in washed sludge is very low, the effects of variations in the fluoride concentration were not evaluated in this study, however, it was always present at the maximum expected level. The compositions of the simulant solutions were adjusted by the addition or removal of the appropriate sodium salts.

After each scan was completed, the specimens were cleaned with Clarke's solution ${ }^{7}$ and examined with an optical microscope for evidence of pitting and crevice corrosion. Pitting was defined as the presence of corrosion on the exposed portion of the specimen.

\section{RESULTS and DISCUSSION}

The effects of the concentration of the primary aggressive anions (nitrate, chloride, and sulfate) in washed sludge on the minimum nitrite concentration required for inhibition are shown in Figures 1,2, and 3. All species were present at the concentrations specified above, except for the one being varied. The line in each of the plots represents the minimum nitrite concentration required to inhibit pitting as a function of the aggressive anion concentration. A minimum of $0.05 \mathrm{M}$ nitrite is required to inhibit the washed sludge simulant used in this study.

All three $\log -\log$ plots show a region in which the minimum nitrite concentration is independent of the aggressive anion concentration. This behavior has also been reported for washed precipitate ${ }^{1}$ and indicates that there are no interaction effects between the aggressive anions. 
These results also indicate that nitrate controls the inhibitor requirement in "fresh" washed sludge. If the soluble concentration of chloride increases to $>0.002 \mathrm{M}$ (which is 10x the concentration predicted in BDR-90), the nitrite requirements will be controlled by the soluble chloride concentration. If chloride concentrations are this high, the required sodium nitrite additions could be sufficiently high to necessitate rewashing of the slurry to lower the total sodium to concentrations acceptable to the DWPF process. ${ }^{4}$ At present, there is no information on the dissolution of chloride into washed sludge during storage. Chloride levels in washed sludge will be monitored very closely during processing and storage.

Radiolysis effects during the storage of washed sludge make the slurry less corrosive as nitrate is converted to nitrite. Since there is no tetraphenylborate anion (TPB) in washed sludge, nitrite depletion is not a problem. Nitrite depletion in washed precipitate is apparently related to the volatile decomposition products of TPB. ${ }^{8}$

The results presented in Figure 3 indicate that nearly a ten fold increase in the sulfate concentration is necessary before the nitrite requirements for washed sludge begin to increase. This is important since the concentration of soluble sulfate is difficult to predict for the various stages of sludge washing because of the presence of insoluble calcium sulfate. The sulfate concentration determines the critical nitrite concentration $(0.009 \mathrm{M})$ on the nitrite/nitrate plot (Figure 1) based on an extrapolation of the slope of nitrite/sulfate plot to the BDR-90 sulfate concentration $(0.00258 \mathrm{M})$. Therefore, the inhibitor requirements for "aged" BDR-90 washed sludge (i.e. nitrate depleted) will be controlled by the sulfate concentration if the sulfate is fully soluble. The data indicates that, if the solubility splits in Table 1 are correct, the inhibitor requirements for the soluble chloride and sulfate in "aged" washed sludge are both $0.005 \mathrm{M}$ nitrite. Hence, an increase in the soluble concentration of either species would increase the inhibitor requirements for the aged slurry. As discussed earlier, the nitrite concentration resulting from the radiolytic conversion of nitrate to nitrite will be more than sufficient to inhibit "aged" washed if the solubility split for chloride is correct in BDR-90. 
DPST-87-379

\section{PROGRAM}

Four month coupon tests to demonstrate the effectiveness of nitrite inhibition at selected washed sludge compositions are in progress. Electrochemical tests are in progess to establish the nitrite requirements for partially washed sludge at each stage of processing. Electrochemical tests to establish the nitrite requirements in a worst case composition of washed sludge are planned, if the conservative assumptions in this report do not adequately represent a worstcase solution composition.

\section{REFERENCES}

1. J. W. Congdon, DPST-86-803, "Aggressive Anions in Washed Precipitate," November 24, 1986.

2. A. F. Riechman, DPST-86-236, In-Tank Processing: Corrosion Phenomena Due to Storage of Dilute Waste Solutions, January 20, 1986.

3. J. W. Congdon, DPST-86-446, "Corrosion Mechanism of Carbon Steel in Washed Precipitate," May 19, 1986.

4. D. F. Bickford, C. M. Jantzen, DPST-86-546, "Inhibitor Limits for Washed Precipitate Based on Glass Quality and Solubility Limits," October 6, 1986.

5. "Basic Data Report Defense Waste Processing Facility Sludge Plant, DPST-80-1033, Volume 2, Rev. 90, October 30, 1984.

6. J. W. Congdon, DPST-86-457, "Evaluation of Corrosion Inhibitors for Washed Precipitate," May 27, 1986.

7. ASTM Designation: G1-81, "Standard Practices for Preparing, Cleaning, and Evaluating Corrosion Test Specimens," (1981).

8. D. D. Walker and B. S. Johnson, Radiolytically Induced Changes in the Concentration of Nitrate and Nitrite Ions in Potassium Tetraphenylborate Slurries, DPST-86-716, October 14, 1986.

JWC:khs 
Table 1. Total Concentration and the Percentage Soluble of Selected Species in Washed Sludge

\begin{tabular}{|c|c|c|}
\hline \multicolumn{3}{|c|}{ Total Concentration } \\
\hline Species & $\mathbf{M}$ & \% Soluble \\
\hline $\mathrm{NaOH}$ & 0.152 & 20 \\
\hline $\mathrm{Na}_{2} \mathrm{CO}_{3}$ & 0.00148 & 100 \\
\hline $\mathrm{NaNO}_{2}$ & 0.0158 & 100 \\
\hline Total $\mathrm{NO}_{3}$ & 0.0630 & 36 \\
\hline Total Cl & 0.0245 & 1.3 \\
\hline $\mathrm{NaF}$ & 0.00341 & 4.5 \\
\hline $\mathrm{Na}_{2} \mathrm{SO}_{4}$ & 0.00258 & 53 \\
\hline $\mathrm{Na}_{2} \mathrm{C}_{2} \mathrm{O}_{4}$ & 0.0000726 & 100 \\
\hline $\mathrm{Na}_{2} \mathrm{CrO}_{4}$ & 0.0000298 & 100 \\
\hline $\mathrm{Na}_{2} \mathrm{MoO}_{4}$ & 0.00000387 & 100 \\
\hline $\mathrm{Na}_{2} \mathrm{SiO}_{3}$ & 0.0000368 & 80 \\
\hline $\mathrm{Na}_{3} \mathrm{PO}_{4}$ & 0.000188 & 44 \\
\hline
\end{tabular}




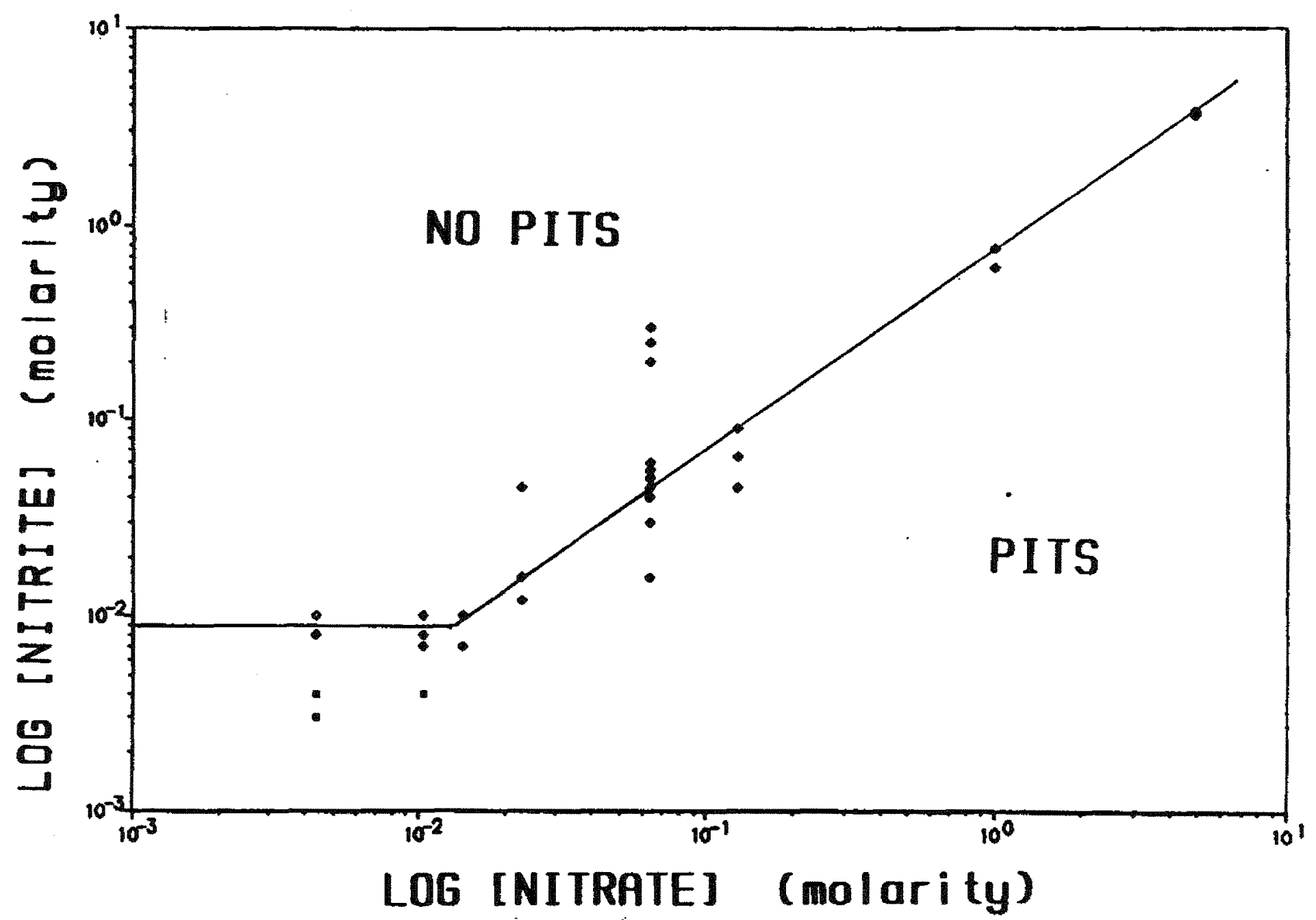

Figure 1: Effect of Nitrate Concentration on the

Minimum Nitrite Concentration Required

to Prevent Localized Corrosion of A-537

Carbon Steel in Washed Sludge.

$$
\text { Key: } \bigcirc \text { No Pits }
$$

Occasional Pitting

Pits 


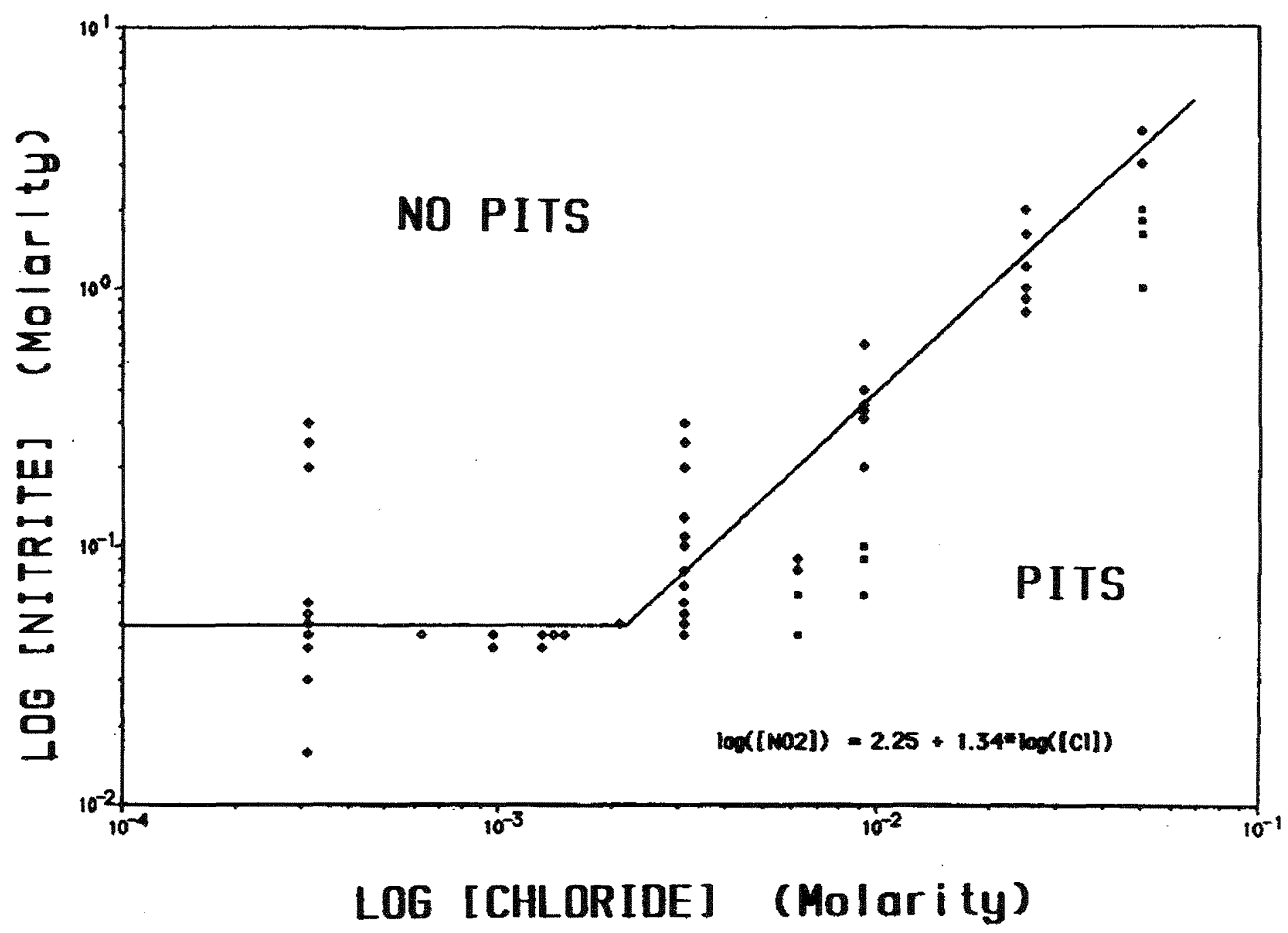

Figure 2: Effect of Chloride Concentration on the Minimum Nitrite Concentration Required to Prevent Localized Corrosion of A-537

Carbon Steel in Washed Sludge.

Key: $\diamond$ No Pits

Occasional Pitting 


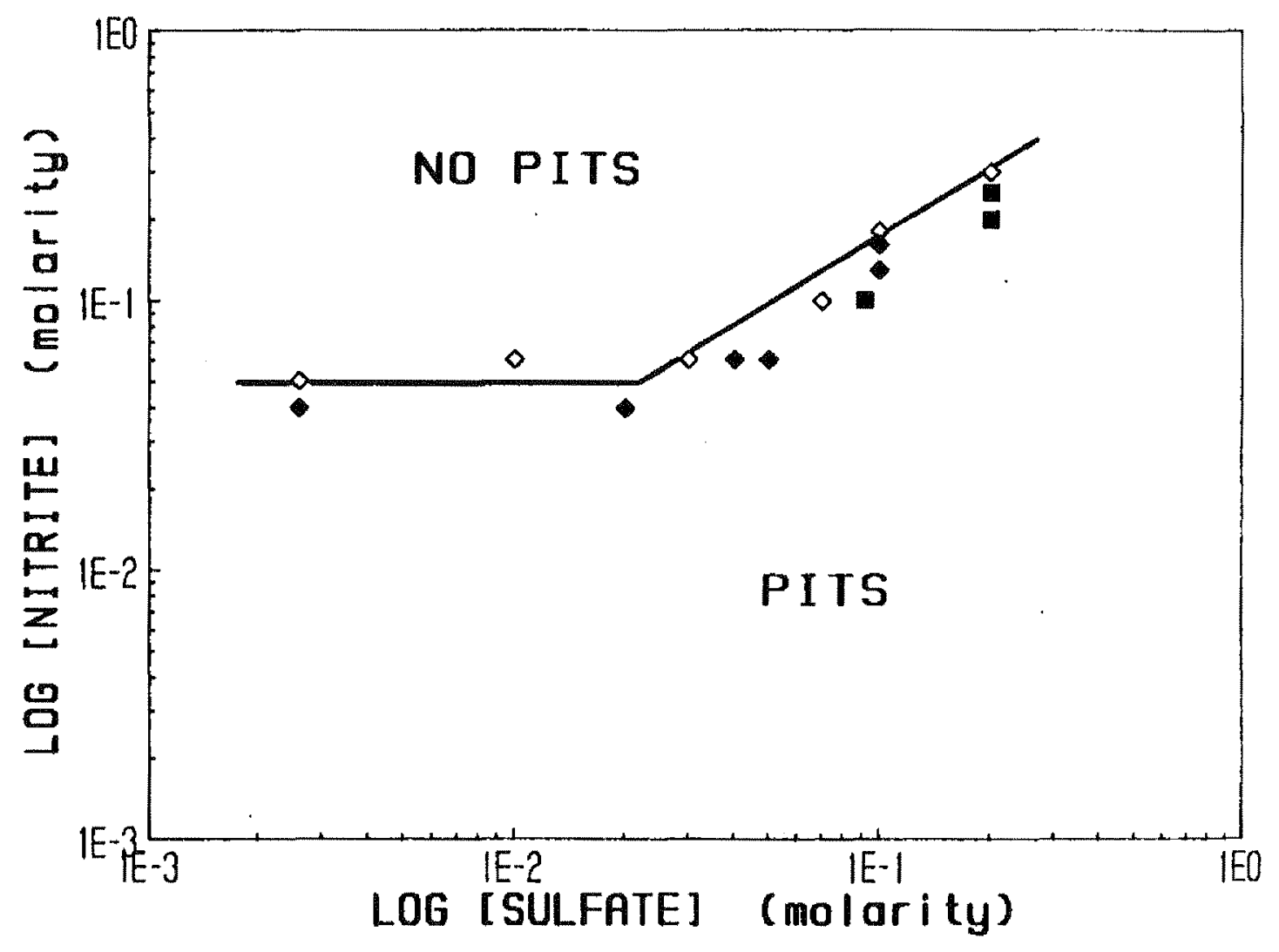

Figure 3: Effect of Sulfate Concentration on the Minimum Nitrite Concentration Required to Prevent Localized Corrosion of A-537 Carbon Steel in Washed Sludge.

$\begin{aligned} & \text { Key: } \text { No Pits } \\ & \text { Occasional Pitting } \\ & \text { Pits }\end{aligned}$ 
Rev. 0

3.21 WSRC-TR-94-0250, 1994, Recommended Nitrite Limits for Chloride and Sulfate in ESP Slurries (U), Westinghouse Savannah River Company, Aiken, South Carolina. 
$\checkmark$

\section{Westinghouse Savannah River Company Document Approval Sheet}

\begin{tabular}{|c|c|c|c|}
\hline \multicolumn{3}{|c|}{$\begin{array}{l}\text { TItle RECOMMENDED NITRITE LIMITS FOR CHLORIDE AND SULFATE IN ESP } \\
\text { SLURRIES }\end{array}$} & \multirow{2}{*}{\begin{tabular}{|l|}
$\begin{array}{l}\text { Kev Word } \\
\text { Corrosio }\end{array}$ \\
Position \\
\end{tabular}} \\
\hline $\begin{array}{l}\text { Primarv Author/Contact (Must be WSRC) } \\
\text { P. E. Zapp }\end{array}$ & $\begin{array}{l}\text { Location } \\
773-A\end{array}$ & $\begin{array}{l}\text { Phone No. } \\
5-2567\end{array}$ & \\
\hline Oraanization Code & \multicolumn{3}{|c|}{$\begin{array}{l}\text { Orqanization (No Abbreviations) } \\
\text { Materials Application and Corrosion Technology }\end{array}$} \\
\hline \multicolumn{4}{|l|}{ Other Authors } \\
\hline \multicolumn{2}{|c|}{$\begin{array}{l}\text { Has an invention disclosure, patent application or copyright application } \\
\text { been submitted related to this information? }\end{array}$} & Yes & submitted \\
\hline \multicolumn{2}{|c|}{ Disclosure No. (ff Known) ___ Title } & . & \\
\hline If no, do you intend to submit one? & If yes, pro & date & \\
\hline
\end{tabular}

\section{Information Product Description}

$\square$ Technical Report

$\square$ Topical $\square$ Semiannual $\square$ Annual $\square$ Final

$\square$ Journal Article Journal Name

Administrative Report Other:

$\square$ Topical $\square$ Semiannual $\square$ Annual $\square$ Final

GVideotape/Multimedia Other:

DBook/Book Chapter Book Name

Conference Submission*

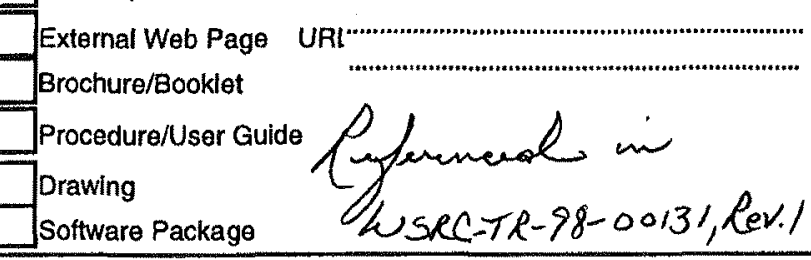


August 9, 1999

\author{
Bruce Cadotte, \\ WSRC Public Relations Officer \\ Public Relations Department \\ Building 705-A
}

Dear Mr. Cadotte:

\title{
REQUEST FOR APPROVAL TO RELEASE SCIENTIFIC/TECHNICAL INFORMATION (U)
}

The attached document is submitted for classification and technical approvals for the purpose of external release. Please complete the WSRC-PRD response section of this letter and return the letter to the undersigned by the date listed below. Patent clearance, if necessary, is requested and received via direct communications between this office and the WSRC Patent Attorney. The document has been reviewed for classification by a WSRC classification staff member. Technical questions pertaining to the contents of this document should be addressed to the author or the manager. Questions concerning the processing of this document should be addressed to the WSRC STI Program office at (803) 725-4432.

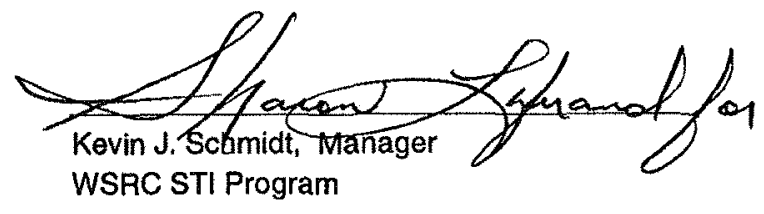

Document No. WSRC-TR-94-0250

Document Titlo RECOMMENDED NITRITE LIMITS FOR CHLORIDE AND SULFATE IN ESP SLURRIES

Author P. E. Zapp

WSRC,PRD response due by August 13,1999

पApproved $\square$ Approved with Changes $\square$ Not Approved

WSRC-PRD Remarks

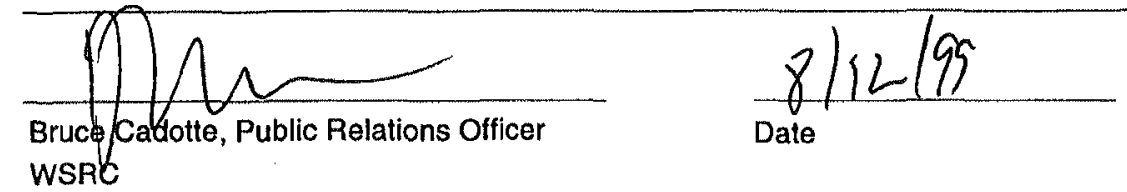




\section{RECOMMENDED NITRITE LIMITS FOR CHLORIDE AND SULFATE IN ESP SLURRIES}

by

P. E. Zapp

Westinghouse Savannah River Company

Savannah River Site

Aiken, South Carolina 29808

This paper was prepared in connection with work done under the above contract number with the U.S.

Department of Energy. By acceptance of this paper, the publisher and/or recipient acknowledges the U. S. Government's right to retain a nonexclusive, royalty-free license in and to any copyright covering this paper, along with the right to reproduce and to authorize others to reproduce all or part of the copyrighted paper. 
WESTINGHOUSE SAVANNAH RIVER COMPANY SAVANNAH RIVER TECHNOLOGY CENTER

INTER-OFFICE MEMORANDUM

TO: J. E. Marra, 703-H

FROM: P.E.Zapp, 773-A F. Zagp

Approyed by:
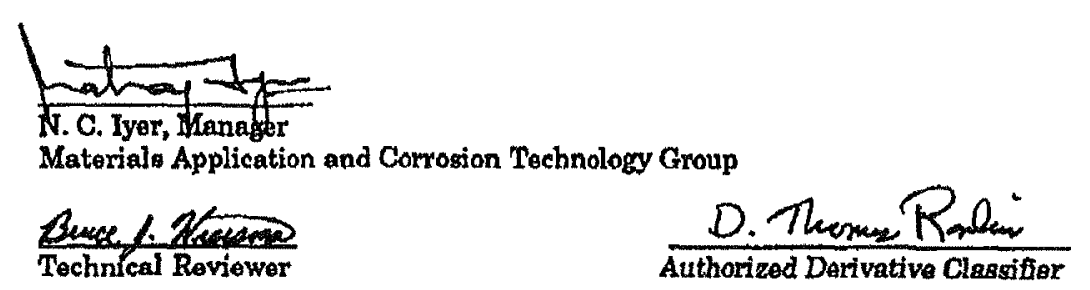

\section{RECOMMENDED NTTRITE LMMTSS FOR CEIORIDEAND SULFATEIN ESP SLURRIES (U)}

\section{SUMMARY}

Two additional nitrite limits are developed and recommended for Extended Sludge Processing slurries. These limits apply to slurries in whist the chloride or suifate concentrations exceed specified percentages of the nitrate concentration.

\section{DISCUSSION}

In a previous report additional nitrite limits were developed and recommended for inclusion in the In-Tank Precipitation (ITP) Operational Safety Requirements. 1 These limits specify nitrite concentrations which prevent pitting corrosion of carbon steel exposed to waste solutions which contain high chloride or sulfate concentrations. Such additional limits cover the conditions in which a specified percentage of the concentration of nitrate, which is normally the principal corrosive anion, is exceeded by the chloride or sulfate concentration. The new limits are based on previously obtained laboratory corrosion data on the corrosivity of simulated washed precipitate solutions. They permit the inhibition of pitting with nitrite additions to the ITP tanks rather than caustic additions to raise the hydroxide level to $>1 \mathrm{M}$.

Nitrite concentrations based on chloride and sulfate can be developed also for Extended Sludge Processing (ESP) operations. The approach to developing these was identical to that followed for the ITP limits. In previously conducted electrochemical corrosion tests, the nitrite concentration which is required to inhibit pitting was established in a simulated fully washed ESP solution with varied chloride or sulfate levels. 2 The fixed concentrations of the various ions in the simulant were those reported in the "Basic 
J. E. Marra

Page 2 of 5

WSRC-TR-94-250

Data Report Defense Waste Processing Facility Sludge Plant, DPST-80-1033, Vol. 2, Rev. $90 "$ except for the nitrate, sulfate, and fluoride concentrations, which were calculated under the assumption of the complete solubility of these species. This assumption yielded, for example, a nitrate concentration in the simulant solution of $0.063 \mathrm{M}$, rather than $0.022 \mathrm{M}$. Pitting susceptibility or immunity was assessed with cyclic potentiodynamic polarization scans on specimens of ASTM A537 Class 1 carbon steel. Testing was conducted at $40^{\circ} \mathrm{C}$ only.

The tests revealed that, as with the ITP test results, the logarithm of the inhibiting nitrite concentration is independent of the logarithm of the corrosive anion below a certain critical value and then linearly dependent upon it above that value. The general form of the linearly dependent relationship is

$$
\log \left[\mathrm{NO}_{2}^{-}\right]=\mathrm{a}+\mathrm{b} * \log [\mathrm{CA}]
$$

where CA stands for any corrosive anion, and $\mathrm{a}$ and $\mathrm{b}$ are constants, which are dependent upon the composition of the simulant under test.

The equation for nitrite to prevent chloride-induced pitting in the washed sludge is

$$
\log \left[\mathrm{NO}_{2}^{-}\right]=2.25+1.34^{*} \log \left[\mathrm{Cl}^{-}\right]
$$

obtained at $40^{\circ} \mathrm{C}$. Equation 2 applies when the chloride concentration exceeds $3 \%$ of the nitrate concentration.

In order to provide a temperature dependence to the nitrite concentration, one can adopt the temperature dependence expressed in the equation developed for the minimum nitrite equation as a function of the nitrate concentration in ESP solutions:

$$
\left[\mathrm{NO}_{2}\right]=0,025 * 10^{0.041 \mathrm{~T}_{*}} *\left[\mathrm{NO}_{3}^{-}-\mathrm{j} 0.98\right.
$$

where $\mathrm{T}$ is in ${ }^{\circ} \mathrm{C} .3^{3}$ Equation 3 was developed from laboratory data obtained at $23,30,40$, 50 , and $60^{\circ} \mathrm{C}$, and is applicable over that range only. Equation 3 incorporates the increase in corrosivity with temperature due to nitrate in ESP solutions. With a change in temperature $\mathrm{T}$ away from $40^{\circ} \mathrm{C}$, the nitrite requirement changes by a factor of

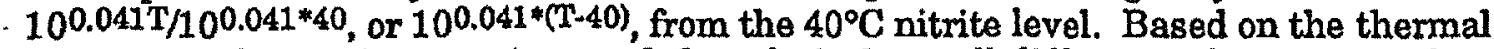
activation of corrosion reactions and the relatively small differences between $40^{\circ} \mathrm{C}$ and temperatures of interest, it is reasonable to apply the same temperature factor to Equation 2. Thus Equation 2 becomes, with the antilogarithmic transformation and the inclusion of the temperature dependence and a safety factor of 1.5 ,

$$
\left[\mathrm{NO}_{2}^{-}\right]=1.5 * 10^{0.041 *(T-40)} * 10^{(2.25+1.34 * \log [\mathrm{Cl}-])}
$$

The equation for the minimum nitrite concentration required to inhibit pitting caused by sulfate is

$$
\log \left[\mathrm{NO}_{2}^{-}\right]=-0.0675+0.835 * \log \left[\mathrm{SO}_{4}\right]
$$

Equation 5 applies when the sulfate concentration exceeds $30 \%$ of the nitrate 
J. E. Marra

WSRC-TR-94-250

Page 3 of 5

concentration. After the antilogarithmic transformation; the same temperature dependence and safety factor may be introduced to the nitrite-sulfate relationship to give

$$
\left[\mathrm{NO}_{2}=1.5 * 10^{0.041 *(\mathrm{~T}-40)} * 10^{(0.067 \mathrm{6}}+0.835 * \log \left(\mathrm{SO}_{4}=\mathrm{]}\right)\right.
$$

It has been shown that corrosive anions act independently, nọt additively. ${ }^{4}$ Pitting corrosion is prevented, when the highest nitrite concentration required by any corrosive anion is present in the waste. Thus the minimum nitrite limit is the highest of the three nitrite concentrations calculated from the nitrate (see Reference 3 ), chloride, or sulfate concentration.

\section{RECOMMENDED ESP PROCESS REQUTREMENT LIMTIS}

Equations 4 and 6 may be inserted as additional limits in the Requirements for Corrosion Control of Waste Tank Contents in the ESP Process Requirements. The new limits may take the form

\begin{tabular}{|c|c|c|c|c|}
\hline Applicability & Parameter & Minimum & Maximum & Units \\
\hline \multirow{2}{*}{$\begin{array}{l}\left.\mathrm{NO}_{3}{ }^{-}\right] \leq 1.0 \text { Molar } \\
\left.\text { and }\left[\mathrm{OH}^{-}\right]<1.0 \mathrm{Molar}^{-}<1.03 \mathrm{NO}_{3}^{-}\right] \\
\text {and }[\mathrm{Cl}-]>0.03\end{array}$} & {$\left[\mathrm{NO}_{2}{ }^{*}\right]$} & A & - & Molar \\
\hline & $\begin{array}{l}\text { Temperature } \\
\text { pH }\end{array}$ & 10.3 & 6 & $\begin{array}{l}{ }^{\circ} \mathrm{C} \\
\text { pH units }\end{array}$ \\
\hline
\end{tabular}

where $A=1.5 * 10^{0.041 *(T-40)} * 10^{(2.25+1.34 * \log [\mathrm{Cl}-])}$

$\left[\mathrm{NO}_{3}{ }^{-}\right] \leq 1.0$ Molar

and $\left[\mathrm{OH}^{-}\right]<1.0$ Molar

and $\left[\mathrm{SO}_{4}=\right]>0.3\left[\mathrm{NO}_{3}{ }^{-}\right]$

$$
\left[\mathrm{NO}_{2}^{-}\right]
$$

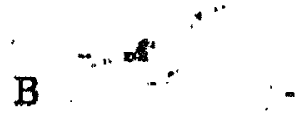

6 10.3
Molar

$\begin{array}{llll}\text { Temperature } & 0.3 & 60 & { }^{\circ} \mathrm{C} \\ \text { pH } & 10.3 & \text { pH units }\end{array}$

where $\mathrm{B}=1.5 * 10^{0.041 *(\mathrm{~T}-40)} * 10^{\left(0.0675+0.835 * \log \left[\mathrm{SO}_{4}=\right]\right)}$

For these limits the $\mathrm{pH}$ has been changed to 10.3, so that the limits are valid at any ESP dilution.

\section{REFERENCES}

1. P. E. Zapp, "Effect of Chloride and Sulfate on Nitrite Requirements for ITP (U)," WSRC-TR-94-0217, May 5, 1994.

2. J. W. Congdon and J. S. Lozier, "Inhibition of Washed Sludge with Sodium Nitrite," DPST-87-379, April 71987. 
J. E. Marra

WSRĆ-TR-94-250 Page 4 of 5

3. P. E. Zapp, "Effect of Temperature on the Nitrite Requirement to Inhibit Washed Sludge (U)," WSRC-TR-90-292, September 18, 1990.

4. J. W. Congdon, "Inhibition of Nuclear Waste Solutions Containing Multiple Aggressive Anions," Materials Performance 22, 34 (1988). 


\subsection{Supporting Documentation for RPP-ASMT-53793, Section 4.1.8, Tank AY-102 Ultrasonic Testing}


The primary wall UT measurements for Tank AY-102 from FY2007 were reviewed by the Level III NDE to look for the amount of un-recorded pitting in the tank. These pits became a concern when the chemistry evaluation of the Tank AY-102 showed the presence of historic waste composition that could have led to pitting. The UT protocol for recording the presence of pits could have masked the presence of pits caused by these historic waste compositions. The data from FY2007 re-evaluated was to look for pits at a depth of greater than 40 mils and to see whether the lower levels of the tank (especially the bottom knuckle) had an increased pit population.

During the evaluation of the chemistry in Tank AY-102, the current composition of the waste doesn't show a propensity for corrosion. However, since the current corrosion control limits were adopted in 1984, there may have been waste in the tank that would show a propensity for corrosion. If a layer of this waste exists in the tank, the addition of higher heat waste in 1998 may have led to conditions in which corrosion could have occurred. There is uncertainty as to the presence of this layer because the core sampling system is kept from sampling the very bottom of the tank because of concerns of the drill string damaging the primary tank.

The discussion of this potential layer is found in Chemistry, Section 4.1.4. From the Chemistry Summary Section 4.1.4.5 on page 4-26 of RPP-ASMT-53793:

Although there were opportunities for corrosion in the early operation of the tank, there are no definite indications of a high propensity for corrosion in Tank AY-102 because of its operating history. One scenario that should be considered is that remnants of incompletely inhibited nitrate-rich interstitial liquids that were present in the low temperature solids layer in Interval 2 remained at the bottom of the tank after 20 years of storage. It is conceivable that pitting and SCC occurred on the bottom of the tank when the tank temperature increased significantly after the addition of solid waste from Tank C-106 in 1999.

However, the concern remains that the cores have not sampled the waste at the actual bottom of the tank or detected elements of its lateral heterogeneity. As discussed above, the interstitial liquid at the bottom of the tank may have retained interstitial liquids with nitrate ion that was deposited in Interval 2. The solids that deposited in Interval 2 traversed at least three different supernatant layers. The first and third supernatant layers, through which the solids traveled, had low concentrations of nitrite ion and a low nitrite ion/nitrate ion concentration. The supernatant layer that was present for the most of Interval 2 had about $2 M$ hydroxide ion and nitrite ion with about $3 M$ nitrate ion. It is very difficult to judge the composition of the interstitial liquid that existed at the bottom of the tank 15 years later in 1999 when it experienced the large increase in temperature. However, it is well established that pitting and SCC occur much more readily at higher temperatures, and the possibility that pitting and SCC occurred as a consequence of the addition of the hot waste cannot be dismissed on the basis of the information that is now available. Any remaining tensile stresses from bulging in the Tank AY-102 bottom 
liner following stress relieving during construction would have also increased the propensity for SCC initiation.

The presence of un-recorded pits is due to the reporting of pits starting at 25 percent of the wall thickness. The value is half the action level of the 50 percent wall thickness developed by the DOE Tank Structural Integrity Panel. To further capture the presence of pits, WRPS used a ten percent criterion to identify un-reportable pits. The concern was raised the protocol could mask the presence of pits below this lower level and should this population show an increase with depth it could be an indication that the historic waste could have led to a reduced integrity of the tank.

The discussion of the UT results is found in Section 4.1.8. From the Comparison from Section 4.1.8.3 for the UT of Tank AY-102 on page 4-44:

Of the 23 areas of greater than ten percent wall reduction found in FY2007, 18 were identified as non-reportable pits. In the FY2007 inspection, the Level III NDE inspector reported pitting on plates 3, 4, and 5 whereas the FY1999 inspector did not. In FY1999, Level III NDE inspector reported "laminations detected throughout plate" for Plate 3 with inspector's notes suggesting potential existence of pitting. The distinction between laminations and the presence of pitting could be attributed to equipment resolution and wall contact of the UT system. In FY2007, the Level III NDE only reported non-reportable pits as plate minima, but his notes indicated the presence of other non-reportable pits.

As such, WRPS contacted the Level III NDE inspector to review scans at a constant 40 mils off-set from the local average of the plate. In principle this review would have been conducted at other off-sets, but the initial review showed no increase in the pit population with depth so these additional reviews weren't conducted.

Though the Level III NDE looked at over 70 scans to come to his conclusion about the absence of an increase in the pitting population only nine of those scans are presented here as examples. The tables list the sample scans. The scans are from Riser 88 and Riser 89.

Riser 88 Ultrasonic Testing Scans from Fiscal Year 2007

\begin{tabular}{|c|c|c|l|}
\hline $\begin{array}{c}\text { Scan } \\
\text { Number }\end{array}$ & Location & $\begin{array}{c}\text { Nominal Thickness } \\
\text { of the Plate } \\
\text { (inches) }\end{array}$ & Comment \\
\hline 1 & Plate 4 & 0.500 & Moderate pitting \\
\hline 2 & Plate 4 & 0.500 & Moderate pitting \\
\hline 3 & Plate 5 & 0.875 & Light pitting \\
\hline 4 & Plate 5 & 0.875 & Light pitting \\
\hline
\end{tabular}


Riser 89 Ultrasonic Testing Scans from Fiscal Year 2007

\begin{tabular}{|c|c|c|l|}
\hline $\begin{array}{c}\text { Scan } \\
\text { Number }\end{array}$ & Location & $\begin{array}{c}\text { Nominal Thickness } \\
\text { of the Plate } \\
\text { (inches) }\end{array}$ & Comment \\
\hline 1 & Plate 4 & 0.500 & Light pitting \\
\hline 2 & Plate 5 & 0.875 & Moderate pitting \\
\hline 3 & Plate 5 & 0.875 & Moderate pitting \\
\hline 4 & Plate 5 & 0.875 & Light pitting \\
\hline 5 & Knuckle & 0.875 & Light pitting \\
\hline
\end{tabular}

The determination of a pit or general thinning is determined by the Level III NDE, but as a general guide for these scans the color pixels represent the average thickness, the pits, and the raised areas on the plate. The average thickness of the plate is reflected the gray and light purple coloration. Pits are indicated by dark purple pixels on the scans. Raised areas are shown by green, red, and yellow pixels. The causes for raised areas may be due to the presence of material not removed in cleaning of the scanning surface or lift off of the transducer from the surface. 
Printed on 2012-10-16 at 14:26: HP CLJ 3600

T-scan pres.1 $<3,4,5>$ of Job : Vert.Wall/Plate4/88

End Data

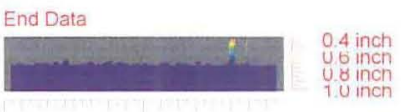

Images : 3

\section{set@.040"less than nominal}

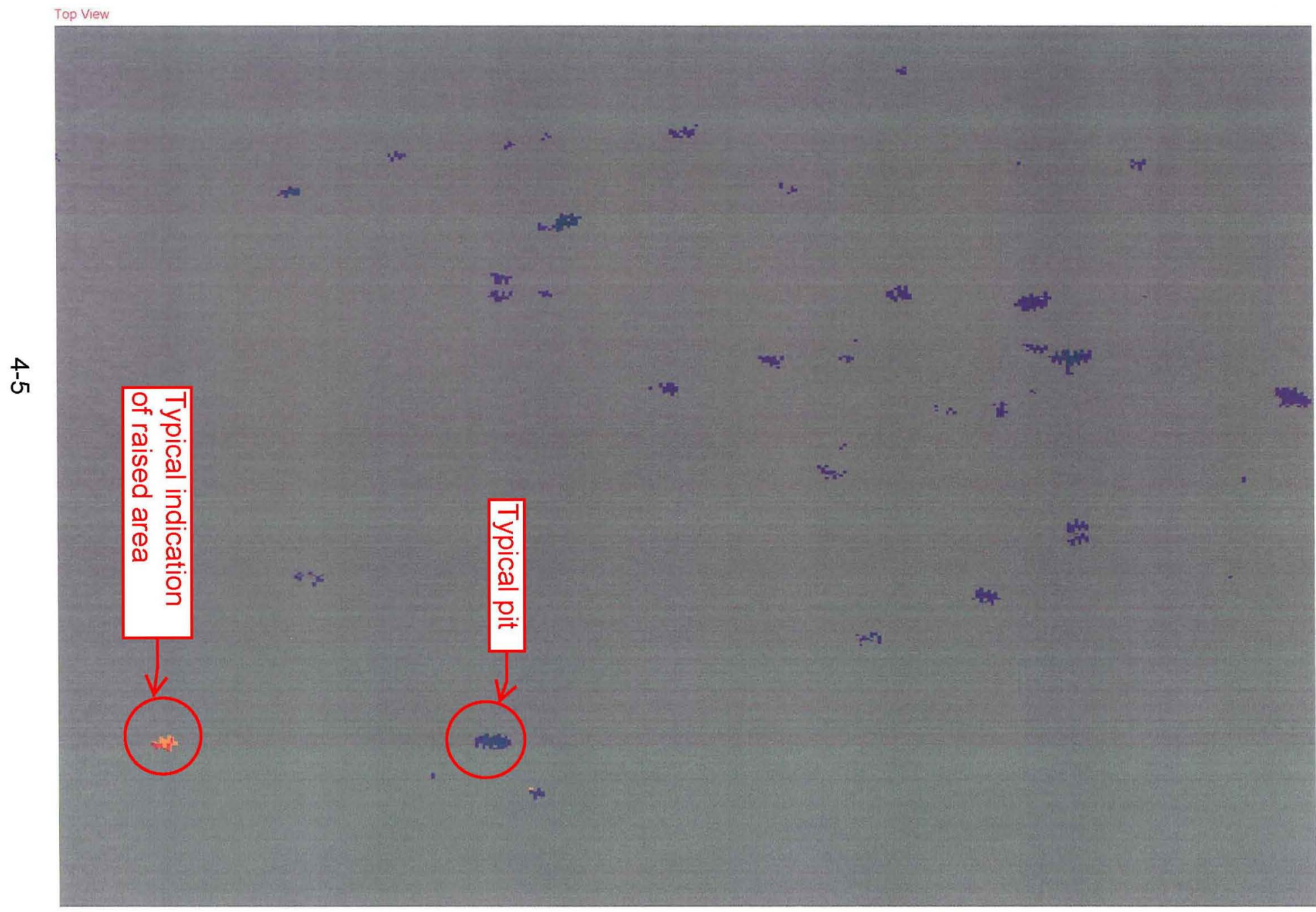


Printed on 2012-10-16 at 14:33: HP CLJ 3600

T-scan pres. $1<3,4,5>$ of Job : Vert.Wall/2nd/Plate $4 / 88$

Vert.Wall/2nd/Plate $4 / 88$

jsp

AY-102-2

End Data

0.6 inch
0.8 inch
3: T-scan, Images, t-scan data1, 11/17/2006 15:19

4: T-scan, Images, t-scan data2, 11/17/2006 15:19

5: T-scan, Images, t-scan data3, 11/17/2006 15:19

set@.040" Lessthannominal
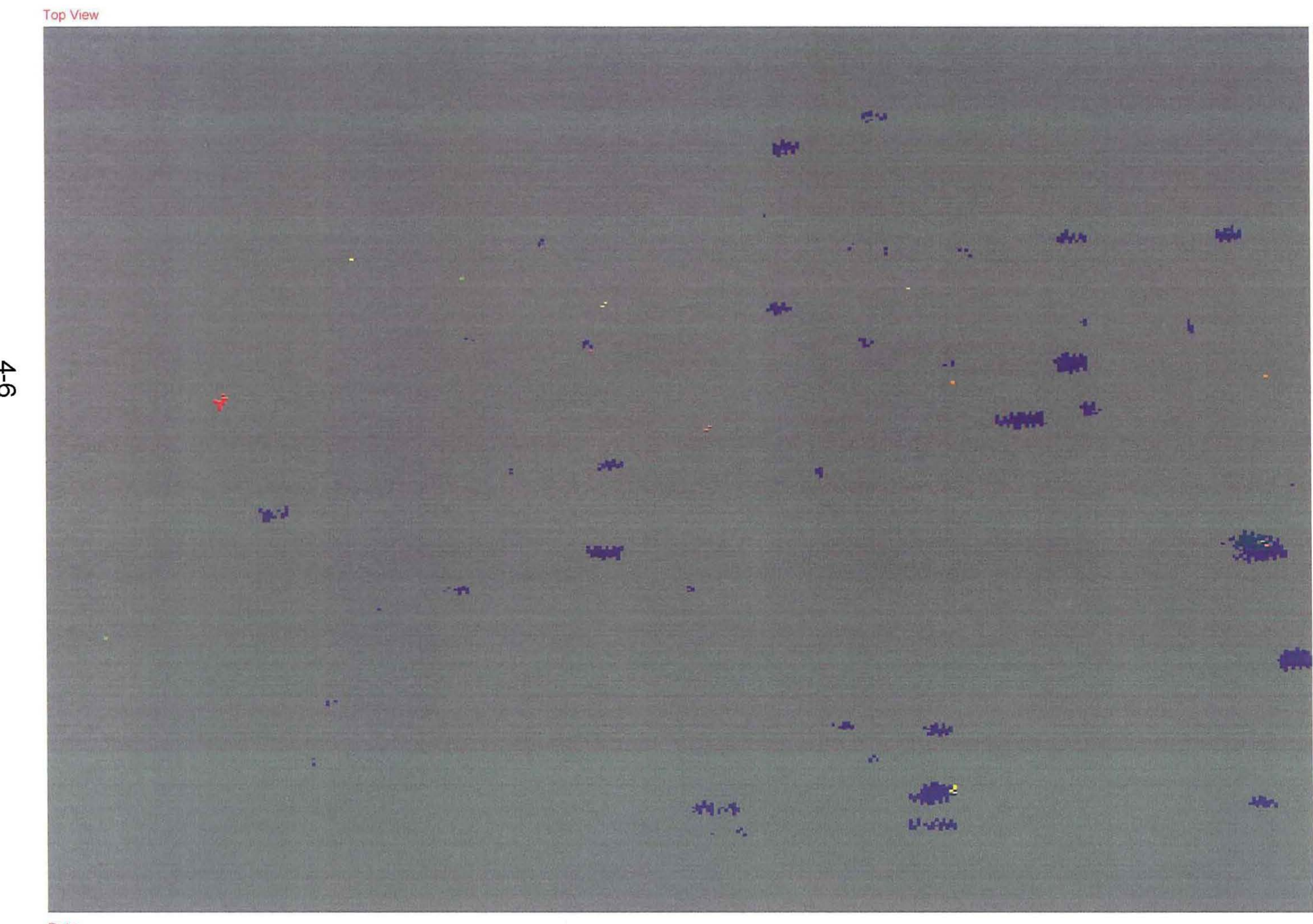

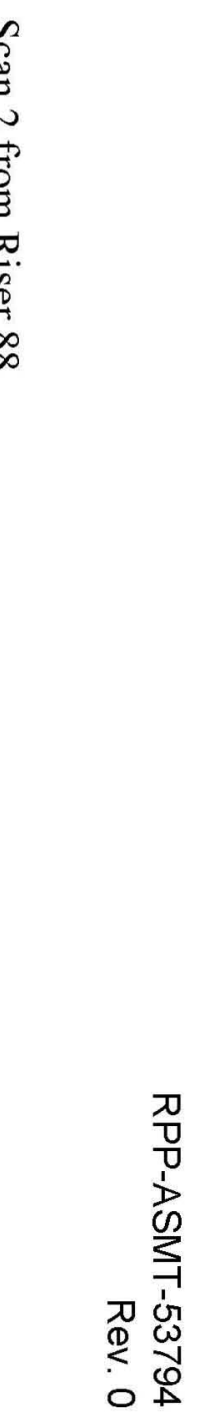


Printed on 2012-10-16 at 14:51: HP CLJ 3600

T-scan pres. $1<3,4,5>$ of Job : Vert.Wall/2nd/Plate5/88

Vert.Wall/2nd/Plate5/88

3: T-scan, Images, t-scan data1, 11/20/2006 13:11

4: T-scan, Images, t-scan data2, 11/20/2006 13:11

AY-102-2

5: T-scan, Images, t-scan data3, 11/20/2006 13:11

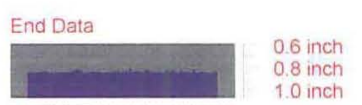

Images : 34

$$
\text { set } e .040^{\prime \prime} \text { less than nominal }
$$

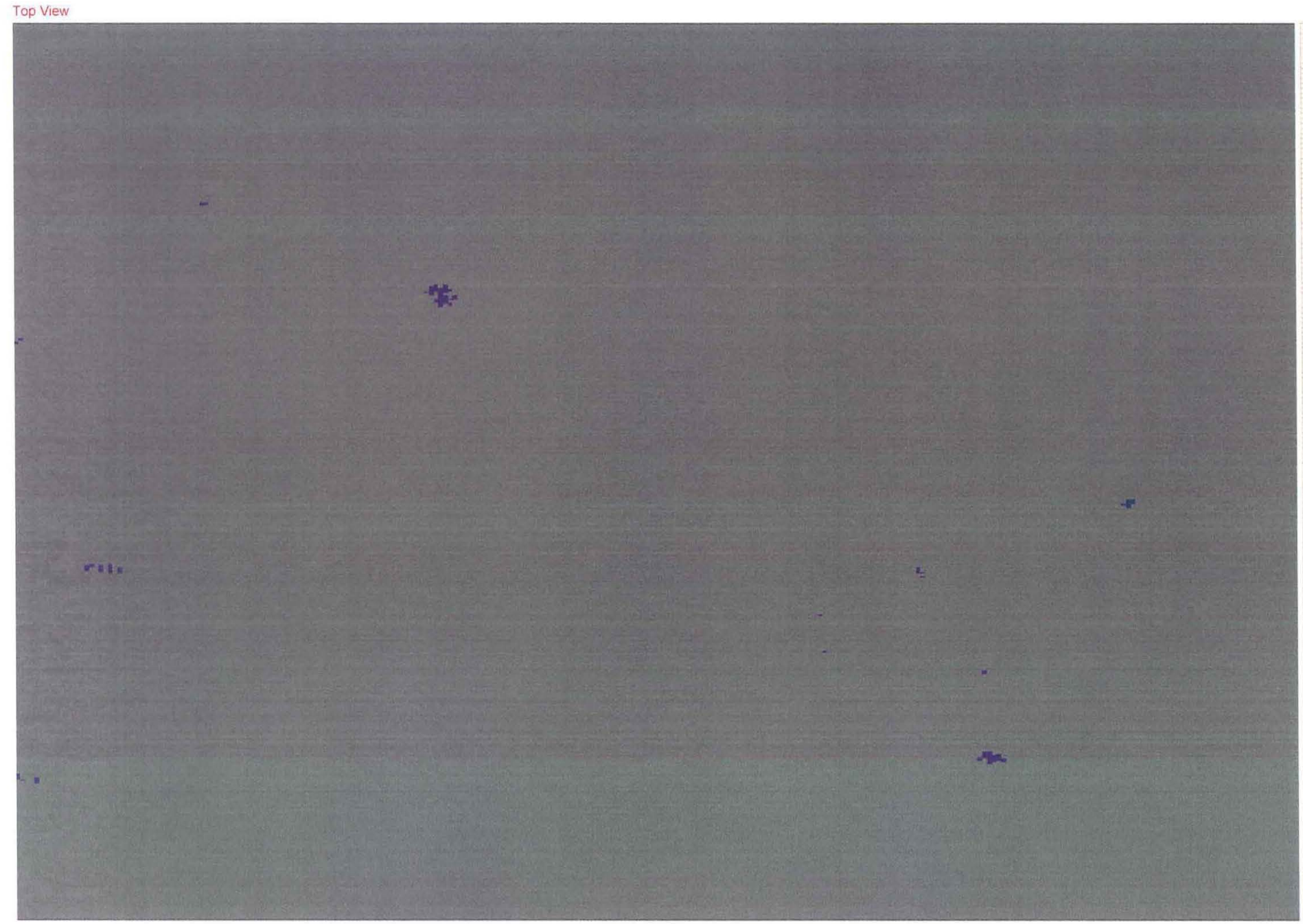



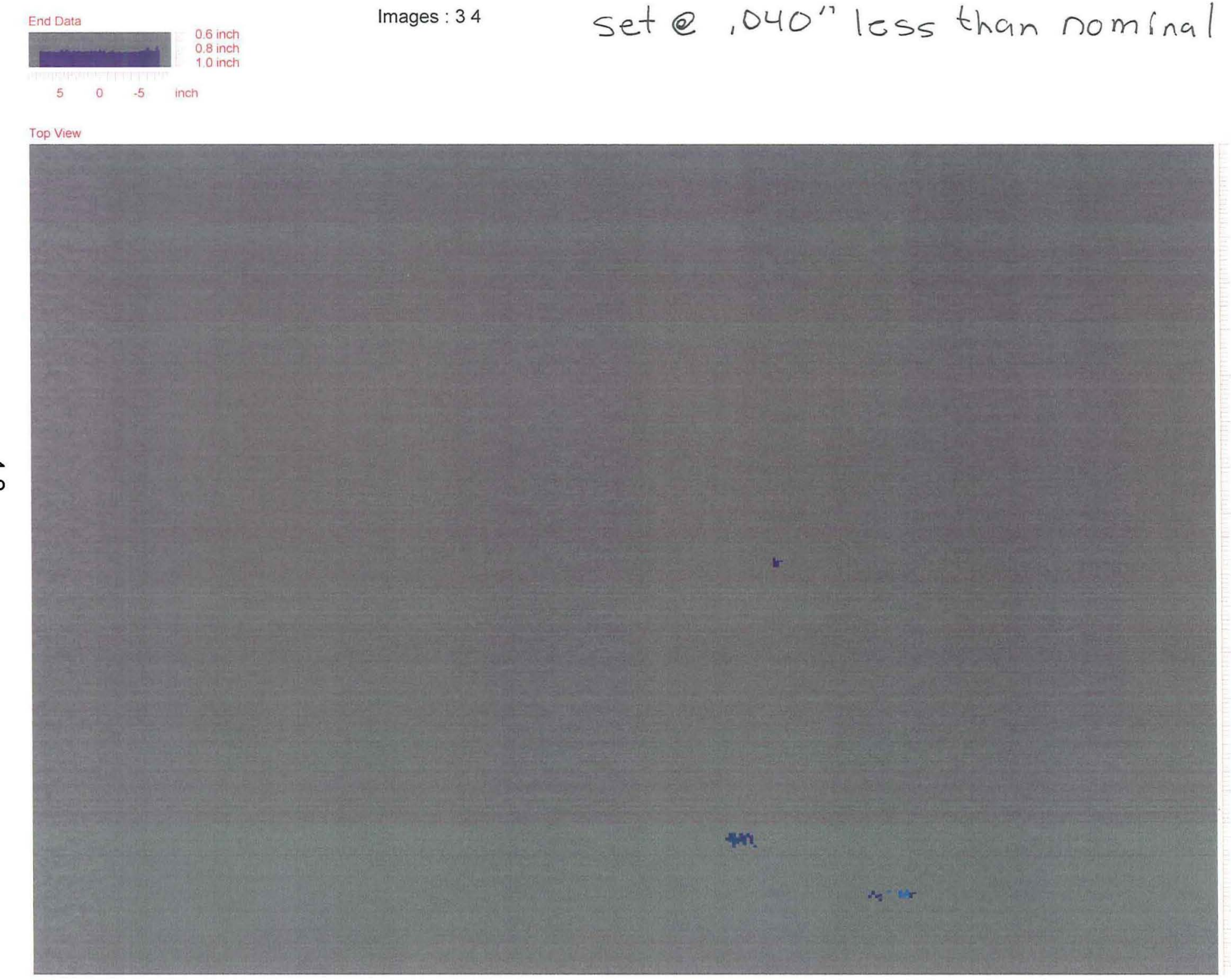
Printed on 2012-10-17 at 6:08: HP CLJ 3600

T-scan pres. $1<3,4,5>$ of Job : Vert.Wall/2nd/Plate3/89 Vert.Wall/2nd/Plate/89

jsp

ay -102

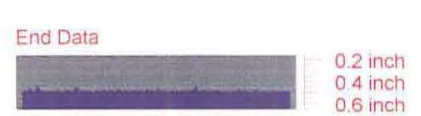

Images : 3
3: T-scan, Images, t-scan data1, 10/19/2006 08:38

4: T-scan, Images, t-scan data2, 10/19/2006 08:38

5: T-scan, Images, t-scan data3, 10/19/2006 08:38
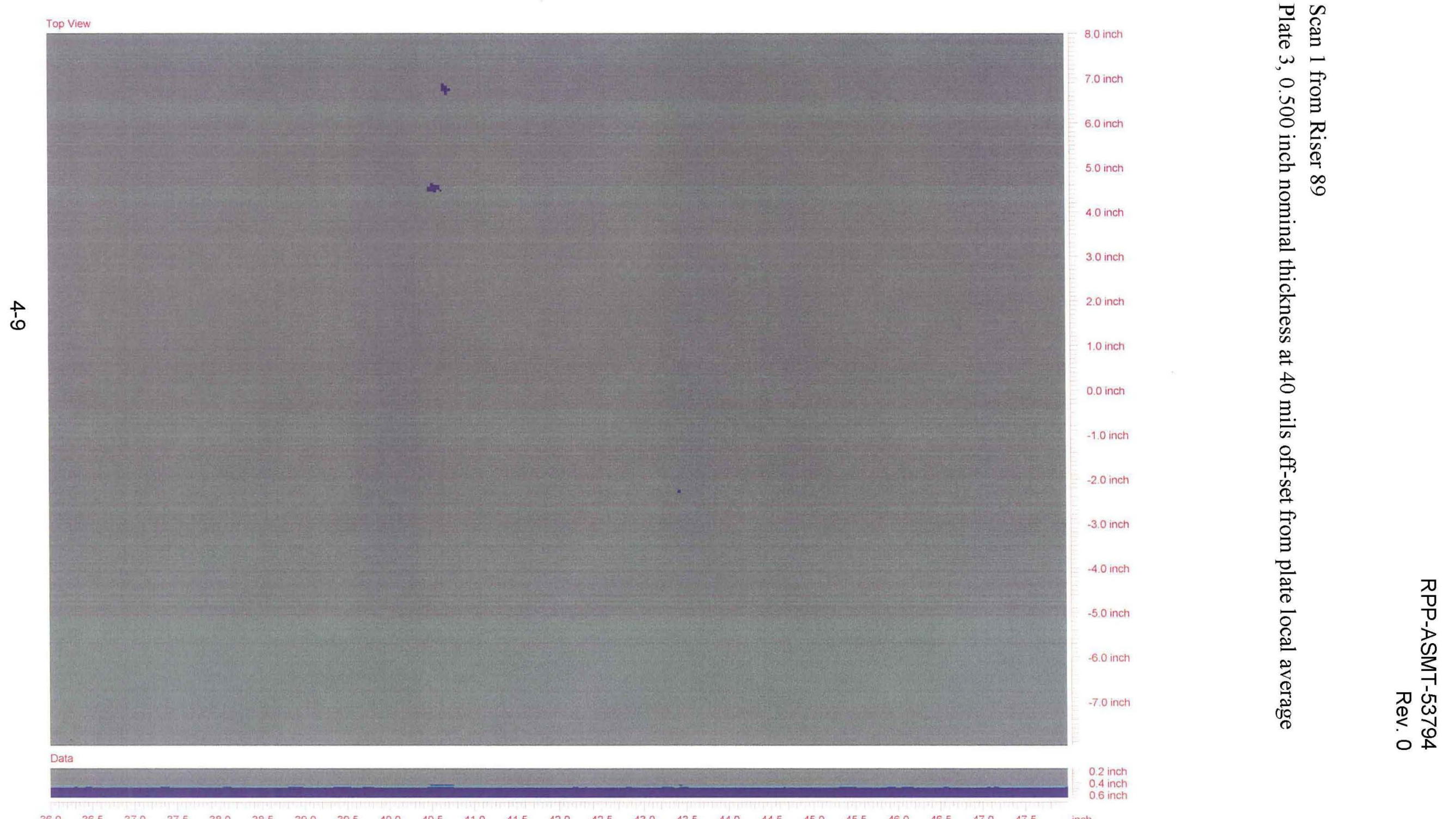

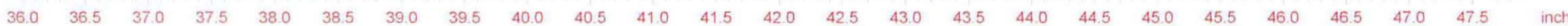


Printed on 2012-10-16 at 15:36: HP CLJ 3600

T-scan pres. $1<3,4,5>$ of Job : Vert.Wall/Plate5/89.

Vert.Wall/Plate

3: T-scan, Images, t-scan data1, 10/23/2006 16:00

WDP

4: T-scan, Images, t-scan data2, 10/23/2006 16:00

102-AY

riser 89

5: T-scan, Images, t-scan data3, 10/23/2006 16:00

End Data

Images : 3

set e. 040" less than nominal (.875")

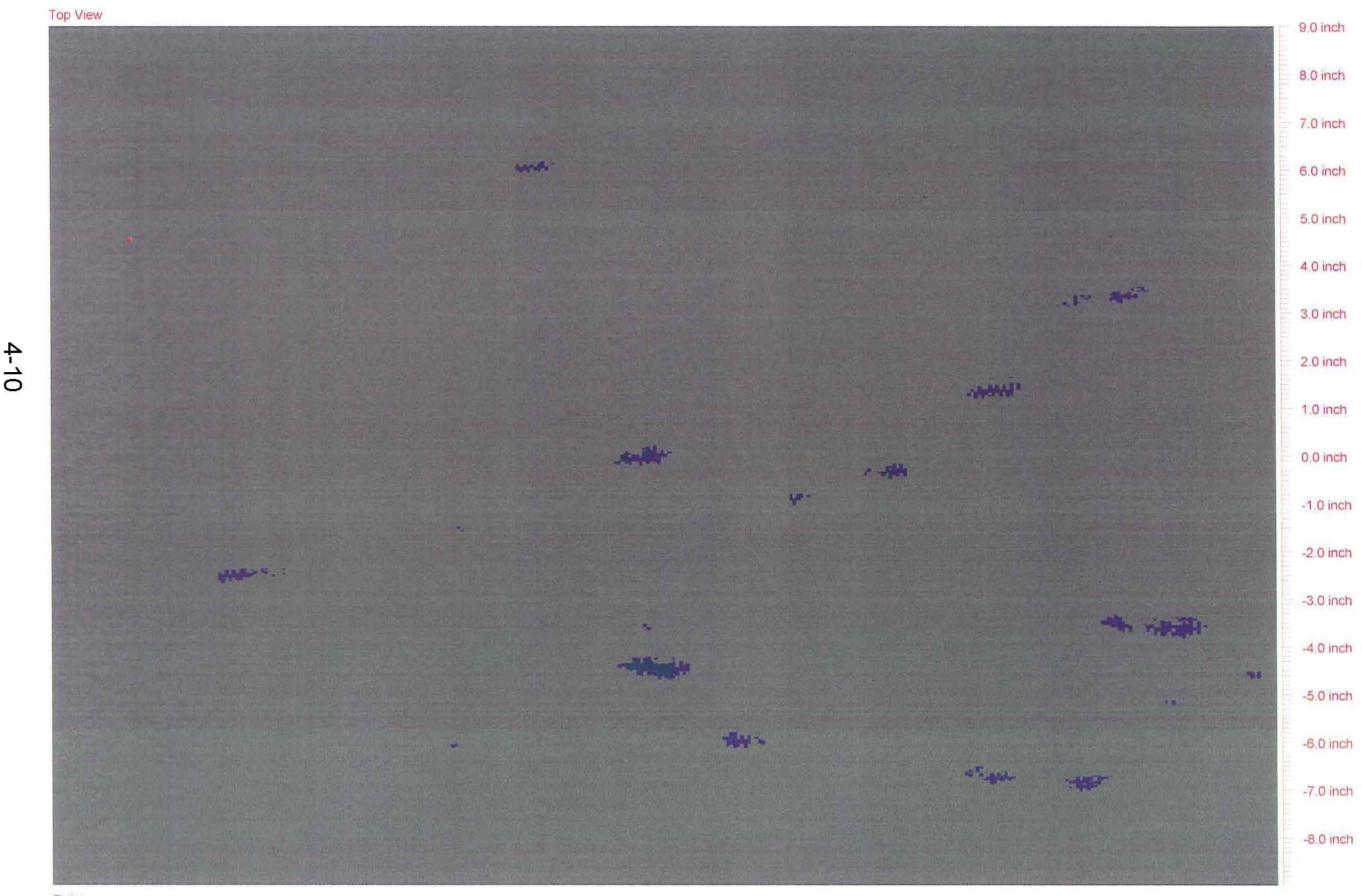


Printed on 2012-10-16 at 15:51: HP CLJ 3600

T-scan pres. $1<3,4,5>$ of Job : Vert.Wall/2nd/Plate5/89 Vert.Wall/Plate

WDP

102-AY

riser 89

End Data

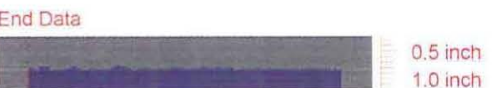

3: T-scan, Images, t-scan data1, 10/23/2006 18:41

4: T-scan, Images, t-scan data2, 10/23/2006 18:41

5: T-scan, Images, t-scan data3, 10/23/2006 18:41

Images : 3

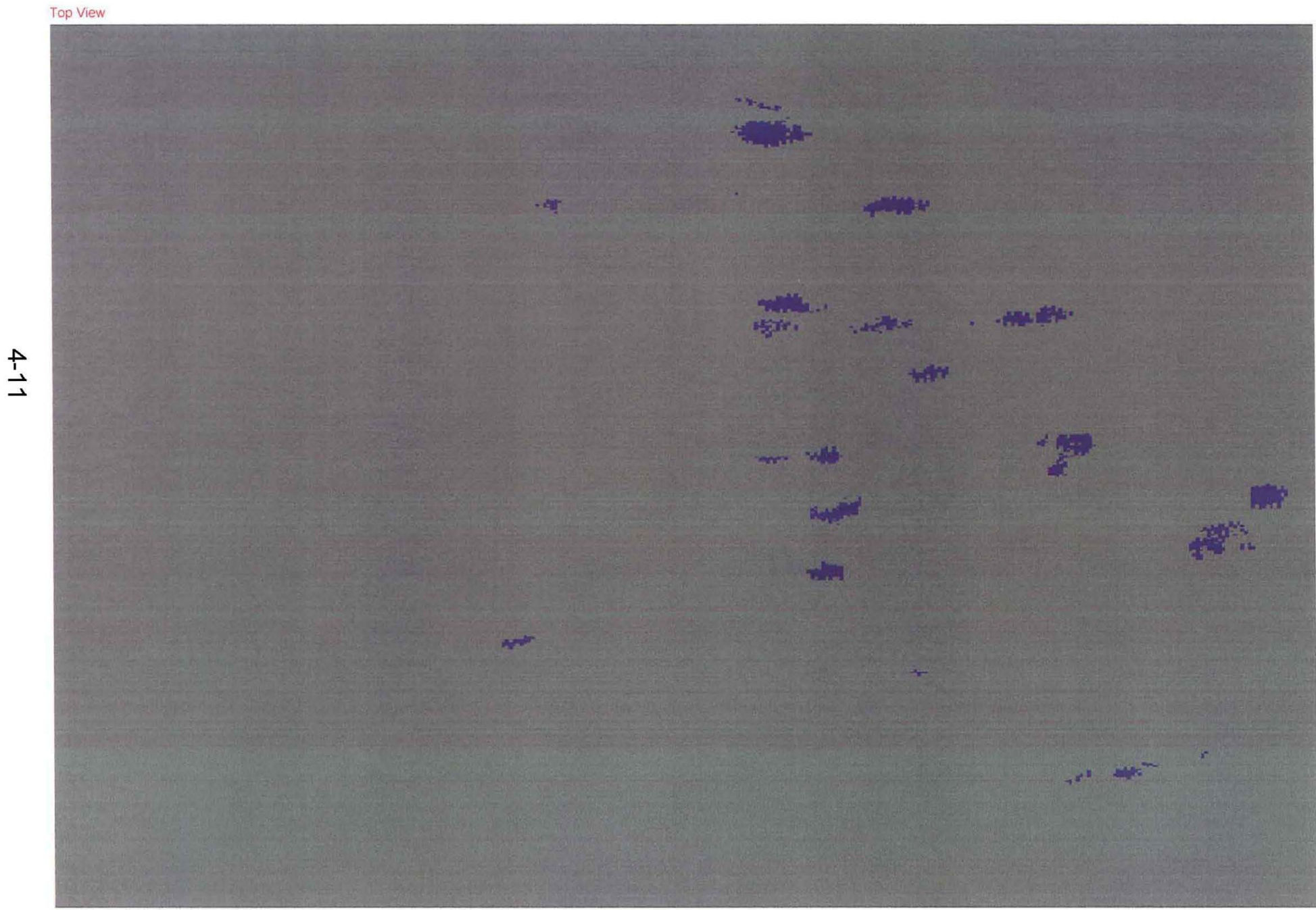


Printed on 2012-10-16 at 15:50: HP CLJ 3600

T-scan pres. $1<3,4,5>$ of Job : Vert.Wall/2nd/Plate5/89.

Vert.Wall/Plate

WDP

102-AY

riser 89

3: T-scan, Images, t-scan data1, 10/23/2006 18:41

4: T-scan, Images, t-scan data2, 10/23/2006 18:41

5: T-scan, Images, t-scan data3, 10/23/2006 18:41

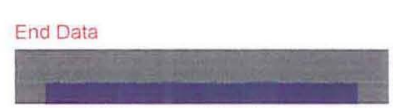

Images : 3

sete. $040^{\prime \prime}$ less than nominal $\left(.875^{\prime \prime}\right)$

Top View

(n)

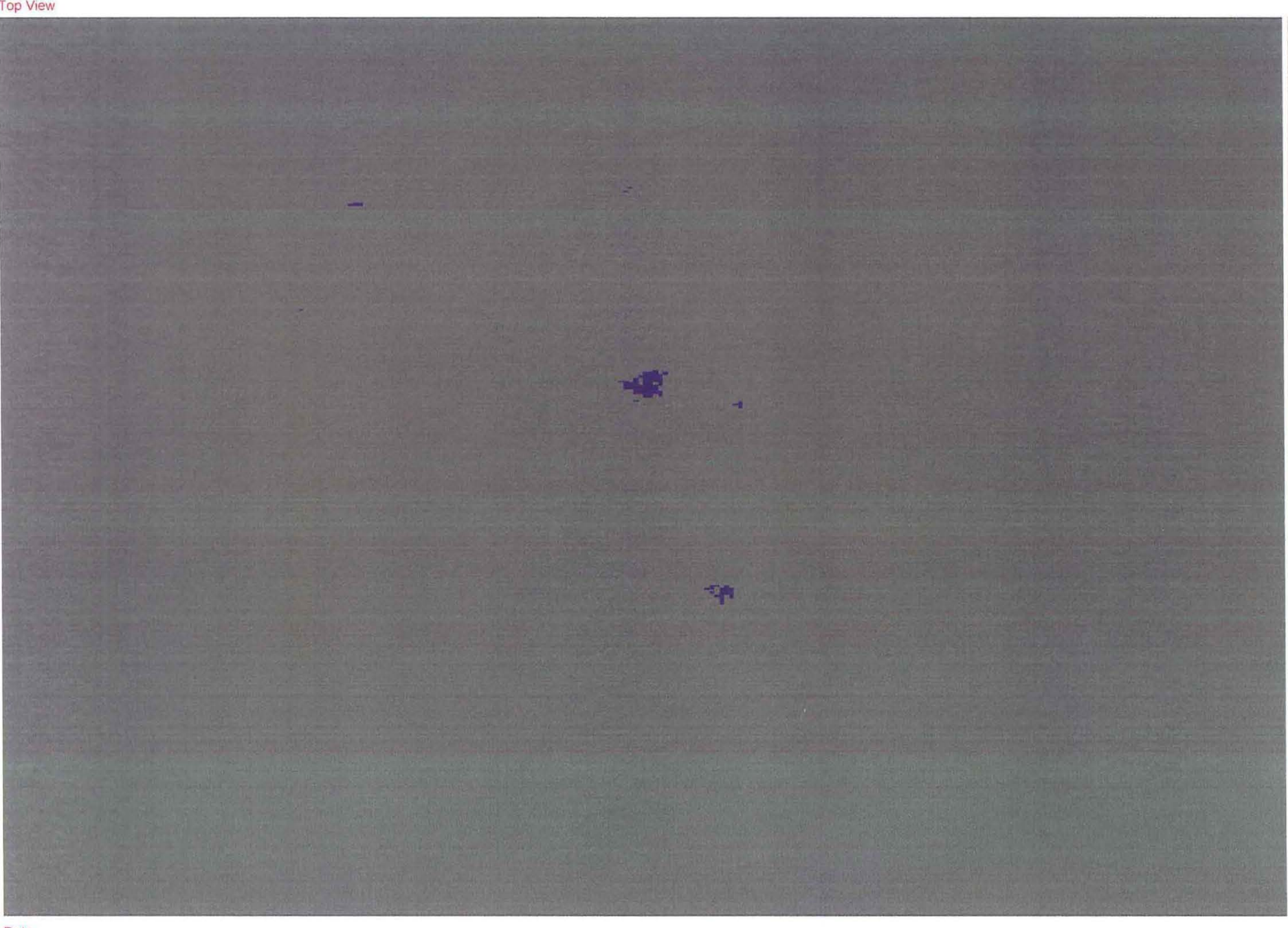

h 
Printed on 2012-10-17 at 15:17: HP CLJ 3600

T-scan pres. $1<1,2,3>$ of Job: Knuckle.

Knuckle

1: T-scan, Images, t-scan data1, 11/9/2006 08:33

WHN/LAS

2: T-scan, Images, t-scan data2, 11/9/2006 08:33

AY-102

3: T-scan, Images, t-scan data3, 11/9/2006 08:33

Riser\#89

End Data

Images : 34

set e. $040^{\prime \prime}$ less than nominal $\left(.875^{\prime \prime}\right)$

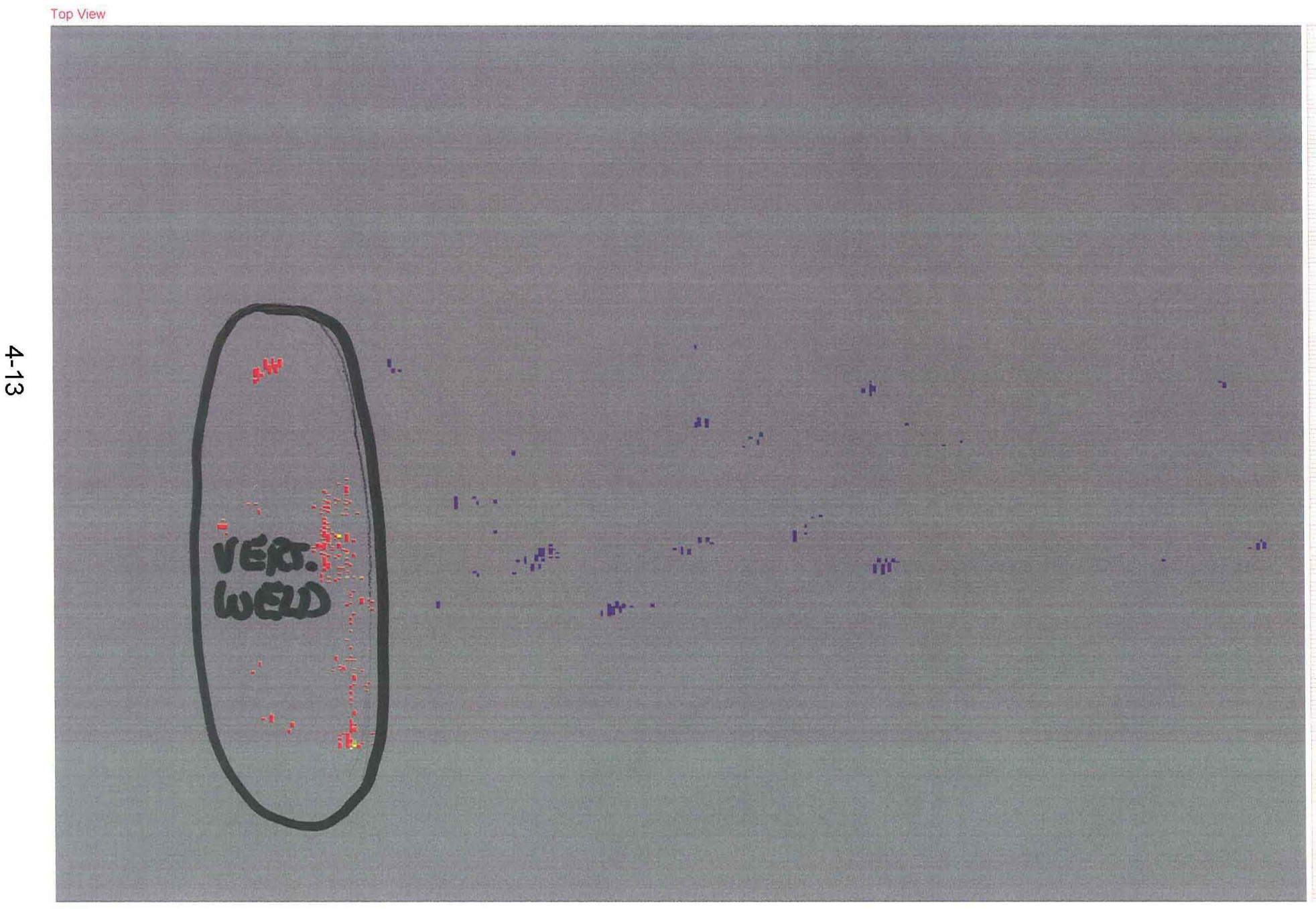




\subsection{Preliminary Annulus Sample Results for RPP-ASMT-53793, Section 4.2.7, Samples 2012}

5.1 Riser 90-August 2012 Sample

5.2 Riser 83-September 2012 Sample

5.3 Riser 90- October 2012 Samples. $5-52$ 
Rev. 0

5.1 Riser 90-August 2012 Sample 
From:

Sent:

To:

Subject:
Venetz, Theodore J

Tuesday, September 25, 2012 4:04 PM

Rosenkrance, Chelsea $\mathrm{L}$

FW: AY102 sample update

From: Boomer, Kayle D

Sent: Monday, August 13, 2012 2:46 PM

To: Venetz, Theodore J; Engeman, Jason $\mathrm{K}$

Subject: FW: AY102 sample update

From: Rice, Andrew D

Sent: Monday, August 13, 2012 2:01 PM

To: McKinney, Steve G; Washenfelder, Dennis J; Boomer, Kayle D; Levy, Gregery

Cc: Renberger, Duane L; Prilucik, John R; Johnson, Jo M; Ritenour, Gerald P; Hansen, Daniel R; Watts, Heather D;

Anderson, Brian P; Noyes, Gary W

Subject: RE: AY102 sample update

Appended below are the preliminary results for the AY-102 Annulus sample collected and delivered to the 222-S laboratory on Friday, 8/10/2012.

These results represent the amount of each nuclide that could be acid leached from one portion of the duct tape sample.

\begin{tabular}{|l|c|c|l|}
\hline \multicolumn{1}{|c|}{ Nuclide } & Result each $(\mu \mathrm{Ci})$ & MDA $(\mu \mathrm{Ci})$ & \multicolumn{1}{c|}{ Comments } \\
\hline Cs-137 & $3.9 \mathrm{E}+00$ & $9.8 \mathrm{E}-04$ & Gamma spectroscopy \\
\hline Sr-90 & $1.0 \mathrm{E}-01$ & $4.1 \mathrm{E}-03$ & Separation and beta count \\
\hline Pu-239/240 & $4.1 \mathrm{E}-05$ & $2.1 \mathrm{E}-05$ & Separation and alpha spectroscopy \\
\hline Am-241 & $1.6 \mathrm{E}-04$ & $8.3 \mathrm{E}-06$ & Separation and alpha spectroscopy \\
\hline
\end{tabular}

No isotopes of curium were detected.

It should be observed that the Pu/Am results are near the detection limit, and therefore will lack precision. It may be possible to improve these results by analyzing a larger aliquot of digest.

Please note that this is preliminary data and could change upon further review.

Let me know if you have any questions.

Andy Rice

Radiochemistry Manager 222-S

509.372.2057

509.551 .8401 
From: McKinney, Steve $\mathrm{G}$

Sent: Saturday, August 11, 2012 12:07 PM

To: Washenfelder, Dennis J; Boomer, Kayle D

Cc: Renberger, Duane L; Prilucik, John R; Johnson, Jo M; Rice, Andrew D; Ritenour, Gerald P

Subject: AY102 sample update

Just a heads up on where ATL is - Andy Rice will send out a more detailed summary later, once he is out of the lab. The AY102 annulus sample was broken down this morning. Based on appearance, it was decided to remove the doublesided tape along with the sample and not try to scrape sample off the tape (ATL took photographs). The tape and sample were removed from the weight and was then divided into four sections. The section with the least amount of plastic adhering to the tape was chosen for digest. This section was digested (chemist noted slight fizzing upon addition of acid) and by appearance, all sample material dissolved off the tape. GEA prep will be completed today, radiochemical separations and counting are scheduled for tomorrow and tomorrow night. We expect data, as planned, by Monday. Added observation - there was a towel in with the sample that appeared to have been used to wipe down the cable as the sample was withdrawn through the riser. This towel also was contaminated but at this time, nothing has been done with it.

Thanks. 


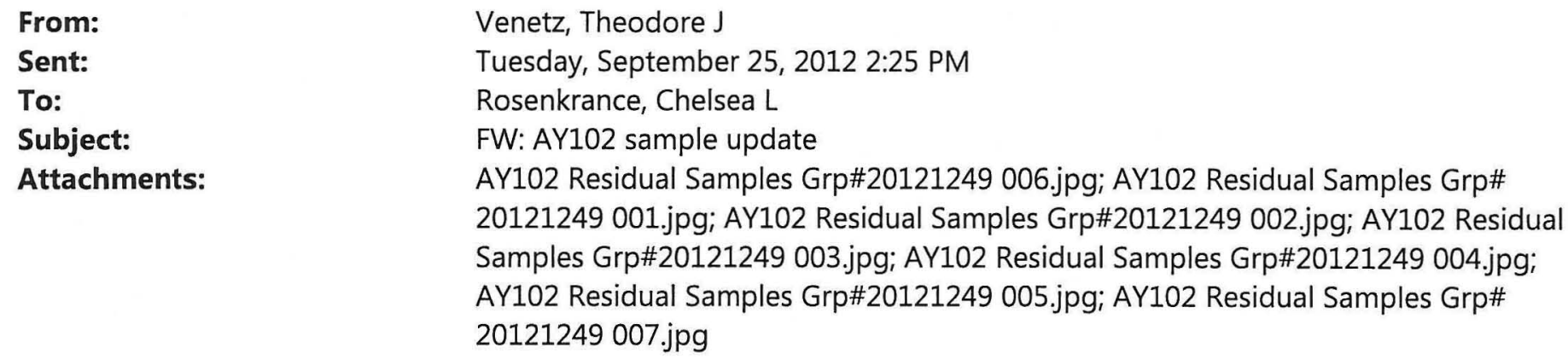

From: Boomer, Kayle D

Sent: Monday, August 13, 2012 7:34 AM

To: Venetz, Theodore ]

Subject: FW: AY102 sample update

From: Rice, Andrew D

Sent: Saturday, August 11, 2012 1:29 PM

To: McKinney, Steve G; Washenfelder, Dennis J; Boomer, Kayle D

Cc: Renberger, Duane L; Prilucik, John R; Johnson, Jo M; Ritenour, Gerald P; Hansen, Daniel R

Subject: RE: AY102 sample update

Steve did a good job of summarizing what happened, I will add the photos and a few details. The photos will put you in email jail, but I wanted the detail to remain.

A masslin-type cloth was included with the "weight and tape" sample. This cloth was contaminated and was saved for future analysis, if desired.

The tape did a great job of trapping the particulate matter, so it was decided to digest the tape itself. Most of the particulates appeared to be rust, with a few interestingly colored flecks interspersed.

Once we had removed the tape from the weight, the tape was cut into 4 sections. Based on appearance and dose rates, the tape surrounding the steel weight was fairly homogeneous, so the section analyzed should be reasonably representative of the whole. The other sections have been saved for future analysis, if needed.

Duct tape is not an ideal analytical substrate, so the digest was performed so as to minimize possible matrix effects from the tape while removing as much contamination as possible. This appeared to be successful.

Separations and counting will occur Sunday, we plan on providing preliminary results by Monday, 8/13.

Let me know if I can be of additional assistance.

Andy 
From: McKinney, Steve G

Sent: Saturday, August 11, 2012 12:07 PM

To: Washenfelder, Dennis J; Boomer, Kayle D

Cc: Renberger, Duane L; Prilucik, John R; Johnson, Jo M; Rice, Andrew D; Ritenour, Gerald P

Subject: AY102 sample update

Just a heads up on where ATL is - Andy Rice will send out a more detailed summary later, once he is out of the lab. The AY102 annulus sample was broken down this morning. Based on appearance, it was decided to remove the doublesided tape along with the sample and not try to scrape sample off the tape (ATL took photographs). The tape and sample were removed from the weight and was then divided into four sections. The section with the least amount of plastic adhering to the tape was chosen for digest. This section was digested (chemist noted slight fizzing upon addition of acid) and by appearance, all sample material dissolved off the tape. GEA prep will be completed today, radiochemical separations and counting are scheduled for tomorrow and tomorrow night. We expect data, as planned, by Monday. Added observation - there was a towel in with the sample that appeared to have been used to wipe down the cable as the sample was withdrawn through the riser. This towel also was contaminated but at this time, nothing has been done with it.

Thanks. 


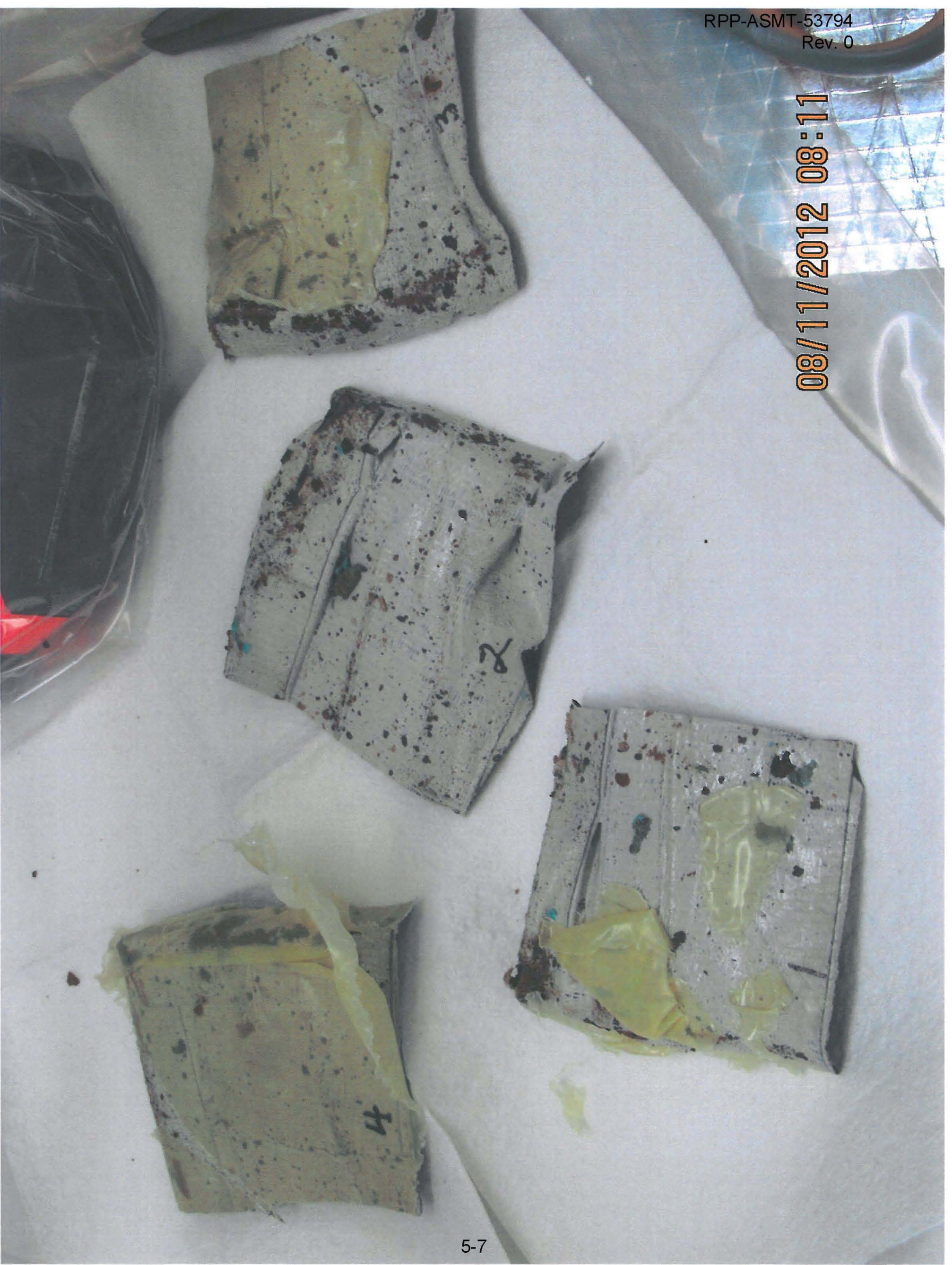




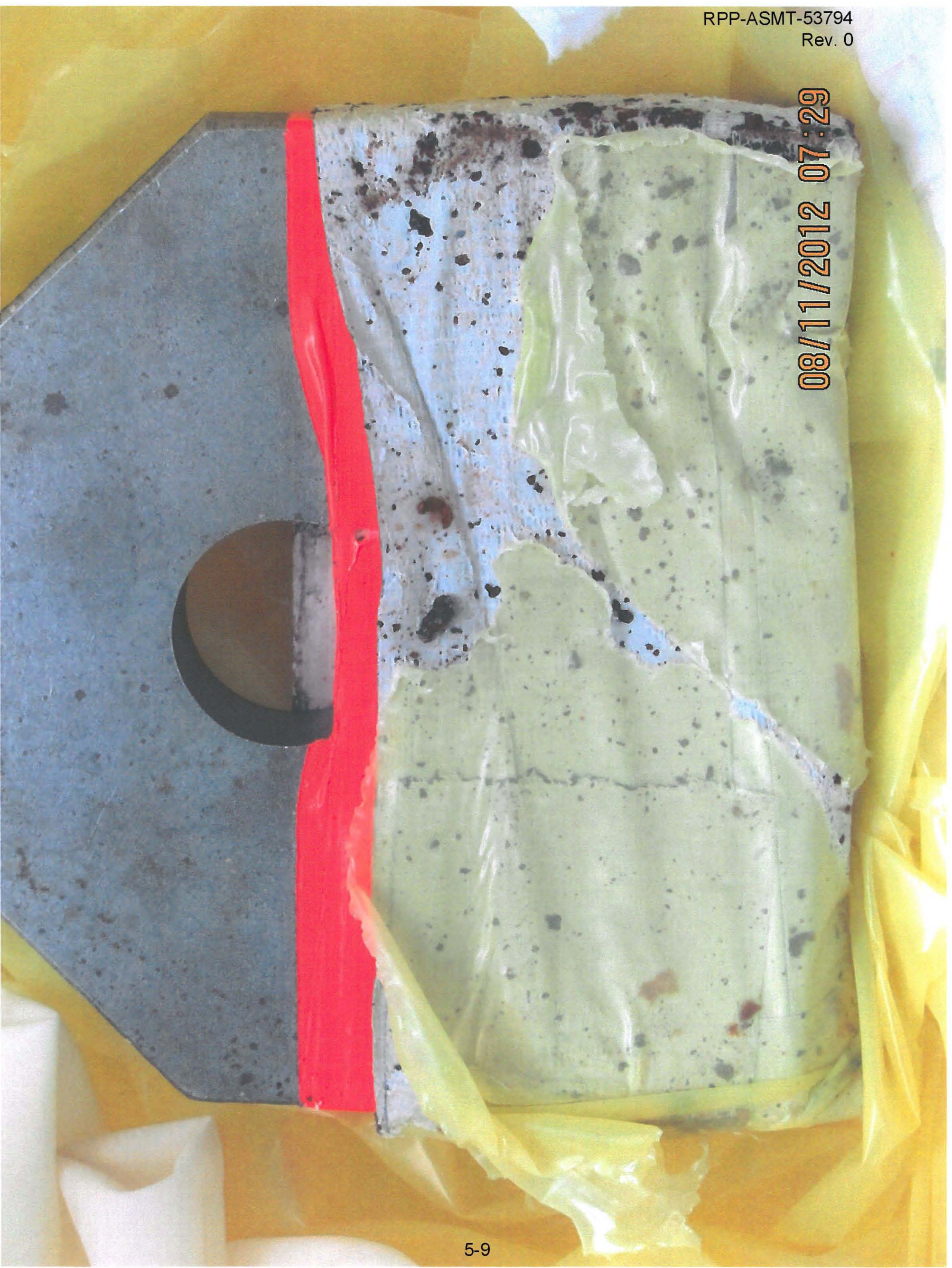




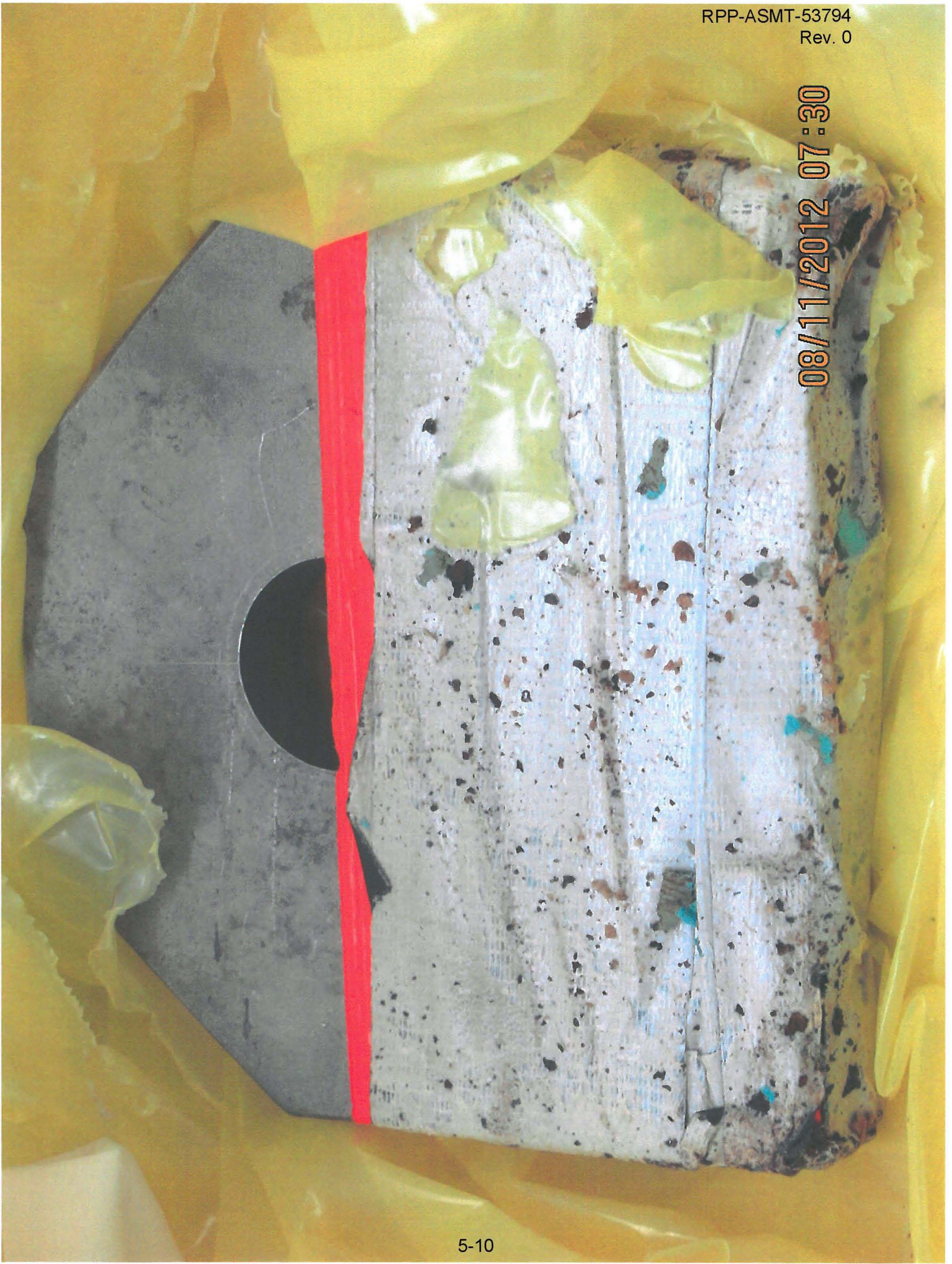




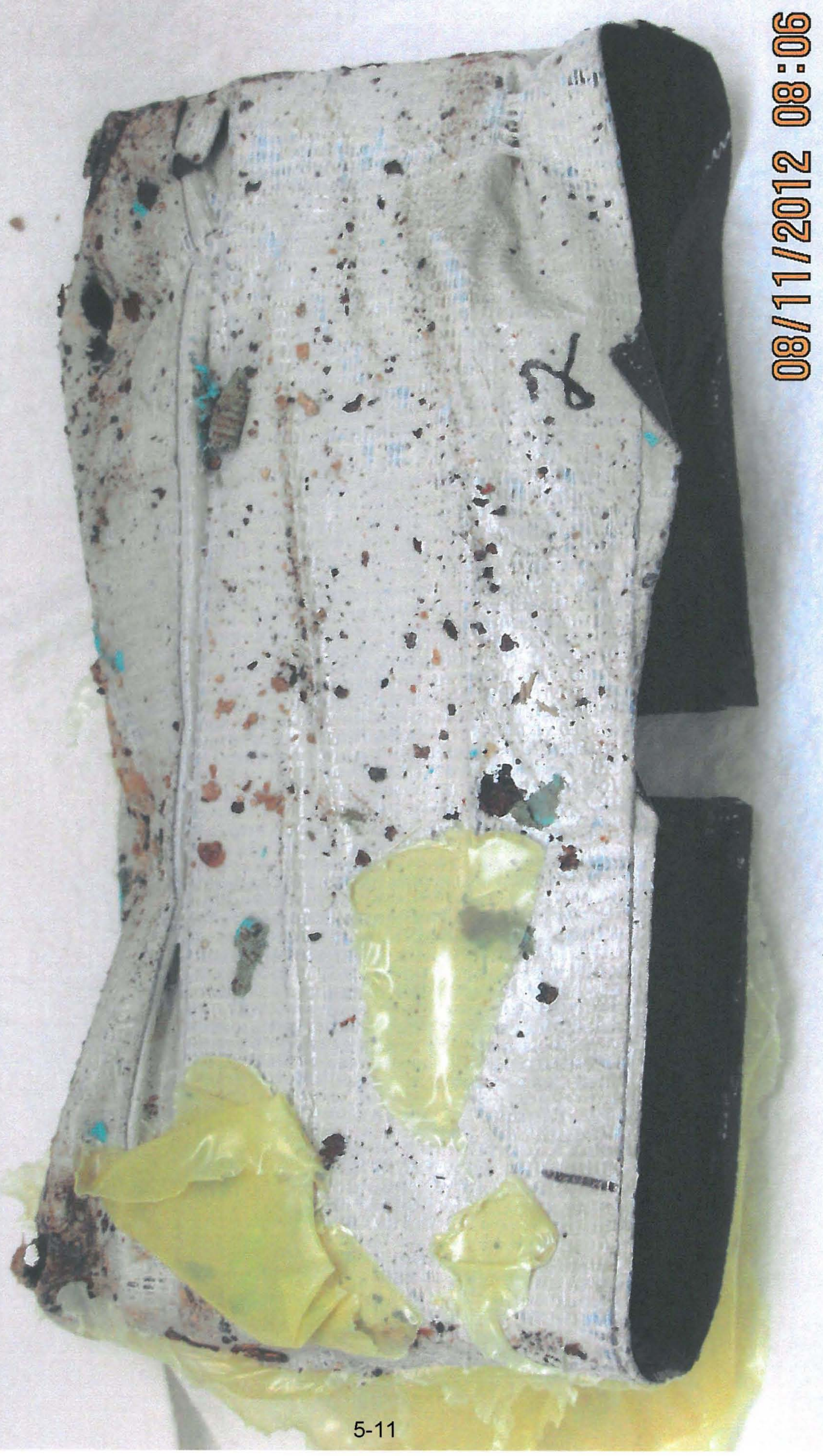




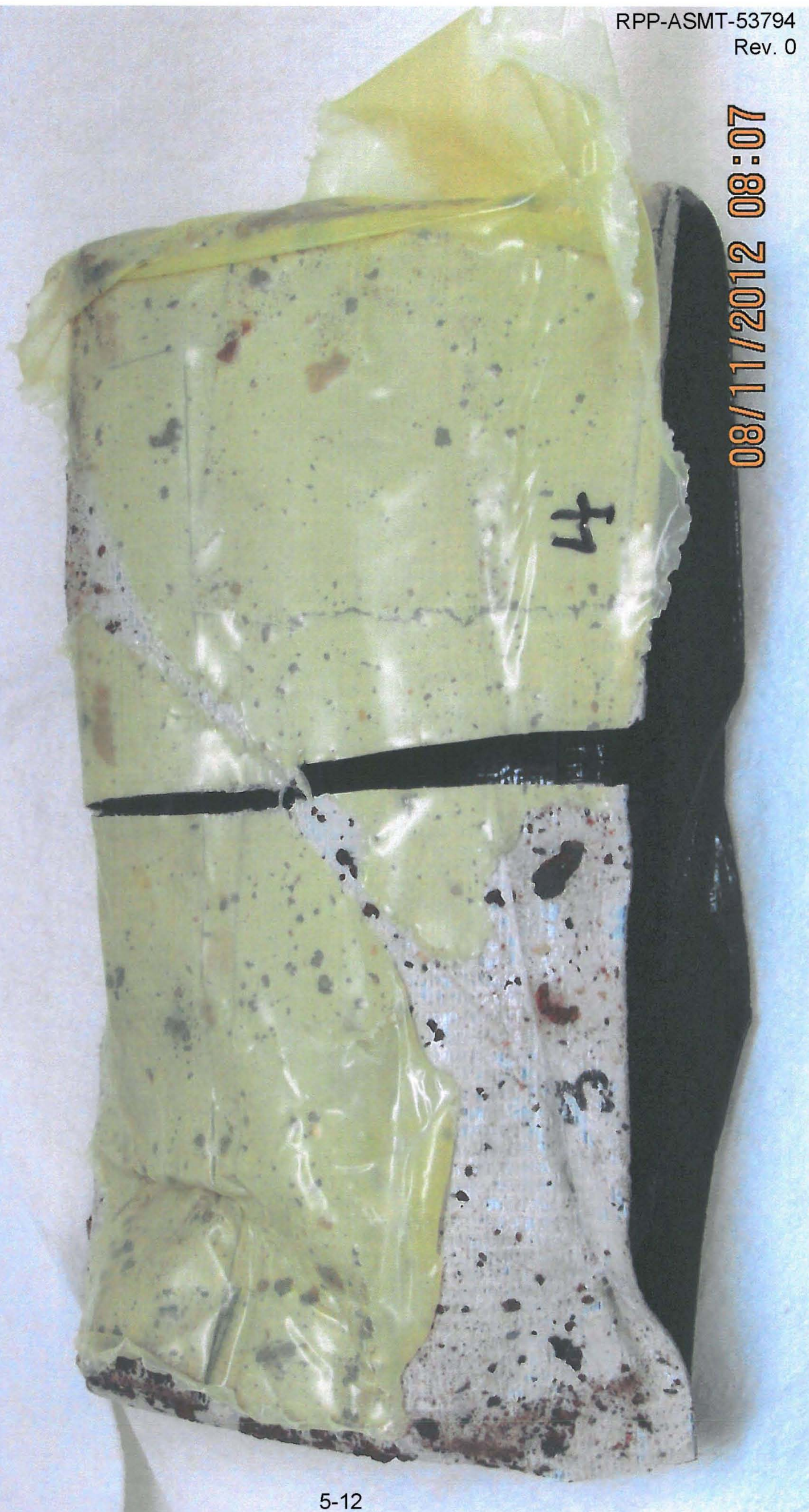




\section{RPP-ASMT-53794}

Rev. 0

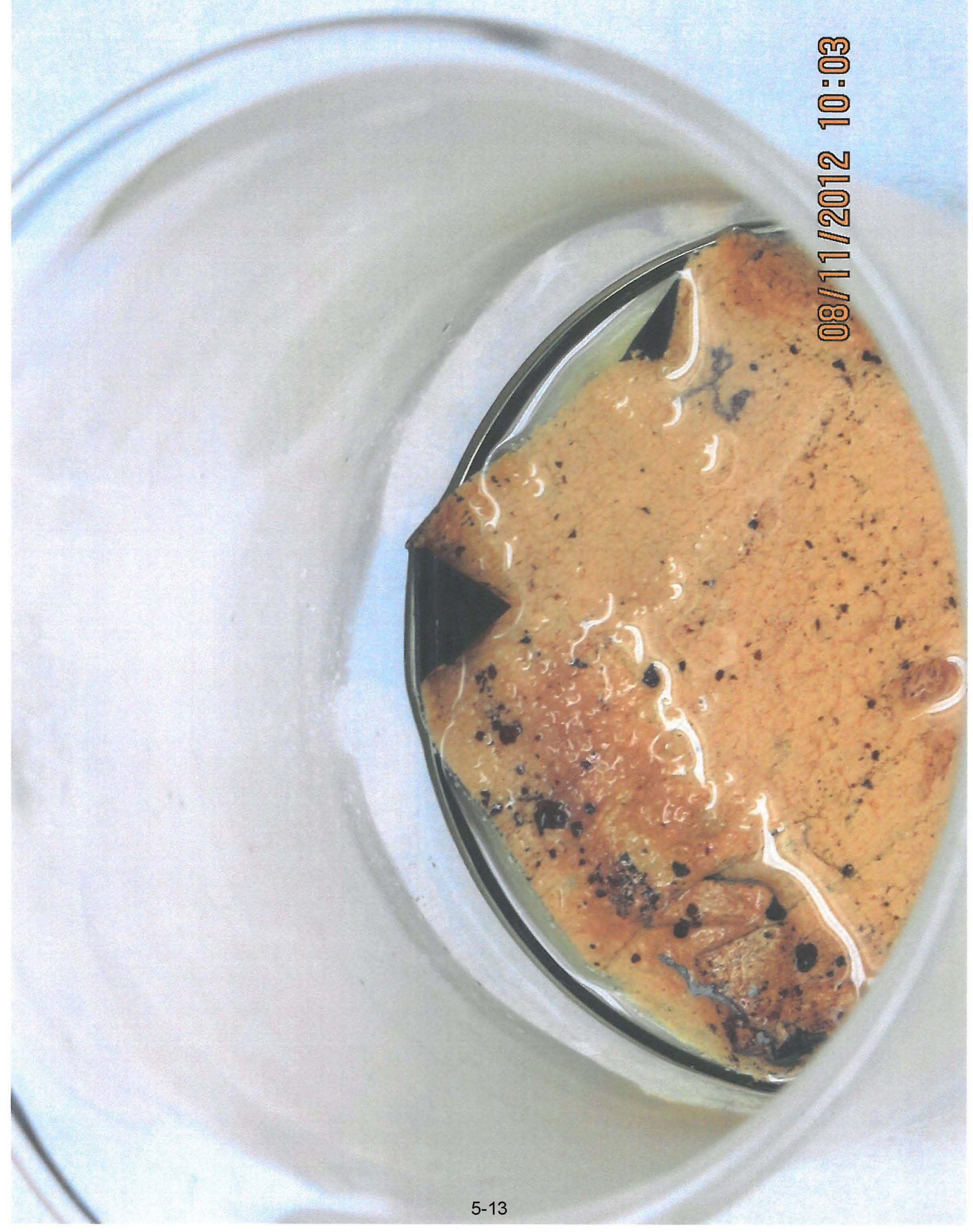


From:

Sent:

To:

Subject:
Venetz, Theodore J

Tuesday, September 25, 2012 2:37 PM

Rosenkrance, Chelsea L

FW: Optical and scanning electron microscope examination of AY102 residues

From: Rasmussen, Juergen $\mathrm{H}$

Sent: Tuesday, September 25, 2012 2:35 PM

To: Venetz, Theodore ]

Subject: FW: Optical and scanning electron microscope examination of AY102 residues

Juergen Rasmussen

Washington River Protection Solutions, contractor to the United States Department of Energy

From: McKinney, Steve G

Sent: Tuesday, August 14, 2012 3:28 PM

To: Renberger, Duane L; Sams, Terry L; Rasmussen, Juergen H; Washenfelder, Dennis J; Boomer, Kayle D

Cc: Patten, Elester; Wilkinson, Robert $\mathrm{E}$

Subject: FW: Optical and scanning electron microscope examination of AY102 residues

From: Cooke, Gary

Sent: Tuesday, August 14, 2012 3:11 PM

To: McKinney, Steve G

Cc: Johnson, Jo M; Seidel, Cary M; Prilucik, John R

Subject: Optical and scanning electron microscope examination of AY102 residues

Steve:

We examined the particulate recovered from three samples from the Tank 241-AY-102. The samples consisted of particulate adhering to duct tape which had been placed in clear yellow plastic bags. The samples were identified as: AY102Annulus-1-1 (S12R000485)

AY102Annulus-1-3 (S12R000487)

AY102Annulus-1-4 (S12R000488)

The three samples were examined and individual particles were removed and placed on an adhesive tab on an SEM specimen mount. The selected particulate was examined first on a binocular microscope and then carbon coated and examined on the SEM. The SEM images, below are paired, with the image on the left with the area or spot examined by the energy dispersive x-ray (EDS) detector marked by the yellow cross or box, and the EDS spectrum on the right.

The particulate appears to be dominated by rust. Only a few examples of the rust were examined and found to be composed primarily of iron and oxygen, as expected: 
Rev. 0
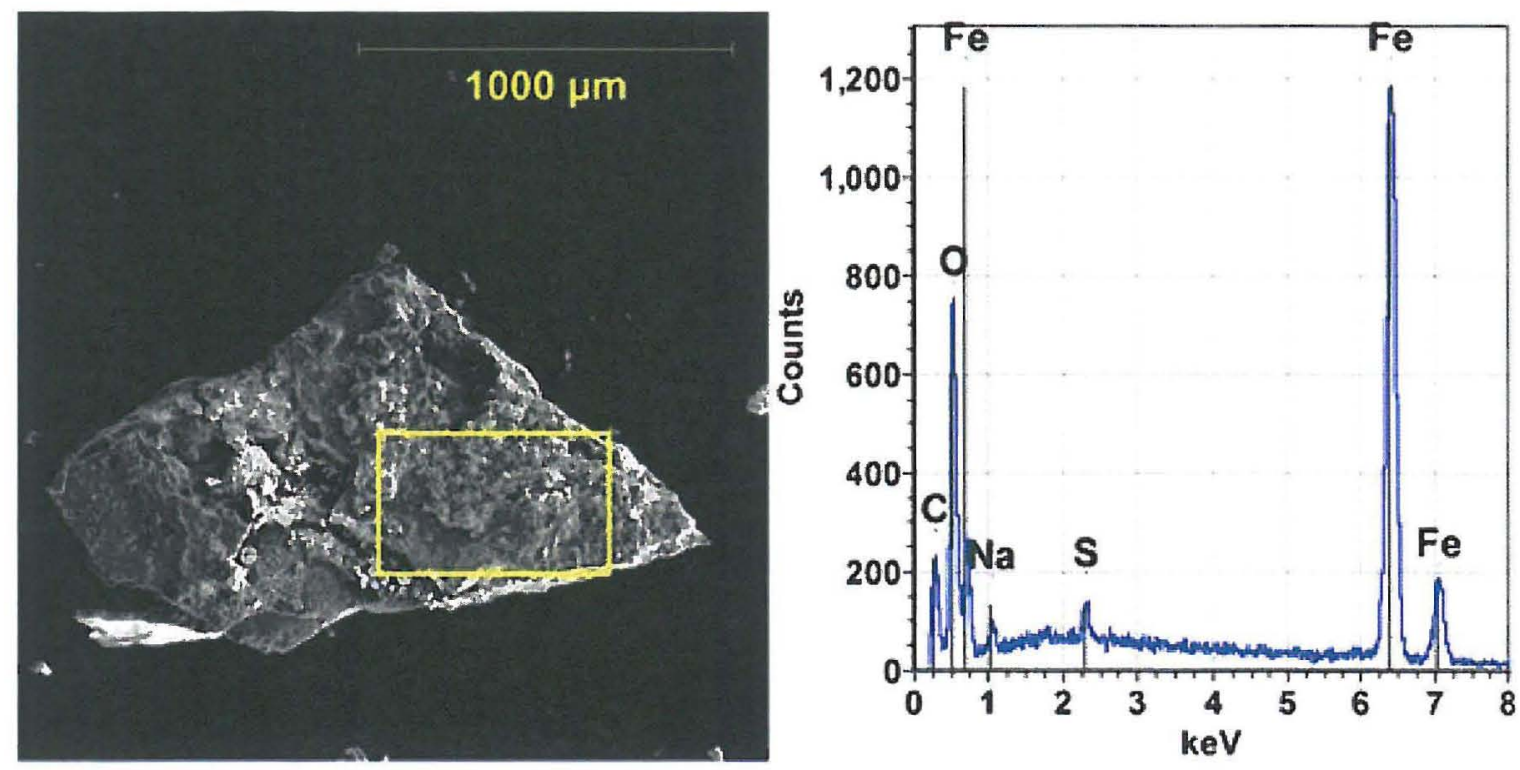

The scattered blue particulate appears to be some type of paint. The EDS signature indicates a kaolinite mineral is the filler in the paint and there are cellulose fibers present as well.

The remainder of the particulate is mostly light gray to amber colored aggregates of fine-grained crystalline material. Several of these particles were examined. The chemistry was fairly uniform, with sodium, potassium, carbon, oxygen, nitrogen, phosphorous and chlorine identified in the EDS spectra:
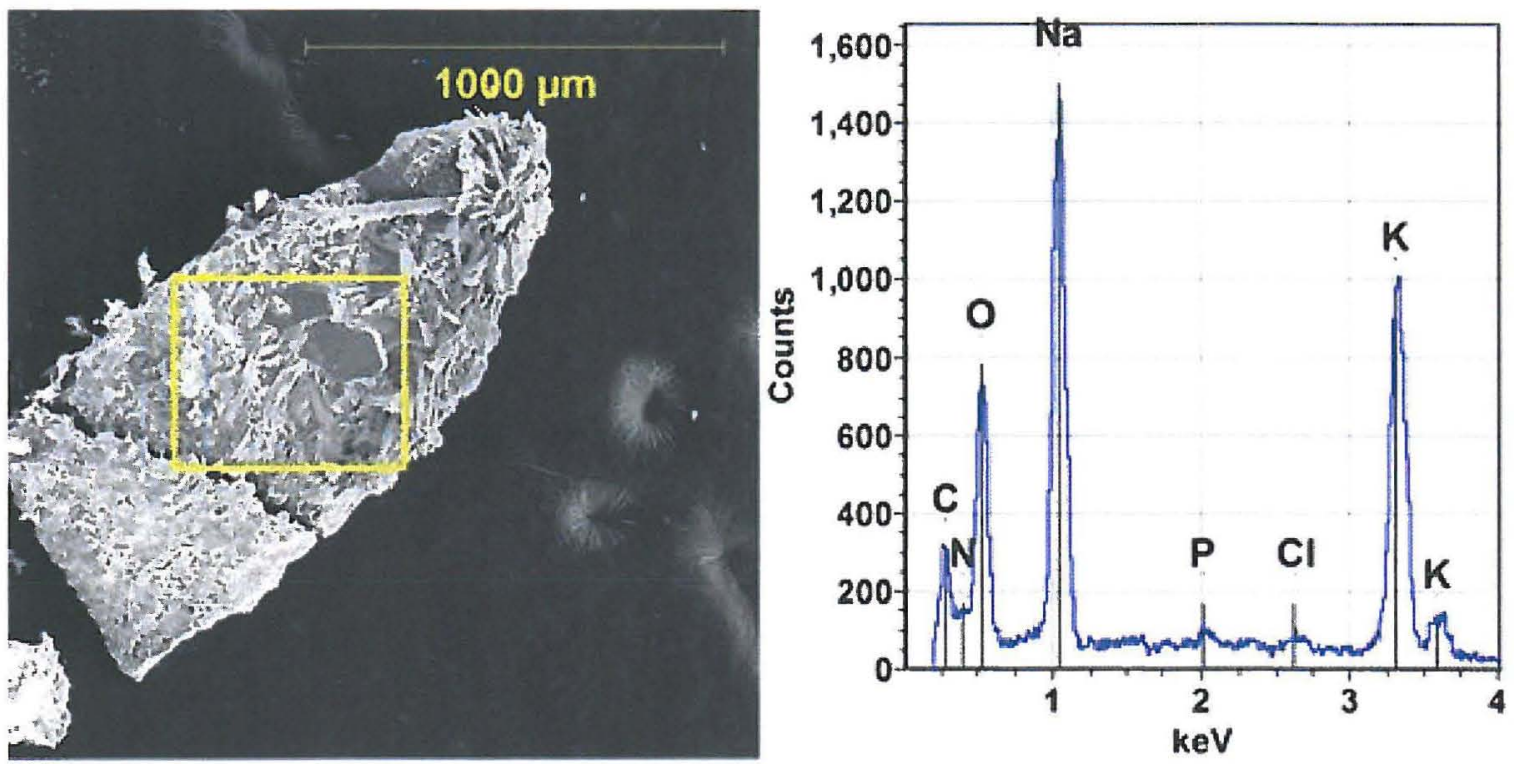

The largest crystals are blocky, equant crystals of sodium nitrate (Nitratine): 

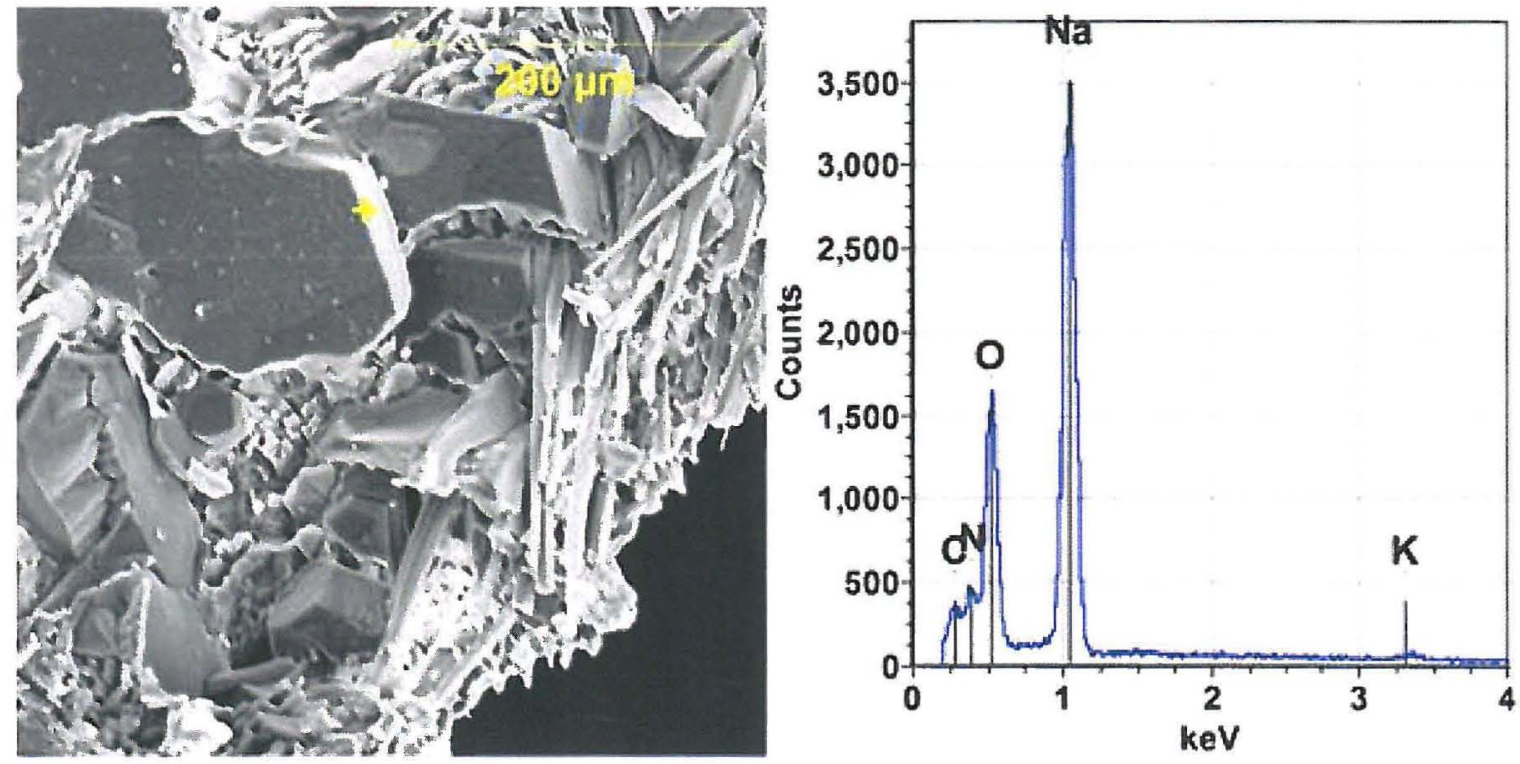

These are mixed with a blade-like or lath-like potassium-rich phase:
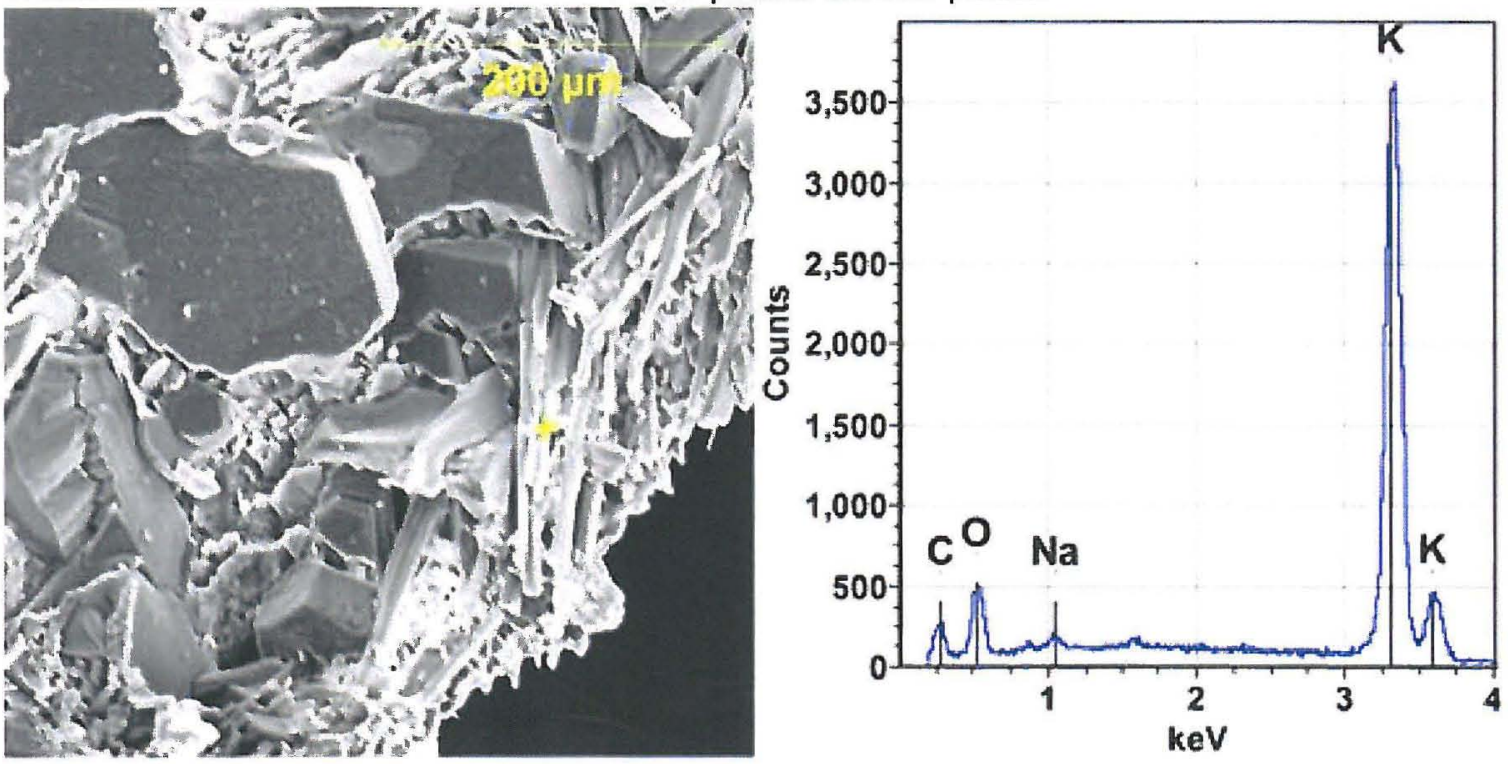

Also found with these salt phases was potassium chloride:
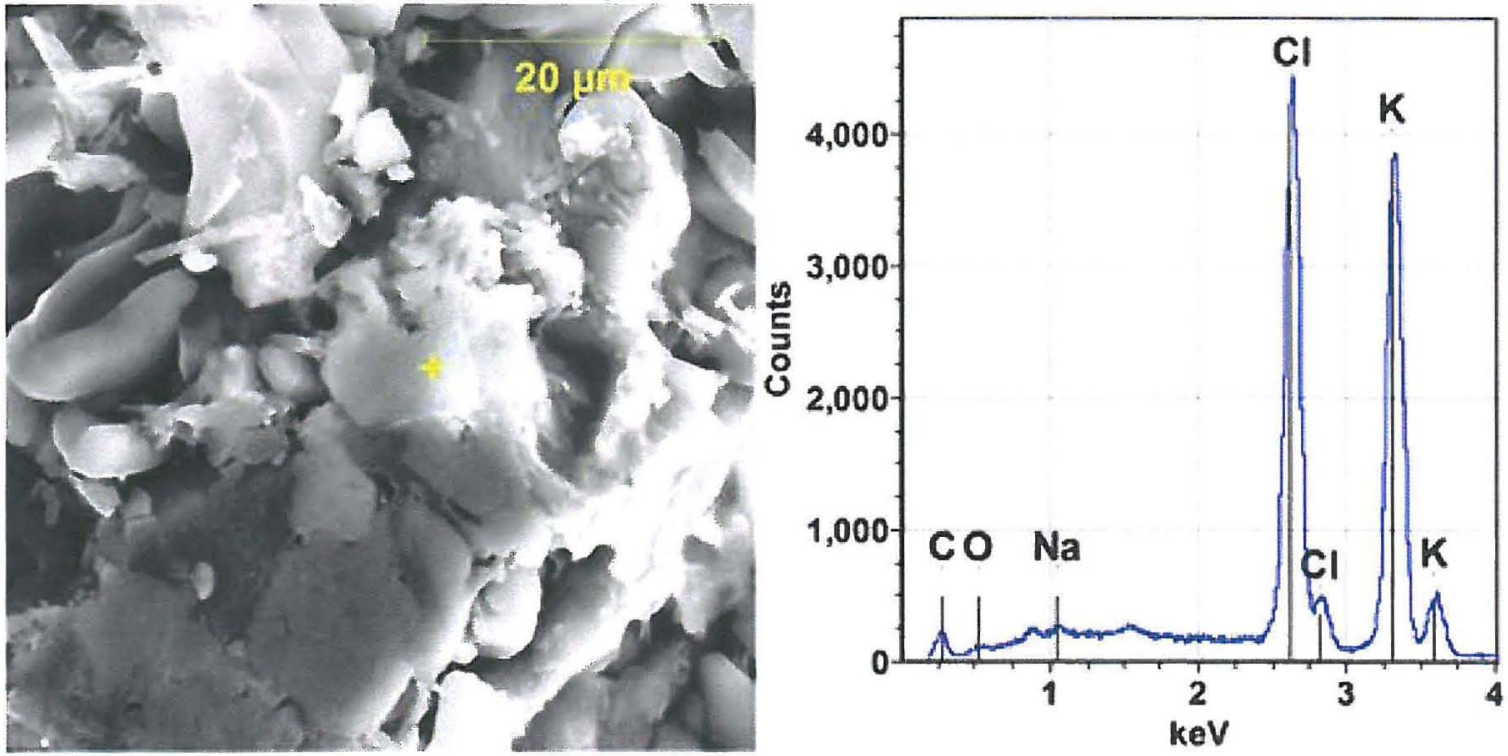
Sodium phosphate dodecahydrate:
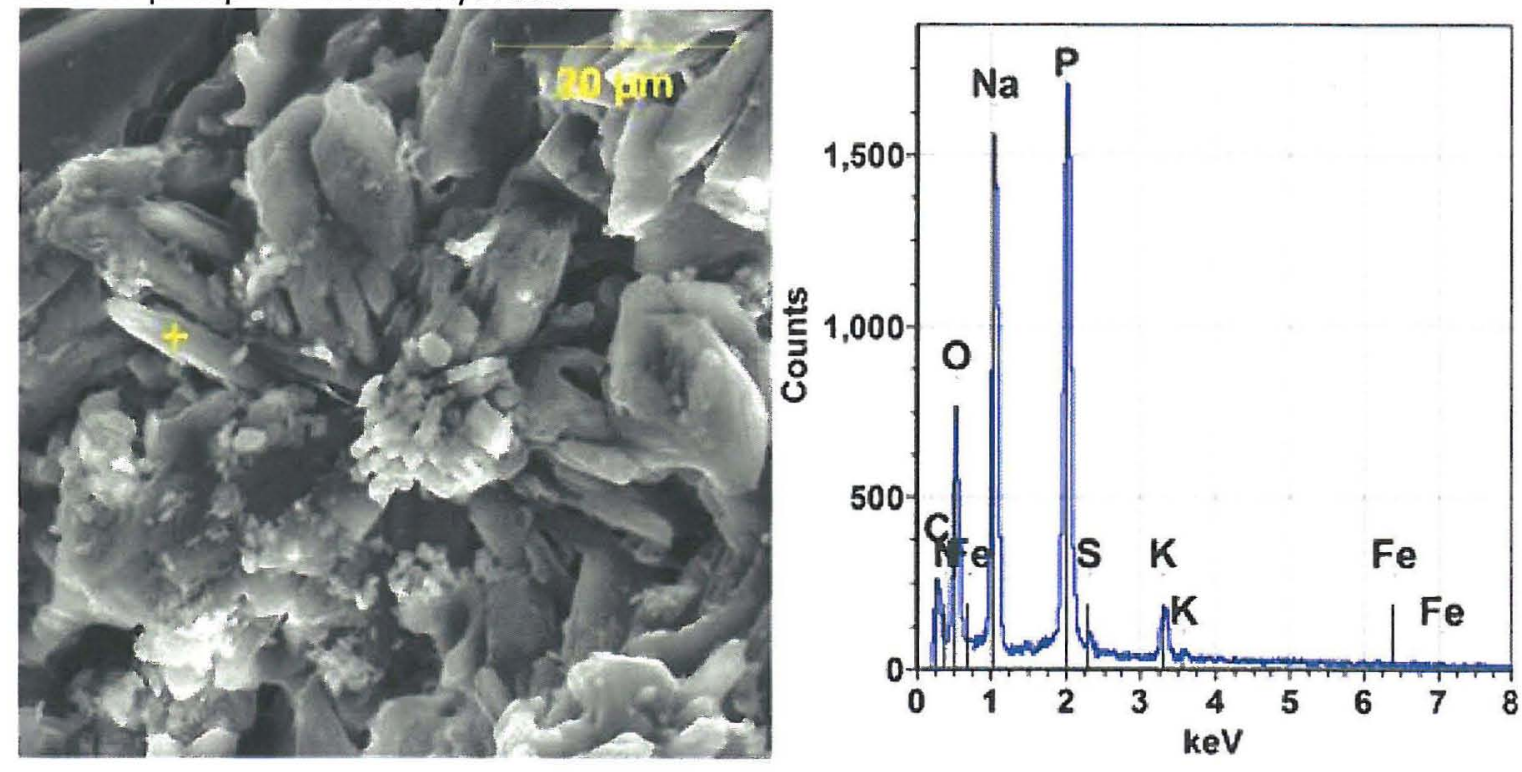

Possible sodium carbonate (Thermonatrite):
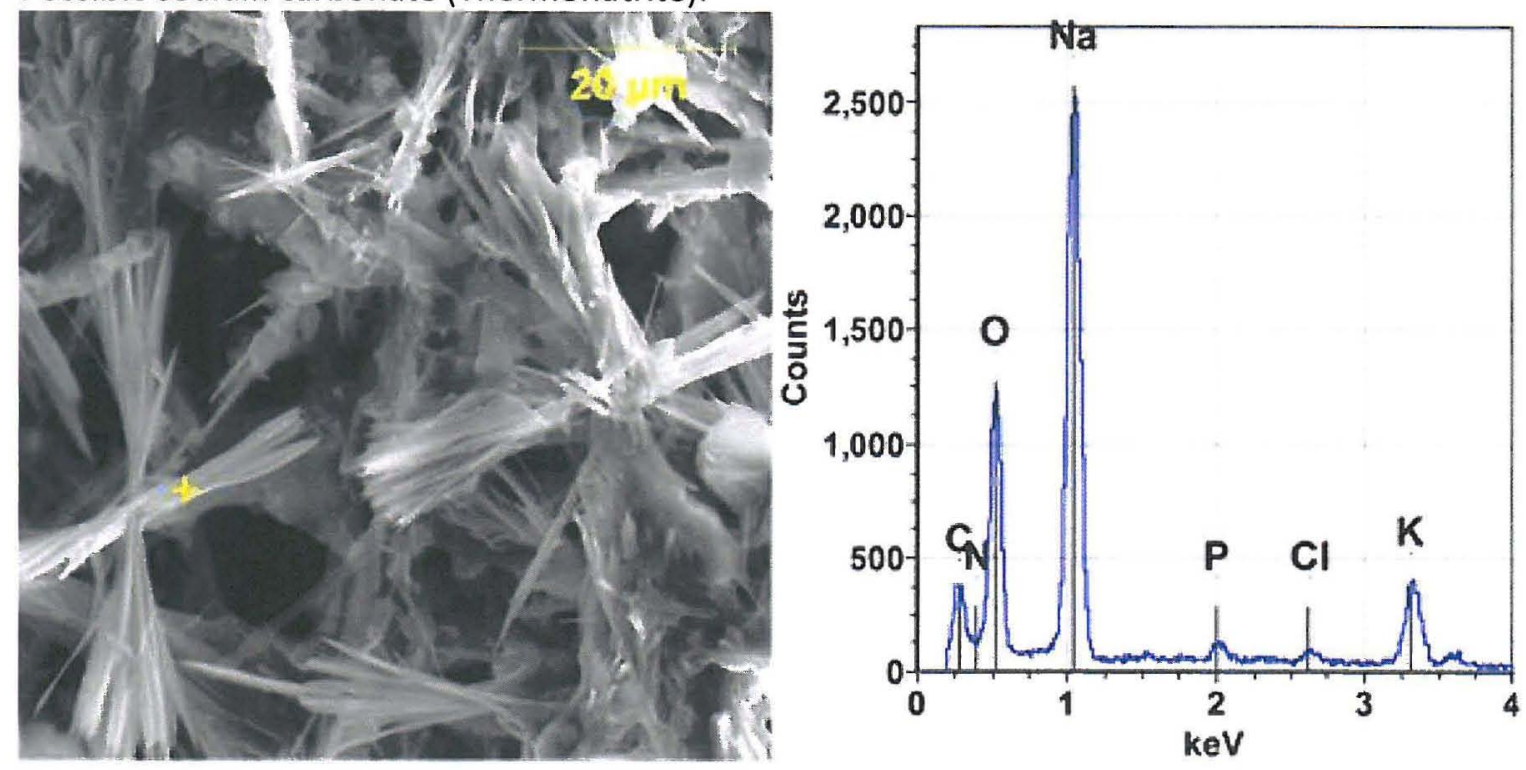

and a trace amount of sodium fluoride phosphate hydrate (Kogarkoite): 

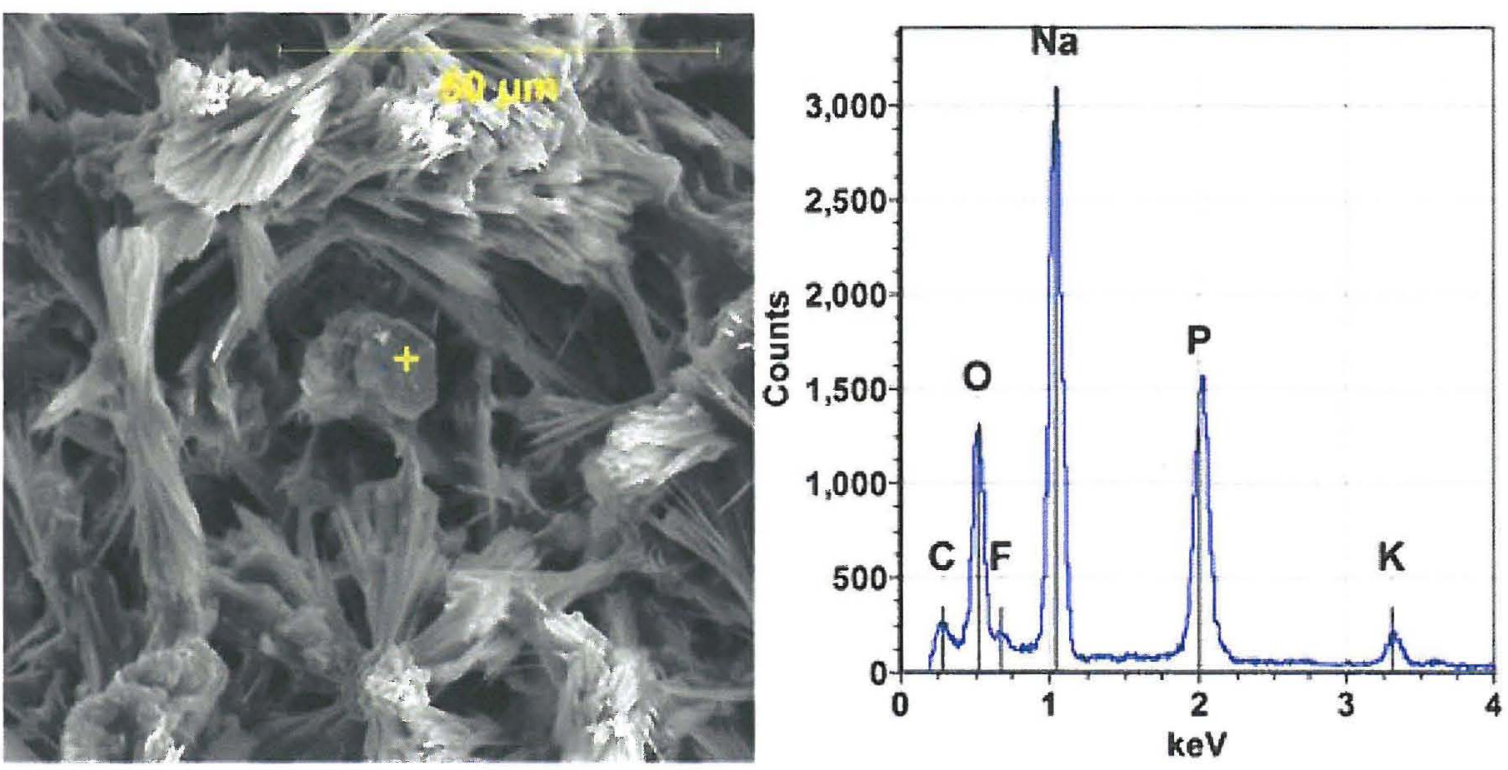

The sodium phases listed above are all water soluble phases that have been identified in tank waste. The source of the potassium is uncertain. Potassium is generally rare in tank waste.

Please pass this on to whoever needs to see it. If you have any questions, please let me know.

\section{Gary A. Cooke}

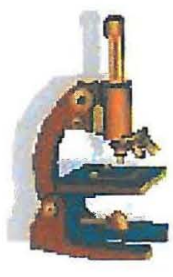

gary cooke@rl.gov (509) 373-2154 Cell: (509) 845-3988

Washington River Protection Solutions, contractor to the United States Department of Energy 
5.2 Riser 83- September 2012 Sample 
Rev. 0

Venetz, Theodore J

\section{From: \\ Sent: \\ To: \\ Cc: \\ Subject:}

Importance:
Harrington, Stephanie J

Wednesday, October 24, 2012 4:11 PM

Rosenkrance, Chelsea L; Sams, Terry L; Washenfelder, Dennis J; Kirch, Nicholas W (Nick); Venetz, Theodore J; Boomer, Kayle D

Rasmussen, Juergen H; Nguyen, Duc M; Templeton, Andrew M; Reynolds, Jacob G FW: Interim Results for AY102 Annulus - TIC/TOC (ANU1) and ICP (ANU3A)

High

Please find the preliminary results below for the TIC/TOC analyses on the sample from near riser 83 (the floor sample) as well as the ICP metals analysis results for the second air duct sample taken on Oct. $17^{\text {th }}$ near riser 90 .

Stephanie dtateington, Dh D

Chemical Process Engineer

Washington River Protection Solutions,

contractor to the United States Department of Energy

2750E Room A219 or 639 Cullum B119

(509) $376-1336$

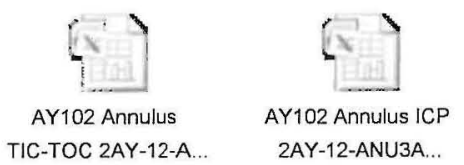

From: Bushaw, Ruth A

Sent: Wednesday, October 24, 2012 3:54 PM

To: Harrington, Stephanie J

Cc: Bushaw, Thomas H; McKinney, Steve G; Cooke, Gary

Subject: Interim Results for AY102 Annulus - TIC/TOC (ANU1) and ICP (ANU3A)

Importance: High

Stephanie,

The attached spreadsheets provide the interim results for the TIC/TOC analysis requested for sample 2AY-12ANU1 and the ICP results for sample 2AY-12-ANU3A.

For the TIC/TOC analysis, the spike recovery for the TIC was $207 \%$ but the amount of spike added was much less than $25 \%$ of the concentration in the sample, so no qualifier flags or reanalyses were required.

For the ICP analysis, there was no preparation standard because the digest that was requested was originally just for radchem, so no standard was prepared. Also, we forgot to run the preparation blank associated with this sample, the chemist is going to ask the technician if maybe it had been consumed with the radchem analyses and wasn't available. If it was just overlooked, I asked them to run that and rerun the sample to see if some of the instrument QC issues will not be present in the rerun.

Recall that there was also insufficient sample material to digest a duplicate sample portion or a spike. The analytical batch also contained solid samples from the recent AN101/C104 sampling event, and one of those 
samples was used for the sample QC. I'm reluctant to include that QC with this report because the sample matrix isn't quite the same.

As I stated in my previous email with ICP results, the digest methods that we have available at 222-S lab are not appropriate for digesting silicon. Therefore, it's likely that the LCS and spike recovery, if prepared for this sample, might have failed low, as they did with the SW846 Method 3050B prep that was used to digest the previous AY102 Annulus sample. I will discuss in the narrative that the silicon result might not be very accurate. Note that silicon was detected in the instrument blanks. For two of the blanks, the silicon was $>$ EQL and $>5 \%$ of the sample result, so I added a "B" flag. Since these were instrument blanks, I'm expecting that the reanalysis might be better. Silicon also failed high on the low level standard (LLS). Since the result in the sample was at approximately the same level as the LLS, this could indicate a high bias. This failure does not require a reanalysis, but since we are going to rerun anyway, the LLS might meet the requirement on the rerun.

Remember that these results have not been fully reviewed and may change, especially since we plan to rerun the ICP.

Thanks,

Ruth A. Bushaw

Project Coordinator

Advanced Technologies and Laboratories International, Inc.

Contractor to the Office of River Protection

U.S. Department of Energy

222-S Laboratory

office: $509-373-4314$

cell: 509-554-4978

This email and any accompanying documents contain confidential and / or privileged information. This information is intended only for the use of the individuals or entity named in this email. If you are not the intended recipient, please notify the sender and delete this message. You are hereby notified that any disclosure, copying, distribution or taking of any reliance on the contents of the information contained herein is strictly prohibited. 
INTERIM

AY102 Annulus

Data Summary of All Results

\begin{tabular}{|l|l|l|l|l|l|l|l|}
\hline Riser & Segment Number & Segment Portion & SAMPLE R & A & CAS \# & ANALYTE \\
\hline
\end{tabular}

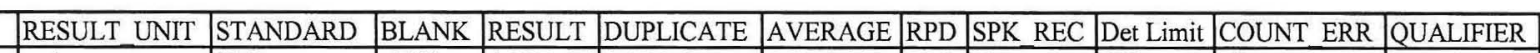

\begin{tabular}{|l|l|l|l|l|l|l|l}
\hline 83 & 2AY-12-ANU1 & Grab Sample (Total) & S12T021101 & TIC & Total inorganic carbon & ug/g \\
\hline
\end{tabular}

\begin{tabular}{|l|l|l|l|l|l|l|l}
\hline 83 & 2AY-12-ANU1 & Grab Sample (Total) & S12T021101 & TOC & Total organic carbon & ug/g
\end{tabular}

\begin{tabular}{l|l|l}
\hline $\mathrm{g} / \mathrm{g}$ & 98.8 \\
\hline $\mathrm{g} / \mathrm{g}$ & 94.7 \\
\hline
\end{tabular}

98.8

\begin{tabular}{l|l|l|l|l}
$<7.00$ & $4.20 \mathrm{E}+04$ & $4.42 \mathrm{E}+04$ \\
\hline
\end{tabular}

\begin{tabular}{l|l|l|l|l}
\hline $4.31 \mathrm{E}+04$ & 5.10 & 207 \\
\hline
\end{tabular}

\begin{tabular}{l|l|l|l}
$1.50 \mathrm{E}+03$ & 14.7 & 207 \\
\hline
\end{tabular}

\begin{tabular}{l|l|}
\hline & Det Limit \\
\hline 572
\end{tabular}

nia

$\mathrm{J}$ - Estimated

N

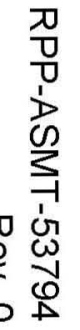


From:

Sent:

To:

Subject:
Boomer, Kayle D

Tuesday, September 25, 2012 4:20 PM

Girardot, Crystal L; Harlow, Donald G; Rosenkrance, Chelsea L; Engeman, Jason K FW: Off-riser Sampling System Image

From: Harrington, Stephanie J

Sent: Tuesday, September 25, 2012 4:16 PM

To: Boomer, Kayle D; Venetz, Theodore J

Subject: Off-riser Sampling System Image

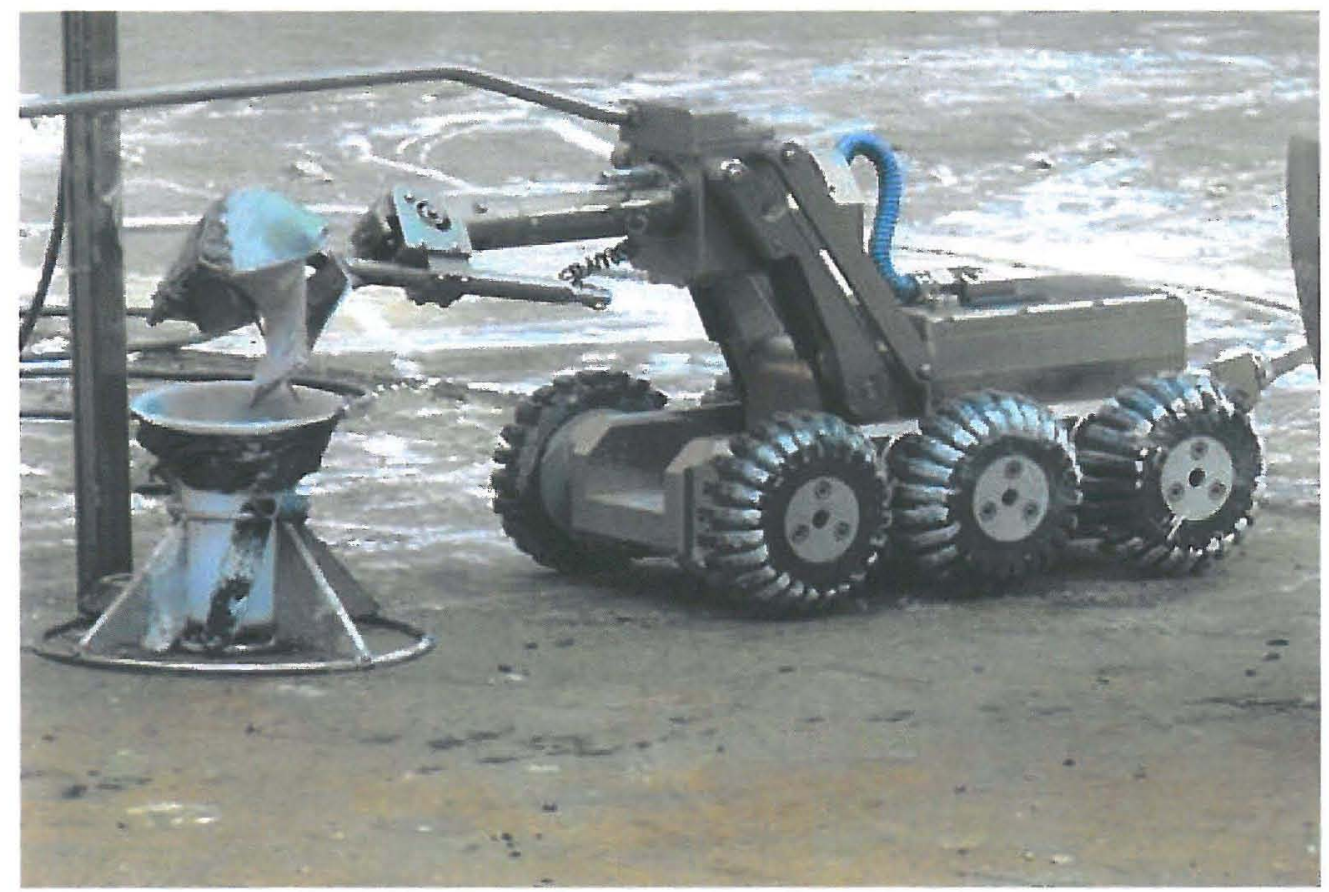

Thank you,

Stephanie dtarrington, 8 h $D$

Chemical Process Engineer

Washington River Protection Solutions,

contractor to the United States Department of Energy

2750E Room A219 or 639 Cullum B119

(509) 376-1336 


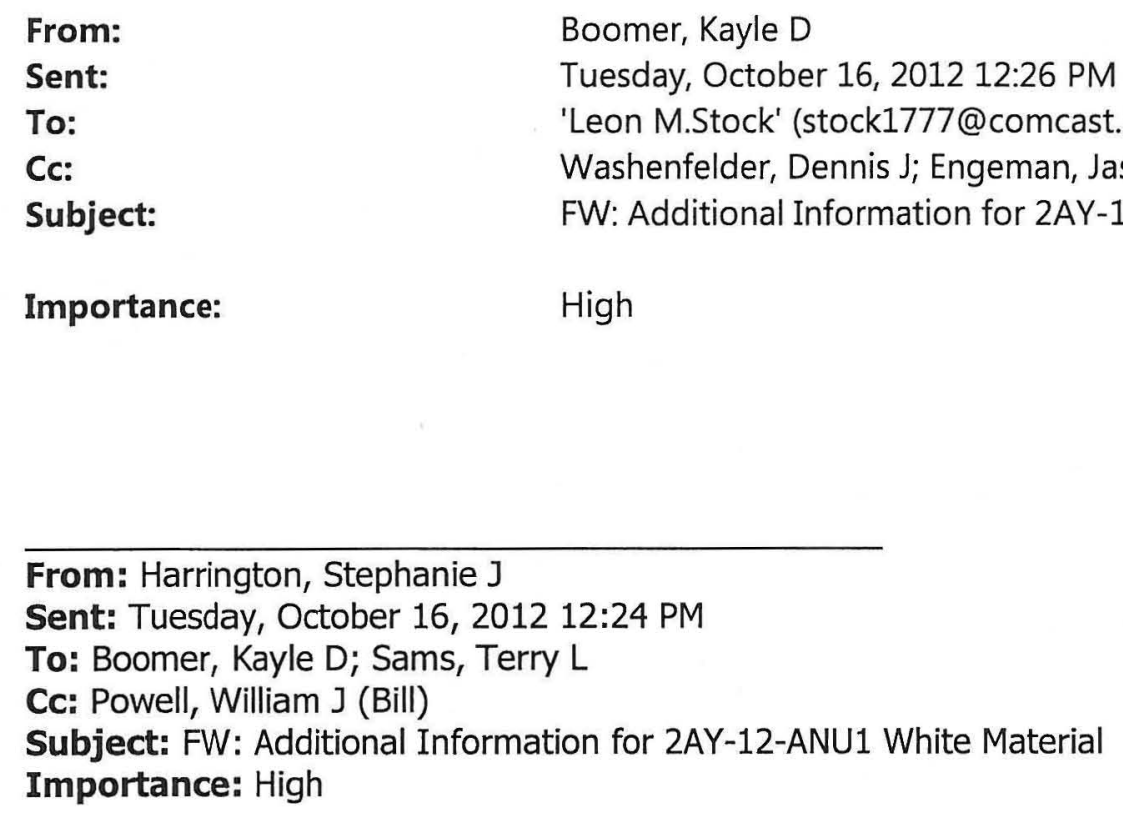

High

\author{
From: Harrington, Stephanie J \\ Sent: Tuesday, October 16, 2012 12:24 PM \\ To: Boomer, Kayle D; Sams, Terry L \\ Cc: Powell, William J (Bill) \\ Subject: FW: Additional Information for 2AY-12-ANU1 White Material \\ Importance: High
}

\section{Kayle,}

Is this good enough information for the annulus sample in terms of $\mathrm{pH}$ for the sample from the material near riser 83 ? can make sure this gets into the report, but it will be qualitative, not quantitative. I will find out more for the TIC/TOC you were wanting for the remaining material in archive. It shouldn't be a problem as there is still the 1 gram of material in archive to work with.

Thank you,

\section{Stephanie ottatrington, oth $D$}

Chemical Process Engineer

Washington River Protection Solutions, contractor to the United States Department of Energy

2750E Room A219 or 639 Cullum B1 19

(509) 376-1336

\section{From: Bushaw, Ruth A}

Sent: Tuesday, October 16, 2012 12:14 PM

To: Harrington, Stephanie J

Cc: McKinney, Steve G; Cooke, Gary

Subject: Additional Information for 2AY-12-ANU1 White Material

Importance: High

Stephanie,

I asked Gary Cooke if he would do a quick check for the $\mathrm{pH}$ of the white material from AY102 Annulus riser 83 sample 2AY-12-ANU1. 
He said that he estimated that he used $<1 \mathrm{mg}$ of sample with a couple of drops of water and the $\mathrm{pH}$ was $\sim 11$ using $\mathrm{pH}$ test paper. He said that Hanford soils would give a $\mathrm{pH}$ around $8.5-9$. The only thing that he could think of that would give a $\mathrm{pH}$ that high would be tank waste.

He also wanted me to let you know that he is ready to put the new samples on the scope to get better pictures and run the solid phase tests that you requested.

Thanks,

Ruth A. Bushaw

Project Coordinator

Advanced Technologies and Laboratories International, Inc.

Contractor to the Office of River Protection

U.S. Department of Energy

222-S Laboratory

office: $509-373-4314$

cell: $509-554-4978$

This email and any accompanying documents contain confidential and / or privileged information. This information is intended only for the use of the individuals or entity named in this email. If you are not the intended recipient, please notify the sender and delete this message. You are hereby notified that any disclosure, copying, distribution or taking of any reliance on the contents of the information contained herein is strictly prohibited. 
From:

Sent:

To:

Cc:

Subject:
Harrington, Stephanie J

Wednesday, October 10, 2012 12:06 PM

Rosenkrance, Chelsea L; Sams, Terry L; Washenfelder, Dennis J; Kirch, Nicholas W (Nick);

Powell, William J (Bill); Venetz, Theodore J

Rasmussen, Juergen H; Nguyen, Duc M; Templeton, Andrew M; Reynolds, Jacob G

FW: UPDATE: AY102 Annulus 10-Working Day Interim Report

All,

Please find the 10 -working day interim report attached. Please note the following disclaimer from the laboratory:

"Note that these results are identified as interim because they have not been fully reviewed and, therefore, are potentially subject to change upon final review. If any result changes, I will identify that in the final report."

Thank you,

Etephanie oftatrington, oh $D$

Chemical Process Engineer

Washington River Protection Solutions, contractor to the United States Department of Energy

2750E Room A219 or 639 Cullum B119

(509) $376-1336$

From: Bushaw, Ruth A

Sent: Wednesday, October 10, 2012 11:58 AM

To: Bushaw, Ruth A; Harrington, Stephanie J

Cc: Bushaw, Thomas H; McKinney, Steve G; Hansen, Daniel R; Prilucik, John R; Johnson, Jo M

Subject: UPDATE: AY102 Annulus 10-Working Day Interim Report

I forgot to rerun the DSR to show the "B" flag on the formate result. Here is the new report.

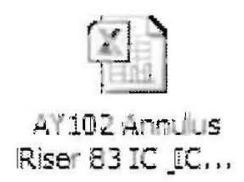

Thanks,

Ruth A. Bushaw

Project Coordinator

Advanced Technologies and Laboratories International, Inc.

Contractor to the Office of River Protection

U.S. Department of Energy 222-S Laboratory

373-4314 
From: Bushaw, Ruth A

Sent: Wednesday, October 10, 2012 11:47 AM

To: Harrington, Stephanie J

Cc: Bushaw, Thomas H; McKinney, Steve G; Hansen, Daniel R; Prilucik, John R; Johnson, Jo M

Subject: AY102 Annulus 10-Working Day Interim Report

Importance: High

Stephanie,

The attached file contains the interim results for the IC and ICP analyses for sample 2AY-12-ANU1. Note that 12-CCN-24 indicates that Sr-90 results are also required for this 10 -Working Day report, but those results were already provided to you in the 7-Working Day report.

Here is a brief discussion of the QC:

1. Following the fusion digest, it was noted that there was a very small amount of fine black solids in the bottom of the bottle.

2. Following the acid digest, the digestate was described as clear with no solids remaining.

3. The RPD for Fe from the fusion digest is $74.9 \%$. No qualifier flag was required because the sample result is less than the quantitation limit. Recall that this sample had small black flecks of solid that were attracted to a magnet, so it's not surprising to have a high RPD for Fe.

4. A number of analytes were detected in the preparation blanks.

a. For the fusion digest, $\mathrm{Al}, \mathrm{Na}$, and $\mathrm{Si}$ were detected in the preparation blank, but the concentration was below the quantitation limit and the QAPP does not require comparison to the sample result or a qualifier flag. The QAPP does not require reanalysis of blanks if the results are below the quantitation limit.

b. For the acid digest, $\mathrm{Ca}, \mathrm{Fe}$, and $\mathrm{Si}$ were detected in the preparation blank. The results for $\mathrm{Ca}$ and Fe were below the quantitation limit, so no qualifier flag or reanalysis was required. The Si preparation blank result was above the quantitation limit; but Si was not detected in the sample, so no qualifier flag was required and no reanalysis was performed. This is a good example of the typical inconsistent results that the laboratory obtains for $\mathrm{Si}$.

c. For the water digest, formate, nitrite, sulfate, and nitrate were detected in the preparation blank. Results for all analytes, except formate, were below the quantitation limit and no qualifier flags or reanalysis were required. For formate, the blank result is greater than $5 \%$ of the sample result and a " $\mathrm{B}$ " flag was applied. Since this is not a required analyte, no repreparation or reanalysis is required.

5. The LCS (prep standard) for Si in the acid digest had a very low recovery; 49\%. This digest method, SW-846 Method 3050B, is not an appropriate digest for Si analysis. The laboratory currently does not have an appropriate digest for $\mathrm{Si}$ analysis. Note that no Si was detected in the sample using this digest, and an "a" flag was applied to the sample result to indicate the failed LCS recovery. No repreparation and reanalysis was requested because of the limited sample size and because the laboratory does not expect to obtain a better result using this same digestion method.

《< File: AY102 Annulus Riser 83 IC \& ICP Interim Results.xIsx >>

Note that these results are identified as interim because they have not been fully reviewed and, therefore, are potentially subject to change upon final review. If any result changes, I will identify that in the final report.

Thanks,

Ruth A. Bushaw 
Project Coordinator

Advanced Technologies and Laboratories International, Inc.

Contractor to the Office of River Protection

U.S. Department of Energy

222-S Laboratory

office: $509-373-4314$

cell: $509-554-4978$ 
AY102 Annulus

Data Summary of All Results

\begin{tabular}{|c|c|c|c|c|c|c|c|c|c|c|c|c|c|c|c|c|c|}
\hline Riser & Segment Number & Segment Portion & SAMPLE_R & A & CAS \# & ANALYTE & RESULT_UNIT & STANDARD & BLANK & RESULT & DUPLICATE & AVERAGE & RPD & SPK_REC & Det Limit & COUNT_ERR & QUALIFIER \\
\hline 83 & 2AY-12-ANU1 & Grab Sample (Total) & S12T021142 & $\mathrm{F}$ & $7429-90-5$ & Aluminum & ug/g & 97.4 & $1.69 \mathrm{E}+03$ & $9.95 \mathrm{E}+03$ & $9.17 \mathrm{E}+03$ & $9.56 \mathrm{E}+03$ & 8.15 & 102 & 429 & $\mathrm{n} / \mathrm{a}$ & \\
\hline 83 & 2AY-12-ANU1 & Grab Sample (Total) & S12T021142 & $\mathrm{F}$ & $7440-70-2$ & Calcium & ug/g & 98.8 & $<5.72 \mathrm{E}+03$ & $<5.72 \mathrm{E}+03$ & $<5.88 \mathrm{E}+03$ & $n / a$ & $n / a$ & 96.5 & $5.72 \mathrm{E}+03$ & $n / a$ & $\mathrm{U}$ \\
\hline 83 & 2AY-12-ANU1 & Grab Sample (Total) & S12T021142 & $\mathrm{F}$ & $7440-47-3$ & Chromium & ug/g & 97.8 & $<71.5$ & 334 & 272 & 303 & 20.3 & 98.8 & 71.5 & $n / a$ & $\mathrm{~J}$ \\
\hline 83 & 2AY-12-ANU1 & Grab Sample (Total) & S12T021142 & $\mathrm{F}$ & $7439-89-6$ & Iron & ug/g & 99.0 & $<715$ & $2.40 \mathrm{E}+03$ & $5.28 \mathrm{E}+03$ & $3.84 \mathrm{E}+03$ & 74.9 & 99.1 & 715 & $\mathrm{n} / \mathrm{a}$ & $\mathrm{J}$ \\
\hline 83 & 2AY-12-ANU1 & Grab Sample (Total) & S12T021142 & $\mathrm{F}$ & $7439-95-4$ & Magnesium & ug/g & 96.5 & $<143$ & $<143$ & $<147$ & $n / a$ & $n / a$ & 101 & 143 & $n / a$ & $\mathrm{U}$ \\
\hline 83 & 2AY-12-ANU1 & Grab Sample (Total) & S12T021142 & $\mathrm{F}$ & $7440-23-5$ & Sodium & ug/g & 95.9 & $6.02 \mathrm{E}+03$ & $2.76 \mathrm{E}+05$ & $2.70 \mathrm{E}+05$ & $2.73 E+05$ & 2.12 & 100 & $2.86 \mathrm{E}+03$ & $\mathrm{n} / \mathrm{a}$ & \\
\hline 83 & 2AY-12-ANU1 & Grab Sample (Total) & S12T021142 & $\mathrm{F}$ & $7723-14-0$ & Phosphorus & ug/g & 94.1 & $<214$ & 653 & 635 & 644 & 2.73 & 96.6 & 214 & $n / a$ & $\mathrm{~J}$ \\
\hline 83 & 2AY-12-ANU1 & Grab Sample (Total) & S12T021142 & $\mathrm{F}$ & $7440-21-3$ & Silicon & $\mathrm{ug} / \mathrm{g}$ & 95.4 & 503 & $1.32 \mathrm{E}+03$ & $<3.67 \mathrm{E}+02$ & $n / a$ & $n / a$ & 97.2 & 357 & $n / a$ & $\mathrm{~J}$ \\
\hline 83 & 2AY-12-ANU1 & Grab Sample (Total) & S12T021143 & $\mathrm{A}$ & $7429-90-5$ & Aluminum & ug/g & 95.2 & $<6.00 \mathrm{E}-03$ & $9.42 \mathrm{E}+03$ & $9.14 \mathrm{E}+03$ & $9.28 \mathrm{E}+03$ & 2.99 & 103 & 27.5 & $\mathrm{n} / \mathrm{a}$ & \\
\hline 83 & 2AY-12-ANU1 & Grab Sample (Total) & S12T021143 & A & $7440-70-2$ & Calcium & ug/g & 95.9 & 0.118 & $<366$ & $<356$ & $\mathrm{n} / \mathrm{a}$ & $\mathrm{n} / \mathrm{a}$ & 98.7 & 366 & $\mathrm{n} / \mathrm{a}$ & $\mathrm{U}$ \\
\hline 83 & 2AY-12-ANU1 & Grab Sample (Total) & S12T021143 & A & $7440-47-3$ & Chromium & ug/g & 94.4 & $<1.00 \mathrm{E}-03$ & 251 & 241 & 246 & 4.08 & 99.8 & 4.58 & $\mathrm{n} / \mathrm{a}$ & \\
\hline 83 & 2AY-12-ANU1 & Grab Sample (Total) & S12T021143 & $\mathrm{A}$ & $7439-89-6$ & Iron & ug/g & 95.4 & 0.0102 & $2.16 \mathrm{E}+03$ & $2.24 \mathrm{E}+03$ & $2.20 \mathrm{E}+03$ & 3.62 & 100 & 45.8 & $\mathrm{n} / \mathrm{a}$ & \\
\hline 83 & 2AY-12-ANU1 & Grab Sample (Total) & $\mathrm{S} 12 \mathrm{~T} 021143$ & $\mathrm{~A}$ & $7440-09-7$ & Potassium & ug/g & 91.3 & $<0.0200$ & $4.01 \mathrm{E}+04$ & $3.79 \mathrm{E}+04$ & $3.90 \mathrm{E}+04$ & 5.48 & 97.8 & 91.5 & $\mathrm{n} / \mathrm{a}$ & \\
\hline 83 & 2AY-12-ANU1 & Grab Sample (Total) & S12T021143 & $\mathrm{A}$ & $7439-95-4$ & Magnesium & ug/g & 92.7 & $<2.00 \mathrm{E}-03$ & $<9.15$ & $<8.89$ & $\mathrm{n} / \mathrm{a}$ & $\mathrm{n} / \mathrm{a}$ & 101 & 9.15 & $\mathrm{n} / \mathrm{a}$ & $\mathrm{U}$ \\
\hline 83 & 2AY-12-ANU1 & Grab Sample (Total) & S12T021143 & $\mathrm{A}$ & $7439-96-5$ & Manganese & $\mathrm{ug} / \mathrm{g}$ & 94.6 & $<1.00 \mathrm{E}-03$ & 15.3 & 13.1 & 14.2 & 15.1 & 100 & 4.58 & $\mathrm{n} / \mathrm{a}$ & $\mathrm{J}$ \\
\hline 83 & 2AY-12-ANU1 & Grab Sample (Total) & S12T021143 & $\mathrm{A}$ & $7440-23-5$ & Sodium & ug/g & 93.8 & $<0.0400$ & $2.94 \mathrm{E}+05$ & $2.88 \mathrm{E}+05$ & $2.91 \mathrm{E}+05$ & 2.02 & 90.6 & 183 & $\mathrm{n} / \mathrm{a}$ & \\
\hline 83 & 2AY-12-ANU1 & Grab Sample (Total) & S12T021143 & A & $7723-14-0$ & Phosphorus & ug/g & 84.0 & $<3.00 \mathrm{E}-03$ & 878 & 864 & 871 & 1.60 & 96.9 & 13.7 & $\mathrm{n} / \mathrm{a}$ & \\
\hline 83 & 2AY-12-ANU1 & Grab Sample (Total) & S12T021143 & $\mathrm{A}$ & $7440-21-3$ & Silicon & $\mathrm{ug} / \mathrm{g}$ & 49.0 & 0.0518 & $<22.9$ & $<22.2$ & $n / a$ & $n / a$ & 96.8 & 22.9 & $\mathrm{n} / \mathrm{a}$ & Ua \\
\hline 83 & 2AY-12-ANU1 & Grab Sample (Total) & S12T021143 & A & $7440-31-5$ & Tin & ug/g & 98.7 & $<3.00 \mathrm{E}-03$ & 60.3 & 62.5 & 61.4 & 3.46 & 101 & 13.7 & $\mathrm{n} / \mathrm{a}$ & $\mathrm{J}$ \\
\hline 83 & 2AY-12-ANU1 & Grab Sample (Total) & S12T021144 & $\mathrm{w}$ & $16984-48-8$ & Fluoride & $\mathrm{ug} / \mathrm{g}$ & 103 & $<1.61 \mathrm{E}-03$ & 859 & 861 & 860 & 0.208 & 106 & 55.9 & $\mathrm{n} / \mathrm{a}$ & \\
\hline 83 & 2AY-12-ANU1 & Grab Sample (Total) & S12T021144 & W & $12311-97-6$ & Formate & ug/g & 112 & 0.331 & $1.33 \mathrm{E}+03$ & $1.32 \mathrm{E}+03$ & $1.32 \mathrm{E}+03$ & 0.665 & 101 & 469 & $\mathrm{n} / \mathrm{a}$ & $\mathrm{JB}$ \\
\hline 83 & 2AY-12-ANU1 & Grab Sample (Total) & S12T021144 & W & $16887-00-6$ & Chloride & ug/g & 101 & $<9.98 \mathrm{E}-03$ & $1.45 \mathrm{E}+03$ & $1.40 \mathrm{E}+03$ & $1.43 \mathrm{E}+03$ & 3.32 & 100 & 179 & $\mathrm{n} / \mathrm{a}$ & \\
\hline 83 & 2AY-12-ANU1 & Grab Sample (Total) & S12T021144 & W & 14797-65-0 & Nitrite & ug/g & 103 & 0.138 & $6.01 \mathrm{E}+04$ & $5.73 \mathrm{E}+04$ & $5.87 \mathrm{E}+04$ & 4.80 & 103 & 782 & $n / a$ & \\
\hline 83 & 2AY-12-ANU1 & Grab Sample (Total) & S12T021144 & W & $14808-79-8$ & Sulfate & $\mathrm{ug} / \mathrm{g}$ & 102 & 0.0330 & $1.04 \mathrm{E}+03$ & $1.01 \mathrm{E}+03$ & $1.02 \mathrm{E}+03$ & 2.17 & 101 & 514 & $\mathrm{n} / \mathrm{a}$ & $\mathrm{J}$ \\
\hline 83 & 2AY-12-ANU1 & Grab Sample (Total) & S12T021144 & W & $14797-55-8$ & Nitrate & ug/g & 102 & 0.0970 & $1.84 \mathrm{E}+05$ & $1.77 \mathrm{E}+05$ & $1.81 \mathrm{E}+05$ & 3.91 & 98.7 & 704 & $\mathrm{n} / \mathrm{a}$ & \\
\hline 83 & 2AY-12-ANU1 & Grab Sample (Total) & S12T021144 & W & $14265-44-2$ & Phosphate & ug/g & 98.6 & $<0.0167$ & $2.16 \mathrm{E}+03$ & $2.13 E+03$ & $2.14 \mathrm{E}+03$ & 1.10 & 99.1 & 224 & $\mathrm{n} / \mathrm{a}$ & $\mathrm{J}$ \\
\hline
\end{tabular}

$\mathrm{NA}=$ Not Analyzed, ND $=$ Not Detected

b - MS/MSD Outside Range

$\mathrm{J}$ - Estimated

a - LCS Outside Range

$U$ - Less Than Detection Limit 
Rev. 0

Harlow, Donald G
From:
Harrington, Stephanie J
Sent:
Wednesday, October 10, 2012 12:09 PM
To:
Rosenkrance, Chelsea L; Sams, Terry L; Washenfelder, Dennis J; Kirch, Nicholas W (Nick);
Cc: Powell, William J (Bill); Venetz, Theodore J
Subject:
Rasmussen, Juergen $\mathrm{H}$; Nguyen, Duc M; Templeton, Andrew M; Reynolds, Jacob G FW: AY102 Annulus 10-Working Day Interim Report - SPC Data

All,

The solids SPC data is attached.

Thank you,

Ftephanie oftatington, o h $D$

Chemical Process Engineer

Washington River Protection Solutions,

contractor to the United States Department of Energy

2750E Room A219 or 639 Cullum B119

(509) 376-1336

From: McKinney, Steve G

Sent: Wednesday, October 10, 2012 11:51 AM

To: Harrington, Stephanie J

Cc: Bushaw, Thomas H; Hansen, Daniel R; Prilucik, John R; Johnson, Jo M; Bushaw, Ruth A; Pestovich, John A; Cooke, Gary; Huber, Heinz J

Subject: RE: AY102 Annulus 10-Working Day Interim Report

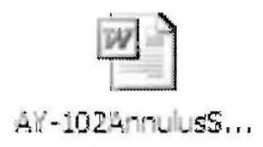

..and here is the SPC data...

Thanks.

From: Bushaw, Ruth A

Sent: Wednesday, October 10, 2012 11:47 AM

To: Harrington, Stephanie J

Cc: Bushaw, Thomas H; McKinney, Steve G; Hansen, Daniel R; Prilucik, John R; Johnson, Jo M

Subject: AY102 Annulus 10-Working Day Interim Report

Importance: High

Stephanie, 
The attached file contains the interim results for the IC and ICP analyses for sample 2AY-12-ANU1. Note that 12-CCN-24 indicates that Sr-90 results are also required for this 10-Working Day report, but those results were already provided to you in the 7-Working Day report.

Here is a brief discussion of the QC:

1. Following the fusion digest, it was noted that there was a very small amount of fine black solids in the bottom of the bottle.

2. Following the acid digest, the digestate was described as clear with no solids remaining.

3. The RPD for Fe from the fusion digest is $74.9 \%$. No qualifier flag was required because the sample result is less than the quantitation limit. Recall that this sample had small black flecks of solid that were attracted to a magnet, so it's not surprising to have a high RPD for Fe.

4. A number of analytes were detected in the preparation blanks.

a. For the fusion digest, $\mathrm{Al}, \mathrm{Na}$, and $\mathrm{Si}$ were detected in the preparation blank, but the concentration was below the quantitation limit and the QAPP does not require comparison to the sample result or a qualifier flag. The QAPP does not require reanalysis of blanks if the results are below the quantitation limit.

b. For the acid digest, $\mathrm{Ca}, \mathrm{Fe}$, and $\mathrm{Si}$ were detected in the preparation blank. The results for $\mathrm{Ca}$ and Fe were below the quantitation limit, so no qualifier flag or reanalysis was required. The $\mathrm{Si}$ preparation blank result was above the quantitation limit; but $\mathrm{Si}$ was not detected in the sample, so no qualifier flag was required and no reanalysis was performed. This is a good example of the typical inconsistent results that the laboratory obtains for $\mathrm{Si}$.

c. For the water digest, formate, nitrite, sulfate, and nitrate were detected in the preparation blank. Results for all analytes, except formate, were below the quantitation limit and no qualifier flags or reanalysis were required. For formate, the blank result is greater than $5 \%$ of the sample result and a "B" flag was applied. Since this is not a required analyte, no repreparation or reanalysis is required.

5. The LCS (prep standard) for $\mathrm{Si}$ in the acid digest had a very low recovery; $49 \%$. This digest method, SW-846 Method 3050B, is not an appropriate digest for Si analysis. The laboratory currently does not have an appropriate digest for $\mathrm{Si}$ analysis. Note that no $\mathrm{Si}$ was detected in the sample using this digest, and an "a" flag was applied to the sample result to indicate the failed LCS recovery. No repreparation and reanalysis was requested because of the limited sample size and because the laboratory does not expect to obtain a better result using this same digestion method.

«< File: AY102 Annulus Riser 83 IC \& ICP Interim Results.x|sX >>

Note that these results are identified as interim because they have not been fully reviewed and, therefore, are potentially subject to change upon final review. If any result changes, I will identify that in the final report.

Thanks,

Ruth A. Bushaw

Project Coordinator

Advanced Technologies and Laboratories International, Inc.

Contractor to the Office of River Protection

U.S. Department of Energy

222-S Laboratory

office: $509-373-4314$

cell: 509-554-4978 


\section{SPC Analysis of AY-102 Annulus Space Sample received 09-27-2012}

The Special Analytical Studies Group at the 222-S Laboratory examined the particulate recovered from the floor of the annulus space in Tank 241-AY-102 and delivered to the 222-S Laboratory on September $27^{\text {th }}, 2012$ (Field sample ID 2AY-12-ANU1). The purpose of this analysis was to perform solid phase characterization (SPC) to determine the compounds present in the material as requested in RPP-PLAN53352. It was expected that identifying the compounds in the sample could elucidate the source of the material.

The analyses that were conducted included scanning electron microscopy (SEM), X-ray Diffraction (XRD) and polarized light microscopy (PLM). The SEM analysis was conducted by Gary A. Cooke using procedure ATS-LT-161-100. XRD analysis was performed by John A. Pestovich utilizing procedure ATSLT-507-101. PLM analysis was done by Dr. Heinz J. Huber under procedure ATS-LT-519-107.

The sample received from Tank Farms consisted of a mixture of light and dark particulate. The majority of the dark particulate was contained in a single, intact piece in the form of a thin sheet of material (Figure 1). This material was tested with a magnet and was found to be slightly attracted by it.

Figure 1: Hot Cell Photo of Sample

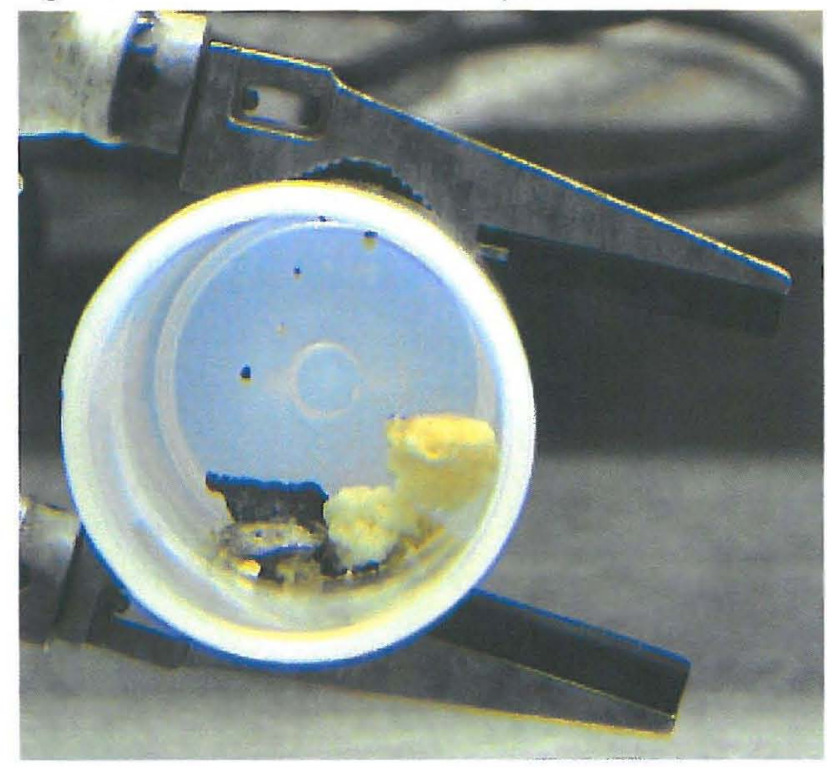

The material was split in the 11A Hot Cells into two fractions. The white salt-like crystalline portion of the sample was identified as Sample S12T021101 (renumbered S12R000514 for solid phase characterization (SPC)). The large dark piece which showed an attraction to a magnet was separated and identified as sample S12R000516. The characterization change notice $12-\mathrm{CCN}-24$ was issued to describe changes in the analytical scheme that resulted from the limited amount of sample material that was available.

Both subsamples were crushed in a mortar and pestle in the hot cells. During crushing, the white chunks became noticeably moister, either through release of pore water or bound water, or through 
deliquescence. Water was not used in subsequent sample preparation steps, to avoid altering watersoluble compounds.

All SEM images shown below are secondary electron images (SEI) paired with an energy dispersive x-ray spectrum (EDS) of the area marked with the + in the photo, unless otherwise noted.

Sample S12R000514 (S12T021101 - 2AY-12-ANU1, White particulate). The major phases of the sample were identified by XRD analysis as Thermonatrite $\left[\mathrm{Na}_{2} \mathrm{CO}_{3} \cdot\left(\mathrm{H}_{2} \mathrm{O}\right)\right]$ and Nitratine $\left[\mathrm{NaNO}_{3}\right]$. Sodium Nitrite $\left[\mathrm{NaNO}_{2}\right]$ and Niter $\left(\mathrm{KNO}_{3}\right)$ were identified as minor phases. The XRD pattern, along with the stick diagrams for the phases that were identified is presented in Figure 2.

Figure 2. XRD Pattern and Matching Phases for Sample S12R000514

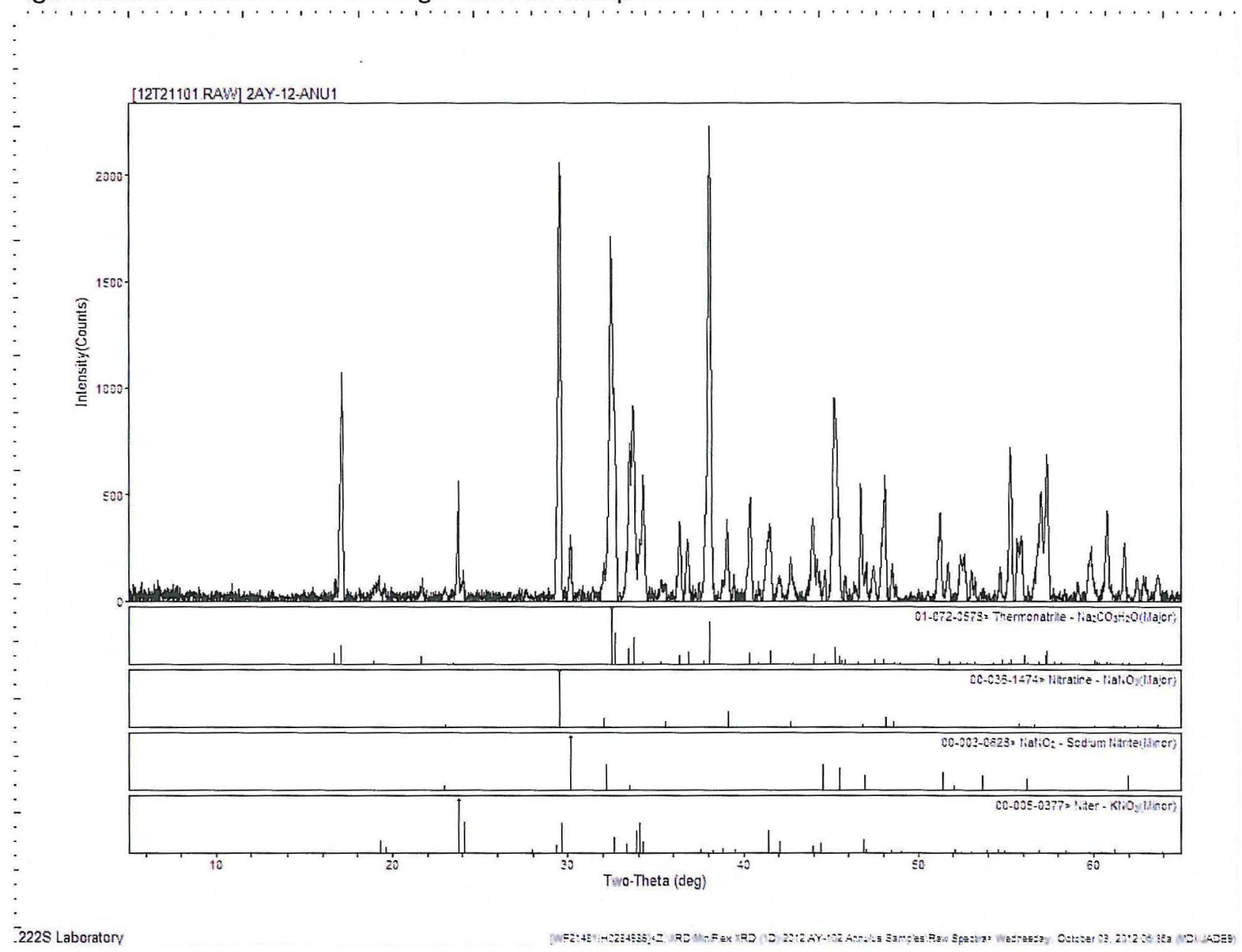

The SEM analysis confirms the presence of the Thermonatrite and the nitrate/nitrite phases.

Thermonatrite was the dominant phase (Figure 3). 
Figure 3. SEI Picture (left) from Sample S12R000514 and EDS spectrum from spot marked with a cross.
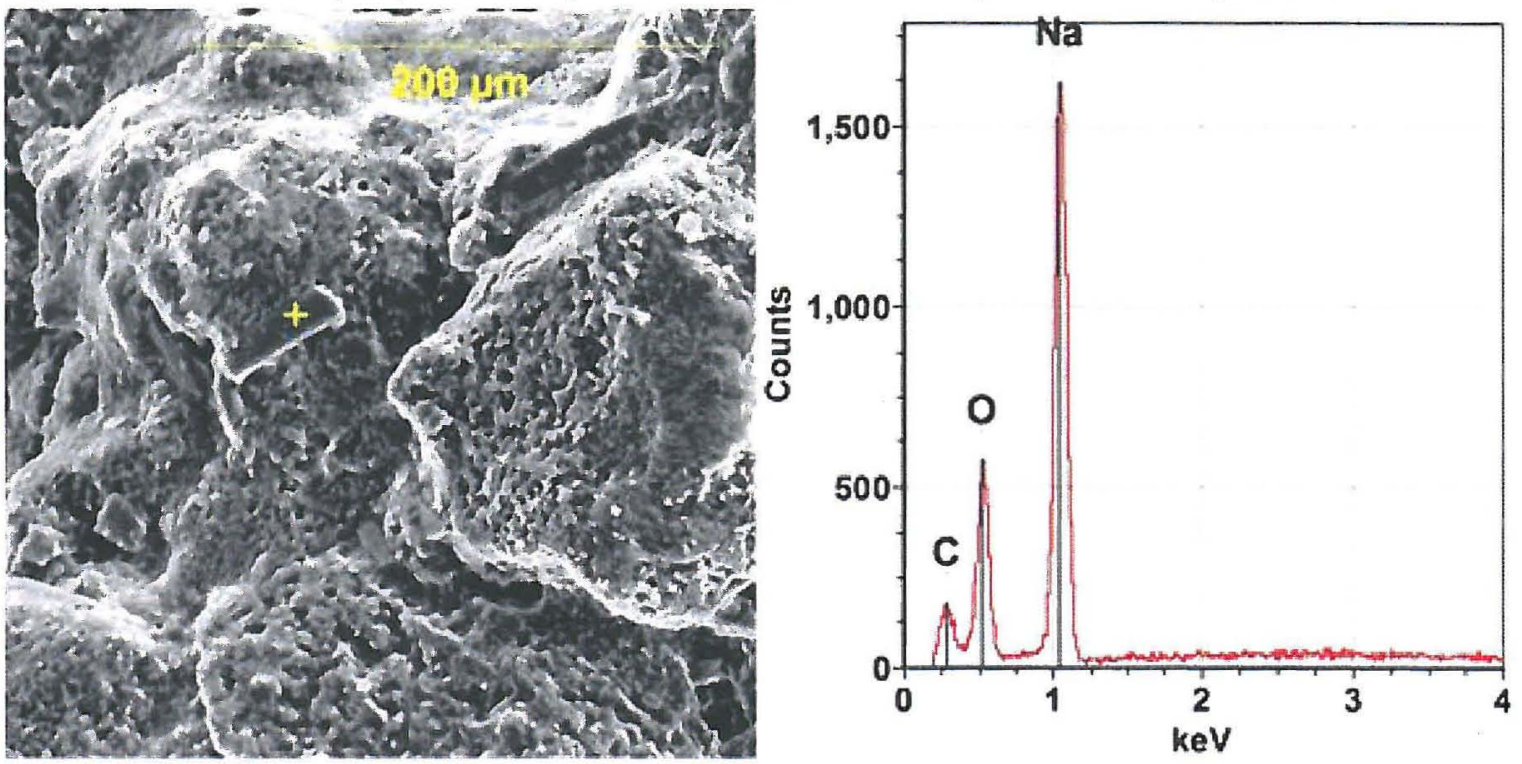

It is difficult for the SEM to distinguish the sodium nitrate from the nitrite, although one or both of these phases are certainly present (Figure 4). The EDS detection for nitrogen, in the presence of the carbon coating, is very poor.

Figure 4. SEI Picture (left) from Sample S12R000514 and EDS spectrum from spot marked with a cross.
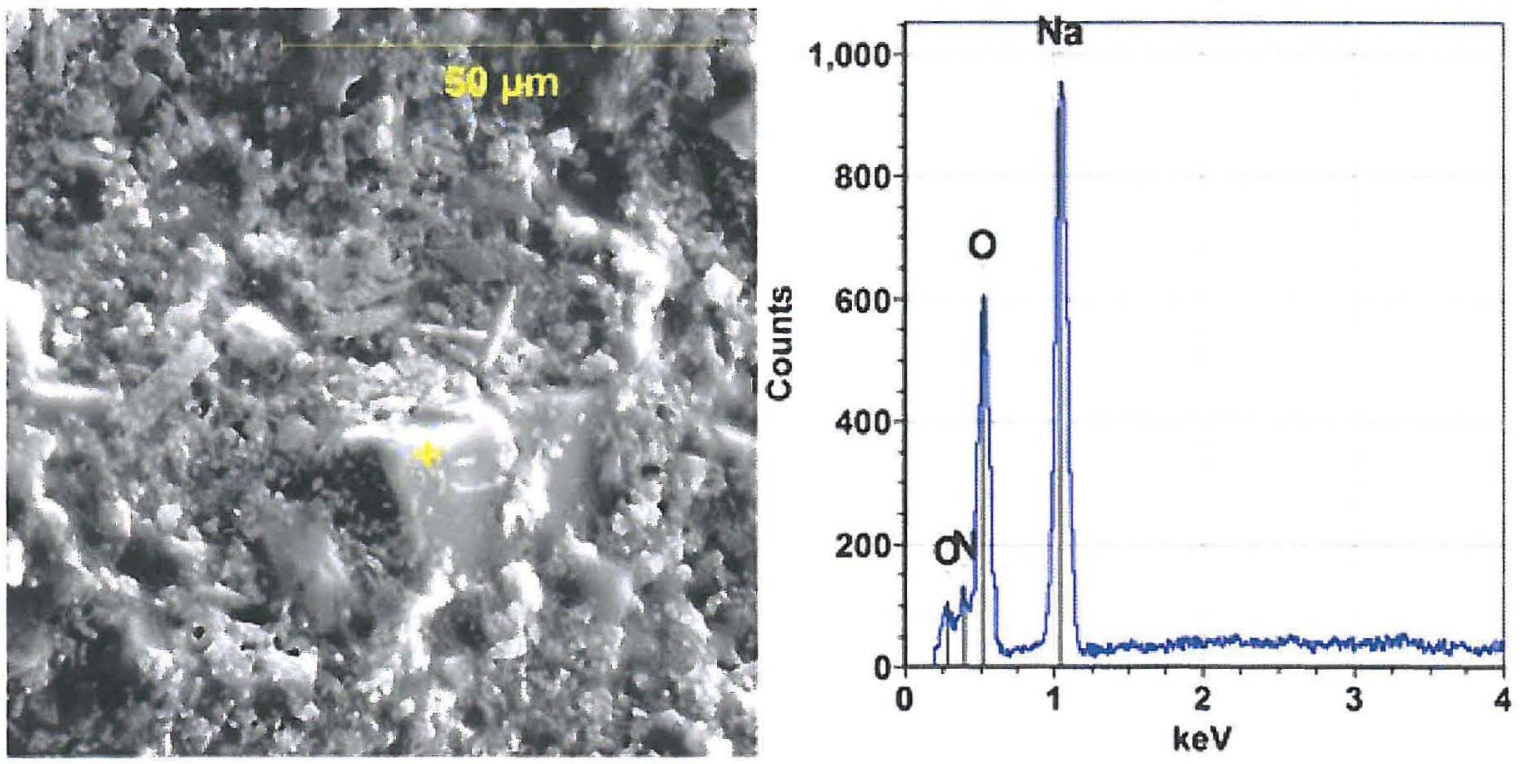

A trace of amount of Sodium Fluoride Sulfate (Kogarkoite, $\mathrm{Na}_{3} \mathrm{FSO}_{4}$ ) was also observed in the SEM analysis of this sample (Figure 5). 
Figure 5. SEI Picture (left) from Sample S12R000514 and EDS spectrum from spot marked with a cross.
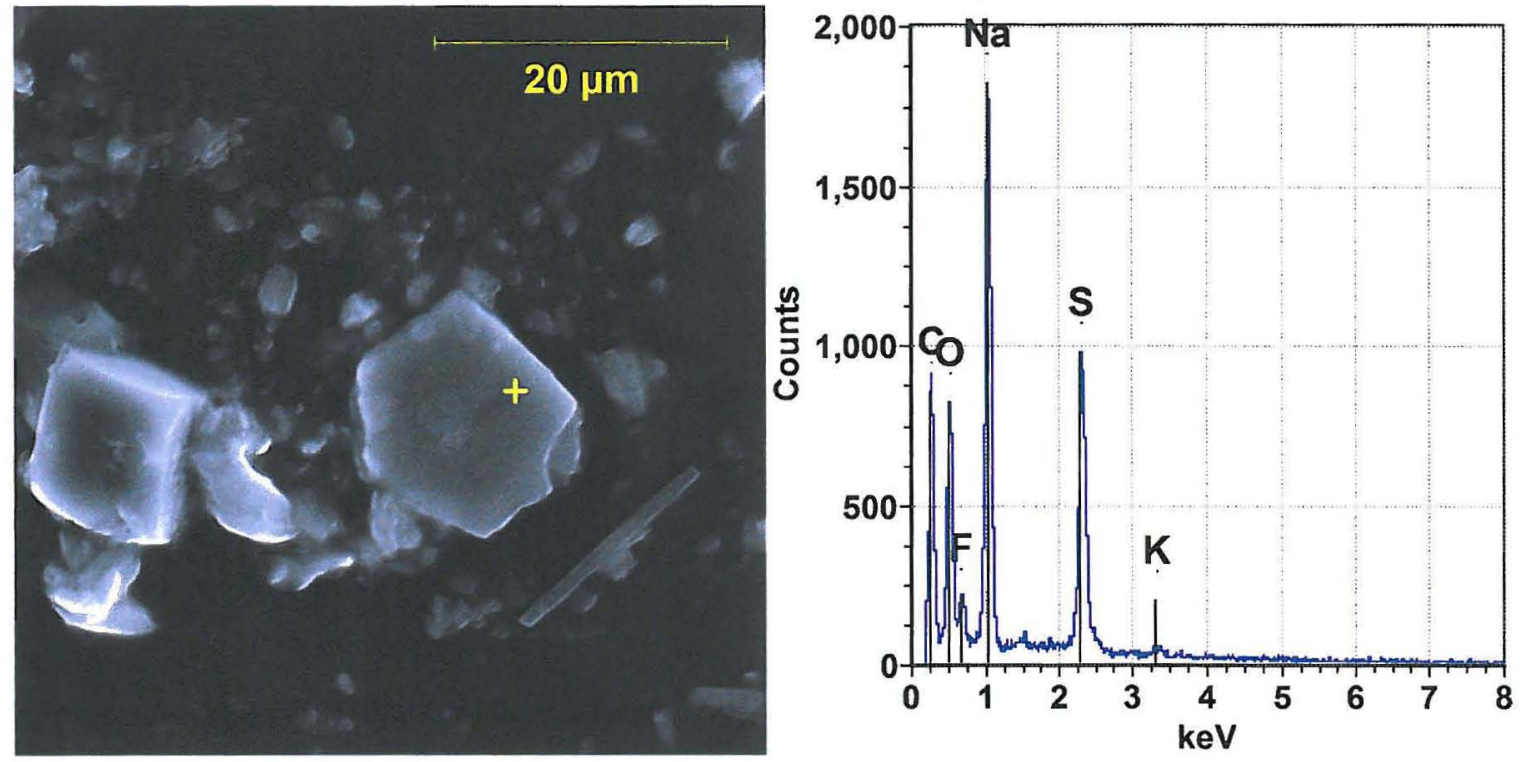

The SEM analysis indicates that the remaining material in the white particulate is one or more potassium salt (Figure 6).

Figure 6. SEI Picture (left) from Sample S12R000514 and EDS spectrum from spot marked with a cross.
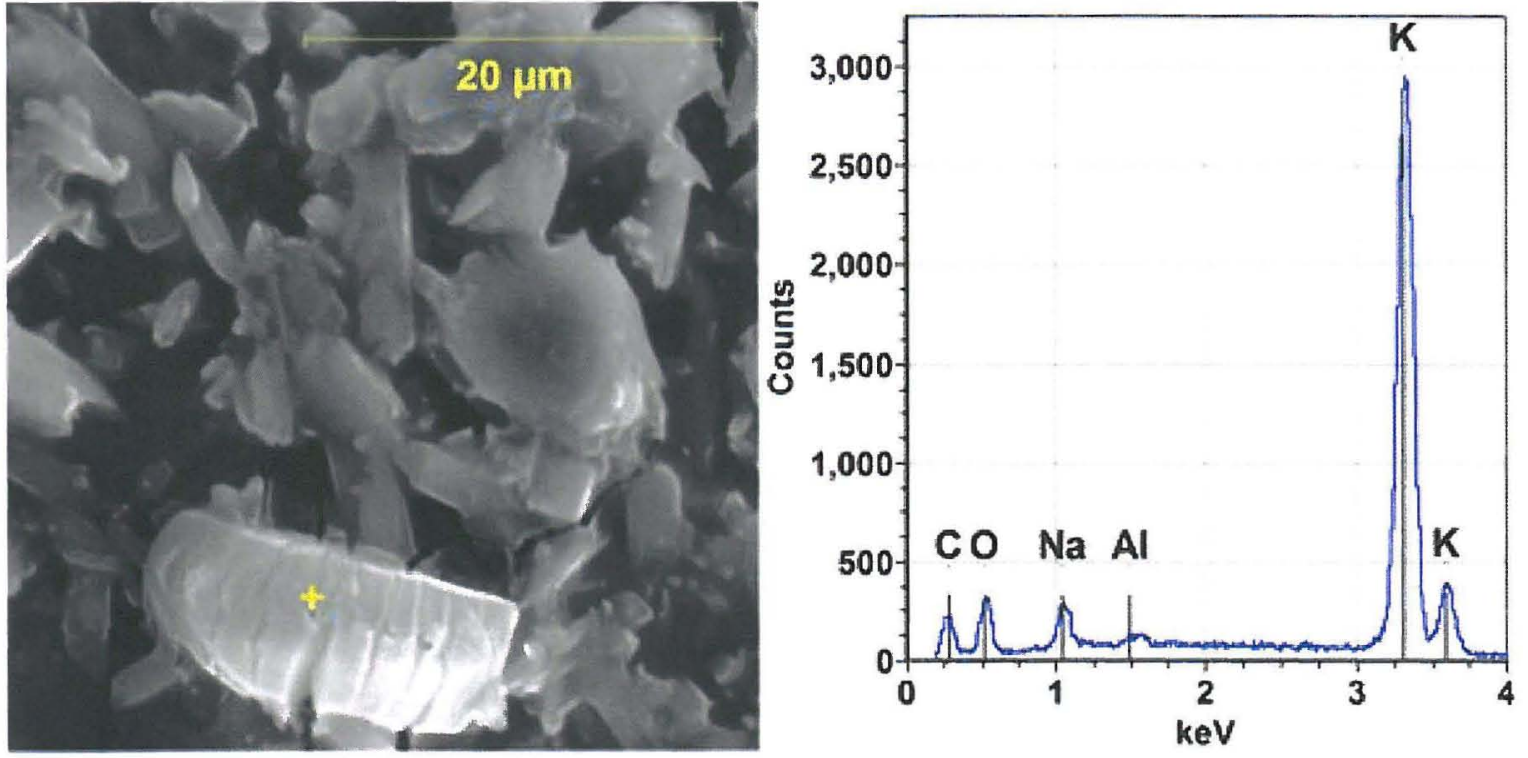

The primary potassium-bearing phase is identified as potassium nitrate using XRD analysis. Detection of nitrogen can be very difficult on the carbon-coated specimens that are examined on the SEM. The nitrogen content of the sodium nitrate/nitrite is 16 to $20 \%$ by weight, yet the nitrogen peak is barely visible in the sodium nitrate/nitrite in Figure 4. For the heavier cation in the potassium nitrate, the nitrogen content falls below $14 \%$, making detection with the EDS detector that much harder.

The largest nitrogen peak associated with the potassium-rich phase is shown in Figure 7. 
Figure 7. SEI Picture (left) from Sample S12R000514 and EDS spectrum from spot marked with a cross.
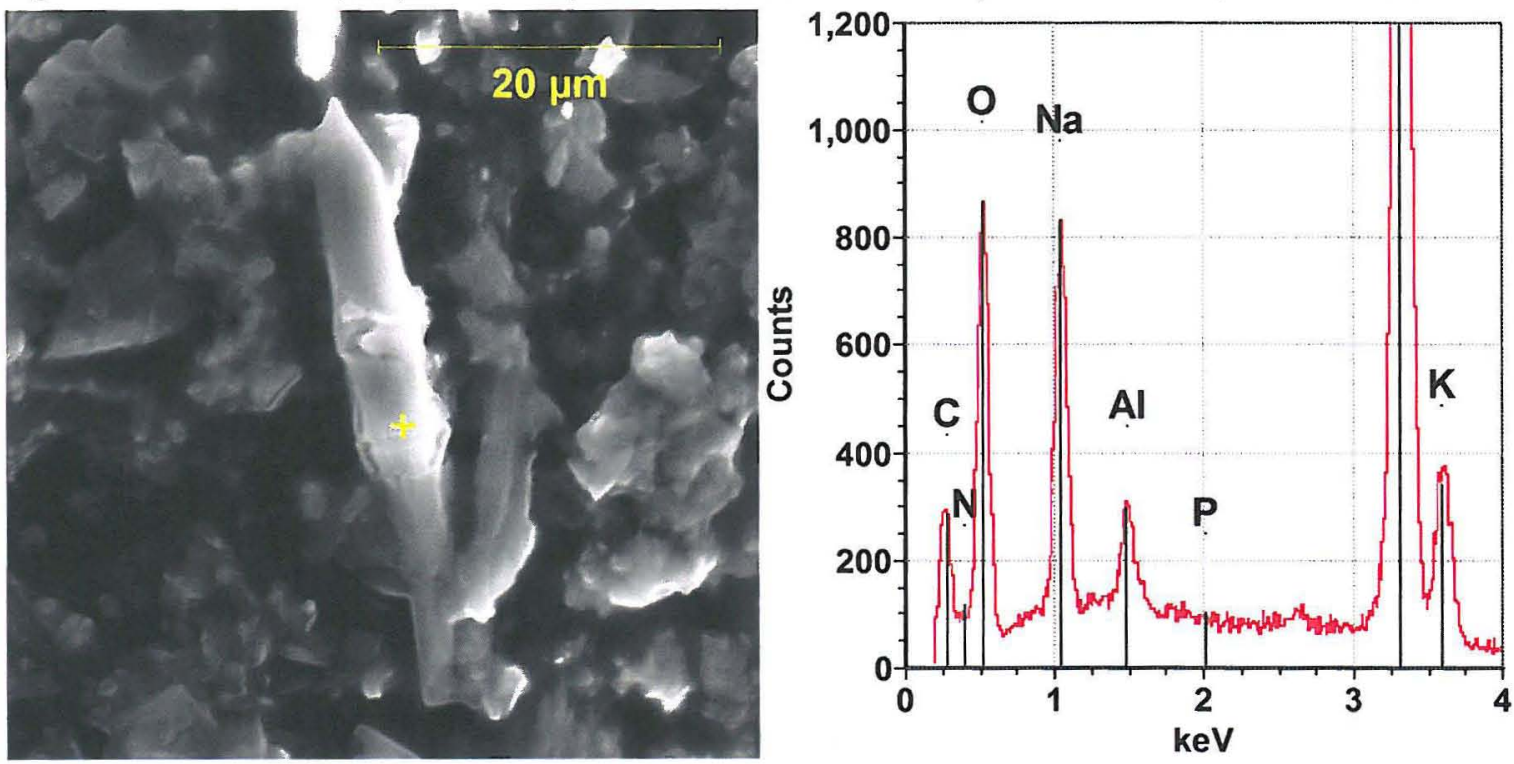

The potassium-bearing phase can be made to stand out in the SEM backscatter electron image (BEI). It is distinctly brighter than the sodium-bearing phases. The potassium-bearing phase appears to comprise about $5-10 \%$ of the sample by volume (Figure 8 ).

Figure 8. BEI Image from Sample S12R000514 showing brighter potassium-bearing phase(s).

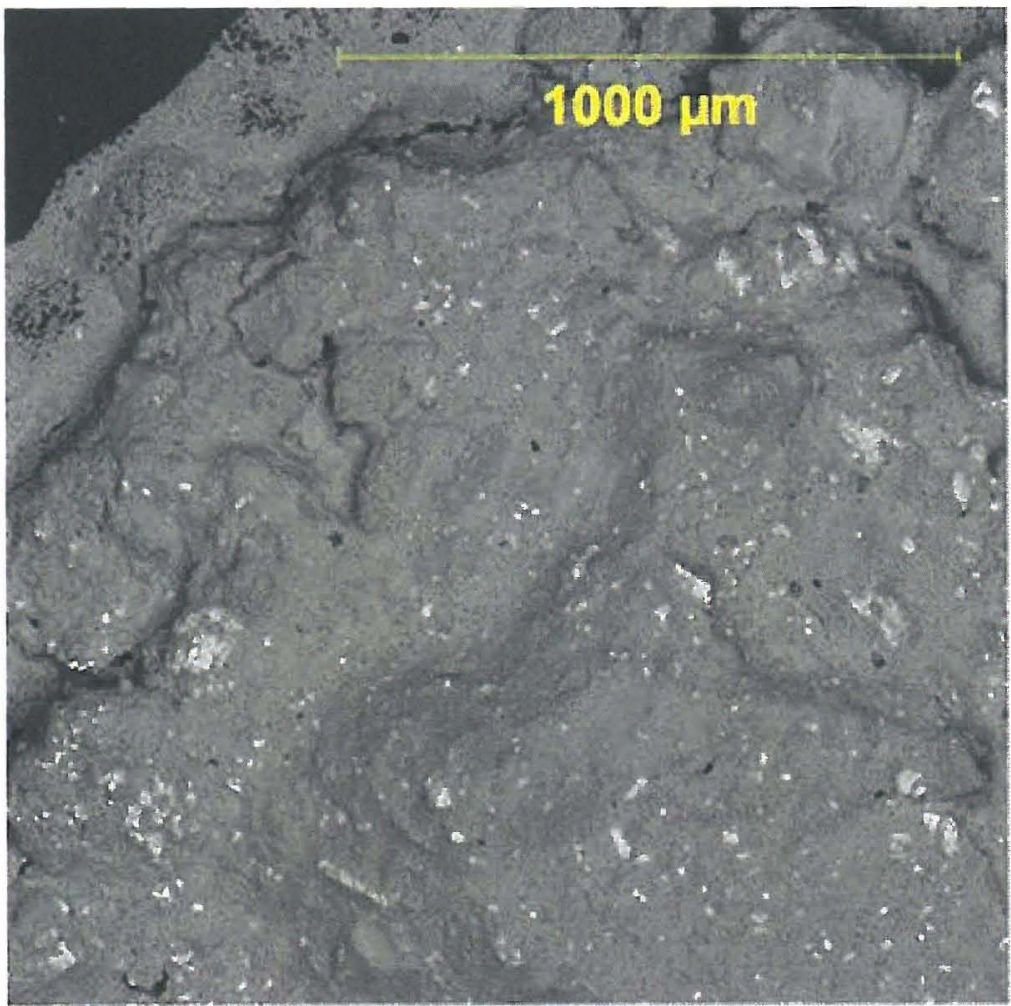


Trace amounts of a uranium-rich particulate were also observed in this sample. A single particle of potassium-rich particulate was observed that contained a significant amount of the element: ruthenium. The sodium phosphate and potassium chloride particulate that were observed on the earlier sample (See attachment B in RPP-53434) were not observed in this current sample.

Polarized light microscopy (PLM) generally confirmed the SEM and XRD observations. Sodium carbonate and sodium nitrate dominate the PLM specimen; trace amounts of sodium oxalate were also observed (Figure 9, Left). An unknown triangular phase with high birefringence (Figure 9, Right) was found on several occasions.

Figure 9. Crossed Polarizers, Red Compensator, Left: 40x Magnification, Right: 60x. Magnification.
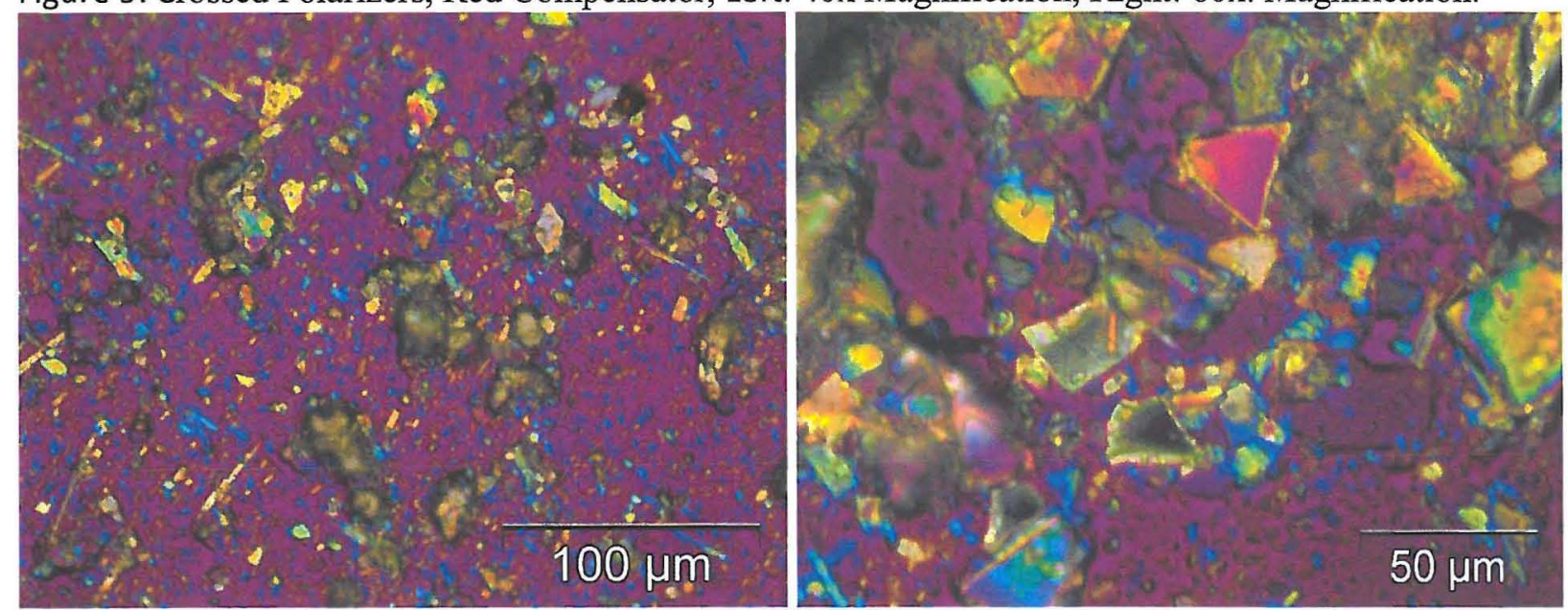

\section{Sample S12R000516 (2AY-12-ANU1-Dark Metallic material).}

The XRD analysis of this material revealed that the presumed iron-bearing, partially magnetic phase is not crystalline. The only crystalline peaks observed were of the same sodium-bearing phases found in S12R000514. However, the intensity (and therefore concentration) of these sodium phases is about a tenth as large as in sample S12R000514. SEM analysis confirmed that the sodium and potassium salts were present in this sample as well. However, the bulk of the sample is an iron oxide (Figure 10). PLM analysis revealed a mixture of the sodium salts and a fine-grained opaque material. 
Rev. 0

DRAFT $10 / 10 / 2012$

Figure 10. SEI Picture (left) from Sample S12R000516 and EDS spectrum from spot marked with a cross.
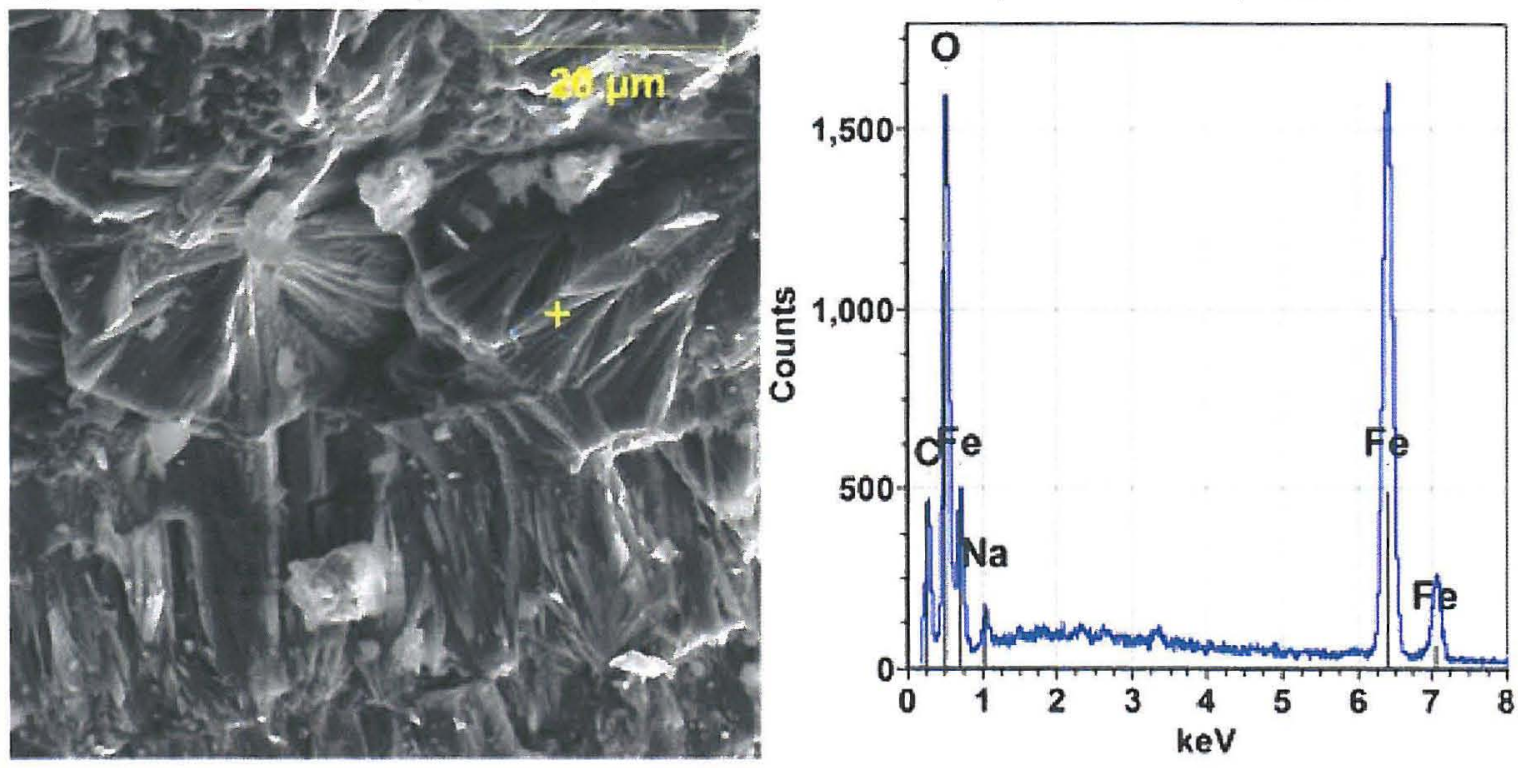

The iron-rich particulate in this sample appears layered, parallel to the long axis of the larger particles, as shown in Figure 11, a BEl image.

Figure 11. BEI Image from Sample S12R000516 Showing Evidence of Layering. 


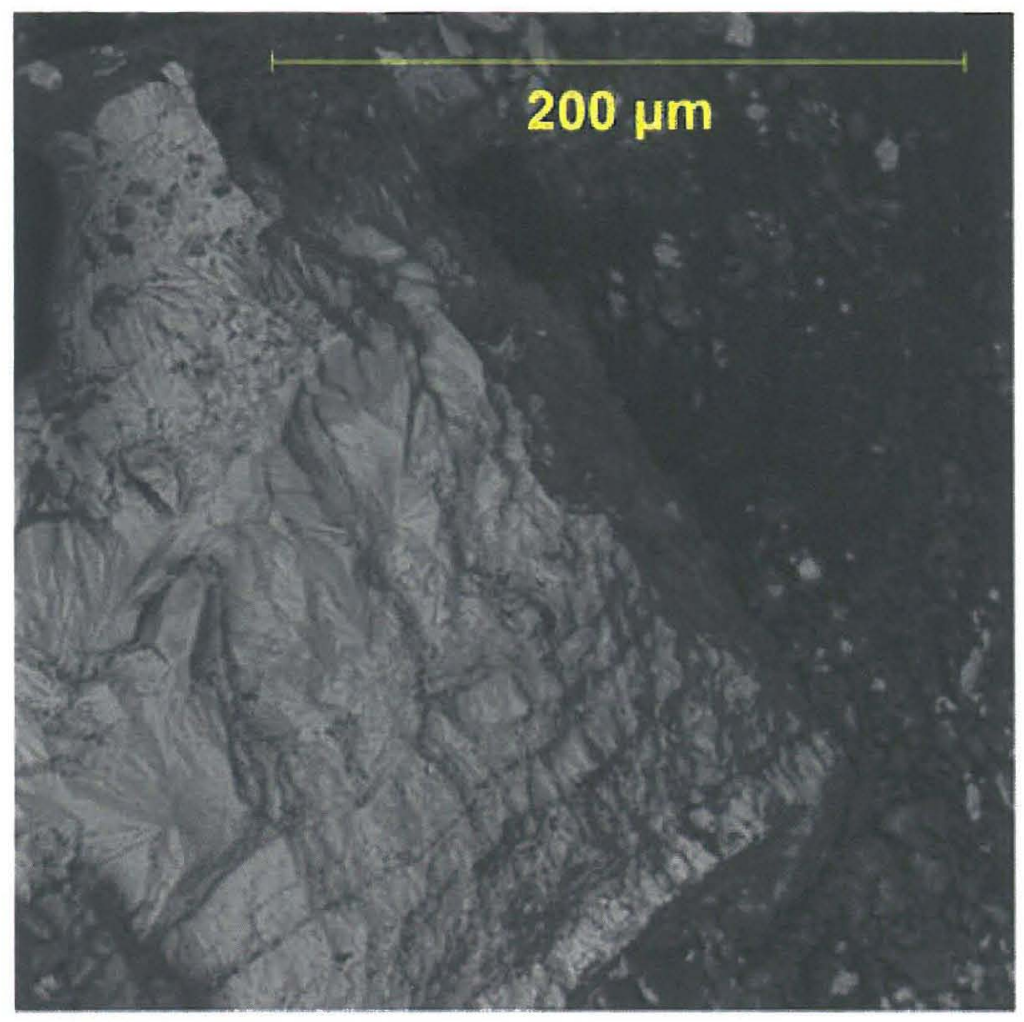

The chemistry, magnetic attraction and morphology of the dark material are consistent with mill scale, or a mixture of mill scale and corrosion.

\section{Discussion}

The sodium phases identified in these samples are all water soluble phases that have been identified in tank waste. The presence of soluble potassium salts is notable. Potassium is generally rare in tank waste.

However, a review of the BBI for the current supernatant liquid in Tank AY-102 (RPP-RPT-44630, Rev. 3) reveals high potassium concentrations in the current supernatant (96000 ug/g Na versus 24281 ug/g K, mass ratio 3.95). RPP-RPT-44630 states:

"In December 2006, most of the supernatant was transferred to tanks 241-AN-106 and 241-AW-102. The tank was refilled with supernatant from tank 241-AP-101 in January 2007."

Prior to this transfer, the liquid supernatant that was to be moved from AP-101 to AY-102 was examined as part of a study examining the effects of mixing the AP-101 supernatant with AY-102 solids or residual supernatant (7S110-RWW-04-029, October 14, 2004). The AP-101 supernatant composite used in that study contained $133000 \mathrm{ug} / \mathrm{ml}$ sodium, $31000 \mathrm{ug} / \mathrm{ml}$ potassium and a mass ratio of about 4.3. This is consistent with the current BBI value for AY-102 supernatant. 
The evaporation study conducted with the AP-101 supernatant in 7S110-RWW-04-029 only reduced the volume by $25 \%$. The solids that formed on evaporation were dominated by sodium fluoride ( $\mathrm{NaF}$ ) and sodium oxalate $\left(\mathrm{Na}_{2} \mathrm{C}_{2} \mathrm{O}_{4}\right)$. If the solids currently found in the $\mathrm{AY}-102$ annulus are derived from this supernatant, they precipitated out during the later stages of evaporation. Solids that precipitated earlier would be expected to have more fluoride bearing salts.

If you have any questions, please contact Gary A. Cooke (509) 373-2154. 

From:
Sent:
To:
Cc:
Subject:
Importance:
Harrington, Stephanie J
Friday, October 05, 2012 1:15 PM
Rosenkrance, Chelsea L; Sams, Terry L; Washenfelder, Dennis J; Kirch, Nicholas W (Nick); Powell, William J (Bill); Venetz, Theodore J
Rasmussen, Juergen $\mathrm{H}$; Nguyen, Duc M; Templeton, Andrew M; Reynolds, Jacob G
FW: AY102 Annulus ATL 7-Working Day Report
High

Please see the 7-Working day report for the preliminary AY-102 annulus sample analyses below.

\section{Otephanie oftattington, DhD}

Chemical Process Engineer

Washington River Protection Solutions,

contractor to the United States Department of Energy

2750E Room A219 or 639 Cullum B119

(509) 376-1336

From: Bushaw, Ruth A

Sent: Friday, October 05, 2012 12:38 PM

To: Harrington, Stephanie J

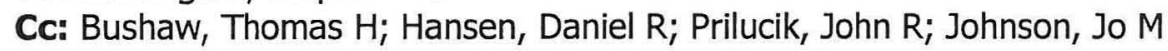

Subject: AY102 Annulus ATL 7-Working Day Report

Importance: High

Stephanie,

We placed a high priority on the AY102 Annulus project and were able to expedite the analyses. At this time, I am able to provide you chemist-reviewed results for both the GEA and Sr-90 analyses. Note that these results are identified as interim because they have not been fully reviewed and, therefore, are potentially subject to change upon final review. If any result changes, I will identify that in the final report.

I sent a message yesterday discussing the RPD $>20 \%$ for the Sr-90 results. Upon further evaluation, it was determined that the results are below the mean difference confidence level. Therefore, the reported results are acceptable per our QAPP and HASQARD, with no data flag required for the high RPD.

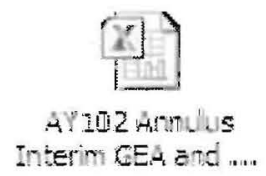

Thanks,

Ruth A. Bushaw

Project Coordinator

Advanced Technologies and Laboratories International, Inc. 
Contractor to the Office of River Protection

Rev. 0

U.S. Department of Energy

222-S Laboratory

office: $509-373-4314$

cell: 509-554-4978 
05-oct-2012 10:52:29

INTERIM

AY102 Annulus

Data Summary of All Results

\begin{tabular}{|l|l|l|l|l|l|l|}
\hline Riser & Segment Number & Segment Portion & SAMPLE R & A & CAS \# & ANALYTE \\
\hline
\end{tabular}

\begin{tabular}{|l|l|l|l|l|l|l|l|}
\hline 83 & 2AY-12-ANU1 & Grab Sample (Total) & S12T021142 & F & $10198-40-0$ & Cobalt-60 & uCi/g \\
\hline 83 & 2AY-12-ANU1 & Grab Sample (Total) & S12T021142 & F & $10045-97-3$ & Cesium-137 & uCi/g \\
\hline 83
\end{tabular}

83 2AY-12-ANU1

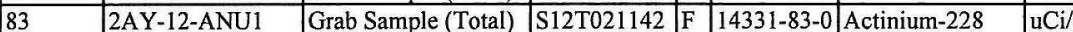

83 2AY-12-ANU1

NA $=$ Not Analyzed, ND $=$ Not Detected

$U$ - Less Than Detection Limit 
Rev. 0

Girardot, Crystal L

From:

Sent:

To:

Subject:
Venetz, Theodore J

Tuesday, November 06, 2012 3:04 PM

Girardot, Crystal L

FW: Preliminary SPC of AY-102 Residual Solids sample received 09-27-2012 at 222-S

From: Cooke, Gary

Sent: Thursday, October 04, 2012 6:26 AM

To: Washenfelder, Dennis J; Rosenkrance, Chelsea L

Cc: Seidel, Cary M; McKinney, Steve G; Venetz, Theodore J; Harrington, Stephanie J

Subject: FW: Preliminary SPC of AY-102 Residual Solids sample received 09-27-2012 at 222-S

Mr. McKinney sent this out earlier this week. It is the preliminary results from the latest sample.

We have some additional information on the Potassium-bearing salt(s) that suggest at least some of it is Potassium Nitrate (KNO3), the mineral Niter.

Gary

From: McKinney, Steve G

Sent: Tuesday, October 02, 2012 12:30 PM

To: Harrington, Stephanie J; Kirch, Nicholas W (Nick); Nguyen, Duc M; Rasmussen, Juergen H; Templeton, Andrew M; Reynolds, Jacob G; Sams, Terry L; Boomer, Kayle D; Washenfelder, Dennis J; Powell, William J (Bill)

Cc: Johnson, Jo M; Prilucik, John R

Subject: FW: Preliminary SPC of AY-102 Residual Solids sample received 09-27-2012 at 222-S

See below.

Thanks.

From: Cooke, Gary

Sent: Tuesday, October 02, 2012 11:53 AM

To: McKinney, Steve G

Subject: Preliminary SPC of AY-102 Residual Solids sample received 09-27-2012 at 222-S

Mr. Pestovich and I have completed our examination of the AY-102 Residual Solids sample that was delivered to the 222-S Laboratory on September 27, 2012. The material was split in the 11A Hot Cells into two fractions. The white saltlike crystalline portion of the sample was identified as Sample S12T021101 (renumbered S12R000514 for solid phase characterization (SPC)). A large dark chunk which showed an attraction to a magnet was separated and identified as sample S12R000516.

Hot Cell Photo: 


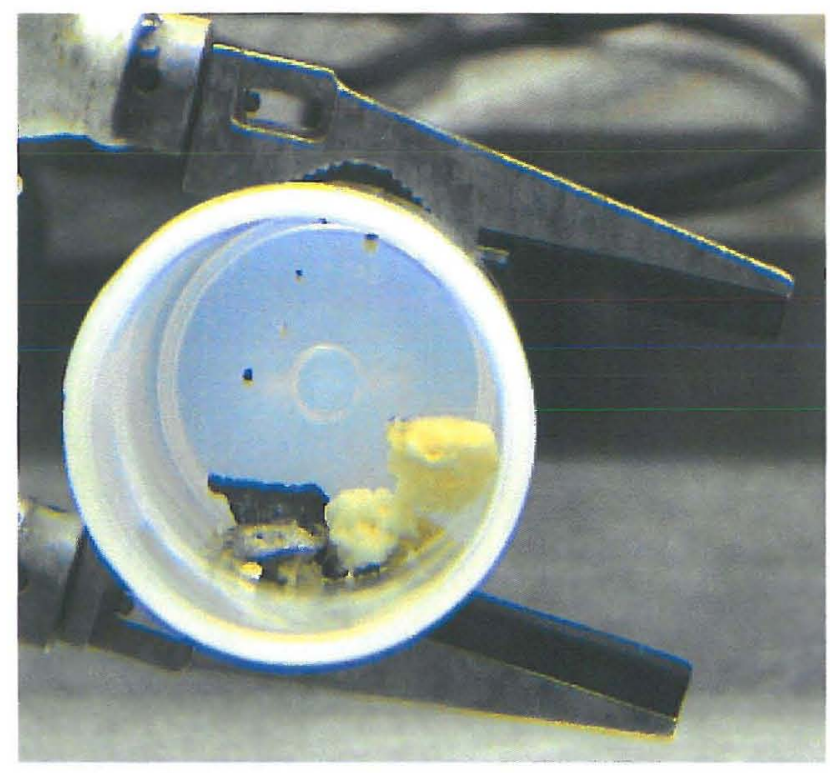

Both subsamples were crushed in a mortar and pestle in the hot cells. During crushing, the white chunks became noticeably moister, either through release of pore water or bound water, or through deliquescence.

Samples were prepared for XRD and SEM analysis using standard procedures ATS-LT-507-101 and ATS- LT-161-100, respectively. Water was not used in the sample preparation steps, to avoid altering water-soluble compounds. All SEM images shown below are secondary electron images (SEI) paired with an energy dispersive $x$-ray spectrum (EDS) of the area marked with the + in the photo, unless otherwise noted.

S12R000514 (S12T021101 - 2AY-12-ANU1, White particulate). The major phases of the sample were identified by XRD analysis as Thermonatrite $\left[\mathrm{Na}_{2} \mathrm{CO}_{3} \cdot\left(\mathrm{H}_{2} \mathrm{O}\right)\right]$ and Nitratine $\left[\mathrm{NaNO}_{3}\right]$. Sodium Nitrite $\left[\mathrm{NaNO}_{2}\right]$ was identified as a minor phase. At least one minor/trace phase remains unidentified in the diffraction pattern.

The SEM analysis confirms the presence of the Thermonatrite and the nitrate/nitrite phases. Thermonatrite was the dominant phase:
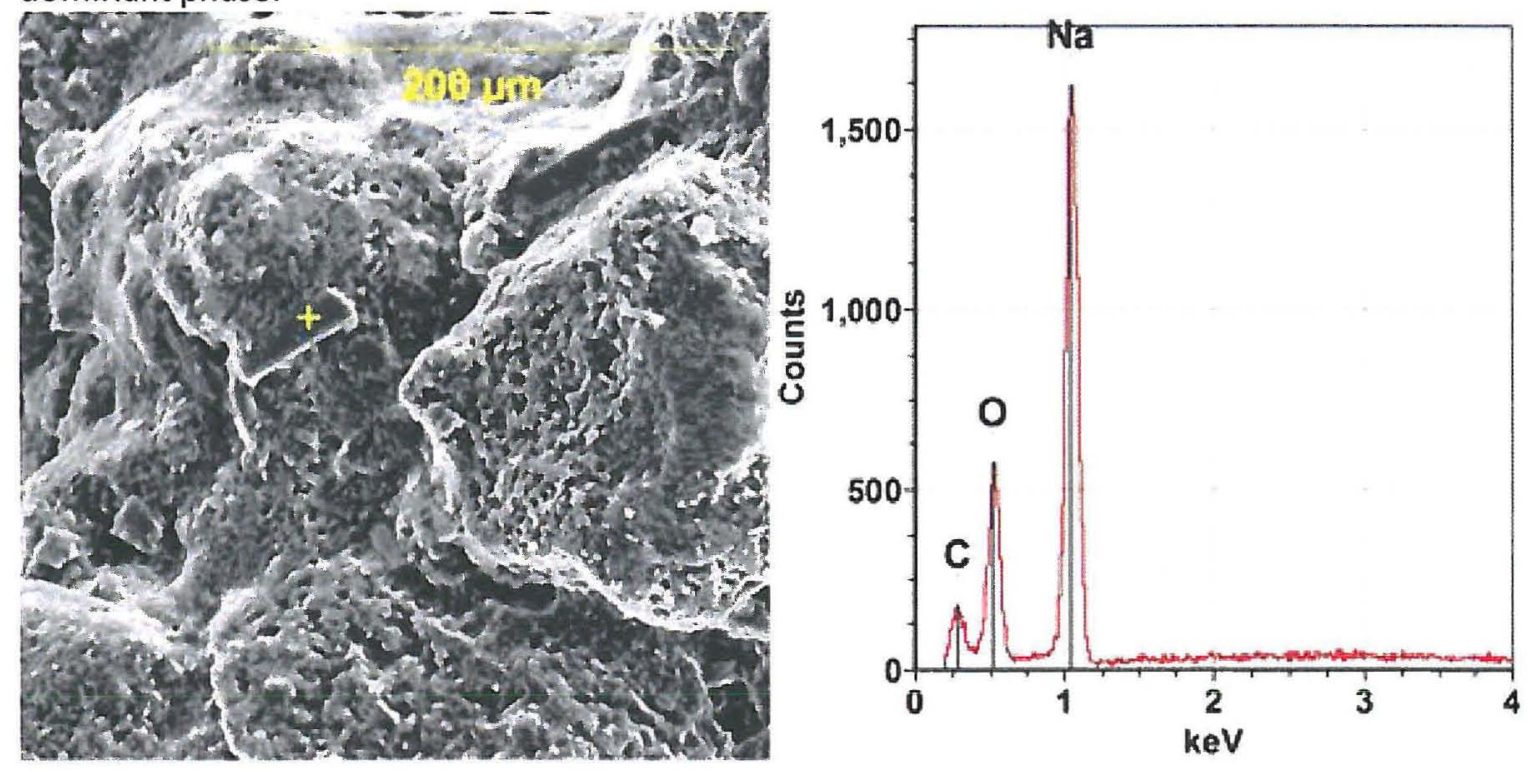

It is difficult for the SEM to distinguish the sodium nitrate from the nitrite, although one or both of these phases is certainly present: 

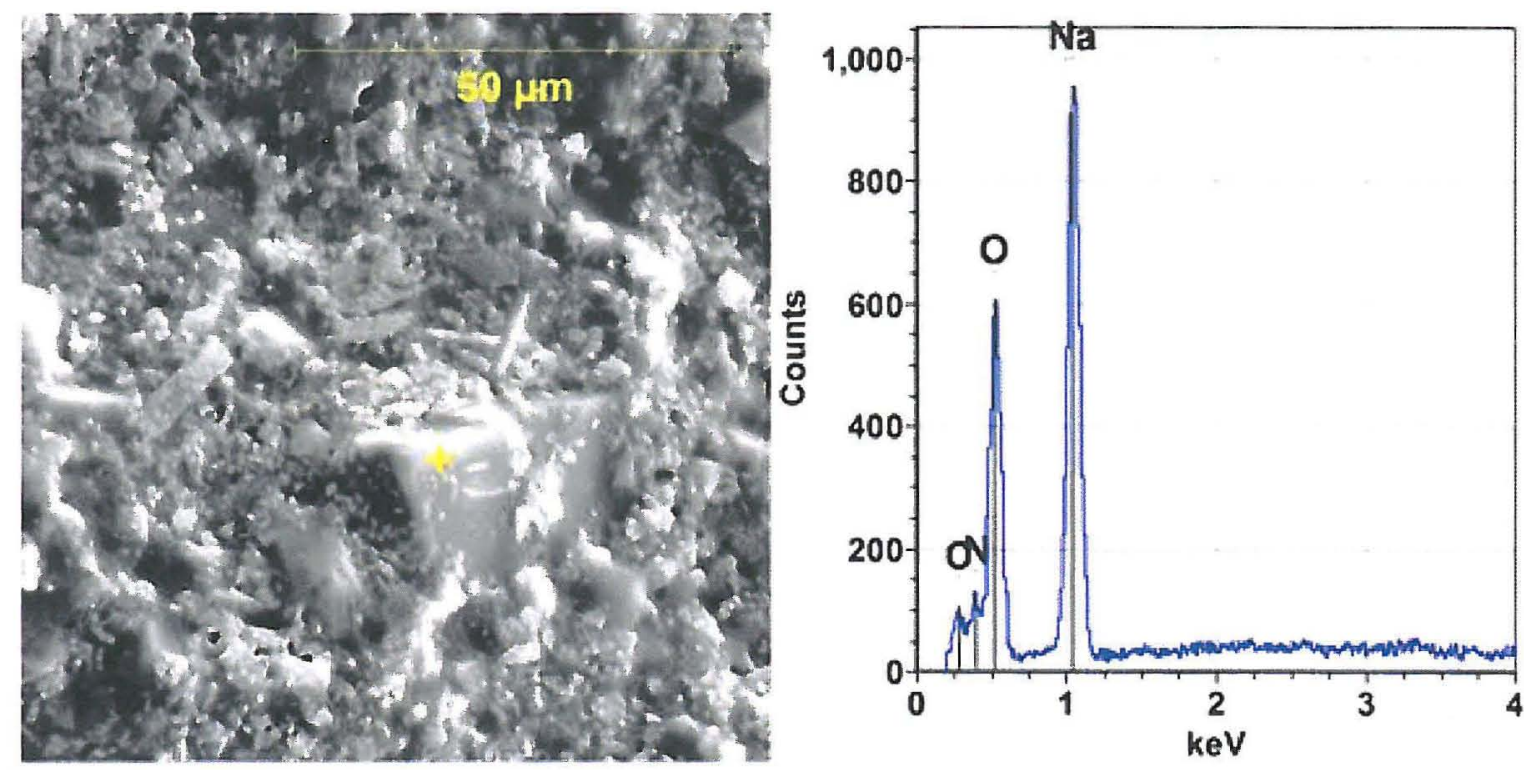

Rev. 0

The SEM analysis indicates that the remaining material in the white particulate is a potassium salt:
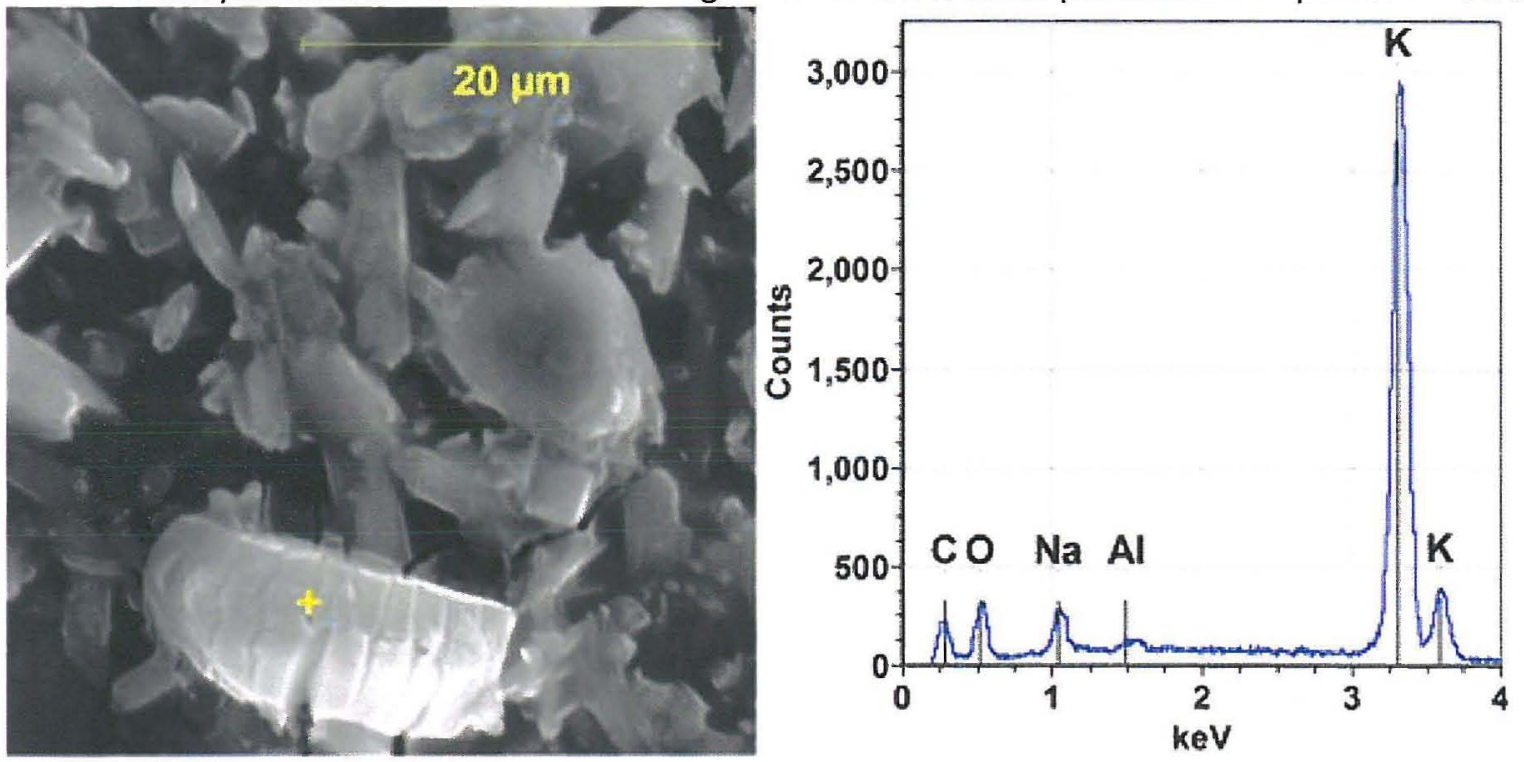

This phase is probably a hydrated potassium carbonate. It has not been identified in the XRD pattern, although there are peaks in the pattern that could not be attributed to the sodium phases mentioned above. The potassium-bearing phase can be made to stand out in the SEM backscatter electron image (BEI). It is distinctly brighter than the sodiumbearing phases. The potassium-bearing phase appears to comprise about $5-10 \%$ of the sample by volume: 
Rev. 0

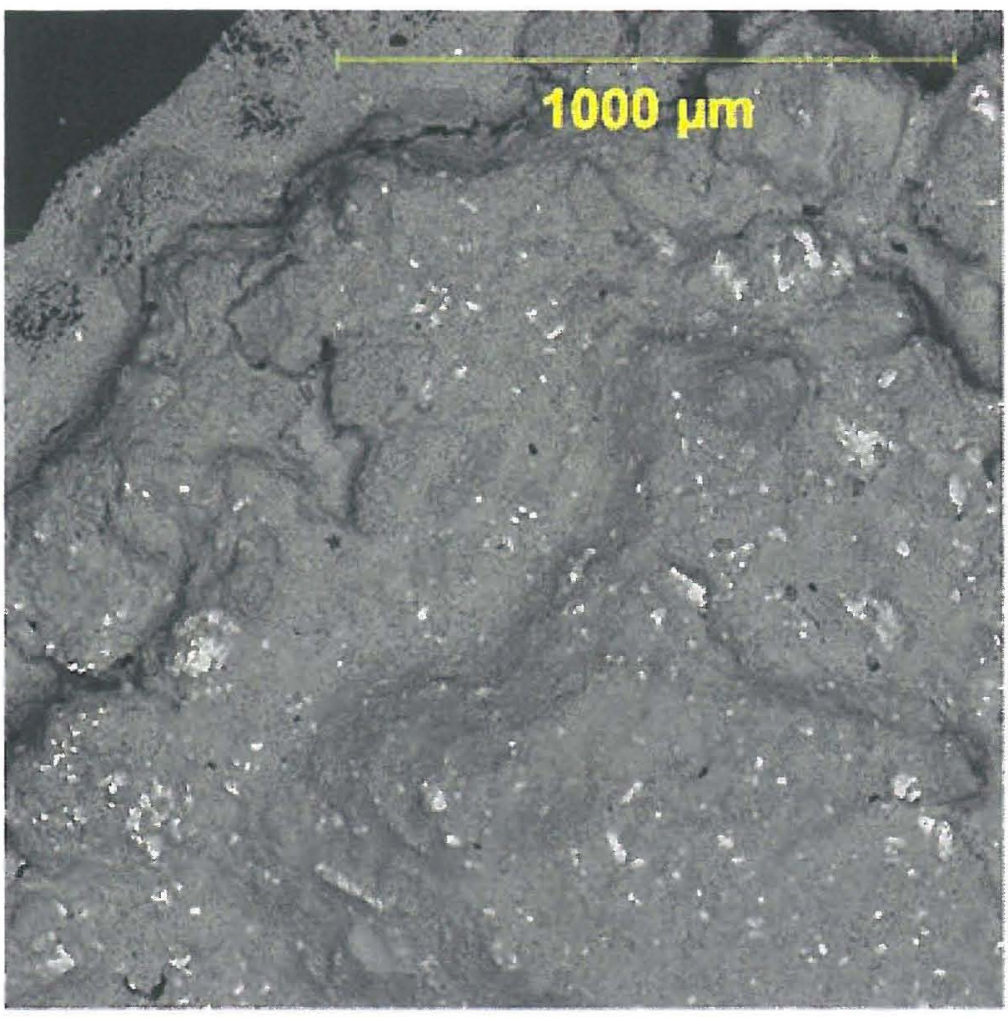

Trace amounts of a uranium-rich particulate were also observed in this sample. A single particle of potassium-rich particulate was observed that contained a significant amount of the element: ruthenium. The sodium phosphate and potassium chloride particulate that were observed on the earlier sample (See attachment B in RPP-53434) were not observed in this current sample.

\section{S12R000516 (2AY-12-ANU1-Dark Metallic material).}

The XRD analysis of this material revealed that the presumed iron-bearing, partially magnetic phase is not crystalline. The only crystalline peaks observed were of the same sodium-bearing phases found in S12R000514. However, the intensity (and therefore concentration) of these sodium phases is about a tenth as large as in sample S12R000514. SEM analysis confirmed that the sodium and potassium salts were present in this sample as well. However, the bulk of the sample is an iron oxide:
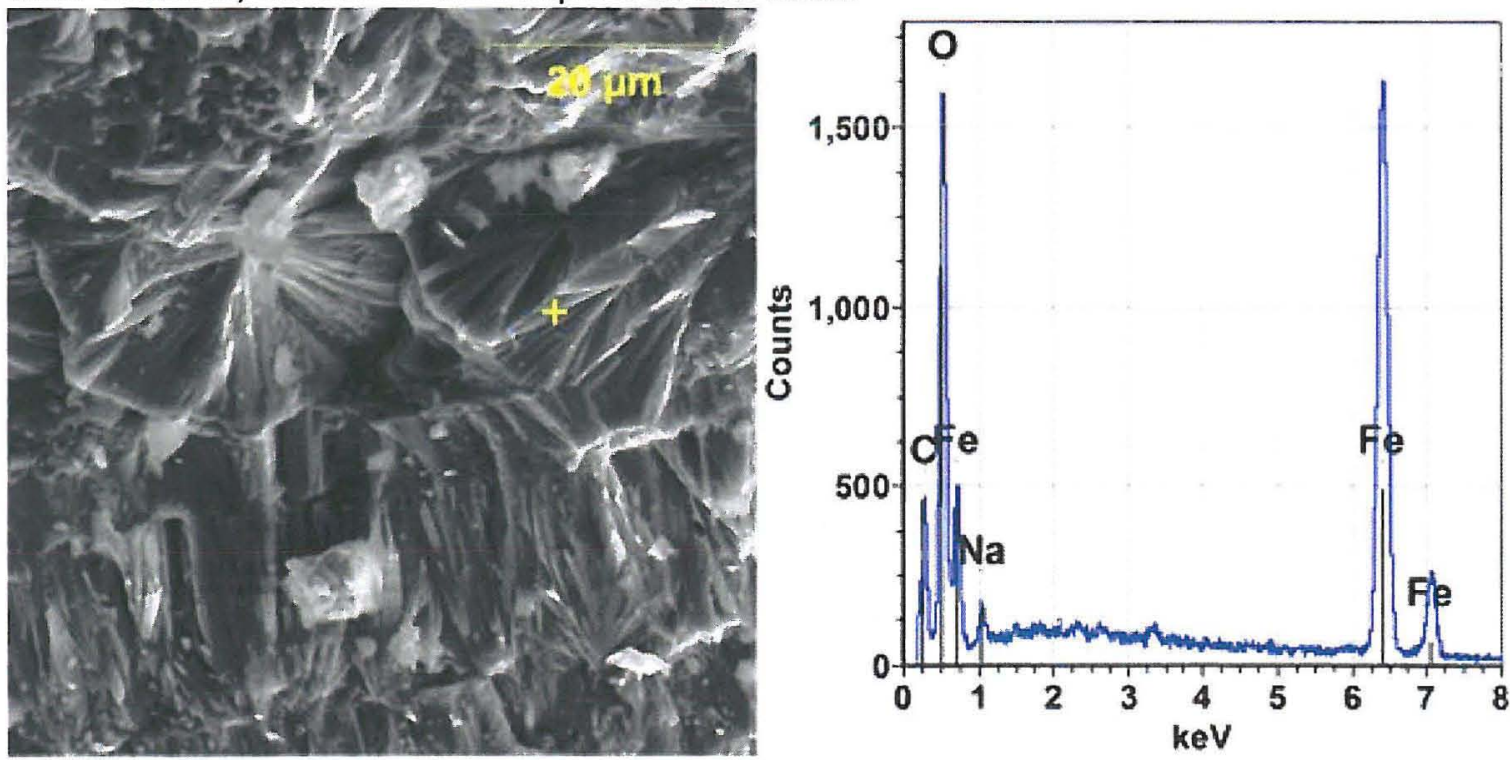

The iron-rich particulate in this sample appears layered, parallel to the long axis of the larger particles, as shown in this BEl image: 
Rev. 0

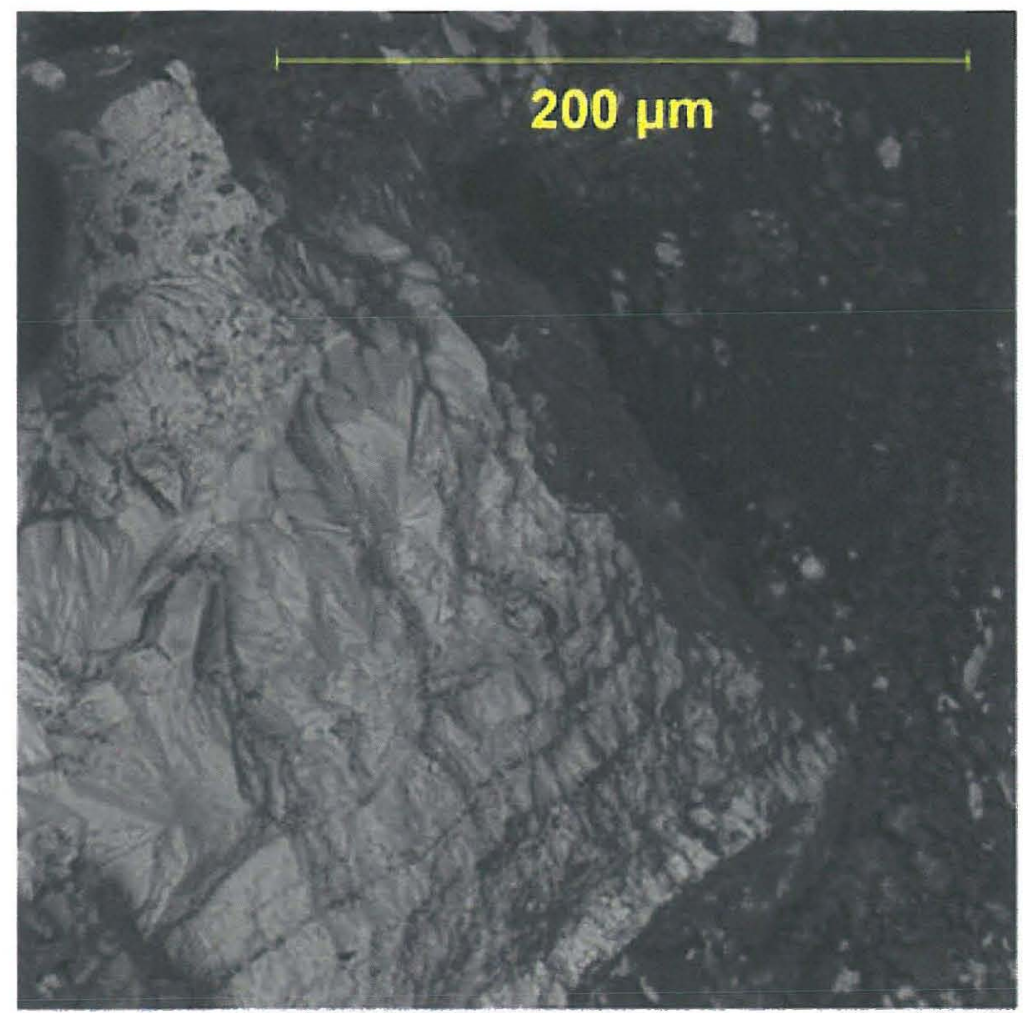

The chemistry, magnetic attraction and morphology of the dark material are consistent with mill scale, or a mixture of mill scale and corrosion.

We are scheduling the PLM examination of these samples for tomorrow, and we will report those results when they are available.

Please forward this email to those you feel should see it. If you or anyone you share this with have any questions please let me know.

\section{Gary A. Cooke}

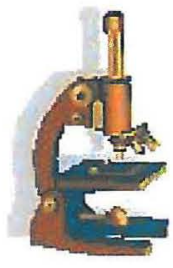

gary cooke@rl.gov (509) 373-2154 Cell: (509) 845-3988

Washington River Protection Solutions, contractor to the United States Department of Energy 


\section{From:}

Sent:

To:

Subject:
Venetz, Theodore J

Monday, October 01, 2012 10:58 AM

Rosenkrance, Chelsea L

FW: AY102 Annulus Update for Requested Analyses

From: Bushaw, Ruth A

Sent: Monday, October 01, 2012 10:49 AM

To: Venetz, Theodore J; Harrington, Stephanie J

Subject: RE: AY102 Annulus Update for Requested Analyses

The archive of the white material was only $0.9 \mathrm{~g}$. Because of the sticky consistency of that material after they ground it in the mortar, I don't think that we will be able to recover the entire $0.9 \mathrm{~g}$ for analysis.

Thanks,

\section{Ruth A. Bushaw}

Project Coordinator

Advanced Technologies and Laboratories International, Inc.

Contractor to the Office of River Protection

U.S. Department of Energy 222-S Laboratory

$373-4314$

From: Venetz, Theodore J

Sent: Monday, October 01, 2012 8:20 AM

To: Bushaw, Ruth A

Subject: RE: AY102 Annulus Update for Requested Analyses

That would be it, requires less sample than I would have thought. Do you know how much archive was salvaged. Ted

From: Bushaw, Ruth A

Sent: Monday, October 01, 2012 8:18 AM

To: Venetz, Theodore J

Cc: Harrington, Stephanie J

Subject: RE: AY102 Annulus Update for Requested Analyses

Ted,

If by "quantitative identification of carbonate" you mean that you would like us to run the TIC/TOC analysis (TIC would be carbonate and bicarbonate), we would need about $0.75 \mathrm{~g}$ (if none is lost on the spatula when taking the aliquots). 
Thanks,

\section{Ruth A. Bushaw}

Project Coordinator

Advanced Technologies and Laboratories International, Inc.

Contractor to the Office of River Protection

U.S. Department of Energy 222-S Laboratory

373-4314

From: Venetz, Theodore J

Sent: Monday, October 01, 2012 7:25 AM

To: Bushaw, Ruth A

Cc: Harrington, Stephanie J

Subject: RE: AY102 Annulus Update for Requested Analyses

Ruth,

Thanks,

Do you know how much of the sample they were actually able to retain as the archive.

Also, if we wanted quantitative identification of carbonate, how much sample would that take. I think we will get some qualitative identification from Gary Cooke, if it is there.

Ted

From: Bushaw, Ruth A

Sent: Thursday, September 27, 2012 5:08 PM

To: Harrington, Stephanie J

Cc: Cooke, Gary; McKinney, Steve G; Venetz, Theodore J

Subject: AY102 Annulus Update for Requested Analyses

Importance: High

Stephanie,

The attached file contains my updated breakdown diagram based on what we discussed back in $11 \mathrm{~A}$ today.

« File: AY102 Annulus SBD.pdf >>

As you know, we loaded out $3.2 \mathrm{~g}$ of the white material and about $0.6 \mathrm{~g}$ of the black material.

Here is my understanding of our new requirements for analysis:

1. Gary Cooke will take aliquots for SEM, PLM, and XRD analysis from our vial containing $3.2 \mathrm{~g}-$ he expects to only need $0.3-0.5 \mathrm{~g}$

2. ATL will prep a sample and duplicate $(\sim 0.5 \mathrm{~g}$ ea) by fusion digest for ICP, GEA, and Sr-90 analysis (therefore $\sim 1 \mathrm{~g}$ used)

3. ATL will prep a sample and duplicate $(\sim 0.25 \mathrm{~g}$ ea) by acid digest for ICP analysis (therefore $\sim 0.5 \mathrm{~g}$ used)

4. ATL will prep a sample and duplicate $(\sim 0.25 \mathrm{~g}$ ea) by water digest for IC analysis (therefore $\sim 0.5 \mathrm{~g}$ used)

5. Gary Cooke received $\sim 0.6 \mathrm{~g}$ of the black material for SEM, PLM, and XRD analysis 
Since we are limited in the amount of sample we have available, and the customer would like to have some material held in archive for potential future testing, please provide a CCN to indicate the following:

Due to limited sample material, preparation and analysis of predigestion spikes for the acid and water digests are not required. Since ratios of results of a small number of major expected constituents will be used for determination of the presence of tank material in the annulus, possible minor losses of constituents during digestion, that would be monitored by a predigestion spike, are not expected to affect the use of the data. Post digestion spikes should be analyzed to monitor instrument performance.

In addition, the laboratory is directed to NOT perform the following analyses for sample 2AY-12-ANU1, due to insufficient sample material:

- $\mathrm{pH}$

- TGA

- TIC/TOC

- Ammonium

For the Format II report, the interim results for GEA, PLM, SEM, and XRD will be transmitted via electronic mail within 7 working days after receipt of sample 2AY-12-ANU1. Results for ICP, IC, and Sr-90 will be transmitted within 10 working days.

Thanks,

Ruth A. Bushaw

Project Coordinator

Advanced Technologies and Laboratories International, Inc.

Contractor to the Office of River Protection

U.S. Department of Energy

222-S Laboratory

office: $509-373-4314$

cell: 509-554-4978 
Rev. 0

5.3 Riser 90- October 2012 Samples 


$\begin{array}{ll}\text { From: } & \text { Cooke, Gary } \\ \text { Sent: } & \text { Tuesday, October 30, 2012 1:30 PM } \\ \text { To: } & \text { McKinney, Steve G; Harrington, Stephanie J; Sams, Terry L; Reynolds, Jacob G; Boomer, } \\ & \text { Kayle D; Venetz, Theodore J } \\ \text { Cc: } & \text { Bushaw, Ruth A; Seidel, Cary M; Pestovich, John A; Huber, Heinz J; Page, Jason S; Herting, } \\ \text { Subject: } & \text { Daniel L } \\ & \text { RE: Solid Phase Characterization of 2AY-12-ANU-3A and 2AY-12-ANU-5A }\end{array}$

One unfortunate typo found, bottom of page six:

the floor sample (2AY-12-ANU-3A)

should be:

the floor sample (2AY-12-ANU-1)

Gary

\section{From: Cooke, Gary}

Sent: Tuesday, October 30, 2012 12:48 PM

To: McKinney, Steve G; Harrington, Stephanie J; Sams, Terry L; Reynolds, Jacob G; Boomer, Kayle D; Venetz, Theodore J Cc: Bushaw, Ruth A; Seidel, Cary M; Pestovich, John A; Huber, Heinz J; Page, Jason S; Herting, Daniel L Subject: Solid Phase Characterization of 2AY-12-ANU-3A and 2AY-12-ANU-5A

See attached.

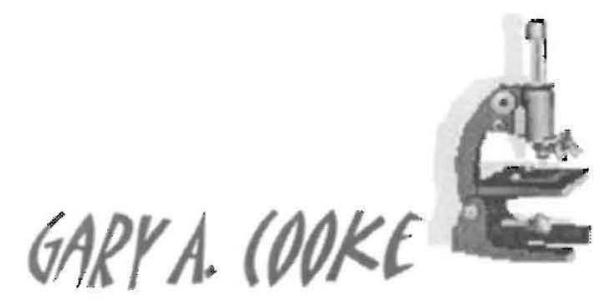

gary cooke@rl.gov (509) 373-2154 Cell: (509) 845-3988

Washington River Protection Solutions, contractor to the United States Department of Energy 


\title{
Harlow, Donald G
}

\author{
From: $\quad$ Harrington, Stephanie J \\ Sent: $\quad$ Tuesday, October 30, 2012 1:07 PM \\ To: $\quad$ Rasmussen, Juergen $\mathrm{H}_{i}$ Nguyen, Duc $\mathrm{M}$; Templeton, Andrew M; Washenfelder, Dennis J; \\ Girardot, Crystal L; Rosenkrance, Chelsea L \\ Subject: \\ FW: Solid Phase Characterization of 2AY-12-ANU-3A and 2AY-12-ANU-5A \\ Attachments: \\ Samples12-ANU-3A5A.doc
}

See attached write-up for the solid phase characterization of the last AY-102 annulus samples from the air duct ( $3 A$ ) and mound (5A).

Thank you,

\section{Stephanie othattington, ofh $D$}

Chemical Process Engineer

Washington River Protection Solutions, contractor to the United States Department of Energy

2750E Room A219 or 639 Cullum B119

(509) 376-1336

From: Cooke, Gary

Sent: Tuesday, October 30, 2012 12:48 PM

To: McKinney, Steve G; Harrington, Stephanie J; Sams, Terry L; Reynolds, Jacob G; Boomer, Kayle D; Venetz, Theodore J Cc: Bushaw, Ruth A; Seidel, Cary M; Pestovich, John A; Huber, Heinz J; Page, Jason S; Herting, Daniel L

Subject: Solid Phase Characterization of 2AY-12-ANU-3A and 2AY-12-ANU-5A

See attached.

\section{Gary A. Cooke $=$}


This document reports on our solid phase characterization (SPC) of two samples: samples 2AY-12-ANU-3A and sample 2AY-12-ANU-5A, received at the 222-S laboratory on October 17, 2012. The SPC analyses consist of $x$-ray diffraction (XRD), scanning electron microscopy (SEM) equipped with an energy dispersive spectrometer (EDS) and polarized light microscopy (PLM).

The analysis of samples using this instrumentation is conducted in accordance with the following procedures:

ATS-LT-161-100, 222-S "Laboratory Sample Preparation and Operating Procedure for Scanning Electron Microscopes" and ATS-LT-161-101, 222-S "Laboratory Technology Procedure for the FEl Quanta 600 Scanning Electron Microscope" are employed for SEM analysis. For XRD analysis ATS-LT-507-101, "222-S Laboratory X-Ray Diffractometry (XRD)" details the analysis steps. The PLM analysis is conducted in accordance with ATS-LT-519-107, "222-S Laboratory Polarized Light Microscopy".

Prior to sub-sampling, all the sample material was poured into a 2 inch diameter Petri dish. Macro photographs and photomicrographs were taken of this material. Figures 1 and 2 show a representative macro photograph and photomicrograph for the two samples. Both samples appear to be mixtures of light colored aggregates along with dark reddish brown material that is assumed to be a mix of rust and mill scale. Sample 2AY-12-ANU-3A is mostly composed of light colored particulate while sample 2AY-12-ANU-5A consists primarily of rust and scale.

Figure 1. Optical Images of 2AY-12-ANU-3A. Petri Dish is 2 Inches in Diameter.
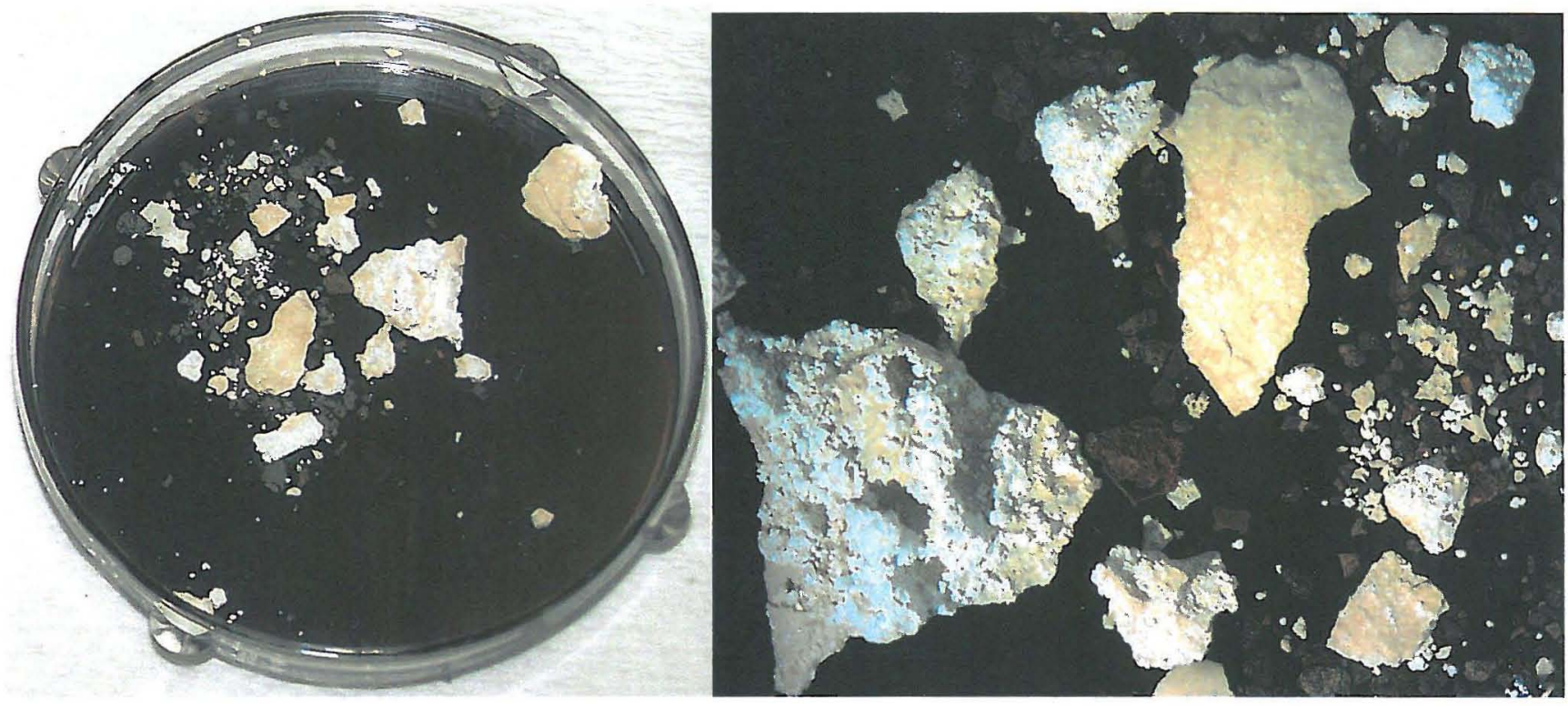
Figure 2. Optical Images of 2AY-12-ANU-5A. Petri Dish is 2 Inches in Diameter.
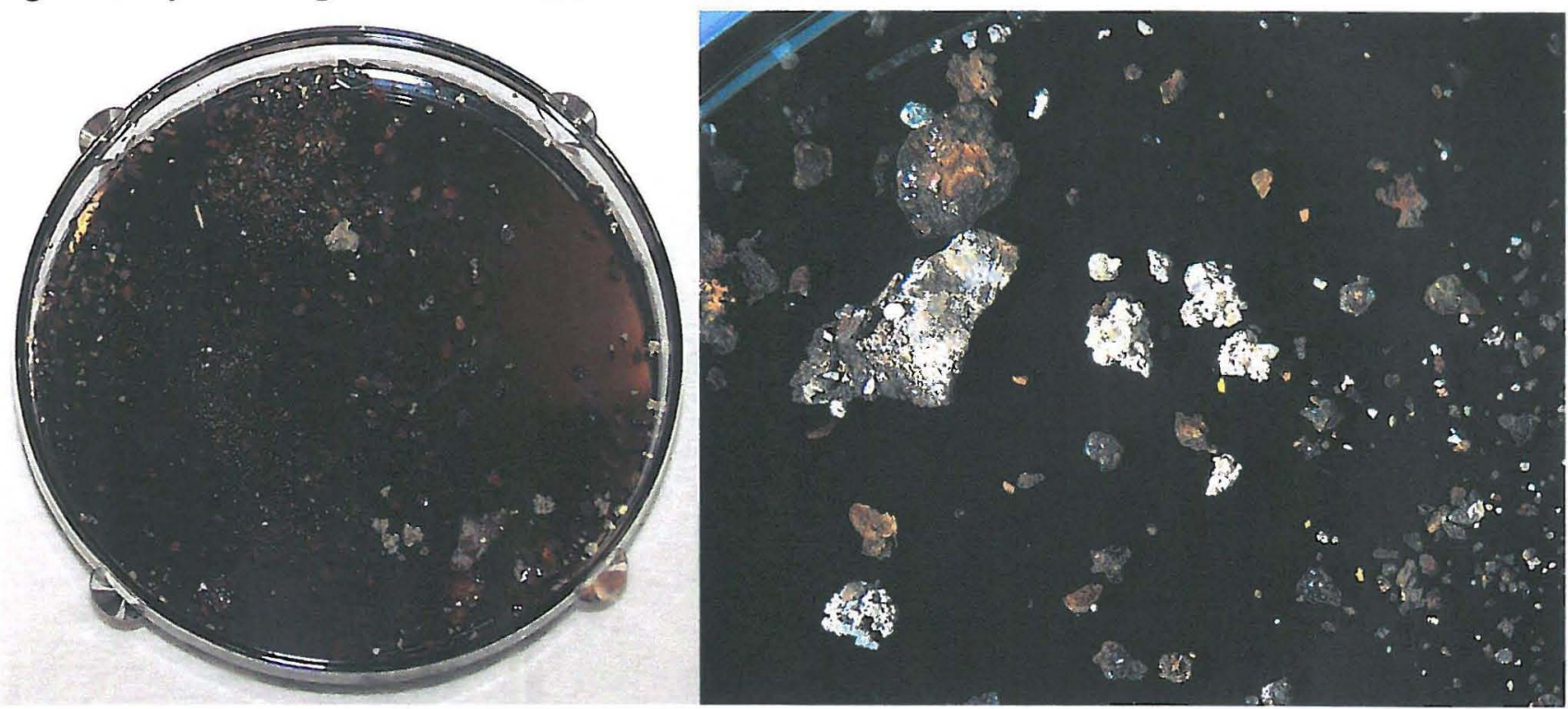

Close-up optical images of some of the white particulate in both samples show that they consist primarily of aggregates of smaller particles. In the case of the 2AY-12-ANU-3A sample, these appear to be aggregates of salt crystals, either botryoidal (Figure 3), lath- or blade-like (Figure 4) or glassy and vesicular (Figure 5). These appear to be at least two different salt crystals. The glassy vesicular surface appears to have been at the surface of the "cascade" and to have crystallized in the presence of gas bubbles.

Figure 3. Aggregate of Salt Crystals showing Botryoidal Morphology from Sample 2AY-12-ANU-3A.

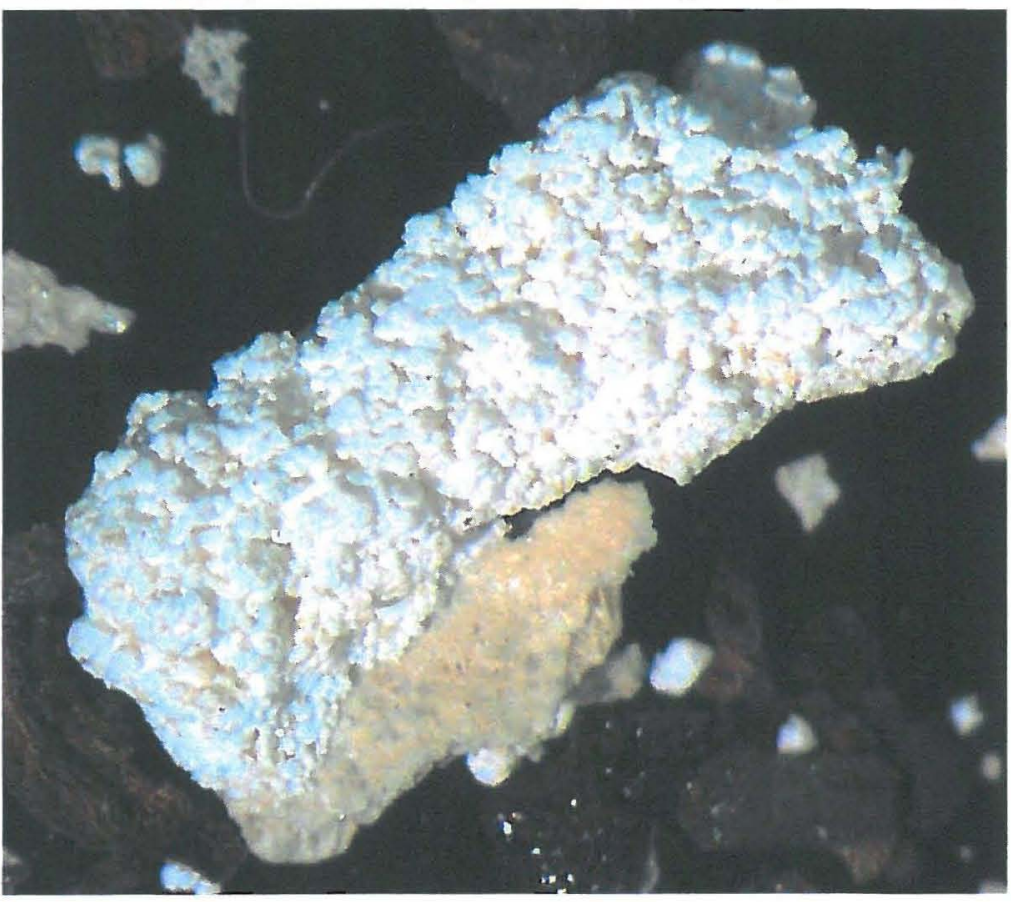


Figure 4. Aggregate of Salt Crystals showing Blade- or Lath-like Morphology from Sample 2AY-12-ANU-3A.

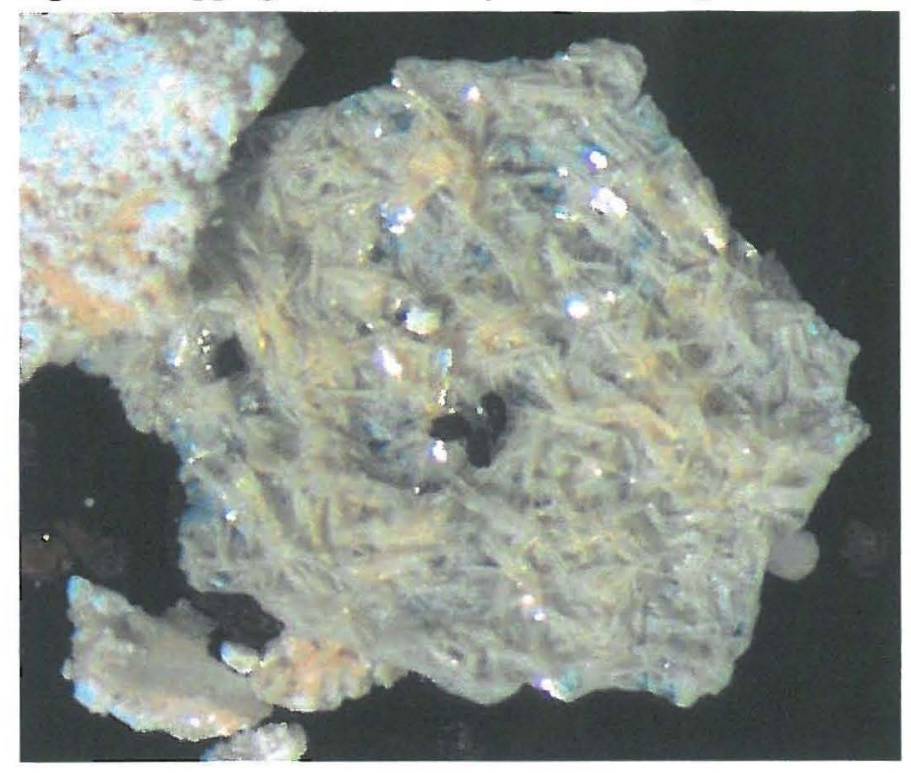

Figure 5 Aggregate of Salt Crystals showing Glassy and Vesicular Morphology from Sample 2AY-12-ANU-3A.

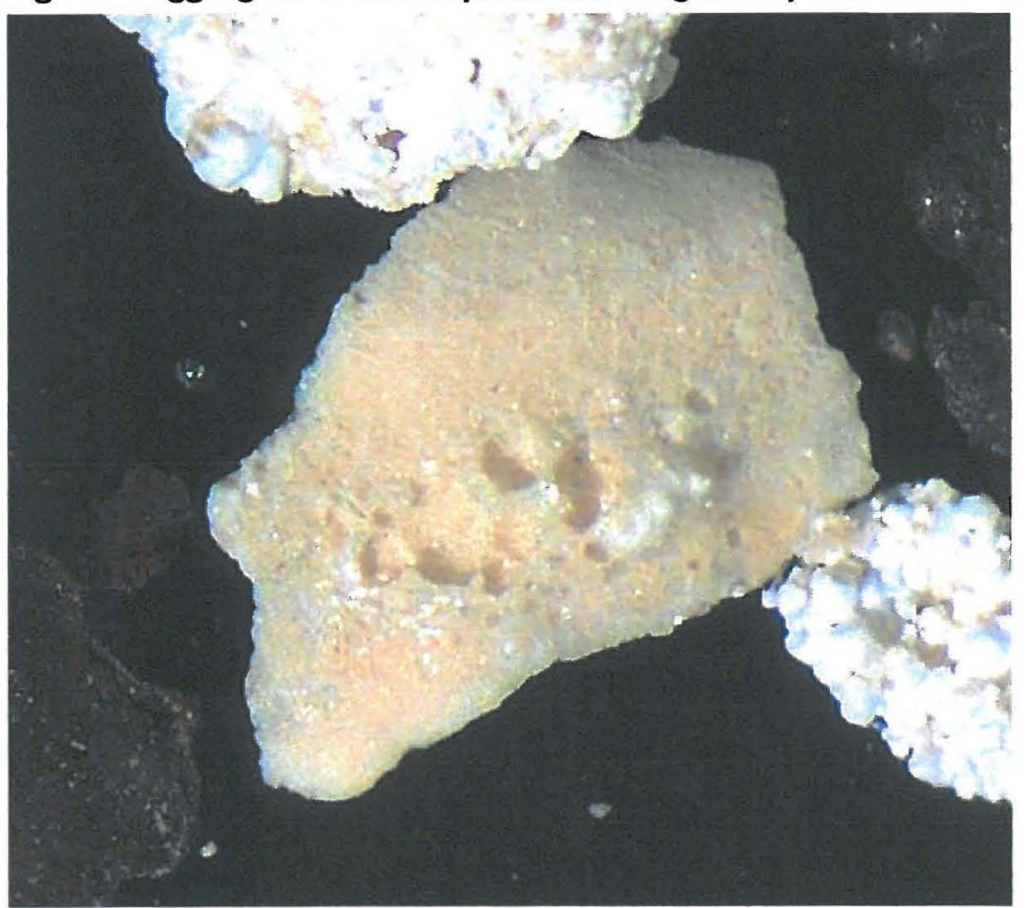

The light colored particulate in sample 2AY-12-ANU-5A was much rarer than in 2AY-12-ANU3A. They appear to be aggregates of darker material cemented by white salt (Figure 6). 
Figure 6. Figure 5 Aggregate of Light and Dark Colored Particulate from Sample 2AY-12-ANU-5A.

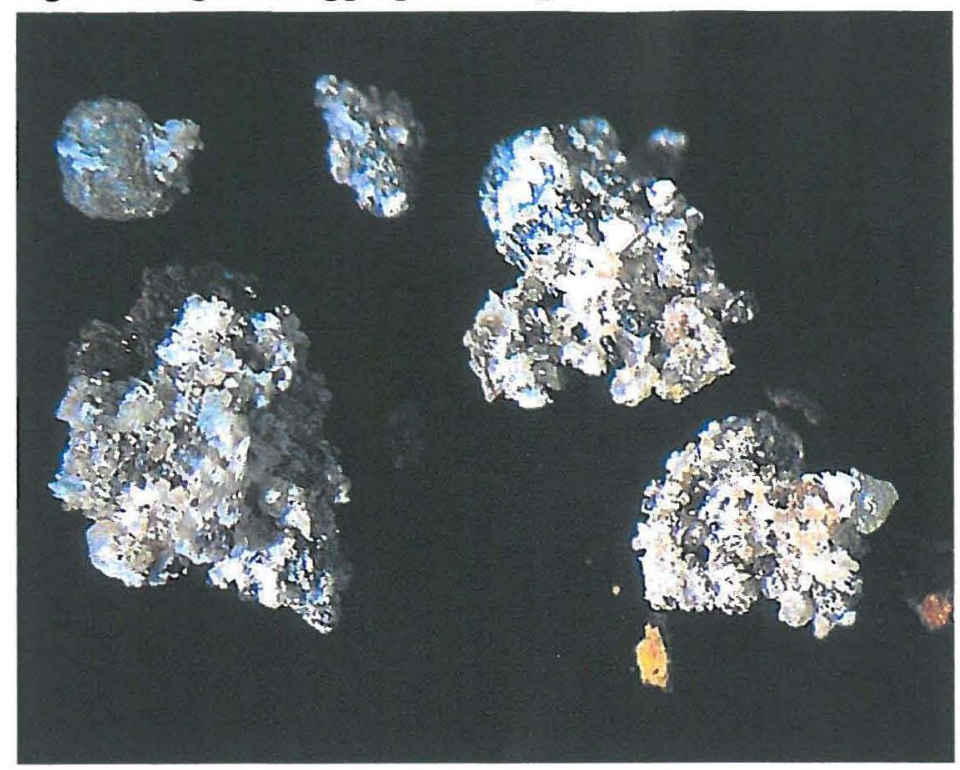

Samples were prepared for SEM, XRD and PLM by crushing the entire sample (2AY-12-ANU-5A)

\section{SPC of Sample 2AY-12-ANU-3A}

Sample 2AY-12-ANU-3A consisted of dry white solid aggregates with a minor amount of reddish-brown particles. The sample weighed 0.20 grams. The light colored particulate was separated from the reddish brown rust and scale. This light colored material was crushed in an agate mortar and pestle and sub-sampled for Solid Phase Characterization (SPC). Prior to complete crushing, several pieces were removed and reserved for SEM analysis. A portion of the crushed powder was transferred to an adhesive carbon tab mounted on an SEM planchet. The fine particulate was pressed into place and the larger particulate was added and also pressed into the adhesive surface. For XRD analysis, a portion of the completely ground material was placed in the well of a zero background mount, compressed with a glass slide and fixed with a collodion binder. A portion of the crushed sample was examined by PLM. The PLM specimen was prepared by transferring a small amount of the dry powder onto a glass slide, adding a drop of oil with a 1.55 index of refraction.

XRD analysis revealed a series of strong peaks. Nearly all of them could be attributed to crystalline phases that are consistent with tank waste salts. The following phases and relative abundances were found:

\section{Chemical Name}

Sodium Carbonate Anhydrous

Sodium Hydrogen Phosphate

Sodium Nitrite

Sodium Oxalate

\begin{tabular}{l} 
Mineral Name \\
\hline Natrite \\
Nahpoite \\
-- \\
Natroxalate
\end{tabular}

$\frac{\text { Formula }}{\mathrm{Na}_{2} \mathrm{CO}_{3}}$
$\mathrm{Na}_{2} \mathrm{HPO}_{4}$
$\mathrm{NaNO}_{2}$
$\mathrm{Na}_{2} \mathrm{C}_{2} \mathrm{O}_{4}$

\begin{tabular}{c}
$\sim$ Relative Amount \\
\hline Major \\
Minor \\
Minor \\
Minor
\end{tabular}

The SEM analysis confirmed the presence of a phase consistent with the anhydrous sodium carbonate (Figure 7). This figure, and the other SEM images in this report are paired with an EDS spectrum taken from the area marked with the yellow + . This phase is responsible for the blade and lath-like crystals observed in the optical microscope (Figure 4). Sodium carbonate occurs in tank waste. However, it is found as the monohydrate phase Thermonatrite $\left(\mathrm{Na}_{2} \mathrm{CO}_{3}-\mathrm{H}_{2} \mathrm{O}\right)$. Apparently, the temperature near this sample was high enough to dehydrate the normally hydrated sodium carbonate or to allow the anhydrous form to precipitate directly. This is consistent with a temperature above 90 degrees Centigrade. 
Figure 7. Sodium Carbonate laths in Sample 2AY-12-ANU-3A.
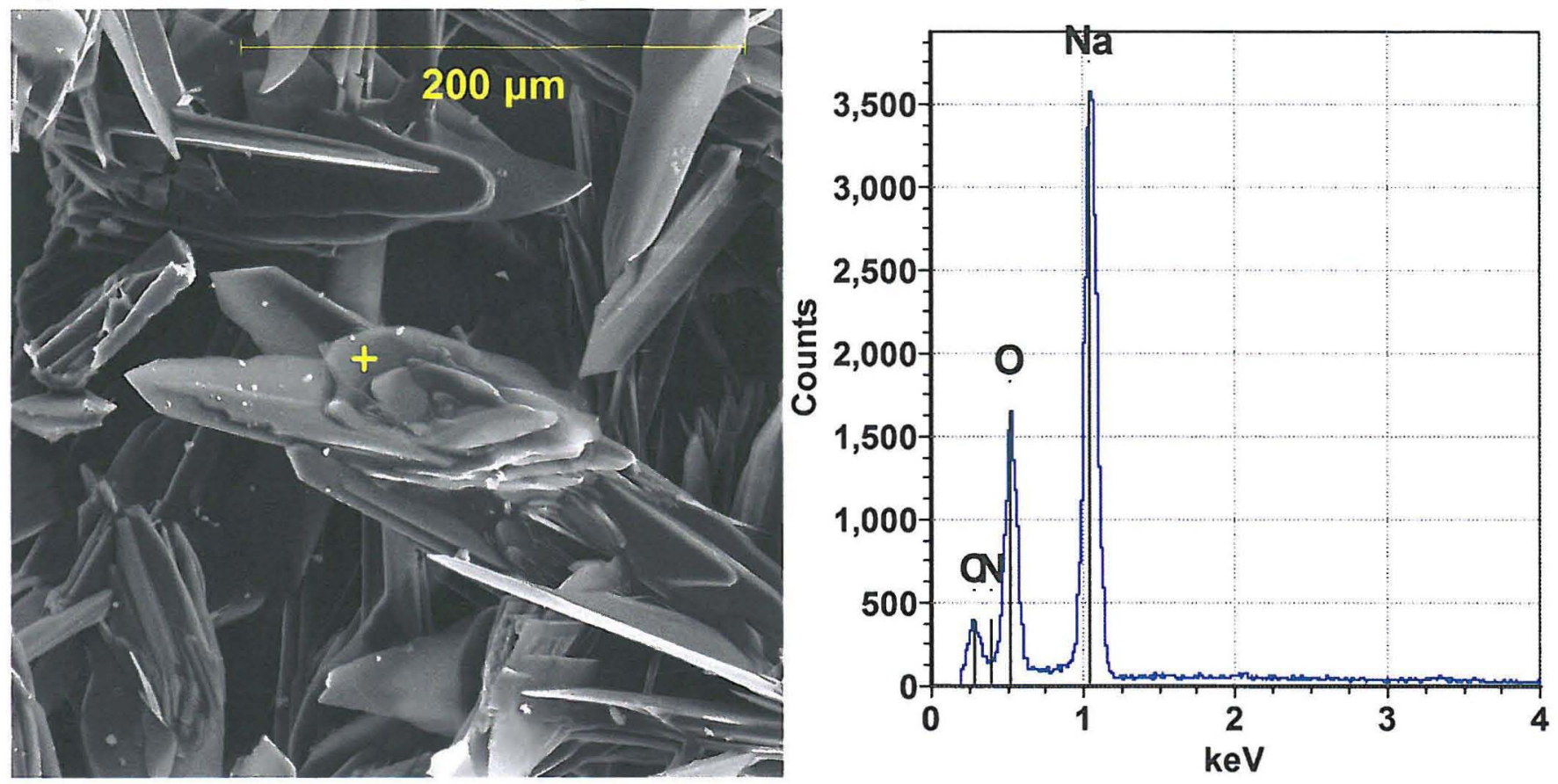

The SEM could not confirm the sodium nitrite that was observed in the XRD scan. The nitrogen peak is particularly insensitive, and there needs to be a nearly pure sodium nitrite before the peak can be observed on the EDS spectrum. The presence of an elevated background where the nitrogen peak is located could be seen on many of the EDS spectra, but never a discrete peak.

The phase identified as Nahpoite $\left(\mathrm{Na}_{2} \mathrm{HPO}_{4}\right)$ in the XRD pattern was not observed in the SEM specimen. Instead, equant octahedral crystals with the appearance and the EDS spectra consistent with the common tank waste phase Natrophosphate $\left(\mathrm{Na}_{7} \mathrm{~F}\left(\mathrm{PO}_{4}\right)_{2}-19 \mathrm{H}_{2} \mathrm{O}\right)$ was seen (Figure 8). However, the SEM image shows crystals that are pock-marked and pitted. This would be consistent with dehydration.

Figure 8. Sodium Fluoride Phosphate in sample 2AY-12-ANU-3A.
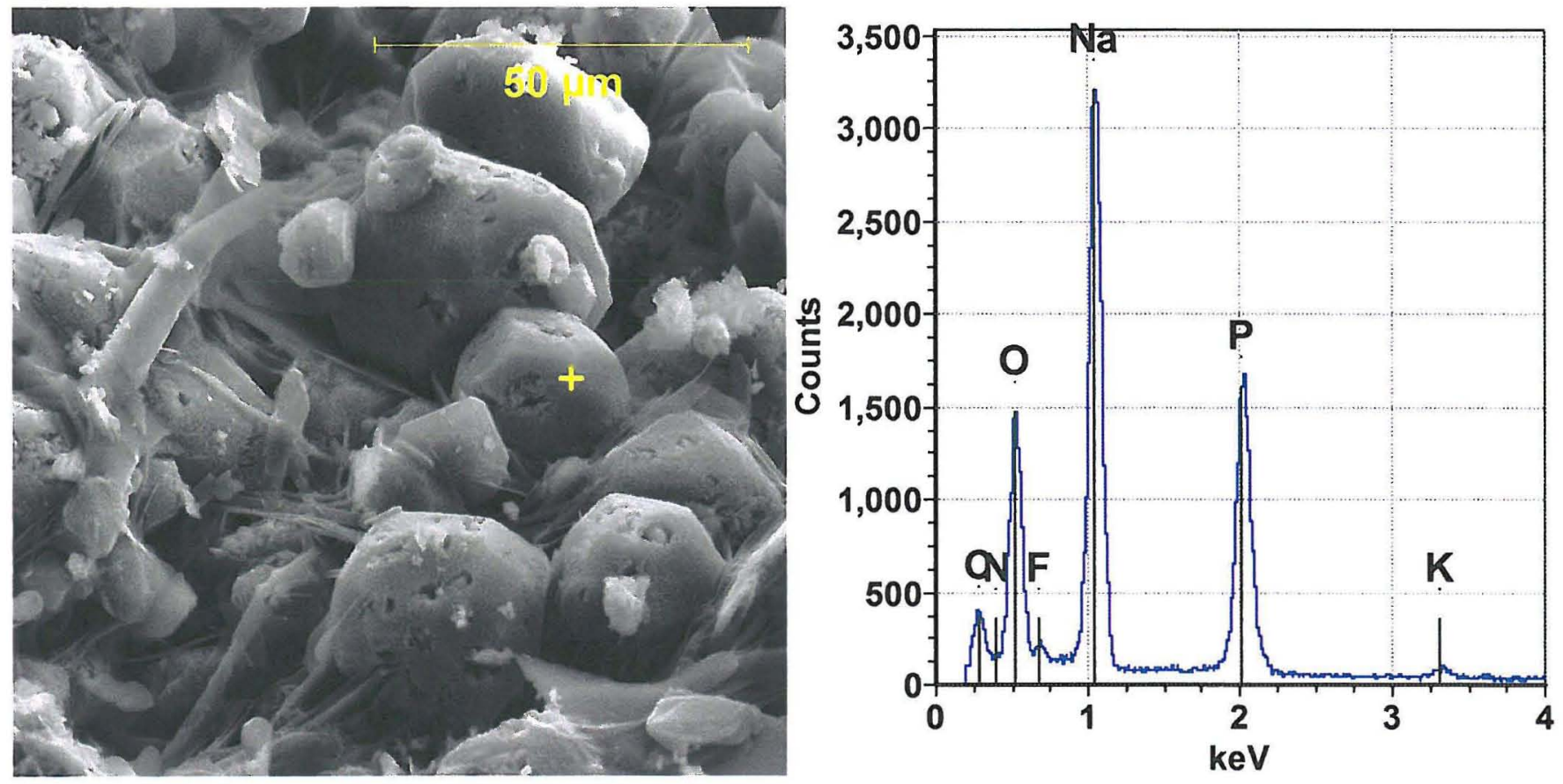
Rev. 0

Little is known about the dehydration of this phase. The lack of reference information on the anhydrous $\left(\mathrm{Na}_{7} \mathrm{~F}\left(\mathrm{PO}_{4}\right)_{2}\right.$ suggest that it is rare or non-existent. It appears that eventually, the phase will dehydrate and recrystallize as the simple salts $\mathrm{NaF}$ and $\mathrm{Na}_{3} \mathrm{PO}_{4}$. The SEM and XRD results here can be reconciled if the dehydrated phase(s) are amorphous, and the sample contains $\mathrm{Na}_{2} \mathrm{HPO}_{4}$ unseen on the SEM but identified in XRD sample. If so, this would suggest a more neutral $\mathrm{pH}$ than the 2AY-12-ANU-1 sample from the floor of the annulus. Alternatively, there could be an intermediate dehydrated phase with the composition $\mathrm{Na}_{7} \mathrm{~F}\left(\mathrm{PO}_{4}\right)_{2}$ that has a crystalline structure identical to the $\mathrm{Na}_{2} \mathrm{HPO}_{4}$.

No evidence of the sodium oxalate was observed in the SEM. However, that phase cannot be chemically distinguished from the sodium carbonate on the EDS spectra. Therefore we would be relying on slight differences in the morphology. No crystals with a morphology that is consistent with sodium oxalate were observed.

Polarized light microscopy of this sample revealed the coarser particulate to be composed of fine crystallites (Figure 9). The PLM analysis was able to confirm the presence of sodium oxalate and found a trace amount of Gibbsite $\left(\mathrm{Al}(\mathrm{OH})_{3}\right)$. Gibbsite was not observed in the XRD and SEM analysis. The fine-grained aggregate nature of the larger particles lends credence to the decomposition of the sodium fluoride phosphate into $\mathrm{NaF}$ and $\mathrm{Na}_{3} \mathrm{PO}_{4}$.

Figure 9. PLM Images with Crossed Polarizers and the Red Compensation Plate, Sample 2AY-12-ANU-3A
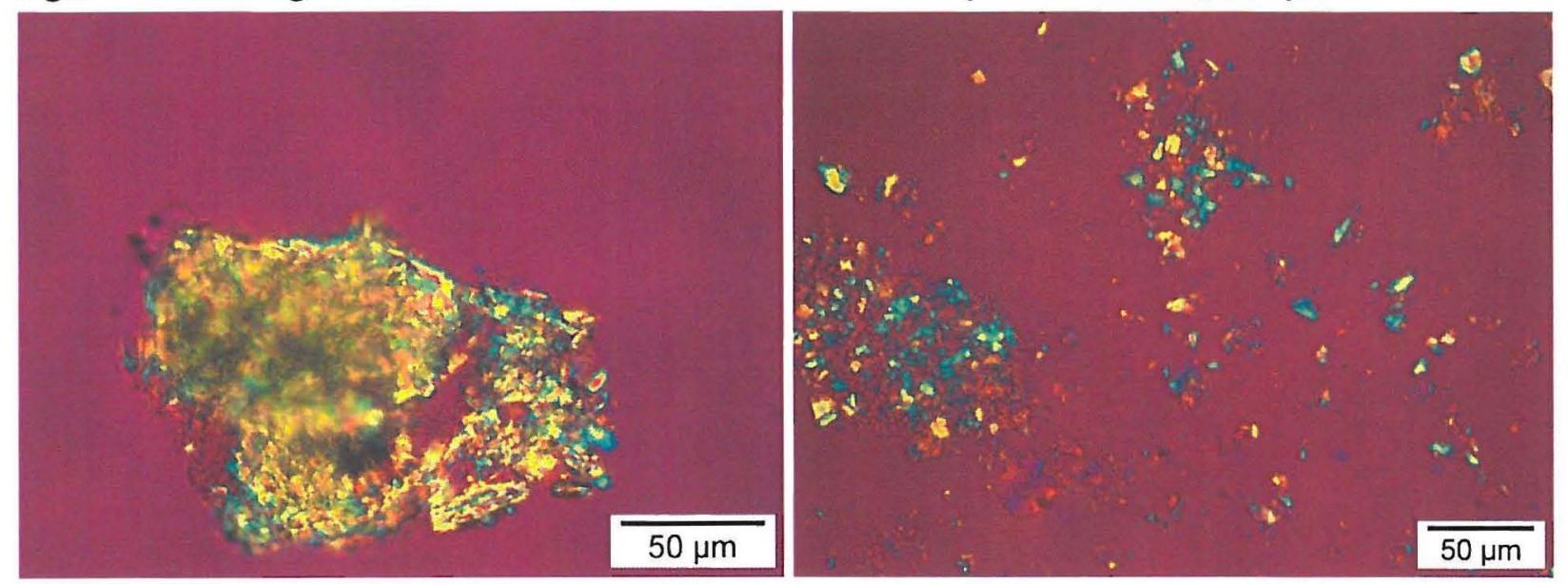

While there appeared to be some potassium in the sample, there was no evidence of a discrete potassium nitrate phase, as had been seen on the floor sample (2AY-12-ANU-3A). The highest concentration of potassium observed in the EDS spectra was from a particle that was largely obscured by sodium carbonate laths (Figure 10). 
Figure 10. Minor Potassium Peak in EDS Spectrum from Sample 2AY-12-ANU-3A.
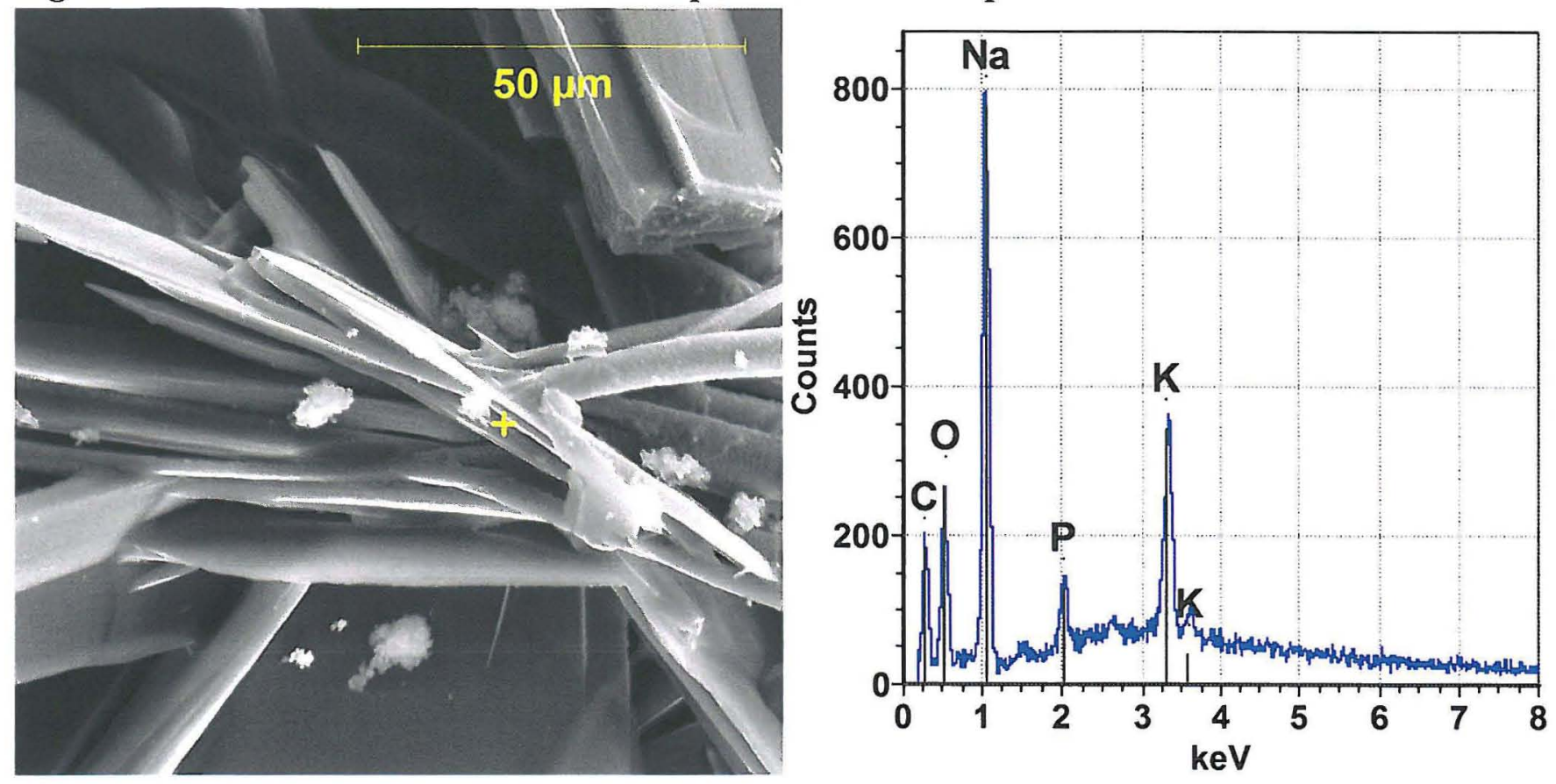

\section{SPC of Sample 2AY-12-ANU-5A}

The 2AY-12-ANU-5A sample weighed only 0.12 grams and was crushed in its entirety. No attempt was made to separate the rust from the few light colored fragments that were present. XRD and SEM analysis was conducted on this material, consuming nearly the entire sample. As a result of our preliminary examination, we recommended that both samples be examined by PLM as well.

The particulate from sample 2AY-12-ANU5A was seen on the SEM to consist predominantly of rust or mill scale (Figure 11). Soil particles are the next most abundant particle type. Figures 12 through 15 show particles with chemical compositions consistent with minerals found in Hanford soil or sand. There was also a small amount of a sodium-rich phase (Figure 16), and a single particle of a sodium sulfate was also seen (Figure 17).

The XRD pattern for this sample showed no significant peaks for any crystalline phase. This suggests that the crystalline mineral material and the sodium-rich phase (if crystalline) make up less than 20 percent of the sample. The diffraction peaks from these phases would be difficult to detect in the high iron matrix of the sample. Visual estimates from the PLM and SEM sample preparations suggest that the rust/scale makes up 75 to 85 percent of the 12 -ANU-5A sample

The SEM sample specimen contained no detectible beta/gamma radiation using the room monitors. The only evidence for tank waste material in this sample was the sodium-rich particulate, estimated to make up about $5 \%$ of the sample. The only source outside of tank waste that could provide a sodium rich particulate is clean caustic. 
Figure 11. SEM Secondary Electron Image of Rust/Scale, Sample 12-ANU-5A
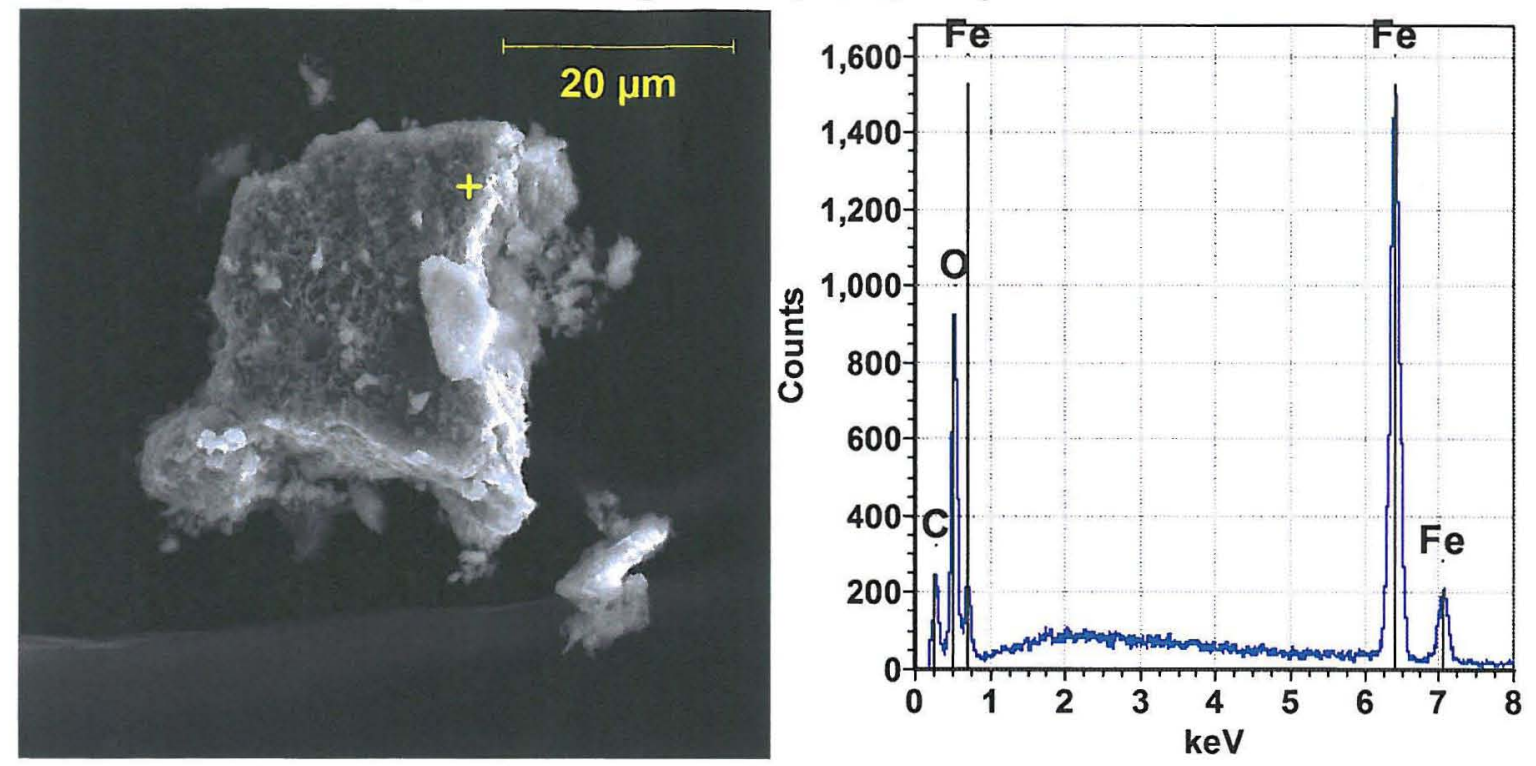

Figure 12. SEM Secondary Electron Image of Quartz, Sample 12-ANU-5A
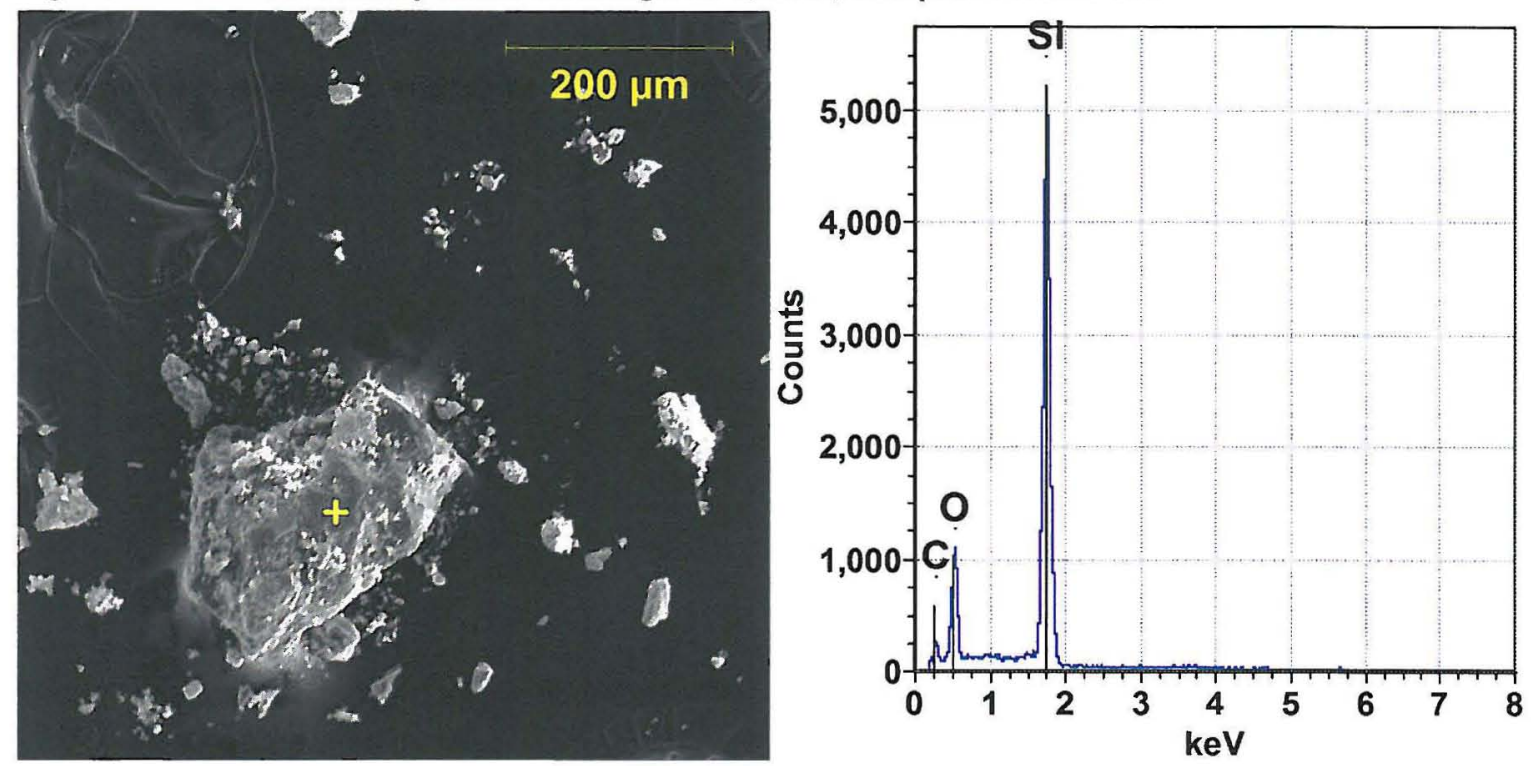

Figure 13. SEM Secondary Electron Image of Potassium Feldspar, Sample 12-ANU-5A
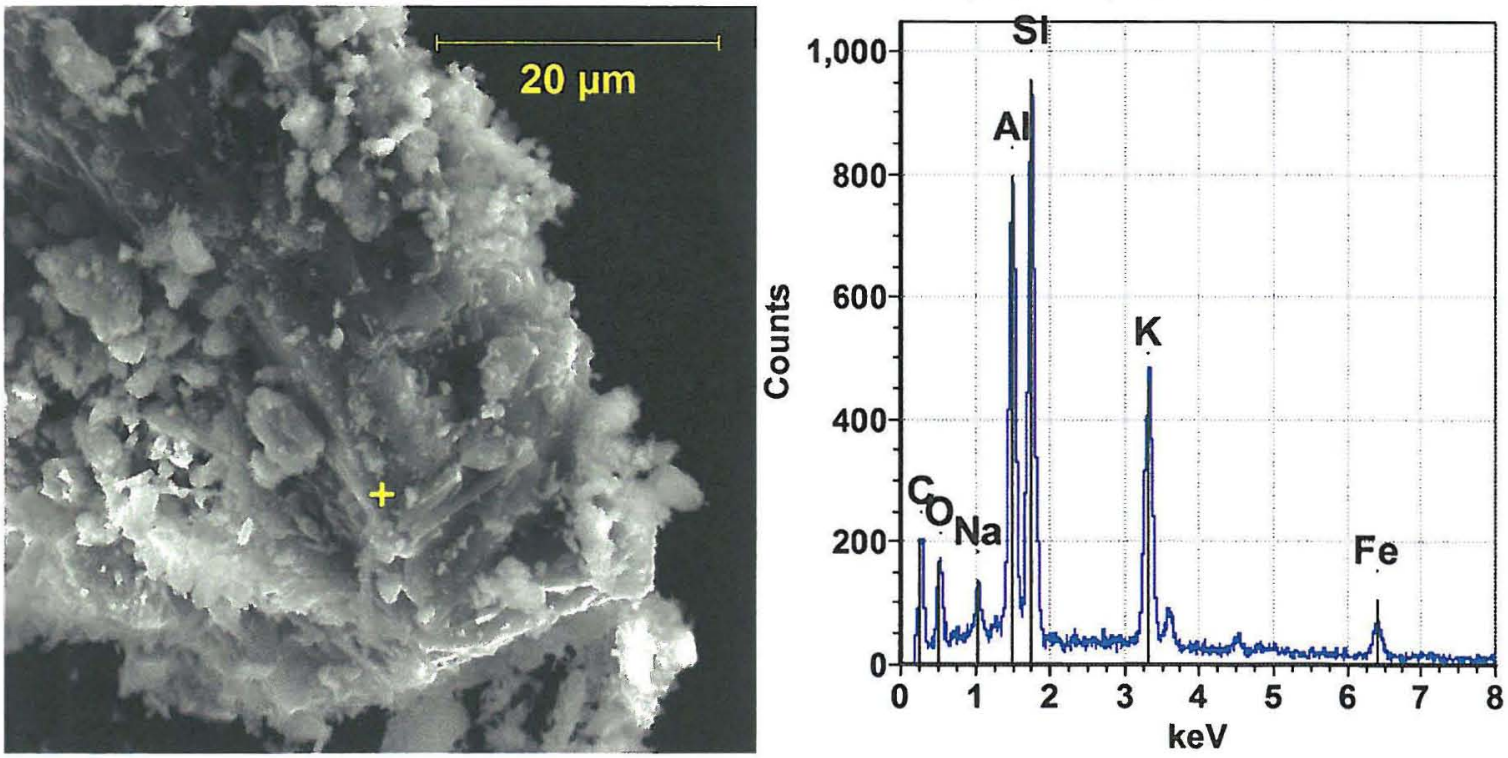
Figure 14. SEM Secondary Electron Image of Plagioclase Feldspar, Sample 12-ANU-5A
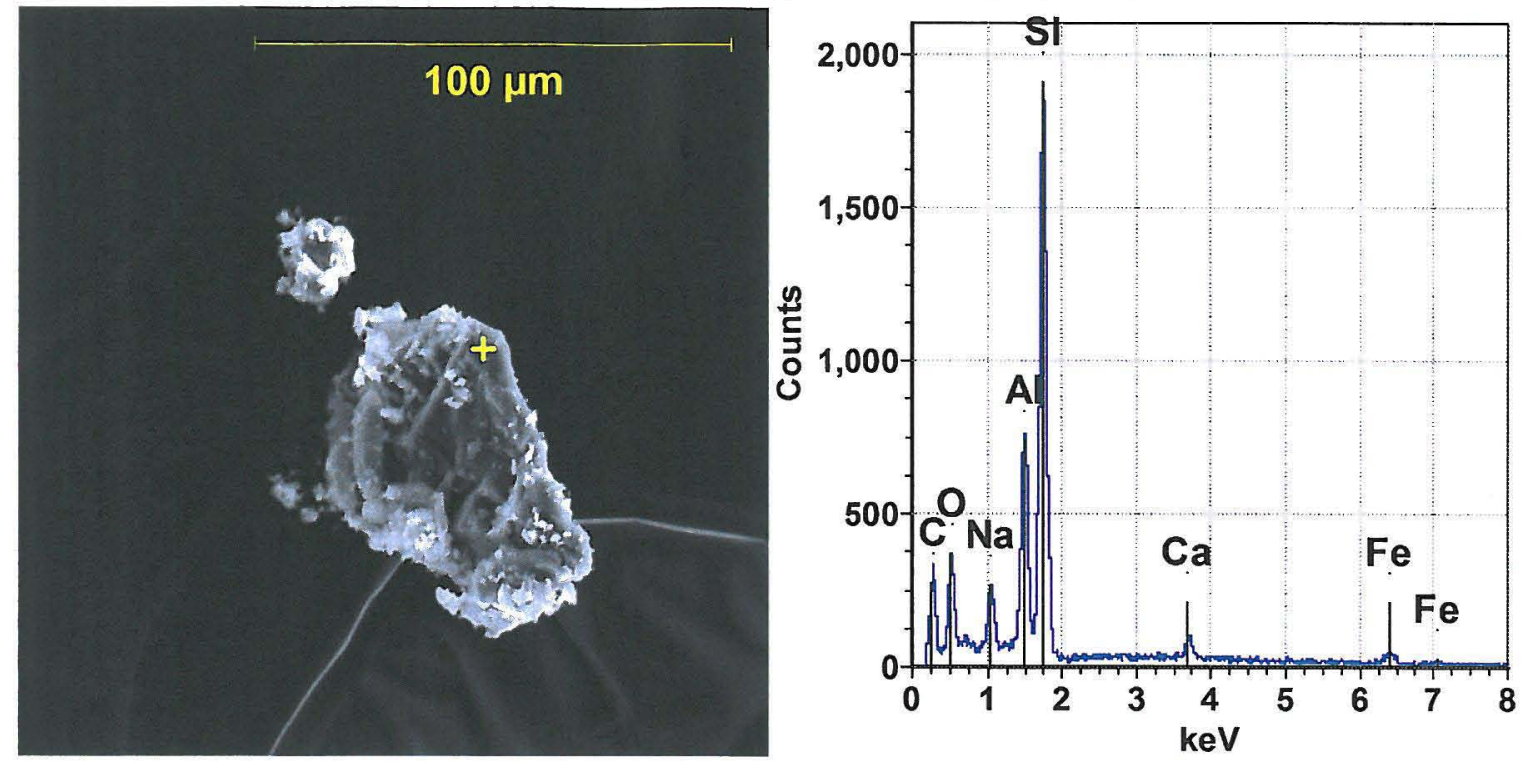

Figure 15. SEM Secondary Electron Image of Amphibole or Pyroxene, Sample 12-ANU-5A
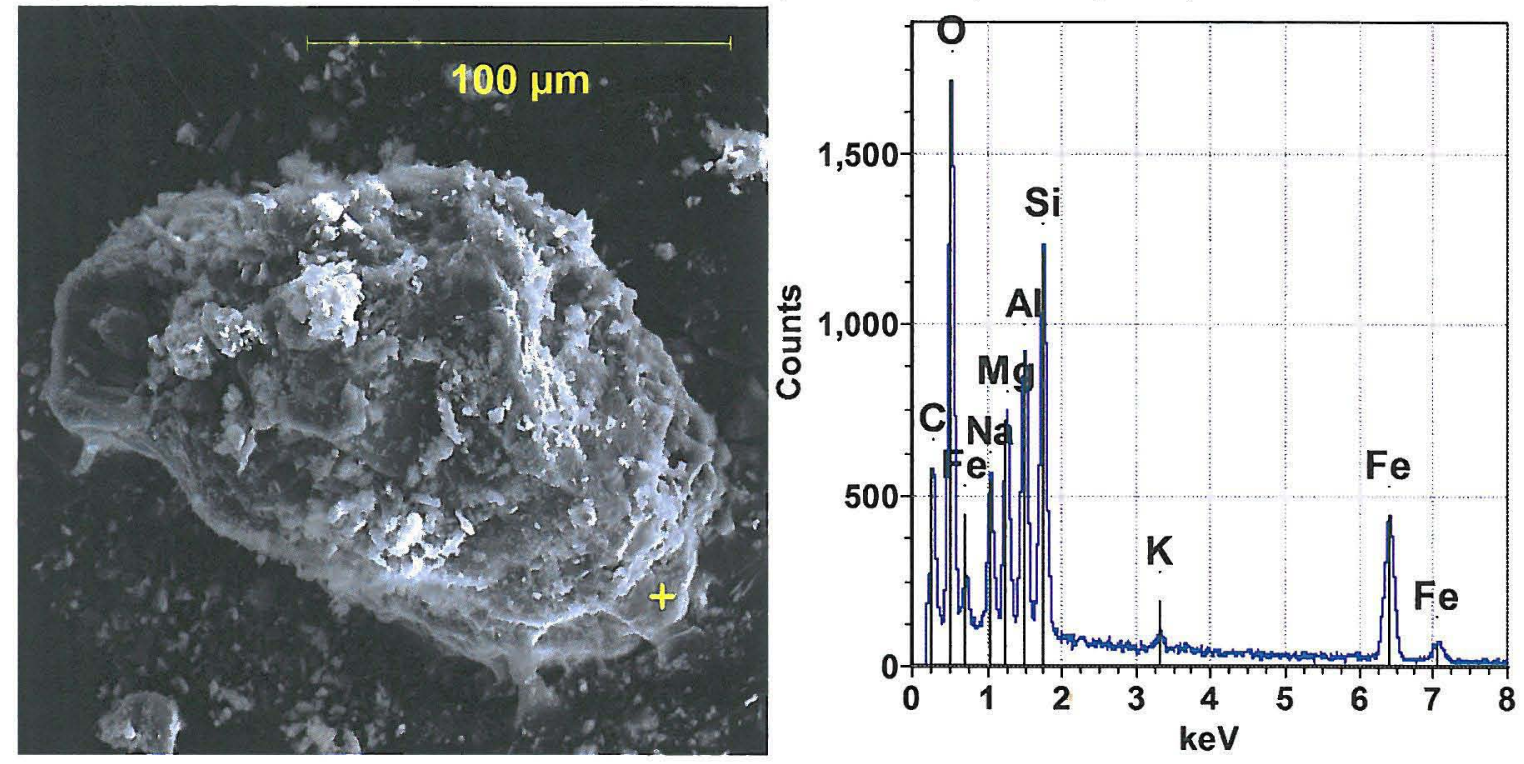

Figure 16. SEM Secondary Electron Image of Sodium-Rich Particulate, Sample 12-ANU-5A
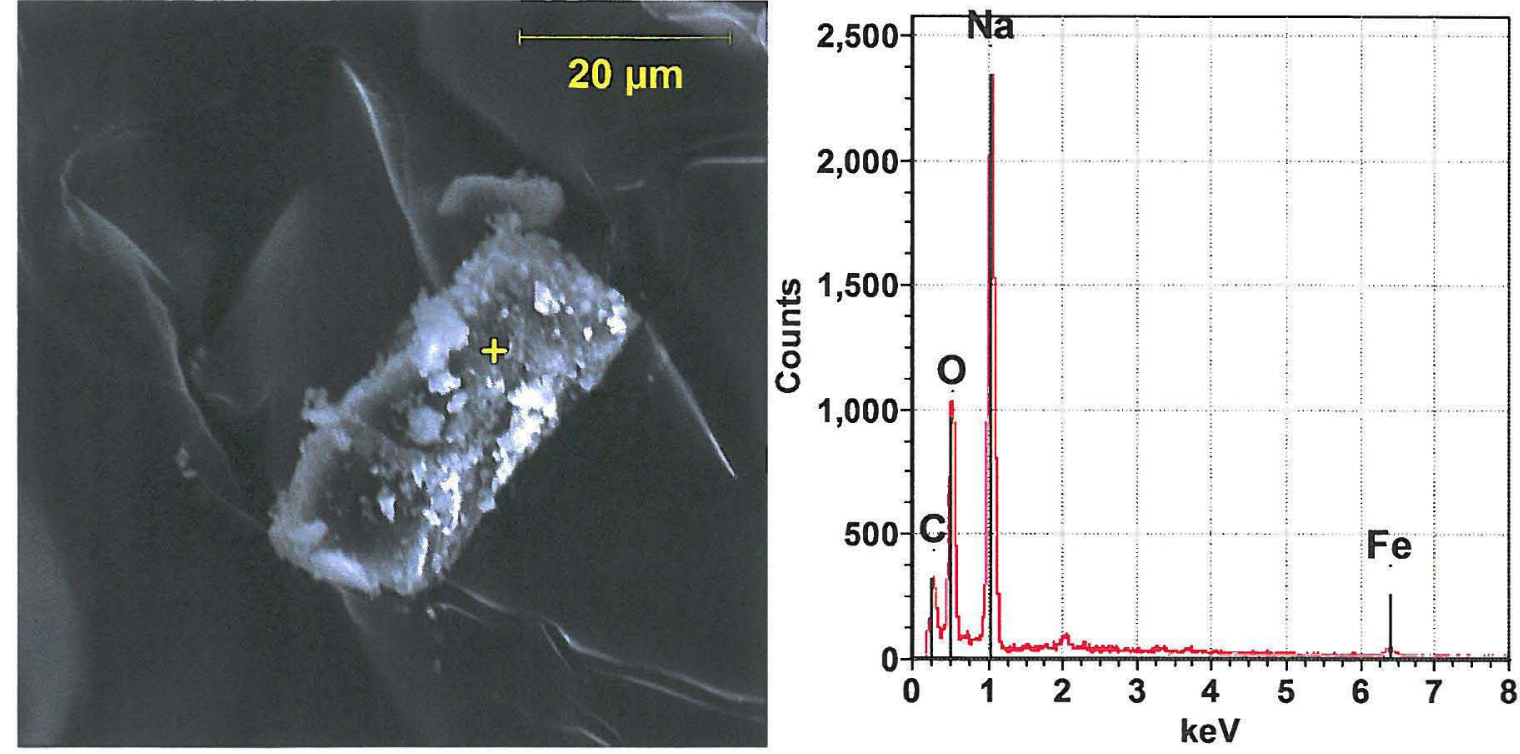
Rev. 0

Figure 17. SEM Secondary Electron Image of Sodium Sulfate Particulate, Sample 12-ANU-5A
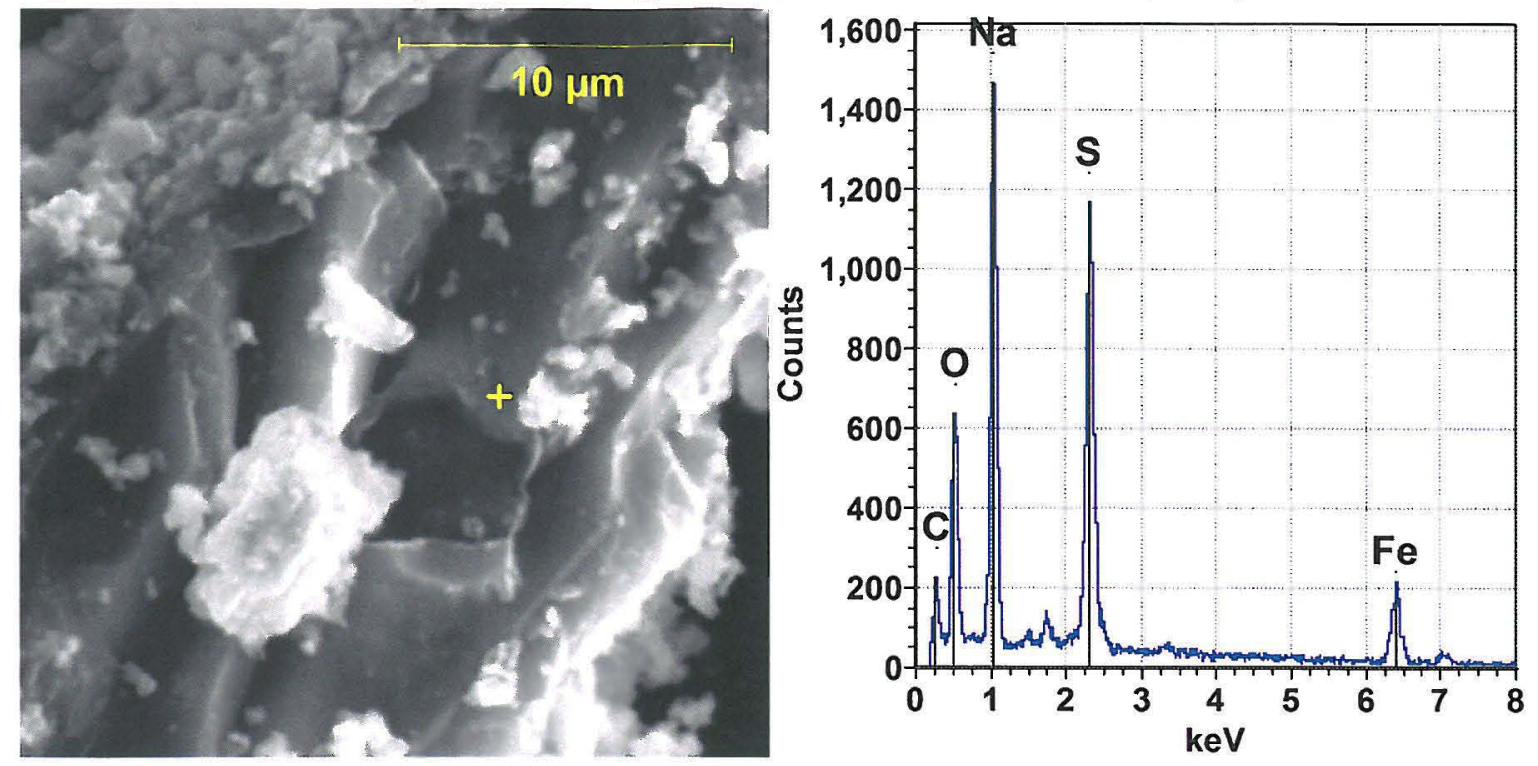

The PLM analysis indicated that the material was greater than $90 \%$ opaque (Figure 18). The remaining material was a fine-grained and birefringent particulate, consistent with ground soil.

Figure 18. PLM Images with Crossed Polarizers and the Red Compensation Plate, Sample 2AY-12-ANU-5A

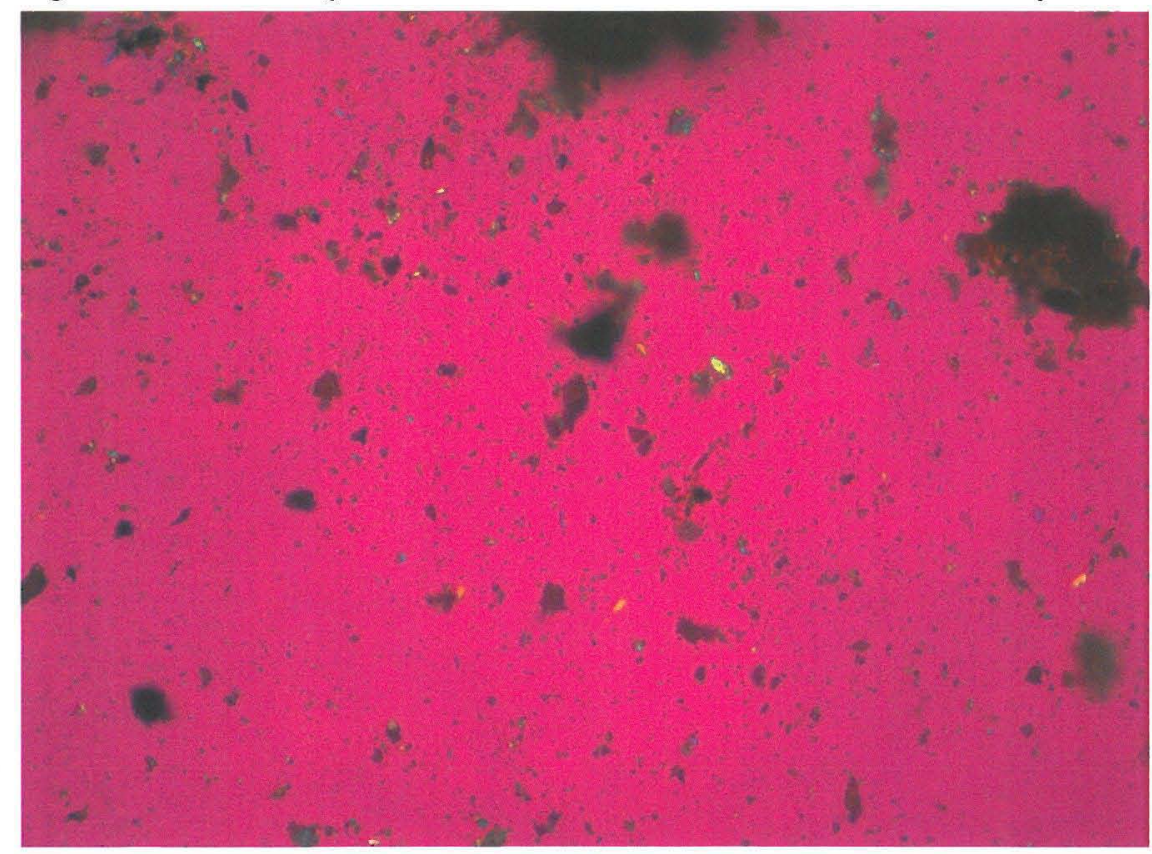


Rev. 0

Harlow, Donald G

\section{From:}

Sent:

To:

Subject:

Attachments:
Harrington, Stephanie J

Thursday, October 25, 2012 3:20 PM

Rosenkrance, Chelsea L; Venetz, Theodore J; Boomer, Kayle D; Girardot, Crystal L; Washenfelder, Dennis J

FW: 12-ANU-5A sample discussion

Sample12-ANU-5ASEM.doc

Please find the (pre-preliminary) AY-102 annulus sample 5A solid results attached for use in the leak assessment report.

Stephanie otharington, oPh

Chemical Process Engineer

Washington River Protection Solutions,

contractor to the United States Department of Energy

2750E Room A219 or 639 Cullum B119

(509) $376-1336$

From: Cooke, Gary

Sent: Thursday, October 25, 2012 3:12 PM

To: Harrington, Stephanie J

Subject: 12-ANU-5A sample discussion

See attached.
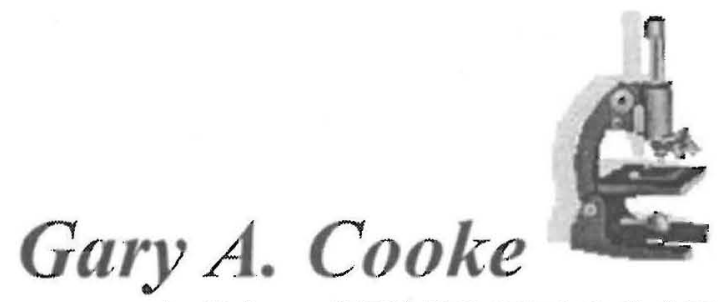

gary cooke@rl.gov (509) 373-2154 Cell: (509) 845-3988

Washington River Protection Solutions, contractor to the United States Department of Energy 
The 2AY-12-ANU-5A weighed only 0.12 grams and was crushed in its entirety. No attempt was made to separate the rust from the few light colored fragments that were present. XRD and SEM analysis was conducted on this material, consuming nearly the entire sample. As a result of our preliminary examination, we recommended that both samples be examined

The particulate from sample 2AY-12-ANU5A was seen on the SEM to consist predominantly of rust or mill scale (Figure 1). Soil particles are the next most abundant particle type. Figures 2 through 5 show particles with chemical compositions consistent with minerals found in Hanford soil or sand. There was also a small amount of a sodium-rich phase (Figure 6), and a single particle of a sodium sulfate was also seen (Figure 7).

The XRD pattern for this sample showed no significant peaks for any crystalline phase. This suggests that the crystalline mineral material and the sodium-rich phase (if crystalline) make up less than 20 percent of the sample. The diffraction peaks from these phases would be difficult to detect in the high iron matrix of the sample. Visual estimates from the PLM and SEM sample preparations suggest that the rust/scale makes up 75 to 85 percent of the 12-ANU-5A sample

The SEM sample specimen contained no detectible beta/gamma radiation using the room monitors. The only evidence for tank waste material in this sample was the sodium-rich particulate, estimated to make up about $5 \%$ of the sample. The only source outside of tank waste that could provide a sodium rich particulate is clean caustic.

Figure 1. SEM Secondary Electron Image of Rust/Scale, Sample 12-ANU-5A
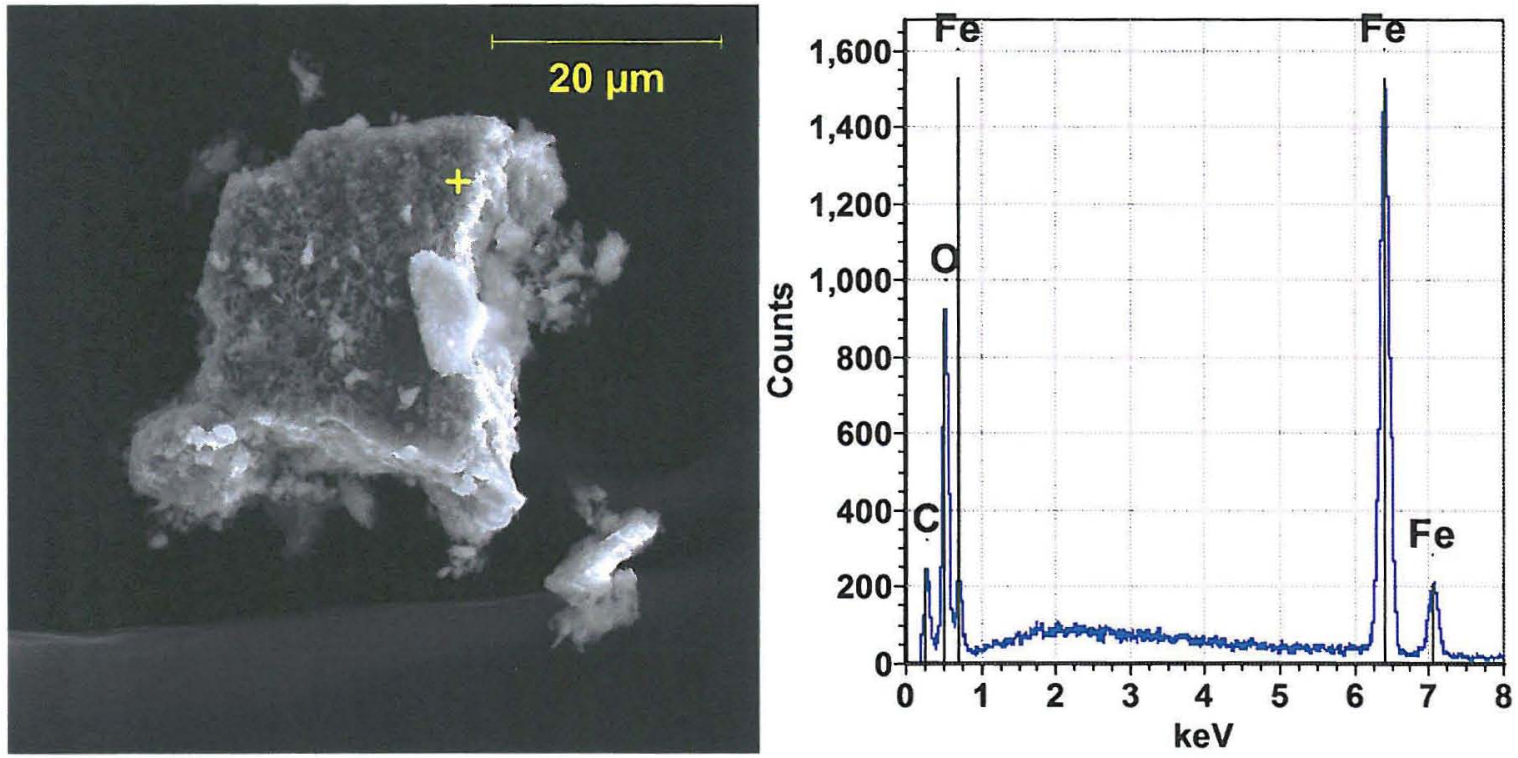

Figure 2. SEM Secondary Electron Image of Quartz, Sample 12-ANU-5A 

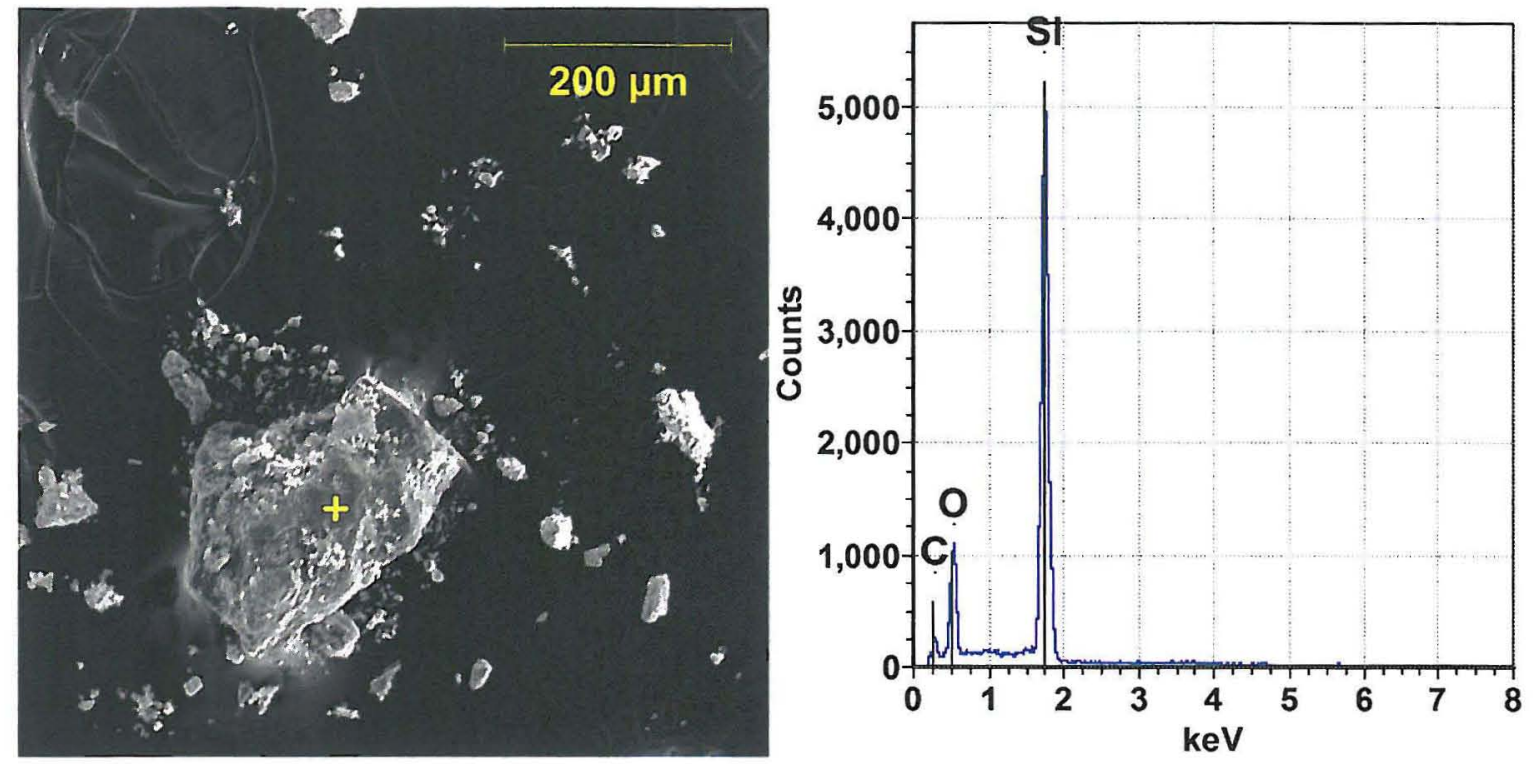

Figure 3. SEM Secondary Electron Image of Potassium Feldspar, Sample 12-ANU-5A
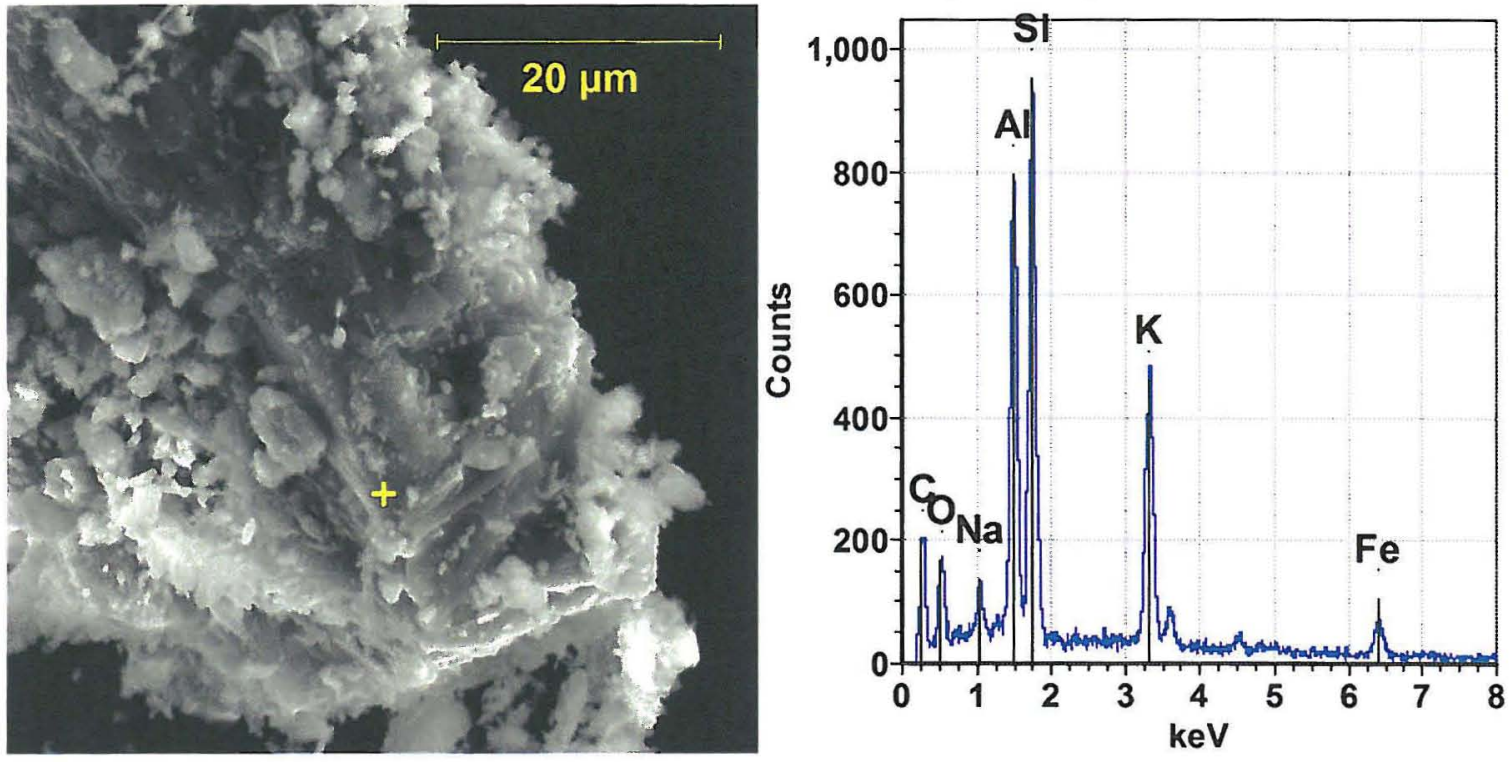

Figure 4. SEM Secondary Electron Image of Plagioclase Feldspar, Sample 12-ANU-5A 

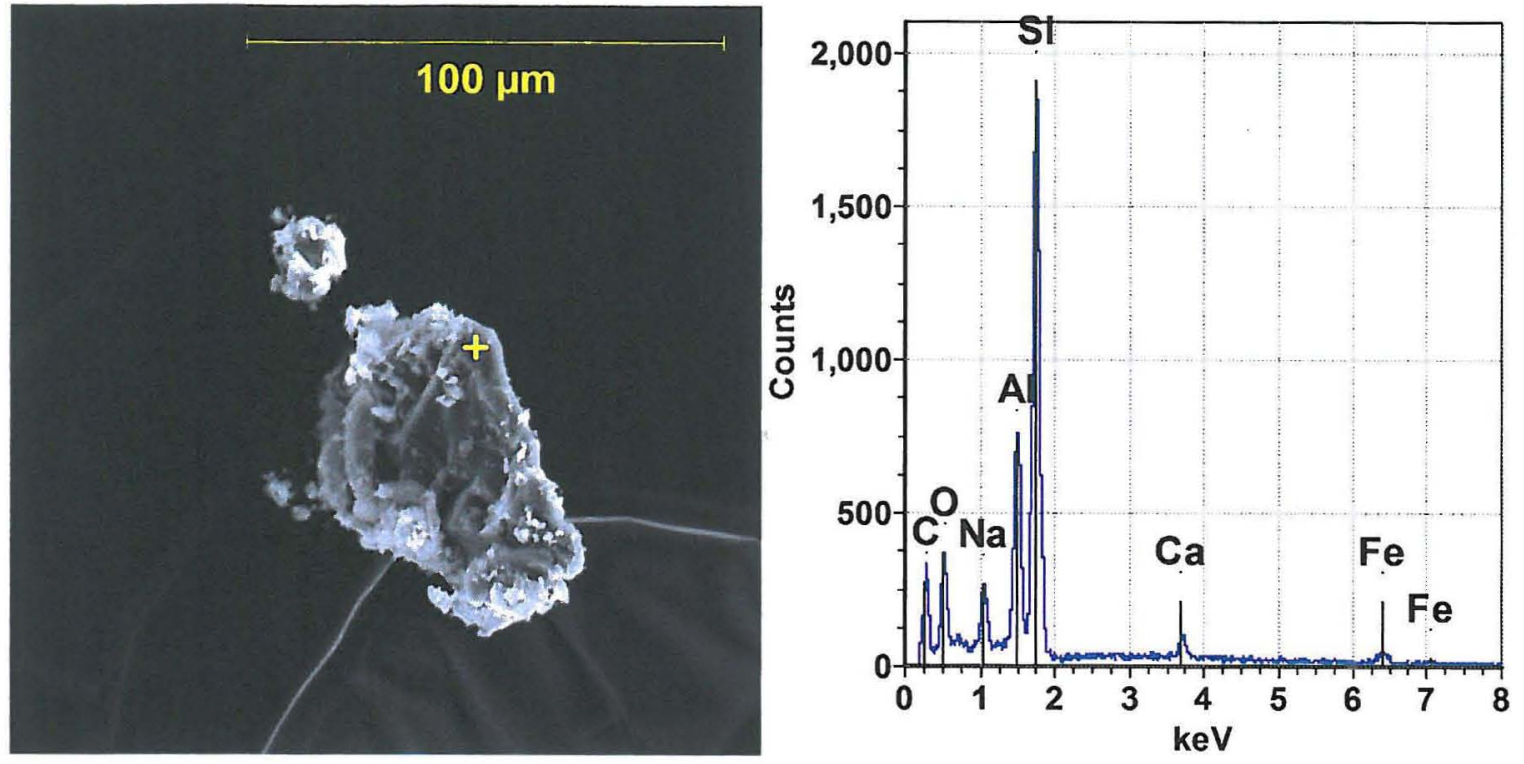

Figure 5. SEM Secondary Electron Image of Amphibole or Pyroxene, Sample 12-ANU-5A
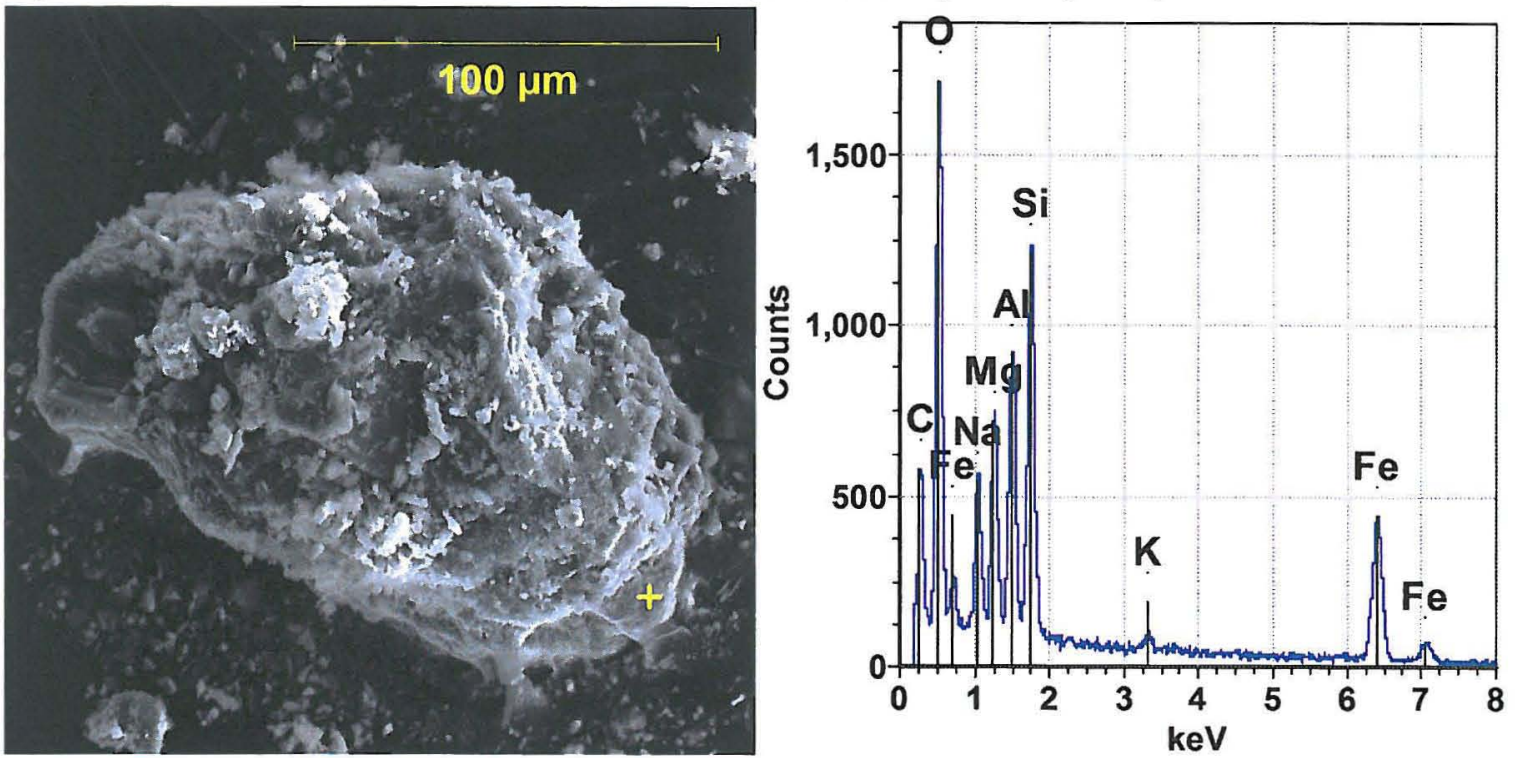

Figure 6. SEM Secondary Electron Image of Sodium-Rich Particulate, Sample 12-ANU-5A 

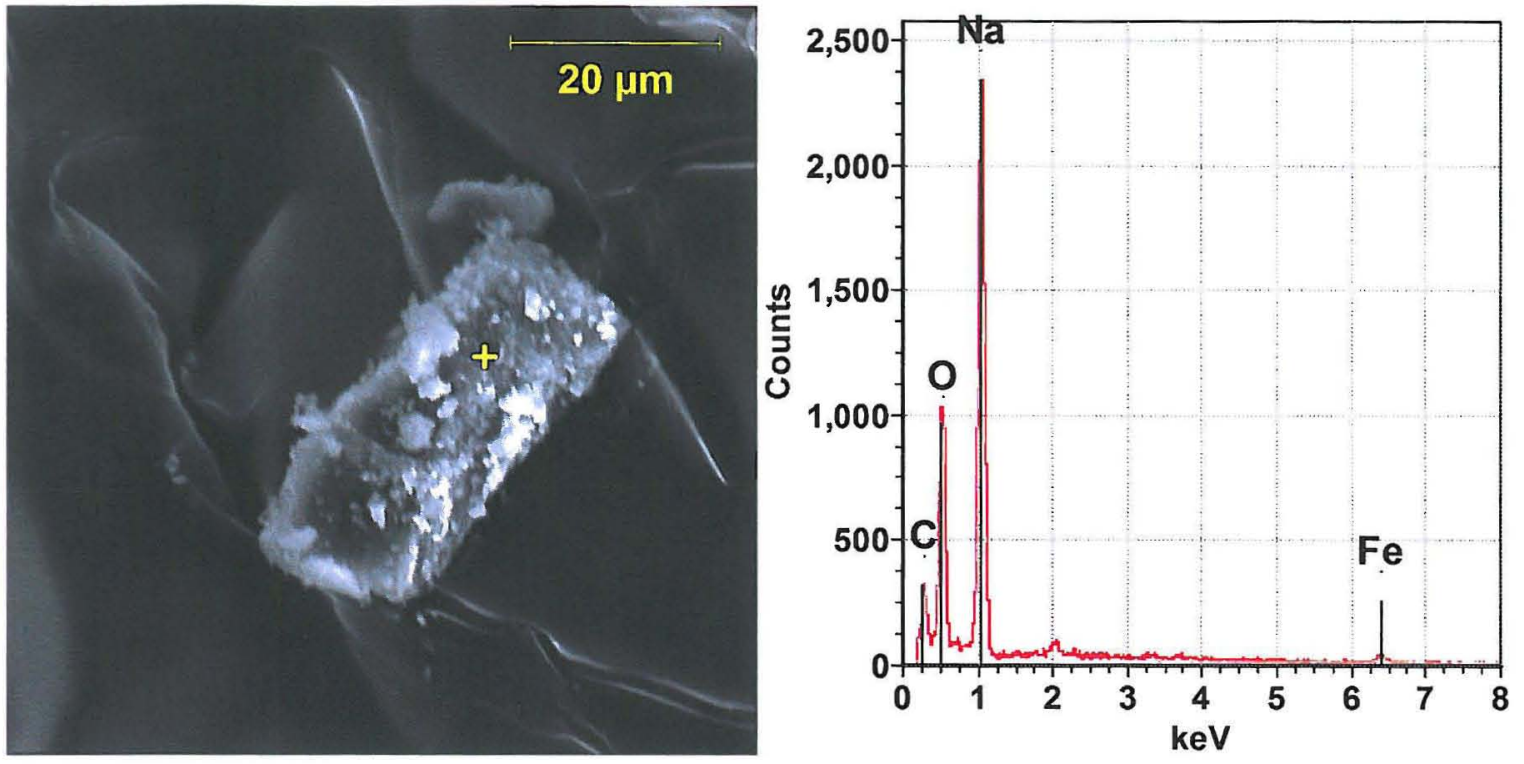

Figure 7. SEM Secondary Electron Image of Sodium Sulfate Particulate, Sample 12-ANU-5A
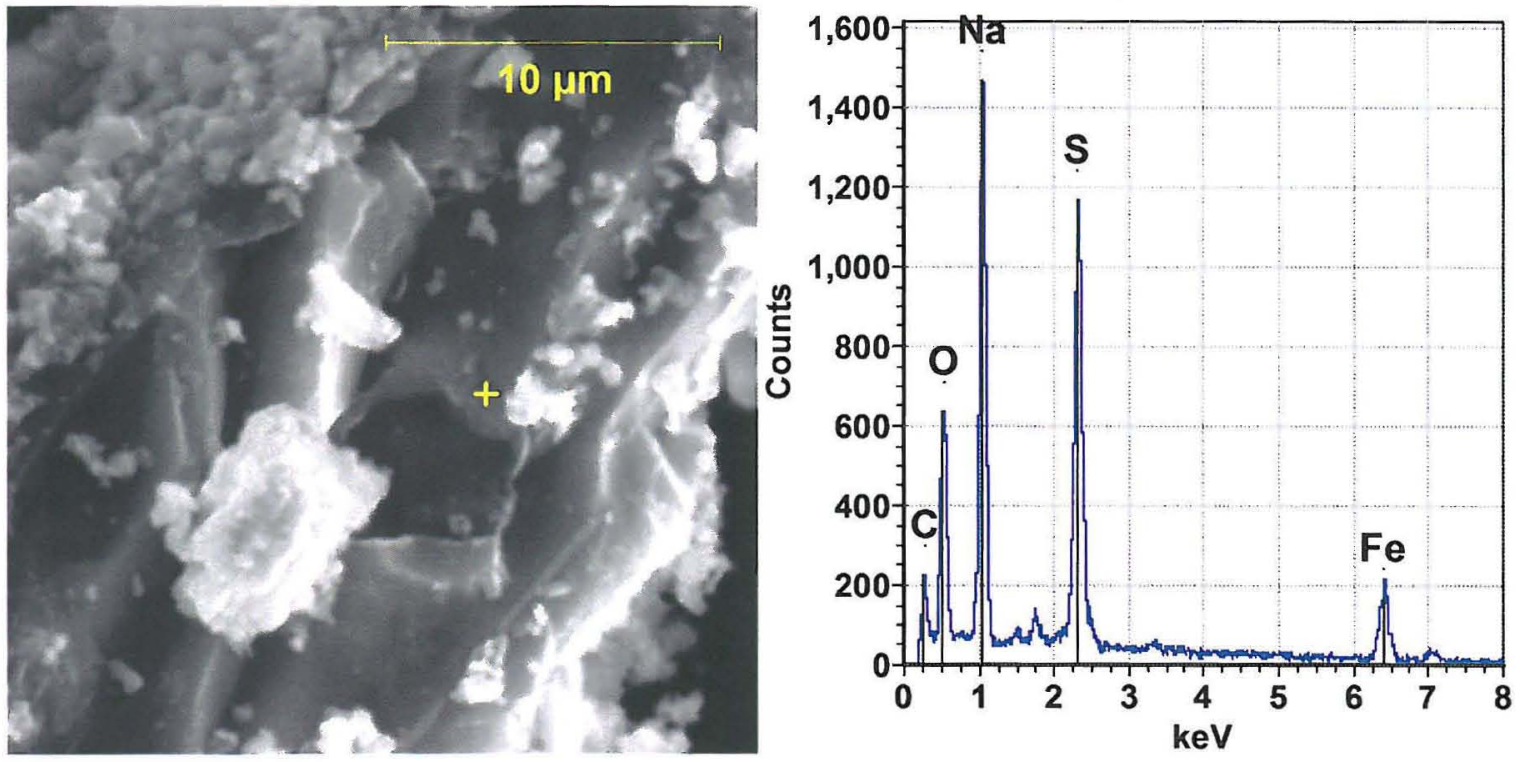
From:

Sent:

To:

Cc:

Subject:

Importance:
Harrington, Stephanie J

Wednesday, October 24, 2012 4:11 PM

Rosenkrance, Chelsea L; Sams, Terry L; Washenfelder, Dennis J; Kirch, Nicholas W (Nick); Venetz, Theodore J; Boomer, Kayle D

Rasmussen, Juergen H; Nguyen, Duc M; Templeton, Andrew M; Reynolds, Jacob G

FW: Interim Results for AY102 Annulus - TIC/TOC (ANU1) and ICP (ANU3A)

High

Please find the preliminary results below for the TIC/TOC analyses on the sample from near riser 83 (the floor sample) as well as the ICP metals analysis results for the second air duct sample taken on Oct. $17^{\text {th }}$ near riser 90.

\section{Stephanie ftattington, Dh $D$}

Chemical Process Engineer

Washington River Protection Solutions, contractor to the United States Department of Energy

2750E Room A219 or 639 Cullum B119

(509) $376-1336$

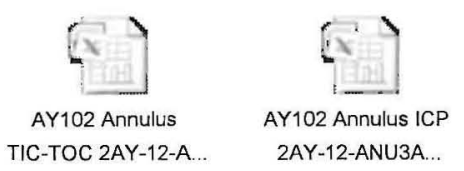

From: Bushaw, Ruth A

Sent: Wednesday, October 24, 2012 3:54 PM

To: Harrington, Stephanie J

Cc: Bushaw, Thomas H; McKinney, Steve G; Cooke, Gary

Subject: Interim Results for AY102 Annulus - TIC/TOC (ANU1) and ICP (ANU3A)

Importance: High

Stephanie,

The attached spreadsheets provide the interim results for the TIC/TOC analysis requested for sample 2AY-12ANU1 and the ICP results for sample 2AY-12-ANU3A.

For the TIC/TOC analysis, the spike recovery for the TIC was $207 \%$ but the amount of spike added was much less than $25 \%$ of the concentration in the sample, so no qualifier flags or reanalyses were required.

For the ICP analysis, there was no preparation standard because the digest that was requested was originally just for radchem, so no standard was prepared. Also, we forgot to run the preparation blank associated with this sample, the chemist is going to ask the technician if maybe it had been consumed with the radchem analyses and wasn't available. If it was just overlooked, I asked them to run that and rerun the sample to see if some of the instrument QC issues will not be present in the rerun.

Recall that there was also insufficient sample material to digest a duplicate sample portion or a spike. The analytical batch also contained solid samples from the recent AN101/C104 sampling event, and one of those 
samples was used for the sample QC. I'm reluctant to include that QC with this report because the sample matrix isn't quite the same.

As I stated in my previous email with ICP results, the digest methods that we have available at 222-S lab are not appropriate for digesting silicon. Therefore, it's likely that the LCS and spike recovery, if prepared for this sample, might have failed low, as they did with the SW846 Method 3050B prep that was used to digest the previous AY102 Annulus sample. I will discuss in the narrative that the silicon result might not be very accurate. Note that silicon was detected in the instrument blanks. For two of the blanks, the silicon was $>$ EQL and $>5 \%$ of the sample result, so I added a "B" flag. Since these were instrument blanks, I'm expecting that the reanalysis might be better. Silicon also failed high on the low level standard (LLS). Since the result in the sample was at approximately the same level as the LLS, this could indicate a high bias. This failure does not require a reanalysis, but since we are going to rerun anyway, the LLS might meet the requirement on the rerun.

Remember that these results have not been fully reviewed and may change, especially since we plan to rerun the ICP.

Thanks,

\section{Ruth A. Bushaw}

Project Coordinator

Advanced Technologies and Laboratories International, Inc.

Contractor to the Office of River Protection

U.S. Department of Energy

222-S Laboratory

office: $509-373-4314$

cell: 509-554-4978

This email and any accompanying documents contain confidential and / or privileged information. This information is intended only for the use of the individuals or entity named in this email. If you are not the intended recipient, please notify the sender and delete this message. You are hereby notified that any disclosure, copying, distribution or taking of any reliance on the contents of the information contained herein is strictly prohibited. 
24-oct-2012 15:15:09

INTERIM

AY102 Annulus

Data Summary of All Results

\begin{tabular}{|c|c|c|c|c|c|c|c|c|c|c|c|c|c|c|c|c|c|}
\hline Riser & Segment Number & Segment Portion & SAMPLE R & $\mathrm{A}$ & CAS \# & ANALYTE & RESULT_UNIT & STANDARD & BLANK & RESULT & DUPLICATE & AVERAGE & RPD & SPK REC & Det Limit & COUNT_ERR & QUALIFIER \\
\hline 90 & 2AY-12-ANU3A & Grab Sample (Total) & S12T021347 & $\mathrm{E}$ & 7429-90-5 & Aluminum & $\mathrm{ug} / \mathrm{g}$ & 99.0 & $<6.00 \mathrm{E}-03$ & 982 & $\mathrm{n} / \mathrm{a}$ & $\mathrm{n} / \mathrm{a}$ & $\mathrm{n} / \mathrm{a}$ & $\mathrm{n} / \mathrm{a}$ & 27.8 & $\mathrm{n} / \mathrm{a}$ & \\
\hline 90 & 2AY-12-ANU3A & Grab Sample (Total) & S12T021347 & $\mathrm{E}$ & $7440-70-2$ & Calcium & ug/g & 100 & $<0.0800$ & $<370$ & $\mathrm{n} / \mathbf{a}$ & $\mathrm{n} / \mathrm{a}$ & $\mathrm{n} / \mathrm{a}$ & $\mathrm{n} / \mathrm{a}$ & 370 & $\mathrm{n} / \mathrm{a}$ & $\mathrm{U}$ \\
\hline 90 & 2AY-12-ANU3A & Grab Sample (Total) & S12T021347 & $\mathrm{E}$ & $7440-47-3$ & Chromium & $\mathrm{ug} / \mathrm{g}$ & 98.7 & $<1.00 \mathrm{E}-03$ & 133 & $\mathrm{n} / \mathrm{a}$ & $n / a$ & $\mathrm{n} / \mathrm{a}$ & $n / a$ & 4.63 & $\mathrm{n} / \mathrm{a}$ & \\
\hline 90 & 2AY-12-ANU3A & Grab Sample (Total) & S12T021347 & $\underline{E}$ & $7439-89-6$ & Iron & $\mathrm{ug} / \mathrm{g}$ & 100 & $<0.0100$ & 54.7 & $\mathrm{n} / \mathrm{a}$ & $\mathrm{n} / \mathrm{a}$ & $\mathrm{n} / \mathrm{a}$ & $\mathrm{n} / \mathrm{a}$ & 46.3 & $\mathrm{n} / \mathrm{a}$ & $\mathrm{J}$ \\
\hline 90 & 2AY-12-ANU3A & Grab Sample (Total) & $\mathrm{S} 12 \mathrm{~T} 021347$ & $\mathrm{E}$ & $7440-09-7$ & Potassium & $\mathrm{ug} / \mathrm{g}$ & 99.0 & $<0.0200$ & $7.15 \mathrm{E}+03$ & $\mathrm{n} / \mathrm{a}$ & $\mathrm{n} / \mathrm{a}$ & $\mathrm{n} / \mathrm{a}$ & $\mathrm{n} / \mathrm{a}$ & 92.6 & $\mathrm{n} / \mathrm{a}$ & \\
\hline 90 & 2AY-12-ANU3A & Grab Sample (Total) & S12T021347 & $\mathrm{E}$ & $7439-95-4$ & Magnesium & $\mathrm{ug} / \mathrm{g}$ & 98.4 & $<2.00 \mathrm{E}-03$ & $<9.26$ & $\mathrm{n} / \mathrm{a}$ & $\mathrm{n} / \mathrm{a}$ & $\mathrm{n} / \mathrm{a}$ & $\mathrm{n} / \mathrm{a}$ & 9.26 & $\mathrm{n} / \mathrm{a}$ & U \\
\hline 90 & 2AY-12-ANU3A & Grab Sample (Total) & S12T021347 & $\mathrm{E}$ & $7440-23-5$ & Sodium & $\mathrm{ug} / \mathrm{g}$ & 97.9 & $<0.0400$ & $3.75 \mathrm{E}+05$ & $\mathrm{n} / \mathrm{a}$ & $\mathrm{n} / \mathrm{a}$ & $\mathrm{n} / \mathrm{a}$ & $\mathrm{n} / \mathrm{a}$ & 185 & $\mathrm{n} / \mathrm{a}$ & \\
\hline 90 & 2AY-12-ANU3A & Grab Sample (Total) & S12T021347 & $E$ & $7440-02-0$ & Nickel & $\mathrm{ug} / \mathrm{g}$ & 101 & $\angle 1.00 \mathrm{E}-03$ & $<4.63$ & $\mathrm{n} / \mathrm{a}$ & $\mathrm{n} / \mathrm{a}$ & $\mathrm{n} / \mathrm{a}$ & $n / a$ & 4.63 & $\mathrm{n} / \mathrm{a}$ & $\mathrm{U}$ \\
\hline 90 & 2AY-12-ANU3A & Grab Sample (Total) & S12T021347 & $\mathrm{E}$ & $7723-14-0$ & Phosphorus & $\mathrm{ug} / \mathrm{g}$ & 101 & $<3.00 \mathrm{E}-03$ & $3.34 \mathrm{E}+04$ & $\mathrm{n} / \mathrm{a}$ & $n / a$ & $\mathrm{n} / \mathrm{a}$ & $n / a$ & 13.9 & $\mathrm{n} / \mathrm{a}$ & \\
\hline 90 & 2AY-12-ANU3A & Grab Sample (Total) & S12T021347 & $\mathrm{E}$ & $7704-34-9$ & Sulfur & $\mathrm{ug} / \mathrm{g}$ & 104 & $<5.00 \mathrm{E}-03$ & 858 & $n / a$ & $n / a$ & $n / a$ & $n / a$ & 23.1 & $\mathrm{n} / \mathrm{a}$ & \\
\hline 90 & 2AY-12-ANU3A & Grab Sample (Total) & S12T021347 & $\mathrm{E}$ & $7440-21-3$ & Silicon & $\mathrm{ug} / \mathrm{g}$ & 108 & 0.0662 & 509 & $\mathrm{n} / \mathrm{a}$ & $\mathrm{n} / \mathrm{a}$ & $\mathrm{n} / \mathrm{a}$ & $\mathrm{n} / \mathrm{a}$ & 23.1 & n/a & B \\
\hline 90 & 2AY-12-ANU3A & Grab Sample (Total) & S12T021347 & $\mathrm{E}$ & $7440-62-2$ & Vanadium & $\mathrm{ug} / \mathrm{g}$ & 99.3 & $<1.00 \mathrm{E}-03$ & 19.3 & $\mathrm{n} / \mathrm{a}$ & n/a & $\mathrm{n} / \mathrm{a}$ & $\mathrm{n} / \mathrm{a}$ & 4.63 & $\mathrm{n} / \mathrm{a}$ & $\mathrm{J}$ \\
\hline 90 & 2AY-12-ANU3A & Grab Sample (Total) & S12T021347 & $\mathrm{E}$ & $7440-33-7$ & Tungsten & $\mathrm{ug} / \mathrm{g}$ & 95.9 & $<6.00 \mathrm{E}-03$ & 96.3 & $\mathrm{n} / \mathrm{a}$ & $\mathrm{n} / \mathrm{a}$ & $n / a$ & $n / a$ & 27.8 & $\mathrm{n} / \mathrm{a}$ & $\mathrm{J}$ \\
\hline
\end{tabular}

NA $=$ Not Analyzed, ND $=$ Not Detected

J - Estimated

a - LCS Outside Range

$U$ - Less Than Detection Limit

$\stackrel{\text { UN }}{N}$ 
From:

Sent:

To:

Subject:

Attachments:
Harrington, Stephanie J

Wednesday, October 24, 2012 9:17 AM

Rosenkrance, Chelsea L

RE: Riser 90 sample pictures from 10/15

2AY-12-ANU3 Open.jpg; 2AY-12-ANU5 Open.jpg

Chelsea,

These are the photos taken in the hotcell of the samples taken on the $15^{\text {th }}$. Most of the material in the images is rust (dark material), with some white material visible in sample 5. There was very little sample recovery on the $15^{\text {th }}$.

Hope this helps.

Stephanie dtattington, dh $D$

Chemical Process Engineer

Washington River Protection Solutions, contractor to the United States Department of Energy

2750E Room A219 or 639 Cullum B1 19

(509) 376-1336

From: Rosenkrance, Chelsea L

Sent: Wednesday, October 24, 2012 9:11 AM

To: Harrington, Stephanie J

Cc: Venetz, Theodore J

Subject: Riser 90 sample pictures from 10/15

Stephanie,

Do you have any pictures of the samples taken on $10 / 15$ ? I was going to include them in the sample analysis in the leak assessment report.

Thanks,

Chelsea

Chelsea Rosenkrance

Phone: (509) 373-0098

Email: Chelsea L Rosenkrance@rl.gov

washington river

protectionsolutions

Washington River Protection Solutions is a

Contractor to the United States Department of Energy 
From:

Sent:

To:

Subject:

Attachments:
Venetz, Theodore J

Monday, October 22, 2012 9:58 AM

Rosenkrance, Chelsea L; Boomer, Kayle D

FW: Photographs of samples $3 A$ and $5 A$ in the hotcells

2AY-12-ANU5A open.jpg; 2AY-12-ANU3A open.jpg

From: Harrington, Stephanie J

Sent: Monday, October 22, 2012 7:36 AM

To: Venetz, Theodore J

Subject: Photographs of samples $3 \mathrm{~A}$ and $5 \mathrm{~A}$ in the hotcells

Ted,

Hope this does not put you in e-mail jail...

Otephanie otarrington, $\mathrm{Dh} D$

Chemical Process Engineer

Washington River Protection Solutions,

contractor to the United States Department of Energy

2750E Room A219 or 639 Cullum B119

(509) 376-1336 


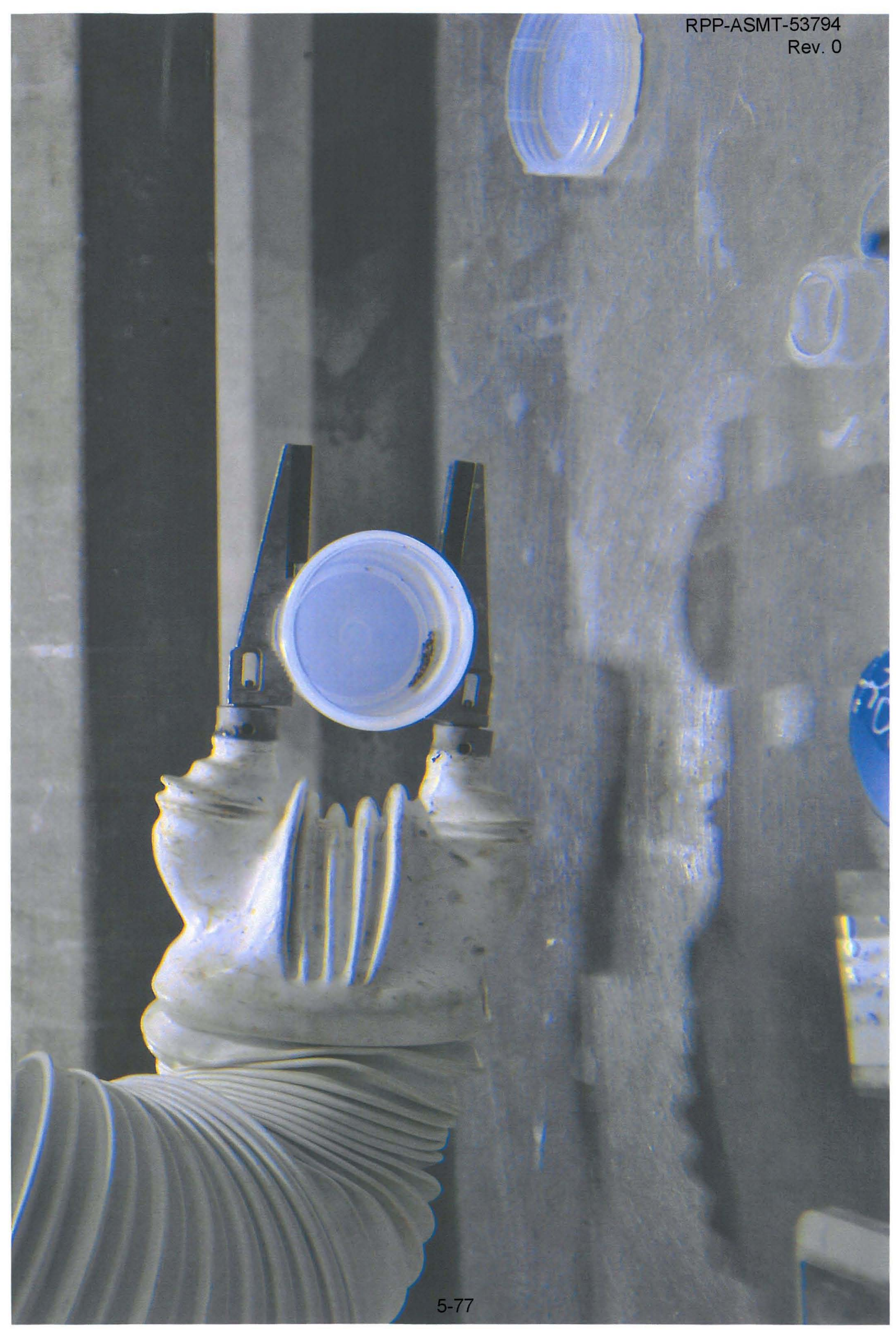


Rev. 0

\section{Harlow, Donald G}
From:
Sent:
To:
Cc:
Subject:
Attachments:

Harrington, Stephanie J

Friday, October 19, 2012 10:29 AM

Rosenkrance, Chelsea L; Sams, Terry L; Washenfelder, Dennis J; Kirch, Nicholas W (Nick); Venetz, Theodore J

Rasmussen, Juergen H; Nguyen, Duc M; Templeton, Andrew M; Reynolds, Jacob G Cs-137 analytical results for AY-102 annulus sample 3A (air slot)

AY102 Annulus Cs-137 2AY-12-ANU3A.xIs; AY102 Annulus Interim GEA and Sr90 Results.xlsx

Please find the results fresh from the laboratory for the Cs-137 analysis on the white material from the air slot (AY102 Annulus Cs-137 2AY-12-ANU3A.xls file). It is about half of the concentration measured from the floor on the other side of the tank (see AY102 Annulus Interim GEA and Sr90 Results.xlsx). We have some material remaining following GEA and $\mathrm{Sr}-90$ analyses (which is currently being performed). I believe the plan will be to use this in an ICP analysis for sample 3A. I will keep you updated as new results are provided. If you do not want the updated preliminary laboratory data as it trickles in, please let me know.

Thank you, Stephanie otartington, oPh $D$

Chemical Process Engineer

Washington River Protection Solutions, contractor to the United States Department of Energy

2750E Room A219 or 639 Cullum B119

(509) 376-1336

From: Ritenour, Gerald $\mathrm{P}$

Sent: Friday, October 19, 2012 10:16 AM

To: Harrington, Stephanie J

Cc: McKinney, Steve G; Bushaw, Ruth A; Bushaw, Thomas H

Subject:

\section{Stephanie,}

The attached spreadsheet contains the preliminary result for the GEA of sample 2AY-12-ANU3A. During the digestion the sample effervesced very strongly indicating carbonate content. If you have any questions or need additional information please feel free to contact me at anytime.

$J R$

Gerald "JR" Ritenour

Project Manager

ATL Analytical Operations

Advanced Techologies and Laboratories International, Inc.

Contractor to the Office of River Protection

U.S. Department of Energy

(509) $372-2742$ office

(509) 438-8837 cell

gerald $p$ ritenour@rl.gov 
AY102 Annulus

Segment Numt Segment Portio SAMPLE_R

Riser 2AY-12-ANU: Grab Sample (7 S12T021347

CAS \# ANALYTE RESULT_UNI STANDARD BLANK

RESULT

10045-97-3 Cesium-137 uCi/g

104

$<0.0587$

42.1

n/a
SPK_REC

$n / a$

0.0531

0.22

0
1
0
0

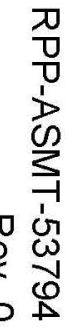


05-oct-2012 10:52:29

INTERIM

AY102 Annulus

Data Summary of All Results

\begin{tabular}{l|l|l|l|l} 
SAMPLE R & A & CAS \# & ANALYTE \\
\hline
\end{tabular}

\begin{tabular}{|l|l|l|l|l|l|l|l|l|l|l|}
\hline RESULT UNIT & STANDARD & BLANK & RESULT & DUPLICATE & AVERAGE & RPD & SPK REC & Det Limit & COUNT ERR & QUALIFIER \\
\hline
\end{tabular}

\begin{tabular}{l|l|l|l|l|l|l}
\hline AY-12-ANU1 & Grab Sample (Total) & S12T021142 & F & LCi \\
\hline
\end{tabular}

2AY-12-ANU1 Grab Sample (Total) S12T021142

$\mathrm{uCi} / \mathrm{g}$ \begin{tabular}{l|l|l|l|l|l|l} 
2AY-12-ANU1 & Grab Sample (Total) & S12T021142 & F & $14331-83-0$ & Actinium-228 & uCi/g \\
\hline 2AY-12-ANU1 & Grab Sample (Total) & S12T021142 & F & SR-89/90 & Strontium-89/90 & uCi/g \\
\hline
\end{tabular}

83 2AY-12-ANU1

$U$ - Less Than Detection Limit

\begin{tabular}{l|l|l|l|l|l|}
$<0.0161$ & 0.0194 & $<.0107$ & n/a & $\mathrm{n} / \mathrm{a}$ & $\mathrm{n} / \mathrm{a}$ \\
\hline
\end{tabular}

\begin{tabular}{l|l|l}
$<0.0192$ & 92.7 & 89.2
\end{tabular}

\begin{tabular}{l|l|l|}
$<0.0637$ & 0.0618 & $<0.0433$ \\
\hline
\end{tabular}

\begin{tabular}{ll|l}
\hline $4.75 \mathrm{E}-03$ & 0.105 & 0.135 \\
\hline
\end{tabular}

\begin{tabular}{l|l|l}
90.9 & 3.89 & $\mathrm{n} / \mathrm{a}$ \\
\hline
\end{tabular}

n/a

$\mathrm{n} / \mathbf{a} \mathrm{n} / \mathrm{a}$

104

0.135

\begin{tabular}{l|l}
24.7 & $\mathrm{n} / \mathrm{a}$ \\
\hline
\end{tabular}

$0.0194 \quad \mathrm{n} / \mathrm{a}$

\begin{tabular}{ll}
0.0951 & 0.21 \\
\hline
\end{tabular}

\begin{tabular}{l|l|l|}
\hline 0.0567 & 30.34 \\
\hline $4.76 \mathrm{E}-03$ & 12.902
\end{tabular}

\begin{tabular}{|l|l|}
\hline U \\
\hline & \\
\hline
\end{tabular}


From:

Sent:

To:

Cc:

Subject:

Attachments:

Importance:
Harrington, Stephanie J

Monday, October 22, 2012 2:06 PM

Kirch, Nicholas W (Nick); Sams, Terry L; Boomer, Kayle D; Powell, William J (Bill); Venetz, Theodore J; Rosenkrance, Chelsea L

Nguyen, Duc M; Rasmussen, Juergen $H$; Templeton, Andrew M; Reynolds, Jacob G

FW: Interim Results for AY102 Annulus Sample 2AY-12-ANU3A

AY102 Annulus Cs-137 2AY-12-ANU3A.xls; AY102 Annulus Sr-90 2AY-12-ANU3A.xlsx

High

Update from the laboratory and preliminary Cs-137 and Sr-90 results for sample 3A (air duct).

Stephanie oftateington, $P$ h $D$

Chemical Process Engineer

Washington River Protection Solutions,

contractor to the United States Department of Energy

2750E Room A219 or 639 Cullum B119

(509) $376-1336$

From: Bushaw, Ruth A

Sent: Monday, October 22, 2012 12:51 PM

To: Harrington, Stephanie $]$

Cc: Bushaw, Thomas H; McKinney, Steve G; Cooke, Gary

Subject: Interim Results for AY102 Annulus Sample 2AY-12-ANU3A

Importance: High

Stephanie,

CCN 12-CCN-31 for AY102 Annulus sample 2AY-12-ANU3A requests Sr-90 and Cs-137 results within 2 business days of issue (10/18/2012), which is today. The GEA Cs-137 result was already provided on Friday, $10 / 19 / 2012$, but I included it again in this message that adds the Sr-90 result.

The TIC/TOC rerun for 2AY-12-ANU1 and the ICP analysis for 2AY-12-ANU3A are being run today.

If you have any question about the attached results, please feel free to contact me.

Thanks,

\section{Ruth A. Bushaw}

Project Coordinator

Advanced Technologies and Laboratories International, Inc.

Contractor to the Office of River Protection

U.S. Department of Energy 222-S Laboratory

$373-4314$

From: Ritenour, Gerald P

Sent: Friday, October 19, 2012 10:16 AM

To: Harrington, Stephanie J 
Cc: McKinney, Steve G; Bushaw, Ruth A; Bushaw, Thomas H Subject:

\section{Stephanie,}

The attached spreadsheet contains the preliminary result for the GEA of sample 2AY-12-ANU3A. During the digestion the sample effervesced very strongly indicating carbonate content. If you have any questions or need additional information please feel free to contact me at anytime.

JR

Gerald "JR" Ritenour

Project Manager

ATL Analytical Operations

Advanced Technologies and Laboratories International, the.

Contractor to the Office of River Protection

U.S. Department of Energy

(509) 372-2742 office

(509) 438-8837 cell

gerald p ritenour@rl.gov 
19-oct-2012 10:09:36 Page:

INTERIM

Y102 Annulus

DSRSpreadsh LSR.Jar v. $2 \cdot 7.27$

Segment Numt Segment Portic SAMPLE R

90 2AY-12-ANU3 Grab Sample (' S12T021347

CAS\# ANALYTE RESULT_UNI STANDARD BLANK

10045-97-3

Cesium-137 uCi/g

104

0.0587

RESULT

$\mathrm{D}$

$\mathrm{NA}=$ Not Analyzed, ND $=$ Not Detected

SPK_REC

Det Limit

COUNT_ERR QUALIFIER

0
1
$\infty$
$\perp$

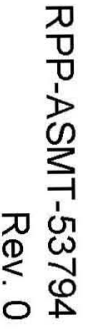


22-oct-2012 12:44:40

INTERIM

AY102 Annulus

Data Summary Report

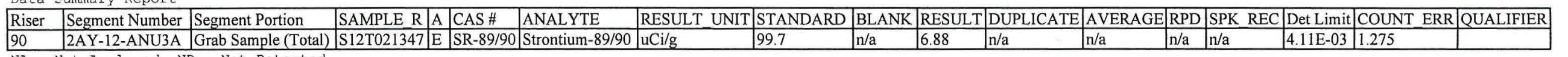

= Not Analyzed, ND - Not Detected 


$\begin{array}{ll}\text { From: } & \text { Harrington, Stephanie J } \\ \text { Sent: } & \text { Thursday, October 18, } 20124: 20 \text { PM } \\ \text { To: } & \text { Venetz, Theodore J; Boomer, Kayle D; Washenfelder, Dennis J; Rosenkrance, Chelsea L } \\ \text { Cc: } & \text { Reynolds, Jacob G; Nguyen, Duc M; Templeton, Andrew M; Rasmussen, Juergen H } \\ \text { Subject: } & \text { FW: Status of AY-102 samples received at 222-S 10-17-2012 }\end{array}$

Preliminary results for the samples taken yesterday are described below...

Thank you,

Stephanie ditatington, P $\mathrm{D}$

Chemical Process Engineer

Washington River Protection Solutions,

contractor to the United States Department of Energy

2750E Room A219 or 639 Cullum B1 19

(509) 376-1336

From: Cooke, Gary

Sent: Thursday, October 18, 2012 3:59 PM

To: McKinney, Steve G; Harrington, Stephanie J; Sams, Terry L; Prilucik, John R; Seidel, Cary M; Hardy, Don B; Bushaw, Ruth A

Cc: Pestovich, John A; Page, Jason S; Rice, Andrew D; Huber, Heinz J

Subject: Status of AY-102 samples received at 222-S 10-17-2012

All,

We have completed an SEM and XRD examination of two samples received at the 222-S Laboratory on 10/17/2012.

The samples, identified as 2AY-12-ANU3A, 2AY-12-ANU5A were examined in the 11-A Hot Cells, photographed, weighed, transferred to glass jars and transferred to the CA portion of the lab. The samples were again photographed in the lab prior to analysis.

The 2AY-12-ANU3A sample consisted of pieces of rust and large (up to $1 / 2$ ") white pieces that appeared to be aggregates of finer material. The white pieces were separated and crushed. XRD and SEM splits were removed from this crushed material. The remaining ground white material was placed in a pre-weighed $60 \mathrm{ml}$ plastic bottle and given to ATL personnel for GEA analysis. Approximately 0.1 gram was available for this analysis.

The 2AY-12-ANU5A was crushed in its entirety. No attempt was made to separate the rust from the few light colored fragments that were present. XRD and SEM analysis was conducted on this material, consuming nearly the entire sample.

The white particulate from sample 2AY-12-ANU3A consists entirely of water soluble salts that are consistent with tank waste saltcake or supernatant dissolved solids. However, there are some notable differences between this material and the previous tank waste material that has been retrieved from the AY-102 annulus. These are being investigated further.

The particulate from sample 2AY-12-ANU5A was seen on the SEM to consist of a mixture of rust and soil with a small amount of a sodium-rich phase. The XRD pattern for this sample showed no significant peaks for any crystalline 
phase. The SEM sample specimen contained no detectible beta/gamma radiation using the room monitors. The only evidence for tank waste material in this sample was the sodium-rich particulate. The only source outside of tank waste that could provide a sodium rich particulate is clean caustic.

We recommend that Polarized Light Microscopy should be performed on these samples. It will aid in interpreting the XRD and SEM results. We have enough material left over from the SEM and XRD sample preparation to provide the small amount of material required for PLM analysis.

We will provide additional details on the XRD and SEM analysis tomorrow.

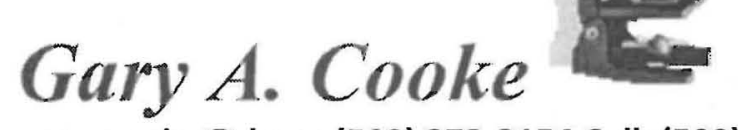

gary cooke@rl.gov (509) 373-2154 Cell: (509) 845-3988

Washington River Protection Solutions, contractor to the United States Department of Energy 


\section{From:}

Sent:

To:

Cc:

Subject:
Harrington, Stephanie J

Wednesday, October 17, 2012 9:38 PM

Johnson, Jo M; Cooke, Gary; Bushaw, Ruth A; McKinney, Steve G; Prilucik, John R

Sams, Terry L; Rasmussen, Juergen $\mathrm{H}$; Rosenkrance, Chelsea L

RE: AY-102 Annulus Sample Analysis

So, as most of you know we only got 0.12 grams of material from the mound (sample 5A) and 0.2 grams from the air slot (sample 3A). I was told that we needed at least $0.5(+/-0.1)$ grams for radiochemistry (Cs-137 and Sr-90). Since there is not enough material for that, I believe that the solid phase characterization (SEM, PLM, and XRD) is the best bet to get good results with the material we have. I am putting together a CCN to this effect, and will bring it around tomorrow morning for signatures.

Thank you, Stephanie tharrington, ofh $D$

Chemical Process Engineer

Washington River Protection Solutions, contractor to the United States Department of Energy

2750E Room A219 or 639 Cullum B119

(509) $376-1336$

From: Johnson, Jo M

Sent: Wednesday, October 17, 2012 3:48 PM

To: Johnson, Jo M; Hansen, Daniel R; Bushaw, Thomas H; Schroeder, Robert W; Akita, Raymond (Ray); Rice, Andrew D; Bushaw, Ruth A; Duchsherer, Mark J; Purcell, Michael A; Menjivar, Carolina S; Osborn, Julie A; Ritenour, Gerald P; Greenough, Keith J Jr; Seidel, Cary M; Keltner, Katherine A; Templeton, Andrew M; Nguyen, Duc M; Steele, Richard T; Soto, Edward; McKinney, Steve G; Cooke, Gary; Lucas, Daniel R (Dan); McColloch, Todd A

Cc: Sosa, Robert W; Fuller, Richard K (Keith); Hardy, Don B; Renberger, Duane L; Kimmel, Thomas S; George, Thomas E; Prilucik, John R; Frazier, Jason E; Sondag, Joseph M; Bamberger, Michael G; Cheadle, Jeffry E; McKinney, Steve G; Sams, Terry L; Brannan, Patrick B (Brad); Harrington, Stephanie J

Subject: FW: AY-102 Annulus Sample Analysis

Importance: High

The samples are expected to be to the lab around 6PM tonight. Tom Craft is the FWS. Thanks.

Jo Marie Johnson

Project Coordinator/Acting Manager-Sample Management Office (222-S Laboratory)

RJ Lee Group, Inc.

subcontractor to Washington River Protection Solutions

contractor to the United States Department of Energy

Phone: (509) 372-9474

Fax:(509) 372-1878

From: Johnson, Jo M

Sent: Wednesday, October 17, 2012 2:50 PM

To: Johnson, Jo M; Hansen, Daniel R; Bushaw, Thomas H; Schroeder, Robert W; Akita, Raymond (Ray); Rice, Andrew D; Bushaw, Ruth A; Duchsherer, Mark J; Purcell, Michael A; Menjivar, Carolina S; Osborn, Julie A; Ritenour, Gerald P; Greenough, Keith J Jr; Seidel, Cary M; Keltner, Katherine A; Templeton, Andrew M; Nguyen, Duc M; Steele, Richard T; Soto, Edward; McKinney, Steve G; Cooke, Gary; Lucas, Daniel R (Dan)

Cc: Sosa, Robert W; Fuller, Richard K (Keith); Hardy, Don B; Renberger, Duane L; Kimmel, Thomas S; George, Thomas E; Prilucik, John R; Frazier, Jason E; Sondag, Joseph M; Bamberger, Michael G; Cheadle, Jeffry E; McKinney, Steve G; 
Sams, Terry L; Brannan, Patrick B (Brad); Harrington, Stephanie J

Rev. 0

Subject: FW: AY-102 Annulus Sample Analysis

Importance: High

AY-102 sampling is complete for today, and the samples will be delivered tonight on swings. Thanks.

Jo Marie Johnson

Project Coordinator/Acting Manager-Sample Management Office (222-S Laboratory)

RJ Lee Group, Inc.

subcontractor to Washington River Protection Solutions

contractor to the United States Department of Energy

Phone: (509) 372-9474

Fax:(509) 372-1878

From: Johnson, Jo M

Sent: Wednesday, October 17, 2012 12:07 PM

To: Johnson, Jo M; Hansen, Daniel R; Bushaw, Thomas H; Schroeder, Robert W; Akita, Raymond (Ray); Rice, Andrew D; Bushaw, Ruth A; Duchsherer, Mark J; Purcell, Michael A; Menjivar, Carolina S; Osborn, Julie A; Ritenour, Gerald P; Greenough, Keith J Jr; Seidel, Cary M; Keltner, Katherine A; Templeton, Andrew M; Nguyen, Duc M; Steele, Richard T; Soto, Edward; McKinney, Steve G; Cooke, Gary; Lucas, Daniel R (Dan)

Cc: Sosa, Robert W; Fuller, Richard K (Keith); Hardy, Don B; Renberger, Duane L; Kimmel, Thomas S; George, Thomas E; Prilucik, John R; Frazier, Jason E; Sondag, Joseph M; Bamberger, Michael G; Cheadle, Jeffry E; McKinney, Steve G; Sams, Terry L; Brannan, Patrick B (Brad); Harrington, Stephanie J

Subject: FW: AY-102 Annulus Sample Analysis

Importance: High

Sampling for AY-102 is expected to continue throughout the afternoon, and the current plan is to ship on swing shift tonight-10/17. Process Engineering has requested that sample breakdown be scheduled for tonight as well, so that the sample(s) are ready for analysis ASAP. Thanks.

Jo Marie Johinson

Project Coordinator/Acting Manager-Sample Management Office (222-S Laboratory)

RJ Lee Group, Inc.

subcontractor to Washington River Protection Solutions

contractor to the United States Department of Energy

Phone: (509) 372-9474

Fax:(509) 372-1878 


\subsection{Preliminary Leak Detection Pit Sample Results for RPP-ASMT-53793, Section 4.3.5, Leak Detection Pit Sample Results}

6.1 Leak Detection Pit September 2012 Samples. $.6-2$ 
Rev. 0

6.1 Leak Detection Pit September 2012 Samples 


\section{From:}

Sent:

To:

Cc:

Subject:

Importance:
Nguyen, Duc M

Wednesday, September 12, 2012 10:20 AM

Kirch, Nicholas W (Nick); Powell, William J (Bill); Reynolds, Jacob G; Jo, Jaiduk;

Uytioco, Elise M; Rasmussen, Juergen H; Sams, Terry L; Boomer, Kayle D; Venetz, Theodore J

Prilucik, John R; Ritenour, Gerald P; Strasser, David W; Shultz, M V Jr (Milt)

RE: AY102A LDP 3-Day Format II Interim Rpt

All,

The lab re-measured $\mathrm{pH}$ for the field blank and samples and the new results are consistent with the results from the first round. OC results were good. Ion chromatography results indicate that the anomaly was not due to an acid residue ( $\mathrm{HNO}$ or $\mathrm{HCl}$ ) from the sample bottle cleaning. So what we have is a field blank pH result that indicates there is an unknown contaminant that is affecting (lowering) the pH of the field blank and, therefore, could be affecting (lowering) the pH of the LDP liquid samples. The lab verbally indicates that the sample $\mathrm{pH}$ results should be used as lower bounds for the actual $\mathrm{pH}$ of the liquid in the leak detection pit. They will send us an email summarizing what they found along with the usage recommendation.

Thanks,

Duc M. Nguyen

Washington River Protection Solutions LLC

Contractor to the United States Department of Energy

(509) $372-3042$

\section{From: Kirch, Nicholas W (Nick)}

Sent: Tuesday, September 11, 2012 2:28 PM

To: Rasmussen, Juergen H; Sams, Terry $L$

Cc: Powell, William J (Bill); Nguyen, Duc M; Reynolds, Jacob G; Jo, Jaiduk; Uytioco, Elise M

Subject: RE: AY102A LDP 3-Day Format II Interim Rpt

A quick comparison of these results to the December 2007 :

The C $5-137$ is lower by an order of magnitude, the $5 r-90$ is lower by about half. pH is just below 7

\begin{tabular}{|l|l|l|}
\hline Analyte & 2007 Result & 2012 Result \\
\hline $\mathrm{Cs}-137$ & Between 3.3 and $6.3(10-4) \mathrm{uCl} / \mathrm{ml}$ & Between 2.2 and $2.4(10-5) \mathrm{uCl} / \mathrm{ml}$ \\
\hline $\mathrm{Sr}-90$ & Between 5.5 and $5.6(10-3) \mathrm{uCl} / \mathrm{ml}$ & Between 2.2 and $2.3(10-3) \mathrm{uCi} / \mathrm{ml}$ \\
\hline $\mathrm{pH}$ & Between 7.9 and 8.1 & Between 6.6 and 6.9 \\
\hline
\end{tabular}

The field blank pH was below 4 , which is a bit of a head scratcher.

The plan is to transfer this to AY-101. We will need Milt Shultz as CSR to approve it since it is less than pH 7.

Nick Kirch, Manager

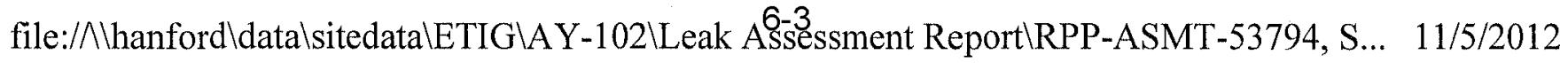


Base Operations Process Engineering Washington River Protection Solutions Contractor to the US Department of Energy phone (509) 373-2380

cell (509) $438-9537$

From: Rasmussen, Juergen $\mathrm{H}$

Sent: Tuesday, September 11, 2012 1:54 PM

To: Kirch, Nicholas W (Nick); Sams, Terry L

Cc: Powell, William J (Bill); Nguyen, Duc M; Reynolds, Jacob G

Subject: FW: AY102A LDP 3-Day Format II Interim Rpt

Nick,

Here is the 3-day early report for the AY-102 leak detection pit samples. Being preliminary results, the values are subject to change when the data are reviewed and formally reported. The very low Cs-137 values are consistent with slightly contaminated rainwater. The lab is investigating the low pH of the field blank. This might possibly indicate an issue with the bottle cleaning procedure or the water used for the field blank.

Thanks-m

Juergen Rasmussen

Washington River Protection Solutions,

contractor to the United States Department of Energy

From: Ritenour, Gerald $P$

Sent: Tuesday, September 11, 2012 1:20 PM

To: Rasmussen, Juergen $\mathrm{H}$

Subject: FW: AY102A LDP 3-Day Format II Interim Rpt

Gerald "JR" Ritenour

Project Manager

ATL Analytical Operations

Advanced Technologies and Laboratories International, the.

Contractor to the Office of River Protection

U.S. Deparimen of Energy

(509) $372-2742$ offico

(509) $438 \mathrm{~m} 8837 \mathrm{cell}$

gerald p ritenouron.gov

From: Ritenour, Gerald $P$

Sent: Monday, September 10, 2012 1:41 PM

To: Nguyen, Duc M

Cc: McKinney, Steve G; Bushaw, Thomas H; Johnson, Jo M

Subject: AY102A LDP 3-Day Format II Interim Rpt

Duc,

file:/N \hanford \datalsitedatalETIG $\backslash A Y-102 \backslash$ Leak Assęssment Report\RPP-ASMT-53794, S... 11/5/2012 
The attached spreadsheet is the Format II Interim report for AY102A LDP samples. I have also included the Sr $89 / 90$ results. If you have any question or need additional information please let me know.

$J R$

Gerald "SR" Fitonour

Project Manager

ATL Analyical Operations

Advanced Techologies and Laboratories Intewational, The.

Contractor to the Offue of River protection

Y.S. Depamment of Energy

(509) $372 m 2742$ ofics

(509) $438-8337 \mathrm{coll}$

gerald o ritenourontoov

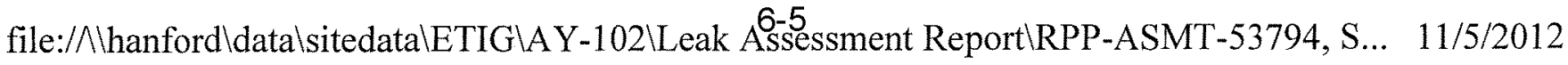


From:

Sent:

To:

\section{Subject:}

Attachments:
Nguyen, Duc $M$

Tuesday, October 02, 2012 10:29 AM

Sams, Terry L; Venetz, Theodore J; Boomer, Kayle D; Reynolds, Jacob G; Kirch, Nicholas W (Nick); Uytioco, Elise M; Harrington, Stephanie J; Rasmussen, Juergen $\mathrm{H}$; Washenfelder, Dennis J; Tardiff, Gary R FW: AY102A LDP 14-Day Format II Interim Rpt AY102A-LDP Format II 14-Day Rpt.xls

Attached is the second round of interim results on the AY-102 LDP samples. These data confirm that the liquid in the LDP is just slightly contaminated water.

Thanks,

Duc M. Nguven

Washington River Protection Solutions LLC

Contractor to the United States Department of Energy

(509) $372-3042$

From: Ritenour, Gerald P

Sent: Monday, October 01, 2012 10:18 AM

To: Ritenour, Gerald P; Nguyen, Duc M

Cc: McKinney, Steve G; Bushaw, Thomas H; Johnson, Jo M

Subject: RE: AY102A LDP 14-Day Format II Interim Rpt

Duc,

The attached spreadsheet is the 14 Day Format II Interim report for AY102A LDP samples. Results should be consider preliminary and are subject to change upon further review. If you have any questions or need additional information please let me know.

$\mathrm{JR}$

Gerald "JR" Ritenour

Project Manager

ATL Analytical Operations

Advanced Technologies and Laboratories Intemational, Inc.

Contractor to the Office of River Protection

U.S. Department of Energy

(509) $372-2742$ office

(509) $438-8837 \mathrm{cell}$

gerald o ritenourourloov 
Segment

Segment Portion

2AY-LDP-12-01 Grab Sample (Total) 2AY-LDP-12-01 Grab Sample (Total)

2AY-LDP-12-01 Grab Sample (Total)

2AY-LDP-12-01 Grab Sample (Total) 2AY-LDP-12-01 Grab Sample (Total) 2AY-LDP-12-01 Grab Sample (Total) 2AY-LDP-12-01 Grab Sample (Total) 2AY-LDP-12-01 Grab Sample (Total) 2AY-LDP-12-01 Grab Sample (Total) 2AY-LDP-12-01 Grab Sample (Total) 2AY-LDP-12-01 Grab Sample (Total) 2AY-LDP-12-01 Grab Sample (Total) 2AY-LDP-12-01 Grab Sample(Total) 2AY-LDP-12-01 Grab Sample (Total) 2AY-LDP-12-01 Grab Sample (Total) 2AY-LDP-12-01 Grab Sample (Total) 2AY-LDP-12-01 Grab Sample (Total) 2AY-LDP-12-01 Grab Sample (Total) 2AY-LDP-12-01 Grab Sample (Total) 2AY-LDP-12-01 Grab Sample (Total) 2AY-LDP-12-01 Grab Sample (Total) 2AY-LDP-12-01 Grab Sample (Total) 2AY-LDP-12-01 Grab Sample (Total) 2AY-LDP-12-01 Grab Sample (Total) 2AY-LDP-12-01 Grab Sample (Total) 2AY-LDP-12-01 Grab Sample (Total) 2AY-LDP-12-01 Grab Sample (Total) 2AY-LDP-12-01 Grab Sample (Total) 2AY-LDP-12-01 Grab Sample (Total) 2AY-LDP-12-01 Grab Sample (Total) 2AY-LDP-12-01 Grab Sample (Total) 2AY-LDP-12-01 Grab Sample (Total) 2AY-LDP-12-01 Grab Sample (Total) 2AY-LDP-12-01 Grab Sample (Total) 2AY-LDP-12-01 Grab Sample (Total) 2AY-LDP-12-01 Grab Sample (Total) 2AY-LDP-12-01 Grab Sample (Total) 2AY-LDP-12-01 Grab Sample (Total) 2AY-LDP-12-01 Grab Sample (Total) 2AY-LDP-12-01I Grab Sample (Total) 2AY-LDP-12-01I Grab Sample (Total) 2AY-LDP-12-01I Grab Sample (Total) 2AY-LDP-12-01I Grab Sample (Total) 2AY-LDP-12-01I Grab Sample (Total) 2AY-LDP-12-011 Grab Sample (Total) 2AY-LDP-12-01I Grab Sample (Total) 2AY-LDP-12-01I Grab Sample (Total) 2AY-LDP-12-01I Grab Sample (Total) 2AY-LDP-12-01I Grab Sample (Total) 2AY-LDP-12-01I Grab Sample (Total) 2AY-LDP-12-01I Grab Sample (TotaI) 2AY-LDP-12-01I Grab Sample (Total) 2AY-LDP-12-01I Grab Sample (Total) 2AY-LDP-12-01I Grab Sample (Total)
SAMPLE_R A

S12T019902 S12T019902 S12T019902 S12T019902 S12T019902 S12T019902 S12T019902 S12T019902 S12T019902 S12T019902 S12T019902 S12T019902 S12T019902 S12T019902 $12 T 019902$ \$12T019902 S12T019902 S12T019902 S12T019902 S12T019902 \$2T019902 S12T019902 S12T019902 S12T019902 S12T019902 12T019902 $\$ 12$ T019902 S12T019902 S12T019902 S12T019902 S12T019902 S12T019902 S12T019902 S12T019902 S12T019902 S12T019904 \$12T019904 S12T019904 S12T019904 S12T019904 S12T019904 S12T019904 S12T019904 S12T019904 S12T019904 S12T019904 S12T019904 S12T019904 S12T019904
CAS \# ANALYTE

6984-48-8 Fluoride ug/mL 101 666-14-8 Glycolate ug/mL 101 71-50-1 Acetate ug/mL 97.3 $\begin{array}{llll}12311-97-6 & \text { Formate } & \mathrm{ug} / \mathrm{mL} & 94.7 \\ 16887-00-6 & \text { Chloride } & \mathrm{ug} / \mathrm{mL} & 99.9\end{array}$ 14797-65-0 Nitrite $\quad \mathrm{ug} / \mathrm{mL} \quad 94.1$ 14808-79-8 Sulfate ug/mL 338-70-5 Oxalate ug/mL 956 24959-67-9 Bromide ug/mL 92.6 14797-55-8 Nitrate ug/mL 92.4 14265-44-2 Phosphate ug/mL 90.6 7440-22-4 Silver ug/mL 101 7429-90-5 Aluminum ug/mL 99.1 7440-38-2 Arsenic ug/mL 100 7440-41-7 Beryllium ug $/ \mathrm{mL} \quad 978$ 7440-69-9 Bismuth ug/mL 102 7440-70-2 Calcium ug/mL 101 7440-43-9 Cadmium ug/mL 102 7440-48-4 Cobalt ug/mL 102 7440-47-3 Chromium ug/mL 100 7439-89-6 Iron $\mathrm{ug} / \mathrm{mL} \quad 100$ 7440-09-7 Potassium ug/mL 97.1 7439-91-0 Lanthanum ug/mL 99.1 7439-96-5 Manganese ug/mL 102 7440-23-5 Sodium $\quad \mathrm{ug} / \mathrm{mL} \quad 98.1$ 7440-02-0 Nickel ug/mL 103

Phosphorus ug/mL 99.0 $7439-92-1$ Lead ug/mL 102

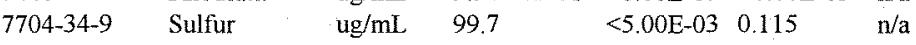
7782-49-2 Selenium ug/mL $100 \quad<6.00 \mathrm{E}-03 \quad<6.00 \mathrm{E}-03 \quad \mathrm{n} / \mathrm{a}$ $\begin{array}{lllllll}7440-21-3 & \text { Silicon } & \mathrm{ug} / \mathrm{mL} & 106 & 0.0221 & 1.07 & \mathrm{n} / \mathrm{a}\end{array}$ 7440-24-6 Strontium ug/mL $101 \quad<200 \mathrm{E}-030.0555 \quad \mathrm{n} / \mathrm{a}$

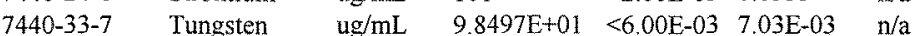

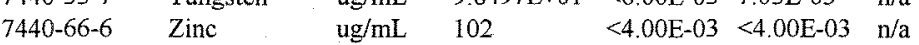
7440-67-7 Zirconium ug/mL $96.1<1.00 \mathrm{E}-03<1.00 \mathrm{E}-03 \quad \mathrm{n} / \mathrm{a}$ $\begin{array}{lllll}\text { SPECGRAVIT Specific gravity unitless } & 100.4 & \mathrm{n} / \mathrm{a} & 1.003 & 1.003\end{array}$ SR-89/90 Strontium-89/9 uCi/mL 98.0 \%WATER Percent water \%

16984-48-8 Fluoride 98. $666-14-8$ G 101 71-50-1 Acetate $\mathrm{ug} / \mathrm{mL} \quad 97.3$ 12311-97-6 Formate ug/mL 94.7 16887-00-6 Chloride ug/mL 99.9 14797-65-0 Nitrite ug/mL 94.1 14808-79-8 Sulfate ug/mL. 96.5 338-70-5 Oxalate $\mathrm{ug} / \mathrm{mL} \quad 95.6$ 24959-67-9 Bromide $\mathrm{ug} / \mathrm{mL} \quad 92.6$ 14797-55-8 Nitrate $\quad \mathrm{ug} / \mathrm{mL} \quad 92.4$ 14265-44-2 Phosphate ug/mL 906 7440-22-4 Silver ug/mL 101 7429-90-5 Aluminum ug/mL 99.1 7440-38-2 Arsenic ug/mL 100 7440-41-7 Beryllium ug/mL 97.8
3.92E-07 2.21E-03 2.20E-03 n/a $\quad 107 \quad n / a$

$<1.61 \mathrm{E}-03<1.61 \mathrm{E}-03 \quad \mathrm{n} / \mathrm{a}$ $<9.37 \mathrm{E}-03<9.37 \mathrm{E}-03 \quad \mathrm{n} / \mathrm{a}$ $<6.04 \mathrm{E}-03<6.04 \mathrm{E}-03 \quad \mathrm{n} / \mathrm{a}$ $<4.67 \mathrm{E}-03<4.67 \mathrm{E}-03 \quad \mathrm{n} / \mathrm{a}$ $<9.98 \mathrm{E}-03 \quad 0.0770 \quad \mathrm{n} / \mathrm{a}$ $<0.0192<0.0192 \quad \mathrm{n} / \mathrm{a}$ $<0.0187 \quad 0.215$ $<0.0231<0.0231$

$<0.0580<0.0580$

$<0.0208 \quad 1.86$

$<0.0167 \quad \mathrm{n} / \mathrm{a} \quad \mathrm{n} / \mathrm{a}$ $1.00 \mathrm{E}-03<1.00 \mathrm{E}-03<1.00 \mathrm{E}-03 \quad \mathrm{n} / \mathrm{a}$ $<6.00 \mathrm{E}-03<6.00 \mathrm{E}-03 \quad 6.63 \mathrm{E}-03 \quad \mathrm{n}$ $<5.00 \mathrm{E}-03<5.00 \mathrm{E}-03<5.00 \mathrm{E}-03 \quad \mathrm{n} / \mathrm{a}$ $<1.00 \mathrm{E}-03<1.00 \mathrm{E}-03<1.00 \mathrm{E}-03 \quad \mathrm{n} / \mathrm{a}$

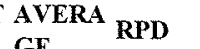

GE RPD

SPK- Det Limit COUN QUALIFIER

$105 \quad 161 \mathrm{E}-03 \quad \mathrm{n} / \mathrm{a} \quad \mathrm{U}$

$105 \quad 9.37 \mathrm{E}-03 \quad \mathrm{n} / \mathrm{a} \quad \mathrm{U}$

$103 \quad 6.04 \mathrm{E}-03 \quad \mathrm{n} / \mathrm{a} \quad \mathrm{U}$

$98.7 \quad 4.67 \mathrm{E}-03 \quad \mathrm{n} / \mathrm{a}$

$103 \quad 9.98 \mathrm{E}-03 \quad \mathrm{n} / \mathrm{a}$

$\begin{array}{llll}98.4 & 0.0192 & \mathrm{n} / \mathrm{a} & \mathrm{a}\end{array}$

$\begin{array}{lll}94.7 & 0.0187 \quad \mathrm{n} / \mathrm{a}\end{array}$

$\begin{array}{llll}90.7 & 0.0231 & \mathrm{n} / \mathrm{a} \quad \mathrm{U}\end{array}$

$\begin{array}{llll}84.2 & 0.0580 & \mathrm{n} / \mathrm{a}\end{array}$

$91.7 \quad 0.0167 \quad \mathrm{n} / \mathrm{a}$

$\mathrm{n} / \mathrm{a} \quad 1.00 \mathrm{E}-03 \quad \mathrm{n} / \mathrm{a} \quad \mathrm{U}$

$\mathrm{n} / \mathrm{a} \quad 6.00 \mathrm{E}-03 \quad \mathrm{n} / \mathrm{a} \quad \mathrm{U}$

n/a $5.00 \mathrm{E}-03 \quad \mathrm{n} / \mathrm{a}$

$\mathrm{n} / \mathrm{a} \quad 100 \mathrm{E}-03 \quad \mathrm{n} / \mathrm{a}$

$\mathrm{n} / \mathrm{a} \quad 6.00 \mathrm{E}-03 \quad \mathrm{n} / \mathrm{a}$

$\mathrm{n} / \mathrm{a} \quad 0.0800 \quad \mathrm{n} / \mathrm{a}$

$\mathrm{n} / \mathrm{a} \quad 1.00 \mathrm{E}-03 \quad \mathrm{n} / \mathrm{a} \quad U$

$\mathrm{n} / \mathrm{a} \cdot 1.00 \mathrm{E}-03 \quad \mathrm{n} / \mathrm{a} \quad \mathrm{U}$

$\mathrm{n} / \mathrm{a} \quad 1.00 \mathrm{E}-03 \quad \mathrm{n} / \mathrm{a}$

$\begin{array}{lll}\mathrm{n} / \mathrm{a} & 0.0100 \quad \mathrm{n} / \mathrm{a}\end{array}$

$\mathrm{n} / \mathrm{a} \quad 0.0200 \quad \mathrm{n} / \mathrm{a}$

$\begin{array}{lll}\mathrm{n} / \mathrm{a} & 1.00 \mathrm{E}-03 & \mathrm{n} / \mathrm{a} \\ \mathrm{n} / \mathrm{a} & 1.00 \mathrm{E}-03 & \mathrm{n} / \mathrm{a}\end{array}$

a.a. $\quad 0.0400 \quad \mathrm{n} / \mathrm{a}$

$1.00 \mathrm{E}-03 \quad \mathrm{n} / \mathrm{a}$

$3.00 \mathrm{E}-03 \mathrm{n} / \mathrm{a}$

$6.00 \mathrm{E}-03 \mathrm{n} / \mathrm{a}$

$8.00 \mathrm{E}-03 \mathrm{n} / \mathrm{a}$

$5.00 \mathrm{E}-03 \mathrm{n} / \mathrm{a}$

$6.00 \mathrm{E}-03 \quad \mathrm{n} / \mathrm{a}$

$5.00 \mathrm{E}-03 \quad \mathrm{n} / \mathrm{a}$

$2.00 \mathrm{E}-03 \quad \mathrm{n} / \mathrm{a}$

$6.00 \mathrm{E}-03 \mathrm{n} / \mathrm{a}$

$4.00 \mathrm{E}-03 \quad \mathrm{n} / \mathrm{a}$

$1.00 \mathrm{E}-03 \mathrm{n} / \mathrm{a}$

$1.000 \mathrm{E}-03 \mathrm{n} / \mathrm{a}$

$2.79 \mathrm{E}-07 \quad 0.62$

$\mathrm{n} / \mathrm{a} \quad 0.0100 \quad \mathrm{n} / \mathrm{a}$

$\mathrm{n} / \mathrm{a} \quad 1.61 \mathrm{E}-03 \quad \mathrm{n} / \mathrm{a}$

$\mathrm{n} / \mathrm{a} \quad 9.37 \mathrm{E}-03 \quad \mathrm{n} / \mathrm{a}$

$\mathrm{n} / \mathrm{a} \quad 6.04 \mathrm{E}-03 \quad \mathrm{n} / \mathrm{a}$

9.98E-03 $\mathrm{n} / \mathrm{a}$

$\mathrm{n} / \mathrm{a} \quad 9.98 \mathrm{E} 03 \mathrm{n} / \mathrm{a}$

n/a 0.0187

$\mathfrak{n} / \mathrm{a} \quad 0.0187$

$\begin{array}{ll}\mathrm{n} / \mathrm{a} & 0.0231 \\ \mathrm{n} / \mathrm{a} & 0.0580\end{array}$

$\mathrm{n} / \mathrm{a} \quad 0.0208$

$\begin{array}{lll}\mathrm{n} / \mathrm{a} & 0.0167 \quad \mathrm{n} / \mathrm{a}\end{array}$

$92.4 \quad 1.00 \mathrm{E}-03 \quad \mathrm{n} / \mathrm{a}$

$95.7 \quad 6.00 \mathrm{E}-03 \quad \mathrm{n} / \mathrm{a}$

$98.3 \quad 5.00 \mathrm{E}-03 \quad \mathrm{n} / \mathrm{a}$

$95.1 \quad 1.00 \mathrm{E}-03 \mathrm{n} / \mathrm{a}$

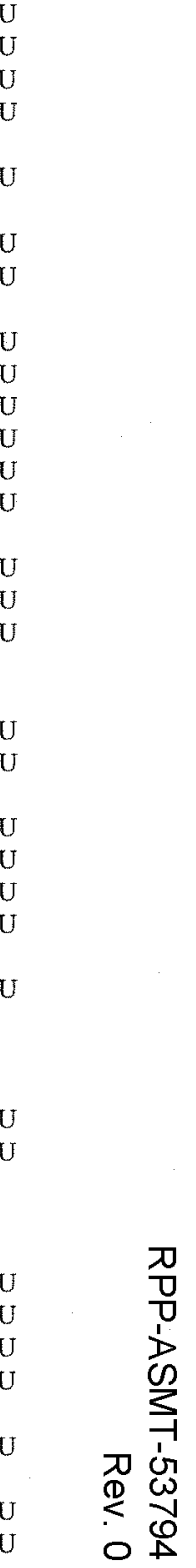




\begin{tabular}{|c|c|c|c|c|c|c|c|c|c|c|c|c|c|c|}
\hline na & 2AY-LDP-12-01I Grab Sample (Total) & S12T019904 & $7440-69-9$ & Bismuth & $\mathrm{ug} / \mathrm{mL}$ & 102 & $<6.00 \mathrm{E}-03$ & $<6.00 \mathrm{E}-03$ & $<6.00 \mathrm{E}-03$ & $\mathrm{n} / \mathrm{a}$ & $\mathrm{n} / \mathrm{a}$ & 96.2 & $6.00 \mathrm{E}-03$ & n/a \\
\hline na & 2AY-LDP-12-01L Grab Sample (Total) & S12T019904 & $7440-70-2$ & Calcium & $\mathrm{ug} / \mathrm{mL}$ & 101 & $<0.0800$ & 3.11 & 3.09 & 3.10 & 0.562 & 95.1 & 0.0800 & $\mathrm{n} / \mathrm{a}$ \\
\hline na & 2AY-LDP-12-01I Grab Sample (Total) & S12T019904 & $7440-43-9$ & Cadmium & $\mathrm{ug} / \mathrm{mL}$ & 102 & $<1.00 \mathrm{E}-03$ & $<1.00 \mathrm{E}-03$ & $<1.00 \mathrm{E}-03$ & $\mathrm{n} / \mathrm{a}$ & $\mathrm{n} / \mathrm{a}$ & 95.7 & $1.00 \mathrm{E}-03$ & $\mathrm{n} / \mathrm{a}$ \\
\hline na & 2AY-LDP-12-01I Grab Sample (Total) & S12T019904 & $7440-48-4$ & Cobalt & $\mathrm{ug} / \mathrm{mL}$ & 102 & $<1.00 \mathrm{E}-03$ & $<1.00 \mathrm{E}-03$ & $<1.00 \mathrm{E}-03$ & $\mathrm{n} / \mathrm{a}$ & $\mathrm{n} / \mathrm{a}$ & 97.3 & $1.00 \mathrm{E}-03$ & $\mathrm{n} / \mathrm{a}$ \\
\hline na & 2AY-LDP-12-01I Grab Sample (Total) & S12T019904 & $7440-47-3$ & Chromium & $\mathrm{ug} / \mathrm{mL}$ & 100 & $<1.00 \mathrm{E}-03$ & $<1.00 \mathrm{E}-03$ & $<1.00 \mathrm{E}-03$ & $\mathrm{n} / \mathrm{a}$ & $\mathrm{n} / \mathrm{a}$ & 96.8 & $1.00 \mathrm{E}-03$ & $\mathrm{n} / \mathrm{a}$ \\
\hline na & 2AY-LDP-12-01I Grab Sample (Total) & S12T019904 & $7439-89-6$ & Iron & $\mathrm{ug} / \mathrm{mL}$ & 100 & $<0.0100$ & 0.0493 & 0.0489 & 0.0491 & 0.776 & 96.1 & 0.0100 & $\mathrm{n} / \mathrm{a}$ \\
\hline na & 2AY-LDP-12-01I Grab Sample (Total) & S12T019904 & $7440-09-7$ & Potassium & $\mathrm{ug} / \mathrm{mL}$ & 97.1 & $<0.0200$ & 7.30 & 7.84 & 7.57 & 7.24 & 97.7 & 0.0200 & $\mathrm{n} / \mathrm{a}$ \\
\hline na & 2AY-LDP-12-01I Grab Sample (Total) & S12T019904 & $7439-91-0$ & Lanthanum & $\mathrm{ug} / \mathrm{mL}$ & 99.1 & $<1.00 \mathrm{E}-03$ & $<1.00 \mathrm{E}-03$ & $<1.00 \mathrm{E}-03$ & $\mathrm{n} / \mathrm{a}$ & $\mathrm{n} / \mathrm{a}$ & 94.6 & $1.00 \mathrm{E}-03$ & $\mathrm{n} / \mathrm{a}$ \\
\hline na & 2AY-LDP-12-01I Grab Sample (Total) & S12T019904 & $7439-96-5$ & Manganese & $\mathrm{ug} / \mathrm{mL}$ & 102 & $<1.00 \mathrm{E}-03$ & $<1.00 \mathrm{E}-03$ & $<1.00 \mathrm{E}-03$ & $\mathrm{n} / \mathrm{a}$ & $\mathrm{n} / \mathrm{a}$ & 96,6 & $1.00 \mathrm{E}-03$ & $\mathrm{n} / \mathrm{a}$ \\
\hline na & 2AY-LDP-12-01I Grab Sample (Total) & S12T019904 & $7440-23-5$ & Sodium & $\mathrm{ug} / \mathrm{mL}$ & 98.1 & $<0.0400$ & 36.5 & 38.3 & 37.4 & 4.65 & 98.9 & 0.0400 & $\mathrm{n} / \mathrm{a}$ \\
\hline na & 2AY-LDP-12-01I Grab Sample (Total) & S12T019904 & $7440-02-0$ & Nickel & $\mathrm{ug} / \mathrm{mL}$ & 103 & $<1,00 \mathrm{E}-03$ & $<1.00 \mathrm{E}-03$ & $<1.00 \mathrm{E}-03$ & $n / a$ & $\mathrm{n} / \mathbf{a}$ & 97.0 & $1.00 E-03$ & $\mathrm{n} / \mathrm{a}$ \\
\hline na & 2AY-LDP-12-01I Grab Sample (Total) & S12T019904 & $7723-14-0$ & Phosphorus & $\mathrm{ug} / \mathrm{mL}$ & 99.0 & $<3.00 \mathrm{E}-03$ & $<3.00 \mathrm{E}-03$ & $<3.00 \mathrm{E}-03$ & $\mathrm{n} / \mathrm{a}$ & $\mathrm{n} / \mathrm{a}$ & 96.9 & $3.00 \mathrm{E}-03$ & $\mathbf{n} / \mathbf{a}$ \\
\hline na & 2AY-LDP-12-011 Grab Sample (Total) & S12T019904 & $7439-92-1$ & Lead & $\mathrm{ug} / \mathrm{mL}$ & 102 & $<6.00 \mathrm{E}-03$ & $<6.00 \mathrm{E}-03$ & $<6.00 \mathrm{E}-03$ & $\mathrm{n} / \mathrm{a}$ & $n / a$ & 102 & $6.00 \mathrm{E}-03$ & $\mathrm{n} / \mathbf{a}$ \\
\hline na & 2AY-LDP-12-01I Grab Sample (Total) & S12T019904 & $7440-16-6$ & Rhodium & $\mathrm{ug} / \mathrm{mL}$ & $9.9044 \mathrm{E}+01$ & $<8.00 \mathrm{E}-03$ & $<8.00 \mathrm{E}-03$ & $<8.00 \mathrm{E}-03$ & $\mathrm{n} / \mathrm{a}$ & $\mathrm{n} / \mathrm{a}$ & 95.5 & $8.00 \mathrm{E}-03$ & $\mathrm{n} / \mathrm{a}$ \\
\hline na & 2AY-LDP-12-01I Grab Sample (Total) & S12T019904 & $7704-34-9$ & Sulfur & $\mathrm{ug} / \mathrm{mL}$ & 99.7 & $<5.00 \mathrm{E}-03$ & 0.116 & 0.113 & 0.114 & 2.05 & 97.6 & $5.00 \mathrm{E}-03$ & $\mathrm{n} / \mathrm{a}$ \\
\hline na & 2AY-LDP-12-01I Grab Sample (Total) & S12T019904 & $7782-49-2$ & Selenium & $\mathrm{ug} / \mathrm{mL}$ & 100 & $<6.00 \mathrm{E}-03$ & $<6.00 \mathrm{E}-03$ & $<6.00 \mathrm{E}-03$ & $\mathrm{n} / \mathrm{a}$ & $\mathrm{n} / \mathrm{a}$ & 99.3 & $6.00 \mathrm{E}-03$ & $\mathrm{n} / \mathrm{a}$ \\
\hline na & 2AY-LDP-12-01I Grab Sample (Total) & S12T019904 & $7440-21-3$ & Silicon & $\mathrm{ug} / \mathrm{mL}$ & 106 & 0.0221 & 1.00 & 1.02 & 1.01 & 1.52 & 107 & $5.00 \mathrm{E}-03$ & $\mathrm{n} / \mathrm{a}$ \\
\hline na & 2AY-LDP-12-01I Grab Sample (Total) & S12T019904 & $7440-24-6$ & Strontium & $\mathrm{ug} / \mathrm{mL}$ & 101 & $<2.00 \mathrm{E}-03$ & 0.0560 & 0.0556 & 0.0558 & 0.627 & 96.5 & $2.00 \mathrm{E}-03$ & $\mathrm{n} / \mathrm{a}$ \\
\hline na & 2AY-LDP-12-01I Grab Sample (Total) & S12T019904 & $7440-33-7$ & Tungsten & $\mathrm{ug} / \mathrm{mL}$ & $9.8497 \mathrm{E}+01$ & $<6.00 \mathrm{E}-03$ & 0.102 & 0.0173 & 0.0599 & 142 & 94.1 & $6.00 \mathrm{E}-03$ & $\mathrm{n} / \mathrm{a}$ \\
\hline na & 2AY-LDP-12-01I Grab Sample (Total) & S12T019904 & $7440-66-6$ & Zinc & $\mathrm{ug} / \mathrm{mL}$ & 102 & $<4.00 \mathrm{E}-03$ & $<4.00 \mathrm{E}-03$ & $<4.00 \mathrm{E}-03$ & $\mathrm{n} / \mathrm{a}$ & $\mathrm{n} / \mathrm{a}$ & 97.5 & $4.00 \mathrm{E}-03$ & $\mathrm{n} / \mathbf{a}$ \\
\hline na & 2AY-LDP-12-01I Grab Sample (Total) & S12T019904 & $7440-67-7$ & Zirconium & $\mathrm{ug} / \mathrm{mL}$ & 96.1 & $<1.00 \mathrm{E}-03$ & $<1.00 \mathrm{E}-03$ & $<1.00 \mathrm{E}-03$ & $\mathrm{n} / \mathrm{a}$ & $\mathrm{n} / \mathrm{a}$ & 95.2 & $1.00 \mathrm{E}-03$ & $\mathrm{n} / \mathrm{a}$ \\
\hline na & 2AY-LDP-12-0II Grab Sample (Total) & S12T019904 & SPECGRAVT & Specific gravity & unitless & 100.4 & $n / a$ & 1.010 & $\mathrm{n} / \mathrm{a}$ & $\mathrm{n} / \mathrm{a}$ & $\mathrm{n} / \mathrm{a}$ & $\mathrm{n} / \mathbf{a}$ & $1.000 \mathrm{E}-03$ & $\mathrm{n} / \mathrm{a}$ \\
\hline na & 2AY-LDP-12-01I Grab Sample (Total) & S12T019904 & SR-89/90 & Strontium-89/9 & $\mathrm{uCi} / \mathrm{mL}$ & 98.0 & $3.92 \mathrm{E}-07$ & $2.22 \mathrm{E}-03$ & $\mathrm{n} / \mathrm{a}$ & $\mathrm{n} / \mathrm{a}$ & $\mathrm{n} / \mathbf{a}$ & $\mathrm{n} / \mathrm{a}$ & $2.78 \mathrm{E}-07$ & 0.617 \\
\hline na & 2AY-LDP-12-01I Grab Sample (Total) & S12T019904 & \%WATER & Percent water & $\%$ & 98.4 & $\mathrm{n} / \mathrm{a}$ & 105 & n/a & $n / a$ & $\mathrm{n} / \mathrm{a}$ & $\mathrm{n} / \mathrm{a}$ & 0.0100 & $\mathrm{n} / \mathrm{a}$ \\
\hline na & 2AY-LDP-12-01f Field Blank & S12T019901 & $16984-48-8$ & Fluoride & $\mathrm{ug} / \mathrm{mL}$ & 101 & $<1.61 \mathrm{E}-03$ & $<1.61 \mathrm{E}-03$ & $\mathrm{n} / \mathrm{a}$ & $\mathrm{n} / \mathrm{a}$ & $\mathrm{n} / \mathrm{a}$ & $\mathrm{n} / \mathrm{a}$ & $1.61 \mathrm{E}-03$ & $\mathrm{n} / \mathrm{a}$ \\
\hline na & 2AY-LDP-12-01F Field Blank & S12T019901 & $666-14-8$ & Glycolate & $\mathrm{ug} / \mathrm{mL}$ & 101 & $<9.37 \mathrm{E}-03$ & $<9.37 \mathrm{E}-03$ & $\mathrm{n} / \mathrm{a}$ & $\mathrm{n} / \mathbf{a}$ & $\mathrm{n} / \mathrm{a}$ & $\mathrm{n} / \mathbf{a}$ & $9.37 \mathrm{E}-03$ & $\mathrm{n} / \mathrm{a}$ \\
\hline na & 2AY-LDP-12-01f Field Blank & S12T019901 & $71-50-1$ & Acetate & $\mathrm{ug} / \mathrm{mL}$ & 97.3 & $<6.04 \mathrm{E}-03$ & $<6.04 \mathrm{E}-03$ & $\mathrm{n} / \mathrm{a}$ & $\mathrm{n} / \mathrm{a}$ & $\mathrm{n} / \mathrm{a}$ & $\mathrm{n} / \mathrm{a}$ & $6.04 \mathrm{E}-03$ & $\mathrm{n} / \mathrm{a}$ \\
\hline na & 2AY-LDP-12-01F Field Blank & S12T019901 & $12311-97-6$ & Formate & $\mathrm{ug} / \mathrm{mL}$ & 94.7 & $<4.67 \mathrm{E}-03$ & $<4.67 \mathrm{E}-03$ & $\mathrm{n} / \mathrm{a}$ & $\mathrm{n} / \mathrm{a}$ & $n / \mathbf{a}$ & $\mathrm{n} / \mathrm{a}$ & $4.67 \mathrm{E}-03$ & $n / a$ \\
\hline na & 2AY-LDP-12-01F Field Blank & S12T019901 & $16887-00-6$ & Chloride & $\mathrm{ug} / \mathrm{mL}$ & 99.9 & $<9.98 \mathrm{E}-03$ & $<9.98 \mathrm{E}-03$ & $\mathrm{n} / \mathrm{a}$ & $\mathrm{n} / \mathrm{a}$ & $\mathrm{n} / \mathrm{a}$ & $\mathrm{n} / \mathrm{a}$ & $9.98 \mathrm{E}-03$ & $\mathrm{n} / \mathrm{a}$ \\
\hline na & 2AY-LDP-12-01F Field Blank & S12T019901 & $14797-65-0$ & Nitrite & $\mathrm{ug} / \mathrm{mL}$ & 94.1 & $<0.0192$ & $<0.0192$ & $\mathrm{n} / \mathrm{a}$ & $\mathrm{n} / \mathrm{a}$ & $\mathrm{n} / \mathrm{a}$ & $\mathrm{n} / \mathrm{a}$ & 0.0192 & $\mathrm{n} / \mathrm{a}$ \\
\hline na & 2AY-LDP-12-01F Field Blank & S12T019901 & $14808-79-8$ & Sulfate & $\mathrm{ug} / \mathrm{mL}$ & 96.5 & $<0.0187$ & $<0.0187$ & $\mathrm{n} / \mathrm{a}$ & $\mathrm{n} / \mathrm{a}$ & $\mathrm{n} / \mathrm{a}$ & $\mathrm{n} / \mathbf{a}$ & 0.0187 & $\mathrm{n} / \mathrm{a}$ \\
\hline na & 2AY-LDP-12-01F Field Blank & S12T019901 & $338-70-5$ & Oxalate & $\mathrm{ug} / \mathrm{mL}$ & 95.6 & $<0.0231$ & $<0.0231$ & $\mathrm{n} / \mathrm{a}$ & $\mathrm{n} / \mathrm{a}$ & $\mathrm{n} / \mathrm{a}$ & $\mathrm{n} / \mathrm{a}$ & 0.0231 & $\mathrm{n} / \mathrm{a}$ \\
\hline na & 2AY-LDP-12-01F Field Blank & \$12T019901 & $24959-67-9$ & Bromide & $\mathrm{ug} / \mathrm{mL}$ & 92.6 & $<0.0580$ & $<0.0580$ & $\mathrm{n} / \mathrm{a}$ & $\mathrm{n} / \mathrm{a}$ & $\mathrm{n} / \mathrm{a}$ & n/a & 0.0580 & $\mathrm{n} / \mathrm{a}$ \\
\hline na & 2AY-IDP-12-01F Field Blank & S12T019901 & $14797-55-8$ & Nitrate & $\mathrm{ug} / \mathrm{mL}$ & 92.4 & $<0.0208$ & $<0.0208$ & $n / a$ & $n / a$ & $\mathrm{n} / \mathrm{a}$ & $\mathrm{n} / \mathrm{a}$ & 0.0208 & $\mathrm{n} / \mathbf{a}$ \\
\hline na & 2AY-LDP-12-01I Field Blank & S12T019901 & $14265-44-2$ & Phosphate & $\mathrm{ug} / \mathrm{mL}$ & 90.6 & $<0.0167$ & $<0.0167$ & $\mathrm{n} / \mathbf{a}$ & $\mathrm{n} / \mathrm{a}$ & $n / a$ & $\mathrm{n} / \mathrm{a}$ & 0.0167 & $\mathrm{n} / \mathrm{a}$ \\
\hline na & 2AY-LDP-12-01F Field Blank & S12T019901 & $7440-22-4$ & Silver & $\mathrm{ug} / \mathrm{mL}$ & 101 & $<1.00 \mathrm{E}-03$ & $<1.00 \mathrm{E}-03$ & $\mathrm{n} / \mathrm{a}$ & $\mathrm{n} / \mathrm{a}$ & $\mathrm{n} / \mathrm{a}$ & $\mathrm{n} / \mathrm{a}$ & $1.00 \mathrm{E}-03$ & $\mathrm{n} / \mathrm{a}$ \\
\hline na & 2AY-LDP-12-01I Field Blank & S12T019901 & $7429-90-5$ & Aluminum & $\mathrm{ug} / \mathrm{mL}$ & 99.1 & $<6.00 \mathrm{E}-03$ & $<6.00 \mathrm{E}-03$ & $\mathrm{n} / \mathrm{a}$ & $n / a$ & $\mathrm{n} / \mathrm{a}$ & $\mathrm{n} / \mathrm{a}$ & $6.00 \mathrm{E}-03$ & $\mathrm{n} / \mathrm{a}$ \\
\hline na & 2AY-LDP-12-01f Field Blank & S12T019901 & $7440-38-2$ & Arsenic & $\mathrm{ug} / \mathrm{mL}$ & 100 & $<5.00 \mathrm{E}-03$ & $<5.00 \mathrm{E}-03$ & $\mathrm{n} / \mathrm{a}$ & $\mathrm{n} / \mathrm{a}$ & $\mathrm{n} / \mathrm{a}$ & $\mathrm{n} / \mathrm{a}$ & $5.00 \mathrm{E}-03$ & $\mathrm{n} / \mathrm{a}$ \\
\hline na & 2AY-LDP-12-01F Field Blank & S12T019901 & $7440-41-7$ & Beryllium & $\mathrm{ug} / \mathrm{mL}$ & 97.8 & $<1.00 \mathrm{E}-03$ & $<1.00 \mathrm{E}-03$ & $\mathrm{n} / \mathrm{a}$ & $\mathrm{n} / \mathrm{a}$ & $\mathrm{n} / \mathrm{a}$ & $\mathrm{n} / \mathrm{a}$ & $1.00 \mathrm{E}-03$ & $\mathrm{n} / \mathrm{a}$ \\
\hline na & 2AY-LDP-12-01F Field Blank & S12T019901 & $7440-69-9$ & Bismuth & $\mathrm{ug} / \mathrm{mL}$ & 102 & $<6.00 \mathrm{E}-03$ & $<6.00 \mathrm{E}-03$ & $\mathrm{n} / \mathrm{a}$ & $\mathrm{n} / \mathrm{a}$ & $\mathrm{n} / \mathrm{a}$ & $\mathrm{n} / \mathrm{a}$ & $6.00 \mathrm{E}-03$ & $\mathrm{n} / \mathrm{a}$ \\
\hline na & 2AY-LDP-12-01F Field Blank & S12T019901 & $7440-70-2$ & Calcium & $\mathrm{ug} / \mathrm{mL}$ & 101 & $<0.0800$ & 0.0868 & $\mathrm{n} / \mathrm{a}$ & $\mathrm{n} / \mathrm{a}$ & $\mathrm{n} / \mathrm{a}$ & $\mathrm{n} / \mathrm{a}$ & 0.0800 & $\mathrm{n} / \mathrm{a}$ \\
\hline na & 2AY-LDP-12-01F Field Blank & S12T019901 & $7440-43-9$ & Cadmium & $\mathrm{ug} / \mathrm{mL}$ & 102 & $<1.00 \mathrm{E}-03$ & $<1.00 \mathrm{E}-03$ & $\mathrm{n} / \mathrm{a}$ & $\mathrm{n} / \mathrm{a}$ & $\mathrm{n} / \mathrm{a}$ & $\mathrm{n} / \mathrm{a}$ & $1.00 \mathrm{E}-03$ & $\mathrm{n} / \mathrm{a}$ \\
\hline na & 2AY-LDP-12-01f Field Blank & S12T019901 & $7440-48-4$ & Cobalt & $\mathrm{ug} / \mathrm{mL}$ & 102 & $<1.00 \mathrm{E}-03$ & $<1.00 \mathrm{E}_{-}-03$ & $\mathrm{n} / \mathrm{a}$ & $\mathrm{n} / \mathrm{a}$ & $\mathrm{n} / \mathrm{a}$ & $\mathrm{n} / \mathrm{a}$ & $1.00 \mathrm{E}-03$ & $\mathrm{n} / \mathrm{a}$ \\
\hline na & 2AY-LDP-12-01F Field Blank & S12T019901 & $7440-47-3$ & Chromium & $\mathrm{ug} / \mathrm{mL}$ & 100 & $<1.00 \mathrm{E}-03$ & $<1.00 \mathrm{E}-03$ & $\mathrm{n} / \mathrm{a}$ & $\mathrm{n} / \mathrm{a}$ & $\mathrm{n} / \mathrm{a}$ & $\mathrm{n} / \mathrm{a}$ & $1.00 \mathrm{E}-03$ & $\mathrm{n} / \mathrm{a}$ \\
\hline na & 2AY-LDP-12-01F Field Blank & S12T019901 & $7439-89-6$ & Iron & $\mathrm{ug} / \mathrm{mL}$ & 100 & $<0.0100$ & $<0.0100$ & $\mathrm{n} / \mathrm{a}$ & $\mathrm{n} / \mathrm{a}$ & $n / a$ & $\mathrm{n} / \mathrm{a}$ & 0.0100 & $\mathrm{n} / \mathbf{a}$ \\
\hline na & 2AY-LDP-12-01F Field Blank & S12T019901 & $7440-09-7$ & Potassium & $\mathrm{ug} / \mathrm{mL}$ & 97.1 & $<0.0200$ & $<0.0200$ & $\mathrm{n} / \mathrm{a}$ & $\mathrm{n} / \mathrm{a}$ & $\mathrm{n} / \mathrm{a}$ & $\mathrm{n} / \mathrm{a}$ & 0.0200 & $\mathrm{n} / \mathrm{a}$ \\
\hline na & 2AY-LDP-12-01I Field Blank & S12T019901 & $7439-91-0$ & Lanthanum & $\mathrm{ug} / \mathrm{mL}$ & 99.1 & $<1.00 \mathrm{E}-03$ & $<1.00 \mathrm{E}-03$ & $\mathrm{n} / \mathrm{a}$ & $\mathrm{n} / \mathrm{a}$ & $\mathrm{n} / \mathrm{a}$ & $\mathrm{n} / \mathbf{a}$ & $1.00 \mathrm{E}-03$ & $\mathrm{n} / \mathrm{a}$ \\
\hline na & 2AY-LDP-12-01F Field Blank & S12T019901 & $7439-96-5$ & Manganese & $\mathrm{ug} / \mathrm{mL}$ & 102 & $<1,00 \mathrm{E}-03$ & $<1.00 \mathrm{E}-03$ & $\mathrm{n} / \mathrm{a}$ & $n / a$ & $\mathrm{n} / \mathrm{a}$ & $\mathrm{n} / \mathrm{a}$ & $1.00 \mathrm{E}-03$ & $\mathrm{n} / \mathrm{a}$ \\
\hline na & 2AY-LDP-12-01F Field Blank & S12T019901 & $7440-23-5$ & Sodium & $\mathrm{ug} / \mathrm{mL}$ & 98.1 & $<0.0400$ & 0.348 & $\mathrm{n} / \mathrm{a}$ & $\mathrm{n} / \mathrm{a}$ & $n / a$ & $\mathrm{n} / \mathrm{a}$ & 0.0400 & $\mathrm{n} / \mathrm{a}$ \\
\hline na & 2AY-LDP-12-01f Field Blank & S12T019901 & $7440-02-0$ & Nickel & $\mathrm{ug} / \mathrm{mL}$ & 103 & $<1.00 \mathrm{E}-03$ & $<1.00 \mathrm{E}-03$ & $\mathrm{n} / \mathrm{a}$ & $\mathrm{n} / \mathrm{a}$ & $\mathrm{n} / \mathrm{a}$ & $\mathrm{n} / \mathrm{a}$ & $1.00 \mathrm{E}-03$ & $\mathrm{n} / \mathrm{a}$ \\
\hline na & 2AY-LDP-12-01F Field Blank & S12T019901 & $7723-14-0$ & Phosphorus & $\mathrm{ug} / \mathrm{mL}$ & 99.0 & $<3.00 \mathrm{E}-03$ & $<3.00 \mathrm{E}-03$ & $\mathrm{n} / \mathrm{a}$ & $\mathrm{n} / \mathrm{a}$ & $\mathrm{n} / \mathrm{a}$ & $\mathrm{n} / \mathrm{a}$ & $3.00 \mathrm{E}-03$ & $\mathrm{n} / \mathrm{a}$ \\
\hline na & 2AY-LDP-12-01F Field Blank & S12T019901 & $7439-92-1$ & Lead & $\mathrm{ug} / \mathrm{mL}$ & 102 & $<6.00 \mathrm{E}-03$ & $<6.00 \mathrm{E}-03$ & $\mathrm{n} / \mathrm{a}$ & $\mathrm{n} / \mathrm{a}$ & $\mathrm{n} / \mathrm{a}$ & $\mathrm{n} / \mathrm{a}$ & $6.00 \mathrm{E}-03$ & $\mathrm{n} / \mathrm{a}$ \\
\hline na & 2AY-LDP-12-01F Field Blank & S12T019901 & $7440-16-6$ & Rhodium & $\mathrm{ug} / \mathrm{mL}$ & $9.9044 \mathrm{E}+01$ & $<8.00 \mathrm{E}-03$ & $<8.00 \mathrm{E}-03$ & $\mathrm{n} / \mathrm{a}$ & n/a & $\mathrm{n} / \mathrm{a}$ & $\mathrm{n} / \mathrm{a}$ & $8.00 \mathrm{E}-03$ & $\mathrm{n} / \mathrm{a}$ \\
\hline na & 2AY-LDP-12-01I Field Blank & S12T019901 & $7704-34-9$ & Sulfur & $\mathrm{ug} / \mathrm{mL}$ & 99.7 & $<5.00 \mathrm{E}-03$ & $<5.00 \mathrm{E}-03$ & $\mathrm{n} / \mathrm{a}$ & $n / a$ & $\mathrm{n} / \mathrm{a}$ & $\mathrm{n} / \mathrm{a}$ & $5.00 \mathrm{E}-03$ & $n / a$ \\
\hline na & 2AY-LDP-12-01F Field Blank & S12T019901 & $7782-49-2$ & Selenium & $\mathrm{ug} / \mathrm{mL}$ & 100 & $<6,00 \mathrm{E}-03$ & $<6.00 \mathrm{E}-03$ & $\mathrm{n} / \mathrm{a}$ & $n / a$ & $\mathrm{n} / \mathrm{a}$ & $\mathrm{n} / \mathrm{a}$ & $6.00 \mathrm{E}-03$ & $\mathrm{n} / \mathrm{a}$ \\
\hline na & 2AY-LDP-12-01F Field Blank & S12T019901 & $7440-21-3$ & Silicon & $\mathrm{ug} / \mathrm{mL}$ & 106 & 0.0221 & 0.137 & $\mathrm{n} / \mathrm{a}$ & n/a & $\mathrm{n} / \mathrm{a}$ & $\mathrm{n} / \mathrm{a}$ & $5.00 \mathrm{E}-03$ & $\mathrm{n} / \mathrm{a}$ \\
\hline na & 2AY-LDP-12-01f Field Blank & S12T019901 & $7440-24-6$ & Strontium & $\mathrm{ug} / \mathrm{mL}$ & 101 & $<2.00 \mathrm{E}-03$ & $<2.00 \mathrm{E}-03$ & $\mathrm{n} / \mathrm{a}$ & $\mathrm{n} / \mathrm{a}$ & $\mathrm{n} / \mathrm{a}$ & $\mathrm{n} / \mathrm{a}$ & $2.00 \mathrm{E}-03$ & $\mathrm{n} / \mathrm{a}$ \\
\hline na & 2AY-LDP-12-01F Field Blank & S12T019901 & $7440-33-7$ & Tungsten & $\mathrm{ug} / \mathrm{mL}$ & $9.8497 \mathrm{E}+01$ & $<6.00 \mathrm{E}-03$ & $<6.00 \mathrm{E}-03$ & $\mathrm{n} / \mathrm{a}$ & $\mathrm{n} / \mathrm{a}$ & $n / a$ & $\mathrm{n} / \mathrm{a}$ & $6.00 \mathrm{E}-03$ & $\mathrm{n} / \mathrm{a}$ \\
\hline na & 2AY-LDP-12-01F Field Blank & S12T019901 & $7440-66-6$ & Zinc & $\mathrm{ug} / \mathrm{mL}$ & 102 & $<4.00 \mathrm{E}-03$ & $<4.00 \mathrm{E}-03$ & n/a & $\mathrm{n} / \mathrm{a}$ & $n / a$ & n/a & $4.00 \mathrm{E}-03$ & $\mathrm{n} / \mathrm{a}$ \\
\hline na & 2AY-LDP-12-01F Field Blank & S12T019901 & $7440-67-7$ & Zirconium & $\mathrm{ug} / \mathrm{mL}$ & 96.1 & $<1.00 \mathrm{E}-03$ & $<1.00 \mathrm{E}-03$ & $\mathrm{n} / \mathrm{a}$ & $\mathrm{n} / \mathrm{a}$ & $\mathrm{n} / \mathrm{a}$ & $\mathrm{n} / \mathrm{a}$ & $1.00 \mathrm{E}-03$ & $\mathrm{n} / \mathbf{a}$ \\
\hline na & 2AY-LDP-12-02 Grab Sample (Total) & S12T019906 & $16984-48-8$ & Fluoride & $\mathrm{ug} / \mathrm{mL}$ & 101 & $<1.61 \mathrm{E}-03$ & $<1.61 \mathrm{E}-03$ & $\mathrm{n} / \mathbf{a}$ & $\mathrm{n} / \mathrm{a}$ & $\mathrm{n} / \mathrm{a}$ & $\mathrm{n} / \mathrm{a}$ & $1.61 \mathrm{E}-03$ & $\mathrm{n} / \mathrm{a}$ \\
\hline na & 2AY-LDP-12-02 Grab Sample (Total) & S12T019906 & $666-14-8$ & Glycolate & $\mathrm{ug} / \mathrm{mL}$ & 101 & $<9.37 \mathrm{E}-03$ & $<9.37 \mathrm{E}-03$ & $\mathrm{n} / \mathrm{a}$ & $\mathrm{n} / \mathrm{a}$ & $\mathrm{n} / \mathrm{a}$ & $\mathrm{n} / \mathrm{a}$ & $9.37 \mathrm{E}-03$ & $\mathrm{n} / \mathrm{a}$ \\
\hline
\end{tabular}


2AY-LDP-12-02 Grab Sample (Total) S12T019906 2AY-LDP-12-02 Grab Sample (Total) 2AY-LDP-12-02 Grab Sample (Total) 2AY-LDP-12-02 Grab Sample (Total) 2AY-LDP-12-02 Grab Sample (Total) 2AY-LDP-12-02 Grab Sample (Total) 2AY-LDP-12-02 Grab Sample (Total) 2AY-LDP-12-02 Grab Sample (Total) 2AY-LDP-12-02 Grab Sample (Total) 2AY-LDP-12-02 Grab Sample (Total) 2AY-LDP-12-02 Grab Sample (Total) 2AY-LDP-12-02 Grab Sample (Total) 2AY-LDP-12-02 Grab Sample (Total) 2AY-LDP-12-02 Grab Sample (Total) 2AY-LDP-12-02 Grab Sample (Total) 2AY-LDP-12-02 Grab Sample (Total) 2AY-LDP-12-02 Grab Sample (Total) 2AY-LDP-12-02 Grab Sample (Total) 2AY-LDP-12-02 Grab Sample (Total) 2AY-LDP-12-02 Grab Sample (Total) 2AY-LDP-12-02 Grab Sample (Total) 2AY-LDP-12-02 Grab Sample (Total) 2AY-LDP-12-02 Grab Sample (Total) 2AY-LDP-12-02 Grab Sample (Total) 2AY-LDP-12-02 Grab Sample (Total) 2AY-LDP-12-02 Grab Sample (Total) 2AY-LDP-12-02 Grab Sample (Total) 2AY-LDP-12-02 Grab Sample (Total) 2AY-LDP-12-02 Grab Sample (Total) 2AY-LDP-12-02 Grab Sample (Total) 2AY-LDP-12-02 Grab Sample (Total) 2AY-LDP-12-02 Grab Sample (Total) 2AY-LDP-12-02 Grab Sample (Total) 2AY-LDP-12-02 Grab Sample (Total) 2AY-LDP-12-02 Grab Sample (Total) 2AY-LDP-12-02 Grab Sample (Total)

-Less Than Detection Limit

e - SERDIL Outside Range
S12T019906

S12T019906

\$12T019906

S12T019906

S12T019906

$\$ 121019906$

S12T019906

S12T019906

S12T019906

S12T019906

S12T019906

$\$ 121019906$

\$12T019906

S12T019906

$\$ 12 T 019906$

$12 \mathrm{~T} 019906$

S12T019906

$\$ 12 \mathrm{~T} 019906$

S12T019906

S12T019906

S12T019906

12T019906

\$12T019906

$\$ 12 \mathrm{~T} 019906$

S12T019906

4808-79-8 Sulfate

24959-67-9 Bromide

14797-55-8 Nitrate

7440-22-4 Silver
338-70-5 Oxalate

4265-44-2 Phosphate

7440-38-2 Arsenic ug/mL 100

7440-41-7 Beryllium ug/mL 97.8

7440-69-9 Bismuth ug/mL 102

7440-70-2 Calcium ug/mL 10

7440-43-9 Cadmium ug/mL 102

7440-48-4 Cobalt ug/mL 102

Chromium ug/mL 100

Iron $\quad \mathrm{ug} / \mathrm{mL} \quad 100$

7440-09-7 Potassium ug/mL 97.1

7439-91-0 Lanthanum ug/mL 99.1

$7439-96-5$ Manganese $\mathrm{ug} / \mathrm{mL} \quad 102$

7440-23-5 Sodium ug/mL 98.1

$\begin{array}{lll}7440-02-0 & \text { Nickel ug/mL } 103\end{array}$

Phosphorus ug/mL 99.0

7439-92-1 Lead ug/mL 102

7440-16-6 Rhodium ug/mL 9.9044E+01

Sulfur $\quad \mathrm{ug} / \mathrm{mL} \quad 99.7$

Selenium ug/mL 100

Silicon ug/mL 106

7440-33-7 Tungsten

$\mathrm{ug} / \mathrm{mL} \quad 9.849$

7440-67-7 Zirconium ug/mL 96

SPECGRAVIT Specific gravity unitless 100.4

SR-89/90 Strontium- $89 / 9 \mathrm{uCi} / \mathrm{mL} \quad 98$

\%WATER Percent water \%
$<604 \mathrm{E}-03<6.04 \mathrm{E}-03 \quad \mathrm{n} / \mathrm{a}$ $<4.67 \mathrm{E}-03<4.67 \mathrm{E}-03 \quad \mathrm{~m} / \mathrm{a}$ $<9.98 \mathrm{E}-03 \quad 0.0720 \quad \mathrm{n} / \mathrm{a}$ $<0.0192<0.0192 \quad \mathrm{n} / \mathrm{a}$

$<0.0187 \quad 0.208 \quad \mathrm{n} / \mathrm{a}$

$<0.0231<0.0231 \quad \mathrm{n} / \mathrm{a}$

$<0.0580<0.0580 \quad \mathrm{n} / \mathrm{a}$

$<0.0208 \quad 1.83 \quad \mathrm{n} / \mathrm{a}$

$<0.0167<0.0167 \quad \mathrm{n} / \mathrm{a}$

$<1.00 \mathrm{E}-03<1.00 \mathrm{E}-03 \quad \mathrm{n} / \mathrm{a}$

$<6.00 \mathrm{E}-03<6.00 \mathrm{E}-03 \quad \mathrm{n} / \mathrm{a}$

$<5.00 \mathrm{E}-03<5.00 \mathrm{E}-03 \quad \mathrm{n} / \mathrm{a}$

$<100 \mathrm{E}-03<1.00 \mathrm{E}-03 \quad \mathrm{n} / \mathrm{a}$

$<6.00 \mathrm{E}-03<6.00 \mathrm{E}-03 \quad \mathrm{n} / \mathrm{a}$

$<0.0800 \quad 3.11 \quad \mathrm{n} / \mathrm{a}$

$<1.00 \mathrm{E}-03<1.00 \mathrm{E}-03 \quad \mathrm{n} / \mathrm{a}$

$<1.00 \mathrm{E}-03<1.00 \mathrm{E}-03 \quad \mathrm{n} / \mathrm{a}$

$<1.00 \mathrm{E}-03<1.00 \mathrm{E}-03 \quad \mathrm{n} / \mathrm{a}$

$<0.0100 \quad 0.0799 \quad \mathrm{n} / \mathrm{a}$

$<0.0200 \quad 7.59 \quad \mathrm{n} / \mathrm{a}$

$<1.00 \mathrm{E}-03<1.00 \mathrm{E}-03 \quad \mathrm{n} / \mathrm{a}$

$<1.00 \mathrm{E}-03 \quad 1.32 \mathrm{E}-03 \quad \mathrm{n} / \mathrm{a}$

$<0.0400 \quad 37.5$

$<1.00 \mathrm{E}-03<1.00 \mathrm{E}-03 \quad \mathrm{n} / \mathrm{a}$

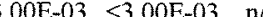

$<6.00 \mathrm{E}-03<6.00 \mathrm{E}-03 \quad \mathrm{~m} / \mathrm{a}$

$<.00 \mathrm{E}-03<8.00 \mathrm{E}-03 \quad \mathrm{n} / \mathrm{a}$

$<5.00 \mathrm{E}-03 \quad 0.112 \quad \mathrm{n} / \mathrm{a}$

$<6.00 \mathrm{E}-03<6.00 \mathrm{E}-03 \quad \mathrm{n} / \mathrm{a}$

$0.0221 \quad 1.03 \quad n / a$

$4600503 \quad 0.0102 \quad n / a$

$<4.00 \mathrm{E}-03<4.00 \mathrm{E}-03 \quad \mathrm{n} / \mathrm{a}$

$<1.00 \mathrm{E}-03<1.00 \mathrm{E}-03 \quad \mathrm{n} / \mathrm{a}$ $1.008 \mathrm{n} / \mathrm{a}$

$3.92 \mathrm{E}-07 \quad 2.29 \mathrm{E}-03 \quad \mathrm{n} / \mathrm{a}$

$\begin{array}{llll}\mathrm{n} / \mathrm{a} & 6.04 \mathrm{E}-03 & \mathrm{n} / \mathrm{a} & \mathrm{U} \\ \mathrm{n} / \mathrm{a} & 4.67 \mathrm{E}-03 & \mathrm{n} / \mathrm{a} & \mathrm{U} \\ \mathrm{n} / \mathrm{a} & 9.98 \mathrm{E}-03 & \mathrm{n} / \mathrm{a} & \\ \mathrm{n} / \mathrm{a} & 0.0192 & \mathrm{n} / \mathrm{a} & \mathrm{U} \\ \mathrm{n} / \mathrm{a} & 0.0187 & \mathrm{n} / \mathrm{a} & \\ \mathrm{n} / \mathrm{a} & 0.0231 & \mathrm{n} / \mathrm{a} & \mathrm{U} \\ \mathrm{n} / \mathrm{a} & 0.0580 & \mathrm{n} / \mathrm{a} & \mathrm{U} \\ \mathrm{n} / \mathrm{a} & 0.0208 & \mathrm{n} / \mathrm{a} & \\ \mathrm{n} / \mathrm{a} & 0.0167 & \mathrm{n} / \mathrm{a} & \mathrm{U} \\ \mathrm{n} / \mathrm{a} & 1.00 \mathrm{E}-03 & \mathrm{n} / \mathrm{a} & \mathrm{U} \\ \mathrm{n} / \mathrm{a} & 6.00 \mathrm{E}-03 & \mathrm{n} / \mathrm{a} & \mathrm{U} \\ \mathrm{n} / \mathrm{a} & 5.00 \mathrm{E}-03 & \mathrm{n} / \mathrm{a} & \mathrm{U} \\ \mathrm{n} / \mathrm{a} & 1.00 \mathrm{E}-03 & \mathrm{n} / \mathrm{a} & \mathrm{U} \\ \mathrm{n} / \mathrm{a} & 6.00 \mathrm{E}-03 & \mathrm{n} / \mathrm{a} & \mathrm{U} \\ \mathrm{n} / \mathrm{a} & 0.0800 & \mathrm{n} / \mathrm{a} & \\ \mathrm{n} / \mathrm{a} & 1.00 \mathrm{E}-03 & \mathrm{n} / \mathrm{a} & \mathrm{U} \\ \mathrm{n} / \mathrm{a} & 1.00 \mathrm{E}-03 & \mathrm{n} / \mathrm{a} & \mathrm{U} \\ \mathrm{n} / \mathrm{a} & 1.00 \mathrm{E}-03 & \mathrm{n} / \mathrm{a} & \mathrm{U} \\ \mathrm{n} / \mathrm{a} & 0.0100 & \mathrm{n} / \mathrm{a} & \\ \mathrm{n} / \mathrm{a} & 0.0200 & \mathrm{n} / \mathrm{a} & \\ \mathrm{n} / \mathrm{a} & 1.00 \mathrm{E}-03 & \mathrm{n} / \mathrm{a} & \mathrm{U} \\ \mathrm{n} / \mathrm{a} & 1.00 \mathrm{E}-03 & \mathrm{n} / \mathrm{a} & \\ \mathrm{n} / \mathrm{a} & 0.0400 & \mathrm{n} / \mathrm{a} & \\ \mathrm{n} / \mathrm{a} & 1.00 \mathrm{E}-03 & \mathrm{n} / \mathrm{a} & \mathrm{U} \\ \mathrm{n} / \mathrm{a} & 3.00 \mathrm{E}-03 & \mathrm{n} / \mathrm{a} & \mathrm{U} \\ \mathrm{n} / \mathrm{a} & 6.00 \mathrm{E}-03 & \mathrm{n} / \mathrm{a} & \mathrm{U} \\ \mathrm{n} / \mathrm{a} & 8.00 \mathrm{E}-03 & \mathrm{n} / \mathrm{a} & \mathrm{U} \\ \mathrm{n} / \mathrm{a} & 5.00 \mathrm{E}-03 & \mathrm{n} / \mathrm{a} & \\ \mathrm{n} / \mathrm{a} & 6.00 \mathrm{E}-03 & \mathrm{n} / \mathrm{a} & \mathrm{U} \\ \mathrm{n} / \mathrm{a} & 5.00 \mathrm{E}-03 & \mathrm{n} / \mathrm{a} & \\ \mathrm{n} / \mathrm{a} & 2.00 \mathrm{E}-03 & \mathrm{n} / \mathrm{a} & \\ \mathrm{n} / \mathrm{a} & 6.00 \mathrm{E}-03 & \mathrm{n} / \mathrm{a} & \\ \mathrm{n} / \mathrm{a} & 4.00 \mathrm{E}-03 & \mathrm{n} / \mathrm{a} & \mathrm{U} \\ \mathrm{n} / \mathrm{a} & 1.00 \mathrm{E}-03 & \mathrm{n} / \mathrm{a} & \mathrm{U} \\ \mathrm{n} / \mathrm{a} & 1.000 \mathrm{E}-03 & \mathrm{n} / \mathrm{a} & \\ \mathrm{n} / \mathrm{a} & 2.77 \mathrm{E}-07 & 0.607 & \\ \mathrm{n} / \mathrm{a} & 0.0100 & \mathrm{n} / \mathrm{a} & \end{array}$


From:

Sent:

To:

Subject:

Attachments:
Venetz, Theodore J

Thursday, September 13, 2012 7:44 AM

Rosenkrance, Chelsea L

FW: Anomalously Low pH results for AY102A-LDP Samples

AY102A-LDP pH Anions Rpt.xls

From: Nguyen, Duc M

Sent: Wednesday, September 12, 2012 10:34 AM

To: Kirch, Nicholas W (Nick); Powell, William J (Bill); Reynolds, Jacob G; Jo, Jaiduk; Uytioco, Elise M; Rasmussen, Juergen H; Sams, Terry L; Boomer, Kayle D; Venetz, Theodore J; Prilucik, John R; Ritenour, Gerald P; Strasser, David W; Shultz, MV Jr (Milt)

Subject: FW: Anomalously Low pH results for AY102A-LDP Samples

FYI

Duc M. Nguyen

Washington River Protection Solutions LLC

Contractor to the United States Department of Energy

(509) $372-3042$

From: Ritenour, Gerald $P$

Sent: Wednesday, September 12, 2012 10:28 AM

To: Nguyen, Duc M

Subject: Anomalously Low pH results for AY102A-LDP Samples

Duc,

As we have discussed, the $\mathrm{pH}$ results for all AY102A-LDP samples were anomalously low (see attached). Since the low results included the field blank, we might conclude that somehow during clean process an acid residue was left in the sample containers. However, the process used to clean the samples make this very unlikely - two acid soakings, drying, acetone rinse, drying, methylene chloride, and oven drying. More importantly the acids use are $\mathrm{HCL}$ and HNO3, which means that if the cleaning process resulted in contamination, chloride and/or nitrate anions should be present in the sample at concentration well above the MDL. As you can see from the attachment they were not present. This raise the question, what is causing the low $\mathrm{pH}$ ? A significant unknown peak is present in all samples. It eludes between nitrite and sulfate at approximately $15 \mathrm{~min}$. We will continue to investigate this.

The laboratory believe the low $\mathrm{pH}$ will only affect the TIC and $\mathrm{pH}$ results. TIC has not yet been analyzed. The $\mathrm{pH}$ results for the samples are anomalously low, but do represent a low boundary for the "actual" sample pH. If you have any question please let me know.

Thanks, JR

Gerald "UR" Ritenour

Project Manager

ATL Analytical Operations

Advanced Techologies and Laboratories Intemational, Inc.

Contractor to the Office of River Protection

U.S. Department of Energy 
Data Summary Report

$\begin{array}{ll}\text { Riser } & \text { Segment Number } \\ \text { na } & \text { 2AY-LDP-12-01 } \\ \text { na } & \text { 2AY-LDP-12-01 } \\ \text { na } & \text { 2AY-LDP-12-01 } \\ \text { na } & \text { 2AY-LDP-12-01 } \\ \text { na } & \text { 2AY-LDP-12-01 } \\ \text { na } & \text { 2AY-LDP-12-01 } \\ \text { na } & \text { 2AY-LDP-12-01 } \\ \text { na } & \text { 2AY-LDP-12-01 } \\ \text { na } & \text { 2AY-LDP-12-01 } \\ \text { na } & \text { 2AY-LDP-12-01 } \\ \text { na } & \text { 2AY-LDP-12-01 } \\ \text { na } & \text { 2AYYDP-12-01DUP } \\ \text { na } & \text { 2AY-LDP-12-01DUP } \\ \text { na } & \text { 2AY-LDP-12-01DUP } \\ \text { na } & \text { 2AY-LDP-12-01DUP } \\ \text { na } & \text { 2AY-LDP-12-01DUP } \\ \text { na } & \text { 2AY-LDP-12-01DUP } \\ \text { na } & \text { 2AY-LDP-12-01DUP } \\ \text { na } & \text { 2AY-LDP-12-01DUP } \\ \text { na } & \text { 2AY-LDP-12-01DUP } \\ \text { na } & \text { 2AY-LDP-12-01DUP } \\ \text { na } & \text { 2AY-LDP-12-01DUP } \\ \text { na } & \text { 2AY-LDP-12-01FB } \\ \text { na } & \text { 2AY-LDP-12-01FB } \\ \text { na } & \text { 2AY-LDP-12-01FB } \\ \text { na } & \text { 2AY-LDP-12-01FB } \\ \text { na } & \text { 2AY-LDP-12-01FB } \\ \text { na } & \text { 2AY-LDP-12-01FB } \\ \text { na } & \text { 2AYYLDP-12-01FB } \\ \text { na } & \text { 2AYYLDP-12-01FB } \\ \text { na } & \text { 2AYYLDP-12-01FB } \\ \text { na } & \text { 2AY-LDP-12-01FB } \\ \text { na } & \text { 2AY-LDP-12-01FB } \\ \text { na } & \text { 2AY-LDP-12-02 } \\ \text { na } & \text { 2AY-LDP-12-02 } \\ \text { na } & \text { 2AY-LDP-12-02 } \\ \text { na } & \text { 2AY-LDP-12-02 } \\ \text { na } & \text { 2AY-LDP-12-02 } \\ \text { na } & \text { 2AY-LDP-12-02 } \\ \text { na } & \text { 2AY-LDP-12-02 } \\ \text { na } & \text { 2AY-LDP-12-02 } \\ \text { na } & \text { 2AY-LDP-12-02 } \\ \text { na } & \text { 2AY-LDP-12-02 } \\ \text { na } & \text { 2AY-LDP-12-02 } \\ & \end{array}$

\begin{tabular}{|c|c|c|c|c|c|c|c|c|c|c|c|c|c|c|c|}
\hline Segment Portion & SAMPLE_R & A & CAS \# & ANALYTE & $\begin{array}{l}\text { RESULT_ } \\
\text { UNIT }\end{array}$ & $\begin{array}{l}\text { STAN } \\
\text { DAR } \\
\text { D }\end{array}$ & BLANK & RESULT & $\begin{array}{l}\text { DUPLICA } \\
\text { TE }\end{array}$ & $\begin{array}{l}\text { AVERAG } \\
\mathrm{E}\end{array}$ & RPD & SPK_REC & Det Limit & $\begin{array}{l}\text { COUNT_ } \\
\text { ERR }\end{array}$ & $\begin{array}{l}\text { QUALIFI } \\
\text { ER }\end{array}$ \\
\hline Grab Sample (Total) & S12T019902 & & $16984-48-8$ & Fluoride & $\mathrm{ug} / \mathrm{mL}$ & 101 & $<1.61 \mathrm{E}-03$ & $<1.61 \mathrm{E}-03$ & $<1,61 \mathrm{E}-03$ & $n / a$ & $\mathbf{n} / \mathbf{a}$ & $\mathrm{n} / \mathrm{a}$ & $1.61 \mathrm{E}-03$ & $\mathrm{n} / \mathrm{a}$ & \\
\hline Grab Sample (Total) & S12T019902 & & $666-14-8$ & Glycolate & $\mathrm{ug} / \mathrm{mL}$ & 101 & $<9.37 \mathrm{E}-03$ & $<.37 \mathrm{E}-03$ & $<9.37 \mathrm{E}-03$ & $n / a$ & $\mathrm{n} / \mathbf{a}$ & $n / a$ & $9.37 \mathrm{E}-03$ & $\mathrm{n} / \mathrm{a}$ & \\
\hline Grab Sample (Total) & S12T019902 & & $71-50-1$ & Acetate & $\mathrm{ug} / \mathrm{mL}$ & 97.3 & $<6.04 \mathrm{E}-03$ & $<6.04 \mathrm{E}-03$ & $<6.04 \mathrm{E}-03$ & $\mathrm{n} / \mathbf{a}$ & $\mathrm{n} / \mathbf{a}$ & $n / a$ & $6.04 \mathrm{E}-03$ & $n / a$ & \\
\hline Grab Sample (Total) & S12T019902 & & $12311-97-6$ & Formate & $\mathrm{ug} / \mathrm{mL}$ & 94.7 & $<4.67 \mathrm{E}-03$ & $<4.67 \mathrm{E}-03$ & $<4.67 \mathrm{E}-03$ & $\mathrm{n} / \mathbf{a}$ & $\mathrm{n} / \mathbf{a}$ & $\mathrm{n} / \mathrm{a}$ & $4.67 \mathrm{E}-03$ & $\mathrm{n} / \mathrm{a}$ & \\
\hline Grab Sample (Total) & S12T019902 & & $16887-00-6$ & Chloride & $\mathrm{ug} / \mathrm{mL}$ & 99.9 & $<9.98 \mathrm{E}-03$ & 0.0900 & 0.0890 & 0.0895 & 1.12 & n/a & $9.98 \mathrm{E}-03$ & $n / a$ & \\
\hline Grab Sample (Total) & S12T019902 & & $14797-65-0$ & Nitrite & $\mathrm{ug} / \mathrm{mL}$ & 94.1 & $<0.0192$ & $<0.0192$ & $<0.0192$ & $\mathrm{n} / \mathrm{a}$ & $\mathbf{n} / \mathbf{a}$ & $\mathrm{n} / \mathrm{a}$ & 0.0192 & $\mathrm{n} / \mathrm{a}$ & \\
\hline Grab Sample (Total) & S12T019902 & & $14808-79-8$ & Sulfate & $\mathrm{ug} / \mathrm{mL}$ & 96.5 & $<0.0187$ & 0.204 & 0.217 & 0.210 & 6.18 & $\mathrm{n} / \mathrm{a}$ & 0.0187 & $\mathrm{n} / \mathrm{a}$ & \\
\hline Grab Sample (Total) & S12T019902 & & $24959-67-9$ & Bromide & $\mathrm{ug} / \mathrm{mL}$ & 92.6 & $<0.0580$ & $<0.0580$ & $<0.0580$ & n/a & $\mathrm{n} / \mathbf{a}$ & $\mathrm{n} / \mathrm{a}$ & 0.0580 & $\mathrm{n} / \mathrm{a}$ & \\
\hline Grab Sample (Total) & S12T019902 & & $14797-55-8$ & Nitrate & $\mathrm{ug} / \mathrm{mL}$ & 92.4 & $<0.0208$ & 1.91 & 1.91 & 1.91 & 0.262 & $\mathrm{n} / \mathrm{a}$ & 0.0208 & n/a & \\
\hline Grab Sample (Total) & S12T019902 & & $7723-14-0$ & Phosphorus & $\mathrm{ug} / \mathrm{mL}$ & 99.0 & $<3.00 \mathrm{E}-03$ & $<.00 \mathrm{E}-03$ & $n / a$ & n/a & $\mathbf{n} / \mathbf{a}$ & $n / a$ & $3.00 \mathrm{E}-03$ & $n / a$ & \\
\hline Grab Sample (Total) & S12T019902 & & PH & $\mathrm{pH}$ & unitless & $\mathrm{n} / \mathbf{a}$ & $\mathrm{n} / \mathbf{a}$ & 6.83 & n/a & $\mathrm{n} / \mathbf{a}$ & $\mathrm{n} / \mathbf{a}$ & $n / a$ & 0.0100 & n/a & \\
\hline Grab Sample (Total) & S12T019904 & & $16984-48-8$ & Fluoride & $\mathrm{ug} / \mathrm{mL}$ & 101 & $<1.61 \mathrm{E}-03$ & $<1.6 \mathrm{lE}-03$ & ña & $n / \mathbf{a}$ & $\mathrm{n} / \mathrm{a}$ & $\mathrm{n} / \mathrm{a}$ & $1.61 \mathrm{E}-03$ & $\mathrm{n} / \mathrm{a}$ & \\
\hline Grab Sample (Total) & S12T019904 & & $666-14-8$ & Glycolate & $\mathrm{ug} / \mathrm{mL}$ & 101 & $<9.37 \mathrm{E}-03$ & $<9.37 \mathrm{E}-03$ & $\mathrm{n} / \mathrm{a}$ & $\mathrm{n} / \mathrm{a}$ & $\mathbf{n} / \mathbf{a}$ & $n / a$ & $9.37 \mathrm{E}-03$ & $n / a$ & \\
\hline Grab Sample (Total) & S12T019904 & & $71-50-1$ & Acetate & $\mathrm{ug} / \mathrm{mL}$ & 97.3 & $<6.04 \mathrm{E}-03$ & $<6.04 \mathrm{E}-03$ & n/a. & $\pi / \mathbf{a}$ & $\mathrm{n} / \mathrm{a}$ & $\mathrm{n} / \mathrm{a}$ & $6.04 \mathrm{E}-03$ & $\mathrm{n} / \mathrm{a}$ & \\
\hline Grab Sample (Total) & S12T019904 & & $12311-97-6$ & Formate & $\mathrm{ug} / \mathrm{mI}$ & 94.7 & $<4.67 \mathrm{E}-03$ & $<4.67 \mathrm{E}-03$ & $n / a$ & $\mathrm{n} / \mathrm{a}$ & $\mathrm{n} / \mathbf{a}$ & n/a & $4.67 \mathrm{E}-03$ & $\mathrm{n} / \mathrm{a}$ & \\
\hline Grab Sample (Total) & S12T019904 & & $16887-00-6$ & Chloride & $\mathrm{ng} / \mathrm{mL}$ & 99.9 & $9.98 \mathrm{E}-03$ & 0.0770 & $\mathbf{n} / \mathbf{a}$ & $\mathrm{n} / \mathrm{a}$ & $\mathbf{n} / \mathbf{a}$ & n'a & $9.98 \mathrm{E}-03$ & $\mathrm{n} / \mathrm{a}$ & \\
\hline Grab Sample (Total) & S12T019904 & & $14797-65-0$ & Nitrite & $\mathrm{ug} / \mathrm{mL}$ & 94.1 & $<0.0192$ & $<0.0192$ & n/a & $\mathrm{n} / \mathrm{a}$ & $\mathrm{n} / \mathbf{a}$ & n/a & 0.0192 & $\mathbf{n} / \mathbf{a}$ & \\
\hline Grab Sample (Total) & S12T019904 & & $14808-79-8$ & Sulfate & $\mathrm{ug} / \mathrm{mL}$ & 96.5 & $<0.0187$ & 0.215 & $n / a$ & $n / \mathbf{a}$ & $\mathrm{n} / \mathbf{a}$ & $\mathrm{n} / \mathrm{a}$ & 0.0187 & $\mathrm{n} / \mathrm{a}$ & \\
\hline Grab Sample (Total) & S12T019904 & & $24959-67-9$ & Bromide & $\mathrm{ug} / \mathrm{mL}$ & 92.6 & $<0.0580$ & $<0.0580$ & $\mathrm{n} / \mathrm{a}$ & $n / \mathbf{a}$ & $\mathrm{n} / \mathbf{a}$ & n/a & 0.0580 & $\mathrm{n} / \mathrm{a}$ & \\
\hline Grab Sample (Total) & S12T019904 & & $14797-55-8$ & Nitrate & $\mathrm{ug} / \mathrm{mL}$ & 92.4 & $<0.0208$ & 1.86 & $\mathbf{n} / \mathbf{a}$ & $\mathrm{n} / \mathrm{a}$ & $\mathrm{n} / \mathbf{a}$ & $n / a$ & 0.0208 & $n / a$ & \\
\hline Grab Sample (Total) & S12T019904 & & $7723-14-0$ & Phosphorus & $\mathrm{ug} / \mathrm{mL}$ & 99.0 & $<.00 \mathrm{E}-03$ & $<3.00 \mathrm{E}-03$ & $<.00 \mathrm{E}-03$ & $n / a$ & $\mathrm{n} / \mathbf{a}$ & 96.9 & $3.00 \mathrm{E}-03$ & $\mathrm{n} / \mathrm{a}$ & \\
\hline Grab Sample (Total) & S12T019904 & & PH & $\mathrm{pH}$ & unitless & $\mathrm{n} / \mathbf{a}$ & $\mathrm{n} / \mathbf{a}$ & 6.89 & n'a & $\mathrm{n} / \mathrm{a}$ & $\mathrm{n} / \mathbf{a}$ & $\mathrm{n} / \mathbf{a}$ & 0.0100 & $\mathrm{n} / \mathrm{a}$ & \\
\hline Field Blank & S12T019901 & & $16984-48-8$ & Fluoride & $\mathrm{ug} / \mathrm{mL}$ & 101 & $<1.61 \mathrm{E}-03$ & $<1.61 \mathrm{E}-03$ & $\mathrm{n} / \mathrm{a}$ & $n / a$ & $\mathrm{n} / \mathrm{a}$ & $\mathrm{n} / \mathrm{a}$ & $1.61 \mathrm{E}-03$ & $\mathrm{n} / \mathbf{a}$ & \\
\hline Field Blank & S12T019901 & & $666-14-8$ & Glycolate & $\mathrm{ug} / \mathrm{mL}$ & 101 & $<.37 \mathrm{E}-03$ & $<9.37 \mathrm{E}-0.3$ & $\mathbf{n} / \mathbf{a}$ & $\mathrm{n} / \mathrm{a}$ & $\mathrm{n} / \mathbf{a}$ & $\mathbf{n} / \mathbf{a}$ & $9.37 \mathrm{E}-03$ & $\mathrm{n} / \mathrm{a}$ & \\
\hline Field Blank & S12T019901 & & $71-50-1$ & Acetate & $\mathrm{ug} / \mathrm{mL}$ & 97.3 & $<6.04 \mathrm{E}-03$ & $<6.04 \mathrm{E}-03$ & $\mathrm{n} / \mathbf{a}$ & $\mathrm{n} / \mathrm{a}$ & $\mathrm{n} / \mathbf{a}$ & $\mathrm{n} / \mathrm{a}$ & $6.04 \mathrm{E}-03$ & $\mathrm{n} / \mathrm{a}$ & \\
\hline Field Blank & S12T019901 & & $12311-97-6$ & Formate & $\mathrm{ug} / \mathrm{mL}$ & 94.7 & $<4.67 \mathrm{E}-03$ & $<4.67 \mathrm{E}-03$ & $\mathbf{n} / \mathbf{a}$ & $\mathrm{n} / \mathrm{a}$ & $n / a$ & $\mathrm{n} / \mathbf{a}$ & $4.67 \mathrm{E}-03$ & n/a & \\
\hline Field Blank & S12T019901 & & $16887-00-6$ & Chloride & $\mathrm{ug} / \mathrm{mL}$ & 99.9 & $8.98 \mathrm{E}-03$ & $<9.98 \mathrm{E}-03$ & $\mathrm{n} / \mathbf{a}$ & $\mathrm{n} / \mathrm{a}$ & $\mathrm{n} / \mathbf{a}$ & $\mathrm{n} / \mathrm{a}$ & $9.98 \mathrm{E}-03$ & $\mathrm{n} / \mathrm{a}$ & \\
\hline Field Blank & S12T019901 & & $14797-65-0$ & Nitrite & $\mathrm{ug} / \mathrm{mL}$ & 94.1 & $<0,0192$ & $<0.0192$ & $\mathrm{n} / \mathbf{a}$ & $\mathrm{n} / \mathrm{a}$ & $\mathrm{n} / \mathrm{a}$ & $\mathrm{n} / \mathrm{a}$ & 0.0192 & $\mathrm{n} / \mathrm{a}$ & \\
\hline Field Blank & S12T019901 & & $14808-79-8$ & Sulfate & $\mathrm{ug} / \mathrm{mL}$ & 96.5 & $<0.0187$ & $<0.0187$ & $\mathrm{n} / \mathbf{a}$ & n/a & $\mathrm{n} / \mathbf{a}$ & $\mathbf{n} / \mathbf{a}$ & 0.0187 & $\mathrm{n} / \mathrm{a}$ & \\
\hline Field Blank & S12T019901 & & $24959-67-9$ & Bromide & $\mathrm{ug} / \mathrm{mL}$ & 92.6 & $<0.0580$ & $<0.0580$ & $n / a$ & $\mathrm{n} / \mathrm{a}$ & $\mathrm{n} / \mathbf{a}$ & $\mathrm{n} / \mathrm{a}$ & 0.0580 & $n / a$ & \\
\hline Field Blank & S12T019901 & & $14797-55-8$ & Nitrate & $\mathrm{ug} / \mathrm{mL}$ & 92.4 & $<0.0208$ & $<0.0208$ & $\mathbf{w} / \mathbf{a}$ & $\mathrm{n} / \mathrm{a}$ & $\mathrm{n} / \mathbf{a}$ & $\mathrm{n} / \mathbf{a}$ & 0.0208 & $\mathrm{n} / \mathrm{a}$ & \\
\hline Field Blank & S12T019901 & & $7723-14-0$ & Phosphorus & $\mathrm{ug} / \mathrm{mL}$ & 99.0 & $<3.00 \mathrm{E}-03$ & $<3.00 \mathrm{E}-03$ & n/a & n/a & $\mathrm{n} / \mathbf{a}$ & n/a & $3.00 \mathrm{E}-03$ & $\mathrm{n} / \mathrm{a}$ & \\
\hline Field Blank & S12T019901 & & $\mathrm{PH}$ & $\mathrm{pH}$ & unitless & $n / a$ & $\mathrm{n} / \mathbf{a}$ & 3.82 & $\mathbf{n} / \mathbf{a}$ & n/a & $\mathrm{n} / \mathbf{a}$ & n/a & 0.0100 & $\mathrm{n} / \mathrm{a}$ & \\
\hline Grab Sample (Total) & S12T019906 & & $16984-48-8$ & Fluoride & $\mathrm{ug} / \mathrm{mL}$ & 101 & $<1.61 \mathrm{E}-03$ & $<1.61 \mathrm{E}-03$ & $\mathrm{n} / \mathbf{a}$ & n/a & $\mathrm{n} / \mathbf{a}$ & $n / a$ & $1.61 \mathrm{E}-03$ & $\mathrm{n} / \mathrm{a}$ & \\
\hline Grab Sample (Total) & S12T019906 & & $666-14-8$ & Glycolate & $\mathrm{ug} / \mathrm{mL}$ & 101 & $<9.37 \mathrm{E}-03$ & $<9.37 \mathrm{E}-03$ & $n / \mathbf{a}$ & $n / a$ & $\mathrm{n} / \mathrm{a}$ & $\mathrm{n} / \mathrm{a}$ & $9.37 \mathrm{E}-03$ & $\pi / \mathbf{a}$ & \\
\hline Grab Sample (Total) & S12T019906 & & $71-50-1$ & Acetate & $\mathrm{ug} / \mathrm{mL}$ & 97.3 & $<6.04 \mathrm{E}-03$ & $<6.04 \mathrm{E}-0.3$ & $\mathrm{n} / \mathbf{a}$ & $n / a$ & $\mathrm{n} / \mathrm{a}$ & $\mathrm{n} / \mathrm{a}$ & $6.04 \mathrm{E}-03$ & $n / a$ & \\
\hline Grab Sample (Total) & S12T019906 & & $12311-97-6$ & Formate & $\mathrm{ug} / \mathrm{mL}$ & 94.7 & $<4.67 \mathrm{E} \cdot 03$ & $<4.67 \mathrm{E}-03$ & $\mathrm{n} / \mathbf{a}$ & $n / a$ & $\mathrm{n} / \mathrm{a}$ & $\mathrm{n} / \mathrm{a}$ & $4.67 \mathrm{E}-03$ & n/a & \\
\hline Grab Sample (Total) & S12T019906 & & $16887-00-6$ & Chloride & $\mathrm{ug} / \mathrm{mL}$ & 99.9 & $<9.98 \mathrm{E}-03$ & 0.0720 & $\mathrm{n} / \mathbf{a}$ & $n / a$ & $n / a$ & $\mathbf{n} / \mathbf{a}$ & $9.98 \mathrm{E}-03$ & n/a & \\
\hline Grab Sample (Total) & S12T019906 & & $14797-65-0$ & Nitrite & $\mathrm{ug} / \mathrm{mL}$ & 94.1 & $<0.0192$ & $<0.0192$ & $n / a$ & $\mathrm{n} / \mathrm{a}$ & $\mathrm{n} / \mathrm{a}$ & $\mathrm{n} / \mathbf{a}$ & 0.0192 & $\mathbf{n} / \mathbf{a}$ & \\
\hline Grab Sample (Total) & S12T019906 & & $14808-79-8$ & Sulfate & $\mathrm{ug} / \mathrm{mL}$ & 96.5 & $<0.0187$ & 0.208 & $\mathrm{n} / \mathbf{a}$ & n/a & $\mathrm{n} / \mathrm{a}$ & $\mathrm{n} / \mathbf{a}$ & 0.0187 & $\mathrm{n} / \mathbf{a}$ & \\
\hline Grab Sample (Total) & S12T019906 & & $24959-67-9$ & Bromide & $\mathrm{ug} / \mathrm{mL}$ & 92.6 & $<0.0580$ & $<0.0580$ & $\mathrm{n} / \mathbf{a}$ & $\mathrm{n} / \mathrm{a}$ & $n / a$ & $\mathrm{n} / \mathbf{a}$ & 0.0580 & $\mathrm{n} / \mathbf{a}$ & \\
\hline Grab Sample (Total) & S12T019906 & & $14797-55-8$ & Nitrate & $\mathrm{ug} / \mathrm{mL}$ & 92.4 & $<0.0208$ & 1.83 & $\mathrm{n} / \mathrm{a}$ & $\mathrm{n} / \mathrm{a}$ & $\mathrm{n} / \mathrm{a}$ & $\mathbf{n} / \mathbf{a}$ & 0.0208 & $\mathrm{n} / \mathbf{a}$ & \\
\hline Grab Sample (Total) & S12T019906 & & $7723-14-0$ & Phosphorus & $\mathrm{ug} / \mathrm{mL}$ & 99.0 & $<3.00 \mathrm{E}-03$ & $<.00 \mathrm{E}-03$ & $\mathrm{n} / \mathbf{a}$ & náa & $\mathrm{n} / \mathrm{a}$ & $\mathrm{n} / \mathbf{a}$ & $3.00 \mathrm{E}-03$ & $\mathrm{n} / \mathbf{a}$ & \\
\hline Grab Sample (Total). & S12T019906 & & $\mathrm{PH}$ & $\mathrm{pH}$ & unitless & $\mathrm{n} / \mathrm{a}$ & $\mathrm{n} / \mathbf{a}$ & 6.66 & 6.76 & 6.71 & 1.49 & $\mathrm{n} / \mathbf{a}$ & 0.0100 & $\mathrm{n} / \mathbf{a}$ & \\
\hline
\end{tabular}




\subsection{Tardiff, G. R., 2001, Evaluation of AY-102 Annulus CAM Readings, CH2M HILL Hanford Group, Inc., Richland, Washington.}




\section{EVALUATION OF AY-102 ANNULUS CAM READINGS}

G. R. Tardiff, AWF System Engineer CH2M Hill Hanford Group, Inc.

June 29, 2001 


\section{I. $\quad$ Purpose}

In April of this year, the 241-AY-102 annulus continuous air monitor (CAM) began to show an upward trend in radiation readings. This paper provides a technical evaluation of the possible causes for the trend and discusses activities planned to resolve the elevated CAM readings. It also addresses the concerns of an ORP Facility Representative raised in June 2001.

\section{Introduction}

The annulus CAM samples air after it is discharged from the annulus, just upstream of the exhaust HEPA filters. The purpose of the CAM is to detect leaks from the primary tank into the annulus. The latest readings have been less than 1500 counts per minute (cpm). The Action Limit setpoint for the CAM is $3000 \mathrm{cpm}$. Elevated CAM readings will result when contamination from the primary tank enters the annulus system. The contamination can enter the annulus via a direct leak, either liquid or vapor, from the primary tank, or as a vapor through other pathways that connect the primary tank vapor space with the annulus. The following discussion will address the various pathways that exist that may have allowed primary tank vapors to enter the annulus. The discussion will focus on past contamination of the annulus that may be contributing to the elevated CAM readings, and will describe the expected response of the CAM system to a leak from the primary tank to the annulus.

\section{AY-102 Leak Path Evaluation}

An overview of potential contamination pathways between the primary tank and the annulus, which were considered during the 1999 and 2001 investigations of elevated annulus CAM readings, is provided below. The potential leak pathways are shown on the attached AY-102 Leak Path Diagram. The pathways are color coded to correspond to the color noted in the parenthesis at the end of each of the following Section headings.

Leak Detection Pit and Annulus Pump Pit Cross-ties to Annulus Vent System (Green and $\underline{\text { Red) }}$

All leak detection pits and annulus pump pits in AY and AZ tank farms are designed and built with an upper pit and lower pit. All upper pits contain components such as a drain line with a drain plug, 1 or 2 blanked wall nozzle connector heads, a transfer leak detector and either a transfer pump (mounted on a flange in the upper pit but extending into the lower pit) or a shield plug. All lower pits contain equipment such as the lower section of the pump; weight factor dip tubes and vent lines that tie into the annulus vent system.

All central pump pits (Blue), sluice pits, annulus pump pits and leak detection pits have drain-down legs that are piped back to the primary tank and are designed to discharge underneath the waste surface. However, the leak detection pits and annulus pump pits have the greatest potential to contaminate the annulus ventilation system since the lower 
part of these pits are vented directly to the annulus vent system. The purpose of the draindown leg is to seal vapors from the pits. This was a critical design feature since the Aging Waste Facility (AWF) tanks were designed to handle high heat boiling waste at elevated temperatures. Each drain-down leg stops approximately 60 inches above the bottom of the tank, and is normally submerged below the waste surface.

The drain-down leg design creates a potential contamination pathway from the primary tank vapor space to any of the connected pits, if the liquid level in the double shell tank (DST) drops below 60 inches. The amount of contamination going into the top part of the pits will be increased if an open pathway exists from the top part of the pit to the bottom part of the pit. The magnitude of the contamination spread will be greatly increased if the shield plug and drain plug are removed or improperly sealed. In the event that the annulus vacuum is greater than the primary tank vacuum, contamination spread could be further increased.

To reduce the potential for cross contamination from the primary tank into the lower part of the pits, shield plugs or metal plate covers have been installed in all pump positions for all the AY/AZ annulus pump pits, leak detection pits, central pump pits and sluice pits. All shield plugs and plate covers are fitted with gasket material to provide a positive seal. In most cases the gasket is made of neoprene. However, since most of these plugs have been in service for 20-30 years, gasket degradation is a credible possibility.

Verification that shield plugs or metal plate covers are in place cannot be completed without entering each pit or dropping a camera (if possible) into the pit. Within the last two years, three out of four annulus pump pits have been visually confirmed as having shield plugs or metal plate covers (all except AZ-102 annulus pump pit). None of the six leak detection pit shield plugs have been visually verified within the last 10 years.

Another potential pathway into the annulus vent system is through the pump out routes from the annulus pump pits. These transfer lines are potential sources of cross contamination into the upper part of the annulus pits. Based on the 200 East Area Routing Board, all transfer route nozzles in AY and AZ annulus pump pits and leak detection pits have either a PUREX head process blank (H-2-72284 and H-2-72285) or an isolation blank (H-2-73453).

Therefore, the potential for a large cross contamination pathway from these pits into the annulus ventilation system is substantially reduced. The largest leak would be reduced to small cracks in the gasket material as the gasket material deteriorates over time. This type of leak will most likely show up as a small increase in the contamination sensed by the annulus CAM.

\section{$\underline{\text { Side Fill Lines in AWF DSTs (Light Blue) }}$}

Each of the four tanks in the AWF have four side fill lines. The lowest transfer line is at an elevation of approximately 370 inches from the bottom of the tank. Each side fill line is sleeved or encased and runs through the annulus space. The sleeving material is Type 
304 stainless steel. The sleeve consists of a bellows (or expansion joint) and a packed flanged section welded to the primary tank. The transfer line itself is not welded to the primary tank but is supported by the flanged section. Between the flanged section and the primary tank, and between the transfer pipe and encasement is a packing material sealing the encasement section from the primary tank. The packing material is graphite impregnated with long fiber asbestos (Ref H-2-67316 and H-2-64448).

There is a potential for this flanged section to leak waste or vapors from the primary tank into the annulus. To date, vapor leaks via annulus side fill lines have been theorized but never confirmed. Operation Limits contained within operating procedures are designed to control AWF liquid level below 364 inches to prevent waste attacking the packing or waste pressurizing the packing.

\section{Cross-Tie Lines in AY and AZ DSTs (Light Purple)}

The cross-tie lines are 8 inch lines connected to the annulus at one end and connected to the 20 inch primary tank vent line. Between the primary and annulus there were two 8 inch butterfly valves which could be opened. In theory, both the primary tank and the annulus could be ventilated on the primary tank vent system in the event of a primary tank failure. Project W-030 removed all 4 cross ties when they removed the old 20 inch vent lines from each of the AWF DSTs (Ref. H-2-131086 and H-2-131087) during construction of the 702-AZ ventilation system. Originally, the AZ cross-tie lines were going to be left in place since the project was going to tee into the $4 \mathrm{~A}$ riser above the cross-tie lines. Project plans changed when the 14 inch vent line encasement had to be run to the top of the riser to meet environmental requirements. As a result, removal of the cross-tie lines in AZ Farms was necessary. The AY farm cross-ties were also removed as originally planned.

Consequently, the cross-tie lines connected to the annulus tanks do not present any risk of contamination spread from the primary tank to the annulus ventilation system.

\section{$\underline{\text { AY Annulus Ventilation System (Yellow) }}$}

The AY-101 and AY-102 annulus vent systems were originally designed and built with a supply fan as well as an exhaust fan. Each system had air dryers and heaters to deliver dry air to the annulus system at less than 12 percent relative humidity. The exhaust fan had more capacity than the supply fan, so the annulus pressure operated slightly negative most of the time. The annulus operated at approximately $2000 \mathrm{scfm}$ flow rate at -1 to +1 inch water gauge pressure inside the annulus. In 1983, this system was modified to the existing system, eliminating the supply fans and operating the annulus under negative pressure.

In 1997, after a long down time ( $\sim 7$ years), both annulus systems were repaired and new HEPA filter housings installed. The exhausters were repaired and adjusted to allow approximately $1200-1500 \mathrm{scfm}$ through the system at approximately -1 inch vacuum. The AY-101 system ran only 6 weeks before it was shutdown because the tank's liquid 
level was being pumped below 64 in to support an Evaporator Campaign. At 64 inches, the annulus exhaust system must be shutdown as required per OSD 17.2.1.1, Primary Tank Liquid Level limit. The AY-102 system continued to operate for approximately 8 months, until W-320 annulus modification work required the system to be shutdown.

In 1998 , the W-320 project modified the AY-102 vent system to allow $100 \%$ of the flow through the air slots under the primary tank. In order to achieve enough airflow through the slots, the annulus vacuum had to be significantly increased. Project W-320 evaluated the structural design of the AY DSTs and concluded that the annulus primary tank could withstand a 20 inch water gauge vacuum in the annulus. The exhaust fan was modified to allow the higher vacuums of -12 inches to -18 inches of vacuum at approximately $1000 \mathrm{scfm}$ flow. It should be noted that the W-320 design change for the AY-102 annulus did not significantly change the flow rate. Sampling systems for both the record sampler and annulus CAM were evaluated by Engineering to determine if equipment changes were required to maintain representative sampling for the new flow conditions. No changes were made since the overall flow rate had not changed significantly.

OTP-320-001 was performed to test the new high vacuum system (Ref. HNF-2317 Operability Test Report). The system performed well. The average flow rate for the test was $1077 \mathrm{scfm}$ with -16 inch vacuum. The average CAM reading was $413 \mathrm{cpm}$ with a maximum CAM reading of $1100 \mathrm{cpm}$. The test demonstrated that there was no significant source of cross contamination as a result of the increased vacuum.

\section{1-AY-102 Tank Integrity Evaluation}

Over the past several months UT and video examinations were performed on the primary tank liner of AY-102. Cameras, UT equipment, light sources and reach rods were used inside several risers and the annulus space. All equipment placed into the annulus space was removed with no measurable amount of contamination. Additional annulus and primary tank video examinations are planned for this year to view and then evaluate as much of the tank as practical.

\section{History of Elevated AY-102 Annulus CAM Readings}

The 241-AY-102 annulus has been subjected to numerous potential cross-contamination events over the years. The first event of interest occurred in October 1976 when a transfer of waste lowered the 241-AY-102 primary tank level to 15 inches. At this level, the leak detection pits drain-down legs, the central pump pit drain-down leg, the annulus pump pits drain-down legs and all the sluice pits drain-down legs were uncovered, exposing the drain-down legs to the primary tank vapor space. Between January 1982 and January 1990, all of the drain-down legs were uncovered twelve additional times. The attached Figure, AY 102 LEVEL \& ANNULUS DATA, provides a comparison of tank level and annulus CAM readings from January 1984 to January 1999.

The annulus exhauster has an operating history of periods of operation followed by periods of shutdown. After each startup, the annulus CAM count rate has been in the 
range of 600 to $2,800 \mathrm{cpm}$ with occasional higher peaks. The annulus exhauster was on line from late 1984 until mid 1987. In late 1986 and early 1987, the annulus leak detection CAM count rate showed fourteen peaks between 5,000 cpm and 20,000 cpm; these peaks correspond to periods when the tank waste level uncovered the drain-down legs. The annulus exhauster was off line from mid 1987 to early 1988 . The exhauster was restarted and was on line from early 1988 to mid 1991. The CAM count rate during this period was nominally 1,000 to $2,000 \mathrm{cpm}$ with many peaks in excess of 2,000 cpm. The largest peak was $10,000 \mathrm{cpm}$. The annulus exhauster was again secured in mid 1991 and remained offline until early 1997.

The exhauster was next operated for a short period between early 1997 and early 1998 . CAM count rates during this period fluctuated between 500 and $1,500 \mathrm{cpm}$. The annulus exhauster's last shutdown period was early 1998 to mid 1998. In mid 1998, the annulus exhauster was started and has been on line since (except when shutdown for repairs). The CAM count rate increased upon startup with the count rate being a nominal 1,500 cpm with many peaks between $1,800 \mathrm{cpm}$ and $2,800 \mathrm{cpm}$; four peaks were recorded at $3,000 \mathrm{cpm}$ or higher.

In December 1998, the Tank Farm Contractor (TFC) issued Discrepancy Report 98-857 concerning the higher than normal count rate observed on the 241-AY-102 annulus CAM. As follow-on documentation, the TFC issued an Occurrence Report against the count rate. To resolve the Occurrence Report, HNF-4798, Tank 241-AY-102 Annulus Continuous Air Monitor High Readings was issued in July 1999. HNF-4798 states that surveillance data for the 1984 and 1986 level decreases clearly indicate a correlation between the level drop and the annulus CAM count rates.

Several historical incidents of contamination of pump pits have been documented. In October 1994, the AY-102 central (O2D) pump pit became contaminated from a failed transfer line. This line failed in the wall of the O2D pit and sprayed waste into the O2D pit, and set off the leak detector. At that time, there was an open wall nozzle in the O2D pit. This wall nozzle is part of a transfer line system connected to the annulus pump pit. The open wall nozzle could have allowed contamination to move into the upper part of the annulus pump pit. However, a PUREX blank was installed (and still is installed) on the annulus pump pit side. The condition of the PUREX head is unknown but historically PUREX heads when installed properly create a pressure tight seal.

A 1997 video of the annulus pump pit showed that the pump had been removed and all of the transfer lines had been blanked. On February 17, 1999, smears were obtained of the annulus pump pit pump opening, the pit drain area, and the floor of the pit. Smearable contamination was found on all samples with contamination levels ranging from 2,000 to $3,000 \mathrm{dpm} / 100 \mathrm{~cm}^{2}$. Laboratory analysis revealed the presence of very low levels of Cs137 and $\mathrm{Sr}-90$.

During the activity to obtain annulus pump pit radiological contamination smears in 1999 , it was discovered that the plug on the drain line leading to the primary tank, was lying on its side near the drain line. The plug was reseated in an effort to better seal the 
primary tank from the annulus pump pit. After sealing the drain line, CAM count rate remained in the range of $200 \mathrm{cpm}$ to $2500 \mathrm{cpm}$

It is not known how long the drain line plug had been removed. With the drain line open, contamination from the primary tank has a much easier pathway to get into the upper annulus pump pit. In addition, a significant amount of moisture was observed in the annulus pump pit when reviewing the 1997 video of the pit. Water could be seen beading off the cover block and walls. The pit floor also looked wet. Contamination water could pass from the upper pit to the lower pit, if the shield plug has a deteriorated gasket.

The investigation conducted for HNF-4798 concluded that the increased annulus CAM count rate in the 241-AY-102 annulus was related to historical smearable contamination of the annulus pump pit. The existing contamination may be re-disturbed by changes in ventilation flow (startups and shutdowns) coupled with water intrusion into the annulus pump pit.

Review of the CAM data has shown that, since late 1984, the annulus CAM has indicated count rates of $500 \mathrm{cpm}$ to as high as $20,000 \mathrm{cpm}$ with the normal reading being 1,500 cpm to 2,500 cpm. During the week preceding the CAM shutdown on June 21, 2001, CAM readings ranged from $600 \mathrm{cpm}$ to $900 \mathrm{cpm}$.

Investigation of the elevated count rate in the 241-AY-102 annulus has continued. As stated above, it is known that the annulus pump pit is contaminated. It is suspected that moisture (condensation, intrusion) within the annulus pump pit, as observed in a 1997 video, becomes contaminated as it drips down the pit walls. It then seeps through a deteriorated shield plug gasket and enters the annulus.

\section{Annulus CAM Response to a Leak}

In August 1998, Pacific Northwest National Laboratory issued PNNL-11956, "Calculation of SY Tank Annulus Continuous Air Monitor Readings After Postulated Leak Scenarios," in support of a Washington State Department of Ecology compliance inspection at 241-SY Farm. Table 1 of the report provides the expected CAM response for a 0.01 gallon per minute leak of tank waste. SY annulus exhaust rate was assumed to be $300 \mathrm{cfm}$. The report indicates that the count rate resulting from a leak of waste will be significantly higher than the CAM alarm set-point in a matter of minutes for a leak totaling 73 gallons, and a matter of just a few hours for the 0.01 gallon per minute leak. The CAMs are expected to reach their alarm state as a result of a very small leak well within the required twenty-four hour detection period required under $40 \mathrm{CFR} 265$ and WAC 173-303-640. Although the PNNL report was prepared to specifically address the SY tanks, the methodology of the analysis is applicable to AY-102.

When using the PNNL equation for AY-102 to make a direct comparison, the following assumptions are made: 
1. The source terms in both tanks are approximately the same (AY-102 source term is actually greater).

2. The two annulus systems have approximately the same annulus volume $-21,900$ $\mathrm{ft}^{3}$

3. The flow rate for AY-102 will be assumed to average $850 \mathrm{cfm}$ (based on Operator Round Sheets).

Below is a comparison of the two tanks at the lowest leak rate $(0.01 \mathrm{gal} / \mathrm{min}$ or 14 $\mathrm{gal} / \mathrm{day})$ :

\begin{tabular}{|c|l|l|}
\hline & \multicolumn{2}{|l|}{$\begin{array}{l}\text { CAM Readings above } \\
\end{array}$} \\
Background (CPM)
\end{tabular}

The table above shows that the AY system will take longer to alarm than the SY system. The SY annulus system will alarm in approximately 140 minutes at the 3,000 cpm CAM setpoint, while the AY system will take approximately 215 minutes. Both are well within the 24 hour guide established by 40 CFR 265 and WAC 173-303-640, and will provide positive indication that waste has leaked from the tank.

A question has been raised regarding the setpoint for the annulus CAM system. CHG is currently reviewing the W-320 project files for the AY-102 annulus CAM setpoint calculation. In parallel we are reconstituting the setpoint calculation for the AY-102 annulus CAM. Preliminary results of the calculation indicate that the setpoint of 3000 cpm for the AY-102 annulus CAM is valid for the current system flow rate. The calculation demonstrates that the CAM sample flow rate is subisokinetic, which is conservative. The sample that enters the probe will be more concentrated than the effluent in the duct. Additionally, a preliminary calculation of the collection efficiency of the sample system indicates that it is approximately $83 \%$ efficient. This satisfies the requirement of ANSI N 13.1-1999, which requires a minimum of 50\% sampling efficiency. The field configuration will be verified against the drawing and the calculation completed and verified prior to submittal to ORP.

\section{CHG Conclusion}

CHG believes that the cross-contamination scenario, rather than a leak of waste from the primary tank, is considered the most probable cause of the increased count rate on the 241-AY-102 annulus leak detection CAM. This position is based on the following:

- High CAM counts have been observed in AY-102 since 1976 (ARHCO 1976b and 1976c, Rodgers 1976). In the past this phenomenon has been infrequent, and 
typically lasts for a few months and then disappears. The evidence and data for these past increases point to a slightly contaminated annulus pump pit that resulted from the lowering of tank waste levels below 60 inches, with the annulus ventilation running. This allowed contamination to travel up the drain-down keg and deposit onto pit surfaces. As a direct result of these occurrences, OSD-17.2.1 was written (Pan 1981) to ensure the annulus ventilation is shutdown prior to lowering tank liquid level below 64 inches.

- The tank integrity program has not identified any significant liner corrosion in 241AY-102.

- There have been no annulus CAM alarms or annulus conductivity leak detector alarms.

- A leak from the primary tank would exceed the annulus CAM setpoint in a short period of time (i.e., hours), even for a very small leak.

- If the primary tank liner or any of the side fill lines were leaking, the annulus would be highly contaminated. Any equipment lowered into the annulus vapor space would also likely become contaminated. To date, no contamination has been found on any of the equipment lowered into the tank annulus space to perform tank integrity inspections.

Based on the review of historical data and potential contamination paths, the source of increased count rate in the 241-AY-102 annulus is postulated to be a result of previous contamination of the annulus pump pit and the subsequent movement of contamination into the annulus through deteriorating seals/gaskets in the pump pit. Present and past operating modes (i.e., greater vacuum in the annulus relative to the primary tank) of the annulus ventilation system coupled with moisture in the pit support the movement of liquid from the annulus pump pit into the annulus via the seals/gaskets.

\section{Path Forward}

The following path forward is planned to resolve the elevated CAM problem:

Work package 2E-01-01027, "Seal 102-AY 02F Pit" is currently in the planning stage. The work will include resealing the funnel/plug assembly and replacing the gasket on the 12 inch shield plug. A second work package will spray the pit with fixative to prevent further contamination into the annulus system. Once this work has been completed, the pit will be closed up and resealed to prevent water or moisture intrusion. This work is anticipated to complete by the end of September 2001.

Field verification of the sample probe may require entry into the annulus exhaust duct, which will require planning and preparation of a work package. Alternately, additional document reviews may provide the information to verify the type of probe installed in the duct. If a field inspection is required, it will take two to three weeks to complete the 
CAM setpoint calculation. If the proper documentation is available, the calculation will be complete early next week.

After the completion of the above actions, the annulus CAM will be monitored (i.e., tracked and trended) for at least a year (in order to see all the seasonal changes) to ensure that the problem has been resolved. 


\section{REFERENCES}

ARHCO, 1972, 241-AY Tank Farm Information Manual, ARH-MA-102, October, Atlantic Richfield Hanford Company, Richland Washington.

ARHCO, 1975, Alarm Signal from the 101-AY "B" Leak Detection Pit, Occurrence Report 75-110, October 2, Atlantic Richfield Hanford Company, Richland Washington.

ARHCO, 1976a, High Radiation in Tank 101-AY Annulus Exhaust Air, Occurrence Report 76-132, September21, Atlantic Richfield Hanford Company, Richland Washington.

Rodgers, J.G., 1976, Surveillance Operational Survey on the 102-AY Liquid Level Drop, Letter to H. F. Jensen, October 20, Atlantic Richfield Hanford Company, Richland Washington.

Pan, R. B., 1981, Structural Analysis of the 241-AW/AN Primary Steel Tank For Revised Operating Criteria, Letter to G. T. Dukelow, July 29, Rockwell Hanford Company, Richland Washington.

WHC, 1989, Double-Shell Tank Annulus Air Flows, SD-WM-TA-017, July 24, Westinghouse Hanford Company, Richland Washington.

PNNL, 1998, Calculation of SY Tank Annulus Continuous Air Monitor Readings After Postulated Leak Scenarios, PNNL-11956, Pacific Northwest National Laboratory, Richland Washington.

LMH, 1999, Tank 241-AY-102 Annulus Contamination Air Monitor High Readings, HNF-4798, July 28, Lockheed Martin Hanford Company, Richland, Washington. 
ATTACHMENT 1 


\section{Aging Waste Facility (AWF) Leak Path Evaluation}

Below is an overview of potential contamination pathways from the various AWF structures and ancillary equipment considered during the 1999 and 2001 investigations of the elevated annulus CAM readings. The potential leak pathways are shown in the color noted in the parenthesis on the attached AWF Diagram.

Leak Detection Pit and Annulus Pump Pit Cross-ties to Annulus Vent System (Green and $\underline{\text { Red) }}$

All leak detection pits and annulus pump pits in AY and AZ Tank Farms are designed and built with an upper pit and lower pit. All upper pits contain components such as a drain line with a drain plug, 1 or 2 blanked wall nozzle connector heads, a transfer leak detector and either a transfer pump (mounted on a flange in the upper pit but extending into the lower pit) or a shield plug. All lower pits contain equipment such as the lower section of the pump; weight factor dip tubes and vent lines which tie into the annulus vent system.

All central pump pits (Blue), sluice pits, annulus pump pits and leak detection pits have drain lines that are piped back to the primary tank and are designed to discharge underneath the waste surface. However, the leak detection pits and annulus pump pits have the greatest potential to contaminate the annulus ventilation system since the lower part of these pits are vented directly to the annulus vent system. The purpose of the drain line is to seal vapors from the pits. This was a critical design feature since the AWF DSTs were designed to handle high heat boiling waste at elevated temperatures. Each drain line stops approximately 60 inches off the bottom of the tank and is normally submerged beneath the waste.

The drain line design creates a potential contamination pathway from the primary tank vapor space to any of the connected pits, if the liquid level in the DST drops below 60 inches. The amount of contamination going into the top part of the pits will be increased if an open pathway exists from the top part of the pit to the bottom part of the pit. The magnitude of the contamination spread will be greatly increased if the shield plug and drain plug are removed or improperly sealed. In the event that the annulus vacuum is greater than the primary tank vacuum, contamination spread could be further increased.

To reduce the potential for cross contamination from the primary tank into the lower part of the pits, shield plugs or metal plate covers have been installed in all pump positions for all the AY/AZ annulus pump pits, leak detection pits, central pump pits and sluice pits. All shield plugs and plate covers are fitted with gasket material to provide a positive seal. In most cases the gasket is made of neoprene. However, since most of these plugs have been in service for 20-30 years, gasket degradation is a credible possibility.

Verification that shield plugs or metal plate covers are in place can not be completed without entering each pit or dropping a camera (if possible) into the pit. Within the last two years, three out of four annulus pump pits have been visually confirmed as having 
shield plugs or metal plate covers (all except AZ-102 annulus pump pit). None of the six leak detection pit shield plugs have been visually verified within the last 10 years.

Another potential pathway into the annulus vent system is through the pump out routes from the annulus pump pits. These transfer lines are potential sources of cross contamination into the upper part of the annulus pits. Based on the 200 East Area Routing Board, all transfer route nozzles in AY and AZ annulus pump pits and leak detection pits have either a PUREX head process blank (H-2-72284 and H-2-72285) or an isolation blank (H-2-73453).

Therefore, the potential for a large cross contamination pathway from these pits into the annulus ventilation system is substantially reduced. The largest leak would be reduced to small cracks in the gasket material as the gasket material deteriorates over time. This type of a leak will not produce sustainable elevated CAM readings, which is what has been observed over the past 20 years.

$\underline{\text { Side Fill Lines in AWF DSTs (Light Blue) }}$

All 4 tanks in the AWF have side fill lines. Each tank has 4 side fill lines. The lowest transfer line is at an elevation of approximately 370 inches from the bottom of the tank. Each side fill line is sleeved or encased and runs through the annulus space. The sleeving is made out of 304 stainless steel with a bellows or expansion joint and a packed flanged section welded to the primary tank. The transfer line itself is not welded to the primary tank but is supported by the flanged section. Between the flanged section and the primary tank, and between the transfer pipe and encasement is a packing material sealing the encasement section from the primary tank. The packing material is graphite impregnated with long fiber asbestos (Ref H-2-67316 and H-2-64448).

There is a potential for this flanged section to leak waste or vapors from the primary tank into the annulus. To date vapor leaks via annulus side fill lines have been theorized but never confirmed. Operation Limits contained within operating procedures are designed to control AWF liquid level below 364 inches to prevent waste attacking the packing or waste pressurizing the packing.

\section{Cross-Tie Lines in AY and AZ DSTs (Light Purple)}

The cross-tie lines are 8 inch lines connected to the annulus at one end and connected to the 20 inch primary tank vent line. Between the primary and annulus there were $2-8$ inch butterfly valves which could be opened. In theory, both the primary tank and the annulus could be ventilated on the primary tank vent system in the event of a primary tank failure. Project W-030 removed all 4 cross ties when they removed the old 20 inch vent lines from each of the AWF DSTs (Ref. H-2-131086 and H-2-131087) during construction of the 702-AZ ventilation system. Originally, the AZ cross-tie lines were going to be left in place since the project was going to tee into the $4 \mathrm{~A}$ riser above the cross-tie lines. Project plans changed when the 14 inch vent line encasement had to be run to the top of the riser to meet environmental requirements. As a result, removal of 
the cross-tie lines in AZ Farms was necessary. The AY farm cross-ties were also removed as originally planned.

Consequently, the cross-tie lines connected to the annulus tanks do not present any risk of contamination spread from the primary tank to the annulus ventilation system.

\section{AY Annulus Ventilation System (Yellow)}

The AY-101 and AY-102 annulus vent systems were originally designed and built with a supply fan as well as an exhaust fan. Each system had air dryers and heaters to deliver dry air to the annulus system at less than 12 percent relative humidity. The exhaust fan had more capacity than the supply fan, so the annulus pressure operated slightly negative most of the time. The annulus operated at approximately $2000 \mathrm{scfm}$ flow rate at -1 to +1 inch water gauge pressure inside the annulus. In 1983, this system was modified to the existing system, eliminating the supply fans and operating the annulus under negative pressure.

In 1997, after a long down time ( $\sim 7$ years), both annulus systems were repaired and new HEPA filter housings installed. The exhausters were repaired and adjusted to allow approximately 1200-1500 scfm flow rate through the system at approximately -1 inch vacuum. 101-AY system ran only 6 weeks before it was shutdown because the tank's liquid level was being pumped below 64 in to support an Evaporator Campaign. At 64 inches, the annulus exhaust system must be shutdown as required per OSD 17.2.1.1, Primary Tank Liquid Level limit. 102-AY continued to operate for approximately 8 months until W-320 annulus modification work required the system to be shutdown.

In 1998 , the W-320 project modified the AY-102 vent system to allow $100 \%$ of the flow through the air slots under the primary tank. In order to achieve enough airflow through the slots, the annulus vacuum had to be significantly increased. Project W-320 evaluated the structural design of the AY DSTs and concluded that the annulus primary tank could withstand a 20 inch water gauge vacuum in the annulus. The exhaust fan was modified to allow the higher vacuums of -12 inches to -18 inches of vacuum at approximately $1000 \mathrm{scfm}$ flow. It should be noted, that the W-320 design change for the 102-AY annulus did not significantly change the flow rate. Sampling systems for both the record sampler and annulus CAM were evaluated by Engineering to determine if equipment changes were required to maintain representative sampling for the new flow conditions. No changes were made since the overall flow rate had not changed significantly.

OTP-320-001 was performed to test the new high vacuum system (Ref. HNF-2317 Operability Test Report). The system performed well. The average flow rate for the test was $1077 \mathrm{scfm}$ with -16 inch vacuum. The average CAM reading was $413 \mathrm{cpm}$ with a maximum CAM reading of $1100 \mathrm{cpm}$. The test demonstrated that there was no significant source of cross contamination as a result of the increased vacuum. 


\section{1-AY-102 Tank Integrity Evaluation}

Over the past several months UT and video examinations were performed on the primary tank liner of 102-AY. Cameras, UT equipment, light sources and reach rods were used inside several risers and the annulus space. All equipment placed into the annulus space was removed with no measurable amount of contamination. Additional annulus and primary tank video examinations are planned for this year to view and then evaluate as much of the tank as practical.

\section{Annulus CAM Behavior Evaluation}

In August 1998, the Pacific Northwest National Laboratory issued PNNL-11956, "Calculation of SY Tank Annulus Continuous Air Monitor Readings After Postulated Leak Scenarios," in support of a Washington State Department of Ecology compliance inspection at 241-SY Farm. Table 1 of the report provides the expected CAM response for a 0.01 gallon per minute leak of tank waste. SY annulus exhaust rate was assumed to be $300 \mathrm{cfm}$. The report indicates that the count rate resulting from a leak of waste will be significantly higher than the CAM alarm set-point in a matter of minutes for a leak totaling 73 gallons, and a matter of just a few hours for the 0.01 gallon per minute leak. The CAMs are expected to reach their alarm state as a result of a very small leak well within the required twenty-four detection period required under 40 CFR 265 and WAC 173-303-640. Since the source term in AY-102 is greater than the source term in SY source term the response time should be similar.

We are currently reviewing the W-320 project files for the same setpoint calculation. In parallel we will reconstitute the setpoint calculation for the AY-102 annulus CAM. The calculation will be completed by July $6^{\text {th }}$. 


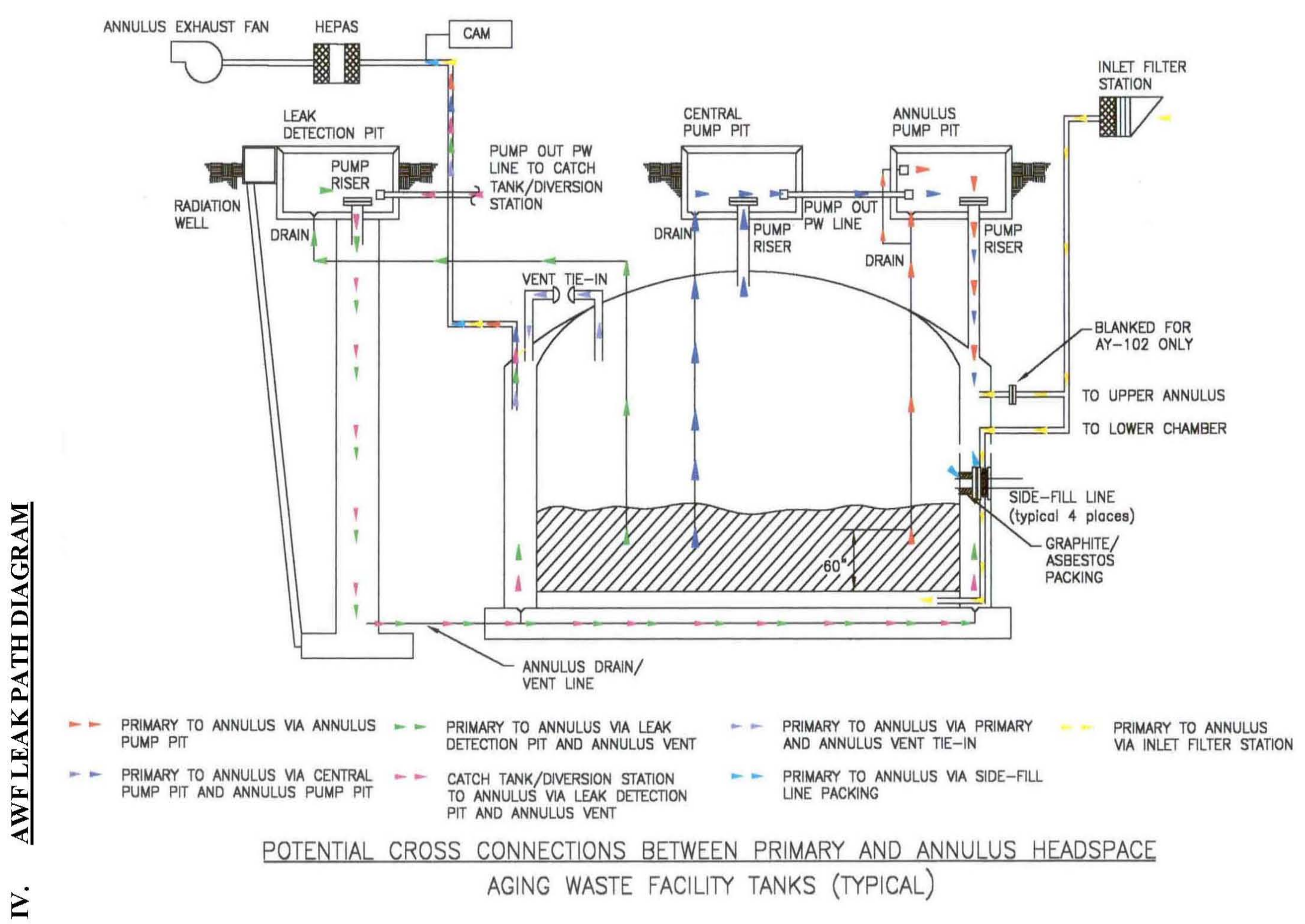




\subsection{Tank AY-102 Time Line of Events: Annulus ENRAF Leak Detectors, Continuous Air Monitor, Operational History, and Annulus Visual Inspections}

8.1 Tank AY-102 Annulus ENRAF Leak Detectors Time Line................................. 8-2

8.2 Tank AY-102 Continuous Air Monitor Time Line.............................................. $8-5$

8.3 Tank AY-102 Operational Time Line........................................................ $8-8$

8.4 Tank AY-102 Annulus Visual Inspection Time Line............................................ 8-19 
Rev. 0

8.1 Tank AY-102 Annulus ENRAF Leak Detectors Time Line 


\begin{tabular}{|c|c|c|}
\hline \multicolumn{3}{|c|}{ AY-102 Annulus ENRAF Leak Detectors } \\
\hline Date & Event & Reference \\
\hline May to June 2007 & $\begin{array}{l}\text { Riser } 90 \text { ENRAF above normal range and } \\
\text { Environmental was notified. On 06-03-2007 } \\
\text { Environmental was notified that all three annulus } \\
\text { ENRAFs were out of range. }\end{array}$ & $\begin{array}{l}\text { Personal Computer } \\
\text { Surveillance Analysis } \\
\text { Computer System } \\
\text { (PCSACS) }\end{array}$ \\
\hline $05-21-2007$ & $\begin{array}{l}\text { Work package was created to fix a faulty 10-in. gasket } \\
\text { on Riser } 88 \text { (where ENRAF AY102-WSTA-LDT-151 } \\
\text { is located). Air was sucking (easily heard standing } \\
\text { near riser) into the annulus. If air could get in so could } \\
\text { water. Metal tape has been used as a temporary patch } \\
\text { to reduce the air/water in-leakage. This problem was } \\
\text { never fixed and could be a source of water intrusion } \\
\text { into the annulus. }\end{array}$ & $\begin{array}{l}\text { WFO-WO-07-1451; } \\
\text { Riser } 88 \text { Photo; } \\
\text { Personal } \\
\text { Communication G. R. } \\
\text { Tardiff }\end{array}$ \\
\hline $07-02-2007$ & $\begin{array}{l}\text { Riser } 90 \text { ENRAF declared out of service; plummet was } \\
\text { stuck and needs calibration. }\end{array}$ & PCSACS \\
\hline $08-13-2007$ & Riser 90 ENRAF returned to service. & PCSACS \\
\hline Jan. 2008 to Feb. 2009 & $\begin{array}{l}4 \text { incidents of ENRAF issues reported during this time } \\
\text { relating to a broken ENRAF (AY102-WSTA-LDT- } \\
153 \text { ) at Riser } 91 \text {. Riser } 91 \text { ENRAF was replaced } \\
02 / 02 / 2009 \text { which fixed the drifting and other } \\
\text { problems. }\end{array}$ & $\begin{array}{l}\text { RPP-ASMT-53793, } \\
\text { Tank 241-AY-102 Leak } \\
\text { Assessment Report }\end{array}$ \\
\hline $10-09-2011$ to $10-10-2011$ & $\begin{array}{l}0.46 \text { in. of rain occurred over a } 6 \text { day period. An } \\
\text { additional } 0.11 \text { in. of rain fell on } 10-10-2011 .\end{array}$ & $\begin{array}{l}\text { Hanford } \\
\text { Meteorological } \\
\text { Station- October } 2011 \\
\text { Month Summary }\end{array}$ \\
\hline $10-09-2011$ & $\begin{array}{l}\text { Riser 90 ENRAF (AY102-WSTA-LDT-152) alarm } \\
\text { above normal range; declared out of service. }\end{array}$ & $\begin{array}{l}\text { PER-2011-2120, } \\
\text { Create Pre-Planned } \\
\text { Work Package to } \\
\text { Investigate Annulus } \\
\text { Water Intrusion }\end{array}$ \\
\hline $10-12-2011$ & $\begin{array}{l}\text { Riser } 90 \text { ENRAF plummet is found wet } \sim 1 / 2 \text {-in. up the } \\
\text { plummet; some dose rate } 2-4 \mathrm{mrem} / \mathrm{hr} \text { in enclosure. } \\
\text { Rainwater intrusion is thought to be the cause of the } \\
\text { wetness. }\end{array}$ & $\begin{array}{l}\text { TFC-WO-11-5469; } \\
\text { TOC-ENV-NOT- } \\
2011-0012\end{array}$ \\
\hline $10-13-2011$ & Ecology notified; Ecology visits. & $\begin{array}{l}\text { TOC-ENV-NOT- } \\
2011-0012\end{array}$ \\
\hline $10-13-2011$ & $\begin{array}{l}\text { Bolts were reported to be missing on the AY-102 Riser } \\
783 \text {-in. shield plug and the riser was only being held in } \\
\text { place by some black tape. Bolts could have been } \\
\text { missing as early as } 2006 \text {. The flange was not very } \\
\text { secure on the riser and could be a course of water } \\
\text { intrusion into the annulus. Gasket and bolts were } \\
\text { installed to reduce any in-leakage. }\end{array}$ & $\begin{array}{l}\text { WRPS-PER-2011- } \\
\text { 2099, Water intrusion } \\
\text { into the AY-102 } \\
\text { annulus; } \\
\text { Riser } 78 \text { Photo 1; } \\
\text { Riser } 78 \text { Photo } 2\end{array}$ \\
\hline $10-17-2011$ & Ecology questions answered. & $\begin{array}{l}\text { IDMS Accession } \\
166681854\end{array}$ \\
\hline $10-24-2011$ & $\begin{array}{l}\text { Riser } 90 \text { ENRAF flushed with } 10 \text { gal of water and } \\
\text { allowed to dry; dose } 5 \mathrm{mrem} / \mathrm{hr} \text { before flush then } 1.5 \\
\mathrm{mrem} / \mathrm{hr} \text { after flush. }\end{array}$ & $\begin{array}{l}\text { TFC-WO-11-5545; } \\
\text { RSR WTO-022533 }\end{array}$ \\
\hline $10-27-2011$ & Riser 90 ENRAF recalibrated and returned to service. & TFC-WO-11-5469 \\
\hline 03-10-2012 & $\begin{array}{l}\text { Riser } 90 \text { ENRAF was declared out of service with a } \\
\text { required repair date of } 06-08-2012 \text {. }\end{array}$ & $\begin{array}{l}\text { TOC-ENV-NOT- } \\
2012-0053\end{array}$ \\
\hline $05-24-2012$ & $\begin{array}{l}\text { During planned repairs to the Riser } 90 \text { ENRAF, the } \\
\text { ENRAF displacer wire broke while attempting to } \\
\text { retrieve the stuck displacer on the annulus floor. }\end{array}$ & $\begin{array}{l}\text { TOC-ENV-NOT- } \\
2012-0053\end{array}$ \\
\hline
\end{tabular}




\begin{tabular}{|c|c|c|}
\hline \multicolumn{3}{|c|}{ AY-102 Annulus ENRAF Leak Detectors } \\
\hline Date & $\begin{array}{c}\text { Event } \\
\end{array}$ & Reference \\
\hline 06-04-2012 & $\begin{array}{l}\text { A bullet-style video camera used to inspect Riser } 90 \\
\text { ENRAF displacer in the annulus; Drum \& reel } \\
\text { contaminated } 20,000 \mathrm{dpm} / 100 \mathrm{~cm}^{2} \text {. Identified that the } \\
\text { displacer was in a location that would interfere with the } \\
\text { performance of the replacement ENRAF. }\end{array}$ & $\begin{array}{l}\text { RPP-ASMT-53793; } \\
\text { TOC-ENV-NOT- } \\
2012-0053\end{array}$ \\
\hline 06-05-2012 & $\begin{array}{l}\text { Attempt to retrieve the stuck Riser } 90 \mathrm{ENRAF} \\
\text { displacer unsuccessful from the bottom of the annulus. }\end{array}$ & $\begin{array}{l}\text { TOC-ENV-NOT- } \\
2012-0053\end{array}$ \\
\hline $07-24-2012$ & $\begin{array}{l}\text { Rotated upper flange of the riser to avoid the displacer } \\
\text { and debris on the annulus floor; installed replacement } \\
\text { drum and displacer on Riser } 90 \text {. Functionally tested } \\
\text { and returned to service. }\end{array}$ & TFC-WO-12-2156 \\
\hline 08-05-2012 & $\begin{array}{l}\text { Annulus visual inspection in Riser } 77 \text { (mound) and } \\
\text { Riser } 87 \text { (floor deposit) indicate material in vicinity of } \\
\text { Riser } 90 \text {. }\end{array}$ & $\begin{array}{l}\text { RPP-RPT-34311, Rev. } \\
\text { 1, Double-Shell Tank } \\
\text { Integrity Inspection } \\
\text { Report for 241-AY } \\
\text { Tank Farm }\end{array}$ \\
\hline $08-10-2012$ & $\begin{array}{l}\text { Removed Riser } 90 \text { ENRAF and performed visual } \\
\text { inspection in Riser } 90 \text {; floor sample } \sim 800,000 \\
\text { dpm/probe area field measurement. }\end{array}$ & $\begin{array}{l}\text { TFC-WO-12-4563; } \\
\text { PER-2012-1379 }\end{array}$ \\
\hline $08-13-2012$ & $\begin{array}{l}\text { 222-S Laboratory results of the annulus floor sample } \\
\text { confirmed }{ }^{137} \mathrm{Cs} \text { and }{ }^{90} \mathrm{Sr} \text { in a ratio similar to sludge } \\
\text { interstitial liquid }(\sim 40: 1) \text {. }\end{array}$ & RPP-ASMT-53793 \\
\hline $08-27-2012$ & $\begin{array}{l}\text { Relocated Riser } 90 \text { ENRAF (AY102-WSTA-LDT-152) } \\
\text { to Riser } 89 .\end{array}$ & TFC-WO-12-4863 \\
\hline $08-29-2012$ & $\begin{array}{l}\text { Riser } 89 \text { ENRAF (AY102-WSTA-LDT-152) } \\
\text { calibration which was completed the following day on } \\
08-30-2012 \text {. }\end{array}$ & TFC-WO-12-4740 \\
\hline
\end{tabular}

Note: Riser 90- ENRAF - AY102-WSTA-LDT-152 (moved to Riser 89 on 08-27-2012)

Riser 88- ENRAF - AY102-WSTA-LDT-151

Riser 91- ENRAF - AY102-WSTA-LDT-153

$\mathrm{dpm} \quad=\quad$ disintegrations per minute

IDMS $\quad=\quad$ integrated document management system

$\mathrm{mrem} / \mathrm{hr} \quad=\quad$ millirem per hour

PCSACS = personal computer surveillance analysis computer system 
Rev. 0

8.2 Tank AY-102 Continuous Air Monitor Time Line 


\begin{tabular}{|c|c|c|c|c|}
\hline \multicolumn{5}{|c|}{ AY-102 Annulus Continuous Air Monitor (CAM) } \\
\hline Date & \multicolumn{3}{|c|}{ Event } & Reference \\
\hline Aug. 1975 & \multicolumn{3}{|c|}{$\begin{array}{l}\text { A new radiation monitoring sampling system } \\
\text { (continuous air monitor) was installed on AY-102 } \\
\text { annulus exhaust. }\end{array}$} & $\begin{array}{l}\text { ARH-LD-208-B, } \\
\text { ARHCO Monthly } \\
\text { Report for August } \\
1975 \text {, page } 11\end{array}$ \\
\hline 1986-1987 & \multicolumn{3}{|c|}{$\begin{array}{l}\text { High annulus CAM readings (between 5,000 and } \\
20,000 \mathrm{cpm} \text { ) were reported during this time (cause } \\
\text { attributed to low liquid level in the tank uncovering } \\
\text { drain leg from annulus pump pit). }\end{array}$} & $\begin{array}{l}\text { Tardiff 2001, } \\
\text { Evaluation of } A Y-102 \\
\text { Annulus } C A M \\
\text { Readings }\end{array}$ \\
\hline 1997-1998 & \multicolumn{3}{|c|}{$\begin{array}{l}\text { Four CAM readings were reported over } 3,000 \mathrm{cpm} \\
\text { (cause likely attributed to the significant changes made } \\
\text { to the airflow through the annulus in 1998). }\end{array}$} & Tardiff 2001 \\
\hline 01-09-1999 to 01-11-1999 & \multicolumn{3}{|c|}{$\begin{array}{l}\text { Swabs of the tank annulus were taken on the sides of } \\
\text { the primary tank and the annulus floor. No } \\
\text { contamination was found. }\end{array}$} & $\begin{array}{l}\text { HNF-4798, Rev. 0, } \\
\text { Tank 241-AY-102 } \\
\text { Annulus Continuous } \\
\text { Air Monitor High } \\
\text { Readings, RL-PHMC- } \\
\text { TANKFARM-1999- } \\
\text { 0024, AY-102 CAM } \\
\text { Anomalous Readings }\end{array}$ \\
\hline 02-17-1999 & \multicolumn{3}{|c|}{$\begin{array}{l}\text { AY-102 annulus pump pit smears showed } 2,000-3,000 \\
\mathrm{dpm} / 100 \mathrm{~cm}^{2} . \text { Drain line plug reseated during } \\
\text { swabbing and annulus CAM counts decreased } \\
\text { afterwards. }\end{array}$} & HNF-4798, Rev. 0 \\
\hline 2001 & \multicolumn{3}{|c|}{$\begin{array}{l}\text { Increased count rates on the AY- } 102 \text { annulus leak } \\
\text { detection CAM. Concluded to be the result of previous } \\
\text { contamination of the annulus pump pit and movement } \\
\text { into the annulus through deteriorating seals/gaskets in } \\
\text { the pump pit. }\end{array}$} & Tardiff 2001 \\
\hline $10-21-2011$ & \multicolumn{3}{|c|}{$\begin{array}{l}\text { Annulus CAM sample paper changed as part of regular } \\
\text { biweekly monitoring routine. }\end{array}$} & RPP-ASMT-53793 \\
\hline $10-26-2011$ & $\begin{array}{l}\text { AY-102 ann } \\
\text { ENRAF flus } \\
\text { cpm via fiel } \\
\text { sample sent } \\
\text { identified in } \\
\text { decay. } \\
\text { Counting lat } \\
2011 \text { : } \\
\text { Initial } \\
1 \text { day decay } \\
7 \text { day decay } \\
{ }^{137} \text { Cs in CAI } \\
2011 \text { ) identi } \\
11 / 14 / 2011 \text {, }\end{array}$ & $\begin{array}{l}\text { S CAM ala } \\
\text { air sample } \\
\text { bunt (CAM } \\
\text { counting lat } \\
\text { nple by alp } \\
\text { sults. Air s } \\
\alpha \mu \mathrm{Ci} / \mathrm{mL} \\
6.40 \mathrm{E}-13 \\
2.16 \mathrm{E}-13 \\
3.06 \mathrm{E}-14 \\
\text { ir sample ( } \\
\text { in gamma } \\
6 \mathrm{E}-11 \mu \mathrm{Ci}\end{array}$ & $\begin{array}{l}\text { (2 days after Riser } 90 \\
\text { lected identified as } 4,200 \\
\text { point } 2,000 \mathrm{cpm}) \\
\text { Some radon progeny } \\
\text { spectroscopy after } 1 \text { day } \\
\text { ple } 10-21-2011 \text { to } 10-26- \\
\beta \mu \mathrm{Ci} / \mathrm{mL} \quad \beta \mathrm{ncpm} \\
4.32 \mathrm{E}-11 \quad 18,840 \\
4.22 \mathrm{E}-11 \quad 18,400 \\
4.14 \mathrm{E}-11 \quad 18,270 \\
\text { m } 10-21-2011 \text { to } 10-26- \\
\text { ergy analysis on }\end{array}$ & $\begin{array}{l}\text { Sample CR11-02070; } \\
\text { RPP-ASMT-53793 }\end{array}$ \\
\hline $11-08-2011$ & $\begin{array}{l}\text { AY-102 ann } \\
\text { failed penetr }\end{array}$ & $\begin{array}{l}\text { s exhaust } \mathrm{s} \\
\text { on test, } 99.9\end{array}$ & $\begin{array}{l}\text { down; } 2 \text { of } 8 \text { HEPAs } \\
\% \text { and } 99.986 \% \text {. }\end{array}$ & $\begin{array}{l}\text { TOC-ENV-NOT- } \\
2011-0022\end{array}$ \\
\hline $11-09-2011$ & WDOH noti & & & $\begin{array}{l}\text { TOC-ENV-NOT- } \\
2011-0022\end{array}$ \\
\hline $01-13-2012$ & Annulus HV & back on li & & TFC-WO-11-5789 \\
\hline $08-14-2012$ & Annulus CA & calibration & function test completed. & TFC-WO-12-4589 \\
\hline
\end{tabular}




\begin{tabular}{|c|c|c|c|}
\hline \multicolumn{4}{|c|}{ AY-102 Annulus Continuous Air Monitor (CAM) } \\
\hline & Date & Event & Reference \\
\hline & $09-27-2012$ & $\begin{array}{l}\text { Annulus CAM alarmed } \sim 11 \mathrm{am} \text {. CAM paper was } \\
\text { changed and the alarm cleared. The record sampler } \\
\text { paper was also changed; no action levels detected on } \\
\text { the record sampler paper. CAM alarmed after } 09-26- \\
2012 \text { sampling event at Riser } 83 \text {, less than } 24 \mathrm{hrs} \text {. } \\
\text { Field count } 7,734 \mathrm{cpm} \text {. }\end{array}$ & $\begin{array}{l}\text { Sample CR12-01573; } \\
\text { RPP-ASMT-53793 }\end{array}$ \\
\hline & $10-16-2012$ & $\begin{array}{l}\text { Annulus CAM alarmed 8-9pm the day after the } 10-15- \\
2012 \text { sampling event during dayshift at Riser } 90.1 \text { day } \\
\text { decay sample count } 18,729 \mathrm{cpm} \text { on } 10-17-2012 \text {. }\end{array}$ & $\begin{array}{l}\text { Sample CR12-01717; } \\
\text { RPP-ASMT-53793 }\end{array}$ \\
\hline & $10-18-2012$ & $\begin{array}{l}\text { Annulus CAM alarmed the day after the 10-17-2012 } \\
\text { sampling event during dayshift at Riser } 90 .\end{array}$ & RPP-ASMT-53793 \\
\hline & $\begin{array}{l}\text { PCSACS } \\
\text { WDOH }\end{array}$ & $\begin{array}{l}\text { personal computer surveillance analysis computer } \\
\text { Washington State Department of Health }\end{array}$ & \\
\hline
\end{tabular}


Rev. 0

8.3 Tank AY-102 Operational Time Line 


\begin{tabular}{|c|c|c|}
\hline \multicolumn{3}{|c|}{ AY-102 Operational History } \\
\hline Date & Event & Reference \\
\hline $1968-1971$ & AY Farm construction. AY-102 was the first DST to be constructed. & RPP-ASMT-53793 \\
\hline Feb. 1971 & $\begin{array}{l}\text { AY-102 initially filled with } 264 \mathrm{kgal} \text { of water and heated to prepare the } \\
\text { tank to receive HLW. Tank designated as aging waste spare. }\end{array}$ & $\begin{array}{l}\text { PPD-421-DEL, U.S. AEC } \\
\text { Richland Operations Office } \\
\text { Monthly Report for February } \\
\text { 1971, Page AIV-16 }\end{array}$ \\
\hline March 1971 & $\begin{array}{l}\text { Preheating of AY- } 102 \text { continued intermittently throughout the month. } \\
\text { Water temperature was } 163^{\circ} \mathrm{F} \text { at month end. }\end{array}$ & $\begin{array}{l}\text { PPD-429-DEL, U.S. AEC } \\
\text { Richland Operations Office } \\
\text { Monthly Report for March } \\
\text { 1971, Page AIV-16 }\end{array}$ \\
\hline March 1972 & $\begin{array}{l}\text { Received waste water from tank A-104: } 62 \mathrm{kgal} \text { in the } 1^{\text {st }} \text { quarter and } \\
60 \text { kgal in the } 2^{\text {nd }} \text { quarter. AY-102 was maintained at } \sim 160^{\circ} \mathrm{F} \text { to } \\
\text { evaporate added water. }\end{array}$ & $\begin{array}{l}\text { WHC-MR-0132, A History of } \\
\text { the } 200 \text { Area Tank Farms, page } \\
\text { 102-AY-3 }\end{array}$ \\
\hline April 1972 & AY-102 water level of 86 in. and water temperature of $166^{\circ} \mathrm{F}$ & $\begin{array}{l}\text { PPD-493-4-DEL, U.S. AEC } \\
\text { Richland Operations Office } \\
\text { Monthly Report for April 1972, } \\
\text { Page AIV-18 }\end{array}$ \\
\hline July 1972 & $\begin{array}{l}\text { AY-102 was reported at a temperature } \sim 126^{\circ} \mathrm{F} \text { and holding } 91 \text { in. of } \\
\text { water. }\end{array}$ & $\begin{array}{l}\text { PPD-493-7-DEL, U.S. AEC } \\
\text { Richland Operations Office } \\
\text { Monthly Report for July } 1972, \\
\text { Page AIV-18 }\end{array}$ \\
\hline 1972 & $\begin{array}{l}\text { Condensate was periodically added from tank A-417 to maintain the } \\
\text { liquid level between } 72 \text { in. and } 80 \text { in. }\end{array}$ & $\begin{array}{l}\text { Internal Memo } 1007190520 \text {, } \\
\text { December } 1972 \text { Monthly } \\
\text { Report }\end{array}$ \\
\hline May 1974 & $\begin{array}{l}\text { The liquid in AY-102 was sampled and showed a pH of } 11.1 \text {. It is } \\
\text { plausible the waste water and/or condensate added from tank A-417 } \\
\text { was alkaline. }\end{array}$ & $\begin{array}{l}\text { Occurrence Report 74-30, } \\
\text { Failure to Obtain Routine } \\
\text { Monthly Samples in Tank 102- } \\
\text { AY }\end{array}$ \\
\hline Aug. 1975 & $\begin{array}{l}\text { A new radiation monitoring sampling system (continuous air monitor) } \\
\text { was installed on AY-102 annulus exhaust. }\end{array}$ & $\begin{array}{l}\text { ARH-LD-208-B, ARHCO } \\
\text { Monthly Report for August } \\
\text { 1975, page } 11\end{array}$ \\
\hline $11-09-1975$ & $\begin{array}{l}\text { Misrouting of } 2,750 \text { gal of B Plant waste into waste into tank } 241-\mathrm{AY}- \\
102 \text { instead of } 241-\mathrm{A}-103 \text {. AY- } 102 \text { reported to be maintained at } 120 \text { to } \\
140^{\circ} \mathrm{F} \text { as an aging waste spare; also receives "... sump batches from the } \\
\text { diverter stations." [Note: PUREX Current Acid Waste was transferred } \\
\text { from } 1968 \text { to } 1972 \text { through the } 151 \text {-AX diverter station to AR Vault } \\
\text { and then to B Plant for processing. Waste from the PUREX acified } \\
\text { sludge solvent extraction process was transferred to AY-101 (not AY- } \\
102 \text { ) beginning in 1971]. }\end{array}$ & $\begin{array}{l}\text { ARH-LD-211-B, ARHCO } \\
\text { Monthly Report for November } \\
\text { 1975, page 11; } \\
\text { Occurrence Report 75-127, } \\
\text { Misrouting of Process Solution; } \\
\text { ARH-CD-691, 1976 Strontium } \\
\text { Recovery from PUREX Acified } \\
\text { Sludge }\end{array}$ \\
\hline $\begin{array}{l}\text { May-June } \\
1976\end{array}$ & $\begin{array}{l}\text { Excessive annulus ventilation system negative pressure was reported in } \\
\text { the AY Farm tanks. The system was reported in June } 1976 \text { to be } \\
\text { operating with a riser open on the annulus. }\end{array}$ & $\begin{array}{l}\text { ARH-LD-217-B, ARHCO } \\
\text { Monthly Report for May } 1976 \text {, } \\
\text { page } 12\end{array}$ \\
\hline June 1976 & $\begin{array}{l}\text { Steam coil was reported to be operated to maintain the tank liquid level } \\
\text { and reduce buildup of radioactive material on the filters of the } 702 \text {-A } \\
\text { vessel ventilation building. }\end{array}$ & $\begin{array}{l}\text { ARH-LD-218-B, ARHCO } \\
\text { Monthly Report for June } 1976, \\
\text { page } 12\end{array}$ \\
\hline July 1976 & $\begin{array}{l}\text { It was reported that direct steam addition was installed on the tank AY- } \\
101 \text { seal loop to provide the necessary moisture for controlling the } \\
\text { contamination of the filters in the } 702-\mathrm{A} \text { vessel ventilation building. } \\
\text { Operation of the steam coil in tank AY-102 "... must be limited due to } \\
\text { the low pH condensate which is produced and the excess heat which is } \\
\text { added to Tank 102-AY." }\end{array}$ & $\begin{array}{l}\text { ARH-LD-219-B, ARHCO } \\
\text { Monthly Report for July } 1976 \text {, } \\
\text { page } 16\end{array}$ \\
\hline
\end{tabular}




\begin{tabular}{|c|c|c|}
\hline \multicolumn{3}{|c|}{ AY-102 Operational History } \\
\hline Date & $\begin{array}{l}\text { Event } \\
\end{array}$ & Reference \\
\hline 10-04-1976 & $\begin{array}{l}\text { Liquid level decrease of } 2.5 \mathrm{in} \text {. over } 5 \text { days exceeded criteria of } 0.5 \mathrm{in} \text {. } \\
\text { over } 7 \text { days following shutting off steam to heating coil. }\end{array}$ & $\begin{array}{l}\text { ARH-LD-222-B, ARHCO } \\
\text { Monthly Report for October } \\
\text { 1976, page 7; } \\
\text { Occurrence Report 76-138, } \\
\text { Liquid Level Decrease } \\
\text { Exceeding Criteria }\end{array}$ \\
\hline $10-22-1976$ & $\begin{array}{l}\text { Tank liquid level was pumped down to } 15 \text { in. Minimum liquid level } \\
\text { specification was } 15 \mathrm{in} \text {. (with the annulus ventilation system operating) } \\
\text { during this time period to prevent bottom uplift. The standard states a } \\
\text { minimum liquid level of } 17 \mathrm{in.} \text { Liquid level below } 60 \text { in. opens a } \\
\text { pathway for contamination in the annulus pump pit. On } 10-29-1976 \text {, } \\
\text { the annulus ventilation was shut off and process condensate was added } \\
\text { to raise the tank liquid level to } 20 \mathrm{in} \text {. }\end{array}$ & $\begin{array}{l}\text { ARH Occurrence Report 76- } \\
\text { 148, Possible Specification } \\
\text { Violation: Liquid Level } \\
\text { Decrease to Below a Minimum } \\
\text { Level; ARH-1601, } \\
\text { Specifications and Standards } \\
\text { for the Operation of } \\
\text { Radioactive Waste Tank Farms } \\
\text { and Associated Facilities }\end{array}$ \\
\hline Oct. 1976 & $\begin{array}{l}\text { Liquid pumped from AY-102 to A-101. A system was installed for } \\
\text { direct steam addition on the Tank AY-102 seal loop, similar to Tank } \\
\text { AY-101 to eliminate the use of the steam coil in Tank AY-102. }\end{array}$ & $\begin{array}{l}\text { ARH-LD-222-B, ARHCO } \\
\text { Monthly Report for October } \\
1976, \text { page } 14\end{array}$ \\
\hline $\begin{array}{l}\text { March- } \\
\text { April } 1977\end{array}$ & $\begin{array}{l}\text { AY-102 started receiving evaporator feed "aging waste" (dilute } \\
\text { supernatant) from B Plant. }\end{array}$ & $\begin{array}{l}\text { WHC-MR-0132, A History of } \\
\text { the } 200 \text { Area Tank Farms, } \\
\text { WHC-SD-WM-ER-454, Rev. } \\
\text { 0, Tank Characterization } \\
\text { Report for Double-Shell Tank } \\
241-A Y-102\end{array}$ \\
\hline May 1977 & $\begin{array}{l}\text { AY-102 received } 198 \mathrm{kgal} \text { of Battelle Northwest Laboratory (BNW) } \\
\text { waste which apparently included } 16 \text { casks of high-level waste (HLW) } \\
\text { received from BNW at B Plant, } 130 \text { kgal of waste from B Plant which } \\
\text { was low in }{ }^{137} \mathrm{Cs} \text { and }{ }^{90} \mathrm{Sr} \text {, and } 35 \text { casks in preparation for the } \\
\text { Commercial Nuclear Waste Vitrification Program. }\end{array}$ & $\begin{array}{l}\text { ARH-LD-229-B, ARHCO } \\
\text { Monthly Report for May } 1977 \text {, } \\
\text { page } 31\end{array}$ \\
\hline 1978 & $\begin{array}{l}\text { In the } 1^{\text {st }} \text { and } 2^{\text {nd }} \text { quarters of } 1978 \text {, Tank AY-102 received } \\
\text { approximately } 157 \mathrm{kgal} \text { of commercial vitrification process test waste. } \\
\text { In the } 3^{\text {rd }} \text { and } 4^{\text {th }} \text { quarters, AY-102 received } 14 \text { kgal of double-shell } \\
\text { slurry feed (DSSF). }\end{array}$ & $\begin{array}{l}\text { WHC-SD-WM-TI-689, Rev. 1, } \\
\text { Waste Status and Transaction } \\
\text { Record Summary for the } \\
\text { Southeast Quadrant of the } \\
\text { Hanford 200 Area; WHC-SD- } \\
\text { WM-ER-454, Rev. 0, Tank } \\
\text { Characterization Report for } \\
\text { Double-Shell Tank 241-AY-102 }\end{array}$ \\
\hline 1980 & $\begin{array}{l}\text { In the } 2^{\text {nd }} \text { quarter of } 1980, \sim 302 \mathrm{kgal} \text { of DSSF was added with a } \\
\text { reported solids level at } 21 \mathrm{kgal} \text { on June } 20,1980 \text {. }\end{array}$ & $\begin{array}{l}\text { WHC-SD-WM-ER-454, Rev. } \\
\text { 0, Tank Characterization } \\
\text { Report for Double-Shell Tank } \\
241-A Y-102\end{array}$ \\
\hline 08-17-1981 & $\begin{array}{l}\text { Misrouting of waste to Tank AY-102 from Tank AY-101 leading to a } \\
\text { liquid level increase of } 0.2 \mathrm{in.}\end{array}$ & $\begin{array}{l}\text { Occurrence Report } 81-52 \\
\text { Misrouting TK-AY-101 to TK- } \\
\text { AY-102 }\end{array}$ \\
\hline 1981 & $\begin{array}{l}\text { AY-102 received plutonium uranium extraction miscellaneous waste, } \\
\text { low-level dilute non-complexed waste from B-Plant cesium and } \\
\text { strontium processing, and other dilute non-complexed wastes, and } \\
\text { water until the second quarter of } 1985 \text {. }\end{array}$ & $\begin{array}{l}\text { RPP-RPT-42920, Rev. 0, } 2009 \\
\text { Auto-TCR for Tank } 241-A Y-102\end{array}$ \\
\hline 1983 & $\begin{array}{l}\text { AY-102 ventilation system modified to eliminate the supply fans and } \\
\text { begin operating the annulus under more negative pressure than the } \\
\text { primary tank. }\end{array}$ & Tardiff 2001 \\
\hline
\end{tabular}




\begin{tabular}{|c|c|c|}
\hline \multicolumn{3}{|c|}{ AY-102 Operational History } \\
\hline Date & Event & Reference \\
\hline 1984 & $\begin{array}{l}\text { Failure of line SL-233 (from B Plant to 244-A) after being in service } \\
\text { since } 1975 .\end{array}$ & $\begin{array}{l}\text { WHC-SD-RE-TI-148, Rev. 0, } \\
\text { Metallurgical Analysis of Leak } \\
\text { Failure of } 241-A-B \text { Valve Pit } \\
\text { Jumper }\end{array}$ \\
\hline 1985 & $\begin{array}{l}\text { AY-102 received dilute non-complexed waste from N Reactor, B-Plant } \\
\text { vessel clean out and B-Plant low-level wastes from B-Plant, low-level } \\
\text { non-complexed waste from T-Plant, and laboratory wastes until the } \\
\text { first quarter of 1996. Large transfers were made to Tanks AW-102, } \\
\text { AW-106, AP-103, AP-104, AP-106, and AP-108 during this period. }\end{array}$ & $\begin{array}{l}\text { RPP-RPT-42920, Rev. 0, } 2009 \\
\text { Auto-TCR for Tank 241-AY-102 }\end{array}$ \\
\hline $\begin{array}{c}\text { Jan. and } \\
\text { May } 1986\end{array}$ & $\begin{array}{l}\text { During transfers from AY-102 to AW-102, liquid levels indicate level } \\
\text { was below } 60 \text { in. (the minimum operating specification at this time). } \\
\text { Potential pathway exists for contamination in the annulus pump pit. }\end{array}$ & $\begin{array}{l}\text { TWINS; PCSACS; OSD-T- } \\
\text { 151-00017, Rev. B-0 }\end{array}$ \\
\hline 03-31-1986 & Annulus vent system was punctured and found severely corroded. & $\begin{array}{l}\text { 7G410-JKE/MJR-007-005, } \\
\text { Evidence of Annulus Moisture } \\
\text { Accumulation in Tanks 241-AY- } \\
101 \text { and } 241-A Y-102\end{array}$ \\
\hline $1988-1989$ & $\begin{array}{l}\text { Original annulus ventilation system replaced for AY }-102 \text { by Project B- } \\
672 \text {. The original annulus ventilation system was abandoned in place, } \\
\text { cut and capped piping, installed new/upgraded ventilation system. }\end{array}$ & 7G410-JKE/MJR-007-005 \\
\hline June 1991 & $\begin{array}{l}\text { AY-102 annulus ventilation system shut down and remained down } \\
\text { until March } 1997 .\end{array}$ & 7G410-JKE/MJR-007-005 \\
\hline $11-28-1991$ & $\begin{array}{l}\text { Misrouting from the saltwell receiver tank } 244-\mathrm{CR}-003 \text { leading to a } \\
\text { liquid level rise of } 0.2 \mathrm{in} \text {. in Tank AY-102. }\end{array}$ & $\begin{array}{l}\text { Occurrence Report RL-WHC- } \\
\text { TANKFARM-1991-1068, } \\
\text { Unexpected Rise in DST 241- } \\
\text { AY-102 Liquid Level during } \\
\text { Transfer of Waste from Catch } \\
\text { Tank 244-CR-003 to DST 241- } \\
\text { AY-101 }\end{array}$ \\
\hline 06-08-1994 & $\begin{array}{l}\text { AY-102 grab samples reported to be out-of-specification for hydroxide } \\
\text { (pH reported to be between } 10.4 \text { to } 10.7 \text { ). Samples were re-analyzed } \\
\text { 08-19-1994 and consistent with June } 1994 \text { results. }\end{array}$ & $\begin{array}{l}\text { Occurrence Report RL-WHC- } \\
\text { TANKFARM-1994-0046, } \\
\text { Analysis of Waste Samples } \\
\text { Results in Discovery of Out-of- } \\
\text { Specification Levels of } \\
\text { Hydroxide in } 200 \text { East Area } \\
\text { Waste Tanks }\end{array}$ \\
\hline $\begin{array}{l}\text { Sept. to } \\
\text { Nov. } 1994\end{array}$ & $\begin{array}{l}\text { Approximately } 90,000 \text { gram moles of } \mathrm{NaOH} \text { was added to Tank AY- } \\
102 \text {. }\end{array}$ & $\begin{array}{l}\text { RPP-7795, Rev. 9, Technical } \\
\text { Basis for Chemistry Control } \\
\text { Program }\end{array}$ \\
\hline $10-26-1994$ & $\begin{array}{l}\text { During a flush of line SL-503 (connects AY-102 sluice pit } 02 \mathrm{D} \text { to } \\
\text { central pump pit } 02 \mathrm{~A} \text { ), a leak was discovered within the AY-102 } 02 \mathrm{D} \\
\text { sluice pit. It was determined that line SL-503 failed and a } 1 / 2 \text { in. by } 3 / 4 \\
\text { in. hole was discovered in the carbon steel section and appeared to } \\
\text { have developed from the inside and progressed through the pipe wall. } \\
\text { The stainless steel section of the pipe appeared to be in good condition. }\end{array}$ & $\begin{array}{l}\text { Occurrence Report RL-WHC- } \\
\text { TANKFARM-1994-0059, } \\
\text { During a Flush of Waste } \\
\text { Transfer Line SL-503, a Leak } \\
\text { within the } 241-A Y-102 \text { 02D } \\
\text { Sluice Pit was Discovered }\end{array}$ \\
\hline 09-18-1995 & $\begin{array}{l}\text { AY-102 supernatant reported to be out-of-specification with a } \\
\text { hydroxide concentration less than } 0.0025 \mathrm{M} \text {. }\end{array}$ & $\begin{array}{l}\text { Occurrence Report RL-WHC- } \\
\text { TANKFARM-1995-0105, Tank } \\
\text { 102-AY Chemistry Analysis } \\
\text { Reveals Low Hydroxide } \\
\text { Content, RPP-7795, Rev. } 9\end{array}$ \\
\hline $01-16-1996$ & Added $1,700 \mathrm{gal}$ of $50 \mathrm{wt} \% \mathrm{NaOH}$ to Tank AY- 102. & RPP-7795, Rev. 9 \\
\hline July 1996 & AY-102 chemistry reported to be out-of-specification. & RPP-7795, Rev. 9 \\
\hline $\begin{array}{l}\text { Aug. to } \\
\text { Oct. } 1996\end{array}$ & $\begin{array}{l}\text { Waste mixing }+5,500 \text { gal } 50 \mathrm{wt} \% \mathrm{NaOH}+4,200 \text { gal } 10-15 \mathrm{wt} \% \\
\mathrm{NaOH} \text {. }\end{array}$ & RPP-7795, Rev. 9 \\
\hline
\end{tabular}




\begin{tabular}{|c|c|c|}
\hline \multicolumn{3}{|c|}{ AY-102 Operational History } \\
\hline Date & Event & Reference \\
\hline March 1997 & $\begin{array}{l}\text { AY-102 annulus ventilation system comes back online after being off } \\
\text { for approximately } 6 \text { years. The AY- } 102 \text { annulus ventilation system } \\
\text { operates for } \sim 8 \text { months until Project W-320 required the system to be } \\
\text { shut down. }\end{array}$ & $\begin{array}{l}\text { RPP-7695, Double-Shell Tank } \\
\text { Annulus Ventilation } \\
\text { Engineering Study }\end{array}$ \\
\hline 09-08-1997 & $\begin{array}{l}\text { Misrouting to Tank AY-102 as a result of a leaking valve from AY- } \\
101 .\end{array}$ & $\begin{array}{l}\text { Occurrence Report RL-PHMC- } \\
\text { TANKFARM-1997-0073, Leak } \\
\text { through of a Newly Installed } \\
\text { Process Valve }\end{array}$ \\
\hline Sept. 1997 & $\begin{array}{l}\text { Addition of approximately } 10 \mathrm{kgal} \text { of caustic deficient waste from AY- } \\
101 .\end{array}$ & $\begin{array}{l}\text { TWINS, Tank Transfers (Pre- } \\
\text { 2001) }\end{array}$ \\
\hline Jan. 1998 & $\begin{array}{l}\text { Sludge interstitial liquid of AY-102 was less than the detection limit } \\
\text { for hydroxide. }\end{array}$ & $\begin{array}{l}\text { Interoffice memo } 7 \mathrm{KNO0-00-} \\
\text { TCO-039 }\end{array}$ \\
\hline $\begin{array}{c}\text { June to July } \\
1998\end{array}$ & $\begin{array}{l}\text { Addition of } 21,650 \text { gal of } 50 \mathrm{wt} . \% \mathrm{NaOH} \text { with subsequent mixing } \\
\text { with air lift circulators. }\end{array}$ & $\begin{array}{l}\text { Interoffice memo } 7 \mathrm{KNO0-00-} \\
\text { TCO-039 }\end{array}$ \\
\hline July 1998 & $\begin{array}{l}389 \text { kgal of dilute non-complexed waste was transferred out of Tank } \\
\text { AY-102 to Tank AW-102. }\end{array}$ & $\begin{array}{l}\text { TWINS, Tank Transfers (Pre- } \\
\text { 2001) }\end{array}$ \\
\hline $\begin{array}{l}\text { Nov. } 1998 \\
\text { to Oct. } \\
1999\end{array}$ & $\begin{array}{l}97 \% \text { of the high-heat sludge from tank C-106 was sluiced to Tank AY- } \\
102 \text { using the supernatant in Tank AY-102 as the sluicing medium; } \\
187 \mathrm{kgal} \text { of waste from C-106. }\end{array}$ & $\begin{array}{l}\text { RPP-RPT-32137, Rev. 0, } \\
\text { Ultrasonic Inspection Results } \\
\text { for Double-Shell Tank 241-AY- } \\
102-\text { FY2007; } \\
\text { RPP-19919, Rev. 0, Campaign } \\
\text { Report for the Retrieval of } \\
\text { Waste Heel from Tank } 241 \text {-C- } \\
\text { 106 }\end{array}$ \\
\hline March 1999 & $\begin{array}{l}\text { Tank annulus swabs of primary wall and floor were taken with no } \\
\text { contamination detected. }\end{array}$ & $\begin{array}{l}\text { Occurrence Report RL-PHMC- } \\
\text { TANKFARM-1999-0024, AY- } \\
102 \text { CAM Anomalous Readings }\end{array}$ \\
\hline 1999 & $\begin{array}{l}\text { Annulus exhaust system modified by Project W-320 to support C-106 } \\
\text { sluicing. Rerouted all airflow through vent lines leading into AY-102 } \\
\text { refractory concrete. Annulus vacuum increased to } \sim 15 \text { in. }\end{array}$ & $\begin{array}{l}\text { RPP-RPT-25731, Rev. 27, } \\
\text { System Health Report for East } \\
\text { Base Operations AY/AZ Farm } \\
\text { Waste Tank Structures Mixing } \\
\text { and Monitoring System for the } \\
\text { Fourth Quarter CY } 2011 \text {; } \\
\text { Project W-320 for vent } \\
\text { upgrades. }\end{array}$ \\
\hline 1999 & $\begin{array}{l}\text { Level in AY-102 leak detection pit starts to increase after years of a } \\
\text { low, steady level. Increased to above OSD limit in September } 1998 \text {. } \\
\text { Coincident with increase of annulus negative and C-106 transfers. }\end{array}$ & PCSACS \\
\hline 06-04-1999 & $\begin{array}{l}\text { Initial UT inspection of AY-102 and data showed no reportable } \\
\text { indications. }\end{array}$ & $\begin{array}{l}\text { HNF-4818, Final Results of } \\
\text { Double-Shell Tank } 241-A Y-102 \\
\text { Ultrasonic Inspection }\end{array}$ \\
\hline July 1999 & $\begin{array}{l}\text { Added } 4.5 \mathrm{kgal} \text { of } 50 \mathrm{wt} . \% \mathrm{NaOH}-\text { predicted to be out of } \\
\text { specification. Prior depletion rate was approximately } 0.5 \mathrm{M} / \mathrm{yr} \text {. }\end{array}$ & $\begin{array}{l}\text { Interoffice memo 7KN00-00- } \\
\text { TCO-039 }\end{array}$ \\
\hline $12-13-1999$ & $\begin{array}{l}\text { During excavation for Project W-320, holes were found in original } \\
\text { annulus ventilation piping. }\end{array}$ & 7G410-JKE/MJR-007-005 \\
\hline Dec. 1999 & AY-102 chemistry reported to be out-of-specification. & RPP-7795, Rev. 9 \\
\hline June 2000 & $\begin{array}{l}\text { Interstitial liquid in sludge layer of AY-102 below administrative } \\
\text { control (AC) } 5.16 \text { lower limit for both hydroxide and nitrite. }\end{array}$ & $\begin{array}{l}\text { CH2M-0303535, R21, Contract } \\
\text { Number DE-AC27-99RL14047- } \\
\text { Revised Tank 241-AY-102 } \\
\text { Recovery Plan to Restore } \\
\text { Chemistry Control; } \\
\text { Tank 241-AY-102 Recovery } \\
\text { Plan, Rev. } 5 \\
\end{array}$ \\
\hline
\end{tabular}




\begin{tabular}{|c|c|c|}
\hline \multicolumn{3}{|c|}{ AY-102 Operational History } \\
\hline Date & Event & Reference \\
\hline $10-20-2000$ & $\begin{array}{l}\text { AY-102 calculated hydroxide (based on } \mathrm{pH} \text { results) reported to be out- } \\
\text { of-specification. Nitrite concentrations in sludge were below the } \\
\text { detectable limit. }\end{array}$ & $\begin{array}{l}\text { Occurrence Report RP-CHG- } \\
\text { TANKFARM-2000-0073, } \\
\text { Calculated Hydroxide and } \\
\text { Nitrite Readings are below } \\
\text { Specification Limits of TSR } \\
\text { Administrative Control } 5.15 \\
\text { Limits }\end{array}$ \\
\hline $1999-2003$ & AY-102 leak detection pit hovers around "historical" level of 39 in. & PCSACS \\
\hline Feb. 2001 & Added $72 \mathrm{kgal}$ of $25-\mathrm{wt} \% \mathrm{NaOH}$ for corrosion control. & $\begin{array}{l}\text { RPP-RPT-34311, Double-Shell } \\
\text { Tank Integrity Inspection } \\
\text { Report for 241-AY Tank Farm }\end{array}$ \\
\hline March 2001 & $\begin{array}{l}\text { Interstitial liquid from the sludge layer of AY- } 102 \text { was below the AC } \\
5.16 \text { limit for both nitrite and hydroxide. } \\
\text { Established the TSR Corrosion Mitigation Control. }\end{array}$ & $\begin{array}{l}\text { Occurrence Report RP-CHG- } \\
\text { TANKFARM-2003-0033; } \\
\text { Recovery Plan No. TFRP-03- } \\
\text { 02; Sample results, Letter FH- } \\
0103293\end{array}$ \\
\hline 04-19-2001 & $\begin{array}{l}\text { AY-102 sludge chemistry identified as out-of-specification for } \\
\text { chemistry control for nitrite concentration. }\end{array}$ & $\begin{array}{l}\text { Occurrence Report RP-CHG- } \\
\text { TANKFARM-2000-0073, } \\
\text { Calculated Hydroxide and } \\
\text { Nitrite Readings are below } \\
\text { Specification Limits of TSR } \\
\text { Administrative Control } 5.15 \\
\text { Limits }\end{array}$ \\
\hline $11-30-2001$ & Added $62 \mathrm{kgal}$ of $40-\mathrm{wt} \% \mathrm{NaNO}_{2}$ for corrosion control. & RPP-RPT-34311 \\
\hline $12-06-2001$ & $\begin{array}{l}\text { Corrosion observed on AY-102 primary tank during video inspection } \\
\text { of the annulus section attributed to water intrusion from external } \\
\text { sources, coupled with shutdown of the annulus ventilation system for } \\
\text { an extended period. }\end{array}$ & $\begin{array}{l}\text { Occurrence Report RP-CHG- } \\
\text { TANKFARM-2001-0106, } \\
\text { Corrosion Observed in Double- } \\
\text { Shell Tank 241-AY-102 during } \\
\text { Video Inspection of the Annulus } \\
\text { Section }\end{array}$ \\
\hline 06-12-2002 & $\begin{array}{l}\text { Failure to support a Defense Nuclear Facilities Safety Board (DNFSB) } \\
\text { staff request to review the reasoning for considering AY-102 to be a } \\
\text { unique event in nitrite depletion. }\end{array}$ & $\begin{array}{l}\text { PER-2002-3409, Low Nitrite } \\
\text { Cause Not Evaluated }\end{array}$ \\
\hline July 2002 & $\begin{array}{l}\text { AY-102 began receiving dilute non-complexed condensate transfers } \\
\text { from catch tank } 241 \text {-AZ-151 (Periodic condensate additions starting } \\
\text { July } 2002 \text { until October } 2005 \text { ). }\end{array}$ & $\begin{array}{l}\text { Letter Report CH2M-0303535, } \\
\text { R21, Recovery Plan No. TFRP- } \\
\text { 03-02 }\end{array}$ \\
\hline Sept. 2002 & $\begin{array}{l}\text { Electrochemical corrosion testing out-of-specification, AY-102 sludge } \\
\text { results in little to no corrosion. }\end{array}$ & $\begin{array}{l}\text { RPP-12077, Electrochemical } \\
\text { Corrosion Study for tank } 241 \text { - } \\
\text { AY-102 Sludge }\end{array}$ \\
\hline $10-17-2002$ & $\begin{array}{l}\text { The condensate added to AY- } 102 \text { does not appear to be mixing with } \\
\text { the supernatant which could result in the surface layer of the waste not } \\
\text { being in compliance with the AC } 5.15 \text { Chemistry Control Limits. It } \\
\text { was recommended that samples should be taken. }\end{array}$ & $\begin{array}{l}\text { PER-2002-5680, Potential } \\
\text { Mixing of Condensate not } \\
\text { Occurring Causing AC } 5.15 \\
\text { Compliance Question }\end{array}$ \\
\hline Nov. 2002 & $\begin{array}{l}\text { Grab samples were taken from AY-102. Sample results showed the } \\
\text { tank waste was in chemistry limits and reasonably well-mixed just four } \\
\text { days after condensate addition. }\end{array}$ & PER-2002-5680 \\
\hline Feb. 2003 & $\begin{array}{l}\text { Corrosion product sampled from annulus side of primary tank and } \\
\text { found no radioactivity. }\end{array}$ & $\begin{array}{l}\text { RPP-15758, Analysis of } \\
\text { Corrosion Product Retrieved } \\
\text { From The Primary Tank Wall } \\
\text { in the Annulus of Tank } 241-A Y- \\
102\end{array}$ \\
\hline 2003 & Unknown drop in level in AY-102 leak detection pit. & $\begin{array}{l}\text { PER-2003-1048, AY801-WSTA- } \\
\text { WFI-122 Level Going Down }\end{array}$ \\
\hline
\end{tabular}




\begin{tabular}{|c|c|c|}
\hline \multicolumn{3}{|c|}{ AY-102 Operational History } \\
\hline Date & Event & Reference \\
\hline April 2003 & $\begin{array}{l}\text { Received a transfer of } 29.2 \mathrm{kgal} \text { from Tank C-106 retrieval decant } \\
\text { operation (18 kgal residual supernatant and } 11 \mathrm{kgal} \text { flush water). } \\
\text { AY-102 sludge samples were out-of-specification for hydroxide and } \\
\text { nitrite concentrations. }\end{array}$ & $\begin{array}{l}\text { Letter Report CH2M-0303535 } \\
\text { R21; Occurrence Report RP- } \\
\text { CHG-TANKFARM-2003- } \\
\text { 0033, Sample Results from 241- } \\
\text { AY-102 Below Required } \\
\text { Administrative Control (AC) } \\
\text { 5.15 Limits; } \\
\text { RPP-19919, Rev. 0; TWINS; } \\
\text { PER-2003-2580, AY-102 Core } \\
\text { Sample pH Results Non- } \\
\text { Reportable }\end{array}$ \\
\hline Nov. 2003 & $\begin{array}{l}\text { Bottom region of sludge layer is still outside the AC } 5.16 \text { limit for } \\
\text { nitrite and hydroxide. Dynamic mixing model indicates } \mathrm{OH}^{-} \\
\text {concentration will be within limits between Feb } 2004 \text { and July } 2005 \text {. } \\
\text { A PER was written as a result of an immiscible liquid phase found in } \\
\text { the AY-102 sludge samples. } \\
\text { Core sample results indicated layering of the supernatant with a large } \\
\text { concentration gradient. This indicates mixing is not occurring between } \\
\text { the AZ-151 condensate transferred into AY-102 with the rest of the } \\
\text { supernatant forming a "cold cap." }\end{array}$ & $\begin{array}{l}\text { Letter Report CH2M-0303535, } \\
\text { R21, Recovery Plan No. TFRP- } \\
\text { 03-02; PER-2004-1247, } \\
\text { Continued Condensate } \\
\text { Transfers into AY-102 May } \\
\text { Cause Supernate to Fall } \\
\text { Outside Corrosion Limits; } \\
\text { PER-2003-5225, An Immiscible } \\
\text { Liquid Phase was Found in } \\
\text { Tank 241-AY-102 Sludge } \\
\text { Samples Being Analyzed at the } \\
\text { 222-S Laboratory }\end{array}$ \\
\hline 2004 & $\begin{array}{l}\text { ENRAFs installed in AY/AZ annulus for leak detection replacing } \\
\text { conductivity probe. }\end{array}$ & $\begin{array}{l}\text { ECN-720173 R2,241-AY-102 } \\
\text { Annulus Leak Detection using } \\
\text { Three ENRAF Level Gauges }\end{array}$ \\
\hline $04-15-2005$ & $\begin{array}{l}\text { In the process of removing a drill string from Riser } 58 \text {, the lower half } \\
\text { of the drill string (approximately } 33 \mathrm{ft} \text { long and weighing } 125 \mathrm{lbs} \text { ) fell } \\
\text { into Tank AY-102 (approximately } 27 \mathrm{ft} \text { ) after it disconnected from the } \\
\text { upper section. Dropped portion of the drill string has remained upright } \\
\text { through a waste transfer to } 80 \text { in. with } 60 \text { in. of solids as identified in } \\
\text { the } 2012 \text { in-tank visual inspection. }\end{array}$ & $\begin{array}{l}\text { PER-2005-1582, Lower half of } \\
\text { drill string fell into AY-102 } \\
\text { when it was disconnected from } \\
\text { the upper section; } \\
\text { RPP-RPT-25778, Analysis for } \\
\text { Continuing Core Sampling of } \\
\text { Tank 241-AY-102, Riser 058 }\end{array}$ \\
\hline $\begin{array}{l}\text { April/May } \\
2005\end{array}$ & $\begin{array}{l}\text { Supernatant sample data indicated the waste surface of AY-102 was } \\
\text { nearing the AC 5.16 lower limit of } 0.01 \mathrm{M} \text { as a result of } 241 \text {-AZ-151 } \\
\text { condensate additions since July } 2002 \text {. Interstitial liquid data was } \\
\text { invalid for this sampling event. } \\
\text { From the surface layer and thermocouple readings, it was evident that a } \\
\text { "cold cap" formed from condensate additions not mixing with } \\
\text { supernatant below it. }\end{array}$ & $\begin{array}{l}\text { Letter Report CH2M-0303535, } \\
\text { R21, Recovery Plan No. TFRP- } \\
\text { 03-02; } \\
\text { Interoffice Memo 7G300-03- } \\
\text { MAK-004, Effect of Tank 241- } \\
\text { AZ-151 Condensate Additions } \\
\text { on Tank } 241 \text {-AY-102 Chemistry } \\
\text { Control, February } 18,2003\end{array}$ \\
\hline May 2005 & $\begin{array}{l}\text { Added } 10 \mathrm{kgal} \text { of } 4-\mathrm{wt} \% \mathrm{NaOH} \text { for corrosion control to mitigate the } \\
\text { "cold cap." }\end{array}$ & $\begin{array}{l}\text { Letter Report CH2M-0303535, } \\
\text { R21 }\end{array}$ \\
\hline July 2005 & $\begin{array}{l}\text { Concerns related to the } \mathrm{pH} \text { measurement from the May dilute } \mathrm{NaOH} \\
\text { addition led to a } 9,900 \text { gal second addition of } 1 \mathrm{MNaOH} \text { in mid-July, } \\
\text { prior to the sampling event. }\end{array}$ & $\begin{array}{l}\text { Letter Report CH2M-0303535, } \\
\text { R21; Recovery Plan No. TFRP- } \\
03-02\end{array}$ \\
\hline
\end{tabular}




\begin{tabular}{|c|c|c|}
\hline \multicolumn{3}{|c|}{ AY-102 Operational History } \\
\hline Date & Event & Reference \\
\hline Aug. 2005 & $\begin{array}{l}\text { Interstitial liquid in lower portion of sludge of AY-102 remains below } \\
\text { the AC } 5.16 \text { chemistry limits for nitrite and hydroxide, however } \\
\text { concentrations are slowly increasing due to natural mixing. AY- } 102 \\
\text { supernatant was an order of magnitude above the AC } 5.16 \text { chemistry } \\
\text { limit. } \\
\text { The Riser } 29 \text { temperature profile indicates the "cold cap" is still } \\
\text { present. }\end{array}$ & $\begin{array}{l}\text { Letter Report CH2M-0303535, } \\
\text { R21; PER-2005-3074, AY-102 } \\
\text { Preliminary Results Below } \\
\text { (AC) 5.16 Chemistry Control } \\
\text { Limit; PER-2005-3187, AY-102 } \\
\text { Preliminary Results Below } \\
\text { (AC) 5.16 Chemistry Control } \\
\text { Limit }\end{array}$ \\
\hline $09-27-2005$ & $\begin{array}{l}\text { Authorization to combine hot commission low activity waste (LAW) } \\
\text { (AP-101) with HLW (AY-102/C-106). }\end{array}$ & $\begin{array}{l}\text { Letter DOE-ORP: 05-TPD- } \\
082, \text { Contract Number DE- } \\
\text { AC27-99RL14047-Approval to } \\
\text { Consolidate Waste Treatment } \\
\text { and Immobilization Plant } \\
\text { (WTP) Hot Commissioning } \\
\text { Feeds Stored in Tanks 241-AP- } \\
101 \text { and } 241-\text { AY-102 }\end{array}$ \\
\hline Oct. 2006 & $\begin{array}{l}\text { Concern of Stress Corrosion Cracking in lower knuckle of AY-102 due } \\
\text { to out-of-specification chemistry. }\end{array}$ & $\begin{array}{l}\text { PER-2006-1799, UT } \\
\text { Examination of the AY-102 } \\
\text { Knuckle Region (for cracking } \\
\text { and pitting) is Vital to Assure } \\
\text { the Safe Operation of the Tank }\end{array}$ \\
\hline Dec. 2006 & 715 kgal of AY-102 supernatant pumped out to AN-106 and AW-102. & $\begin{array}{l}\text { Letter Report CH2M-0502844 } \\
\text { R5, Contract Number DE- } \\
\text { AC27-99RL14047-Request for } \\
\text { Approval of Revised Tank } 241 \text { - } \\
\text { AY-102 Recovery Plan; TWINS }\end{array}$ \\
\hline Dec. 2006 & $\begin{array}{l}\text { AY Farm visual inspections capture signs of ongoing water intrusion in } \\
\text { the AY annuluses. Follow-up investigations include identifying } \\
\text { possible water sources and pathways. Report issued July } 2007 \text {. }\end{array}$ & $\begin{array}{l}\text { 7G410-JKE/MJR-007-005; } \\
\text { RPP-RPT-34311 }\end{array}$ \\
\hline 2006 & $\begin{array}{l}\text { Tested corrosion potential of AY-102 of out-of-specification of sludge } \\
\text { interstitial liquid using waste simulants. }\end{array}$ & $\begin{array}{l}\text { RPP-RPT-31932, Interim } \\
\text { Report Hanford Tanks AY-102 } \\
\text { and AP-102: Effect of } \\
\text { Chemistry and Other Variables } \\
\text { on Corrosion and Stress } \\
\text { Corrosion Cracking }\end{array}$ \\
\hline Jan. 2007 & $\begin{array}{l}\text { Addition of } 782 \mathrm{kgal} \text { of AP-101 supernatant as authorized by Letter } \\
05-\mathrm{TPD}-082 \text { on } 09-27-2005 \text {. This was the last transfer for AY-102 to } \\
\text { present. The calculated supernatant concentration after AP-101 } \\
\text { transfer was } 2.19 \mathrm{M} \mathrm{OH}^{-}, 0.87 \mathrm{M} \text { nitrite, and } 1.73 \mathrm{M} \text { nitrate. }\end{array}$ & $\begin{array}{l}\text { Letter Report CH2M-0502844 } \\
\text { R5; TWINS; SVF-1342, AY102 } \\
\text { FY07 Q3 Supernatant PK } \\
\text { Vector }\end{array}$ \\
\hline March 2007 & $\begin{array}{l}\text { Tanks AY-101 and AY-102 Annulus Corrosion Recovery Plan, Rev. 0, } \\
\text { submitted to the U.S. Department of Energy. }\end{array}$ & $\begin{array}{l}\text { CH2M-0700558, Contract } \\
\text { Number DE-AC27-99RL14047- } \\
\text { Request for Approval of Tanks } \\
241-A Y-101 \text { and } 241-A Y-102 \\
\text { Annulus Corrosion Recovery } \\
\text { Plan }\end{array}$ \\
\hline
\end{tabular}




\begin{tabular}{|c|c|c|}
\hline \multicolumn{3}{|c|}{ AY-102 Operational History } \\
\hline Date & Event & Reference \\
\hline May 2007 & $\begin{array}{l}\text { Moisture intrusion analysis indicates that natural precipitation is the } \\
\text { likely source of water intruding into annulus of tanks AY-101 and AY- } \\
\text { 102. Tanks AY-101 and AY-102 settlement surveys completed to } \\
\text { check for dome deflection. }\end{array}$ & $\begin{array}{l}\text { RPP-RPT-37440, Rev. 0; } \\
\text { RPP-ASMT-34090, Rev. 0, } \\
\text { Hanford Double-Shell Tank } \\
\text { Thermal and Seismic Project- } \\
\text { Effects of Dome Rebar and } \\
\text { Concrete Degradation; } \\
\text { RPP-RPT-33273, Rev. 0, 241- } \\
\text { AY-101/AY-102 Annulus } \\
\text { Moisture Intrusion Analysis }\end{array}$ \\
\hline Aug. 2007 & $\begin{array}{l}\text { Analysis of neutron probe data indicated no buildup of water in the soil } \\
\text { above the AY tanks indicative of preferential or collection areas. }\end{array}$ & $\begin{array}{l}\text { 7G410-JKE/MJR-007-005; } \\
\text { CH2M-0700558 R4 }\end{array}$ \\
\hline 08-14-2007 & AY-102 leak detection pit pumped out. & $\begin{array}{l}\text { CH2M-PER-2007-1975, The } \\
\text { AY-102 Leak Detection Pit has } \\
\text { been Increasing }\end{array}$ \\
\hline Sept. 2007 & $\begin{array}{l}\text { Closed check valves downstream of valve V-141 to isolate raw water } \\
\text { supply to } 241-\mathrm{AX},-\mathrm{AY} \text {, and }-\mathrm{AZ} \text { Farms. }\end{array}$ & RPP-RPT-37440, Rev. 0 \\
\hline $09-28-2007$ & Leak detection pit exceeds OSD of 20 in. & CH2M-PER-2007-1975 \\
\hline $10-25-2007$ & $\begin{array}{l}\text { The Tanks AY-101 and AY-102 Annulus Corrosion Recovery Plan } \\
\text { included a requirement to complete collection of the AY-101 annulus } \\
\text { psychrometric data and make recommendations for future data } \\
\text { collected needed to identify the ingress of water to the annulus. It was } \\
\text { concluded that psychrometric data are not a reliable detection method } \\
\text { for the onset of water ingress. }\end{array}$ & $\begin{array}{l}\text { CH2M-0700558 R5; } \\
\text { RPP-35008, Rev. 0, AC-5.16 } \\
\text { Engineering Evaluation } \\
\text { Methodology and Sampling } \\
\text { Strategy }\end{array}$ \\
\hline $10-26-2007$ & $\begin{array}{l}\text { Failed attempt to pump out the leak detection pit due to contamination } \\
\text { detected in the transfer tubing. }\end{array}$ & CH2M-PER-2007-1975 \\
\hline $10-30-2007$ & $\begin{array}{l}\text { AY-102 leak detection pit level increasing by } \sim 1.6 \text { gal/day since } 08 \text { - } \\
14-2007 \text {. }\end{array}$ & CH2M-PER-2007-1975 \\
\hline $11-08-2007$ & $\begin{array}{l}\text { The Tanks AY-101 and AY-102 Annulus Corrosion Recovery Plan } \\
\text { included assessing the technical feasibility of performing a Fluorescein } \\
\text { dye tracer test for potential leakage. It was determined the dye tracer } \\
\text { test was not a feasible water ingress pathway detection method. }\end{array}$ & CH2M-0700558 R6 \\
\hline $12-21-2007$ & $\begin{array}{l}\text { Safety Evaluation Report replacing the annulus psychrometric data } \\
\text { with periodic annulus video inspections as a result of the closure of the } \\
\text { Tanks AY-101 and AY-102 Annulus Corrosion Recovery Plan. }\end{array}$ & DOE-ORP: 07-TED-055 \\
\hline 2007 & $\begin{array}{l}\text { Expert panel reviewed and concurred of AY-102 sludge interstitial } \\
\text { liquid corrosion potential and concluded low propensity for corrosion. } \\
\text { Recommended installation of a corrosion probe. }\end{array}$ & $\begin{array}{l}\text { RPP-ASMT-35619, Expert } \\
\text { Panel Oversight Committee } \\
\text { Assessment of FY2007 } \\
\text { Corrosion \& Stress Corrosion } \\
\text { Cracking Simulant Testing } \\
\text { Program \& the Impact on DST } \\
241-A Y-102\end{array}$ \\
\hline 2007 & $\begin{array}{l}\text { UT inspection of AY-102 and data indicated } 5 \text { areas of reportable wall } \\
\text { thinning, multiple pit-like indications, but no cracking in any of the } \\
\text { areas examined. Observed pit depth remained unchanged between } \\
1999 \text { and } 2007 \text {. After UT inspection, no contamination of the } \\
\text { equipment was observed. }\end{array}$ & $\begin{array}{l}\text { RPP-RPT-32137, Rev. 0, } \\
\text { Ultrasonic Inspection Results } \\
\text { for Double-Shell Tank } 241-A Y \text { - } \\
\text { 102- FY2007 }\end{array}$ \\
\hline $12-05-2007$ & $\begin{array}{l}\text { Samples collected from AY-102 leak detection pit resulting in a } \mathrm{pH} \text { of } \\
7.92 \text {, clear colorless liquid, and low but detectable uranium, }{ }^{137} \mathrm{Cs},{ }^{90} \mathrm{Sr} \text {. } \\
\text { Low but detectable sulfate, chloride, and nitrate. Confirmed that waste } \\
\text { was not leaking from the primary tank. }\end{array}$ & $\begin{array}{l}\text { RPP-RPT-36150, Final Report } \\
\text { for the } 241-A Y-102 \text { A Leak } \\
\text { Detection Pit Grab Samples in } \\
\text { Support of the Waste } \\
\text { Compatibility Program; } \\
\text { CH2M-PER-2007-1975 }\end{array}$ \\
\hline
\end{tabular}




\begin{tabular}{|c|c|c|}
\hline \multicolumn{3}{|c|}{ AY-102 Operational History } \\
\hline Date & Event & Reference \\
\hline Jan. 2008 & $\begin{array}{l}\text { Raw water header cut and capped west of AN Farm to isolate all raw } \\
\text { water supplies to } 241-\mathrm{AX},-\mathrm{AY} \text {, and }-\mathrm{AZ} \text { Farm. }\end{array}$ & $\begin{array}{l}\text { RPP-RPT-37440, Rev. 1, Tank } \\
\text { 241-AY-101 Interim Surface } \\
\text { Barrier Feasibility Study }\end{array}$ \\
\hline $02-25-2008$ & $\begin{array}{l}\text { Leak detection pit pumped out and the level in the pit remained } \\
\text { constant. }\end{array}$ & CH2M-PER-2007-1975 \\
\hline $05-21-2008$ & Leak detection pit pumped out. & PCSACS \\
\hline July 2008 & Leak detection pit exceeds OSD level. & PCSACS \\
\hline 03-26-2009 & $\begin{array}{l}\text { A } 12 \text {-in. spool piece was installed on Riser } 73 \text { after it was found that } \\
\text { the probe came in contact with the bottom of the tank } 4-6 \text { times as the } \\
\text { probe was being installed. A recent dimensional analysis indicated the } \\
\text { riser and bottom of the tank elevations were incorrect resulting in an } \\
\text { approximate } 8 \text {-in. discrepancy. However, there was limited potential } \\
\text { for damage due to controlled installation speed. }\end{array}$ & RPP-ASMT-53793 \\
\hline July 2009 & $\begin{array}{l}\text { The new interstitial liquid chem istry limits for } \mathrm{AY}-102 \text { were } \\
\text { implem ented into OSD-T-151-00007, Table } 1.5 .1-2 \text {. The limits for } \\
\text { AY-102 interstitial liquid require a } \mathrm{pH} \geq 10 \text { with a temperature of } \leq \\
122^{\circ} \mathrm{F} \text {. }\end{array}$ & OSD-T-151-00007, Rev. 2 \\
\hline 08-14-2009 & $\begin{array}{l}\text { Closure of Technical Safety Requirement Recovery Plan for water } \\
\text { intrusion into the annuli of Tanks AY-101 and AY-102. Concluded } \\
\text { water no longer entering annuli of Tanks AY-101 and AY-102. }\end{array}$ & $\begin{array}{l}\text { WRPS-0901335, Contract } \\
\text { Number DE-AC27-08RV14800- } \\
\text { Washington River Protection } \\
\text { Solutions LLC Closure of } \\
\text { Technical Safety Requirement } \\
\text { Recovery Plan for Water } \\
\text { Intrusion into the Annuli of } \\
\text { Tanks } 241-A Y-101 \text { and } 241-A Y- \\
102\end{array}$ \\
\hline 09-29-2009 & $\begin{array}{l}\text { Closure of Operating Specification document Recovery Plan for Tank } \\
\text { AY-102. }\end{array}$ & WRPS-0901379 \\
\hline $2010-2012$ & $\begin{array}{l}\text { Manual readings for the AY-102 leak detection pit marked as suspect } \\
\text { should be } 13-15 \text { in. higher due to high annulus vacuum. }\end{array}$ & PCSACS \\
\hline $12-29-2011$ & $\begin{array}{l}\text { Insulating concrete exceeds } 161^{\circ} \mathrm{F} \text { (TE- } 005, \mathrm{TE}-006,21 \text {-ft from the } \\
\text { center of the tank). }\end{array}$ & $\begin{array}{l}\text { RPP-RPT-25731, Rev. } 27, \\
\text { System Health Report for East } \\
\text { Base Operations AY/AZ Farm } \\
\text { Waste Tank Structures Mixing } \\
\text { and Monitoring System for the } \\
\text { Fourth Quarter CY } 2011\end{array}$ \\
\hline 01-02-2012 & $\begin{array}{l}\text { A sludge temp of } 165^{\circ} \mathrm{F} \text { is recorded in AY- } 102 \text { (TE- } 073 / \text { Riser } 72 \mathrm{TIC} \\
\text { 1), exceeds DST Time to Lower Flammability Limit of } 161^{\circ} \mathrm{F} \text {. }\end{array}$ & RPP-RPT-25731, Rev. 27 \\
\hline 05-01-2012 & $\begin{array}{l}\text { The AY-102 supernatant consists of } 702 \mathrm{kgal} \text {, the sludge solid is } 119 \\
\mathrm{kgal} \text {, and the interstitial is } 32 \mathrm{kgal} \text {. }\end{array}$ & TWINS \\
\hline 09-05-2012 & $\begin{array}{l}\text { Sampled the AY-102 leak detection pit and sent samples to } 222-\mathrm{S} \\
\text { Laboratory. Sample indicated very low levels of }{ }^{137} \mathrm{Cs} \text { and }{ }^{90} \mathrm{Sr} \text { with a } \\
\text { pH between } 6.6 \text { and } 6.9 \text {, all of which indicated the liquid was not tank } \\
\text { waste. }\end{array}$ & $\begin{array}{l}\text { RPP-RPT-53805, Final Report } \\
\text { for } 241 \text {-AY-102A Leak } \\
\text { Detection Pit Grab Samples in } \\
\text { Support of Waste Compatibility }\end{array}$ \\
\hline 09-10-2012 & $\begin{array}{l}\text { Survey swabs of the material on the annulus floor underneath Riser } 90 \\
\text { were retrieved. Contamination reading of } 800,000 \mathrm{dpm} \text { was reported. }\end{array}$ & RPP-ASMT-53793 \\
\hline 09-19-2012 & $\begin{array}{l}\text { Completed pumping of the AY-102 leak detection pit to Tank AY-101 } \\
\text { central pump pit. Level at AY-102 leak detection pit following } \\
\text { pumping was approximately } 1 \text {-in. }\end{array}$ & $\begin{array}{l}\text { Personal communication J. K. } \\
\text { Engeman }\end{array}$ \\
\hline
\end{tabular}




\begin{tabular}{|c|c|c|}
\hline \multicolumn{3}{|c|}{ AY-102 Operational History } \\
\hline Date & Event & Reference \\
\hline 09-24-2012 & $\begin{array}{l}\text { At } 0900 \text {, AY-102 leak detection pit sump level reading was zero (Riser } \\
\text { closed and annulus pressure }-12 \text { in.). Camera confirmed that no } \\
\text { bubbles were being forced into the sump liquid. } \\
\text { At } 1330 \text {, the sump level reading was } 1.65 \text { in. Camera confirmed that } \\
\text { air was being forced into the water below the dip tube. } \\
\text { At } 1350 \text {, the level was at } 1.84 \text { in. (Riser open). Top hat was not sealed } \\
\text { during these inspections. }\end{array}$ & $\begin{array}{l}\text { Personal communication J. K. } \\
\text { Engeman }\end{array}$ \\
\hline 09-25-2012 & $\begin{array}{l}\text { The AY-102 leak detection pit sump level was reading zero at } 1400 \mathrm{hrs} \\
\text { (Riser closed and annulus pressure }-12 \text { in). The level had apparently } \\
\text { diminished substantially from the previous day ( } 1 \text { in. }=7.5 \text { gal). }\end{array}$ & $\begin{array}{l}\text { Personal communication J. K. } \\
\text { Engeman }\end{array}$ \\
\hline 09-26-2012 & $\begin{array}{l}\text { Took a sample }(\sim 1 \mathrm{Tbl}) \text { of the material (beneath Riser } 83 \text { ) through } \\
\text { Riser } 91 \text {. Dose rate readings of the sample were } 45 \mathrm{mr} / \mathrm{hr} \text {. The sample } \\
\text { was sent to the lab on } 09-27-2012 \text {. A video under Riser } 83 \text { was taken } \\
\text { to support the sampling effort. Sample results indicate principal } \\
\text { constituents included: } \mathrm{NaNO}_{3}, \mathrm{Na}_{2} \mathrm{CO}_{3}, \mathrm{NaNO}_{2}, \mathrm{KNO}_{3}, \mathrm{Cs}-137 \text { ( } 90.9 \\
\mu \mathrm{Ci} / \mathrm{g}) \text {, and } \mathrm{Sr}-90(0.120 \mu \mathrm{Ci} / \mathrm{g}) \text {. } \\
\\
\text { The AY-102 leak detection pit sump level was } 0.6 \mathrm{in} \text {. at } 0900 \mathrm{hrs} \\
\text { (Riser closed and annulus pressure }-3.5 \text { in.). At } 0930 \mathrm{hrs,} \mathrm{sump} \mathrm{level} \\
\text { was } 2.22 \text { in. (Riser open and annulus pressure }-3.5 \mathrm{in} \text {.). At } 0935 \mathrm{hrs} \text {, } \\
\text { sump level was } 0.62 \text { in. (Riser closed and annulus pressure }-3.5 \mathrm{in} \text {.). }\end{array}$ & $\begin{array}{l}\text { RPP-ASMT-53793; } \\
\text { Personal communication J. K. } \\
\text { Engeman }\end{array}$ \\
\hline $\begin{array}{l}10-01-2012 \\
\text { to } \\
10-05-2012\end{array}$ & $\begin{array}{l}\text { Took liquid level reading of AY-102 leak detection pit each day. Last } \\
\text { level reading on 10-05-2012. }\end{array}$ & $\begin{array}{l}\text { Personal communication J. K. } \\
\text { Engeman }\end{array}$ \\
\hline 10-10-2012 & $\begin{array}{l}\text { Sampling event at Riser } 90 \text { during day and swing shift. Due to } \\
\text { difficulties, no sample was retrieved. }\end{array}$ & $\begin{array}{l}\text { Personal communication J. K. } \\
\text { Engeman }\end{array}$ \\
\hline $10-15-2012$ & Sampling event at Riser 90 during dayshift. & RPP-ASMT-53793 \\
\hline $10-17-2012$ & Sampling event at Riser 90 during dayshift. & RPP-ASMT-53793 \\
\hline $\begin{array}{ll}\text { Note: } & \text { AC } \\
& \text { OSD } \\
& \text { PCS }\end{array}$ & 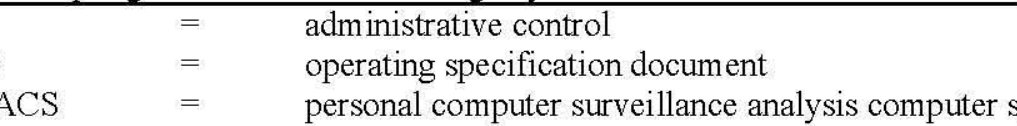 & \\
\hline
\end{tabular}


Rev. 0

8.4 Tank AY-102 Annulus Visual Inspection Time Line 


\begin{tabular}{|c|c|c|}
\hline \multicolumn{3}{|c|}{ AY-102 Annulus Visual Inspection History } \\
\hline Date & Event & Reference \\
\hline 1992 & $\begin{array}{l}\text { Limited video inspections of AY-102 annuluses completed which did } \\
\text { not indicate any leakage, degradation, or defect that would cause any } \\
\text { of the tanks or the insulating concrete to be unfit for service. }\end{array}$ & $\begin{array}{l}\text { WHC-SD-WM-RPT-078, } \\
\text { Visual Examination Report for } \\
\text { Tank Annuli at the 241-AY and } \\
\text { AZ Tank Farm }\end{array}$ \\
\hline $\begin{array}{l}\text { July } 12,13 \text {, } \\
\quad 19,2001\end{array}$ & $\begin{array}{l}\text { Video inspections of AY- } 102 \text { annuluses through Risers } 79,80,84 \text {, and } \\
\text { 86. Areas of corrosion were identified on the primary tank, with } \\
\text { multiple regions showing a large increase in corrosion product } \\
\text { compared to } 1992 \text { inspections. }\end{array}$ & $\begin{array}{l}\text { RPP-RPT-34311, Rev. } 0 \text {, } \\
\text { Double-Shell Tank Integrity } \\
\text { Inspection Report for } 241-A Y \\
\text { Tank Farm }\end{array}$ \\
\hline $09-5-2001$ & $\begin{array}{l}\text { In-tank visual inspection of AY-102 through Riser } 51 \text {. All visible } \\
\text { older in-tank piping and instrumentation appears to be lightly corroded, } \\
\text { with no significant cracking or pitting evident. }\end{array}$ & RPP-RPT-34311, Rev. 0 \\
\hline $02-12-2003$ & $\begin{array}{l}\text { Riser } 80 \text { visual inspection for surveillance of a corrosion product } \\
\text { sample collection. }\end{array}$ & $\begin{array}{l}\text { RPP-RPT-34311, Rev. 0; } \\
\text { Occurrence Report RP-CHG- } \\
\text { TANKFARM-2001-0106 }\end{array}$ \\
\hline $\begin{array}{l}\text { Oct. to Dec. } \\
2006\end{array}$ & $\begin{array}{l}\text { Video inspections of AY-102 annuluses through Risers } 77,79,80,82 \text {, } \\
84,86,88 \text {, and } 89 \text {. Corrosion product identified in } 2001 \text { on the } \\
\text { primary tank wall as seen from the annulus appears to have increased } \\
\text { over the course of the last } 5 \text { years. }\end{array}$ & RPP-RPT-34311, Rev. 0 \\
\hline Dec. 2006 & $\begin{array}{l}\text { In-tank visual inspection of AY-102 through Riser } 65 \text {. Signs of light } \\
\text { and moderate corrosion product accumulation on the tank dome. } \\
\text { Difficult to compare with } 2001 \text { in-tank inspection due to the poor } \\
\text { visibility in the } 2001 \text { inspection. }\end{array}$ & RPP-RPT-34311, Rev. 0 \\
\hline $07-26-2012$ & $\begin{array}{l}\text { In-tank visual inspection of AY- } 102 \text { through Riser } 51 \text {. Identified the } \\
\text { portion of the drill string that is visible above the tank waste surface. } \\
\text { The shaft is probably being held in place by } \sim 5 \mathrm{ft} \text { of solids on the } \\
\text { bottom of the tank. }\end{array}$ & $\begin{array}{l}\text { RPP-RPT-34311, Rev. 1, } \\
\text { Double-Shell Tank Integrity } \\
\text { Inspection Report for 241-AY } \\
\text { Tank Farm }\end{array}$ \\
\hline 08-01-2012 & $\begin{array}{l}\text { Video inspections of AY-102 annuluses through Risers } 87 \text { (white } \\
\text { material on annulus floor) and } 89 \text { (crystal-like material on upper } \\
\text { haunch). First indications of anomalies. }\end{array}$ & $\begin{array}{l}\text { PER-2012-1363; } \\
\text { RPP-RPT-34311, Rev. } 1\end{array}$ \\
\hline $08-05-2012$ & $\begin{array}{l}\text { Video inspections of AY-102 annulus through Riser } 77 \text { (mound on } \\
\text { annulus floor) which was the first indication at this location. No } \\
\text { anomalies noted during the visual inspection through Riser } 80 \text {. }\end{array}$ & $\begin{array}{l}\text { PER-2012-1363; } \\
\text { RPP-RPT-34311, Rev. } 1\end{array}$ \\
\hline $08-10-2012$ & $\begin{array}{l}\text { Video inspections of AY- } 102 \text { annulus through Riser } 90 \text { (Riser } 90 \\
\text { ENRAF) which provided a better view of the areas of interest, the } \\
\text { mound and the white deposits on the annulus floor. }\end{array}$ & TFC-WO-12-4563 \\
\hline 08-16-2012 & $\begin{array}{l}\text { Visual inspection of AY-102 annulus through Riser } 90 \text { indicated no } \\
\text { change in condition. }\end{array}$ & TFC-WO-12-4829 \\
\hline $08-20-2012$ & $\begin{array}{l}\text { Visual inspection of AY-102 annulus through Riser } 90 \text { indicated no } \\
\text { change in condition from } 08-10-2012 \text {. }\end{array}$ & TFC-WO-12-4829 \\
\hline $08-23-2012$ & $\begin{array}{l}\text { Visual inspection of AY-102 annulus through Riser } 90 \text { indicated no } \\
\text { change in condition from } 08-10-2012 \text {. }\end{array}$ & TFC-WO-12-4829 \\
\hline $08-27-2012$ & $\begin{array}{l}\text { Visual inspection of AY-102 annulus through Riser } 90 \text { indicated no } \\
\text { change in condition from } 08-10-2012 \text {. }\end{array}$ & TFC-WO-12-4829 \\
\hline $08-29-2012$ & $\begin{array}{l}\text { Visual inspection of AY-102 annulus through Riser } 83 \text {. First indicated } \\
\text { the area adjacent to the refractory retainer ring shows yellow and pink- } \\
\text { colored nodules and evaporated material on the annulus floor. }\end{array}$ & RPP-ASMT-53793 \\
\hline $08-30-2012$ & Visual inspection of AY-102 annulus through Riser 90 and Riser 87. & TFC-WO-12-4829 \\
\hline $09-04-2012$ & Visual inspection of AY-102 annulus through Riser 90. & TFC-WO-12-4829 \\
\hline 09-05-2012 & $\begin{array}{l}\text { Engineering determined no additional videos were required through } \\
\text { Riser } 90 \text {. This completes the twice per week video at Riser } 90 \text {. } \\
\text { Performed visual inspection of AY-102 annulus through Riser } 88 \text { and } \\
\text { Riser } 89 \text {. No anomalies identified in the Riser } 88 \text { inspection on the } \\
\text { primary tank wall or the annulus floor. }\end{array}$ & TFC-WO-12-4829 \\
\hline
\end{tabular}




\begin{tabular}{|c|c|c|}
\hline \multicolumn{3}{|c|}{ AY-102 Annulus Visual Inspection History } \\
\hline Date & $\begin{array}{c}\text { Event } \\
\end{array}$ & Reference \\
\hline 09-06-2012 & $\begin{array}{l}\text { Visual inspection of AY-102 annulus through Riser 91. No anomalies } \\
\text { were identified along the primary tank wall or the annulus floor. }\end{array}$ & RPP-ASMT-53793 \\
\hline 09-07-2012 & $\begin{array}{l}\text { Completed the } 100 \% \text { video inspection of the AY- } 102 \text { annulus. } \\
\text { Performed visual inspection through Riser } 90 \text {, Riser } 80 \text {, Riser } 79 \text {, and } \\
\text { Riser } 86 . \text { No additional anomalies identified. }\end{array}$ & RPP-ASMT-53793 \\
\hline 09-10-2012 & $\begin{array}{l}\text { Visual inspection of AY-102 annulus through Riser } 83 \text {. Will be } \\
\text { performed twice a week starting now. }\end{array}$ & RPP-ASMT-53793 \\
\hline 09-13-2012 & $\begin{array}{l}\text { Visual inspection of AY-102 annulus through Riser } 83 \text {. No change in } \\
\text { condition. }\end{array}$ & RPP-ASMT-53793 \\
\hline 09-17-2012 & $\begin{array}{l}\text { Visual inspection of AY-102 annulus through Riser 83. No change in } \\
\text { condition. }\end{array}$ & RPP-ASMT-53793 \\
\hline 09-24-2012 & $\begin{array}{l}\text { Visual inspection of AY-102 annulus through Riser 83. No change in } \\
\text { condition. }\end{array}$ & RPP-ASMT-53793 \\
\hline 09-26-2012 & $\begin{array}{l}\text { Visual inspection of AY-102 annulus through Riser } 83 \text { to support } \\
\text { sampling efforts. }\end{array}$ & RPP-ASMT-53793 \\
\hline $10-01-2012$ & $\begin{array}{l}\text { Visual inspection of AY-102 annulus through Riser } 83,5 \text { days after } \\
\text { sampling event. Liquid present on } 09-26-2012 \text { was beginning to return } \\
\text { to the state seen prior to the sampling. }\end{array}$ & RPP-ASMT-53793 \\
\hline $10-04-2012$ & $\begin{array}{l}\text { Visual inspection of AY-102 annulus through Riser } 83 \text {. No change in } \\
\text { condition. }\end{array}$ & RPP-ASMT-53793 \\
\hline $10-08-2012$ & $\begin{array}{l}\text { Visual inspection of AY-102 annulus through Riser } 83 \text {. No change in } \\
\text { condition since first Riser } 83 \text { inspection. }\end{array}$ & RPP-ASMT-53793 \\
\hline $10-18-2012$ & $\begin{array}{l}\text { Visual inspection of AY-102 annulus through Riser } 83 . \text { Identified } \\
\text { changes since previous } 10-08-2012 \text { inspection. }\end{array}$ & RPP-ASMT-53793 \\
\hline $10-21-2012$ & $\begin{array}{l}\text { Visual inspection of AY-102 annulus through Riser } 83 \text {. Identified } \\
\text { further changes since previous } 10-18-2012 \text { inspection. }\end{array}$ & RPP-ASMT-53793 \\
\hline $10-25-2012$ & Visual inspection of AY-102 annulus through Riser 83. & TFC-WO-12-5018 \\
\hline $10-30-2012$ & Visual inspection of AY-102 annulus through Riser 83 . & TFC-WO-12-5018 \\
\hline $11-01-2012$ & Visual inspection of AY-102 annulus through Riser 83. & TFC-WO-12-5018 \\
\hline $11-05-2012$ & Visual inspection of AY-102 annulus through Riser 83. & TFC-WO-12-5018 \\
\hline
\end{tabular}




\section{DISTRIBUTION SHEET}

\begin{tabular}{|c|c|c|c|c|c|c|}
\hline $\begin{array}{l}\text { To } \\
\text { Distribution }\end{array}$ & \multicolumn{3}{|c|}{$\begin{array}{l}\text { From } \\
\text { Technical Integration }\end{array}$} & \multicolumn{3}{|c|}{ Page 1 of 2} \\
\hline \multirow{2}{*}{\multicolumn{7}{|c|}{$\begin{array}{l}\text { Project Title/Work Order } \\
\text { Tank 241-AY-102 Leak Assessment Supporting Documentation: }\end{array}$}} \\
\hline & & & & & & \\
\hline \multicolumn{4}{|c|}{$\begin{array}{l}\text { Tank 241-AY-102 Leak Assessment Supporting Documentation: } \\
\text { Miscellaneous Reports, Letters, Memoranda, and Data }\end{array}$} & \multicolumn{3}{|c|}{ ECN No. } \\
\hline Name & & MSIN & $\begin{array}{l}\text { Text } \\
\text { With All } \\
\text { Attach. }\end{array}$ & Text Only & $\begin{array}{l}\text { Attach.l } \\
\text { Appendix } \\
\text { Only }\end{array}$ & $\begin{array}{l}\text { EDT/ECN } \\
\text { Only }\end{array}$ \\
\hline T. J. Barnes & & R2-53 & $x$ & & & \\
\hline A. D. Basche & & $\mathrm{H} 6-02$ & $\mathrm{x}$ & & & \\
\hline K. D. Boomer & & $R 2-53$ & $x$ & & & \\
\hline W. C. Clark & & H6-63 & $\bar{x}$ & & & \\
\hline G. A. Cooke & & T6-05 & $\mathrm{x}$ & & & \\
\hline B. L. Duffy & & R1-05 & $\mathrm{x}$ & & & \\
\hline D. L. Dyekman & & $55-07$ & $x$ & & & \\
\hline J. K. Engeman & & $R 3-26$ & $\mathrm{X}$ & & & \\
\hline J.G. Field & & $57-90$ & $\mathrm{x}$ & & & \\
\hline C. L. Girardot & & $R 2-53$ & $x$ & & & \\
\hline R. E. Gregory & & $57-68$ & $x$ & & & \\
\hline D. G. Harlow & & $R 2-53$ & $x$ & & & \\
\hline S. J. Harrington & & $R 2-58$ & $x$ & & & \\
\hline G. J. Johnson & & H6-18 & $\mathrm{x}$ & & & \\
\hline M. D. Johnson & & H6-63 & $x$ & & & \\
\hline C. C. Joslyn & & $\mathrm{R} 2-53$ & $x$ & & & \\
\hline D. B. Little & & $R 2-58$ & $\mathrm{x}$ & & & \\
\hline J.A. McDonald & & $\mathrm{R} 2-53$ & $x$ & & & \\
\hline J. E. Meacham & & $R 2-58$ & $\mathrm{x}$ & & & \\
\hline K. J. Peltier & & $55-07$ & $\mathrm{x}$ & & & \\
\hline A. C. Prince & & S5-08 & $\mathrm{X}$ & & & \\
\hline R. S. Rast & & $R 2-58$ & $x$ & & & \\
\hline C. I. Rosenkrance & & $\mathrm{R} 2-53$ & $\mathrm{x}$ & & & \\
\hline T. I. Sams & & $R 2-52$ & $x$ & & & \\
\hline R. J. Skwarek & & H3 -28 & $x$ & & & \\
\hline D. K. Smith & & $57-75$ & $x$ & & & \\
\hline B. R. Thomas & & H6-11 & $x$ & & & \\
\hline R. P. Tucker & & $55-23$ & $\mathrm{X}$ & & & \\
\hline T. J. Venetz & & $\mathrm{R} 2-53$ & $\mathrm{x}$ & & & \\
\hline J. A. Voogd & & $\mathrm{R} 1-51$ & $\mathrm{X}$ & & & \\
\hline D. J. Washenfelder & & $R 2-53$ & $\mathrm{x}$ & & & \\
\hline R. E. Wilkinson & & S5-07 & $\mathrm{x}$ & & & \\
\hline
\end{tabular}




\section{DISTRIBUTION SHEET}

To

Distribution

Project Title/Work Order

Tank 24I-AY-102 Leak Assessment Supporting Documentation:

Miscellaneous Reports, Letters, Memoranda, and Data

\begin{tabular}{|c|c|c|c|c|c|}
\hline Name & MSIN & $\begin{array}{c}\text { Text } \\
\text { With All } \\
\text { Attach. }\end{array}$ & Text Only & $\begin{array}{l}\text { Attach./ } \\
\text { Appendix } \\
\text { Only }\end{array}$ & $\begin{array}{c}\text { EDT/ECN } \\
\text { Only }\end{array}$ \\
\hline T. W. Fletcher & $\mathrm{H} 6-60$ & $\mathrm{x}$ & & & \\
\hline E. M. Mattlin & H6-60 & $\mathrm{x}$ & & & \\
\hline J. M. Johnson & $\mathrm{H} 6-60$ & $\mathrm{x}$ & & & \\
\hline P. G. Harrington & $\mathrm{H} 6-60$ & $\mathrm{x}$ & & & \\
\hline R. M. Irwin & $\mathrm{H} 6-60$ & $\mathrm{x}$ & & & \\
\hline J. H. Wicks & H6-60 & $\mathrm{x}$ & & & \\
\hline M. E. Johnson & A0 -26 & $\mathrm{x}$ & & & \\
\hline D. $s \cot t$ & $R 3-26$ & $x$ & & & \\
\hline & & & & & \\
\hline & & & & & \\
\hline & & & & & \\
\hline & & & & & \\
\hline & & & & & \\
\hline & & & & & \\
\hline & & & & & \\
\hline & & & & & \\
\hline & & & & & \\
\hline & & & & & \\
\hline & & & & & \\
\hline & & & & & \\
\hline & & & & & \\
\hline & & & & & \\
\hline & & & & & \\
\hline & & & & & \\
\hline & & & & & \\
\hline & & & & & \\
\hline & & & & & \\
\hline & & & & & \\
\hline & & & & & \\
\hline & & & & & \\
\hline & & & & & \\
\hline
\end{tabular}

From

Technical Integration 